\author{
Universidad Jaume I \\ Facultad de Ciencias Humanas y Sociales \\ Departamento de Traducción y Comunicación
}

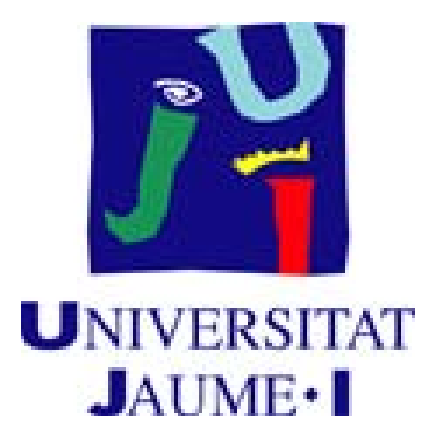

\title{
LA COMUNICACIÓN INTERCULTURAL EN EL ÁMBITO DE LA SALUD REPRODUCTIVA.
}

Propuestas de mejora desde la interpretación en los servicios públicos y la mediación lingüística y cultural.

Estudio de caso de un hospital aragonés.

TESIS DOCTORAL PRESENTADA POR:

Almudena Nevado Llopis

DIRIGIDA POR:

Dr. Francisco Raga Gimeno

Dra. Adoración Sales Salvador 

"Dentro de una gota, hay un universo entero. Lo particular nos dice más que lo general; nos resulta más asequible."

RYSZARD KAPUŚCIŃSKI (1987)

El Sha o la desmesura del poder 



\section{AGRADECIMIENTOS}

Si hoy me encuentro escribiendo estas líneas es gracias a numerosas personas que, de uno $u$ otro modo, han contribuido a que pudiera embarcarme en la estimulante aventura de elaborar esta tesis doctoral, y quienes directa o indirectamente han estado a mi lado durante todo este proceso, a las cuales quisiera hacer llegar mi más sincero y profundo agradecimiento.

En primer lugar, a mis incansables y siempre disponibles directores, Patxi y Dora, el binomioguía ideal con el que todo doctorando quisiera contar, por sus inestimables consejos, por reconducirme cuando me alejaba del "camino correcto" respetando siempre mis decisiones, y por el apoyo incondicional que me han brindado, que me ha hecho sentirles tan cerca a pesar de la distancia que nos separaba.

A mis compañeros y amigos de la Universidad San Jorge, por haberme allanado el camino durante este periodo. En especial, a Sisa, quien ha vivido esta misma experiencia de modo casi simultáneo $\mathrm{y}$, por tanto, ha podido acercarme a las técnicas e instrumentos metodológicos llegados "del otro lado del charco" y, al mismo tiempo, ha estado ahí para apoyarme y animarme cuando más lo necesitaba. A Pilar y a Alberto, quienes desinteresadamente se han convertido en mis gatekeepers, facilitándome los contactos y la ayuda necesarios para llegar a mis informantes. A Joe, mi compañero diario de viaje hacia la universidad, por su paciencia a la hora de escuchar los progresos que iba haciendo, pese a que su campo de estudio se aleja considerablemente de los fines de esta tesis. A Joseba, por haberme servido como referente en muchos aspectos y por haberme permitido ausentarme cuando lo precisaba. A Teresa, por su sustento $y$, sobre todo, por haber accedido a tomar el relevo en este último periodo, sin lo cual no sé si habría sido posible concluir este proyecto. Y a mis dos exalumnas Marina y Sofía, por sus labores de intermediación y observación en el trabajo de campo, a las cuales deseo toda la suerte del mundo para que algún día consigan ellas también escribir su propia tesis.

Al hospital donde he desarrollado la investigación, por haberme abierto sus puertas y haberme hecho sentir tan cómoda durante los meses en los que he compartido la cotidianeidad con sus trabajadores y sus usuarias. En particular, a los profesionales sanitarios que han accedido a colaborar en el estudio y me han dedicado parte de su valioso y escaso tiempo. Y a las mujeres inmigrantes que han participado, quienes me han permitido conocer sus vivencias en un momento tan especial y tan íntimo como es el de la maternidad.

A las empresas, organizaciones y entidades, como Interpret Solutions, Fundación Adunare, Médicos del Mundo, o la Casa de las Culturas, cuyos responsables me han atendido amablemente y me han facilitado datos que han resultado de gran utilidad para este estudio.

A los componentes del grupo The Bronson, por haberme servido de banda sonora y válvula de escape en estos años.

$\mathrm{Y}$, muy especialmente, a mi familia y amigos a los que dedico esta tesis: a mis padres, por su infatigable apoyo y por haberme enseñado el valor del esfuerzo y el tesón; a mis abuelos, emigrantes errantes, por ser fuente de inspiración y, sobre todo, a Remediets, quien ha sido la única que ha podido estar a mi lado en el camino, y quien con amor ha confeccionado el "disfraz" que un día podré lucir como doctora; a mi amigo Javier, perseverante trabajador y 
modelo a seguir; a mi hermano Jorge y a Marta, a mis primos Xavi, Alba y Luisito, y a mis amigos Patricia, Ana y Miguel, quienes han sabido comprender mis ausencias y me han alentado en el camino.

A todas estas personas, así como a aquellas a las que no he nombrado, pero que también han puesto su granito de arena para que esta empresa llegara a buen puerto, de verdad, millones de GRACIAS, pues sin vosotros no habría logrado llegar hasta aquí. 


\section{ÍNDICE GENERAL}

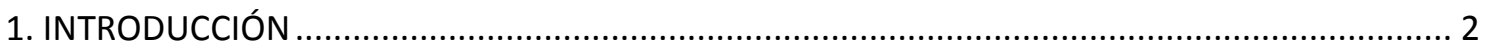

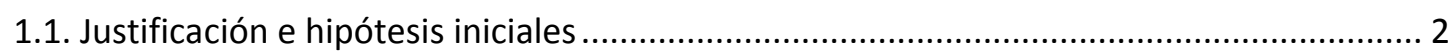

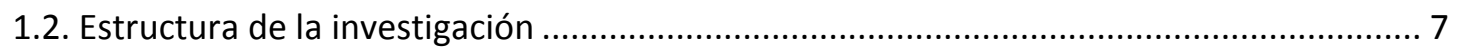

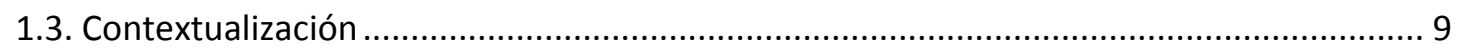

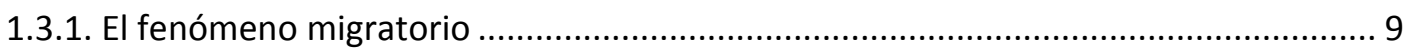

1.3.1.1. Breve descripción de los movimientos migratorios: pasado, presente y futuro10

1.3.1.2. Historia reciente del fenómeno migratorio en Europa y en España ................... 16

1.3.1.3. Datos demográficos de la población inmigrante de Aragón y Zaragoza............. 27

1.3.1.4. Modelos de gestión de la diversidad cultural .................................................... 35

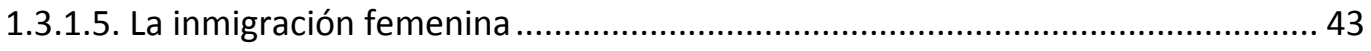

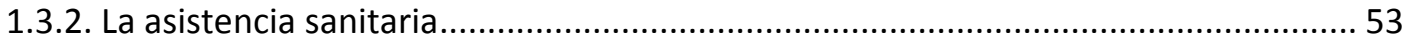

1.3.2.1. Cuestiones básicas sobre el sistema de salud español ...................................... 53

1.3.2.2. Los servicios sanitarios en Aragón y Zaragoza .................................................... 55

1.3.2.3. El hospital contexto de nuestro estudio ......................................................... 58

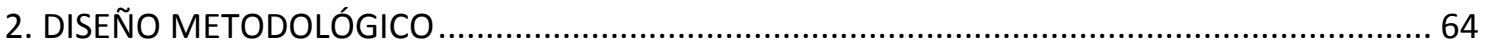

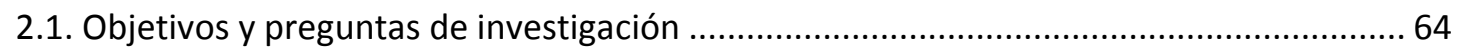

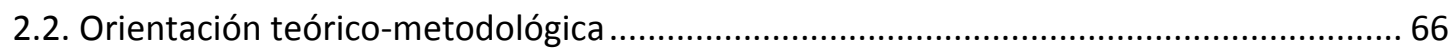

2.3. Estrategias de selección de informantes. Muestreo y características generales de los

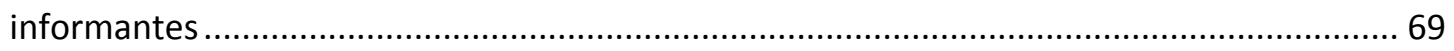

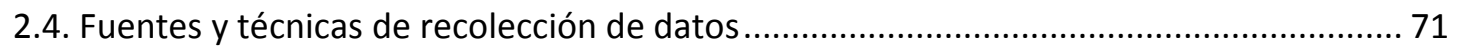

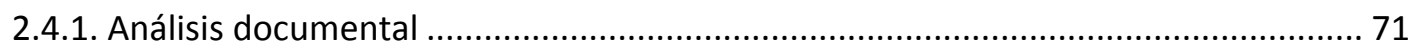

2.4.1.1. Documentos sobre el derecho a emigrar/inmigrar.......................................... 72

2.4.1.2. Documentos sobre el acceso y uso de los servicios sanitarios por parte de la

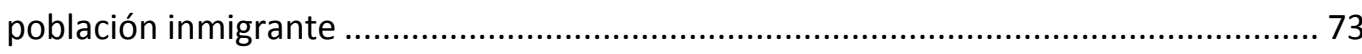

2.4.1.3. Documentos relacionados con la salud reproductiva y la atención durante el parto

2.4.1.4. Documentos relativos a las estrategias empleadas por los servicios sanitarios de Aragón para facilitar la comunicación y la asistencia a usuarios inmigrantes ................. 75

2.4.2. Entrevistas semi-estructuradas en profundidad ...................................................... 76

2.4.2.1. Selección de los participantes ............................................................................... 77

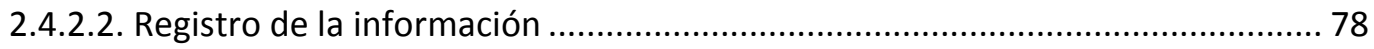

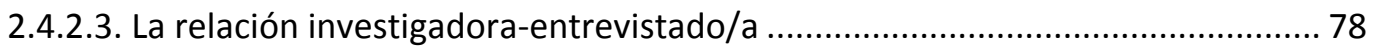


2.4.2.4. Guion de la entrevista

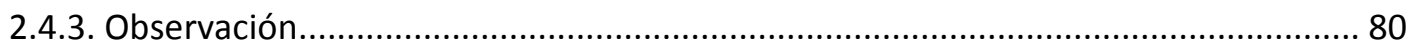

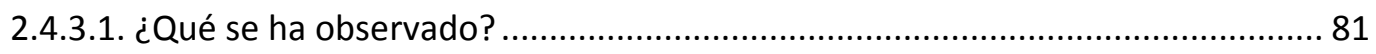

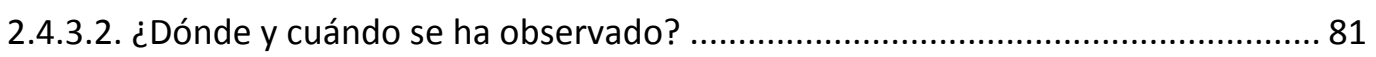

2.4.3.3. ¿Cómo se ha registrado la observación? .......................................................... 82

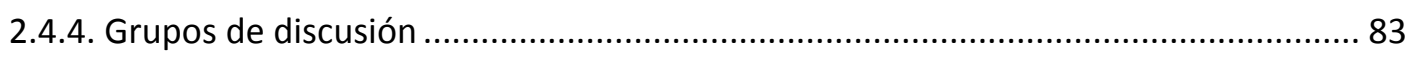

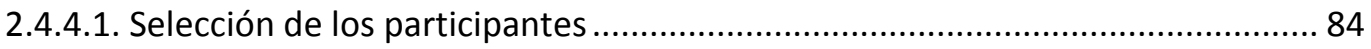

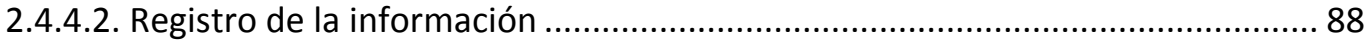

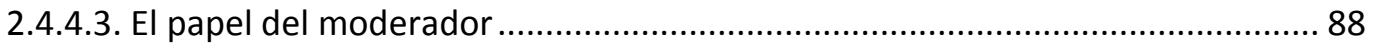

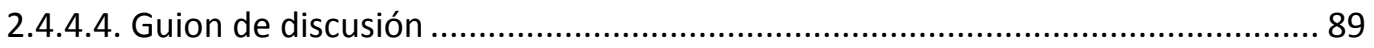

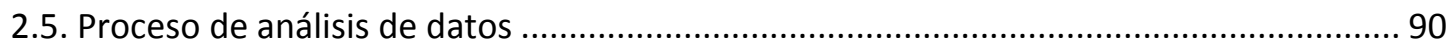

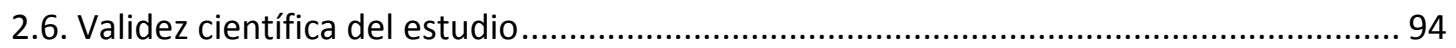

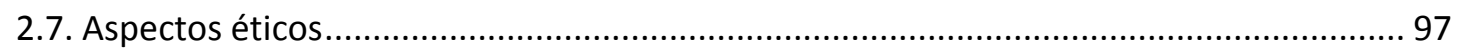

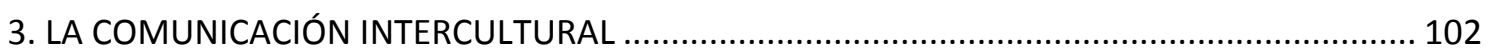

3.1. Definición y características de la comunicación intercultural........................................ 103

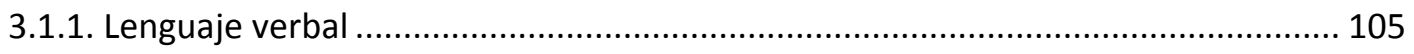

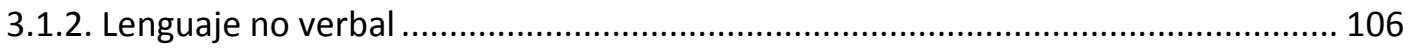

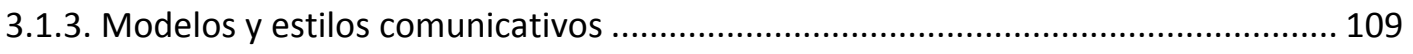

3.2. Barreras que dificultan o impiden la comunicación en los encuentros interculturales 118

3.2.1. Dificultades específicas de la comunicación intercultural en ámbito sanitario...... 121

3.3. Claves para una comunicación intercultural eficaz ...................................................... 135

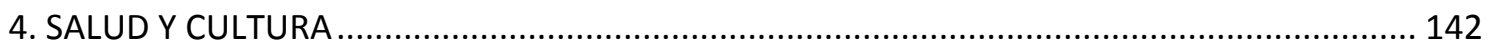

4.1. Patrones culturales en la asistencia sanitaria general ...................................................... 144

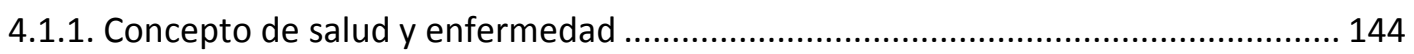

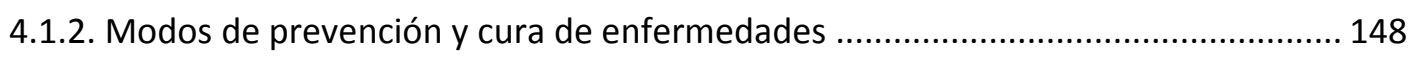

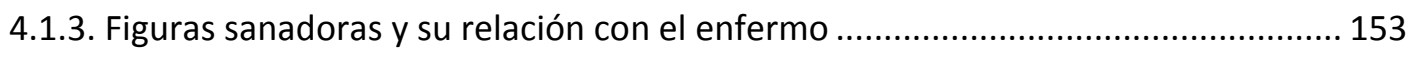

4.2. Patrones culturales relacionados con la salud reproductiva ......................................... 155

4.2.1. Comportamientos, creencias y actitudes asociados a la fecundidad y la infertilidad 158

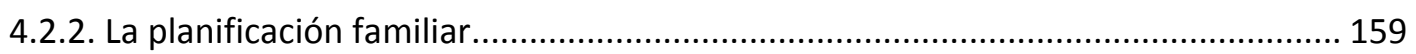

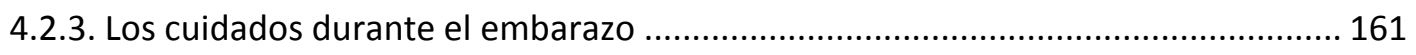

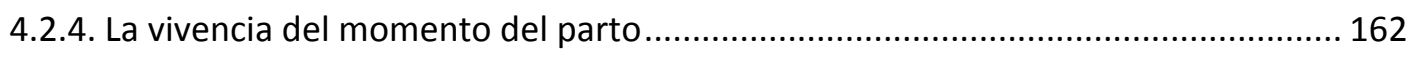

4.2.5. Comportamientos, creencias y actitudes durante el puerperio .............................. 164

4.3. Algunas conclusiones sobre la relación entre salud y cultura ...................................... 166 


\section{LA INTERPRETACIÓN EN LOS SERVICIOS PÚBLICOS Y LA MEDIACIÓN LINGÜÍSTICA Y}

CULTURAL: DOS ESTRATEGIAS ¿DIFERENTES? ANTE UNA MISMA NECESIDAD.......................... 170

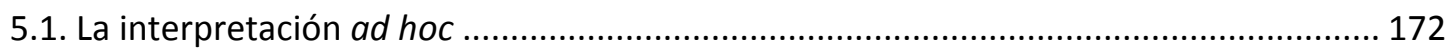

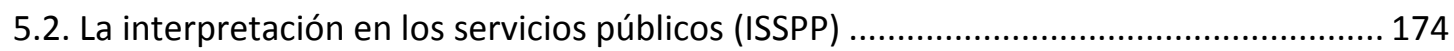

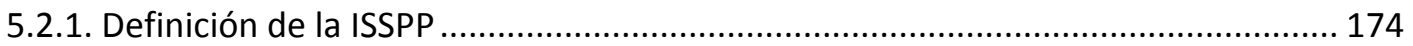

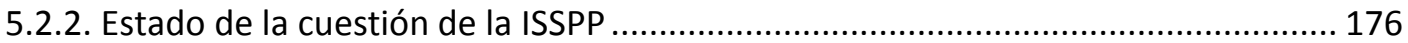

5.2.3. La complejidad del rol del intérprete en los servicios públicos .............................. 182

5.2.4. Otros tipos de interpretación: la interpretación telefónica (IT) .............................. 188

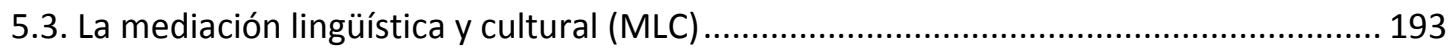

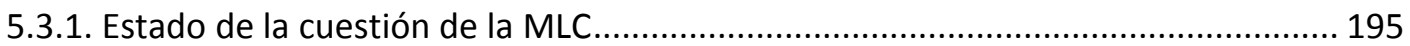

5.3.2. Definición de la MLC. Los límites difusos de la figura mediadora lingüística y cultural 198

5.3.3. Funciones de la figura mediadora lingüística y cultural ........................................... 201

5.3.4. Conocimientos, habilidades y actitudes de la figura mediadora lingüística y cultural 205

5.3.5. Perfil de la figura mediadora lingüística y cultural................................................. 209

5.4. Hacia la profesionalización del intérprete-mediador en los servicios públicos .............. 212

6. ANÁLISIS DESCRIPTIVO DE LOS RESULTADOS DEL ESTUDIO DE CASO .................................. 220

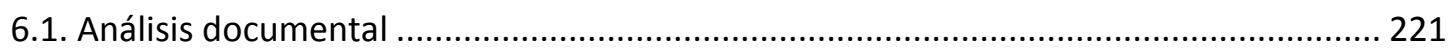

6.1.1. Documentos sobre el derecho a emigrar/inmigrar............................................... 222

6.1.2. Documentos sobre el acceso y uso de los servicios sanitarios por parte de la

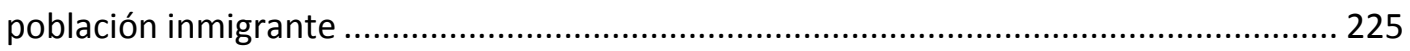

6.1.2.1. El derecho a la salud en el contexto internacional ......................................... 226

6.1.2.2. Legislación y políticas nacionales relacionadas con el acceso y uso de los servicios sanitarios por parte de la población inmigrante ............................................... 228

6.1.2.3. Planes integrales y estratégicos de Aragón......................................................... 234

6.1.2.4. Otra documentación del ámbito sanitario en el contexto aragonés ............... 237

6.1.3. Documentos relacionados con la salud reproductiva y la atención durante el parto

6.1.3.1. Actuaciones y estrategias nacionales en el ámbito de la salud reproductiva y la atención al parto

6.1.3.2. Documentos relacionados con el parto y la salud reproductiva en el contexto aragonés 261

6.1.4. Documentos relativos a las estrategias empleadas por los servicios sanitarios de Aragón para facilitar la comunicación y la asistencia a usuarios inmigrantes

6.1.4.1. Documentos sobre los servicios de interpretación disponibles en el sistema de salud aragonés 
6.1.4.2. Documentos sobre los servicios de mediación intercultural disponibles en el sistema de salud aragonés

6.1.4.3 Documentos traducidos a varios idiomas disponibles en los servicios sanitarios de Aragón 292

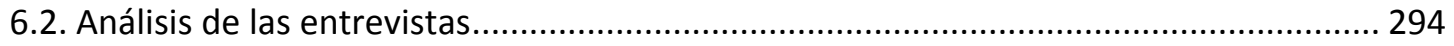

6.2.1. Datos contextuales y demográficos ......................................................... 295

6.2.2. Datos conceptuales o teóricos ................................................................ 301

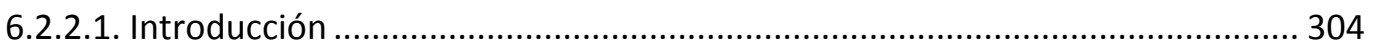

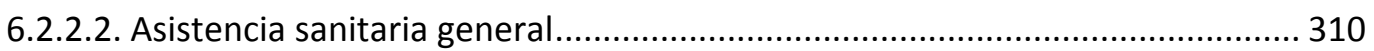

6.2.2.3. Embarazo, parto y puerperio ............................................................ 337

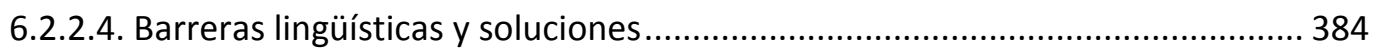

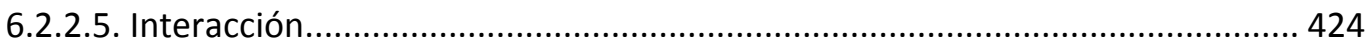

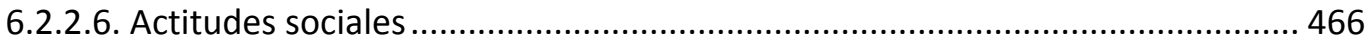

6.3. Análisis de la observación no participante....................................................... 485

6.3.1. Datos contextuales y demográficos ............................................................... 487

6.3.2. Datos conceptuales o teóricos ............................................................... 495

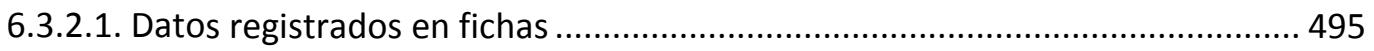

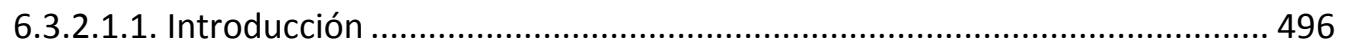

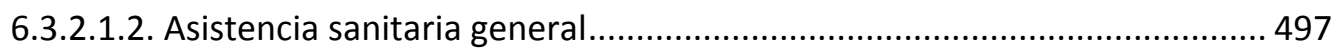

6.3.2.1.3. Embarazo, parto y puerperio ............................................................ 499

6.3.2.1.4. Barreras lingüísticas y soluciones ................................................. 500

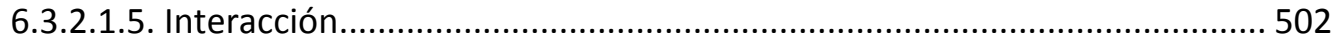

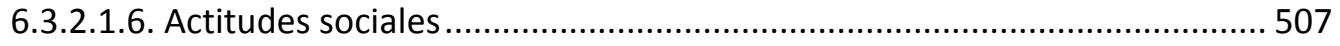

6.3.2.2. Datos registrados en el diario de campo............................................... 508

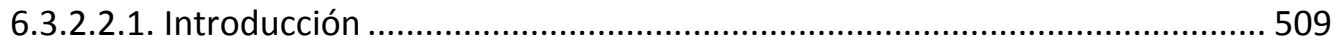

6.3.2.2.2. Asistencia sanitaria general...................................................... 511

6.3.2.2.3. Embarazo, parto y puerperio ............................................................ 514

6.3.2.2.4. Barreras lingüísticas y soluciones................................................... 515

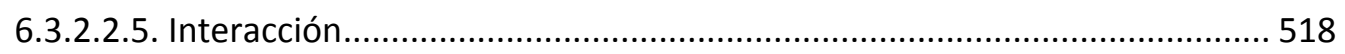

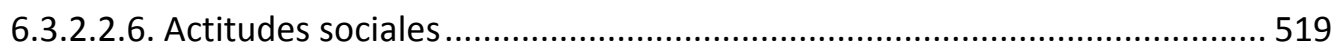

6.4. Análisis de los grupos de discusión ............................................................... 520

6.4.1. Datos contextuales y demográficos .......................................................... 520

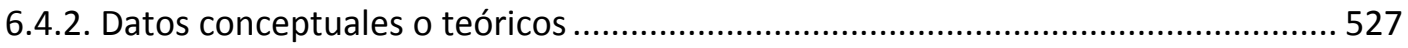

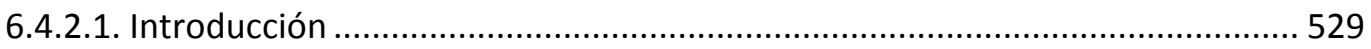

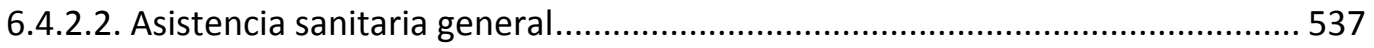


6.4.2.4. Barreras lingüísticas y soluciones....................................................................... 561

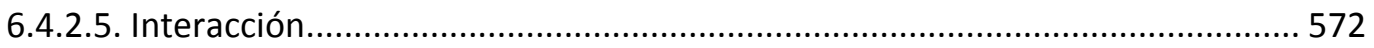

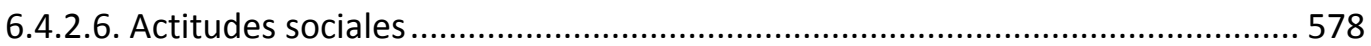

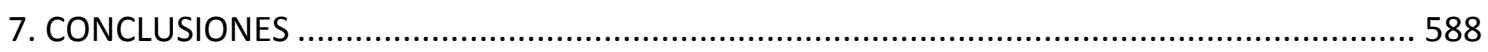

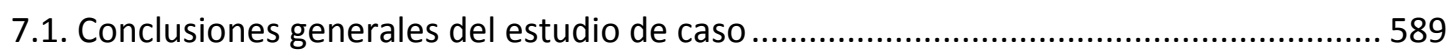

7.1.1. Opiniones e impresiones iniciales de los grupos implicados .................................. 589

7.1.2. Barreras que dificultan la comunicación y la asistencia a las usuarias inmigrantes 593

7.1.2.1. Barreras culturales en el ámbito de la salud ..................................................... 593

7.1.2.2. Barreras en las interacciones comunicativas en el ámbito de la salud............. 611

7.1.2.3. Actitudes ante la diversidad cultural en el ámbito de la salud ........................ 621

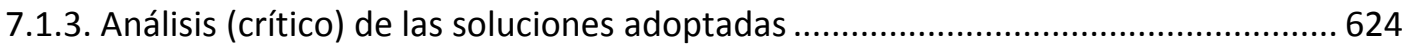

7.1.3.1. Soluciones para superar las barreras lingüísticas .......................................... 625

7.1.3.2. Soluciones para reducir las barreras culturales y otro tipo de iniciativas ....... 634

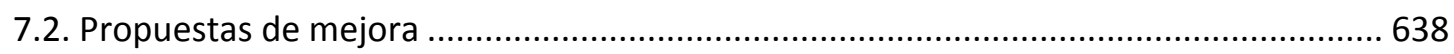

7.2.1. Propuestas de mejora para el hospital contexto de estudio ................................... 638

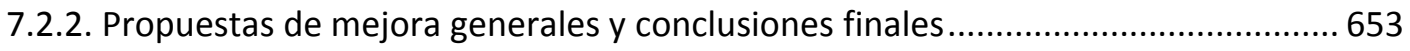

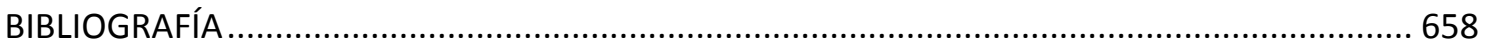

ANEXOS $^{1}$

\footnotetext{
${ }^{1}$ Los anexos se adjuntan en un CD-ROM distribuidos en carpetas y ficheros y sin paginación. En la lista de anexos que se incluye en páginas sucesivas puede observarse la organización y contenidos de los mismos.
} 


\section{ÍNDICE DE GRÁFICOS, TABLAS E IMÁGENES²}

Gráfico 1.1. Restricciones en la accesibilidad y en la utilización de los servicios de salud

Gráfico 1.2. Áreas geográficas de procedencia de la población extranjera residente en la UE (excluidos los originarios de los estados miembros) a 1 de enero de 2012

Gráfico 1.3. Pirámide poblacional de Europa a 1 de enero de 2012

Gráfico 1.4. Evolución del número de nacimientos (en millones) en la UE (1961-2011)

Gráfico 1.5. Distribución de los extranjeros residentes en los países europeos a 1 de enero de 2012

Gráfico 1.6. Países de la UE con mayor número de población extranjera residente a 1 de enero de 2012

Gráfico 1.7. Principales nacionalidades de los extranjeros residentes en la UE a 1 de enero de 2012

Gráfico 1.8. Principales nacionalidades de los extranjeros residentes en España a 1 de enero de 2012 y a 1 de enero de 2013

Gráfico 1.9. Población extranjera residente en las comunidades autónomas de España a 1 de enero de 2012

Gráfico 1.10. Pirámide poblacional de España a 1 de enero de 2012

Gráfico 1.11. Distribución por edades de las cinco nacionalidades extranjeras con mayor presencia en España a 1 de enero de 2013

Gráfico 1.12. Distribución por sexos de las cinco nacionalidades extranjeras con mayor presencia en España a 1 de enero de 2013

Gráfico 1.13. Evolución de la población inmigrante en Aragón (2000-2011)

Gráfico 1.14. Incidencia de la población inmigrante con respecto a la población total en Aragón (2000-2011)

Gráfico 1.15. Población extranjera total empadronada en Aragón y provincias a 1 de enero de 2012

Gráfico 1.16. Áreas geográficas de procedencia de la población extranjera empadronada en Aragón a 1 de enero de 2012

Gráfico 1.17. Principales nacionalidades de los extranjeros empadronados en Aragón a 1 de enero de 2012

\footnotetext{
${ }^{2}$ Los gráficos, tablas e imágenes se encuentran numerados de acuerdo con el número del capítulo en el que están incluidos y el orden de aparición dentro de cada capítulo.
} 
Gráfico 1.18. Distribución por sexos de las principales nacionalidades extranjeras de Aragón a 1 de enero de 2012

Gráfico 1.19. Pirámide poblacional de Aragón a 1 de enero de 2012

Gráfico 1.20. Evolución de la tasa de natalidad en Aragón según nacionalidad (española o extranjera) de la madre (2003-2011)

\section{Gráfico 1.21.}

Gráfico 1.22. Principales nacionalidades de los extranjeros empadronados en Zaragoza (provincia) a 1 de enero de 2012

Gráfico 1.23. Evolución de los partos anuales atendidos en el hospital contexto de estudio (1999-2011)

Gráfico 2.1. Procedimiento de análisis de datos (elaboración propia basada en el Modelo de Miles y Huberman, 1984)

Gráfico 3.1. Continuum de las culturas de alto y bajo contexto

Gráfico 3.2. Modelo de las cinco dimensiones de Hofstede

Gráfico 5.1. La mediación lingüística y cultural en el ámbito sanitario

Gráfico 6.1. Evolución anual del Servicio Permanente de Interpretación (2009-2011)

Gráfico 6.2. Evolución trimestral del Servicio Permanente de Interpretación (2011)

Gráfico 6.3. Idiomas demandados en los servicios de interpretación (2011)

Gráfico 6.4. Servicios de interpretación demandados según entidad solicitante (2011)

Gráfico 6.5. Servicios de interpretación prestados a entidades del Ayuntamiento de Zaragoza (2011)

Gráfico 6.6. Servicios de interpretación prestados a entidades de la DGA (2011)

Gráfico 6.7. Servicios de interpretación prestados en ámbito sanitario (2011)

Gráfico 6.8. Servicios de interpretación prestados en entidades sin ánimo de lucro (2011)

Gráfico 6.9. Seminarios del SAMI y participantes por sector (2008)

Gráfico 6.10. Participantes de los seminarios del SAMI para profesionales de atención especializada (2008)

Gráfico 6.11. Participantes de los seminarios del SAMI para profesionales de atención primaria (2008)

Gráfico 6.12. Seminarios del SAMI y participantes por sector (2009) 
Gráfico 6.13. Participantes de los seminarios del SAMI para profesionales de atención especializada (2009)

Gráfico 6.14. Seminarios del SAMI y participantes por sector (2010)

Gráfico 6.15. Seminarios del SAMI y participantes por sector (2011)

Gráfico 6.16. Perfil profesional y sexo de los profesionales participantes en las entrevistas

Gráfico 6.17. Perfil profesional y edad de los profesionales participantes en las entrevistas

Gráfico 6.18. Lenguas extranjeras habladas por los profesionales participantes en las entrevistas

Gráfico 6.19. Colectivo inmigrante y edad de las usuarias participantes en las entrevistas

Gráfico 6.20. Usuarias participantes en las entrevistas y tiempo de permanencia en España

Gráfico 6.21. Análisis de los temas más mencionados por parte de los profesionales sanitarios entrevistados

Gráfico 6.22. Análisis de los temas más mencionados por parte de las usuarias inmigrantes entrevistadas

Gráfico 6.23. 50 palabras más usadas por los profesionales sanitarios entrevistados

Gráfico 6.24. 50 palabras más usadas por las usuarias inmigrantes entrevistadas

Gráfico 6.25. Subnodos del nodo INTRODUCCIÓN

Gráfico 6.26. Subnodos del nodo ASISTENCIA SANITARIA

Gráfico 6.27. Subnodos del nodo EMBARAZO, PARTO y PUERPERIO

Gráfico 6.28. Subnodos del nodo BARRERAS LINGÜÍSTICAS y SOLUCIONES

Gráfico 6.29. Subnodos del nodo INTERACCIÓN

Gráfico 6.30. Subnodos del nodo ACTITUDES SOCIALES

Gráfico 6.31. Nodos de la OBSERVACIÓN NO PARTICIPANTE

Gráfico 6.32. Subnodos de los nodos DIARIO DE CAMPO y FICHAS_NOTAS DE CAMPO

Gráfico 6.33. Perfil profesional y sexo de los profesionales observados en las consultas a puérperas

Gráfico 6.34. Perfil profesional y edad de los profesionales observados en las consultas a puérperas

Gráfico 6.35. Colectivo inmigrante y edad de las usuarias observadas en las consultas a puérperas 
Gráfico 6.36. Usuarias inmigrantes observadas en las consultas a puérperas y tiempo de permanencia en España

Gráfico 6.37. Colectivo inmigrante y dominio del español de las usuarias inmigrantes observadas en las consultas a puérperas

Gráfico 6.38. Perfil profesional y sexo de los profesionales observados en diversas zonas del hospital

Gráfico 6.39. Perfil profesional y sexo de los profesionales participantes en el grupo de discusión

Gráfico 6.40. Perfil profesional y edad de los profesionales participantes en el grupo de discusión

Gráfico 6.41. Lenguas extranjeras habladas por los profesionales participantes en el grupo de discusión

Gráfico 6.42. Perfil profesional y experiencia en el ámbito de la obstetricia de los profesionales participantes en el grupo de discusión

Gráfico 6.43. Colectivo inmigrante y edad de las usuarias participantes en los grupos de discusión

Gráfico 6.44. Usuarias participantes en los grupos de discusión y tiempo de permanencia en España

Gráfico 6.45. Usuarias latinoamericanas participantes en el grupo de discusión y número de hijos

Gráfico 6.46. Usuarias magrebíes participantes en el grupo de discusión y número de hijos

Gráfico 6.47. 50 palabras más usadas por los participantes en los grupos de discusión

Tabla 1.1. Competencias de las administraciones públicas en materia sanitaria

Tabla 1.2. Centros de los sectores sanitarios de Zaragoza

Tabla 1.3. Estructura del servicio de tocología-obstetricia

Tabla 3.1. Patrones comunicativos de los modelos próximo y distante

Tabla 3.2. Patrones comunicativos de los modelos simétrico y asimétrico

Tabla 3.3. Clasificación tetrapartita de los modelos comunicativos

Tabla 3.4. Esquema de los patrones comunicativos en las interacciones en ámbito sanitario

Tabla 4.1. Las nueve facetas interrelacionadas de la salud (física, mental y espiritual) y los métodos para mantenerla, protegerla y recuperarla 
Tabla 6.1. Grado de dificultad de la asistencia sanitaria a usuarias inmigrantes de acuerdo con los profesionales participantes en el grupo de discusión

Tabla 6.2. Mayores dificultades en la asistencia a determinados colectivos de usuarias inmigrantes de acuerdo con los profesionales participantes en el grupo de discusión

Tabla 6.3. Causas de las dificultades para tratar a usuarias inmigrantes de acuerdo con los profesionales participantes en el grupo de discusión

Tabla 6.4. Valoración de la atención recibida durante el embarazo, el parto y el puerperio de acuerdo con las usuarias participantes en los grupos de discusión

Tabla 6.5. Clasificación de los métodos anticonceptivos de acuerdo con las usuarias participantes en los grupos de discusión

Tabla 6.6. Valoración del dolor percibido durante el parto de acuerdo con las usuarias participantes en los grupos de discusión

Tabla 6.7. Deseo de mayor implicación de los maridos y familiares en los cuidados durante el embarazo, el parto y el puerperio por parte de las usuarias participantes en los grupos de discusión

Tabla 6.8. Valoración de la comunicación con los profesionales sanitarios de acuerdo con las usuarias participantes en los grupos de discusión

Tabla 6.9. Suficiencia de los instrumentos y estrategias para facilitar la comunicación con usuarias inmigrantes de acuerdo con los profesionales participantes en los grupos de discusión

Imagen 1.1. Mapa de los sectores sanitarios de Aragón

Imagen 2.1. Visión general del proyecto con NVivo 10

Imagen 3.1. La analogía del iceberg 


\section{LISTA DE ANEXOS}

\section{A. Documentos relacionados con la autorización para efectuar el trabajo de campo}

A.1. Solicitudes remitidas a la Unidad de Calidad del hospital contexto de estudio

A.2. Autorización concedida por el Presidente de la Comisión de Investigación del Sector Zaragoza II del Servicio Aragonés de Salud

A.3. Autorización concedida por el Jefe de Servicio de la Sección de Obstetricia del hospital contexto de estudio

\section{B. Documentos relacionados con el análisis documental}

B.1. Tabla de servicios lingüísticos que se han implantado en quince países receptores de inmigración (Ozolins, 2010)

B.2. Tablas con los principios, objetivos, programas y acciones principales de los planes integrales y estratégicos de la comunidad autónoma de Aragón

B.3. Cuestionario de valoración de los servicios de interpretación prestados por la empresa Interpret Solutions

B.4. Código ético por el que se rigen los intérpretes de la empresa Interpret Solutions

B.5. Cuestionario para intérpretes telefónicos

B.6. Contenidos formativos del curso para mediadores organizado por el Servicio de Apoyo a la Mediación Intercultural (SAMI)

B.7. Tríptico sobre la mutilación genital femenina elaborado por la organización Médicos del Mundo

B.8. Portada e índice de las guías "Maternidad responsable: Opciones y recursos ante un embarazo no planificado" (versiones en español, árabe, francés, inglés y rumano)

B.9. Portada e índice del documento "Cuídame: guía para padres y madres" (versiones en español, árabe, francés y rumano)

B.10. Gráficos relativos al año 2011 sobre el número de partos atendidos, el porcentaje de partos vaginales o por cesárea, y el número de analgesias practicadas en el hospital contexto de estudio

B.11. Documentos informativos sobre el funcionamiento del servicio de obstetricia del hospital contexto de estudio (versiones en árabe, chino, francés, inglés y rumano) 
B.12. Documentos informativos con pautas y recomendaciones para el cuidado de los recién nacidos elaborados por el hospital contexto de estudio (versiones en español, árabe, francés, inglés y rumano)

B.13. Consentimientos informados para el suministro de la anestesia epidural (versiones en español, árabe, chino, francés, inglés y rumano)

\section{Documentos relacionados con la técnica de las entrevistas}

C.1. Modelo de Consentimiento informado empleado en las entrevistas

C.2. Guion de las entrevistas

C.3. Pautas de transcripción empleadas para las entrevistas y los grupos de discusión

C.4. Transcripción de las entrevistas

C.5. Tablas con los principales datos demográficos de los sujetos participantes en las entrevistas

\section{Documentos relacionados con la técnica de la observación no participante}

D.1. Modelo de las fichas de registro para las notas de campo

D.2. Fichas cumplimentadas con los datos recabados en la observación

D.3. Tablas con los principales datos demográficos de los sujetos de la observación no participante

\section{E. Documentos relacionados con la técnica de los grupos de discusión}

E.1. Pautas de transcripción empleadas para las entrevistas y los grupos de discusión

E.2. Guion de los grupos de discusión

E.3. Transcripción de los grupos de discusión

E.4. Modelo de los cuestionarios individuales cumplimentados tras la participación en los grupos de discusión

E.5. Tablas con los principales datos demográficos de los sujetos participantes en los grupos de discusión 


\section{CAPÍTULO 1}

Introducción 


\section{INTRODUCCIÓN}

\subsection{Justificación e hipótesis iniciales}

Desde la década de los noventa del pasado siglo hasta la actualidad, la población española ha experimentado una importante transformación, especialmente motivada por la llegada de personas procedentes de muy diversos países y culturas. El notable incremento de los flujos migratorios recibidos en las últimas décadas ha supuesto un reto para la sociedad española, en general, y para los servicios públicos, en particular. Así, como sostienen Juan Oliva y Gloria Pérez (2009:1),

La llegada de tal cantidad de población en tan escaso tiempo y su desigual distribución geográfica en el territorio, además de la diversidad cultural y social, han supuesto un importante desafío de adaptación social y convivencia tanto para los recién llegados como para la población autóctona, no escapando a ello las cuestiones relacionadas con la salud pública y con la organización del sistema sanitario.

Por lo que respecta específicamente al ámbito sanitario, los servicios del sistema de salud, concebidos para una población más o menos homogénea y basados en el sistema biomédico hegemónico, no han sabido por el momento adaptarse a las particularidades y necesidades de los "nuevos" usuarios, ${ }^{3}$ los cuales se enfrentan, como explicaremos a continuación, a una serie de barreras que les impiden acceder y usar estos servicios en condiciones de calidad y equidad.

En primer lugar, cabe señalar que, en el estudio de la relación entre la población inmigrante y el sistema de salud, se deberían tener en cuenta una serie de aspectos que caracterizan a los miembros de dicha población, entre los cuales, se encuentran el propio proyecto migratorio, la no inclusión de la salud entre sus principales prioridades (a menos que afecte a su capacidad laboral), los roles y desigualdades de género (tanto en la sociedad de origen como en la de acogida), el concepto de los servicios sanitarios y las expectativas sobre estos basadas en la experiencia previa en el país de origen, el concepto de salud y enfermedad, la preferencia de determinados modos de prevención, tratamiento y cura, y las prácticas de promoción de la salud (Ros y Ollé, 2006: 86-87).

Estos determinantes se materializan, además, en una serie de barreras que dificultan considerablemente el acceso y uso de los servicios sanitarios por parte de la población de origen extranjero, y que disminuyen la calidad de la asistencia prestada a este colectivo. En resumen, de acuerdo con Marisa Ros y Carmen Ollé (2006:90-91) y como se puede observar en el siguiente gráfico, estas barreras pueden dividirse en dos tipos de restricciones:

\footnotetext{
${ }^{3}$ Cabe señalar que la incapacidad de adaptación de los servicios sanitarios españoles quedaba ya reflejada en la Ley General de Sanidad (Ley 14/1986, de 25 de abril) promulgada hace casi treinta años, en la que se afirmaba que "[...] las respuestas públicas al reto que en cada momento ha supuesto la atención a los problemas de salud de la colectividad han ido siempre a la zaga de la evolución de las necesidades sin conseguir nunca alcanzarlas, de manera que se ha convertido en una constante entre nosotros la inadaptación de las estructuras sanitarias a las necesidades de cada época".
} 


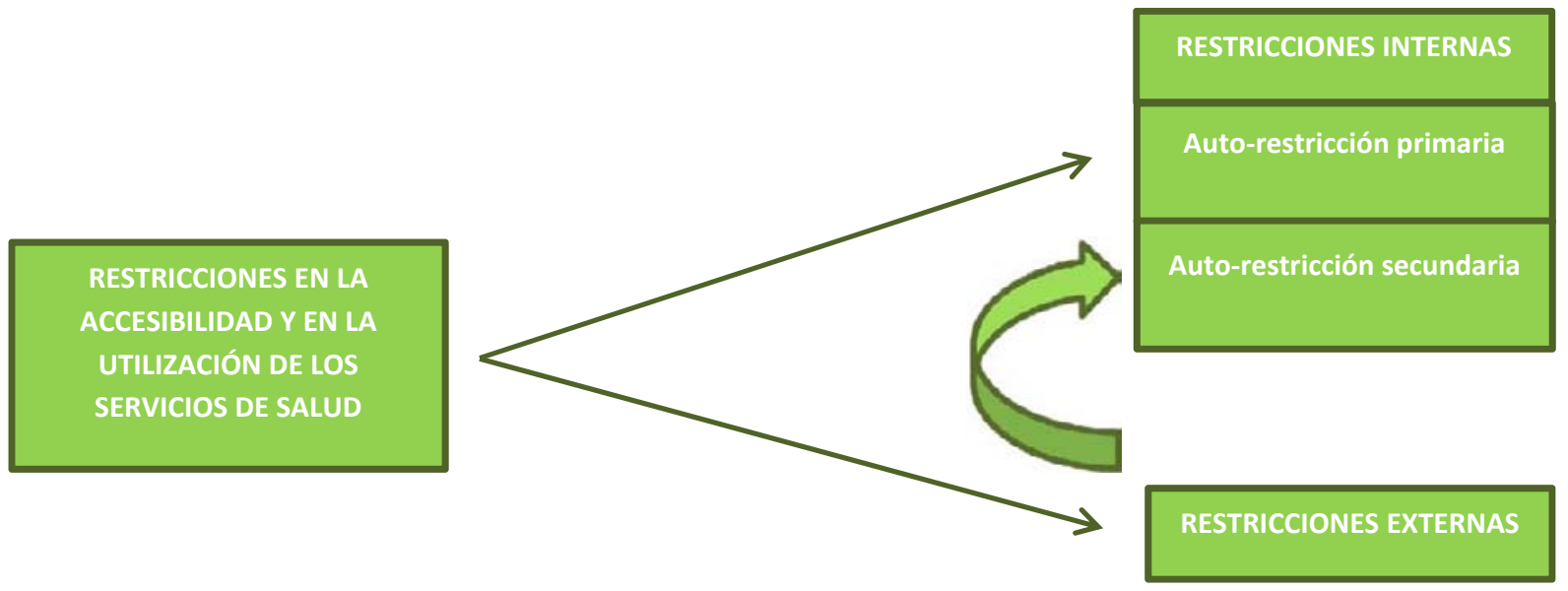

Gráfico 1.1. Restricciones en la accesibilidad y en la utilización de los servicios de salud

Por una parte, las denominadas restricciones internas atañen a los factores personales que influyen en la percepción del propio estado de salud y en la toma de decisiones sobre si acudir o no a los servicios sanitarios. Dentro de estas restricciones internas se encuentran las que se conocen como auto-restricciones primarias, las cuales pueden surgir por la falta de información sobre los derechos de utilización de los servicios y el funcionamiento de los mismos, por los anteriormente mencionados conceptos de salud y enfermedad, o por la experiencia previa que presenten los pacientes de origen extranjero en el sistema de salud de su país de origen. Asimismo, la experiencia en los servicios del país receptor, en caso de haber sido negativa, puede conllevar que el paciente decida no solicitar asistencia médica, incluso cuando perciba la necesidad de hacerlo, lo cual constituiría una auto-restricción secundaria.

Por otra parte, las restricciones externas se manifiestan una vez se ha decidido acceder y usar los servicios sanitarios, y conciernen a las dificultades de carácter legal-administrativo (por ejemplo, a la posibilidad de obtener la tarjeta sanitaria), a las barreras estructurales (relativas a la concertación de citas, las visitas de control y seguimiento, etc.), a las condiciones socioeconómicas de la población inmigrante (caracterizadas a menudo por la precariedad laboral, las condiciones insalubres de la vivienda, etc.), a las diferencias lingüísticas y culturales y, por último, y en gran parte como consecuencia del resto de restricciones señaladas, a las dificultades, malentendidos y conflictos que surgen en la interacción con los profesionales sanitarios autóctonos.

Centrándonos específicamente en las restricciones que afectan a la comunicación entre el personal de los servicios de salud y los pacientes de origen extranjero, la barrera más evidente a la que suelen enfrentarse estos últimos a la hora de solicitar asistencia está causada por el desconocimiento de la lengua del país de acogida y la consecuente imposibilidad de solicitar asistencia o manifestar el malestar padecido y de comprender la explicación que les ofrece el profesional sanitario en relación con dicho malestar.

Asimismo, la comunicación puede verse también afectada por las diferencias culturales. Al respecto, debemos considerar que, en las interacciones comunicativas en el ámbito sanitario (incluso aquellas que tienen lugar entre interlocutores que comparten el mismo origen étnico y cultural), se encuentran dos sistemas de referencia a menudo contrapuestos, lo cual requiere un esfuerzo de negociación y adaptación por ambas partes. Sin embargo, cuando estas interacciones tienen lugar entre un profesional sanitario y un paciente con diferentes 
procedencias, la contraposición de sus sistemas de referencia es incluso mayor, por la diversidad cultural y el desconocimiento mutuo que suelen caracterizar este tipo de interacciones. Cabe señalar que la cultura juega un papel fundamental en el proceso de saludenfermedad, ya que los miembros de las distintas comunidades otorgan la condición de enfermo en determinadas circunstancias, delimitan y construyen un conjunto específico de respuestas ante la pérdida de la salud, y proponen una serie de interpretaciones y actitudes que inducen a vivir la enfermedad de una manera específica (Spector, 2001). Cuanto más se aleja la percepción de la salud y la enfermedad por parte del paciente de la que presenta el profesional sanitario, más difícil será para este último comprender la dolencia padecida y dar una respuesta adecuada a la misma. De hecho, como señalan Bernd Meyer et al. (2003:155),

In a cross-cultural setting [...] the negotiation of meaning, information and trust may be difficult, and the biomedical and "native" frameworks may be incompatible. Medical anthropology has shown that there are always two different systems at play: the illness system -the patient's perspective- and the disease system -the health professional's perspective(Helman, 2000). Thus every medical encounter is a negotiation with the goal that both sides find a common ground of understanding, enabling them to reach a compromise. The health professional's imperative is to use an interpretive approach to explore the meanings of the patient's perceptions and "decode the patient's semantic network of the illness" in order to arrive at appropriate therapeutic responses (Marshall, 1988). (comillas del original)

Al analizar la asistencia sanitaria que recibe la población de origen extranjero, nos hallamos, por tanto, ante una situación caracterizada por las diferencias lingüísticas y culturales que presentan los interlocutores, a las que se suman otros factores como, por ejemplo, la existencia de una organización asistencial no adaptada a las necesidades actuales ${ }^{4}$ y determinada por una gran presión asistencial (que conlleva falta de tiempo para la escucha y la atención adecuadas a las particularidades y expectativas de los pacientes), la escasa formación de los profesionales en competencia (inter)cultural, y las actitudes de incertidumbre y miedo ante la ambigüedad que los implicados presentan. Todo ello conlleva que surjan tanto en los profesionales sanitarios autóctonos como en los pacientes inmigrantes sentimientos de frustración, desconfianza e impotencia, los cuales no hacen sino perjudicar la comunicación entre ambos $y$, por consiguiente, provocan un deterioro en la calidad de la asistencia prestada.

Asimismo, no es infrecuente que, por la mencionada falta de competencia intercultural en los profesionales sanitarios, estos atribuyan a los pacientes de origen extranjero una serie de estereotipos y prejuicios, basados en el desconocimiento y en la actitud etnocéntrica que les lleva a valorar los comportamientos ajenos desde el prisma de la propia cultura.

En resumen, podemos afirmar que las barreras lingüísticas y culturales, (junto con las barreras de carácter legislativo-administrativo, estructural o socio-económico), pueden provocar una falta de comunicación efectiva entre los profesionales sanitarios y los pacientes inmigrantes, lo cual, de acuerdo con numerosos estudios (Brach y Fraser, 2000; Collins et al., 2002; Denboba et al., 1998; Hornberger, 1996; Lee, 2003), podría dificultar el acceso y uso de los servicios sanitarios por parte de estos últimos y derivar en una asistencia inadecuada.

\footnotetext{
4 Esta inadecuación podría enmarcarse en lo que se conoce como "racismo institucional", consistente en la imposibilidad global de una organización de proporcionar un servicio apropiado y profesional a determinados individuos debido a su origen étnico y cultural (Macpherson, citado en Fuller, 2003:193).
} 
Llegados a este punto, quisiéramos recordar que la salud es un derecho humano universal del que todos los ciudadanos de las actuales sociedades multiculturales deberían gozar. Sin embargo, dicho derecho se ve vulnerado en los casos en los que los pacientes no logran entender o ser entendidos por los profesionales encargados de proporcionarles asistencia. ¿De qué manera podrá el profesional entender el malestar del paciente y ser capaz de establecer un diagnóstico y un tratamiento apropiados si no es capaz de comunicarse con él? ¿Cómo podrá el paciente expresar sus dolencias, sus dudas e inquietudes en relación con su estado de salud si existen barreras comunicativas que se lo impiden?

En definitiva, si los profesionales de la salud no pueden comunicarse adecuadamente con sus pacientes, si no pueden entender las explicaciones de estos ni hacer entender las propias, difícilmente podrán ofrecer una asistencia sanitaria apropiada. (Wadensjö, 1998:51).

Por consiguiente, podemos concluir que la comunicación efectiva es fundamental para que el acceso y uso de los servicios sanitarios sean igualitarios para todos los usuarios, independientemente de su origen étnico y cultural. Cabe precisar que la comunicación efectiva en el ámbito sanitario, de acuerdo con Sharon M. Lee (2003:5), es aquella en la que tanto el profesional como el paciente comprenden el contenido de los mensajes transmitidos por su interlocutor, sienten que este les está comprendiendo, tienen la posibilidad de expresar todos sus pensamientos y dudas relacionados con el encuentro comunicativo, consideran que la duración de la interacción es suficiente para que ambos interlocutores puedan escuchar y decir todo lo necesario, y se sienten satisfechos en general con los resultados del intercambio comunicativo.

Un vez descritas las dificultades que pueden surgir en la asistencia a los pacientes lingüística y culturalmente diversos, pasamos a presentar brevemente la respuesta que se ha dado en el contexto español a dichas dificultades.

Las reacciones ante la llegada de la población inmigrante a los servicios sanitarios han sido muy diversas, y han ido desde la negación de la complejidad que entraña la asistencia a este colectivo, hasta el reconocimiento de las dificultades inherentes a la misma y la búsqueda de posibles soluciones que permitieran reducir o eliminar las barreras que causaban dichas dificultades. La estrategia adoptada más comúnmente ha consistido en el recurso por parte de los hospitales y centros de salud a intérpretes y mediadores ad hoc (generalmente familiares, amigos o conocidos de los pacientes o personas voluntarias), a los cuales raramente se les ha exigido que probaran su formación y preparación para actuar como intermediarios en la comunicación. De hecho, a menudo, el único criterio para seleccionarlos ha sido el conocimiento personalmente declarado de las dos lenguas de trabajo por parte de estos voluntarios y, por supuesto, la remuneración y el reconocimiento de su labor han sido en estos casos equivalentes $\mathrm{y}$, por tanto, tan pobres como los criterios aplicados para su selección (Mikkelson, 1999:10). Como demuestran numerosas investigaciones (Bischoff, Loutan y García, 2009; Flores, 2010; Sánchez-Reyes y Martín, 2005), la intervención de estas personas, más que facilitar la comunicación, puede conllevar consecuencias negativas, no solo por lo que respecta a la interacción comunicativa en sí, sino también, y lo que resulta más grave, en relación con la atención a la salud de los pacientes. 
Son escasos los servicios sanitarios que, por el contrario, han optado por contratar a intérpretes y mediadores profesionales $y$, en dichos casos, se ha cumplido en muchas ocasiones la descripción ofrecida por Holly Mikkelson (1999:10) sobre las condiciones laborales en las que estos deben desempeñar su labor, es decir, han sido contratados por hospitales públicos con presupuestos cada vez más limitados, y han debido trabajar, por un lado, para unos profesionales sanitarios con escasa formación antropológica y, además, mal pagados y sobresaturados $y$, por otro, para comunidades inmigrantes con escasos recursos $y$ un desconocimiento general del funcionamiento del sistema público de salud. $Y$, como en el caso del pez que se muerde la cola, todo ello ha provocado que gran parte de las personas que podrían llevar a cabo estas funciones adecuadamente perdiesen el interés por formarse y ejercer en este ámbito, y se dedicasen al desempeño de otras profesiones.

Observamos, por tanto, que la que podría ser una de las estrategias más exitosas a la hora de favorecer la comunicación intercultural en ámbito sanitario (el recurso a los intérpretes y mediadores profesionales) se encuentra actualmente en España carente del apoyo institucional y el reconocimiento que merecería.

Tras esta brevísima exposición de las dificultades que pueden surgir en la atención sanitaria a la población de origen extranjero residente en España, de las posibles causas de dichas dificultades, y de las principales actitudes y soluciones adoptadas hasta el momento, pasamos a presentar resumidamente las características y objetivos de nuestra investigación. ${ }^{5}$

El propósito principal de la presente tesis doctoral consiste en analizar el modo en el que se comunican los profesionales sanitarios y los pacientes procedentes de otros países y culturas, así como en estudiar en qué medida las barreras comunicativas a las que deben enfrentarse estos sujetos pueden dificultar el acceso y uso equitativo de los servicios sanitarios por parte de la población inmigrante.

En concreto y, partiendo de la base de que una de las áreas de la salud que más influenciada está por la cultura es la reproducción (Penn et al., 1995), la investigación se centra en el ámbito de la salud reproductiva, es decir, en la comunicación profesional-usuaria durante el embarazo, el parto y el puerperio.

Cabe resaltar que en España se ha producido una progresiva feminización de los flujos migratorios, y que las mujeres inmigrantes residentes en este país son mayoritariamente jóvenes y se encuentran, por tanto, en edad fértil, lo cual, sumado a las elevadas tasas de fecundidad que suelen presentar, ha conllevado un aumento considerable de su presencia en los servicios de ginecología y obstetricia. Dicho aumento ha fomentado la proliferación gradual de estudios (mayoritariamente cuantitativos y de carácter epidemiológico) que se ocupan de estudiar los patrones reproductivos de diferentes colectivos sociales y culturales. Sin embargo, siguen existiendo numerosas lagunas en este campo, especialmente por lo que se refiere a las investigaciones de corte cualitativo que podrían favorecer que existiera un mayor conocimiento y entendimiento de las prácticas y las necesidades específicas de las mujeres inmigrantes por lo que respecta a su salud reproductiva (Oliver, Baraza y Martínez, 2007:101).

\footnotetext{
${ }^{5}$ Por tratarse de una introducción, no nos detenemos, por el momento, a ofrecer mayores detalles. En los próximos capítulos, ampliaremos la información relativa tanto a las características de la comunicación intercultural en ámbito sanitario como al diseño metodológico y los objetivos de nuestro estudio.
} 
Así, como sostiene Mari Luz Esteban (2000:224),

La maternidad es uno de los ámbitos de la salud y de la experiencia general donde los factores sociales y culturales son más invisibles, tanto para la población general, como para los sanitarios y científicos sociales. En este sentido, el estudio de las representaciones, valores y vivencias concretas de mujeres y hombres, de las contradicciones entre discursos y prácticas, entre el nivel ideal y el real de la experiencia, de la variabilidad entre diferentes colectivos sociales y culturales, es fundamental para ampliar el análisis y poner de manifiesto los entresijos y consecuencias de dicha ideología, así como para ir contribuyendo a que la maternidad sea considerada dentro de la antropología y las ciencias sociales un ámbito de estudio y reflexión similar a otros.

Partiendo de esta carencia en cuanto a la investigación en este ámbito, nuestro estudio persigue el objetivo de analizar, desde el punto de vista tanto de las propias protagonistas (las mujeres inmigrantes) como de los profesionales de los servicios de obstetricia que las atienden, cuáles pueden ser las barreras que limitan o impiden el acceso y uso de dichos servicios por su parte, las causas que subyacen a estas barreras, y las estrategias que se podrían emplear para reducirlas o eliminarlas.

Concretamente, la investigación consiste en un estudio de caso contextualizado en un hospital materno-infantil de una ciudad española, en particular, de la ciudad de Zaragoza.

Por una parte, hemos analizado las dificultades comunicativas entre los profesionales sanitarios de dicho centro hospitalario y las usuarias de origen extranjero que acuden al mismo para realizar un seguimiento de su embarazo o para dar a luz. Por otra parte, hemos tratado de descubrir el origen de dichas dificultades (el cual, en principio y como ya hemos comentado, podría residir especialmente, aunque no únicamente, en las barreras lingüísticas y/o culturales), así como las consecuencias que de estas se derivan. Igualmente, aparte de las necesidades objetivas, hemos estudiado las necesidades percibidas por ambos grupos, es decir, su propia consideración de la existencia o ausencia de obstáculos que impiden la comunicación. Asimismo, hemos examinado los recursos de los que dispone el hospital para disminuir o superar las barreras comunicativas, y hemos comprobado si dichos recursos son suficientes y se emplean de manera eficaz.

Todo ello nos ha permitido, en última instancia, proponer una serie de acciones de mejora que podrían aumentar la eficacia de la comunicación intercultural entre los profesionales y las usuarias, las cuales, en consecuencia, ayudarían a promover la calidad de la asistencia sanitaria ofrecida a las gestantes y puérperas lingüística y culturalmente diversas. Podemos afirmar, por tanto, que esta investigación, mediante el compromiso con la realidad estudiada, pretende contribuir a fomentar posibles procesos de transformación futuros.

\subsection{Estructura de la investigación}

En este apartado, como su título indica, presentamos la estructura de nuestra investigación, y ofrecemos un resumen de los contenidos que hemos tratado en cada uno de los capítulos que componen esta tesis.

En el capítulo 1, de carácter introductorio, aparte de la justificación e hipótesis iniciales previamente presentadas, incluimos un apartado de contextualización en el que analizamos el 
ámbito y el universo en los que se centra nuestro estudio. Así, abordamos, por una parte, el fenómeno migratorio y, por otro, la organización y funcionamiento del sistema de salud y los servicios sanitarios. En ambos casos partimos de un enfoque general de los aspectos analizados y vamos gradualmente centrándonos en los sujetos principales y en el contexto específico de la investigación.

En el capítulo 2 describimos de manera detallada la metodología que hemos empleado en nuestro estudio. Iniciamos con la exposición de los objetivos generales y específicos perseguidos y del enfoque metodológico adoptado. A continuación, presentamos las estrategias de selección de los informantes, y las fuentes y técnicas de investigación utilizadas para recabar los datos. Seguidamente, explicamos las estrategias e instrumentos que hemos utilizado en el proceso de análisis de los datos obtenidos. Para concluir este capítulo, dedicamos dos apartados, respectivamente, a la justificación de la validez científica de la investigación y a la exposición de los aspectos éticos que hemos debido tener en cuenta a la hora de llevar a cabo el estudio de caso.

Los siguientes capítulos constituyen el bloque destinado al marco teórico de la investigación. En concreto, se ocupan del estudio de los tres grandes ámbitos en los que esta se centra.

En primer lugar, en el capítulo 3, dedicado a la comunicación intercultural, estudiamos las características propias de las interacciones comunicativas entre personas lingüística y culturalmente diversas. Por un lado, analizamos los elementos verbales y no verbales que intervienen en los intercambios comunicativos $y$, por otro, describimos a grandes rasgos las particularidades de los modelos conversacionales propios de las distintas culturas. Asimismo, enumeramos las principales barreras que pueden dificultar o impedir la comunicación intercultural, con especial énfasis, atendiendo a los fines de nuestra investigación, en las interacciones que tienen lugar entre los profesionales sanitarios y los pacientes que no comparten un mismo origen étnico y cultural. Por último, proponemos una serie de claves y pautas que podrían contribuir a garantizar la eficacia de la comunicación intercultural.

A continuación, en el capítulo 4, nos ocupamos del análisis de la relación entre la cultura y los comportamientos, creencias y actitudes concernientes al ámbito de la salud. En concreto, estudiamos de qué manera los diferentes modos de concebir la salud y la enfermedad, así como las percepciones y preferencias en cuanto a la prevención y la cura de las enfermedades pueden influir en la comunicación entre los profesionales sanitarios y los pacientes culturalmente diversos. Por lo que respecta al ámbito concreto de nuestra investigación, dedicamos un apartado específico a los distintos modos de percibir y vivir el proceso reproductivo.

Una vez descritas las barreras lingüísticas y culturales que pueden surgir en la comunicación entre el personal sanitario y los pacientes de origen extranjero, pasamos, en el capítulo 5, a presentar dos de las estrategias que, a nuestro modo de ver, pueden contribuir con más garantías de éxito a reducir o eliminar dichas barreras, las cuales consisten en el recurso a la interpretación en los servicios públicos y a la mediación lingüística y cultural. En particular, analizamos el estado de la cuestión de estas dos disciplinas, describimos el papel y las funciones que corresponden a los intérpretes y a los mediadores, los retos a los que estos se 
enfrentan, y los pasos que se deberían dar para que recibieran el reconocimiento profesional y social que les corresponde.

Tras la exposición de carácter teórico de estos tres grandes ámbitos, nos centramos en el propio estudio de caso realizado.

Comenzamos, en el capítulo 6, con una presentación descriptiva y exhaustiva de los datos recabados con cada una de las técnicas empleadas en nuestro estudio. Dividimos dicha presentación en diferentes bloques, los cuales se centran en los distintos aspectos de la asistencia a las usuarias de origen extranjero del hospital contexto de estudio y en la comunicación entre estas y los profesionales sanitarios. Por un lado, incluimos los datos obtenidos mediante el análisis documental y la observación no participante efectuada en nuestro trabajo de campo y, por otro, con el fin de dar voz a los propios sujetos estudiados, incluimos gran parte de las opiniones transmitidas por estos en las entrevistas y en los grupos de discusión en los que han participado.

Para finalizar, en el capítulo 7, exponemos las conclusiones a las que hemos podido llegar mediante la triangulación de todos los datos y la relación entre estos y anteriores investigaciones que versan sobre esta área de estudio. Retomando las hipótesis inicialmente planteadas, tratamos de describir las barreras lingüísticas y culturales que dificultan la comunicación entre las usuarias inmigrantes y los profesionales que las atienden, y analizamos las soluciones que ha adoptado el hospital contexto de estudio para fomentar dicha comunicación y la eficacia de las mismas. Por último, proponemos una serie de acciones y estrategias que podrían contribuir a mejorar la comunicación intercultural entre dichos sujetos, tanto en el ámbito concreto de nuestro estudio, como, por extensión, en el contexto nacional, entre las cuales resaltamos el empleo de intérpretes y mediadores.

\subsection{Contextualización}

Con el fin de contextualizar socialmente el universo y el ámbito en los que se sitúa nuestra investigación, en este apartado, abordamos, por un lado, el fenómeno de las migraciones y, por otro, la organización del sistema de salud y de los servicios sanitarios. Como se observará en las próximas páginas, en ambos casos, nuestro análisis parte de un enfoque general, para ir acercándose progresiva y respectivamente a los sujetos principales del estudio, las mujeres inmigrantes, y el contexto específico en el que este tiene lugar, un hospital materno-infantil de la ciudad de Zaragoza.

\subsubsection{El fenómeno migratorio}

En el presente apartado, como su título indica, tratamos el tema del fenómeno de las migraciones, por su relación directa con uno de los grupos generales de sujetos que estudiamos en nuestra investigación: la población inmigrante.

Partimos de un acercamiento global a dicho tema, en el que realizamos una breve descripción de los movimientos migratorios que se han dado en la historia de la humanidad. Somos conscientes de que resulta muy ambicioso abordar la complejísima naturaleza de las migraciones en escasas páginas; sin embargo, consideramos que el fenómeno migratorio per se no forma parte del núcleo central de nuestro estudio, sino que este se centra en un 
contexto (nacional, autonómico y, en última instancia, provincial y municipal) muy concreto. Por consiguiente, quisiéramos destacar que el primer subapartado es una simple introducción, con la que pretendemos presentar las características generales de la emigración/inmigración. Nuestra intención consiste, precisamente, en evidenciar la complejidad del fenómeno migratorio (y resaltar que los factores que motivan a una persona a emigrar pueden ser múltiples, que los flujos pueden tener orígenes y destinos muy variados, etc.), y en incidir, además, en el hecho de que, aunque con variaciones a lo largo de la historia, las migraciones siempre han existido y (casi) seguro que continuarán existiendo. En esta introducción, comentamos, además, las principales causas que pueden conducir a una persona a emigrar y las consecuencias que conlleva abandonar el lugar de origen para instalarse en otro.

En segundo lugar, analizamos concisamente la historia reciente de las migraciones que se han producido en Europa y en España. Seguidamente, nos centramos en el contexto específico de nuestro estudio, y presentamos los datos demográficos de los inmigrantes residentes en la comunidad autónoma de Aragón, así como los relativos a la población inmigrante de Zaragoza (provincia y ciudad). Cabe señalar que el objetivo que perseguimos al presentar los datos numéricos de la población extranjera residente en el contexto en el que se enmarca nuestra investigación (tanto en sentido amplio -Europa y España-, como en el sentido estricto Aragón y Zaragoza-) consiste, principalmente, en dejar constancia de la dimensión cuantitativa del fenómeno migratorio. No pretendemos, sin embargo, realizar un examen exhaustivo de la evolución de la población inmigrante, sino simplemente analizar su presencia y su contribución a las transformaciones sociales dentro del territorio europeo, español y aragonés.

A continuación, presentamos los principales modelos de gestión de la diversidad cultural que se han adoptado en los diferentes países receptores de inmigración, y esbozamos las características básicas del modelo adoptado en el contexto español para hacer frente a las nuevas situaciones y retos que plantea la presencia en nuestro país de personas procedentes de otros países y culturas.

Por último, concluimos el apartado de contextualización centrándonos ulteriormente en el ámbito y los sujetos principales de nuestro estudio (las mujeres inmigrantes), con unos breves apuntes sobre la inmigración femenina, en los que analizamos cuestiones como las diferentes tipologías de mujer emigrante/inmigrante, sus rasgos distintivos, las barreras y dificultades a las que deben hacer frente en la sociedad de acogida, su frecuente condición de discriminación y exclusión, y las vías de empoderamiento que pueden emplear para mejorar su situación.

\subsubsection{Breve descripción de los movimientos migratorios: pasado, presente y futuro}

La historia de la humanidad, desde tiempos inmemoriales, se ha relacionado estrechamente con el desplazamiento de un lugar a otro; dicho en otras palabras, las migraciones han existido siempre y continuarán existiendo.

En general, existen tres tipos de factores que condicionan los flujos migratorios y que intervienen, en ocasiones de manera simultánea y complementaria, como causas de la migración: 
1) factores de expulsión o alejamiento del país de origen, relativos a fenómenos como, por ejemplo, el empeoramiento de las condiciones de vida, el incremento demográfico, la situación política de opresión (guerras, dictaduras, etc.), o los factores ambientales y las catástrofes naturales;

2) factores de atracción por el país de acogida, relacionados a menudo con la globalización y la difusión de los modelos de vida occidentales, y que consisten en expectativas culturales, mejores posibilidades económicas, demanda de mano de obra, reagrupaciones familiares, etc.;

3) factores de elección personal, es decir, factores que condicionan la elección por parte de una persona de emigrar a un país o lugar en vez de a otro; entre estos, cabe mencionar la existencia de normas más o menos restrictivas por lo que se refiere al control de la inmigración, la presencia de una gran comunidad de personas procedentes del mismo país de origen, el clima, la lengua oficial del país de acogida, la aceptación social del extranjero en dicho país, etc.

Por otro lado, podemos clasificar las migraciones sobre la base de los siguientes ejes: de la obligatoriedad a la voluntariedad, de las cortas a las largas distancias entre el país de origen y el de acogida, y de la migración económica a la no económica (Jansá y García de Olalla, 2004:207).

En resumen, tal y como se afirma en un documento sobre migración publicado por la Organización Internacional para las Migraciones (2006):

Las personas siempre se han movilizado dentro de su región o de una región a otra con el fin de mejorar su nivel de vida, proporcionar a sus hijos mayores oportunidades para salir adelante $o$ escapar de la pobreza, la guerra y el hambre. Esta es la regla de oro que ha regido la migración desde los albores del tiempo.

Los procesos migratorios son enormemente selectivos, ya que solo determinados individuos abandonarán su lugar de origen, y quienes lo hagan no se dirigirán inconscientemente hacia cualquier país con más recursos que el suyo que les prometa acogerles. Por el contrario, las vías de las migraciones presentan una estructura reconocible, conectada con las relaciones e interacciones que se establecen entre el país de origen y el de acogida y, además, estas vías van variando con el paso del tiempo. De hecho, si analizamos el fenómeno migratorio centrándonos en los movimientos de población entre grandes territorios, podemos observar cómo en las últimas décadas se han producido algunos cambios de tendencia. Así, mientras que en los últimos siglos el flujo de emigrantes partía principalmente desde los países europeos para instalarse en los Estados Unidos, Canadá, Brasil, Argentina o Australia, en la actualidad, los países de origen son en su mayoría iberoamericanos, asiáticos y africanos, y los países receptores se encuentran fundamentalmente en Norteamérica y Europa Occidental (Oliva y Pérez, 2009:1).

Asimismo, cabe considerar que el fenómeno de la migración es principalmente un acto sociológico. Un individuo o una familia abandonan su país de origen para trasladarse a otro por razones que, como ya hemos comentado, pueden ser múltiples: políticas, económicas, personales, etc. Independientemente del motivo por el cual se decide emigrar, se trata de un acto que requiere fuerza y valor, puesto que, para el emigrante, dejar el propio país para ir a 
otro significa abandonar su universo, sus puntos de referencia, de protección y apoyo, y reconstruir todo, desde la lengua y las pertenencias, hasta los lazos sociales y los modos de pensar, sentir y actuar.

Así, la migración se puede definir como un largo proceso que causa profundos cambios en la identidad del sujeto. En palabras de Marta Castiglioni (1997:15), emigrando se produce un "punto de ruptura", una pérdida de orientación o referencia, que conducirá a la adopción de una nueva "estrategia identitaria".

En este mismo sentido, cabe citar la opinión de Adel Jabbar (2006:83) con respecto al proceso de transformación de la propia identidad por el que atraviesa generalmente la persona que decide emigrar, caracterizado por la adquisición e interiorización de nuevos elementos socioculturales, o por lo que este autor denomina ciudadanización:

II mondo di questi soggetti è innazi tutto un mondo "scosso", poiché la loro identità rimane, almeno inizialmente, come incompiuta, sospesa fra il paese di origine e il luogo di arrivo. Si tratta dunque di un'identità costretta ad attraversare un processo di trasformazione. Lo straniero intraprende in effetti un percorso di ricomposizione della propria identità. Durante questo processo gli universi simbolici originari si rielaborano alla luce delle nuove condizioni materiali, sociali e culturali, dando luogo ad un'identità soggettiva [...]. È evidente che la permanenza nella realtà ospitante richiede allo straniero di percorrere un secondo processo di socializzazione, o forse, meglio, di cittadizzazione, ossia di progressiva acquisizione e interiorizzazione degli elementi socioculturali, relazionali, ecomici e istituzionali che caratterizzano la società di arrivo. (cursivas y comillas del original)

En los inmigrantes se produce, en consecuencia, lo que Young Yun Kim (2004:339) denomina "cross-cultural adaptation", que consiste en un proceso de adaptación cultural en el que "on relocating to an unfamiliar sociocultural environment, strive to establish and maintain a relatively stable, reciprocal and functional relationship with the environment". Para esta autora, sin embargo, este proceso de transformación personal en el que se modifican algunos de los patrones culturales propios con el fin de entender el funcionamiento de la sociedad de acogida y desenvolverse con éxito en la misma no debe suponer obligatoriamente el rechazo de la cultura original, sino la creación de una nueva identidad cultural en la que se conjugan elementos antiguos y nuevos.

Por otro lado, en numerosas ocasiones, las personas que emigran, divididas entre dos países, dos universos sociales, dos contextos divergentes en muchos de sus aspectos, se esfuerzan por ocultar a los demás y a sí mismos las contradicciones de su situación, convenciéndose de su carácter provisional, cuando en realidad probablemente se prolongará en el tiempo e incluso será definitiva. Otras veces, el abandono del país de origen conlleva la idealización del mismo, con el fin de garantizar una estabilidad que el cambio geográfico ha disminuido o anulado.

Por parte de las sociedades de acogida, la actitud ante estos fenómenos migratorios adopta a menudo una visión etnocéntrica y parcial, puesto que no se tienen en cuenta las condiciones de origen y las características socioculturales de los emigrados; parece como si la existencia de los mismos comenzase en el momento en el que llegan al país receptor, es decir, se considera 
solo su carácter de inmigrantes ${ }^{6}$ y no el de emigrantes. Tal y como afirma Lucien Hounkpatin (2003:18),

Migrare [...] comporta due sensi: emigrare e migrare. Emigrare è lasciare, perderé l'involucro dei luoghi, suoni, odori, sensazioni di ogni tipo, che costituiscono le prime impronte sulle quali si è impiantato il codice di funzionamento psichico. Tanto quanto immigrare è ricostruire soli, nello spazio di qualche anno, quello che generazioni hanno lentamente elaborato e trasmesso.

Del mismo modo, es posible que en el país de acogida se vea la llegada de inmigrantes como algo alarmante o transitorio, que más tarde o más temprano llegará a su fin. Raramente se tiene en cuenta un aspecto importante del fenómeno: la posibilidad de recibir notables aportaciones de las personas procedentes de otros países y culturas, ya que las diferencias (y las semejanzas) entre "ellos" y "nosotros" pueden conllevar una reflexión sobre los propios valores y prácticas culturales y, en definitiva, un enriquecimiento cultural.

Hoy en día, paradójicamente, por una parte, se trabaja con el fin de crear áreas económicas sin fronteras, en las que circulen libremente mercancías y capitales y, por otra, se efectúan controles y cierres a los flujos migratorios para impedir la llegada de inmigrantes. ${ }^{7}$ De este modo, por ejemplo, en Europa, con la constitución de la Unión Europea,

[...] a la par que nace una nueva dimensión de la ciudadanía -la comunitaria, que integra a los nacionales de los diversos Estados que conforman este nuevo espacio supra-estatal- aparece el no-ciudadano o inmigrante no documentado desprovisto de los elementales derechos de la ciudadanía. (Bonilla, 2004:48)

A pesar de los esfuerzos que se realizan por frenarlas, las migraciones se han convertido en uno de los temas decisivos para entender e interpretar las relaciones internacionales y los grandes cambios que se están dando en el mundo desde un punto de vista tanto social y cultural, como económico y político. Así, de acuerdo con un informe sobre migración internacional y desarrollo publicado por la Secretaría General de las Naciones Unidas (2006:5):

Throughout human history, migration has been a courageous expression of the individual's will to overcome adversity and to live a better life. Today, globalization, together with advances in communications and transportation, has greatly increased the number of people who have the desire and the capacity to move to other places.

\footnotetext{
${ }^{6}$ Cuando hablamos de inmigrantes, nos referimos a personas de origen o de nacionalidad extranjeros que residen en un lugar diferente a aquel en el que nacieron. Sin embargo, cabe destacar que existe gran variedad y heterogeneidad de atribuciones posibles en la construcción de esta categoría y, de hecho, a menudo discrepan el significado que se da a este concepto en el discurso social y el construido bajo los cánones de las ciencias jurídicas y demográficas (Gijón, 2010:93). Así, en el imaginario colectivo, se asocia con frecuencia este término a las personas procedentes de países menos desarrollados, concediéndole un carácter negativo, e incluso se atribuye esta calificación a personas nacidas en el país de acogida, pero cuyos padres proceden de otros países. Por el contrario, en ocasiones, no se identifica bajo esta denominación a las personas provenientes de países más ricos que, por uno u otro motivo, se trasladan a vivir a un determinado país.

${ }^{7}$ Cabe señalar que dichos cierres y controles son contrarios a la Declaración Universal de los Derechos Humanos, en la que, como veremos en el apartado de análisis documental del capítulo 6, se estipula el derecho de todas las personas a circular libremente y a elegir su lugar de residencia.
} 
De acuerdo con los datos ofrecidos por distintos organismos internacionales, ${ }^{8}$ existen actualmente en el mundo más de 230 millones de migrantes internacionales, los cuales suponen aproximadamente el $3,2 \%$ de la población mundial.

La lista de países en los que reside un mayor número de extranjeros la encabezan, según se afirma en el último informe sobre desarrollo publicado por las Naciones Unidas (2013), los Estados Unidos (con 45,8 millones de inmigrantes), seguidos de Rusia (con 11 millones), Alemania (donde residen 9,8 millones), y los Emiratos Árabes Unidos y el Reino Unido (los cuales cuentan con 7,9 millones cada uno). En sexto lugar, se encuentra Francia (con una población inmigrante que asciende a 7,4 millones), a la que siguen Canadá (con 7,3 millones), Australia (con 6,5 millones), y España (5,5 millones), la cual ocupa el décimo puesto.

Si bien, normalmente, al hablar de flujos migratorios, se suele pensar casi exclusivamente en los movimientos que se producen entre los países menos desarrollados y aquellos con un nivel más alto de desarrollo, cabe considerar que, en la actualidad, "menos de la mitad del total de los migrantes internacionales se desplaza de Sur a Norte, ${ }^{9}$ y prácticamente el mismo número se desplaza entre los países del Sur" (Laczko y Anich, 2013:36).

Es posible hablar de cuatro tendencias o direcciones que caracterizan los flujos migratorios actuales (Anich, Brian y Laczko, 2013:55-57):

- Norte-Norte: con flujos que parten, por ejemplo, de Alemania a los Estados Unidos, del Reino Unido a Australia, o de Canadá, la República de Corea y el Reino Unido a los Estados Unidos. Estos flujos representan el $17 \%$ del total.

- Sur-Sur: con flujos procedentes, por ejemplo, de Ucrania a la Federación de Rusia (o a la inversa, de la Federación de Rusia a Ucrania), de Bangladesh a Bután, y de Kazajstán a la Federación de Rusia y Afganistán. Otro ejemplo de esta dirección en los flujos migratorios está representado por los movimientos que se producen entre diferentes países del África Occidental, caracterizados por la inmigración procedente de, por ejemplo, Malí, Burkina Faso, Guinea Bissau, Guinea Conakry, Liberia, o Sierra Leona que se traslada a países como Senegal y Costa de Marfil. A pesar de la poca atención que suelen recibir este tipo de flujos migratorios en la literatura al respecto, estos suponen casi el mismo porcentaje (equivalente a un $35 \%$ del total) que los desplazamientos que se producen entre los países del Sur y los del Norte.

- Sur-Norte: con flujos de México y de algunos países de Centroamérica (como Guatemala o El Salvador) a los Estados Unidos, de Turquía a Alemania, y de China, Filipinas y la India a los Estados Unidos, por citar algunos. Se trata de la corriente migratoria más importante (representa el $45 \%$ del total) y la que ha aumentado más en las últimas décadas. La mayoría de los flujos migratorios que recibe España, como veremos más adelante, se encuadraría dentro de esta corriente, pues, entre los países de procedencia de la población inmigrante residente

\footnotetext{
${ }^{8}$ Por lo que respecta a los datos globales sobre los flujos migratorios, se ha recopilado principalmente la información relativa a los últimos años ofrecida por la Organización de las Naciones Unidas (ONU), la Organización para la Cooperación y el Desarrollo Económicos (OCDE), y la Organización Internacional para las Migraciones (OIM). Véase bibliografía.

${ }^{9}$ En el informe elaborado por la Organización Internacional para las Migraciones del que se ha extraído esta cita se explicita que, por países del "Norte", se entienden los países de ingresos altos y, al indicar a los países del "Sur", se hace referencia a los países de ingresos bajos y medios, de conformidad con la clasificación propuesta por el Banco Mundial.
} 
en nuestro país, destacan los que se consideran "países del Sur", principalmente de África y Latinoamérica.

- Norte-Sur: con flujos que van, por ejemplo, de los Estados Unidos a México y Sudáfrica, de Alemania a Turquía, de Portugal a Brasil, o de Italia a Argentina. Se trata de los desplazamientos menos cuantiosos (3\%) y cuyo número ha variado menos en las últimas décadas. ${ }^{10}$ Este tipo de flujos migratorios están impulsados por diversos motivos, entre los que se encuentran la intención de explorar nuevas oportunidades económicas en el mercado mundial, o el deseo de estudiar o de jubilarse en el extranjero.

Por lo que se refiere a las características principales de los emigrantes y, más concretamente, en relación con su sexo, en términos generales, podemos afirmar que la mayoría son hombres, salvo en el caso de la migración Norte-Norte, en la que predominan las mujeres (Anich, Brian y Laczko, 2013:67). También pueden darse variaciones en el porcentaje de hombres y mujeres que emigran en base al país de procedencia, como veremos detalladamente en los datos que presentamos en los siguientes subapartados.

En cuanto a la edad de los emigrantes, estos suelen ser mayoritariamente jóvenes. En concreto, el porcentaje de inmigrantes que no superan los 24 años de edad es mucho más elevado en el Sur que en el Norte. En el Norte, los inmigrantes tienen una mayor presencia en los grupos de población en edad de trabajar (principalmente, se trata de personas con edades comprendidas entre los 25 y los 49 años). Por último, en el Sur, los inmigrantes constituyen un porcentaje más alto en los grupos de personas mayores, sobre todo en comparación con los nacionales; la edad elevada cobra una especial relevancia en el caso de las corrientes NorteSur, por la presencia de jubilados que deciden emigrar a otros lugares donde el nivel de vida es menor que en sus países de origen.

A pesar de que la actual crisis económica mundial ha conllevado un receso en los flujos migratorios, estos continúan, aunque a marchas menos aceleradas. Asimismo, el ligero descenso en los flujos que han experimentado los países con mayores dificultades económicas (como España, Islandia, Irlanda y Portugal) se ha visto compensado por el número de inmigrantes recibidos por países menos afectados por la crisis (como Dinamarca, Noruega, los Países Bajos o Suiza), en los que el saldo migratorio neto es incluso mayor al registrado en el periodo antecedente a la recesión económica (OCDE, 2013:18).

El fenómeno migratorio, como indican las diversas fuentes consultadas, está destinado a aumentar y perdurar, al menos en el futuro más inmediato. A pesar de las repercusiones negativas que, en ocasiones, se mencionan al tratar el tema de los flujos migratorios internacionales, cabría destacar el enorme potencial positivo de la migración en términos sociales, culturales, económicos y políticos. Al respecto, nos gustaría concluir este subapartado citando las palabras del entonces Secretario General de las Naciones Unidas, Kofi Annan (2006:5), en su informe sobre inmigración internacional y desarrollo:

\footnotetext{
${ }^{10}$ Cabe señalar que los desplazamientos de Norte a Sur están aumentando en el último periodo. Así, a pesar de que quizás es demasiado pronto para que los cambios en esta corriente de migraciones queden reflejados en las bases de datos mundiales, los casos de países concretos y los hechos observados parecen indicar que esta tendencia está adquiriendo una importancia creciente (Anich, Brian y Laczko, 2013:79).
} 
The advantages that migration brings, both to migrants and to the societies they join, are not as well understood as they should be. Migration stirs passionate debate. [...] For all the good it can bring, it can also generate social tensions. [...] Nevertheless, the answers to many of the problems raised by migration may be found through constructive engagement and debate. This will lead to a broader recognition of the enormous benefits and opportunities that migration provides.

\subsubsection{Historia reciente del fenómeno migratorio en Europa y en España}

Como hemos comentado en la parte introductoria del presente apartado, este subapartado está dedicado, por una parte, al fenómeno de las migraciones que han tenido lugar en Europa a lo largo de los últimos siglos y, por otra, al estudio de los flujos migratorios recibidos por España en las pasadas décadas y las características principales de la población inmigrante que actualmente reside en este país. Las fuentes consultadas para extraer los datos que aquí presentamos han sido, fundamentalmente, la Oficina Estadística de la Comisión Europea (Eurostat), por lo que respecta al contexto europeo, y el Instituto Nacional de Estadística (INE), en referencia al territorio español. ${ }^{11}$

Por lo que se refiere a la inmigración en Europa, este ha sido el continente que ha vivido más procesos migratorios. Se calcula que entre 1750 y 1990 abandonaron sus países de origen más de 140 millones de europeos.

Comenzando nuestro análisis desde el pasado siglo, cabe comentar que la Segunda Guerra Mundial (1939-1945) supone un cambio decisivo en las migraciones europeas. El continente se divide en dos mitades: por una parte, los países receptores, como Francia, Alemania, Suiza, Bélgica o Inglaterra, los cuales, una vez iniciado el proceso de reconstrucción e industrialización después del conflicto bélico, presentan una gran demanda de mano de obra; por otra, los países de emigración, situados en el sur de Europa, como España, Italia, Grecia y Portugal. Estos últimos ya habían experimentado procesos migratorios a otros continentes en el pasado y, en este periodo, comienzan a cambiar el destino de sus migraciones.

La situación de los países del sur de Europa varía sobre todo a partir de los años ochenta, principalmente a causa de los importantes avances en su desarrollo. En esta década, desciende enormemente el número de emigrantes y se inicia en estos países un doble proceso de inmigración: por un lado, regresan algunos de los emigrados en décadas anteriores y, por otro, comienzan a recibir inmigración procedente del exterior.

Los años noventa presentan una novedad: la existencia simultánea de un crecimiento económico y un descenso demográfico favorece el aumento de la inmigración en general, incluidos los países de la llamada Europa mediterránea que, con anterioridad, habían sido más bien lugares de tránsito hacia el norte de Europa. De todos modos, a diferencia de España e

\footnotetext{
${ }^{11}$ Si bien podríamos haber consultado una única fuente, pues, con la entrada en vigor del Reglamento 862/2007 del Parlamento Europeo y del Consejo de Estadísticas de Migraciones y Protección Internacional, desde el año 2009 los estados miembros de la UE han ido proporcionando información sobre los flujos migratorios que reciben a la Oficina de Estadística de la Comisión Europea, la cual los publica en su página web, hemos comprobado que la información sobre España proporcionada por Eurostat no coincide con los datos del INE, por lo que hemos decidido usar una fuente distinta para cada contexto. Al respecto, podemos señalar que, como se afirma en un documento reciente del Instituto Nacional de Estadística (2013:17), "la conciliación entre cifras de migración internacional es todavía objeto de estudio y debate a nivel mundial".
} 
Italia, en el resto de países de la cuenca mediterránea (Grecia y Portugal), la presencia de inmigrantes no alcanza cifras tan considerables. Es en esta época cuando se "consolida la dimensión universal del fenómeno migratorio" (AEP Desenvolupament Comunitari y Andalucía Acoge, 2002:39). Así, como sostiene Lorenzo Cachón (2002:99, citado en Coduras y Gómez, 2008:167),

[...] consecuencia del nuevo desorden mundial (Hobsbawn, 1998) que vivimos, en donde los factores que vienen explicando las migraciones [...] se han complejizado, por primera vez, la posición de España (y la de los otros tres países comunitarios del sur de Europa) en el sistema migratorio europeo tiene la misma hora que la de los países del centro y del norte de la UE, tanto por su situación como país inmigrante como por los desafíos y políticas que esta situación requiere.

Desde principios de este nuevo siglo, los flujos migratorios recibidos por Europa han experimentado un constante aumento, hasta alcanzar, en el año 2011, los 33,3 millones de extranjeros residentes en los países de la UE, equivalentes a un 6,6\% del total de la población (Vasileva, 2012). ${ }^{12}$ Este número ha sido superado en el año 2012, en el que se alcanza la cifra de 34,3 millones. La gran mayoría de estos extranjeros (20,7 millones) proceden de países de fuera de la UE, mientras que los 13,6 millones restantes son originarios de países de la Unión (Eurostat, 2013).

En concreto, en referencia a las zonas de procedencia de los inmigrantes residentes en la Unión Europea, como acabamos de comentar, casi el 35\% de la población extranjera procede de otro estado miembro, y el $65 \%$ restante se distribuye por áreas de la siguiente manera:

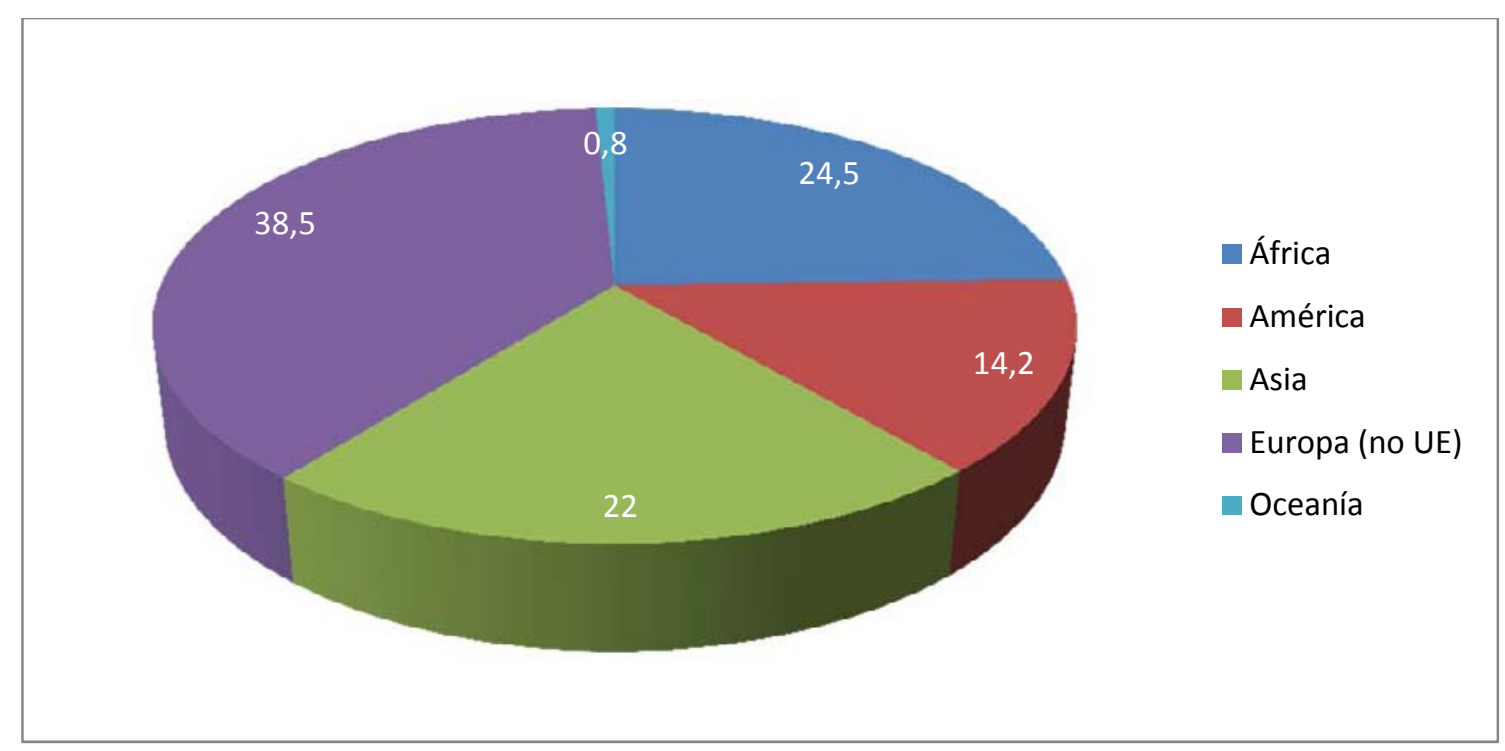

Gráfico 1.2. Áreas geográficas de procedencia de la población extranjera residente en la UE (excluidos los originarios de los estados miembros) a 1 de enero de 2012

(Fuente: Eurostat)

Dentro de cada una de estas zonas, destaca el número de inmigrantes procedentes de Albania, Turquía y Ucrania, por lo que respecta a los países europeos de fuera de la UE, los originarios

${ }^{12}$ Estas cifras son superiores si se consideran no solo a los extranjeros, sino también a aquellos que, habiendo nacido en el extranjero, han adquirido la nacionalidad de uno de los países de la UE, en cuyo caso se contabilizarían 48,9 millones, que representarían un 9,7\% de la población total. 
del norte de África, principalmente Marruecos y Argelia, por lo que se refiere a dicho continente, los chinos y los indios, en cuanto a los que provienen de Asia, y los de Ecuador y los Estados Unidos, en relación con América.

En referencia al sexo de la población inmigrante, de acuerdo con los datos más recientes proporcionados por Eurostat (2013), predominan ligeramente los hombres (52,1\%) con respecto a las mujeres $(47,9 \%)$.

$\mathrm{Y}$, en cuanto a la edad de la población extranjera residente, tal y como puede apreciarse en el gráfico que mostramos a continuación, esta es de media bastante más joven $(34,7$ años) que la población europea autóctona (41,9 años).

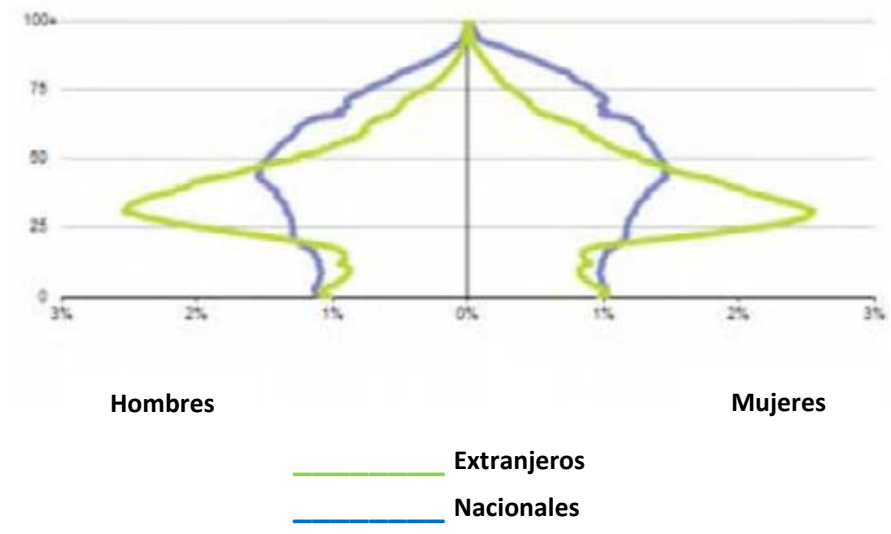

Gráfico 1.3. Pirámide poblacional de Europa a 1 de enero de 2012 (Fuente: Eurostat)

Cabe señalar que la creciente presencia de inmigrantes de sexo femenino, sumada a la edad joven ( $y$, por tanto, fértil) que presenta este segmento de la población, de acuerdo con los datos sobre fertilidad proporcionados por Eurostat (2012), pueden haber contribuido al ligero aumento que ha experimentado el número de nacimientos que se han dado en la Unión Europea en los últimos años, tal y como puede observarse en el siguiente gráfico:

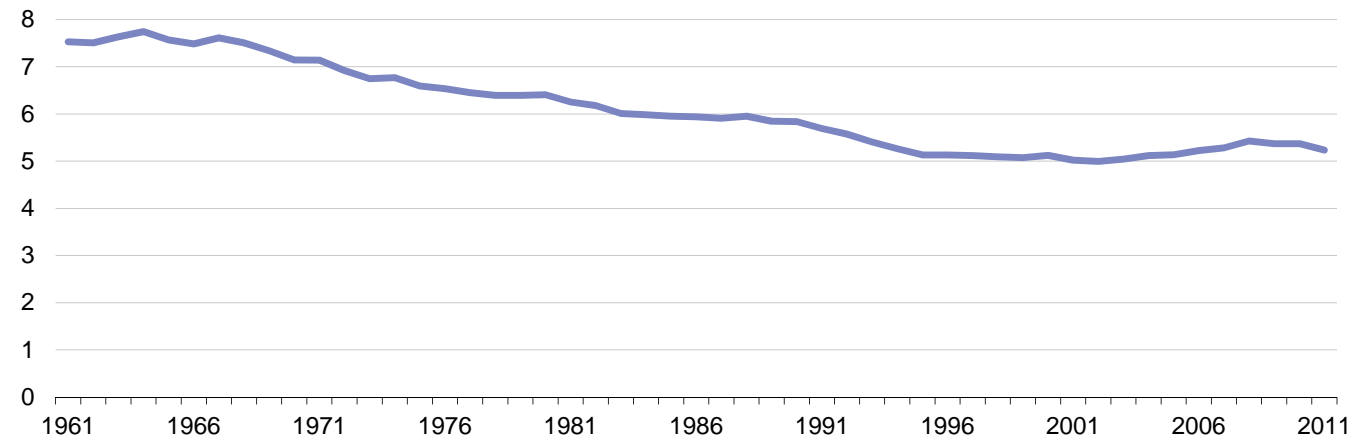

Gráfico 1.4. Evolución del número de nacimientos (en millones) en la UE (1961-2011) (Fuente: Eurostat) 
Por otro lado, la población extranjera en este continente, siempre de acuerdo con los datos de Eurostat (2013) relativos al año 2012, se distribuye de la siguiente manera:

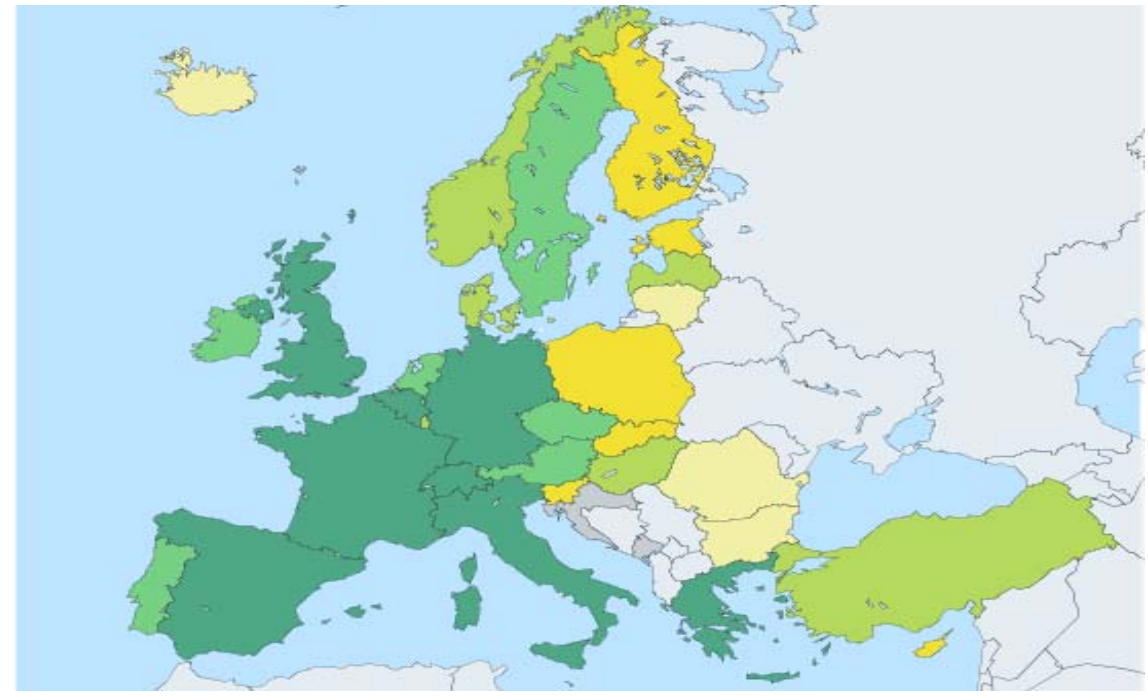
$12144-42423$
$42423-206558$
$206558-409193$
$409193-947717$
$947717-7409754$
Datos no disponibles

Gráfico 1.5. Distribución de los extranjeros residentes en los países europeos a 1 de enero de 2012 (Fuente: Eurostat)

Como puede apreciarse en el mapa que acabamos de mostrar, continúan siendo metas privilegiadas los clásicos países receptores, como Alemania, Francia y Reino Unido, pero a ellos se suman países como Italia o España. Estos cinco países acogen, de acuerdo con datos proporcionados por la Oficina Estadística de la Comisión Europea (Vasileva, 2012), a más del $75 \%$ de la población extranjera residente en Europa. Cabe señalar, sin embargo, que si bien presentan un mayor número de extranjeros residentes en términos absolutos, en términos relativos destacan países como Austria, Bélgica, Chipre, España, Estonia, Lituania y Luxemburgo, cuya población extranjera supera el 10\% de la población total nacional (Eurostat, 2013:3). 
Concretamente, como se observa en el gráfico presentado a continuación, entre los cinco países con mayor número de inmigrantes, encabeza la lista Alemania, seguida por España. Poco detrás se encuentran Italia y el Reino Unido, los cuales presentan un número similar de extranjeros residentes y, por último, se sitúa Francia.

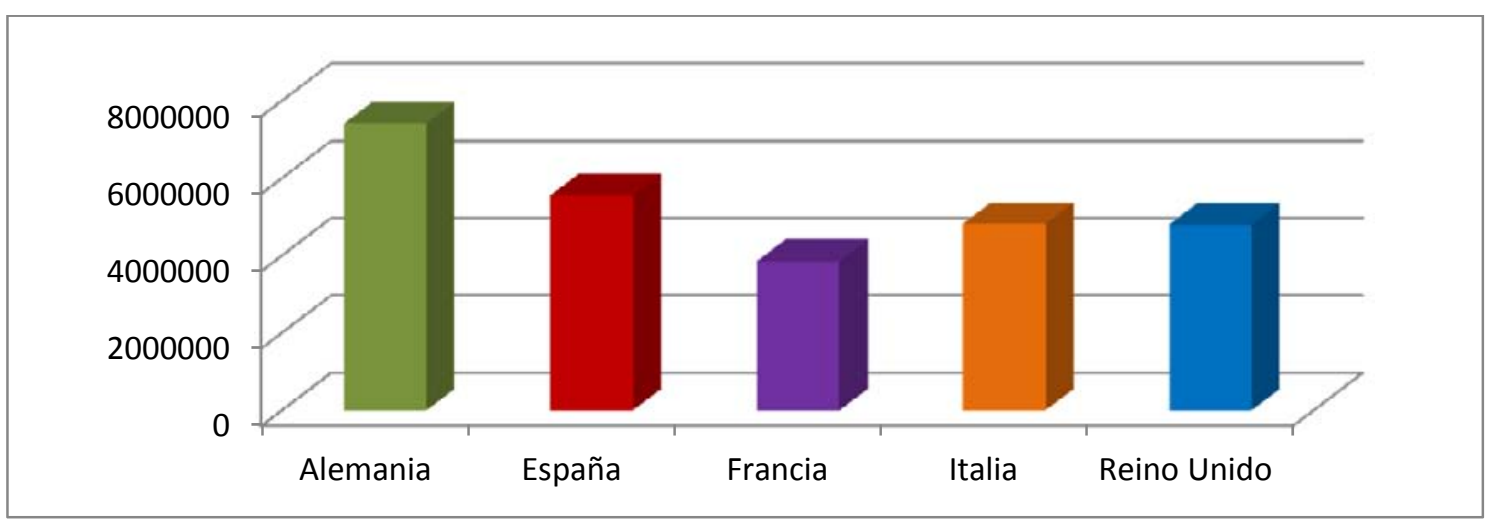

Gráfico 1.6. Países de la UE con mayor número de población extranjera residente a 1 de enero de 2012 (Fuente: Eurostat)

En cuanto a los países de origen de los extranjeros residentes en la UE, a finales del año 2011, tal y como se puede apreciar en el gráfico que mostramos a continuación, los procedentes de Rumanía y Turquía son los inmigrantes más numerosos y, en ambos casos, exceden los 2,3 millones. El tercer grupo de extranjeros más cuantioso está constituido por los originarios de Marruecos, con 1,9 millones, seguido por los de Polonia, con 1,6 millones.

Cabe, además, mencionar que algunos estados miembros de la UE, en particular, Italia, el Reino Unido y Alemania, se encuentran a finales de 2011 tanto entre los más importantes receptores de inmigrantes, como entre los principales lugares de origen de los extranjeros residentes en la UE. Este fenómeno se puede explicar, por un lado, por las elevadas cifras de población total de estos países $y$, por otro, por la gran movilidad de ciudadanos que se da dentro del espacio de la Unión.

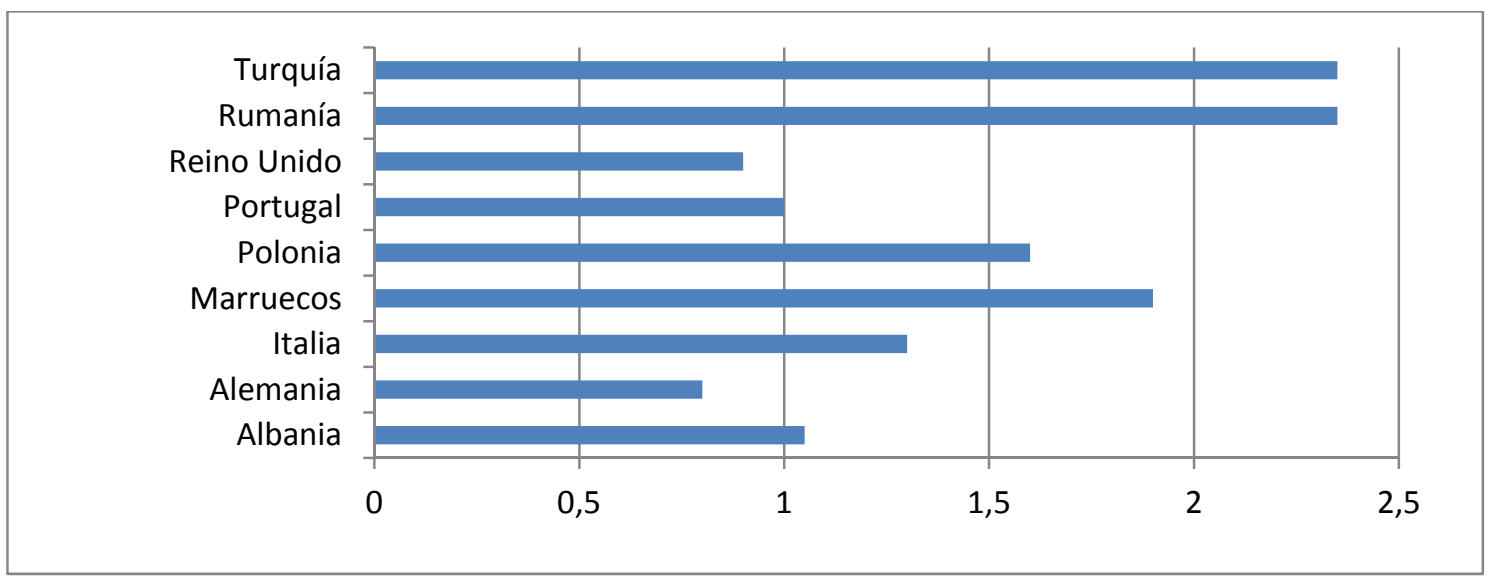

Gráfico 1.7. Principales nacionalidades de los extranjeros residentes en la UE a 1 de enero de 2012 (Fuente: Eurostat)

Al estudiar la distribución de los extranjeros de acuerdo con su país de origen, es posible observar que, a menudo, una gran proporción de los mismos se asientan en uno o dos estados 
miembros determinados. Así, por ejemplo, de acuerdo con las estimaciones realizadas por la Oficina Estadística de la Comisión Europea (2013), el 78\% de los rumanos que residen en otro país de la UE se encuentran en Italia (42\%) o en España (36\%), mientras que el $75 \%$ de los extranjeros originarios de Turquía viven en Alemania. Asimismo, el $88 \%$ de los marroquíes que han emigrado a la UE se hallan en España, Francia o Italia, y el $64 \%$ de los procedentes de Polonia viven en el Reino Unido o en Alemania. Igualmente, casi todos los extranjeros de Albania se han trasladado a Grecia o Italia, y la mitad de los portugueses residentes en otro país de la UE se encuentran en Francia.

En líneas generales, los factores que conducen a la elección de uno u otro país de destino pueden resumirse en una combinación entre la proximidad geográfica, la existencia de una lengua oficial igual o similar, los vínculos históricos, la demanda de mano de obra, las redes de inmigrantes previamente establecidas, y las oportunidades de movilidad dentro del Espacio Europeo. Tal y como sostiene Katya Vasileva (2012), normalmente, los inmigrantes se suelen asentar en países próximos, tanto por las cortas distancias de desplazamiento que ello supone, como por las semejanzas lingüísticas y culturales que pueden existir entre el país de origen y el de destino. Del mismo modo, existen flujos migratorios relacionados con el pasado colonial de determinados países, incluso cuando dicha colonización llegó a su fin largo tiempo atrás, como es el caso de las excolonias del Reino Unido y los Países Bajos. De manera similar, en el asentamiento de extranjeros en un determinado lugar influye también la pasada configuración de algunos países o la fragmentación de los mismos (como es el caso de la antigua Unión Soviética o la ex Yugoslavia, gran parte de cuyos ciudadanos han emigrado a países como Lituania y Eslovenia). Además, las guerras, como las que se han dado en países como Irak o en Yugoslavia, junto con las redes previamente establecidas de flujos migratorios de personas originarias de estas zonas, pueden explicar el gran número de refugiados procedentes de las mismas que se han trasladado a países como Suecia. ${ }^{13}$ Por último, las sucesivas ampliaciones de la Unión Europea, unidas al hecho de que, en algunos países, existe una mayor demanda de mano de obra, pueden justificar, por ejemplo, el gran número de rumanos que viven en España e Italia, o la gran cantidad de polacos residentes en el Reino Unido, Noruega, Dinamarca e Islandia.

En relación con esta última cuestión señalada, cabe destacar que, en Europa, con la creación y ampliación progresiva de la UE, se han ido estrechando los lazos de cooperación entre los estados miembros para eliminar fronteras internas $y$, al mismo tiempo, frenar o contener la llegada de personas procedentes de países terceros. Por un lado, se han endurecido gradualmente los requisitos para acceder de manera regular al Espacio Europeo, pero, por otro, han aumentado de forma considerable los modos y lugares de entrada y la permanencia irregular. De todas maneras, todavía queda mucho por hacer en materia de consenso y acuerdos conducentes a una unificación legislativa europea en materia de inmigración. Así,

A la hora de hablar de la realidad europea, o del contexto europeo de la inmigración, hemos de tener ciertas precauciones y evitar dos extremos que pueden falsear nuestro análisis: el de pensar en el espacio de la Unión Europea como un todo uniforme y, por el otro extremo,

\footnotetext{
${ }^{13}$ Otro ejemplo que podríamos aportar en referencia a los flujos migratorios provocados por guerras y conflictos, aunque tal vez sea demasiado pronto para poder extraer datos concluyentes, estaría representado por los países protagonistas de lo que se ha venido a denominar "la primavera árabe", como, por ejemplo, Egipto y Siria.
} 
entender la realidad y las políticas migratorias como aisladas y ajenas entre los países y regiones. (AEP Desenvolupament Comunitari y Andalucía Acoge, 2002:40)

Asimismo, quisiéramos señalar que, si bien normalmente se incide en su condición de trabajadores al considerar a los inmigrantes que llegan a España o al resto de Europa (los cuales, además, dicho sea de paso, suelen ocupar los puestos laborales menos deseados por los autóctonos, como pueden ser los del sector de la construcción, la hostelería, la agricultura y los cuidados de niños y ancianos),

[...] resulta evidente que su cotidianeidad en los países de destino engloba más facetas que las meramente laborales. Una de las cuestiones fundamentales con las que se enfrentan los países receptores de inmigración es la consecución de una convivencia armoniosa entre los nuevos y los antiguos habitantes. Para que esto sea así se debe aceptar la idea de los inmigrantes como ciudadanos de las estructuras sociales en las que se insertan y no únicamente como "aves de paso" (Díaz, 2009:80). (comillas del original)

Por lo que respecta concretamente a la inmigración en España, como hemos comentado, representa un punto de atracción migratoria solo desde hace unas décadas. Así, tal y como sostiene Magdalena Díaz (2009:70),

España se constituye en un claro ejemplo de las transformaciones acaecidas en los procesos migratorios en base al desarrollo de las nuevas dinámicas globales y a las cambiantes realidades y necesidades sociales que éstas han generado. La posición de España en la ecuación migratoria se ha transformado sobremanera en las últimas décadas y el país se ha convertido en un actor protagonista dentro del tan manido cambio de país de emigración a uno de inmigración.

Numerosos estudios sitúan a mediados de los años ochenta el periodo clave en el que se inicia la inversión de tendencia que señala el paso de un país de emigración a un país de inmigración. Desde ese momento, la presencia de ciudadanos extranjeros en España ha ido aumentando, hasta llegar a incluir a un elevado número de personas con múltiples nacionalidades establecidas en todas las regiones del territorio español, aunque su distribución geográfica, como veremos un poco más adelante, es bastante desigual, y se concentra especialmente en algunas comunidades autónomas. De hecho, el relativamente reciente fenómeno migratorio en España está caracterizado por la magnitud de la población recibida, la velocidad de su llegada en un corto espacio de tiempo, y la gran diversidad de los países de origen (Oliva y Pérez, 2009:1). Asimismo, una de las particularidades del fenómeno actual de la migración en España es "su constitución como país de destino final deseado, con asentamientos permanentes o a largo plazo, y no ya como mero trampolín hacia otros destinos de la Unión Europea y del mundo" (Díaz, 2009:71).

Cabe señalar, sin embargo, que, de acuerdo con la información ofrecida por el Instituto Nacional de Estadística (2013), en el año 2012 se produce el primer descenso de población en España desde el momento en el que se dispone de datos anuales (1971). Esta reducción poblacional no está causada por el saldo vegetativo (pues tienen lugar casi 50.000 nacimientos más con respecto a las defunciones), sino que se debe principalmente al saldo migratorio 
negativo de 162.390 personas provocado porque el número de emigraciones (476.748) es superior al de inmigraciones (314.358). ${ }^{14}$

En concreto, a 1 de enero de 2013, la población extranjera está compuesta por 5.118.112 inmigrantes (que suponen aproximadamente un $11 \%$ de la población total), los cuales proceden en su mayoría de Rumanía y Marruecos, seguidos, en este orden, de los originarios del Reino Unido, Ecuador, Colombia, China, Bolivia, Alemania, Bulgaria y Portugal. Los únicos extranjeros residentes cuyo número ha aumentado en el último año son, tal y como puede observarse en el gráfico que mostramos a continuación, los británicos y los alemanes.

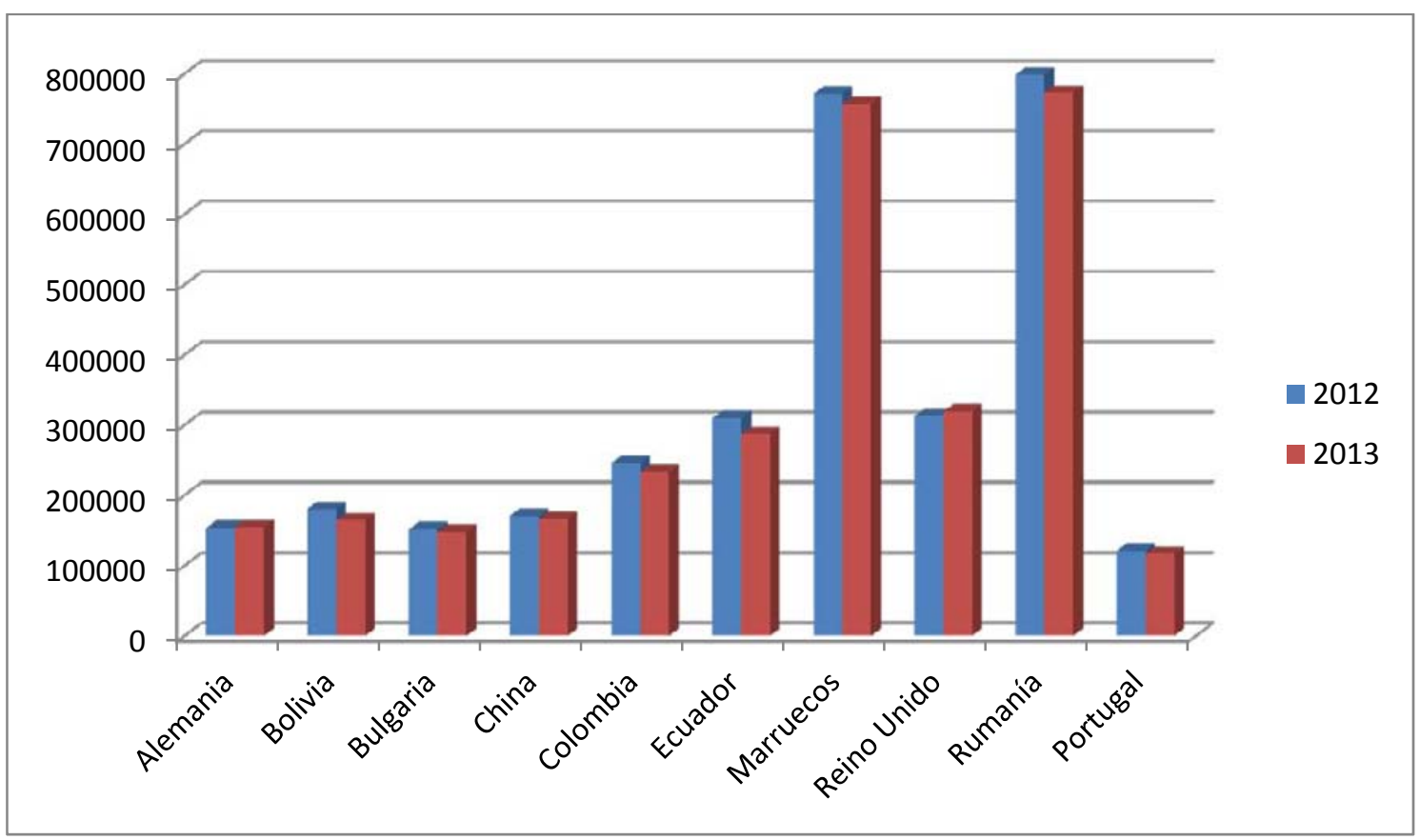

Gráfico 1.8. Principales nacionalidades de los extranjeros residentes en España a 1 de enero de 2012 y a 1 de enero de 2013

(Fuente: INE)

\footnotetext{
${ }^{14}$ Cabe resaltar que, en los dos años anteriores (2010 y 2011), también se había producido un saldo migratorio negativo, incluso superior al del año 2012, probablemente a consecuencia de la crisis económica que está atravesando el país.
} 
En cuanto a la distribución geográfica de la población extranjera residente en España, las comunidades autónomas con mayor número de inmigrantes, son, tal y como puede apreciarse en el gráfico que mostramos a continuación, y en este orden, Cataluña, la Comunidad de Madrid, la Comunidad Valenciana, Andalucía, y las Islas Canarias. Por el contrario, las tres comunidades con un menor número de población inmigrante son Cantabria, Extremadura y La Rioja. Sin embargo, por lo que se refiere a la proporción de extranjeros con respecto a la población total, destacan las Islas Baleares $(20,1 \%)$, la Comunidad Valenciana $(16,8 \%)$ y la Región de Murcia (15,7\%), y las que presentan una menor incidencia son Extremadura $(3,7 \%)$, Galicia (4,0\%) y el Principado de Asturias (4,5\%).

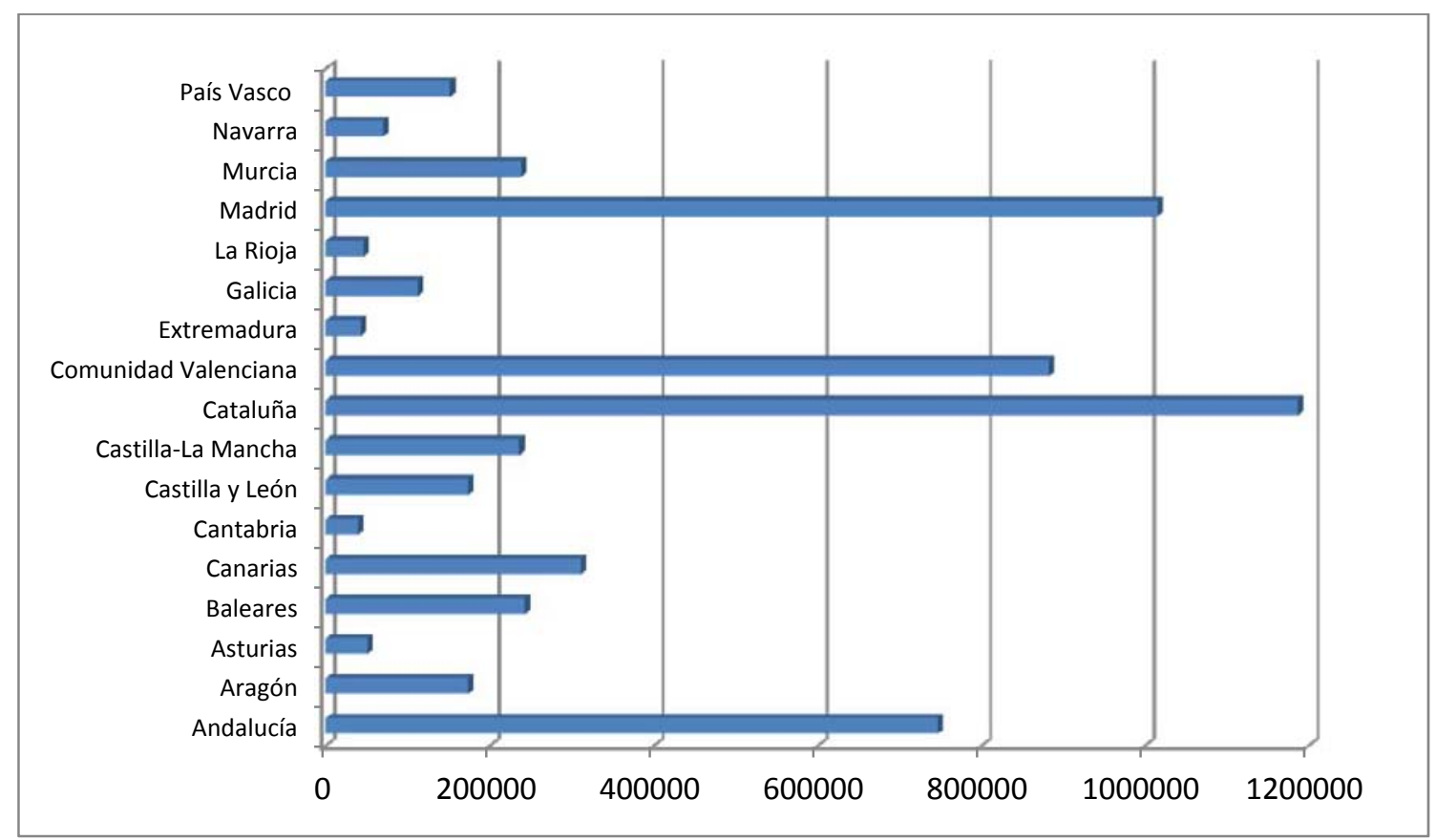

Gráfico 1.9. Población extranjera residente en las comunidades autónomas de España a 1 de enero de 2012 (Fuente: INE) 
Se trata en su mayoría de una población joven, principalmente con edades comprendidas entre los 20 y los 45 años y, a diferencia de la población autóctona, con pocos representantes que superen los 70 años, tal y como puede observarse en el siguiente gráfico:

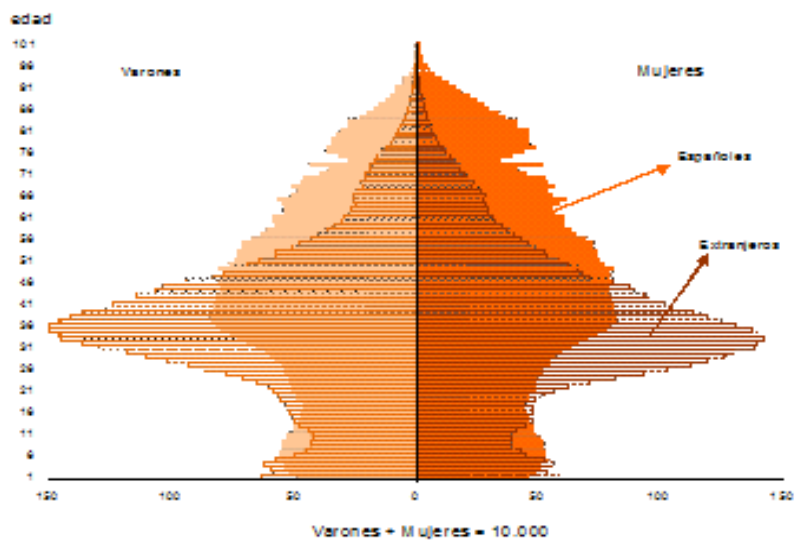

Gráfico 1.10. Pirámide poblacional de España a 1 de enero de 2012

(Fuente: INE)

Quisiéramos destacar, sin embargo, que el perfil por edades varía considerablemente según la nacionalidad del inmigrante, de modo que, como puede apreciarse en el gráfico que incluimos a continuación, mientras que, en la población rumana y la marroquí, sobresalen las personas adultas jóvenes, en el caso británico, hay un claro predominio de las personas en edad de jubilación.

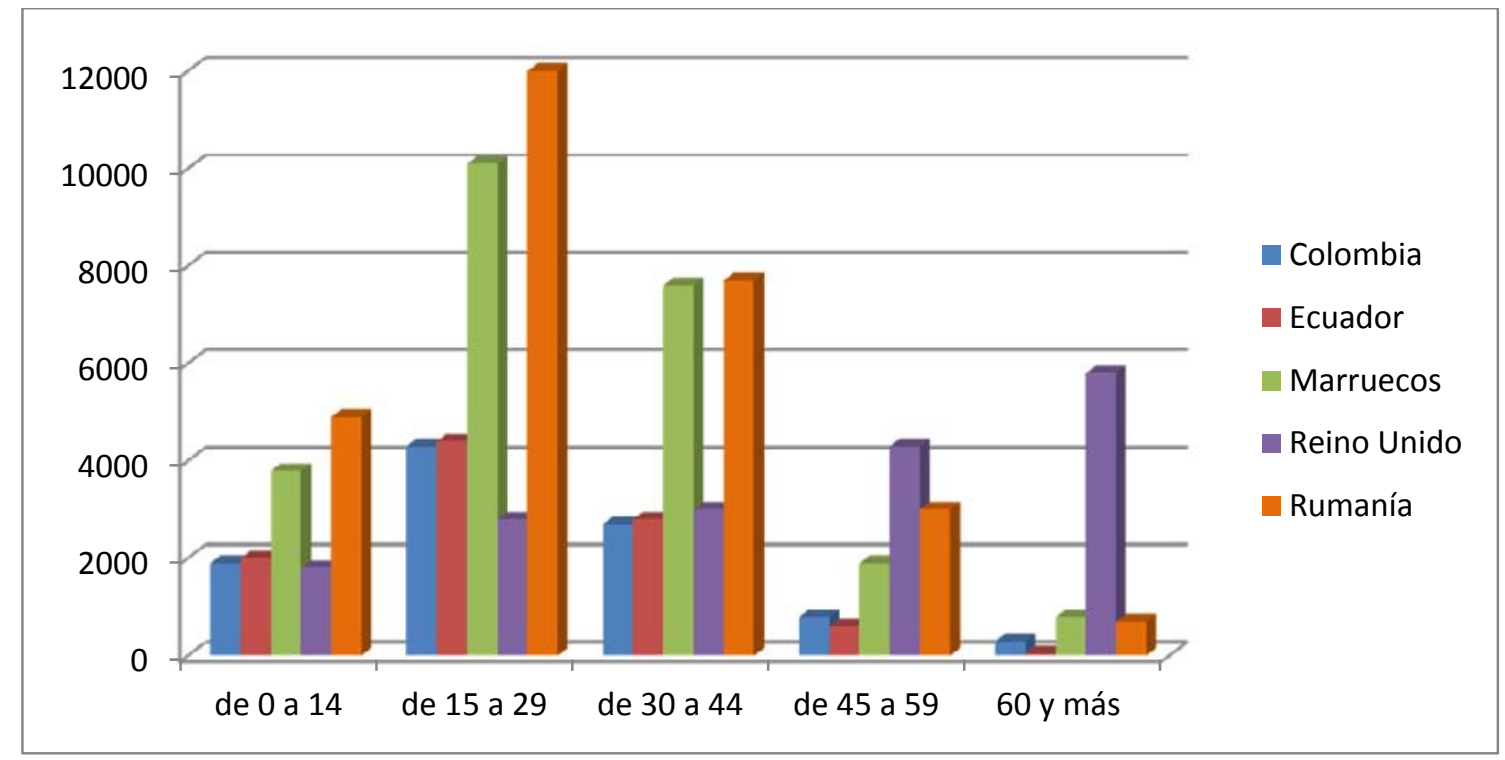

Gráfico 1.11. Distribución por edades de las cinco nacionalidades extranjeras con mayor presencia en España a 1 de enero de 2013

(Fuente: INE)

Por otro lado, siempre de acuerdo con los datos proporcionados por el Instituto Nacional de Estadística (2013), la presencia de hombres inmigrantes es superior a la de las mujeres, aunque los porcentajes se han ido asimilando con el paso del tiempo, hasta alcanzar, en el año 2012 , cifras de 2.842 .913 y de 2.677 .220 respectivamente. También en este caso se observan 
variaciones dependiendo del origen de la población. Así, a pesar de que la distribución por sexos es bastante cercana en número en todos los casos, predominan los hombres entre los británicos y los marroquíes y, por el contrario, en el caso de los inmigrantes procedentes de Rumanía, Ecuador y Colombia, hay un mayor número de mujeres, como puede observarse en el siguiente gráfico:

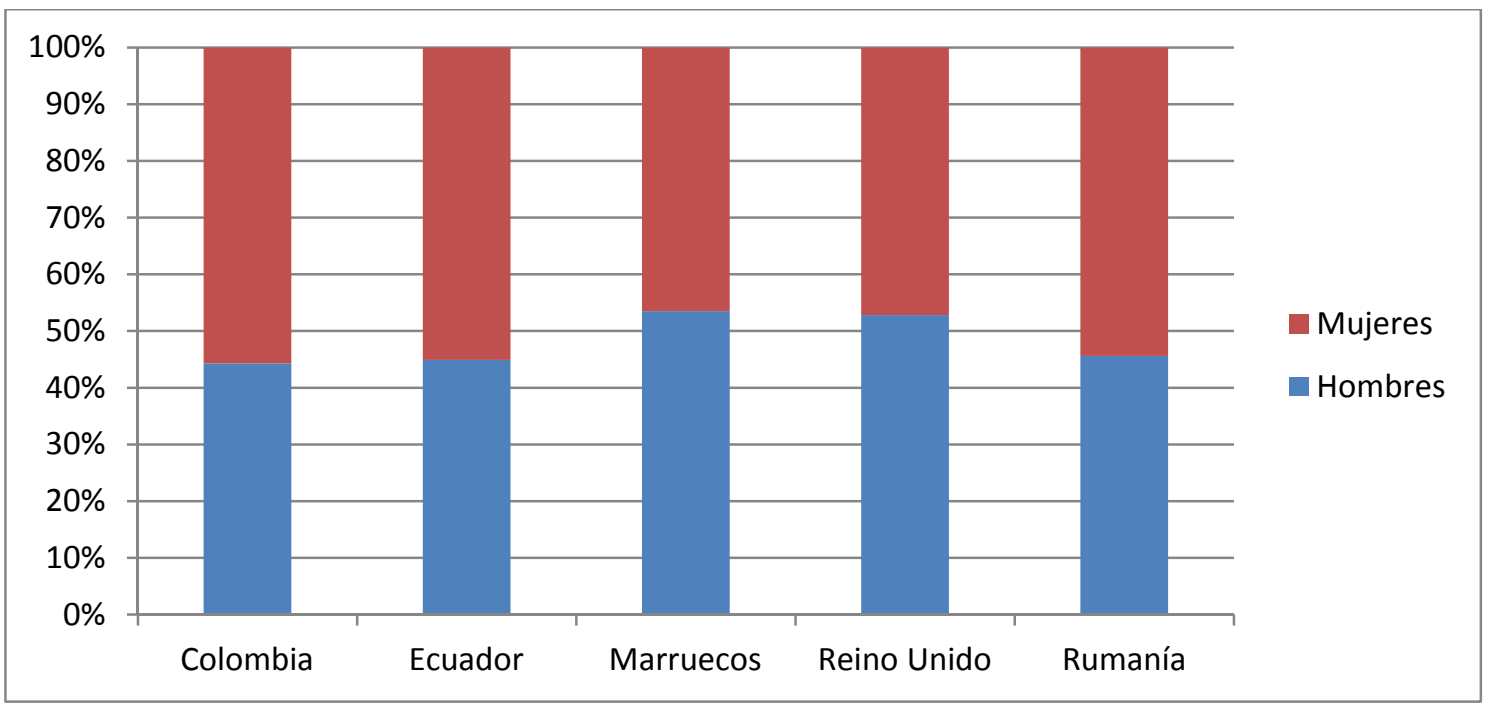

Gráfico 1.12. Distribución por sexos de las cinco nacionalidades extranjeras con mayor presencia en España a 1 de enero de 2013

(Fuente: INE)

Para finalizar el análisis de la población inmigrante residente en España y, en relación con el objeto de nuestro estudio, quisiéramos destacar la contribución de las mujeres inmigrantes al número de nacimientos que se han producido en los últimos años en este país. De acuerdo con los datos proporcionados por el Instituto Nacional de Estadística (2012a y 2012b), los nacimientos de madres de nacionalidad extranjera residentes en España, en el primer semestre de 2012 , constituyeron el $18,7 \%$ del total, si bien este porcentaje es algo inferior que el presentado en el año $2011(19,1 \%)$, y en $2010(20,4 \%)$.

En términos absolutos, en los últimos años se ha producido un descenso de los nacimientos en España, provocado por el efecto combinado de un menor número de mujeres en edad fértil y de una menor fecundidad. Así, el Indicador Coyuntural de Fecundidad (o número medio de hijos por mujer) se redujo en 2011 hasta 1,36, frente al 1,38 de 2010. La menor fecundidad durante el último año del que se disponen datos al respecto (2011) se dio tanto entre las mujeres españolas como entre las extranjeras; de hecho, el número medio de hijos por mujer española descendió en 2011 hasta 1,32, frente al 1,33 de 2010. En el caso de las extranjeras, este indicador se redujo con mayor intensidad, pues del 1,64 del año 2010 se pasó a 1,55 en el 2011. Con estas disminuciones generalizadas, la tasa bruta de natalidad se situó en 2011 en 10,2 nacidos por cada 1.000 habitantes, por debajo del 10,5 de 2010, y ya lejos de los 11,4 de 2008. Por último, en cuanto a la edad media a la maternidad, ${ }^{15}$ esta sigue siendo muy distinta en ambos colectivos, estimándose, para ese mismo periodo, en 32 años para las españolas, y en 28,8 para las extranjeras.

\footnotetext{
${ }^{15}$ La edad media a la maternidad se corresponde con la media aritmética de las edades a las que las mujeres tienen a sus hijos, ponderada por las tasas específicas de fecundidad de cada grupo de edad.
} 


\subsubsection{Datos demográficos de la población inmigrante de Aragón y Zaragoza}

Existen distintas fuentes que ofrecen información sobre las características demográficas de la población extranjera residente en las distintas comunidades autónomas españolas, entre las que se encuentran el Instituto de Estadística (tanto el nacional, INE, como, en la comunidad contexto de nuestro estudio, el autonómico, laest), o el Padrón Municipal. Todas ellas proporcionan información sobre el volumen, la procedencia y el asentamiento de dicha población en el país de acogida; sin embargo, a menudo, los datos presentados discrepan y pueden variar a la alza o a la baja dependiendo de la fuente consultada. Igualmente, los datos ofrecidos no siempre son exactos al cien por cien. Así, por ejemplo, si los datos se basan en los empadronamientos, cabría considerar que estos pueden presentar limitaciones de omisión, pues no todos los extranjeros residentes se inscriben en el Padrón Municipal, "por diferencias culturales, miedo o rechazo en el proceso de registro" (Gijón, 2010:95).

La fuente principal de los datos que presentamos en este subapartado ha sido el Instituto Aragonés de Estadística (laest), cuyos datos, a su vez, se basan en el Padrón Municipal. El criterio que hemos escogido para seleccionar dicha fuente ha sido, en primer lugar, el de la máxima proximidad temporal o actualidad (en concreto, los datos se refieren al 1 de enero de 2012). Asimismo, nos hemos decantado por el uso mayoritario de fuentes locales, atendiendo a las recomendaciones que presenta Ma Teresa Gijón (2010:101), la cual sostiene que

Si pretendemos conocer con detalle etnográfico qué ocurre en un microespacio, como puede ser un centro de salud o un hospital, entonces nuestro interés se reducirá al contexto local y será necesario usar fuentes locales, aunque no aisladamente.

Comenzamos el análisis de la población inmigrante en el contexto de nuestro estudio con los datos relativos a la comunidad autónoma de Aragón. A continuación, separadamente, presentamos los datos referentes a la provincia y la ciudad de Zaragoza, contexto específico en el que se encuentra el hospital en el que hemos llevado a cabo nuestra investigación.

Por lo que se refiere a la población inmigrante residente en Aragón, el caso del fenómeno migratorio en esta comunidad autónoma es particular si lo comparamos con el resto de España, por el hecho de que, en cuestión de una década, ha pasado de ser una comunidad en la que apenas residían personas extranjeras, a encontrarse entre las diez primeras tanto por lo que atañe al número total de inmigrantes, como en referencia a su incidencia con respecto a la población total. 
En los gráficos que presentamos a continuación, puede observarse la evolución que ha experimentado la población inmigrante residente en Aragón en el periodo que transcurre entre principios de siglo y 2011. Cabe, de todos modos, señalar que, en los dos últimos años de los que se disponen datos (2011 y 2012), esta tendencia ha variado ligeramente a la baja, pasando de superar los 173.000 extranjeros residentes en el año 2010 a no alcanzar los 171.000 en 2012.

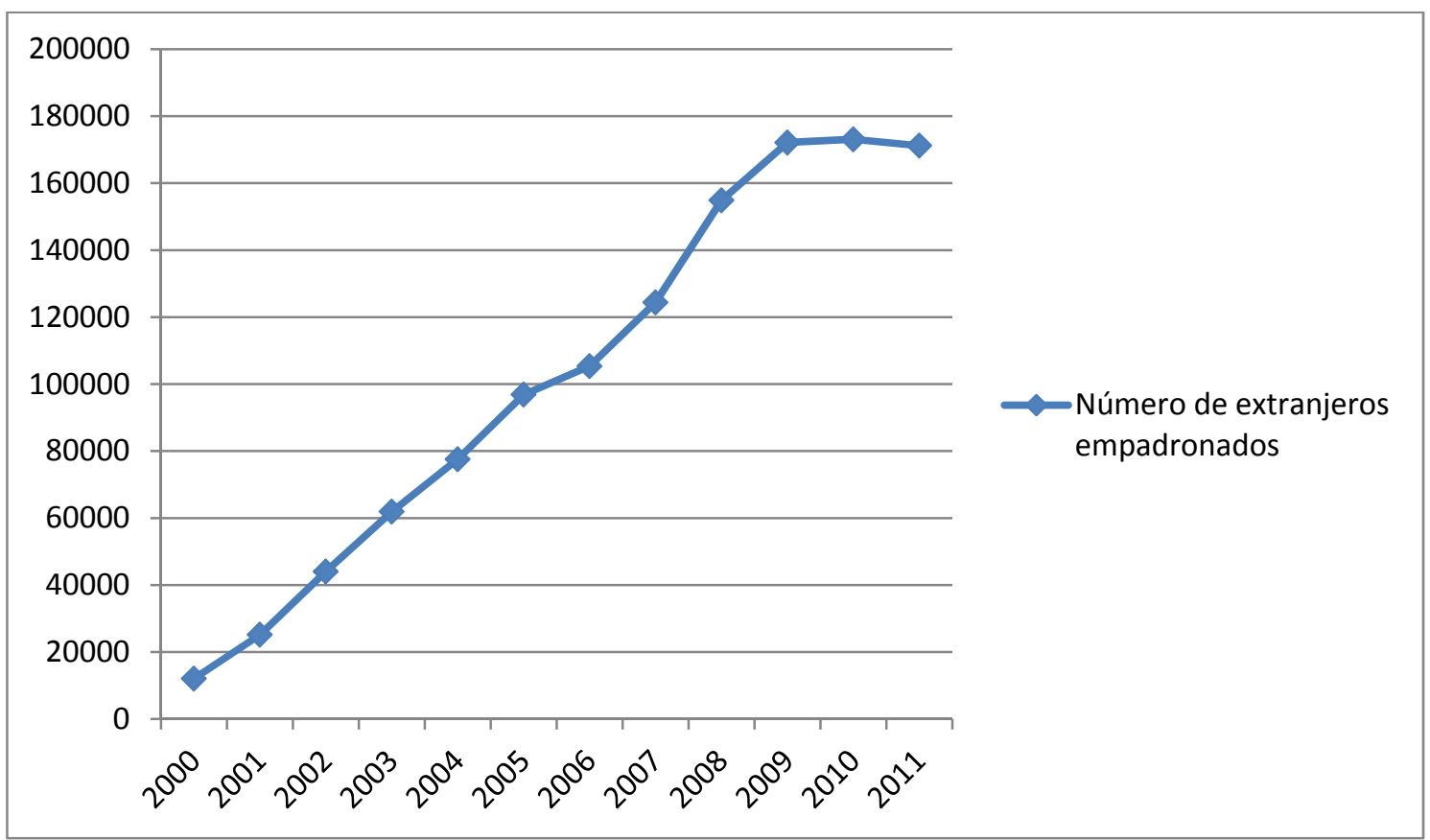

Gráfico 1.13. Evolución de la población inmigrante en Aragón (2000-2011) (Fuente: Padrón Municipal)

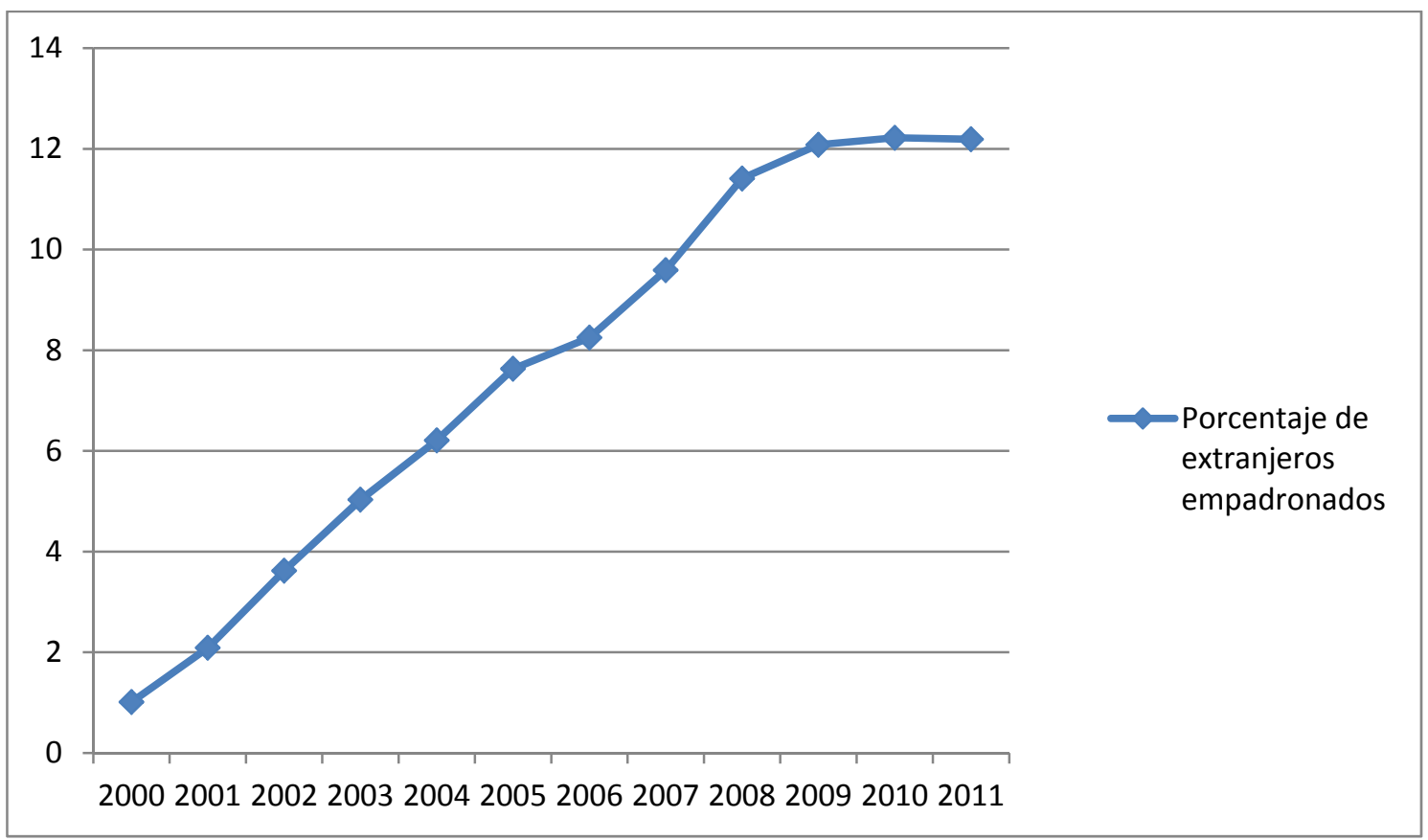

Gráfico 1.14. Incidencia de la población inmigrante con respecto a la población total en Aragón (2000-2011) (Fuente: Padrón Municipal) 
A 1 de enero de 2012, Aragón cuenta con un total de 170.956 extranjeros empadronados, de los cuales, 125.640 (un 73,5\%), tal y como puede observarse en el gráfico que presentamos a continuación, residen en la provincia de Zaragoza. Su incidencia con respecto a la población total se acerca al $12,7 \%$, siendo, por tanto, superior a la que presenta de media la población inmigrante en España. Cabe señalar, además, que dicho porcentaje es incluso mayor en el caso de la población inmigrante residente en la provincia de Zaragoza (12,9\%), como veremos más adelante.

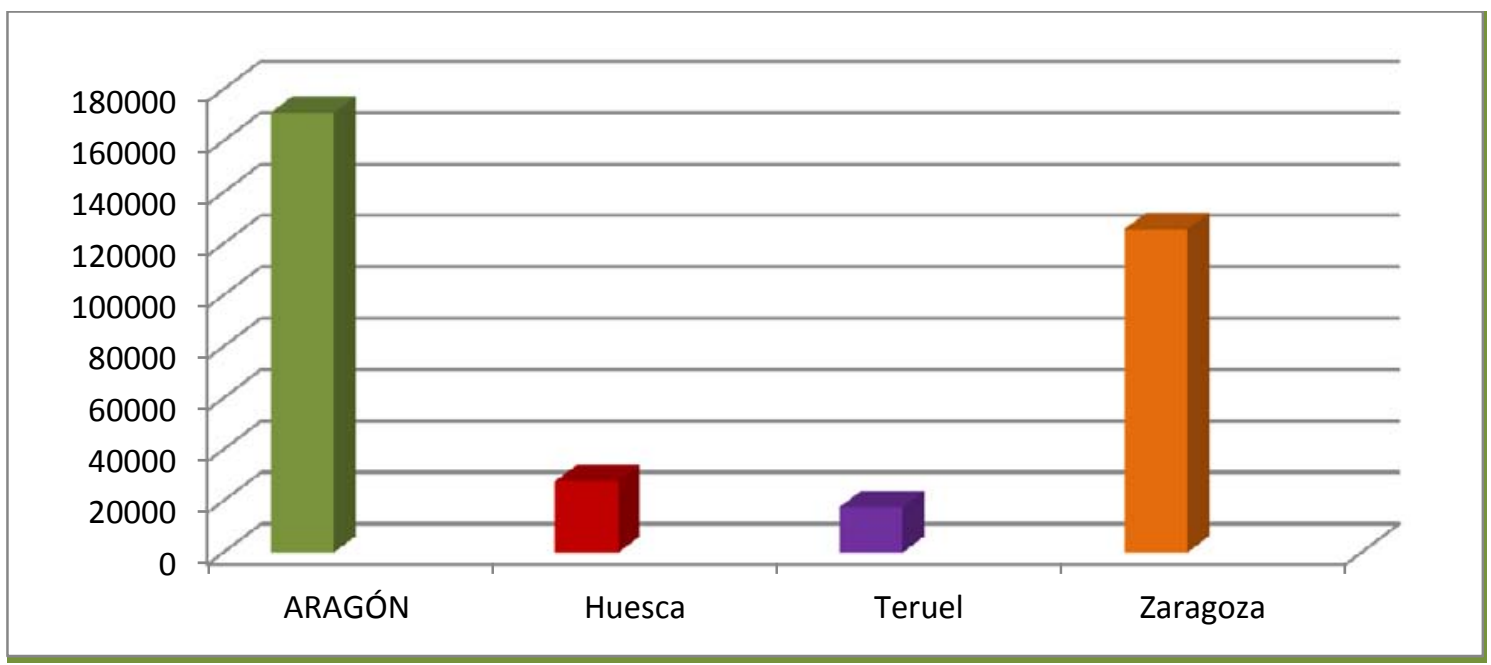

Gráfico 1.15. Población extranjera total empadronada en Aragón y provincias a 1 de enero de 2012

(Fuente: laest)

Por lo que se refiere al área geográfica de procedencia, en Aragón, destacan los ciudadanos provenientes de Europa (en su mayoría, originarios de estados miembros de la UE), seguidos, con cifras bastante similares entre sí, por los procedentes de África y América (principalmente, de Latinoamérica), y por los asiáticos, cuyo número total es bastante exiguo en relación con los inmigrantes de otras áreas. El número de inmigrantes apátridas o el de los que proceden de Oceanía es tan bajo (respectivamente, 27 y 40 ) que apenas puede percibirse su presencia en el gráfico que mostramos a continuación.

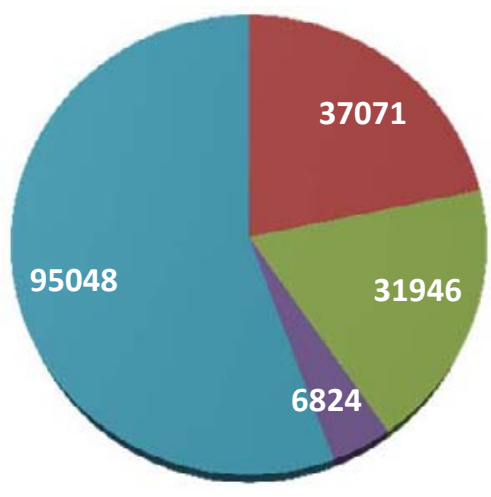

Apátridas

África

América

Asia

Europa

Oceanía

Gráfico 1.16. Áreas geográficas de procedencia de la población extranjera empadronada en Aragón a 1 de enero de 2012

(Fuente: laest) 
En referencia a los países de procedencia, dentro del grupo de inmigrantes originarios de Europa, destacan de modo extraordinario los rumanos $(39,6 \%)$, a los que siguen, pero con un número notablemente inferior, los búlgaros $(3,7 \%)$, los portugueses $(2,8 \%)$, y los polacos (2,5\%). En cuanto a los inmigrantes procedentes de África, sobresalen los de Marruecos $(10,8 \%)$ y, bastante por detrás, los de Argelia $(3,1 \%)$, Senegal $(1,8 \%)$, Gambia $(1,4 \%)$, y Ghana (1\%). Por su parte, entre los inmigrantes del continente americano, cabe señalar a los que provienen de Ecuador $(1,8 \%)$ y de Colombia $(3,5 \%)$, así como a los de Nicaragua (2\%), la República Dominicana (1,5\%), y Perú $(1,2 \%)$. Y, por último, dentro del grupo de los asiáticos, la gran mayoría procede de China (2,8\%); el único país de Asia que, junto con China, supera los 1.000 inmigrantes residentes en Aragón es Paquistán (0,9\%). ${ }^{16}$

En cuanto a las diez nacionalidades extranjeras con mayor presencia, destacan notablemente los inmigrantes procedentes de Rumanía, seguidos de los de Marruecos, y ya, en menor medida, los de Bulgaria, Colombia y Argelia, tal y como puede apreciarse en el siguiente gráfico:

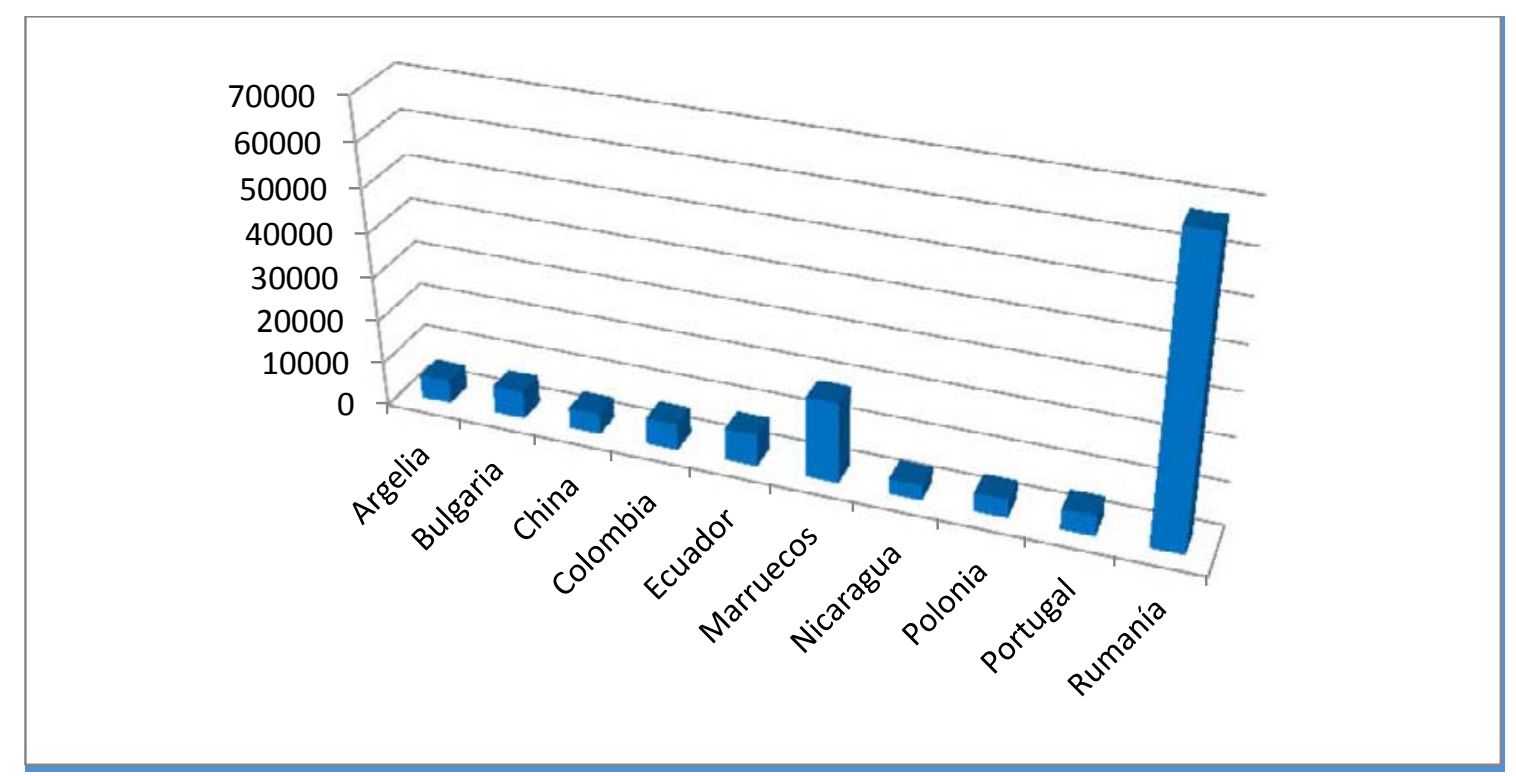

Gráfico 1.17. Principales nacionalidades de los extranjeros empadronados en Aragón a 1 de enero de 2012 (Fuente: laest)

En cuanto al sexo de las comunidades inmigrantes residentes en Aragón, en los últimos años la cuota femenina ha ido aumentando $y$, actualmente, de los más de 170.000 extranjeros residentes en esta comunidad, 92.157 son hombres y 78.799 son mujeres, por lo que el porcentaje de ambos es bastante similar ( $54 \%$ y $46 \%$ respectivamente).

\footnotetext{
${ }^{16}$ Los porcentajes señalados se refieren a la incidencia de las distintas nacionalidades sobre el total de población extranjera residente en Aragón.
} 
En el gráfico que mostramos a continuación, se puede observar la distribución por sexos de las diez nacionalidades con mayor presencia en territorio aragonés.

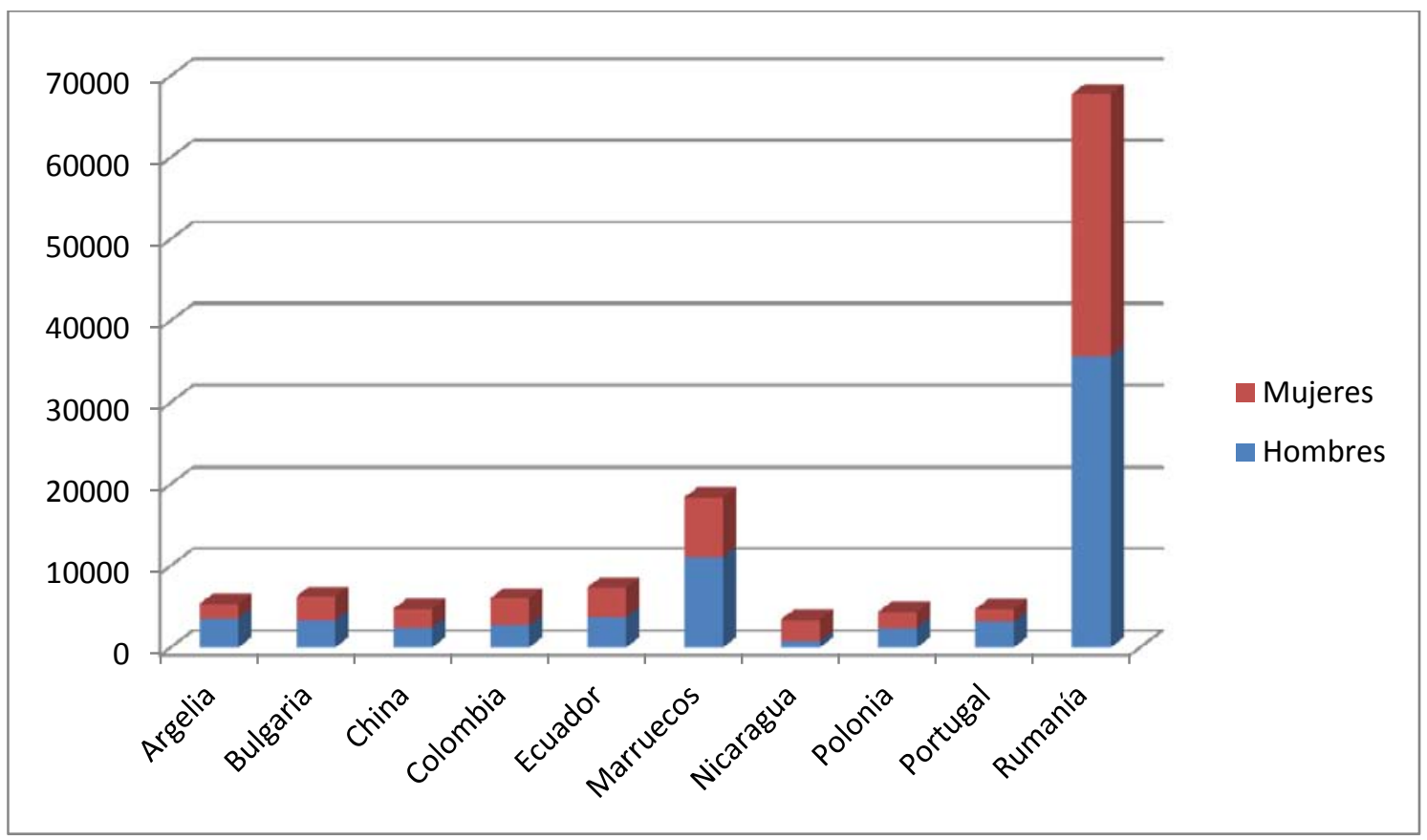

Gráfico 1.18. Distribución por sexos de las principales nacionalidades extranjeras de Aragón a 1 de enero de 2012 (Fuente: laest)

En relación con esta cuestión, quisiéramos destacar diversos aspectos:

- existen comunidades prevalentemente masculinas, especialmente la senegalesa, en la cual, más de tres cuartas partes son hombres $(81 \%)$, aunque también destacan por la predominancia de inmigrantes de sexo masculino otros países de África Subsahariana (como Gambia, con $74 \%$ de hombres, Ghana, con $75 \%$, y Malí, con $82 \%$ ), ${ }^{17}$ los países del subcontinente indio (la India, con 64\%, y Paquistán, con 77\%), así como los países del norte de África (Argelia, con 66\%, y Marruecos, con 60\%);

- en general, en la población inmigrante proveniente de los países de Latinoamérica, predomina la presencia femenina (especialmente, en el caso de Brasil, con $71 \%$ de mujeres, Honduras, con $70 \%$, y Nicaragua, con $77 \%$, y, en menor medida, por lo que respecta a países como Colombia, con 55\%, Cuba, con 59\%, Perú, con 51\%, y la República Dominicana, con $58 \%) ;^{18}$

- se observa un sustancial equilibrio entre sexos en las comunidades inmigrantes procedentes de países de Europa del este (como Bulgaria, con $54 \%$ de hombres y $46 \%$ de mujeres, Rumanía, con $53 \%$ de hombres y $47 \%$ de mujeres), así como en la comunidad originaria de China (también con $53 \%$ de hombres y $47 \%$ de mujeres).

\footnotetext{
${ }^{17}$ Dentro del grupo de inmigrantes procedentes de África Subsahariana, cabe señalar el caso de Nigeria, que, a diferencia del resto de países de esa zona, presenta un número casi idéntico de hombres (468) y mujeres (434) residentes en Aragón.

18 Por el contrario, Ecuador es uno de los pocos países de Latinoamérica donde el porcentaje de hombres inmigrantes residentes en Aragón (51\%) es superior (aunque ligeramente) al de las mujeres (49\%).
} 
El constante y rápido aumento de la población inmigrante ha incidido notablemente en las características estructurales de la población residente en Aragón, ya que, además de contribuir al aumento del número total de residentes, ha favorecido en gran medida su rejuvenecimiento, tanto porque se ha visto incrementado el número de jóvenes, como porque ha incidido positivamente en la tasa de natalidad. Así, esta comunidad autónoma, que presenta una de las poblaciones más envejecidas de España y un grave problema de despoblación, con la llegada de la población inmigrante, ha visto reequilibrarse en cierta medida su pirámide poblacional.

De hecho, tal y como puede observarse en el gráfico que incluimos a continuación, por lo que se refiere a la edad, entre los residentes extranjeros, se observa un predominio de los jóvenes: aproximadamente un $71 \%$ de los inmigrantes tiene menos de 40 años (en contraste con un 44\% de los autóctonos), de los cuales un 17\% tiene menos de 14 años, y un 54\% tiene entre 15 y 39. Asimismo, casi no hay inmigrantes cuya edad supere los 70 años (en total 1.488 , lo que supone un $8,5 \%$ del total de extranjeros residentes, frente al porcentaje de los autóctonos que rebasa dicha edad, que alcanza un $18 \%$ ). Estas características determinan una edad media de la población extranjera de 31 años, que se oponen a los 43 años de media de la población residente en general, y los 45 años de la población autóctona.

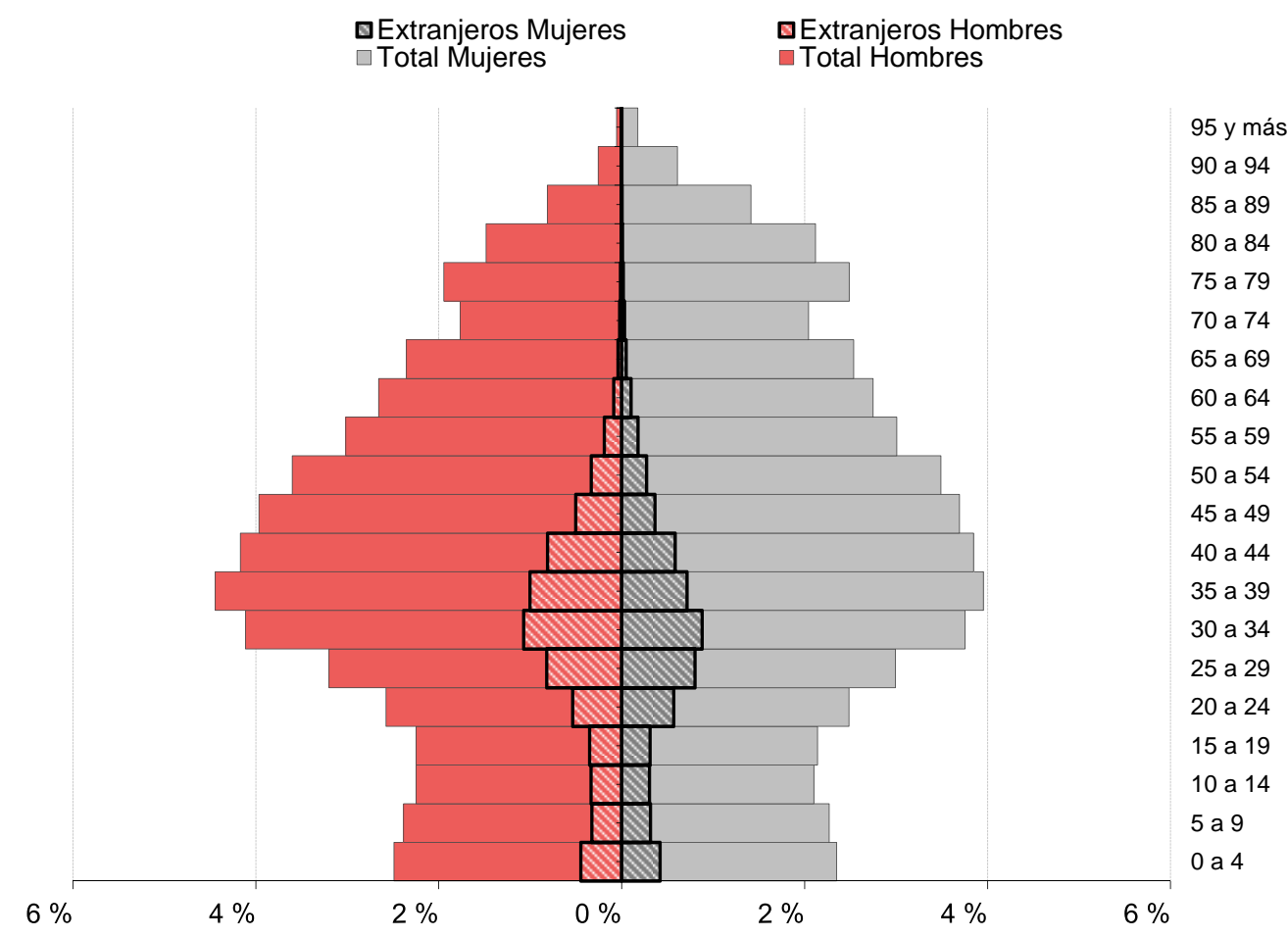

Gráfico 1.19. Pirámide poblacional de Aragón a 1 de enero de 2012

(Fuente: laest)

Además, en estrecha relación con el ámbito principal de nuestro estudio, cabe resaltar la contribución de la población inmigrante al saldo vegetativo de Aragón por el número de nacimientos que se producen de madres de origen extranjero en esta comunidad. Por una parte, como se observa en el gráfico que mostramos a continuación, de acuerdo con los datos 
proporcionados por el Instituto Nacional de Estadística (2012), a pesar de que la tasa de natalidad ${ }^{19}$ de las mujeres inmigrantes residentes en Aragón ha disminuido en los últimos años (situándose, en el año 2011, en unos 184 nacimientos por cada 1.000 habitantes), continúa siendo netamente superior a la de las mujeres autóctonas (equivalente, siempre en el año 2011, a unos 84 nacimientos por cada 1.000 habitantes).

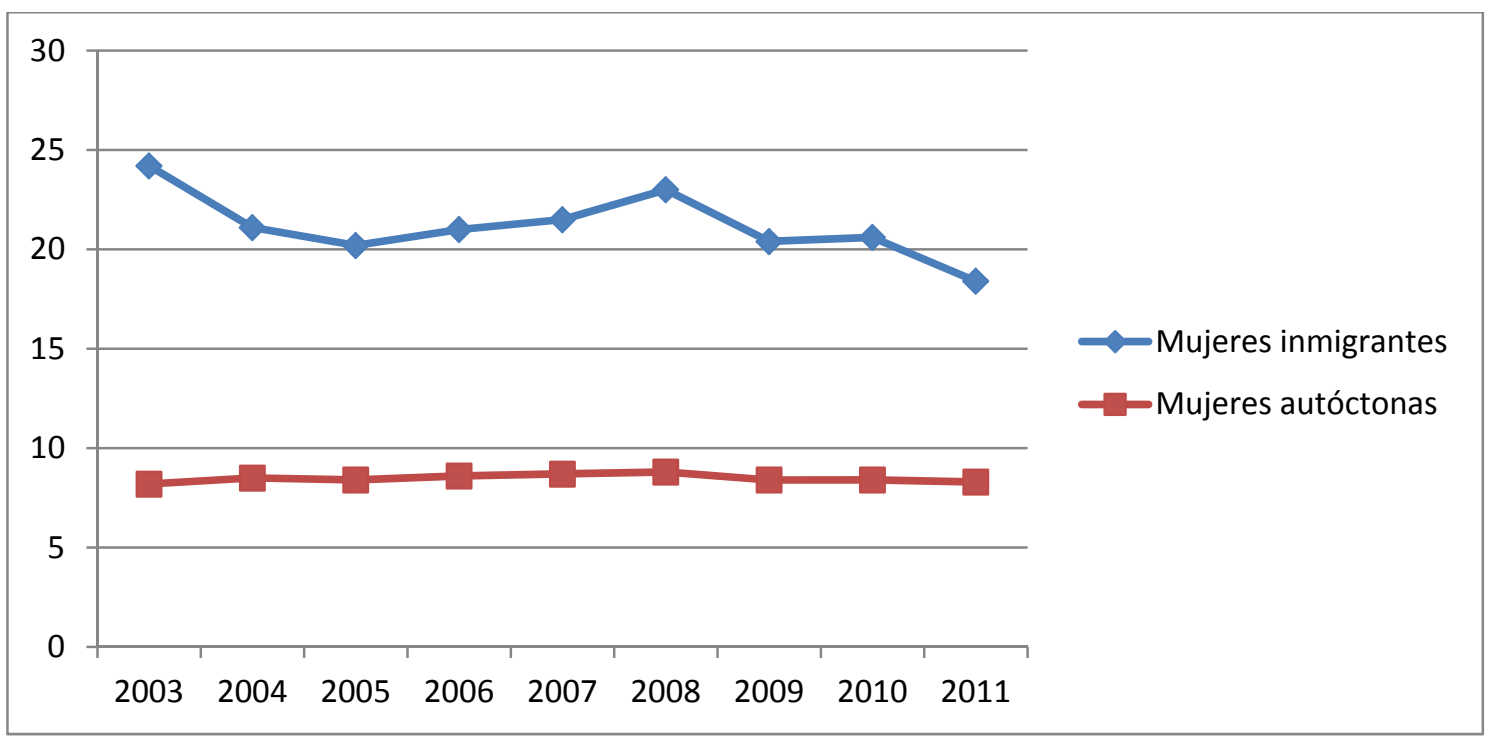

Gráfico 1.20. Evolución de la tasa de natalidad en Aragón según nacionalidad (española o extranjera) de la madre (2003-2011)

Fuente: INE

En concreto, por lo que se refiere al número de nacimientos que han tenido lugar en Aragón en el año 2011, de acuerdo con los datos publicados por el Instituto Aragonés de Estadística (2013), casi 1 de cada 4 nacimientos (un 23,24\%) de los 12.610 que han tenido lugar en este año eran de padres inmigrantes. ${ }^{20}$

Por tanto, podemos deducir que, si bien en esta comunidad autónoma se experimentó un considerable descenso demográfico durante toda la última década del pasado siglo, por el contrario, en los últimos diez años, el saldo vegetativo se ha recuperado gradualmente, y resulta evidente que las familias extranjeras (tanto con su presencia como con su contribución al número de nacimientos) han favorecido dicha recuperación demográfica.

Por lo que respecta a la población inmigrante residente en la provincia de Zaragoza, de acuerdo con los últimos datos disponibles del Instituto Aragonés de Estadística, correspondientes al año 2012, esta cuenta con una población extranjera empadronada de 125.640 personas, lo que supone un $12,9 \%$ de su población total.

\footnotetext{
${ }^{19}$ La tasa de natalidad se refiere a la cantidad proporcional de nacimientos que tiene lugar en una comunidad en un lapso de tiempo determinado. Indica la cantidad de niños que nacieron en un determinado año en una cierta población por cada 1.000 ciudadanos. Por ejemplo, si la tasa de natalidad de un segmento de la población determinado es del $12 \%$, está señalando que allí se producen 120 nacimientos al año por cada 1.000 habitantes.

${ }^{20}$ Por los datos proporcionados por el laest, sabemos que el Indicador Coyuntural de Fecundidad medio de Aragón es de 1,34; sin embargo, no nos ha resultado posible obtener datos disgregados por nacionalidad (autóctona/extranjera) del número medio de hijos por mujer.
} 
En relación con el área geográfica de procedencia, como sucede a nivel autonómico, destacan los ciudadanos procedentes de Europa (principalmente los originarios de estados miembros de la UE), seguidos, con cifras bastante similares entre sí, por los provenientes de África y América (en su mayoría, latinoamericanos), y por los asiáticos, cuyo número total es escaso si lo comparamos con los inmigrantes de otras áreas. También en este caso el número de inmigrantes apátridas o de los procedentes de Oceanía es tan bajo ( 27 y 18 , respectivamente) que su presencia es apenas perceptible en el siguiente gráfico:

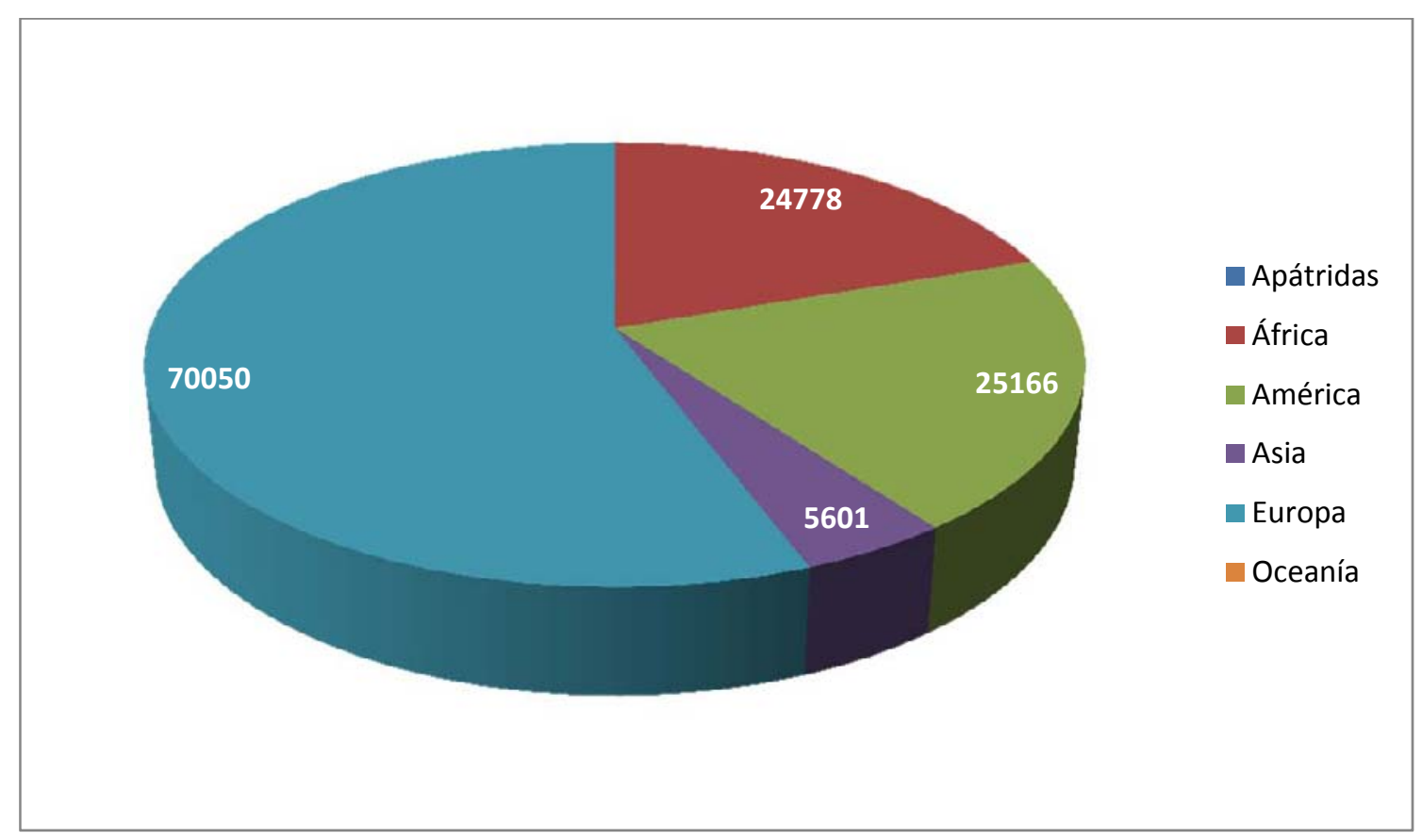

Gráfico 1.21. Áreas geográficas de procedencia de la población extranjera empadronada en la provincia de Zaragoza a 1 de enero de 2012

(Fuente: laest)

En referencia a los países de procedencia, dentro del grupo de inmigrantes originarios de Europa, destacan sobre todo los rumanos $(41,4 \%)$, seguidos de lejos por los búlgaros $(3,1 \%)$, los portugueses $(2,7 \%)$ y los polacos $(2,1 \%)$. En cuanto a los inmigrantes africanos, cabe señalar a los de Marruecos $(8,3 \%)$ y, en número bastante inferior, a los de Argelia $(3,4 \%)$, Senegal $(2,1 \%)$, Gambia $(1,2 \%)$ y Ghana $(1,3 \%)$. Por su parte, entre los inmigrantes procedentes de América, sobresalen los que provienen de Ecuador $(5,1 \%)$ y de Colombia $(3,6 \%)$, así como los de Nicaragua $(2,6 \%)$, la República Dominicana $(1,4 \%)$ y Perú $(1,3 \%)$. Y, por último, dentro del grupo de los asiáticos, la gran mayoría procede de China $(3,4 \%) .{ }^{21}$

\footnotetext{
${ }^{21}$ Los porcentajes señalados se refieren a la incidencia de las distintas nacionalidades sobre el total de población extranjera residente en Zaragoza (provincia).
} 
En cuanto a las diez nacionalidades extranjeras con mayor presencia, aunque destacan las mismas a nivel autonómico y provincial, no ocupan el mismo orden por número de inmigrantes. De hecho, mientras las tres primeras comunidades son en ambos casos la rumana, la marroquí y la ecuatoriana, varían los siguientes puestos, que, en Aragón, como hemos comentado previamente, están ocupados por los extranjeros procedentes de Bulgaria, Colombia y Argelia y, en cambio, en la provincia de Zaragoza, los representan los inmigrantes de Colombia, Argelia y China, tal y como puede apreciarse en el siguiente gráfico:

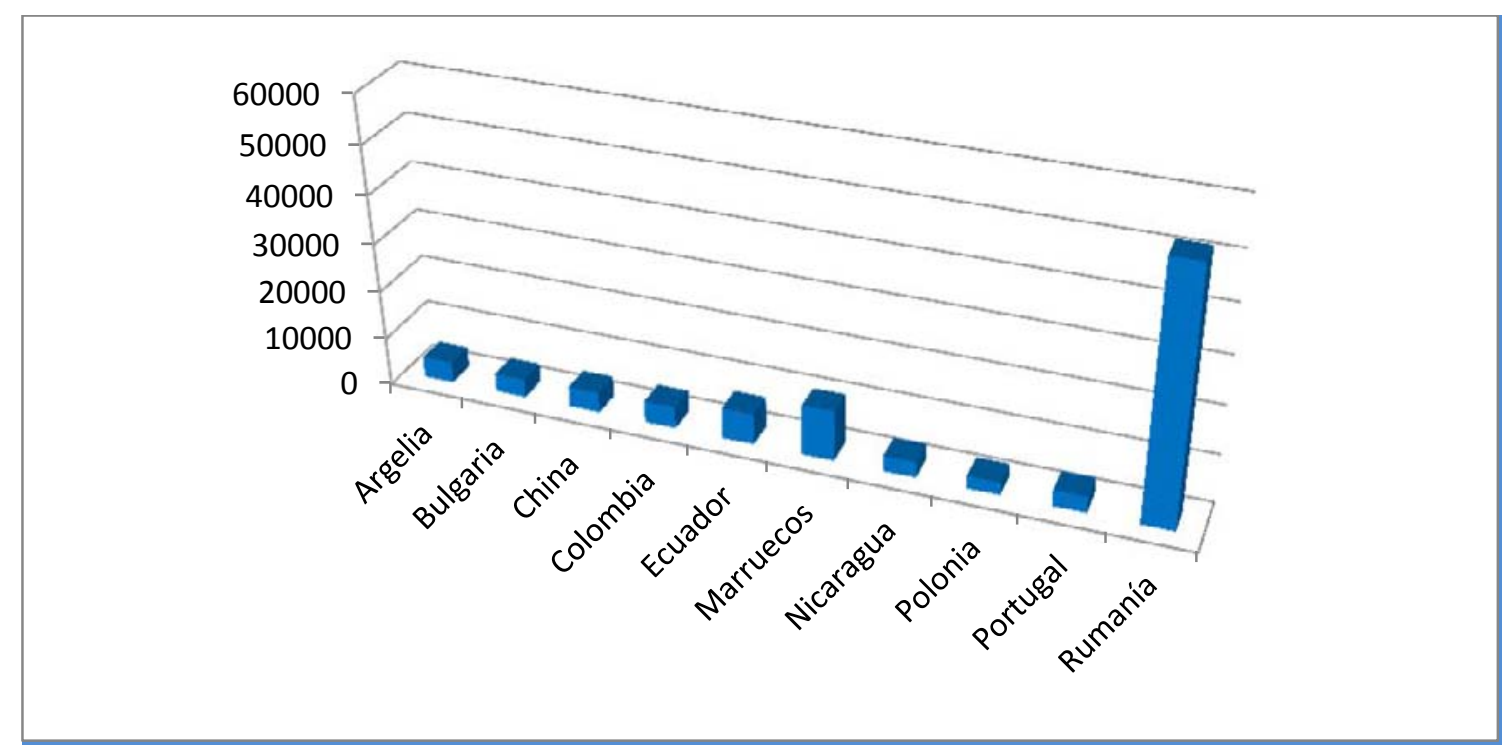

Gráfico 1.22. Principales nacionalidades de los extranjeros empadronados en Zaragoza (provincia) a 1 de enero de 2012

(Fuente: laest)

Ya, para concluir este apartado, en relación con la población inmigrante residente en la ciudad de Zaragoza, cabe señalar que casi el $70 \%$ de la población extranjera empadronada en la provincia de Zaragoza reside en su capital, la cual cuenta entre sus ciudadanos con 87.444 inmigrantes, que suponen el $12,9 \%$ de su población total. De estos, 45.855 son hombres (alrededor del $52 \%$ del total de la población inmigrante de Zaragoza), y 41.589, mujeres (equivalente a aproximadamente el $48 \%$ ).

\subsubsection{Modelos de gestión de la diversidad cultural}

Como hemos comentado en los subapartados anteriores, la época actual se caracteriza por un gran caudal de flujos migratorios que destacan por su dimensión y por su extensión a escala planetaria. Este fenómeno implica compartir el tiempo y el espacio con personas de otros países y culturas y vivir en un entorno pluricultural, lo cual plantea una serie de consecuencias $y$ retos a afrontar.

De hecho, la entrada en un determinado país de personas que emigran de otros lugares y se instalan de manera más o menos estable (cada vez más frecuentemente acompañadas de sus familias), así como el consiguiente contacto entre diferentes culturas e identidades, ponen en marcha un proceso que transforma de modo evidente el entramado social, aumentando en cierto sentido su complejidad. Así, 
[...] en cada encuentro de personas y culturas se ponen en marcha procesos dinámicos de cambio en la identidad de unos y otros, donde los valores y las costumbres de origen se modifican al entretejerse, en mayor o menor medida, con aquellos que el otro trae a la relación. (AEP Desenvolupament Comunitari y Andalucía Acoge, 2002:55)

Para hacer frente a estas nuevas realidades y a este proceso de transformación que implica a todo el cuerpo social, así como para gestionar la diversidad cultural que caracteriza a la gran mayoría de las sociedades en la actualidad, se han adoptado a lo largo de la historia diferentes modelos, y se han puesto en marcha políticas variadas con el fin de abordar la convivencia entre la población autóctona y la población inmigrante.

Siguiendo el esquema propuesto por Miquel Rodrigo Alsina (2009), podríamos dividir los modelos principales de gestión de la diversidad cultural en tres mundos distintos: el mundo monocultural, el mundo multicultural, y el mundo intercultural.

Dentro del primer "tipo de mundo", se encontrarían modelos como el asimilacionismo y el segregacionismo. En ambos casos, se da una ausencia notable de interés por otras realidades culturales. Por lo general, en este mundo, la intolerancia es muy frecuente, las diferencias son difícilmente aceptadas, y se busca la homogeneidad. Así, como sostiene Miquel Rodrigo Alsina (2009:108),

[...] en el mundo monocultural la cultura ajena tiene poco espacio. A partir de la ignorancia y el desconocimiento, el pensamiento monocultural propugna la conversión cultural, la marginación o el exterminio.

Por lo que se refiere en concreto al segregacionismo, este se da cuando la presencia de personas procedentes de otros países y culturas se percibe como un cuestionamiento y como una amenaza, por lo que se desarrolla una gran predisposición para afirmar y mantener la propia identidad cultural y, al mismo tiempo, un escaso o nulo interés por conocer y establecer relaciones con los miembros de otros grupos culturales. Con el fin de preservar lo propio, se ve necesario tomar distancia de los Otros, poniendo en marcha estrategias que favorecen la separación, la segregación y la exclusión, en función de aspectos como el origen cultural o nacional, las creencias religiosas, etc. En el modelo segregacionista se busca, por tanto, la invisibilidad de las culturas y de las personas que componen los diferentes grupos culturales $y$, a menudo, se considera a los inmigrantes únicamente como mano de obra, separándolos de la población autóctona y negando su condición de ciudadanos y, por consiguiente, suprimiendo sus derechos sociales y políticos. El caso más flagrante de segregacionismo se dio en Sudáfrica con el apartheid, y, en menor medida, se corresponde al modelo adoptado en los años 50 del pasado siglo en países como Alemania, en el que se instauró la política del gastarbeiter, o trabajador invitado.

Por lo que respecta al asimilacionismo, este no solo propone la invisibilidad de las culturas de origen de la población inmigrante, como el modelo que acabamos de presentar, sino que, además, pretende que esta población adopte los patrones propios de la sociedad de acogida. Tal y como señala Cristina Blanco (2000), las teorías de la asimilación nacieron en los Estados Unidos a principios del siglo XX, época en la que comenzó a condicionarse la admisión de nuevos inmigrantes a su capacidad de asimilación. Este modelo se fundamentaba en la idea de que, para que los grupos culturales diferentes al grupo mayoritario dejaran de sufrir las 
consecuencias negativas derivadas de la diferencia cultural, estos debían dejar de ser diferentes. El objetivo principal de las presiones asimiladoras era pues, como sostiene Zygmunt Bauman (2006:89-90), "privar a los otros de su otredad, hacerlos indiscernibles del cuerpo de la nación". Sin embargo, siempre de acuerdo con este mismo autor,

La igualdad que promete la asimilación puede ser retirada en cualquier momento sin dar explicaciones. Además, siempre les quedará el estigma de su origen extraño, que no borra ningún juramento de lealtad ni ningún esfuerzo extremo por negarse a sí mismos.

Al respecto de este modelo de gestión de la diversidad cultural, cabe señalar que la iniciativa de asimilación puede venir de una o ambas partes en la relación. De hecho, en numerosas ocasiones, es la misma población inmigrante la que decide someter y ocultar la propia cultura de origen para asumir los patrones de la cultura dominante. Con frecuencia, se trata simplemente de una estrategia de supervivencia, pues el conocer y usar, por ejemplo, la lengua del país de acogida o ciertas normas básicas del mismo, fomentarán su integración en la sociedad. El problema, por así llamarlo, surge cuando la adopción de esos nuevos patrones culturales supone el rechazo y la eliminación radical de su cultura de origen.

No importa quién decide (la población autóctona o la inmigrante) optar por la asimilación, ni si esta es elegida o impuesta, pues

[....] no deja de ser una estrategia que ha de realizarse a costa de la violencia amputadora de lo que uno es para sumarse, o al menos parecerse, a lo que son los otros. Una violencia, cuando menos simbólica, que tarde o temprano acaba apareciendo, sobre todo cuando el asimilado ha realizado un gran esfuerzo, alejándose de su mundo de pertenencias, y al final no acaba de encontrar un sitio en el mundo de los otros. (AEP Desenvolupament Comunitari y Andalucía Acoge, 2002:59)

Aparte de los modelos propios del que Miquel Rodrigo Alsina (2009) denomina "mundo monocultural", existen otros modelos pertenecientes al "mundo multicultural" y al "mundo intercultural".

Numerosos estudiosos de diversas disciplinas, como la filosofía, la política, la antropología y la sociología, se han ocupado de la definición y descripción de los términos "interculturalidad" y "multiculturalismo"; sin embargo, a menudo son utilizados indistintamente, tanto en el uso cotidiano como en el debate político, como si fueran simples atributos que describen situaciones de relación entre personas que proceden de distintos lugares y culturas, cuando, en realidad, se trata de dos conceptos diferentes.

Por su parte, el adjetivo "multicultural" ha entrado a formar parte del uso común para describir la nueva condición en la que se encuentran, en general, las sociedades occidentales como consecuencia de un crecimiento de la inmigración.

En la práctica, el multiculturalismo se asocia, por una parte, a la experiencia de algunos países caracterizados por la presencia de relevantes minorías étnicas o por profundas separaciones culturales, como Australia y Canadá y, por otra, a las políticas de inmigración adoptadas por los principales países occidentales importadores de mano de obra a partir del final de la Segunda Guerra Mundial, como Gran Bretaña u Holanda. 
Las políticas multiculturales están destinadas a tutelar a las minorías, pero, al mismo tiempo, provocan una separación de las diferentes culturas. Para definir el multiculturalismo se utiliza a menudo la metáfora del mosaico: las personas con diversos orígenes culturales viven en un mismo lugar, pero entre ellas no se dan prácticamente interferencias recíprocas, siguiendo una lógica de sustancial separación.

De acuerdo con Miquel Rodrigo Alsina (2009:104), en el modelo multicultural "podemos apreciar un cierto interés por el conocimiento de las otras culturas, aunque, en ocasiones, es una fascinación que no va más allá de lo exótico o lo folclórico". Asimismo, este autor (2009:108) sostiene que, en dicho modelo, "la tolerancia se convierte en una exigencia", aunque reconoce que esta "parte de la posición de poder de lo propio que acepta la diferencia de lo ajeno [...] desde una posición de poder donde el tolerado está en una posición de inferioridad".

Por otra parte, el multiculturalismo se relaciona con un modelo de respuesta a la inmigración basado en la consideración de los inmigrantes no tanto como individuos, sino más bien como miembros de grupos étnicos o nacionales que se han instalado en un determinado país. Este modelo se caracteriza por percibir a esos grupos como minorías que se deben tutelar, pero no establece una relación entre los antiguos residentes y los nuevos, sino que estos viven en una situación de recíproca tolerancia, pero con una neta separación. Según este modelo, los residentes extranjeros deberían contar con los mismos derechos que los residentes autóctonos, y se deberían suprimir las desigualdades tanto en ámbito laboral y educativo, como por lo que se refiere a aspectos como la vivienda y la sanidad, eliminando las discriminaciones de cualquier tipo.

El multiculturalismo se puede definir, de manera simplificada, por su carácter pasivo, ya que establece que las culturas que conviven en un mismo territorio, una vez han establecido las reglas de convivencia, pueden, en general, ignorarse las unas a las otras. Por el contrario, la interculturalidad se identifica con una participación activa, puesto que los individuos de las diferentes culturas, a través de la relación que se establece entre ellos, están dispuestos no solo a establecer normas de convivencia, sino también a reflexionar sobre las culturas ajenas y la propia, dando lugar a una transformación por parte de todos los individuos implicados, independientemente de la comunidad a la que pertenezcan. Así, como afirma Carlos Giménez (2003:20),

Si en el movimiento multiculturalista el acento está puesto en la cultura, en el planteamiento intercultural lo que preocupa es abordar la relación entre ellas. Si el multiculturalismo acentúa, con acierto, la identidad de cada cual como un paso absolutamente necesario para reclamar el reconocimiento, y ello conlleva el énfasis en las diferencias, la perspectiva intercultural buscará las convergencias sobre las cuales establecer vínculos y puntos en común.

La interculturalidad requiere una búsqueda común de equilibrio en una situación inestable, así como el esfuerzo de comprender a los demás. Esta idea de comunidad intercultural no niega la diversidad, ya que cada grupo e individuo puede conservar y expresar su propia identidad.

Frecuentemente, se asocia la interculturalidad a la integración, entendida esta última como un proceso en el que los elementos del grupo minoritario se interrelacionan con los del grupo mayoritario, el cual acepta los patrones culturales ajenos sin forzar al cambio o a la 
asimilación. Así, la integración "supone siempre una gran disposición, tanto a afirmar y mantener la propia identidad, como a establecer relaciones e intercambios con los miembros de otros grupos" (AEP Desenvolupament Comunitari y Andalucía Acoge, 2002:13).

El concepto de interculturalidad implica, al menos idealmente, un diálogo, una reciprocidad y un debate entre los individuos procedentes de contextos culturales distintos, que den lugar, con el paso del tiempo, a la existencia de una cultura híbrida con objetivos comunes y compartidos. Con el fin de promover el diálogo intercultural, se deberá, por tanto, promover el encuentro y la comunicación entre las personas culturalmente diversas, presentando una actitud activa de búsqueda de espacios y ocasiones en los que llevar a cabo el encuentro; actuar contra las visiones estereotipadas y prejuiciosas, así como contra las discriminaciones que estas comportan; potenciar la diversidad cultural $y$, al mismo tiempo, promover el contraste y una perspectiva abierta al desarrollo cultural y el aprendizaje mutuo; tomar conciencia de la diferencia y de la desigualdad, considerando que es difícil establecer la comunicación partiendo de una posición completamente asimétrica; y afrontar los conflictos que pueden derivar del contacto intercultural de manera positiva, no negándolos, sino intentando solucionarlos de forma pacífica (García, 2009:18-19).

Así, para hablar de diálogo intercultural, no basta con yuxtaponer interlocutores que representen diferentes identidades, sino que, como afirma Tzvetan Todorov (2008:285, citado en de Lucas, 2009:31), será necesario "reconocer la diferencia de voces y que ninguna de ellas es la verdad, la norma, y admitir la posibilidad de un cuadro común no impuesto por ningún interlocutor", sino basado en el conocimiento mutuo y la capacidad de crítica y autocrítica. En resumen, la interculturalidad es, de acuerdo con Miquel Rodrigo Alsina (2009:98),

[...] un concepto relacional y, como tal, puede servir para establecer puentes entre culturas, disciplinas y teorías, porque la interculturalidad es una mirada que se sabe mirada -en todos los sentidos (como sustantivo y como participio) - y, al mismo tiempo, busca el cruce de miradas con otras culturas, disciplinas y teorías. [...] nos puede ayudar a replantearnos formas de pensamiento que pensábamos indiscutibles. Puede ser un buen instrumento para repensar, para cuestionar, para generar dudas.

En el modelo intercultural se debería producir, por tanto, una cohesión social fruto de la adaptación mutua entre los autóctonos y los inmigrantes, de manera que estos convivan en igualdad de derechos, obligaciones y oportunidades, sin por ello tener que perder su identidad cultural. En este modelo subyacen, pues, dos principios fundamentales. Por un lado, el de la interacción, que implica que entre las culturas existen diferencias, pero también semejanzas, gracias a las cuales es posible establecer un diálogo entre los miembros pertenecientes a distintas comunidades culturales. Y, por otro lado, el de la bidireccionalidad, de acuerdo con el cual, todas las culturas son, en principio, igual de respetables y de cuestionables, por lo que no es posible sostener la superioridad ni la invisibilización de ninguna.

A pesar de tratarse, al menos en teoría, del modelo ideal de gestión de la inmigración, cabe ser realistas, pues la interculturalidad no se aplica prácticamente en ningún país del mundo. De hecho, por lo general, ante las diferencias culturales existentes entre los grupos mayoritarios y los minoritarios, no se suele construir un diálogo y un (re)conocimiento mutuo, sino que lo más habitual es invisibilizar a los miembros de la población inmigrante y pretender su 
asimilación a los patrones de la sociedad de acogida o, en el mejor de los casos, tolerar las prácticas y modos de pensar, sentir y actuar ajenos, siempre y cuando no interfieran o afecten a la población autóctona.

Por lo que respecta al modelo de gestión de la diversidad adoptado por España, como hemos comentado en páginas previas, este país cuenta con una historia breve en lo que se refiere a recepción de inmigrantes, por lo que a la hora de determinar "su modelo" de actuación ante dicho fenómeno, podría haber considerado la experiencia de países con una más longeva historia de la inmigración; el problema era que los resultados obtenidos por estos países no eran, tal y como afirma Marta Castiglioni (2006:144), "particolarmente entusiasmanti", y

Le loro politiche si prestavano a critiche tutt'altro che marginali sotto il profilo etico-politico e inoltre erano già allora in crisi. [...] L'assimilazione con la perdita di identità culturale e I'affermazione dissimulata da pluralismo, nel caso britannico, la coltivazione della reciproca estraneità, nel caso tedesco [...], erano lì a mettere in evidenza le difficoltà che nella costruzione di una società "multiculturale pacificata" si avrebbe dovuto afrontare.

En un principio, la actitud española frente al fenómeno de la inmigración no se inclinó claramente por uno u otro modelo; se puede afirmar que adoptó un modelo heterogéneo en el que se entremezclaban rasgos de multiculturalismo $y$, en menor medida, de interculturalidad.

La relativa actualidad de los flujos migratorios llegados a España ha conllevado el hecho de que todavía no haya sido reconocido plenamente como un fenómeno fundamental para entender a su sociedad. La inmigración no ha sido explícitamente ni aceptada ni rechazada, puesto que aún no ha quedado claramente definido qué oportunidades y problemas concretos puede ofrecer a la sociedad española. De hecho, como sostienen Josep Maria Comelles et al. (2010:126), las autoridades españolas,

Demasiado atareadas adaptándose a una realidad vertiginosamente cambiante [...]; concentradas en el diseño y aplicación de una política de control de fronteras [...]; y sin haber zanjado una crisis de identidad nacional latente desde la segunda mitad del siglo XX, no han sido capaces (y/o no se han mostrado dispuestas) de articular un modelo coherente de incorporación de la diversidad interna derivada del asentamiento de colectivos de origen inmigrante.

Resulta evidente que el fenómeno migratorio en España y el consiguiente encuentro en su sociedad de sujetos pertenecientes a grupos étnicos y culturales diferentes han desembocado en muchos casos en formas de discriminación a nivel individual e institucional. A pesar de que, como veremos en el apartado de análisis documental del capítulo 6, tanto la Constitución española como las leyes promulgadas en los últimos años en materia de inmigración se basan en el reconocimiento de la igualdad de todos los ciudadanos, independientemente de su raza, religión, lengua, sexo o edad, a menudo no se respetan estos principios, y la pluriculturalidad y la multietnicidad presentes en territorio español siguen siendo cuestiones sin resolver.

La inmigración en España es, pues, una realidad todavía poco conocida y, por este motivo, a menudo se ve con preocupación, sospecha y temor. Los únicos elementos claros, aparte de los datos estadísticos sobre las presencias, son los que ofrece la cotidianidad: las ciudades y 
pueblos se llenan de nuevos rostros, las zonas periféricas se pueblan de residentes extranjeros, las actividades habituales adquieren formas inusuales, etc. En general, la imagen que se atribuye a la inmigración es la de una amenaza, una invasión del territorio, y el inmigrante es visto como un "clandestino", un "ilegal", un "irregular" o, en definitiva, un "no-ciudadano" (Bonilla, 2004:48-49). De hecho, una gran parte de la población española, en referencia al encuentro con personas culturalmente distintas, presenta una actitud general de rechazo y no aceptación, alimentada por prejuicios y estereotipos negativos o por sentimientos de miedo ante lo desconocido. Esta actitud ante la población inmigrante se ha visto recrudecida por la situación económica desfavorable por la que está pasando actualmente España. Al respecto, estamos de acuerdo con Javier de Lucas (2009:26), cuando sostiene que

[...] son tiempos difíciles para hablar de migración y diálogo intercultural, cuando la omnipresencia de la crisis y la frivolidad con la que se evoca para justificar cualquier medida de carácter reductivo en los derechos de los más vulnerables ha propiciado un planteamiento tan simplista como eficaz, que adjudica ahora a los inmigrantes la responsabilidad de las dificultades en la distribución de los bienes primarios y ha hecho posible el argumento no sólo raramente pragmático sino propio del más burdo planteamiento xenófobo de la "preferencia nacional", que sugiere que los inmigrantes -que ya eran invisibles- deben desaparecer porque están de más en tiempos de dificultad. (comillas y cursivas del original)

En teoría, la presencia de personas portadoras de principios, valores y tradiciones diferentes debería resultar estimulante. En cambio, los inmigrantes a veces sienten que no son bien recibidos o, en el mejor de los casos, son simplemente tolerados. Es evidente que los recién llegados deben respetar las reglas fundamentales y los principios constitucionales de la sociedad que los acoge; pero, al mismo tiempo, es necesario que la población autóctona realice por su parte un esfuerzo de adaptación y de aceptación de la diversidad. De acuerdo con Marta Castiglioni (2006:144), el modelo a seguir debería ser, por tanto,

[...] un modello di integrazione che doveva innescare un proceso dialettico fra culture e modelli sociali differenti, nel reciproco riconoscimento e nella disponibilità all'incontro e allo scambio e che supponeva il cambiamento degli uni e degli altri, di chi ospita e di chi è ospitato.

Por el contrario, el clima social predominante, unido, como ya hemos comentado, a los efectos negativos de la actual crisis económica, desgraciadamente, tienden a enfatizar los elementos de imposibilidad de convivencia entre personas autóctonas y extranjeras, y a relacionar el fenómeno de la inmigración con problemas de orden público, marginalidad y malestar social. A ello contribuyen también en gran medida los medios de comunicación de masas, que suelen dar una imagen negativa y generalizadora de los inmigrantes, asociada en la mayoría de los casos a la criminalidad, la ilegalidad, etc.

Todo ello ha dado lugar a ciertos episodios de exclusión, segregación, racismo y discriminación, ${ }^{22}$ condiciones de ghetización y una creciente fragmentación del entramado

\footnotetext{
${ }^{22}$ En el informe anual sobre racismo en el estado español que publica la organización SOS Racismo, se recogen numerosos casos de discriminación racial, xenofobia y exclusión por parte del discurso político, los servicios públicos, los medios de comunicación, etc. Para consultar la última edición, puede visitarse la página web: [http://www.sosracismomadrid.es/web/blog/2012/07/06/informe-anual-sobre-el-racismo-en-el-estado-espanol2012/] (última consulta: 12 de abril de 2013).
} 
social, lo cual ha hecho disminuir la cohesión y ha impedido el nacimiento y el refuerzo de la solidaridad entre los autóctonos y los inmigrantes.

Según afirman Pedro Coduras y Carlos Gómez (2008:177-178) y, por lo que se refiere al contexto específico de Aragón, algunos sectores sociales aragoneses consideran los flujos migratorios como una amenaza para la población autóctona por tres razones: económica (por ver a los inmigrantes como competencia en el mercado laboral y como generadores de un enorme gasto social), ${ }^{23}$ cultural (por la expansión y consolidación de nuevos estilos de vida, tradiciones religiosas, etc.), y psicológica (por la inseguridad generada por el asentamiento de colectivos étnica y culturalmente diversos). Sin embargo, estos autores señalan una serie de repercusiones positivas que tiene la inmigración en la estructura económica, social y cultural de la sociedad aragonesa, como, por ejemplo, su contribución a incrementar la riqueza de este territorio (tanto en términos de PIB como por su participación en la actividad productiva), su aportación, como hemos comentado en páginas previas, en cuanto al rejuvenecimiento de la estructura demográfica de esta comunidad, la generación de nuevos empleos que surgen para atender a las necesidades y requerimientos de los colectivos inmigrantes y, por último, aunque no por ello menos importante, por el enriquecimiento cultural que supone su presencia para los ciudadanos autóctonos, pues les permite conocer formas de vida, comportamientos, valores y tradiciones diferentes a los propios.

Como sostiene Alfonso García (2009:25), la persistencia de los flujos migratorios y su asentamiento estable, los cuales conllevan la presencia de numerosos extranjeros en nuestras comunidades, ya no pueden considerarse como un hecho circunstancial, sino que deberían "impulsar la necesidad de establecer puentes de relación y avance intercultural".

En los últimos años, ha comenzado a admitirse la necesidad de una política que disciplinase y encuadrase el fenómeno migratorio en su totalidad, y se ha iniciado un proceso de no discriminación y de inclusión de las diferencias, con la consecuente experimentación de nuevas formas de comportamiento y nuevas relaciones. El modelo hacia el que se orienta la sociedad española empieza a reconocer la existencia de una pluralidad cultural, y a admitir la expresión y la perpetuación de las diferentes identidades culturales e individuales.

No obstante, en muchos casos, las políticas e iniciativas relativas a la inmigración están todavía en manos de organismos de voluntariado o de algunas administraciones locales, lo cual conduce a la fragmentación, la falta de coordinación y el desconocimiento de las iniciativas.

Las políticas sobre la inmigración deberían considerar a los inmigrantes como parte integrante de la sociedad de acogida, y ver a los antiguos y a los nuevos residentes no como dos grupos separados y antagonistas, sino como un conjunto heterogéneo, garantizando la igualdad de oportunidades y evitando cualquier forma de discriminación.

Por una parte, es necesario que los poderes públicos (nacionales y locales) garanticen y tutelen los derechos fundamentales de todos los ciudadanos por igual; sin embargo, por otra parte, la existencia de leyes destinadas a este objetivo no garantiza la aceptación por parte de la

\footnotetext{
${ }^{23}$ Cabe señalar que, a pesar de que existe esta opinión generalizada entre la población autóctona de que los inmigrantes generan un elevado gasto social, la evidencia empírica contradice los argumentos de abuso y sobreutilización de prestaciones y servicios sociales por su parte. (Moreno y Bruquetas, 2011:174).
} 
sociedad en su conjunto de la pluralidad cultural. Así, como afirma Javier de Lucas (2009:29), "mientras no haya una voluntad política de igualdad, la interculturalidad será un buen proyecto, pero al menos en lo que toca a la inmigración, [...] no pasará de papel mojado".

Para que se respeten las diferencias y los inmigrantes se sientan parte de la sociedad de acogida, sin que ello suponga una ruptura de sus vínculos culturales y nacionales, es necesario ante todo que exista un conocimiento recíproco. El conocimiento y la relación conllevarían una eliminación de los estereotipos, los prejuicios y la discriminación. Al mismo tiempo, la "contaminación" entre diversas culturas comportaría una transformación positiva y un enriquecimiento de la propia cultura, de manera que se pudiera "convertir la polifonía en armonía y evitar que degenere en cacofonía" (Baumann, 2001, citado en de Lucas, 2009:30).

Por consiguiente, es fundamental promover ocasiones de encuentro y valorización de las diferentes aportaciones culturales, así como superar las desigualdades jurídicas, políticas y económicas, de manera que se alcance una convivencia pacífica entre las personas con diferentes orígenes e identidades, una cohesión social basada en la igualdad de derechos y oportunidades, en el respeto recíproco de las diferencias, y en los deberes y objetivos compartidos.

\subsubsection{La inmigración femenina}

Teniendo en cuenta que nuestra investigación se centra en el análisis de la comunicación y la relación entre mujeres inmigrantes gestantes o puérperas y los profesionales sanitarios autóctonos, consideramos adecuado dedicar parte de la contextualización del estudio específicamente a la inmigración femenina.

En las páginas previas, hemos comentado cómo los flujos migratorios femeninos están cobrando cada vez más relevancia, llegando a alcanzar, en líneas generales (aunque con excepciones según la comunidad de origen), un número muy similar al de los hombres.

Sin embargo, hasta hace relativamente poco tiempo, las mujeres inmigrantes se caracterizaban por su completa invisibilidad, y se conocía bien poco de la inmigración femenina. Las principales razones de dicha invisibilidad eran, entre otras, el poco valor que se otorgaba a su actividad y contribución económicas, la consideración de estas mujeres como sujetos pasivos que se limitaban a seguir al hombre en el proceso migratorio, la ausencia (o la limitada presencia) de las mujeres en las investigaciones sociales en general, y la escasez de datos registrados sobre los movimientos migratorios, especialmente por lo que se refiere a la división y distribución de las comunidades inmigrantes de acuerdo a su sexo. De hecho, como sugiere María Dolores Pérez (2008:137), "tradicionalmente se ha subestimado el papel activo y el protagonismo de la mujer dentro de las redes migratorias, lo que ha dificultado el estudio de este colectivo".

Su presencia va haciéndose cada vez más visible, y las mujeres inmigrantes aparecen citadas con mayor frecuencia en los estudios dedicados a los fenómenos migratorios, aunque, a menudo, continúan considerándose sujetos sin autonomía, dependientes de sus familias. Asimismo, el interés por parte de los legisladores responsables de la elaboración de 
normativas y políticas de integración por la participación de las mujeres en la inmigración sigue resultando escaso. De hecho, como sostiene Maria Helena Bedoya (2000:243),

Es como si fuera suficiente el ocuparse de la reagrupación familiar a partir del concepto de familia nuclear y de los niños, ya que a éstas se les "intuye" unidas tanto a la una como a los otros. La utilización de términos como "población", "colectivo", "unidad familiar", etc. sugiere la posibilidad de utilizar cifras y nociones sin sesgo de género, negando a la extranjera su propio proyecto migratorio. (comillas del original)

Del mismo modo, sigue existiendo entre la población autóctona la imagen generalizada del inmigrante como un sujeto de sexo masculino que decide abandonar su país únicamente por motivos laborales o económicos (cuando los factores que pueden influir en esta decisión pueden ser, como hemos visto, múltiples), y no se tiene en cuenta el gran número de mujeres que han emigrado y continúan emigrando, ni las características diferenciales de la inmigración femenina ${ }^{24}$ con respecto a la masculina.

Así, a pesar de que en los discursos públicos no suele haber cabida para comentarios claramente discriminatorios relativos a las inmigrantes, "sí existe una percepción social muy distorsionada que no refleja para nada la capacidad y/o la posibilidad de las mujeres extranjeras para inmigrar" (Bedoya, 2000:247). Por este motivo, con frecuencia, la sociedad de acogida percibe a estas mujeres bajo una imagen estereotipada, sin tener en cuenta que se trata de un colectivo muy diverso, complejo y heterogéneo, procedente de distintos países y culturas, con diferentes patrones de emigración, y con características personales muy diversas.

De acuerdo con María Dolores Pérez (2008:144-145), los estereotipos más comunes asociados a la mujer inmigrante son los de "analfabeta, ignorante y pobre", generalización que no coincide con los datos objetivos de los que se dispone, puesto que existe un alto porcentaje de estas mujeres que poseen estudios superiores. También se le asignan otros atributos aparentemente contradictorios, ya que, según esta misma autora (2008:145-146), por un lado, en los discursos públicos, se suele transmitir una representación de la mujer inmigrante "como responsable del equilibrio, bienestar e integración familiar" $y$, por otro, se la describe como una persona "débil, frágil y vulnerable, incapaz de tomar iniciativas y necesitada de protección". Asimismo, en ocasiones, se emplean generalizaciones para hablar de colectivos de mujeres inmigrantes concretos. Por ejemplo, a las latinoamericanas se las define como "dulces, complacientes y abnegadas", y se resalta su "resignación y sumisión"; las mujeres procedentes de África Subsahariana, por su parte, se identifican con el desempeño de los "trabajos más sucios y peligrosos"; y a las musulmanas se las considera como "marginadas y explotadas por los varones de su colectivo, pasivas, sumisas, ignorantes" (2008:147-148).

\footnotetext{
${ }^{24}$ Sin ánimo de establecer generalizaciones, cabe señalar que, entre las diferencias señaladas en la bibliografía al respecto, se encuentra el hecho de que las mujeres inmigrantes normalmente poseen un grado de integración/estabilidad superior al de los hombres; asimismo, diversas fuentes hacen referencia a la usual pertenencia de estas mujeres a una estructura familiar o comunitaria en la sociedad de acogida, así como, en comparación con los inmigrantes de sexo masculino, una menor tasa de clandestinidad y un periodo de permanencia más breve en el país receptor.
} 
Al respecto de este último colectivo, quisiéramos destacar que, como señala Djaouida Moualhi (2000:294),

Una gran parte de los periodistas continúa viendo a estas mujeres como víctimas dependientes en un estado de semiesclavitud, culpando de ello a la religión musulmana. Los medios de comunicación propagan imágenes deformadas y estereotipadas sobre el velo, la clitoridectomía [...] (cuando) El hecho de haber emigrado es un claro signo de que no son pasivas ni sumisas, y sugiere también que su sociedad de origen está en un proceso de cambio, al aceptar e incluso apoyar en muchos casos la emigración de sus mujeres.

En contraposición con esta idea preconcebida sobre las mujeres inmigrantes, los datos sugieren que los flujos migratorios femeninos están cada vez más constituidos por

[...] mujeres que emigran solas, por iniciativa propia, con un proyecto migratorio autónomo y pionero; frente a un perfil de mujeres rurales y analfabetas, se está produciendo un tipo de inmigración más selectiva, ya que, cada vez más, se encuentran mujeres provenientes de medios urbanos, con una cultura migratoria interna, y con un nivel de instrucción y cualificación más elevado que el de la media de sus propios países. (Barandica, 1998:177, citada en Bedoya, 2000:247).

En consecuencia, junto al aumento de la presencia femenina en los flujos migratorios, asistimos a una mayor pluralidad de proyectos de emigración. Actualmente, las mujeres deciden emigrar por una gran variedad de razones, entre las que podemos mencionar el deseo de mejoras económicas, la reagrupación familiar, la búsqueda de oportunidades para ellas mismas, o para sus hijos y familiares, la huida de situaciones de violencia o persecución, etc. Cabe señalar que, de acuerdo con un informe publicado por la Organización de las Naciones Unidas sobre los aspectos femeninos de la migración internacional (2006), las mujeres, al abandonar sus países de origen, están cada vez más motivadas por razones de mejora personal, y menos por cargas familiares, siendo sus decisiones de emigrar tomadas a menudo de forma autónoma, y aumentando sus aportaciones tanto para los países de origen como para los de acogida.

Además, en el estudio de la inmigración femenina, se debe tener en cuenta que el proceso que experimentan las mujeres inmigrantes no comienza en el momento en el que llegan al país receptor, sino que cada una de ellas parte de un contexto social y cultural determinado, de una realidad diversa, que tendrán una notable influencia en sus elecciones de vida tanto antes de partir como al instalarse en la sociedad de acogida.

Por consiguiente, al analizar a las mujeres inmigrantes cabría considerar factores como su entorno social, su procedencia de un entorno rural o urbano, la estructura familiar a la que pertenecen, o la distribución de los roles de género en sus países de origen.

Así, por ejemplo, en las comunidades en las que se ejerce un mayor control social o familiar sobre las mujeres, y en las que se las suele relegar a la esfera doméstica o reproductiva, serán mayores las dificultades que estas encuentren a la hora de emigrar. Por ello, en estos casos, probablemente su experiencia migratoria se deberá a procesos de reagrupación familiar. No obstante, no podemos afirmar que estas mujeres dependerán siempre de sus maridos o de su familia para iniciar el proyecto migratorio, ya que, incluso en los contextos más tradicionales, el creciente acceso de la mujer a la educación, los procesos de urbanización, la globalización 
económica y de la información, así como los cambios culturales que se producen en la sociedad de origen (en ocasiones, provocados por la emigración de otros miembros de la familia o de la comunidad) incitarán y ayudarán a las mujeres a iniciar por su cuenta dicho proyecto.

Partiendo de estos presupuestos, en general, de acuerdo con Carlota Solé (1994:352-356), las características principales de la población inmigrante femenina se pueden resumir del siguiente modo:

- Por lo que respecta a la edad, el perfil mayoritario suele ser el de una mujer joven.

- En la distribución según el estado civil, predominan las solteras, las divorciadas y las separadas, aunque también un número considerable están casadas.

- Entre las inmigrantes casadas, la mayoría contrajo matrimonio en su país de origen, y un menor número se casó en el país de acogida.

- En cuanto a su procedencia, existe un porcentaje muy alto de mujeres que provienen de zonas urbanas.

- En general, al partir, no preveían la duración de su permanencia en el país de acogida; algunas lo consideraban un proyecto de por vida, y otras, un proyecto temporal.

- En referencia al nivel de estudios, es posible establecer tres grupos diferenciados: las que no han sido previamente escolarizadas, las que cuentan con estudios de educación primaria, y las que tienen estudios universitarios, finalizados o sin concluir.

Asimismo, entre las características generales de la inmigración femenina, cabe señalar que, de acuerdo con los datos proporcionados por la Organización de las Naciones Unidas (2006), las mujeres son protagonistas en las migraciones hacia países desarrollados, en los que presumiblemente encontrarán un asentamiento permanente, mientras que los hombres constituyen la mayoría en los flujos hacia países en vías de desarrollo. Igualmente, se observan, como hemos comentado previamente, diferencias regionales en cuanto a la participación de las mujeres en los flujos migratorios internacionales. Así, en numerosos países de África, Asia y Oceanía, la proporción de hombres que emigran es mayor que la de las mujeres, mientras que existe un relativo equilibrio entre sexos (incluso un predominio de la emigración femenina) en la mayor parte de los países americanos y europeos (Vicente, 2002:30).

Igualmente, factores como las leyes y regulaciones en materia de emigración/inmigración (tanto en los países de partida como en los receptores) determinarán una mayor o menor presencia de las mujeres en los procesos migratorios. Por una parte, las sociedades de origen desempeñan un papel importante a la hora de estimular u obstaculizar la emigración femenina; por otra, las sociedades de acogida, con la presencia o ausencia de posibilidades ofrecidas (tanto económicas como de otro tipo) atraerán a más o menos mujeres inmigrantes.

Por lo que se refiere a su situación una vez se asientan en la sociedad de acogida, las experiencias migratorias de las mujeres se distinguen de las de los hombres por su diferente ubicación social, por el reparto de los roles de género, y por la división sexual del trabajo, la cual, en numerosas ocasiones, las limita a los denominados "nichos laborales femeninos", situándolas en una posición de inferioridad. Así, en base a una ideología patriarcal que las relega a la esfera doméstica intrafamiliar (Walby, 1986; Sáez, 1997; Ribas et al., 2000, citados 
en Pérez, 2008:139), las mujeres inmigrantes a menudo se ven abocadas a desempeñar labores y profesiones consideradas típicamente femeninas, como el servicio doméstico, el cuidado de personas dependientes, tareas de limpieza o relacionadas con el sector de la hostelería, etc. Se trata de ocupaciones poco prestigiosas, mal remuneradas y, generalmente, poco visibles, a pesar de que son imprescindibles dentro del denominado estado del bienestar, pues afectan a necesidades básicas. De este modo, las mujeres autóctonas han ido abandonando este tipo de labores que son asumidas por las inmigrantes, dando lugar a lo que Sònia Parella (2002:480) identifica como un "proceso de transferencia de las tareas reproductivas" entre mujeres pertenecientes a distintos grupos étnicos y clases sociales.

Otro yacimiento laboral femenino al que a menudo se ven abocadas las mujeres inmigrantes, todavía más invisible y desprestigiado, está constituido por la prostitución. Resulta difícil, por el mero hecho de no ser una profesión legalmente regulada, calcular las cifras de población inmigrante femenina que debe (en la mayoría de los casos, por obligación, bien por necesidades económicas o por ser víctimas de la trata de mujeres controlada por organizaciones criminales) ejercer la prostitución, aunque de acuerdo con diversas fuentes, el porcentaje de inmigrantes alcanza entre el 80 o el $90 \%$ del total de prostitutas que trabajan en territorio español.

Cabe, además, considerar que las personas inmigrantes, en general, y las mujeres, en particular, tal y como hemos comentado previamente, suelen experimentar un "desclasamiento" (Pérez, 2008:140), consistente en un notable descenso de estatus social con respecto al que tenían en sus sociedades de origen, que se traduce en la ocupación de puestos laborales por debajo de sus capacidades y de su cualificación profesional.

A pesar de que, como ya hemos comentado, la tipología de las mujeres inmigrantes se aleja de un modelo único, y estas pueden presentar características muy variadas, podríamos clasificarlas, según Trinidad L. Vicente (2002:34-37), en los siguientes grupos:

- Mujeres casadas que inician su proyecto migratorio a consecuencia de un proceso de reagrupación familiar. Este es el típico ejemplo que se ofrece de la inmigración femenina, en el que las mujeres juegan un papel pasivo y dependiente de sus maridos y familias, quienes abandonaron en primer lugar el país de origen. El hecho de depender de sus cónyuges y familiares, unido al desconocimiento inicial de la lengua del país de acogida, pueden suponer para ellas una fuente de aislamiento social y un obstáculo para encontrar empleo. Con el tiempo, su incorporación al mercado laboral puede conllevar una mayor independencia y socialización, aunque a menudo deban soportar la doble carga del trabajo doméstico y el de fuera de casa.

- Mujeres casadas que emigran junto con sus maridos. En este caso, el grado de dependencia del cónyuge suele ser menor, ya que las mujeres que emigran acompañadas de sus maridos suelen acceder a un empleo más rápidamente. Igualmente, cabe señalar que, por lo general, en estas circunstancias, las parejas tienden a reproducir la distribución por roles propia de su comunidad de origen.

- Mujeres que emigran para mantener económicamente a sus familias. Este tipo de inmigración femenina se ve favorecida por la demanda de mano de obra en el país receptor para ocupar puestos laborales asociados a las mujeres, como el servicio 
doméstico. En algunas ocasiones, las mujeres englobadas dentro de esta tipología pueden haberse visto obligadas a iniciar el proceso migratorio por viudedad, separación o repudio por parte de sus maridos. Otras simplemente emigrarán solas para, más tarde, una vez alcanzada cierta estabilidad económica, reagruparse con sus maridos e hijos en el país de acogida. En este caso, los roles establecidos en la comunidad de origen tienden a variar en la sociedad receptora.

- Mujeres solteras que inician su proceso migratorio para ayudar económicamente a sus familias. Este tipo de emigración está protagonizado por mujeres responsables de sus familiares (principalmente, sus padres y hermanos menores) desde el punto de vista económico. También en este caso juegan un papel fundamental las mayores posibilidades de incorporarse al mercado laboral que ofrece el país de acogida a las mujeres con respecto a los hombres. Estas mujeres suelen enviar gran parte de las ganancias que reciben a la familia que ha permanecido en el país de origen y, para ellas, la emigración supone una mayor independencia del control patriarcal o de la comunidad, así como un mayor prestigio dentro de la familia, por la contribución económica que realizan.

- Mujeres solteras que compaginan la ayuda económica a sus familias con proyectos de promoción personal. Las mujeres que emigran con este doble objetivo suelen tomar por sí mismas la decisión de abandonar su país de origen. Se trata normalmente de mujeres procedentes de zonas urbanas, con un nivel de estudios medio-alto y, en su mayoría, también con un estatus económico medio-alto, por lo que su responsabilidad a la hora de enviar remesas a sus familiares que han permanecido en el país de origen suele ser menor que en el caso anterior. Es posible que estas mujeres, con la emigración, no solo busquen una mayor independencia y autonomía o un alejamiento de los roles que desempeñaban en sus países, sino también una mejora personal y social. Con frecuencia son inducidas por relatos de experiencias migratorias previas que escuchan en los medios de comunicación o por boca de amigos y familiares. Por desgracia, en muchos casos, al llegar a la sociedad de acogida, la idea que tenían previamente de esta sociedad contrasta con la realidad que deben afrontar $y$, en general, experimentan un movimiento vertical descendente que las obliga a ocupar puestos de trabajo que requieren menor cualificación que aquellos que, por su experiencia y/o formación podrían desempeñar (a menudo a causa de las trabas administrativas en la convalidación de los títulos). ${ }^{25}$

- Mujeres solteras jóvenes, normalmente menores de edad, que emigran para reagruparse con sus familias. En este caso, evidentemente, no son las propias mujeres las que deciden emigrar, sino sus familiares presentes en el país de acogida. Si llegan a dicho país a una edad temprana y consiguen incorporarse al sistema educativo, probablemente les resultará más fácil en un futuro acceder a un empleo y obtener una mayor autonomía. Si, por el contrario, emigran un poco más mayores, tendrán grandes probabilidades de ser relegadas a los mismos nichos laborales a los que se ven abocadas otras compatriotas. El hecho de que en la sociedad de acogida sigan manteniendo los mismos roles que se atribuyen a las mujeres en sus países de origen o de que, en cambio, gocen de mayor

\footnotetext{
${ }^{25}$ Al respecto de las dificultades que suelen hallar los extranjeros a la hora de convalidar los títulos de estudios obtenidos en sus respectivos países de origen, estamos de acuerdo con María Dolores Pérez (2008:170), cuando afirma que se debería disponer de un procedimiento sistemático mediante el cual se pudiera obtener un reconocimiento de las titulaciones cursadas o de las habilidades y capacidades profesionales que no quedan reflejadas en un título, de modo que se pudiera favorecer su inserción laboral en puestos acordes a su formación u ofrecerles la posibilidad de continuar sus estudios en el país de acogida.
} 
independencia, dependerá en gran medida de quién inició el proceso migratorio en sus familias (por ejemplo, si fue el padre o la madre solos, o ambos juntos).

Por otra parte, de acuerdo con un conjunto de variables culturales y socioeconómicas, las mujeres inmigrantes, una vez instaladas en la sociedad de acogida, podrían dividirse en tres categorías (López et al., 2003:16):

- Las "establecidas", quienes suelen trabajar de manera más o menos continuada y se encuentran en un proceso de integración laboral o formativa en el país receptor. Normalmente, estas mujeres conocen el idioma y los referentes culturales básicos de dicho país.

- Las "transitorias", las cuales presentan habitualmente un menor conocimiento del idioma del país de acogida y una menor adaptación cultural. Por lo general, con el transcurso del tiempo, pasan a formar parte del primer grupo mencionado.

- Las "aisladas", que viven según los parámetros de sus comunidades de origen y presentan un elevado índice de aislamiento social, debido, en gran parte, a su desconocimiento del idioma, pero también a factores culturales, económicos y religiosos. Su contacto con la población autóctona es bastante reducido, y sus relaciones se limitan al ámbito familiar, del que dependen en gran medida.

Quisiéramos señalar que nuestra intención al presentar estos grupos y categorías no consiste en absoluto en establecer tipologías cerradas en las que encuadrar a las mujeres inmigrantes, sino más bien en exponer cuáles podrían ser sus principales características, siempre considerando que las particularidades culturales, socioeconómicas y personales de cada mujer podrán acercarla más o menos a un determinado grupo o categoría de los expuestos (o a varios a la vez), e incluso que su situación podrá ir cambiando a lo largo del tiempo.

Igualmente, la aproximación de las mujeres de origen extranjero a uno u otro grupo dependerá en parte del hecho de que pertenezcan a comunidades inmigrantes predominantemente femeninas (como es el caso de la comunidad filipina o de las procedentes de Latinoamérica), o a aquellas en las que el porcentaje de hombres es superior al de las mujeres (como las originarias del Magreb, África Subsahariana o el subcontinente indio).

Independientemente de su pertenencia a una u otra comunidad, al llegar al país de acogida, las mujeres inmigrantes suelen experimentar una serie de cambios que pueden afectar a todos los ámbitos de sus vidas: desde, como hemos señalado, la distribución de los roles familiares y de género, hasta su ocupación en trabajos no realizados hasta el momento, o incluso en relación con la organización temporal. Al respecto de esta última cuestión, comenta Franca Balsamo (2003:163) cómo la falta de tiempo libre supone para numerosas mujeres inmigrantes una ausencia de las relaciones de apoyo, solidaridad e intercambio. Así, por ejemplo, esta autora sostiene que las mujeres procedentes de países africanos en los que las relaciones de mutua ayuda son consideradas un deber, frecuentemente se ven privadas de la posibilidad de mantener este tipo de relaciones en el país de acogida, por lo que se pone de manifiesto la contraposición entre una sociedad (la de origen) basada en la solidaridad y otra (la de destino) en la que predomina el individualismo. Asimismo, Carlota Solé (1994:180) señala la falta de tiempo como una de las causas que dificultan el desarrollo personal de las mujeres inmigrantes, al impedirles participar en actividades de formación o de asociacionismo. 
En cuanto a su grado de integración, este también variará dependiendo de otros factores, como el tiempo de permanencia en el país de acogida, su situación legal, sus conocimientos del idioma, su condición laboral y sus fuentes de ingresos, sus redes de apoyo, así como las relaciones que tengan con la población autóctona.

En cualquier caso, la condición de mujer que reside en un país extranjero implica deber afrontar una serie de transformaciones, conflictos y contradicciones internas que afectarán al núcleo central de sus certezas y a la percepción de su propia identidad.

Del mismo modo, y en relación con el ámbito principal de nuestra investigación, esta nueva situación provocará cambios en la representación del propio cuerpo por parte de las mujeres inmigrantes, así como en su salud y su capacidad reproductivas. Como sostiene Marta Castiglioni (2007:25), en las mujeres inmigrantes se producen, entre otros, cambios que afectan a su propio cuerpo y al concepto del mismo, en los que,

[...] natura e cultura, biologia e psichismo si incrociano. Il corpo è il luogo dove nella donna si incontrano funzioni produttive e riproduttive che determinano comportamenti riguardo la domanda di salute e le scelte che riguardano la cura di sé, dei figli e della familia.

En consecuencia, el hecho de estar atravesando un proceso de adaptación a un nuevo contexto sociocultural y de creación de una nueva identidad, unido a las condiciones económicas y personales en la sociedad de acogida, podrán determinar modificaciones en los patrones reproductivos de las mujeres, que conlleven, por ejemplo, un menor número de hijos - la reproducción a una edad más tardía en comparación con lo que resulta habitual en las mujeres de su comunidad de origen.

Por otro lado, cabe destacar que las mujeres inmigrantes se hallan entre los colectivos con mayor riesgo de exclusión social, ya que no solo se enfrentan a dificultades causadas por la discriminación racial, económica y de género a la que se suelen ver sometidas, sino que, además, se ejerce sobre ellas una gran presión provocada por el precario equilibrio entre los papeles que desempeñan y que se les exigen desde sus comunidades de origen, por un lado, y los que se les atribuyen a las mujeres en las sociedades occidentales, a los que se espera que se adapten en su proceso de integración social, por otro. Así, como sostiene María Helena Bedoya (2000:255),

Las mujeres extranjeras sufren una doble discriminación, pues a la discriminación de género padecida también por las mujeres autóctonas- debe sumarse la situación de desprotección que su estatus jurídico conlleva, que las expone a una situación de precariedad, inseguridad e indefensión, tanto en sus relaciones familiares como respecto a los poderes públicos.

Carmen Gregorio (1998) identifica cinco variables que determinan la posición de las mujeres inmigrantes dentro de sus comunidades y, por extensión, en la sociedad en general: la extranjería (el mero hecho de ser extranjeras); el estatus socioeconómico (que, en muchas ocasiones, suele ser bajo); la raza (si es igual o diferente a la del grupo mayoritario); la cultura, la religión y la lengua (también, en este caso, si son iguales o similares a las de la población autóctona, o si, por el contrario, son diversas); y el género (femenino). La combinación de todas estas variables determinará el grado de su invisibilidad, inferioridad y dependencia. 
Factores como la formación o el empleo pueden contribuir a mejorar la condición de las mujeres inmigrantes; sin embargo, dentro del colectivo inmigrante, que ya de por sí encuentra dificultades para acceder a programas educativos u ocupaciones laborales, las mujeres suelen ser el grupo más desfavorecido.

Por lo que se refiere a los cursos de formación, la participación de las mujeres inmigrantes suele ser escasa, debido a factores como los requisitos administrativos exigidos, el bajo nivel de conocimiento de la lengua del país de acogida, el difícil acceso a la información sobre estos programas formativos, o la organización de los mismos en horarios estándares en los que estas mujeres no pueden asistir.

En cuanto a la ocupación laboral, si bien en los últimos años ha aumentado la tasa de actividad de las mujeres en Europa, el desempleo suele ser más elevado en el caso de las inmigrantes con respecto a las autóctonas. Este fenómeno podría englobarse dentro de lo que Carlota Solé (1994:122) denomina "discriminación laboral categórica", por la cual los empleadores pueden actuar en contra de un candidato por razón de su género, su raza o su nacionalidad. Cabría, además, considerar que muchas de ellas se encuentran trabajando en lo que se conoce como economía sumergida, un elemento más de su carácter invisible.

Por otro lado, en numerosas ocasiones, no les resulta posible obtener un permiso de trabajo, con lo cual, quedan limitadas casi podríamos decir perpetuamente a cumplir con su papel de esposas, madres y amas de casa, ya que sus responsabilidades en el cuidado del hogar y de la familia disminuyen sus posibilidades para iniciar procesos formativos o laborales, al mismo tiempo que las sumergen en un estado de aislamiento.

E incluso en los casos en los que consiguen emplearse regularmente, el principal problema, como ya hemos señalado, consiste en que normalmente se las relega a trabajos considerados marginales en la estructura ocupacional de la sociedad de acogida, en un mercado segmentado por el género y la etnicidad. Así, se las suele situar en los sectores más desprotegidos del mercado laboral, con horarios extensos, duras tareas, y pocas posibilidades de movilidad profesional ascendente.

A modo de resumen, podríamos decir que las mujeres inmigrantes se suelen enfrentar a tres tipos de barreras a la hora de acceder al empleo o la formación (López et al., 2003:17): barreras psicológicas (como la falta de confianza en sí mismas, la carencia de apoyo familiar, o la tradicional imagen personal de esposa y madre); sociales (como el desconocimiento de los recursos que le ofrece la sociedad de acogida o las responsabilidades familiares); y culturalesreligiosas (como el impedimento impuesto por la propia familia o comunidad de compartir espacios públicos con hombres que no formen parte de su entorno familiar, la dependencia de sus padres o sus maridos a la hora de tomar decisiones, o la falta de interés por realizar actividades que les podrían aportar beneficios futuros a causa de una percepción temporal orientada hacia el presente).

Las denominadas barreras psicológicas no son exclusivamente propias de las mujeres inmigrantes, aunque en su caso se manifiestan de manera más tenue, minando su confianza en sus capacidades. Las barreras sociales suelen ser las más evidentes y, por tanto, al menos en teoría, más fáciles de afrontar y superar. Por ejemplo, para combatir el desconocimiento 
por su parte de los recursos y servicios disponibles, pueden llevarse a cabo acciones de información, orientación y asesoramiento que les permitan conocer las prestaciones y ayudas relativas a la vivienda, la sanidad, el empleo, la formación, etc. Por último, las llamadas barreras culturales y religiosas variarán dependiendo tanto de la comunidad de origen como del entorno social en el país de acogida.

Las barreras mencionadas tendrán una gran influencia en su proceso de integración y las situarán en una posición de desigualdad que podría clasificarse en tres tipos (Setién y López, 2002:67):

- La desigualdad de género existente en la sociedad de acogida, que desemboca en altas tasas de desempleo entre la población femenina, la existencia de trabajos "típicamente para mujeres" (los denominados nichos laborales), las diferencias salariales entre trabajadores de sexo masculino y femenino, y la escasa participación económica y política por parte de las mujeres.

- La desigualdad en función de las características personales de las mujeres inmigrantes, como son el origen étnico, el desconocimiento de la lengua del país receptor, o el bajo nivel de formación, que las sitúa en una posición de inferioridad con respecto a las mujeres autóctonas.

- La desigualdad de género existente en su sociedad de origen, que se puede manifestar en una dependencia de los miembros de su comunidad de sexo masculino y en una limitación de sus movimientos y de su capacidad para tomar decisiones, generalmente basadas en valores culturales o religiosos.

La presencia de uno o más tipos de desigualdad colocará a las mujeres inmigrantes en una posición de exclusión social, y limitará su acceso a los recursos ofrecidos en la sociedad de acogida.

Con el fin de combatir esta situación de exclusión, desigualdad y discriminación en la que se encuentran gran parte de las mujeres inmigrantes, sería conveniente que estas iniciasen un proceso de empoderamiento ${ }^{26}$ que les permitiera acceder y usar los servicios y recursos de la sociedad de acogida. El empoderamiento se relaciona con el poder como relación social. Todas las sociedades se encuentran estructuradas de acuerdo a una serie de relaciones de poder (como las que se establecen entre un hombre y una mujer, en el seno de las familias, entre un alumno y un maestro, o entre el que sabe y el que no sabe), las cuales se instauran mediante la acumulación, la circulación y el funcionamiento de un "discurso de verdad", y que se convierten en relaciones de dominación bajo formas de derechos (leyes, aparatos, instituciones, reglamentos, etc.) (Foucault, 1979:157-161). En nuestro caso, entendemos el empoderamiento tal y como lo define Margaret Schuler (1997:29), es decir, como

[...] el proceso por medio del cual las mujeres incrementan su capacidad de configurar sus propias vidas y su entorno, una evolución en la concienciación de las mujeres sobre sí mismas, en su estatus y en su eficacia en las interacciones sociales.

\footnotetext{
${ }^{26}$ La teoría del empoderamiento (empowerment) nace en los Estados Unidos, en la década de los sesenta del pasado siglo, durante los movimientos por los derechos civiles, para, más tarde, concretamente en los setenta, aplicarse a los movimientos feministas cuyo objetivo era producir cambios en las relaciones de poder entre los distintos géneros.
} 
Para experimentar dicha evolución, de acuerdo con esta autora (1997:54), serían necesarias una serie de manifestaciones que normalmente se encuentran ausentes en la mayoría de las mujeres inmigrantes, como son el sentido de seguridad y la visión de futuro, la capacidad de ganarse la vida, las habilidades para actuar eficazmente en la esfera pública, el poder a la hora de tomar decisiones en el ámbito del hogar, la participación social fuera de la familia, el recurso a redes de apoyo e información, y la movilidad y la visibilidad en la sociedad. Se deberían, por tanto, establecer las condiciones que permitieran a las mujeres inmigrantes, siempre que así lo deseen, ser partícipes de las manifestaciones descritas, de modo que se aumentara su visibilidad, se reconocieran sus capacidades, y tuvieran un mayor acceso a las oportunidades de mejora y, en consecuencia, lograran empoderarse.

\subsubsection{La asistencia sanitaria}

En este apartado, como hemos comentado previamente, describimos el ámbito en el que se desarrolla nuestro estudio (el sistema de salud español), para, a continuación, presentar el contexto específico en el que este se desarrolla (los servicios sanitarios de Aragón y Zaragoza y, más concretamente, uno de sus hospitales materno-infantiles).

\subsubsection{Cuestiones básicas sobre el sistema de salud español}

Antes de pasar a analizar las características que presenta el Sistema de Salud español, cabría puntualizar qué se entiende precisamente por "sistema de salud". Este podría definirse como el conjunto de servicios y recursos destinados a la atención de la salud de la población de un determinado territorio, dentro de los cuales, se incluyen: los derechos de dicha población con respecto al acceso a los servicios sanitarios; las características de financiación del sistema; la producción, organización y articulación de los servicios; y la regulación sobre diversos determinantes de salud, como podrían ser aquellos relacionados con la higiene de los alimentos y con el medio ambiente (Alonso y Lizana, 2009:35).

El objetivo principal de los sistemas de salud suele consistir en contribuir, de la forma más equitativa y eficiente posible, a la mejora de la salud de la población a la que dicho sistema está destinado. Las cuestiones relativas a los derechos de acceso y uso, las prestaciones ofrecidas, las condiciones de acceso, y los profesionales encargados de su funcionamiento se encuentran recogidas en leyes y planes de salud y en planes estratégicos.

Estas normativas pueden variar de uno a otro país, e incluso dentro de un mismo país, dependiendo del desarrollo que haya experimentado el sistema de salud y de las políticas territoriales y sociales vigentes.

Por lo que se refiere al contexto español, su sistema sanitario evolucionó de un modelo de Seguridad Social (financiado por las cuotas de empresarios y trabajadores) a, con la Ley de Sanidad de 1986, pasar a constituirse como un Sistema Nacional de Salud cohesionado, financiado mediante los impuestos, y con cobertura para toda la población. ${ }^{27}$ Cabe, además,

\footnotetext{
${ }^{27}$ El acceso y uso de los servicios sanitarios españoles se encuentra actualmente restringido a los ciudadanos autóctonos y a los extranjeros con permiso de residencia que cumplan una serie de requisitos. Así, los extranjeros, dependiendo de factores como su origen, su condición laboral, o los acuerdos y tratados bilaterales o internacionales firmados entre su país de origen y España, tendrán derecho a utilizar o no dichos servicios. Para mayor información, véase el apartado de análisis documental del capítulo 6.
} 
señalar que se trata de un sistema descentralizado, en el que determinadas competencias o funciones se encuentran trasferidas desde el gobierno central a niveles inferiores del mismo.

En resumen, el sistema de salud español presenta las siguientes características generales: ${ }^{28}$

- Se trata de un sistema con financiación pública, "universal" y gratuito.

- Su objetivo principal consiste en la prestación de una atención integral de la salud, en la que se procura mantener unos niveles altos de calidad debidamente sometidos a control y evaluación.

- Las diferentes estructuras que lo conforman se hallan integradas dentro del sistema nacional.

- Las funciones y prestaciones sanitarias son responsabilidad de los poderes públicos.

Como hemos comentado previamente, se trata de un sistema descentralizado, que atribuye diferentes competencias al Estado, por una parte, y a las comunidades autónomas y los municipios, por otra. En concreto, el Estado se encarga, de conformidad con la legislación vigente, de las bases y la coordinación general de la sanidad, de las cuestiones relacionadas con la salud general y con las relaciones y acuerdos sanitarios internacionales, y de la legislación de los productos farmacéuticos. Por su parte, las comunidades autónomas se ocupan de la planificación sanitaria, de la salud pública, y de la gestión de los servicios de salud. El fin que se persigue con la atribución de competencias a los gobiernos autonómicos y locales es principalmente aproximar la gestión de la asistencia sanitaria a los ciudadanos, fomentando de este modo la calidad de los servicios y la participación de los usuarios en los mismos.

En la tabla que mostramos a continuación, puede observarse la distribución general de competencias de las administraciones sanitarias por lo que respecta a las prestaciones y servicios de salud.

\begin{tabular}{|c|c|c|}
\hline $\begin{array}{c}\text { Administración del } \\
\text { Estado }\end{array}$ & $\begin{array}{l}\text { Bases y coordinación general de la Sanidad } \\
\text { Sanidad Exterior } \\
\text { Legislación de productos farmacéuticos }\end{array}$ & \multirow{2}{*}{$\begin{array}{l}\text { Consejo Interterritorial del } \\
\text { Sistema Nacional de Salud }\end{array}$} \\
\hline $\begin{array}{l}\text { Comunidades } \\
\text { autónomas }\end{array}$ & $\begin{array}{l}\text { Planificación sanitaria } \\
\text { Salud pública } \\
\text { Gestión de los servicios de salud }\end{array}$ & \\
\hline Corporaciones locales & $\begin{array}{l}\text { Salubridad } \\
\text { Colaboración en la gestión de los servicios }\end{array}$ & \\
\hline
\end{tabular}

Tabla 1.1. Competencias de las administraciones públicas en materia sanitaria

(Fuente: Alonso y Lizana, 2009:39)

\footnotetext{
${ }^{28}$ Aparte de las modificaciones introducidas con el Real Decreto-ley 16/2012, de 20 de abril, de medidas urgentes para garantizar la sostenibilidad del Sistema Nacional de Salud y mejorar la calidad y seguridad de sus prestaciones, el cual, como veremos en el capítulo 6, limita sustancialmente el acceso de la población inmigrante a los servicios sanitarios, nos hallamos en la actualidad inmersos en un periodo convulso en cuanto al funcionamiento y la organización de la asistencia sanitaria en España (valga como ejemplo el recientemente introducido sistema de copago farmacéutico, en vigor desde el 1 de julio de 2012, o las alarmantes noticias sobre posibles futuras privatizaciones de hospitales públicos). Por este motivo, es posible que las características generales sobre el Sistema de Salud español aquí señaladas varíen en el transcurso de los próximos meses o años.
} 
Para concluir este subapartado, cabe señalar que la clave de acceso a los servicios sanitarios del Sistema Nacional de Salud está constituida por la tarjeta sanitaria individual. Se trata de un documento personal e intransferible que identifica al usuario de dichos servicios, y acredita que este cumple con las condiciones necesarias para poder recibir asistencia sanitaria. Si bien, hasta hace menos de un año, el requisito legal para poder obtener esta tarjeta era el empadronamiento (es decir, la inscripción administrativa en el registro municipal del lugar de residencia), con la aprobación y aplicación del Real Decreto-ley 16/2012, dicho requisito deja de ser suficiente en el caso de los extranjeros.

\subsubsection{Los servicios sanitarios en Aragón y Zaragoza}

El Sistema de Salud de Aragón se configura de acuerdo a la Ley de Salud de Aragón (Ley 6/2002), y en virtud del artículo 50 de la Ley General de Sanidad (Ley 14/1986, de 25 de abril), según el cual,

En cada Comunidad Autónoma se constituirá un Servicio de Salud integrado por todos los centros, servicios y establecimientos de la propia Comunidad, Diputaciones, Ayuntamientos y cualesquiera otras Administraciones territoriales intracomunitarias, que estará gestionado como se establece en los artículos siguientes bajo la responsabilidad de la respectiva Comunidad Autónoma.

Dicho Sistema de Salud se estructura en niveles de atención a la salud progresivos y relacionados entre sí, con el fin de garantizar una prestación sanitaria integral y coordinada. Dichos niveles son los siguientes:

- Salud pública

- Atención primaria ${ }^{29}$

- Atención especializada

- Atención a la salud mental

- Atención sanitaria urgente

- Atención a la dependencia

Por otro lado, la asistencia sanitaria se organiza según una estructura territorial que se divide en áreas o sectores sanitarios, los cuales están clasificados, a su vez, en zonas de salud. Cada zona de salud tiene un centro de salud en el que desarrolla sus actividades el equipo de atención primaria.

\footnotetext{
${ }^{29}$ La Declaración de Alma Ata, de 12 de septiembre de 1978 (consultable en la página web [http://www.almaata.es/]), surgida a raíz de la Conferencia internacional de atención primaria de salud, celebrada con la finalidad de promover y proteger la salud para todas las personas del mundo, ("Salud para todos"), establece en su punto cinco que, "La atención primaria de salud es la asistencia esencial, basada en métodos y tecnologías prácticos, científicamente fundados y socialmente aceptables, puesta al alcance de todos los individuos y familias de la comunidad, mediante su plena participación, y a un coste que la comunidad y el país puedan soportar, en todas y cada una de las etapas de su desarrollo, con un espíritu de autorresponsabilidad y autodeterminación, llevando lo más cerca posible la atención de salud al lugar donde residen y trabajan las personas, constituyendo el primer elemento de un proceso permanente de asistencia sanitaria".
} 
En concreto, los ocho sectores que configuran el mapa sanitario de Aragón, ${ }^{30}$ en los que se incluyen todos los centros de atención primaria, atención especializada, atención a la salud mental y otras prestaciones de atención socio-sanitaria correspondientes a su área geográfica son los siguientes:

- Sector Sanitario Alcañiz

- Sector Sanitario Barbastro

- Sector Sanitario Calatayud

- Sector Sanitario Huesca

- Sector Sanitario Teruel

- Sector Sanitario Zaragoza I

- Sector Sanitario Zaragoza II

- Sector Sanitario Zaragoza III

- 061 Aragón - Urgencias y emergencias sanitarias

- Banco de Sangre y Tejidos de Aragón

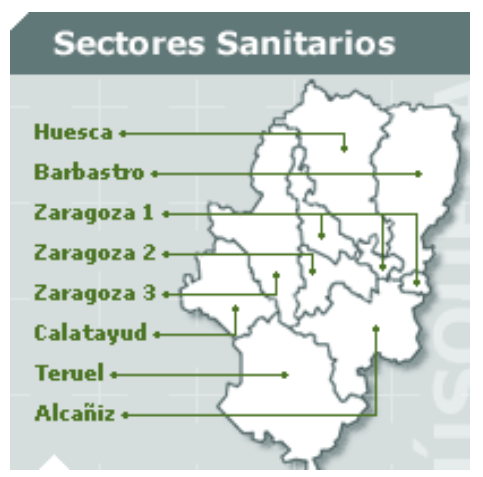

Imagen 1.1. Mapa de los sectores sanitarios de Aragón

\footnotetext{
${ }^{30}$ El mapa sanitario de la Comunidad Autónoma de Aragón se aprueba mediante el Decreto 130/1986, de 19 de diciembre, de la Diputación General de Aragón (Boletín Oficial de Aragón no 133 de 31 de diciembre de 1986), modificado por los siguientes decretos: Decreto 29/1988, de 1 de marzo, Decreto 23/1989, de 13 de marzo, Decreto 73/1990, de 8 de mayo, Decreto 120/1991, de 21 de junio, Decreto 85/1992, de 28 de abril, Decreto 52/1993, de 19 de mayo, Decreto 85/1994, de 12 de abril, Decreto 27/1995, de 21 de febrero, Decreto 154/1996, de 26 de julio, Decreto 156/1997, de 2 de septiembre, Decreto 160/1998, de 1 de septiembre, Decreto 43/1999, Decreto 22/2001, de 16 de enero, Decreto 151/2001, de 24 de julio, Decreto 81/2002, de 6 de marzo, Decreto 207/2003, de 22 de julio, Decreto 82/2004, de 13 de abril, Decreto 25/2005, de 8 de febrero, Decreto 84/2006, de 4 de abril, Decreto 58/2007, de 17 de abril, 167/2008, de 9 de septiembre, todos ellos consultables en la página web: [http://www.boa.aragon.es/] (última consulta: 2 de septiembre de 2013).
} 
En concreto, los sectores sanitarios de Zaragoza, contexto específico de nuestro estudio, incluyen los siguientes centros:

\begin{tabular}{|c|c|c|}
\hline Sector Zaragoza I & Sector Zaragoza II & Sector Zaragoza III \\
\hline $\begin{array}{l}\text { ATENCIÓN PRIMARIA } \\
\text { (CENTROS DE SALUD) } \\
\text { Actur Norte, Actur Sur, Actur Oeste, } \\
\text { Alfajarín, Arrabal, Bujaraloz, La Jota, } \\
\text { Luna, Parque Goya, Picarral, Santa } \\
\text { Isabel, Villamayor y Zuera. }\end{array}$ & $\begin{array}{l}\text { ATENCIÓN PRIMARIA } \\
\qquad \text { (CENTROS DE SALUD) } \\
\text { Azuara, Belchite, Canal Imperial-San } \\
\text { José Sur, Canal Imperial-Venecia, } \\
\text { Casablanca, Fernando el Católico, } \\
\text { Fuentes de Ebro, Hermanos Ibarra } \\
\text { (consultorio), La Almozara, Las } \\
\text { Fuentes Norte, Parque Roma, } \\
\text { Rebolería, Sagasta-Miraflores, } \\
\text { Sagasta-Ruiseñores, San José } \\
\text { Centro, San José Norte, San Pablo, } \\
\text { Sástago, Seminario, Torre Ramona y } \\
\text { Torrero-La Paz. }\end{array}$ & $\begin{array}{l}\text { ATENCIÓN PRIMARIA } \\
\qquad \text { (CENTROS DE SALUD) } \\
\text { Alagón, Bombarda, Borja, Cariñena, } \\
\text { Casetas, Delicias Norte, Delicias Sur, } \\
\text { Ejea de los Caballeros, Épila, Gallur, } \\
\text { Herrera de los Navarros, La Almunia } \\
\text { de Doña Godina, María de Huerva, } \\
\text { Miralbueno, Oliver, Sádaba, Sos del } \\
\text { Rey Católico, Tarazona, Tauste, } \\
\text { Univérsitas, Utebo y Valdefierro. }\end{array}$ \\
\hline $\begin{array}{l}\text { ATENCIÓN ESPECIALIZADA } \\
\text { (CENTROS DE ESPECIALIDADES) } \\
\text { C.M.E. Grande Covián. }\end{array}$ & $\begin{array}{l}\text { ATENCIÓN ESPECIALIZADA } \\
\text { (CENTROS DE ESPECIALIDADES) } \\
\text { C.M.E. San José y C.M.E. Ramón y } \\
\text { Cajal. }\end{array}$ & $\begin{array}{l}\text { ATENCIÓN ESPECIALIZADA } \\
\text { (CENTROS DE ESPECIALIDADES) } \\
\text { C.M.E. Inocencio Jiménez, C.M.E. } \\
\text { Ejea y C.M.E. Tarazona. }\end{array}$ \\
\hline $\begin{array}{l}\qquad \text { ATENCIÓN ESPECIALIZADA } \\
\text { (HOSPITALES) } \\
\text { Hospital Nuestra Señora de Gracia y } \\
\text { Hospital Royo Villanova. }\end{array}$ & 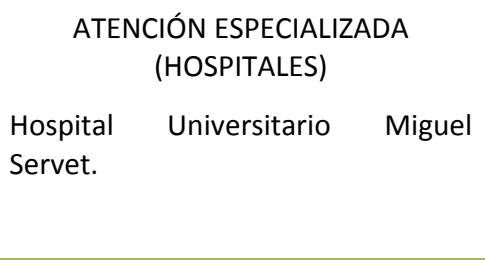 & 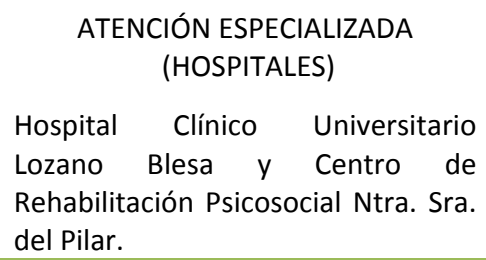 \\
\hline $\begin{array}{l}\text { SALUD MENTAL } \\
\text { Unidad de Salud Mental Actur Sur, } \\
\text { Unidad de Salud Mental Hospital } \\
\text { Royo Villanova, Unidad de Salud } \\
\text { Mental Hospital Nuestra Señora de } \\
\text { Gracia, Unidad de Salud Mental } \\
\text { Infanto-Juvenil Actur Sur y Centro } \\
\text { de Promoción de la Salud Mental. }\end{array}$ & $\begin{array}{l}\text { SALUD MENTAL } \\
\text { Unidad de Salud Mental Rebolería, } \\
\text { Unidad de Salud Mental Romareda- } \\
\text { Casablanca, Unidad de Salud Mental } \\
\text { Torrero-La Paz, Unidad de Salud } \\
\text { Mental Madre Vedruna-Miraflores, } \\
\text { Unidad de Salud Mental Sagasta- } \\
\text { Ruiseñores, Unidad de Salud Mental } \\
\text { Las Fuentes, Unidad de Salud } \\
\text { Mental San José-Norte y Unidad de } \\
\text { Salud Mental Infanto-Juvenil } \\
\text { Muñoz-Fernández. }\end{array}$ & $\begin{array}{l}\text { SALUD MENTAL } \\
\text { Unidad de Salud Mental Cinco Villas } \\
\text { (Ejea), Unidad de Salud Mental- } \\
\text { Consultas Externas Hospital Clínico } \\
\text { Universitario, Unidad de Salud } \\
\text { Mental Delicias y Unidad de Salud } \\
\text { Mental Infanto-Juvenil Hospital } \\
\text { Clínico Universitario. }\end{array}$ \\
\hline & $\begin{array}{l}\text { ATENCIÓN SOCIOSANITARIA } \\
\text { Hospital San Juan de Dios. }\end{array}$ & \\
\hline
\end{tabular}

Tabla 1.2. Centros de los sectores sanitarios de Zaragoza

Por lo que respecta al ámbito de la salud concreto estudiado en nuestra investigación, la salud reproductiva, esta se encuentra incluida dentro de la cartera de servicios de atención primaria, en concreto, entre los servicios específicos de atención a la mujer, los cuales comprenden las siguientes prestaciones:

- Captación y valoración de la embarazada

- Visita en el primer mes posparto

- Información y seguimiento sobre métodos anticonceptivos

- Vacunación de rubeola 
- Diagnóstico precoz del cáncer de cérvix

- Diagnóstico precoz del cáncer de endometrio

- Diagnóstico precoz del cáncer de mama

- Atención a la mujer en climaterio

\subsubsection{El hospital contexto de nuestro estudio}

Con el fin de comprender las características complejas de la comunicación intercultural en el ámbito de la salud reproductiva, hemos contextualizado nuestro estudio, como hemos señalado previamente, en un hospital materno-infantil de la ciudad de Zaragoza, en el que hemos realizado trabajo de campo durante un periodo de tiempo prolongado. ${ }^{31}$

En este subapartado vamos a presentar, en primer lugar, los motivos que nos llevaron a escoger este contexto de estudio determinado frente a otros $y$, a continuación, describiremos las características generales del mismo, siempre atendiendo al principio ético de confidencialidad que rige nuestro trabajo de campo. ${ }^{32}$

Las razones que nos llevaron a escoger el contexto específico en el que desarrollaríamos nuestra investigación fueron múltiples y variadas.

Por lo que respecta al área geográfica elegida (la comunidad autónoma de Aragón), hemos comentado en las páginas previas que esta se encuentra entre las diez primeras comunidades de España con mayor presencia de población inmigrante, tanto en relación con el número total de extranjeros residentes, como en referencia a la incidencia de los mismos con respecto a la población total (con un porcentaje que incluso supera la media nacional, a nivel autonómico $12,7 \%-$, y provincial y municipal $-12,9 \%$ ).

Además, en cuanto a las áreas de procedencia y las nacionalidades de los inmigrantes residentes en Aragón, el patrón es bastante similar al que presenta el conjunto de la nación, por lo que puede considerarse un área representativa de la población inmigrante española.

Por otro lado, teniendo en cuenta las características generales de la inmigración recibida por esta comunidad (constituida predominantemente por población joven -siendo más del $70 \%$ menor de 40 años- y un alto porcentaje de mujeres -equivalente al $46 \%$ de la población inmigrante total), podemos deducir que en ella se da presumiblemente un elevado número de nacimientos de madres extranjeras. Como prueba de esta conjetura, se encuentra el dato del número de nacimientos de padres inmigrantes que tuvieron lugar en 2011, que supusieron un cuarto del total de los que se produjeron ese año. Asimismo, si bien no disponemos de la disgregación por nacionalidad (extranjera/autóctona) de la tasa de fecundidad de las mujeres residentes en Aragón, considerando que la tasa de fecundidad media es muy similar a la que presentan las mujeres en España (1,4 y 1,3, respectivamente), podemos establecer la hipótesis de que, probablemente, la distribución de dicha tasa a nivel nacional de acuerdo con el origen de la madre (1,32 para las autóctonas, y 1,55 para las extranjeras), será también semejante en

\footnotetext{
${ }^{31}$ Para mayor información, véanse el capítulo 2, en el que se describe el diseño metodológico de nuestra investigación, y el capítulo 6, en el que se exponen los resultados del trabajo de campo que hemos llevado a cabo.

32 Para la descripción del hospital contexto de nuestro estudio, hemos tomado como referencia la obra de Claudia V. Angelelli (2004), en la que esta autora presenta los resultados de una investigación sobre comunicación intercultural realizada en un hospital público de California.
} 
Aragón. Por todo ello, podemos concluir que el número de mujeres inmigrantes que dan a luz en esta comunidad es lo suficientemente representativo como para seleccionar esta zona como contexto general de nuestro estudio.

Dentro de Aragón, la elección de la provincia y la ciudad de Zaragoza ha estado principalmente motivada por el alto porcentaje que ambas representan en cuanto a la población inmigrante total de esta comunidad (equivalente a más del 70\%).

Por último, los factores que han determinado la selección del hospital concreto en el que hemos llevado a cabo nuestro trabajo de campo han sido, en primer lugar, su carácter público (que conlleva un mayor número de usuarias extranjeras que los de carácter privado, por las condiciones socio-económicas que presenta, por lo general, este segmento de la población), las características generales del mismo (con un alto número de prestaciones, instalaciones y personal contratado, que comportan la posibilidad de atender a un número considerable de usuarias) y, por último, aunque no por ello menos importante, las redes personales con las que contábamos (que suponían una relación directa o indirecta con algunos de los profesionales que trabajan en él, lo que facilitaría el acceso y la concesión de autorizaciones para llevar a cabo nuestra investigación).

Pasamos a continuación a presentar las principales características del hospital en el que hemos centrado el estudio. Se trata de un hospital público monográfico (materno-infantil) perteneciente al Servicio Aragonés de Salud. Se encuentra ubicado en la ciudad de Zaragoza y presenta diferentes servicios generales: cirugía pediátrica, pediatría, reproducción asistida humana, ginecología, y tocología-obstetricia.

De acuerdo con los fines perseguidos, enmarcamos el trabajo de campo en el ámbito del último servicio mencionado, el cual se ocupa de la atención maternal y, por tanto, se centra en la salud de la mujer gestante en todas sus facetas.

Las diferentes áreas en las que se estructura dicho servicio son las siguientes:

1. Área clínica de la salud reproductiva

2. Área clínica de la salud materno-fetal

3. Área clínica de paritorios y puerperio

4. Sección de ecografía y diagnóstico prenatal 
En la siguiente tabla puede observarse la estructura del servicio de tocología-obstetricia por lo que respecta al personal sanitario que trabaja en sus diferentes áreas:

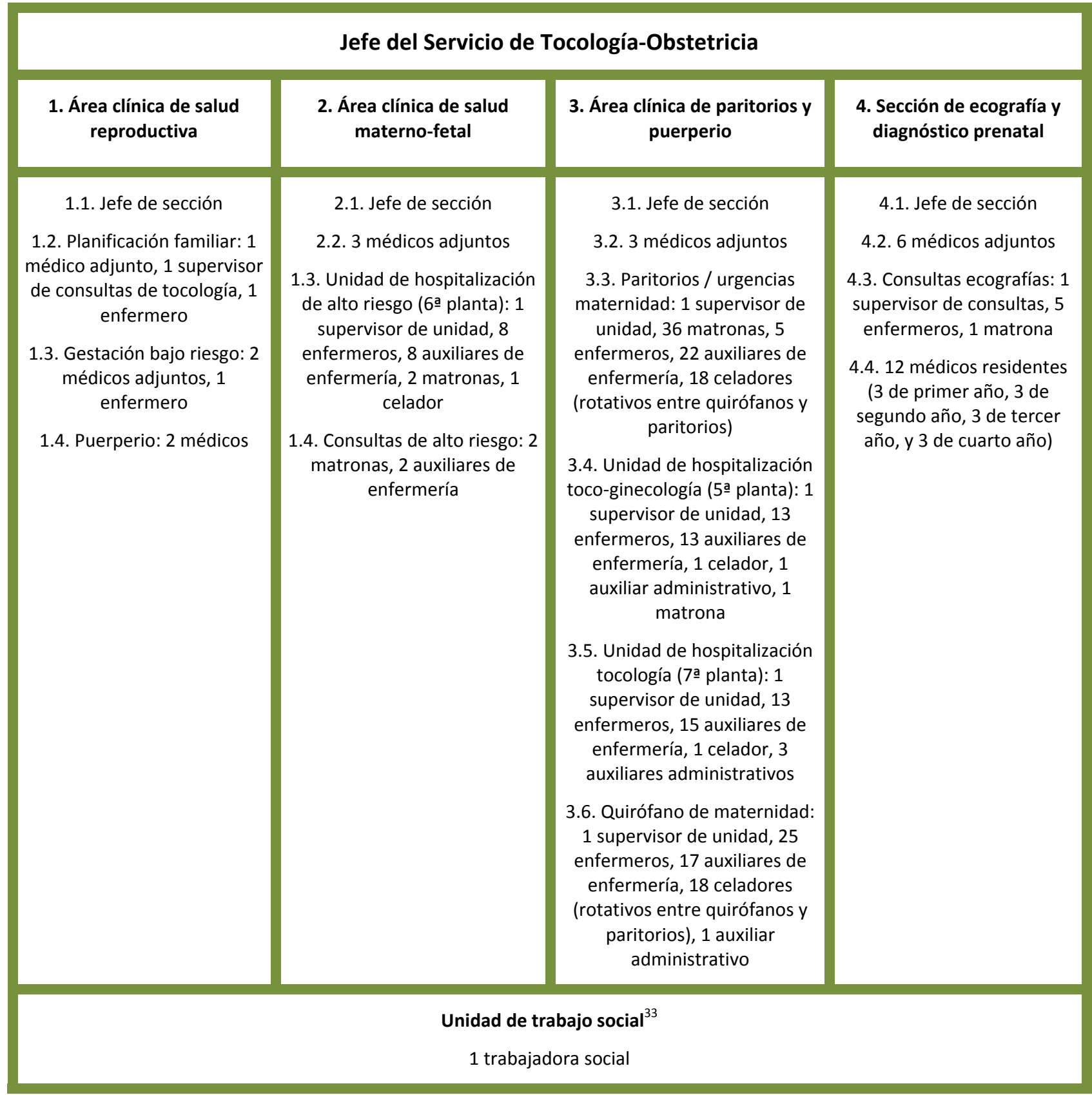

Tabla 1.3. Estructura del servicio de tocología-obstetricia

\footnotetext{
${ }^{33}$ Entre las funciones de la Unidad de Trabajo Social del hospital, se encuentra la detección de las carencias y necesidades sociales de los usuarios que pueden incidir en su estado de salud, con el objetivo de evitar que dichas carencias obstaculicen el mantenimiento y/o recuperación de la salud. Una de sus líneas de actuación se dirige específicamente a la población inmigrante, con acciones como la acogida, la ayuda en la obtención de la documentación para acceder al servicio sanitario, o la derivación a otros organismos encargados de ámbitos como la formación, la vivienda o la búsqueda de empleo. A partir de estos datos, podemos deducir que la relación de la trabajadora social de esta unidad con las usuarias de origen extranjero es frecuente, por lo que, desde el principio de nuestra investigación, establecimos contactos con la misma, y la incluimos entre los sujetos participantes en el estudio.
} 
Para finalizar, cabe señalar que, como puede observarse en el gráfico que incluimos a continuación, el número de partos atendidos en el hospital, ${ }^{34}$ a pesar de haber experimentado un ligero descenso en los últimos tres años de los que se disponen datos, continúa siendo bastante elevado. En concreto, en 2011, se atendieron en él 4.382 partos, lo que supone un $35 \%$ del total de los alumbramientos que tuvieron lugar durante ese año en todo Aragón.

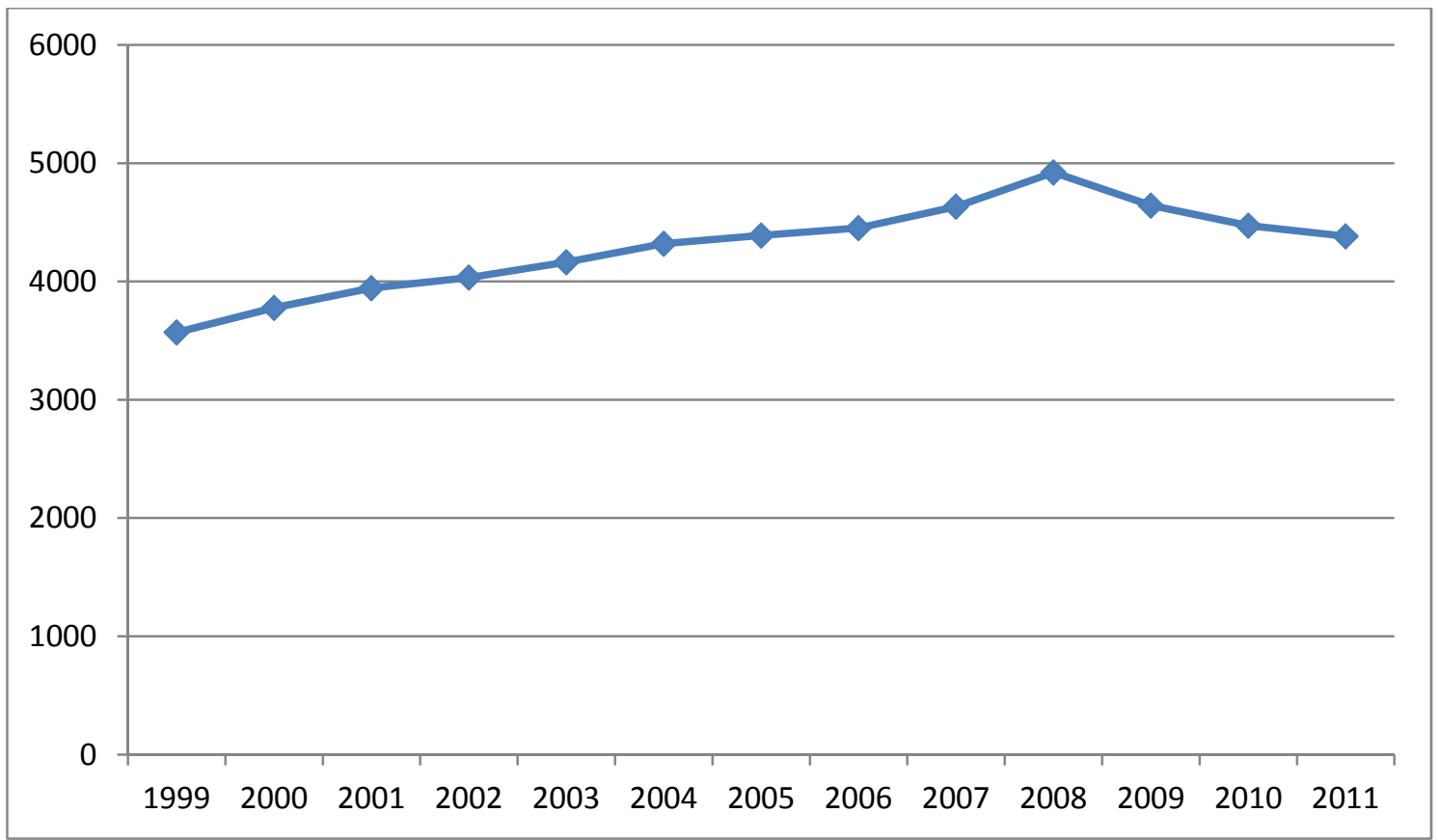

Gráfico 1.23. Evolución de los partos anuales atendidos en el hospital contexto de estudio (1999-2011) (Fuente: Servicio de documentación del hospital)

\footnotetext{
${ }^{34}$ Como comentaremos en el capítulo de análisis de los resultados del estudio, el hospital no dispone de datos disgregados por nacionalidad de las usuarias, por lo que no podemos saber qué porcentaje del total de mujeres atendidas son inmigrantes. No obstante, aunque sea a título anecdótico, cabe mencionar que, durante nuestra presencia en el centro hospitalario para llevar a cabo el trabajo de campo, no hubo un solo día en el que la presencia de mujeres inmigrantes no fuera, al menos visiblemente, considerable.
} 


\section{CAPÍTULO 2 \\ Diseño metodológico}




\section{DISEÑO METODOLÓGICO}

En el presente capítulo describimos de manera detallada la metodología empleada en nuestro estudio.

Comenzamos con la presentación de los objetivos generales perseguidos y de las preguntas de investigación que hemos tratado de responder, para pasar a continuación a definir la orientación metodológica del estudio y a exponer justificadamente tanto las disciplinas relacionadas con la investigación como los métodos empleados.

En el siguiente apartado comentamos de forma general las estrategias de selección de informantes, es decir, cómo hemos llevado a cabo el muestreo y qué características genéricas buscábamos en la muestra, sin describirla exhaustivamente, ya que la descripción pormenorizada de los datos contextuales y los datos demográficos del universo de estudio se presentará posteriormente en el capítulo 6, en concreto antes de analizar los datos obtenidos con cada una de las técnicas utilizadas en nuestra investigación.

En el apartado sucesivo del presente capítulo explicaremos las diferentes fuentes y técnicas empleadas para recolectar los datos, que en nuestro caso han sido múltiples, pues hemos recurrido, como se verá más adelante, al análisis documental, a las entrevistas en profundidad, a la observación no participante y a los grupos de discusión. Ofreceremos información detallada en relación con cada una de las fuentes y técnicas, como, por ejemplo, la descripción y justificación de su empleo en nuestro estudio, el modo en que se han seleccionado los informantes, o los datos a analizar y la manera en que se han registrado dichos datos.

A continuación, pasamos en otro apartado a describir cómo hemos realizado el proceso de análisis de los datos obtenidos mediante el uso de las diferentes técnicas. Aparte de las características generales del análisis, el cual se desarrollará ampliamente en el capítulo 6, aquí hacemos referencia al programa de análisis de datos cualitativos que hemos empleado en el estudio, en concreto, el NVivo 10, y justificamos por qué ha resultado de utilidad para conseguir los fines perseguidos en nuestra investigación.

En el penúltimo apartado de este capítulo, nos centramos en analizar la validez científica del estudio y tratamos de demostrar que este reúne características de confirmabilidad, transferibilidad, reflexividad, veracidad y rigor científico.

Por último, comentamos los aspectos éticos que hemos debido tener en cuenta a la hora de realizar una investigación con estas particularidades, y hacemos especial referencia al principio de beneficencia, a la voluntariedad de la participación en el estudio, y al mantenimiento tanto del anonimato de los sujetos investigados como de la confidencialidad de los datos aportados por los mismos.

\subsection{Objetivos y preguntas de investigación}

El objetivo principal de esta investigación, como hemos comentado previamente, consiste en el análisis de la comunicación intercultural en ámbito sanitario y, más concretamente, en el ámbito de la salud reproductiva. En particular, pretendemos, partiendo de la perspectiva de los propios implicados, estudiar las dificultades que pueden surgir en las interacciones 
comunicativas entre los profesionales sanitarios y las usuarias de origen extranjero, identificar las posibles causas de dichas dificultades $y$, en última instancia, presentar una serie de propuestas que permitan mejorar la comunicación, haciendo especial hincapié en el recurso a figuras profesionales como los intérpretes en los servicios públicos y los mediadores lingüísticos y culturales.

En consecuencia, nuestra pregunta central de investigación es la siguiente:

- ¿CÓMO se comunican los profesionales sanitarios con las usuarias inmigrantes en el ámbito de la salud reproductiva?

De esta pregunta central derivan otras dos preguntas:

- ¿POR QUÉ en algunas ocasiones esta comunicación (intercultural) no es eficaz?

- ¿CÓMO podría mejorarse esta comunicación (intercultural)?

Partiendo de estos objetivos generales, nos hemos planteado los objetivos específicos que exponemos a continuación:

- Analizar la evolución de los flujos migratorios en España y la respuesta que se ha dado en este país (tanto desde el punto de vista legislativo como desde el punto de vista social) al fenómeno de la inmigración.

- Describir las características básicas de la comunicación intercultural (con especial referencia a la que tiene lugar en ámbito sanitario), así como las dificultades y retos que esta plantea.

- Estudiar la influencia que puede tener la cultura (tanto en sentido amplio como por lo que respecta a lo que se conoce como cultura sanitaria) en las interacciones comunicativas entre los profesionales sanitarios y los pacientes inmigrantes.

- Plantear acciones y estrategias que podrían emplearse para facilitar la comunicación intercultural en ámbito sanitario, las cuales, en consecuencia, servirían asimismo para mejorar la calidad y la equidad en la atención a la salud de los pacientes de origen extranjero.

- Por último, en relación con las citadas acciones y estrategias, destacar el recurso a la interpretación en los servicios públicos y a la mediación lingüística y cultural, describir la situación en la que se encuentran actualmente en España estas profesiones, y proponer pautas para que estas alcancen el grado de profesionalización y reconocimiento que merecen.

Antes de pasar al siguiente apartado, quisiéramos señalar que, al iniciar este estudio, partíamos de unos interrogantes y unas hipótesis generales, pero ha sido el trabajo de campo el que ha ido enfocando la investigación y planteando nuevos interrogantes. De hecho, siguiendo un diseño metodológico "emergente y en cascada" (Amezcua, 2000:32), la investigación ha ido evolucionando a medida que el trabajo de campo iba avanzando, lo cual ha conllevado que fuéramos abandonando progresivamente algunas de las ideas preconcebidas sobre los sujetos y los fenómenos analizados que poseíamos antes de iniciar nuestro estudio. 


\subsection{Orientación teórico-metodológica}

Debido a nuestro interés por estudiar experiencias e interacciones en el contexto natural en el que estas tienen lugar y desde el punto de vista de los propios sujetos investigados (emic), podemos enmarcar el estudio que nos ocupa dentro del ámbito de la investigación cualitativa. Con el fin de alcanzar un conocimiento profundo de la realidad estudiada, hemos centrado nuestra atención en el mundo social en el que participa el sujeto, "el mundo de significaciones en donde el mismo interviene, llenando los significados con su experiencia personal" (Mejía Navarrete, 2004:279).

Entendemos el método cualitativo como algo más que un conjunto de técnicas de recolección de datos, es decir, como un "modo de encarar el mundo empírico" (Taylor y Bogdan, 2010:20) en el que todas las personas y escenarios son dignos de estudio y todos los puntos de vista se consideran valiosos. Se trata, por tanto, de un estudio descriptivo e interpretativo realizado desde una perspectiva holística y en el que los sujetos y acontecimientos estudiados aparecen contextualizados en su propio marco de referencia.

La complejidad del fenómeno social investigado conlleva que, para una adecuada aprehensión del mismo, se deba acceder a él desde diferentes disciplinas. La investigación tiene, en consecuencia, un carácter interdisciplinar que parte de las ciencias humanas y sociales para centrarse en aspectos relacionados, en primer lugar, con la antropología, entendida como el estudio de la realidad humana, de los aspectos biológicos y sociales del hombre y, en sentido algo más estricto, también con lo que se conoce como antropología de la salud, ${ }^{35}$ en la que se estudia de qué manera la cultura puede influir en las creencias, comportamientos y actitudes en relación con la salud, la enfermedad y la cura. Más concretamente, al centrarse en el ámbito de la salud reproductiva, nuestra investigación está relacionada con la antropología de la reproducción, según la cual y a partir de las múltiples investigaciones que empiezan a publicarse a partir de los años setenta, ${ }^{36}$ aunque el embarazo y el parto son procesos universales en lo que se refiere a la fisiología del cuerpo femenino, no pueden considerarse como meros procesos biológicos, sino que se encuentran "culturalmente moldeados, dándose de diferentes maneras en cada sociedad y en los diferentes grupos sociales" (Blázquez, 2005:2).

Nuestro universo de estudio está compuesto por individuos pertenecientes a diferentes grupos sociales y culturales, y uno de nuestros propósitos consiste precisamente en estudiar las relaciones e interacciones entre los mismos. Por ello, nuestra investigación se vincula asimismo con la sociología, entendida como el estudio de la estructura y funcionamiento de las sociedades humanas, basándonos en la idea de que el individuo existe no solo como un ser particular, sino también y especialmente como miembro de una comunidad estructurada y regida por una serie de normas socialmente establecidas que se siguen de forma tanto consciente como inconsciente.

\footnotetext{
${ }^{35}$ En nuestra investigación, por lo que respecta a esta disciplina, se hace especial referencia a los estudios de Polly A. Begley y Debbie A. Ockey (2009), Josep Maria Comelles (2009, 2010), Geri-Ann Galanti (1999, 2000, 2008), Sharon M. Lee (2003), y de Rachel E. Spector (1999, 2001, 2003).

${ }^{36}$ En este ámbito, cabría citar las publicaciones de autoras como María Isabel Blázquez (2005, 2008), Sheila Cominsky (1976, 1992), Robbie Davis-Floyd (1997, 2000), Mari Luz Esteban (2000,2006), y María Isabel Oliver $(2002,2007)$.
} 
El objetivo principal de esta investigación, como ya hemos comentado, consiste en analizar la comunicación intercultural entre profesionales sanitarios y usuarias inmigrantes, detectar qué posibles barreras pueden dificultar o impedir dicha comunicación y descubrir las causas de las mismas. En consecuencia, la investigación está entroncada, además, con los estudios interculturales y, más concretamente, con los estudios de comunicación intercultural, ${ }^{37}$ así como con la lingüística aplicada, entendida como el estudio de los problemas que puede plantear el lenguaje como medio de relación social.

Por último, una parte de la investigación, en concreto aquella que se centra en las soluciones a los problemas de comunicación detectados, se relaciona con la traductología y, de manera específica, con la rama de la misma centrada en la traducción y la interpretación en los servicios públicos ${ }^{38}$, así como con la mediación intercultural, que, entendida como

una modalidad de intervención de terceras partes, en y sobre situaciones sociales de multiculturalidad significativa, orientada hacia la consecución del reconocimiento del Otro y el acercamiento de las partes, la comunicación y comprensión mutua, el aprendizaje y desarrollo de la convivencia, la regulación de conflictos y la adecuación institucional, entre actores sociales o institucionales etnoculturalmente diferenciados. (Giménez, 1997:142)

puede suponer, junto con otras iniciativas, una posible vía para mejorar la comunicación intercultural en el ámbito estudiado.

Por lo que respecta al método concreto dentro de las múltiples formas que puede adoptar una investigación cualitativa, basándonos en la clasificación por tipologías de métodos cualitativos propuestas por Norman K. Denzin e Yvonna S. Lincoln (1994) y por John Cresswell (2007), podemos afirmar que hemos seguido, por una parte, el método etnográfico $\mathrm{y}$, por otra, el método del estudio de caso, no planteados como dos métodos independientes, sino como un método resultante de la combinación de ambos.

Entendemos el método etnográfico como "una concepción y práctica de conocimiento que busca comprender los fenómenos sociales desde la perspectiva de sus miembros" (Guber, 2001:12). Desde esta perspectiva, hemos estudiado los patrones culturales de diferentes grupos sociales y la interacción entre estos últimos dentro de un contexto determinado, de acuerdo con la consideración holística de que cada patrón cultural influye y se encuentra influido por el resto de los patrones de una cultura.

Aunque todavía se sigue considerando por parte de algunos profesionales de la salud que los estudios etnográficos podrían carecer de la objetividad más propia de los estudios científicos cuantitativos, ${ }^{39}$ consideramos que el análisis cualitativo de los comportamientos relacionados

\footnotetext{
${ }^{37}$ Se han tenido en cuenta en relación con esta disciplina, en especial, aunque no exclusivamente, los estudios de Milton J. Bennett $(1986,1993,1998)$, Edward T. Hall $(1959,1976,1998)$, Geert Hofstede (1991), Francisco Raga (2003, 2006), Miquel Rodrigo Alsina (1999, 2000, 2009), y Larry A. Samovar et al. (2001, 2009).

${ }^{38}$ En lo que respecta a esta disciplina, nos hemos basado, entre otros, en los estudios publicados por autores como Claudia V. Angelelli (2003, 2004, 2006, 2008), Ann Corsellis (2002, 2003, 2009), Sandra Hale (2008, 2010), Anne Martin (2003), Holly Mikkelson (1996, 1999, 2003), Franz Pöchhacker (1999, 2004, 2007, 2008), Carmen Valero $(2003,2005,2008)$ y Cecilia Wadensjö $(1998,1999,2007)$.

${ }^{39}$ A este respecto, si bien aún se siguen observando ciertas reticencias en el empleo de métodos cualitativos para estudiar fenómenos relacionados con la salud (hecho que quedó evidenciado al inicio de esta misma investigación, ya que costó que los sanitarios responsables de autorizar que se esta se llevara a cabo entendieran la metodología que se iba a emplear y las ventajas que esta supondría), son cada vez más numerosas las investigaciones en este
} 
con la salud desde la perspectiva social y cultural puede aportar nuevos y válidos enfoques. Así, de acuerdo con Ventres y Frankel (1996, citados en Galanti, 1999:20), la etnografía podría definirse como un conjunto de métodos de investigación que puede emplearse para conocer los diferentes conceptos de salud y enfermedad y que se rige por tres principios: se basa en la observación, con el fin de comprender los significados que subyacen en el comportamiento de los sujetos observados; se centra en el estudio de la vida diaria de dichos sujetos, observando los acontecimientos tal y como transcurren de forma natural; y su propósito es entender los comportamientos de los sujetos objeto de estudio desde su propio punto de vista. En conclusión y de acuerdo con Manuel Amezcua y Alberto Gálvez (2002:434), en las investigaciones realizadas en el ámbito de la salud, "la mirada cualitativa provee al investigador de un espíritu crítico [...] necesario para afrontar cambios "desde dentro" y combatir la posición hegemónica de la medicina como pensadora única del sistema de salud". (comillas del original)

Por otra parte, como ya se ha mencionado, esta investigación de corte etnográfico se ha encuadrado dentro del método conocido como estudio de caso, ${ }^{40}$ ya que hemos llevado a cabo la exploración en profundidad, con la combinación de diferentes fuentes de datos, de un caso particular; en concreto, hemos analizado la comunicación intercultural en el contexto específico de un determinado hospital materno-infantil.

Con la investigación mediante el estudio de caso se persigue "el examen intensivo, en sus múltiples características, de un fenómeno particular" (Mejía Navarrete, 2004:297), y consiste en un análisis profundo y minucioso de una determinada realidad durante un periodo prolongado de tiempo.

Existe una gran variedad de opiniones entre los investigadores sociales acerca de qué se puede considerar un caso. Para algunos, tal y como afirma Gilberto Giménez (2012:43),

[...] casi todo lo que se estudia en las ciencias sociales puede considerarse como "caso", lo que se explica por el hecho de que, en última instancia, todos los hechos sociales se definen por su "historicidad", es decir, por su obligada inscripción en un contexto espacio-temporal.

No obstante, en la presente investigación nos ceñimos a la noción de estudio de caso ofrecida por metodólogos como John Gerring (2007) y Robert K. Yin (2009), según los cuales un caso estaría constituido por un fenómeno espacialmente delimitado que se observa durante un periodo de tiempo.

Entendemos, por tanto, el estudio de caso como "el estudio intensivo de un caso particular con el propósito -al menos parcial- de echar luz sobre una clase más amplia de casos" (Gerring, 2007:20) (cursiva del original), y como "una indagación empírica que investiga un fenómeno contemporáneo en profundidad y en el contexto de la vida real” (Yin, 2009:32).

ámbito que tratan de desentrañar los aspectos culturales que influencian los comportamientos y creencias sobre la salud y que se amparan bajo el marco de la denominada antropología de la salud y de la enfermedad. Cabría citar los trabajos de Madeleine Leiniger y su teoría de los cuidados transculturales, así como las investigaciones citadas por Janice M. Morse (1994) o por Norman K. Denzin e Yvonna S. Lincoln (1994), entre otros.

${ }^{40}$ En relación con las investigaciones basadas en el método del estudio de caso, cabe resaltar las publicaciones de John Gerring (2007), de Charles C. Ragin y Howard S. Becker (2000), y de Robert K. Yin (2009). 
Frecuentemente se ha asociado este método con el estudio práctico de un caso concreto que no puede contribuir al desarrollo científico y que solo es útil en la fase previa de una investigación para generar hipótesis. Sin embargo, estamos de acuerdo con el sociólogo Bent Flyvbjerg (2004) en que no es cierto que el estudio de caso "no pueda proporcionar información fiable sobre su clase general" (Flyvbjerg, 2004:35), y en que la proximidad continuada con la realidad estudiada y la retroalimentación de los sujetos investigados resultan muy útiles para generar conocimiento concreto y dependiente del contexto, lo cual es más valioso "que la vana búsqueda de teorías predictivas y de universales" (Flyvbjerg, 2004:39). Asimismo, consideramos que la selección estratégica del caso que nos ocupa, que ha sido elegido por tratarse de un caso ejemplar o paradigmático, el cual reúne las características más comunes de un hospital materno-infantil y atiende a un número considerable de usuarias de origen extranjero, justifica el empleo de este método y la validez del mismo teniendo en cuenta los fines de nuestra investigación.

Por último, en cuanto al método del estudio de caso, cabe mencionar que, dentro de los diferentes tipos de diseño identificados por Robert K. Yin (2009:46), nuestra investigación se enmarca en el Tipo 1, es decir, en el diseño centrado en un solo caso (el del hospital maternoinfantil contexto de nuestro estudio), considerado holísticamente como una sola unidad de análisis. Aunque nuestra investigación esté centrada en un solo caso, mediante la misma podremos confirmar, refutar o ampliar la teoría existente en relación con nuestro ámbito de estudio (Yin, 2009:47).

\subsection{Estrategias de selección de informantes. Muestreo y características generales de los informantes}

En este apartado, como hemos señalado anteriormente, describimos de manera general cómo hemos llevado a cabo el muestreo y qué características generales buscábamos en la muestra que conforma nuestro universo de estudio.

La selección de la muestra presenta un carácter crucial en toda investigación cualitativa, ya que "al obtenerse mediante la aleatoriedad, se aspira a que tal muestra tenga la misma distribución normal del universo y, por ende, los resultados obtenidos puedan generalizarse" (Álvarez-Gayou, 2003:11). No obstante, no se persigue la generalización como objetivo principal en esta investigación, sino que, como ya se ha comentado, se centra en el estudio de un centro sanitario particular que presenta un interés intrínseco para descubrir significados o reflejar múltiples realidades.

El diseño de muestreo en nuestra investigación no se basa en criterios probabilísticos ni estadísticos, sino que los sujetos han sido elegidos en función de la representatividad de sus propiedades y estructura social, con el objetivo de incluir las características principales del universo objeto de estudio, de modo que "cada unidad seleccionada expresa la posición diferencial que ocupa en la estructura social [...] y todas juntas reproducen en su composición y dinámica las situaciones sociales del objeto de estudio" (Mejía Navarrete, 2000:167).

Por un lado, hemos buscado la heterogeneidad compleja propia del contexto estudiado mediante la combinación de diferentes niveles estructurales de la muestra (Valles, 2007:308310): el eje socioeconómico (con participantes en el estudio que presentan diferentes 
características sociodemográficas), el eje espacial (mediante la investigación en diferentes áreas que conforman el contexto de estudio, en nuestro caso, un determinado hospital materno-infantil), y el eje temporal (con un estudio prolongado en el tiempo y realizado en diferentes lapsos temporales).

Sin embargo, por otro lado, hemos perseguido también un cierto equilibrio entre los participantes, es decir, hemos tratado de hallar un punto intermedio entre los extremos de heterogeneidad y homogeneidad de los mismos. Considerábamos que, por una parte, el carácter homogéneo podía permitir que existieran unos parámetros simétricos en los datos ofrecidos y, por otra, la heterogeneidad fomentaría la confrontación de los diferentes puntos de vista de todos los implicados en las situaciones analizadas.

Asimismo, con el fin de garantizar que la muestra había sido seleccionada de manera adecuada, establecimos sistemáticamente unos criterios o dimensiones a tener en cuenta en la extracción de la misma. En primer lugar, la dimensión del tiempo, ya que tratamos de estudiar la interacción de los participantes en el estudio en diferentes espacios temporales, partiendo de la base de que las actividades y actitudes en el campo podían variar dependiendo de factores como la hora del día o el día de la semana. Al respecto del tiempo, cabe también mencionar que el trabajo de campo se llevó a cabo en periodos no demasiado extensos e interrumpidos, que permitieran la sistematización y la reflexión sobre los datos obtenidos. En segundo lugar, la dimensión personal, de acuerdo con la cual tuvimos en cuenta que ningún contexto de estudio es socialmente homogéneo, por lo que, para obtener una representación adecuada, era necesario seleccionar a los participantes de acuerdo con una serie de criterios demográficos o de relevancia para los objetivos de la investigación. $Y$, en tercer lugar, la dimensión espacial, puesto que tratamos de analizar los diferentes contextos en los que los sujetos del estudio pudieran interactuar (Salamanca y Martín-Crespo, 2007:3).

El muestreo se llevó a cabo en diferentes fases y empleando distintas técnicas. De hecho, tal y como se explicará más detalladamente en el siguiente apartado, iniciamos con una fase de observación y realización de entrevistas en el propio hospital contexto de estudio durante aproximadamente seis meses del año 2012 y, finalmente, procedimos a la realización de grupos de discusión durante los meses de junio y julio del año 2013.

Tras la localización del contexto (el hospital materno-infantil), iniciamos el proceso de accesibilidad al mismo, mediante la solicitud formal de autorizaciones ${ }^{41}$ para llevar a cabo el estudio, y la detección de informantes clave dentro del mismo.

Una vez obtenido el acceso de manera oficial, pasamos al establecimiento de lo que se conoce como rapport. Entendemos el rapport como el punto de convergencia entre el investigador y los informantes obtenido mediante el contacto directo con los mismos y que crea el clima de confianza necesario para que estos últimos se abran al investigador. A nuestro juicio y, tal y como afirma Erving Goffman (1959, citado en Taylor y Bogdan, 2010:55), el rapport conlleva en cierto sentido "interrumpir a través de las "fachadas» que las personas imponen en la vida

\footnotetext{
${ }^{41}$ Véase en los anexos las solicitudes redactadas por uno de los directores de la tesis y por la propia investigadora y remitidas a la Unidad de Calidad del hospital contexto de estudio, así como las autorizaciones concedidas por el Presidente de la Comisión de Investigación del Sector Zaragoza II del Servicio Aragonés de Salud y por el Jefe de Servicio de la Sección de Obstetricia del mencionado hospital.
} 
cotidiana" (comillas del original). Y, precisamente con el fin de interrumpir a través de dichas "fachadas", seguimos algunos de los consejos ofrecidos por Samuel James Taylor y Robert Bogdan en su obra sobre métodos cualitativos de investigación (2010:56-58); en concreto, tratamos de acomodarnos a las rutinas y modos de actuar de los informantes, y procuramos hallar puntos en común con los mismos y mostrar interés por lo que los sujetos investigados tenían que contar.

Partimos, por tanto, de un muestreo por conveniencia (Scribano, 2007: 37; Berg, 2009: 50), en el que seleccionamos aleatoriamente estos primeros informantes por su fácil disponibilidad, muchas veces motivada por las relaciones personales de la propia investigadora. Estos mismos informantes clave, que actuaron como gatekeepers (o "porteros") (Berg, 2009:206) indispensables para acceder al contexto de estudio, nos proporcionaron a su vez el contacto con otros posibles participantes, mediante la técnica en cadena o bola de nieve. De este modo, unos informantes nos condujeron a otros hasta que se configuró un grupo lo suficientemente nutrido que permitiera alcanzar los objetivos de la investigación. Por último, en las fases posteriores de la investigación, recurrimos al muestreo intencionado, basado en una estrategia de selección deliberada y centrada en las necesidades de información previamente detectadas.

El tamaño de la muestra no estaba previamente definido, sino que nos regimos por el principio del punto de saturación de los datos, en el que los resultados desprendidos de dichos datos representan el colectivo objeto de estudio en su conjunto. Por tanto, la muestra se consideró suficiente cuando los nuevos datos tendían a reproducir el mismo contenido de los anteriores y no introducían correcciones ni información adicional sobre la realidad estudiada, puesto que repetían el contenido de la pauta social definida (Bertaux y Bertaux-Wiame 1993, citados en Mejía Navarrete, 2000:171).

\subsection{Fuentes y técnicas de recolección de datos}

La elección de las técnicas de recolección de datos es realizada siempre por el propio investigador en base a los fines que persigue con su estudio. De hecho, tal y como afirma Miguel S. Valles (2007:56), las técnicas de investigación "son instrumentos que están ahí (disponibles), a la espera de que cada investigador haga un uso específico de ellas en un estudio real". En nuestra investigación, como hemos comentado previamente, recurrimos al empleo de diferentes fuentes y técnicas de recolección de datos, tanto directas como indirectas, las cuales se presentan y describen a continuación.

\subsubsection{Análisis documental}

Son numerosos los estudios que consideran el análisis documental como una estrategia imprescindible en la investigación social; de hecho, la documentación es considerada por algunos autores como "una tercera fuente de evidencia" o como "una tercera técnica de recogida de datos" (Erlandson et al. 1993; Ruiz Olabuénaga e Ispizue 1989, citados en Valles, 2007:119) en los estudios cualitativos, siendo la primera y la segunda técnica la observación y la entrevista, respectivamente.

Partiendo de la base de que "en los estudios cualitativos cabe plantear un uso mínimo (o complementario) de documentos de todo tipo [...] para dar perspectiva histórica a un estudio o 
contrastarlo con los datos cuantitativos existentes" (Valles, 2007:58), en nuestra investigación recurrimos al análisis de determinados documentos escritos con el fin de que nos ayudaran a entender el contexto y los antecedentes del objeto de estudio, así como a identificar cuestiones de interés para la investigación.

El análisis documental no era la técnica principal en la que se iba a apoyar nuestro estudio, sino que tenía un carácter secundario o complementario con respecto a otras técnicas empleadas que se describirán más adelante. Este carácter secundario se debe a que consideramos que esta técnica "no intrusiva" no nos permitiría conocer el modo en el que se percibe y experimenta la realidad estudiada ni analizar el "lado subjetivo de la vida social" (Taylor y Bogdan, 2010:146).

Entre las ventajas del empleo de la documentación como técnica de recolección de datos, podemos señalar el bajo coste que supone recopilar los documentos a analizar, la no reactividad de dichos documentos ante la presencia del investigador, o la historicidad, es decir, la dimensión histórica aportada por los mismos. Por el contrario, los inconvenientes principales serían la interpretabilidad múltiple, la posible presencia de sesgo en los documentos analizados dependiendo de la persona o entidad que los haya redactado y, en ocasiones, la falta de disponibilidad o acceso a determinados documentos (Valles, 2007:129-130).

En nuestra investigación hicimos uso de determinados documentos tanto antes de iniciar el trabajo de campo como a medida que este se iba desarrollando. Podemos dividir dichos documentos en cuatro grandes grupos: por un lado, analizamos dos grupos de documentos, generalmente de carácter oficial, relacionados respectivamente con el derecho a emigrar/inmigrar y con el acceso y uso de los servicios sanitarios por parte de la población inmigrante; por otro lado, estudiamos determinados documentos relacionados con el ámbito específico de nuestro estudio, es decir, con la salud reproductiva y, más concretamente, con la atención durante el parto; por último, examinamos algunos documentos relativos a las diferentes estrategias empleadas por los servicios sanitarios de Aragón para facilitar la comunicación y la asistencia a los usuarios de origen extranjero.

En este apartado enumeramos los documentos analizados y realizamos una breve descripción de los mismos, pues el análisis propiamente dicho se presentará en el capítulo 6.

\subsubsection{Documentos sobre el derecho a emigrar/inmigrar}

Por lo que respecta a los documentos relativos al derecho a emigrar/inmigrar, partimos de un enfoque más general, en el que examinamos las disposiciones concernientes al derecho a circular libremente, a escoger el lugar de residencia o a solicitar asilo contenidas en la Declaración Universal de los Derechos Humanos, aprobada y adoptada en 1948.

A continuación, nos centramos en el ámbito europeo, dentro del cual analizamos documentos relacionados con el derecho a la libre circulación y residencia de los ciudadanos de los estados miembros (Tratado de Maastricht, 1992), o con cuestiones sobre seguridad interior y cooperación en la lucha contra la delicuencia organizada (Acuerdo de Schengen, 1985). Asimismo, presentamos algunos textos jurídicos en materia de inmigración en el área de la 
Unión Europea, en los que se recogen aspectos referentes, por ejemplo, a la reagrupación familiar o la admisión de estudiantes e investigadores en los estados miembros.

Para concluir este grupo de documentos, estudiamos la legislación española en materia de inmigración. Por una parte, el artículo 13 de la Constitución española, aprobada en 1978, sobre derechos y deberes fundamentales de los españoles y los extranjeros. Por otra, la Ley orgánica 7/1985 sobre Derechos y Libertades de los Extranjeros en España, en la que se estipulan los requisitos que deben cumplir los extranjeros para acceder a la condición de residentes, así como las medidas para el control de la entrada y permanencia de los mismos. Por último, la Ley Orgánica 4/2000 sobre Derechos y Libertades de los Extranjeros en España y su integración social (modificada sucesivamente por otras leyes orgánicas), en la cual se presentan, entre otros aspectos, el régimen jurídico por el que se rigen los extranjeros, los trámites de admisión, o los requisitos para solicitar un visado o un permiso de trabajo.

\subsubsection{Documentos sobre el acceso y uso de los servicios sanitarios por parte de la población inmigrante}

Dentro del segundo grupo señalado, analizamos los siguientes documentos:

a) El derecho a la salud en el contexto internacional

En cuanto a la legislación y políticas en materia sanitaria, el derecho a la salud se encuentra recogido en diversos documentos de ámbito internacional. Entre ellos, en primer lugar, presentamos el artículo 25 de la Declaración Universal de los Derechos Humanos (1948), en el que se estipula el derecho a la salud y el bienestar, la vivienda, la alimentación y la asistencia médica. Además, en relación con el ámbito específico de nuestro estudio, se establece el derecho a cuidados y asistencia especiales durante la maternidad y la infancia.

Asimismo, analizamos otros documentos como la Declaración de Ginebra (adoptada en 1948 por la Asamblea General de la Asociación Médica Mundial y basada en el juramento hipocrático), la revisión de la definición de salud contenida en los Estatutos de la Organización Mundial de la Salud (2000), o la descripción de los ámbitos que abarca la salud de acuerdo con la Observación general sobre el derecho a la salud (adoptada también en el año 2000 por el Comité de Derechos Económicos, Sociales y Culturales de las Naciones Unidas).

Por lo que se refiere al contexto europeo, en ausencia de una normativa común en materia de salud, analizamos diversos instrumentos jurídicos (como la Carta Social Europea, la Declaración de Ámsterdam o el Tratado de Lisboa), mediante los cuales los países de la Unión Europea han reconocido formalmente el derecho de todas las personas al más alto nivel de salud.

b) Legislación española relacionada con el acceso y uso por parte de la población inmigrante de los servicios sanitarios.

Por ser el documento más reciente en materia de acceso a los servicios sanitarios, estudiamos detenidamente el Real Decreto-ley 16/2012, de 20 de abril, de medidas urgentes para garantizar la sostenibilidad del Sistema Nacional de Salud y mejorar la calidad y seguridad de sus prestaciones, y examinamos las novedades que introduce y los inconvenientes que podría acarrear. Asimismo, analizamos brevemente la legislación anterior en materia de acceso a la 
sanidad por parte de la población inmigrante, en concreto, el artículo 12 de la Ley General de Sanidad, ley 14/1986, de 25 de abril, por una parte, y la conocida como "Ley de Extranjería", la Ley Orgánica 14/2003, de 20 de noviembre, de Reforma de la Ley Orgánica 4/2000, de 11 de enero, sobre derechos y libertades de los extranjeros en España y su integración social, modificada por la Ley Orgánica 8/2000, de 22 de diciembre. Asimismo, por lo que respecta a la legislación de ámbito autonómico, analizamos los derechos en materia de salud establecidos en el Estatuto de Autonomía de Aragón.

c) Planes integrales y estratégicos de Aragón.

Por una parte, dentro de este subgrupo, estudiamos el Plan Integral para la Inmigración en Aragón 2004-2007 y el Plan Integral para la Convivencia Intercultural 2008-2011. Se trata de documentos publicados por el Gobierno de Aragón en los que se establecen las iniciativas y estrategias que se van a poner en marcha en un periodo de 4 años con el fin de prestar servicios básicos a los ciudadanos y para coordinar, gestionar y evaluar las distintas políticas autonómicas relacionadas con el fenómeno de la inmigración. Los planes se dividen en secciones dedicadas a diferentes áreas, de las cuales en nuestro análisis prestamos especial atención a aquellas dedicadas al ámbito de la salud y a las mujeres. Por otra parte, examinamos el Plan Estratégico de Servicios Sociales de Aragón 2012-2015 y, también en este caso, nos centramos en los objetivos de este plan en materia de salud, así como en aquellos destinados a la población inmigrante, en general, o a las mujeres, en particular.

d) Otra documentación del ámbito sanitario en el contexto aragonés.

Por lo que respecta a este subgrupo, incluimos en nuestro análisis los siguientes documentos: Carta de Compromisos del Departamento de Salud y Consumo con los Usuarios del Sistema de Salud de Aragón; Inmigración y Salud en Aragón (2007), y Estado de Salud de Aragón: Determinantes y Actuaciones del Departamento de Salud y Consumo (2010). El primer documento citado tiene como objetivo establecer garantías adicionales en el cumplimiento del derecho a la salud que tienen los usuarios del Sistema de Salud público de Aragón en los ámbitos de la información, la accesibilidad, la calidad y la participación. El segundo documento persigue dar a conocer tanto el modo en que ha influido la llegada de los usuarios inmigrantes al Sistema de Salud aragonés, como las características de la atención sanitaria prestada a dichos usuarios en esta región. El tercero, elaborado por el Departamento Aragonés de Salud y Consumo y por el Servicio Aragonés de Salud, tiene como objetivo principal medir el estado de salud de los aragoneses, identificando y cuantificando desigualdades de salud en todos los ámbitos, así como los determinantes que influyen en el mismo, con el fin de proporcionar información para la toma de decisiones en los diferentes órganos de Gobierno.

\subsubsection{Documentos relacionados con la salud reproductiva y la atención durante el parto}

El tercer grupo, relativo a la salud reproductiva y la atención durante el parto, estaba compuesto por los siguientes documentos:

a) Actuaciones y estrategias nacionales en el ámbito de la salud reproductiva y la atención al parto. 
Dentro de este primer subgrupo, estudiamos los siguientes documentos de carácter nacional ordenados cronológicamente: "Estrategia de atención al parto normal en el Sistema Nacional de Salud" (2007), "Maternidad Hospitalaria. Estándares y Recomendaciones" (2009), y "Estrategia Nacional de Salud Sexual y Reproductiva" (2011). Se trata en todos los casos de documentos oficiales de carácter nacional en los que se incluyen recomendaciones sobre las actuaciones y estrategias a desarrollar en el ámbito de la salud reproductiva y la atención al parto en los hospitales.

b) Documentos relacionados con el parto y la salud reproductiva en el contexto aragonés.

En segundo lugar, estudiamos otros documentos relativos al contexto autonómico aragonés; en concreto, analizamos el "Plan de atención a la salud de la mujer 2010-2012" y el Plan de parto publicado por el hospital contexto de nuestro estudio. Examinamos, además, el documento elaborado por el Instituto Aragonés de Servicios Sociales denominado "Maternidad responsable: Opciones y recursos ante un embarazo no planificado", en el que se dan una serie de recomendaciones sobre el modo de actuar ante un embarazo no planificado, y que fue editado en diferentes lenguas, en concreto, en español, árabe, francés, inglés y rumano.

\subsubsection{Documentos relativos a las estrategias empleadas por los servicios sanitarios de Aragón para facilitar la comunicación y la asistencia a usuarios inmigrantes}

Por lo que respecta al cuarto grupo de documentos, aquellos que, como se ha mencionado previamente, estaban relacionados con los recursos y estrategias de los que dispone (o disponía) el Sistema Aragonés de Salud para facilitar la comunicación y asistencia a la población inmigrante, se encontraban los siguientes:

a) Documentos sobre los servicios de interpretación disponibles en el Sistema de Salud aragonés.

En este subgrupo analizamos diversos documentos relacionados, por un lado, con el Servicio Permanente de Interpretación, un servicio de interpretación presencial de gestión municipal que se prestaba en la ciudad de Zaragoza hasta marzo de 2012 y, por otro, con el servicio de interpretación telefónica externalizado que presta la empresa Interpret Solutions en diversos servicios públicos de Aragón.

b) Documentos sobre los servicios de mediación intercultural disponibles en el sistema de salud aragonés.

En primer lugar, estudiamos diversos documentos relativos al Servicio de Apoyo a la Mediación Intercultural (SAMI), servicio financiado por la Administración pública a través de la Dirección General de Inmigración y Cooperación al Desarrollo que tiene como finalidad asesorar a organizaciones públicas o privadas que deseen adecuar o mejorar su oferta de servicios y sus resultados con respecto a la población inmigrante de Aragón mediante acciones de formación, asesoramiento, mediación, investigación y edición de materiales informativos y divulgativos.

En segundo lugar, analizamos documentación referente a los servicios de mediación prestados por miembros de la organización Médicos del Mundo-Aragón, centrados principalmente en la 
mediación intercultural en ámbito socio-sanitario, y, en concreto, en el ámbito de la salud sexual y reproductiva y en la prevención y la erradicación de la mutilación genital femenina.

En tercer lugar, dentro de este subgrupo, realizamos también un análisis de la Proposición no de ley núm. 28/12, sobre la mediación intercultural y apoyo a profesionales y colectivos, que fue presentada en marzo de 2012 en las Cortes de Aragón por parte del Grupo Parlamentario de Izquierda Unida, y que fue aprobada por unanimidad. Uno de los objetivos principales de esta Proposición no de ley consistía en la adopción de medidas y actuaciones con el fin de garantizar que los proyectos de mediación y formación en interculturalidad que hasta el momento se habían implantado con éxito se siguieran desarrollando.

c) Documentos traducidos a varios idiomas disponibles en los servicios sanitarios de Aragón

El primer documento analizado en relación con los documentos traducidos o multilingües fue "Cuídame: guía para padres y madres". Se trata de una guía informativa elaborada por el Departamento de Salud y Consumo de Aragón y editada en español, árabe, francés y rumano, en la cual se ofrecen consejos y recomendaciones relacionados con el estado físico y la salud de las puérperas y los recién nacidos. Entre otros datos, ofrece información relativa a la inscripción del recién nacido, los controles sanitarios maternales y neonatales, la alimentación aconsejada, etc.

En segundo y último lugar, por lo que respecta concretamente al hospital contexto de nuestro estudio, estudiamos diversos documentos traducidos que se encuentran disponibles en el mismo. Por una parte, dos documentos informativos editados en diversos idiomas (en concreto, en español, árabe, chino, francés, inglés y rumano), y que contienen, respectivamente, datos de interés sobre el servicio de obstetricia, y consejos para los cuidados de los recién nacidos. Por otra parte, analizamos las principales ventajas e inconvenientes de los consentimientos informados traducidos de los que dispone el centro hospitalario.

\subsubsection{Entrevistas semi-estructuradas en profundidad}

Podemos definir la técnica de las entrevistas en la investigación cualitativa simplemente como una conversación con un propósito, que consiste en obtener información relevante para los fines del estudio (Berg, 2009:101). Sin embargo, no se trata de una conversación "ordinaria", ya que está dirigida por un entrevistador, el cual plantea preguntas que el entrevistado responde, en ocasiones, condicionado por la presencia del propio entrevistador y buscando lo que se considera "aceptable" (Callejo, 2002:416).

El uso de las entrevistas puede conllevar, de acuerdo con John Cresswell (2008:226), tanto ventajas como desventajas. En relación con las ventajas, podemos mencionar que las entrevistas proporcionan información que no es posible obtener mediante otras técnicas, como por ejemplo la observación, ya que permiten a los entrevistados describir de manera detallada relatos y opiniones personales. Además, en comparación con el observador, el entrevistador puede ejercer un mayor control sobre el tipo de datos recibidos, ya que puede realizar preguntas específicas que le conduzcan a una determinada información. Por lo que respecta a las desventajas, cabe tener en cuenta que las respuestas estarán "filtradas" por el punto de vista de los entrevistados, los cuales, como ya anticipábamos en el párrafo anterior, 
pueden verse afectados por la presencia del entrevistador y pueden ofrecerle la información que creen que este desea escuchar. Por último, otra de las desventajas está constituida por el hecho de que, en algunas ocasiones, las respuestas pueden no estar correctamente articuladas o no ser lo suficientemente claras.

El empleo de esta técnica en nuestra investigación estaba orientado a obtener información de forma oral y personalizada, mediante un "discurso conversacional continuo" (Alonso, 1994:228 citado en Mejía Navarrete, 2004:293), sobre acontecimientos y experiencias vividos por los propios entrevistados, los cuales expresaban de forma subjetiva sus opiniones, percepciones y sensaciones en relación con el objeto de estudio. Con el fin de interpretar la realidad, partimos de la percepción interna de los propios sujetos (emic) expresada con sus propias palabras. En este sentido, tal y como se ha mencionado anteriormente, cabe tener en cuenta que puede existir por parte de los entrevistados una falsificación de los hechos, es decir, una diferencia entre aquello que estos narran y lo que realmente hacen. Por ello, hemos evitado la aceptación acrítica de los datos proporcionados por los sujetos y, con el fin de aumentar la fiabilidad de los resultados, hemos tratado de verificar dichos datos mediante el uso de otras técnicas.

Pasamos a continuación a detallar algunos aspectos relevantes en relación con las entrevistas realizadas.

\subsubsection{Selección de los participantes}

En la selección de los participantes en las entrevistas seguimos criterios de representatividad, de pertinencia y de predisposición, es decir, tuvimos en cuenta que estos contaran con información relevante en relación con el objeto de estudio, que fueran accesibles, que estuvieran dispuestos a informar y que fueran representativos de uno de los grupos estudiados (Valles, 2007:212).

Previamente a la realización de las entrevistas, informábamos de forma breve a los participantes sobre los objetivos del estudio, les garantizábamos el anonimato y la confidencialidad de los datos aportados, y les ofrecíamos la posibilidad de tener un acceso posterior a los resultados de la investigación. Asimismo, todos los entrevistados firmaron un consentimiento informado ${ }^{42}$ mediante el cual se les solicitaba su participación en el estudio, se les indicaba el objetivo principal que se perseguía con las entrevistas y se les ofrecían los datos de contacto de la investigadora.

Por supuesto, la participación en las entrevistas se planteaba desde el primer momento como un acto voluntario $y$, aunque la mayoría de las personas que contactamos mostraron disponibilidad y voluntad para participar, en algunas ocasiones no fue posible realizar la entrevista a algunas usuarias, bien porque su acompañante o su marido se negaba o bien porque el nivel de conocimientos de español de la usuaria no era lo suficientemente elevado para poder responder ampliamente a las preguntas formuladas. A este respecto, cabe indicar que en dos de las entrevistas realizadas a usuarias, procedentes en concreto de Rumanía y de Mauritania, por sus escasos conocimientos del español, su hermano y su marido respectivamente hicieron labores de intérprete entre la investigadora y la entrevistada.

\footnotetext{
${ }^{42}$ Véase en los anexos el modelo de Consentimiento informado empleado en las entrevistas.
} 
Además, en algunas entrevistas se combinó el uso del español con expresiones en inglés o francés para facilitar tanto el entendimiento de las preguntas planteadas como la propia expresión de las respuestas por parte de la entrevistada, y una entrevista, concretamente a una usuaria procedente de Pakistán, se desarrolló casi íntegramente en inglés.

\subsubsection{Registro de la información}

Las entrevistas se grabaron en formato audio y posteriormente se transcribieron literalmente (verbatim) para facilitar su posterior análisis. En la transcripción ${ }^{43}$ se incluyeron tanto los mensajes verbales intercambiados como las notas con información contextual tomadas por la investigadora durante las entrevistas. Cabe señalar que en la transcripción de las entrevistas se tuvieron especialmente en cuenta las recomendaciones sugeridas por Graham R. Gibbs (2007: 12-20) y Steinar Kvale (2007:92-97).

\subsubsection{La relación investigadora-entrevistado/a}

Se considera que el clima creado en la entrevista tiene una importancia vital para el desarrollo de la misma. Partiendo de la base de que la relación entre el entrevistador y el informante es en gran medida unilateral, creímos desde el principio que era fundamental el mantenimiento de la motivación de los entrevistados y, para ello, tratamos de relacionarnos con estos últimos "como personas y no como si fueran meras fuentes de datos" (Taylor y Bogdan, 2010:128).

Además, tuvimos en cuenta que, tal y como afirma Bruce Berg (2009:130), la entrevista

[...] should not be a dialogue, with more or less equal time allocated to each participant, because the whole point is to obtain information from the subject. In many ways, the ideal situation would be to assist the subject in conveying almost a monologue on the research topic.

Por consiguiente, en todo momento, procuramos que los informantes se sintieran cómodos y escuchados, de modo que respondieran amplia y libremente a las preguntas planteadas.

Con este propósito, mantuvimos, en la medida de lo posible, una actitud discreta y prudente. Evitamos la expresión de juicios, especialmente de aquellos que fueran negativos o peyorativos, e intentamos actuar con la sensibilidad necesaria, siendo conscientes de la incidencia que podían tener las palabras y el comportamiento de la investigadora en los entrevistados. Dicha sensibilidad fue empleada también a la hora de permitir a los informantes que se explayaran en detalles y relatos aparentemente superfluos, ya que no era posible conocer en primera instancia el significado ni la importancia que estos datos podían tener para ellos. Tampoco huimos de la solicitud de explicaciones, aclaraciones o confirmaciones de aquellos datos que en un primer momento no hubieran resultado claros, de manera que estimuláramos la respuesta y pudiéramos contrastar la información, pero sin resultar excesivamente insistentes. Por último, tratamos de observar la reacción de los entrevistados ante aquellas preguntas que pudieran resultarles molestas o de las cuales tuvieran dificultades para hablar abiertamente, y en dichos casos, seguimos lo que Erving Goffman (1967, citado en Berg, 2009:128) denomina "tácticas de evasión", es decir, prescindimos de insistir para

\footnotetext{
${ }^{43}$ En los anexos se incluyen todas las entrevistas transcritas, así como un documento con las pautas de transcripción empleadas, comunes a la transcripción de los datos obtenidos tanto mediante esta técnica como mediante los grupos de discusión, de los que se hablará más adelante.
} 
obtener respuestas, pues ello podría haber conducido al malestar de los entrevistados e incluso al fracaso de la propia entrevista.

\subsubsection{Guion de la entrevista ${ }^{44}$}

Las entrevistas eran semi-estructuradas o semi-estandarizadas, es decir, presentaban un guion variable dependiendo del grupo al que estas iban dirigidas y estaban abiertas a la introducción de modificaciones, variaciones o digresiones propiciadas por las propias respuestas de los participantes. Asimismo, adaptábamos el lenguaje empleado a la hora de formular las preguntas a las características del entrevistado en cada ocasión, de manera que estas resultaran comprensibles e inequívocas para los diferentes participantes.

Las preguntas formuladas eran abiertas, de manera que los entrevistados pudieran expresar sus experiencias sin ceñirse a las perspectivas de la propia investigadora o a resultados de investigaciones previas (Cresswell, 2008:225).

Además, el contenido y la naturaleza de las preguntas eran de diferentes tipos; de hecho, había preguntas de evocación de hechos y comportamientos pasados (p.ej. "¿Cuál es tu experiencia con...?"), preguntas centradas en reacciones afectivas (p.ej. “¿Te has sentido discriminada?"), preguntas comparativas (p.ej. comparación usuarias autóctonas-inmigrantes; sistema sanitario en España-en el país de origen), indagaciones (p.ej. “¿Crees que...?”), y de causa-efecto (p.ej. “¿Cuáles pueden ser las causas de....?”).

Antes de iniciar el proceso de las entrevistas, estas fueron pre-testadas por otros investigadores (en concreto, los directores de la tesis), por profesionales sanitarios que trabajaban en el hospital contexto del estudio, y también en entrevistas realizadas a modo de prueba por la propia investigadora.

Las entrevistas en general presentaban el siguiente esquema:

En la formulación de las preguntas, seguimos una progresión de menor a mayor complejidad. Comenzábamos con las preguntas de carácter demográfico, que servían además para establecer un acercamiento con el entrevistado, para pasar a continuación a las preguntas relacionadas con los objetivos de investigación divididas por bloques.

En un primer bloque, realizábamos preguntas de carácter general o introductorio, centradas en la experiencia en el sistema sanitario por parte de las usuarias inmigrantes o en la percepción a grandes rasgos de estas por parte de los profesionales.

En segundo lugar, efectuábamos preguntas sobre la asistencia concreta durante el embarazo, el parto y el puerperio, que versaban principalmente sobre las diferencias culturales observadas por los dos grupos principales de informantes, es decir, profesionales sanitarios, por un lado, y usuarias, por otro. En el caso de los profesionales, las preguntas se centraban solo en el momento de interacción con las usuarias dependiendo de su perfil profesional, por ejemplo, anestesistas y matronas durante el parto, o enfermeros principalmente durante el puerperio.

\footnotetext{
${ }^{44}$ Véase en los anexos el guion de las entrevistas realizadas a los diferentes grupos de participantes.
} 
A continuación, planteábamos las preguntas relativas a las barreras lingüísticas y las soluciones adoptadas para superar dichas barreras. En este bloque de preguntas, incidíamos en particular en el recurso a intérpretes no cualificados, principalmente familiares y amigos de las usuarias, en el uso del servicio de interpretación telefónica del que dispone el Sistema de Salud de Aragón, y en la visión que tenían los entrevistados sobre las competencias y funciones de los intérpretes profesionales.

De ahí, pasábamos a las preguntas relacionadas propiamente con la interacción profesionalusuaria, en las que se indagaba sobre la opinión de la actitud general y de la forma de hablar del otro grupo, las cuestiones relacionadas con el paralenguaje, la cantidad y tipo de información intercambiada, el uso de mentiras sociales o la distribución espacial y temporal de las interacciones comunicativas.

El último bloque de preguntas presentaba un carácter más delicado. Estas concernían a las actitudes sociales, en concreto, problemas de género, la interacción de los profesionales con los maridos y familiares de las usuarias, el posible sentimiento de discriminación de estas últimas, o la manifestación de actitudes racistas o xenófobas por parte del personal sanitario.

\subsubsection{Observación}

Entendemos la observación como una técnica de análisis de la realidad que sirve para contemplar fenómenos, procesos o situaciones en su contexto natural de manera no intrusiva. De acuerdo con Manuel Amezcua (2000:31), la observación es la base de la investigación etnográfica, y se ocupa "del estudio de los diferentes componentes culturales de las personas en su medio", como por ejemplo, sus relaciones grupales, sus creencias, sus símbolos y rituales, sus valores y sus costumbres.

Se recomienda su uso para el estudio de la vida cotidiana en instituciones, organizaciones y grupos que ocupan un lugar periférico en la sociedad, lo cual, trasladado al ámbito de la salud, consistiría en el análisis de la vida cotidiana y organizativa en salas o áreas de hospitales, centros sanitarios y ambulatorios, clínicas psiquiátricas, etc. Tal y como sostiene Javier Callejo (2002:413), el objetivo que se persigue al emplear esta técnica en estos contextos es que fluya lo que resulta normal en tales espacios sociales, "aunque esté lejos de la norma central de la sociedad dominante, de lo que se considera como normal fuera de tales espacios sociales particulares".

Su ventaja principal radica en que permite el contacto directo con el entorno social y las interacciones investigadas, a diferencia de otras técnicas, como las entrevistas, en las que se obtienen relatos ofrecidos por los sujetos entrevistados. Por el contrario, "el observador no puede retroceder en el tiempo para estudiar hechos del pasado, o forzar su entrada en todos los escenarios y situaciones privadas" (Taylor y Bogdan, 2010:104), por lo que podemos afirmar que una de las desventajas de esta técnica es que la observación no servirá para obtener datos evidentes relacionados con sucesos pasados, opiniones o percepciones, los cuales sí pueden ser obtenidos a través de otras técnicas, como las entrevistas y los grupos de discusión. 
En nuestra opinión, la observación trasciende la mera presencia del investigador en el contexto estudiado e implica un esfuerzo por hallar el significado de los sucesos observados. De hecho, de acuerdo con Miguel Ángel Santos Guerra (1999:425), la observación

[...] no consiste simplemente en mirar, sino en buscar. Lo cual exige un principio estructurador de la mirada y del pensamiento. Para observar con rigor hace falta educar los ojos para ver. Pero no sólo eso. Hay que formar la mente para que las teorías permitan descifrar el significado de lo que se ha visto.

En el presente estudio llevamos a cabo una observación no participante (ya que la investigadora no participaba activamente en los escenarios observados), explícita o abierta (puesto que no se realizaba de manera encubierta, sino que los sujetos observados eran conscientes de que se estaba realizando una investigación), y asistemática (pues no seguíamos unos esquemas ni una programación fijos previamente estipulados).

A continuación, presentamos las principales características de la observación que se llevó a cabo durante nuestro trabajo de campo:

\subsubsection{1. ¿Qué se ha observado?}

Iniciamos con una observación con fines descriptivos, centrada en el espacio físico general, así como en las personas que en este se encontraban y la organización de las mismas, y en la que se registraban nuestras primeras impresiones. A continuación, la observación comenzó a tomar un cariz más focalizado, centrado en las conductas y situaciones de interés más concretas, en el comportamiento y la interacción entre los participantes, y en la comunicación verbal y no verbal que tenía lugar entre estos. En esta fase de la observación teníamos en cuenta no solo qué sucedía sino también qué no sucedía en el contexto observado. Por último, la observación pasó a ser más selectiva, centrada en aspectos más concretos o particulares de interés.

\subsubsection{2. ¿Dónde y cuándo se ha observado?}

El contexto general de la observación era el hospital materno-infantil y, más concretamente, las zonas del mismo relacionadas con los servicios de tocología y obstetricia, es decir, con el embarazo, el parto y el puerperio. Quedaron por tanto excluidas del estudio las zonas del hospital dedicadas a la salud infantil o a la reproducción asistida. En líneas generales, la observación se centró en la zona de urgencias, las zonas de información a usuarias y familiares de las mismas, la zona de consultas durante el embarazo y las plantas de puerperio. La mayor parte de la observación tuvo lugar en las plantas de puerperio, tanto a primera hora de la mañana, cuando se llevan a cabo las visitas de control de las puérperas por parte de un obstetra, siempre acompañado de un enfermero, como durante el resto del día, cuando observábamos actividades cotidianas, como el baño y cuidado de los recién nacidos, el reparto de comidas y medicación a las usuarias, e incluso la interacción entre las enfermeras en la zona de descanso de las plantas.

Cabe mencionar que las observaciones realizadas durante las consultas en las plantas de puerperio se realizaron acompañando directamente a los obstetras encargados de las mismas en su visita en las distintas habitaciones y que, una vez introducidos en el campo, 
solicitábamos a las puérperas su permiso para estar presentes durante la consulta y la exploración. Por el contrario, este tipo de observación no se pudo desarrollar en las consultas a gestantes, ya que, en lugar de estar la investigadora directamente en el despacho de la consulta junto con los obstetras, estos últimos establecieron que el procedimiento a seguir era solicitar la autorización previa a las usuarias, algo que se probó a hacer con resultados negativos, ya que era muy complejo detectar a las usuarias de origen inmigrante que esperaban en la sala de espera sin contar con un listado de visitas programadas y, en los casos en los que localizamos a estas usuarias, fue prácticamente imposible ganarse su confianza para que nos permitieran estar presente durante sus respectivas consultas. Se refleja en este caso una de las desventajas más comúnmente señaladas en cuanto a la técnica de la observación, consistente en que esta debe limitarse a los lugares y situaciones para los que se ha obtenido el permiso de acceder o para los que se facilita el acceso por parte de los sujetos observados (Cresswell, 2008:222).

\subsubsection{3. ¿Cómo se ha registrado la observación?}

Durante la observación, llevamos a cabo un registro pormenorizado del contexto y de los participantes en las situaciones observadas, en el que se trataba de responder a las preguntas de quién, cómo, dónde, qué, etc. En resumen, como aconsejan Samuel James Taylor y Robert Bogdan (2010:75), se procuró registrar todo lo que se podía recordar sobre la observación, ya que "una buena regla establece que si no está escrito, no sucedió nunca".

Ante la imposibilidad por falta de autorización de grabar en formato audiovisual los fenómenos e interacciones observados, empleamos dos tipos de técnicas de registro de la información obtenida mediante la observación:

- Técnicas de registro cerrado: Registro de la información de acuerdo con el guion de las fichas de registro, ${ }^{45}$ en las que había un número finito y determinado de categorías o unidades de observación, fijadas previamente y excluyentes entre sí, aunque relacionadas. A este tipo de registro pertenecen las notas de campo que, en primer lugar, tomábamos de forma breve in situ en el momento de la observación o inmediatamente después de la misma, para, a partir de dichas notas, expandir la información posteriormente.

- Técnicas de registro abiertas: Captación y registro de segmentos más amplios del contexto y la situación observados. En este caso, la información registrada podía partir de categorías predeterminadas, pero estas eran susceptibles de modificación o de inclusión de elementos no fijados. A este tipo de registro pertenece el diario de campo, en el que anotábamos comentarios de carácter más introspectivo y personal.

Tanto las notas como el diario de campo contenían información descriptiva y reflexiva (Cresswell, 2008:225). Por lo que respecta a la información de carácter descriptivo, se incluían retratos sobre los sucesos, actividades o personas observados, mientras que aquella de carácter reflexivo incluía pensamientos, impresiones y sensaciones personales experimentados por la propia investigadora durante la observación y relacionados con los temas objeto de estudio.

\footnotetext{
${ }^{45}$ Véase en los anexos el modelo de Fichas de registro para las notas de campo, así como las Fichas cumplimentadas con los datos de cada observación. En total, se han elaborado cinco Fichas, cada una de las cuales agrupa las observaciones realizadas en un mismo día.
} 


\subsubsection{Grupos de discusión}

Podríamos definir esta técnica como un estilo de entrevista diseñada para pequeños grupos, los cuales discuten entre sí sobre cuestiones relevantes para los fines de una investigación. Su finalidad consiste en la producción controlada (pero no dirigida) de un discurso por parte de un grupo de sujetos, que se reúnen durante un espacio de tiempo limitado para debatir sobre uno o varios temas propuestos por un moderador.

Se caracteriza por su dinamicidad y por la obtención de significados construidos socialmente. Permite que un tema concreto sea abordado desde puntos de vista diferentes, por lo que este puede ser confrontado y analizado más profundamente que con el uso de otras técnicas. De hecho, la discusión grupal tiene un "efecto sinérgico" (Stewart et al. 2006; Sussman, Burton, Dent, Stacy y Flay, 1991, citados en Berg, 2009:163), por lo que cada intervención estimula y condiciona las siguientes y emerge un mayor número de ideas, aspectos y relatos que los que se obtendrían con otras técnicas de recolección de datos individuales. Asimismo, el hecho de reunir a personas que comparten un problema común, hace que estas estén más dispuestas a hablar y debatir entre ellas sobre este problema, y el contexto grupal permite que afloren sus pensamientos, sentimientos y conductas en relación con el mismo (Lederman, 1990:117).

En definitiva, consideramos que

[...] la valoración afectiva que hace el grupo del tópico investigado, sus creencias y expectativas, sus planes, resistencias, temores conscientes e inconscientes que se proyectan sobre él, obtenida en una situación de interacción similar a las que se plantean en la vida real, constituye un tipo de datos que otras técnicas no podrían aportarnos. (Gil Flores, 1993:210)

En concreto, el empleo de esta técnica en el ámbito sanitario se considera adecuado cuando se busca analizar las particulares normas de referencia de determinados grupos sociales con respecto a la salud, el sistema sanitario o las medidas y actuaciones concretas que se observan en este ámbito (Callejo, 2002:418), así como para estudiar las relaciones de los distintos grupos que interactúan en este contexto y las necesidades de salud de la población desde el punto de vista social (Buss Thofehrn et al., 2013:75). Nótese que la mayor parte de los posibles usos de esta técnica señalados por los autores mencionados coinciden con los fines perseguidos con nuestra investigación.

Cabe señalar, además, que los grupos de discusión presentan un carácter híbrido, a caballo entre la entrevista individual y el debate, por lo que su objetivo es precisamente tanto obtener información como generar opiniones discutidas entre los participantes. De hecho, el propósito que se suele perseguir con los grupos de discusión consiste en

[...] to let people spark off one another, suggesting dimensions and nuances of the original problem that any one individual might not have thought of. Sometimes a totally different understanding of a problem emerges from group discussion. (Rubin y Rubin, 1995:140, citados en Berg, 2009:167)

Entre las ventajas que presenta el empleo de los grupos de discusión, algunos autores (Downs y Adrian, 2004; Edmunds, 2000; Salkind, 2008, citados en Berg, 2009:165-166) señalan su flexibilidad en cuanto a la conformación del grupo de participantes o en relación con la duración, el hecho de que permiten recolectar grandes cantidades de información ofrecidas 
por diferentes personas en un breve espacio de tiempo, la mayor profundidad que se obtiene sobre determinados temas que se habían abordado previamente con otras técnicas y que no se habían podido comprender plenamente, o la propia interacción entre los participantes y la consiguiente obtención de datos que emergen de la discusión o el debate. Por el contrario, entre las desventajas se señala el número limitado de preguntas que se pueden plantear, y la posibilidad de que los participantes con personalidades dominantes lleven el flujo del debate y no permitan participar a aquellos más tímidos o con personalidades más débiles. Asimismo, cabe considerar que las respuestas ofrecidas pueden "estar contaminadas" por la opinión manifestada por otros participantes, por lo que los datos recolectados mediante esta técnica deberán interpretarse en el contexto del grupo (Buss Thofehrn et al., 2013:78).

En el estudio que nos ocupa, planteamos los grupos de discusión tras el análisis de los resultados obtenidos a partir del uso del resto de técnicas mencionadas. De hecho, el principal fin de los grupos de discusión consistía precisamente en analizar con mayor profundidad aquellos datos significativos o discordantes que se hubieran desprendido del análisis de las entrevistas individuales y de la observación, o aquellos a los que no se hubiera podido acceder con el empleo de estas técnicas. El propósito era corroborar, contrastar y ampliar los datos obtenidos con otras técnicas, de manera que la combinación de los datos obtenidos a través de todas ellas pudiera aportar mayor fiabilidad a nuestro estudio.

Pasamos a continuación a detallar algunos aspectos relevantes en relación con los grupos de discusión realizados.

\subsubsection{Selección de los participantes}

El número de grupos de discusión se fijó teniendo en cuenta los diferentes subgrupos o segmentos de la población universo de estudio cuyas ideas nos interesaba conocer. Con la selección de los participantes en los grupos de discusión no perseguíamos la representación estadística, sino la tipológica o socio-estructural (Valles, 2007:313).

En total realizamos tres grupos de discusión, divididos a su vez en dos subgrupos: profesionales sanitarios (grupo mixto compuesto por tres obstetras, dos matronas y una enfermera); usuarias de origen extranjero (grupo con latinoamericanas, por un lado, y grupo con magrebíes, por otro).

Aunque la composición de los grupos, tal y como sugieren diferentes autores (Ibáñez, 2003; Krueger, 1991; Morgan, 1997), presentaba cierta homogeneidad interna, buscábamos al mismo tiempo la heterogeneidad de opiniones dentro de cada grupo. Por una parte, la homogeneidad permitiría que los integrantes de cada grupo, al sentirse "entre iguales", estuvieran cómodos y percibieran una cierta libertad para expresar abiertamente sus pensamientos y sentimientos. Por otra, la relativa heterogeneidad proporcionaría a la investigación una mayor amplitud de percepciones y experiencias. Además, de acuerdo con Jesús Ibáñez (2003:275), la excesiva homogeneidad podría producir un discurso redundante, de modo que debíamos buscar cierta heterogeneidad para propiciar el debate sin que llegaran a establecerse relaciones excluyentes, como las que se darían entre miembros de, por ejemplo, diferentes clases sociales, orígenes o profesiones. 
Numerosos autores recomiendan que los participantes en un grupo de discusión no debieran conocerse previamente. De hecho, de acuerdo con Richard A. Krueger (1991:34), las personas que interactúan regularmente, tanto en su entorno social como laboral, "presentan dificultades especiales para las discusiones grupales porque pueden estar respondiendo en función de experiencias, hechos o discusiones anteriores". Al mismo tiempo, cabe la posibilidad de que, si los participantes en un grupo de discusión presentan relaciones previas, la libre expresión de ideas se vea mermada por el temor del impacto (real o imaginario) que dichas opiniones podrían tener posteriormente (Morgan, 1997:38). Sin embargo, por las particularidades de nuestra investigación, centrada en el estudio de caso de un determinado hospital, no fue posible cumplir con esta pauta en el grupo de discusión de los profesionales, ya que todos ellos trabajaban en el hospital contexto de estudio. Tampoco pudimos evitar que las participantes no presentaran relaciones previas en el caso del grupo de discusión con usuarias magrebíes, las cuales frecuentaban todas la misma mezquita y, por tanto, se conocían previamente. Por tanto, en el análisis de los datos obtenidos mediante esta técnica deberemos tener en cuenta que estas relaciones previas pueden haber influido en el funcionamiento y la dinámica de los grupos de discusión y haber condicionado ciertas intervenciones de los participantes.

Pasamos a continuación a justificar por qué se seleccionaron estos grupos y no otros de los que conforman el universo de estudio.

Por lo que respecta al grupo de profesionales sanitarios, este incluía, como hemos indicado, a una enfermera, a dos matronas y a tres obstetras. Por lo que respecta a estos últimos, por un lado, su grado de representatividad en las entrevistas en profundidad había sido muy bajo (solo 3 informantes), por lo que su participación en el grupo de discusión haría aumentar su representatividad en el estudio en su conjunto. Por otro lado, en principio, los obstetras pueden relacionarse con las usuarias en cualquier fase del proceso de reproducción (gestación, parto y puerperio), por lo que podrían aportarnos datos de las distintas fases. Asimismo, como hemos comentado previamente en el apartado dedicado a la técnica de la observación, nos resultó difícil estar presentes durante las consultas de control del embarazo, por lo que pensamos que la participación de obstetras en el grupo de discusión nos podría ofrecer datos en relación con el desarrollo de dichas consultas.

En cuanto a las matronas, por el contrario, se trata del grupo de informantes profesionales entrevistados más numeroso, por lo que con su participación en el grupo de discusión no perseguíamos precisamente aumentar su representatividad. A la hora de seleccionarlas, tuvimos en cuenta que su relación con las usuarias, por el perfil profesional que representan, suele ser muy estrecha. De hecho, entre sus funciones se podrían mencionar las siguientes: ${ }^{46}$

[...] proporciona una atención integral a la salud sexual, reproductiva maternal de la mujer, en su facetas preventiva, de promoción y de atención y recuperación de la salud, incluyendo así mismo la atención a la madre, en el diagnóstico, control y asistencia del embarazo, parto y puerperio normal y la atención al hijo recién nacido sano, hasta el 28 día de vida.

\footnotetext{
${ }^{46}$ Declaración de la Federación de Asociaciones de Matronas de España (FAME) sobre competencias profesionales de las Matronas. [http://www.federacion-matronas.org/documentos] (última consulta: 6 de abril de 2013).
} 
Por consiguiente, consideramos que la participación de matronas en el grupo de discusión, por las características y funciones de su perfil profesional, así como por su relación cercana y prolongada con las embarazadas y puérperas, nos podría ofrecer datos exhaustivos, los cuales, además, podrían servir de contraste en relación con los datos previamente obtenidos en las entrevistas.

Por último, la única enfermera participante en el grupo de discusión con profesionales sanitarios se presentó espontáneamente el día en que celebramos dicho grupo, con la intención manifiesta de aprender de lo que allí se debatiera, ya que hacía poco tiempo que se había incorporado a trabajar en el hospital contexto de estudio. Pensamos que su participación en el grupo de discusión, a pesar de no haber sido previamente acordada, podría aportarnos, por su breve exposición y contacto con el contexto de estudio, ideas novedosas en cuanto a las posibles soluciones para eliminar las barreras de acceso y uso de los servicios de obstetricia por parte de usuarias inmigrantes.

Por lo que se refiere a los grupos de discusión de usuarias, se trataba en los dos casos de usuarias que procedían de zonas cuya representación en cuanto al número de población inmigrante en la ciudad contexto de nuestro estudio es bastante numerosa. ${ }^{47}$

En el caso de las usuarias latinoamericanas, el propósito principal que perseguíamos con la realización del grupo de discusión era verificar si, en el caso de compartir una misma lengua, la comunicación entre los profesionales sanitarios y las usuarias se veía facilitada o si, por el contrario, el hecho de que estos hablaran diferentes variedades diatópicas del español, sumado a sus potenciales diferencias culturales, podrían dificultar también la comunicación. Además, con este grupo de discusión pretendíamos corroborar algunos datos referidos a este colectivo que habíamos obtenido con el uso de otras técnicas, como, por ejemplo, si se daba en este grupo de usuarias un menor uso de métodos anticonceptivos que derivaba en una mayor tasa de fecundidad con respecto a otros grupos, o si presentaban un bajo umbral del dolor que podía derivar en una mayor demanda de la anestesia epidural o en la solicitud personal de partos por cesárea.

Y en referencia a las usuarias procedentes del Magreb, por una parte, se había comprobado que se trataba de uno de los grupos que, por lo general, presentaba un mayor desconocimiento tanto de la lengua española como del funcionamiento del sistema sanitario. Por otra parte, además de las barreras lingüísticas, las referencias a este grupo por lo que respecta a las diferencias culturales habían sido abundantes en los datos recolectados mediante otras técnicas, como, por ejemplo, en relación con los hábitos alimentarios o con el pudor ante el contacto físico y la exploración. Asimismo, en las entrevistas se había mencionado en numerosas ocasiones a este grupo como aquel que presentaba los mayores problemas relacionados con patrones culturales asociados al rol de la mujer en la sociedad de origen. De hecho, muchos de los profesionales entrevistados, como veremos en el capítulo de análisis, habían comentado que las usuarias magrebíes se hallaban frecuentemente supeditadas a las opiniones de sus maridos y que la interacción con estos últimos solía ser complicada.

\footnotetext{
${ }^{47}$ Véanse los datos sobre la población inmigrante en Aragón y Zaragoza en el capítulo anterior.
} 
Por lo que respecta a la captación de los participantes, empleamos diferentes estrategias, principalmente recurriendo a informantes clave o gatekeepers (Berg, 2009:206) dentro del propio hospital o a redes privadas de la investigadora.

Durante la captación, usamos un cuestionario que sirviera de filtro para la selección de los participantes, en el que los candidatos a participar en los grupos de discusión respondían a una serie de cuestiones relacionadas con los fines de la investigación y con sus propias características sociodemográficas. De este modo, nos asegurábamos de que los participantes poseían las características perseguidas en la muestra y estaban dispuestos a participar en el grupo de discusión para el que se les convocaba. En dicho cuestionario se incluía, además, una breve descripción del estudio, con el fin de evitar que los sujetos acudieran a la reunión con opiniones o posturas preestablecidas y para que comprendieran que se iban a tratar temas de los cuales podrían hablar cómodamente (Gil Flores, 1992:205).

En concreto, el modelo empleado para el cuestionario enviado a las usuarias, por una parte, y a los profesionales, por otra, era el siguiente:

\section{Cuestionario de selección para usuarias}

\section{Breve descripción del estudio:}

Se solicita su colaboración para participar en un estudio sobre la comunicación intercultural entre los profesionales socio-sanitarios y las usuarias inmigrantes en el ámbito de la salud reproductiva centrado en la asistencia durante el embarazo, el parto y el puerperio un hospital materno-infantil de Zaragoza.

Datos a completar por la persona contactada:

Nombre y apellidos

País de origen

Número de hijos nacidos en España

Conocimientos de español

Datos de contacto (e-mail o teléfono)*

Disponibilidad (fechas y horarios)

* Se mantendrá la total confidencialidad. Se solicitan estos datos únicamente para poder contactar con las interesadas. 


\section{Cuestionario de selección para profesionales}

Breve descripción del estudio:

Se solicita su colaboración para participar en un estudio sobre la comunicación intercultural entre los profesionales socio-sanitarios y las usuarias inmigrantes en el ámbito de la salud reproductiva centrado en la asistencia durante el embarazo, el parto y el puerperio un hospital materno-infantil de Zaragoza.

\section{Datos a completar por la persona contactada:}

Nombre y apellidos

Perfil profesional

Años/Meses trabajados en el hospital contexto de estudio

Años/Meses trabajados en otros centros de salud en el área de obstetricia

Datos de contacto (e-mail o teléfono)*

Disponibilidad (fechas y horarios)

* Se mantendrá la total confidencialidad. Se solicitan estos datos únicamente para poder contactar con los interesados.

\subsubsection{Registro de la información}

Los grupos de discusión se grabaron en formato audio para facilitar el posterior análisis de los discursos orales producidos por los participantes. Se consideró que, aunque la presencia de una grabadora podía resultar inhibidora para los participantes, "la experiencia ha demostrado que el inicial efecto inhibidor desaparece tras un breve periodo de tiempo" (Folch-Lyon y Trost, 1981, citados en Gil Flores, 1993:207). Confiábamos en que los participantes comprendieran la necesidad que teníamos de registrar el discurso y se sumergieran rápidamente en la discusión ignorando los equipos de grabación presentes (Morgan, 1997).

A continuación, procedimos a la transcripción ${ }^{48}$ y codificación de los mensajes verbales intercambiados por los participantes, incluyendo datos de carácter contextual y del comportamiento y el lenguaje no verbal de los participantes que pudieran resultar de interés para el estudio.

\subsubsection{El papel del moderador}

El papel a desempeñar por la moderadora, ejercitado en nuestro caso por la propia investigadora, como recomienda Javier Gil Flores (1993:206), estaba condicionado por el enfoque adoptado, la naturaleza de la investigación y las características de los datos que se deseaba obtener.

En nuestro estudio, seguimos el modelo propuesto por Jesús Ibáñez (2003), que consiste en la mínima intervención por parte del moderador, el cual se limita a proponer los temas de

\footnotetext{
${ }^{48}$ Véase en los anexos la transcripción de los grupos de discusión.
} 
discusión, provocar el deseo de discutirlos deshaciendo posibles bloqueos y controlando el desarrollo del debate, para que los participantes no se alejen de los temas propuestos.

Otra de las funciones que asumió la moderadora fue la de crear el ambiente distendido necesario para que los participantes hablaran con libertad. Para ello, trató de evitar la manifestación de acuerdo o desacuerdo con las opiniones expresadas por los participantes, e intervino solamente para plantear nuevos temas a debatir y facilitar el flujo de la conversación.

Antes de iniciar la discusión, los participantes se presentaron entre sí y, a continuación, la moderadora se ocupó de proporcionarles una explicación breve de las características y la dinámica del encuentro. Estableció unas reglas básicas de participación y advirtió de que todos tenían la posibilidad de expresar libremente sus puntos de vista, por lo que sus posturas no debían ser obligatoriamente convergentes. Asimismo, informó a los participantes de que todos los datos revelados serían tratados con la máxima confidencialidad, de manera que estos se sintieran menos cohibidos a la hora de expresar sus pensamientos y opiniones (Berg, 2009:181). A continuación, solicitó a los participantes que manifestaran verbalmente su consentimiento a participar en el estudio, de manera que quedara confirmada su voluntariedad de participación.

Tras esta introducción, que sirvió además para el establecimiento inicial del rapport entre la moderadora y los participantes, la moderadora pasó a fomentar el debate mediante el planteamiento de diferentes cuestiones que iban dirigiendo la discusión hacia los temas de interés. En todo momento, trató de verificar que ningún participante se sentía cohibido y de impedir que algunos participantes dominaran excesivamente la discusión. Consideramos que el moderador de un grupo de discusión debe saber escuchar y mostrar empatía, por lo que las intervenciones de la moderadora fueron breves, y esta, como hemos comentado previamente, evitó la expresión abierta de juicios o de sus propias opiniones. No obstante, en algún momento, fue necesario solicitar aclaraciones, reformulaciones, cambios de tema o conclusiones.

Tal y como recomiendan diversos autores (Berg, 2009; Morgan 1997), además de la moderadora, participó en el grupo una observadora externa, cuyas funciones principales consistieron en la observación de los sujetos y la toma de notas de datos adicionales que pudieran resultar de interés, el manejo de los equipos de grabación y la colaboración en el análisis posterior, mediante el intercambio con la moderadora de sus impresiones sobre la dinámica del grupo y los aspectos más llamativos surgidos en el mismo.

\subsubsection{Guion de discusión ${ }^{49}$}

Elaboramos un guion variable y flexible que atendía a los fines de esta fase de la investigación y que era diferente dependiendo del grupo al que iban a plantearse los temas. Dichos temas estaban relacionados con los datos recolectados mediante el uso de las técnicas empleadas con anterioridad en nuestro trabajo de campo y, al mismo tiempo, en el caso de los grupos de

\footnotetext{
${ }^{49}$ En los anexos se incluye el guion de los diferentes grupos de discusión.
} 
discusión con usuarias, se referían a cuestiones de carácter cultural señaladas en investigaciones previas sobre la salud reproductiva de estos colectivos. ${ }^{50}$

El orden en que formulamos los temas iba de aquellos más generales a los más específicos y, por último, planteamos los temas considerados más complejos o sensibles. Observamos cierta flexibilidad a la hora de tratar otros temas que iban surgiendo en la discusión, siempre y cuando no se alejaran de nuestros objetivos. Por otro lado, tratamos de adaptar el lenguaje a las características de los participantes, de modo que los temas planteados resultaran comprensibles e inequívocos para todos ellos.

Además, al finalizar la discusión y tras agradecer a los participantes su colaboración y plantearles la posibilidad de realizar ulteriores comentarios que no hubieran podido expresar durante el encuentro, les pedimos que rellenaran un cuestionario individual ${ }^{51}$ en el que debían responder a una serie de preguntas específicas. Este cuestionario permitiría que los participantes asumieran una especie de compromiso con la posición que habían presentado durante la discusión y garantizaría que tanto los participantes más dominantes como aquellos que habían participado menos en la discusión pudieran expresar brevemente su opinión en relación con algunas cuestiones relevantes para nuestro estudio. Asimismo, nos ayudaría a contrastar si las ideas presentadas durante la discusión podían haberse visto influidas por la interacción grupal (Sussman et al., 1991; Wimmet y Dominick, 2006, citados en Berg, 2009:178).

\subsection{Proceso de análisis de datos}

A pesar de que la fase de análisis es una de las más importantes en toda investigación, esta se encuentra poco descrita en la literatura sobre metodología cualitativa en comparación con otras fases investigadoras (Morse, 1994:23, citada en Berg, 2009:146). Una cuestión en la que sí que concuerdan diversos autores (Cresswell, 2007; Kvale, 2011; Wolcott, 1994; Yin, 2009) es en la imposibilidad de determinar un tipo de análisis cerrado y válido para cualquier investigación, ya que este se realizará de manera creativa adaptándose a la naturaleza del estudio y de los datos obtenidos a través del mismo.

En nuestra investigación, hemos realizado un análisis descriptivo (exponiendo QUÉ sucede y CóMO) e interpretativo (mediante el uso de los datos para ilustrar teorías o conceptos). De acuerdo con John W. Cresswell (2007:151), la descripción supone un buen punto de partida en las investigaciones cualitativas y juega un papel fundamental en los estudios etnográficos y de caso, como es el nuestro. A través de la descripción, el investigador se convierte en narrador, invitando a los lectores a ver a través de sus ojos lo que él previamente ha observado (Wolcott, 1990:28, citado en Cresswell, 2007:162).

De acuerdo con Graham R. Gibbs (2008:2), para que la comprensión y la interpretación de las palabras y las acciones de los sujetos investigados sean adecuadas, es necesario relacionar dichas palabras y acciones con el contexto amplio en el que estas se han producido. Así, con el

\footnotetext{
${ }^{50}$ Entre las investigaciones relacionadas con la salud reproductiva de las mujeres del colectivo magrebí y del colectivo latinoamericano, cabe citar los trabajos de Yolanda Aixelà (2010), Marta Alonso (2010), Miguel Ángel Luque y María Isabel Oliver (2005), Djaouida Moualhi (2000), María Isabel Oliver (2002), y Carmen Ollé (2009).

${ }^{51}$ Véase en los anexos el guion de los cuestionarios individuales, cuyos datos aportados por los participantes se estudian en el apartado del capítulo de análisis centrado en la técnica de los grupos de discusión.
} 
fin de conseguir objetividad analítica y el conocimiento profundo de la realidad estudiada, hemos incluido la descripción del contexto social estudiado, así como de los sujetos y los sucesos que forman parte de dicho contexto. Aunque en principio la mera descripción debería huir de la conceptualización y basarse en la narración objetiva de los datos, para que sean los propios lectores los que, a partir de dichos datos, extraigan sus propias conclusiones, cabe considerar que la "pretendida escasa intervención del investigador es solo aparente, pues de él depende la selección de los mismos y su ordenamiento, que está en función de lo que para él es importante" (Amezcua y Gálvez, 2002:426).

Además, como se ha comentado, en nuestro proceso de análisis dicha descripción va acompañada de la interpretación de los datos, tanto mediante comparaciones entre los mismos como basándonos en la teoría existente sobre el objeto de estudio. Podemos decir, por tanto, que se ha empleado una fórmula mixta entre el análisis inductivo (derivado del material de análisis) y el deductivo (derivado de la teoría existente sobre el problema de investigación).

Steinar Kvale (2011:104) propone dos formas de análisis de los datos cualitativos obtenidos mediante entrevistas, que podríamos hacer extensibles al análisis de los datos obtenidos mediante otras técnicas de investigación cualitativa: la primera consistiría en el análisis centrado en el significado de lo que se ha dicho, y la segunda se centraría en el análisis de las formas lingüísticas mediante las que se ha expresado dicho significado. En nuestro caso, nos hemos decantado por la primera de estas formas de análisis, es decir, hemos estudiado el significado de los datos obtenidos, no hemos realizado un análisis del discurso centrado en el lenguaje empleado por los diferentes informantes.

Nuestro análisis se presenta mediante un informe narrativo en el que hemos huido de la presentación de los datos siguiendo el mismo esquema empleado en las diferentes técnicas, sino que estos se han organizado conceptualmente. Más allá de la mera enumeración de elementos, hemos recurrido a la comparación entre grupos o dentro de los mismos y a la búsqueda de relaciones entre las unidades de análisis con el fin de identificar modelos o tendencias. El informe, tal y como se verá en el capítulo 6 , se ha dividido en diferentes bloques relacionados con cada una de las técnicas empleadas para, posteriormente, en el capítulo 7, realizar un análisis comparativo general de los datos obtenidos con todas las técnicas.

Por cuestiones organizativas, hemos ordenado los datos en ejes temáticos. En primer lugar, se han segmentado los datos en unidades de análisis o de significado. Estos segmentos se han codificado por categorías, para sucesivamente, combinar y clasificar las distintas categorías en temas principales, relevantes y descartables. Cabe señalar que los temas analizados presentan una estrecha relación entre sí y las líneas que los separan son sutiles y difusas, por lo que en algunas ocasiones un mismo segmento o unidad de análisis se ha incluido en más de una categoría. Asimismo, algunas unidades de análisis se han clasificado en categorías afirmativas o negativas, lo cual ha permitido una clara presentación de las opiniones o los comportamientos contrapuestos. Sin embargo, a pesar de esta clasificación por ejes temáticos, hemos tratado en todo momento de realizar una contextualización de los datos y un tratamiento de los mismos de manera holística. 
Asimismo, en el informe de los resultados de investigación, hemos incluido citas textuales de las afirmaciones y opiniones presentadas por los informantes o contenidas en los textos objeto de análisis, de modo que, según afirma Harry F. Wolcott (1994:10), los datos "speak for themselves", así como para dar voz a los participantes en el estudio y corroborar las interpretaciones a las que hemos llegado. ${ }^{52}$

Cabe además señalar que el proceso de análisis ha sido flexible, sistemático y concurrente con la recolección de los datos. Los procedimientos empleados en nuestro análisis no son científicos ni mecánicos, sino que se ha recurrido a lo que se conoce como "artesanía intelectual" (Wright Mills, 1959:142), ya que no hemos seguido directrices rígidas, sino orientadoras, y ha sido la propia investigadora quien ha ido creando su propio método. De hecho, hemos tratado los datos de forma ecléctica, huyendo de esquemas extremadamente definidos y conciliando los diferentes sistemas de análisis que nos parecían adecuados para los fines de la investigación.

En conclusión, tal y como se muestra en el gráfico que aparece a continuación, la recolección y la reducción de los datos, así como su análisis y verificación, han tenido lugar simultáneamente y se han retroalimentado.

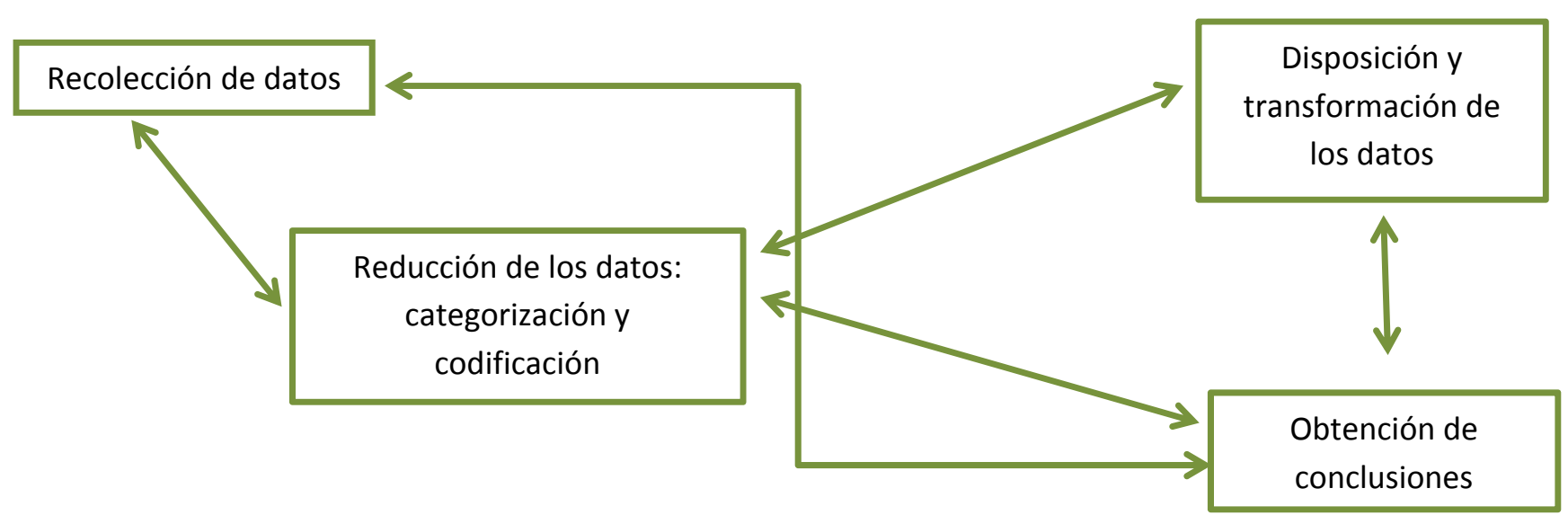

Gráfico 2.1. Procedimiento de análisis de datos

(Elaboración propia basada en el Modelo de Miles y Huberman, 1984)

Por otro lado, hemos realizado también un análisis basado en la inducción analítica, procedimiento para verificar teorías y proposiciones mediante datos cualitativos, cuyo primer impulsor fue Florian Znaniecki en la década de los treinta del pasado siglo en los Estados Unidos (Cicourel, 2011:12; Berg, 2009:358). En concreto, hemos tratado de verificar si las teorías existentes sobre el problema de investigación concordaban con los resultados de los datos recogidos en nuestro estudio. Así, nos hemos centrado en la búsqueda activa de casos negativos que refutaran las hipótesis iniciales, las cuales se han reformulado una y otra vez.

Cabe considerar, tal y como sugiere lan Dey (1993:222, citado en Gibbs, 2008:14), que en el proceso de análisis,

52 En los anexos se incluyen las transcripciones íntegras, así como las pautas que hemos empleado en la transcripción de las entrevistas y grupos de discusión, las cuales se basan principalmente en las recomendaciones de Graham R. Gibbs (2007) y Steinar Kvale (2011). 
We tend to make more of the evidence that confirms our beliefs, and pay less attention to any evidence that contradicts them. [...] Because the data are voluminous, we have to be selective and we can select out the data that doesn't suit. Because the data are complex, we have to rely more on imagination, insight and intuition - and we can quickly leap to the wrong conclusions.

Por estos motivos, hemos tratado de evitar en la medida de lo posible una serie de circunstancias que podrían haber puesto en peligro la calidad de la investigación. En concreto, hemos intentado prescindir de determinados elementos, como la inclusión de sesgos personales en la transcripción y la interpretación de los datos, el énfasis en los casos positivos o en los casos exóticos o inusuales, las definiciones vagas de conceptos, o las generalizaciones injustificadas.

Por último, cabe señalar que para el análisis de los datos obtenidos con las diferentes técnicas expuestas hemos empleado la última versión del programa informático NVivo (NVivo 10), lanzada al mercado en junio de 2012 por QSR International. ${ }^{53}$ Se trata de un software de apoyo a la investigación cualitativa y de métodos mixtos que ayuda a compilar, organizar y analizar contenido de entrevistas, grupos de discusión, encuestas, audio, redes sociales y páginas web.

Mostramos a continuación una imagen del proyecto creado con NVivo para los fines de nuestra investigación, en la que se pueden observar algunos de los documentos usados como fuentes y divididos por informantes, así como las diferentes funcionalidades (clasificación por nodos, análisis, búsqueda, etc.) que presenta el programa.

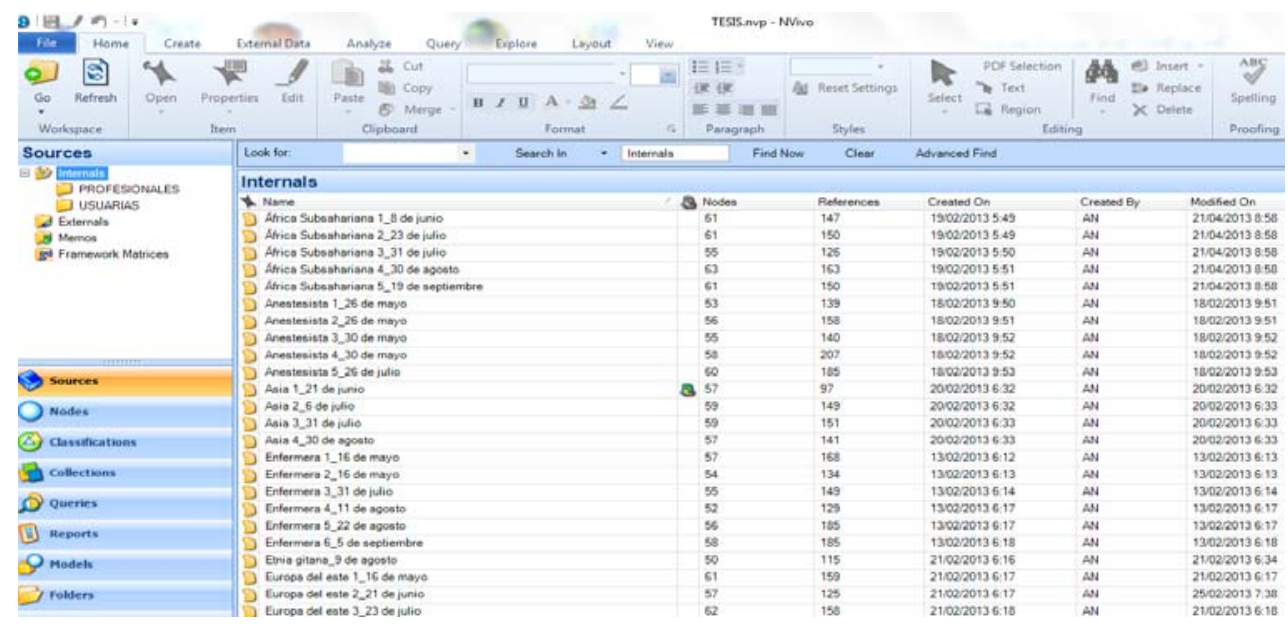

Imagen 2.1. Visión general del proyecto con NVivo 10

NVivo ha sido empleado por investigadores de ámbitos variados, entre los que se incluyen diferentes áreas de las ciencias sociales, como la antropología o la sociología. Su propósito es ayudar a los investigadores a ordenar y clasificar datos no numéricos ni estructurados. Permite además examinar las relaciones entre los datos y combinarlos. De este modo, los investigadores que recurren a su uso pueden verificar teorías, identificar tendencias o realizar análisis cruzados de los datos mediante las diferentes herramientas de búsqueda y consulta.

Entre las ventajas que proporciona el uso de un programa informático para analizar los datos cualitativos, cabe citar la posibilidad de almacenar y localizar la información de manera sencilla

53 Para mayor información sobre este programa, se puede visitar la página oficial: [http://www.qsrinternational.com/products.aspx] (última consulta: 22 de abril de 2013). 
y rápida y de visualizar las conexiones entre unidades analíticas o temas. El empleo de estos programas permite además crear una serie de memos que se asocian a determinados segmentos o códigos y que señalan ideas e interpretaciones del propio investigador que se desea incluir posteriormente en el informe. Otros beneficios que implica el empleo de programas en el análisis cualitativo (Valles, 2001:15-17) consistirían en la "hipertextualidad", es decir, la posibilidad de conectar los diferentes textos o documentos analizados, y la "modelización y visualización analíticas", es decir, la capacidad de trazar mapas o redes conceptuales que facilitan la generación de modelos teóricos.

Por el contrario, entre las desventajas que se citan se incluye la necesidad de aprender a usar el programa elegido. Además, algunos autores opinan que el uso de programas informáticos podría distanciar al investigador de los datos. Cabe además recordar que, aunque el programa asista al investigador en su labor de análisis, "any computer program still requires that the researcher think through the analytical and theoretical relationships between original conceptualizations and eventual empirical evidence" (Berg, 2009:370). Esta última idea es reforzada por otros autores, como por ejemplo Graham R. Gibbs (2008:10), quien afirma que "the real heart of analysis requires an understanding of the meaning of the texts, and that is something that computers are still a long way from being able to do".

En nuestro caso y a modo de resumen, el uso del programa NVivo nos ha permitido analizar detalladamente grandes cantidades de datos usando herramientas de búsqueda, de consulta y de visualización. Asimismo nos ha ayudado a descubrir conexiones sutiles, agregar nuestras opiniones e ideas durante el proceso de análisis, y justificar rigurosamente los hallazgos.

\subsection{Validez científica del estudio}

Las investigaciones cualitativas se han criticado a menudo por su falta de fiabilidad o validez entendidas en sentido tradicional (Le Compte y Goez, 1982:31, citados en Cresswell, 2007:202). Aunque este problema de la validez o el rigor de los datos en los estudios cualitativos "es una cuestión polémica y aún no resuelta" (Amezcua, 2000:34), en el presente estudio hemos tenido en cuenta que, en toda investigación, se debe velar por que los datos sean completos, de calidad y expuestos en un formato que facilite su organización y comprensión. Así, a pesar de las limitaciones que puede presentar un estudio con estas características (como el hecho de no hayamos conseguido la autorización para grabar en formato audiovisual el escenario de nuestras observaciones, la imposibilidad de acceso a determinadas áreas del hospital, o la probabilidad de haber influido en las respuestas de los participantes en las entrevistas y los grupos de discusión), consideramos que existen determinados criterios o principios que pueden ayudar a garantizar su validez.

En primer lugar, la calidad de nuestra investigación puede apoyarse en diferentes aspectos que hemos tratado de observar: la congruencia entre la pregunta o problema de investigación y el método escogido; la selección de la muestra siguiendo criterios específicos adecuados al objeto de estudio; el empleo de técnicas y fuentes de recolección de datos apropiados para los objetivos que se persiguen; la estrategia de análisis de datos explícita y desarrollada de manera sistemática y clara; y la descripción detallada de todo el proceso de investigación (diseño, recolección y análisis) (Delgado et al., 2006:84). 
En segundo lugar, con el fin de garantizar el rigor, la amplitud, la profundidad y la consecuente confirmabilidad de la investigación, entendida esta última como el criterio que vela por que los resultados y la interpretación de los mismos estén confirmados, hemos recurrido a varias formas de triangulación (Denzin y Lincoln, 1998): la triangulación de datos, mediante el recurso a diversas fuentes que los proporcionen; la triangulación metodológica, alcanzada por el uso de diferentes métodos para estudiar un mismo problema; y la triangulación de teorías, ya que hemos empleado múltiples perspectivas para interpretar un mismo conjunto de datos.

Asimismo, para asegurar la validez del estudio realizado, hemos tenido en cuenta una serie valores y hemos seguido determinadas estrategias, los cuales han sido asociados con la calidad de la investigación por diversos autores (Cresswell, 2007; Kvale, 2011; Lincoln y Guba, 1985 y 1999; Miles y Huberman, 1984; Wolcott, 1994). Entre dichos valores y estrategias, podríamos citar los siguientes:

- Veracidad y credibilidad, entendidas respectivamente como la correspondencia entre los datos recogidos y la realidad, y como el criterio que asegura que los resultados y las conclusiones son creíbles. Con el fin de cumplir con estos valores, hemos llevado a cabo una observación persistente, hemos realizado un trabajo de campo prolongado en el tiempo, hemos recurrido a la triangulación de técnicas y hemos comprobado con algunos de los participantes la veracidad de los resultados.

- Reflexividad, o "subjetividad rigurosa" en palabras de Harry F. Wolcott (1994:354), que consiste en tener en cuenta cómo el proceso y la propia investigadora han podido influir en los resultados. Según María Eugenia Delgado et al. (2006:87),

No se trata de alcanzar la "neutralidad de valores" del investigador, ya que todos tenemos valores, sino de hacer expresar las opiniones propias con respecto a la situación estudiada y a la estrategia investigativa y analizar de qué manera pueden haber influido en los resultados. [...] representa el esfuerzo, no ya por evitar la influencia del investigador sobre el objeto de estudio, sino por reconocerlo y así posibilitar que sea tenido en cuenta tanto por él como por los destinatarios del trabajo de investigación.

- Transferibilidad o aplicabilidad, entendidas como la posibilidad de aplicar y transferir los resultados obtenidos a otros sujetos o contextos. Aunque somos conscientes que el mero hecho de cambiar el contexto, los participantes o incluso el responsable de la investigación podría conllevar variaciones en los resultados del estudio si este se replicase, hemos tratado de cumplir con el valor de transferibilidad mediante la recogida abundante de información, la muestra heterogénea y con carácter representativo, y el desarrollo de descripciones minuciosas. Al respecto de la transferibilidad, cabe señalar que esta no debe confundirse con la generalización, aspecto que, como hemos comentado en el apartado relativo al muestreo del presente capítulo, no se encuentra entre los objetivos de nuestro estudio. En todo caso, lo que perseguimos es lo que Robert K. Yin denomina "generalización analítica", que se corresponde con la generalización de teorías y no con la enumeración de frecuencias. De acuerdo con este autor (Yin, 2009:15, citado en Giménez, 2012:49), 
Lo que se generaliza no son los resultados particulares y específicos de un análisis de caso, sino el modelo teórico que ha conducido exitosamente a esos resultados, y que se supone conducirá a resultados análogos (y no idénticos) en otros casos.

En cuarto lugar, hemos seguido una serie de recomendaciones que propone el reputado etnógrafo Harry F. Wolcott en el capítulo de su obra dedicado a la validez en la investigación cualitativa (Wolcott, 1994:348-355). A continuación, reproducimos textualmente los enunciados de algunas de las recomendaciones de Harry F. Wolcott y explicamos cómo las hemos aplicado en las distintas fases de nuestro estudio:

\section{Talk Little, Listen a Lot}

Tal y como hemos comentado en el apartado de este capítulo centrado en las técnicas y fuentes de recolección de datos, en las entrevistas y grupos de discusión hemos tratado de mantener una actitud discreta y prudente, interviniendo lo menos posible y fomentando que fueran los participantes quienes expresaran libremente sus ideas, creencias y comportamientos en relación con el objeto de estudio.

\section{Record Accurately}

Por lo que respecta a la técnica de la observación, escribimos las notas y el diario de campo en el propio contexto de estudio, tan pronto como por las circunstancias observadas era posible, y tratamos de que estas fueran lo más completas y exhaustivas posibles. Por lo que se refiere a las entrevistas y grupos de discusión, estas fueron grabadas y posteriormente transcritas literalmente, incluyendo en la transcripción comentarios contextuales o sobre los participantes.

\section{Begin Writing Early}

Como se ha comentado previamente, en nuestro estudio se han llevado a cabo de forma concurrente la recolección de los datos y el análisis de los mismos. Esta simultaneidad nos permitía ir registrando los datos que se iban conociendo o intuyendo, así como identificar posibles lagunas de información y contradicciones que hacían necesaria una ulterior recolección de datos.

\section{Report Fully}

En el análisis e interpretación de los datos hemos realizado descripciones minuciosas y detalladas y hemos incluido también cuestiones que discrepaban con nuestras hipótesis iniciales, así como aquellas que eran contradictorias con los datos obtenidos de otros informantes o a través de otras técnicas, y aquellas que eran difíciles de comprender y para las que la interpretación resultaba compleja, dejando en estos últimos casos la labor de interpretación a los propios lectores.

Por último, y en relación con los dos métodos principales empleados en nuestro estudio, la etnografía, por una parte, y el estudio de caso, por otra, hemos tenido en cuenta una serie de criterios establecidos respectivamente por George Spindler y Louise Spindler (1987) y por Robert Stake (1995) y que, de acuerdo con estos autores, garantizan la validez de una investigación. 
Por lo que respecta a la etnografía, hemos considerado los siguientes criterios de validez (Spindler y Spindler, 1987:20 citados en Cresswell, 2007:217): la observación ha sido prolongada y repetitiva y los datos derivados de la misma se han contextualizado; las hipótesis han ido surgiendo in situ a medida que se avanzaba en el estudio; hemos obtenido el punto de vista de los sujetos investigados mediante el uso de diferentes técnicas (observación, entrevistas y grupos de discusión); hemos tratado de no predeterminar las respuestas obtenidas por parte de los diferentes informantes; y en el informe de los resultados hemos intentado explicitar e interpretar lo que los informantes habían presentado de forma implícita o tácita.

En cuanto al estudio de caso, hemos contemplado los siguientes criterios de validez (Stake, 1995:131, citado en Cresswell, 2007:218): hemos definido ampliamente el caso estudiado; hemos estudiado diferentes lugares del contexto objeto de estudio y hemos recurrido a diferentes fuentes de datos; hemos elaborado un informe de resultados conceptualmente estructurado por temas; hemos empleado citas textuales para corroborar los datos e interpretaciones presentados; y hemos evidenciado claramente los comentarios que se correspondían con nuestros puntos de vista personales.

\subsection{Aspectos éticos}

Son numerosos los autores que han tratado en sus manuales sobre metodología las consideraciones éticas que se deben observar a la hora de realizar una investigación cualitativa $y$, en nuestro estudio, nos hemos basado en las recomendaciones al respecto ofrecidas por algunos de estos (en concreto, Babbie, 2007; Berg, 2009; Cresswell, 2008; Kvale, 2011; Patton, 2002; Taylor y Bogdan, 2010).

Con el fin de organizar de algún modo los aspectos éticos tenidos en cuenta en el presente estudio, hemos dividido su presentación en las diferentes fases del mismo, tal y como realiza Steinar Kvale (2011:24):

- Elección del objeto de estudio: Entre los principios éticos observados en las investigaciones sociales, destaca la noción de "do not harm", es decir, el no infligir en los sujetos investigados ningún daño físico o psicológico (Berg, 2009: 60). Así, a la hora de elegir nuestro objeto de estudio, basándonos en el principio ético de beneficencia (Beauchamp y Childress, 1979: 197), que se refiere a que el riesgo de infligir daños en los sujetos investigados debe ser el menor posible y a que los potenciales beneficios para los sujetos y la relevancia del conocimiento derivado del estudio deben ser superiores al riesgo de perjuicios, tuvimos en cuenta a la hora de determinar el propósito de nuestra investigación que este debía consistir no solo en el conocimiento perseguido, sino también en la mejora humana de la situación que íbamos a investigar.

- Diseño metodológico: De acuerdo con Michael Quinn Patton (2002), debido a que en las investigaciones de corte cualitativo se establecen en cierto sentido relaciones personales con los informantes, resulta necesario clarificar el rol del investigador y establecer una serie de compromisos antes de que estos participen en el estudio. En nuestro caso, antes de la participación de los sujetos analizados, les informamos del papel de la investigadora como observadora no participante y, previamente a la realización de las entrevistas y los 
grupos de discusión, les proporcionamos un consentimiento informado con el cual mostraban su conformidad a participar en el estudio y en el que se les aseguraba la confidencialidad y el anonimato. Asimismo, se les presentó una descripción previa de nuestro propósito general y de los posibles riesgos y beneficios de su participación en la investigación. En todos los casos notificamos a los posibles informantes que su participación era voluntaria, les garantizamos que podían abandonar el estudio en el momento en que desearan, y les confirmamos que su aprobación o negación a participar no les influiría en modo alguno en su situación en el entorno objeto de estudio. Además, les comunicamos qué se haría con la información obtenida y quién tendría acceso a la misma.

- Observación, entrevistas y grupos de discusión: Por una parte, consideramos los efectos que podía tener la participación en el estudio para los sujetos, como el estrés que podían sufrir durante la observación, las entrevistas y las discusiones grupales, o los cambios que se podían producir por parte de dichos sujetos en la comprensión de sí mismos. Como ejemplo de la consideración de este principio, no realizamos entrevistas en la sexta planta del hospital, pues por la complejidad del embarazo o del parto que habían experimentado las puérperas ingresadas en dicha planta, podría aumentar el estrés y el malestar que probablemente experimentaban ya en su situación estas posibles informantes. Por otra parte, teniendo en cuenta que la relación con los informantes era asimétrica, tratamos de lograr un equilibrio entre la distancia emotiva y la empatía.

- Transcripción: Los aspectos éticos que hemos observado en la fase de transcripción de los datos aportados se han centrado especialmente en la garantía y la protección del anonimato de los sujetos investigados y en la fidelidad a los mensajes orales proporcionados por los mismos.

- Análisis: En cuanto a los aspectos éticos considerados en el análisis, tratamos que este fuera profundo y detallado, y ofrecimos a los sujetos investigados la posibilidad de valorar las interpretaciones derivadas del análisis.

- Verificación: En cuanto a este principio, hemos contemplado la responsabilidad ética del investigador de presentar los resultados con las mayores garantías y verificaciones como sea posible, tal y como se ha explicado detalladamente en el apartado anterior relativo a las distintas estrategias empleadas para garantizar la validez de nuestra investigación.

- Elaboración del informe: En la presentación de los resultados de investigación, hemos tratado de asegurar la confidencialidad y el anonimato de los sujetos investigados. De acuerdo con John W. Cresswell (2008:240), en los informes de investigación se deben narrar las experiencias y opiniones de los participantes, sin que ello ayude a revelar la identidad de los distintos sujetos. Por ello, hemos evitado el uso de nombres propios y hemos identificado a los diferentes informantes a través de su perfil profesional o su origen, dependiendo de si se trataba de profesionales sanitarios o usuarias, y asignándoles un número que se correspondía con el orden cronológico en el que participaron en el estudio. Asimismo, de acuerdo con las recomendaciones de Earl R. Babbie (2007), se debería evitar la posibilidad de identificar el contexto de estudio, algo que en nuestro caso se ha intentado en la medida de lo posible, aunque podría no haberse conseguido, 
considerando que el número de hospitales materno-infantiles en la ciudad donde ha tenido lugar el trabajo de campo no es numeroso (especialmente si se consideran solo los hospitales de titularidad pública) y, por consiguiente, la descripción del hospital en el que se contextualiza nuestro estudio ofrecida en el capítulo 1 podría facilitar su identificación.

A modo de resumen de los diferentes principios éticos observados en la realización de nuestro estudio, exponemos las recomendaciones de Samuel James Taylor y Robert Bogdan (2010:9495) que hemos tratado de tener en cuenta en todo momento:

El ingreso en un escenario generalmente implica una especie de pacto, la seguridad implícita o explícita de que no se desea violar la privacidad o confidencialidad de los informantes, ni exponerlos a perjuicios, ni interferir en sus actividades. [...] La bibliografía sobre la ética de la investigación generalmente sostiene una posición no intervencionista en el trabajo de campo. La mayor parte de los investigadores deben ser leales a sus informantes o a la consecución de las metas de la investigación. Hay que evitar cualquier compromiso que interfiera la investigación o viole el pacto con los informantes. 


\section{CAPÍTULO 3}

\section{La comunicación intercultural}




\section{LA COMUNICACIÓN INTERCULTURAL}

En este capítulo nos ocupamos de uno de los temas centrales de nuestra investigación: la comunicación intercultural. ${ }^{54}$ En concreto, exponemos las características de este tipo de comunicación, analizamos los elementos (verbales y no verbales) que intervienen en la misma, y describimos a grandes rasgos las particularidades de los modelos comunicativos 0 conversacionales que predominan en las distintas culturas. Asimismo, enumeramos las barreras que pueden dificultar o impedir que los intercambios comunicativos interculturales se desarrollen con éxito. Al respecto, atendiendo a los fines de nuestro estudio, hacemos especial hincapié en los obstáculos añadidos que se pueden dar cuando la comunicación tiene lugar en el ámbito sanitario, y el profesional de la salud y el paciente no comparten el mismo origen étnico y cultural. Por último, proponemos una serie de claves y pautas que podrían servir para garantizar la eficacia de la comunicación intercultural.

Antes de pasar a analizar cada uno de los puntos señalados, nos gustaría precisar que, si bien somos conscientes de la interrelación inevitable entre lengua y cultura, ${ }^{55}$ por motivos metodológicos y epistemológicos hemos separado en dos capítulos el estudio de los elementos comunicativos (del que nos ocupamos a continuación) y el de los factores de índole cultural (tanto de carácter más general como los centrados en lo que se conoce como cultura sanitaria) que intervienen en las interacciones entre personas lingüística y/o culturalmente diversas. ${ }^{56}$ Estamos de acuerdo con Godwin C. Chu (1977, citado en Jandt, 2010:37), ${ }^{57}$ cuando afirma que

[...] every cultural pattern and every single act of social behavior involve communication. To be understood, the two must be studied together. Culture cannot be known without a study of communication, and communication can only be understood with an understanding of the culture it supports.

Por ello, si bien por cuestiones organizativas tratamos por separado el estudio de la comunicación y de los patrones culturales, las referencias a uno y a otro son frecuentes en ambos capítulos y la información en ellos contenida debe considerarse en conjunto, no de manera aislada.

\footnotetext{
${ }^{54}$ Cabe señalar que, al hablar de comunicación intercultural, nos referimos a la comunicación interpersonal (cara a cara) entre individuos culturalmente distintos. No nos ocupamos en nuestra investigación de los estudios de comunicación intercultural que se centran en los intercambios comunicativos en el ámbito específico de los negocios, en las relaciones institucionales o gubernamentales, o en la comunicación internacional a través de los medios de comunicación de masas.

${ }^{55}$ A modo de resumen, podemos decir que la lengua constituye en sí misma un elemento cultural y, al mismo tiempo, sirve de vehículo para transmitir la cultura.

${ }^{56}$ En la selección de los aspectos que tratamos tanto en este capítulo como el siguiente hemos tenido en cuenta, de manera especial aunque no exclusivamente, el Modelo de Asesoramiento e Intervención en Enfermería Transcultural de Joyce Newman Giger y Ruth Elaine Davidhizar (1995), de acuerdo con el cual, cada persona posee una identidad cultural única, y su estado de salud se debe valorar teniendo en cuenta seis fenómenos: la comunicación, el espacio, el tiempo, la organización social, el entorno y las variables biológicas.

${ }^{57}$ De este autor, recomendamos la lectura de la obra The Great Wall in Ruins. Communication and Cultural Changes in China (1993), que ofrece un detallado panorama de los cambios que se han producido en el último siglo en la cultura china por lo que respecta a las relaciones sociales y familiares, las creencias, los valores y los comportamientos, basado en un exhaustivo trabajo de campo realizado junto con Yanan Ju durante catorce años (1964-1978).
} 


\subsection{Definición y características de la comunicación intercultural}

La comunicación intercultural, entendida como la interacción comunicativa que se da entre personas procedentes de diferentes países y culturas, es casi tan antigua como la historia de la humanidad, pues surge desde el momento en que comienzan a producirse contactos entre comunidades con distintos orígenes étnicos y culturales. Sin embargo, los estudios de comunicación intercultural solo comienzan a proliferar en la última mitad del siglo XX, siendo algunos de sus principales exponentes investigadores como Edward T. Hall $(1959,1976,1998)$, William B. Gudykunst y Young Y. Kim (1984, 1988, 1992), Milton J. Bennett (1998), Fred E. Jandt (1995, 2001), y Larry A. Samovar y Richard Porter (1972, 2001).

El interés creciente por este ámbito de estudio está motivado, entre otros factores, por el hecho de que, en la época actual, se han producido una serie de cambios económicos, políticos, tecnológicos, etc. ${ }^{58}$ que han conllevado un notable aumento de los intercambios comerciales, los flujos migratorios y las relaciones internacionales en general. En consecuencia, son cada vez más comunes las situaciones en las que personas procedentes de diversos países y culturas comparten el tiempo y el espacio, y se comunican (o tratan de comunicarse) entre sí.

Las interacciones comunicativas con personas culturalmente distintas a las que nos enfrentamos hoy en día nos conducen a plantearnos nuevos interrogantes sobre la manera en que estas deberían afrontarse; así, tal y como sostiene Milton J. Bennett (1998:1),

Today, living in multicultural societies within a global village, we all face the question [How do people understand one another when they do not share a common cultural experience?].

No son pocos los obstáculos que deben superar los estudiosos de esta disciplina; de hecho, estamos de acuerdo con Miquel Rodrigo Alsina (1999:32), autor de numerosas publicaciones al respecto en el contexto español, cuando afirma que una las principales dificultades con las que se encuentra el investigador en comunicación intercultural consiste en la "sensación de ignorancia abismal" que percibe a medida que profundiza en el tema, ignorancia que se fundamenta en la gran complejidad del concepto mismo de comunicación intercultural, el cual necesariamente debe relacionarse con la cultura, con los distintos sistemas de valores, con las diferentes percepciones del tiempo y el espacio, con las creencias, los ritos, las costumbres y, evidentemente, con la lengua y los modelos comunicativos de los interlocutores. De hecho, los estudios de comunicación intercultural presentan un carácter interdisciplinario en el que tienen cabida numerosas y variadas disciplinas, como la antropología cultural, la lingüística, la sociología, la filosofía, o la etnografía.

La comunicación en general, incluso aquella que tiene lugar entre personas culturalmente afines, no siempre fluye con facilidad $y$, en algunas ocasiones, se genera entre los interlocutores un cierto malestar, surgen malentendidos o, incluso, conflictos. Sin embargo, en la comunicación intercultural, aquella que tiene lugar entre individuos con "referentes culturales tan distintos que se autoperciben como pertenecientes a culturas diferentes" (Rodrigo Alsina, 1999:12), es más probable que se llegue a estas situaciones de malestar o

\footnotetext{
${ }^{58}$ Entre dichos cambios, destacan el avance en los medios de transporte y en las nuevas tecnologías de la información y la comunicación (TIC), la globalización de la economía, o el surgimiento de organismos internacionales y de alianzas político-económicas entre diferentes estados.
} 
conflicto, por los motivos que explicaremos más adelante. Por consiguiente, cuando nos comunicamos con personas procedentes de otros países y culturas, debemos asumir que "el malentendido puede ser la norma y no la excepción" (Rodrigo Alsina, 2000:7).

Aunque la comunicación entre individuos pertenecientes a una misma cultura puede igualmente fallar, coincidimos con Francisco Raga (2006b:222) cuando afirma que

[...] lo que hace especialmente graves los problemas de comunicación intercultural es su carácter inconsciente, la sensación de incomodidad o frustración que provocan en los interlocutores, sin que éstos sean capaces de identificar de manera clara el origen de los mismos.

En primer lugar, cabe considerar que la comunicación no se basa simplemente en la transmisión y recepción de mensajes verbales, sino que, en toda interacción comunicativa, intervienen tanto elementos lingüísticos como elementos extra-lingüísticos, entre los que se incluyen factores como la distribución espacial y temporal o el paralenguaje, sin olvidar los valores psicológicos, emotivos, individuales y sociales relativos a los interlocutores que participan en el encuentro comunicativo. ${ }^{59}$

Además, del mismo modo en que cada comunidad organiza sus diferentes prácticas sociales, regula igualmente sus interacciones, de manera que los individuos de dicha comunidad interiorizan una cultura comunicativa, que incluye normas acerca de cómo hablar, cuándo hablar, quién puede hablar, de qué y con quién.

Cuando aprendemos nuestra lengua materna, adquirimos también estos conocimientos, por lo que, en una situación comunicativa y un contexto determinados, sabemos qué se espera de nosotros y de nuestros interlocutores $y$, en consecuencia, optamos por una lengua, por una variedad y unos usos específicos, y seguimos un modelo conversacional concreto.

Los modelos conversacionales que presentan las diferentes culturas varían, como veremos posteriormente, en aspectos como el uso y la interpretación de los silencios, las formas de expresión (directas o indirectas), el grado de formalidad en un determinado acto de habla, el contacto físico y la distancia, el límite entre lo público y lo privado, etc. En las conversaciones interculturales, normalmente los interlocutores suelen presentar un desconocimiento mutuo de la forma de conversar del otro y, en ocasiones, ni siquiera consideran o dan importancia a la existencia de tales diferencias, lo cual puede perjudicar o impedir que exista una comunicación efectiva.

Así, en general, cuando nos comunicamos con personas de otras culturas, somos conscientes de la diversidad lingüística, pero no solemos percibir o considerar la diversidad en los modelos comunicativos. Tal diversidad es un ejemplo más de la creatividad humana y una fuente de enriquecimiento de los procesos de comunicación. Sin embargo, a menudo las diferencias (lingüísticas $y$, especialmente, culturales) entre los interlocutores hacen surgir lo que

\footnotetext{
${ }^{59}$ Cabe resaltar que los aspectos lingüísticos, a los que a veces se les concede una excesiva importancia en las interacciones interculturales, no son en realidad tan relevantes. De hecho, como se afirma en la literatura al respecto (véase, por ejemplo, Hall, 1998:53), los elementos verbales de la comunicación desempeñan un papel marginal en el desarrollo de la misma, mientras que el resto de factores mencionados influyen notablemente (80$90 \%$ ) en la obtención de los objetivos comunicativos. En efecto, como veremos más adelante, la competencia lingüística, aunque es una condición necesaria, no es suficiente para que la comunicación intercultural sea eficaz.
} 
comúnmente se denomina choque cultural, ${ }^{60}$ fenómeno causado por la incomprensión del comportamiento ajeno que puede provocar sentimientos negativos, como la preocupación, la frustración, la incomodidad, la desconfianza o la ansiedad.

Igualmente, las diferencias en los modelos comunicativos resultan en algunas ocasiones ser fuente de exclusión o dominio, ya que, por lo general, se da mayor importancia a un modelo, y se rechazan o se malinterpretan otros. Especialmente en los casos en los que existe una asimetría social entre los participantes en una situación comunicativa, es decir, cuando existen diferencias de estatus o de poder entre los interlocutores, es posible que estas diferencias en los modelos comunicativos den lugar a la exclusión o al rechazo social, puesto que a los hablantes que presentan un estatus superior o gozan de mayor poder se les concederá cierta legitimidad social para imponer sus formas y sus reglas sobre otros. También cabría considerar si los interlocutores se encuentran físicamente en su cultura, en su país de origen, o en otra cultura. En este último caso, es posible que hayan adoptado los patrones comunicativos de la cultura de acogida, siguiendo las pautas del modelo asimilacionista, el cual, desgraciadamente, como hemos comentado en el capítulo 1 , es el modelo de gestión de la diversidad más extendido en los países receptores de inmigración.

Tras la exposición de las características generales que presenta la comunicación intercultural, pasamos a continuación a analizar los diferentes elementos (verbales y no verbales) que intervienen en la misma, así como las propuestas de clasificación de los modelos comunicativos planteadas por diversos autores. Cabe considerar que esta división responde a cuestiones de organización del texto, pero somos conscientes de que la comunicación, siendo un sistema integrado en el que todos los elementos se relacionan entre sí, no puede analizarse por unidades separadas (Davis, 2010:19). Por consiguiente, algunos de los conceptos tratados se plantean en más de un apartado, por la fuerte interrelación entre los mismos.

\subsubsection{Lenguaje verbal}

Como hemos comentado previamente, las diferencias lingüísticas son las primeras que percibimos cuando nos comunicamos con personas culturalmente diversas, especialmente, aunque no únicamente, ${ }^{61}$ cuando no compartimos con dichos interlocutores la lengua materna.

Sin embargo, una vez superada esta barrera puramente lingüística, seguirán existiendo ciertas diferencias por lo que respecta al lenguaje verbal condicionadas por una serie de normas compartidas por una comunidad de hablantes, de acuerdo con las cuales, en una determinada situación comunicativa, en un determinado contexto, e interactuando con un determinado interlocutor, presentamos un comportamiento comunicativo concreto. Así, partiendo de dichas normas y teniendo en cuenta los referentes y los conocimientos que tenemos en común con nuestro interlocutor, ofrecemos, por ejemplo, más o menos información, empleamos

\footnotetext{
${ }^{60}$ La expresión "choque cultural" fue popularizada por Kalvero Oberg, quien lo definía como un sentimiento de ansiedad causado por la pérdida de los símbolos familiares y sociales. A dicha definición, Edward T. Hall añadió el hecho de que los referentes familiares se ven reemplazados por elementos nuevos y extraños (Bennet, 1998:215).

${ }^{61}$ Aun en el caso de países que presentan una misma lengua materna, como puede el de los países anglófonos o los hispanófonos, pueden surgir malentendidos derivados de las diferencias lingüísticas y culturales que estos presentan.
} 
formas de hablar más o menos directas, o concedemos a nuestro discurso mayor o menor formalidad.

Nuestro comportamiento comunicativo se basa, por tanto, en lo que se conoce como principio de cooperación (cooperative principle), en el cual se fundamentan las denominadas máximas conversacionales (Grice, 1975), cuyo cumplimiento supone un requisito indispensable para garantizar el éxito de los intercambios comunicativos.

De acuerdo con dicho principio, en las interacciones conversacionales, se sigue la siguiente instrucción: "Adecúe su contribución conversacional, en el estadio en que tenga lugar, a los requisitos que marque el propósito o la dirección del intercambio que usted sostenga" (Grice, 1975:516).

Los hablantes presuponemos que nuestros interlocutores son cooperativos, es decir, que siguen las normas que conforman cada una de las máximas. De este modo, cuando mantenemos una conversación, damos por sentado que nuestro interlocutor nos va a dar la información justa que necesitamos (máxima de cantidad), que esta será pertinente (máxima de relevancia), ${ }^{62}$ y verdadera (máxima de calidad), y que será expuesta de manera clara y ordenada (máxima de manera). Sin embargo, el grado de aplicación de las máximas es una cuestión en gran medida subjetiva y, además, siendo una forma de expresar y establecer las relaciones sociales, varía de una cultura a otra. Así, nuestro comportamiento comunicativo, esto es, la cantidad, la pertinencia, la veracidad y la claridad de los mensajes que transmitamos dependerán de la cultura comunicativa en la que nos hayamos socializado.

En consecuencia, es probable que, al comunicarnos con personas culturalmente diversas, su comportamiento comunicativo sea diferente a aquel que, basándonos en nuestros propios patrones, esperamos de nuestro interlocutor. Podrá extrañarnos, por tanto, que este nos ofrezca más o menos información de la deseada, que surjan temas en la conversación considerados por nosotros superfluos o, por el contrario, tabúes, que su modo de expresión sea demasiado directo o indirecto, que no sea todo lo sincero que esperaríamos, ${ }^{63}$ etc.

Solo si tenemos en cuenta que el grado de aplicación de las máximas es una manifestación más de la cultura comunicativa, podremos comprender determinados comportamientos que, a nuestros ojos, pueden resultar cuanto menos extraños.

\subsubsection{Lenguaje no verbal}

Las diferencias relativas a los usos verbales pueden resultar más fáciles de identificar que aquellas referentes a los usos no verbales, lo cual no significa necesariamente que, una vez

\footnotetext{
${ }^{62}$ En el análisis de las máximas de Grice que realizaremos tanto más adelante en este mismo capítulo como en el capítulo 6, en el que exponemos los resultados de nuestro trabajo de campo, hemos obviado las referencias a la máxima de relevancia, y la hemos fusionado con la máxima de cantidad, ya que opinamos, tal y como sostiene Francisco Raga (2003:40), que ambas parecen redundantes; esto es, si consideramos que nuestro interlocutor nos está ofreciendo más información de la que esperamos, es porque percibimos esa información sobrante como no relevante.

${ }^{63}$ Con respecto al grado de veracidad, el comportamiento comunicativo asiático, caracterizado por las formas indirectas y la relatividad de las afirmaciones, presenta comúnmente lo que podría considerarse como un incumplimiento de esta máxima. Así, por ejemplo, como relata Miquel Rodrigo Alsina (1999:97), "Como me decía un compañero japonés: «Cuando un japonés dice sí, no siempre significa sí»".
} 
identificadas, les demos la interpretación adecuada. Por el contrario, normalmente no apreciamos las diferencias existentes en cuanto al uso y la interpretación del lenguaje no verbal, quizás por el carácter más natural, espontáneo y sutil del que algunos autores denominan "the silent language" (Hall, 1959; Samovar y Porter, 1991; Jandt, 1995). De hecho, los usos no verbales que empleamos al comunicarnos, la mayoría de las veces, no se emplean ni identifican de manera consciente $y$, además, como afirman Myron W. Lustig y Jolene Koester (2010:219), son específicos de cada cultura.

The rules and norms that govern most nonverbal communication behaviors are both culturespecific and outside of conscious awareness. That is, although members of a culture know and follow their culture's expectations, they probably learned the norms for proper nonverbal expressiveness very early in childhood, and these norms may never have been articulated verbally. Sometimes, therefore, the only way you will know that a cultural norm exists is when you break it!

Así, por ejemplo, resultaría difícil decir quién y cómo nos han enseñado a colocarnos a una cierta distancia de nuestro interlocutor cuando hablamos; sin embargo, respetamos esta distancia y, si alguien la sobrepasa (por exceso o por defecto), provoca en nosotros cierta incomodidad. Se trata, por lo tanto, de una dimensión inconsciente y difícil de distinguir.

A pesar de este carácter inconsciente que presenta la comunicación no verbal, esta es tanto o más relevante que la comunicación verbal por lo que respecta a la transmisión de mensajes y significados, y está intrínsecamente ligada a los elementos verbales de la comunicación. Como afirma Flora Davis (2010:16),

[...] la comunicación no verbal es más que un simple sistema de señales emocionales y en realidad no puede separarse de la comunicación verbal. Ambas están estrechamente vinculadas entre sí, ya que cuando dos seres humanos se encuentran cara a cara se comunican simultáneamente a muchos niveles, conscientes e inconscientes.

Si bien, tal y como sostienen algunos autores, es posible hablar de comportamientos universales en relación con el lenguaje no verbal, ${ }^{64}$ las diferencias culturales por lo que se refiere a los usos no verbales, de acuerdo con Mark L. Knapp (1982:76), se manifiestan en "el momento en que la conducta se presenta, la frecuencia con la que aparece y las reglas de ejecución que la acompañan". Estas diferencias no son innatas, sino que se aprenden en el seno de la comunidad en la que crecemos. Como sostiene Sheila Ramsey (1979, citada en Lustig y Koester, 2010:198),

[...] according to culturally prescribed codes, we use eye movement and contact to manage conversations and to regulate interactions; we follow rigid rules governing intra and interpersonal touch, our bodies synchronously join in the rhythm of others in a group, and gestures modulates our speech. We must internalize all this in order to become and remain fully functioning and socially appropriate members of our culture.

Podemos dividir el análisis de los usos no verbales del lenguaje en tres áreas, de las que nos ocupamos a continuación: la distribución temporal, la distribución espacial y el paralenguaje.

\footnotetext{
${ }^{64}$ Al respecto, véase por ejemplo la obra de Paul Ekman, Wallace V. Friesen y Phoebe Ellsworth (1972), en la que se afirma que determinadas expresiones faciales tienen un significado (felicidad, miedo, sorpresa, etc.) que puede ser reconocido en casi cualquier parte del mundo.
} 


\section{Distribución del tiempo}

Las intervenciones de los distintos interlocutores que participan en una interacción comunicativa se distribuyen a lo largo del tiempo que esta dura, dependiendo, entre otros factores, de la relación social que se establece entre dichos interlocutores.

Así, los intercambios comunicativos pueden variar en cuanto a la duración global y de las distintas secuencias de los mismos, la distribución de los turnos de palabra, y las características de la transición entre estos turnos. Durante la conversación, pueden producirse, por tanto, más o menos silencios, interrupciones o solapamientos entre una y otra intervención. Asimismo, la distribución de los turnos de palabra puede ser libre o predeterminada por uno o por ambos interlocutores.

Todos estos elementos relacionados con la distribución temporal de la conversación están determinados por la cultura a la que pertenecemos, y las diferencias al respecto pueden ser fuente de malentendidos o conflictos en los encuentros interculturales, ya que

We each take our time system for granted and project it onto other cultures. When this happens, we fail to read the hidden messages in the foreign time system, and thereby deny ourselves vital feedback. (Hall y Hall, 1990:23)

\section{Distribución del espacio}

Toda interacción comunicativa se desarrolla en un espacio determinado dentro del cual se organizan los interlocutores. Dentro de esta distribución espacial, que transmite determinados valores sociales, podemos distinguir entre los elementos macroespaciales (distribución global, objetos presentes en el contexto en el que se desarrolla la conversación, vestimenta de los interlocutores, etc.), y los elementos microespaciales (relacionados con el cuerpo de los participantes, como, por ejemplo, la distancia entre los mismos, la postura, el contacto físico, el contacto visual, los gestos o las expresiones faciales). ${ }^{65}$

Dependiendo de la cultura comunicativa a la que pertenezcamos, así como de otros factores más específicos, como la situación, el contexto o la relación entre los interlocutores, en una determinada interacción se considerará "aceptable" que se mantenga una mayor o menor distancia entre los participantes, que estos se miren o no a los ojos, que recurran más o menos frecuentemente a la expresión mediante gestos, que exista o no exista entre ellos contacto físico, etc.

Como ocurre con otros elementos del lenguaje no verbal, el carácter inconsciente y anclado en la cultura de la distribución espacial conlleva una incomprensión de aquellos comportamientos que se alejan del modelo propio. Así, como comentan Edward T. Hall y Mildred R. Hall (1990:14),

All human beings learn literally hundreds of spatial cues as they mature. The meaning of these spatial cues is learned in the context of their own culture. [...] When people travel and experience how space is handled in other parts of the world, the startling variations they

\footnotetext{
${ }^{65}$ Las disciplinas que se encargan del estudio de estos elementos son la kinesia y la proxemia. La primera se ocupa de analizar el lenguaje corporal (gestos, contacto visual, expresiones faciales, etc.), mientras que la segunda se centra en el empleo y la percepción que el ser humano tiene de su espacio físico.
} 
encounter release a visceral response. Since most people don't think about space as being culturally patterned, foreign spatial cues are often misinterpreted and can lead to bad feelings.

\section{Paralenguaje}

Cuando hablamos de paralenguaje, nos referimos al "conjunto de características sonoras que se desarrollan a lo largo de las interacciones y que cumplen funciones comunicativas no específicamente gramaticales o referenciales" (Raga, 2003:42).

Dentro de los elementos paralingüísticos, se incluyen cualidades primarias de la voz (como el timbre y el tono), calificadores (características sonoras dependientes del control del aire que modifican segmentos de habla), diferenciadores (sonidos producidos habitualmente de manera involuntaria y que pueden acompañar o no al habla, entre los que se incluyen los producidos al llorar, reír, bostezar, toser, suspirar, etc.), y alternantes (sonidos que, al contrario que los anteriores, se suelen producir voluntariamente y presentan carácter onomatopéyico) (Poyatos, 1994, citado en Raga, 2006a:29-30).

Como sucede en el caso de los aspectos relacionados con la distribución temporal y aquellos relativos a la distribución espacial, las características paralingüísticas que emplean los interlocutores representan valores sociales aplicados a los mismos, y se darán de un modo similar o diferente y con un grado variable de énfasis dependiendo de la cultura comunicativa propia de dichos interlocutores.

\subsubsection{Modelos y estilos comunicativos}

Como hemos comentado en el anterior apartado, los usos verbales y no verbales del lenguaje varían de una cultura a otra y transmiten una serie de valores sociales compartidos y entendibles en el seno de una determinada comunidad, estableciendo lo que se conocen como modelos conversacionales o comunicativos.

Con respecto a los modelos que presentan las diferentes culturas, se han propuesto diferentes clasificaciones y taxonomías, de entre las cuales, nos hemos centrado, en concreto, en las planteadas por Edward T. Hall (1976), Geert H. Hofstede (1991), y Francisco Raga (2006a). En ellas se definen y categorizan los patrones comunicativos y culturales (así como la interrelación entre dichos patrones) que caracterizan a las distintas comunidades de hablantes. En nuestra opinión, las tres propuestas son igualmente válidas para los fines de nuestra investigación y se complementan entre sí.

En primer lugar, antes de analizar estas taxonomías, cabe señalar, por una parte, que las características del modelo conversacional adoptado dentro de una misma cultura pueden variar dependiendo de la situación comunicativa concreta, y que cada individuo, asimismo, presenta un estilo comunicativo propio que no tiene por qué coincidir plenamente con el estilo del resto de miembros de su comunidad.

\section{Las culturas de alto y bajo contexto (Edward T. Hall)}

De acuerdo con la clasificación propuesta por el antropólogo Edward T. Hall (1976), quien diferencia entre culturas de alto y bajo contexto, el modelo comunicativo de cada comunidad presentará unas características determinadas dependiendo de una mayor aproximación a uno 
u otro tipo de cultura. Esta clasificación se basa en la proporción de elementos (verbales y no verbales) que se necesitan en cada cultura para transmitir un mensaje concreto.

En una comunicación de bajo contexto, en la que incluiríamos a la cultura española, la mayor parte de la información se encuentra en el mensaje verbal, primando más la claridad en dicho mensaje y el estilo directo y funcional, que la información transmitida por el lenguaje no verbal o el contexto y la relación entre los interlocutores. Por lo general, en este tipo de cultura, los mensajes se transmiten de forma explícita, y la expresión de las reacciones y los sentimientos resulta bastante visible. ${ }^{66}$ Asimismo, el objetivo principal del acto comunicativo en una cultura de bajo contexto consiste en el intercambio de información y de opiniones, que se suelen presentar claramente, aunque no coincidan con las del interlocutor.

Por el contrario, en una comunicación de alto contexto, propia de algunas culturas colectivistas presentes en Asia o África, la comunicación no verbal (la postura, los gestos y expresiones faciales, etc.) adquiere una gran importancia, y se sigue un modelo comunicativo indirecto $\mathrm{y}$, generalmente, formal; más que en las palabras pronunciadas, el significado se encuentra en el contexto y en las relaciones existentes entre los interlocutores. Por ello, habitualmente los mensajes son implícitos, y se recurre con frecuencia a las metáforas. Además, las reacciones y sentimientos no se suelen expresar enfáticamente y, como el objetivo que se persigue al establecer la comunicación es normalmente formar y desarrollar relaciones y promover la armonía, las opiniones discordantes, por lo general, no se plantean de forma abierta. De ahí que, como comentábamos anteriormente, en ocasiones se incumpla la máxima de la veracidad y se recurra a las conocidas como mentiras sociales, en señal de respeto o halago hacia el interlocutor.

Así, tal y como ilustran Myron W. Lustig y Jolene Koester (2010:110), podría compararse la comunicación entre personas de una cultura de alto contexto con aquellas situaciones en las que entablamos una conversación sobre un tema que nos resulta muy familiar tanto a nosotros como a nuestros interlocutores y, por tanto, no debemos ser demasiado explícitos ni específicos para hacer comprender las ideas que deseamos transmitir. Por el contrario, la comunicación entre personas de una cultura de bajo contexto se asemejaría a aquella que se establece entre dos interlocutores que no presentan el mismo grado de familiaridad con el tema del que se está hablando y, en consecuencia, se deberá ofrecer más información (especialmente de carácter verbal), y esta deberá ser precisa y específica, con el fin de que la persona que no presenta amplios conocimientos sobre el tema logre entender lo que se está diciendo.

Esta clasificación entre culturas de alto y bajo contexto es apoyada por otros autores, como Miquel Rodrigo Alsina (1999:97), quien sostiene que

La forma de comunicación occidental es directa y explícita. Lo importante del mensaje es el contenido, lo que se dice y las afirmaciones que contiene. Los occidentales pretenden convencer a los oyentes por medio de la razón, [...] Mientras que los occidentales empiezan la

\footnotetext{
${ }^{66}$ Uno de los investigadores que más ha profundizado en el estudio de la manifestación de los sentimientos, las emociones y las reacciones a través de las expresiones faciales, y las diferencias culturales al respecto, ha sido el psicólogo Jerry D. Boucher, quien cuenta con numerosas publicaciones sobre este tema (entre otras, 1969, 1971, 1974, 1979).
} 
comunicación con un objetivo claro, para los asiáticos el intercambio emocional, el estar juntos, el placer de la comunicación son igualmente importantes. [...] En Oriente la comunicación es más indirecta e implícita, la forma de comunicarse es muy importante y las afirmaciones que se hacen son relativas.

Si bien cabe recordar que las culturas son interiormente plurales y que el modelo conversacional adoptado podrá variar en función de cada individuo y de cada situación comunicativa, podríamos clasificar las diferentes culturas en un continuum que se acerca más o menos a los modelos de alto o bajo contexto propuestos por Edward T. Hall, tal y como puede observarse en la figura que presentamos a continuación:

Culturas de ALTO CONTEXTO

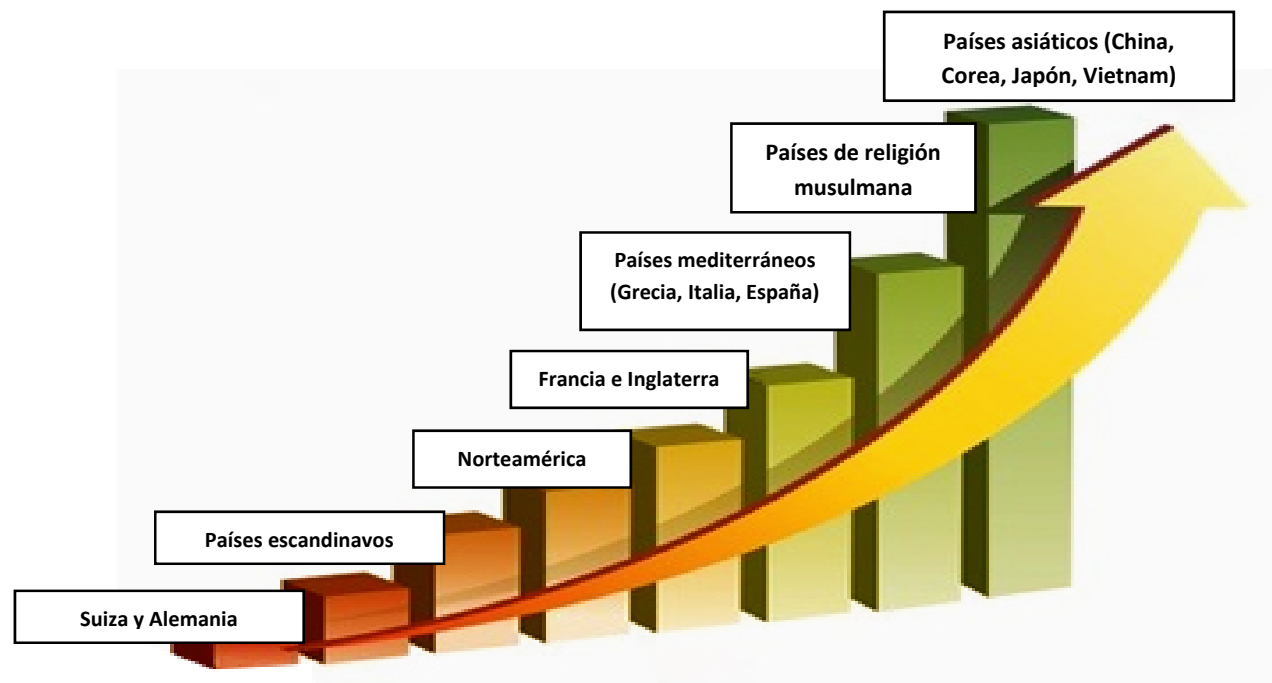

Culturas de BAJO CONTEXTO

Gráfico 3.1. Continuum de las culturas de alto y bajo contexto (elaboración propia)

Cuando se instaura la comunicación entre personas que pertenecen a culturas muy lejanas en esta escala, es bastante probable que se produzcan sentimientos de malestar provocados por el hecho de que el interlocutor presenta un comportamiento comunicativo diferente al esperado de acuerdo con sus propios patrones. Así, por ejemplo, tal y como sostiene el propio Edward T. Hall (1959:10-11),

$\mathrm{HC}$ (high-context) people are apt to become impatient and irritated when LC (low-context) people insist on giving them information they don't need. Conversely, low-context people are at loss when high-context people do not provide enough information.

\section{Modelo de las Cinco Dimensiones (Geert H. Hofstede)}

Las diferencias culturales, de acuerdo con Geert H. Hofstede (1991), se expresan a través de los valores o patrones dominantes que los miembros de una determinada comunidad desarrollan desde su infancia y van reforzando durante su enculturación. ${ }^{67}$

\footnotetext{
${ }^{67}$ Por enculturación (o endoculturación), entendemos el proceso de aprendizaje cultural (consciente e inconsciente) mediante el cual las personas que viven en el seno de una determinada comunidad van haciendo gradualmente
} 
Esos valores o patrones culturales, que determinarán la prevalencia de unos determinados comportamientos sociales, pueden clasificarse de acuerdo a las cinco dimensiones que mostramos en el gráfico que incluimos a continuación:

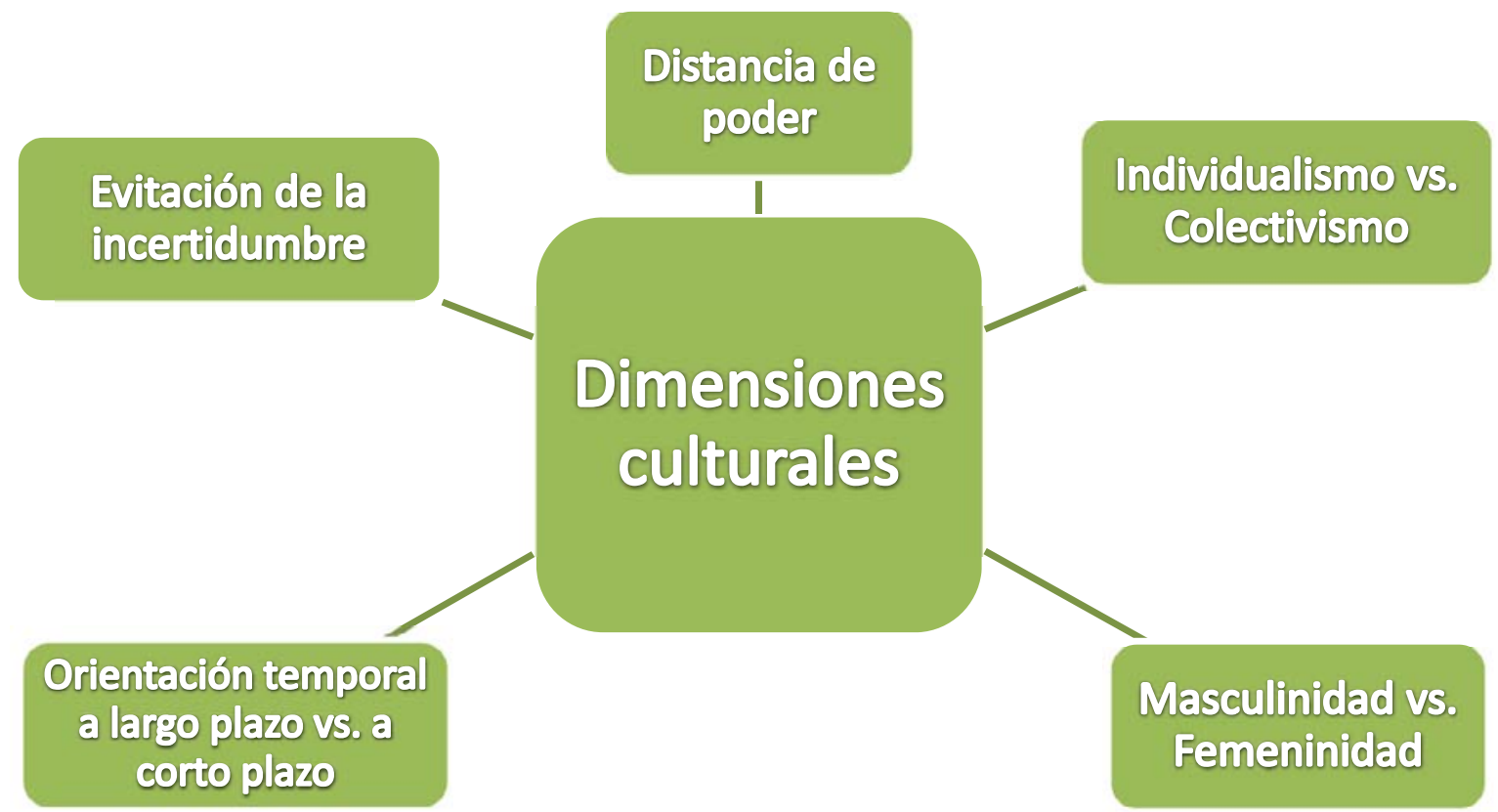

Gráfico 3.2. Modelo de las cinco dimensiones de Hofstede (elaboración propia)

Por lo que respecta a la distancia de poder, cabe señalar, en primer lugar, que en todas las culturas se establecen diferencias de estatus o poder social entre sus miembros. Así, dependiendo de la cultura determinada, algunas personas se considerarán superiores de acuerdo con diversas variables, como puede ser el origen familiar, el sexo, la edad, la educación, la profesión, etc. Igualmente, las culturas difieren en su percepción de estas desigualdades sociales como algo positivo y justo o negativo e injusto, y darán mayor o menor importancia al establecimiento de estatus y jerarquías.

En las culturas en las que las distancias sociales son menores, entre las que se encuentran, por ejemplo, países como Austria, Dinamarca, Israel o Nueva Zelanda, se suele minimizar la importancia de las desigualdades sociales o de clase, las estructuras organizativas jerárquicas no son muy frecuentes, y se admiten las contradicciones o desafíos a las figuras de autoridad. Por el contrario, en las culturas que prefieren mantener grandes distancias sociales, como Filipinas, Guatemala o Malasia, se sostiene que cada persona debe ocupar un lugar concreto en la escala social, que las desigualdades y las jerarquías son no solo apropiadas, sino también beneficiosas, y que las personas que ostentan el poder tienen derecho a usarlo del modo y con la intención que consideren más adecuados y no deben ser cuestionadas.

Las distancias de poder que se mantengan en cada cultura determinarán el comportamiento y el lenguaje empleado por los miembros de dicha cultura, así como las relaciones establecidas entre los mismos. De esta manera, tal y como afirman Myron W. Lustig y Jolene Koester (2010:114),

suyo un sistema de significados y símbolos que les ayuda a guiar su comportamiento y sus percepciones, y que emplean para definir su mundo, expresar sus sentimientos y hacer sus juicios (Kottak, 2003:22). 
The consequences of the degree of power distance that a culture prefers are evident in family customs, the relationships between students and teachers, organizational practices, and in other areas of social life. Even the language systems in high power-distance cultures emphasize distinctions based on social hierarchy.

Por consiguiente, a modo de ejemplo de la aplicación de estos valores en la elección de un determinado modelo comunicativo, podemos decir que, en las culturas donde la distancia de poder sea mayor, no se desafiará a las personas que ostenten la autoridad, realizándoles demasiadas preguntas o contradiciéndoles, y serán estas personas las que comúnmente establezcan la distribución de los turnos de palabra. Asimismo, es posible que, en dichas culturas, se indique explícitamente mediante el lenguaje empleado qué posición social ocupa cada uno de los interlocutores que participan en una determinada interacción comunicativa. ${ }^{68}$

En cuanto a la evitación de la incertidumbre, si bien esta provoca en todos los seres humanos, en mayor o menor medida, una cierta ansiedad, los miembros de las distintas culturas presentan diferencias en cuanto al modo de enfrentarse a las situaciones inciertas y con respecto a la capacidad de adaptación a los cambios.

En consecuencia, en determinadas culturas, como en Francia o los Estados Unidos, se tolera o incluso se prefiere la ambigüedad, mientras que, en otras, como Irlanda o Suecia, se genera ante la misma un sentimiento de amenaza, y se trata de evitar la incertidumbre mediante el establecimiento de estructuras, reglas y rituales. En las primeras, por consiguiente, se admitirá y se incentivará la expresión de ideas contrarias a las del interlocutor, se asumirán mayores riesgos, y no se tendrá inconveniente en probar nuevas experiencias. Por el contrario, en las segundas, no se tolerarán las expresiones de disenso, y se considerarán negativamente las desviaciones de lo que se considere socialmente aceptable.

Por lo que atañe a la comunicación, podemos afirmar que los modelos conversacionales de las culturas más preocupadas por la incertidumbre presentarán probablemente patrones comunicativos ritualizados, donde cada interlocutor actuará del modo en que, de acuerdo con la situación y la relación entre los interlocutores, se espera que actúe.

En referencia a las relaciones que establecen los miembros de una determinada comunidad en el seno de la misma y al grado en que la autonomía del individuo se ve favorable o desfavorablemente, podemos hablar de culturas individualistas o colectivistas. Las sociedades occidentales, como por ejemplo, Austria, Bélgica o los Estados Unidos, se caracterizan por conceder una gran importancia al individuo, mientras que, en Oriente y, más concretamente en países como Indonesia o Paquistán, por lo general, la identidad de cada individuo se basa en su pertenencia a un grupo, por lo que el énfasis recae sobre la colectividad. Así, tal y como sostiene Miquel Rodrigo Alsina (1999:97), "los occidentales están orientados hacia el «yo», y los asiáticos hacia el «nosotros»". (comillas del original)

Del mismo modo, en las culturas en las que predomina el colectivismo, las decisiones se basarán en lo que se considere más positivo para el propio grupo (the ingroup), y se

\footnotetext{
${ }^{68}$ Por ejemplo, como reflejo de la importancia concedida a las distancias de poder en Corea, en coreano se emplean términos diferentes para referirse a las personas dependiendo de factores como su estatus social o el grado de confianza que se tiene con ellas (Jandt, 2010:40).
} 
establecerá una gran distancia con respecto a aquellos que pertenecen a otros grupos (the outgroup), mientras que en las que prevalece el individualismo, las decisiones dependerán de los intereses de cada individuo, y no se percibirán diferencias notables en las distancias entre los miembros del mismo u otros grupos.

El hecho de que una cultura presente patrones dominantes más orientados hacia el individualismo o hacia el colectivismo también influirá en los modelos conversacionales empleados por los miembros de dicha cultura. De este modo, tal y como sostienen Myron W. Lustig y Jolene Koester (2010:118),

[...] people from individualistic cultures are more likely than those from collectivistic cultures to use confrontational strategies when dealing with interpersonal problems; those with collectivistic orientation are likely to use avoidance, third-party intermediaries, or other facesaving techniques.

La pertenencia a una cultura más individualista o más colectivista puede reflejarse también en otros patrones comunicativos, como el uso y la interpretación de los silencios. Así, por ejemplo, en países en los que predomina el colectivismo, como la India, el silencio se emplea para fomentar la armonía y la cooperación, y es un símbolo de sensibilidad, respeto mutuo, dignidad personal y sabiduría. Por el contrario, en países típicamente individualistas, como pueden ser los Estados Unidos, el silencio se interpreta como falta de atención o de iniciativa, y se espera que el interlocutor demuestre su interés en la conversación hablando (Jandt, 2010:119).

Por otro lado, cada cultura asigna unos determinados roles a las personas dependiendo de su sexo. Asimismo, algunas culturas valoran más positivamente los comportamientos considerados "masculinos", como podría ser la asertividad, frente a los "femeninos", como, por ejemplo, el apoyo social. Podemos hablar, por consiguiente, de culturas femeninas y culturas masculinas.

En las primeras, entre las que se encuentran países como Chile, Portugal o Tailandia, no se persiguen los logros personales, sino que se concede importancia a valores y comportamientos "típicamente femeninos", como la compasión o el servicio a la comunidad. En estas culturas, se muestra preferencia por la equidad entre los sexos, y los roles atribuidos a hombres y mujeres no están tan predeterminados. Por el contrario, en las segundas, entre las que figuran países como Austria, Italia, Japón o México, es habitual la ostentación, los roles de los diferentes sexos están claramente definidos, y se consideran positivamente las desigualdades entre los mismos.

Podemos deducir, por tanto, que, en las culturas masculinas, probablemente el modelo conversacional empleado por hombres y mujeres presentará evidentes diferencias, mientras que estas serán más sutiles en las culturas femeninas.

El último elemento presente en las dimensiones culturales propuestas por Geert H. Hofstede se refiere a la orientación temporal. De acuerdo con esta dimensión, existen culturas más orientadas a largo plazo y culturas más orientadas a corto plazo. En las primeras, entre las que se encuentra, por ejemplo, China, se admira la persistencia y la humildad, y se clasifica y respeta a las personas de acuerdo con factores como su mayor edad. Por el contrario, en las 
segundas, representadas por la mayoría de los países europeos, se esperan resultados rápidos como consecuencia de las propias acciones.

Esta orientación, como sucede con el resto de dimensiones anteriormente presentadas, influirá en el lenguaje y en el modelo comunicativo de cada cultura. Así, por ejemplo, en algunas culturas orientadas temporalmente a largo plazo se harán distinciones lingüísticas entre los hermanos dependiendo de su orden de nacimiento.

Antes de pasar a analizar la siguiente propuesta de modelos conversacionales, quisiéramos concluir, por una parte, que las culturas más similares por lo que respecta a las dimensiones planteadas por Geert H. Hofstede probablemente presentarán patrones comunicativos semejantes $y$, en principio, la comunicación intercultural entre los miembros de las mismas será menos susceptible de presentar dificultades o malentendidos.

Por otra parte, cabe señalar que existen diferencias en cuanto a las dimensiones tanto dentro de una misma cultura como en las culturas geográficamente próximas $y$, por tanto, no se deberían realizar generalizaciones por zonas o regiones, como Latinoamérica u Oriente Medio.

\section{Clasificación de los modelos comunicativos (Francisco Raga)}

Como hemos señalado previamente, los mensajes intercambiados en toda interacción comunicativa transmiten valores sociales. De entre dichos valores, Francisco Raga (2006a) se centra en dos de ellos para elaborar la clasificación de modelos comunicativos que propone. En concreto, su propuesta se basa en el grado de igualdad y el grado de preocupación por el conflicto que presentan las diferentes culturas. Partiendo de estos parámetros, establece una clasificación que se divide, por un lado, en el modelo "próximo" (que se da en las culturas con una escasa preocupación por evitar o resolver los conflictos) en contraposición con el modelo "distante" (propio de las culturas en las que la preocupación por el conflicto es alta) y, por otro lado, en el modelo "simétrico" (habitual en las culturas en las que existe igualdad entre sus miembros), que se opone al modelo "asimétrico" (que está presente en aquellas culturas en las que son comunes las desigualdades y jerarquías sociales).

Cabe señalar que, al igual que ocurría con las propuestas de Edward T. Hall y de Geert H. Hofstede analizadas previamente, tampoco es posible entender esta clasificación de manera categórica, sino que los modelos planteados suponen dos extremos de una escala, en la que se van situando las diferentes culturas de acuerdo con la mayor o menor aproximación a uno u otro modelo, configurando un continuum. Asimismo, factores como la situación comunicativa concreta o la relación entre los interlocutores (junto con elementos de tipo psicológico o emocional, más dependientes del individuo), conllevarán que existan variaciones dentro de una misma cultura en la adopción de un modelo determinado.

Una de las cuestiones que, en nuestra opinión, resultan más interesantes con respecto a esta propuesta, consiste en el hecho de que, para cada uno de los modelos planteados, se determinan las características relativas a los usos verbales y no verbales que serán más frecuentes. Así, por ejemplo, como puede verse en las tablas que incluimos a continuación, el modelo próximo se caracterizará, entre otros, por los siguientes patrones comunicativos: intercambio de información abundante; inclusión de temas personales o comprometidos; 
escaso recurso a las mentiras sociales; lenguaje directo; proximidad entre los interlocutores; y contacto físico y visual.

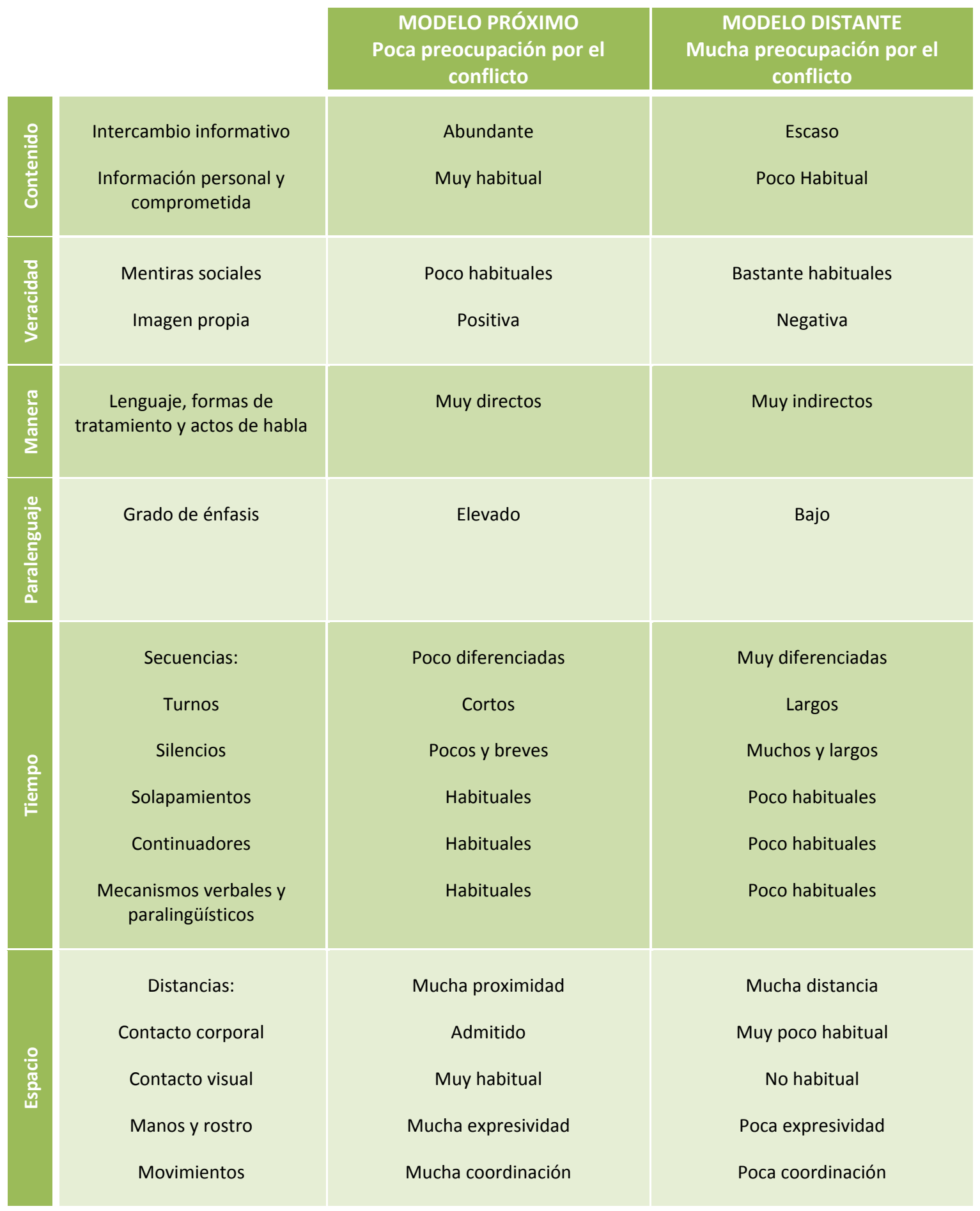

Tabla 3.1. Patrones comunicativos de los modelos próximo y distante (Raga, 2006a:35) 


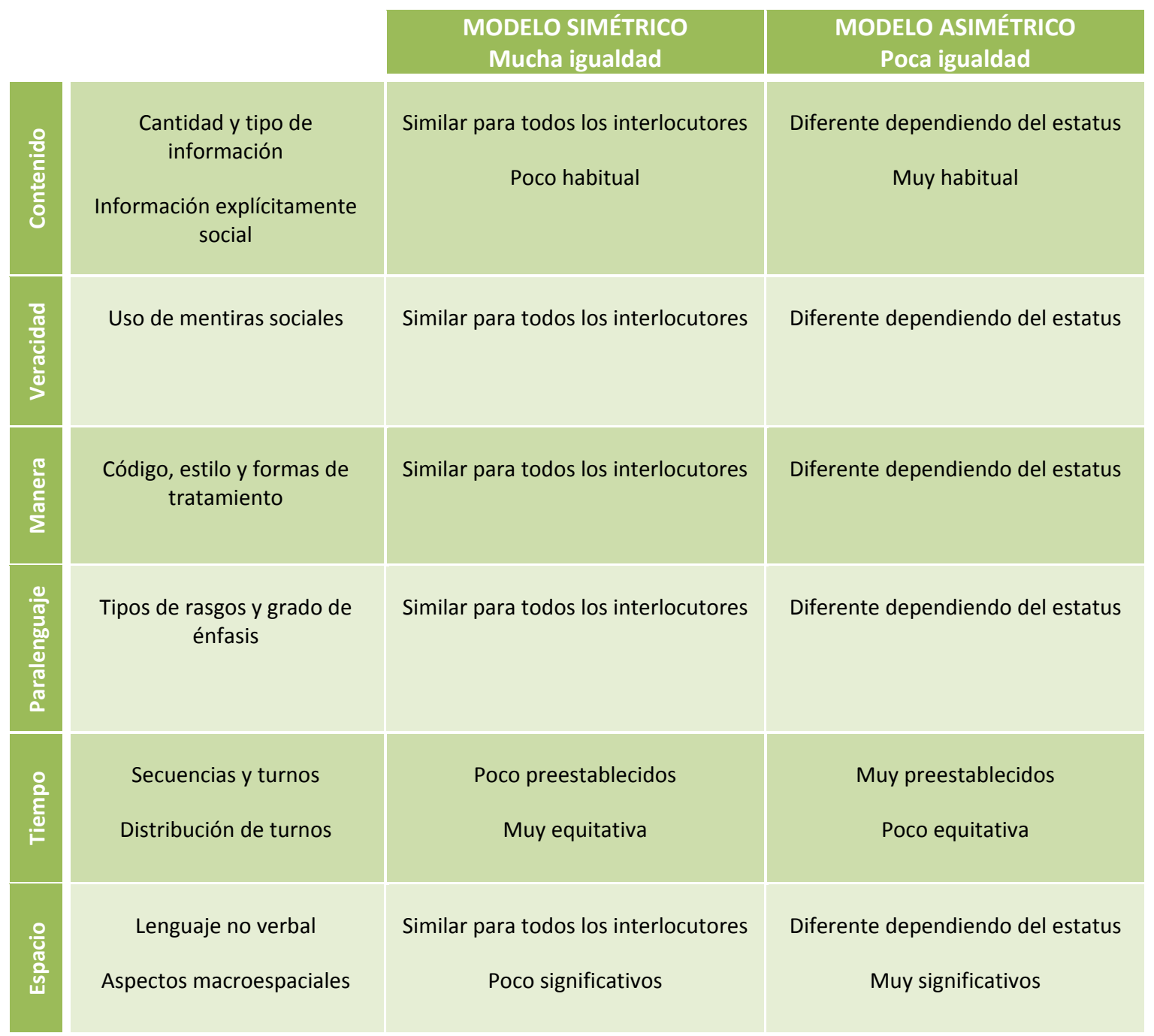

Tabla 3.2. Patrones comunicativos de los modelos simétrico y asimétrico (Raga, 2006a:36)

Cabe señalar que estos patrones incluidos en las tablas no se suelen aplicar de forma independiente, sino que, por lo general, dentro de cada cultura, en una determinada situación comunicativa, se aplica el mismo modelo por lo que respecta a los usos verbales y no verbales del lenguaje. Dicho en otras palabras, si el modelo predominante en una cultura concreta se encuentra a caballo entre el modelo distante y el próximo, los patrones comunicativos de dicha cultura no variarán de uno a otro extremo, sino que se manifestarán en su conjunto en un grado intermedio entre ambos modelos.

Partiendo de la idea de que esta doble clasificación presenta, en cierto sentido, puntos comunes ( $y$, así, por ejemplo, las culturas con mayor grado de igualdad suelen mostrar menor preocupación por el conflicto), Francisco Raga propone, además, la posibilidad de integrar todos los datos en una ulterior clasificación tetrapartita, que se corresponde con las cuatro combinaciones posibles entre los modelos presentados anteriormente. Así, establece cuatro posibles tipos de culturas:

Cultura tipo A: alto grado de igualdad y bajo grado de preocupación por el conflicto

Cultura tipo B: bajo grado de igualdad y alto grado de preocupación por el conflicto 
Cultura tipo C: alto grado de igualdad y alto grado de preocupación por el conflicto

Cultura tipo D: bajo grado de igualdad y bajo grado de preocupación por el conflicto

\begin{tabular}{|c|c|c|}
\hline & $\begin{array}{l}\text { - PREOCUPACIÓN POR EL } \\
\text { CONFLICTO }\end{array}$ & $\begin{array}{l}\text { + PREOCUPACION POR EL } \\
\text { CONFLICTO }\end{array}$ \\
\hline + IGUALDAD & $\begin{array}{l}\text { Cultura A } \\
\text { Cultura mediterránea septentrional } \\
\text { Cultura caribeña }\end{array}$ & $\begin{array}{l}\text { Cultura C } \\
\text { Culturas indígenas de América del } \\
\text { Norte } \\
\text { Culturas aborígenes australianas }\end{array}$ \\
\hline - IGUALDAD & $\begin{array}{l}\text { Cultura D } \\
\text { Culturas de castas subsaharianas } \\
\text { Culturas árabes }\end{array}$ & $\begin{array}{l}\text { Cultura B } \\
\text { India } \\
\text { China }\end{array}$ \\
\hline
\end{tabular}

Tabla 3.3. Clasificación tetrapartita de los modelos comunicativos (Raga, 2006a:38-39)

Si bien, tal y como puede observarse en la tabla que acabamos de mostrar, hay culturas que se aproximan más a un tipo determinado $(A, B, C \circ D)$ de los propuestos, no podemos hablar de culturas "puras" o "ideales", totalmente identificadas con un tipo concreto, sino que la propuesta refleja cuatro extremos de una escala en la que se situarán las distintas culturas según su aproximación a uno u otro tipo. Cabe, además, recordar, que las culturas son internamente plurales y heterogéneas, por lo que sus miembros no presentarán obligatoriamente los mismos conceptos de igualdad y conflicto y, por tanto, podrán aplicar diferentes patrones y modelos comunicativos. Asimismo, el contexto y la situación en los que se desarrolle la interacción determinarán que se sigan en mayor o menor medida los patrones asociados a un tipo de cultura en particular. Por ejemplo, en situaciones muy formales, incluso los miembros de las culturas de tipo A aumentarán su preocupación por el conflicto y la distancia social entre los interlocutores. Del mismo modo, en situaciones más íntimas, en las que exista una gran confianza entre los interlocutores, los miembros de culturas de tipo B se relajarán, no estarán tan (social y físicamente) distanciados, y no se mostrarán tan preocupados por evitar el conflicto.

Para finalizar, antes de pasar a analizar detalladamente las barreras que pueden surgir en la comunicación intercultural, quisiéramos de nuevo señalar que, cuanto mayores sean las diferencias en los usos verbales y no verbales y en los modelos comunicativos propios de las culturas de las personas implicadas en la interacción, y cuanto mayor sea el desconocimiento mutuo, más probabilidades habrá de que surjan malentendidos y conflictos durante el intercambio comunicativo.

\subsection{Barreras que dificultan o impiden la comunicación en los encuentros interculturales}

En las páginas previas hemos descrito la forma en que cada cultura presenta un modelo y unos patrones comunicativos, los cuales se basan en un conjunto de normas que comparten los miembros de una comunidad y que les guían a la hora de comunicarse entre ellos. Partiendo de la base de que resulta imposible que una persona aprenda las normas que rigen la aceptabilidad de determinados comportamientos comunicativos en todas las culturas con las que podría entrar en contacto, podemos afirmar que es bastante probable que, en las interacciones interculturales, los hablantes incumplan dichas normas, y este incumplimiento 
constituirá la barrera principal para que se produzca una comunicación efectiva (Jandt, 2010:81).

Sin embargo, antes incluso de iniciar la comunicación, los participantes en un encuentro intercultural se toparán con un obstáculo importante. En concreto, se trata del sentimiento de ansiedad que genera el enfrentamiento con lo desconocido, del cual se han ocupado diferentes autores del ámbito de la comunicación intercultural (Gudykunst, 1983; Barna, 1997; ${ }^{69}$ Hammer, Bennett y Wiseman, 2003). Dicho sentimiento puede comprometer desde un principio el éxito de la comunicación; en otras palabras, "when you are anxious because of not knowing what you are expected to do, it is only natural to focus on that feeling and not be totally present in the communication transaction" (Jandt, 2010:82).

La primera barrera que percibimos ya una vez iniciamos la comunicación con personas de otros países y culturas suele ser la barrera lingüística, apreciada principalmente por la ausencia de una lengua común. No obstante, esta barrera está conformada también, como hemos visto, por las diferencias en relación con el uso y la interpretación del lenguaje verbal y no verbal $y$, en sentido amplio, por la diversidad en los modelos conversacionales de los interlocutores.

A la dificultad que suponen las diferencias en los estilos y modelos comunicativos, se añade, frecuentemente, el desconocimiento del Otro, o incluso en ocasiones la propia ignorancia o negación de la existencia de posibles diferencias. Como sostiene Fred E. Jandt (2010:83), cuando no disponemos de información sobre una cultura determinada, "it might make sense to assume that there are no differences, to behave as you would in your home culture. But making that assumption could result in miscommunication".

Igualmente, ante la mencionada diversidad en los modelos comunicativos, a menudo adoptamos una posición etnocentrista, y consideramos nuestro modelo algo lógico y normal, o el mejor de los modelos existentes; como afirma Edward T. Hall (1966, citado en Raga, 2006a:40), tendemos a hacer de nuestro modelo "un modelo moral universal". En consecuencia, interpretamos el comportamiento de nuestro interlocutor desde nuestra propia cultura comunicativa, elaborando a menudo juicios de valor negativos con respecto a dicho comportamiento. El etnocentrismo, llevado a su extremo, conlleva un rechazo de la riqueza que supone la diversidad cultural, impide la comunicación y bloquea el intercambio de ideas entre culturas; al excluir los puntos de vista ajenos, la posición etnocentrista es restrictiva y limitante (Jandt, 2010:86).

No obstante, si aceptamos el hecho de que todas las culturas son igualmente válidas y merecedoras de respeto e igualmente imperfectas y sujetas a críticas y cambios, llegaremos a la conclusión de que "la única forma de comprender correctamente las culturas es interpretar

\footnotetext{
${ }^{69}$ La selección y descripción de las barreras que dificultan o impiden la comunicación intercultural presentes en este apartado han sido elaboradas por nosotros mismos, basándonos en la literatura al respecto. Sin embargo, quisiéramos destacar, entre las diferentes propuestas relacionadas con este tema, la de LaRay M. Barna, pues creemos que describe de forma clara y concisa los principales obstáculos a los que pueden enfrentarse los participantes en un encuentro intercultural. En concreto, este autor plantea la existencia de seis barreras en la comunicación entre personas lingüística y culturalmente diversas: el sentimiento de ansiedad, la presunción de semejanzas en lugar de diferencias, el etnocentrismo, los prejuicios y estereotipos, los malentendidos o interpretaciones erróneas de los elementos no verbales, y las diferencias lingüísticas.
} 
sus manifestaciones de acuerdo con sus propios criterios culturales" (Rodrigo Alsina, 2000:2), lo cual no implica que eliminemos nuestro juicio crítico, pero sí que, al menos inicialmente, lo dejemos en suspenso, hasta que hayamos comprendido la complejidad simbólica de las prácticas culturales ajenas.

Asimismo, cabe considerar que, cuando nos comunicamos, también negociamos nuestras relaciones con los otros, construimos nuestra identidad y la de nuestros interlocutores, transmitimos una imagen propia, y percibimos la de los demás participantes en la interacción. A menudo, encasillamos a nuestros interlocutores en imágenes preconcebidas e injustificadas, normalmente basadas en el desconocimiento y en generalidades sobre la cultura a la que pertenecen. Así, al relacionarnos con personas de otras culturas, solemos emplear estereotipos $^{70}$ y prejuicios, $^{71}$ los cuales nos permiten explicar realidades para nosotros desconocidas, mediante un ejercicio de economía mental consistente en la generalización.

Los estereotipos y prejuicios son también fuente de malentendidos y conflictos, y quienes los formulan no tienen en cuenta dos aspectos fundamentales: por un lado, las culturas son interiormente plurales, dinámicas y cambiantes, y no es posible establecer generalizaciones sobre las mismas, ya que "se construyen gracias a la interacción de los seres humanos, por lo que siempre están en proceso de construcción" (Oliver, 2002:22); por otro, las personas son ante todo individuos, con una identidad personal que se va formando a lo largo de su vida, por lo que no debemos caracterizarlas atendiendo solamente a su comunidad de origen. En relación con esta idea, cabe citar las palabras de Miquel Rodrigo Alsina (1999:69), quien sostiene que no existen culturas homogéneas, puras o "no contaminadas", sino que,

Aunque una persona nace en una comunidad de vida, las sociedades modernas se caracterizan por un pluralismo cultural que hace difícil establecer cuáles son las fronteras culturales o los criterios de diferenciación cultural.

Otra de las barreras que dificultan la comunicación intercultural está constituida por el sobredimensionamiento de las diferencias que nos separan de nuestro interlocutor. Esta actitud constituye el extremo opuesto de las presentadas hasta ahora, pues en ella no se ignoran las diferencias ni se trata de imponer un modelo único basado en los patrones de la propia cultura, sino que se concede una importancia excesiva a la diversidad cultural. Si bien dichas diferencias existen, debemos evitar la tendencia a poner el acento en las mismas, olvidándonos de los elementos que tenemos en común. Tal y como afirma Miquel Rodrigo Alsina (1999:12),

En muchas ocasiones, en los contactos interculturales caemos en la percepción selectiva de fijarnos sólo en las diferencias. [...] siempre hay la duda aceptable de que el sentido y el orden que se atribuyen a los acontecimientos pueden ser distintos para el interlocutor. Mientras que

\footnotetext{
${ }^{70}$ El término "estereotipo" fue empleado por primera vez por el periodista Walter Lippman en 1922 para describir los juicios aplicados a otras personas en base a su pertenencia a un grupo étnico determinado. Actualmente, el término se usa con un significado algo más amplio para referirse a juicios aplicados a los miembros de cualquier tipo de grupo, no solo el que está configurado por personas con un mismo origen étnico y cultural, sino también por lo que respecta a grupos de igual o semejante edad, sexo, profesión, etc. (Jandt, 2010:86)

${ }^{71}$ Los prejuicios se manifiestan en los sentimientos de desprecio, desconfianza o aversión hacia las personas de un determinado grupo, basados en su origen, religión, orientación sexual, etc. (Rothenberg, 1992, citado en Jandt, 2010:91). Una de las principales diferencias entre los prejuicios y los estereotipos consiste en que estos últimos pueden ser tanto positivos como negativos, mientras que los prejuicios siempre implican un sentimiento negativo.
} 
en la comunicación intracultural se podría sostener, de forma errónea, la comprensibilidad indudable de los discursos, en la comunicación intercultural se podría mantener el principio falso de la incomprensibilidad necesaria.

Para garantizar el éxito de la comunicación intercultural, no debemos, por consiguiente, negar la posible existencia de patrones distintos, sino relativizar su importancia y tratar de encontrar el sentido profundo que estos patrones poseen.

Entre las causas que pueden derivar en problemas o dificultades comunicativas, cabe también señalar que, al entablar una conversación intercultural, es posible que uno de los interlocutores se halle ante una situación comunicativa nueva, que no se le había planteado hasta el momento, por lo que probablemente desconocerá qué modelo conversacional debería seguir. En otras ocasiones, los interlocutores pueden enfrentarse a situaciones comunicativas conocidas por ambos, pero reguladas de forma diferente en sus culturas de origen.

Del mismo modo, es posible que los hablantes pertenecientes a diferentes comunidades atribuyan distintos valores a un mismo uso del lenguaje, guiándose por los patrones comunicativos que han adquirido en su comunidad de origen. Dichos patrones darán pautas a los participantes también a la hora de interpretar lo que su interlocutor dice o hace, lo que puede llevarles a realizar algunas inferencias erróneas sobre la situación comunicativa, que podrían no corresponderse con la intención de su interlocutor.

\subsubsection{Dificultades específicas de la comunicación intercultural en ámbito sanitario}

Aparte de las barreras que pueden dificultar o impedir la comunicación intercultural en general, dependiendo del contexto en el que se produce el intercambio comunicativo y las características concretas de los participantes, pueden añadirse ulteriores barreras a la comunicación. Tal es el caso del ámbito sanitario, ámbito central de nuestra investigación, de cuyas particularidades por lo que respecta a los intercambios comunicativos interculturales que en él tienen lugar nos ocupamos a continuación.

Las dificultades en la comunicación intercultural que se da en situaciones de carácter general pueden tener, como hemos señalado previamente, consecuencias negativas; sin embargo, coincidimos con Roberto Ortí, Dora Sales y Enric Sánchez (2007:118), cuando afirman que "si trasladamos esta situación al contexto de la sanidad, las consecuencias pueden ser mucho más graves".

Al hablar de los servicios y los profesionales sanitarios se hace referencia a realidades muy diferentes, con áreas específicas de intervención, pero que coinciden en gran parte de las dificultades encontradas al tratar con los usuarios procedentes de otros países y culturas. Dificultades que nacen, en principio, por la falta de una lengua común, ${ }^{72}$ y que se encuadran dentro de un complejo cuadro de malestar físico, psicológico y social, por lo que se generan inevitables sentimientos negativos recíprocos entre los usuarios y los profesionales del sector.

\footnotetext{
${ }^{72}$ Al respecto, cabe destacar que la barrera que se percibe de manera más patente y que señalan la mayoría de los participantes en nuestro estudio es, como veremos en el análisis de los resultados del trabajo de campo, la barrera lingüística, aquella que se produce por la ausencia de una lengua común entre los sujetos implicados.
} 
El principal requisito para garantizar la eficacia de cualquier interacción comunicativa, tal y como hemos comentado, es que los interlocutores compartan una misma lengua. ${ }^{73}$ En relación con esta cuestión, creemos conveniente recordar que, en España, de acuerdo con la Ley de Sanidad 14/1968, de 25 de abril, todo paciente tiene derecho a "que se le dé en términos comprensibles información completa y continuada, verbal y escrita, sobre su proceso, incluyendo diagnóstico, pronóstico y alternativas de tratamiento". Sin embargo, en los servicios sanitarios españoles, no siempre se emplean medidas adecuadas para eliminar las barreras comunicativas en los casos en los que los usuarios y los profesionales no comparten una misma lengua.

La ausencia de una lengua común y la consiguiente imposibilidad de establecer una comunicación eficaz compromete la calidad de la asistencia sanitaria, y genera tanto en los profesionales como en los usuarios sentimientos de incomodidad, ansiedad, frustración o estrés. La eliminación de dicha barrera lingüística podría, cuanto menos, facilitar la comunicación y la expresión de ideas y sentimientos por parte de ambas partes, aunque no resulta suficiente para garantizar la eficacia de las interacciones comunicativas e, incluso, a veces, la ausencia de esta barrera puede conllevar una excesiva confianza en la capacidad de comprensión del paciente alófono. Así, tal y como comentan Roberto Ortí, Dora Sales y Enric Sánchez (2007:128),

[...] el hecho de que no haya problemas de comunicación con el idioma hace que nos sintamos cómodos en la interacción y sobrevaloremos el nivel de dominio y de corrección gramatical de nuestro interlocutor, por lo que no veremos inconveniente en tratarlo como si debiera conocer, por ejemplo, el lenguaje técnico de la medicina, o preguntas o frases de léxico complejo en español, justo lo contrario de lo que espera el paciente: un lenguaje claro y sencillo.

Antes de pasar a analizar las dificultades específicas que se plantean en las interacciones comunicativas interculturales entre profesionales sanitarios y usuarios, cabe señalar, por una parte, que, de acuerdo con numerosos autores, la comunicación entre estos interlocutores es fundamental para garantizar la calidad de la asistencia. Por citar solo algunas de las opiniones al respecto, podemos decir que "without effective use of language, the physician-patient relationship is seriously impaired" (Woloshin et al. 1995:727); "the clinician must communicate with the patient [...] to learn the patient's problems, needs, and concerns and to convey information and offer recommendations about care" (Hornberger et al., 1996:846); "the conversation between physician and patient has long been recognized to be of diagnostic importance and therapeutic benefit" (Jacobs et al. 2001:468); "effective communication between patient and doctor is critical to good medical outcomes" (Collins et al., 2002:9).

De hecho, diferentes estudios demuestran que la falta de una comunicación eficaz en ámbito sanitario puede derivar en diagnósticos inapropiados, falta de adherencia al tratamiento, falta de control o seguimiento del paciente, exámenes incompletos o ingresos hospitalarios innecesarios. (Pöhhacker and Shlesinger, 2007:11-12).

\footnotetext{
${ }^{73}$ Centrándonos en el ámbito específico de nuestra investigación (la salud reproductiva) y, en relación con uno de los grupos de sujetos estudiados (las usuarias inmigrantes), creemos interesante señalar que, por lo general, el desconocimiento de la lengua del país de acogida por parte de la población de origen extranjero es más frecuente en las mujeres que en los hombres, debido principalmente a su aislamiento en el ámbito doméstico y su consecuente exclusión social, lo que dificulta el aprendizaje de la lengua por su parte.
} 
En resumen, si los profesionales sanitarios no pueden comunicarse adecuadamente con sus pacientes, si no pueden entender las explicaciones de estos ni hacer entender las propias, difícilmente podrán ofrecer una adecuada asistencia sanitaria (Wadensjö, 1998:51).

Para que la comunicación intercultural en ámbito sanitario sea eficaz y, por tanto, se pueda garantizar la calidad de la asistencia, deberán cumplirse los siguientes requisitos: tanto el profesional sanitario como el usuario se comprenderán, y sentirán que su interlocutor les ha entendido; ambos podrán expresar todas las dudas, pensamientos y sentimientos que les surjan durante la situación comunicativa; considerarán que el tiempo que ha durado la interacción ha sido suficiente; $y$, sobre todo, se sentirán plenamente satisfechos con los resultados de la comunicación (Lee, 2003:5).

Por otra parte, las dificultades que surjan en la comunicación intercultural en ámbito sanitario estarán en gran medida determinadas por las características de los participantes en la interacción. Por ello, a modo de preámbulo, vamos a pasar a describir los elementos principales que caracterizan a los protagonistas de la comunicación intercultural en este ámbito: el usuario inmigrante, por un lado, y el profesional sanitario autóctono, por otro. Esta descripción nos servirá principalmente para resaltar que las expectativas de ambos son diversas y que su relación es notablemente asimétrica.

Los usuarios inmigrantes, por lo general, llegan al país de acogida con un patrimonio de salud prácticamente íntegro; es lo que se denomina "efecto emigrante sano". Las personas que deciden emigrar suelen ser sujetos jóvenes, fuertes, con un gran espíritu de iniciativa y una fuerte estabilidad psicológica. Cabe tener en cuenta que su propio cuerpo, junto con su capacidad laboral, constituyen, al menos inicialmente, su único medio de subsistencia en los países de acogida. Por lo tanto, la salud representa un elemento fundamental para que su emigración tenga éxito.

De todos modos, aunque en el pasado se afirmara que el emigrante partía de su lugar de origen sano y llegaba en las mismas condiciones al país de acogida, esta afirmación ya no se corresponde siempre con la realidad, ya que los duros viajes que los emigrantes realizan para llegar a su destino ponen cada vez más en peligro su vida y su salud.

Estas consideraciones sobre las condiciones de salud del emigrante tampoco se pueden aplicar a las personas que se ven obligadas a huir de sus países por graves situaciones políticas, de guerra o persecución, como es el caso de los prófugos o los refugiados.

El llamado "efecto emigrante sano" tiende también a tener menor relevancia a medida que la inmigración se estabiliza en el país de acogida, es decir, dicho efecto no se encuentra siempre en las personas que llegan al país receptor por vías trazadas y simplificadas por familiares o amigos, como ocurre con las reagrupaciones familiares.

Además, hoy en día, por una serie de factores complejos, deciden emigrar personas de más edad, con un nivel más bajo de educación, con proyectos migratorios temporales o que ellos mismos no han elegido, o que participan voluntaria o involuntariamente en operaciones internacionales de tráfico de drogas y prostitución. Este tipo de emigrantes pueden no 
presentar las condiciones de salud íntegras que se corresponden con el mencionado "efecto emigrante sano".

En la primera etapa del proceso migratorio, por tanto, influirán en la salud de los inmigrantes factores como las particularidades de su país de origen y las posibles desigualdades económicas y sociales (hábitos alimentarios, tradiciones culturales en relación con la salud, deficiente control sanitario, factores de riesgo ambiental, limitaciones de acceso a los servicios sanitarios, etc.) (Jansá y García de Olalla, 2004:208).

Desgraciadamente, sea cual sea el patrimonio de salud del inmigrante que llega al país de acogida, este está destinado a deteriorarse fácilmente. Se ha calculado que el denominado "intervalo de bienestar", es decir, el tiempo que transcurre entre la llegada del inmigrante y el momento en que se dirige a los servicios sanitarios, varía, dependiendo de los diferentes casos, entre ochenta días y doce meses (Morrone, 2000). Los motivos por los cuales el patrimonio de salud del inmigrante se deteriora rápidamente se pueden atribuir a varios factores.

Entre dichos factores se encuentran el malestar psicológico relacionado con la condición de inmigrante, la falta de trabajo y de dinero, la realización de trabajos peligrosos y no tutelados, las condiciones degradantes de la vivienda, la ausencia de apoyo familiar, las diferencias del clima y de las costumbres alimentarias, y la dificultad de acceso a los servicios sanitarios.

En primer lugar, los inmigrantes presentan en numerosas ocasiones enfermedades que no están directamente relacionadas con su experiencia migratoria, sino que se pueden atribuir más bien a su condición de degradación y de extrema marginación. Son enfermedades relacionadas con la pobreza y típicas de la población que no posee una vivienda fija o que vive en condiciones infrahumanas, como pueden ser la tuberculosis, la sarna, las infecciones virales o venéreas, etc.

Por otra parte, existen las llamadas "enfermedades de importación", a veces tan temidas en los países de acogida, como puede ser la malaria. Cabe recordar que este tipo de patologías son las más irrelevantes entre la población inmigrante.

Del mismo modo, existen patologías relacionadas con el desarraigo o la adaptación. El malestar psicológico que provoca el proceso migratorio, el dolor causado por la separación del lugar de origen, el sentimiento de soledad, o la ansiedad provocada por lo desconocido son algunos de los factores principales que pueden deteriorar el estado de salud del inmigrante y causarle numerosas patologías funcionales, psicosomáticas, de depresión, etc. Los numerosos cambios que afronta el inmigrante en la nueva realidad y la pérdida del reconfortante punto de referencia constituido por el entramado cultural de su país de origen, hacen que sienta su cuerpo como algo diverso o nuevo, porque cambia la representación que, hasta aquel momento, le había atribuido en su grupo social de pertenencia.

Asimismo, el inmigrante puede presentar enfermedades profesionales o relacionadas con los accidentes en el lugar de trabajo, debidas a la realización de tareas peligrosas o no tuteladas, a la dificultad de adaptarse a ambientes, instrumentos de trabajo, sustancias, o ritmos laborales que para él pueden resultar nuevos. 
En cualquier caso, poco a poco su estado de salud tiende a identificarse con el de la población autóctona en sus mismas condiciones socio-económicas.

A pesar del posible deterioro en la salud del inmigrante por los motivos que hemos expuesto, según investigaciones recientes, es relativamente bajo el uso que la población inmigrante realiza de los servicios sanitarios. Entre las causas de este escaso uso, se encuentran el desconocimiento de la existencia y funcionamiento de los servicios, los problemas de comunicación (no solo lingüísticos), y la percepción personal de conceptos como el riesgo, la enfermedad y la cura.

Existen también una serie de elementos que disminuyen la confianza de los usuarios inmigrantes en la medicina occidental moderna, como podrían ser la incomprensión de los mecanismos burocráticos, las largas listas de espera, el trato poco personalizado que reciben, el interés de la medicina occidental en determinadas partes del cuerpo (en vez de considerarlo como un concepto global, interrelacionado con la mente), etc.

Además, si el usuario inmigrante ya ha estado en contacto con la medicina de tipo occidental (personalmente o a través de los medios de comunicación), se verán modificadas sus expectativas con respecto a los profesionales sanitarios, así como su interpretación sobre lo que dichos profesionales esperan de él.

La situación de dificultad en la que gran parte de la población inmigrante se encuentra también retrasa la solicitud de asistencia sanitaria. Dicha situación puede bloquear cualquier tipo de atención y cuidado personal, y frenar la exigencia de derechos, como el acceso y el uso de los servicios sanitarios. Los inmigrantes, en primer lugar, se preocuparán por ver reconocida su plena personalidad jurídica y por responder a necesidades primarias y, solo más tarde, se ocuparán de hacer valer sus peculiaridades culturales y reivindicar el reconocimiento de sus derechos.

Cabe igualmente recordar que el proceso migratorio para muchos no solo ha significado un movimiento horizontal (de un país a otro), sino también un movimiento vertical hacia una posición social y profesional más baja de la que ocupaban en su país de origen. Los inmigrantes, a pesar de que muchas veces presentan títulos de estudios superiores, realizan labores inferiores a sus capacidades y experiencias. La presencia o ausencia de algunas variables definirán su estatus social en el país de acogida y, en cierta medida, determinarán su acceso a los servicios sanitarios: la situación jurídica (si tienen o no permiso de residencia); el domicilio (si tienen o no una casa, cuáles son las condiciones higiénicas de la misma, con cuántas personas la deben compartir); el empleo (si trabajan o si están desocupados, qué tipo de trabajo realizan), etc.

Por todas estas razones, frecuentemente la población inmigrante acude a los centros de salud cuando su enfermedad ya se encuentra en un estado avanzado, y son escasas las solicitudes de diagnosis precoz y prevención.

Los profesionales sanitarios, por su parte, se encuentran en una posición de mayor poder y conocimiento con respecto al usuario, tanto por la función que ejercen como por las relaciones y apoyos con los que cuentan. Tal y como ilustra Sharon M. Lee (2003:13), 
The clinical encounter between physician and patient is intrinsically an encounter of unequal actors. The physician possesses authority, knowledge, and prestige, while the patient is vulnerable and dependent. [...] The interaction is therefore mostly shaped by the physician's preferences. $^{74}$

Ante la llegada a los servicios sanitarios de personas culturalmente distintas, los profesionales suelen reaccionar, al menos inicialmente, con preocupación, sospecha y paternalismo y, por lo general, recurren a los estereotipos para tratar de explicar comportamientos cuyas causas les resultan desconocidas. Como sostienen Berta Artigas-Lelong y Miquel Bennassar-Veny (2009:43),

Esta doble mirada, sospechosa y paternalista, ha calado hondo en los profesionales de la salud. Desde esas miradas se clasifica y etiqueta al inmigrante de forma bastante subjetiva, hablando de ellos como colectivos y agrupándoles por nacionalidades (rumanos, ecuatorianos, marroquíes, etc.) o por regiones más amplias (sudamericanos, magrebíes, subsaharianos, asiáticos, del Este, etc.), sin tener en cuenta diferencias como la procedencia de ámbitos rurales o urbanos, o el grado de escolarización.

Las expectativas del médico o del personal sanitario en general se suelen basar en el sistema científico-teórico que conocen, la práctica y la cultura médica por las que se rige su labor, y el contexto institucional en el que trabajan. La valoración del comportamiento del usuario inmigrante desde su propio punto de vista conduce a menudo al profesional sanitario a interpretar erróneamente dicho comportamiento; así, asocia los silencios de los pacientes a la pasividad, critica que estos se presenten a la consulta acompañados de parientes y amigos, etc.

Tal y como se ilustra en la anécdota presentada por Sonia Bacetti (2001:102) que incluimos a continuación, son pocas las ocasiones en las que se atribuye el origen de las dificultades para atender a los pacientes inmigrantes a la incapacidad de los centros de salud o de los propios profesionales sanitarios de comunicarse con ellos.

Chi cerchi di valutare i referti di pazienti stranieri rimane stupito dalla ripetizione ossessiva di frasi tipo: "Esame non completamente effettuato per mancata collaborazione del paziente", "impossibilità di eseguire la terapia per mancata risposta del paziente" e così via. A un osservatore superficiale potrebbe sembrare che gli utenti stranieri siano veramente bizzarri [...] si rifiutino di collaborare per l'esecuzione degli esami o non vogliano rispondere alle domande dei sanitari. [...] Sarebbe bello che nei referti si avesse l'abitudine di scrivere: "Scusate, ci stiamo organizzando, ma attualmente non abbiamo potuto esseguire l'esame nelle condizioni ottimali perché né io né l'azienda siamo in grado di comunicare con questo utente". (comillas del original)

Al mismo tiempo, en general, el profesional sanitario trata a los pacientes inmigrantes siguiendo los mismos patrones con los que trataría a los pacientes autóctonos, y no se plantea la posibilidad de aplicar otro tipo de asistencia o terapia que difieran de su comportamiento habitual, lo cual, de acuerdo con María Isabel Oliver (2002:21), compromete, entre otras cuestiones, la efectividad de la comunicación profesional-paciente.

\footnotetext{
${ }^{74}$ El dominio de la conversación por parte del profesional sanitario puede derivar, por ejemplo, de acuerdo con Sharon M. Lee, en numerosas interrupciones por su parte mientras está hablando el paciente (2003:14), así como en el poco espacio concedido al paciente para explayarse en sus explicaciones o plantear dudas (2003:16).
} 
[...] el etnocentrismo de los sanitarios, esto es, pensar que nuestros valores y prácticas de cuidados son los "adecuados" y los ajenos son "erróneos", conduce con frecuencia a un déficit en la calidad de la comunicación, en la confianza en el profesional y en la relación terapéutica. Comprometen, además, las prácticas de prevención y promoción de la salud.

Una vez señaladas las consecuencias generales que puede tener la ausencia de una comunicación eficaz en ámbito sanitario, así como las características principales de los protagonistas del intercambio comunicativo, pasamos a analizar las barreras que, de manera específica, se presentan en las interacciones interculturales que se dan en dicho ámbito.

La comunicación intercultural en ámbito sanitario se caracteriza, en general, por la dificultad experimentada, por una parte, por el usuario inmigrante para expresar y describir su malestar $y$, por otra, por el profesional sanitario para comprenderle, interpretar los síntomas, y entender comportamientos connotados culturalmente.

Más detalladamente, de acuerdo con autores como Riccardo Colasanti y Salvatore Geraci (1995:71-73), las incomprensiones y problemas que pueden surgir en la comunicación en ámbito sanitario se sitúan en cinco niveles diferentes: ${ }^{75}$

El primero, denominado nivel pre-lingüístico, se refiere a la no manifestación de las sensaciones internas. La incomprensión, en este caso, está relacionada con la dificultad de comunicar dichas sensaciones, con el hecho de que no se pueden indicar ni mostrar a los demás señalándolas simplemente con un dedo. Este obstáculo no atañe exclusivamente a las relaciones interculturales, ya que la dificultad de reconocer y expresar este tipo de sensaciones es más bien una experiencia difundida; no obstante, en el ámbito intercultural, se agrava, en parte porque la relación con la propia interioridad puede variar de una cultura a otra.

El segundo nivel, el nivel lingüístico, está relacionado con la lengua y con la arbitrariedad del significado y del valor semántico. Se trata, en principio, como ya hemos comentado, de la dificultad más obvia e inmediata que se presenta cuando dos interlocutores no comparten un idioma común.

Este problema, muy frecuente en los primeros años de la inmigración, puede ir reduciéndose con el paso del tiempo, al aumentar la capacidad del inmigrante de comprender y expresarse en la lengua del país de acogida. Sin embargo, en el ámbito sanitario, no basta con conocer el lenguaje común empleado en las situaciones comunicativas cotidianas, sino que es frecuente también el uso de terminología médica específica, que los usuarios (tanto inmigrantes como autóctonos) suelen desconocer.

Junto a los problemas léxicos que puede conllevar el desconocimiento de una lengua, se encuentran también los problemas semánticos. En algunas ocasiones, no existe una total correspondencia entre los valores semánticos de las palabras utilizadas en lenguas diferentes. Por ejemplo, en somalí, el término kili significa "riñones", e identifica el área abdominal que se

\footnotetext{
${ }^{75}$ Si bien esta clasificación propuesta por Riccardo Colasanti y Salvatore Geraci incluye los principales problemas que pueden surgir en la comunicación intercultural entre profesionales sanitarios y usuarios, cabe considerar que todos los niveles descritos están interrelacionados, por lo que su separación resulta, cuanto menos, artificial. Deben, por tanto, entenderse todos los niveles como un conjunto, dentro del cual, atendiendo a las características de los participantes en la interacción y al contexto en el que esta se desarrolle, podrán darse las dificultades de uno u otro nivel con mayor o menor intensidad.
} 
encuentra en la parte anterior-lateral, mientras que, en español, en el lenguaje cotidiano, se entiende por riñones la parte dorsal, situada en la zona lateral o raquídea. En consecuencia, cuando un español afirma que le duelen los riñones, quiere decir que tiene un dolor en la zona lumbar y, en cambio, para un somalí, puede significar que le duele la zona del colon, por lo que en una interacción comunicativa con hablantes de somalí no será suficiente con conocer el equivalente del término (riñones/kili), sino que será preciso conocer además su valor semántico. Se trata de un simple ejemplo de malentendido semántico, con el que, a menudo, se enfrentan el usuario extranjero y el profesional sanitario, y ante el cual deben saber reaccionar, no dando nunca nada por sentado y comprobando lo que creen haber entendido.

El tercer nivel, denominado nivel metalingüístico, se refiere a la arbitrariedad de los valores simbólicos. En las diversas lenguas, existe un nivel simbólico, según el cual, a un determinado término se le pueden atribuir significados abstractos. Dichos significados pueden ser diferentes en la mente de quien habla y en la de quien escucha, por lo que también pueden ser causa de malentendidos. Por ejemplo, la significación que se le da al símbolo de la cruz en nuestra cultura (empleado para representar, entre otras cosas, un centro sanitario, una farmacia o a la organización Cruz Roja Internacional) ${ }^{76}$ no presenta el mismo valor en otras culturas.

Una de las dificultades relacionadas con este nivel en el ámbito sanitario puede derivar de la referencia simbólica de una determinada enfermedad: por ejemplo, en nuestra cultura, la palabra "cáncer" se asocia a una enfermedad grave, en algunas ocasiones mortal y, por lo tanto, se relaciona con la idea de la muerte. Si utilizamos esta palabra con este significado simbólico, una persona procedente de otro país donde la mayor causa de muerte son, por ejemplo, las enfermedades infecciosas, podría no entenderla; para esta persona, ese significado se asociaría más bien a términos como "diarrea" (en referencia a enfermedades como la malaria). Por el contrario, si una persona utilizara un término de este tipo para mandar un mensaje simbólico relacionado con la muerte, no sería entendida en nuestra cultura, en la que se asocia la palabra "diarrea" a una breve y transitoria molestia física. Así, por ejemplo, en la novela Medicine in Translation. Journeys with My Patients, escrita por la doctora Danielle Ofri, en la que la autora presenta algunos de los encuentros con pacientes extranjeros que ha vivido a lo largo de su trayectoria profesional, se describe, tal y como puede verse en la cita que incluimos a continuación, una situación en la que una paciente, procedente en concreto de Haití, no es capaz de atribuir el significado correspondiente al término "cáncer", pues, en su cultura de origen, no se concibe que pueda existir una enfermedad que no presente síntomas físicos evidentes.

[...] the patient had no concept of cancer, that in Haitian culture most people could not fathom having a disease if they didn't see any actual evidence of it. It took almost an hour, step by step, to explain about cancer and what it was and what it could do. (Ofri, 2010:47)

Para evitar los posibles malentendidos simbólicos resulta necesaria una actitud de explicación y comprobación constante, tanto de lo que se quiere decir simbólicamente como de lo que puede entender nuestro interlocutor.

\footnotetext{
${ }^{76}$ Muestra de la arbitrariedad de los valores aplicados a determinados símbolos en las distintas culturas es el símbolo de la cruz roja sobre fondo blanco para referirse a la organización Cruz Roja Internacional, el cual se sustituye, en los estados musulmanes, por la media luna roja y, en Israel, por la Estrella de David.
} 
Las dificultades a nivel metalingüístico son inevitables en las relaciones interculturales, pero existen igualmente en el diálogo isocultural, es decir, entre personas que aparentemente comparten el mismo origen geográfico y cultural se dan también con frecuencia este tipo de malentendidos.

El cuarto nivel, el nivel cultural, se relaciona con la denominada impronta o los elementos culturales inconscientes. El resto de niveles de incomprensión descritos hasta el momento, a pesar de estar directamente relacionados con la lengua, forman parte también de la dimensión cultural; de hecho, no es fácil delimitar la cultura de una persona, pero se podría describir como una especie de "ficha" con la que define su propia identidad, los conocimientos de los que dispone, las opiniones fundadas en convicciones más que en un saber, que marcan su comportamiento como miembro de una sociedad (Porcher, 1986). En dicha "ficha" se incluye la información que un individuo absorbe indeliberadamente durante sus primeros años de vida a través de su familia, la sociedad en la que vive, su entorno, su religión, etc.

Dentro de este nivel cultural incluiríamos los aspectos relacionados específicamente con la cultura sanitaria, es decir, con el modo de percibir la salud, así como los distintos modos de prevenir o curar la enfermedad. Los autores mencionados separan este tipo de cultura de aquella asociada directamente con las creencias (religiosas, ideológicas, etc.) y las manifestaciones materiales de las mismas, las cuales quedarían englobadas en otro nivel, el nivel metacultural, del que hablaremos a continuación.

En el ámbito sanitario, los elementos culturales juegan un papel fundamental tanto en la interpretación del malestar como en la eficacia de la terapia. Estos elementos culturales están relacionados con el comportamiento ante la enfermedad, las modalidades de cura y los sistemas médicos preferidos por una $u$ otra comunidad $y$, como hemos comentado en el capítulo 2, son estudiados desde la disciplina de la antropología de la salud.

Tal y como señalábamos al principio de este capítulo, no vamos a ahondar aquí (sino en el capítulo siguiente) en las diferencias por lo que respecta a la cultura sanitaria, aun entendiendo su estrecha relación con la cultura comunicativa dentro del ámbito en el que se centra nuestro estudio.

En una situación ideal, la solución para superar la barrera configurada por este nivel sería conocer a fondo la cultura de nuestro interlocutor, pero es muy difícil (por no decir imposible) que contemos con conocimientos de todas las culturas. Además, como ya hemos afirmado, hay que tener en cuenta que la identidad cultural de un individuo no es algo estático, sino dinámico, en continua transformación. Por ello, en la relación con una persona inmigrada hay que considerar que las referencias de su impronta cultural se relacionan con las referencias que absorbe en el ambiente del país de acogida; en otras palabras, es necesario considerar que esta persona está experimentando una transición cultural, un proceso de reformulación de su propia identidad.

A su vez, las referencias culturales de estos nuevos ciudadanos modifican y transforman la cultura del país receptor. Por consiguiente, la superación de la incomprensión cultural en ámbito sanitario resultará posible no solo explorando la cultura del Otro, sino también 
entrando en el dinámico proceso de transculturación en el que están implicados tanto el usuario inmigrante como el profesional sanitario.

El quinto y último nivel que definen los autores mencionados es el nivel metacultural, y se refiere a las diferencias ideológicas, filosóficas y religiosas. Si bien profundizaremos más en los aspectos relativos a este nivel en el próximo capítulo, al respecto, quisiéramos señalar aquí la interrelación de valores y creencias (por ejemplo, la religión) con otros elementos que conforman nuestra identidad. Tal y como afirman Francisco Raga y Dora Sales (2010:178),

[...] algunas creencias culturales (religiosas, filosóficas, científicas, sociales...) se expresan a través de determinadas costumbres, y a su vez algunas costumbres se pueden apoyar o materializar en objetos culturales. (cursivas del original)

En el ámbito sanitario, las creencias de los usuarios inmigrantes se materializarán, por ejemplo, en aspectos como la vestimenta, los hábitos alimentarios, o el sentido del pudor manifestado por dichos usuarios. Cabe señalar, de todos modos, que el nivel metacultural es el nivel relacionado con la expresión consciente de la propia visión de la vida y, aunque puede igualmente ser fuente de incomprensiones y conflictos interculturales, tratándose de elementos explícitos, reconocidos y declarados, resulta más fácil reaccionar ante los mismos de manera adecuada.

Por otra parte, la exigencia declarada de la población inmigrante de respetar ciertos patrones metaculturales puede ocultar una necesidad implícita e inconsciente de anclarse a sus propios orígenes. Por consiguiente, el personal sanitario debería tener en cuenta las normas personales del usuario y, además, comprender su necesidad de sentirse miembro de un grupo y salvaguardar su propia identidad.

A los niveles descritos por Salvatore Geraci y Riccardo Colasanti, nosotros añadiríamos igualmente otro nivel, relacionado con la cultura comunicativa de cada individuo, cuya diversidad, como hemos visto, podría derivar en problemas o dificultades de interacción. Las diferentes formas de comunicarse, marcadas en gran parte por nuestros orígenes culturales, pueden tener implicaciones en la práctica asistencial y en las actividades de prevención y promoción de la salud (Oliver, 2002:3). Pasamos a continuación a analizar de qué manera pueden influir las diferencias en la cultura comunicativa en las interacciones entre profesionales sanitarios y pacientes, y acompañamos dicho análisis de algunos ejemplos que podrían ilustrar las dificultades e incomprensiones que estas diferencias podrían provocar.

Por lo que respecta a los usos verbales del lenguaje y, más concretamente, a las máximas conversacionales, las diferencias culturales en cuanto a la aplicación de las mismas pueden derivar en problemas de comunicación entre el profesional sanitario y el usuario inmigrante.

Así, por ejemplo, en referencia a la máxima de cantidad, un paciente procedente de la India o de Paquistán, cuyas prácticas sanitarias se fundamentan, entre otros aspectos, "en la narración pormenorizada [...] sobre su estado físico y emocional” (Ortí, Sales y Sánchez, 2007:121), puede sentirse incómodo por las escasas intervenciones que el profesional sanitario español le permite efectuar o si, extrañamente, este paciente consigue explicar todos sus síntomas con tanta exhaustividad como desearía, quizás será el profesional sanitario español quien se 
extrañe al recibir una cantidad de información, a su parecer, excesiva, ante la cual puede incluso llegar a impacientarse.

Con relación a la máxima de veracidad, pacientes de culturas como la china o la magrebí, podrán no ser del todo sinceros y recurrir a lo que se conocen como mentiras sociales cuando interactúan con el personal sanitario, "para no provocar la ofensa del interlocutor, para no perder el prestigio social, por su situación de desprotección, o por desconfianza" (Ortí, Sales y Sánchez, 2007:131).

En cuanto a la máxima de manera, los pacientes podrán emplear expresiones más o menos directas al relacionarse con los profesionales sanitarios, en señal de respeto o, en especial, al referirse a determinados temas que pueden resultar delicados o comprometidos en sus culturas de origen, como podrían ser aquellos relacionados con la salud y las prácticas sexuales y reproductivas en los pacientes de religión musulmana. Asimismo, estos mismos pacientes, aunque consideren en general al profesional sanitario como alguien jerárquicamente superior, emplearán modos de expresión muy enfáticos cuando crean que se está degradando su imagen social, que se les está ofendiendo o discriminando (Ortí, Sales y Sánchez, 2007:132).

Por su parte, los aspectos de la cultura comunicativa del profesional sanitario y del paciente relativos a los usos no verbales del lenguaje, como el contacto visual y físico, el paralenguaje, o la distribución espacial y temporal de las conversaciones, cobran especial relevancia en el ámbito sanitario.

Por lo que se refiere a la distribución temporal de las conversaciones, los pacientes tendrán unas determinadas expectativas con respecto a la distribución de los turnos de palabra basadas en sus patrones culturales. Por ejemplo, un paciente procedente de Europa del este esperará que, en señal de mutuo respeto, ambos interlocutores (el profesional y el usuario) tengan la oportunidad de expresarse y ser escuchados, mientras que, por el contrario, en culturas más caracterizadas por las desigualdades sociales, como puede ser el caso de las culturas asiáticas, se esperará que sea el profesional quien distribuya los turnos de palabra, aunque ello no debe significar necesariamente que sea este quien hable en más ocasiones ni durante más tiempo. De hecho, los pacientes de origen extranjero suelen considerar las numerosas interrupciones y solapamientos por parte de los profesionales sanitarios como una señal clara de descortesía.

Con respecto a la distribución espacial, son significativas tanto las cuestiones relativas al macroespacio (distribución global, objetos presentes, etc.) como aquellas referidas al microespacio (posición y postura de los interlocutores). Así, como señala María Isabel Oliver (2002:10),

En las consultas, una mesa nos separa del paciente que tenemos enfrente, y puede ser percibida como una barrera. En los hospitales, atendemos a los pacientes desde una posición erguida, mientras que ellos están tumbados o sentados, lo que les hace estar en una posición que puede interpretarse como subordinación.

Siempre en referencia a los usos no verbales, destacan especialmente las cuestiones relacionadas con el contacto físico y el contacto visual. En cuanto al primero, en el caso de las pacientes de religión musulmana, estas suelen presentar ciertas reticencias a la hora de ser 
exploradas, sobre todo cuando el profesional sanitario es de sexo masculino y la parte a explorar es por ellas considerada íntima, como consecuencia del pudor que sienten ante el contacto físico. En relación con el segundo, la ausencia de contacto visual por parte de pacientes de origen chino en señal de respeto hacia el profesional sanitario puede ser interpretada por este último como una falta de interés, como insinceridad o como una señal de que el paciente tiene algo que ocultar.

Las diferencias culturales relativas al paralenguaje también pueden provocar problemas en la comunicación intercultural en ámbito sanitario. Así, por ejemplo, la expresión del dolor puede ser más o menos enfática e ir acompañada o no de sonidos diferenciadores (así como de expresiones faciales y gestos) dependiendo de la cultura de origen del paciente. Por tanto, un bajo nivel de expresividad por parte de un paciente cuyo paralenguaje suela ser poco enfático podría llevar a malas interpretaciones por parte del personal sanitario con respecto al dolor real que soporta dicho paciente.

En relación con los modelos comunicativos y, más concretamente, atendiendo a la clasificación propuesta por Edward T. Hall (1976) entre culturas de alto y bajo contexto, podrían surgir malentendidos o conflictos en la comunicación intercultural en ámbito sanitario en el caso en que los interlocutores no presenten patrones culturales similares por lo que respecta a esta clasificación. En consecuencia, por ejemplo, si el paciente procede de una cultura de alto contexto, como puede ser la china, y el profesional presenta un modelo conversacional más próximo a la cultura de bajo contexto, el paciente podrá sorprenderse ante la gran cantidad de información verbal que le proporciona su interlocutor y ante el modo directo en que la presenta, mientras que al profesional le podrá resultar difícil inferir el significado del mensaje y la intención del paciente, por el modo implícito en el que este probablemente se comunicará.

Por lo que se refiere a las dimensiones culturales propuestas por Geert H. Hofstede (1991) y, en particular, a la distancia de poder, un paciente de una cultura en la que las distancias sociales sean muy pronunciadas, probablemente no desafiará la autoridad del profesional sanitario realizándole numerosas preguntas, aunque ello signifique que le queden algunas dudas sin resolver. Si, por otro lado, el paciente pertenece a una cultura donde sea habitual la evitación de la incertidumbre, este no tolerará las expresiones directas de disenso, y considerará negativamente las desviaciones por parte del profesional de aquello que, de acuerdo con su cultura, se califique como socialmente aceptable. Además, por ejemplo, si el paciente procede de una cultura más cercana al individualismo, deseará ser informado en primera persona de todo lo que ataña a su estado físico y al tratamiento prescrito, y será él mismo quien tome las decisiones al respecto, mientras que si su cultura de origen es colectivista, el grado de implicación de su familia en todo el proceso de cura será bastante mayor. Asimismo, dependiendo de si el paciente pertenece a una cultura más femenina o más masculina, se atribuirán roles similares o diferentes a los hombres y a las mujeres de dicha comunidad por lo que respecta a la atención al enfermo. Así, por ejemplo, en una cultura más orientada hacia la masculinidad, donde las funciones asignadas a los hombres y a las mujeres están claramente delimitadas, se podrá preferir que sean las figuras femeninas de la familia las que se ocupen de los cuidados de un recién nacido. Por último, en cuanto a la orientación 
temporal, un paciente de una cultura orientada a corto plazo esperará unos resultados inmediatos del tratamiento que se le prescriba para curar su enfermedad.

Para concluir este apartado, en relación con la clasificación de los modelos comunicativos basada en la igualdad o desigualdad de los interlocutores y en el grado de preocupación por el conflicto propuesta por Francisco Raga (2006a), hemos elaborado una tabla en la que se presentan las características principales de los modelos comunicativos que adoptarían los profesionales sanitarios y los pacientes en las distintas culturas. ${ }^{77}$

\footnotetext{
${ }^{77}$ Nótese que las culturas incluidas en la tabla se corresponden con las culturas estudiadas en nuestra investigación. Véanse, al respecto, el capítulo 2, relativo a la metodología, y el capítulo 6, de análisis de resultados del estudio de caso.
} 


\begin{tabular}{|c|c|c|c|c|c|c|}
\hline $\begin{array}{l}\text { Patrón } \\
\text { comunicativo }\end{array}$ & Contenido & Veracidad & Manera & Paralenguaje & $\begin{array}{l}\text { Turnos de } \\
\text { palabra }\end{array}$ & $\begin{array}{l}\text { Comunicación } \\
\text { no verbal }\end{array}$ \\
\hline $\begin{array}{l}\text { Prof. sanitario } \\
\text { (España) }\end{array}$ & $\begin{array}{l}\text { Poca información } \\
\text { y comprometida }\end{array}$ & $\begin{array}{l}\text { Casos de } \\
\text { insinceridad }\end{array}$ & $\begin{array}{l}\text { Lenguaje } \\
\text { directo y, a } \\
\text { veces, } \\
\text { ininteligible }\end{array}$ & $\begin{array}{l}\text { En ocasiones, } \\
\text { ceremonial }\end{array}$ & $\begin{array}{l}\text { Dirige e } \\
\text { interrumpe }\end{array}$ & $\begin{array}{l}\text { Dirige y muy } \\
\text { próximo }\end{array}$ \\
\hline $\begin{array}{l}\text { Paciente } \\
\text { (España) }\end{array}$ & $\begin{array}{l}\text { Mucha } \\
\text { información y } \\
\text { comprometida }\end{array}$ & Sinceridad & $\begin{array}{l}\text { Lenguaje } \\
\text { directo e } \\
\text { inteligible }\end{array}$ & Coloquial & $\begin{array}{l}\text { Es dirigido y } \\
\text { no } \\
\text { interrumpe }\end{array}$ & $\begin{array}{l}\text { Es dirigido y } \\
\text { distante }\end{array}$ \\
\hline $\begin{array}{l}\text { Prof. Sanitario } \\
\text { (Asia) }\end{array}$ & $\begin{array}{l}\text { Mucha } \\
\text { información y, si } \\
\text { cabe, } \\
\text { comprometida }\end{array}$ & $\begin{array}{l}\text { Tanta } \\
\text { sinceridad } \\
\text { como se } \\
\text { pueda }\end{array}$ & $\begin{array}{l}\text { Lenguaje } \\
\text { directo y, a } \\
\text { veces, } \\
\text { metafórico }\end{array}$ & $\begin{array}{l}\text { En ocasiones, } \\
\text { ceremonial }\end{array}$ & $\begin{array}{l}\text { Dirige, pero } \\
\text { no suele } \\
\text { interrumpir }\end{array}$ & $\begin{array}{l}\text { Dirige y es distante. } \\
\text { Mucho contacto } \\
\text { físico }\end{array}$ \\
\hline Paciente (Asia) & $\begin{array}{l}\text { Mucha } \\
\text { información y, si } \\
\text { cabe, } \\
\text { comprometida }\end{array}$ & $\begin{array}{l}\text { Sinceridad } \\
\text { en general, } \\
\text { aunque } \\
\text { puede } \\
\text { recurrir en } \\
\text { ocasiones a } \\
\text { las mentiras } \\
\text { sociales }\end{array}$ & $\begin{array}{l}\text { Lenguaje } \\
\text { directo e } \\
\text { inteligible }\end{array}$ & Formal & $\begin{array}{l}\text { Es dirigido y } \\
\text { no } \\
\text { interrumpe }\end{array}$ & $\begin{array}{l}\text { Es dirigido y } \\
\text { distante }\end{array}$ \\
\hline $\begin{array}{l}\text { Prof. sanitario } \\
\text { (África } \\
\text { Subsahariana) }\end{array}$ & Poca información & $\begin{array}{l}\text { Tanta } \\
\text { sinceridad } \\
\text { como se } \\
\text { pueda }\end{array}$ & $\begin{array}{l}\text { Lenguaje } \\
\text { metafórico y, } \\
\text { a veces, } \\
\text { ininteligible }\end{array}$ & Ceremonial & $\begin{array}{l}\text { Respeta el } \\
\text { turno de } \\
\text { palabra del } \\
\text { paciente }\end{array}$ & Dirige y es distante \\
\hline $\begin{array}{l}\text { Paciente (África } \\
\text { Subsahariana) }\end{array}$ & Poca información & $\begin{array}{l}\text { Sinceridad } \\
\text { en general, } \\
\text { aunque } \\
\text { puede } \\
\text { recurrir en } \\
\text { ocasiones a } \\
\text { las mentiras } \\
\text { sociales }\end{array}$ & $\begin{array}{l}\text { Lenguaje no } \\
\text { siempre } \\
\text { directo }\end{array}$ & Formal & $\begin{array}{l}\text { Respeta el } \\
\text { turno de } \\
\text { palabra del } \\
\text { profesional } \\
\text { sanitario }\end{array}$ & $\begin{array}{l}\text { Es dirigido y es } \\
\text { distante }\end{array}$ \\
\hline $\begin{array}{l}\text { Prof. sanitario } \\
\text { (Europa del } \\
\text { este) }\end{array}$ & $\begin{array}{l}\text { Mucha } \\
\text { información y, si } \\
\text { cabe, } \\
\text { comprometida }\end{array}$ & $\begin{array}{l}\text { Tanta } \\
\text { sinceridad } \\
\text { como se } \\
\text { pueda }\end{array}$ & $\begin{array}{l}\text { Lenguaje } \\
\text { directo y tan } \\
\text { inteligible } \\
\text { como se } \\
\text { pueda }\end{array}$ & $\begin{array}{l}\text { No muy } \\
\text { ceremonial }\end{array}$ & $\begin{array}{l}\text { Dirige } y, a \\
\text { veces, } \\
\text { interrumpe }\end{array}$ & Dirige y es distante \\
\hline $\begin{array}{l}\text { Paciente } \\
\text { (Europa del } \\
\text { este) }\end{array}$ & $\begin{array}{l}\text { Mucha } \\
\text { información y } \\
\text { comprometida }\end{array}$ & Sinceridad & $\begin{array}{l}\text { Lenguaje } \\
\text { directo e } \\
\text { inteligible }\end{array}$ & Coloquial & $\begin{array}{l}\text { Es dirigido, } \\
\text { pero puede } \\
\text { interrumpir }\end{array}$ & $\begin{array}{l}\text { Es dirigido y } \\
\text { distante }\end{array}$ \\
\hline $\begin{array}{l}\text { Prof. sanitario } \\
\text { (Latinoamérica) }\end{array}$ & $\begin{array}{l}\text { Poca información } \\
\text { y comprometida }\end{array}$ & $\begin{array}{l}\text { Casos de } \\
\text { insinceridad }\end{array}$ & $\begin{array}{l}\text { Lenguaje } \\
\text { directo y, a } \\
\text { veces, } \\
\text { ininteligible }\end{array}$ & $\begin{array}{l}\text { En ocasiones } \\
\text { ceremonial }\end{array}$ & $\begin{array}{l}\text { Dirige, pero } \\
\text { no suele } \\
\text { interrumpir }\end{array}$ & Dirige y distante \\
\hline $\begin{array}{l}\text { Paciente } \\
\text { (Latinoamérica) }\end{array}$ & $\begin{array}{l}\text { Mucha } \\
\text { información y } \\
\text { comprometida }\end{array}$ & $\begin{array}{l}\text { Casos de } \\
\text { insinceridad }\end{array}$ & $\begin{array}{l}\text { Lenguaje } \\
\text { directo e } \\
\text { inteligible }\end{array}$ & Formal & $\begin{array}{l}\text { Es dirigido y } \\
\text { no } \\
\text { interrumpe }\end{array}$ & $\begin{array}{l}\text { Es dirigido y } \\
\text { distante }\end{array}$ \\
\hline $\begin{array}{l}\text { Prof. sanitario } \\
\text { (Magreb) }\end{array}$ & $\begin{array}{l}\text { Poca información } \\
\text { y no } \\
\text { comprometida }\end{array}$ & $\begin{array}{l}\text { Casos de } \\
\text { insinceridad }\end{array}$ & $\begin{array}{l}\text { Lenguaje } \\
\text { directo y, a } \\
\text { veces, } \\
\text { ininteligible }\end{array}$ & $\begin{array}{l}\text { En ocasiones, } \\
\text { ceremonial }\end{array}$ & $\begin{array}{l}\text { Dirige e } \\
\text { interrumpe }\end{array}$ & Dirige y distante \\
\hline $\begin{array}{l}\text { Paciente } \\
\text { (Magreb) }\end{array}$ & $\begin{array}{l}\text { Mucha } \\
\text { información y } \\
\text { comprometida }\end{array}$ & $\begin{array}{l}\text { Casos de } \\
\text { insinceridad }\end{array}$ & $\begin{array}{l}\text { Lenguaje no } \\
\text { siempre } \\
\text { directo }\end{array}$ & Formal & $\begin{array}{l}\text { Es dirigido y } \\
\text { no } \\
\text { interrumpe }\end{array}$ & $\begin{array}{l}\text { Es dirigido y } \\
\text { distante }\end{array}$ \\
\hline
\end{tabular}

Tabla 3.4. Esquema de los patrones comunicativos en las interacciones en ámbito sanitario (elaboración propia; basada en Ortí, Sales y Sánchez, 2007:134 y en Grupo CRIT, 2009) 
Con respecto a la tabla presentada, cabe destacar, en primer lugar, que esta refleja una serie de generalizaciones ${ }^{78}$ que, por supuesto, están sujetas a muchos matices y no se pueden aplicar a todos los profesionales y pacientes de las culturas analizadas, ya que, como hemos señalado previamente, el modelo comunicativo elegido por los participantes en una situación comunicativa concreta estará también condicionado por factores individuales, psicológicos y emotivos, así como por las particularidades que presente la situación en sí. Además, se debe considerar que algunas de las culturas que aparecen mencionadas en la tabla se corresponden con áreas muy amplias (como es el caso de Latinoamérica y Asia), y es posible que los países que conforman estas áreas presenten notables diferencias entre ellos. Asimismo, quisiéramos hacer notar que, entre las distintas culturas, existen patrones comunicativos tanto diferentes como semejantes. Por supuesto, serán principalmente las diferencias las que podrán provocar malentendidos e incomprensiones.

La clasificación tetrapartita ${ }^{79}$ de los modelos comunicativos propuesta por Francisco Raga se relaciona de la siguiente manera con los datos expuestos en la tabla. A modo de ejemplo, y centrándonos en algunas de las dimensiones analizadas, podemos decir que en una cultura de tipo A (como la española), donde existe un bajo grado de preocupación por el conflicto y un alto grado de igualdad entre los interlocutores (aunque en este caso la igualdad será menor que en una conversación coloquial, por la posición jerárquica de cierta superioridad que ocupan los profesionales sanitarios), la información intercambiada por parte del profesional y del usuario podrá incluir temas comprometidos y delicados y, en ocasiones, los interlocutores se interrumpirán mutuamente. En una cultura de tipo B (como la asiática), en la que predomina un bajo grado de igualdad entre los interlocutores y la preocupación por el conflicto suele ser alta, los pacientes podrán recurrir a las mentiras sociales en señal de respeto de la posición de superioridad del profesional, y el contacto visual no será tan frecuente como en los encuentros comunicativos en ámbito sanitario que se produzcan en otras culturas. Y en una cultura de tipo D (como la magrebí o la de África Subsahariana), en la que se suele dar un bajo grado de igualdad acompañado por un bajo grado de preocupación por el conflicto, la comunicación no verbal será, por lo general, distante, y el paralenguaje empleado por parte del profesional sanitario será formal o, incluso, ceremonial.

\subsection{Claves para una comunicación intercultural eficaz}

Es cierto que las diferencias culturales pueden ser origen de malentendidos y conflictos; sin embargo, si aprendemos a mirar sin prejuicios, veremos que es posible la comunicación

\footnotetext{
78 Al respecto de las generalizaciones, cabe señalar la diferencia entre estas y los estereotipos. Cuando estereotipamos, no tenemos en cuenta que cada persona es un ser único con una identidad propia que se va conformando a lo largo de su vida y que, aunque sea originario de una cultura concreta, puede presentar patrones que sean comunes o ajenos a dicha cultura. Por el contrario, al generalizar, establecemos una serie de características que pueden ser compartidas por un grupo, pero reconocemos que es necesario verificar si estas características se aplican a todos los miembros del mismo. Como sostiene Geri-Ann Galanti (2000:335), los estereotipos son un "ending point", es decir, al aplicarlos a las personas, las clasificamos y no damos cabida a las múltiples diferencias que se dan dentro de cada cultura, mientras que las generalizaciones son un "starting point", esto es, un punto desde el que partir para tratar de comprender el comportamiento del Otro. Así, estas generalizaciones sobre los modelos comunicativos que emplean determinados grupos culturales pueden ofrecer pistas a los profesionales sanitarios sobre posibles patrones de comportamiento que los miembros de dichos grupos podrían presentar, sin por ello dar por supuesto que todos ellos deben actuar o pensar de manera uniforme.

${ }^{79}$ No haremos aquí referencia a los patrones del modelo comunicativo de las culturas de tipo C, pues ninguna de las incluidas en la tabla y estudiadas en nuestra investigación pertenece a este tipo.
} 
intercultural. Para que dicha posibilidad se materialice, se debería intentar encontrar un punto de encuentro entre las distintas culturas y ver el intercambio entre las mismas como algo enriquecedor para ambas.

La comunicación intercultural es, en definitiva, un "two-way process" (Bennett, 1998) que exige reciprocidad, pues en él todos los participantes deben esforzarse por construir un marco común en el que se persiga un objetivo compartido, y en el que se tengan en cuenta las diversas características de los participantes. Tal y como resume Ray L. Birdwhistell (1970, citado en Davis, 2010:29), la comunicación

[...] es una negociación entre dos personas, un acto creativo. No se mide por el hecho de que el otro entienda exactamente lo que uno dice, sino porque él también contribuya con su parte, ambos cambien con la acción. Y, cuando se comunican realmente, lo que forman es un sistema de interacción y reacción bien integrado.

A modo de resumen, podemos decir que el requisito principal para que dos personas culturalmente diversas consigan comunicarse es que estas posean lo que se conoce como "competencia comunicativa intercultural", entendida como la habilidad para "facilitating successful intercultural communication outcomes in terms of satisfaction and other positive assessments of the interaction and the interaction partner" (Kim, 2005, citado en Jandt 2010:52).

Dicha habilidad permitirá que se negocien los significados culturales y se actúe de conformidad con las identidades de los participantes en el intercambio comunicativo, de manera que la comunicación intercultural sea eficaz (Chen y Starosta, 1996, citados en Jandt 2010:53).

Esta competencia comunicativa intercultural (dentro de la cual se incluyen componentes cognitivos, afectivos y comportamentales), incluye no solo los aspectos estrictamente relacionados con la comunicación, sino también el conocimiento de los condicionantes culturales con respecto al proceso de salud y enfermedad (Plaza del Pino y Soriano Ayala, 2009:193-194), de los cuales nos ocuparemos, como ya hemos comentado, en el próximo capítulo.

Pasamos, a continuación, a exponer las claves que, en nuestra opinión, pueden contribuir a garantizar la eficacia de los intercambios comunicativos interculturales, entre las que se incluyen una serie de factores cognitivos, emocionales y actitudinales que deberían poseer ambos interlocutores. ${ }^{80}$

En primer lugar, no cabe la menor duda de que, para que dos personas puedan comunicarse, estas deben hablar una lengua común. Cabe recordar, sin embargo, que se trata de una condición estrictamente necesaria, pero no suficiente para garantizar una óptima comunicación intercultural.

\footnotetext{
${ }^{80}$ Cabría realizar un inciso para recalcar que, cuando hablamos de la eficacia de la comunicación intercultural, no nos referimos a aquella situación completamente controlada y sin ningún tipo de ambigüedad (situación prácticamente inalcanzable incluso en los encuentros intraculturales), sino que aludimos a "un grado de comprensión aceptable para los interlocutores" (Rodrigo Alsina, 2000:3) y al hecho de que "se comprendan y respeten las múltiples identidades de los participantes" (Oliver, 2002:26).
} 
Los hablantes deberán poseer, además, una competencia comunicativa, basada en el conocimiento de los elementos (verbales y no verbales) que intervienen en la comunicación y de las características generales de los diferentes modelos conversacionales. Ello no implica que los participantes en una interacción intercultural deban conocer los patrones comunicativos que se dan en todas las culturas (algo que, como hemos comentado con anterioridad, resultaría literalmente imposible), sino que estos deberán ser conscientes, por una parte, de los valores sociales e individuales que pueden transmitir las diferentes dimensiones de los modelos conversacionales y, por otra, de la enorme variabilidad cultural al respecto. Estos conocimientos permitirán a los hablantes comprender la sensación de malestar que puede surgir en las interacciones con personas culturalmente distintas, y les ayudarán a no interpretar los comportamientos comunicativos ajenos desde el punto de vista de su propio modelo.

Asimismo, otra condición imprescindible para que la comunicación intercultural sea exitosa consiste en que los interlocutores posean lo que podríamos denominar competencia (inter)cultural, que, en el ámbito concreto que nos ocupa, podría definirse como un conjunto de comportamientos, actitudes y políticas que se dan tanto un centro sanitario como entre los profesionales del mismo, y que les permiten trabajar de manera efectiva en situaciones caracterizadas por la multiculturalidad (Cross et al., 1989, citados en Brach y Fraser, 2000:182). Esta competencia incluye, en primer lugar, la existencia de un interés efectivo en conocer otras culturas, interés que no debe ser "anecdótico" o "dirigido a confirmar nuestros propios valores" (Rodrigo Alsina, 2000:7), sino que debe perseguir el verdadero aprendizaje. A ello, debería sumarse, por una parte, un conocimiento efectivo de la cultura del interlocutor y una toma de conciencia de la propia cultura, los cuales, a su vez, desembocarán en una eliminación de los estereotipos y prejuicios que se suelen atribuir a las personas culturalmente diversas.

Igualmente, se deberá manifestar una actitud de empatía, entendida como la facultad de identificarse con el Otro, de comprender y experimentar sus sentimientos a partir sus propios referentes culturales.

Para permitir que la comunicación intercultural sea realmente efectiva es, por tanto, necesario

[...] adquirir una mirada pluricultural que nos permita distanciarnos de la cultura en la que hemos sido socializados para, por un lado, ser autoreflexivos en relación con la propia cultura y, por otro lado, llegar a comprender el punto de vista de otras culturas. (Rodrigo Alsina, 2000:4)

Por otra parte, como hemos comentado previamente, la comunicación no es simplemente un intercambio de mensajes, sino que es, sobre todo, una construcción de sentido, sentido que se atribuirá en base a los patrones culturales de los participantes en el encuentro. Por ello, las interacciones comunicativas interculturales comportan normalmente un elevado grado de incertidumbre, tanto en relación con las actitudes que se pueden prever en el interlocutor, como en la explicación de las actitudes efectivamente mostradas por el mismo. ${ }^{81}$ Así, será necesario que, al comunicarse con personas culturalmente diversas, se cuente con cierta tolerancia a la ambigüedad, la cual eliminará o, al menos, reducirá, el grado de ansiedad y preocupación iniciales que caracterizan a este tipo de intercambios.

\footnotetext{
${ }^{81}$ Estos dos posibles tipos de incertidumbre son denominados por William B. Gudykunst (1995:10) "incertidumbre predictiva" e "incertidumbre explicativa", respectivamente.
} 
Del mismo modo, se deberá demostrar cierta flexibilidad y capacidad para adaptarse a las nuevas situaciones, sin anclarse en los propios patrones, sino estando siempre abiertos a modificar determinados comportamientos y actitudes.

Por los numerosos malentendidos que, como hemos señalado, pueden producirse en la comunicación entre personas culturalmente diversas, es preciso, además, que estas posean la capacidad de metacomunicarse, es decir, de explicar lo que pretenden decir con sus palabras, el sentido de sus mensajes y el efecto que se supone que estos deberían causar, sin dar por sentado que su interlocutor interpretará adecuadamente dichos mensajes, especialmente cuando en ellos hay elementos implícitos que comparten solo los miembros de una determinada comunidad.

En la comunicación intercultural debe existir, además, como hemos comentado previamente, una cierta negociación, que partirá necesariamente de una posición de igualdad entre los interlocutores, lo cual no significa ignorar la existencia de "poderes desequilibrantes" o anclarse en actitudes de "paternalismo o victimismo" (Rodrigo Alsina, 1999:243), sino que requerirá un esfuerzo por hallar, en la medida de lo posible, un reequilibrio en las posiciones y relaciones asimétricas que caracterizan, por lo general, a los interlocutores en los intercambios comunicativos interculturales. Así, tal y como sostiene Edgard Weber (1997:12, citado en Rodrigo Alsina, 1999:80),

El encuentro de las culturas no es forzosamente intercultural. Un fenómeno cultural no se debe a que las culturas se encuentran, puede haber simplemente agresión o eliminación de uno por el otro. El encuentro de las culturas se convierte en un fenómeno cultural si, de alguna manera, existe aceptación y proyecto común.

Esta posición de igualdad no solo deberá referirse individualmente a los interlocutores, sino que tendrá también que aplicarse a las culturas que cada uno de ellos representa. Así, será necesario abandonar las posiciones etnocentristas que sitúan los valores de una cultura por encima de los valores de otra, y adoptar una actitud de relativismo cultural, en la que se aporten críticas y autocríticas constructivas, y se consideren y respeten los diferentes puntos de vista.

Al respecto de las pautas indicadas, nos gustaría aclarar un par de conceptos. En primer lugar, cuando hemos mencionado el conocimiento de la cultura del Otro, no nos referíamos exclusivamente a los elementos externos de una determinada cultura, aquellos que nos resultan más fáciles de identificar, como la vestimenta, la lengua, o los rituales. Cuando nos relacionamos con personas de otras culturas, si simplemente tenemos en cuenta estos aspectos, correremos el riesgo de estereotipar. Conocer realmente una cultura significa comprender los elementos y valores internos e inconscientes de la misma, aquellos que son menos perceptibles a simple vista, tales como su organización social, sus modelos comunicativos, la relación entre los sexos, o la organización espacial y temporal.

Ilustra claramente la distinción entre elementos externos e internos de las culturas la conocida como "analogía del iceberg", analizada extensamente por R. Michael Paige (1993). Según dicha analogía, la cultura externa (aquella que es visible por encontrarse "por encima del nivel del agua") está representada por aquellos elementos aprendidos de manera explícita, conscientes, 
y que se corresponden con el conocimiento objetivo, mientras que la cultura interna (aquella más difícil de percibir por estar "sumergida bajo el agua") está formada por elementos aprendidos implícitamente, inconscientes y relacionados con el conocimiento subjetivo.

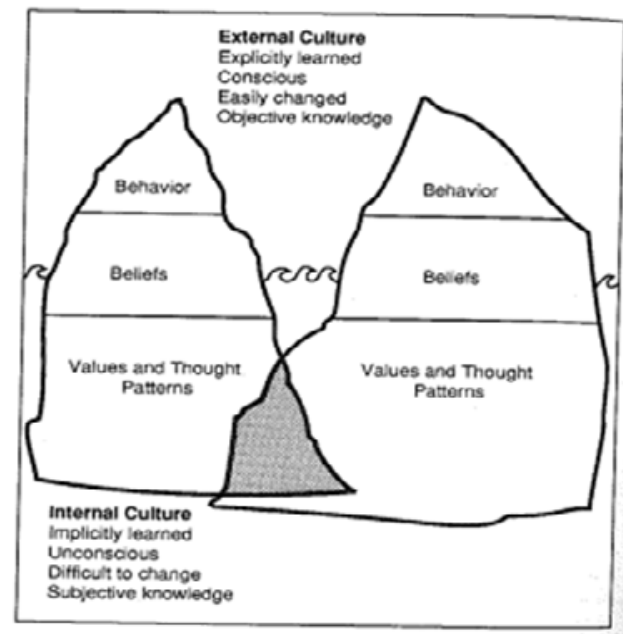

Imagen 3.1. La analogía del iceberg

(Paige, 1993:160)

Como ilustra la imagen que acabamos de mostrar, el encuentro con otras culturas a menudo es equiparable a la colisión de dos icebergs; el verdadero choque se produce "bajo la superficie del agua", donde entran en conflicto los valores y patrones de pensamiento. Solamente conociendo los elementos internos de la cultura de nuestro interlocutor, seremos capaces de interpretar correctamente su comportamiento y los aspectos externos de su cultura.

Asimismo, creemos conveniente delimitar el concepto de relativismo cultural, que se refiere a la actitud "que no pretende buscar universales, sino sólo entender cada cultura a partir de su propio universo simbólico" (Rodrigo Alsina, 1999:33), y que implica el reconocimiento de que la cultura del Otro no puede juzgarse de forma arbitraria a través de los patrones y valores de nuestra propia cultura. Esta actitud relativista nos conducirá a repensar algunos de los comportamientos, creencias y actitudes que, hasta el momento, considerábamos fundamentales y universalmente válidos. De hecho, tal y como sostiene Sonia Baccetti (2001:121),

[...] comunicare è anche conoscere l'altro soggetto della comunicazione, saper ascoltare, accogliere un'altra versione dei fatti, saper modificare i propri attegiamenti e la propia cultura.

Si se desea que la comunicación intercultural sea eficaz, resulta, pues, necesario un acercamiento a lo que nos resulta incógnito, para descubrir su valor, sus potenciales y afinidades, así como para identificar los posibles puntos de fricción a los que buscar una solución. En las situaciones comunicativas interculturales, la diversidad debería afrontarse

[...] non in termini gerarchici, di sopraffazione di valori, di pregudizio, di discriminazione, ma sottolineando l'inter-relazione, la relatività del giudizio, la richezza di diversi punti di vista, la molteplice ottica di valutazione dell'esistente [...]. È l'accetazione e il riconoscimento della propia identità e dell'identità dell'altro, dell'alterità, dell'interdipendenza, della consapevolezza (Baccetti, 2001:127). 
Por tanto, la comunicación intercultural implica una continua revisión de nuestro modo de pensar, sentir y actuar y, en consecuencia, puede resultar en cierta medida más difícil para los interlocutores, si se compara con los intercambios comunicativos con personas de la propia cultura.

A pesar de las dificultades que puede plantear la comunicación intercultural, consideramos acertadas las palabras del sociólogo Ulrich Beck (2005:118), quien afirma que, en la actualidad, vivimos en un mundo en el cual

[...] è diventata una necessità comprendere, riflettere, criticare l'alterità degli altri e dunque affermare e conoscere se stessi e gli altri come diversi e perciò di uguale valore, come prassi nella vita quotidiana.

En resumen, la reflexión, la comprensión, el (re)conocimiento del Otro y de uno mismo que derivan de la comunicación intercultural nos enriquecerán como personas, y nos llevarán a comunicar de manera más fluida y eficaz con nuestros interlocutores, independientemente de la cultura o el país del que estos procedan. 


\section{CAPÍTULO 4}

Salud y cultura 


\section{SALUD Y CULTURA}

En el presente capítulo nos ocupamos del estudio de la relación entre la cultura y las creencias, actitudes y comportamientos relativos al ámbito de la salud, y analizamos de qué manera las diferencias culturales al respecto podrían afectar a la relación entre los profesionales sanitarios y los pacientes inmigrantes. No abordamos cuestiones específicamente de carácter comunicativo, aunque cabe recordar que consideramos que es muy difícil establecer una separación neta entre comunicación y cultura, pues están estrechamente vinculadas entre sí. Así, tal y como sostiene Sharon M. Lee (2003: 16),

If there is cultural discordance between doctor and patient, effectiveness of communication is expected to be lower. Communication is additionally influenced by how familiar each is with the other's cultural background. The higher the degree of cultural knowledge and familiarity each has of the other's culture, the more effective the communication.

En concreto, presentamos las variaciones que se pueden dar, tanto en las diferentes culturas como a título personal, entre los conceptos de salud y enfermedad (relacionados a su vez, como veremos más adelante, con el concepto de cuerpo), las creencias relacionadas con el origen de las enfermedades, y las posibles discrepancias entre la percepción de las mismas por parte de los profesionales sanitarios y de los pacientes. Además, estudiamos los diversos modos elegidos para prevenir y curar la enfermedad, así como las diferentes figuras sanadoras a las que se puede encomendar la misión de establecer cuál es el mejor tratamiento para recuperar el estado de salud. Por último, centrándonos en el ámbito específico de nuestra investigación, examinamos las creencias, actitudes y comportamientos que se suelen dar en las distintas culturas en relación con la salud reproductiva.

Con el fin de ilustrar los aspectos mencionados, proporcionamos (generalmente, en notas al pie) ejemplos de los patrones relativos a la salud de determinadas culturas; ${ }^{82}$ sin embargo, cabe señalar que no es posible aplicar dichos patrones a todos los individuos pertenecientes a una misma comunidad, ya que cada uno tendrá una identidad personal que se irá formando y transformando a lo largo de su vida, y que podrá incluir patrones asociados a distintos grupos culturales.

En el capítulo anterior hemos visto cómo la eliminación de las barreras lingüísticas (entendidas en sentido amplio, no solo por lo que respecta a las diferencias en el idioma) es un requisito indispensable para asegurar la eficacia de la comunicación entre los profesionales sanitarios y los pacientes inmigrantes. Sin embargo, la supresión de estas barreras no es suficiente para garantizar una asistencia sanitaria equitativa y de calidad, ya que las diferencias culturales pueden afectar igualmente a la relación entre los dos sujetos mencionados. Dichas diferencias, sumadas a la falta de conocimiento mutuo de la cultura del Otro y a la presencia de actitudes

\footnotetext{
${ }^{82}$ Tal y como hemos realizado en el capítulo anterior al exponer ejemplos de los patrones comunicativos habituales en algunas culturas, procuraremos que los ejemplos aportados en este capítulo también se centren principalmente en los colectivos inmigrantes de los que nos hemos ocupado en nuestro estudio de caso. El hecho de incluir los ejemplos concretos en notas al pie responde a dos motivos: por una parte, no pretendemos elaborar un tratado sobre los patrones relacionados con la salud en general, y la salud reproductiva en particular, en el que se recojan todas las creencias, comportamientos y actitudes de los colectivos señalados; por otra, nuestro propósito es exponer patrones generales, normalmente contraponiendo las culturas occidentales $y$, más concretamente, la española, a las culturas tradicionales, y los ejemplos incluidos tratan solo de ilustrar dichos patrones generales para facilitar su comprensión.
} 
etnocentristas, estereotipos y prejuicios, constituyen, en consecuencia, ulteriores obstáculos que pueden reducir el acceso a los servicios sanitarios por parte de los pacientes inmigrantes, así como la calidad de la asistencia que se les ofrece.

A modo de resumen, podemos decir que las dificultades para acceder al sistema de salud por parte de la población inmigrante y el consecuente escaso uso que estos realizan de los servicios sanitarios pueden deberse, además de a las barreras comunicativas descritas en las páginas previas, a otros factores de índole cultural, ${ }^{83}$ entre los cuales se encuentran, por ejemplo, la creencia que tienen los miembros de algunas comunidades de que el sufrimiento causado por la enfermedad es algo inevitable ${ }^{84}$ la desconfianza o la falta de familiaridad con el sistema sanitario occidental, la preferencia de tratamientos propios de la medicina tradicional, y el desconocimiento por parte de los profesionales sanitarios de la influencia que tiene la cultura sobre la salud (Lee, 2003:7-8).

En referencia al último aspecto mencionado y, centrándonos en el caso específico de los usuarios inmigrantes de los servicios sanitarios, cabe considerar que estos probablemente combinarán (dependiendo del grado de aculturación que hayan alcanzado en la sociedad de acogida) patrones culturales de su cultura de origen relativos al ámbito de la salud junto con patrones propios del país al que han emigrado. ${ }^{85}$ Para verificar en qué medida estos usuarios continúan manteniendo los valores, creencias y actitudes concernientes a la salud de su cultura de origen, autores como George Estes y Darryl Zitzow (1980) y Rachel E. Spector (2003) proponen emplear el que se conoce como "modelo de la consistencia hereditaria". Esta consistencia hereditaria se considera como un continuum en el que cada persona "can possess value characteristics and health beliefs and practices of both a heritage consistent (traditional) and a heritage inconsistent (modern) nature" (Spector, 2001:72).

De acuerdo con Nolan E. Penn et al. (1995), existen cinco áreas del ámbito de la salud que están influenciadas por la cultura:

- Solicitud de asistencia sanitaria: las creencias relacionadas con el origen de las enfermedades y con el concepto mismo de enfermedad influirán a la hora de determinar si el paciente solicita o no asistencia.

- Preferencia por determinados tratamientos: una vez se manifiestan los síntomas de una enfermedad, se preferirá un tratamiento concreto, en base a las creencias sobre la salud y la enfermedad y sobre los métodos de tratamiento de esta última.

- Aceptación de la asistencia sanitaria: la aceptación dependerá en gran medida de la familiaridad que el paciente tenga con el sistema sanitario.

\footnotetext{
${ }^{83}$ A las barreras lingüísticas y culturales cabría añadir, como hemos comentado en anteriores ocasiones, las barreras de carácter institucional o administrativo (como puede ser la dificultad para obtener la tarjeta sanitaria individual) o las de índole personal y social (como pueden ser las condiciones laborales y el hecho de que el trabajo constituya una prioridad para muchos inmigrantes).

${ }^{84}$ Por ejemplo, en la religión musulmana se cree que todas las personas tienen su destino escrito, de manera que, ante determinadas enfermedades, se reacciona con resignación, ya que se considera que estas son fruto de la voluntad de Dios y no es posible hacer nada por evitarlas (Ortí, 2009:23).

${ }^{85}$ Cabe considerar que la mayoría de inmigrantes residentes en España ya han tenido contacto previo en sus países de origen con la medicina occidental, la cual coexiste con las medicinas tradicionales en prácticamente todos los países del mundo, incluidos los europeos, donde la medicina tradicional sigue teniendo más peso del que se suele creer.
} 
- Comportamiento en cuanto a la salud: los valores y creencias culturales influirán en las medidas de prevención y promoción de la salud y en el estilo de vida.

- Interacción con los profesionales sanitarios: los patrones socioculturales generales y los estereotipos y prejuicios que derivan de la falta de comprensión de dichos patrones afectarán a las relaciones interpersonales e interculturales entre los profesionales y los pacientes.

Analizamos, a continuación, las cuatro primeras áreas, ya que la última de ellas se ha tratado de manera particular en el capítulo anterior, aunque querríamos recordar una vez más que las diferencias en los valores, creencias y actitudes relativos a la preservación y la recuperación de la salud (lo que se conoce como cultura sanitaria) están relacionados con los patrones socioculturales generales, e influyen en la interacción y la comunicación entre el personal sanitario y los pacientes.

\subsection{Patrones culturales en la asistencia sanitaria general}

\subsubsection{Concepto de salud y enfermedad}

Cada cultura posee una serie de pautas y normas específicas por las que se rigen sus miembros a la hora de enfrentarse a acontecimientos de la vida universales, como son el nacimiento, el apareamiento, la crianza, la enfermedad, el dolor y la muerte (Luckman, 2000:21 citado en Begley y Ockey, 2009:325). Este conjunto de representaciones y prácticas culturalmente estructuradas de las que disponen las distintas sociedades para hacer frente a los mencionados acontecimientos está relacionado con un determinado concepto de salud y enfermedad, el cual, a su vez, conllevará una preferencia por una manera de mantener y recuperar la salud y por una atención sanitaria concretas. De este modo, podemos afirmar que los conceptos de salud y enfermedad

[...] envuelven una compleja interacción entre los aspectos físicos, psicológicos, sociales y ambientales de la condición humana y de atribución de significados. [...] Salud y enfermedad son fenómenos clínicos y sociológicos vividos culturalmente [...], importan tanto por sus efectos en el cuerpo como por sus repercusiones en el imaginario: ambos son reales en sus consecuencias (De Souza Minayo, 1997:12-13, citada en Goldberg, 2003:15).

Así, si bien la salud, de acuerdo con la Organización Mundial de la Salud (1946), ${ }^{86}$ podría definirse como "el estado caracterizado por el bienestar físico, mental y social, y no solamente la ausencia de afecciones o enfermedades", cada cultura y cada persona percibirán dicho bienestar ${ }^{87}$ de manera distinta, y definirán qué puede considerarse enfermedad, así como el origen y la gravedad de la misma.

\footnotetext{
${ }^{86}$ Esta cita procede del Preámbulo de la Constitución de la Organización Mundial de la Salud, la cual fue adoptada por la Conferencia Sanitaria Internacional, celebrada en Nueva York del 19 de junio al 22 de julio de 1946, y fue firmada por los representantes de más de sesenta Estados. Dicha Constitución entró en vigor el 7 de abril de 1948 y, desde entonces hasta el año 2000, como veremos en el apartado del capítulo 6 dedicado al análisis documental, no se había modificado la definición de salud.

${ }^{87}$ Ya el mismo término "bienestar" se asocia a diferentes significados y, entre los factores que lo determinan, se señalan elementos variados, como la vida laboral, las relaciones sociales, la economía personal, o la salud. De hecho, el bienestar es un concepto amplio y con límites difusos, que abarca una serie de dimensiones distintas. Así, tal y como se afirma en el último informe publicado por la Organización Internacional para las Migraciones (Laczko y Anich, 2013:38), el bienestar se puede medir formulando preguntas a las personas sobre sus sentimientos y
} 
La disciplina que se encarga de estudiar la estrecha relación entre los patrones culturales y la salud es, como hemos comentado en capítulos anteriores, la antropología de la salud (también denominada antropología médica o antropología de la medicina).$^{88}$ Se trata de una rama de la antropología social y cultural que ha experimentado un gran desarrollo en las últimas décadas, y cuyas aportaciones han sido fundamentales en la revisión de la teoría de la enfermedad, ya que establece un vínculo entre la biología, la cultura y la sociedad. Asimismo, las investigaciones llevadas a cabo dentro de esta disciplina han permitido reconsiderar el concepto de cuerpo desde la perspectiva de sus representaciones culturales y de las prácticas sociales, y que se produzca una revalorización de los saberes y prácticas populares aplicados al mantenimiento de la salud y la atención a la enfermedad.

Aparte de los niveles descritos por Riccardo Colasanti y Salvatore Geraci (1995) ${ }^{89}$ resulta importante recordar la diferencia entre dos conceptos entre los cuales frecuentemente existe discrepancia; se trata, en concreto, de illness y disease. ${ }^{90}$ El primero, que podría calificarse en castellano como "padecimiento", se refiere a la experiencia subjetiva de la enfermedad, al modo en que el paciente (y quienes le rodean) entiende e interpreta su malestar según modalidades connotadas culturalmente y aprendidas en su entorno, la percepción personal de la enfermedad que lo lleva a solicitar asistencia médica. El segundo se corresponde con la representación médico-científica objetiva de la enfermedad, y su incidencia podría calificarse como universal, ya que "members of all carefully studied human groups are prone to develop [...] biological changes analogous to those that we term disease" (Fabrega, 1973:470). Tal y como explica Sonia Bacetti (2001:129):

[...] il medico o qualsiasi altro professionista della salute ha un approccio basato sulla razionalità scientifica, sull'esclusiva valorizzazione dell'oggettività e sulla misurazione quantitativa dei fenomeni, sulla dominanza dei dati fisico-chimici, sul dualismo corpo-mente, sulla concezione della malattia come entità, sulla separazione del corpo in tanti universi fra loro incomunicabili, sulla disponibilità di terapie efficaci, sull'impossibilità di affrontare da un punto di vista terapeutico i mille disturbi del vivere quotidiano.

[...] il paziente, invece, si contradistingue per l'attitudine a descrivere ciò che sente, a dare un'interpretazione che dipende dalla sua specifica cultura, a collegare le parti del suo corpo in una visione globale, a descrivere i sintomi di nessun significato diagnostico per il sanitario, a valorizzare il particolare rispetto al generale, a sottolineare ciò che sucede a lui, proprio a lui, indipendentemente da tutti gli studi epidemiologici.

percepciones relativas a diferentes aspectos de su vida, como la satisfacción con el trabajo, las relaciones personales y el apego a la comunidad, o mediante la recopilación y la verificación de datos objetivos, como pueden ser las tasas de empleo, los niveles salariales, la esperanza de vida y las condiciones de vivienda.

${ }^{88}$ En el contexto español, destaca la labor del grupo de investigación sobre Antropología de la Universitat Rovira i Virgili, una de cuyas líneas se centra precisamente en la Antropología médica y salud global, y entre cuyos investigadores se encuentra el Dr. Josep Maria Comelles, autor de numerosas publicaciones sobre este tema.

${ }^{89}$ Véanse, en el capítulo 3, las referencias al nivel cultural, relativo a la cultura sanitaria, y al nivel metacultural, concerniente a la manifestación de las creencias religiosas, ideológicas, filosóficas, etc.

${ }^{90}$ La distinción entre estas dos dimensiones de la enfermedad fue propuesta por el médico y antropólogo Horacio Jr. Fabrega en la década de los setenta del pasado siglo, haciéndose eco del desarrollo notable que estaban adquiriendo en esa época en los Estados Unidos los estudios sociológicos sobre la medicina occidental (Comelles y Martínez, 1993:52-54). 
Vemos, por tanto, que la visión del profesional sanitario se basará en la separación entre cuerpo y mente, ${ }^{91} \mathrm{y}$ en la percepción de cada caso a tratar de acuerdo con la enfermedad que, de conformidad con los datos obtenidos, se considera que padece el paciente. Por el contrario, en la visión del paciente, predominará su vivencia personal y global de la enfermedad, en la que tendrán cabida elementos subjetivos relacionados con la propia experiencia de padecimiento.

Si las expectativas fundadas en lo que el paciente siente (illness) no se cumplen, la interacción comunicativa entre este y el profesional de la salud podría verse afectada por los malentendidos, la falta de confianza y la hostilidad, de modo que resultará complicado obtener un diagnóstico fiable $y$, en caso de que este se consiga, el tratamiento o terapia aconsejados podrían no ser tenidos en cuenta.

Las expectativas recíprocas del profesional sanitario y el paciente, así como la consideración de la eficacia o ineficacia del tratamiento, dependerán de sus conceptos de cuerpo, salud y enfermedad, que estarán determinados, como hemos comentado previamente, por la cultura a la que pertenecen. Al mismo tiempo, cabe señalar que dichos conceptos, así como los valores asignados a temas como la vida y la muerte, son, por una parte, colectivos, es decir, representativos de la cultura a la que pertenecemos, pero, por otra, son personales e individuales, por lo que "no pueden reducirse a etiquetas étnicas clasificatorias y rígidas" (Comelles, 2009:26).

Además, cabe considerar que el profesional sanitario y el paciente no son los únicos implicados en el proceso de atención, sino que además participan dos entidades sociales, respectivamente, la institución sanitaria y la familia a las que pertenecen, las cuales influirán en las creencias y actuaciones de los primeros concernientes a la salud. Como sostiene Eduardo Menéndez (1994:71), "enfermar, morir, atender la enfermedad y la muerte deben ser pensados como procesos que no sólo se definen a partir de profesiones e instituciones dadas [...] sino como hechos sociales".

En consecuencia, a los conceptos de illness y disease se suma el concepto de sickness, que añade una dimensión social a la percepción de la salud y las enfermedades. Con esta incorporación de la dimensión social, autores como Allan Young (1987:257, citado en Comelles y Martínez, 1993:57-58), critican la perspectiva culturalista e interpretativista centrada en las dimensiones individuales de la enfermedad, frente a una orientación más sociológica y que tiene en consideración las prácticas y contextos sociales.

Por otro lado, el concepto del cuerpo ( $y$, por lo tanto, de la salud y la enfermedad) en las sociedades tradicionales forma parte de un conjunto de elementos interrelacionados que dan lugar a la identidad individual y social. Para muchas culturas tradicionales, individual y social son dos conceptos no opuestos $y$, por lo tanto, se es sujeto cuando se pertenece a la comunidad y se está integrado en la misma. En cambio, en las culturas occidentales, el ser humano suele considerarse una identidad individual, irrepetible y autónoma.

\footnotetext{
${ }^{91}$ Esta separación entre cuerpo y mente es, en cierto modo, relativa, ya que en el sistema médico occidental también se tienen en cuenta cuestiones como las somatizaciones, el efecto placebo, etc.
} 
En el mundo occidental, además, disociamos los conceptos de cuerpo y espíritu: para nosotros pueden existir interacciones entre estos dos elementos, pero los consideramos como dos categorías separadas. Por el contrario, en la mayor parte de las sociedades tradicionales, el cuerpo y el espíritu forman parte de un todo y, es más, como hemos señalado, a este concepto se incorporan también la familia y el grupo social. Por consiguiente, en la atención sanitaria a los pacientes inmigrantes, se deberían también tener en cuenta aspectos tales como la importancia de que el paciente esté acompañado por sus familiares, o el hecho de que se prefiera que determinados miembros de la familia o de la comunidad tomen decisiones a la hora de escoger una terapia o tratamiento.

Con respecto a la cuestión de los valores y creencias culturales relacionados con el rol y las responsabilidades de la familia, cabe señalar que, en las sociedades occidentales, en las que predomina, como veremos más adelante, el sistema biomédico, los profesionales de la salud han pasado de adoptar un enfoque paternalista al relacionarse con el enfermo, de acuerdo con el cual era el profesional quien, por los conocimientos de los que disponía, decidía según su criterio qué información necesitaba el paciente y cuáles eran las medidas terapéuticas más adecuadas en su caso, a incorporar el paradigma autonomista, surgiendo así un nuevo perfil de enfermo, que ahora cuenta con la capacidad de decidir, consentir o rechazar la propuesta de tratamiento que le plantee el profesional. Nace, de este modo, lo que se conoce como el derecho al consentimiento informado, que se ha ido configurando como una obligación legal en la mayoría de los países occidentales. En resumen, este derecho se materializa en las siguientes pautas: los pacientes tienen derecho a conocer toda la información respecto a su estado de salud; dicha información debe ser proporcionada de manera comprensible y adecuada a sus necesidades y requerimientos, con el fin de ayudarles a tomar decisiones autónomamente; debe respetarse la voluntad de aquellos pacientes que no quieran ser informados; y el titular de la información será el propio paciente, a menos que este se encuentre incapacitado para tomar decisiones, y solo si este lo permite, se podrá informar también a sus familiares o allegados. El derecho a la información y los tratamientos que enfatizan el rol del individuo en la recuperación de la salud propios del sistema médico occidental pueden entrar en conflicto con las expectativas de aquellos pacientes que consideran que la familia debe implicarse en dicha recuperación. Así, frente a la consideración en el sistema sanitario occidental de que el paciente tiene derecho a conocer el diagnóstico de su enfermedad, la prognosis y el tratamiento recomendado, en otras culturas, como es el caso de la cultura china o la mexicana, se prefiere que esta información se transmita a la familia, quien se encargará de este modo de proteger al paciente. Del mismo modo, la autonomía casi exigida al paciente en los servicios de salud occidentales, basada en los valores propios de su cultura (como son el individualismo y la independencia), choca con la importancia concedida a la familia en el proceso de atención propia de otras culturas. Tal y como afirman Polly A. Begley y Debbie A. Ockey (2009:328),

Caregivers teach patients to give themselves injections, change bandages, and take medications on their own. Hospital visiting hours are limited and most hospital rooms have only on visitor's chair. In other cultures, the importance of the extended family in the healing process is clearly recognized. 
En relación con el origen de las enfermedades, el sistema sanitario occidental se basa, como hemos comentado, en la separación general entre el cuerpo y la mente y, a partir de esta dicotomía, se sostiene que la enfermedad es causada por alteraciones fisiológicas (trastornos genéticos, desequilibrios bioquímicos, y organismos infecciosos) (Luckman, 2000:44). Por el contrario, en las sociedades tradicionales, en base a la unión entre los conceptos de cuerpo y mente y a la consideración de la enfermedad desde un punto de vista social, el origen de las enfermedades puede atribuirse a diversos factores, como, por ejemplo, la posesión por parte de espíritus o fuerzas malignas, la pérdida del equilibrio entre el calor y el frío, o entre conceptos como el yin y el yang, ${ }^{92}$ la falta de armonía con el entorno natural y social, etc. ${ }^{93}$

\subsubsection{Modos de prevención y cura de enfermedades}

Nuestra cultura no solo determinará el concepto que tengamos de salud y enfermedad, sino también el modo de enfrentarnos a esta última. Así, podemos afirmar que el origen cultural de una persona (sus valores, creencias, comportamientos, etc.) influye en el enfoque médico que adopta y en los remedios que escoge para prevenir la enfermedad o, en caso de que esta aparezca, para recuperar su salud. De hecho, las diversas culturas perciben, conocen y practican la asistencia de variadas maneras, a pesar de que existan algunos puntos en común en las diferentes culturas del mundo.

Tal y como afirma Eduardo Menéndez (1994:71),

[...] los padecimientos, como las respuestas hacia los mismos, constituyen procesos estructurales en todo sistema y en todo conjunto social, y, en consecuencia, dichos sistemas y conjuntos sociales no sólo generarán representaciones y prácticas, sino que estructurarán un saber para enfrentar, convivir, solucionar $y$, si es posible, erradicar los padecimientos.

De acuerdo con diversos autores (Spector, 2003; Galanti, 2008; Begley y Ockey, 2009), existen diferentes modelos de atención a la salud, entre los que se encuentran los siguientes:

Sistema biomédico: Este sistema, que cuenta con un conjunto específico de normas y valores basados en la evidencia científica, es el que predomina en la mayoría de las sociedades occidentales. Algunos de los parámetros por los que se rige datan de la medicina hipocrática del siglo $V$ a.C., en la cual se estableció un código de conducta y un enfoque científico que todavía hoy influyen en la práctica de la medicina moderna actual (Porter, 2002: 25, citado en Begley y Ockey, 2009, 326).

Se trata de un sistema distinguido por su carácter analítico, no holista, centrado en el funcionamiento de un determinado órgano, y no en el funcionamiento global del cuerpo. Se caracteriza, además, por "su biologicismo, su individualismo, su ahistoricidad, su asocialidad, su mercantilismo y su eficacia pragmática" (Menéndez, 1978, citado en Comelles, 2009:17). De hecho, entre sus particularidades, se encuentran, como hemos comentado previamente, el

\footnotetext{
92 El yin y el yang son dos conceptos empleados en la medicina tradicional china, entre los cuales debe existir un equilibrio que garantice el correcto funcionamiento del cuerpo. Al concepto de yin se atribuyen valores como la noche o el frío y, en contraposición, al yang le corresponden significados simbólicos asociados al día o al calor.

${ }^{93}$ Cabría matizar que las diferencias entre la medicina occidental y las medicinas tradicionales presentadas no son tan radicales, sino que también es posible hallar semejanzas entre ambos sistemas. Así, por ejemplo, en nuestra cultura, la enfermedad sigue presentando en muchos casos una fuerte consideración moral y social desde el punto de vista de los pacientes.
} 
concepto de la naturaleza biológica de la enfermedad (excluyendo o teniendo en poca consideración las variables relativas a la diversidad cultural o social), ${ }^{94}$ así como la priorización de las intervenciones clínicas sobre sujetos individuales, quedando relegadas a un segundo plano las políticas de salud colectiva y la contextualización histórica o sociocultural de los casos, en base a "la teórica igualdad de la especie humana y la universalidad de la enfermedad biológica" (Comelles, 2009:17).

Asimismo, por lo general, la biomedicina tiende a reducir los síntomas a signos, sin considerar el dolor del paciente como sufrimiento, sino más bien como un indicador subjetivo del trastorno padecido, y es "a partir de este esquema tan simple (cómo) se construye el conocimiento clínico" de este sistema médico (Comelles y Martínez, 1993, citados en Comelles, 2009:18).

La escasa consideración de los factores emotivos y psicológicos del paciente en el proceso de atención y cura puede provocar sentimientos negativos en el mismo; así, tal y como sostienen Polly A. Begley y Debbie A. Ockey (2009:327),

The major paradox of the biomedical approach is that even with an advanced and sophisticated understanding of the human body and disease, the individual patient often feels afraid, isolated and left out of the process.

Como hemos mencionado anteriormente, en el sistema biomédico se considera que las enfermedades están causadas por factores biológicos y agentes externos (virus, parásitos, etc.), de ahí que, entre los diversos modos que recomienda a la hora de prevenirlas se encuentren cuestiones relacionadas con los hábitos diarios (como la alimentación o el ejercicio físico) y el recurso a métodos científicos (como las vacunaciones). En cuanto a los tratamientos para recuperar la salud que propone este sistema, destacan los medicamentos o las operaciones quirúrgicas.

Sistema médico basado en creencias mágico-religiosas: En contraste con el sistema biomédico, este sistema de medicina tradicional considera que las enfermedades están causadas por espíritus malignos, la posesión del cuerpo por parte de fuerzas ajenas, hechizos y maleficios, o sustos que provocan que las almas abandonen el cuerpo y vaguen errantes. Este sistema médico se basa en la creencia de que el mundo es un escenario dominado por fuerzas supernaturales y que, en ocasiones, la enfermedad es un castigo por un determinado comportamiento trasgresor (Galanti, 2008:21) ${ }^{95}$ Cabe destacar que este sistema de medicina

\footnotetext{
${ }^{94}$ Si bien en el ámbito español, en los últimos años, han proliferado el número de investigaciones que estudian la salud de la población inmigrante (véanse, por ejemplo, los artículos publicados en las últimas décadas en revistas como Cultura de los Cuidados, Gaceta Sanitaria o Index de Enfermería), el hecho de que en numerosos informes oficiales elaborados en España relativos al estado de salud de la población no se incluyan datos sobre el origen étnico y cultural de los pacientes es una muestra de esta escasa consideración de las variables culturales en el sistema sanitario español. Así, por ejemplo, en nuestro estudio de caso, cuyos resultados presentaremos en el capítulo 6, no nos resultó posible obtener información (sobre el número de nacimientos, los abortos y cesáreas practicadas, la preferencia por la anestesia epidural u otros analgésicos para reducir el dolor del parto, el recurso a la lactancia materna, etc.) referente a madres de origen extranjero, ya que el hospital contexto de estudio no disponía de datos disgregados de sus usuarias en los que se reflejara la variable de la nacionalidad.

${ }_{95}$ Por ejemplo, los chamanes del Amazonas que creen en el sistema médico mágico-religioso consideran que todos los pensamientos negativos son espíritus malignos que nos hablan tratando de asustarnos y que, a través de nuestra reacción ante el miedo que nos provocan, aumentan su fortaleza hasta que consiguen dominarnos completamente (Salak, 2006:4, citada en Begley y Ockey, 2009, 326). Por su parte, los sanadores de la comunidad
} 
popular, muy marcado espiritualmente, también cuenta con profundos conocimientos sobre plantas curativas y similares. En él, además, tiene un peso muy importante la que quizás sea la forma de atención sanitaria más usada universalmente: la familiar.

Sistema médico basado en una concepción holística de la salud: De acuerdo con el enfoque holístico de la salud, se considera que una persona debe vivir en armonía con las leyes naturales y ser capaz de ir ajustándose a los cambios que se producen en su entorno para reestablecer el equilibrio del cuerpo (Luckman, 2000:45). Según este sistema médico, la salud es un estado positivo de bienestar determinado por factores ambientales, socioculturales y de comportamiento, y los tratamientos para recuperarla cuando se ha perdido tratan de devolver al paciente al estado de equilibrio (Galanti, 2008:21). Es bastante frecuente en este sistema médico que, en base a la concepción holística del cuerpo, se conceda especial importancia a los canales o conductos energéticos que conectan orgánicamente las diferentes partes del mismo, y por los que circulan flujos o humores, así como aires o vientos que penetran en él y pueden afectar negativamente al buen funcionamiento del organismo (Raga, 2009:124). Dentro de este sistema médico se encuentran, por ejemplo, la medicina tradicional china o la medicina ayurvédica india.

Medicina alternativa o tradicional: Las prácticas médicas mágico-religiosas y holísticas no están claramente delimitadas, de manera que no existe un acuerdo sobre qué enfoques médicos se incluirían en cada uno de estos dos sistemas, e incluso algunas prácticas presentan características de ambos sistemas a la vez. En consecuencia, se emplea a menudo el término "medicina alternativa" para describir cualquier tipo de práctica médica que no está aceptada o no se utiliza en el sistema biomédico. Dentro de este grupo de prácticas se incluirían, entre otras, la quiropráctica, los masajes terapéuticos, la hipnosis, las terapias basadas en hierbas naturales, la homeopatía y la naturopatía. Hoy en día, este tipo de medicina está cobrando cada vez más relevancia y es creciente el número de personas que recurren a la misma, incluso en las sociedades occidentales en las que predomina el sistema biomédico. ${ }^{96}$

Cabría precisar una cuestión con respecto a la terminología empleada para definir estas prácticas. El término "alternativa" implica una dicotomía entre el sistema biomédico y cualquier otra práctica de cura y prevención, por lo que la biomedicina parece ser la alternativa por defecto a la que puede optar cualquier persona. Tal y como sostiene Cecilia Oleck (2007, citada en Begley y Ockey, 2009, 327), el uso del adjetivo "alternativo" para referirse a todas las prácticas que no se engloban dentro del sistema biomédico no resulta adecuado, ya que "as more healthcare providers offer such services, it makes sense to refer to these therapies as complementary or integrative".

Así, estamos de acuerdo con Eduardo Menéndez (1994:72), cuando sostiene que

[...] la medicina denominada científica constituye una de las formas institucionalizadas de atención de la enfermedad y, en gran parte de las sociedades, ha llegado a ser identificada como la forma más correcta y eficaz de atender el proceso salud/enfermedad. Pero desde

hmong, llamados twiv neeb, consideran que las enfermedades son muestra de que la persona que las padece ha perdido una de sus almas, y llevan a cabo ceremonias para poder recuperarlas (Fadiman, 1997).

${ }^{96}$ Cabe señalar que la adopción de prácticas de medicina alternativa por parte de personas que proceden de países en los que el sistema dominante es el biomédico no supone casi nunca el rechazo absoluto de este sistema, sino la combinación o alternancia de ambos. 
nuestra perspectiva, tanto ésta como las otras formas académicas y/o academizadas (homeopatía, quiropracia, etcétera), o populares (herbolaria, espiritualismo, entre otros) de atender a los padecimientos, tienen el carácter de "instituciones", es decir instituyen una determinada manera de "pensar" e intervenir sobre las enfermedades y, por supuesto, sobre los enfermos. (comillas del original)

Por su parte, Rachel E. Spector (2003:33-34) también defiende el uso de la expresión "medicina tradicional" con respecto al uso de "medicina alternativa", y considera que los métodos tradicionales pueden usarse en sustitución o como complemento de otros métodos científicos o modernos, por lo que hablaremos de "métodos alternativos" al referirnos a "aquellos que la persona elegiría usar y que no son parte de su herencia particular". En relación con los métodos tradicionales, Rachel E. Spector propone un modelo (el Modelo de tradiciones de la salud), que recoge los diferentes modos que tienen las personas para mantener, proteger o recuperar la salud. Se trata de un modelo holístico, en el que, al tratar la salud y la enfermedad, no se consideran únicamente los aspectos físicos, sino también los mentales o espirituales, y se sostiene que el estado de salud dependerá del equilibrio o armonía con la familia, la comunidad y las fuerzas de la naturaleza. De acuerdo con la mencionada autora, la salud, en este contexto tradicional, posee nueve facetas interrelacionadas, divididas, tal y como figura en la tabla que presentamos a continuación, en diferentes métodos empleados por las personas para el mantenimiento, la protección y la recuperación de su salud física, mental y espiritual.

\begin{tabular}{|c|c|c|c|}
\hline & Salud FísICA & Salud MENTAL & Salud ESPIRITUAL \\
\hline $\begin{array}{l}\text { Mantenimiento de la } \\
\text { SALUD }\end{array}$ & $\begin{array}{l}\text { Ropa adecuada } \\
\text { Dieta adecuada } \\
\text { Ejercicio/descanso }\end{array}$ & $\begin{array}{l}\text { Concentración } \\
\text { Redes de apoyo social y } \\
\text { familiar } \\
\text { Aficiones }\end{array}$ & $\begin{array}{l}\text { Culto religioso } \\
\text { Oración } \\
\text { Meditación }\end{array}$ \\
\hline $\begin{array}{l}\text { Protección de la } \\
\text { SALUD }\end{array}$ & $\begin{array}{l}\text { Ciertos alimentos y } \\
\text { combinaciones } \\
\text { Prendas simbólicas }\end{array}$ & $\begin{array}{l}\text { Evitar personas que se } \\
\text { cree que causan algún } \\
\text { mal }\end{array}$ & $\begin{array}{l}\text { Costumbres religiosas } \\
\text { Supersticiones } \\
\text { Amuletos y otros } \\
\text { objetos simbólicos }\end{array}$ \\
\hline $\begin{array}{l}\text { Recuperación de la } \\
\text { SALUD }\end{array}$ & $\begin{array}{l}\text { Remedios } \\
\text { homeopáticos } \\
\text { Alimentos especiales } \\
\text { Masajes } \\
\text { Acupuntura, } \\
\text { moxibustión }\end{array}$ & $\begin{array}{l}\text { Relajación } \\
\text { Exorcismo } \\
\text { Infusiones }\end{array}$ & $\begin{array}{l}\text { Rituales religiosos y } \\
\text { oraciones } \\
\text { Meditaciones } \\
\text { Curaciones } \\
\text { tradicionales } \\
\text { Exorcismo }\end{array}$ \\
\hline
\end{tabular}

Tabla 4.1. Las nueve facetas interrelacionadas de la salud (física, mental y espiritual) y los métodos para mantenerla, protegerla y recuperarla (Spector, 2003:34)

En primer lugar, en cuanto al mantenimiento de la salud, los métodos tradicionales para preservar la salud física son aquellos usados a diario de forma activa, como puede ser el uso de una vestimenta o el seguimiento de una dieta concretas. Estos aspectos pueden estar fuertemente influenciados por los valores y creencias culturales y religiosos, que podrían exigir, por ejemplo, que se preparen y se ingieran determinados alimentos, estableciendo 
algunos tabúes y restricciones. ${ }^{97}$ De hecho, la alimentación puede considerarse también un fenómeno social, cultural e identitario. Así, tal y como afirma Jesús Contreras (2007:1),

Creamos categorías de alimentos (saludables y no saludables, convenientes y no convenientes, ordinarios y festivos, buenos y malos, femeninos y masculinos, adultos e infantiles, calientes y fríos, puros e impuros, sagrados y profanos, etc.) y, mediante estas clasificaciones, construimos las normas que rigen nuestra relación con la comida e, incluso, nuestras relaciones con las demás personas, de acuerdo, también, con sus diferentes categorías. La alimentación, pues, está pautada por el sistema de creencias y valores existente en cualquier cultura y momento, que puede determinar, a su vez, qué alimentos son objeto de aceptación o rechazo en cada situación y para cada tipo de persona.

Por lo que respecta al mantenimiento de la salud mental, de acuerdo con los métodos tradicionales, este se fundamenta principalmente en las relaciones con la familia y con otras redes de apoyo social, en base al carácter colectivista que presentan generalmente las culturas que siguen estos métodos. Y, con relación a la salud espiritual, cabe destacar, entre las diferentes formas para mantenerla, la celebración de ritos de paso ${ }^{98}$ y de ceremonias sagradas (Spector, 2003:35).

En segundo lugar, en referencia a los modos tradicionales de proteger la salud, estos se fundamentan en la creencia de que "el mal, la enfermedad y el infortunio se pueden prevenir cuidándose, evitando personas y situaciones perjudiciales y elementos dañinos que no se entienden" (Spector, 2003:35). Como hemos mencionado previamente al hablar del origen atribuido a las enfermedades, en ocasiones este se asocia a un castigo por un mal comportamiento, a una maldición o a la influencia de una persona que desea causarnos algún daño. Así, la salud física se protegerá mediante determinados comportamientos relacionados con cuestiones alimentarias o de vestimenta. Por su parte, la protección de la salud mental se basará en evitar a las personas o situaciones que podrían comprometerla, así como en mantener un fuerte lazo de unión con la familia y la comunidad. Y, por lo que se refiere a la salud espiritual, en base a las creencias relacionadas con la religión o la superstición, esta se podrá proteger, por ejemplo, usando determinados amuletos o talismanes. ${ }^{99}$

\footnotetext{
${ }^{97}$ Por ejemplo, el Islam establece una serie de normas que todos los practicantes de esta religión deben seguir en relación con su alimentación. Entre dichas normas, destaca la prohibición de ingerir carne de cerdo o bebidas alcohólicas, o la obligación de consumir carne halal, que implica que el sacrificio del animal debe seguir un ritual consistente en el degüelle del mismo cortándole la garganta, el conducto respiratorio y el conducto alimentario, así como las dos venas yugulares. De este modo, el alma del animal escapa del cuerpo con su sangre. Asimismo, la columna vertebral del animal no debe ser tocada, pues, de lo contrario, el animal resultaría impuro. Además, el degüelle debe ser efectuado por un musulmán. Otro de los preceptos de la religión musulmana relativos a la alimentación se refiere al ayuno estricto $(s a w m)$ en el mes del Ramadán, periodo durante el cual, desde el alba hasta el anochecer, se excluye la posibilidad de ingerir cualquier comida o bebida (así como de mantener relaciones sexuales o fumar).

${ }^{98}$ Por ejemplo, en algunos países de África Subsahariana (con variabilidad con respecto a las zonas geográficas y el grado de amplitud de la zona amputada), se practica la mutilación genital femenina como parte del rito de paso de niña a mujer (Raga, 2009:129).

${ }^{99}$ Por ejemplo, en algunas culturas del África occidental existe la creencia de que los espíritus pueden atacar a los recién nacidos (y a los adultos), por lo cual se sigue la costumbre de intentar protegerlos de diversas maneras, entre las que se incluiría el uso de determinados objetos como amuletos (Raga, inédito: 15).
} 
En tercer lugar, a la hora de recuperar la salud física, mental y espiritual, las personas que se guíen por los métodos tradicionales emplearán remedios naturales (como infusiones, masajes), así como rituales sanatorios (como el exorcismo, la oración o la meditación) ${ }^{100}$.

Los tratamientos y modos de cura propuestos por los diferentes sistemas médicos pueden chocar entre sí y conducir a malentendidos o conflictos entre los profesionales sanitarios y los pacientes culturalmente diversos. Así, por ejemplo, un gran número de profesionales sanitarios occidentales no presenta conocimientos sobre los tratamientos de la medicina tradicional y la influencia que pueden tener sobre la salud del paciente, especialmente cuando se combinan con tratamientos propios de la medicina occidental. Asimismo, determinados tratamientos tradicionales, como la moxibustión ${ }^{101}$ o la curación con monedas, ${ }^{102}$ pueden producir marcas superficiales en la piel, que podrían ser malinterpretadas por los profesionales sanitarios occidentales como lesiones producidas por abusos o por patologías. Igualmente, los análisis de sangre prescritos en la medicina occidental pueden ser negativamente vistos o no aceptados por pacientes procedentes de culturas como las asiáticas, que consideran la sangre como el canal por el que discurre la energía vital y que se distribuye armónicamente por todo el cuerpo.

\subsubsection{Figuras sanadoras y su relación con el enfermo}

Un elemento común a todas las sociedades es que sus miembros, cuando están o se sienten enfermos, acuden en busca de alguien que sea capaz de ayudarles a recuperar su salud. Sin embargo, los miembros de cada cultura escogerán recurrir a determinadas figuras sanadoras dependiendo de su concepto de salud y enfermedad, así como de una serie de patrones culturalmente connotados y de su experiencia previa.

En el sistema biomédico, los responsables de los cuidados de la salud son una serie de profesionales con diferentes categorías (médicos, enfermeros, etc.) que han recibido una educación universitaria formal que les habilita para desempeñar su profesión. Por el contrario, en los sistemas médicos tradicionales, esta responsabilidad recae sobre figuras sanadoras específicas que ostentan el poder de curar y que, normalmente, son poseedores de conocimientos y costumbres milenarios. De acuerdo con Rachel E. Spector (1999:70), "el

\footnotetext{
${ }^{100}$ Por ejemplo, la práctica de la meditación es uno de los métodos empleados en el sistema tradicional ayurvédico propio de la comunidad hindú, de acuerdo con el cual, esta práctica, junto con otras como el yoga o la respiración rítmica, se emplean para recuperar la salud gracias a su propiedad de transmitir a varias partes del cuerpo energía (o prana) a través de los siete chacras o "fuentes de energía" (Galanti, 2008:211-212).

${ }^{101}$ La moxibustión es una técnica médica tradicional china que consiste en introducir calor en el organismo del paciente, en concreto, en los puntos de acupuntura de los meridianos principales, con el objetivo de tonificar el cuerpo. Para ello se utilizan los moxas, unos bastoncitos elaborados con hojas secas de artemisa que se calientan hasta la incandescencia y, a continuación, se acercan al punto de acupuntura. Se emplea principalmente en los reumatismos. Fuente de la definición: Diccionario médico Doctissimo. [http://salud.doctissimo.es/diccionariomedico/moxibustion.html] (última consulta: 2 de septiembre de 2013).

102 La curación con monedas (coining o cao gio) es un tratamiento tradicional común en el sudeste asiático para enfermedades de poca relevancia, como la gripe, el dolor de cabeza, la tos, o bajo nivel de energía. Consiste en untar la piel con aceite caliente (las áreas de tratamiento más habituales son el pecho, la espalda o los hombros) y luego frotar una moneda por encima del área hasta que se vea una marca roja, estableciendo así un "un portal para que salga el viento maligno" que ha entrado en la sangre del paciente. [http://www.ucsfchildcarehealth.org/pdfs/factsheets/Coining_En0210.pdf] (última consulta: 2 de septiembre de 2013).
} 
sanador puede ser un hombre o una mujer y lo más frecuente es que la persona piense que ha recibido el regalo de poder sanar desde una fuente divina".

Las figuras sanadoras tradicionales reciben diferentes nombres (curanderos, chamanes, brujos, adivinos, parteras o, más específicamente y a modo de ejemplo, marabouts, ${ }^{103}$ vaids y hakims, ${ }^{104}$ o twiv neeb) ${ }^{105}$ y a ellas se les atribuyen determinados poderes y capacidades que varían de una cultura a otra.

Los miembros de las culturas en las que se recurre a la medicina tradicional pueden consultar a este tipo de sanadores antes, simultáneamente o en sustitución de los profesionales de la salud occidentales, o pueden escoger a uno o a otro dependiendo de la dolencia específica que padezcan.

Aparte del recurso a una $u$ otra figura sanadora con el fin de recuperar el estado de salud, los miembros de las diferentes culturas verán de modo distinto la relación que se debe establecer entre dicho sanador y el paciente. La relación suele ser más fría, distante y asimétrica en el caso de las sociedades occidentales, mientras que, en otras culturas, se espera del paciente y del sanador una implicación personal y emocional y una relación mucho más cercana, por lo que el comportamiento de los profesionales sanitarios occidentales podría interpretarse negativamente por parte de los usuarios inmigrantes. Así, tal y como sostiene Rena C. Gropper (1996:3),

[...] the professional's family background and temperament, not just the professional credentials and experience, are necessary components of the relationship. In other words, members of these cultures emphasize the personal and emotional in interpersonal relations, while middle-class American professionals ${ }^{106}$ are trained to an instrumental, fragmented, coolheated approach, which leads them to believe that a limited piece of the total personality is appropriate to a health encounter. Not surprisingly, such a professional approach may be interpreted by the client-family as insincere, if not secretive.

Asimismo, las expectativas del paciente con respecto a su relación con el profesional también pueden variar en relación con el tiempo que espera que este le dedique durante la consulta. Como afirma Dora Sales (2009:105),

En la medicina tradicional las entrevistas médico-paciente no tienen una duración determinada: cada paciente es un caso, se atiende a la persona y se emplea con ella el tiempo que haga falta, lo que choca mucho con lo que estos pacientes perciben como excesiva rapidez en las consultas occidentales. En la medicina occidental el paciente recibe preguntas directas y la duración de la entrevista médica es corta con respecto a sus expectativas.

\footnotetext{
${ }^{103}$ Los marabouts son líderes religiosos musulmanes, considerados también como maestros, a los que se atribuye el poder de preservar y recuperar el estado de salud en países como Argelia, Marruecos, Túnez o Senegal, y que en sus tratamientos suelen combinar prácticas y simbolismos musulmanes y animistas.

104 Los vaids y los hakims son figuras sanadoras a las que se recurre en países como la India, Bangladesh o Paquistán.

${ }^{105}$ Los twiv neeb son, como hemos comentado previamente, figuras sandaoras a las que se recurre comúnmente en la cultura hmong.

${ }^{106}$ Si bien la autora citada se refiere a los profesionales del sistema sanitario de los Estados Unidos, nosotros hacemos extensible el comportamiento descrito a la mayoría de los profesionales de la salud occidentales que se rigen por el sistema biomédico.
} 
Por último, cabe señalar que el origen cultural del paciente también podrá determinar su preferencia por profesionales sanitarios o figuras sanadoras de uno u otro sexo. Así, por ejemplo, las usuarias de religión musulmana, de acuerdo con el sentido del pudor propio de su cultura, así como en relación con otras cuestiones culturales relativas al concepto del espacio y a los roles atribuidos a los hombres y las mujeres, preferirán, por lo general, y como comentaremos más detalladamente en el próximo apartado, que el profesional sanitario que las trate sea de sexo femenino.

\subsection{Patrones culturales relacionados con la salud reproductiva}

Como hemos comentado en el capítulo 1, la progresiva feminización de los flujos migratorios que ha recibido nuestro país, junto con el hecho de que las mujeres inmigrantes, por lo general, presenten una edad joven $y$, por tanto, fértil, ha conllevado que su presencia en los servicios de obstetricia españoles sea cada vez más significativa.

La asistencia sanitaria a estas mujeres en el ámbito de la salud reproductiva, al igual que sucede con la asistencia sanitaria general, puede presentar barreras no solo de tipo lingüístico, sino también de tipo cultural; así lo confirman autores como Miguel Ángel Luque Fernández y María Isabel Oliver (2005:10), cuando sostienen que la reproducción y la maternidad "constituyen fenómenos bio-culturales donde se reflejan valores, sentimientos y creencias".

Cabe destacar, de todos modos, que los fenómenos asociados a la reproducción y a la maternidad que experimentan las mujeres de origen extranjero no pueden atribuirse únicamente a su condición de inmigrantes y a sus patrones culturales, sino que será necesario tener en cuenta la influencia que podrían ejercer otros factores, entre los que se encuentran los siguientes (Oliver, Baraza y Martínez, 2007:82):

a) Las desigualdades con respecto a la salud que se basan en cuestiones de tipo socioeconómico, y que podrían afectar tanto a la población inmigrante como a la autóctona.

b) Las desigualdades de género, que se puede dar tanto en los países de origen como en los de destino.

c) La situación y funcionamiento de los servicios sanitarios de sus países de origen, que influirán en la aceptación de los patrones sanitarios propios del país de acogida.

Dicho en otras palabras, a la hora de atender a las mujeres inmigrantes en los servicios de obstetricia, será necesario conocer su realidad y su contexto, tanto antes como después de la emigración, esto es, la situación y el rol de la mujer en su país de origen, la experiencia sanitaria que las pacientes hayan podido vivir en dicho país, y su adaptación al sistema sanitario de la sociedad de acogida (Alonso, 2010:360).

Cuando hablamos de salud reproductiva, nos referimos a

[...] un estado general de bienestar físico, mental y social, y no de una mera ausencia de enfermedades o dolencias, en todos los aspectos relacionados con el sistema reproductivo y con sus funciones y procesos (Organización Mundial de la Salud, 1994). 
Esta definición fue propuesta por la Organización Mundial de la Salud y aprobada en la Conferencia Internacional sobre la Población y el Desarrollo celebrada en El Cairo en 1994. En ella se incluye la capacidad de procrear (o no) y la libertad para decidir cuándo hacerlo y con qué frecuencia, lo cual lleva implícito el derecho de los hombres y las mujeres a obtener información que les permita planificar el tipo de familia que desean formar, a conocer y tener acceso a diferentes métodos anticonceptivos, y a recibir una asistencia sanitaria adecuada durante el embarazo y el parto, que garantice la minimización de los riesgos y ofrezca las máximas posibilidades de que tanto la madre como el hijo no presenten problemas de salud.

De conformidad con la definición presentada, cuando hablamos de la atención a la salud reproductiva, nos referimos a "un conjunto de métodos, técnicas y servicios que contribuyen a la salud y al bienestar reproductivos, al evitar y resolver los problemas asociados" a este ámbito de la salud (Ollé, 2009:100).

Del estudio de la relación entre la cultura y la salud reproductiva se encarga la disciplina de la antropología de la reproducción, según la cual, a pesar de que el embarazo y el parto son procesos universales en lo que se refiere a la fisiología del cuerpo femenino, no pueden considerarse como meros procesos biológicos, sino que se encuentran "culturalmente moldeados, dándose de diferentes maneras en cada sociedad y en los diferentes grupos sociales" (Blázquez, 2005:2). La aproximación antropológica a los aspectos relacionados con la salud reproductiva ha contribuido a demostrar que "no hay un único modelo ni un sólo discurso sobre la maternidad, existiendo, tanto intra como interculturalmente, múltiples modos de ser madre" (Heras y Téllez, 2005:66).

De hecho, las distintas comunidades pueden presentar diferencias culturales en relación con las creencias, comportamientos y actitudes durante todo el proceso reproductivo (embarazo, parto y puerperio), y las expectativas, decisiones y obstáculos que las familias perciban durante dicho proceso estarán condicionadas, además, por sus circunstancias materiales de vida, por el tipo de relaciones y el apoyo de redes sociales con los que cuenten, por las oportunidades que tengan de acceder a los servicios de salud $y$, especialmente, por su bagaje cultural .

Así, para las mujeres inmigrantes, el hecho de acudir a nuestros servicios sanitarios durante la gestación o para dar a luz puede suponer un gran choque, por

[...] enfrentarse no sólo con una población que habla en una lengua distinta, sino que concibe universos simbólicos que hacen referencia a las cosas importantes de la vida de las mujeres (matrimonio, maternidad, percepción de su estado de salud, de su cuerpo, de su identidad étnica y de género) de una forma muy diferente y muchas veces estigmatizada (Kaplan, 2006:110).

En el presente apartado, analizamos aspectos como las especificidades culturales en relación con el sentido del pudor, la preferencia por parte de las usuarias de uno u otro género (masculino o femenino) en los profesionales dedicados a la asistencia obstétrica, las costumbres relacionadas con la planificación familiar y el uso de métodos anticonceptivos, la percepción y la expresión del dolor durante el parto, la aceptación del parto medicalizado (por ejemplo, mediante la suministración de la anestesia epidural) y otras preferencias al respecto 
de este momento (acompañamiento, posturas, etc.), así como las principales pautas de comportamiento de las puérperas y su interacción con el recién nacido.

En nuestro análisis de los patrones culturales relacionados con la salud reproductiva, adoptamos una perspectiva antropológica y, al mismo tiempo, aplicamos un enfoque de género, con la finalidad de manifestar cómo los comportamientos y creencias relacionados con el proceso de reproducción son, en cierto sentido, indicadores de los roles atribuidos a los hombres y las mujeres en las distintas sociedades. Muestra de la relación entre los patrones reproductivos y los roles de género son, por ejemplo, las distintas representaciones de la mujer gestante o los modelos de maternidad y paternidad aplicados en las diferentes culturas. Asimismo, cabe señalar que las desigualdades de género y la doble situación de discriminación a la que están sujetas las mujeres inmigrantes (por su condición de inmigrantes y de mujeres) podrán determinar mayores dificultades de acceso a los servicios sanitarios.

Antes de pasar a estudiar las cuestiones mencionadas, es necesario tener en cuenta que, por lo general, las mujeres inmigrantes suelen combinar las concepciones socio-culturales y sanitarias de origen, previas a la inmigración, con las concepciones propias del país de destino, es decir, modifican algunos de los comportamientos que presentaban antes de emigrar y conservan otros. Esto demuestra que no es posible establecer una concepción rígida, estática y estereotipada de las mujeres de una determinada comunidad cultural en cuanto a sus patrones reproductivos, sino que sus creencias y prácticas en el ámbito de la salud variarán en función de diferentes aspectos, ${ }^{107}$ como la edad, las condiciones socio-laborales, el nivel educativo, el nivel de desarrollo de sus países de origen, la procedencia rural o urbana, la religión, el tiempo de permanencia en el país de acogida, o su dominio de la lengua de dicho país (Oliver, Baraza y Martínez, 2007:83).

Al respecto de la posibilidad de conjugar los patrones de origen con los de la sociedad de acogida, estamos de acuerdo con Zuanilda Mendoza (2009:313), cuando sostiene que

Postular la existencia de un sistema mixto nos lleva a aceptar la presencia de diferentes alternativas de atención -no siempre integradas armónicamente-, así como a pensar que todo proyecto o programa (de atención a la salud reproductiva) debe advertir la importancia de la diversidad.

Igualmente, quisiéramos precisar que las creencias, valores y actitudes relacionados con el proceso de reproducción, con el paso del tiempo, experimentan modificaciones en todas las sociedades. Así, por ejemplo, en nuestro contexto, se ha pasado de otorgar un carácter privado a este proceso, vinculándolo al espacio del hogar y, generalmente, contando con el apoyo de miembros femeninos de la comunidad, a convertirse progresivamente en un suceso de interés social sobre el cual se puede ejercer control y que presenta un importante valor político y económico. La gradual medicalización de la asistencia durante el embarazo, el parto y el puerperio que se ha dado en los países occidentales ha propiciado que un hecho de carácter fisiológico pasara a considerarse como un proceso patológico, entendido como un problema de salud, justificando así la intervención sanitaria que recibe. Con la transición del espacio privado al espacio público, el proceso reproductivo

\footnotetext{
107 Aunque las autoras citadas no lo mencionan, otro aspecto que influirá en los patrones reproductivos de las mujeres será, obviamente, su personalidad individual.
} 
[...] deja de ser un fenómeno compartido por la mujer con sus redes sociales, y es el personal médico, principalmente obstetras, quienes dirigen, deciden y están presentes; se concibe como un acontecimiento aislado de su entorno, igual y uniforme para todas las gestantes, basado fundamentalmente en su carácter biológico (García y Díaz, 2010:331).

Si bien este control biomédico de la salud reproductiva presenta algunos beneficios (como pueden ser la reducción de la morbilidad y la mortalidad maternales y perinatales o la erradicación de algunos problemas de infertilidad), la medicalización de un proceso biológico que, en condiciones "normales", 108 no plantea apenas riesgos para la salud, así como la consideración del mismo desde un punto de vista fisiológico, sin tener en cuenta sus características psicosociales, convierte la gestación en un problema médico aislado, en el que la mujer gestante pasa de ser la protagonista a convertirse en un sujeto pasivo y dependiente y "asistible". Como afirma María Jesús Montes (2010:20),

Ser "asistible" en nuestro contexto significa que la persona obtiene unas prerrogativas, pero sobre todo la obligación -para el mantenimiento de la buena salud- de utilizar los servicios institucionales que se proporcionan [...]. Y ello debe hacerse aceptando sus propuestas y cumpliendo sus normas y dictámenes, los únicos -se entiende- que podrán exorcizar los riesgos. En las mujeres gestantes esta obligatoriedad se acompaña además de una profunda dimensión social: ya no es solo su salud la que parece estar en juego, sino la salud y seguridad del feto. (comillas del original)

Además, como señalan Dailys García y Zoe Díaz (2010:332), en esta concepción del proceso reproductivo "se dota de personalidad al feto, y la mujer se convierte en el entorno, lo que conduce a su invisibilización".

Frente a esta excesiva medicalización, se han realizado esfuerzos por devolver el protagonismo a las mujeres, siendo un ejemplo de los mismos la Conferencia Internacional sobre la Humanización del Parto celebrada en Fortaleza (Brasil) en el año 2010, donde, con la intención de garantizar el bienestar de los propios sujetos implicados en el proceso de reproducción, se plantea devolver la responsabilidad y el protagonismo a dichos sujetos, como muestra de progreso y desarrollo humanos. ${ }^{109}$

\subsubsection{Comportamientos, creencias y actitudes asociados a la fecundidad y la infertilidad}

Históricamente, a las mujeres se les ha asociado el rol de madres como una característica innata a su condición femenina. Así, durante muchos siglos,

Las mujeres han sido contempladas como meras reproductoras biológicas; la paternidad ha sido vista como un hecho social variable, mientras que la maternidad se ha pensado dependiente de la naturaleza, a partir de la separación absoluta entre lo doméstico y lo público, lo productivo y lo reproductivo (Narotzky, 1995, citada en Esteban, 2006:12).

En las sociedades occidentales, factores como la progresiva incorporación de la mujer al mercado laboral, el mayor acceso a la educación y los avances en los métodos anticonceptivos

\footnotetext{
108 Cabe señalar que el concepto de "normalidad" en la gestación y en el parto no está estandarizado ni universalizado, sino que puede presentar diferentes matices en las distintas culturas.

${ }^{109}$ La intención de humanizar el proceso del parto queda también reflejada en la" Estrategia de atención al parto normal en el Sistema Nacional de Salud" aprobada en nuestro país en el año 2007, y de cuyo análisis nos ocuparemos en el capítulo 6.
} 
han limitado la visión de la maternidad como una obligación o un fin en sí misma, pasando a ser una posibilidad más entre otras de su vida. Por el contrario, en algunas sociedades tradicionales, se sigue considerando fundamental que las mujeres sean capaces de procrear, por lo que se concede una gran importancia a la fecundidad, y se califica negativamente la infertilidad. ${ }^{110}$ Como sostiene Susana Narotzky (1995:90, citada en Heras y Téllez, 2005:65), "la infertilidad es una enfermedad para unos, mientras que la fertilidad es una enfermedad para otros".

Cabe señalar, de todos modos, que, incluso en los países donde la tasa de natalidad era bastante elevada hasta hace unos años, diversos factores (como las migraciones, tanto internas como externas, los procesos de industrialización, la escolarización femenina, y la incorporación de las mujeres al mercado laboral) han contribuido a que disminuyera dicha tasa, modificando al mismo tiempo las estructuras familiares (Aixelà, 2010:251).

Asimismo, la reproducción es concebida en algunas culturas como una cuestión inherente al matrimonio, y se le atribuye un notable valor al mantenimiento de la virginidad hasta el momento en que este se contrae.

A pesar de que diversos estudios confirman que las tasas de fecundidad de las mujeres inmigrantes en España son superiores a las de las autóctonas, cabría realizar algunas distinciones de acuerdo con su lugar de procedencia; así, las mujeres procedentes de Europa del este presentan, por lo general, un número de hijos similar al de las autóctonas, mientras que dicho número es superior en las africanas y las latinoamericanas. De todos modos, en el caso de las mujeres inmigrantes, como hemos comentado previamente, los patrones de comportamiento pueden modificarse tras la emigración, de manera que es posible que aquellas mujeres en cuyos países de origen se den unas altas tasas de fecundidad, reduzcan la media del número de hijos al llegar al país de acogida, entre otros motivos, por las condiciones socio-económicas en las que se encuentran. ${ }^{111}$

\subsubsection{La planificación familiar}

Partimos de la base de que la planificación familiar puede contribuir a la salud de las mujeres, los niños y las comunidades, ya que las familias menos numerosas podrán dedicar más recursos físicos y emocionales a garantizar que sus hijos tengan una alimentación suficiente, una vivienda digna y oportunidades de educación y, al mismo tiempo, las mujeres con menos hijos tendrán probablemente más posibilidades de participar en actividades educativas, económicas y sociales (Ollé, 2009:103). ${ }^{112}$

\footnotetext{
${ }^{110}$ Las parejas que presentan problemas de infertilidad, en determinados países, suelen experimentar fuertes presiones socioculturales. En ocasiones, para evitar dichas presiones, dichas parejas ocultan la infertilidad, o se ponen en juego cuestiones identitarias tanto de género como de grupo (Heras y Téllez, 2005:82). Además, es bastante común que se estigmatice a las mujeres infértiles y que se atribuya la infertilidad a la mujer, la cual, en muchos casos, puede ser repudiada o de la cual se puede solicitar el divorcio por este motivo.

${ }^{111}$ Entre los factores que pueden incitar a las mujeres inmigrantes a tener un menor número de hijos en los países de acogida, podemos señalar: la ausencia de los maridos o parejas (en el caso de las mujeres que inician el proceso migratorio solas), las precarias condiciones laborales, el acceso a mayor información con respecto a la planificación familiar y los métodos anticonceptivos, o la ausencia de redes de apoyo social y familiar.

${ }^{112}$ De todos modos, cabe considerar que, en determinadas sociedades, los hijos son mano de obra imprescindible para la subsistencia, y serán quienes mantendrán a los padres cuando sean ancianos, de ahí la importancia concedida a las familias numerosas en dichas sociedades.
} 
Por los motivos expuestos, consideramos fundamental que las familias puedan disponer de información adecuada que les permita decidir libremente el número de hijos que desean tener, qué espacio de tiempo prefieren esperar entre uno y otro embarazo, y qué métodos anticonceptivos quieren utilizar, ajustándose a sus valores y creencias y a sus necesidades.

En la elección sobre si acudir o no a los servicios de planificación familiar, así como en la consideración de qué métodos anticonceptivos pueden ser aceptables, juegan un papel importante las creencias culturales y religiosas de las usuarias. ${ }^{113}$

Además, algunas mujeres inmigrantes (procedentes, principalmente, de países de religión musulmana) pueden mostrar reticencias a la hora de acudir a las consultas de planificación familiar motivadas por el hecho de que, en sus culturas de origen, se consideran tabúes determinados temas, como los referidos a los aparatos genitales, las relaciones sexuales o la menstruación, los cuales serán evitados casi siempre en los espacios públicos y en situaciones de desigualdad (por ejemplo, de sexo) entre los interlocutores y, a veces, incluso en los ámbitos domésticos o privados. ${ }^{114}$

Asimismo, en el caso de los embarazos no planificados (más frecuentes, según la literatura al respecto, en mujeres de Latinoamérica y Europa del este), el deseo de llevar a cabo una interrupción voluntaria del mismo por parte de las mujeres inmigrantes estará igualmente determinado por sus patrones culturales. ${ }^{115}$

\footnotetext{
${ }^{113}$ Por ejemplo, en el Magreb, el uso de determinados métodos anticonceptivos (como la píldora, los dispositivos intrauterinos, los diafragmas, los espermicidas y los preservativos), aunque no están prohibidos por el Islam, se consideran poco recomendables, por lo que, a pesar de que desde las instituciones gubernamentales se impulsa su uso, este está justificado desde el punto de vista religioso solo en los casos en los el embarazo sea contraproducente para la salud de la madre. Por el contrario, el método Ogino y el coitus interruptus, así como otros métodos tradicionales o naturales (como el amamantamiento tardío o los espermicidas elaborados con jabón y vinagre utilizados tras el acto sexual) son formas aceptables de contracepción (Aixelà, 2010:257). Cabe, además, señalar que, por lo general, en los países que conforman esta área geográfica, la responsabilidad de la contracepción suele recaer sobre las mujeres (Ortí, 2009:30-31). De todos modos, el uso de los métodos anticonceptivos en las mujeres magrebíes dependerá también de su nivel de estudios y de su grado de islamización (Oliver, Baraza y Martínez, 2007:87).

${ }^{114}$ Esta situación de incomodidad al tratar determinados temas considerados tabúes puede acrecentarse cuando, por el desconocimiento por parte de la mujer de la lengua del país de acogida, su marido o sus hijos mayores deben estar presentes durante la consulta y realizar labores de interpretación para facilitar la comunicación entre dicha mujer y el profesional sanitario. Esto podría conllevar, incluso, que la mujer deje de revelar información importante para el buen desarrollo de la consulta por vergüenza a hablar de temas tabúes delante de sus familiares.

${ }^{115}$ De acuerdo con diversas fuentes (Oliver, Baraza y Martínez, 2007:87; Sánchez, 2009:154; Fabre, 2010:31), el número de interrupciones voluntarias del embarazo (IVEs) en los países de Europa del este es bastante elevado, y se considera el aborto como un método anticonceptivo. Las mujeres de esta procedencia que residen en España también se encuentran entre aquellas a las que se practican más IVE's, tanto en comparación con mujeres de otras nacionalidades extranjeras como con las autóctonas (Oliver, Baraza y Martínez, 2007:90). Por el contrario, en países como los pertenecientes a la zona del Magreb, o en la India y Paquistán, el aborto no está permitido ni social ni legalmente (lo cual no quiere decir que no se practique). Al respecto, desconocemos si las mujeres inmigrantes con estas procedencias seguirán evitando la interrupción voluntaria del embarazo al trasladarse al país de destino, donde el aborto puede estar permitido en determinadas condiciones, y en el que quizás la presión social y familiar por parte de su entorno sea menor.
} 


\subsubsection{Los cuidados durante el embarazo}

Los cuidados durante el embarazo pueden también estar relacionados con creencias culturales o religiosas, ${ }^{116}$ las cuales establecen qué tipo de cuidados y comportamientos se deben dar o se deben evitar durante la gestación para garantizar que esta concluya con éxito.

Si bien los efectos positivos que tiene el control gestacional en la reducción de la mortalidad materna y perinatal y en la mejora de las condiciones del parto están demostrados por numerosos estudios epidemiológicos, las embarazadas de origen inmigrante suelen presentar un déficit de atención prenatal y, por lo general, inician más tarde las consultas, y las realizan en menor número y con menos frecuencia. Los motivos de la escasa utilización de estos servicios sanitarios por parte de las mujeres inmigrantes pueden ser muy variados; entre ellos, se encuentran los patrones de comportamiento relacionados con el seguimiento del embarazo en sus respectivos países de origen, así como las barreras lingüísticas y culturales que les impiden conocer el modo de acceso y el funcionamiento de dichos servicios en la sociedad de acogida. Asimismo, dependiendo de la propia visión del mundo, podrá concederse mayor o menor importancia a la realización de controles prenatales; por ejemplo, como se señala en la cita que incluimos a continuación, las malformaciones en el feto pueden considerarse como aspectos inevitables provocados por el destino o por castigos de los dioses a consecuencia de un mal comportamiento.

[...] someone with a scientific worldview might perceive birth defects as a mistake in the transcription of the DNA during the process of meiosis, ${ }^{117}$ while someone whose worldview encompasses the notion of reincarnation might see it as resulting from improper behavior in a past life, and someone who believes that God rewards good behavior and punishes bad behavior might interpret it as a punishment for one's sins (Galanti, 2008:15).

No obstante, cabe señalar que estos mismos patrones de escasa utilización se pueden dar también en las mujeres autóctonas con un nivel de estudios bajo o en situación de pobreza, las cuales presentan un peor seguimiento del embarazo con respecto a las autóctonas con un mayor nivel socio-económico (Dueñas y col., 1997, citados en Oliver, Baraza y Martínez, 2007:93).

Con respecto a la posibilidad de que se produzca una pérdida del feto durante el embarazo, cabe recordar que, como hemos señalado anteriormente, en algunas culturas, se asocia la enfermedad a un mal comportamiento social y, de esta manera, se atribuirán los problemas durante la gestación o la causa del aborto, en caso de que este se produzca, al incumplimiento

\footnotetext{
${ }^{116}$ Por ejemplo, en algunos países de Latinoamérica, durante el embarazo existen prohibiciones para las gestantes (como la de realizar esfuerzos físicos o la de tocar hilos o cordones), así como determinadas restricciones dietéticas (entre las que se encuentra la prohibición de comer grasa o miel, pues se cree que esto podría provocar que "la placenta se pegue") (Mendoza, 2009:318). Otro ejemplo podría estar constituido por la cultura china, en la que, de acuerdo con la medicina tradicional, basada en gran medida en el concepto de equilibrio, se cree que, durante el embarazo, el cuerpo de la mujer permanece en un estado yin ("frío") y, por consiguiente, esta deberá evitar ingerir alimentos considerados yin (como pueden ser las alubias, los plátanos o el melón), así como bebidas frías (en el sentido térmico de la palabra) (Raga, 2009:65).

${ }^{117}$ La meiosis es el término científico para referirse a la sucesión de dos divisiones celulares durante la formación de los gametos, de la que resultan cuatro células que tienen un cromosoma de cada pareja de la célula original. Fuente de la definición: Diccionario de la Real Academia Española online. [http://lema.rae.es/drae/?val=meiosis](última consulta: 5 de septiembre de 2013).
} 
de determinadas normas por parte de la madre o a las malas relaciones que esta tenga dentro del seno familiar o social.

\subsubsection{La vivencia del momento del parto}

El modo en que cada madre vive el momento del parto estará determinado, indudablemente, por cuestiones personales, pero también por sus patrones culturales, que conllevarán una serie de creencias, actitudes y comportamientos comunes en las mujeres que pertenecen a una misma cultura.

En concreto, de acuerdo con los resultados de un estudio presentado por Miguel Ángel Luque y María Isabel Oliver (2005:9), centrado en las diferencias culturales en la percepción y vivencia del parto, y en el que se realiza una especial referencia a las mujeres inmigrantes,

[...] se han encontrado especificidades culturales en cuanto al sentido del pudor y la preferencia en la feminización de la asistencia obstétrica, en la percepción y actitud ante el dolor durante las contracciones, en las preferencias en el acompañamiento durante el parto, en su vivencia y percepción (postura durante el expulsivo, aceptación del parto medicalizado, etc.), así como en las pautas de interacción inmediata con el recién nacido.

Por lo que se refiere a las especificidades culturales relativas al sentido del pudor, estas pueden estar relacionadas con las creencias religiosas de las usuarias. En concreto, en el caso de la religión musulmana, por ejemplo, el pudor estará determinado por aspectos como la construcción social del cuerpo femenino, la segregación sexual del espacio, o el sentido del honor. Al respecto, es posible que las mujeres que practican la mencionada religión muestren reticencias a la hora de ser atendidas durante el parto por personal de sexo masculino o que expresen explícitamente su deseo de ser tratadas solo por personal femenino, aunque no deberíamos sobredimensionar esta posibilidad estereotipando a todas las mujeres de esta comunidad bajo este posible patrón.

Asimismo, un alto sentido del pudor suele conllevar una escasa participación de los familiares de sexo masculino en el proceso reproductivo, de modo que, en algunas culturas, no es común la presencia de los hombres durante el parto, y será más habitual que realicen las funciones de acompañamiento familiares o amigas del mismo origen cultural que la parturienta, generalmente con mayor tiempo de permanencia y más experiencia en el país de acogida. ${ }^{118}$ Por el contrario, en los países occidentales, se observa una implicación cada vez más frecuente de los maridos en el momento en que sus mujeres dan a luz, como muestra de apoyo emocional a las mismas, así como, como comentaremos más adelante, una mayor participación por su parte en los cuidados del recién nacido. Esto conlleva que, desde una posición etnocentrista, con frecuencia se califique erróneamente la ausencia de los maridos de las mujeres inmigrantes durante el parto como una muestra de su actitud fría y desinteresada con respecto a la madre y el hijo.

\footnotetext{
${ }^{118}$ La presencia de los maridos o los familiares de la parturienta, cuando esta no presenta suficientes conocimientos de español, es aprovechada con frecuencia por los profesionales sanitarios para que estos realicen labores de interpretación, sin considerar las posibles consecuencias negativas que el desempeño de estas funciones por parte de personas no preparadas ni formadas para ello puede conllevar, tal y como señalaremos en los capítulos 6 y 7 , en los que exponemos los resultados y las conclusiones de nuestro estudio de caso.
} 
En cuanto al contexto específico donde tiene lugar el parto, cabe señalar, además, que muchas de las usuarias inmigrantes que acuden a los servicios sanitarios españoles para dar a luz se enfrentan a situaciones completamente nuevas para ellas, ya que, en las culturas tradicionales (especialmente en los ámbitos rurales), el parto suele tener lugar en el propio domicilio y es asistido por parteras $u$ otras figuras de apoyo, mientras que en nuestro país se produce en un ambiente hospitalario caracterizado por un alto grado de medicalización, y es asistido por profesionales sanitarios (de sexo tanto masculino como femenino) que han recibido una educación formal que les habilita para desempeñar sus respectivas labores. ${ }^{119}$ Las propias experiencias previas de estas mujeres inmigrantes podrán determinar, por tanto, que rechacen cualquier tipo de intervención obstétrica durante el parto. ${ }^{120}$

En cuanto a la percepción, la soportación y la expresión del dolor, se observan diferencias culturales en cuanto al mayor o menor énfasis al manifestar el dolor percibido. ${ }^{121}$

Además, cabe considerar que la menor soportación del dolor puede verse incrementada por el hecho de que las mujeres se hallan en un contexto desconocido, en unas condiciones psicosociales de vulnerabilidad y miedo y, en ocasiones, de soledad. Con el fin de aliviar dicho dolor, en los servicios sanitarios españoles, se ofrece la posibilidad de suministrar la anestesia epidural, cuya aceptación por parte de las usuarias inmigrantes dependerá en gran medida del conocimiento o uso previo de estos métodos analgésicos, así como de sus patrones culturales, como puede ser el valor otorgado a la estoicidad ante el dolor en su cultura de origen. Al respecto, quisiéramos destacar que, en los casos en los que las parturientas no expresen enfáticamente el dolor padecido siguiendo los patrones de su cultura de origen, esta falta de énfasis podría ser malinterpretada por los profesionales sanitarios españoles como una ausencia de dolor.

En relación con el comportamiento y la postura adoptada durante el parto, los profesionales sanitarios occidentales, por lo general, esperan que las usuarias acepten las normas y costumbres propias, y no suelen dar opción a que se sigan otras pautas de comportamiento que difieran de las habituales en el sistema de salud. En el caso concreto de los servicios obstétricos españoles, se solicita a la parturienta que adopte una postura horizontal desde la dilatación hasta el expulsivo, por resultar más cómoda para los profesionales sanitarios, sin

\footnotetext{
${ }^{119}$ Cabe señalar, de todos modos, que, en nuestro país, se está produciendo un cambio de tendencia con respecto al parto, fruto de nuevas "modas", consistente en un aumento progresivo del número de mujeres españolas que desean tener un parto "lo más natural posible", evitando cualquier intervención médica durante el mismo que no sea estrictamente necesaria. La posibilidad de poder llevar a cabo este tipo de partos, sin embargo, dependerá en gran medida del conocimiento de los lugares donde estos partos no medicalizados pueden practicarse y de la posesión de los recursos económicos que permitan sufragar los gastos derivados de los mismos, por lo que muchas de las mujeres inmigrantes que podrían también preferir este tipo de práctica no podrán acceder a ella.

${ }^{120}$ Entre las mujeres que rechazan las intervenciones obstétricas durante el parto (como podría ser el uso de fórceps) destacan las del colectivo magrebí (Fabre, 2010: 133).

${ }^{121}$ Por ejemplo, en la India y en Paquistán, por lo general, los pacientes son estoicos en la expresión de dolor, aunque gemir y gritar resulta aceptable, por ejemplo, en el parto del primer hijo (Sales, 2009: 108). Por el contrario, en el caso de las mujeres chinas, la expresión muy enfática del dolor durante del parto puede ser considerada socialmente inaceptable (Raga, 2009:67) y, por lo que respecta a las mujeres de origen subsahariano, las excesivas quejas durante el parto pueden llegar a considerarse incluso como una ofensa para la familia (Raga, 2009: 129). Cabe señalar, sin embargo, que, si bien las mujeres de África Subsahariana no suelen expresar verbalmente el dolor, como veremos en el capítulo 6, dedicado al análisis de los datos recolectados en nuestro trabajo de campo, sí que suelen efectuar cuando lo padecen movimientos rítmicos del cuerpo, chasquear los dedos y pronunciar repetidas letanías.
} 
tener en cuenta que, en otras culturas, puede ser más común presentar otra serie de comportamientos durante el proceso de parto, como podría ser la costumbre de caminar para acelerar la dilatación o la preferencia por dar a luz en posición vertical o en cuclillas.

\subsubsection{Comportamientos, creencias y actitudes durante el puerperio}

El último aspecto a tratar dentro del ámbito de la salud reproductiva se centra en la relación entre la madre y el hijo. De acuerdo con Mari Luz Esteban (2000:217), esta relación

[...] se ha definido como la relación afectiva por excelencia, la principal, al margen de que sea así o no en las experiencias concretas, y ocultándose totalmente el contexto en el que esto surge.

Así, por ejemplo, por lo que respecta a la interacción con el recién nacido durante los primeros momentos tras el alumbramiento, en nuestra cultura, por lo general, esperamos una manifestación explícita del amor materno-filial mediante el contacto, los gestos y las expresiones faciales y verbales dirigidas a los hijos. Por ello, cuando dicha manifestación no se produce de manera evidente, se suele calificar la actitud de las madres como fría, desinteresada o falta de cariño, sin comprender que, en realidad,

[...] el amor materno no es un amor natural; representa más bien una matriz de imágenes, significados, prácticas y sentimientos que siempre son social y culturalmente producidos (Schepper-Hughes, 1995:329, citada en Heras y Téllez, 2005:87).

Debemos entender, por tanto, que la expresión menos explícita del amor por sus hijos por parte de algunas madres de origen inmigrante puede deberse a factores personales, sociales y culturales, como podrían ser los altos niveles de mortalidad infantil presentes en sus países de origen, que conllevan que los primeros días de vida se consideren una etapa altamente peligrosa, para la que hay que tomar todas las precauciones posibles. De ahí que, en algunas culturas, se empleen diferentes métodos de protección de los recién nacidos de carácter religioso o sobrenatural. ${ }^{122}$

Asimismo, en ocasiones se llevan a cabo celebraciones y rituales para presentar al recién nacido en sociedad o para protegerle de posibles males o, con este mismo fin, se les coloca algún tipo de amuleto protector. ${ }^{123} \mathrm{Al}$ respecto, cabe tener en cuenta que la imposibilidad de llevar a cabo las ceremonias tradicionales tras el nacimiento del niño o de colocarle un amuleto (que, en nuestros servicios sanitarios podría considerarse como una muestra de falta de higiene) puede suponer un grave problema para algunas familias inmigrantes residentes en nuestro país.

Son también numerosas las manifestaciones culturales que existen por lo que se refiere a las creencias, actitudes y comportamientos de las madres durante el puerperio, que pueden

\footnotetext{
122 Por ejemplo, en países como los de la zona del Magreb, la India o Paquistán se considera tabú alabar, decir cumplidos o fijarse demasiado en el recién nacido, porque se considera que eso puede provocar mal de ojo y, en definitiva, mala suerte (Sales, 2009: 101; Ortí, 2009:34). Por ello, en dichos países no se suele insistir en proferir elogios a los niños, algo que, por el contrario, es bastante común en nuestra cultura, hecho que podría ser origen de un choque cultural entre los autores autóctonos de los elogios y las mujeres inmigrantes de estas procedencias.

${ }^{123}$ Por ejemplo, en los países del Magreb, es frecuente colgar a los recién nacidos un amuleto, así como bautizarlos a los siete días con un ritual religioso. El nacimiento se celebra en la mayoría de los casos con el sacrificio de un borrego (Ortí, 2009:33).
} 
abarcar, como sucede con el embarazo, desde prohibiciones de llevar a cabo determinadas actividades hasta recomendaciones de carácter dietético. ${ }^{124}$

Además, existen costumbres variables por lo que respecta al nombre que se da a los recién nacidos que varían de una cultura a otra, ${ }^{125}$ las cuales, en ocasiones, conllevan que no se decida el nombre inmediatamente después del nacimiento. Este hecho, en el caso de las familias inmigrantes que viven en España, podría chocar con los trámites administrativos exigidos en relación con el registro de los recién nacidos, de acuerdo con los cuales, la decisión del nombre de los niños debe tomarse antes de abandonar el hospital donde se ha dado a luz.

En referencia a la lactancia materna, por lo general, tanto en los países menos desarrollados como por parte de algunas organizaciones internacionales (como puede ser la Organización Mundial de la Salud), esta se promueve, por considerar que protege inmunológicamente a los recién nacidos y fomenta la relación psico-afectiva entre estos y sus madres. Sin embargo, no existen acuerdos con respecto al tiempo durante el cual las mujeres deberían continuar dando de mamar a sus hijos (Esteban, 2000:218).

Las usuarias inmigrantes suelen ser bastante proclives a amamantar a sus hijos (incluso durante periodos prolongados que pueden superar los dos años), ${ }^{126}$ y consideran que se trata del alimento por excelencia para los niños, ${ }^{127}$ aunque se observan variaciones al respecto tanto dependientes de patrones culturales como de características y necesidades personales. Estas variaciones se referirán, por ejemplo, al tiempo durante el cual se mantendrá este tipo de lactancia, a si se hará en horarios determinados o a demanda, o a si se considera beneficioso o perjudicial suministrar el calostro a los recién nacidos. ${ }^{128}$

Con respecto a quién se encarga de los cuidados de los hijos, la implicación de los padres en este aspecto ha ido aumentando en los últimos años en las sociedades occidentales, como una muestra más de la evolución permanente de las distintas culturas. En cambio, en numerosas

\footnotetext{
${ }^{124}$ Por ejemplo, en algunos países de Latinoamérica se da una observancia estricta de la cuarentena (con su correspondiente reposo y abstinencia sexual) por parte de las puérperas, y se preparan bebidas y alimentos especiales que se considera que favorecen la producción de leche materna. Asimismo, en algunas comunidades latinoamericanas, se entierra la placenta fuera de la casa familiar o se cuelga en un árbol, para proteger a los niños de posibles problemas futuros. Otra costumbre propia de esta zona son los baños con temazcal, que ayudarán a la puérpera a contrarrestar el "frío" que adquirió durante el embarazo y el parto (Mendoza, 2009:319).

${ }^{125}$ Por ejemplo, en algunos países de África subsahariana, como Nigeria, el nombre de los niños no lo suelen decidir directamente los padres, sino que se considera que el nombre posee algún tipo de significación social, por lo que generalmente se suele dar a los niños los nombres de algún antepasado o de algún conocido. En ocasiones, la familia espera un tiempo después del parto para dar un nombre al niño, hasta que ocurre algún acontecimiento percibido como una señal acerca del nombre que este debe recibir (Raga, 2009:130).

${ }^{126}$ Las mujeres latinoamericanas son las que suelen presentar, junto con las magrebíes, una mayor adhesión a la lactancia materna. Por el contrario, la adhesión suele ser menor en las mujeres procedentes de Europa del este y del colectivo chino, en este último caso, normalmente por cuestiones laborales (Fabre, 2010:69, 73 y 75).

${ }^{127}$ Cabe señalar que, aparte de los beneficios inmunológicos y afectivos señalados, en los países en los que el nivel de pobreza es elevado, la leche materna se recomienda por ser más barata y accesible, de manera que se promueve este tipo de lactancia con el fin de garantizar la buena alimentación de los niños. Por consiguiente, cabe considerar la posibilidad de que las mujeres inmigrantes que amamantan a sus hijos en una mayor proporción que las autóctonas en los países de acogida están reproduciendo los patrones de comportamiento que han observado y aprendido en sus países de origen.

${ }^{128}$ Por ejemplo, en África Subsahariana, las madres normalmente dan el pecho a sus hijos durante un periodo de tiempo prolongado (que puede durar hasta dos años, combinando la leche materna tempranamente con alimentos sólidos). Sin embargo, por lo general, se considera que el calostro no es del todo beneficioso para el niño, de manera que, hasta que la madre acaba la fase del calostro, suelen amamantar al recién nacido otras mujeres de la familia, e incluso después de esta fase es habitual que el amamantamiento sea compartido (Raga, 2009: 131).
} 
sociedades tradicionales, siguen considerándose los cuidados infantiles como una cuestión estrictamente femenina, por lo que será la propia madre (con la ayuda de otras mujeres de su familia, como tías, hermanas, primas o abuelas) quien se encargue de los mismos. Los conocimientos necesarios para asumir la crianza de los hijos serán transmitidos a las madres por parte de las mujeres más mayores de su familia, quienes, basándose en su experiencia, les harán partícipes de una serie de recomendaciones y pautas muchas veces basadas en saberes populares. ${ }^{129}$ No obstante, es posible que la emigración suponga un cambio en los roles asignados dentro de cada familia y, por la ausencia de redes familiares de apoyo o por la asimilación de los patrones propios de la sociedad de acogida, algunos padres participarán activamente en los cuidados de los hijos, algo que quizás no se habrían ni siquiera planteado en sus países de origen.

\subsection{Algunas conclusiones sobre la relación entre salud y cultura}

Los patrones culturales relativos al concepto de salud y enfermedad ( $y$ al concepto de cuerpo), así como aquellos relacionados con la prevención y promoción de la salud y la cura de las enfermedades pueden ser distintos, pero deben ser en todos los casos respetados.

Por consiguiente, la calidad de la asistencia sanitaria y los resultados óptimos de la misma se podrán garantizar solo si el profesional de la salud y el paciente entienden recíprocamente las creencias, valores, actitudes, tradiciones y prácticas del Otro y son capaces de comunicarse gracias a este entendimiento (Begley y Ockey, 2009:325).

Además, resulta necesario tener en cuenta que los demás no son culturas, sino individuos: en la relación entre el usuario y el profesional sanitario no se encuentran, por tanto, dos culturas, sino sobre todo dos personas. La aplicación de un modelo arquetípico a todos los pacientes inmigrantes o a los procedentes de un determinado país conllevará considerar a dichos pacientes bajo un modelo único, lo cual determinará que las políticas sociales y sanitarias destinadas a los mismos sean inadecuadas, por dirigirse exclusivamente a un perfil concreto, sin atender a las posibles variaciones y particularidades que pueden presentar estos pacientes. Partiendo de la base de que cada individuo tiene una percepción de la salud y la enfermedad que se fundamenta en el medio social, cultural y económico en que este ha desarrollado su vida, rechazamos la adopción de un modelo estático, frente al cual

[...] se presenta un modelo dinámico [...] y una visión de la salud como resultante de las actitudes y actividades que desarrolla el sujeto en todas las esferas de la vida: su biografía, la historia en que esta se engarza y la relación entre sujeto y medio sociocultural que le rodea (Uribe, 1989:27, citado en Alonso, 2010:360).

Igualmente, cabe recordar que, en la interacción entre el profesional y el paciente, se deberá considerar además, como hemos comentado en páginas previas, la implicación y la influencia de la institución sanitaria y la familia a las que respectivamente pertenecen.

\footnotetext{
${ }^{129}$ Quisiéramos destacar que estos conocimientos y pautas relacionados con el puerperio, que normalmente son transmitidos de generación en generación por las mujeres más mayores de la familia, en algunas ocasiones, serán reproducidos (total o parcialmente) por las madres más jóvenes $y$, en otras, estas últimas irán adquiriendo representaciones y prácticas diferentes que harán que varíen las costumbres de su sociedad en relación con la crianza.
} 
Por consiguiente, los profesionales de la salud, con el fin de garantizar la equidad y la calidad en los cuidados en las sociedades multiculturales del siglo XXI,

[...] no solo deberán ser capaces de comunicarse eficazmente con el paciente con otros usos culturales, sino que además deberán conocer y tener en cuenta en qué grado su pertenencia cultural condiciona su visión del proceso salud-enfermedad (Plaza del Pino y Soriano, 2009:191).

Asimismo, deberán demostrar la capacidad de respetar los valores y creencias culturales y personales de sus pacientes, y tratar de adaptarse a los mismos sin realizar juicios negativos infundados al respecto durante todo el proceso de asistencia, desde la recolección de la anamnesis en la entrevista clínica hasta a la hora de sugerir el tratamiento más adecuado. Ello no significa que deban aceptar cualquier tipo de práctica relacionada con los patrones sanitarios de los pacientes procedentes de otras culturas, sino que se deberá producir un proceso de acercamiento mutuo, de negociación intercultural, de búsqueda de puntos de encuentro, en el cual, bajo una perspectiva crítica constructiva hacia los patrones culturales tanto propios como ajenos, todos los actores implicados inicien un proceso de cambio basado en el diálogo.

De este modo, lograrán ofrecer lo que Rachel E. Spector (1999:66-67) denomina "cuidados culturales", consistentes en un tipo de cuidados "culturalmente sensibles, culturalmente congruentes y culturalmente competentes", en los cuales se tendrán en cuenta tanto el contexto en el que vive el paciente como las situaciones en las hayan surgido sus problemas de salud. ${ }^{130}$ En el proceso de asistencia sanitaria culturalmente sensible, congruente $y$ competente, por un lado, se valorará de qué manera el paciente se identifica con su legado cultural $^{131} \mathrm{y}$, por otro, se analizarán los fenómenos culturales ${ }^{132}$ que afectan a su salud física, mental y espiritual y las tradiciones que emplea para mantenerla, protegerla y restaurarla, que, en el caso de los pacientes inmigrantes, como hemos señalado previamente, pueden conjugar elementos propios de su cultura de origen y de la del país de acogida.

En consecuencia, podemos afirmar que los cuidados que brinden los profesionales sanitarios no serán de calidad "a menos que las experiencias vitales de los pacientes, así como sus propias interacciones con el ambiente que les rodea, estén cubiertas, sean entendidas, analizadas y articuladas" (Ibarra y Siles, 2006, citados en Plaza del Pino y Soriano, 2009:193).

Para finalizar, por lo que respecta al ámbito específico de la salud reproductiva, cabe destacar que, a pesar de que el proceso de reproducción presenta elementos biológicos compartidos entre todas las mujeres, este contiene asimismo una dimensión sociocultural y personal. A la

\footnotetext{
${ }^{130}$ Si bien Rachel E. Spector aplica el concepto de los cuidados culturales a la práctica específica de la enfermería, por nuestra parte, entendemos que dicho concepto puede aplicarse también a las demás profesiones sanitarias.

${ }^{131} \mathrm{Al}$ respecto, puede resultar de utilidad la guía/herramienta de valoración de la herencia que propone Rachel E. Spector a los profesionales sanitarios, la cual les puede servir de apoyo para descubrir los antecedentes étnicos, culturales y religiosos de sus pacientes inmigrantes, y en la que se incluyen preguntas relativas al lugar de nacimiento (propio y de los padres), el tiempo de permanencia en el país de acogida, o el contacto mantenido desde la emigración con los familiares que han permanecido en el país de origen (Spector, 2002:155-156).

${ }^{132} \mathrm{Al}$ hablar de los fenómenos culturales que pueden afectar a la salud, esta autora hace referencia al Modelo de Asesoramiento e Intervención en Enfermería Transcultural de Joyce Newman Giger y Ruth Elaine Davidhizar (1995), del que hemos hablado en el capítulo anterior y, de acuerdo con el cual, cada persona posee una identidad cultural única, y su estado de salud se debe valorar teniendo en cuenta seis fenómenos: la comunicación, el espacio, el tiempo, la organización social, el entorno y las variables biológicas.
} 
hora de estudiar los patrones culturales de las mujeres procedentes de otros países en relación con este ámbito de la salud, no se debe, sin embargo, categorizarlas por su condición general de inmigrantes o por su procedencia de un determinado país, sin tener en cuenta las características diferenciales de estas mujeres basadas en cuestiones socio-económicas, educativas, etc.

Así, si bien es posible establecer algunos patrones en cuanto a las creencias, actitudes y comportamientos durante el embarazo, el parto y el puerperio en las diferentes sociedades, hay enormes variaciones dentro de las mismas, que conllevan distintas necesidades y preferencias. Por nuestra parte, consideramos que, dentro de lo posible, se debería dar una atención individualizada a las gestantes y puérperas (tanto a las autóctonas como a las inmigrantes), de manera que se garantice que estas vivan todo el proceso, como recomienda la Organización Mundial de la Salud (1994), con un estado pleno de bienestar físico, mental y social. 


\section{CAPÍTULO 5}

La interpretación en los servicios públicos y la mediación lingüística y cultural: dos estrategias ¿diferentes? ante una misma necesidad 


\section{LA INTERPRETACIÓN EN LOS SERVICIOS PÚBLICOS Y LA MEDIACIÓN LINGÜÍSTICA Y CULTURAL: DOS ESTRATEGIAS ¿DIFERENTES? ANTE UNA MISMA NECESIDAD}

En los capítulos anteriores hemos analizado cómo los flujos migratorios recibidos en los últimos años por los países europeos, en general, y por España, en particular han modificado la configuración de sus sociedades, en las que actualmente conviven ciudadanos procedentes de muy variados países y culturas. Asimismo, hemos estudiado cómo la comunicación entre personas culturalmente diversas puede resultar complicada, o incluso fallida, principalmente debido a las diferencias que suelen presentar los interlocutores por lo que se refiere a la lengua, el modelo comunicativo y los patrones culturales, a las que se suman factores como el desconocimiento mutuo y la adopción de posturas etnocéntricas, que imposibilitan que en la interacción exista un acercamiento y un entendimiento entre los participantes.

Si trasladamos estas dificultades comunicativas al ámbito de los servicios públicos y, más concretamente, al de los servicios sanitarios, la falta de una comunicación efectiva entre los profesionales que trabajan en los mismos y los usuarios de origen extranjero impedirá, como también hemos señalado previamente, que estos últimos puedan acceder y usar dichos servicios en igualdad de condiciones con respecto a los usuarios autóctonos $y$, en última instancia, que reciban una adecuada asistencia sanitaria.

De hecho, diferentes estudios demuestran que la falta de una comunicación eficaz en el ámbito sanitario puede derivar en diagnósticos inapropiados, falta de adherencia al tratamiento, falta de control o seguimiento del paciente, exámenes incompletos, o ingresos hospitalarios innecesarios (Leanza, 2007:11-12).

Entre las diferentes estrategias adoptadas para superar las mencionadas barreras, se encuentra el recurso a servicios lingüísticos, los cuales pueden ser proporcionados, en líneas generales, por cuatro tipos de figuras (Phelan y Parkman, 1995:555): profesionales sanitarios bilingües, intérpretes profesionales, familiares o amigos del paciente, e intérpretes voluntarios o no profesionales.

Por lo que respecta a la primera opción planteada, siempre que los citados profesionales sanitarios fueran efectivamente bilingües (es decir, poseyeran un amplio dominio de los dos códigos lingüísticos y culturales implicados) y, al mismo tiempo, contaran con conocimientos sobre técnicas de interpretación y sobre los principios éticos y protocolarios relativos a esta actividad, se trataría de una vía ideal para tratar de superar las barreras que surgen en la comunicación entre el personal de los servicios sanitarios y los pacientes alófonos. Sin embargo, aun cuando se cumplieran las condiciones mencionadas, nos preguntamos de qué manera organizarían su tiempo de trabajo estos profesionales, en base a qué criterios decidirían, ante la disyuntiva en un determinado momento de ejercer como profesionales sanitarios o como intérpretes, por cuál de estas dos actividades se deben decantar. Si, por el contrario, se estipulara emplear a estos profesionales bilingües no como intérpretes, sino como responsables de la asistencia a los pacientes cuya lengua materna dominaran, a pesar de que se conseguiría establecer la comunicación sin la necesidad de recurrir a intermediarios, a nuestro parecer, supondría en cierto sentido una forma de discriminación, tanto para los profesionales como para los pacientes inmigrantes que, por su falta de dominio de la lengua del país de acogida, les fueran obligatoriamente asignados. Asimismo, cabe señalar que la 
presencia en nuestro país de profesionales bilingües es todavía muy escasa, tanto por la ausencia de personal sanitario autóctono que domine otros idiomas, como por las dificultades con las que se encuentran los profesionales sanitarios procedentes de otros países para convalidar sus títulos de estudio.

El empleo de intérpretes profesionales es, sin duda, la vía más adecuada de las cuatro planteadas por Michael Phelan y Sue Parkman (1995) para facilitar la comunicación entre los profesionales sanitarios y los pacientes de origen extranjero, a la cual dedicamos un apartado dentro del presente capítulo. En teoría, esta figura ofrece la garantía de que posee las competencias mínimas para ejercer su labor y de que se regirá por los principios éticos inherentes a esta profesión.

En cuanto a la tercera y a la cuarta estrategias propuestas, podríamos englobarlas dentro de una misma categoría, en la que incluiríamos a cualquier persona que realiza labores de interpretación sin disponer de los conocimientos, habilidades y actitudes necesarios para desempeñarlas con éxito. A este tipo de ejercicio se le suele denominar interpretación ad hoc o natural y, como veremos más adelante, son numerosas las consecuencias negativas que la utilización de la misma puede acarrear.

A estas cuatro alternativas sumaríamos otra propuesta, consistente en el recurso a la mediación lingüística y cultural. Se trata de una figura relativamente nueva que se está empleando cada vez más frecuentemente en algunos hospitales de nuestro país, pero que, por el momento, como veremos más adelante, no cuenta con una definición unívoca por lo que se refiere a su papel y sus funciones, ni está profesionalmente reconocida.

Por lo que se refiere a la adopción de una u otra figura, de acuerdo con Uldis Ozolins (2010), los países receptores de inmigración han dado cuatro tipos de respuestas distintas para superar las barreras lingüísticas que se plantean en la comunicación entre los profesionales de los servicios públicos y los usuarios alófonos, las cuales, en gran medida, han estado determinadas por los modelos de gestión de la diversidad cultural predominantes en cada país: ${ }^{133}$

- Negación de la necesidad de proporcionar servicios de traducción y/o interpretación en el sector público. P.e. en algunos países de Europa del Este.

- Provisión de servicios ad hoc. P.e. en España o Italia.

- Creación de servicios lingüísticos genéricos. P.e. en Canadá.

- Implantación de soluciones globales e integrales. P.e. en Australia, Países Bajos, el Reino Unido o Suecia.

\footnotetext{
${ }^{133}$ En los anexos incluimos una tabla en la que Uldis Ozolins (2010) resume los servicios lingüísticos que se han implantado en quince países receptores de inmigración. En ella señala la denominación que se ha dado a dichos servicios, indica si son ofrecidos por la Administración pública, empresas externas u organizaciones sin ánimo de lucro, y los relaciona con la actitud hacia la inmigración que predomina en los países analizados. Cabe señalar que, en palabras del propio autor (Ozolins, 2010:203), la tabla ofrece una visión general de los factores que pueden determinar los resultados que tendrán los servicios lingüísticos implantados en cada país, pero aclara que ningún factor, por sí solo, tendrá especial relevancia, sino que será la combinación de los mismos la que conlleve unos u otros resultados.
} 
Pasamos, a continuación, a analizar con mayor profundidad las estrategias para mejorar la comunicación intercultural más utilizadas en el contexto de nuestro estudio. Quisiéramos precisar que, si bien al hablar de interpretación en los servicios públicos y de mediación lingüística y cultural, exponemos algunas generalidades por lo que respecta a su definición, evolución y estado de la cuestión, nuestro propósito es centrarnos en el ámbito sanitario, al que dedicamos la parte principal de la exposición.

\subsection{La interpretación ad hoc}

La denominada interpretación ad hoc o interpretación natural en ámbito sanitario, aquella que es puesta en práctica por personas que no poseen la formación ni la preparación necesarias para desempeñar con eficacia esta labor, suelen realizarla familiares, amigos o conocidos del paciente, profesionales sanitarios $u$ otros empleados de los centros de salud (personal sociosanitario, personal de limpieza, etc.) bilingües, o incluso acompañantes de otros pacientes.

En la actualidad, se trata del recurso más frecuentemente empleado en la mayoría de los servicios sanitarios de nuestro país, incluso en el caso de aquellos que disponen de otras estrategias más adecuadas para facilitar la comunicación entre los profesionales y los pacientes alófonos, como veremos en el análisis de los resultados de nuestro estudio de caso.

A pesar de que el empleo de estas personas puede presentar ciertas ventajas, como la reducción de costes, la disponibilidad inmediata o, por lo que respecta a los familiares y amigos del paciente, su conocimiento previo de la patología padecida por este y de la evolución de la misma, son mayores los inconvenientes que el recurso a esta figura puede plantear.

A modo de resumen, podemos decir que, por la falta de preparación y formación previas para ejercer labores de interpretación, existen grandes posibilidades de que, pese a la intervención de estos intérpretes, la comunicación entre el profesional sanitario y el paciente no sea eficaz. Numerosos estudios (Bischoff, Loutan y García, 2009; Flores, 2010; Sánchez-Reyes y Martín, 2005) demuestran que los errores cometidos por los intérpretes que no cuentan con las competencias necesarias son más que frecuentes, con las funestas consecuencias que los mismos pueden acarrear.

La mayoría de los profesionales sanitarios no parecen ser conscientes de las deficiencias que presenta el desempeño de la labor de interpretación por parte de personas no debidamente preparadas, y consideran que estas les permiten comunicarse con el paciente, si no en modo óptimo, al menos suficiente. Sin embargo, como señala Sandra Hale (2010:46), "la cuestión importante aquí no es si el médico se contenta con un arreglo, sino si el paciente recibe el tratamiento adecuado".

Los intérpretes ad hoc pueden presentar carencias de carácter lingüístico (tanto por lo que se refiere al lenguaje general como en relación con la terminología específica), y seguramente desconocerán las principales técnicas de interpretación, así como el rol y los principios éticos que rigen esta profesión. Asimismo, principalmente en el caso de familiares y amigos del paciente o acompañantes de otros pacientes, es más que probable que no cuenten con 
conocimientos sobre el funcionamiento de los servicios sanitarios, los protocolos de actuación y las figuras profesionales que operan dentro de los mismos.

Aparte de estas insuficiencias mencionadas, cabe además señalar que los intérpretes naturales, posiblemente, no estarán preparados para afrontar las dificultades propias de este trabajo, especialmente las de carácter psicológico, y desconocerán los principios inherentes al papel que deben desempeñar (Wadensjö, 1998:52).

En consecuencia, el riesgo de que estos intérpretes ad hoc cometan los cinco errores básicos identificados por Carmen Vásquez y Rafael Javier (1991) es bastante elevado. Podrán, por tanto, producir errores de: omisión (proceso por el cual el intérprete omite total o parcialmente el mensaje expresado por un interlocutor), ampliación (o inclusión de información no expresada por un interlocutor), condensación (o tendencia a simplificar o explicar el mensaje expresado por un interlocutor), sustitución (o tendencia a remplazar conceptos), e intercambio de roles (cuando el intérprete asume el papel de uno de los interlocutores y es él mismo quien realiza preguntas o da respuestas) (Vásquez y Javier, 1991, citados en Hale, 2007:47). Así, por ejemplo, los familiares o amigos del paciente que realicen funciones de intérpretes podrán decidir ocultar determinada información por afán protector, o porque consideran que esta es demasiado íntima o es tabú en su cultura de origen. Del mismo modo, por su conocimiento personal de la dolencia padecida por el paciente o de las características personales y las vivencias del mismo, podrán incluir información no aportada por este, incurriendo además en un intercambio de roles (pues dejan de ser intérpretes para convertirse en sujetos activos de la conversación).

La falta de formación y preparación pude conducir, además, al incumplimiento de determinados principios asociados a esta profesión, tales como los principios de fidelidad al mensaje (al omitir, añadir o interpretar personalmente determinada información), de imparcialidad (por ejemplo, debido a la dificultad de distanciarse emocionalmente, por pertenecer a la misma familia o comunidad del paciente), o de confidencialidad (Flores et al. 2003:6-14).

Como sostiene Bernd Meyer (1998:6),

[...] family members act only partially as interpreters. For them it is quite natural to leave the interpreting task aside. They introduce a lot of own opinions and statements in the conversation and do not restrict these interventions to cases where the mutual understanding of the primary interlocutors is endangered.

Igualmente, ejercer estas labores supone para los intérpretes ad hoc un gran impacto emocional, especialmente en el caso de los menores (a los que, desgraciadamente, se recurre con frecuencia), porque su participación en este contexto implica un cambio de roles en el seno de la familia, y conlleva que estos reciban información de carácter demasiado grave para su grado de madurez, todo lo cual podría desembocar en importantes secuelas psicológicas. 
Por último, por lo que respecta al paciente, este puede sentirse cohibido por la presencia de un miembro de su familia o de su comunidad y, por tanto, mentir u ocultar información, ${ }^{134}$ lo cual puede repercutir negativamente en la obtención de la anamnesis y en el establecimiento de un diagnóstico y un tratamiento adecuados.

En conclusión, el empleo de intérpretes profesionales es más que recomendable en detrimento del recurso a intérpretes ad hoc. Como señalan John Hornberger, Haruka Itakura y Sandra R. Wilson (1997: 410-411) al presentar los resultados de una investigación en la que recolectaron la opinión de los profesionales de centros de salud del norte de California sobre las diferencias en la calidad de los resultados comunicativos al emplear intérpretes con formación o sin ella,

Trained interpreters are more costly than using untrained staff or family members, but the quality of interpretation may suffer when untrained interpreters are used, placing the patient at risk for medical mishaps due to misunderstandings and the clinician at risk for medical malpractice suits.

\subsection{La interpretación en los servicios públicos (ISSPP) $)^{135}$}

\subsubsection{Definición de la ISSPP}

La interpretación en los servicios públicos nace como respuesta a una necesidad social que surge en el siglo $\mathrm{XX}$, a raíz de los numerosos flujos migratorios que se producen durante dicho periodo, con el objetivo de resolver los problemas de comunicación lingüística y cultural existentes entre los profesionales de los servicios públicos del país de acogida y los usuarios inmigrantes, de manera que estos últimos puedan ejercer su derecho a acceder y usar dichos servicios.

Son numerosas las denominaciones que ha recibido, y todavía recibe, la práctica de esta modalidad de interpretación, muestra de que, aunque, como veremos en el siguiente apartado, han transcurrido décadas desde que esta se implantó en diversos países y, pese a que la investigación en este campo es cada vez más prolífica, se trata todavía de una profesión emergente. Así, en los países anglófonos, se la denomina community interpreting, ${ }^{136}$ public service interpreting, social interpreting, y liason o dialogue interpreting, ${ }^{137}$ por citar las más

\footnotetext{
${ }^{134}$ Con esto, no queremos decir que todos los pacientes sean sinceros y que la ocultación de información solo se produzca en el caso de que familiares o amigos estén presentes, sino que, la presencia de los mismos (tanto si realizan funciones de intérpretes como si están allí meramente como acompañantes), puede hacer aumentar la probabilidad de que esto se produzca.

${ }^{135}$ Si bien, en el contexto español, la denominación más frecuente de este tipo de interpretación, propuesta atendiendo al ámbito en el que esta tiene lugar, suele ir asociada también a la traducción (y se emplea el acrónimo TISP), en nuestro estudio, nos centramos principalmente en la interpretación, por lo que hemos decidido obviar la mención a la traducción.

${ }^{136}$ Nos parece interesante resaltar la puntualización que realiza Franz Pöchhacker (1999:126-127), quien indica que, con el término "comunidad", en este contexto, se hace referencia tanto a las comunidades mayoritarias o dominantes como a las minoritarias (dentro de las cuales incluye a las diversas comunidades aborígenes y étnicas, las minorías lingüísticas o las que presentan problemas de audición) que residen una misma sociedad.

${ }^{137}$ A pesar de que la modalidad de interpretación de enlace (o dialógica) es la más usual en este tipo de interpretación, no se descarta el uso de otras modalidades, como la simultánea, el susurrado o la traducción a la vista, por lo que no consideramos adecuado el empleo de esta denominación para referirse a aquella que tiene lugar en el contexto específico de los servicios públicos. De hecho, la interpretación de enlace es también usada frecuentemente en otros ámbitos (como el empresarial o el de las relaciones políticas internacionales), por lo que
} 
comunes $y$, en el contexto español, se le atribuye el apelativo interpretación social o interpretación en los servicios públicos, ${ }^{138}$ siendo este último el que parece haber recibido una mayor aceptación y el que se ha consensuado emplear.

Con estas diferentes denominaciones, aunque con matices y ligeras variaciones, se suele hacer referencia a la interpretación que tiene lugar en el ámbito de los servicios públicos (hospitales, comisarías, cárceles, juzgados, y servicios sociales, en general), y en la que los participantes en la interacción suelen presentar una relación asimétrica y un estatus social, por lo que respecta a los usuarios de los servicios, generalmente bajo. Como sostienen Mette Rudvin y Elena Tomassini (2011:14), la asimetría, en este contexto, está, en gran medida, determinada por el hecho de que

[...] migration is largely perceived as a phenomenon by which developing world "takers" move to the developed modern world "givers", the former being indebted to the latter through receiving housing, jobs, schooling, healthcare services, legal protection, transport and access to various other goods. In short, the industrialized world provide for, assist and protects the "new" immigrants. (comillas del original)

Quizás, en parte, el hecho de que la gran mayoría de los usuarios destinatarios de este tipo de interpretación posea escaso poder (especialmente si los comparamos con los destinatarios de otros tipos de interpretación: políticos, conferenciantes e investigadores, empresarios, etc.), unido a otros factores, como la desorganización y desestructuración del sector, la falta de formación universitaria obligatoria, o el desconocimiento general de la complejidad que entraña (Hale, 2010:25), han conferido un "estatus inferior" ${ }^{139}$ a esta profesión, a diferencia de la alta consideración que recibe, por ejemplo, la interpretación de conferencias.

Uno de los ámbitos donde se desarrolla la interpretación en los servicios públicos es, como hemos señalado, el sanitario, ámbito concreto de nuestra investigación. Los denominados intérpretes médicos o sanitarios (Hale, 2010:35) trabajan en una gran variedad de contextos, desde consultas de carácter más general en centros de salud y hospitales, hasta aquellas de carácter más especializado, con profesionales como psicoterapeutas, logopedas, dietistas, etc. Entre otros posibles contextos, se señalan, además, las urgencias, la clases de preparación al parto o la realización de análisis de laboratorio complejos (Frishberg, 1986:115, citado en Mikkelson, 1999).

Tradicionalmente, se ha considerado la interpretación en el ámbito sanitario como una variedad de interpretación menos prestigiosa, en comparación con la que se lleva a cabo en otros ámbitos, como en el jurídico y judicial, muestra de lo cual, como señala Holly Mikkelson (1999), "some writers consider community interpreting an umbrella term that includes court

abarcaría un campo de acción más amplio que el únicamente referido al de la comunicación entre los profesionales de los servicios públicos y los usuarios alófonos.

138 La denominación de "interpretación social" (Martin, 2003) parte de la Universidad de Granada, y en ella se incide en la presencia de esta modalidad de interpretación en los servicios sociales. Por su parte, la denominación de "interpretación en los servicios públicos" (Valero, 2003), propuesta por la Universidad de Alcalá, subraya la presencia en cualquier ámbito de los servicios públicos.

${ }^{139}$ Dicho estatus inferior se refiere al prestigio social de esta profesión. No obstante, si se tuviera en cuenta la importancia real de la labor de los intérpretes en los servicios públicos, se le debería atribuir un estatus superior. La profesionalización de esta figura, como comentaremos en páginas sucesivas, contribuiría, sin duda, a aumentar el prestigio de la misma. 
and medical interpreting, while others (mainly court interpreters) regard it as a separate category". Este menor prestigio de la interpretación médica se traduce, además, en tarifas más bajas, o en un mayor recurso a intérpretes ad hoc, en comparación con otros ámbitos en los que tiene lugar la interpretación, y no se corresponde con la complejidad de la labor del intérprete que trabaja en los servicios de salud (Angelelli, 2008:155).

\subsubsection{Estado de la cuestión de la ISSPP}

Ante las dificultades comunicativas anteriormente descritas que surgen a raíz de la llegada y permanencia de población que no habla la lengua mayoritaria de la sociedad de acogida, los diferentes países receptores han adoptado, como hemos comentado, diferentes estrategias, entre las que se encuentra la interpretación en los servicios públicos, cuyo desarrollo ha dependido, en gran medida, de factores como los flujos migratorios recibidos y las necesidades que estos plantean, las políticas en materia de inmigración, las políticas lingüísticas, la organización de las instituciones y de los servicios de la Administración pública, la legislación relativa al acceso a dichos servicios, etc. propias de cada estado (Abril, 2006:87).

En consecuencia, las particularidades de la inmigración y el modelo de gestión de la diversidad cultural predominante en cada país han influido notablemente en la diferente evolución que esta profesión ha presentado. Así, ha sido mucho menor su desarrollo en países donde prevalecen los modelos segregacionistas (como Alemania, Austria y Suiza), y asimilacionistas, (como Francia y Bélgica), en los que los servicios de interpretación han sido impulsados en la mayoría de los casos por entidades voluntarias y organizaciones sin ánimo de lucro. Por el contrario, en los países en los que la gestión de la población inmigrante asume un modelo más cercano al multiculturalismo, como Reino Unido, Suecia y los Países Bajos, el reconocimiento oficial de los derechos de las minorías y el respeto a la diversidad imperantes han contribuido a implantar servicios profesionales de interpretación en los servicios públicos, aunque no siempre acompañados de una respuesta pública generalizada o con un mismo nivel de desarrollo (Sauvêtre, 2000:39-41).

Cabe señalar, de todos modos, que el progreso y el estado actual de la profesión en los distintos países no puede encuadrarse categóricamente dentro de uno de estos modelos de desarrollo de la ISSPP (como tampoco pueden hacerlo sus modelos de gestión de la diversidad cultural), y se observan diferencias internas tanto a nivel local, como por lo que respecta a los sectores en los que los intérpretes desempeñan su labor. Así, por lo general, se ha producido una mayor concienciación y una subsiguiente creación de estructuras organizadas en relación con la interpretación en el ámbito jurídico y judicial, ${ }^{140}$ con respecto a la que tiene lugar en el ámbito sanitario.

Asimismo, de acuerdo con Anne Corsellis (2010:12-13), el avance de esta profesión puede atribuirse a las actitudes y comportamientos que tres grupos interdependientes han mostrado en cada contexto nacional.

\footnotetext{
${ }^{140}$ Valga como ejemplo del mayor interés que suscita la interpretación en ámbito jurídico y judicial con respecto a la interpretación en otros servicios públicos la relativamente reciente aprobación de la Directiva 2010/64/UE del Parlamento Europeo y del Consejo, de 20 de octubre de 2010, referente al derecho a interpretación y a traducción en los procesos penales, cuya implantación en diversos países europeos, dicho sea de paso, se encuentra todavía en una fase muy incipiente.
} 
En primer lugar, por lo que respecta a los servicios públicos y a los profesionales que trabajan en ellos, lo más común ante la llegada de usuarios alófonos, en un primer estadio, es negar la existencia de problemas de comunicación. Por ejemplo, no es infrecuente, de acuerdo con los resultados de diversas investigaciones (Castillo y Taibi, 2005; Sánchez-Reyes y Martín, 2005) y con los de nuestra propia investigación, como veremos en el próximo capítulo, que los profesionales de la salud manifiesten que son capaces de comunicarse con los pacientes alófonos apoyándose en otras estrategias de dudoso éxito (como, por ejemplo, el recurso a los gestos y expresiones faciales o el empleo de lenguas como el inglés o el francés, que supuestamente "dominan"). Tras la aceptación de que, efectivamente, se plantean dificultades comunicativas, normalmente, se recurre a los intérpretes ad hoc que hemos descrito anteriormente: familiares, amigos y conocidos del usuario que presentan "ciertos" conocimientos de la lengua del país de acogida, o a voluntarios que reciben algún tipo de remuneración (por lo general, bastante exigua) por desempeñar la labor de intérpretes sin haber sido formalmente preparados para ello. Finalmente, ante los resultados insatisfactorios de estas "soluciones-parche" y, en especial, con el aumento de la presencia de usuarios alófonos y de la multitud de lenguas requeridas para la comunicación con los mismos, o cuando los errores cometidos por alguno de estos intérpretes improvisados conllevan nefastas consecuencias, ${ }^{141}$ se llega a la conclusión de que es necesario dar un enfoque más sistemático a esta cuestión.

Otro de los grupos de los que depende el desarrollo de la interpretación en los servicios públicos está constituido por los gobiernos, responsables en última instancia de establecer estructuras y sistemas nacionales para la contratación de intérpretes. Si se justifica adecuadamente, mediante investigaciones rigurosas, que destinar fondos públicos a mejorar la comunicación entre los profesionales de los servicios de la Administración y los usuarios que no hablan la lengua mayoritaria supondrá un beneficio para todos los implicados, se fomentará el interés de los gobiernos por establecer una estructura coherente a nivel nacional que fomente la contratación de intérpretes debidamente cualificados y determine las competencias que estos deben poseer para desarrollar con éxito su labor. ${ }^{142}$

Por último, son los propios intérpretes los que, según Anne Corsellis (2010:13-14), deben luchar porque se establezca un marco que regule su desempeño profesional, contribuyendo, de este modo, a que se reconozca su formación y su experiencia en este ámbito y a que se les conceda el valor (en todos los sentidos, tanto social como económico) que se merecen.

De todos modos, cabe señalar que serán los dos primeros grupos mencionados los que ejerzan una mayor influencia a la hora de desarrollar esta profesión que, en palabras de Uldis Ozolins

\footnotetext{
${ }^{141}$ El conocido como "caso Begum", acontecido en el Reino Unido en los años ochenta del pasado siglo, es uno de los ejemplos más citados como "impulsores" (desgraciadamente) de la concienciación de la necesidad de contratar intérpretes profesionales en los servicios públicos para facilitar la comunicación entre los usuarios alófonos y los profesionales de dichos servicios. En él, una mujer de origen paquistaní fue acusada de asesinato y condenada a cadena perpetua y, tras pasar varios años en la cárcel, fue absuelta cuando se probó que esta desconocía el dialecto que se había empleado en la interpretación realizada durante el juicio y que, por tanto, la comunicación durante el mismo había presentado seguramente múltiples malentendidos y lagunas. No solo se privó de libertad a esta mujer injustamente, sino que, además, al salir de prisión, esta, repudiada por su familia, se quitó la vida.

${ }^{142}$ Valgan como ejemplo de investigaciones en las que se exponen los beneficios de contratar intérpretes cualificados para facilitar la comunicación con pacientes alófonos, los estudios de Elizabeth A. Jacobs et al. (2004), de Leighton Ku y Glenn Flores (2005), y de Leah S. Karliner (2007).
} 
(2000:32) es "institution-driven", en contraste con otras, como la interpretación de conferencias, cuyo desarrollo ha sido impulsado mayoritariamente por los propios profesionales que la practican. Como muestra de la necesidad de una mayor implicación por parte de los poderes públicos en el desarrollo de la ISSPP, cabe señalar que, en la mayoría de los países, estos servicios de interpretación han sido organizados por parte de las instituciones y gobiernos, antes de que los propios intérpretes lograran organizarse ellos mismos (Pöchhacker, 1999:136).

Asimismo, como sostiene María Isabel Abril (2006:89), en la práctica, el modelo de gestión de la inmigración y de la diversidad cultural propio de cada país no solo ha condicionado el desarrollo de esta profesión, sino que, además, ha influido en el ejercicio de las labores y funciones del intérprete, de modo que este

[...] no ejerce de la misma forma en un país donde el refugiado o el inmigrante se encuentra inmerso en un proceso de acogida asumido por los servicios públicos y en otro donde su situación de clandestinidad lo ha relegado a la marginalidad.

Por consiguiente, dependiendo de las particularidades propias de cada país y el impulso que en ellos han dado los diferentes actores implicados a la implantación la ISSPP, esta profesión ha presentado una evolución diferente.

Uno de los países en los que la interpretación en los servicios públicos se ha desarrollado más ampliamente, considerado pionero en este campo, es Australia. Fruto de los flujos migratorios que recibió tras la Segunda Guerra Mundial, ya en los años 50 del pasado siglo, se comenzó a reconocer la necesidad de adoptar estrategias que permitieran la comunicación entre los nuevos ciudadanos y los servicios de la Administración pública, por lo que empezaron a implantarse servicios de interpretación en escuelas y hospitales de diferentes ciudades, lo que dio lugar, posteriormente, a la creación de organizaciones y asociaciones de intérpretes (entre las que destaca, el Australian Institute of Interpreters and Translators -AUSIT- y, por lo que respecta al ámbito sanitario, el NSW Health Care Interpreters Service), así como a la instauración de un sistema nacional de acreditación (National Accreditation Authority for Translators and Interpreters -NAATI).

Otro de los países donde la interpretación en los servicios públicos ha experimentado una mayor evolución es Canadá, en el cual, a diferencia de Australia, el desarrollo de esta profesión se ha producido mayoritariamente a nivel provincial o local. De hecho, no cuenta con un sistema nacional de acreditación, sino que son algunas agencias de servicios lingüísticos (como la Cultural Interpretation Services of Ottawa-Carlton) y algunas universidades (como la British Columbia University) las que se ocupan de formar y/o evaluar a los futuros intérpretes. EI mayor hito por lo que respecta al reconocimiento de esta profesión en Canadá se ha dado a nivel investigador, pues es en este país donde se organizó hace casi veinte años el primer congreso de la red Critical Link, el cual tuvo lugar en Toronto, bajo el título The Critical Link: Interpreters in the Community. A la primera edición de este congreso le han seguido otras seis más en distintas ciudades (como Vancouver o Montreal y, en el contexto europeo, Estocolmo o Birmingham), de las cuales, la séptima y última se celebró el pasado junio, volviendo a la sede originaria, Toronto. Los diferentes congresos Critical Link y las sucesivas publicaciones de las actas a las que estos han dado lugar se han ocupado de cuestiones tan variadas como el 
reconocimiento de la profesión, la formación y la acreditación, las condiciones laborales de los intérpretes y los límites de su papel y sus funciones, o el análisis del estado de la cuestión en diferentes países, y, de acuerdo con Anne Martin (2003:432), son de referencia obligada para los investigadores y profesionales de este ámbito.

Por lo que respecta a los Estados Unidos, en este país, que también cuenta con una larga experiencia por lo que a recepción de inmigrantes se refiere, se ha pasado progresivamente de recurrir a intérpretes ad hoc a implantar servicios de interpretación en algunos servicios públicos, especialmente en el ámbito jurídico y judicial. No existe, sin embargo, una estructura o un sistema de acreditación a nivel estatal o federal, sino que se ponen en marcha iniciativas aisladas en determinadas zonas o sectores del país, con enfoques y resultados bien diversos (Mikkelson, 1995; González, Vázquez y Mikkelson, 1991; Rosenberg, 2002, citados en Valero, 2008:48), entre las que destacan las actividades de asociaciones consolidadas, como la National Association of Judiciary Interpreters and Translators (NAJIT) o, en el ámbito que nos compete, la International Medical Interpreters Association, la cual ha desarrollado un código de conducta para los intérpretes médicos.

En cuanto al contexto europeo, ${ }^{143}$ uno de los países donde se ha desarrollado más la ISSPP ha sido el Reino Unido, en el que, fruto del incremento de la población inmigrante, principalmente procedente de las excolonias de la Commonwealth, en los años setenta y ochenta del pasado siglo, comienzan a surgir actuaciones puntuales,

[...] sin ninguna organización nacional, regional, institucional o privada que prestase apoyo a los individuos o comunidades que no dominaban el inglés en sus relaciones con la administración o el estado. Los únicos intermediarios eran generalmente voluntarios o funcionarios que conocían la lengua requerida. [...] Muy pocas personas eran contratadas por sus servicios lingüísticos y con frecuencia realizaban tareas que nada tenían que ver con el trabajo de intérprete [...] solían pertenecer a las comunidades de inmigrantes o refugiados, no solían dominar el inglés y carecían de formación específica como traductores y/o intérpretes. [...] Existía formación académica a nivel universitario en las lenguas mayoritarias de Europa en diversos centros, pero no se ofrecía formación en lenguas minoritarias (Valero, 2008: 43). ${ }^{144}$

Poco a poco fueron surgiendo en este país iniciativas para favorecer la comunicación entre los profesionales de los servicios públicos y los usuarios inmigrantes, entre las cuales cabe citar la labor de investigadores como Anne Corsellis, Christine Adams y Anita Harmer, artífices del Diploma in Public Service Interpreting, y el establecimiento de una acreditación a nivel nacional (National Register of Public Service Interpreter-NRPSI) que se implantó en 1994, impulsados en la actualidad por el Institute of Linguists, organismo encargado de la acreditación y asociación que reúne a lingüistas, traductores e intérpretes de este país.

\footnotetext{
${ }^{143}$ Para obtener una visión más exhaustiva del desarrollo y estado actual de la interpretación en los servicios públicos en la Unión Europea, se recomienda la consulta de la comunicación que presentó María Isabel Abril en la III Jornada Internacional de bones pràctiques de gestió del multilingüisme. Els serveis de traducció, interpretació i mediació les llengües dels immigrants (2008). [http://www10.gencat.cat/casa_llengues/binaris/conferencia_abril_tcm302-113452.pdf] (última consulta: 28 de septiembre de 2013).

${ }^{144}$ Nos ha parecido interesante incluir esta cita en la que se describe el estado en el que se encontraba la ISSPP hace unas décadas en el Reino Unido por las semejanzas que presenta, como veremos posteriormente, con respecto a la actual situación que está viviendo esta profesión en España.
} 
Actualmente, en el Reino Unido, los centros y organismos públicos disponen de manera generalizada de servicios de interpretación, pero, a pesar de que estos presentan una amplia cobertura, no responden a un sistema uniformado ni centralizado, y en los distintos sectores y zonas del país se contratan tanto intérpretes pertenecientes al registro nacional (lo cual es obligatorio en el caso del ámbito judicial), como intérpretes autónomos o pertenecientes a agencias externas. Asimismo, uno de los servicios de ISSPP más desarrollados y empleados en este país, especialmente por lo que se refiere al ámbito sanitario, es el de interpretación telefónica, en la provisión de la cual destaca la empresa Language Line, junto a otras como EITI y National Interpreting Service (NIS) (Alexander et al., 2004:3).

Por lo que respecta específicamente al desarrollo de la interpretación en los servicios sanitarios en este país, cabe destacar la creación en 2007 del grupo de trabajo Working Group on Language Support in Healthcare, el cual surgió por el impulso del National Register of Public Service Interpreter y de las autoridades sanitarias, y está conformado por una nutrida representación de los principales implicados en la provisión de servicios de interpretación en este ámbito, desde funcionarios de los departamentos gubernamentales y miembros de asociaciones o agrupaciones relacionadas con los servicios lingüísticos, hasta usuarios de dichos servicios y profesionales sanitarios. El propósito perseguido con la creación de este grupo de trabajo consiste definir las bases de una política uniforme para la interpretación en ámbito sanitario, basada en un sistema sólido y estable, con estándares de calidad coherentes, y constituido por intérpretes formados, evaluados y certificados que puedan trabajar en condiciones laborales y profesionales dignas (Cambridge, 2008, citada en Abril, 2008:22).

Un último país cuya evolución de la interpretación en los servicios públicos quisiéramos analizar brevemente antes de pasar a exponer la situación del contexto español, es Suecia, que presenta un modelo de servicios de interpretación globales e integrales similar al de Australia, y que cuenta con un sistema de acreditación nacional desde 1976, dentro del cual existe una especialización centrada específicamente en la interpretación en ámbito sanitario.

La ISSPP en España se encuentra, a diferencia de los países que acabamos de analizar, en un estadio menos avanzado por lo que respecta al desarrollo de la profesión. Por el momento, no se ha producido una respuesta uniforme a nivel nacional por parte de la Administración pública por lo que respecta a la provisión de servicios de interpretación para facilitar la comunicación entre los profesionales de los servicios públicos y los usuarios alófonos, y las barreras comunicativas entre estos se niegan, se intentan suprimir recurriendo a intérpretes ad hoc o, en el mejor de los casos, se delegan a empresas privadas y organizaciones sin ánimo de lucro, cuyos intérpretes no siempre cuentan con la necesaria preparación y/o formación para desempeñar su labor. Mención aparte merecen las figuras oficiales como la del traductor e intérprete jurado del Ministerio de Justicia y del Ministerio del Interior, los cuales, para poder ejercer, deben superar un examen, o la del mediador intercultural, estipulada por el Real Decreto 638/2000 de 11 de mayo, de la cual hablaremos en el apartado de este capítulo dedicado a la mediación lingüística y cultural.

En el ámbito sanitario, la estrategia más frecuentemente adoptada es el recurso a familiares, amigos o conocidos de los pacientes, siendo en ocasiones incluso considerado como una obligación de estos últimos el acudir a los hospitales o centros de salud acompañados por 
alguien que "domine" el español, como veremos en el análisis de los resultados de nuestro trabajo de campo. Sin embargo, cabe citar la experiencia de algunos hospitales pioneros en el contexto español por lo que se refiere a la implantación de servicios lingüísticos que favorezcan la comunicación con los pacientes alófonos, como puede ser el Hospital Ramón y Cajal de Madrid, o el Hospital Punta Europa de Algeciras, ${ }^{145}$ por citar algunos.

Si bien la implantación en España de servicios de interpretación en los servicios públicos, en general, y en los servicios sanitarios, en particular, ofrece un panorama fragmentado y, por el momento, está lejos de alcanzar un desarrollo de calidad, son numerosos los esfuerzos que se están realizando desde el ámbito de la investigación y de la formación para transformar positivamente esta situación.

Por lo que se refiere al ámbito de la investigación, destacan por un lado, el grupo FITISPos (Grupo de Formación e Investigación en Traducción e Interpretación en los Servicios Públicos) y el grupo GRETI (una de cuyas líneas principales se dedica al estudio de la interpretación en los servicios públicos), de la Universidad de Alcalá de Henares y de la Universidad de Granada, respectivamente. El primero de ellos es responsable de la organización de los Congresos Internacionales sobre Traducción e Interpretación en los Servicios Públicos que, desde 2002, se vienen celebrando cada tres años, y cuya última edición estuvo centrada en la interpretación en ámbito sanitario, así como de las numerosas publicaciones que derivan de los mismos.

Cabe resaltar, asimismo, la labor de los miembros de la Red Comunica, ${ }^{146}$ compuesta por diversos grupos de investigadores de diferentes universidades españolas ubicadas en las distintas comunidades autónomas, y cuyo objetivo principal consiste en convertirse en un Observatorio Permanente de la Comunicación entre lenguas y culturas en nuestro país, centrándose en el área específica de la traducción y la interpretación en los servicios públicos.

En reconocimiento de esta labor investigadora, Uldis Ozolins (2010:207), señala, al hablar del desarrollo de la ISSPP en España, que "A particular contribution [...] has been the involvement of high level activist academics in the birth and development of language services, in relatively difficult circumstances", a lo este mismo autor añade que

What is surprising with respect to the other countries under investigation in this report is that Spain has a very active research community which focuses intensively on $\mathrm{Cl}$ [Community Interpreting] [...] There are several research groups which have published a wealth of publications (Pöllabauer 2008:7).

Reflejo de este creciente interés investigador por la ISSPP son, además, las tesis doctorales sobre esta disciplina presentadas en las universidades españolas en los últimos años, como la de María Isabel Abril (2006) en la Universidad de Granada, la de Raquel Lázaro (2010) en la Universidad de Alcalá de Henares, la de Mireia Vargas (2012) en la Universidad Autónoma de Barcelona, o la de Lluís Baixauli (2012) en la Universidad Jaume I. (Véase bibliografía)

\footnotetext{
${ }^{145}$ Cabe señalar que el Hospital Punta de Europa participó en el proyecto "Hospitales amigos del inmigrante en una Europa etnoculturalmente diversa", en el que colaboraron un grupo de doce hospitales europeos unidos por el fin de afrontar los desafíos derivados de la presencia de personas con diferentes orígenes étnicos y culturales en los servicios de salud. Hablaremos más extensamente de este proyecto en el siguiente capítulo y en las conclusiones generales.

${ }^{146}$ Para mayor información sobre los miembros y actividades de la Red Comunica, puede visitarse la página web: [http://red-comunica.blogspot.com.es/] (última consulta: 10 de septiembre de 2013).
} 
Por último, por lo que respecta a la formación en interpretación en los servicios públicos, en el último periodo se ha producido un notable incremento de la oferta formativa en este ámbito, como demuestra la inclusión de materias e itinerarios de especialización relacionados con la ISSPP, los cuales pueden cursarse en los Grados en Traducción e Interpretación de distintas universidades españolas, ${ }^{147}$ o los cursos de posgrado y máster centrados en esta disciplina u otras afines, entre los cuales, cabe destacar el Máster Universitario en Comunicación Intercultural, Traducción e Interpretación en los Servicios Públicos (Universidad de Alcalá), el Título de Experto Universitario en Traducción e Interpretación para los Servicios Comunitarios - EUTISC (Universidad de La Laguna), o el Posgrado en Interpretación en los Servicios Públicos de Cataluña (Universidad Autónoma de Barcelona), entre cuyas particularidades sobresalientes quisiéramos resaltar la inclusión de combinaciones lingüísticas que se corresponden no solo con las lenguas mayoritarias en Europa, sino también con las lenguas maternas de las principales comunidades de inmigrantes residentes en nuestro país (rumano, árabe, chino, ruso, etc.).

Los esfuerzos realizados en cuanto a la formación y la investigación sobre la ISSPP en España podrían contribuir en un futuro (esperemos no demasiado lejano) al desarrollo de la profesión, así como a la concienciación por parte de los responsables de la Administración y del personal de los servicios públicos sobre la necesidad de recurrir a intérpretes profesionales para superar las barreras comunicativas presentes en la interacción entre los profesionales de dichos servicios y los usuarios alófonos.

\subsubsection{La complejidad del rol del intérprete en los servicios públicos}

La definición del rol del intérprete, en general, y del intérprete en los servicios públicos, en particular, ha sido objeto de numerosas investigaciones y publicaciones en las últimas décadas, sin que por ello se haya alcanzado un consenso al respecto. Valgan como ejemplo los trabajos de Claudia Angelelli $(2003,2004)$, la publicación que recoge los artículos académicos de la tercera edición de Critical Link, Interpreting in the Community: the Complexity of the Profession (2001), la editada por Carmen Valero en 2005 Traducción como mediación entre lenguas y culturas, o la que editan Carmen Valero y Anne Martin (2008) Crossing Borders in Community Interpreting. Definitions and Dilemmas, donde se debate extensamente sobre el papel de intérprete, y en los que, si bien confluyen algunas ideas básicas, no se llega a un establecimiento concluyente de los límites que presenta el papel del intérprete.

En primer lugar, quisiéramos precisar que, en este apartado, nos centramos en la interpretación en el ámbito sanitario, pues consideramos que el papel del intérprete en este contexto difiere en numerosos aspectos del que desempeña el intérprete que trabaja en otros contextos, incluso si se trata de otros servicios públicos (Angelelli, 2008:152). Por una parte, cabe tener en cuenta que la interpretación en los servicios de salud tiene lugar en un contexto determinado, un contexto institucional con un funcionamiento y unos protocolos muy concretos, en el que las situaciones intensamente emotivas son bastante comunes, y donde lo que está en juego (la salud y la vida de las personas) es especialmente relevante. Por otra

\footnotetext{
147 Para mayor información, véase la publicación de la Red Comunica en el Libro Blanco sobre Traducción Institucional (2011:123-127).
} 
parte, el intérprete que trabaja en este ámbito actúa entre dos interlocutores ${ }^{148}$ que presentan diferencias no solo por lo que respecta a la lengua, sino también en relación con la cultura. Al hablar de cultura en este ámbito, además, no nos referimos únicamente a los patrones culturales generales, sino que debemos considerar también los conceptos de salud y enfermedad y la percepción que se tiene de las mismas por parte de los profesionales y los pacientes, lo que se conoce como disease e illness, respectivamente. Si bien es cierto que la representación de la dolencia por parte del paciente y por parte del profesional sanitario puede variar en cualquier circunstancia, incluso cuando ambos pertenecen a una misma comunidad cultural, en las situaciones interculturales, la distancia entre ambas representaciones será probablemente mayor, por la influencia que tiene la cultura, como hemos visto en el capítulo anterior, sobre nuestro concepto de enfermedad y los orígenes de la misma, sobre los modos de preservar y proteger la salud, así como a la hora de decidir cuándo solicitar asistencia médica, a quién solicitarla y qué tratamiento es el más adecuado para recuperar nuestra salud. Igualmente, cabe señalar que la relación entre el profesional sanitario y el paciente suele ser una relación asimétrica, en la que el primero cuenta con unos conocimientos y un poder notablemente superiores a los que presenta el segundo.

Por consiguiente, teniendo en cuenta las características específicas del contexto y de los participantes en la interacción comunicativa, las condiciones y el papel de los intérpretes que trabajan en ámbito sanitario presentarán diferencias con respecto a las condiciones y el papel de los intérpretes que trabajan, por ejemplo, en ámbito jurídico y judicial.

Otra cuestión que consideramos importante resaltar es que la intención que perseguimos al tratar este tema no consiste en absoluto en presentar afirmaciones resolutorias e irrebatibles sobre el rol del intérprete (algo que, como hemos señalado, no han conseguido lograr ni los investigadores con amplia experiencia y conocimientos en este ámbito), sino simplemente exponer una serie de reflexiones y conclusiones a las que hemos ido llegando mediante la lectura de la bibliografía al respecto y gracias a nuestra labor investigadora, en la que hemos podido percibir, tanto a través de la observación como mediante la solicitud de opinión a los propios implicados, las dificultades comunicativas que pueden surgir en la comunicación entre los profesionales sanitarios y los pacientes lingüística y culturalmente diversos. Estas reflexiones nos permitirán, asimismo, analizar en el último apartado del presente capítulo los aspectos que coinciden y divergen en la labor del intérprete y la del mediador lingüístico y cultural que trabajan en los servicios de salud.

En la controversia en cuanto al rol del intérprete participan prácticamente todos los implicados en el proceso de interpretación. Por una parte, la gran mayoría de los usuarios de los servicios de interpretación (profesionales sanitarios y pacientes) desconocen cuáles son las funciones que le corresponden al intérprete, la complejidad de su labor, e incluso las características que presenta la interacción cuando en ella se recurre a esta figura profesional. Son numerosos los ejemplos que demuestran la falta de conocimiento sobre la interpretación que presentan

\footnotetext{
${ }^{148}$ Véase el capítulo 3, centrado en el estudio de la comunicación intercultural, en el que se exponen de manera más exhaustiva los elementos principales que caracterizan al usuario inmigrante y al profesional sanitario, presentados en dicho capítulo con el fin mostrar cómo las dificultades que surgen en las interacciones interculturales en ámbito sanitario están en gran medida determinadas por las características de los participantes en dicha interacción.
} 
tanto el personal sanitario como los pacientes (al respecto, véanse, por ejemplo, las publicaciones de Leanza, 2007; Hans Verrept, 2008; Hale, 2010; o Phelan y Martín, 2010).

Así, a menudo, estos atribuyen al intérprete la función de mero trasvase lingüístico, considerando dicho trasvase como una actividad mecánica que se limita a la transmisión palabra por palabra de un mensaje, originariamente enunciado en una lengua $A$, en una lengua $B$, y viendo a los intérpretes como una "translation-machine", sin tener en cuenta que "reproducing or rendering speech actions of others is a fairly creative activity" (Wadensjö, 1998:69).

En otras ocasiones, por el contrario, le solicitan que realice tareas que exceden ampliamente su labor, como el acompañamiento de los pacientes para resolver cuestiones burocráticas. Es posible también que los profesionales, por la limitación del tiempo del que disponen para asistir a cada paciente, soliciten a los intérpretes que resuman lo que este ha expuesto. Otra de las situaciones que se presenta frecuentemente es aquella en la que uno o ambos interlocutores se dirigen directamente al intérprete $(y$, en lugar de plantear sus preguntas $y$ afirmaciones a su interlocutor, establecen la comunicación únicamente con el intérprete, empleando las "clásicas" fórmulas "Dile que..." o "Pregúntale si..."), por lo que uno de los implicados en la interacción queda excluido. Del mismo modo, es común que vean al intérprete como su aliado, bien porque trabaja directamente para la institución, en el caso del profesional, o bien porque presenta el mismo origen étnico y cultural, en el caso del paciente, o porque al menos conoce la lengua y la cultura de este último. En consecuencia, no es infrecuente que le pidan su opinión, que exijan que les defienda o que les conceda un trato diferencial con respecto al otro interlocutor. Todas estas situaciones descritas plantean graves problemas éticos a los intérpretes que trabajan en ámbito sanitario. ${ }^{149}$

$\mathrm{Y}$, precisamente, para tratar de resolver dichos dilemas éticos, los intérpretes suelen basarse en su formación y, en caso de que existan, en los principios de los códigos éticos que rigen su labor en una institución o en un contexto geográfico determinados.

Ahora bien, ¿se hallan todas las respuestas a estos dilemas éticos en las propuestas teóricas sobre interpretación en los servicios públicos y en los códigos éticos en los que se basa su profesión? En nuestra opinión, y como veremos a continuación, no siempre es así.

Una de las cuestiones más ampliamente debatidas al analizar el rol del intérprete es su supuesta invisibilidad en el acto comunicativo, la cual es prácticamente imposible, partiendo del hecho de su mera presencia física en el contexto en el que se encuentran los dos interlocutores. Así lo demuestran, por ejemplo, los estudios de Cecilia Wadensjö (1998) y de Claudia Angelelli $(2004 ; 2008)$, en los que se sostiene, en base a la evidencia empírica, la imposibilidad para los intérpretes de asumir el rol de nonpersons. En concreto, Claudia Angelelli (2008:151) va más allá, y defiende la visibilidad del intérprete cuando afirma que

[...] interpreters not only participate linguistically but [...] also bring to the interpreted communicative event all the social and cultural factors that allow them to co-construct a

\footnotetext{
${ }^{149}$ Al respecto, recomendamos la lectura del capítulo de la obra Traducción como mediación entre lenguas y culturas (2005:108-113) en el que Gema S. Castillo y Mustapha Taibi nos relatan algunos de los dilemas éticos a los que ellos mismos han debido enfrentarse al ejercer como intérpretes en servicios sanitarios de España y de los Estados Unidos.
} 
definition of reality with the other co-participants to the interaction. [...] They are powerful parties who are capable of altering the outcome of the interaction. [...] They are visible coparticipants who possess agency.

Del mismo modo, cabe señalar que la aportación del intérprete al intercambio comunicativo es patente desde el momento en que realiza una interpretación personal del mensaje y elige los mecanismos que, en su opinión, resultan más adecuados para transmitir dicho mensaje en otra lengua. Como indica Theo Hermans (2001:6-7), se trata de "[...] a matter of voice, of the discursive presence and the subject-position that inevitably enters translation, as it enters every form of speaking, from the moment text production begins". ${ }^{150}$

Asimismo, con el fin de cumplir con la función principal que se le atribuye, consistente en facilitar la comunicación entre dos personas que no comparten una lengua común, el intérprete se ve obligado a realizar una serie de acciones que implican su visibilidad y su participación activa en la interacción. Así, en ocasiones, deberá solicitar aclaraciones, o coordinar los turnos de palabra (por ejemplo, cuando se producen solapamientos). Además, en los casos en los que se le solicite que realice tareas que exceden sus funciones, deberá clarificar el límite de las mismas, hablando, por tanto, en primera persona y de forma autónoma con respecto a la interacción comunicativa que se produce entre los implicados.

Mención aparte merecen los casos en los que el intérprete se debate entre si, precisamente para favorecer el entendimiento mutuo, debe omitir partes irrelevantes del discurso, variar el registro empleado por los interlocutores, evitar reproducir fielmente expresiones verbales y no verbales que pueden resultar ofensivas en la cultura de uno de ellos, o añadir explicaciones de carácter cultural. Con respecto a estas situaciones descritas no existe una respuesta unívoca, ni entre los propios intérpretes ni entre los investigadores que estudian su labor. ¿Hasta qué punto puede el intérprete saber cuándo una afirmación es irrelevante o contiene, por el contrario, información que puede comprometer la comprensión de la dolencia del paciente por parte del profesional sanitario? ¿Cuándo es realmente necesario añadir una aclaración de carácter cultural? ¿O, en qué medida, los conocimientos del intérprete sobre los patrones culturales de los interlocutores se pueden aplicar homogéneamente a todos los miembros de una determinada comunidad cultural? Al respecto, de acuerdo con Sandra Hale (2007:134, citada en Phelan y Martín, 2010:7), "cultural differences can be varied and complex and interpreters need to be confident that the cause of the misunderstanding is a cross-cultural issue before deciding to offer an explanation". Por su parte, Claudia Angelelli (2006:185) sostiene que "the role of cultural clarifier may prove to be unrealistic, since the concept of culture is too broad to be applied universally". ${ }^{151}$

En nuestro caso, no disponemos de respuestas ante estas preguntas planteadas, y consideramos que, en cada situación comunicativa, se deberá aplicar un criterio diferente, muchas veces basado en el sentido común del propio intérprete.

\footnotetext{
${ }^{150} \mathrm{Si}$ bien el autor citado se refiere a la actividad traductora (de textos escritos), hacemos extensible esta presencia discursiva a la labor del intérprete.

${ }^{151}$ Algunos códigos éticos, como el del National Council on Interpreting in Health Care - NClHC (citado en Phelan y Martín, 2010:7), indican explícitamente en qué ocasiones o bajo qué condiciones puede el intérprete añadir aclaraciones de carácter cultural y, entre ellas, se encuentran aquellas en las no existe una equivalencia lingüística o cuando se produce un choque entre las creencias o comportamientos de los interlocutores basado en las diferencias culturales entre ambos.
} 
Estas cuestiones que acabamos de plantear están estrechamente relacionadas con otro de los principios que se incluyen en prácticamente todos los códigos éticos, en concreto, el principio de la fidelidad al mensaje original a la hora de transmitirlo en otra lengua. En primer lugar, cabría precisar qué se entiende por "fidelidad". ¿Significa, como consideran numerosos usuarios de los servicios de interpretación, traducir oralmente palabra por palabra el mensaje transmitido por un interlocutor? De acuerdo con Holly Mikkelson (2008:115), para el intérprete, la mayor dificultad reside, precisamente, en "to attempt to understand the intention of the utterance and portray it as faithfully as possible in the other language [...] working on the level of meaning rather on a word for word level".

Al mismo tiempo, la fidelidad plena es una meta prácticamente inalcanzable para el intérprete, "given the personal (subjective) cognitive interpretation of what the interpreter needs to understand and make understood" (Pöchhacker, 2008:15).

Por último, la imparcialidad del intérprete ${ }^{152}$ es también uno de los temas extensamente discutidos al analizar el papel que este debe desempeñar. Si bien estamos de acuerdo en que el intérprete no debe pronunciarse ni decantarse abiertamente por ninguna de las partes implicadas, y en que, al interpretar, debe dejar de lado sus propias opiniones y creencias, aun cuando estas sean opuestas a las de los interlocutores, nos planteamos si realmente es posible que el intérprete sea completamente imparcial, en especial teniendo en cuenta que trabaja en un contexto en el que, como hemos señalado, está en juego la vida y la salud de una persona, la cual, además, presenta una condición de inferioridad social con respecto al profesional sanitario que le proporciona asistencia médica.

Asimismo, no podemos exigir al intérprete una neutralidad pura, ${ }^{153}$ puesto que, como persona, lleva consigo una serie de valores y creencias que no podrá eliminar completamente al ejercer su labor. Como señala Theo Hermans (2001:7) refiriéndose a la imposibilidad de pretender la neutralidad del traductor (y, por extensión, del intérprete),

The translator's textual presence cannot be neutral, located nowhere in particular. The way a translation overwrites its original may be deliberate and calculated on the translator's part but as often as not it is unconscious or barely conscious, dictated by values, preferences, presuppositions and perceptions built into the individual and social beings that we are.

Lo importante es que dichos valores no afloren mediante la manifestación directa de consejos, juicios y opiniones mientras se está interpretando. Así, coincidimos con Robert N. Bellah (1977, citado en Bahadir, 2001:1), cuando sostiene que

What is dangerous is not the presence of value judgments [...] but only those judgments that remain beyond the reach of critical reflection and are not subject to revision in the light of experience.

\footnotetext{
152 La imparcialidad del intérprete podrá verse seriamente comprometida en los casos en los que este tenga una relación personal con alguno de los interlocutores, por lo que, la mayoría de los códigos de conducta aconsejan, en estos casos, rechazar desde un principio llevar a cabo la interpretación.

${ }^{153}$ Para autores como Hanneke Bot (2003) esta "mythological neutrality" es todavía más inviable en determinados contextos en los que el intérprete debe trabajar; mientras, de acuerdo con esta autora, la neutralidad es pertinente en los contextos legales, no lo es tanto en los ámbitos sanitarios, en los que la implicación personal del intérprete pueden ser beneficiosa para el paciente y el profesional sanitario.
} 
Al intérprete que trabaja en el ámbito sanitario se le han atribuido con frecuencia calificativos como el de "cultural broker", "link worker", "cultural informant" o "cultural mediator" (Leanza, 2007; Verrept, 2008), que han generado el debate entre dos posiciones que van desde la pretensión de la más estricta imparcialidad hasta la inclinación hacia lo que se conoce como "advocacy" o defensa de una de las partes. Tampoco en este caso existe una opinión unívoca al respecto por parte de investigadores e intérpretes. Algunos (Angelelli, 2008; Meyer et al., 2003; Valero, 2003a) sostienen que los resultados comunicativos serán más satisfactorios para todos los implicados si el intérprete asume funciones de coordinación, mediación y negociación de significados culturales o sociales. Por el contrario, otros (Phelan y Martín, 2010) consideran que estas intervenciones deberían limitarse a las situaciones estrictamente necesarias, o que se debería esperar a que sean los propios usuarios de los servicios de interpretación los que soliciten, en caso de necesitarlo, que el intérprete ofrezca aclaraciones de carácter cultural.

Por nuestra parte, creemos que la clave reside en el significado que se le atribuye al término "mediador" en este contexto. Si lo consideramos desde un punto de vista conceptual, el intérprete es, por supuesto, un mediador entre lenguas y culturas, desde el momento en que, mediante su intervención, facilita la comunicación entre personas con códigos lingüísticos y culturales diversos. De hecho, como sostiene Franz Pöchhacker (2008:13),

Since an interpreter's actions have a much more immediate effect on the progress and outcome of the interaction, it has become increasingly common to construe the interpreter's mediation activity as one of "moderating" or "managing" the interaction to guide it toward a felicitous outcome.

Entre dichas actividades mediadoras se incluirían, por ejemplo, la solicitud de aclaraciones o interrupciones cuando existe un solapamiento entre las intervenciones de los interlocutores (Roy, 1996; Zimman, 1994, citados en Pöchhacker, 2008:13), pero también las explicaciones de carácter cultural, las omisiones, la mitigación de los elementos verbales y no verbales que pueden resultar ofensivos de acuerdo con la cultura de uno de los participantes en la interacción (Kondo y Tebble, 1997; Jones, 1998, citados en Pöchhacker, 2008:13), las cuales se acercan más al concepto de mediación cuyo fin es reducir las diferencias y promover el entendimiento.

Sin embargo, si nos ceñimos al significado "contractual" (Pöchhacker, 2008) de mediación como resolución de conflictos, no siempre podrá asociarse este calificativo a la labor de interpretación. En nuestra opinión, solo podemos considerar que el intérprete resuelve conflictos al, como indicábamos en el párrafo anterior, aclarar, omitir o mitigar determinados conceptos, y no creemos que le corresponda la función de sugerir propuestas de resolución cuando los interlocutores no sean capaces de llegar a un acuerdo, puesto que dicha función le correspondería más bien, como expondremos en los próximos apartados, al mediador lingüístico y cultural.

Quisiéramos concluir este apartado con dos observaciones. En primer lugar, si bien los códigos éticos son de importancia relevante por proporcionar una serie de pautas que ayudarán al intérprete a tomar decisiones adecuadas cuando se enfrente a dilemas éticos $y$, al mismo tiempo, fomentarán que exista una idea más clara de su función por parte de los participantes 
en el proceso de interpretación (Hale, 2010:109), consideramos que sus principios no deben ser aplicados en la práctica profesional de manera estricta, sino que, en muchas ocasiones, será el propio intérprete, guiado por su sentido común, su formación y su experiencia, el que decida si es necesario trasgredir, al menos en parte, alguno de los principios contenidos en el código de conducta inherente a su profesión. Estos principios no son "universal truths but are socially determined in and for a given environment" (Meyer et al., 2003:153). Estamos, por tanto, de acuerdo con Şebnem Bahadir (2001:5), cuando sostiene que

A more flexible, dynamic and situation-oriented approach to the position and role of the interpreter and the activities they perform is required. It is time to close the period of interpreters feeling guilty of their visibility and being traumatized by the fear of taking the initiative or of resisting.

$Y$, en segundo lugar, cabe señalar que, en última instancia, siempre que se exceda alguno de los límites establecidos para el rol del intérprete, esto deberá hacerse para facilitar la comunicación entre los interlocutores, sin olvidar que el fin último del entendimiento entre ambos consiste en que los pacientes lingüística y culturalmente diversos puedan acceder y usar los servicios de salud equitativamente, en igualdad de condiciones que los pacientes autóctonos.

\subsubsection{Otros tipos ${ }^{154}$ de interpretación: la interpretación telefónica (IT)}

La interpretación telefónica se incluye dentro de la denominada "interpretación remota" (Pöchhacker, 2004:21), la cual se define como aquella que tiene lugar estando los participantes en la interacción y el intérprete físicamente distanciados. Las situaciones que se pueden dar son principalmente tres: que los participantes se hallen juntos y sea el intérprete el que se esté en otro contexto, que el intérprete se encuentre junto a uno de los participantes, o que los tres implicados se encuentren separados (Lee: 2007:231). ${ }^{155}$

Este tipo de interpretación, por lo general, se realiza en modalidad (bilateral) consecutiva, aunque los avances en las telecomunicaciones han permitido que se creen sistemas que permiten llevarla a cabo en modo simultáneo, los cuales, por el momento, se utilizan sobre todo en algunos servicios sanitarios y tribunales de los Estados Unidos (Mikkelson, 2003:254; Pöchhacker, 2004:22).

En cuanto a los mecanismos tecnológicos que se emplean en la IT, el más frecuente es el dual handset phone (Kelly, 2008:87) o teléfono de doble auricular, con el que se establece una llamada tripartita, lo cual permite a los tres implicados escuchar en todo momento los mensajes transmitidos por cualquiera de los interlocutores. Otros mecanismos menos adecuados, por los inconvenientes que conllevan, son el uso de un teléfono con altavoces

\footnotetext{
${ }^{154}$ A pesar de que, en la bibliografía al respecto, a menudo se identifica la interpretación telefónica con una modalidad de interpretación, en nuestro caso, atendiendo a la clasificación de la traducción oral propuesta por diversos autores (Hurtado, 1996; Jiménez, 1999), no consideramos adecuado atribuirle el calificativo de modalidad, puesto que las modalidades se establecen atendiendo al modo traductor y al momento de reformulación, que, en este caso, puede ser tanto consecutivo como simultáneo. Hemos decidido, por tanto, hablar de "tipo de interpretación", y basamos esta terminología más genérica en el empleo de medios tecnológicos/telefónicos para llevarla a cabo.

${ }^{155}$ En el contexto que nos ocupa, comúnmente se da la primera de las situaciones descritas, pues no es muy frecuente la comunicación entre el profesional sanitario y el paciente a través del teléfono.
} 
(cuyo empleo supone una pérdida de la confidencialidad, y conlleva muchas veces que surjan problemas acústicos, por la mala calidad del sonido, por la distancia a la que se encuentra el altavoz, o por la presencia de ruidos de fondo), y el uso de un solo aparato telefónico, cuyo auricular se van pasando los participantes en la interacción presentes en un mismo contexto (con la pérdida de información para uno de los participantes, que hace que la conversación pase de ser tripartita a convertirse en bipartita, y con la incomodidad que implica tener que intercambiar continuamente el auricular) (Rosenberg, 2005:248-249).

Los avances en las telecomunicaciones han permitido, además, que se desarrollen otras formas de interpretación remota, como aquellas que se basan en un sistema de videoconferencia o teleconferencia a través de Internet, cuyo uso es, por el momento, bastante limitado, aunque algunos autores (Phelan, 2001; Kelly, 2008) prevén avances en este campo en un futuro a corto o medio plazo.

La IT es la más antigua de las formas de interpretación remota. Comenzó a desarrollarse a mediados del pasado siglo, y fue a partir de la década de los ochenta y, sobre todo, los noventa, cuando su uso comenzó a expandirse, principalmente en el ámbito de los servicios públicos (comisarías, servicios sanitarios, etc.). El primer país en el surgió fue Australia, en el que, a raíz de los flujos migratorios recibidos en esa época, y con la dificultad que implicaba disponer de intérpretes en un territorio tan vasto, con el fin de responder a las necesidades lingüísticas de la población inmigrante, se creó un servicio de IT gratuito disponible las veinticuatro horas del día, el cual, en un primer momento, se ofrecía en las ciudades de Melbourne y Sydney, y se empleaba principalmente para situaciones de urgencia (de ahí, su nombre: Emergency Telephone Interpreting Service); sin embargo, a lo largo de los años, dicho servicio se ha ido expandiendo hasta ofrecerse en diferentes ámbitos y dar cobertura a nivel nacional. En los Estados Unidos, desde su primer servicio, instaurado en un departamento policial de California en 1981, se ha desarrollado notablemente esta forma de interpretación remota, que, por lo general, es gestionada por empresas privadas, junto a las cuales, en las últimas décadas, han surgido algunas iniciativas locales por parte de hospitales que gestionan su propio servicio de IT. Asimismo, en algunos lugares del país, se recurre a registros de intérpretes telefónicos voluntarios dependientes de organizaciones sin ánimo de lucro (Kelly, 2008:5-6).

En el Reino Unido, como hemos comentado previamente, el uso de la IT también se encuentra bastante difundido $\mathrm{y}$, actualmente, la empresa más importante en este sector es Language Line Inc., la cual comenzó a operar en 1990. En un principio, nació como una organización sin ánimo de lucro que ofrecía sus servicios al Royal London Hospital, pero, más tarde, se convirtió en una potente empresa privada a escala mundial y, junto al ámbito sanitario, hoy en día ofrece servicios en una gran variedad de sectores, como el empresarial, el de los seguros, etc.

En España, los servicios de interpretación telefónica comienzan a implantarse hace menos de una década, pero su evolución ha sido constante y, en la actualidad, numerosos organismos públicos pertenecientes a diversas comunidades autónomas han incorporado este servicio a 
las áreas de atención a los ciudadanos. ${ }^{156}$ En su mayoría se trata de empresas privadas contratadas mediante concurso público por las administraciones locales. ${ }^{157}$

A pesar de la rápida expansión que está experimentando la IT, especialmente por lo que respecta a su uso en los servicios públicos, las publicaciones que se ocupan de su estudio son todavía bastante escasas. De acuerdo con Francisca García (2009:22), la falta de bibliografía al respecto se debe probablemente a que "se trata de una realidad bastante reciente y no ha habido demasiado tiempo para llevar a cabo estudios empíricos centrados exclusivamente en ella".

Destacan los trabajos centrados en un contexto específico, como el de Sharon Oviatt y Philip Cohen (1992), quienes realizan un análisis del discurso de conversaciones interpretadas telefónicamente en interacciones entre profesionales de los servicios públicos y usuarios, el de Cecilia Wadensjö (1999), quien realiza un estudio comparativo entre diferentes interpretaciones presenciales y telefónicas, o el de Jieun Lee (2007), quien estudia la propia percepción que tienen un grupo de intérpretes telefónicos coreanos que trabajan en Australia. Asimismo, cabe citar las publicaciones de Brett Allen Rosenberg (2005; 2007) y, en especial, la obra de Nataly Kelly (2008), cuyo objetivo, como su título (Telephone Interpreting: A comprehensive guide to the profession) indica, es ofrecer una guía exhaustiva sobre esta profesión.

Las ventajas principales de este tipo de interpretación, en comparación con la interpretación presencial, son la reducción de costes y la inmediatez con la que se puede disponer de los servicios de un intérprete, vital en las situaciones de emergencia que se dan frecuentemente en ámbito sanitario. De todos modos, con respecto a la motivación económica que mueve a las administraciones públicas a optar por la IT, no existe un acuerdo unánime sobre el hecho de que realmente se disminuyan los gastos y, en todo caso, estos dependerán de la frecuencia y la duración de las llamadas (Phelan, 2001; Hewitt, 2000, citados en Mikkelson, 2003:253).

Asimismo, permite disponer de intérpretes en una gran variedad de lenguas minoritarias que presenten una menor demanda y que no se podrían cubrir con la interpretación presencial.

Por otro lado, de acuerdo con Holly Mikkelson (2003:260), entre los beneficios que puede suponer esta actividad para los intérpretes, cabría citar el hecho de que disponen de mayor flexibilidad por lo que respecta a los horarios y lugar de trabajo y, estando físicamente distanciados de los interlocutores, se puede fomentar su concentración y reducir el impacto emocional que pueden sufrir al estar presentes en situaciones traumáticas.

Además, la IT permite que exista una mayor confidencialidad en situaciones comprometidas, como las exploraciones físicas en los centros de salud o durante los interrogatorios, a lo que Holly Mikkelson (2003:260) añade que la preferencia de un intérprete de un determinado sexo

\footnotetext{
${ }^{156}$ Aragón, contexto específico de nuestro estudio, se encuentra, como veremos en el próximo capítulo, entre las comunidades que han implantado un servicio de interpretación telefónica para atender a los usuarios inmigrantes de los servicios públicos autonómicos.

${ }^{157}$ Se recomienda consultar la publicación de Mariola Luque (2008), en la que se realiza un análisis de las agencias de traducción e interpretación españolas, con el fin de conocer si ofrecen servicios de interpretación telefónica y, en dicho caso, cuáles son las principales características de dichos servicios (lenguas más demandadas, tipos de clientes, etc.).
} 
por parte de algunos usuarios podría verse mitigada por su ausencia física. En relación con este último aspecto, en la obra de Nataly Kelly (2008:85), como puede observarse en la cita que reproducimos a continuación, hallamos un testimonio de un intérprete de sexo masculino que refuerza esta idea de que la ausencia física puede conllevar menos reparos en los casos en los que la presencia de un hombre no resulte cómoda para los usuarios.

In my culture is not appropriate for a male to be present during a medical examination of a female, unless he is a close relative or spouse. For this reason, as a male medical interpreter, I was not able to interpret for a large number of in-person assignments, and nearly gave up my career due to a lack of work. Now that I work as a telephone interpreter, there are still certain situations in which a female interpreter is more appropriate, but I can be present over the phone without creating an uncomfortable environment for the patient or myself. This way, I can respect my culture and religion, while still working as an interpreter for health care organizations.

Por lo que respecta a las desventajas, la distancia física entre el intérprete y los interlocutores, con las consecuentes ausencias de un marco de referencia compartido y la falta de visión de los elementos no verbales que intervienen en la interacción, es la que más se señala en la bibliografía al respecto, y se indica que puede conducir a omisiones o malentendidos por parte del intérprete. Así, como afirma Cecilia Wadensjö (1999:254), para el intérprete telefónico,

There is an obvious disadvantage in being on the phone compared to being on site when it comes to capturing the communicative cues provided by interlocutors' gestures, posture, mimics, and other nonverbal behavior, all of which have a role in guiding the interpretation.

Esta ausencia de contacto visual puede suprimirse gracias al avance en las nuevas tecnologías, empleando en lugar del teléfono el sistema de videoconferencia al que hemos hecho referencia anteriormente.

La distancia es, asimismo, causante de una mayor dificultad por parte de los intérpretes para coordinar los turnos de palabra e interpretar los silencios que se producen a lo largo de la conversación. Así, de acuerdo con Cecilia Wadensjö (1999:262),

[...] telephone interpreted encounter interlocutors would be well advised to make special effort to express themselves clearly and verbalize any non-verbal activities that may have an impact on the ongoing interaction. This would partly make up for the loss of visual impressions [...]. But what cannot be compensated for is the sense of immediacy inherent to face-to-face interactions, which is essential for coordination talk.

Del mismo modo, para Sharon Oviatt y Philip Cohen (1992), en este tipo de interpretación, se producen más interrupciones, las cuales, a menudo, tienen lugar con el fin de comprobar la comprensión de los mensajes o que sigue habiendo conexión telefónica.

Otro inconveniente reside en el hecho de que el ruido ambiental o la falta de cobertura pueden entorpecer la escucha por parte del intérprete o de los interlocutores.

A pesar de las limitaciones que supone el medio en sí, no es este el que más dificulta la puesta en práctica de la interpretación telefónica, sino que, en opinión de Brett Allen Rosenberg (2005:243), los mayores obstáculos los causan "los factores situacionales y extralingüísticos", entre otros factores, por la heterogeneidad de clientes y situaciones en las que deben trabajar 
los intérpretes. Además, para estos supone un gran reto tener que responder a múltiples llamadas al día, sin contar con la suficiente preparación previa para poder llevar a cabo su labor con la mayor calidad posible.

Con respecto a la confidencialidad, si bien habíamos comentado que algunos usuarios de los servicios de interpretación telefónica parecen preferir que el intérprete no esté presente durante la interacción, por el contrario, otros manifiestan cierto recelo por su ausencia física, y presentan dudas sobre su capacidad o fiabilidad, precisamente por la imposibilidad de reconocerle (Hewitt, 1995; Vidal, 1998, citados en Mikkelson, 2003:261).

Igualmente, en determinadas circunstancias, según Holly Mikkelson (2003:263), debería evitarse el uso de la IT, como por ejemplo, cuando se prevea que la conversación será muy larga o cuando vayan a intervenir muchos interlocutores. Para otros autores, este tipo de interpretación no debería usarse en las situaciones en las que participen niños, ancianos, personas con problemas de audición, o enfermos mentales, por las dificultades que estos podrían tener para comunicarse por teléfono (Kelly, 2008; Wadensjö, 1999). Roberto GraciaGarcía (2002) va más allá, y opina que no debería recurrirse a la interpretación telefónica siempre que sea posible contar con un intérprete presencial con relativa inmediatez.

Por todo lo expuesto hasta el momento, es posible constatar que la IT presenta ventajas y desventajas, y su uso puede ser más o menos conveniente con respecto a la interpretación presencial en determinadas circunstancias. De todos modos, teniendo en cuenta que, como hemos comentado en páginas previas, es bastante frecuente el recurso a intérpretes ad hoc en los servicios públicos, el empleo de la interpretación telefónica sería "el mejor de los males" (Hewitt, 1995, citado en Mikkelson, 2003:260) o, como sostiene Roberto Gracia-García (2000:200), "a good interpreter at a distance is better that a bad one up close or none at all".

Numerosos intérpretes presenciales temen que la interpretación telefónica reemplace sus servicios. Sin embargo, como sostiene Nataly Kelly (2008:91), hoy por hoy, "is doubtful that telephone interpreting companies are seeking to replace on-site interpreters. However, providers of telephone interpreting services are responding to a demand that exists". Esta misma idea es apoyada por Roberto Gracia-García (2002:199), quien opina que

There seems to be general agreement that in no case can $\mathrm{TI}$ be used without any limit whatsoever. Also, whether interpreters like it or not, TI has been used in various settings for several years now (health care, courts, and private business). It seems to be here to stay and has undoubtedly brought some good things to the community interpreting field.

A pesar del rápido desarrollo que ha experimentado este tipo de interpretación, todavía deben producirse algunas circunstancias para fomentar su ulterior evolución. Así, por ejemplo, de acuerdo con diversos autores (Gracia-García, 2002; Mikkelson, 2003; Ozolins, 2011), debe existir mayor formación tanto para los intérpretes telefónicos como para los usuarios de sus servicios. Asimismo, se deben realizar más investigaciones que ayuden a comprobar determinados aspectos sobre la práctica de la interpretación, como si la pérdida de elementos no verbales tiene una gran influencia en la calidad de la interpretación, si la formación de los 
usuarios puede mejorar y aumentar el uso de este servicio, etc. ${ }^{158}$ Por último, de acuerdo con Roberto Gracia-García (2002:214), tan pronto como sea posible, sería conveniente que la Administración pública contratara a sus propios intérpretes telefónicos certificados, en lugar de recurrir a empresas externas privadas para que sean ellas quienes proporcionen este servicio.

\subsection{La mediación lingüística y cultural (MLC)}

La mediación lingüística y cultural se corresponde con una figura profesional emergente que se está empleando cada vez con mayor frecuencia en los servicios públicos (educativos, jurídicos, sanitarios, laborales, socio-familiares, etc.) de algunos países receptores de población inmigrante para actuar de puente entre esta y los profesionales de dichos servicios.

Para referirse a esta figura se utilizan múltiples denominaciones, entre las que se encuentran, por citar las más comunes, (inter)mediación cultural, intercultural o lingüístico-cultural, y las cuales, en ocasiones, son empleadas de modo diferenciado dependiendo de la función o funciones que se le atribuyen. Por nuestra parte, hemos optado por denominarla mediación lingüística y cultural, ${ }^{159}$ pues deseábamos resaltar la doble faceta que recubre, relacionada, por un lado, con la lengua, pero, asimismo, con la cultura. A este respecto, quisiéramos precisar que la intermediación lingüística no siempre será necesaria, puesto que la mediación se utiliza también en interacciones que presentan una lengua en común, pero que pertenecen a grupos socio-culturales diversos, como puede ser el caso de la comunidad gitana en España. Por otra parte, no hemos considerado necesario incluir el prefijo "inter" empleado en otras denominaciones, ya que creemos que este tipo de mediación, por las funciones que le corresponden y los destinatarios a los que se dirige, ya lleva implícita la idea de relación propia de dicho prefijo.

En este apartado introductorio, cabe señalar, además, que, por el momento, la MLC no cuenta con un estatuto legal o un título de estudios reconocido en la mayoría de los países europeos y, en el ámbito de la formación, como veremos en el siguiente apartado, existen todavía numerosas carencias, lo cual conlleva que, en muchas ocasiones, acaben realizando la labor de mediadores familiares, amigos o conocidos de los usuarios inmigrantes, los cuales, en los momentos iniciales de la llegada al país de acogida, les informan sobre la existencia y funcionamiento de los servicios públicos, les acompañan cuando acuden a los mismos, y

\footnotetext{
${ }^{158}$ A pesar de que en Aragón, como hemos comentado, existe un servicio de interpretación telefónica en los servicios públicos, no nos ha resultado posible incluir el análisis de su uso en nuestro estudio, ya que, como se comprobará en el próximo capítulo, este prácticamente no se emplea en el hospital en el que hemos desarrollado nuestra investigación, y la gran mayoría de profesionales sanitarios y usuarias ni siquiera conocen su existencia. Asimismo, enviamos un cuestionario a los intérpretes de la empresa adjudicataria del servicio en dos ocasiones (la primera en formato de papel y la segunda a través de una encuesta electrónica) y, en ninguna de ellas, recibimos respuesta por su parte.

${ }^{159}$ Cabe señalar que la denominación más comúnmente empleada en el contexto español (AEP Desenvolupament Comunitari, Federación Andalucía Acoge, Giménez, Grupo CRIT, etc.) es "mediación intercultural” y, por supuesto, no tendríamos ningún inconveniente en adoptarla, especialmente si ello contribuyera a un mayor consenso sobre esta figura (el cual, a su vez, fomentaría su profesionalización). Sin embargo, nuestra propuesta de denominación, como hemos comentado, persigue resaltar una de las funciones que puede asumir el mediador, consistente en la intermediación lingüística. El motivo principal que nos conduce a subrayar dicha función reside en que, como explicamos más adelante, consideramos necesario que los mediadores reciban formación para poder llevarla a cabo, es decir, que sus conocimientos de las dos lenguas implicadas no garantizan que estos realicen una correcta intermediación lingüística.
} 
realizan labores de traducción e interpretación ad hoc para facilitar su comunicación con los profesionales de dichos servicios.

Este tipo de intervención es conocida como mediación natural y, por la falta de preparación que presentan las personas que la desempeñan, contiene una serie de límites y contraindicaciones, que derivan de factores como las carencias por lo que respecta al dominio del idioma del país de acogida, el desconocimiento del funcionamiento de los servicios, o la falta de formación por lo que se refiere a técnicas de interpretación. Asimismo, por el hecho de pertenecer a la misma familia o comunidad del usuario, estas personas probablemente presentarán una escasa capacidad para salir del propio marco de referencia cultural, y carecerán de la objetividad e imparcialidad necesarias a la hora de interpretar las demandas de los usuarios o las propuestas de los profesionales. En consecuencia, en nuestra opinión, la mediación natural no debe equipararse con la mediación lingüística y cultural, ya que esta última supone una especialización y una profesionalización considerables.

Por otro lado, el empleo del término "mediación" en la denominación de la MLC conlleva que, a menudo, se la relacione con otras actividades mediadoras más consolidadas a nivel profesional, como puede ser la mediación familiar, la comunitaria, o la penal y penitenciaria, cuyo análisis no nos detendremos a realizar aquí, por alejarse de los fines que perseguimos con nuestra investigación.

Del mismo modo, como señala Montserrat Antonin (2011:77), "con frecuencia la terminología y conceptos que se refieren al ámbito de la mediación y la gestión de los conflictos se utilizan de forma indiscriminada y equívoca". Al respecto, cabe señalar que la MLC, a pesar de que, como veremos más adelante, presenta entre sus funciones la prevención y resolución de conflictos, no debe confundirse con otras actividades que persiguen este mismo fin, tales como la negociación (en la que se produce un encuentro entre partes en conflicto para hallar un acuerdo positivo por sí mismas), el arbitraje (en el que las partes en conflicto deciden delegar su poder de decisión en un árbitro), o el recurso a la ley (situación en la que las partes deciden ponerse en manos de expertos en legislación por la imposibilidad de encontrar una solución al conflicto). Así, como señala Jean-François Six (1990, citado en Antonin, 2011:110),

La mediación, contrariamente a lo que sería un juicio, un arbitraje o una negociación, que son situaciones duales, es una situación "triangular"; implica necesariamente una tercera persona, un tercero estrictamente independiente de ambos protagonistas o antagonistas. (comillas del original)

Antes de pasar a presentar el estado de la cuestión de la MLC y las distintas definiciones que se atribuyen a la figura mediadora, quisiéramos comentar que, aunque esta posee puntos en común con la interpretación en los servicios públicos (del análisis de los cuales nos ocuparemos en el último apartado de este capítulo), en cuanto a su estado de desarrollo, la situación de la MLC dista todavía de parecerse a la de la ISSPP. Por el hecho de que se encuentra en un estado más incipiente, menos definida, en las siguientes páginas, vamos a tratar de aportar una contribución (limitada) a su definición, por lo que la información ofrecida sobre esta forma de intermediación (lingüística y cultural) es más exhaustiva con respecto a la que hemos expuesto en relación con la interpretación, especialmente por lo que se refiere a la descripción del perfil de la figura mediadora, las funciones que le corresponden, y los 
conocimientos, habilidades y actitudes necesarios para desempeñar su labor. Asimismo, cabe señalar que, aunque presentamos aspectos generales de la MLC, los acompañamos de información relativa al ámbito específico de nuestro estudio, los servicios sanitarios.

\subsubsection{Estado de la cuestión de la MLC}

La mediación lingüística y cultural, como hemos comentado previamente, se encuentra en un estado incipiente por lo que se refiere a su desarrollo y reconocimiento profesional. Esta figura se ha venido empleando en las últimas décadas, especialmente en algunos países de Europa, sin que por ello se haya conseguido delimitar su papel y sus funciones, y así quedará patente en las páginas sucesivas. Cabe resaltar que la adopción de la MLC ha estado en gran medida (aunque no únicamente) determinada, como señalábamos en la parte introductoria del presente capítulo, por el modelo de gestión de la diversidad cultural propio de cada país. De hecho, esta figura tiene una mayor presencia en países como Austria, Bélgica, España, Francia e Italia, en los que el modelo predominante se acerca más al asimilacionismo que al multiculturalismo más propio de otros países.

Analizar la situación profesional de la MLC en Europa entraña ciertas dificultades, principalmente por la gran diversidad de experiencias, prácticas y conceptos que presenta esta categoría profesional, tanto por lo que respecta a los distintos países, como por lo que se refiere a las diversas áreas geográficas y los diferentes sectores en los que se recurre a la mediación lingüística y cultural. Podemos hablar, por tanto, de una ausencia de consenso en relación con la figura mediadora en el contexto europeo. No obstante, a continuación, exponemos brevemente la evolución y estado actual de la mediación lingüística y cultural en algunos de los países donde esta ha tenido una mayor "aceptación". 160

En Francia, la figura mediadora lingüística y cultural (conocida en este contexto, principalmente, como femmes-relais) comienza a emplearse a partir de la década de los noventa del pasado siglo, y está especialmente vinculada al contexto educativo (LLevot i Calvet, 2006, citada en Rodríguez y Souto, 2009:157). Cabe señalar que, como hemos indicado en el capítulo 1, la experiencia migratoria de Francia como país receptor es bastante más longeva de la que presentan otros países del sur de Europa. Sin embargo, es a finales del siglo XX cuando se produce un mayor número de reagrupaciones familiares, por lo que aumenta considerablemente la presencia de mujeres y menores inmigrantes, a los que, en un primer momento, se destina la MLC, ocupada, en la mayoría de los casos, por mujeres extranjeras que realizan funciones de "mujeres-enlace" entre diferentes grupos sociales. Sus labores cubren un amplio espectro de actividades, que van desde el acompañamiento y guía de los usuarios extranjeros de los servicios públicos, hasta la ayuda a la inserción y el apoyo durante los procesos de adquisición de autonomía por parte de los grupos o personas que se enfrentan a dificultades en la sociedad francesa (Richarte, 2008:26). Los poderes públicos han mostrado interés por reconocer profesionalmente la labor de esta figura, pero hasta el momento no se encuentra institucionalizada en Francia a nivel nacional. A pesar de esta falta de

\footnotetext{
${ }^{160}$ No se encuentra entre nuestros propósitos el análisis exhaustivo de la evolución y del estado actual de la MLC en distintos países, por lo que este apartado no presenta información detallada a este respecto. Para obtener una visión más amplia, se recomienda consultar las obras de Inés Richarte (2008), Almudena Rodríguez y Esther Souto (2009), y Simone Casadei y Massimiliano Franceschetti (2009) (véase bibliografía), en las que se ofrece un análisis comparativo de la situación de la mediación lingüística y cultural en diferentes países europeos.
} 
reconocimiento oficial, cabe destacar que las femmes-relais cuentan con un código deontológico que regula el desempeño de su profesión. ${ }^{161}$

Italia, país que, al igual que España, ha visto incrementada notablemente la presencia de población extranjera en su territorio en las últimas décadas, ha optado por la figura mediadora lingüística y cultural (mediatore linguistico-culturale) para favorecer la comunicación entre los profesionales de los servicios públicos y los usuarios inmigrantes, y para fomentar la integración de estos últimos en la sociedad. Ya en el año 1998, se aprueba la primera ley marco sobre inmigración en Italia (Legge 6 marzo 1998, numero 40), que prevé la posibilidad de que todas las entidades y organismos públicos, a través de convenios, puedan incorporar mediadores lingüísticos y culturales a sus equipos de trabajo. Su participación está prevista con el fin de "agilizar las relaciones entre las administraciones y las personas extranjeras que pertenecen a distintos grupos étnicos, nacionales lingüísticos y religiosos" (Richarte, 2008:28). A partir de dicho momento, comienza a emplearse esta figura cada vez con mayor asiduidad en los servicios orientados a la atención a la ciudadanía. Sin embargo, el perfil profesional de los mediadores presenta una gran variedad, y tanto los requisitos para acceder a la profesión como los itinerarios formativos que permiten dicho acceso no se encuentran regulados a escala nacional, de manera que el mediador lingüístico y cultural es considerado como un profesional liberal. La formación en MLC es ofrecida por distintas instituciones $y$ organizaciones (que van desde el ámbito universitario, hasta el sector privado y las organizaciones sin ánimo de lucro). Son numerosos los investigadores italianos que se han ocupado en los últimos años del estudio de la mediación lingüística y cultural, entre los cuales, quisiéramos destacar, por las aportaciones que han realizado al análisis de la MLC en el ámbito específico de nuestro estudio, a Marta Castiglioni, Antonio Chiarenza, Danilo De Luise y Mara Morelli. ${ }^{162}$ En la práctica, la mayoría de los mediadores que trabajan en Italia se encuentran empleados en los servicios sociales y en el ámbito educativo, seguidos, en menor medida, por los servicios sanitarios (Richarte, 2008:59). Se trata de iniciativas aisladas que se reducen al ámbito regional o local, y no existe una homogeneidad en cuanto a la incorporación de la figura mediadora en los diferentes servicios públicos del país. Quisiéramos destacar, por la relación directa que presenta con nuestra investigación, el caso de las mediadoras lingüísticas y culturales que trabajan en los servicios sanitarios de la ciudad de Bolonia. Este servicio nace de una experiencia piloto que se formalizó en el Centro per la salute delle donne straniere e dei loro bambini, el cual trabaja, desde 1990, con el fin no solo de garantizar un servicio de acogida e información sobre el acceso a la sanidad, sino también de ocuparse de realizar visitas pediátricas, ginecológicas, psicológicas y de medicina general a usuarias inmigrantes y a sus hijos, con la presencia constante de mediadoras lingüísticas y culturales. Se trata de un modelo de mediación que podríamos denominar de acompañamiento, ya que estas mediadoras se encargan de acompañar a los usuarios no solo durante las visitas, sino también antes y después de las mismas, estableciendo una relación personalizada. ${ }^{163}$

\footnotetext{
${ }^{161}$ Dicho código puede consultarse en el trabajo de Inés Richarte (2008:148-153) incluido en la bibliografía.

${ }^{162}$ Cabe mencionar que las publicaciones sobre mediación lingüística y cultural en Italia son muy numerosas, pero no se encuentra entre los objetivos de nuestro estudio realizar un análisis exhaustivo de la investigación en este ámbito en los diferentes países y, por ello, nos hemos limitado a señalar los nombres de aquellos autores que más han inspirado nuestro trabajo.

${ }^{163}$ Precisamente el trabajo de investigación realizado para la obtención del Diploma de Estudios Avanzados previo a la presente tesis se centró en el estudio de la mediación lingüística y cultural en esta ciudad italiana.
} 
La situación de la MLC en España es bastante similar a la que presenta en Italia. Su paso de un país exportador de emigración a un país receptor de inmigración, como hemos comentado en más de una ocasión a lo largo de nuestro trabajo, es relativamente reciente, y la mediación lingüística y cultural es una de las respuestas que se han ofrecido en este breve espacio de tiempo para fomentar la comunicación y la relación entre "los antiguos" y "los nuevos" ciudadanos y promover la integración de estos últimos en la sociedad española. No existe homogeneidad por lo que respecta a la delimitación de su perfil y sus funciones, y la MLC presenta una situación fragmentada y desigual en este país. Dentro de este contexto, destacan las experiencias de empleo de mediadores lingüísticos y culturales en las comunidades autónomas de Andalucía, Cataluña, Castilla y León, la Comunidad Valenciana, y Madrid. ${ }^{164}$

Por lo que respecta a la formación, no se cuenta con un título de estudios oficialmente reconocido, si bien en los últimos años han proliferado diferentes propuestas formativas que parten tanto de las universidades, como de entidades públicas locales y organizaciones sin ánimo de lucro. Estas propuestas son muy variadas; incluyen desde cursos de larga duración (con inclusión o no de prácticas en entornos reales), hasta talleres, seminarios y jornadas.

En relación con el ámbito universitario, son principalmente los nuevos Grados en Traducción e Interpretación los que comienzan a introducir materias e itinerarios de especialización relacionados con la MLC. Asimismo, se organizan cursos de posgrado, y se implantan másteres universitarios centrados o conducentes al desempeño de la mediación lingüística y cultural. ${ }^{165}$ En concreto, en el contexto aragonés, en el que se centra nuestro estudio, el Grado en Traducción y Comunicación Intercultural de la Universidad San Jorge presenta en su plan de estudios un módulo centrado en los estudios interculturales, en el que se incluyen materias como Mediación intercultural o Comunicación intercultural. ${ }^{166}$

En cuanto a la formación no reglada, destaca la labor llevada a cabo por asociaciones como la Federación Andalucía Acoge, AEP Desenvolupament Comunitari, o la Escuela de Mediadores de la Comunidad de Madrid (EMSI), así como la impartida por la Fundación CeiMigra de Valencia, o la Fundación Social La Caixa.

Por lo que refiere a la investigación, son cada vez más numerosos los estudios y publicaciones que han surgido en relación con la MLC en el contexto español. Destaca la labor de grupos de

\footnotetext{
${ }^{164}$ Por lo que respecta a Aragón, comunidad autónoma contexto de nuestro estudio, la MLC no cuenta con una experiencia tan consolidada como la de Andalucía, Cataluña, Castilla y León, la Comunidad Valenciana, y Madrid, aunque, como veremos en los capítulos 6 y 7 , existen iniciativas concretas de empleo de mediadores lingüísticos y culturales, principalmente impulsadas por entidades sociales sin ánimo de lucro.

165 Para mayor información, véase la publicación de la Red Comunica en el Libro Blanco sobre Traducción Institucional (2011:123-127).

${ }^{166}$ Quisiéramos destacar, asimismo, que, desde el curso 2013-2014, este Grado ha activado un nuevo itinerario de especialización, en el que se encuentran materias como Interpretación en los servicios públicos o Traducción institucional. Además, la Universidad San Jorge oferta desde el año 2008 un Título de experto en patrones culturales y sociedad contemporánea que, a nuestro parecer, constituye un excelente complemento formativo para los estudiantes del Grado en Traducción y Comunicación Intercultural, en general, y para aquellos que quieran dedicar su futuro desempeño profesional a labores de mediación lingüística y cultural o de traducción e interpretación en los servicios públicos, en particular.
} 
investigación como el Grupo CRIT de la Universidad Jaume I, el Grupo MIRAS de la Universidad Autónoma de Barcelona, el Grupo Triángulo, ${ }^{167}$ o la previamente mencionada Red Comunica.

Muestra de este interés que ha suscitado la mediación lingüística y cultural en el terreno investigador son las tesis doctorales presentadas en los últimos años relacionadas con este ámbito de estudio, entre las que podríamos citar la de Jordi Agustí (2003) en la Stanford University o la de Montserrat Antonin (2009) en la Universitat Rovira i Virgili, en las que se estudia en ambos casos la evolución y la práctica de la MLC en Cataluña. (Véase bibliografía)

En la práctica, cabe resaltar la actividad que realizaba el Servicio de Mediación Social Intercultural (SEMSI), un programa de intervención, creado en 1997, y patrocinado mediante un convenio del Área de Servicios Sociales del Ayuntamiento de Madrid y la Fundación General de la Universidad Autónoma de Madrid, el cual, de acuerdo con la información ofrecida en su página web, perseguía el objetivo general de favorecer "la integración social de la población inmigrante extranjera residente en el Municipio de Madrid mediante la filosofía y la metodología de la mediación y más específicamente de la mediación intercultural". Asimismo, destaca la labor llevada a cabo en Cataluña por la Red de mediadores interculturales financiada por la Obra Social La Caixa. En el contexto aragonés, cabe mencionar la labor llevada a cabo por los mediadores del Servicio de Apoyo a la Mediación Intercultural (SAMI), del que ofreceremos mayor información en el apartado de análisis documental del próximo capítulo. Por último, en relación con el ámbito específico de nuestro estudio, quisiéramos señalar los programas de mediación lingüística y cultural que se han implantado en hospitales de diferentes ciudades españolas, como, por ejemplo, el Hospital del Mar, el Hospital Clínic y el Hospital Vall d'Hebron, los tres en la ciudad de Barcelona, o el Hospital de Poniente de El Ejido.

\subsubsection{Definición de la MLC. Los límites difusos de la figura mediadora lingüística y cultural}

La mediación, en sentido amplio, se define como

[...] un proceso en el cual las partes en conflicto se comunican con la ayuda y guía de un mediador neutral con el objeto de finalizar su conflicto. El mediador no asume capacidad de decisión alguna, simplemente orienta a las partes para que éstas lleguen a un acuerdo conjunto (Zeigler, 1998).

[...] el proceso de comunicación entre partes en conflicto con la ayuda de un mediador imparcial, que procurará que las personas implicadas en una disputa puedan llegar, por ellas mismas, a establecer un acuerdo que permita recomponer la buena relación y dar por acabado, o al menos mitigado, el conflicto, que actúe preventivamente o de cara a mejorar las relaciones con los demás (Vinyamata, 2003).

Las definiciones presentadas coinciden en que la mediación es un recurso que emplean partes en conflicto con el fin de poder superarlo, que el protagonismo es de las partes, que el mediador deber ser imparcial, y que este se tiene que dedicar a conducir el proceso que lleve a las partes a una solución satisfactoria para ambas.

\footnotetext{
${ }^{167}$ El Grupo Triángulo es una federación formada por entidades tanto nacionales como autonómicas, entre las que se encuentran las anteriormente mencionadas AEP Desenvolupament Comunitari y Andalucía Acoge, así como otras como la Fundación Secretariado General Gitano (FSGG), el Programa Migración y Multiculturalidad de la Universidad Autónoma de Madrid, La Fundación CeiMigra de la Comunidad Valenciana, o la Asociación para la Cooperación Internacional y la Solidaridad Internacional (ACISI).
} 
Si bien algunos de estos aspectos podrían aplicarse a la MLC, esta última, al actuar en contextos multiculturales, presenta algunas particularidades, las cuales hacen surgir diferentes necesidades en comparación con otros tipos de mediación que se emplean en contextos diversos. En primer lugar, cabe recordar que los destinatarios de la mediación lingüística y cultural son personas (o grupos de personas) pertenecientes a comunidades socio-culturales y étnicas distintas que comparten el mismo espacio social. Por lo general, se trata, por una parte, de un colectivo mayoritario, cuyos valores y códigos culturales son los dominantes, y uno o varios colectivos minoritarios, que persiguen el derecho a la diferencia y tratan de evitar que la hegemonía o el asimilacionismo cultural supriman sus particularidades culturales. A nivel socio-económico, cabe destacar que la mayoría de los miembros de estos colectivos minoritarios se suele encontrar en situación de desventaja con respecto a los miembros del colectivo mayoritario, y presenta dificultades para cubrir una serie de necesidades básicas, como son aquellas relacionadas con la vivienda, la salud, la educación y el empleo.

Asimismo, los grupos minoritarios se encuentran en una situación de discriminación, por las barreras lingüísticas y culturales que deben afrontar a la hora de acceder y usar los servicios públicos, a las que se suman el desconocimiento por su parte del funcionamiento de dichos servicios, la actitud hacia ellos que presenta la sociedad de acogida, y los estereotipos y prejuicios que les asignan. Además, cabe señalar que esta situación de discriminación impide, en última instancia, su plena integración en la sociedad.

Partiendo de estos presupuestos, no podemos limitar la definición de la MLC a cubrir los aspectos que se incluyen en otros tipos de mediación más generales, sino que, como veremos a continuación, esta presenta una serie de características que la alejan de otras actividades mediadoras.

Son múltiples los modos entender, presentar y utilizar la mediación a la que se recurre en contextos multiculturales. La gran diversidad de significados que se atribuyen a este concepto varían, por ejemplo, en base al tipo de servicio en el que desempeñan sus labores los mediadores, según se trate de un servicio exclusivo para usuarios extranjeros o destinado a la ciudadanía en general, de acuerdo con el tipo de intervención y las expectativas de los profesionales y los usuarios, o dependiendo de las decisiones políticas relacionadas con la gestión de los flujos migratorios y la organización de las sociedades multiculturales.

Considerando que el debate sobre esta figura se haya todavía abierto, cómo señala Francisco Raga (2008:2), no podemos (ni pretendemos) "establecer qué es y qué no es mediación intercultural, ni precisar las fronteras externas de la misma, los límites entre la actividad profesional de los mediadores y la de otros profesionales del área social", sino que nuestra intención, simplemente, consiste en presentar algunas de las definiciones que se asocian a esta actividad y analizar qué tipo de tareas suelen desempeñar los mediadores.

En los últimos años, se ha generado un amplio debate sobre la función y el papel de la MLC; sin embargo, todavía no se ha alcanzado un consenso al respecto, por lo que no existe una definición unívoca de esta figura, y se le han asignado diferentes tareas o roles. Así, como sostiene Franca Balsamo (2003:148-151), el mediador ha sido considerado como un intérprete lingüístico, como un informador o traductor de reglas (leyes, derechos y deberes), como un 
acompañante con función psico-social de apoyo, como un dinamizador de encuentros interculturales, o incluso como un asistente social especializado en el campo de la inmigración.

Probablemente, el hecho de que la MLC, como hemos comentado anteriormente, se haya comenzado a utilizar hace relativamente poco tiempo y no sea todavía una profesión plenamente reconocida haya contribuido, junto con otros factores, a la ausencia de un concepto definido y delimitado de la figura mediadora. Al mismo tiempo, como un círculo vicioso, la falta de consenso en cuanto a los límites de su papel y sus funciones impiden su pleno reconocimiento profesional.

Presentamos a continuación diversas definiciones que se han dado de la MLC en el contexto español, sin entrar a valorar, por el momento, cuál(es) de ellas resultan, a nuestro parecer, más adecuadas.

Carlos Giménez, quien fue director del Servicio de Mediación Social Intercultural (SEMSI) del Ayuntamiento de Madrid entre 1997 y 2004, presenta una de las definiciones de mediación más conocidas en España. En palabras de este autor (1997), la mediación es

[...] un recurso al alcance de personas de culturas diversas, que actúa como puente, con el fin de facilitar las relaciones, fomentar la comunicación y promover la integración entre personas o grupos, pertenecientes a una o varias culturas. Dicho proceso es realizado por una persona, grupo o institución, de manera imparcial, a través de una metodología y funciones determinadas.

[...] un proceso de cambio en un contexto de conflicto o de prevención del mismo, que persigue la transformación en los marcos relacionales de personas, grupos e instituciones con diferencias etnoculturales significativas, donde interviene una tercera persona a propuesta de las partes, que guiando el proceso, permite a éstos crear y generar nuevas formas de comunicación y de convivencia intercultural, que beneficie a todos.

[...] una modalidad de intervención de terceras partes en y sobre situaciones sociales de multiculturalidad significativa orientada hacia la consecución del reconocimiento del otro y el acercamiento de las partes, la comunicación o la comprensión mutua, el aprendizaje y desarrollo de la convivencia, la regulación de conflictos y la adecuación institucional entre actores sociales $\mathrm{o}$ institucionales etnoculturalmente diferentes.

Con esta amplia definición comienzan a resaltarse algunos de los valores que generalmente se aplican a la MLC, los cuales se refieren, por ejemplo, a la voluntariedad de las partes en todo el proceso, a la imparcialidad que se espera de la figura mediadora, o a la inclusión, entre sus funciones, no solo de aquella relativa a la mejora de la comunicación, sino también, en un sentido más amplio, al impulso de transformaciones tanto en la actitud de los directamente implicados (personas, grupos e instituciones), como en el contexto en el que las interacciones entre estos tienen lugar. Del mismo modo, Carlos Giménez menciona el concepto de conflicto intercultural, y señala a la figura mediadora como posible agente para prevenirlo o resolverlo, en caso de que este surja. Igualmente, asocia esta figura a la metáfora del puente como signo de unión (metáfora bastante recurrente al referirse a la MLC), y subraya en diversos puntos de su definición que son tres los participantes en la interacción, y que esta se produce en un contexto "de multiculturalidad significativa". 
Por otro lado, asociaciones como AEP Desenvolupament Comunitari y Andalucía Acoge (2002:101) definen conjuntamente la MLC como "un recurso profesionalizado que pretende contribuir a una mejor comunicación, relación e integración entre personas o grupos presentes en un territorio, y pertenecientes a una o varias culturas". Amplían dicha definición añadiendo que se trata de

[...] un proceso que contribuye a mejorar la comunicación, la relación y la integración intercultural entre personas o grupos presentes en un territorio, y pertenecientes a una o varias culturas. [...] abarca tres aspectos fundamentales: facilitar la comunicación, fomentar la cohesión social y promover la autonomía e inserción social de las minorías en orden a construir un nuevo marco común de convivencia (2002:144).

Observamos cómo también en esta descripción de la MLC se incluyen funciones que trascienden al ámbito de la comunicación y, además, se enfatiza el carácter profesional que la esta tiene (o, al menos, debería tener). Para los miembros de estas dos asociaciones (2002:99), existen, por tanto, tres grandes ámbitos de actuación en los que se centra la mediación:

- La mediación preventiva, que consiste en facilitar la comunicación y la comprensión entre personas con códigos culturales diferentes.

- La mediación rehabilitadora, que interviene en la resolución de conflictos de valores, entre minorías culturales y la sociedad mayoritaria, o en el seno de las propias minorías.

- La mediación creativa, consistente en un proceso de transformación de las normas, o más bien de creación de nuevas normas, nuevas acciones basadas en unas nuevas relaciones entre las partes.

De nuevo en este caso se destaca la función preventiva o resolutiva del conflicto, que, si bien es inherente a las relaciones interculturales (así como a cualquier relación interpersonal, incluso aquella que tiene lugar entre interlocutores isoculturales), puede confluir en una visión reductiva y limitada de la MLC, cuyo fin último debería ser promover el diálogo y la convivencia. Así, como sostienen Javier García y Cristina Barragán (2004:127),

Generalmente se concibe que la mediación parte de un conflicto en el que las partes no pueden llegar a un acuerdo y ello es debido, en gran medida, a que los diversos tipos de mediación que se han desarrollado previamente (jurídica, social, familiar, escolar...) condicionan el debate sobre la mediación intercultural, siendo un ejemplo claro el partir de un conflicto como condición previa para la mediación. [...] Pero considerar la mediación intercultural de forma únicamente reactiva ante la presencia de un conflicto resulta muy limitado, sobre todo si tenemos en cuenta que de lo que se trata es de promover la convivencia de grupos culturalmente diversos; es decir, la mediación debe ser la estrategia para la convivencia.

A las funciones previamente mencionadas en las anteriores definiciones, se añade en este caso la promoción de la autonomía de los grupos minoritarios, noción que nos parece fundamental en la actividad mediadora y que retomaremos más adelante.

\subsubsection{Funciones de la figura mediadora lingüística y cultural}

Las funciones atribuidas a la figura mediadora lingüística y cultural son, como sus definiciones, múltiples, y, en ocasiones, dependen de factores como el perfil del mediador, el ámbito en el 
que trabaja, quién contrata sus servicios (o si estos se ofrecen de manera voluntaria), etc. Un aspecto que ha quedado patente en las definiciones previamente expuestas es que el propósito de la MLC no consiste únicamente en facilitar la comunicación. Así, como sostiene Franz Pöchhacker (2008:16), el papel de los mediadores lingüísticos y culturales "includes much more than enabling linguistic communication, even though 'translation' (or, rather, interpreting) usually tops the often extensive list of tasks".

Si bien es cierto que los mediadores dedican buena parte de su desempeño profesional a facilitar la comunicación entre las dos partes implicadas, a dicha tarea le acompañan otras adicionales, como la información, la orientación, la educación o la conciliación, las cuales no se incluirán bajo otras formas de mediación (como la familiar, la comunitaria o la penal) (Bush y Folger, 1994; Folberg y Taylor, 1984, citados en Pöchhacker, 2008:23).

Por su parte, Jean-François Six (1990:164), define cuatro clases de mediación: en primer lugar, la mediación creativa, y la mediación renovadora, destinadas ambas a hacer nacer o renacer "un lazo" o nexo de unión y, en segundo lugar, la mediación preventiva y la mediación curativa, cuyo fin consiste en evitar o resolver un conflicto. Todas ellas contribuyen, de acuerdo con este autor, a (re)establecer la comunicación, previamente inexistente o perturbada, entre diferentes personas o grupos.

Del mismo modo, la vulnerabilidad que a menudo padecen las personas de colectivos culturales minoritarios, de la que hemos hablado previamente, requiere una adaptación de las metodologías de intervención social a las especificidades de estos grupos. Esto conlleva que las funciones que debe desempeñar el mediador lingüístico y cultural pueden variar dependiendo del colectivo o persona concretos a los que dirija su intervención. Con algunos, se pondrá el acento en las desigualdades y en la discriminación a la hora de acceder a los recursos, así como en la cobertura de las necesidades básicas. Con otros, se pretenderá conseguir la sinergia entre los recursos generales y los de la propia comunidad. Con otros, será prioritario prestar apoyo personal (psicosocial) para que superen con éxito la crisis del cambio que supone la emigración/inmigración y la adaptación a nuevo entorno. $Y$ con todos será necesario tener en cuenta las especificidades culturales a la hora de planificar, ejecutar y evaluar la intervención social más adecuada en cada caso (Desenvolupament Comunitari y Andalucía Acoge, 2002).

Por todo lo expuesto hasta el momento, podemos deducir que, además de la función de la MLC consistente en favorecer la comunicación intercultural y la integración entre diferentes sistemas de reglas y actitudes, se tratará, al mismo tiempo, de transformar las líneas fronterizas (rígidas y predefinidas) en "tierras de nadie", en las que exista la posibilidad de encontrarse, (re)conocerse, llegar a acuerdos, establecer pactos (Favaro, 2006:25).

A modo de resumen, las funciones generales que se atribuyen a la figura mediadora lingüística y cultural son:

- Actúa en la PREVENCIÓN DE CONFLICTOS.

- Favorece el RECONOCIMIENTO DEL OTRO.

- Promueve el ACERCAMIENTO, la COMUNICACIÓN y la COMPRENSIÓN mutuas.

- Fomenta el aprendizaje y el desarrollo de la CONVIVENCIA. 
De estas funciones generales, se desprenden las siguientes funciones específicas:

- intermediación lingüística y cultural;

- promoción de los derechos de los usuarios de un determinado servicio;

- orientación de los usuarios y profesionales de los servicios, con el fin de obtener una efectiva igualdad de acceso a los recursos y prestaciones ofertados en los mismos;

Entre las funciones específicas, se incluyen, igualmente, labores de apoyo a los dos grupos implicados. En concreto, por lo que se refiere al colectivo inmigrante, el mediador lingüístico y cultural realizará, entre otras, tareas de: asesoramiento sobre el funcionamiento de los servicios públicos y sobre la relación con los profesionales que trabajan en los mismo; fomento de toma de conciencia sobre los propios estereotipos y prejuicios para poder relativizarlos; información sobre derechos y obligaciones; y promoción de la expresión de las necesidades y demandas. Con respecto a los profesionales, el mediador asumirá, por ejemplo, funciones de: asesoramiento en la relación con los inmigrantes; información sobre patrones culturales de los usuarios inmigrantes; interpretación cultural de las demandas y las necesidades de estos usuarios; promoción del acceso y uso de los servicios públicos en igualdad de condiciones; apelación a cambios de conducta; detección de discriminaciones y (en caso necesario) derivación a entidades pertinentes.

Asimismo, con el fin de fomentar la cohesión social, la MLC se ocupará de:

- Ayudar al colectivo inmigrante a relativizar las tensiones provocadas por el proceso migratorio.

- Derivar a los miembros de dichos colectivos a los recursos y profesionales específicos que sean más apropiados para mejorar su situación.

- Promover el trabajo conjunto para dar respuesta integral a las necesidades de las minorías.

- Dinamizar relaciones y hacer propuestas de colaboración entre inmigrantes, asociaciones, servicios, profesionales, población autóctona, etc.

- Ayudar a la resolución de conflictos.

- Impulsar la difusión de los valores de ambas partes.

Con el propósito de promover la autonomía y la inserción social, los mediadores lingüísticos y culturales se encargarán de:

- Fomentar la autoestima y participación.

- Crear espacios de organización de minorías.

- Fomentar la ayuda mutua y mediación natural.

El desempeño de esta gran variedad de funciones puede producirse en dos situaciones. Por un lado, existe lo que se conoce como "mediación en casos", en la cual el mediador interviene en una situación a tres (como, por ejemplo, entre un médico y un paciente) y, por otro, la denominada "mediación comunitaria", que se lleva a cabo con grupos (y que abarca principalmente labores de formación, información, sensibilización o asesoramiento). 
Por lo que respecta al ámbito específico de los servicios sanitarios, el propósito principal de la mediación lingüística y cultural es mejorar el acceso y el uso de dichos servicios por parte de los pacientes inmigrantes $y$, con dicho fin, entre sus funciones, no solo se encuentra facilitar la comunicación entre los profesionales de la salud y los pacientes lingüística y/o culturalmente diversos, sino también aumentar la respuesta por parte de los hospitales y centros de salud ( $y$, por extensión, del sistema de salud en general) para adaptarse a las necesidades socioculturales propias de los pacientes (Verrept, 2008:188).

El mediador lingüístico y cultural que trabaja en los servicios sanitarios, se encuentra en una compleja situación en la interacción comunicativa triangular.

El gráfico que presenta Marta Castiglioni (1997) que incluimos a continuación refleja claramente la complejidad de su posición, así como los elementos que este mediador debería conocer y tener en cuenta a la hora de desempeñar su labor:

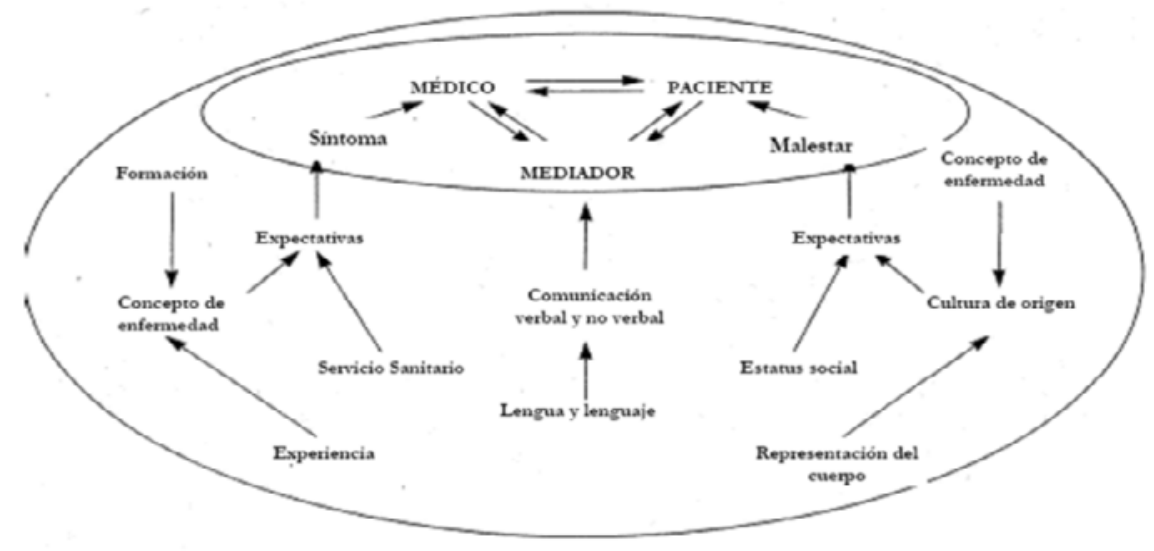

Gráfico 5.1. La mediación lingüística y cultural en el ámbito sanitario (Castiglioni, 1997:57)

Teniendo en cuenta las características específicas que presenta este contexto y las particularidades de los participantes en el encuentro intercultural que tiene lugar en el mismo, las funciones generales que realizará el mediador en ámbito sanitario, serán:

- Facilitar el acceso y uso de los servicios sanitarios por parte de la población inmigrante.

- Mejorar la comunicación y la comprensión (a todos los niveles, no solo lingüísticas) entre los profesionales sanitarios y los usuarios de origen extranjero.

- Ayudar al personal sanitario a desarrollar la competencia intercultural.

Por otro lado, entre las funciones específicas de este mediador lingüístico y cultural, se incluyen, de acuerdo con Antonio Chiarenza (2004), las siguientes:

- Acompañar a los usuarios inmigrantes dentro de un contexto social específico, de modo que se eliminen las barreras lingüísticas y culturales, y se promueva el entendimiento y el respeto de su cultura, así como el acceso a dichos servicios.

- Apoyar a las organizaciones, de manera que los servicios que se ofrecen respondan a las necesidades de los usuarios inmigrantes.

- Identificar los códigos culturales que se encuentran implícitos en las interacciones comunicativas entre los pacientes inmigrantes y sus familias y comunidades, por una parte, y los profesionales de los servicios sanitarios y las instituciones a los que estos 
representan, por otra, de manera que se logren averiguar las posibles causas de las barreras que pueden surgir en estas interacciones, se consiga superarlas, y se fomente, al mismo tiempo, la autodeterminación de cada una de las partes implicadas.

- Promover las oportunidades de encuentro dialéctico entre los profesionales y los pacientes culturalmente diversos.

- Apoyar a los servicios e instituciones del sistema de salud en el proceso de adaptación a las necesidades de los pacientes inmigrantes.

Asimismo, cabe tener en cuenta que, tal y como señalábamos en el capítulo anterior, en numerosas ocasiones, la dificultad de acceso a los servicios sanitarios por parte de la población inmigrante se debe al escaso conocimiento por su parte de los términos, los medios y los modelos comunicativos propios de la sociedad de acogida: leer carteles y prescripciones, rellenar formularios, distinguir las diferentes figuras profesionales, expresar una necesidad, un pensamiento, una duda o una opinión de manera adecuada, o entender el significado de una indicación o de una respuesta pueden suponer un problema para los usuarios inmigrantes, e implicar un obstáculo en su acceso a los servicios sanitarios y en su comunicación con los profesionales de los mismos. La figura mediadora lingüística y cultural que trabaje en este contexto tratará, por tanto, de eliminar estos obstáculos.

Por último, en cierta medida, los mediadores suplen la carencia por lo que se refiere a la formación antropológica de los estudiantes y profesionales que se ocuparán del cuidado de los pacientes y de la organización de los servicios médicos, asistenciales, de rehabilitación y prevención. De todos modos, la presencia de los mediadores no debe exonerar a los profesionales que trabajan en los diferentes servicios de la formación en comunicación intercultural, necesaria para que estos puedan ofrecer una atención más personalizada y adecuada para los diferentes usuarios.

\subsubsection{Conocimientos, habilidades y actitudes de la figura mediadora lingüística y cultural}

Teniendo en cuenta las funciones que, como hemos expuesto en el anterior apartado, se atribuyen a la figura mediadora lingüística y cultural, de acuerdo con las múltiples fuentes consultadas (entre otras, AEP Desenvolupament Comunitari y Andalucía Acoge, 2002; Aguado et al., 2002; Baraldi et al., 2008; Castiglioni, 1997; Malik y Herraz, 2005) esta debería poseer una serie de competencias, que reunimos y clasificamos en conocimientos, habilidades y actitudes.

En primer lugar, por lo que se refiere a los conocimientos (el saber), el mediador lingüístico y cultural debería:

- poseer un amplio conocimiento de la lengua de la sociedad de acogida y de la del país de origen de la comunidad a la que se dirige su intervención (o, en su defecto, una lengua vehicular), así como de los modelos conversacionales propios de cada comunidad;

- conocer una serie de datos de la sociedad y la cultura a la que pertenece el interlocutor inmigrante, así como de la cultura y la sociedad del país de acogida, sin por ello establecer generalizaciones o aplicar estereotipos, sino partiendo de las identidades personales de cada uno de los implicados; 
- manejar un concepto amplio de cultura, teniendo en cuenta el gran abanico de variables que la conforman;

- contar con nociones sobre los distintos modelos de desarrollo personal, grupos sociales y relaciones interpersonales, así como sobre la interrelación entre culturas y entre mayorías y minorías;

- presentar unos conocimientos básicos sobre las redes sociales y la organización y funcionamiento de las instituciones y servicios, tanto en el país de origen de los inmigrantes como en el de acogida, así como sobre las distintas figuras profesionales que trabajan en dichas instituciones y servicios;

- estar al corriente de los recursos disponibles, con el fin de sugerir los más adecuados para mejorar cada caso;

- saber aplicar las técnicas de interpretación (lingüística) básicas;

- por último, tener nociones sobre la legislación vigente en ambos países.

En segundo lugar, por lo que respecta a las habilidades (o el saber hacer), el mediador lingüístico y cultural debería:

- tener dotes personales para la mediación, tales como la escucha activa, el respeto por el otro y el trato adecuado;

- dominar los instrumentos y procedimientos para llevar a cabo el apoyo personal, la moderación de encuentros, el análisis de sistemas socio-culturales, el uso de los recursos disponibles en la sociedad de acogida, la difusión de información y la sensibilización, el trabajo en equipo, y la defensa de derechos e intereses;

- ser capaz de intervenir con la toma de distancia necesaria en las distintas situaciones en las que interviene.

En tercer y último lugar, en referencia a las actitudes (o el saber ser/estar), el mediador debería desarrollar una actitud que presentara en general las siguientes características:

- respeto;

- creatividad;

- compromiso;

- solidaridad;

- participación;

- negociación;

- conciliación;

- coherencia;

- serenidad y equilibrio.

Asimismo, en general, sea cual sea su ámbito de intervención, se valorarán en el mediador una serie de características personales, como pueden ser, por ejemplo:

- La elasticidad emotiva: para los inmigrantes, relacionarse con personas que pertenecen a otras culturas puede causarles sentimientos de frustración, confusión y soledad. En este tipo de situaciones, la figura mediadora debería mantener una actitud positiva, sobrellevar las fuertes emociones, y saber afrontar la ambigüedad y el estrés. 
Otras características asociadas a la elasticidad emotiva serían la confianza en la propia capacidad de afrontar situaciones no familiares y la habilidad para reaccionar positivamente ante nuevas experiencias.

- La flexibilidad y la apertura mental: la figura mediadora debería saber adaptarse a las diferentes maneras de pensar, sentir y actuar, y mostrar una actitud abierta ante las diferentes ideas y personas, con respeto, serenidad y flexibilidad.

- La agudeza perceptiva: la figura mediadora debería ser capaz de captar los diferentes significados del lenguaje, tanto verbal como no verbal, empleado en la comunicación. Tendría que prestar una atención especial al contexto de la comunicación, poder "leer" las emociones de los implicados e interpretar objetivamente la información que se trasmite.

Igualmente, cabe destacar otros requisitos básicos para desempeñar la labor de mediación: la responsabilidad, la imparcialidad, la reserva o confidencialidad, y la posesión de un estatus propio, con un reconocimiento y un establecimiento de los derechos y deberes del mediador. Este último requisito, como hemos señalado anteriormente, no se cumple en muchos de los casos y países en los que se ha recurrido a la MLC.

Por lo que se refiere a la responsabilidad, algunos autores sostienen que el mediador lingüístico y cultural es responsable de definir claramente sus funciones (difícil tarea, cuando ni siquiera las instituciones para las que trabaja y los destinatarios de sus servicios han alcanzado un consenso al respecto). Del mismo modo, se señala que no debe hacerse cargo de funciones que no le corresponden (asistencia social, consejos médicos, apoyo educativo, etc.). Con el fin de clarificar su rol, al principio de cada intervención, el mediador se presentará a las partes, resaltando los fines que se persiguen con su labor. En ningún caso, debe presentarse como "la solución al problema" entre las partes.

En cuanto a la confidencialidad, el mediador lingüístico y cultural debe encontrar el equilibrio en la "doble fidelidad" (por una parte, a los códigos culturales de origen y, por otra, a los principios éticos que rigen su profesión). Cabe señalar que, en casos excepcionales, puede compartir el secreto profesional con compañeros de equipo.

Por lo que respecta a la imparcialidad, el mediador lingüístico y cultural debe ser imparcial (que no neutral) ${ }^{168}$ y mantener una distancia equidistante con las partes. No debe confundir la promoción de la igualdad de derechos con la reivindicación o militancia.

Por otra parte, cabe señalar que el mediador lingüístico y cultural debe cooperar con otros profesionales y adaptar sus funciones al ámbito, servicio o caso específicos en los que esté trabajando. Al respecto, el mediador no debe desempeñar las funciones de otros profesionales y establecerá con ellos una relación "de igual a igual" (siempre que las circunstancias y la estructura interna del servicio lo permitan).

Igualmente, por lo general, a pesar de que se suele resaltar el compromiso social del mediador con la población inmigrante, este debe promover la autonomía de estos colectivos a la hora de relacionarse con los profesionales. Por consiguiente, el mediador puede ser flexible en cuanto

\footnotetext{
${ }^{168}$ Al respecto de la diferencia entre la imparcialidad y la neutralidad, y la imposibilidad de alcanzar esta última, véase el apartado de este capítulo dedicado al rol de los intérpretes en los servicios públicos.
} 
a las demandas, pero sin caer en el paternalismo, que conduciría a una excesiva dependencia. Así, como señala Genisa Prats (2007, citada en Morelli, 2009:107),

La figura mediadora no fomenta la dependencia a través del voluntarismo y la dedicación excesiva, sino que promueve la autonomía en sus relaciones con el colectivo, con los profesionales de los servicios, y con la sociedad en general.

Del mismo modo, resulta necesario que cualquier persona que realice la función de intermediario en la comunicación entre personas de distinto origen posea una competencia cultural, es decir, tome conciencia de la propia cultura y de los mecanismos específicos que la rigen y, al mismo tiempo, aprenda a valorar la cultura ajena (Valero, 2006: 103).

Con frecuencia se afirma que el mediador debería ser una persona bicultural, lo cual implica conocer dos sistemas culturales distintos de manera claramente delimitada. Al respecto, diversos autores han descrito lo que supone ser bicultural y, entre ellos, cabría citar a Ronald Taft (1981:53), quien fija los siguientes requisitos:

- Poseer conocimientos de la historia, tradiciones, costumbres, valores, tabúes, formas de relación, etc. de las dos comunidades implicadas.

- Poseer habilidades comunicativas, dominando no sólo el lenguaje escrito y oral, sino también otros aspectos de la comunicación, como el lenguaje corporal, los gestos, los símbolos y signos, etc. de las dos comunidades implicadas.

- Poseer habilidades sociales, es decir, un conocimiento de las normas que rigen las relaciones sociales en las dos comunidades implicadas.

A su vez, estas habilidades y conocimientos permitirán al mediador lingüístico y cultural desarrollar la competencia intercultural, por lo que será capaz de interpretar el significado de las palabras y el comportamiento de una de las dos comunidades y de transmitirlo a los miembros de la otra comunidad.

Podemos definir la competencia intercultural, en el ámbito de la MLC, como la capacidad de comprensión y comunicación intercultural. Para adquirir dicha competencia, no bastará con poseer una serie de conocimientos teóricos sobre la inmigración y las culturas de origen de los usuarios y de la sociedad de acogida, sino que, será necesario que la figura mediadora tome "plena consciencia y controle los factores de fracaso o riesgo para una interacción cultural y, por tanto, para una acción social adecuada" (Cohen-Emerique, 19997, citada en Antonin, 2011:103). Por consiguiente, con el fin de permitir la relación y la comunicación entre personas culturalmente diversas, el mediador debería ser capaz de llevar a cabo tres procesos vinculados entre sí (AEP Desenvolupament Comunitari y Andalucía Acoge, 2002:82-85):

1) La descentración: hacer emerger el propio marco de referencia y las representaciones que se tienen del otro, para relativizarlas y acceder a una cierta neutralidad cultural, lo cual no supone tolerarlo todo ni perder los propios valores e identidad, sino que permite entender que todos los marcos de referencia y sistemas de valores, por muy distintos que sean, tienen igual importancia. La confrontación con la diferencia revelará al mediador su propia identidad y le hará tomar conciencia de sus prejuicios y estereotipos. 
2) El descubrimiento del marco de referencia del otro: intentar ver el mundo a través de la mirada del otro, es decir, de acuerdo con sus marcos de referencia, para descubrir el sentido de su comportamiento y de sus demandas y poder, así, dar una respuesta adecuada a las mismas. El mediador debe aprender a interpretar todos los aspectos de la comunicación, desde los elementos propiamente lingüísticos, hasta los silencios, los gestos y los modelos conversacionales adoptados, con el fin de descubrir el verdadero significado de los mismos.

3) La negociación-mediación: ayudar a resolver los problemas que derivan de la incomprensión entre los usuarios inmigrantes y los profesionales autóctonos, o entre la comunidad inmigrante y la sociedad receptora, debidos principalmente a la diversidad cultural y la falta de (re)conocimiento mutuo. Cuando existan conflictos culturales que impidan la comunicación, el mediador realizará la función de puente entre ambas partes y las conducirá a la obtención de un compromiso aceptable para las dos, mediante la adaptación, el diálogo y el compromiso mutuos, respetando la identidad y los valores de todos los interlocutores.

Por lo que respecta al ámbito específico de los servicios de salud, aparte de todas las competencias señaladas, el mediador lingüístico y cultural debe contar con conocimientos y habilidades adicionales que le permitan conciliar las expectativas e intereses de los profesionales sanitarios y los de los pacientes inmigrantes. En concreto, debe conocer la organización, el funcionamiento y los modelos de intervención de los servicios sanitarios, así como las figuras profesionales que trabajan en los mismos. Asimismo, debe conocer la terminología específica de dicho campo, la legislación que regula la asistencia sanitaria, así como los conceptos de salud, enfermedad, prevención y cura, y la representación del cuerpo propios de las culturas implicadas.

Este extenso listado de conocimientos, habilidades y actitudes, sumado al gran número de funciones que se le atribuyen a la figura lingüística y mediadora, nos hacen preguntarnos, si realmente, en la práctica, estos profesionales deben enfrentarse a tal cantidad de actividades. La respuesta, como señala Francisco Raga (2008:51), es que "Deban o no deban, el hecho es que, hoy por hoy, mejor o peor, lo hacen".

\subsubsection{Perfil de la figura mediadora lingüística y cultural}

Los rasgos de carácter general atribuidos comúnmente al mediador lingüístico y cultural son los siguientes: suele ser mayor de 25 años; puede ser hombre o mujer, dependiendo de factores como el colectivo con el que interactúa, el rol determinado para el hombre y la mujer en la sociedad de origen, o el ámbito o sector en el que se lleva a cabo la mediación; normalmente está vinculado al origen cultural de los usuarios a los que se dirige su intervención; en general, cuenta con experiencia migratoria y en contextos multiculturales; y la duración de su estancia en el país de acogida suele ser larga.

Con relación a estas características generales asociadas al perfil de la figura mediadora, existen algunas controversias.

¿La MLC debe ser siempre desempeñada por una persona de origen extranjero? ¿Qué limitaciones conllevará dicho origen? ¿Significa esto que una persona autóctona nunca podrá ejercer esta profesión? 
El mediador lingüístico y cultural se suele asociar con el perfil de un inmigrante, con una figura que normalmente interviene en las situaciones comunicativas en las que participan usuarios originarios de su misma cultura, ya que quien forma parte de una comunidad cultural tiene mayores posibilidades de analizar y entender a dicha comunidad, en cuanto ya posee el instrumento de la experiencia y de la observación participante, las cuales le han aportado nociones, datos y conocimientos adquiridos sobre su propia cultura. Asimismo, el hecho de que los mediadores lingüísticos y culturales sean en su mayoría inmigrantes les proporciona un valor añadido, puesto que comparten con los usuarios la experiencia del desarraigo y del esfuerzo de adaptación a un nuevo país y a una nueva realidad. Sin embargo, el hecho de compartir el mismo origen con uno de los colectivos a los dirige su intervención (el de los usuarios de los servicios públicos) cultural puede conllevar que los miembros de dicho colectivo le consideren como un representante, y que esperen de él (incluso le exijan) que tome partido por ellos, que vaya más allá de la defensa de sus derechos y que se posicione de su parte, de manera que perdería la equidistancia y la imparcialidad que se requieren en el desempeño de su labor. ${ }^{169}$ Así, como señala Danilo De Luise (2005:69),

Si pasamos a la percepción que el mediador cultural tiene de su rol, él mismo destaca un aspecto aparentemente obvio, que es el de la empatía hacia el cliente. La pertenencia a la misma etnia con consiguiente conocimiento de la cultura (en todas sus facetas) del solicitante del servicio y el haber "padecido" y experimentado en sus carnes el trauma que supone la migración, parecen ser las condiciones sine qua non para una mediación satisfactoria vista por un mediador cultural. Sin embargo, pretendemos ser provocadores: justamente por esta reivindicación del papel exclusivo del mediador-migrante como único que puede entender perfectamente la situación en la que se encuentra el solicitante, el rol del mediador tal y como él/ella lo percibe, puede convertirlo/la en el "paladín" del cliente, con riesgo de falta de objetividad o, de todas maneras, de poner en entredicho la neutralidad que por otra parte tanto parece preocuparle. (comillas del original)

En consecuencia, estamos de acuerdo con los parámetros por los que se rige el Servicio de Mediación Social Intercultural (SEMSI), entidad que considera que la MLC puede ser llevada a cabo tanto por inmigrantes como por autóctonos, consideración que se basa fundamentalmente en cuatro razones:

a) de principio, pues un autóctono puede mediar entre otras culturas;

b) de enfoque u orientación, ya que, de esta manera, se muestra que la MLC no es solo un "servicio de o para inmigrantes";

c) de empleo, puesto que es positivo que también los autóctonos entren en esta categoría y cuenten con esta salida laboral;

d) de organización y funcionamiento, pues así el equipo es más "multi e intercultural", garantizándose de este modo la aportación específica de los autóctonos.

\footnotetext{
${ }^{169}$ Cabe señalar que esa excesiva identificación con el mediador lingüístico y cultural, así como la exigencia de que tome partido por una de las partes, pueden darse también a la inversa. Es decir, la figura mediadora, al formar parte del equipo profesional de una institución, se ve obligado a seguir la línea de actuación de dicha institución, lo cual, llevado al extremo, puede llevar a que los profesionales de la misma vean en esta figura a un aliado, que, en caso de conflicto, deberá ponerse inmediatamente de su parte y "defender" su posición frente a la del usuario inmigrante.
} 
Esta misma idea es apoyada por Margalit Cohen-Emerique (1997, citada en Antonin, 2011:97)), quien sostiene que el mediador lingüístico y cultural debe haber experimentado en sí mismo el encuentro intercultural y los procesos inherentes al mismo, lo cual va más allá del mero conocimiento teórico sobre culturas y migraciones. En este sentido, define a la figura mediadora como:

Aquel hombre o mujer, autóctono o inmigrante, de primera o segunda generación, hijo de un matrimonio mixto o que ha vivido en el extranjero, que ha de haber experimentado la interculturalidad en sí mismo y ha de ser sensible o estar sensibilizado con el mestizaje cultural que le ha llevado a construir una identidad formada por múltiples pertenencias y experiencias.

Otra de las cuestiones que con frecuencia se plantean a la hora de definir el perfil del mediador lingüístico y cultural es si este debe ser preferentemente un hombre o una mujer. En nuestra opinión, la preferencia/conveniencia de uno u otro sexo en la figura mediadora dependerá en parte del servicio en el que esta intervenga, así como de la comunidad de origen de los usuarios a los que dirija principalmente su intervención. Cabe recordar que existen comunidades en las no se considera adecuado compartir el espacio público con personas que no sean del mismo sexo, a menos que se trate de alguien que pertenezca al mismo entorno familiar. En otras comunidades, se asocia la figura masculina con una mayor autoridad, por lo que, dependiendo del contexto, se tendrán en mayor consideración las opiniones y actuaciones de un hombre con respecto a las de una mujer. En el primer caso, podríamos decir que quizás sería conveniente tratar de hacer coincidir el sexo del mediador o la mediadora con el del usuario con el que trabaje y, en el segundo, que se debería privilegiar la contratación de mediadores de sexo masculino (algo que, por otra parte, nos parece discriminatorio). Al respecto, cabe señalar que, al presentar la idea preconcebida de que la pertenencia a una determinada comunidad cultural conllevará una predilección por una figura mediadora masculina o femenina, estamos cayendo en la generalización, sin tener en cuenta los valores, creencias y características individuales que conforman la identidad personal. Del mismo modo, estas pautas nos parecen inalcanzables en sentido práctico, puesto que se debería disponer de un mediador y una mediadora por cada comunidad cultural, y requerir sus servicios "a la carta", dependiendo del usuario concreto que se encuentre implicado en cada situación. No obstante, es cierto que, en determinados servicios, como es el caso del hospital contexto de nuestro estudio, un hospital materno-infantil, tal vez se pueda observar una cierta inclinación hacia el empleo de mediadoras lingüísticas y culturales, sin que ello deba suponer que no pueda haber mediadores de sexo masculino (como hay, también, enfermeros, matrones, ginecólogos, etc.).

Un aspecto que también se debate a menudo en relación con la MLC se refiere a si los mediadores deben ser polivalentes y tener la capacidad de trabajar en cualquier servicio público o si, por el contrario, es preferible que cuenten con una especialización en un determinado sector. En principio, se exige que los mediadores lingüísticos y culturales sean polivalentes, es decir, que estén preparados para intervenir en los diferentes ámbitos en los que se podría llevar a cabo la mediación. Los motivos de dicho requerimiento son dos: por una parte, el mediador debería mejorar la comunicación entre personas culturalmente diversas, sea cual sea el ámbito en el que estas se interrelacionan y, por otra parte, debería conocer las necesidades sociales generales de las personas de su comunidad, así como saber qué recursos 
y servicios existen en la sociedad de acogida para paliar dichas necesidades. Desde nuestro punto de vista, la figura mediadora lingüística y cultural debe reunir ambas condiciones, es decir, debe tener conocimientos de diferentes sectores y poseer una competencia básica polivalente, pero, al mismo tiempo, es recomendable que, a ser posible, estos conocimientos presenten cierto grado de especialización en un sector o ámbito concretos, lo cual aumentará su profesionalidad y la adecuación de su intervención al contexto específico en el que esta se desarrolle mayoritariamente.

En la especialización por ámbitos de esta figura profesional jugarán un papel fundamental las posibilidades de formación continua, de inserción y de estabilidad laboral que se le ofrezcan. Así, de acuerdo con Javier García, Antolín Granados y Raquel Martínez (2006:18)

\begin{abstract}
La práctica de la mediación intercultural no puede hacerse desde un voluntarismo activista, [...] no cabe pensar en un sujeto "naturalmente" preparado para el ejercicio de la mediación; un sujeto en posesión de especiales características personales, o de una supuesta predisposición innata para tenerlas. [...] el mediador profesional sólo puede "hacerse". (comillas del original)
\end{abstract}

\title{
5.4. Hacia la profesionalización del intérprete-mediador en los servicios públicos
}

En las páginas previas hemos comentado el debate y la confusión existentes con respecto a las funciones y el papel atribuidos a los intérpretes en los servicios públicos y a los mediadores lingüísticos y culturales. Los límites entre estas dos profesiones, ambas emergentes, resultan poco claros para los usuarios de sus servicios (Phelan y Martín, 2010:4) e incluso para las propias personas que las desempeñan. En buena medida, esta situación nace por la falta de una definición unívoca y una delimitación clara de las funciones que les corresponden.

Asimismo, se trata en ambos casos de figuras profesionales relativamente nuevas, que pueden actuar en los mismos ámbitos (los servicios públicos), y para una misma tipología de destinatarios (los profesionales de los servicios y los usuarios inmigrantes). Igualmente, podríamos decir que, en cierto sentido, se solapan sus funciones, ya que en ambos casos se les atribuyen la labor de (inter)mediación lingüística y cultural.

Así, tal y como se desprende de las palabras de M. Kondo y H. Tebble (1997, citados en Pöchhacker, 2008:16), la atribución de la función (inter)mediadora (lingüística y cultural) al intérprete contribuye a esta confusión.

If the ideal function of the interpreter is to ensure smooth communication between the primary parties, then his role is to remedy this potential cultural noise on the channel by adjusting culturally determined peculiarities of the source text to the culturally determined expectations of the receiver. [...] Thus the ideal role of the interpreter is to serve not only as a linguistic but also as a cultural mediator. (cursivas del original)

Para Franz Pöchhacker (2008:21), la solución para distinguir la actividad de interpretación de aquella de mediación podría hallarse restringiendo el papel mediador del intérprete al ámbito lingüístico, y, por tanto, limitando la noción de interpretación al lenguaje, ya que, de acuerdo con este autor, cuando se le atribuyen funciones de mediación no solo entre lenguas, sino también entre culturas, los límites entre una y otra figura se difuminan. Esta propuesta nos plantea notables dudas, ya que consideramos que es prácticamente imposible separar el 
concepto de lengua del de cultura. La lengua forma parte de la cultura de una comunidad y, al mismo tiempo, es uno de los medios que dicha comunidad emplea para transmitir la cultura.

Quizás, más que limitar el papel que desempeñan los aspectos culturales en la actividad de la ISSPP, debería especificarse que, cuando se dice que "every interpreter is a mediator" (Pöchhacker, 2008:14), no se está asociando la mediación con la resolución de conflictos (una de sus acepciones) sino que se relaciona con el favorecimiento de la comunicación entre dos personas (que, en este caso, son lingüística y culturalmente diversas).

Aparte de esta cuestión de carácter terminológico, la confusión entre la MLC y la ISSPP puede venir determinada por el hecho de que ambas presentan muchos puntos en común. En primer lugar, en las dos subyace la función de facilitar la comunicación entre los profesionales de los servicios públicos y los usuarios inmigrantes y, en consecuencia, ambas persiguen fomentar el acceso y el uso de dichos servicios por parte de estos usuarios. Del mismo modo, los intérpretes y los mediadores comparten algunas de las competencias requeridas para desempeñar adecuadamente su labor (como, por ejemplo, el conocimiento de las lenguas y culturas implicadas, de la terminología específica del ámbito en el que trabajan, o de técnicas de interpretación), aunque variará el grado en el que deben adquirir y desarrollar dichas competencias.

Las dos figuras, además, se rigen por una serie de principios éticos comunes, como puede ser el de la fidelidad y el de la imparcialidad. Sin embargo, cabe precisar que será diferente el grado y el modo de aplicación de dichos principios en el caso de una y otra. Así, con respecto a la fidelidad, como señalan Mary Phelan y Mayte Martín (2010:16), "While accuracy is very important in the work of interpreters, it does not apply to CMs (cultural mediators) in the same way". De hecho, por ejemplo, mientras que las situaciones en las que los intérpretes podrían añadir aclaraciones de carácter cultural son limitadas, y se recomienda en todo caso que sean los propios interlocutores quienes se las soliciten si surgen incomprensiones 0 malentendidos, los mediadores, cumpliendo con su función preventiva, las proporcionarán más a menudo, por lo que su visibilidad en la interacción será mayor.

En referencia a la imparcialidad, cabe señalar que, entre las funciones de los mediadores lingüísticos y culturales, se encuentra la de empoderar a los usuarios para que puedan desenvolverse autónomamente con éxito en un futuro y, con el fin de cumplir con dicha función,

Unlike interpreters, CMs (cultural mediators) should express their opinions when meeting HPs (health providers) and HUs (health users) alone. As part of their job, CMs need to evaluate situations and propose plans of action (Phelan y Martín, 2010:15).

Estas autoras consideran, además, que, una vez se ha establecido una relación de confianza mutua entre los pacientes y los profesionales sanitarios, los mediadores deben abandonar el campo y dejar que ambas partes se comuniquen a través de un intérprete. Al respecto, nos preguntamos, ¿de qué manera se puede verificar que se ha establecido una relación de mutua confianza? E incluso en el caso de poder observarla, ¿quién nos garantiza que dicha confianza no se perderá en un momento futuro de la interacción debido a malentendidos y conflictos causados por las diferencias culturales? 
Igualmente, en relación con la cuestión de los principios éticos, cabe señalar que, aunque tanto la ISSPP como la MLC carecen de un código ético unificado, en el caso de la interpretación sí que existe un número considerable de códigos que han sido creados y están apoyados por asociaciones de intérpretes nacionales e internacionales, con principios básicos comunes en (casi) todos ellos, algo que la mediación, por el momento, se haya lejos de alcanzar. Esta diferencia conlleva que, en el caso de la MLC, sean las propias instituciones y organismos en los que trabajan los mediadores los que planteen las "reglas del juego" de acuerdo con su propio concepto de mediación lingüística y cultural, lo cual no hace sino aumentar la confusión en cuanto a su rol.

Por otro lado, cabe mencionar que la ISSPP se encuentra más consolidada y se ha avanzado algo más en el reconocimiento de su profesión, sin alcanzar todavía tampoco en su caso, como señalaremos más adelante, la plena profesionalización. Asimismo, la valoración por parte de los profesionales de los servicios públicos suele ser mayor en el caso de los intérpretes (especialmente si estos son autóctonos y cuentan con un título universitario) que en el de los mediadores (a los que se etiqueta como figuras menos preparadas y, generalmente, se les asocia a las minorías inmigrantes).

Por nuestra parte, consideramos que la mayor diferencia entre ambas figuras radica principalmente en las funciones que les corresponden, las cuales, en el caso de la MLC, son más amplias y variadas. Por supuesto, las diferentes funciones implican diferentes necesidades de formación.

En resumen, como esperamos que haya quedado patente, no hemos pretendido en ningún momento con lo expuesto en estas páginas afirmar que la interpretación en los servicios públicos y la mediación lingüística y cultural sean sinónimas, sino que opinamos que se trata de dos disciplinas y dos actividades diferentes. Así, como sostiene Mara Morelli (2009:106), creemos que "nos puede ayudar un enfoque realmente abarcador donde el trasfondo cultural de la mediación desempeñe el papel clave".

Nuestra propuesta se basa, por consiguiente, en la creación de equipos de trabajo multidisciplinares, en los que ambas figuras se coordinen, se complementen, y tengan funciones y roles definidos.

Sin lugar a dudas, en ambos casos optamos por un profesional que cuente con formación y esté preparado para desempeñar las labores de intermediación lingüística y cultural, teniendo en cuenta que "the ability to speak two languages does not make an interpreter. Similarly, familiarity with two cultures does not make a cultural mediator" (Phelan y Martín (2010:5).

En nuestra opinión, ambas figuras pueden coexistir y desempeñar sus labores de forma constructiva y complementaria. En consecuencia, estamos de acuerdo con Mary Phelan y Mayte Martín (2010:17), cuando señalan que

[...] cultural mediation should not be considered an alternative to interpreting or even worse, an added value that interpreters from different cultural background might provide. (Both) should be availed of in a complementary manner. 
Así, por ejemplo, visto que los principios éticos por los que se rige la labor del intérprete le impiden, por ejemplo, manifestar su opinión, dar consejos, $u$ ofrecer información sobre el funcionamiento de los servicios, el MLC podrá, en los casos en los que estas acciones se requieran, complementar la labor del intérprete. Contribuirá, de este modo, a facilitar el acceso y uso de los servicios sanitarios por parte de los usuarios inmigrantes, o a aumentar el conocimiento de las necesidades de estos por parte de los profesionales sanitarios.

Incluso una misma persona, debidamente preparada, podría asumir las funciones de ambos, con la condición de que este profesional "dually qualified" y los usuarios a los que están destinados sus servicios sean conscientes de qué papel (el de intérprete o el de mediador) está asumiendo en una determinada situación, y siempre y cuando se base en un modelo de práctica profesional de calidad (Pöchhacker, 2008:24).

Por consiguiente, en lugar de debatir sobre si una de estas figuras le está ganando terreno a la otra en un determinado contexto profesional, ambas deberían aunar fuerzas para alcanzar un mismo objetivo, consistente en la profesionalización. Tanto la MLC como la ISSPP se hallan en una situación similar. Ambas reciben denominaciones múltiples, y carecen de una definición clara y homogénea de sus funciones, por lo que coexisten diferentes modos de entender y utilizar los servicios de mediación e interpretación. Del mismo modo, en los dos casos hay una ausencia de estatuto legal que regularice la profesión y, dependiendo de factores como el servicio concreto o el área geográfica donde se ponen en práctica, entre otros, se aplican diferentes tipos de contratación. En la práctica, además, son numerosas las ocasiones en las que se recurre a intérpretes y mediadores ad hoc, generalmente amigos, familiares y conocidos del usuario que no cuentan con la preparación necesaria para desempeñar estas labores. Por último, en ambos casos, se constatan carencias en el ámbito formativo, y no existe un título de estudios reconocido.

Consideramos, por tanto que, tanto en el ámbito de la interpretación en los servicios públicos como en el de la mediación lingüística y cultural, se debe avanzar para obtener un reconocimiento profesional. Los requisitos que, de acuerdo con autoras como Roda Roberts (1994:127-138) o Anne Corsellis (2003:71-89), se deben cumplir para alcanzar la profesionalización serían:

\section{- Denominación universal}

El hecho de que se empleen diferentes términos para designar a estas dos figuras no hace sino aumentar la confusión entre las mismas, y pueden conllevar, como hemos comentado previamente, que se les solicite asumir funciones que no les corresponden.

\section{- Clarificación del papel y de las funciones}

Como señala Mạ Jesús Martínez (2007:208), se debería “Intentar demarcar de manera realista las diferentes funciones a fin de evitar solapamientos, contradicciones manifiestas y, como trasfondo, sensación de desaliento". 


\section{- Desarrollo de programas formación}

La ausencia de propuestas formativas coherentes y homogéneas, como sostiene Dora Sales (2005b),

[...] repercute negativamente en cuanto a la necesaria profesionalización de esta actividad. Es un pez que se muerde la cola: falta formación y un sistema de acreditación, lo que supone un freno para que este campo se profesionalice y sea reconocido.

Se trata, pues, por una parte, de conseguir que se reconozca que estas profesiones requieren de una formación especializada, y que cualquier persona con conocimientos lingüísticos y culturales no será necesariamente apta para desempeñarlas con éxito, sino que los intérpretes y los mediadores profesionales deberán poseer una serie de conocimientos declarativos y procedimentales que les permitan realizar adecuadamente su labor.

Por otra parte, además de esta labor de concienciación, se deberán crear "itinerarios de formación atractivos y pertinentes [...] en justa coherencia con los requerimientos que se demandan a la figura profesional" (Martínez, 2007:209).

Además, una formación adecuada permitirá que se reconozca la complejidad inherente a las funciones que recubren estas dos figuras. Como afirma Franz Pöchhacker (2004:166),

For a practice or occupation to be acknowledged as a profession, it must be perceived to rest on a complex body of knowledge and skills, mastery of which can only be acquired by specialized training.

Junto a la formación de los futuros mediadores e intérpretes, consideramos necesario que se forme también a los destinatarios de sus servicios, de manera que conozcan las funciones que estas figuras pueden desempeñar, los límites de las mismas, y la manera más adecuada para relacionarse e interactuar con ellas (Bischoff, Loutan y García, 2009: 283-287).

\section{- Código de conducta}

Por lo que respecta a los códigos de conducta, estos son necesarios tanto para los mediadores lingüísticos y culturales como para los intérpretes en los servicios públicos. Sin embargo, cabe señalar que, por sí solos, los códigos de conducta no ofrecen las pautas necesarias para que estas figuras consigan hallar la mejor manera de resolver los dilemas éticos a los que se enfrentan frecuentemente en el desempeño de sus labores. Para que sepan cómo interpretarlos y aplicarlos en el ejercicio de su profesión, autores como Mary Phelan y Mayte Martín (2010:8) recomiendan que el análisis y la aplicación práctica de los códigos de conducta se incluyan en los programas de formación.

\section{- Certificación oficial}

La certificación oficial servirá de garantía de la calidad y la preparación de estas figuras y, probablemente, evitará el "intrusismo" por parte de intérpretes y mediadores ad hoc.

En palabras de Anne Martin (2000: 220, citada en Sales 2005b), supondrá, asimismo, un reconocimiento de carácter oficial, aspecto fundamental para la profesionalización. 
[...] tiene que haber un reconocimiento general de este oficio como realidad profesional, no sólo por parte de la Administración sino por parte de otros muchos sectores del país. En España todavía demasiada gente no distingue entre el conocimiento de idiomas y la capacidad para traducir o interpretar.

En este sentido, añadiríamos que, por esa misma razón, también será necesario estimular la concienciación sobre el hecho de que la capacidad para traducir o interpretar no siempre posibilita la de mediar (y viceversa).

\section{- Asociacionismo}

Las asociaciones profesionales pueden contribuir a aumentar la visibilidad y el reconocimiento de estas figuras, y servirán como punto de encuentro para que los mediadores y los intérpretes pongan en común sus propios conocimientos y experiencias.

Una vez se cumplan estas pautas y se alcance la ansiada profesionalización, tanto los propios intérpretes y los mediadores como los destinatarios de sus servicios tendrán más claro cuáles son sus funciones y cómo trabajar conjuntamente y, al mismo tiempo, contarán con un mayor reconocimiento (social y profesional), lo cual se traducirá en una mejora en sus condiciones de trabajo.

Para concluir este capítulo, quisiéramos reafirmar que, en nuestra opinión, la mediación lingüística y cultural y la interpretación en los servicios públicos poseen evidentes puntos en común, y creemos que ambas pueden enriquecer sus actuaciones y aumentar su reconocimiento mediante el trabajo conjunto y el intercambio de conocimientos, experiencias y propuestas. 


\section{CAPÍTULO 6}

Análisis descriptivo de los resultados del estudio de caso 


\section{ANÁLISIS DESCRIPTIVO DE LOS RESULTADOS DEL ESTUDIO DE CASO}

En el presente capítulo analizamos separadamente los datos recolectados mediante cada una de las técnicas empleadas en nuestro estudio: el análisis documental, las entrevistas semiestructuradas en profundidad, la observación no participante y los grupos de discusión. La descripción exhaustiva que ofrecemos a continuación nos permitirá, posteriormente, extraer las conclusiones generales y propuestas de mejora derivadas del análisis contrastivo de los datos obtenidos con las diferentes técnicas, que presentaremos en el próximo capítulo.

La decisión de adoptar esta estructura responde a diversos motivos. En primer lugar, nuestro análisis se divide por temas, pero no todas las técnicas empleadas (en parte, por su propia naturaleza) abordan los diferentes temas. Por ello, nuestro propósito es analizar detalladamente cada fuente de datos y, a continuación, en un capítulo aparte, seleccionar los temas de mayor relevancia y extraer las conclusiones finales, en las que contrastaremos, por una parte, los datos recolectados con las diferentes técnicas y, por otra, estos con la teoría existente.

Además, el modelo de análisis o la estructuración propuesta concuerda con algunas de las características que presenta nuestro estudio y que hemos señalado en el capítulo 2, dedicado al diseño metodológico: se trata de una investigación emergente y en cascada, el análisis (por fases) es concurrente con la recolección de los datos y está basado en la inducción analítica, y recurrimos al uso de la triangulación para verificar datos ya recogidos.

Antes de iniciar el análisis propiamente dicho, cabría tener en cuenta una serie de aspectos sobre el mismo.

El análisis de los datos en una investigación de corte cualitativo y etnográfico, tal y como afirman Ventres y Frankel (1996, citados en Galanti, 1999: 20), debería seguir tres principios que hemos observado en nuestro estudio: la triangulación o el uso de los datos obtenidos mediante diferentes técnicas; la descripción exhaustiva, tratando de situarse bajo la piel de los sujetos, de manera que puedan analizarse los aspectos investigados de acuerdo con su punto de vista; y la saturación, según la cual el análisis se considera completo cuando de este no surgen nuevos conceptos o ideas. Cabe señalar, además, que nuestro fin no es presentar datos estadísticos, por lo que, en general, no presentamos cifras y porcentajes, sino que realizamos un análisis puramente cualitativo.

Asimismo, como hemos comentado en el capítulo 2, nuestro análisis es tanto descriptivo como interpretativo, y se centra en el significado de los datos más que en la forma lingüística de los mismos. En él se muestran tanto los propios puntos de vista de los sujetos que han participado en el estudio como las interpretaciones que la propia investigadora, basándose en los datos obtenidos y en la teoría existente, ha podido desarrollar. De hecho, hemos incluido citas textuales extraídas de los datos a analizar, ${ }^{170}$ de manera que diéramos voz a los propios participantes en el estudio y fuerza a nuestras propias descripciones. Al mismo tiempo, dichas descripciones han estado guiadas por los resultados derivados de investigaciones previas sobre el ámbito de estudio, como, por ejemplo, las de Claudia V. Angelelli (2004, 2006, 2008), Holly

\footnotetext{
170 Para una correcta comprensión de las citas textuales incluidas, véanse las pautas de transcripción de las entrevistas y los grupos de discusión que aparecen en los anexos.
} 
Mikkelson (1999, 2003), María Isabel Oliver (2002, 2007), Franz Pöchhacker y Miriam Schelinger (2007, 2008), Francisco Raga (2003, 2006), Rachel E. Spector $(2001,2003)$, Carmen Valero $(2003,2005,2008)$ y Cecilia Wadensjö (1998).

Por otra parte, en el proceso de análisis, que hemos llevado a cabo de forma concurrente con la recolección de los datos, hemos adoptado un enfoque basado en la inducción analítica (Berg, 2009, 358), es decir, hemos ido verificando o refutando una serie de hipótesis que bien se hallaban expuestas en la teoría sobre el objeto de estudio, o bien estaban basadas en ideas preconcebidas propias sobre el fenómeno investigado.

Por último, cabe recordar que hemos empleado el programa NVivo (concretamente, la última versión del mismo, NVivo 10) como herramienta de apoyo en el análisis de los datos, los cuales se han introducido como fuentes en un proyecto creado con este programa, se han segmentado en unidades de análisis, y se han codificado en relación con una serie de temas (o nodos, de acuerdo con la terminología propia del programa) que resultaban relevantes para nuestra investigación. Tras la codificación de los datos, hemos seguido un método de análisis híbrido en el que hemos empleado diferentes enfoques y técnicas; así, hemos agrupado, condensado, contrastado y relacionado los datos siguiendo un método de análisis que va de lo descriptivo a lo explicativo, y de lo concreto a lo abstracto o conceptual (Miles y Huberman, 1984).

\subsection{Análisis documental}

En nuestra investigación, tal y como hemos comentado en el capítulo 2, centrado en el diseño metodológico, examinamos determinados documentos relacionados con nuestro objeto de estudio, tanto antes de iniciar el trabajo de campo como a medida que este se iba desarrollando. Con el análisis de dichos documentos pretendíamos complementar los datos recolectados mediante el resto de técnicas empleadas, de manera que pudiéramos comprender el contexto y los antecedentes y detectar cuestiones de interés para esta investigación.

Se trata, por tanto, de una técnica secundaria o complementaria, ya que, aunque puede aportar una dimensión contextual e histórica al estudio, a diferencia de las demás técnicas a las que hemos recurrido, no nos va a permitir conocer el modo en que la realidad estudiada se percibe y experimenta por parte de los sujetos implicados.

Si bien es cierto que los documentos analizados han aportado datos valiosos a la investigación, cabe señalar algunos de los inconvenientes o dificultades que hemos hallado en el empleo de esta técnica. En primer lugar, no nos ha resultado posible acceder o disponer de algunos datos que hubieran enriquecido la investigación, como, por ejemplo, aquellos referidos a la disgregación por nacionalidades de las usuarias del hospital contexto de estudio, ya que el servicio de documentación de dicho hospital no contaba con ellos. Asimismo, somos conscientes de que podemos haber introducido un sesgo subjetivo tanto en la selección como en el análisis de la documentación.

Pasamos a continuación a analizar los documentos escogidos, los cuales están divididos en cuatro grandes grupos. Para comenzar, en los dos primeros, incluimos aquellos documentos, 
generalmente de carácter oficial, relacionados con el derecho a emigrar/inmigrar, por una parte, y con el acceso y uso de los servicios sanitarios por parte de la población inmigrante, por otra. En ambos casos, iniciamos con un análisis global, en el que abordamos el contexto internacional, para ir progresivamente acercándonos al contexto concreto de nuestro estudio (con documentación sobre España $y$, cuando resulte pertinente, sobre Aragón). A continuación, se encuentran los documentos relacionados con el ámbito específico de nuestro estudio, es decir, la salud reproductiva y, más concretamente, aquellos referidos a la atención durante el parto. Por último, se hallan los documentos relativos a las diferentes estrategias empleadas por los servicios sanitarios de Aragón para facilitar la comunicación y la asistencia a los usuarios de origen extranjero.

\subsubsection{Documentos sobre el derecho a emigrar/inmigrar}

A pesar de que el estudio de la legislación y las políticas en relación con el fenómeno migratorio, en general, no forman parte del núcleo central de nuestros objetivos, estamos de acuerdo con Magdalena Díaz (2009:69), cuando afirma que

No se debe olvidar un acercamiento jurídico-normativo que brinda información respecto a las posibilidades de actuación en un marco social determinado, así como refleja las preocupaciones fundamentales de esa sociedad y las formas prácticas y simbólicas que se están llevando a cabo.

Por dicho motivo, en este apartado presentamos muy brevemente el marco normativo y las estrategias y políticas que, tanto en el marco internacional como en el estatal, están relacionadas con el fenómeno migratorio.

Antes de iniciar el análisis, cabe señalar que, en los últimos años, se ha observado un aumento del interés de los responsables de proponer normativas y políticas en torno al fenómeno de las migraciones. Así, tal y como sostienen Frank Laczko y Rudolf Anich, (2013:35),

La migración se ha considerado tradicionalmente como un problema derivado de la falta de desarrollo, o se ha visto desde una óptica negativa a causa de los temores relacionados con una posible "fuga de talento" entre los trabajadores calificados. Actualmente hay un reconocimiento cada vez más generalizado de que una migración encauzada y gestionada eficazmente por los encargados de la formulación de políticas puede contribuir al desarrollo. (comillas del original)

A pesar del interés creciente, siguen existiendo, en la actualidad, numerosas carencias por lo que respecta a la legislación y las políticas en materia de inmigración internacional. De hecho, como sostiene la Organización Internacional para las Migraciones (1999:16, citada en Laczko y Appave, 2013:181),

Un gran número de los encargados de la formulación de políticas sigue considerando que la migración internacional es más bien una amenaza para la seguridad y la identidad del país que una oportunidad para la cooperación y el desarrollo. No existe aún una "comunidad internacional" con objetivos e intereses comunes en este ámbito. (comillas del original) 
Ahora bien, aunque no exista una legislación que, a nivel internacional, regule las migraciones, ${ }^{171}$ sí que cabe destacar algunos documentos que de forma directa o indirecta abordan esta cuestión. Un primer documento que quisiéramos señalar en este apartado, por el número de países firmantes que la ratificaron y el alcance (en ocasiones, simbólico) de su contenido, es la Declaración Universal de Derechos Humanos, aprobada y adoptada el 10 de diciembre de 1948, en cuyos artículos 13 y 14 se afirma respectivamente:

13.1. Toda persona tiene derecho a circular libremente y a elegir su residencia en el territorio de un Estado;

13.2. Toda persona tiene derecho a salir de cualquier país, incluso del propio, y a regresar a su país;

14.1. En caso de persecución, toda persona tiene derecho a buscar asilo, y a disfrutar de él, en cualquier país

Estrechando en cierta medida el ámbito de estudio, en relación con Europa, el primer documento que cabe señalar es el Tratado de Maastricht, firmado el 7 de febrero de 1992, y que entró en vigor el 1 de noviembre de 1993, el cual, entre otras disposiciones, establece el derecho de libre circulación y residencia en la Unión Europea por parte de los ciudadanos de los estados miembros. Como hemos comentado en el apartado de contextualización del capítulo 1, este derecho (considerando, además, las sucesivas ampliaciones que ha experimentado la Unión Europea en los últimos años, hasta alcanzar los 27 miembros actuales) ha contribuido al aumento de los flujos migratorios dentro de Europa.

Previamente, en 1985 (aunque entró en vigor diez años después, en marzo de 1995) se había firmado el Acuerdo de Schengen, el cual establecía un espacio común -denominado espacio de Schengen o Schengenland-por el que toda persona que hubiera entrado regularmente por una frontera exterior o residiera en uno de los países que aplicaban el Convenio podía circular libremente. En total, los países que forman parte del espacio de Schengen son 26: Alemania, Austria, Bélgica, Dinamarca, Eslovaquia, Eslovenia, España, Estonia, Finlandia, Francia, Grecia, Holanda, Hungría, Islandia, Italia, Letonia, Liechtenstein, Lituania, Luxemburgo, Malta, Noruega, Polonia, Portugal, República Checa, Suecia y Suiza (nótese que este acuerdo no se aplica a todos los estados miembros de la UE, y que, por el contrario, algunos de los firmantes, en particular, Islandia, Liechtenstein, Noruega y Suiza, no forman parte de la misma). Con objeto de conciliar libertad y seguridad, la libre circulación se acompañó de medidas denominadas "compensatorias". Se trataba de mejorar la cooperación y la coordinación entre los servicios de policía y las autoridades judiciales para proteger la seguridad interior de los estados firmantes y, en particular, para luchar contra la delincuencia organizada. Vemos, por consiguiente, que, frente al deseo de crear áreas en las que se suprimen las fronteras, existe también en este caso una intención de frenar la entrada desde "el exterior".

Por otro lado, de acuerdo con la Oficina Estadística de la Comisión Europea, las políticas sobre el fenómeno migratorio dentro de la UE, con el fin de paliar ciertas deficiencias en relación con cualificaciones profesionales determinadas, están cada vez más centradas en atraer a un

${ }^{171}$ Para obtener una visión más detallada del Derecho internacional, regional y nacional sobre migración, se recomienda consultar la base de datos de la Organización Internacional para las Migraciones, que se encuentra en la página web: [http://www.imldb.iom.int/section.do] (última consulta: 16 de agosto de 2013). 
determinado perfil de inmigrantes. Aparte de estas políticas destinadas a fomentar la contratación laboral, a menudo la política europea de inmigración se centra en dos sectores: por una parte, en evitar la inmigración irregular y el empleo ilegal de personas de origen extranjero que no están autorizadas a trabajar y, por otra, en fomentar la integración de los inmigrantes en la sociedad. Al respecto, se han movilizado recursos significativos para luchar contra el tráfico de seres humanos y las redes de traficantes en la UE.

Algunos de los textos jurídicos aprobados en los últimos años en materia de inmigración en el área de la UE son los siguientes: ${ }^{172}$

Directiva 2003/86/EC de 22 de septiembre de 2003, sobre el derecho a la reagrupación familiar;

Directiva 2003/109/EC de 25 de noviembre de 2003, relativa al estatuto de los nacionales de terceros países residentes de larga duración;

Directiva 2004/114/CE de 13 de diciembre de 2004, sobre la admisión de estudiantes;

Directiva 2005/71/CE de 12 de octubre de 2005, para facilitar la admisión de investigadores en la UE;

Directiva 2008/115/CE de 16 de diciembre de 2008, sobre el retorno de los nacionales de terceros países en situación irregular;

Directiva 2009/50/CE de 25 de mayo de 2009, sobre la admisión de migrantes altamente cualificados.

Por lo que respecta al contexto español, la Constitución española, aprobada en 1978, dedica uno de sus capítulos a los derechos y deberes fundamentales de los españoles y los extranjeros. En concreto, en su artículo 13, establece que

1. Los extranjeros gozarán en España de las libertades públicas que garantiza el presente Título en los términos que establezcan los tratados y la ley.

2. Solamente los españoles serán titulares de los derechos reconocidos en el artículo $23,{ }^{173}$ salvo lo que, atendiendo a criterios de reciprocidad, pueda establecerse por tratado o ley para el derecho de sufragio activo y pasivo en las elecciones municipales.

3. La extradición sólo se concederá en cumplimiento de un tratado o de una ley, atendiendo al principio de reciprocidad. Quedan excluidos de la extradición los delitos políticos, no considerándose como tales los actos de terrorismo.

4. La ley establecerá los términos en que los ciudadanos de otros países y los apátridas podrán gozar del derecho de asilo en España.

En aplicación de este mandato constitucional, se aprobó, el 1 de julio de 1985, la Ley orgánica 7/1985, sobre Derechos y Libertades de los Extranjeros en España, en la que se establecían

172 Para conocer el contenido detallado de estas directivas, visítese la página web: [http://eurlex.europa.eu/es/index.htm] (última consulta: 15 de junio de 2013).

${ }^{173} \mathrm{El}$ artículo 23 al que se hace referencia se centra en los derechos de participación en los asuntos políticos mediante el voto en las elecciones y en el derecho a acceder a las funciones y cargos públicos. 
los requisitos para alcanzar la condición de residente, y se estipulaban ciertas medidas relativas al control de la entrada y la permanencia de extranjeros.

Desde esta perspectiva en la que predominaba el control de los flujos migratorios, se pasó con la Ley Orgánica 4/2000, de 11 de enero, sobre Derechos y Libertades de los Extranjeros en España y su Integración Social, modificada sucesivamente por las LO 8/2000, 14/2003 y 2/2009, y conocida como la Ley de Extranjería, a mostrar cierta preocupación por la integración de los inmigrantes residentes. En dicho texto jurídico se establecen los derechos y libertades de los extranjeros, las disposiciones relativas a la reagrupación familiar, las garantías jurídicas y las medidas antidiscriminatorias que se aplican a este colectivo. Asimismo, se estipula el régimen jurídico por el que se rigen los extranjeros $y$, en concreto, se determinan las normas de entrada y permanencia en el territorio, los requisitos para solicitar un permiso de trabajo, o los trámites administrativos que se deben realizar para solicitar un visado. Cabe señalar, además, que en dicha ley se reconoce, aunque en términos bastante imprecisos, el derecho a la "asistencia de intérprete" a los extranjeros que se hallen retenidos en los casos en que estos "no comprenden o no hablan la lengua oficial que se utilice", siendo difícil determinar cuándo se podrá considerar que los detenidos no poseen los conocimientos lingüísticos suficientes y necesitarán, por tanto, de la labor del intérprete. ${ }^{174}$

Para concluir este apartado, cabe señalar que la legislación en materia de inmigración en España se establece a nivel nacional, si bien cada comunidad autónoma recoge, en sus planes estratégicos e integrales, disposiciones para coordinar, gestionar y evaluar las distintas políticas autonómicas relacionadas con este fenómeno.

\subsubsection{Documentos sobre el acceso y uso de los servicios sanitarios por parte de la población inmigrante}

En este apartado, analizamos una serie de documentos relacionados con el acceso y uso de los servicios sanitarios por parte de la población inmigrante. Dividimos dichos documentos en tres grupos: en primer lugar, incluimos la legislación de ámbito nacional y autonómico; a continuación, presentamos los diferentes planes integrales y estratégicos de Aragón, de los cuales extraemos los datos referentes a la salud, por un lado, y las mujeres, por otro; para finalizar, examinamos otros documentos relacionados con el ámbito sanitario en el contexto aragonés.

\footnotetext{
${ }^{174}$ No nos detenemos aquí a examinar exhaustivamente los contenidos de la mencionada Ley de Extranjería, puesto que este análisis no se corresponde plenamente con los objetivos de nuestra investigación. Sin embargo, volvemos a hacer referencia a la misma en el siguiente subapartado, de análisis de los documentos sobre el acceso y uso de los servicios sanitarios por parte de la población inmigrante, con el fin de examinar las disposiciones que esta ley contenía en materia de salud, las cuales, en cualquier caso, han sido modificadas por el Real Decreto-ley 16/2012, de 20 de abril, de medidas urgentes para garantizar la sostenibilidad del Sistema Nacional de Salud y mejorar la calidad y seguridad de sus prestaciones. Para mayor información sobre la Ley Orgánica 4/2000, de 11 de enero, sobre Derechos y Libertades de los Extranjeros en España y su Integración Social, puede visitarse la página web: [http://extranjeros.empleo.gob.es/es/NormativaJurisprudencia/Ley_Organica_4_2000.pdf] (última consulta: 30 de mayo de 2013).
} 


\subsubsection{El derecho a la salud en el contexto internacional}

Por lo que se refiere a la legislación y políticas en materia sanitaria, ${ }^{175}$ la tutela de la salud es (o debería ser) un derecho fundamental del individuo, independientemente de su estatus jurídico.

En el ámbito internacional, este derecho está garantizado por la Declaración Universal de los Derechos Humanos, aprobada el 10 de diciembre de 1948 por la Asamblea General de las Naciones Unidas. En concreto, en el artículo 25 se afirma

1. Toda persona tiene derecho a un nivel de vida adecuado que le asegure, así como a su familia, la salud y el bienestar, y en especial la alimentación, el vestido, la vivienda, la asistencia médica y los servicios sociales necesarios; tiene asimismo derecho a los seguros en caso de desempleo, enfermedad, invalidez, viudez, vejez u otros casos de pérdida de sus medios de subsistencia por circunstancias independientes de su voluntad.

2. La maternidad y la infancia tienen derecho a cuidados y asistencia especiales.

En ese mismo año, se firma la Declaración de Ginebra (1948), adoptada por la Asamblea General de la Asociación Médica Mundial en la ciudad suiza que le da nombre, y enmendada y revisada en diferentes ocasiones desde 1986 hasta 2006. Dicha Declaración está basada en el juramento hipocrático, y, por lo que respecta nuestro ámbito de estudio, establece que los profesionales sanitarios, en el momento de ser admitidos en la profesión médica, no permitirán que

[...] consideraciones de edad, enfermedad o incapacidad, credo, origen étnico, sexo, nacionalidad, afiliación política, raza, orientación sexual, clase social o cualquier otro factor se interpongan entre mis deberes y mi paciente.

En 1977, la Asamblea Mundial de la Salud, establece, entre los objetivos de "Salud para todos en el año 2000", el conseguir que todos los habitantes del mundo tengan acceso a un nivel de salud que les permita mantener una vida social y económicamente productiva.

En el año 2000, se revisan los Estatutos de la Organización Mundial de la Salud. Dicha revisión incluye una ampliación de la definición del derecho a la salud, el cual queda descrito de la siguiente manera:

El derecho a la salud no sólo abarca la atención de salud oportuna y apropiada sino también los principales factores determinantes de la salud, como el acceso al agua limpia potable y a condiciones sanitarias adecuadas, el suministro adecuado de alimentos sanos, una nutrición adecuada, una vivienda adecuada, condiciones sanas en el trabajo y el medio ambiente, y acceso a la educación e información sobre cuestiones relacionadas con la salud, incluida la salud sexual y reproductiva.

Siempre en el año 2000, el Comité de Derechos Económicos, Sociales y Culturales de las Naciones Unidas adopta la Observación general sobre el derecho a la salud, que, de acuerdo

\footnotetext{
175 Por políticas sanitarias (o de salud) entendemos "el conjunto de decisiones gubernamentales, junto con los recursos e instrumentos para ponerlas en práctica, cuya finalidad consiste en contribuir a lograr objetivos estratégicos para la salud o para el sector de la salud" (Alonso y Lizana, 2009:36).
} 
con dicho documento, abarca cuatro ámbitos: la disponibilidad, la accesibilidad, la aceptabilidad y la calidad.

Por lo que se refiere al contexto europeo, no existe una normativa común en materia de salud, ya que son cada uno de los estados miembros de la UE los que disponen de competencias en sanidad. Sin embargo, todos ellos han aceptado el reconocimiento formal del derecho de todas las personas al más alto nivel de salud física y mental, lo cual se ha materializado en diversos instrumentos legales a los que se someten los estados europeos, entre los que destacan los siguientes (Buron, 2012:51-52):

- El Tratado de Maastricht, del que hemos hablado en el anterior subapartado, determina que la salud pública forma parte de la política compartida entre los estados miembros, aunque la Comunidad Europea solo intervendría en casos de amenazas sanitarias, en la movilidad de los pacientes y en la reducción de las desigualdades en materia de salud, y los servicios sanitarios y la legislación que regula el acceso y uso de los mismos son de ámbito territorial.

- En el año 2004, el Comité Europeo de Derechos Sociales supervisa la aplicación de la Carta Social Europea, incluyendo apartados relativos a la salud. En relación con el ámbito específico de nuestro estudio, cabe destacar una de las afirmaciones señaladas en dicho documento, que estipula que "aquellas legislaciones o prácticas que denieguen el derecho a la asistencia médica de extranjeros en el territorio de un estado miembro, incluso si están en condición ilegal, son contrarios a la Carta".

- También en 2004 se firma la Declaración de Ámsterdam, ${ }^{176}$ en la cual se identifican como principales retos de los países de la UE los derechos de las minorías, el escaso conocimiento de los recursos disponibles, la escasez de recursos sanitarios, el deficiente estado de salud de la población inmigrante (provocado por el nivel socioeconómico y la propia experiencia migratoria), y las barreras lingüísticas y culturales. Su principio básico consiste en aceptar a las personas de origen extranjero como iguales dentro de la sociedad, identificar sus necesidades, y controlar y desarrollar los servicios sanitarios de acuerdo a las mismas. (Vázquez et al., 2007:15).

- Por su parte, la Asamblea Parlamentaria del Consejo de Europa concibe el derecho a la salud y al acceso a las prestaciones sanitarias como un derecho humano fundamental y universal, del que deberían gozar las personas de cualquier categoría, entre las que se incluyen a los inmigrantes, los refugiados y los desplazados.

- En el año 2007, con el Tratado de Lisboa, se establece que el bienestar relacionado con la salud es uno de los objetivos de la UE, uno de cuyos pilares básicos se encuentra en la educación, la formación y la protección de la salud humana.

\footnotetext{
${ }^{176}$ La Declaración de Ámsterdam nace del proyecto "Hospitales amigos del inmigrante en una Europa etnoculturalmente diversa". Dicho proyecto pretendía afrontar los desafíos derivados de la presencia de personas con diferentes orígenes étnicos y culturales en los servicios de salud. En él, un grupo de hospitales de doce países europeos (en concreto, Austria, Dinamarca, Finlandia, Francia, Alemania, Grecia, Irlanda, Italia, Países Bajos, España, Suecia y Gran Bretaña) se presentaron para participar como hospitales piloto. Las características de los mismos eran muy variadas (desde grandes hospitales universitarios a hospitales de ciudades pequeñas, con propiedad pública y privada, o sin ánimo de lucro). Tomando como referencia la experiencia de dichos hospitales, en la Declaración de Ámsterdam se presentan una serie de recomendaciones, que analizaremos más en detalle en el capítulo 7, dedicado a las conclusiones y propuestas de mejora de nuestra investigación.
} 
- Por último, en la revisión del Convenio para la Protección de los Derechos Humanos y de las Libertades Fundamentales que lleva a cabo en el año 2010 el Tribunal Europeo de Derechos Humanos, se incluye de modo implícito en el artículo 3 (el cual estipula que "Nadie podrá ser sometido a tortura, ni a penas o tratos inhumanos o degradantes") el derecho a la atención sanitaria de los inmigrantes (tanto regulares como irregulares).

\subsubsection{Legislación y políticas nacionales relacionadas con el acceso y uso de los servicios sanitarios por parte de la población inmigrante ${ }^{177}$}

Por lo que respecta a la gestión del acceso y uso de los servicios sanitarios por parte de la población inmigrante, en primer lugar, abordamos el contexto nacional, en el cual las políticas sanitarias para la población inmigrante se integran, en numerosas ocasiones, con políticas sociales y laborales, y se centran, fundamentalmente, en garantizar el derecho a la protección de la salud de los inmigrantes, aumentar el conocimiento de sus necesidades, y mejorar la formación de los profesionales sanitarios en habilidades específicas. Estas políticas sanitarias se podrían dividir, según el ámbito de actuación, en las siguientes áreas (Terraza et al., 2010:115.e3-115.e4):

a) acceso a los servicios de salud (con acciones encaminadas a la difusión de la información, la mejora de la comunicación y la simplificación de la burocracia);

b) adaptación de los servicios sanitarios (mediante acciones para recopilar sistemáticamente información sobre el colectivo inmigrante con el fin de mejorar el conocimiento de sus particularidades y necesidades $\mathrm{y}$, en consecuencia, elaborar programas y protocolos de actuación específicos);

c) promoción de la salud (con programas de prevención y promoción de la salud destinados a la población inmigrante, o con la inclusión de la misma en programas ya existentes); ${ }^{178}$

d) análisis de necesidades de salud (consistente en el estudio de los condicionantes y el estado de salud de los inmigrantes); $y$

e) formación de los profesionales (tanto por lo que respecta a la formación continuada, la actualización y las actividades de sensibilización dirigidas al personal sanitario, como por lo que se refiere a la adaptación del contenido curricular de las especialidades médicas).

De todos modos, cabe señalar que, como afirman Rebeca Terraza et al. (2010:115.e7),

\footnotetext{
${ }^{177}$ Cabe recordar que, si bien existe una legislación nacional que regula la asistencia sanitaria en España, el Sistema Nacional de Salud se encuentra descentralizado, es decir, determinadas competencias son transferidas a niveles inferiores de gobierno. Así, corresponden a la Administración del Estado las bases y la formulación general de la sanidad, la sanidad exterior y la legislación sobre productos farmacéuticos, mientras que las comunidades autónomas se ocupan de planificación sanitaria, cuestiones de salud pública y gestión de los servicios sanitarios, y las corporaciones locales, de temas de salubridad y de colaborar en la gestión de los servicios públicos de salud. (Alonso y Lizana, 2009:39)

${ }^{178}$ En relación con nuestro ámbito de estudio, cabe mencionar que, entre las acciones de promoción de la salud destinadas a la población inmigrante, se incluyen con frecuencia programas sobre salud sexual y reproductiva, como, por ejemplo, los centrados en la planificación familiar o en la prevención de la mutilación genital femenina.
} 
La formulación de políticas (sanitarias) ha evolucionado en consonancia con el incremento de la población inmigrante y parece responder a sus necesidades en términos generales. No obstante, las acciones contempladas presentan algunas debilidades que deberían corregirse.

Esta misma idea es reiterada y ampliada por autores como Josep Maria Comelles et al. (2010:125), los cuales sostienen que

La llegada de inmigrantes a España constituye un fenómeno tan reciente que no ha permitido la articulación de una política explícita y coherentemente desarrollada para facilitar la incorporación de dichos colectivos a la sociedad española. Ciertamente, el asentamiento de estas poblaciones ha influido sobre las políticas sanitarias españolas, pero hasta la fecha dicha influencia se ha centrado fundamentalmente en el ámbito de acceso. Las consideraciones acerca del tema de la equidad sanitaria en relación con estos grupos han quedado relegadas al ámbito estrictamente local, donde algunas autoridades sanitarias y organizaciones del tercer sector han desarrollado estudios e iniciativas ${ }^{179}$ en torno al impacto de la intervención del sistema sanitario sobre la salud de los colectivos de origen inmigrante.

En cuanto a la legislación en materia de salud, por ser el documento más reciente en materia de acceso a la sanidad, centramos nuestro análisis en el Real Decreto-ley 16/2012, de 20 de abril, de medidas urgentes para garantizar la sostenibilidad del Sistema Nacional de Salud y mejorar la calidad y seguridad de sus prestaciones. Este documento introduce una serie de novedades que modifican la legislación anterior y que, como veremos más adelante, pueden, a nuestro juicio, conllevar una serie de consecuencias negativas.

Con el fin de comprender las citadas modificaciones, resulta necesario realizar una breve descripción de la legislación anterior en materia de acceso a la sanidad. Por una parte, la Ley General de Sanidad, Ley 14/1986, de 25 de abril, en su artículo 12, reconocía el derecho a la protección de la salud y a la atención sanitaria en las mismas condiciones que los españoles a los ciudadanos extranjeros (tanto del Régimen Comunitario como del General) que tuvieran establecida su residencia en España.

Asimismo, la anteriormente mencionada "Ley de Extranjería", la Ley Orgánica 14/2003, de Reforma de la Ley Orgánica 4/2000, de 11 de enero, sobre derechos y libertades de los extranjeros en España y su integración social, modificada por la Ley Orgánica 8/2000, de 22 de diciembre, establecía en su artículo 12 que todos los extranjeros inscritos en el padrón municipal de su lugar de residencia habitual tenían derecho a asistencia sanitaria en igualdad de condiciones que los españoles. Además, este mismo derecho quedaba reconocido, aun en ausencia de empadronamiento, para los menores de edad, las mujeres durante el embarazo, el parto y el puerperio, y las personas que debieran ser atendidas de urgencia. Por consiguiente, el único requisito para acceder al sistema público de salud, incluso en el caso de la población inmigrante procedente de fuera de la Unión Europea o aquella en situación administrativa irregular, era estar empadronado, pues la inscripción en el padrón suponía automáticamente el derecho a solicitar la tarjeta sanitaria.

\footnotetext{
${ }^{179}$ Por lo que se refiere al contexto aragonés, un ejemplo de estos estudios e iniciativas en el ámbito de la salud llevados a cabo por organizaciones del tercer sector estaría constituido por las actividades del Servicio de Apoyo a la Mediación Intercultural (SAMI), del cual hablaremos en el subapartado de este capítulo centrado en la documentación del ámbito sanitario referida a Aragón.
} 
Por lo que se refiere al mencionado Real Decreto Ley 16/2012, este fue aprobado en el Congreso de los Diputados en mayo de 2012, y entró en vigor a partir del 1 de septiembre de ese mismo año. De conformidad con esta normativa, quedan sin cobertura sanitaria gratuita en el Sistema Nacional de Salud aquellos inmigrantes que residan en España de manera irregular, a excepción de los menores, las mujeres embarazadas y los casos de urgencia. De este modo, un segmento importante de la población queda excluido, por razones administrativas, del derecho a recibir cuidados de salud, relegándola de este modo a una situación de desamparo.

Con el Real Decreto Ley, pasan a considerarse beneficiarios de la asistencia sanitaria del sistema de salud público los españoles y extranjeros con residencia legal en España que cumplan con una de las siguientes condiciones: ser trabajadores por cuenta ajena o propia afiliados a la Seguridad Social, ser pensionistas, o percibir algún tipo de prestación de la Seguridad Social, como la prestación por desempleo. Solo en estos casos se reconocerá automáticamente el derecho a percibir las prestaciones sanitarias del Sistema Nacional de Salud. Asimismo, se considerarán aseguradas, previa solicitud al Instituto Nacional de la Seguridad Social y posterior aprobación por parte de dicho instituto, aquellas personas que residan en España y procedan de un país de la Unión Europea, del Espacio Económico Europeo o de Suiza, o aquellas originarias de un país de fuera de la Unión Europea, pero que cuenten con permiso de residencia en España. Al respecto, cabe destacar que, entre las cinco primeras comunidades inmigrantes residentes en España, se encuentran tres que no pertenecen a la Unión Europea, en concreto, las procedentes de Marruecos, Colombia y Ecuador.

A pesar de que algunas comunidades autónomas (como Andalucía, Asturias, Canarias, Cataluña, Castilla y León, Galicia, Navarra y País Vasco) han manifestado que no adoptarán esta medida y seguirán prestando asistencia a los inmigrantes en situación irregular, Aragón, comunidad contexto de nuestro estudio, sí la ha comenzado a aplicar. De hecho, se calcula que unos 15.000 inmigrantes residentes en territorio aragonés se han quedado sin tarjeta sanitaria a raíz de la entrada en vigor del Real Decreto Ley.

Para estas personas excluidas del sistema de sanidad público español se ha previsto implementar un sistema de "convenio" (término empleado para referirse a una especie de póliza privada de seguro médico), de acuerdo con el cual, podrán acceder a los servicios sanitarios públicos costeándoselos ellos mismos mediante el pago de una cuota mensual que va desde los 60 euros aproximadamente para los menores de 65 años, hasta cerca de 150 euros para los que superen dicha edad. Cabe señalar, además, que esta cuota mensual, a pesar de su elevado coste (que, previsiblemente, un gran número de inmigrantes no podrá asumir) solo cubriría la cartera básica de servicios de prevención, diagnóstico, tratamiento y rehabilitación, quedando exentos otros servicios suplementarios como, por ejemplo, los traslados con transporte sanitario o los descuentos aplicados a la compra de medicamentos. Este podría ser el caso de los métodos anticonceptivos parcialmente financiados por la Seguridad Social, como, por ejemplo, algunos contraceptivos orales hormonales. ${ }^{180}$

\footnotetext{
${ }^{180}$ Al respecto, cabe señalar que, de acuerdo con la Sociedad Española de Ginecología y Obstetricia (2007:338) y con la Sociedad Española de Contracepción (2012:16), los contraceptivos orales hormonales se encuentran, junto con los preservativos, entre los métodos anticonceptivos más usados en España por la población entre 15 y 29 años, y que el porcentaje de mujeres inmigrantes en esa franja de edad es, como puede comprobarse en el apartado de
} 
Asimismo, aquellos ciudadanos sin tarjeta sanitaria que reciban asistencia estarán obligados a firmar un compromiso de pago de la intervención que se les efectúe. Si estos pacientes proceden de un país con el que España no tiene suscrito un convenio sanitario, como sucede con un gran número de países de los que procede la población inmigrante en España, deberán asumir el coste total de la factura. En caso de que no les resulte posible pagar el importe, los pacientes contraerán una deuda con la Administración, lo que les puede impedir en un futuro regularizar su situación administrativa o acceder a determinados servicios públicos.

Una de las cuestiones que quisiéramos destacar en relación con esta nueva normativa es el escaso conocimiento de la misma que presenta la población, en general, y los usuarios afectados, en particular. Fruto de esta falta de información, de acuerdo con la Plataforma Salud Universal, son numerosos los ciudadanos inmigrantes que han dejado de acudir a los centros de salud $\mathrm{u}$ hospitalarios por temor o desconocimiento. ${ }^{181}$

De dicha confusión tampoco quedan exentos los profesionales sanitarios, algunos de los cuales, como podrá verse en el análisis de los datos recolectados mediante la técnica de las entrevistas, parecen no conocer exhaustivamente los contenidos y el alcance de la recién implantada legislación en materia de sanidad, a pesar de que la aplicación de la misma tiene consecuencias directas en su trabajo diario.

Este "maremágnum desinformativo" con respecto a la normativa, podría conllevar, de acuerdo con José Luis Aliaga, portavoz de SOS Racismo, ${ }^{182}$ diferentes interpretaciones de la misma por parte de los centros de salud, e incluso que se niegue la tarjeta sanitaria a personas que, de conformidad con lo establecido legalmente, sí tendrían derecho a ella, como es el caso de las mujeres embarazadas.

Otro aspecto a resaltar consiste en el hecho de que no se ha valorado el impacto que la aplicación de esta normativa podría tener en un futuro. Entre las consecuencias que podría presentar la falta de asistencia sanitaria a la población inmigrante en situación irregular, se encuentra la imposibilidad de detectar y tratar enfermedades de interés para la salud pública, como la tuberculosis, la hepatitis o enfermedades de transmisión sexual.

Además, si bien uno de los objetivos con los que se aprobó el Real Decreto Ley fue la reducción de los gastos de la Administración pública, cabe recordar que la solicitud de prestaciones sanitarias por parte de la población inmigrante es notablemente inferior a la de la población autóctona, hecho constatado en numerosos estudios científicos tanto nacionales como internacionales. ${ }^{183}$

contextualización del capítulo 1, bastante elevado. Por consiguiente, es probable que, con la ausencia del derecho a disponer de la financiación aplicada a estos contraceptivos (bien por no tener tarjeta sanitaria o por no estar dicha financiación incluida en el mencionado convenio/póliza), un gran número de mujeres inmigrantes no podrán adquirirlos.

${ }^{181}$ Castelló Frauca, B. (2013). [http://www.aragondigital.es/noticia.asp?notid=104952] (última consulta: 7 de agosto de 2013). 182

Efe.Zaragoza

(2012).

[http://www.heraldo.es/noticias/aragon/2012/11/21/al_menos_inmigrantes_con_derecho_asistencia_pierden_tarj eta_sanitaria_212573 300.html] (última consulta: 7 de agosto de 2013).

${ }_{183}$ A modo de ejemplo, por lo que se refiere al contexto aragonés, podemos mencionar un exhaustivo estudio llevado a cabo en 2012 por la organización Médicos del Mundo, según el cual, de acuerdo con los datos recogidos en 26 centros de salud de Zaragoza, los usuarios extranjeros acuden a dichos centros una media de 4,6 veces al año, 
Entre otros inconvenientes de esta normativa, ${ }^{184}$ por una parte, cabe señalar que, a pesar de que la aplicación del Real Decreto Ley probablemente no tendrá importantes repercusiones en términos de salud pública, a título individual puede presentar graves consecuencias, ya que los servicios de urgencias a los que los ciudadanos sin tarjeta sanitaria tendrán derecho a acceder no pueden prevenir, diagnosticar precozmente o controlar enfermedades crónicas o degenerativas. Asimismo, las personas excluidas del acceso a la sanidad pública no podrán ser destinatarias de medidas de salud preventivas, como las vacunaciones o las actividades de educación para la salud, entre las que se encuentran, por ejemplo, y en relación con nuestro ámbito de estudio, los servicios de planificación familiar.

Se han cumplido, de este modo, los resultados vaticinados por Magdalena Díaz hace unos años (2009:81), cuando aún no se había aprobado la nueva normativa sobre el acceso a los servicios de salud.

El resultado previsto será la invisibilización de parte de los extranjeros con consecuentes restricciones para acceder a una vida normalizada dentro de la estructura social en la que se encuentran. La ciudadanía, de esta manera, se dualizará, creando habitantes de diferentes categorías y posibilitando la creación de una sociedad fuertemente jerarquizada y escasamente cohesionada.

No podemos dejar de señalar que, en última instancia, esta normativa se contrapone con la Constitución Española y los Estatutos de Autonomía, que reconocen para todas las personas el derecho a la asistencia médica, y plantea importantes problemas éticos para los profesionales sanitarios, quienes, según la anteriormente mencionada Declaración de Ginebra, deberían proteger la salud de la población sin ejercer ningún tipo de discriminación motivada por factores como el origen étnico o la nacionalidad.

Para finalizar el análisis de este Real Decreto Ley, tal y como sostienen desde el Grupo de trabajo Inmigración y Salud del SEMFYC, ${ }^{185}$ consideramos que la creación de estructuras paralelas de atención sanitaria para un segmento considerable de la población inmigrante constituye por sí misma una discriminación que probablemente dificultará aun más su integración en la sociedad de acogida.

Con respecto a la Comunidad Autónoma de Aragón, contexto de nuestro estudio, la Ley 6/2002, de 15 de abril, de Salud de Aragón, modificada por la Ley 2/2005, de 24 de febrero, no incluye acciones específicas para la población inmigrante. Tampoco es posible hallar referencias concretas a este segmento de la población en el Estatuto de Autonomía de Aragón

aproximadamente la mitad en comparación con los españoles, quienes acuden en 8,3 ocasiones. [http://www.heraldo.es/noticias/aragon/2012/05/16/los_inmigrantes_aragon_van_mitad_centro_salud_que_los_e spanoles_187975_300.html] (última consulta: 19 de agosto de 2013).

${ }^{184}$ En cuanto a los efectos de la reforma sanitaria introducida por el Real Decreto Ley 16/2012 y las razones que sustentan su derogación, aconsejamos visionar la serie de cinco vídeos titulada "\#leyesquematan, las consecuencias de la reforma sanitaria en España", que fue editada por la organización Médicos del Mundo. [http://mdmaragon.blogspot.com.es/] (última consulta: 14 de agosto de 2013).

${ }^{185}$ La SEMFYC es la federación de las diecisiete Sociedades de Medicina de Familia y Comunitaria que existen en España y agrupa a más de 19.500 médicos de familia. SEMFYC (2012). [https://www.semfyc.es/grupos_trabajo/inmigraci\%F3n+y+salud/noticias_grupo/detalle/GdT_Inmigracion_TarjetaS anitaria/] (última consulta: 7 de agosto de 2013). 
(2007), si bien cabría mencionar, en relación con el ámbito en el que se centra nuestra investigación, una serie de derechos que en dicho Estatuto se atribuyen a todas las personas:

Derecho a la dignidad, seguridad, autonomía y no discriminación: "Todas las personas tienen derecho a vivir con dignidad, seguridad y autonomía, libres de explotación, de malos tratos y de todo tipo de discriminación, y tienen derecho al libre desarrollo de su personalidad y capacidad personal" (art. 12, 1ㅇ).

Derecho a las prestaciones sociales: "Todas las personas tienen derecho a las prestaciones sociales destinadas a su bienestar, y a los servicios de apoyo a las responsabilidades familiares para conciliar la vida laboral y familiar, en las condiciones establecidas por las leyes" (art. 12, 2ㅇ).

Derecho a la salud: "Todas las personas tienen derecho a acceder a los servicios públicos de salud, en condiciones de igualdad, universalidad y calidad, y los usuarios del sistema público de salud tienen derecho a la libre elección de médico y centro sanitario, en los términos que establecen las leyes" (art. 14, 1ㅇ).

Derecho a la salud: "Los poderes públicos aragoneses garantizarán la existencia de un sistema sanitario público desarrollado desde los principios de universalidad y calidad, y una asistencia sanitaria digna, con información suficiente al paciente sobre los derechos que le asisten como usuario" (art. 14, 2ㅇ).

Derecho a la salud: "Los poderes públicos aragoneses velarán especialmente por el cumplimiento del consentimiento informado" (art. 14, 3).

Derecho a la salud: "Todas las personas podrán expresar su voluntad, incluso de forma anticipada, sobre las intervenciones y tratamientos médicos que desean recibir, en la forma y con los efectos previstos en las leyes" (art. 14, 4).

Derecho a acceder a los servicios públicos: "Todas las personas tienen derecho a acceder en condiciones de igualdad a unos servicios públicos de calidad" (art. 16, 1ㅇ).

Derechos de consumidores y usuarios: "Todas las personas tienen derecho a la protección de la salud y la seguridad en el consumo" (art. 17, 19).

En el caso de la población inmigrante residente en Aragón, aun en el caso de que conozca estos derechos enunciados en el Estatuto autonómico y reúna las condiciones establecidas en el Real Decreto Ley 16/2012, no siempre podrá beneficiarse de los mismos, pues el acceso y uso de los servicios sanitarios por su parte podrán verse comprometidos en los casos en los que, como veremos posteriormente en el análisis del trabajo de campo, se lo impidan las barreras lingüísticas y culturales, por un lado, y el empleo de estrategias inadecuadas para reducir o eliminar dichas barreras, por otro.

Para finalizar este subapartado, quisiéramos comentar que, a pesar de que, como hemos señalado en las páginas previas, el derecho a la salud está contemplado por diversas normas y políticas a nivel tanto nacional como internacional, en nuestra opinión, los buenos principios no son suficientes, sino que es necesario que estos se apliquen, de modo que todos los ciudadanos puedan acceder fácilmente a los servicios sanitarios con el fin de mantener o recuperar su estado de salud. Asimismo, para que las prestaciones y servicios sanitarios se puedan usar adecuadamente, resulta fundamental que se lleve a cabo una adecuada difusión 
de la información (tanto a los profesionales como a los usuarios) y una continua monitorización del acceso y uso de los servicios, de manera que emerjan las necesidades y los problemas hallados, así como las posibles soluciones a estos últimos.

Por último, cabe destacar que la tutela de la salud de todos los ciudadanos responde a una exigencia de solidaridad humana y, al mismo tiempo, a una lógica de prevención colectiva. Dicho en otras palabras, consideramos que favorecer el acceso y uso de los servicios sanitarios por parte de la población inmigrante y garantizar que esta disfrute de la misma tutela de la salud que la población autóctona es ventajoso para la sociedad en su conjunto.

\subsubsection{Planes integrales y estratégicos de Aragón}

Con respecto a las políticas sanitarias autonómicas dirigidas a la población inmigrante en el contexto aragonés, como hemos señalado previamente, estas se recogen en diversos Planes integrales y estratégicos elaborados por el Gobierno de Aragón en colaboración con diferentes agentes sociales, de cuyo análisis nos ocuparemos a continuación. ${ }^{186}$ En estos documentos se establecen los programas y acciones que se van a poner en marcha en un periodo de cuatro años con el fin de prestar servicios básicos a los ciudadanos, así como para coordinar, gestionar y evaluar las distintas políticas autonómicas relacionadas con el fenómeno de la inmigración. Los planes se dividen en secciones dedicadas a diferentes áreas, de las cuales, en nuestro análisis, atendiendo a los objetivos de esta investigación, hemos prestado especial atención a aquellas dedicadas al ámbito de la salud y a las mujeres.

Si bien el primer Plan Integral para la Inmigración en Aragón (2002-2004) se presentó en la primavera de 2002, tuvieron que transcurrir dos años hasta que este fue aprobado y, visto que había finalizado el plazo para su aplicación, el documento definitivo finalmente publicado fue el Plan Integral para la Inmigración en Aragón 2004-2007. Los objetivos generales de dicho Plan consistían en: el fomento de la integración de la población inmigrante, propiciando las condiciones necesarias para la convivencia basada en el reconocimiento de derechos y deberes; la promoción del acceso a los servicios por parte de este segmento de la población; la potenciación de su participación mediante el reconocimiento de la diferencia y la valoración de la diversidad como factor de enriquecimiento mutuo; la difusión de la realidad de la inmigración entre la sociedad aragonesa y la sensibilización de esta última; la colaboración y coordinación entre las distintas administraciones y las entidades sociales; y la cooperación al desarrollo de los países más desfavorecidos. Dichos objetivos generales se plasmaban en diversos programas, acciones y objetivos específicos, de los cuales, tal y como hemos comentado, nos centraremos en aquellos que se refieren a los ámbitos de nuestra investigación: la salud, por un lado, y las mujeres inmigrantes, por otro.

En referencia a la salud de los inmigrantes residentes en Aragón, el Plan 2004-2007 pretendía principalmente detectar las necesidades de salud de este colectivo, elaborar protocolos de actuación comunes para todos los centros que atendieran a usuarios de origen extranjero, y planificar acciones de salud destinadas a dichos usuarios.

\footnotetext{
${ }^{186}$ En los anexos incluimos unas tablas que resumen los principios, objetivos, programas y acciones de los planes integrales y estratégicos analizados, con especial atención al ámbito de la salud y a las mujeres inmigrantes.
} 
En cuanto a las mujeres inmigrantes, son numerosas las referencias a este colectivo en el documento analizado. En resumen, se perseguía garantizar el acceso de estas mujeres a los servicios sociales, fomentar la agrupación familiar, y potenciar el conocimiento por su parte del idioma y la cultura del país de acogida, de modo que se favoreciera su integración social. Asimismo, en el Plan se proponían una serie de acciones para fomentar el empoderamiento de las mujeres inmigrantes, entre las que se encontraban la promoción de su acceso a los programas de formación del Instituto Aragonés de Empleo (INAEM), el estudio de sus condiciones laborales (con especial atención al empleo sumergido y el trabajo doméstico), el fomento de su inserción laboral, y la creación de programas específicos y adecuados a la realidad de estas mujeres por lo que respecta a las víctimas de violencia de género.

Se establecían, además, una serie de iniciativas para promover la salud de las mujeres inmigrantes, como, por ejemplo, el desarrollo de programas de educación para la salud, la difusión de información sobre los servicios de planificación familiar y el fomento del acceso a los mismos, y el desarrollo de proyectos de promoción de la salud en los que se priorizara como destinatarios a los segmentos más vulnerables de la población, entre los que se citaba a las mujeres.

En este Plan 2004-2007 se incluían igualmente dos programas que merecen ser mencionados. Por una parte, el Servicio de Apoyo a la Mediación Intercultural (SAMI), cuyo principal objetivo era intervenir en situaciones de conflicto de acuerdo con los principios de imparcialidad, tolerancia y respeto de la diferencia. En concreto, las áreas de trabajo de este Servicio eran la intervención en situaciones conflictivas derivadas de la diversidad cultural, el asesoramiento técnico a entidades e instituciones sobre multiculturalidad, la edición de materiales y documentación, y la realización de proyectos de investigación.

Por otra parte, con este Plan se desarrolló un servicio de traducción e interpretación, ${ }^{187}$ con el que se pretendía fomentar la comunicación entre los profesionales de los diferentes servicios de la administración autonómica y los usuarios extranjeros, eliminando las posibles barreras lingüísticas y promoviendo la comprensión mutua.

Presentaremos más datos sobre estos dos últimos servicios mencionados en el apartado de análisis documental relativo a las estrategias de promoción de la comunicación y la asistencia a usuarios inmigrantes de los servicios sanitarios.

La primera novedad introducida en el siguiente Plan integral aprobado, el Plan Integral para la Convivencia intercultural en Aragón 2008-2011, estaba constituida por el mismo título del mismo, en el que se pasaba a hablar de "inmigración" sin más a incluir la expresión "convivencia intercultural", en la que implícitamente se daba a entender que el proceso de integración es bidireccional e implica tanto a los inmigrantes como a los autóctonos. Los programas y acciones previstos en este Plan se articulaban en tres grandes líneas estratégicas: acogida, inclusión y convivencia. Como en el caso del Plan previamente analizado, presentamos los objetivos generales y específicos que estaban directamente relacionados con los fines de esta investigación, la salud, por una parte, y las mujeres inmigrantes, por otra.

${ }^{187}$ Este servicio, como veremos más adelante, se denominó Servicio Permanente de Interpretación. 
Cabe destacar que las acciones y programas relativos a estos dos ámbitos son más numerosos en este Plan con respecto al anterior.

Por lo que se refiere a la salud, con el Plan 2008-2011 se pretendía a grandes rasgos lograr los siguientes objetivos: garantizar el acceso de la población inmigrante a los servicios sanitarios y la adecuación de estos servicios a sus características y necesidades; integrar a este segmento de la población en los programas de prevención y promoción de la salud; informar a los usuarios extranjeros sobre los recursos disponibles, así como sobre sus derechos y deberes; dotar a los profesionales sanitarios de los conocimientos necesarios para atender a dichos usuarios; y promover un sistema de salud interculturalmente competente. Nos gustaría resaltar por su carácter novedoso una serie de acciones propuestas relacionadas con estos objetivos, como la implantación de programas de acompañamiento de los usuarios adecuados a la diversidad cultural, la revisión e inclusión en los planes de estudios de los profesionales sanitarios de contenidos relacionados con la adquisición de la competencia intercultural, la consideración de los usuarios inmigrantes a la hora de diseñar la rotulación y la señalización de los servicios sanitarios, y el desarrollo de nuevos protocolos de atención tanto primaria como especializada atendiendo a las características y necesidades de la población inmigrante.

Con respecto a las mujeres inmigrantes, estas, junto con los menores y los jóvenes, constituían sectores poblacionales prioritarios de acuerdo con este Plan. Como en el Plan anterior, se incluían acciones para promocionar su empoderamiento, mediante su formación y su inserción laboral. Además, se planteaba la revisión de los programas de prevención, sensibilización y atención a las víctimas de violencia de género adecuándolos a las particularidades de las mujeres inmigrantes, y se establecía la actualización y revisión de los programas de detección precoz del riesgo de mutilación genital femenina.

De nuevo, en este Plan se presentaban los programas de mediación y traducción previamente mencionados con el fin de garantizar el derecho de acceso a los servicios públicos y dotar a los profesionales de los servicios sociales, educativos, sanitarios, etc. de los conocimientos necesarios para atender a los usuarios inmigrantes. En concreto, por lo que se refiere a la mediación, se planteaba el desarrollo del citado Servicio de Apoyo a la Mediación Intercultural y se pretendía establecer un concepto consensuado de mediación. Con respecto a la traducción, por un lado, se presentaba como objetivo la selección de aquellos documentos cuya traducción fuera imprescindible para garantizar los derechos de ciudadanía en condiciones de igualdad y, por otro, se creó como experiencia piloto un Servicio de traducción telefónica, ${ }^{188}$ del cual hablaremos más extensamente en el apartado de análisis documental centrado en las estrategias y recursos de los que disponen los servicios sanitarios para favorecer la comunicación y la atención a los usuarios inmigrantes.

El Plan 2008-2011 es, hasta la fecha, el último plan integral publicado en materia de inmigración. Si bien se elaboró un borrador del que sería el siguiente plan (Plan integral en materia de Inmigración y Convivencia intercultural 2012-2015), finalmente, desde el Gobierno de Aragón y, más concretamente, desde el Departamento de Sanidad, Bienestar Social y

\footnotetext{
188 Reproducimos textualmente el nombre (erróneo) que se le ha dado a este Servicio, que, a nuestro juicio, fomenta la confusión terminológica y conceptual de los términos "traducción" e "interpretación". De hecho, esta misma confusión la presentan, como veremos en el análisis de los resultados de nuestro trabajo de campo, tanto los profesionales como los usuarios de los servicios sanitarios.
} 
Familia y la Dirección General de Bienestar Social y Dependencia, se decidió elaborar un plan en el que se incluyera de manera transversal a todos los segmentos poblacionales en situación vulnerable, entre los que se hallaba la población inmigrante. Partiendo de las particularidades sociodemográficas de la ciudadanía, de sus necesidades sociales, de las previsiones de su evolución y de las características detectadas en el análisis del Sistema de Servicios Sociales, el I Plan Estratégico de Servicios Sociales de Aragón 2012-2015, establece una serie de prioridades y estrategias a acometer en un periodo de cuatro años, en el que actualmente nos encontramos en curso. Los objetivos de este Plan estratégico en materia de salud o destinados a la población inmigrante, en general, o a las mujeres, en particular, son los siguientes: promover la atención integral de los menores extranjeros no acompañados; impulsar el trabajo en red con la creación de encuentros y espacios de debate entre asociaciones de inmigrantes, organizaciones aragonesas que trabajan en los países de origen de la inmigración y ONG para proporcionar información y orientación sobre codesarrollo; crear una mesa de coordinación entre las administraciones competentes en materia de empleo e inmigración; y elaborar protocolos de coordinación entre los servicios sociales y las diferentes áreas de protección social (salud, educación, empleo, vivienda y justicia). Vuelven a mencionarse en este Plan el servicio de atención a las mujeres víctimas de violencia de género y el servicio de traducción telefónica para inmigrantes. Asimismo, se incluye un servicio de acogimiento familiar temporal de menores no acompañados.

A partir del análisis de los planes integrales y estratégicos aragoneses, podemos concluir que son numerosas las acciones e iniciativas que se incluyen en los mismos destinadas a favorecer el acceso y uso de los servicios sanitarios por parte de la población inmigrante residente en esta Comunidad Autónoma. Sin embargo, como veremos en el análisis del trabajo de campo, algunas de estas no se han llevado a la práctica, y otras, a pesar de haberse implantado, no han sido correctamente difundidas o no se realiza de las mismas un empleo adecuado.

\subsubsection{Otra documentación del ámbito sanitario en el contexto aragonés}

En tercer lugar, dentro de este grupo de documentos, analizamos otra documentación del ámbito sanitario en el contexto aragonés: la Carta de Compromisos del Departamento de Salud y Consumo con los Usuarios del Sistema de Salud de Aragón; el documento "Inmigración y Salud en Aragón" (2007); y el informe "Estado de Salud de Aragón: Determinantes y Actuaciones del Departamento de Salud y Consumo" (2010).

El primer documento citado, la Carta de Compromisos del Departamento de Salud y Consumo con los Usuarios del Sistema de Salud de Aragón, tiene como objetivo establecer garantías adicionales en el cumplimiento del derecho a la salud que tienen los usuarios de los servicios sanitarios aragoneses en los ámbitos de la información, la accesibilidad, la calidad y la participación. En concreto y, con el fin de dar respuesta a las necesidades de los usuarios, con este documento, el Departamento de Salud y Consumo se compromete a mejorar la accesibilidad a los servicios, agilizar los tiempos de respuesta en la atención, y ofrecer un trato más personalizado. En la carta se establecen 34 objetivos divididos en los cuatro ámbitos mencionados.

El primero de estos ámbitos se refiere a la información y el derecho por la autonomía de decisión, y en él se establecen los siguientes compromisos: garantizar el ejercicio del derecho a 
la expresión de las voluntades anticipadas, a la libre elección de profesional sanitario y a la segunda opinión médica, de acuerdo con la regulación normativa; respetar la dignidad, la intimidad y los valores éticos y culturales de cada persona; informar de los derechos que tienen los ciudadanos como usuarios del Sistema de Salud y del funcionamiento de los servicios sanitarios, utilizando las nuevas tecnologías de la información y la comunicación; proporcionar información y atención personalizada a los ciudadanos; facilitar información clínica comprensible y suficiente que permita al paciente tomar decisiones sobre su salud y sobre las alternativas asistenciales y de tratamiento; informar a los pacientes y familiares de los riesgos que pueden conllevar algunas intervenciones quirúrgicas y pruebas diagnósticas para las que es necesario su consentimiento informado y por escrito; e informar sobre los posibles riesgos individuales y ambientales para la salud e impulsar iniciativas que promuevan estilos de vida saludable y programas de educación para la salud. ${ }^{189}$ Con respecto a estos compromisos, por una parte, desconocemos si la población inmigrante ha sido debidamente informada sobre los derechos que le corresponden como usuarios de los servicios sanitarios y sobre el funcionamiento de dichos servicios y, por otra, consideramos que, en los casos en los que la comunicación entre el profesional y el usuario inmigrante se vea dificultada por barreras lingüísticas y culturales, dicho usuario no podrá expresar su voluntad, y difícilmente se le podrá hacer partícipe del diagnóstico y el tratamiento prescrito o de los riesgos que este podría conllevar.

El segundo ámbito de la Carta, relativo a la accesibilidad, presenta, entre otros, los siguientes objetivos que incluimos por estar en cierto sentido relacionados con los sujetos que estudiamos en nuestra investigación: facilitar la obtención de cita con los profesionales de Atención Primaria, a través de un sistema centralizado de citación e información telefónica y por Internet; establecer mecanismos de detección precoz en el recién nacido de enfermedades asociadas a factores genéticos o hereditarios, y del cáncer de mama en todas las mujeres con edades comprendidas entre los 50 y los 69 años; y desarrollar progresivamente el programa gratuito de salud bucodental infantojuvenil para la población con edades comprendidas entre los 6 y 17 años. En relación con el primer objetivo, quisiéramos señalar que el sistema de citación centralizado ofrece la posibilidad de emplear el denominado servicio de traducción telefónica (mencionado en los planes previamente analizados) para aquellos usuarios alófonos que no comprendan las indicaciones ofrecidas telemáticamente en español. Sin embargo, aunque no conocemos si los usuarios inmigrantes están satisfechos con los resultados obtenidos tras emplear este servicio de traducción para obtener cita o recibir información por teléfono, hemos realizado personalmente una prueba del funcionamiento del mismo y hemos observado que quizás resulte complicado y no siempre eficaz, pues el número de códigos a

\footnotetext{
${ }^{189}$ Cabe señalar que, los últimos compromisos mencionados se encuentran también recogidos a nivel nacional en la Ley 41/2002, de 14 de noviembre, reguladora de la autonomía del paciente y, de derechos y obligaciones en materia de información y documentación clínica. En dicha Ley, concretamente en su artículo 3, se define la información clínica como "todo dato, cualquiera que sea su forma, clase o tipo, que permite adquirir o ampliar conocimientos sobre el estado físico y la salud de una persona o la forma de preservarla, cuidarla, mejorarla y recuperarla". Además, en los artículos 4 y 5, se estipula que "los pacientes tienen derecho a conocer, con motivo de cualquier actuación en el ámbito de su salud, toda la información disponible sobre la misma [....]. Además, toda persona tiene derecho a que se respete su voluntad de no ser informada. La información [...] comprende, como mínimo, la finalidad y la naturaleza de cada intervención, sus riesgos y sus consecuencias. La información clínica forma parte de todas las actuaciones asistenciales, será verdadera, se comunicará al paciente de forma comprensible y adecuada a sus necesidades y, le ayudará a tomar decisiones de acuerdo con su propia y libre voluntad".
} 
introducir es muy numeroso y, en ocasiones, no solo se alargan considerablemente los tiempos de espera, sino que se pierde la comunicación telefónica y es necesario volver a llamar. De todos modos, como hemos comentado previamente, ofreceremos más información al respecto en el apartado dedicado a los recursos y estrategias de los que disponen los servicios sanitarios aragoneses para facilitar la comunicación y la atención a usuarios inmigrantes.

El tercer ámbito se refiere a la calidad de la asistencia e incluye 12 compromisos, de los cuales solo destacaremos aquellos directamente relacionados con los fines de nuestra investigación. En concreto, de acuerdo con la Carta, el Departamento de Salud y Consumo tratará de desarrollar un Plan de Atención Integral a la Salud de la Mujer, orientado a promover la salud sexual y reproductiva, la lactancia materna y la posibilidad de optar a un parto más natural. Asimismo, implantará dietas hospitalarias adaptadas a las necesidades, la cultura y los valores éticos de los pacientes. Del primer objetivo mencionado nos ocuparemos en el siguiente apartado de análisis documental, centrado en los documentos relacionados con la salud reproductiva y la atención durante el parto. Por lo que respecta al segundo objetivo, nos consta por el trabajo de campo realizado que los menús de los hospitales se han adaptado en la medida de lo posible a las necesidades personales, culturales y religiosas de los usuarios.

El cuarto y último ámbito de la Carta está relacionado con la participación de los usuarios y, entre otros, establece los siguientes objetivos: elaborar periódicamente una encuesta de satisfacción de todo el conjunto de usuarios del Sistema de Salud de Aragón, ${ }^{190}$ establecer canales de recogida de sugerencias para mejorar el funcionamiento y los resultados de los servicios sanitarios, y facilitar la participación de asociaciones de pacientes y familiares y de las distintas entidades sociales en los proyectos de salud, así como regular la labor de voluntariado de dichas asociaciones y entidades. Veremos en el trabajo de campo cómo, en el contexto que nos ocupa, se ha observado la participación de familiares y entidades en proyectos como el programa de mediación para la prevención de la mutilación genital femenina (dependiente de la organización Médicos del Mundo), la campaña de la Gota de leche impulsada por la Fundación El Refugio para proporcionar leche a aquellos recién nacidos a los que no fuera posible dar lactancia materna y cuyas familias tuvieran escasos recursos, y la creación de una escuela de padres en el hospital en el que se centra nuestra investigación. ${ }^{191}$

El segundo documento, "Inmigración y Salud en Aragón" fue elaborado por el Grupo de trabajo Inmigración y salud de la SEMFYC (Sociedad Española de Medicina de Familia y Comunitaria) en el año 2007. Su objetivo principal consistía en conocer tanto el modo en que había influido la llegada de los usuarios inmigrantes al sistema de salud aragonés, como las características de la atención sanitaria prestada a dichos usuarios en esta región. En él se realizaba un análisis profundo de la situación, en el que se reflejaba el estado de salud de la población inmigrante y el uso que esta realizaba de los servicios sanitarios. Asimismo, se

\footnotetext{
190 Por los datos contenidos en la última encuesta de satisfacción sobre el Sistema de Salud de Aragón publicada (2011), no resulta posible conocer si, entre los usuarios que participaron, se encontraban personas inmigrantes y, en caso afirmativo, no sabemos qué porcentaje constituían estos usuarios con respecto a los autóctonos ni si las respuestas y la valoración de estos dos grupos eran diferenciadas, ya que, en los datos sociodemográficos de los participantes, no se incluía la variable de la nacionalidad.

${ }^{191}$ Si bien la mencionada escuela de padres se creó y llevó a cabo su actividad durante algún tiempo en el hospital contexto de estudio, en el que momento en que realizamos nuestro trabajo de campo, había dejado de funcionar.
} 
estudiaba la valoración de los servicios por parte de estos usuarios y la percepción de las particularidades que, de acuerdo con los profesionales, entrañaba la asistencia sanitaria a los mismos. Se trata de un documento que aporta datos relevantes para nuestro estudio; sin embargo, la información en él expuesta data de hace más de 6 años, por lo que deberán tenerse en cuenta los cambios que pueden haberse producido en dicho periodo.

En cuanto al estado de salud y la utilización de los servicios sanitarios por parte de la población inmigrante, el documento señalaba, en primer lugar, que cabía tener en cuenta que este segmento de la población era mayoritariamente joven. La edad media, junto con otros factores, entre los que se indicaban las cargas laborales y familiares, la diferente percepción del estado de salud y la enfermedad, las barreras de acceso, o el desconocimiento del funcionamiento de los servicios, constituían los motivos por los cuales estos usuarios no los utilizaban frecuentemente.

De acuerdo con los autores del documento analizado, aunque solía afirmarse que la población inmigrante realizaba un sobreuso de los servicios de salud, en su opinión, esta afirmación era infundada. Si bien reconocían desconocer muchos aspectos del patrón de uso de estos usuarios, de los datos disponibles ${ }^{192}$ se desprendía que, en general, tanto su presencia en las consultas como sus ingresos hospitalarios eran menores con respecto a los de los autóctonos. De hecho, los profesionales sanitarios mencionados en el estudio opinaban que las demandas que los usuarios inmigrantes realizaban, tanto en atención primaria como en especializada, no diferían sustancialmente de las de los autóctonos, ni en frecuencia de consulta ni en contenido.

En concreto, según los resultados del estudio, por lo que respecta a atención primaria (medicina familiar, pediatría y enfermería), en todos los grupos de edad la frecuentación media anual era menor en las personas inmigrantes que en las autóctonas. Por el contrario, en referencia a la medicina especializada y los ingresos hospitalarios, cabría realizar una diferenciación por sexos. Dentro de la población analizada (centrada en el grupo con edades comprendidas entre los 15 y los 49 años, es decir, un 90\% de los inmigrantes residentes en Aragón), los usuarios inmigrantes varones suponían en ese momento el $18 \%$ de la población, y representaban el $7 \%$ de las estancias y los ingresos hospitalarios. En general, su contribución era menor en todas las categorías diagnósticas mayores, salvo en las enfermedades infecciosas y parasitarias. Por su parte, las usuarias inmigrantes suponían el $9 \%$ de la población aragonesa $y$, en cambio, su contribución era del $7 \%$ de los ingresos y el $4 \%$ de estancias. Esta diferencia era todavía más notable en las mujeres entre 15 y 30 años (en edad fértil), ya que entre un 10 y un $37 \%$ del total de intervenciones e ingresos relacionados con el embarazo, el parto y el puerperio (partos vaginales, cesáreas, legrados, amenazas de aborto, complicaciones preparto, etc.) habían sido efectuadas en usuarias inmigrantes, con un porcentaje medio de ingresos por patologías obstétricas del $15 \%$. Un dato relevante en relación con la salud reproductiva estaba constituido por el número de abortos practicados en mujeres inmigrantes, las cuales representaban el $47 \%$ de las interrupciones voluntarias del embarazo en un periodo de seis

\footnotetext{
192 La principal dificultad que hallaron los autores de este documento para obtener datos completos de la utilización de los servicios sanitarios por parte de la población inmigrante consistió en conocer la nacionalidad de los pacientes, ya que diversos hospitales no cumplimentaban esta información en el momento en que realizaron el estudio. Nosotros mismos hemos debido enfrentarnos con esta dificultad, puesto que el hospital donde hemos desarrollado nuestra investigación tampoco disponía de datos sobre las usuarias disgregados por país de origen.
} 
meses del año 2007. Dentro de este porcentaje, se destacaba especialmente al colectivo de las rumanas, que suponían un $15 \%$, seguidas por las ecuatorianas, con un $7 \% .{ }^{193}$

Por lo que se refiere a la valoración de los servicios de salud por parte de la población inmigrante, en general, según el estudio, esta era positiva. Estos usuarios destacaban, entre otros aspectos, la organización, la gratuidad y el buen trato dispensado por los profesionales sanitarios.

Con respecto a la accesibilidad, se señalaba, en primer lugar, que los servicios de urgencia eran, en numerosas ocasiones, la puerta de entrada al sistema sanitario por parte de los usuarios inmigrantes, al menos durante el primer periodo de residencia en España. Entre los motivos que podían llevar a este acceso inadecuado, se resaltaba, en primer lugar, la barrera idiomática y, además, el desconocimiento del derecho a utilizar los servicios de salud o del modo para obtener la tarjeta sanitaria. Asimismo, se indicaba la dificultad para obtener el empadronamiento, que, en el momento en que se publicó este documento, como hemos comentado anteriormente, era el trámite administrativo necesario para obtener la mencionada tarjeta. Otras causas del acceso a los servicios sanitarios a través de urgencias, podían ser, según el estudio, los horarios y las cargas laborales, y el desconocimiento de las normas básicas de funcionamiento del sistema de salud. De todos modos, los profesionales sanitarios mencionados en el documento analizado afirmaban que el uso del servicio de urgencias sin pasar por atención primaria era muy similar en inmigrantes y autóctonos y que, en ambos casos, esto sucedía por los mismos motivos, entre los que destacaban el deseo de evitar la burocracia y la espera, o el hecho de que los horarios de los servicios de urgencias no interferían en su actividad laboral.

Los usuarios inmigrantes indicaban, además, otras dificultades para lograr un acceso equitativo al sistema de salud, tales como la falta de información, la excesiva burocracia, y el desconocimiento de los lugares más apropiados para las diferentes demandas o de la oferta de servicios existente. De acuerdo con los autores del estudio, un gran número de los obstáculos mencionados iban superándose con el paso del tiempo mediante un mayor conocimiento del sistema, y gracias al apoyo y la información suministrada por las redes sociales y familiares de los usuarios inmigrantes. Cabe señalar que, como veremos más adelante en el análisis de los resultados de nuestra investigación, son muchas las barreras de acceso a las que se enfrentan actualmente los usuarios inmigrantes que coinciden con las mencionadas en el año 2007.

En relación con la prevención y la promoción de la salud por parte de la población inmigrante, el estudio manifestaba que existían diferencias dependiendo del lugar de origen de los usuarios, así como de los recursos y servicios sanitarios de los que previamente hubieran podido disponer. En líneas generales, se sostenía que las acciones preventivas para la salud por parte de los usuarios inmigrantes, así como su asistencia a las consultas de control y seguimiento de las patologías crónicas, eran bastante escasas. Entre las causas de esta escasez, se señalaban la diferente percepción de la salud y de la enfermedad, así como la necesidad de una curación relativamente rápida para poder continuar desempeñando sus actividades laborales. Estos datos coinciden en cierto sentido con los recolectados en nuestro trabajo de

\footnotetext{
193 Esta misma información en relación con el número considerable de IVEs practicadas en mujeres inmigrantes, principalmente procedentes de Rumanía, se verificará, como veremos más adelante, en nuestro trabajo de campo.
} 
campo, ya que, de acuerdo con los sujetos participantes en nuestro estudio y, en relación con el ámbito que nos ocupa, algunas usuarias inmigrantes (con sutiles diferencias según su procedencia) realizan un control irregular de sus embarazos, principalmente porque en sus países de origen el número de consultas durante la gestación es bastante inferior con respecto a las que se efectúan en España.

En cuanto a la información disponible a la hora de utilizar los servicios de salud, los usuarios inmigrantes, en el periodo inicial de su estancia en el país de acogida, de acuerdo con el estudio analizado, no sentían la exigencia de informarse sobre el funcionamiento de dichos servicios, pues presentaban en general otras necesidades y prioridades. En el momento en que debían acceder por primera vez, solían recurrir a redes sociales y familiares compuestas por personas que llevasen residiendo en este país más tiempo y, por tanto, dispusieran de un mayor conocimiento de los servicios. Los profesionales mencionados en el estudio, por su parte, indicaban que las mayores dificultades a la hora de informar a los usuarios inmigrantes estaban constituidas, en primer lugar, por las diferencias lingüísticas, seguidas de las relativas a la cultura sanitaria. Al respecto, sostenían que a menudo a estos usuarios les resultaba complicado comprender determinados términos y conceptos, como, por ejemplo, y citamos textualmente, "centro de salud, centro de especialidades, derivación, volante, consulta programada, cita, etc." (2007:66), los cuales, para los usuarios autóctonos, podían ser familiares, pero que no tenían un equivalente en algunos de los países de los que procedían los usuarios de origen extranjero. Asimismo, añadían que, en ocasiones, a estos últimos les costaba entender las funciones de los distintos profesionales sanitarios.

Sin embargo, en el documento se afirmaba que los inmigrantes que ya llevaban un tiempo residiendo en Aragón y contaban con experiencia en la utilización del sistema sanitario, realizaban un análisis similar al de los usuarios autóctonos. Los principales problemas que detectaban se encontraban en el funcionamiento de los servicios y, en concreto, se referían a la excesiva burocracia, los tiempos de espera en los servicios de urgencias y las consultas especializadas, así como otras carencias del sistema, de las que, por ejemplo, indicaban la atención odontológica.

En referencia a la relación profesional-usuario inmigrante, el documento analizado señalaba, en primer lugar, las dificultades para establecer una comunicación eficaz debido a las diferencias en el idioma. Nos llama la atención el hecho de que en el estudio se indicase que el obstáculo de las barreras lingüísticas podía superarse con la presencia de un intérprete ad hoc, y que el único problema que se viera en el uso de estos intérpretes fuera la posible falta de confidencialidad, tal y como puede observarse en la cita textual que mostramos a continuación. Al menos, en el documento analizado, se reconocía que, aun superando las barreras lingüísticas, continuaban existiendo otros posibles obstáculos relativos a las diferencias en la cultura sanitaria.

Si bien esta situación puede mejorarse con el acompañamiento de un familiar que hable español (aun con los problemas de confidencialidad que conlleva), sigue siendo difícil tanto para los pacientes expresar lo que sienten como para los sanitarios explicar e informar sobre determinados procesos, ya que, aun superado el problema del idioma, es diferente la forma de comprender e interpretar determinados signos, síntomas y formas de tratamiento. (2007:68) 
Los usuarios inmigrantes que participaron en este estudio indicaban, además, las posibles malas interpretaciones que podían producirse por las diferencias relativas a costumbres, creencias y hábitos en cuanto a la salud entre sus culturas de origen y la española. Señalaban, especialmente, las distintas formas de tratar las enfermedades, el recurso a la medicina tradicional y la automedicación, los hábitos alimentarios, la atención a mujeres por parte de profesionales varones, o cuestiones relacionadas con el pudor y la intimidad. Todos ellos son temas que, como se verá más adelante, abordamos en nuestra investigación.

Por lo que respecta a las diferencias en la atención recibida con respecto a los usuarios autóctonos, la percepción general de los usuarios inmigrantes mencionados en este documento era que el trato que se les ofrecía era igualitario, y no percibían que hubiera discriminación o racismo, salvo contadas excepciones constituidas por casos particulares y dependientes del carácter o la ideología del profesional sanitario.

De acuerdo con el estudio, tanto los profesionales sanitarios como los usuarios inmigrantes consideraban que su relación había mejorado considerablemente en los últimos años, tal y como puede observarse en la cita que incluimos a continuación:

Los profesionales ya no viven la llegada de inmigrantes con la extrañeza y la angustia del principio y, por su parte, los inmigrantes que ya llevan tiempo conocen el sistema y acompañan a los recién llegados facilitándose la comunicación. (2007:71)

Para finalizar el análisis de este documento, cabe señalar que el estudio señalaba, entre las oportunidades de mejora en la atención a usuarios inmigrantes, dos grandes áreas, que se centraban en la información y la comunicación respectivamente.

En relación con la primera de estas áreas, se proponía, por una parte, que se potenciara la figura de los administrativos como informantes en el sistema sanitario y, por otra, la creación de un punto de información centralizado en los hospitales y centros de salud al que los usuarios se pudieran dirigir en caso de desconocimiento o desorientación. En ambos casos, se trata de acciones de mejora de las que se beneficiarían tanto los usuarios inmigrantes como los autóctonos.

Sin embargo, el documento analizado no realizaba ninguna propuesta en firme que ayudara a mejorar la comunicación entre el personal sanitario y los usuarios inmigrantes, aparte de la mención al recurso de intérpretes ad hoc que hemos presentado previamente y la formación de los profesionales en claves culturales. Consideramos insuficientes estas propuestas y, en nuestra investigación, trataremos de aportar otras posibles soluciones a las dificultades comunicativas existentes en las interacciones interculturales en ámbito sanitario.

El tercer documento, el informe "Estado de Salud de Aragón: Determinantes y Actuaciones del Departamento de Salud y Consumo" (2010), elaborado por el Departamento Aragonés de Salud y Consumo y por el Servicio Aragonés de Salud, tenía como objetivo principal medir el estado de salud de los aragoneses, así como los determinantes que influían en dicho estado de salud. En particular, se proponía identificar y cuantificar las desigualdades que podían producirse en los diferentes aspectos relacionados con este ámbito, con el fin de proporcionar información para la toma de decisiones en los diferentes órganos de Gobierno. 
A pesar de que el informe en cuestión es bastante extenso (casi 300 páginas) y sus datos son algo más recientes que los presentados en el documento que acabamos de analizar (pues se refieren, en su mayoría, al periodo 2008-2009), este no incluía en sus múltiples apartados (demografía, estilo de vida, salud laboral, morbilidad percibida y registrada, etc.) un estudio pormenorizado o detallado. ${ }^{194}$ Por nuestra parte, echamos en falta en muchos casos la disgregación por nacionalidades o, en su defecto, la comparación entre la población autóctona y la extranjera. Comentaremos, por tanto, solo aquellos apartados y datos del informe relativos a la población inmigrante y que sean relevantes para los fines de nuestra investigación.

En primer lugar, en cuanto a la demografía, el informe señalaba que la población extranjera residente en Aragón había pasado en los últimos 12 años de tener un peso casi testimonial (0,6\% de la población en 1998) a suponer en 2009 un porcentaje considerable de la población total, en concreto, un $12,8 \%$, porcentaje superior al nacional en ese momento (12,1\%). De ese $12,8 \%$, el $7,1 \%$ eran hombres y el $5,7 \%$ mujeres. Asimismo, se indicaba que el porcentaje de extranjeros con Tarjeta Sanitaria Individual estaba en torno al $12 \%$.

En la pirámide de población presentada en el informe y relativa al año 2009 se observaba que la población extranjera era más joven (en torno a 30 años de media) que la nacional (43 años de media). El porcentaje de población extranjera en las edades superiores era muy pequeño. Por continentes, el mayor número de extranjeros procedía de Europa, seguido de Iberoamérica y África. Rumania, Marruecos y Ecuador eran en ese momento los países con más inmigrantes en Aragón.

En cuanto a la tasa bruta de natalidad y la tasa de fecundidad, se hacía referencia al crecimiento experimentado en ambos casos en los últimos quince años, pero sin señalar el porcentaje de hijos nacidos de padres extranjeros o de madres de origen extranjero. El único dato aportado al respecto se refería al año 2007, en el que, de acuerdo con el informe, se habían producido 2.808 nacimientos de madre extranjera, lo que suponía el $22 \%$ del total de nacimientos, cuando la población extranjera total ese mismo año constituía el $10 \%$ de la población total.

Uno de los apartados de este informe que, a nuestro parecer, resulta más interesante se refiere a las propuestas en él planteadas. A pesar de que tampoco en este apartado se realizaba una referencia explícita a los usuarios inmigrantes, consideramos que de dichas propuestas podrá beneficiarse toda la comunidad de usuarios y, por tanto, vemos pertinente mencionar aquellas que podrían suponer una oportunidad para contribuir a mejorar el estado de salud de la población inmigrante.

En primer lugar, en el informe se sostenía que la estructura demográfica y los movimientos naturales de la población, con la incorporación de personas procedentes de otros países, estaban condicionando los resultados en salud. Por este motivo, de acuerdo con los autores, era necesario que, en los servicios sanitarios, se compaginaran estrategias universales con

\footnotetext{
${ }^{194}$ De acuerdo con los propios autores del informe, la falta de detalles del mismo debía considerarse, más que como una restricción, como una oportunidad para realizar posteriores análisis del estado y los condicionantes de salud de los habitantes de Aragón a otros niveles. Y, precisamente dentro de estos posibles futuros estudios, podría enmarcarse nuestra investigación.
} 
estrategias específicas, dirigidas a colectivos concretos, entre los que podrían encontrarse, a nuestro parecer, los usuarios inmigrantes.

Además, con respecto a los hábitos que condicionan el estado de salud, se señalaban las diferencias existentes según sexo, niveles de ingresos o ámbito geográfico de estudio. El informe no mencionaba, por el contrario, posibles diferencias en los hábitos dependiendo del país o cultura de origen de los usuarios, factor que también puede ser determinante en relación con la salud.

Por otro lado, se planteaba la necesidad de reorientar las actuaciones fundamentalmente asistenciales hacia la promoción de salud y la prevención de la enfermedad, priorizando a los colectivos más vulnerables. Aunque no se menciona directamente a la población extranjera, quizás estas actuaciones de prevención y promoción deberían dirigirse, entre otros destinatarios, a los usuarios inmigrantes, ya que, tal y como se indicaba en el anterior documento analizado, estos suelen presentar, por lo general, una menor preocupación por promover su salud o por prevenir la enfermedad.

Asimismo, en el informe se aconsejaba mejorar los cauces de participación y de transparencia, favoreciendo los procesos de decisión de los ciudadanos sobre su salud. Este proceso también debía incorporar la idea de la corresponsabilidad en el uso de los servicios, y el refuerzo de los consejos de salud y de las redes sociales materiales y virtuales. Si el objetivo es que los usuarios inmigrantes aumenten su participación en los servicios sanitarios, realicen un uso adecuado de los mismos y sean capaces de tomar decisiones informadas sobre su salud, deberán reducirse o eliminarse las barreras de acceso y uso a las que, de acuerdo con los datos presentados previamente, parecen enfrentarse.

Por último, en el informe se hace referencia a documentos relevantes para nuestra investigación, como el "Plan de atención a la salud de la mujer" y la "Estrategia de atención al parto normal", pero que, por su carácter específicamente relacionado con la salud reproductiva, analizaremos en el siguiente apartado.

\subsubsection{Documentos relacionados con la salud reproductiva y la atención durante el parto}

En este apartado, como hemos comentado anteriormente, llevamos a cabo un análisis documental relacionado con el ámbito específico en el que se enmarca nuestra investigación, es decir, con la salud reproductiva. En primer lugar, estudiamos los siguientes documentos de carácter nacional ordenados cronológicamente: "Estrategia de atención al parto normal en el Sistema Nacional de Salud" (2007), "Maternidad Hospitalaria. Estándares y Recomendaciones" (2009), y "Estrategia Nacional de Salud Sexual y Reproductiva" (2011). Se trata en todos los casos de documentos oficiales de carácter nacional en los que se incluyen recomendaciones sobre las actuaciones y estrategias a desarrollar en el ámbito de la salud reproductiva y la atención al parto en los hospitales. En segundo lugar, nos ocupamos de otros documento del contexto autonómico aragonés; en concreto, analizamos el "Plan de atención a la salud de la mujer 2010-2012", el Plan de parto publicado por el hospital contexto de nuestro estudio, y el documento elaborado por el Instituto Aragonés de Servicios Sociales denominado"Maternidad responsable: Opciones y recursos ante un embarazo no planificado". 


\subsubsection{Actuaciones y estrategias nacionales en el ámbito de la salud reproductiva y la atención al parto}

El primer documento que analizamos es la "Estrategia de atención al parto normal en el Sistema Nacional de Salud" (EAPN), elaborado en 2007 por el Ministerio de Salud y Consumo. En él se exponen una serie de recomendaciones basadas en la evidencia y en investigaciones previas con el fin de potenciar la atención al parto normal en el sistema sanitario español, mejorando la calidad asistencial y manteniendo los niveles de seguridad.

Antes de pasar a analizar dichas recomendaciones, presentamos una serie de datos contextuales e introductorios contenidos en el documento estudiado. ${ }^{195}$

Por una parte, cabe considerar que, a pesar de que la tasa de natalidad había ido descendiendo en España desde 1970 hasta 1997, a partir de finales de la década de los noventa se produce un aumento progresivo de dicha tasa, pasando el número de nacimientos de 372.749 durante 1997 a 459.751 en 2004. Asimismo, en 2002, el número medio de hijos por mujer era de 1,26 (cifra que no se había alcanzado desde 1993), y en 2005 la tasa de fecundidad subió ulteriormente hasta 1,34 hijos por mujer. Estos incrementos en la natalidad y la fecundidad en España se deben fundamentalmente, de acuerdo con el documento analizado, a los nacimientos de madre extranjera, que han ido aumentando en los últimos años.

Por otra parte, en la EAPN se recuerda que el nacimiento es un proceso fisiológico y, por ello, se aconseja que en la atención al parto

[...] solo se debe intervenir para corregir desviaciones de la normalidad, y que las y los profesionales sanitarios que participan atendiendo el parto deben favorecer un clima de confianza, seguridad e intimidad, respetando la privacidad, dignidad y confidencialidad de las mujeres. (2007:34)

El documento se redacta en base a unos objetivos específicos, entre los que se encuentran los siguientes: aumentar la participación activa de las gestantes en la toma de decisiones informadas en la atención al parto; ofrecer cuidados individualizados basados en las necesidades de cada mujer, respetando sus decisiones, siempre que no comprometan la seguridad y el bienestar de la madre y la criatura; reorientar la formación del personal sanitario (en especialización y formación continuada) implicado en la atención al parto, para que sean capaces de incorporar los contenidos de esta estrategia en su trabajo diario; fomentar el desarrollo de investigaciones orientadas a mejorar los modelos de provisión de servicios para la asistencia al parto; y promover el uso de prácticas clínicas basadas en el mejor conocimiento disponible.

El objetivo último de la EAPN consiste en garantizar una atención al parto de calidad en todo el territorio español, de manera que todas las mujeres y sus parejas reciban en el Sistema Nacional de Salud la mejor atención, y participen de forma activa e informada en el todo proceso del parto.

\footnotetext{
195 Para mayor información, véase también el apartado del capítulo 1 dedicado al análisis de la población extranjera residente en España.
} 
Los objetivos y recomendaciones se estructuran en torno a unos ejes transversales con el fin de asegurar la equidad en la atención al parto.

Entre dicho ejes, quisiéramos destacar, por un lado, el eje de la multiculturalidad. Al respecto, en el documento se señalan, como ya hemos comentado previamente, el alto índice de fertilidad en la población inmigrante, responsable de entre el 20 y el 50\% de los partos que se producen en España, y los obstáculos con los que puede encontrarse este segmento de la población a la hora de acceder y utilizar los servicios sanitarios, que requieren actuaciones específicas centradas en la humanización y en la introducción de aspectos interculturales en la asistencia sanitaria. En la EAPN se indican algunas iniciativas puestas en marcha para reducir o eliminar dichos obstáculos (como el recurso a la mediación intercultural o la traducción de documentos informativos y guías). Sin embargo, estas iniciativas se consideran insuficientes, por lo que en el documento analizado se recomienda realizar investigaciones que ayuden no solo a detectar las desigualdades que padecen algunos colectivos en riesgo de exclusión (como puede ser la población inmigrante), sino que además propongan intervenciones para suprimir dichas desigualdades, ya que, de acuerdo con los autores de la EAPN, este tipo de publicaciones escasean, especialmente aquellas relativas a la atención durante el embarazo, el parto y el puerperio. Nuestra investigación cumple en parte con esta recomendación, pues, entre sus propósitos, se encuentra aportar datos y propuestas que ayuden a fomentar la asistencia igualitaria de las usuarias inmigrantes en el ámbito de la salud reproductiva.

Otro de los ejes que nos gustaría mencionar es el relativo a la perspectiva de género, desde la cual, se señala que el papel protagonista y responsable que vivían en el pasado las mujeres en el proceso del parto, contando con la experiencia y acompañamiento por parte de familiares, amigas y profesionales de sexo femenino, ha ido desapareciendo en la misma medida en que ha ido aumentando la medicalización y la intervención de los profesionales en dicho proceso. Así, en el documento analizado se afirma que

El parto ha pasado de ser un acontecimiento social compartido por la comunidad, en el que las mujeres contaban con el apoyo y experiencia de otras mujeres familiares, profesionales o amigas, a estar en manos de profesionales de la salud. La pérdida del protagonismo y control de las mujeres durante este proceso ha coincidido con el paso del mismo desde el hogar al centro sanitario, llevando a una mayor intervención sanitaria y a una invisibilidad de las mujeres. (2007:47)

En relación con este eje, en la EAPN se aborda de forma extensa el tema de la participación de la mujer en el proceso completo de parto, abogando por la misma, porque, entre otros aspectos, se considera que dicha participación mejora la salud integral de las mujeres, la relación entre profesionales y usuarias, y la satisfacción en general de todos los implicados.

Con el fin de que la participación de las mujeres sea realmente activa y estas puedan tomar sus propias decisiones, de acuerdo con el documento estudiado, es necesario que tanto ellas como sus familias conozcan en profundidad el proceso reproductivo por el que están pasando, se involucren en los cuidados recibidos, y tengan un papel protagonista durante el parto. Esto podrá lograrse en parte informando a las mujeres de forma adecuada, completa y en el momento oportuno de cuáles son las posibles intervenciones para obtener unos resultados óptimos durante el parto, de manera que estas puedan consensuar con el personal sanitario 
que las atiende cuáles son las conductas y cuidados que más se ajustan a sus preferencias, creencias y pautas culturales.

El acceso a la información es un derecho respaldado por el marco legal vigente (Ley 41/2002, de autonomía del paciente). De conformidad con esta Ley, la información proporcionada al paciente debe ser: a) completa, considerando las razones, los beneficios, los riesgos y los resultados; b) oportuna a las necesidades de las mujeres; c) comprensible en relación al lenguaje y al momento en que se da la información; y d) disponible en el formato adecuado.

Con el objetivo de garantizar la información, la EAPN (2007:51-52) aconseja, entre otras cuestiones:

- Asegurar y garantizar el acceso y comprensión de la información a las mujeres sobre el proceso fisiológico del parto y sobre el conocimiento disponible acerca de las diferentes prácticas clínicas en la atención al parto.

- Ofrecer a las mujeres información basada en la evidencia con la finalidad de permitirles tomar decisiones informadas de acuerdo a sus necesidades y expectativas.

- Respetar las decisiones que tome la mujer acerca de las actuaciones de su parto (por ejemplo, del plan de parto y nacimiento elaborado durante el embarazo) dentro del marco de seguridad y calidad en su atención.

- Garantizar el reconocimiento del derecho de la madre y el padre o tutor legal sobre cualquier decisión en relación a la criatura recién nacida.

- Desarrollar programas que estimulen a las mujeres a participar activamente en la toma de decisiones relativas al proceso del embarazo, parto y postparto.

- Investigar estrategias de difusión efectivas que permitan a las mujeres acceder a información suficiente, relevante y consistente a sus valores y creencias.

- Establecer los mecanismos para garantizar a todas las usuarias hacer uso de su derecho a tomar decisiones informadas en pleno conocimiento de los riesgos y beneficios de su situación de salud.

- Establecer programas de educación sanitaria que propicien la activa participación de la comunidad en temas sanitarios. Fomentar y estimular las asociaciones de usuarias como contribución importante para lograr la participación de las mismas.

- Consignar explícitamente las preferencias de las mujeres durante el proceso de toma de decisión.

Estas condiciones que garantizan una plena información y comprensión por parte de las usuarias, así como el respeto de sus decisiones y preferencias, probablemente no se ven cumplidas en el caso de las inmigrantes alófonas con conocimientos escasos o nulos de español, ya que estas no podrán entender las explicaciones de los profesionales sanitarios ni consensuar con ellos qué tratamientos o prácticas se consideran mejores en su caso. Así, tal y como se afirma en el documento analizado, 
Las mujeres embarazadas que carecen de información carecen también de la capacidad de opinar, discutir y decidir conjuntamente con los profesionales de la salud que las atienden. Esta capacidad de las usuarias contribuye a generar una relación más igualitaria, donde el debate se genera basándose en los conocimientos y expectativas de ambas partes (profesionales y mujeres embarazadas), pero con la inclusión de las necesidades y deseos de las usuarias. De este modo, las decisiones sobre las prácticas a utilizarse serán compartidas, consensuadas y asumidas co-responsablemente. (2007:48)

Por ello, en el documento analizado se recomienda también la introducción de mecanismos correctores de las barreras físicas, psíquicas, lingüísticas y culturales que dificultan la participación de las mujeres en la toma de decisiones y la activación de estrategias adecuadas que permitan a las personas con dificultades de comunicación acceder a la información y ejercer su derecho a participar activamente.

De todos modos, en la EAPN se señala que simplemente informar a las usuarias no es suficiente para garantizar su participación, sino que será igualmente necesario realizar un cambio sustancial en los actuales modelos de actuación e intervención durante el parto y en los momentos anteriores y posteriores al mismo.

Por este motivo, en este documento, tal y como hemos comentado previamente, se exponen una serie de recomendaciones, las cuales se encuentran clasificadas según el momento o el aspecto relativo al proceso reproductivo en los que pueden ser aplicadas. Estudiaremos solo aquellas que o bien podrían aplicarse en el caso de las usuarias inmigrantes (no exclusivamente, pues consideramos que las beneficiarias serían las usuarias en su conjunto, independientemente de sus orígenes y patrones culturales), o que están relacionadas con los fines de nuestra investigación, y dejaremos fuera de nuestro análisis las que se centran en aspectos muy generales o en aspectos médicos de carácter especializado.

Con respecto al acompañamiento durante todo el proceso de parto, este se considera fundamental para contribuir a la humanización de dicho proceso. Asimismo, de acuerdo con la evidencia, el acompañamiento contribuye a que las mujeres que disfrutan del mismo sean menos proclives a recibir analgesia o anestesia, tener partos vaginales instrumentales o por cesárea, y mostrar insatisfacción con la experiencia del parto.

De acuerdo con el documento analizado, sin embargo, la institucionalización y la medicalización progresivas del parto han contribuido a reducir los momentos de acompañamiento, ya que las estructuras físicas y las rutinas hospitalarias han sido diseñadas para atender más a las necesidades de los profesionales de la salud que a las parturientas y sus familias. De hecho, el rol del padre en el proceso de parto continúa viéndose como un posible "factor de riesgo" o, en todo caso, como un apoyo a la madre (o al profesional, cuando realiza funciones de intérprete ad hoc en el caso de las mujeres alófonas, como veremos en el análisis de los resultados de nuestra investigación), más que como un derecho.

En cuanto a la cuestión del acompañamiento, la EAPN recomienda, por consiguiente, que se permita e incluso se aliente a todas las madres para que estén acompañadas ininterrumpidamente durante todo el proceso de parto, desde las fases iniciales del mismo, y que sean ellas mismas quienes decidan libremente quién será la persona que las acompañe. 
Por otra parte, por lo que se refiere al periodo específico de dilatación, se incluyen las siguientes recomendaciones (2007:38-39):

- Informar previamente a las mujeres sobre los diferentes métodos para el alivio del dolor, sus beneficios y potenciales riesgos.

- Informar a las mujeres de la capacidad cerebral de producir sustancias analgésicas (endorfinas) en un parto fisiológico en condiciones de intimidad.

- Informar sobre los riesgos y consecuencias de la analgesia epidural para la madre y la criatura.

- Ofrecer a las mujeres la posibilidad de elegir uno o varios métodos, si lo desean.

- Para aquellas mujeres que no desean emplear fármacos durante el parto, se deberá informar sobre la evidencia de otros métodos alternativos disponibles.

- Considerar la aplicación de la anestesia epidural sin bloqueo motor.

- No realizar analgesia de rutina.

Con relación a las recomendaciones que acabamos de presentar y, más concretamente aquellas concernientes a la información y al derecho a decidir autónomamente que método analgésico se desea utilizar durante el parto, no podrán probablemente seguirse en el caso de las usuarias alófonas, a menos que se eliminen las barreras lingüísticas que les impiden su comunicación con el profesional.

Nos gustaría señalar, además, la recomendación relativa a la posible aplicación de la anestesia epidural sin bloqueo motor, que favorecería a aquellas usuarias inmigrantes (y autóctonas) que prefieran caminar en el periodo inmediatamente anterior al parto, algo que no les resulta posible, como veremos en el análisis de los resultados del trabajo de campo, en el momento en que se les suministra la anestesia epidural.

Por último, en cuanto a la recomendación de no emplear la analgesia de modo rutinario, cabe señalar que, en el contexto objeto de nuestro estudio, si bien no sabemos si su suministro constituye una rutina, sí podemos constatar, por los datos de los que disponemos, ${ }^{196}$ que el número de analgesias practicadas es creciente y elevado, por lo que deducimos que se trata de una práctica bastante habitual.

En relación con el expulsivo durante el parto, a pesar de que en el documento analizado se advierte de que no se dispone de datos clínicos rigurosos, se exponen, entre otras, las siguientes recomendaciones (2007:40):

- Permitir que las mujeres adopten la postura que espontáneamente prefieran.

\footnotetext{
196 Incluimos en los anexos una serie de gráficos relativos al año 2011 en los que se indica, entre otras cuestiones, el número de partos atendidos, si estos han sido vaginales o por cesárea, y el número de analgesias practicadas en el hospital contexto de nuestro estudio. Como hemos comentado previamente, consideramos que habría resultado muy enriquecedor para nuestra investigación el poder disponer de estos mismos datos pero incluyendo la disgregación por nacionalidad de la madre; sin embargo, desde el centro de documentación del hospital no pudieron atender a esta solicitud por no disponer de esos datos específicos.
} 
- Decidir libremente qué posición adoptar durante todo el proceso, incluido el expulsivo.

- Capacitar a profesionales de la atención al parto en las diferentes posiciones.

- Investigar las percepciones de las mujeres y los factores que influyen en la elección de las posiciones que adoptan.

La mayoría de los hospitales españoles no disponen de espacios adecuados ni de profesionales capacitados para cumplir con estas recomendaciones, por lo que se suele solicitar a la parturienta que adopte una postura supina estándar (posición de litotomía) que facilite la labor de apoyo al expulsivo por parte del personal sanitario. Sin embargo, en numerosas culturas, tal y como hemos comentado en el capítulo 4, centrado en los patrones culturales relacionados con la salud, las parturientas prefieren adoptar otras posturas verticales, bien sentadas o en cuclillas, aunque en el sistema de salud público de España casi nunca resulta posible atender a estas preferencias. ${ }^{197}$

A pesar de que los partos con complicaciones no son objeto de análisis en la EAPN, en ella se mencionan algunas pautas relativas al parto instrumental y el parto por cesárea por la interrelación existente, ya que se considera que, si se siguen las recomendaciones presentadas en la Estrategia, este tipo de partos deberían ser menos frecuentes.

En primer lugar, se aconseja respetar el tiempo necesario para el expulsivo y evitar los partos instrumentales, salvo indicación por patología.

En cuanto a las cesáreas, de acuerdo con los indicadores establecidos por la Organización Mundial de la Salud en relación con la calidad de la atención en el parto, estas no deberían superar el $15 \%$ del total de partos, y deberían practicarse solo en aquellos casos con complicaciones potencialmente peligrosas para la salud maternal y neonatal. Por el contrario, en España y otros países europeos, se ha producido progresivamente un incremento del número de partos por cesárea, debido en parte, pero no solo, al aumento de la edad de las madres, al mayor número de partos múltiples, y a las demandas personales de algunas usuarias. En el hospital contexto de nuestro estudio, de acuerdo con los datos de los que disponemos, el año 2011 fue el primero desde 2005 en el que no se superó ese porcentaje; en concreto, en dicho año, el $14,74 \%$ del total de partos atendidos fueron por cesárea, cuando en los seis años precedentes dicho porcentaje había superado el $16 \%$.

En relación con el parto por cesárea, en la EAPN se recomienda, entre otras cuestiones, investigar las causas del incremento de las tasas de este tipo de parto y de su variabilidad, facilitar el acceso de la persona acompañante en la medida de lo posible (teniendo en cuenta que en el ambiente quirúrgico en el que se practica se persiguen unas condiciones de extrema

\footnotetext{
${ }^{197}$ Existe un número limitado de hospitales españoles que han sido acreditados con la certificación iHan (Iniciativa para la Humanización de la Asistencia al Nacimiento y la Lactancia), promovida por la Organización Mundial de la Salud y UNICEF. Dichos hospitales deben superar un proceso en el que demuestren, entre otros requisitos, que cumplen con las recomendaciones de la "Estrategia de Atención al Parto Normal". En el contexto aragonés, el único hospital que cuenta con esta certificación es el Hospital de Barbastro. En el territorio nacional, entre otros, están acreditados el Hospital Costa del Sol de Marbella, el Hospital 12 de Octubre de Madrid, o el Hospital Virgen del Castillo de Murcia. Para mayor información, visítese la página web: [http://www.ihan.es/index1.asp] (última consulta: 8 de julio de 2013).
} 
higiene y asepsia), e implementar programas para la racionalización de las tasas de cesáreas y la disminución de su variabilidad no justificada.

Por lo que se refiere al contacto entre la madre y el recién nacido, en el documento analizado se recomienda que dicho contacto se establezca lo más precozmente posible, ya que se considera que favorece la lactancia materna. Concretamente, se sostiene que colocar al recién nacido sobre el vientre y el pecho de la madre (en decúbito prono), piel con piel, pone en marcha los reflejos de búsqueda del pecho por parte de la criatura y favorece una correcta succión de la leche materna. Se señalan además otros efectos beneficiosos de este contacto, como, por ejemplo, una recuperación más rápida del estrés provocado en el recién nacido, una normalización anterior de los índices de glucemia y la temperatura, así como un aumento del vínculo entre la madre y el hijo, que podría traducirse en una mayor duración de la lactancia materna y, en general, en una vivencia emocional más positiva del nacimiento.

Las recomendaciones relativas al contacto precoz contenidas en el documento analizado son, entre otras (2007:43-44):

- La criatura recién nacida sana y su madre deben permanecer juntos tras el parto y no separarse en ningún momento si el estado de salud de la madre lo permite.

- Inmediatamente después del parto, la criatura recién nacida se coloca sobre el abdomen de la madre, se la seca y se cubre con una toalla seca. Así se agarrará al pecho de forma espontánea en la mayoría de los casos, permaneciendo al menos 70 minutos en estrecho contacto piel con piel con su madre.

- Los únicos procedimientos que se realizarán a la criatura recién nacida durante este tiempo de contacto piel con piel con su madre, son su identificación y la adjudicación de la puntuación del test de Apgar. ${ }^{198}$

- Informar a las madres sobre las ventajas del contacto piel con piel.

- Posponer las prácticas de profilaxis ocular, peso, vitamina K, etc., al finalizar el contacto precoz, intentando realizar todos los procedimientos en presencia de las madres y padres, $\mathrm{y}$ tras su consentimiento.

- Si el estado de salud de la madre no lo permite, se ofrecerá al padre la posibilidad de que haga el contacto piel con piel con su criatura.

No obstante los potenciales beneficios, en la EAPN se afirma que este proceso de contacto no debe forzarse, sino que tendría que ser espontáneo. Por ello, consideramos que, en los casos en los que la madre no sea partidaria de establecer este contacto precoz (como sucede en algunas culturas, tal y como hemos señalado en el capítulo 4), se debería respetar esta decisión.

\footnotetext{
${ }^{198}$ El test de Apgar es un examen rápido que se realiza a los bebés en los minutos 1 y 5 tras su nacimiento. En él se miden una serie de valores, como la frecuencia cardíaca, el esfuerzo respiratorio, el tono muscular o el color de la piel, con el fin de conocer la tolerancia y la evolución del recién nacido. Fuente de la definición: MedlinePlus Servicio de la Biblioteca Nacional de Medicina y los Institutos Nacionales de Salud de EE.UU. [http://www.nlm.nih.gov/medlineplus/spanish/ency/article/003402.htm] (última consulta: 10 de agosto de 2013).
} 
Por lo que respecta al periodo del postparto inmediato, de acuerdo con la EAPN, este es un momento de vital importancia tanto para establecer vínculos afectivos a nivel familiar (madrepadre-recién nacido), como para favorecer la lactancia materna. Por ello, en ella se aconseja reducir los procedimientos médicos y de enfermería (frecuentes en el momento tras el parto) para favorecer el contacto físico y la interacción desde poco después del nacimiento y, al menos, durante dos horas. Con este propósito, se recomienda, entre otras cuestiones (2007:45):

- Abandonar los procedimientos injustificados y retrasar la realización de los procedimientos necesarios pero que supongan separar a la criatura de su madre.

- En el caso de las criaturas recién nacidas hospitalizadas, rodearlas de un ambiente cómodo y placentero, lo más semejante a un hogar para ellas y sus familias, y facilitar la política de Unidades Neonatales abiertas a madres y padres las 24 horas.

- Solicitar el consentimiento de las madres para cualquier procedimiento que interfiera con la lactancia materna (administración de sueros, biberones, etc.).

En cuanto a la lactancia materna, de acuerdo con el documento estudiado, son numerosas las investigaciones que demuestran sus múltiples beneficios tanto para la madre como para el recién nacido, entre los que se encuentran, por lo que se refiere a este último, la reducción de otitis, gastroenteritis, infecciones respiratorias, dermatitis, asma, obesidad, diabetes, leucemia, enterocolitis y síndrome de muerte súbita y, en referencia a la madre, la reducción del riesgo de padecer diabetes, cáncer de mama y ovario, además de los aspectos afectivos y psicológicos que afectan positivamente a ambos.

Por consiguiente, con el fin de favorecer la lactancia materna, en la EAPN se presentan las siguientes recomendaciones (2007:45-46):

- Promover prácticas eficientes en el apoyo a la lactancia materna.

- Facilitar a cada madre la posibilidad de la lactancia materna, su extracción, conservación y mantenimiento para la administración al recién nacido de la leche de su propia madre.

- Fomentar la donación de leche de madre y la puesta en marcha de Bancos de Leche.

- Respetar la decisión informada de las mujeres que opten por la lactancia artificial.

- Dar información adecuada y desarrollar habilidades sobre lactancia artificial a las madres que así lo decidan.

En relación con los fines de nuestra investigación, cabe señalar que, en los casos en los que las usuarias procedentes de otras culturas desconozcan los beneficios aportados por la leche materna o, de acuerdo con sus creencias y hábitos, prefieran la lactancia artificial, se deberá llevar a cabo una minuciosa labor de información y sensibilización, respetando en todo caso la decisión final de la madre. Asimismo, quisiéramos destacar el caso de algunos colectivos, como puede ser el conformado por las usuarias de religión musulmana, las cuales, por respeto a los preceptos del Islam, son muy favorables a la lactancia materna, incluso hasta alcanzar periodos de unos dos años desde el nacimiento. 
Por lo que se refiere al hospital contexto de nuestro estudio, como podrá verse en el análisis de los resultados del trabajo de campo, se cumplen la mayoría de las recomendaciones relativas a la lactancia materna, pues, aunque esta se aconseja y se trata de dar la mayor información posible sobre sus beneficios, no se suele imponer en los casos en los que las madres optan por la lactancia artificial. Asimismo, el hospital colabora, como hemos comentado previamente, con la campaña denominada la Gota de Leche, mediante la que se suministra este alimento a los recién nacidos a los que no sea posible suministrar leche materna.

Para finalizar el análisis de la "Estrategia de atención al parto normal", quisiéramos resaltar algunos aspectos contenidos en la misma. En primer lugar, consideramos que, para poder implementar las recomendaciones que la EAPN plantea, será necesario formar y capacitar a los profesionales, así como modificar en cierto sentido las estructuras y prácticas hospitalarias.

Asimismo, resulta importante conocer y difundir las buenas prácticas en relación con la atención al parto que se efectúen en hospitales y centros de salud, de manera que sea posible la transferencia de conocimiento y la replicación de dichas prácticas en otros centros sanitarios y se puedan incluir en los planes formativos.

Por último, cabe señalar que, de acuerdo con la EAPN, los estudios de corte cualitativo (como es el caso de nuestra investigación) pueden contribuir a mejorar sustancialmente la calidad de la atención al parto, pues en este tipo de estudios se suelen tener en cuenta "las necesidades de las mujeres en función de sus capacidades físicas, intelectuales o sensoriales, en relación a sus distintas culturas, costumbres y afectos, y desde una perspectiva de género" (2007:47).

El segundo documento que estudiamos se denomina "Maternidad Hospitalaria. Estándares y Recomendaciones" (2009) y fue elaborado por el Ministerio de Sanidad y Política Social. Se trata de un documento extenso en el que se recogen una serie de recomendaciones elaboradas desde la Agencia de Calidad del Sistema Nacional de Salud con la colaboración de expertos vinculados con asociaciones científicas, en el marco establecido mediante la "Estrategia de atención al parto normal" aprobada en 2007 que acabamos de presentar. Dichas recomendaciones presentan muchos de los aspectos ya incluidos en la mencionada Estrategia, y tratan fundamentalmente sobre derechos y seguridad del paciente quirúrgico y sobre criterios organizativos y de gestión de la maternidad hospitalaria. No poseen carácter normativo, y su objetivo es poner a disposición de las administraciones públicas sanitarias, de los gestores (tanto públicos como privados) y de los profesionales todos aquellos elementos que pueden contribuir a mejorar las condiciones de seguridad y calidad de la atención hospitalaria al parto.

Cabe resaltar, en primer lugar, la definición ofrecida en el documento analizado de maternidad hospitalaria, considerada como

[...] una organización de profesionales de la sanidad, que ofrece asistencia multidisciplinar a la mujer, al ser recién nacido/a y a la familia en el parto y el nacimiento, y que cumple unos requisitos funcionales, estructurales y organizativos, de forma que garantiza las condiciones adecuadas de seguridad, calidad y eficiencia, para realizar esta actividad. (2009:32) 
En cuanto a las estrategias y recomendaciones, el documento recuerda que la toma de decisiones informadas sobre el parto por parte de las mujeres es un derecho y un elemento clave para garantizar la calidad de la atención e incorporar a la misma una dimensión afectiva y familiar. Asimismo, aconseja que tanto la información durante el seguimiento del embarazo como la que se proporciona en el momento de acogida a la maternidad hospitalaria incluya una descripción completa de la evolución del parto en sus diferentes fases, y que contenga, además, todas las advertencias y consejos necesarios.

Al respecto, nos gustaría señalar una vez más la dificultad para garantizar, en el caso de las usuarias alófonas con escasos o nulos conocimientos de español, que estas reciban información adecuada y suficiente sobre el proceso fisiológico del embarazo y del parto y puedan, por consiguiente, decidir de qué manera desean llevarlos a cabo.

También emite recomendaciones sobre el consentimiento informado $y$, en referencia al mismo, señala que la parturienta puede encontrarse en una situación de gran vulnerabilidad física y psíquica y tener en el momento del parto dificultades para expresar sus deseos y necesidades. Por este motivo, se recomienda a los profesionales sanitarios que se esfuercen por facilitar la expresión de estas necesidades y se aseguren de que las decisiones adoptadas por la madre cumplen con las garantías suficientes en cuanto a información y libertad de elección. Como veremos en el análisis de los resultados de nuestra investigación, dichas garantías no siempre se ven atendidas en el caso de las usuarias inmigrantes, pues, a pesar de que se dispone de consentimientos informados traducidos a los idiomas más frecuentes de los colectivos procedentes de otros países y residentes en Aragón, por ese estado vulnerable en el que se encuentran las mujeres durante el parto, no siempre leen atentamente el consentimiento antes de firmarlo $y$, por las dificultades para comunicarse con los profesionales, ni estos pueden darles ulteriores explicaciones y aclaraciones, ni las usuarias pueden plantearles sus dudas e inquietudes.

Por otro lado, el documento estudiado establece una serie de recomendaciones relativas a la libre elección de la postura durante el parto. En concreto, sostiene que la cama de partos debe permitir a la parturienta colocarse en la posición que le resulte más cómoda, y que debe contemplar la posibilidad de transformar su posición, pasando de ser horizontal a convertirse en un sillón obstétrico apto para el parto vertical. Asimismo, aconseja que, para aquellas mujeres que prefieran no dar a luz en la cama, la sala de partos debería diseñarse de forma que resultara sencillo cambiar el mobiliario conforme a las preferencias individuales y para que pudiera efectuarse no solo el parto en la posición horizontal estándar, sino también en posición erguida o en cuclillas. Ya hemos comentado en el análisis del anterior documento que estas recomendaciones en cuanto a la libre elección de la postura del parto son difícilmente aplicables en las estructuras hospitalarias actuales.

Por lo que respecta al alivio del dolor, en el documento analizado se recomienda que se permita a la parturienta, según lo desee, deambular o permanecer tumbada, así como recibir anestesia/analgesia epidural u otro medio para aliviar el dolor. Se establece, además, que la capacidad de elección solo estará condicionada por la disponibilidad de la opción que la parturienta haya escogido o por aspectos relacionados con una buena praxis, y que, en todo caso, la usuaria puede negarse a recibir el tratamiento analgésico recomendado (lo que se 
conoce como "rechazo informado"). También en este caso dudamos sobre si las usuarias que no dispongan de suficientes conocimientos de español o aquellas que procedan de países donde la anestesia epidural no sea un procedimiento estándar podrán comprender las recomendaciones médicas, tomar decisiones estando debidamente informadas o expresar sus voluntades en cuanto a los métodos (analgésicos o alternativos) para aliviar el dolor.

Por último, el documento hace especial hincapié en los protocolos y sistemas de seguridad y, al respecto, señala que las usuarias de las maternidades hospitalarias deben tener un papel activo en la mejora de su seguridad, por lo que se les debe informar e implicar en sus cuidados y garantizar su participación activa en las decisiones que tomen sobre su tratamiento.

El tercer documento que analizamos es la "Estrategia Nacional de Salud Sexual y Reproductiva" (ENSSR), elaborada en 2011 por el Ministerio de Sanidad, Política Social e Igualdad en colaboración con el Observatorio de Salud de las Mujeres.

El objetivo principal de este documento consiste en ofrecer una atención global, continuada, integral y de calidad al proceso reproductivo en el Sistema Nacional de Salud, basada en el mejor conocimiento disponible, centrada en las necesidades y circunstancias de las usuarias, y orientada a promover una vivencia humana, íntima y satisfactoria para las mujeres, sus parejas, sus bebés y demás familiares.

Asimismo, la ENSSR presenta una serie de objetivos específicos que recogen la mayoría de los objetivos de los dos documentos previamente analizados $y$, asimismo, los complementa con cuestiones relativas no solo al proceso de parto y atención hospitalaria, sino también a otras fases y procesos de la salud reproductiva. En concreto, los objetivos específicos planteados en este documento son (2011:88-89):

1. Promover la salud, el bienestar y autonomía de las mujeres embarazadas. Facilitar adecuadamente su implicación en el proceso fisiológico y en sus cuidados, y proporcionar una atención adaptada a las necesidades y circunstancias de cada mujer y pareja.

2. Potenciar la atención al parto normal. Mejorar la calidad y calidez asistencial, favoreciendo el clima de confianza, seguridad e intimidad de las mujeres, apoyado y respetado por los y las profesionales, manteniendo los niveles de seguridad actuales.

3. Mejorar las condiciones del nacimiento. Orientar la atención al bienestar del bebé, su adecuada adaptación a la vida extrauterina, el establecimiento del vínculo afectivo, la lactancia materna y los cuidados centrados en el desarrollo y las familias.

4. Promover la salud y bienestar de las mujeres puérperas. Continuar la atención facilitando asesoramiento y cuidados, explorando sus necesidades, cambios emocionales y psicológicos, y situación del vínculo, la lactancia y el apoyo de la pareja.

5. Impulsar los aspectos que deben contemplarse de manera transversal en todo el proceso. Destacar la importancia de la formación de profesionales, la participación de las mujeres y sus parejas (considerando la multiculturalidad y la discapacidad), la coordinación institucional, y la investigación y difusión de buenas prácticas. 
6. Impulsar un cambio en los valores sociales en torno a la maternidad y la paternidad, que tradicionalmente se concretan en exigencias inalcanzables para las madres y en la tolerancia de una escasa implicación paterna.

El documento analizado contiene una introducción en la que se recogen datos relacionados con la salud reproductiva en España procedentes de la Encuesta Nacional de Salud (ENS), del Movimiento Natural de la Población del Instituto Nacional de Estadística (INE), de la Organización Mundial de la Salud (OMS), y de otras investigaciones realizadas sobre este tema, de los cuales resaltaremos aquellos que resultan de interés para nuestra investigación.

En primer lugar, en cuanto a la tasa de natalidad en España, se comenta también en este documento que esta había ido disminuyendo desde mediados de los años setenta, debido principalmente al mayor acceso de la mujer a la educación, su incorporación al mercado laboral y la legalización, en 1978, de los métodos anticonceptivos. A partir de principios del siglo XXI comienza una recuperación de la tasa de natalidad, en parte debido a la contribución de las madres de origen extranjero residentes en España. Así, de acuerdo con datos disponibles, el número de nacimientos en España pasó de 466.371 en el año 2005 a 492.527 en 2007, lo que supuso un aumento en dos años del 5,6\%. Por lo que respecta al contexto aragonés, fueron 12.589 en 2007, frente a 11.628 en 2005. El número de nacimientos de madre extranjera en España ha experimentado un mayor ascenso con respecto a los de madre autóctona; de hecho, en 2005 fue de 70.259 y alcanzó la cifra de 93.486 en 2007, representando un aumento del $33 \%$, mientras que los de madre española se han estabilizado desde 2005.

La media de edad de las mujeres al dar a luz, independientemente de si es el primer hijo/a o no, aumentó en los años 80 y 90, pero se ha estabilizado alrededor de los 31 años en este siglo. En cuanto al primer nacimiento, la edad media de las mujeres también ha seguido un patrón semejante, aunque con cifras algo inferiores, siendo en el año 2007 de 29,43 años. Veremos en nuestro trabajo de campo cómo las mujeres primíparas de origen extranjero (especialmente en el caso de las latinoamericanas) suelen presentar una edad media inferior a la de las autóctonas.

A continuación, en la ENSSR se explica brevemente el enfoque de la salud sexual y reproductiva desde una perspectiva de género, y se pasa a presentar dos bloques independientes y diferenciados que se ocupan de la salud sexual, por una parte, y de la salud reproductiva, por otra. Atendiendo a los fines de nuestra investigación, centraremos el análisis de este documento solo en el segundo de los bloques mencionados.

En dicho bloque se presentan las líneas estratégicas específicas para embarazo, parto, neonatal y puerperio, así como las transversales, que se corresponden con los principales aspectos que deben observarse integralmente en todo el proceso reproductivo. En concreto, las líneas estratégicas son las siguientes:

Línea estratégica 1: Promoción de la salud en el embarazo

Línea estratégica 2: Atención sanitaria en el embarazo

Línea estratégica 3: Atención al parto. 
Línea estratégica 4: Cuidados del nacimiento a la primera semana de vida

Línea estratégica 5: Promoción de la lactancia materna

Línea estratégica 6: Cuidados del recién nacido hospitalizado

Línea estratégica 7: Cuidados propios del puerperio

Línea estratégica 8: Atención sanitaria en el puerperio

Línea estratégica 9: Formación de profesionales

Línea estratégica 10: Participación de las mujeres y las parejas

Línea estratégica 11: Coordinación institucional

Línea estratégica 12: Investigación, innovación y buenas prácticas

En cada una de las líneas estratégicas se plantean una serie de objetivos y recomendaciones que, a grandes rasgos, giran en torno al derecho a la información, el respeto a las necesidades, las características, los deseos y las elecciones de la madre, la importancia de que el profesional desarrolle una relación de confianza y empatía con la mujer embarazada, y la implicación y participación de esta y su familia (especialmente su pareja) en todo el proceso reproductivo.

Por lo que respecta a la información, a modo de ejemplo, incluiremos algunos fragmentos concretos del documento analizado en los que se indica expresamente que esta debe proporcionarse de manera completa y adecuada a la madre. En concreto, en la ENSSR, se realizan, entre otras, las siguientes recomendaciones:

- Informar sobre las medidas de prevención de infecciones de transmisión sexual (ITS) tanto a la mujer como a la pareja. (2011:91)

- Informar e identificar de forma temprana a las mujeres con factores de riesgo, problemas de salud, complicaciones del embarazo o anomalías fetales con el objeto de minimizar sus consecuencias. (2011:93)

- Informar a la mujer verbalmente y por escrito del contenido de cada visita. (2011:94)

- Durante la gestación, se debe ofrecer información suficiente y actualizada sobre los métodos disponibles de alivio y tratamiento del dolor durante el parto. Se informará sobre los métodos no farmacológicos, sobre los métodos farmacológicos y sobre la analgesia epidural. [...] Es conveniente entregar en la consulta información escrita, además de la verbal, acerca de todo lo anterior, explicando claramente las ventajas e inconvenientes de cada método. (2011:94)

- Todas las mujeres embarazadas deben recibir información suficiente y actualizada sobre la importancia del amamantamiento y los riesgos de no amamantar, además de formación sobre cómo favorecer el inicio y el establecimiento de la lactancia tras el parto. (2011:94)

- Acordar un programa individual de preparación para el embarazo, parto, nacimiento y crianza [...], proporcionando información adecuada acerca de todo el proceso. (2011:96) 
- Informar a las madres, padres y personas cuidadoras que deseen alimentar a sus bebés con leche de fórmula sobre la mejor manera de hacerlo para garantizar que la alimentación con sucedáneos de leche materna se realice de la manera más segura posible, con el fin de fomentar el desarrollo y salud infantil y cubrir sus necesidades nutricionales. (2011:120)

- Proporcionar consejo contraceptivo y desmontar falsos mitos y creencias. (2011:129)

Continuamos preguntándonos de qué manera una usuaria alófona sin conocimientos suficientes de español podrá ser debidamente informada o informar ella misma al profesional sanitario sobre su estado físico y psíquico, y de qué manera repercutirá esta falta de información en la toma de decisiones por su parte o en la salud de la madre y el bebé. Asimismo, la usuaria que se encuentre con problemas comunicativos, no podrá expresar sus dudas, miedos e inquietudes.

Al respecto, en el documento estudiado se recogen una serie de indicaciones, como, entre las que cabría destacar la capacitación del personal sanitario y auxiliar de los servicios sanitarios para mejorar la comunicación con las mujeres y familias.

En relación con la atención personalizada, que responda a las necesidades y elecciones de la madre, aunque todavía queda un largo camino por recorrer en este sentido (pues, como hemos comentado anteriormente, en ocasiones, la estructura y las rutinas del hospital, así como la formación recibida por parte de los profesionales que en él trabajan, impiden una mayor individualización de aspectos como los métodos analgésicos para calmar el dolor o la postura adoptada durante el parto), consideramos acertado que se solicite realizar un esfuerzo por respetar las características del proceso reproductivo de cada madre, algo de lo que se beneficiarían no solo las usuarias inmigrantes, sino también las autóctonas.

Entre las recomendaciones concretas que incluye la ENSSR relativas a la atención personalizada, se encuentran:

- Conocer el estado de salud de cada mujer, su reacción física y psíquica a factores de estrés, los rasgos básicos de su personalidad y antecedentes, individualizar sus peticiones y elecciones. (2011:90)

- Se explicará el objetivo de la atención al dolor en el parto, [...] tratándolo de forma individualizada según la libre elección de cada mujer. (2011:94-95)

- Responder a las expectativas y circunstancias de cada mujer y pareja y promover la autonomía y el desarrollo personal de la embarazada (empoderamiento) con el apoyo de la pareja. (2011:96)

- Acordar un programa individual de preparación para el embarazo, parto, nacimiento y crianza que facilite una vivencia satisfactoria de la experiencia. (2011:96)

En la ENSSR se resalta, además, como hemos comentado, la importancia de que el profesional desarrolle una relación de confianza y empatía con la mujer embarazada, con el fin de identificar sus opiniones, inquietudes y expectativas. La creación de un clima de confianza y comprensión mutua evitará que la madre viva situaciones de estrés, que, por la ansiedad que 
generan en la madre, podrían perjudicar el desarrollo y estado de salud del bebé. De hecho, en el documento analizado se aconseja

- Desarrollar una relación de confianza y de empatía con la mujer embarazada, explorando sus ideas, preocupaciones y expectativas, asegurándose de que comprende los consejos o directrices proporcionadas y valorando el compromiso por parte de la pareja. (2011:91)

- Cuidar la comunicación verbal y no verbal al inicio y durante la exploración ecográfica, para reducir la ansiedad de la mujer y su pareja, que pueden interpretar cualquier gesto o palabra como indicio de patología. Explicar que lo habitual es que el bebé esté sano, y ofrecer la información durante la prueba y/o al final de ésta en lenguaje claro y comprensible. (2011:9798)

- Tranquilizar y transmitir confianza a la madre cuando el volumen de calostro materno sea insuficiente informando sobre las medidas que le ayudarán a aumentar su producción. (2011:129)

Y, en cuanto a la implicación y participación activa de las mujeres y sus familias, cabe señalar, en primer lugar, que esta no será posible si no existe una comunicación efectiva entre la usuaria y los profesionales que la atienden. Así, en el documento analizado se afirma que

Para que exista una participación real de las mujeres y sus parejas es necesario que dispongan de información global sobre el proceso, de información específica acerca de cada una de las etapas y sobre las posibilidades y recursos existentes para la toma de las decisiones más acertadas y su implicación en el desarrollo del proceso. Además, deben contemplarse las circunstancias específicas de cada mujer y pareja, como son la multiculturalidad y la discapacidad, que requieren una atención concreta. (2011:140)

Mención aparte merecen aquellos puntos del documento en los que implícita o explícitamente se hace referencia a las usuarias inmigrantes, entre los que cabría destacar los siguientes:

Por lo que se refiere a la atención de los colectivos en una situación más vulnerable, entre los cuales se menciona a las usuarias inmigrantes, de acuerdo con la ENSSR, se deberían eliminar las barreras derivadas de las necesidades específicas de mujeres de otras culturas y con diferentes capacidades, así como evitar la adopción de medidas especiales que puedan discriminar.

Además, al exponer las cuestiones transversales y, más concretamente las relativas a la formación de los profesionales sanitarios, aparte de la mencionada capacitación de estos para mejorar su comunicación con las usuarias, el documento analizado recomienda que se les facilite información sobre las necesidades y problemas específicos que tienen las mujeres inmigrantes o de otras culturas.

Por último, en cuanto a la atención específica a la multiculturalidad, la ENSSR plantea las siguientes recomendaciones, que, por su estrecha relación con los fines de nuestra investigación y por considerarlas notablemente acertadas, incluimos íntegramente a continuación (2011:146-147): 
- Asegurar una atención adecuada a las mujeres inmigrantes y sus parejas en el proceso, facilitando su participación, contemplando las particularidades de cada caso y disponiendo de los medios adecuados para minimizar las posibles barreras culturales e idiomáticas.

- Ofrecer atención específica según las diferentes necesidades de las mujeres por su cultura, idioma, distinta capacidad, creencias o experiencias previas.

- Disponer de los protocolos de atención que definan las actuaciones necesarias en estos grupos de mujeres, evitando tomar medidas que puedan significar discriminación. Más que generar recursos especiales, se tratará de normalizar la atención de calidad, ya que en la medida en que las usuarias en general sean bien atendidas, también lo estarán las personas inmigrantes.

- Facilitar materiales informativos (vídeos, folletos, pictogramas, etc.) en los distintos idiomas para facilitar la comunicación y asegurar la comprensión de lo que sucede. Contemplar otros posibles recursos, como la traducción simultánea ${ }^{199}$ y la mediación cultural.

- Potenciar la comunicación ayudando a desarrollar habilidades de empatía y escucha que faciliten mayor bienestar a usuarias y personal sanitario, aumentando la capacidad de tomar decisiones informadas.

- Mejorar la información y el conocimiento de las patologías específicas según los países de origen.

- Asumir la necesidad de garantizar los derechos efectivos de acceso a la atención sanitaria y educativa de los menores y las mujeres embarazadas extranjeras con independencia de su origen y situación administrativa, cumpliendo la legislación vigente (LO/96).

- Prestar atención a posibles signos de violencia de género, del mismo modo que se señala en el apartado general de atención al embarazo de esta Estrategia.

\subsubsection{Documentos relacionados con el parto y la salud reproductiva en el contexto aragonés}

El primer documento que analizamos en relación con el contexto aragonés es el "Plan de atención a la salud de la mujer 2010-2012", el cual se inserta en las políticas del Gobierno de Aragón en materia de salud de la mujer y, en particular, en las acciones del Departamento de Salud y Consumo y del Instituto Aragonés de la Mujer.

Este Plan se propone eliminar, desde un enfoque de género, las desigualdades tanto en el estado de salud como en la atención sanitaria que existen en el contexto aragonés. De acuerdo con los autores del documento, estas desigualdades pueden explicarse en gran parte por la situación de mayor riesgo y vulnerabilidad en la que se encuentran las mujeres con respecto a los hombres. Opinan, además, que dicha situación se debe a las diferencias existentes entre los sexos en cuanto a los roles de género, los estilos de vida y las prácticas preventivas, diferencias que, a su vez, dependen de construcciones sociales y culturales. En el Plan se señalan

\footnotetext{
199 Nótese que, como ocurre en otros documentos oficiales, se emplea el término "traducción" para referirse al concepto de "interpretación".
} 
especialmente como factores determinantes de las desigualdades entre hombres y mujeres que pueden afectar a su estado de salud las condiciones estructurales derivadas de los roles de género, que suelen traducirse, en el caso de las mujeres, en una doble jornada laboral y doméstica, la sobrecarga por responsabilizarse del cuidado familiar, determinadas patologías crónicas, y las tendencias actuales en cuanto a la medicación en situaciones fisiológicas como la menopausia, el estrés o el malestar psíquico.

Asimismo, en el documento analizado se sostiene que el género no solo es un determinante social de salud, sino que puede conllevar diferencias en el acceso a los servicios sanitarios y, por este motivo, se recomienda que el sistema de salud dé una respuesta ajustada a las necesidades planteadas por las mujeres, especialmente por las que pertenecen a sectores más desfavorecidos. Entre los colectivos a los que afecta esta vulnerabilidad por cuestión de género, se señalan las mujeres que ejercen la prostitución, las reclusas, las discapacitadas físicas o psíquicas, las mujeres solas con cargas familiares en situación de extrema vulnerabilidad social y sanitaria, y las mujeres de origen extranjero. En el caso concreto de estas últimas, por una parte, se afirma que pueden tener dificultades añadidas para mantener su salud o para acceder a los servicios sanitarios, por las diferencias lingüísticas y culturales que presentan en relación con los autóctonos. Por otra parte, se sostiene que la cultura y las tradiciones que incorporan algunos inmigrantes pueden conllevar formas de violencia o mutilación de la mujer que, en la sociedad de acogida, constituyen delitos, y en cuya detección y prevención el sistema sanitario ha de tener un papel fundamental. Igualmente, se recuerda que hay mujeres que reúnen varias de las condiciones de vulnerabilidad mencionadas, incrementándose ulteriormente las dificultades para acceder y utilizar el sistema de salud, por lo que requieren una respuesta más específica y coordinada por parte de los departamentos y entidades del ámbito social y sanitario.

En esta atención a la salud de las mujeres desde un enfoque de género, los autores del Plan advierten de que no se centrarán especialmente en la salud reproductiva, no porque no la consideren relevante, sino porque opinan que, cuando se habla de género en cuestiones que afectan a la salud, se tiende a identificarlo bajo este cliché. Por consiguiente, consideran que, para evitar la inequidad por condicionante de género, los servicios sanitarios, en su conjunto, deben contemplar el empoderamiento de la mujer como una de sus estrategias de promoción de la salud.

Tras esta introducción, el Plan ofrece algunos datos relacionados con la demografía de la población femenina aragonesa y con la función reproductora que podrían resultar de interés para nuestro estudio, si bien algunos de estos no aparecen disgregados por nacionalidad. Además, esta información data del año 2007, por lo que cabría tener en cuenta los posibles cambios que se hayan podido producir en los seis años transcurridos.

En primer lugar, en el documento analizado se presentan las cifras relativas a la evolución de la población femenina residente en Aragón. En concreto, según datos del Padrón Municipal de Habitantes, elaborado por el Instituto Aragonés de Estadística, desde 1996 hasta 2007, se ha producido un notable incremento del número de mujeres de origen extranjero (pasando en diez años de 3.242 a 55.709); sin embargo, las mujeres residentes en esta comunidad de nacionalidad española han disminuido (de 599.769 a 593.950). 
Estas mismas cifras pueden observarse en relación con el grupo específico de población femenina en edad fértil (de 15 a 49 años), que, en el caso de las autóctonas, pasó de 284.206 en 1996 a 266.311 en 2007 y, en el caso de las inmigrantes, por el contrario, se produjo un importante incremento, de 2.354 a 41.256. Por tanto, las principales responsables del aumento en Aragón tanto de la población femenina en edad fértil como del número de nacimientos son principalmente las mujeres de origen extranjero residentes en esta comunidad. De hecho, del 23\% de incremento en los nacimientos desde el año 2000 al 2006, un $18,9 \%$ tuvo lugar a expensas de la población femenina inmigrante. Para este mismo periodo (2000-2006), en el Plan se señala también un aumento del número de interrupciones voluntarias del embarazo de entre dos y tres puntos porcentuales en las mujeres con edades comprendidas entre los 19 y los 34 años, sin indicar la nacionalidad de las mujeres a las que se las han practicado.

A continuación, se expone el objetivo principal perseguido con el Plan, que pretende ser el instrumento mediante el cual se desarrolle el principio de igualdad en la promoción y restauración de la salud de la mujer mediante la implicación de los diferentes actores y, más concretamente, busca contribuir a evitar las desigualdades directas e indirectas relativas a la salud de las mujeres residentes en Aragón que se producen por motivo de género.

Por lo que respecta a sus objetivos específicos, estos consisten en (2010:3):

- Subrayar la necesidad de un enfoque específico para mejorar la salud de las mujeres aragonesas.

- Plantear un trabajo coordinado y transversal en las distintas áreas de actuación de las que depende la salud.

- Proponer un marco con las diferentes estrategias que puedan afectar a la salud de las mujeres en el que insertar actuaciones presentes y futuras.

- Identificar los temas prioritarios que han de tenerse en cuenta para promover la salud de las mujeres y reducir las inequidades que se producen por motivo del género, prestando especial atención a los sectores más desfavorecidos.

- Integrar la perspectiva de género en todos los planes de trabajo, programas y actividades de formación e investigación.

Para poder alcanzar estos objetivos, en el Plan se establecen seis líneas estratégicas:

1. Salud en las diferentes etapas de la vida

2. Atención integral a las mujeres con factores de riesgo para su salud derivados de una situación de vulnerabilidad

3. Implicación de las mujeres en la toma de decisiones que afectan a su salud

4. Investigación y formación de profesionales

5. Involucramiento de los hombres 
6. Actuación de los servicios de salud en la disminución de la violencia de género.

Estas líneas estratégicas se desarrollan en 14 objetivos que, a su vez, se materializan en 90 actuaciones concretas. Por el interés que tienen para nuestro estudio, detallaremos únicamente aquellos objetivos y actuaciones que estén relacionados con la salud reproductiva o con las mujeres inmigrantes.

En primer lugar, en cuanto al objetivo centrado en la promoción del autocuidado y la mejora de la salud sexual y reproductiva, en el Plan se proponen las siguientes actuaciones (2010:1213):

- Desarrollo en las consultas de atención primaria de estrategias de promoción de hábitos saludables.

- Información y educación sexual para la prevención de enfermedades de transmisión sexual y embarazos no deseados.

- Programa de información, atención y seguimiento de métodos anticonceptivos sin condicionantes de género.

En segundo lugar, en referencia al objetivo de promoción de la participación de las mujeres y los hombres en la toma de decisiones sobre el embarazo, el parto y el puerperio, el Plan se propone llevar a cabo las siguientes actuaciones (2010:13-14):

- Programa de atención preconcepcional a las mujeres con factores de riesgo.

- Programa de atención a la mujer en el embarazo, el parto y el puerperio.

- Desarrollo en los servicios sanitarios del programa de promoción de la lactancia materna durante el embarazo y postparto.

- Programa de información a padres y madres sobre cuidados del recién nacido en el ámbito hospitalario.

Tal y como hemos señalado en la exposición de los objetivos de documentos analizados previamente, consideramos que las mujeres inmigrantes tendrán probablemente mayores dificultades con respecto a las autóctonas para poder beneficiarse de estas actuaciones propuestas en el Plan, entre otros motivos, por las barreras lingüísticas y culturales a las que deberán enfrentarse, así como por el desconocimiento de la posibilidad de utilizar los programas y servicios incluidos en dichas actuaciones.

Por otro lado, el Plan incluye un objetivo relacionado con el conocimiento y la información sobre la variable de género por parte de los profesionales sanitarios, para el cual propone la inclusión de nuevos contenidos en todas las fases de la formación (pregrado, postgrado y continuada) de estos profesionales. Entre dichos contenidos, el Plan plantea introducir actividades formativas sobre la influencia de la inmigración en la salud de las mujeres.

Por último, en el documento se informa sobre el Acuerdo Marco de colaboración entre el Departamento de Servicios Sociales y Familia y el Departamento de Salud y Consumo, firmado el 3 de marzo de 2008, en el cual se constituyeron diferentes grupos de trabajo con el fin de 
coordinar las actuaciones entre ambos departamentos por lo que respecta a las siguientes áreas: salud mental y drogas; dependencia; atención a la mujer; inmigración; y atención a la juventud. Entre dichos grupos de trabajo, cabría resaltar dos de ellos que, en cierto sentido, están relacionados con nuestra investigación. En concreto, se trata de la Comisión Interdisciplinar de mutilación genital femenina y el Grupo para el desarrollo y seguimiento de las actuaciones en salud dirigidas a las mujeres inmigrantes integradas en el Plan Integral para la convivencia.

El segundo documento analizado es el Plan de parto elaborado por el Servicio de Obstetricia del hospital contexto de nuestro estudio y publicado en su página web. Este documento recoge de manera sintética las recomendaciones del Plan de atención al parto normal previamente presentado, pero con un estilo algo más personalizado que este. De hecho, comienza el texto dando a los remitentes la enhorabuena de parte del personal del hospital por el estado de gestación (en el que probablemente se encontrarán las usuarias que consulten dicha página), y deseando que ese momento suponga para las gestantes y sus familias uno de los más emotivos y gratificantes de sus vidas.

Posteriormente, se exponen las actuaciones que se llevarán a cabo durante el proceso de parto de bajo riesgo, resaltando que este tratará de realizarse del modo más natural posible, evitando intervenciones, tales como el rasado del periné, el suministro de oxitocina o el sondaje vesical, innecesarias si la mujer y el feto se encuentran dentro de los estándares de normalidad.

En el periodo preparto, las usuarias podrán, de acuerdo con el documento analizado, ingerir bebidas ligeras, así como deambular y adoptar las posturas que les resulten más cómodas para favorecer el desarrollo natural del parto.

En cuanto al acompañamiento, se indica que la usuaria podrá elegir quién desea que la acompañe durante todo el proceso, desde la dilatación hasta el expulsivo, siempre y cuando este no deba efectuarse en un área quirúrgica por complicaciones en el parto. Con respecto a la dilatación, se tratará de que esta tenga lugar en salas individuales, excepto cuando haya un gran número de parturientas dilatando al mismo tiempo, en cuyo caso estas deberán compartir sala, y los acompañantes deberán ausentarse por motivos de espacio y para facilitar movilidad del personal sanitario.

En referencia a la anestesia epidural, se señala que esta no se realizará de manera sistemática, a menos que las parturientas lo requieran. Se apunta, además, que las usuarias recibirán información sobre esta técnica, así como sobre sus ventajas e inconvenientes, tanto en los meses anteriores al parto por parte de las matronas del centro de salud, como por parte del personal que las atienda durante el parto. En la exposición de los resultados de nuestra investigación analizaremos de qué manera se proporciona esta información a las usuarias alófonas con conocimientos escasos o nulos de español.

Con respecto a la postura adoptada durante el parto, se indica que, en el presente, este tiene lugar sobre la mesa de parto, y que solo podrán elegirse posturas más ajustadas a las circunstancias y deseos de las usuarias cuando se realicen las obras necesarias para modificar los paritorios. Desconocemos si está previsto efectuar estas modificaciones en un plazo de 
tiempo determinado, aunque sospechamos, por la actual situación económica y los recortes presupuestarios en materia de sanidad que se están aplicando, que se aplazarán para un futuro no muy cercano.

Asimismo, se señala que, en el hospital, se trata de favorecer la lactancia materna, y que las usuarias serán informadas y apoyadas para que esta pueda empezar a producirse lo más precozmente posible.

A continuación, se describen exhaustivamente aquellas complicaciones que podrían comprometer el bienestar maternal o fetal y que, en caso de surgir durante el parto normal, harían necesaria una intervención obstétrica y la puesta en marcha de tratamientos, procedimientos o recursos adecuados a la anomalía detectada.

Para finalizar, se establece que, a pesar de que se espera que tanto la usuaria como su acompañante colaboren y sean protagonistas del proceso de parto, la responsabilidad de tomar decisiones durante el mismo recae en el personal sanitario, en cuyos conocimientos, profesionalidad y criterio se espera que la usuaria y su familia confíen.

Antes de pasar a estudiar el siguiente documento, nos gustaría añadir que, considerando el número de usuarias inmigrantes alófonas que son atendidas en este hospital, quizás se podría plantear la traducción de este Plan de parto a las principales lenguas maternas de estas usuarias, de manera que se facilitase la comprensión por parte de las mismas de los datos, pautas y recomendaciones incluidos en el mencionado Plan.

El último documento que analizamos dentro de este apartado de documentos relacionados con la salud reproductiva y la atención durante el parto es la guía "Maternidad responsable: Opciones y recursos ante un embarazo no planificado", que fue elaborada en 2007 por la Asociación de Desarrollo Comunitario en Áreas de Aragón (ADCARA) y el Instituto Aragonés de Servicios Sociales. En ella se dan una serie de recomendaciones sobre el modo de actuar ante un embarazo no planificado.

Su objetivo principal consiste en informar de las diferentes opciones que existen cuando no se puede asumir la crianza y el cuidado de un recién nacido, y de los recursos de apoyo con los que se puede contar en territorio aragonés en caso de que se decida seguir adelante con la crianza. Asimismo, la guía contiene información sobre planificación familiar, de manera que se favorezca también la prevención de embarazos no programados. Además, incluye unas breves notas respecto a la legislación sobre el aborto en España, las ayudas a las que se puede acceder estando embarazada y los derechos que la mujer trabajadora tiene en dicho estado.

El valor más reseñable de esta guía, atendiendo a los fines de nuestra investigación, es que fue editada en diferentes idiomas, en concreto, en español, árabe, francés, inglés y rumano, ${ }^{200}$ de modo que resultaría más accesible a aquellas usuarias con desconocimiento de español y cuya lengua materna fuera uno de dichos idiomas.

\footnotetext{
${ }^{200}$ En los anexos incluimos la portada y el índice de las guías "Maternidad responsable: Opciones y recursos ante un embarazo no planificado" en cada uno de los idiomas mencionados.
} 


\subsubsection{Documentos relativos a las estrategias empleadas por los servicios sanitarios de Aragón para facilitar la comunicación y la asistencia a usuarios inmigrantes}

Por lo que respecta al tercer grupo de documentos, aquellos que, como se ha mencionado previamente, están relacionados con los recursos y estrategias de los que dispone (o disponía) el Servicio Aragonés de Salud para facilitar la comunicación y la asistencia a la población inmigrante, estos se distribuyen en tres grupos.

El primero de estos grupos está compuesto por documentos relacionados con los servicios de interpretación disponibles en el sistema de salud aragonés. El segundo incluye documentos relativos a los servicios de mediación intercultural prestados en ese mismo contexto. Y, por último, analizamos los documentos traducidos a varios idiomas destinados a los usuarios inmigrantes de los servicios sanitarios de Aragón.

\subsubsection{Documentos sobre los servicios de interpretación disponibles en el sistema de salud aragonés}

El primer servicio de interpretación que comenzó a prestarse de manera oficial en Aragón fue el Servicio Permanente de Interpretación. Se trataba de un servicio de interpretación presencial que se activó en 1999, fruto de un convenio entre el Ayuntamiento de Zaragoza y el Real e llustre Colegio de Abogados de esa misma ciudad. Este Servicio estaba gestionado por la Casa de las Culturas, que es un centro social municipal dirigido a inmigrantes y minorías étnicas que funciona desde el año 1998. Su objetivo principal consistía en poner a disposición de entidades, organismos, instituciones y servicios públicos un cuerpo de intérpretes que facilitaran la comunicación entre los profesionales y los usuarios de origen extranjero. Asimismo, en ocasiones, se encargaban también de realizar labores de traducción de documentos de carácter no oficial (como folletos y carteles informativos o historias clínicas de pacientes de origen extranjero).

El Servicio Permanente de Interpretación pasó a depender exclusivamente del Ayuntamiento de Zaragoza en 2009, y dejó de funcionar en marzo de 2012, por falta de presupuesto. Hasta ese momento, ofrecía interpretación en 22 idiomas, desde las 8:00 hasta las 21:00 horas, de lunes a viernes. Al respecto de los horarios del Servicio, cabría indicar su limitada disponibilidad.

Los destinatarios del Servicio eran profesionales y usuarios de diferentes dependencias municipales y servicios sociales (institutos, hospitales, servicios de protección de mujeres y menores), así como entidades sociales sin ánimo de lucro. La demanda debía partir siempre del profesional del servicio o entidad, quien efectuaba la solicitud telefónicamente y, tras la prestación, entregaba un justificante en el que se indicaban los datos básicos de la intervención (nombre del intérprete, servicio para el que había interpretado, duración de la intervención, etc.).

El único requisito que debían cumplir los intérpretes inscritos en el registro ${ }^{201}$ de este servicio municipal era, en caso de que fueran inmigrantes, lo cual era bastante común, encontrarse en

\footnotetext{
${ }^{201}$ Los datos de contacto de los intérpretes se conservaban por escrito en un archivador distribuidos por lenguas de trabajo.
} 
situación regular. No se les solicitaba, por el contrario, ningún tipo de certificado o acreditación que demostrase sus conocimientos lingüísticos de las lenguas de trabajo ni formación en interpretación. Asimismo, estos intérpretes no se regían por ningún código deontológico común, ni se realizaba ninguna valoración posterior de su prestación. ${ }^{202}$

En septiembre de 2012 nos reunimos con la responsable del Servicio en la Casa de las Culturas, la cual nos proporcionó información impresa sobre sus orígenes, organización y objetivos, así como un resumen estadístico de los servicios específicos prestados en su último año de vigencia (2011), cuyos datos presentaremos a continuación.

Por lo que respecta a la evolución del Servicio en sus últimos tres años de vigencia, en el último año se observó un ligero descenso de las solicitudes, tanto por lo que respecta a las interpretaciones presenciales como en relación con la demanda de traducciones, tal y como puede observarse en el gráfico que aparece a continuación.

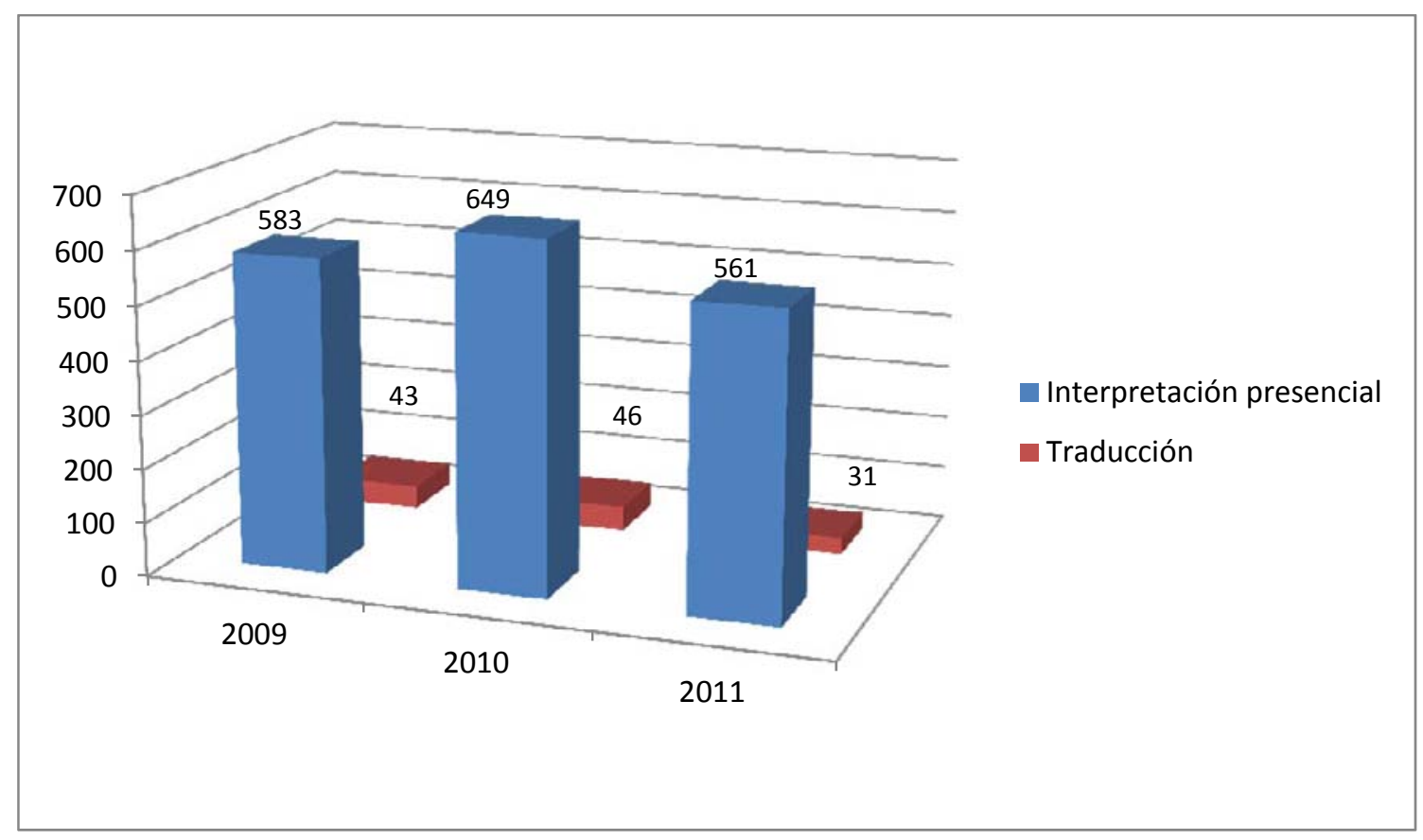

Gráfico 6.1. Evolución anual del Servicio Permanente de Interpretación (2009-2011)

\footnotetext{
202 La falta de formación de los intérpretes y la ausencia de un código deontológico podía conllevar, a nuestro parecer, graves consecuencias. De hecho, en una reunión que mantuvimos con la responsable del Servicio en septiembre de 2012, esta nos hizo partícipes de situaciones en las que el intérprete conocía personalmente al usuario para el que estaba interpretando, lo cual podía comprometer en cierto sentido su imparcialidad, o de sucesos en los que se revelaron datos de la intervención, incumpliendo el principio de confidencialidad que debe regir toda interpretación.
} 
Centrándonos en el año 2011, se observa en el siguiente gráfico que, en el último trimestre, se produjo un repunte considerable de la demanda de interpretaciones presenciales, aunque desconocemos los motivos que llevaron a este aumento.

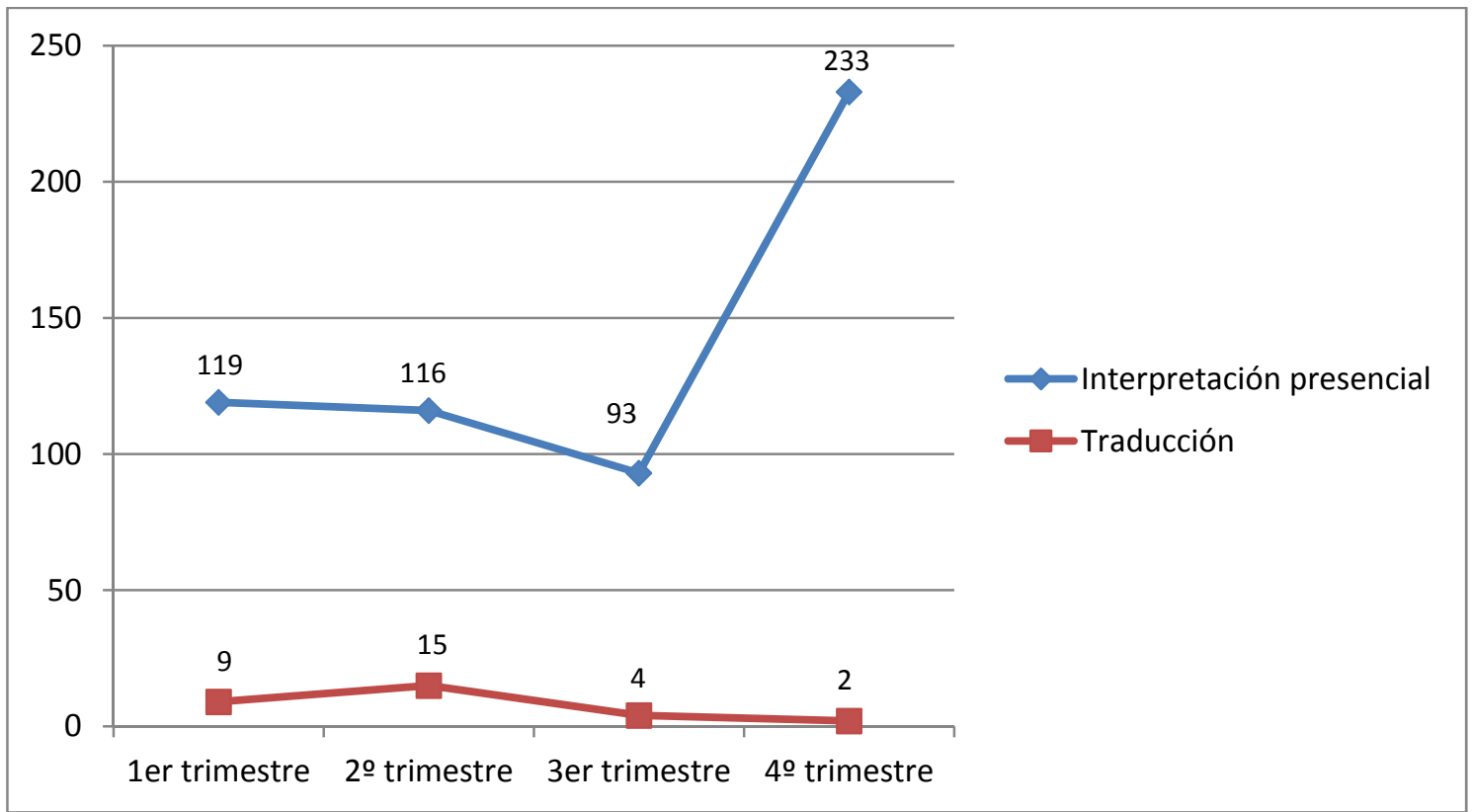

Gráfico 6.2. Evolución trimestral del Servicio Permanente de Interpretación (2011)

El idioma más demandado en las solicitudes de interpretación en dicho año fue, sin duda, el árabe, seguido del rumano y, en menor medida, del chino y del inglés, tal y como puede apreciarse en el gráfico que mostramos a continuación. ${ }^{203}$

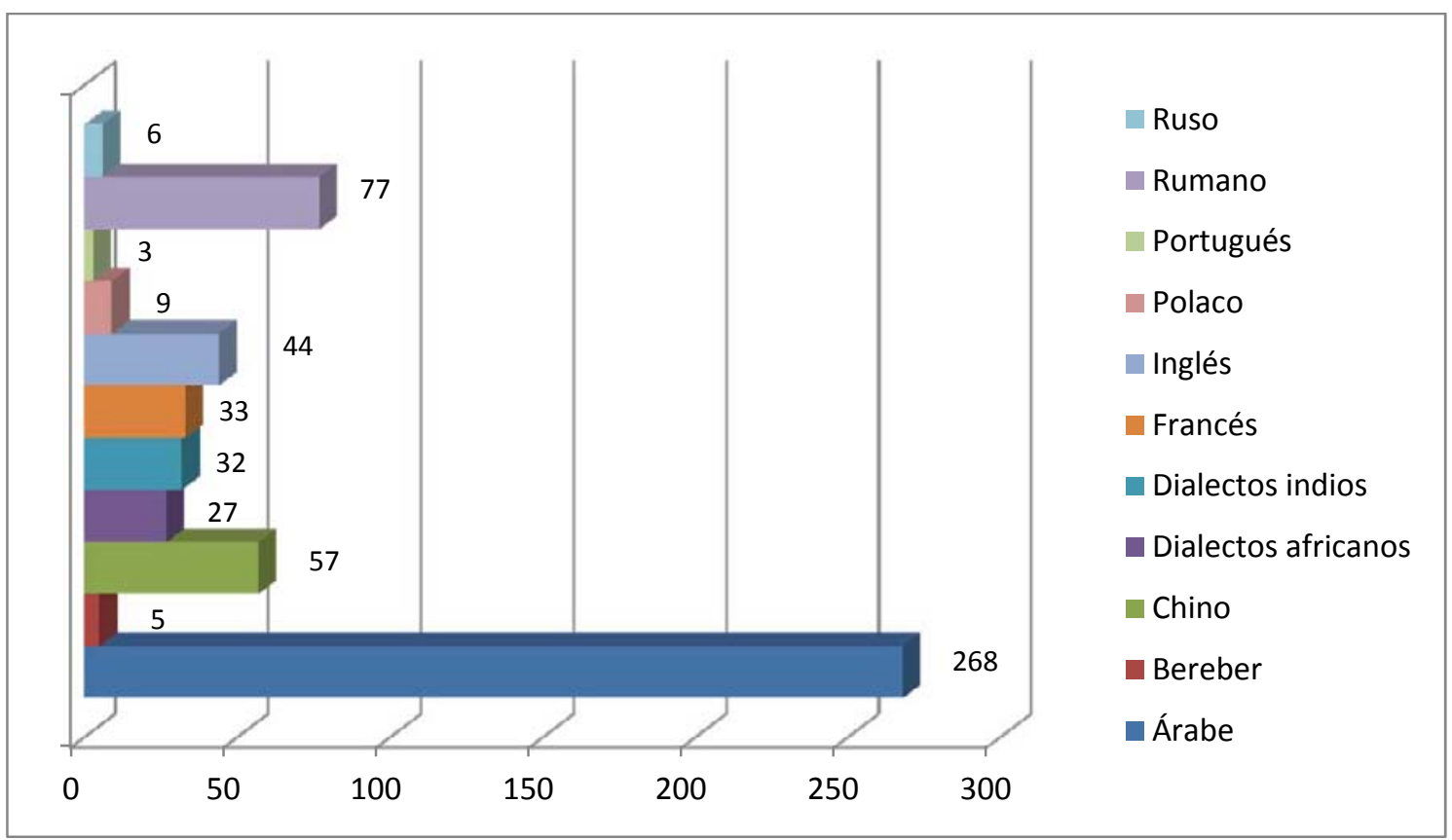

Gráfico 6.3. Idiomas demandados en los servicios de interpretación (2011)

${ }^{203}$ Los idiomas mencionados en el gráfico se corresponden exactamente con los datos ofrecidos por la responsable del Servicio. No obstante, cabe señalar que nos surge la duda sobre si, cuando hablan de "dialectos africanos" o "dialectos indios", se están refiriendo realmente a dialectos o a lenguas. 
En referencia a las entidades solicitantes del Servicio, la mayor demanda fue presentada por el Ayuntamiento de la ciudad de Zaragoza, seguido por la Diputación General de Aragón. Las solicitudes por parte de entidades sin ánimo de lucro fueron mucho más escasas, tal y como puede observarse en el siguiente gráfico:

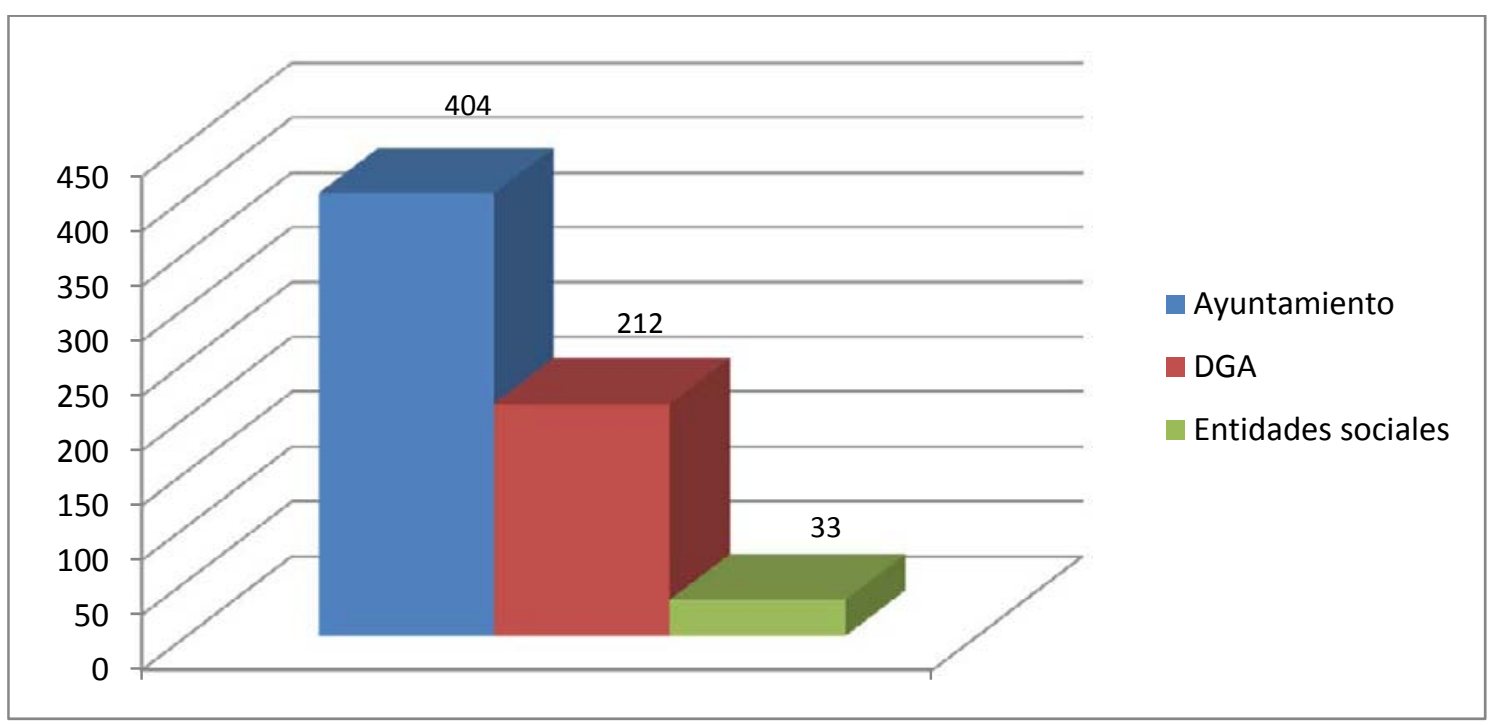

Gráfico 6.4. Servicios de interpretación demandados según entidad solicitante (2011)

Si desglosamos estos datos por grupos de solicitantes, vemos en el gráfico que presentamos a continuación que, por lo que respecta al Ayuntamiento, la mayor demanda de servicios de interpretación fue efectuada por el centro municipal de servicios sociales del distrito de Zaragoza con una mayor densidad de población inmigrante residente, el CMSS San Pablo, seguido por la propia Casa de las Culturas y por la Casa de la Mujer, así como por otros centros municipales de servicios sociales de distritos con un número considerable de inmigrantes residentes, como puede ser el CMSS Valdefierro y el CMSS Magdalena.

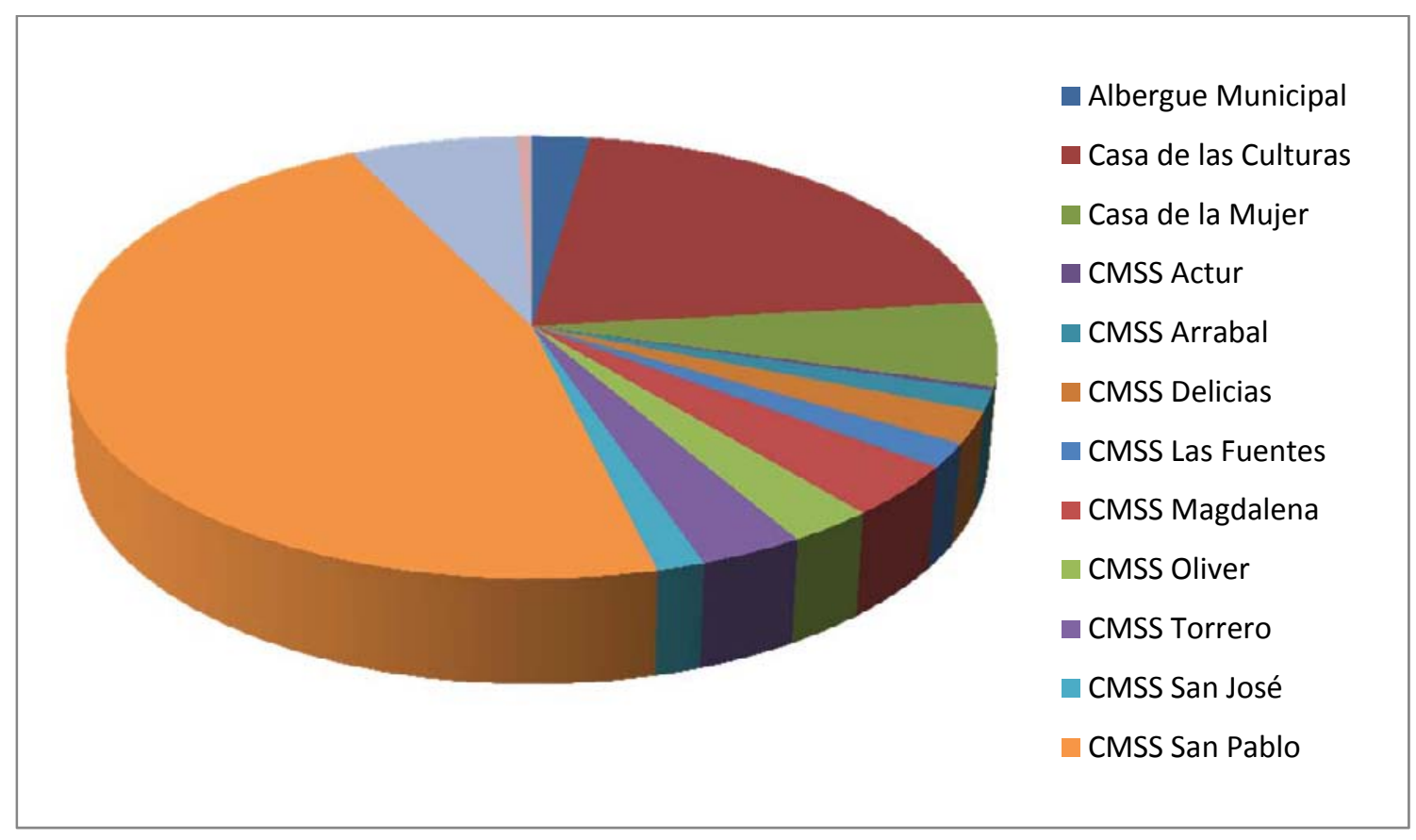

Gráfico 6.5. Servicios de interpretación prestados a entidades del Ayuntamiento de Zaragoza (2011) 
En cuanto a los servicios solicitados por las entidades pertenecientes a la Diputación General de Aragón, el mayor número de demandas fue efectuado por el Servicio de Protección de Menores (que representó más del $60 \%$ de la demanda), seguido por el Sistema de Salud Público (aproximadamente el $31 \%$ ) y, en menor proporción, los centros educativos ${ }^{204}$ (cerca del 7\%), y el Servicio de Asistencia y Orientación Jurídica para Inmigrantes (SAOJI) (con solo un $1 \%)$, como se muestra en el siguiente gráfico:

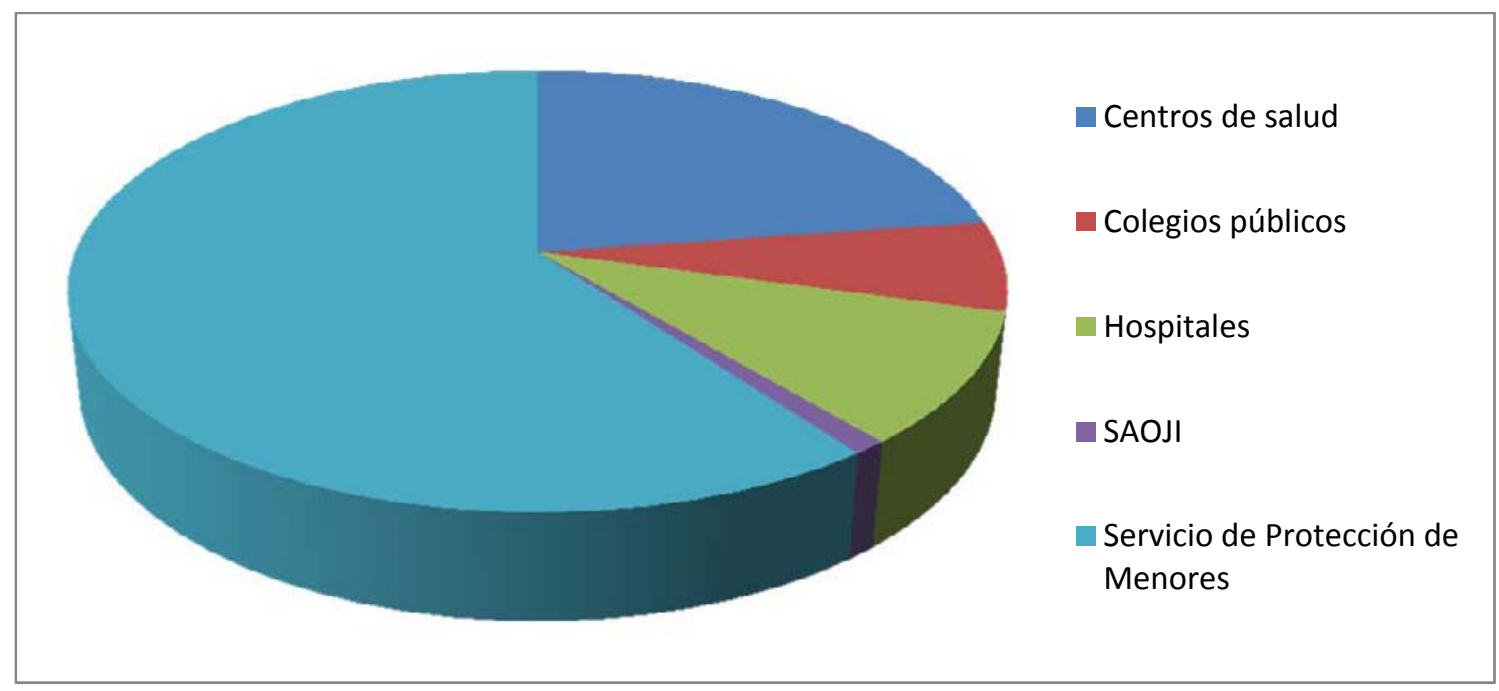

Gráfico 6.6. Servicios de interpretación prestados a entidades de la DGA (2011)

La mayor demanda de servicios de interpretación prestados en los servicios sanitarios, ámbito principal de nuestro estudio, se correspondió al Centro de salud de San José, por una parte, y al Hospital Miguel Servet, por otra. En concreto, las intervenciones efectuadas en este ámbito se distribuyeron tal y como aparece en el siguiente gráfico:

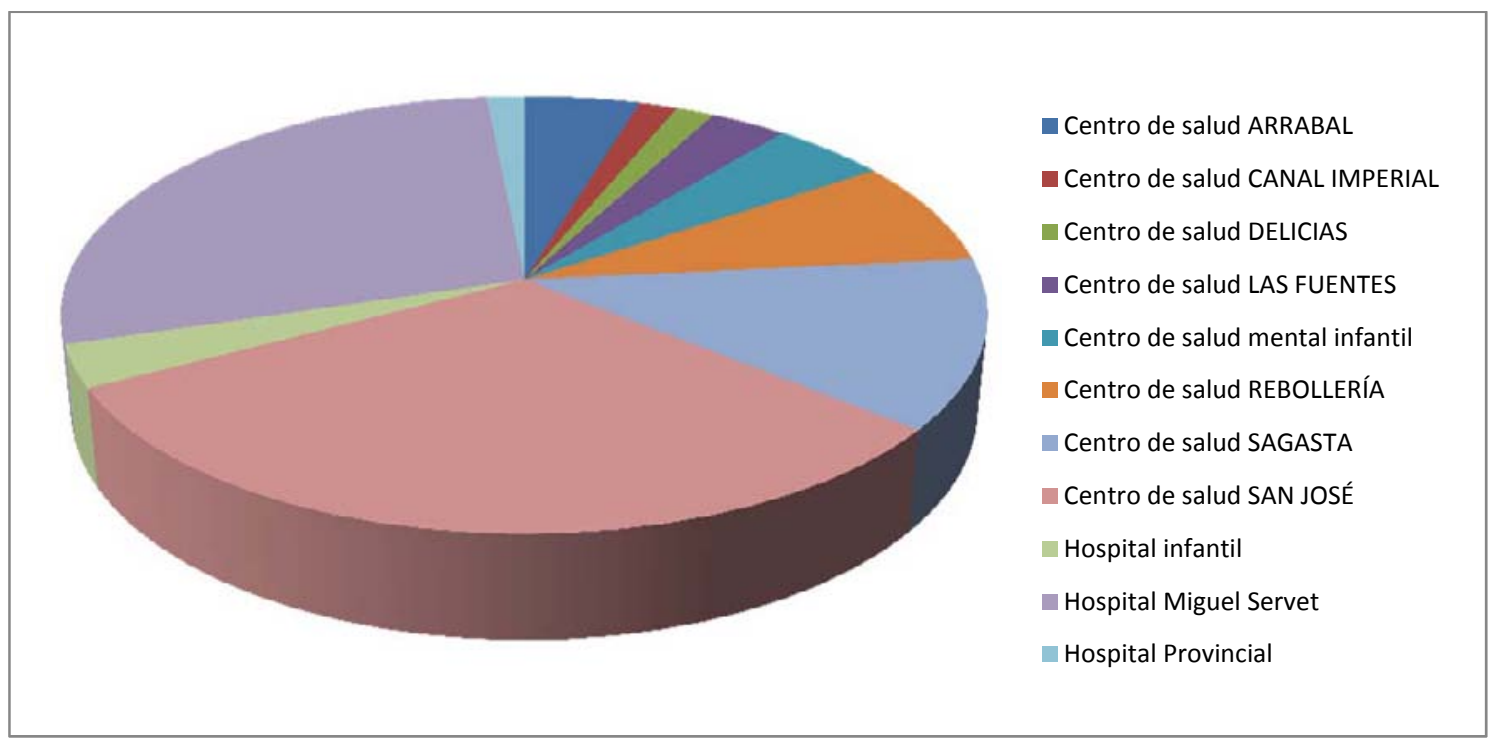

Gráfico 6.7. Servicios de interpretación prestados en ámbito sanitario (2011)

\footnotetext{
${ }^{204}$ Cabe señalar que probablemente esta escasa demanda de servicios de interpretación por parte de los centros educativos se debe a que dichos centros cuentan con el apoyo del Centro Aragonés para la Educación Intercultural (CAREI) creado por el Departamento de Educación, Cultura y Deporte del Gobierno de Aragón, que, entre otros servicios, ofrece un programa de mediación interlingüística e intercultural a la comunidad de docentes y alumnos, así como a las familias de estos últimos.
} 
Por último, por lo que se refiere a las entidades sin ánimo de lucro demandantes de servicios de interpretación, las solicitudes que estas efectuaron durante el año 2011, fueron, como hemos comentado previamente, bastante escasas. Dentro de este grupo, la mayor demanda fue efectuada por la organización Médicos del Mundo (casi un $40 \%$ del total), como puede observarse en el gráfico que incluimos a continuación.

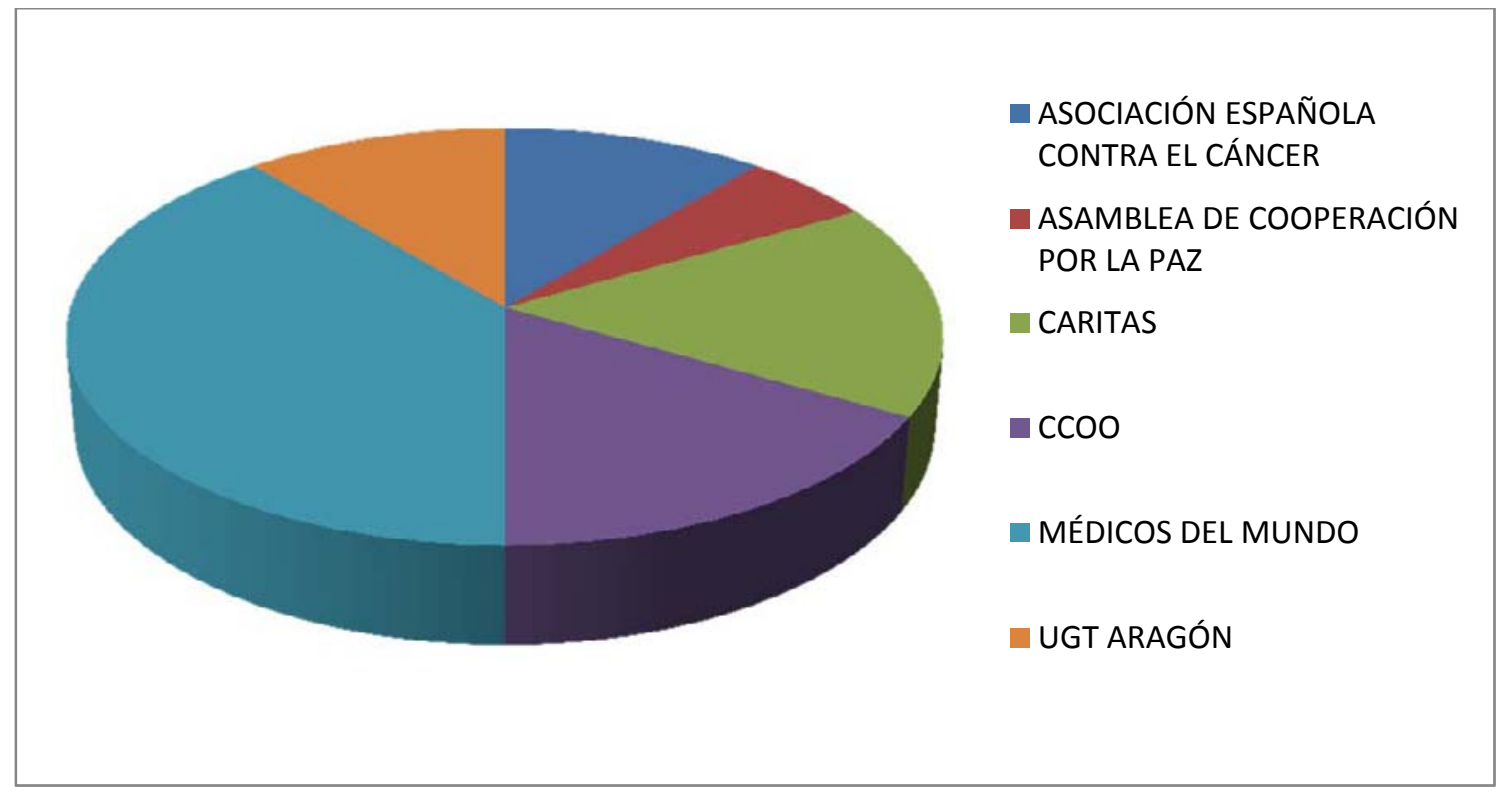

Gráfico 6.8. Servicios de interpretación prestados en entidades sin ánimo de lucro (2011)

Por otra parte, desde junio de 2009 hasta la actualidad, se oferta en los servicios públicos aragoneses un servicio externalizado de interpretación telefónica. La principal empresa responsable de dicho servicio ha sido Interpret Solutions, ${ }^{205}$ la cual ha trabajado para el Gobierno de Aragón en los periodos comprendidos entre junio de 2009 y diciembre de 2010, y desde marzo de 2012 hasta el momento presente. ${ }^{206}$ En el espacio intermedio entre estos dos periodos, se ocupó del servicio de interpretación telefónica la empresa Dualia.

De acuerdo con el pliego de prescripciones técnicas, ${ }^{207}$ el objetivo de esta contratación es eliminar las barreras lingüísticas a las que se enfrentan los usuarios no hispanohablantes de los servicios públicos aragoneses, cumpliendo, de este modo, los principios de equidad e igualdad en el acceso a dichos servicios.

En cuanto al ámbito de prestación, pueden solicitar el servicio los centros y organismos del Departamento de Sanidad, Bienestar Social y Familia (hospitales, centros de salud y centros sanitarios de alta resolución), del Departamento de Educación, Universidad, Cultura y Deporte

\footnotetext{
205 Puede encontrarse mayor información sobre la historia y las características de esta empresa en su página web: [http://www.interpretsolutions.com/] (última consulta: 12 de julio de 2013).

${ }^{206} \mathrm{El}$ actual contrato expira el 14 de septiembre de 2013. Para los meses que quedan hasta que finalice el año, se prevé, de acuerdo con la información aportada por la responsable del servicio en el Gobierno de Aragón, llevar a cabo un negociado para que sea esta misma empresa la que se ocupe de proporcionarlo y, en enero de 2014 , se publicará la próxima licitación pública abierta.

${ }^{207}$ Cabe destacar que el título mismo del mencionado pliego (Pliego de prescripciones técnicas para realización de un contrato de servicios de traducción telefónica para la atención a las personas inmigrantes en sus relaciones con las instituciones públicas) puede haber contribuido a la confusión terminológica y conceptual entre traducción e interpretación que presentan, como podrá comprobarse en el análisis de los resultados de nuestro trabajo de campo, tanto los profesionales de los servicios sanitarios como los usuarios.
} 
(colegios públicos e institutos), del Instituto Aragonés de Empleo (oficinas de empleo y servicio de atención telefónica del INAEM), del Instituto Aragonés de Servicios Sociales (centros de base y comarcales, y centros de menores), así como el Instituto Aragonés de la Mujer.

Con respecto a la disponibilidad del servicio, este se puede solicitar de nueve de la mañana a nueve de la noche ininterrumpidamente, excepto en el caso del ámbito sanitario, en el que se oferta las veinticuatro horas durante todos los días del año. Por consiguiente, a diferencia del servicio de interpretación presencial previamente analizado, este no presenta ninguna restricción en cuanto al horario o calendario de disponibilidad en los servicios sanitarios, ámbito de nuestra investigación.

Por lo que se refiere a los idiomas ofertados por la empresa adjudicataria, esta se compromete a realizar interpretaciones entre español y cualquiera de los siguientes idiomas: alemán, árabe, bambara, bereber, búlgaro, checo, chino cantonés, chino mandarín, danés, esloveno, eslovaco, finés, francés, griego, holandés, húngaro, inglés, italiano, japonés, lituano, mandinga, noruego, polaco, portugués, rumano, ruso, serbo-croata, sueco, turco, ucraniano, urdu y wolof. ${ }^{208} \mathrm{Se}$ cubren, por tanto, la gran mayoría de las lenguas maternas de los colectivos inmigrantes residentes en Aragón. De estas combinaciones lingüísticas, las más demandadas, de acuerdo con los datos proporcionados por la empresa, ${ }^{209}$ son, en este orden, aquellas que incluyen el chino mandarín, el árabe estándar, el húngaro (durante un periodo de tiempo determinado), el portugués, el polaco y el inglés. Nos llama la atención el hecho de que, a pesar de que la comunidad inmigrante más numerosa en Aragón es la procedente de Rumanía, no se señala el rumano entre las lenguas más solicitadas en los servicios de interpretación telefónica, quizás porque los usuarios de esta procedencia, en parte por la similitud entre ambas lenguas, suelen presentar conocimientos medio-altos de español.

Cabe, además, señalar que, en el último periodo de contratación, se han incluido entre las prestaciones a ofertar por la empresa servicios de traducción, aunque no se ofrecen datos específicos al respecto, como, por ejemplo, si existe un límite máximo de palabras que la empresa deberá traducir, qué tipo de documentos podrán ser susceptibles de solicitud de traducción, ni qué combinaciones lingüísticas se ofertarán.

En el mencionado pliego de prescripciones técnicas, se establecen, asimismo, una serie de especificaciones que expondremos a continuación.

En primer lugar, se estipula un número máximo de minutos de interpretación anual, que se estima en 9.600 minutos. Se trata de una cifra indicativa, ya que la Administración no puede garantizar el número de intervenciones que se solicitarán ni la duración de las mismas, sino que estas dependerán de las necesidades reales. Al respecto, la empresa adjudicataria se compromete a realizar informes de seguimiento, en los que se especificarán los datos de uso

\footnotetext{
${ }^{208}$ El número de idiomas disponibles, de acuerdo con la empresa prestataria del servicio, va variando con el paso del tiempo, y, en ocasiones, las interpretaciones a determinadas lenguas se efectúan por relé desde el inglés.

${ }^{209}$ En septiembre de 2012 realizamos una entrevista telefónica a una responsable de la empresa adjudicataria, en la que le planteamos una serie de preguntas relacionadas con los servicios de interpretación telefónica prestados en territorio aragonés. Asimismo, la empresa nos suministró información en formato electrónico sobre los cursos de formación para intérpretes que esta imparte, las pruebas que deben superar los candidatos a formar parte del equipo de interpretación, el código ético que los miembros de dicho equipo deben respetar, y las encuestas de valoración de las intervenciones.
} 
desglosados por centro solicitante, el número de intervenciones solicitadas, la duración, la fecha y hora en que se realizaron, así como la combinación lingüística requerida. Además, la empresa deberá redactar un informe final evaluativo en el que no solo se detallarán las intervenciones realizadas, sino que también se incluirá una valoración de la aceptación del servicio por parte de los usuarios, el grado de satisfacción alcanzado y los principales problemas detectados. Con el fin de garantizar la calidad del servicio, por un lado, en el pliego se establecen unas condiciones (ausencia de ruido y disponibilidad de cobertura) que se deben respetar $y$, por otro, la empresa distribuye un cuestionario ${ }^{210}$ a los usuarios del mismo, que deben cumplimentar al finalizar cada intervención. ${ }^{211} \mathrm{Al}$ mismo tiempo, la empresa cuenta con un Manual de Calidad basado en las directrices establecidas en las Normas UNE-EN ISO 9001:2008 "Sistemas de Gestión de la Calidad" y UNE-EN 15038:2006 "Servicios de Traducción: Requisitos para la prestación del servicio".

Siempre de acuerdo con el pliego de prescripciones técnicas, es la empresa adjudicataria la que debe encargarse de la difusión y publicidad del servicio, mediante folletos informativos o carteles diseñados por ella misma que deberán situarse en la entrada de los centros en los que este se pueda solicitar, o con cualquier otro medio que considere pertinente, de manera que quede asegurado el conocimiento de su existencia por parte de los profesionales que lo necesiten. En relación con estos medios de información y difusión, cabe señalar que, durante nuestro trabajo de campo, no encontramos en el hospital contexto de estudio ningún cartel o folleto sobre el servicio de interpretación que estuviera a la vista del público.

Igualmente, con el mismo fin, según la información proporcionada por la empresa, se suele designar a un profesional responsable en cada centro para que realice las funciones de "embajador" del servicio de interpretación telefónica. En el caso del hospital contexto de nuestro estudio, dichas funciones son desempeñadas por la trabajadora social, quien, como veremos en el análisis de los datos recolectados en la investigación, es una de las pocas profesionales que reconoce haber empleado este recurso.

Además, para facilitar el conocimiento del funcionamiento del servicio por parte de los profesionales demandantes, la empresa celebró, en el primer periodo de adjudicación, charlas informativas de unos 45 minutos de duración destinadas al personal de los centros en los que este servicio se podía prestar. La asistencia a dichas charlas no presentaba carácter obligatorio y, según la empresa adjudicataria, no contaron con un número masivo de participantes. En el pliego se establece que, para el último periodo de contratación, la empresa debía ofrecer formación online para los profesionales solicitantes, pero desconocemos si, en esta ocasión, se les obligó a seguir dicho curso y, en caso negativo, cuántos profesionales lo hicieron.

Por lo que respecta a las características del servicio prestado, en el pliego se acuerda que toda intervención deberá comenzar con una breve introducción por parte del intérprete, en la que

\footnotetext{
210 En los anexos incluimos un modelo del cuestionario proporcionado por la empresa en el que, como podrá observarse, se valoran tanto los aspectos técnicos (ruido y cobertura) y protocolarios (pre-sesión y post-sesión, aclaraciones, etc.), como los aspectos lingüísticos (por ejemplo, la terminología y el nivel de lengua B) y extralingüísticos (entre otros, la neutralidad y la gestión de los turnos de palabra) de la intervención.

${ }^{211}$ Cabe señalar que el sistema de evaluación del servicio ha variado ligeramente en el último año, puesto que el cuestionario de valoración detallado se envía de manera aleatoria únicamente a algunos usuarios, y se ha puesto en marcha un sistema automático que permite evaluar el servicio, en la misma llamada, al finalizar la interpretación, valorando de 1 a 5 (siendo 5 la más alta) los diferentes aspectos de la prestación recibida.
} 
este se presentará e identificará, y explicará a grandes rasgos cómo se va a llevar a cabo la interpretación. La identificación del intérprete permitirá que se puedan solicitar de nuevo los servicios de ese intérprete concreto en una solicitud futura en la que participe el mismo usuario. Asimismo, se establece que será posible seleccionar al intérprete en función de su sexo si el usuario así lo requiere, aspecto que consideramos muy positivo para determinados colectivos (como puede ser el conformado por la comunidad musulmana) que podrían realizar este tipo de requerimientos.

Es durante esta pre-sesión cuando el profesional solicitante suele ofrecer al intérprete información sobre los participantes y la situación comunicativa, de manera que este disponga de unos datos mínimos contextuales que le ayuden a desarrollar su labor.

En cuanto a los tiempos de espera, en el pliego se determina que estos no podrán superar el minuto desde la marcación inicial. Sin embargo, de acuerdo con la empresa prestataria del servicio, el hecho de tener que pasar por diferentes interlocutores antes de conseguir la intervención del intérprete conlleva que, en el $80 \%$ de los casos, no se llegue a efectuar la interpretación (bien porque alguno de los numerosos códigos que se deben introducir no son correctos o porque el tiempo de espera es demasiado prolongado). En particular, en el ámbito que nos ocupa, la solicitud del servicio debe realizarse a través del portal Salud Informa, ${ }^{212}$ lo que aumenta considerablemente el número de interlocutores y el tiempo que se debe esperar hasta que realmente comienza la interpretación. ${ }^{213}$

Otra cuestión técnica del servicio que nos gustaría aclarar se refiere a los aparatos de telefonía que emplean, el intérprete, por una parte, y los usuarios, por otra. Con respecto a estos últimos, la empresa distribuye unos terminales con doble clavija a los centros donde se presta el servicio, de manera que en todo momento ambos interlocutores pueden escuchar la conversación y la intervención del intérprete, y se evita la incomodidad de tener que ir pasando el auricular de uno a otro interlocutor. El intérprete, por su parte, puede encontrarse en cualquier lugar durante la intervención (bien dentro de España o en el extranjero), y puede emplear tanto aparatos de telefonía fija como móvil, siempre y cuando pueda garantizar ausencia de ruidos y suficiente cobertura.

Un dato a resaltar con respecto a los intérpretes de esta empresa (y que la diferencian también del servicio de interpretación presencial anteriormente presentado) son los requisitos que estos deben cumplir para poder trabajar en ella. En concreto, se les plantean dos opciones. La primera opción es que sean licenciados en traducción e interpretación y acrediten tres años de experiencia en interpretación telefónica. Si no cumplen estas condiciones, los

\footnotetext{
212 Salud Informa es un portal para los usuarios del Sistema de Salud de Aragón a través del cual estos pueden conocer, entre otras cuestiones, sus derechos y deberes o el listado de centros de salud y hospitales. Asimismo, pueden realizar algunos trámites, como la solicitud de cita previa, llamando al número 902555321, a través del cual se gestiona también el servicio de interpretación telefónica. Cabe recordar que, anteriormente, ya hemos hecho referencia al sistema centralizado de citación e información telefónica en el análisis de la Carta de compromisos del Departamento de Salud y Consumo con los Usuarios del Sistema de Salud de Aragón, al comentar que realizamos personalmente una prueba del funcionamiento del mismo. Para mayor información sobre el portal Salud Informa, se puede visitar la página web: [http://www.saludinforma.es/opencms/opencms/] (última consulta: 21 de julio de 2013).

${ }^{213}$ Desde el Gobierno de Aragón parecen ser conscientes de esta limitación y, de hecho, en una reunión mantenida en junio de 2013 con la responsable institucional del servicio, esta nos informó de que se estaban planteando la eliminación de la gestión del mismo para el ámbito sanitario a través de Salud Informa.
} 
postulantes deben realizar un curso de formación impartido por la empresa y, al finalizarlo, superar una prueba.

Por lo que se refiere al curso de formación, este se divide en dos bloques. El primero de ellos se centra en los contenidos teóricos, e incluye un módulo introductorio sobre el funcionamiento del servicio, tres módulos que abarcan las distintas fases de cada intervención (pre-sesión, sesión y post-sesión), un módulo de gestión de incidencias (técnicas, humanas y lingüísticas) y, para finalizar, cuatro módulos que tratan sobre los diferentes ámbitos de trabajo (educativo, sanitario, policial y de servicios sociales). El segundo bloque, de carácter práctico, contiene ejercicios de memoria, de sinonimia y paráfrasis, y de terminología propia de cada ámbito de trabajo.

En cuanto a la prueba que los postulantes a trabajar como intérpretes en esta empresa deben superar, esta consiste en la interpretación de un diálogo leído en el que participan un interlocutor nativo de español (en el papel del profesional) y un interlocutor nativo del idioma extranjero escogido para la evaluación (en el papel del usuario). Estos diálogos son siempre adaptaciones de sesiones reales de interpretación telefónica en uno de los ámbitos de trabajo, y tienen una duración aproximada de unos diez minutos. En la prueba se valoran cuestiones de protocolo (como la gestión de la pre-sesión y la post-sesión, o el uso de la primera persona), ${ }^{214}$ aspectos lingüísticos (como la terminología empleada, o las posibles faltas de omisión, adición o modificación de la información transmitida), aspectos extra-lingüísticos (como la neutralidad, la mediación ${ }^{215}$ o la gestión de los turnos de palabra), y aspectos técnicos (como los ruidos de fondo y el nivel de cobertura). Además, se incluye un campo abierto en el que el evaluador, que será siempre un licenciado en traducción e interpretación con conocimientos activos de ambos idiomas, podrá incluir ulteriores observaciones.

Cabe, asimismo, subrayar que todos los intérpretes de la empresa se rigen por un código ético ${ }^{216}$ que fue elaborado a partir de los códigos éticos de otras empresas con mayor experiencia en el sector (como, por ejemplo, Language Line). ${ }^{217}$ En él se recogen, entre otros, los siguientes principios generales: fidelidad, imparcialidad, confidencialidad ${ }^{218}$ y profesionalidad. Igualmente, se describe el rol del intérprete y se establecen las partes en las que deberá dividirse la intervención (pre-sesión, sesión y post-sesión).

\footnotetext{
${ }^{214}$ Según las pautas establecidas por la empresa, los intérpretes deberían usar obligatoriamente la primera persona, aunque, de acuerdo con declaraciones de una responsable de la misma, en la práctica dicho uso es bastante flexible. De hecho, según datos de los cuestionarios de evaluación cumplimentados por los usuarios del servicio, los intérpretes usan la primera persona en el $37 \%$ de las sesiones, y la tercera persona, en el $63 \%$. Al respecto, en los cuestionarios de valoración de la intervención, la nota media que obtuvo este ítem en el año 2011 fue de 2,8 sobre 6.

${ }^{215}$ De acuerdo con los datos proporcionados por la empresa, cuando se evalúe lo que ellos denominan "mediación", se considerará cualquier aclaración de tipo sociocultural que el intérprete deba realizar a alguna de las partes.

${ }^{216}$ Para obtener información más detallada al respecto, en los anexos se incluye el código ético de Interpret Solutions.

${ }^{217}$ Languageline Solutions es una empresa líder en el ámbito de la traducción y la interpretación (presencial, telefónica y por videoconferencia), la cual ofrece sus servicios en 200 idiomas en países como Estados Unidos, Canadá, México, Puerto Rico, Costa Rica, la República Dominicana y Reino Unido. Para obtener mayor información sobre esta empresa, puede visitarse su página web: [https://www.languageline.com/] (última consulta: 27 de agosto de 2013).

${ }^{218}$ La cuestión de la confidencialidad también se incluye en el pliego de prescripciones técnicas, en el cual se indica que la empresa adjudicataria se deberá ajustar a lo establecido en la Ley Orgánica 15/1999, de 13 de diciembre, de protección de Datos de Carácter Personal para el acceso y tratamiento de datos del máximo nivel de sensibilidad, y deberá asimismo respetar el Reglamento que desarrolla la citada ley.
} 
Consideramos que tanto los requisitos que se exigen a los intérpretes, como la prueba que estos deben superar, junto con el código ético por el que rigen su desempeño profesional, son una muestra evidente de la preocupación por la calidad del servicio de interpretación telefónica por parte de la empresa encargada del mismo.

Para finalizar el análisis de este servicio, mencionaremos las ventajas y desventajas que, en nuestra opinión, este presenta. En relación con las ventajas, las principales son, por una parte, el empleo de intérpretes profesionales (que, como hemos comentado, o bien cuentan con una formación reglada en interpretación o deben superar una prueba que determina su capacidad de interpretar telefónicamente) y, por otra, y en comparación con la interpretación presencial, la cantidad de lenguas disponibles, la reducción de costes, la disponibilidad horaria y la inmediatez en la prestación del servicio. Por lo que respecta a las desventajas, la distancia física entre el intérprete y los interlocutores, con las consecuentes ausencias de un marco de referencia compartido y de visión de los elementos no verbales, así como los ruidos contextuales o la falta de cobertura telefónica podrían conducir a omisiones o malentendidos. Asimismo, los diversos interlocutores y los numerosos códigos a introducir antes de acceder al intérprete, pueden conllevar, como hemos comentado, prolongados tiempos de espera o errores en la marcación, por lo que, en ocasiones, finalmente no se lleva a cabo la interpretación.

De todos modos, el principal problema que presenta este servicio en el contexto que nos ocupa es con diferencia su infrautilización. La gran mayoría de los profesionales de los servicios sanitarios, como podrá comprobarse en la exposición de los resultados de nuestra investigación, desconocen la existencia del servicio o no lo emplean, aduciendo falta de tiempo, incomodidad o dificultad de uso. Opinan que disponen de otros recursos para comunicarse con el paciente alófono (como el uso de gestos o expresiones faciales, o el recurso a familiares o amigos del usuario con conocimientos de español para que intervengan como intérpretes ad hoc), y no ven la necesidad de recurrir a intérpretes profesionales que garantizarían una mayor eficacia de la comunicación.

Antes de concluir el análisis del servicio de interpretación telefónica, quisiéramos comentar que habríamos querido enriquecer nuestro estudio incluyendo la opinión de los propios intérpretes que trabajan para la empresa adjudicataria. Con este fin, les enviamos un cuestionario en dos ocasiones (la primera, en 2012, con preguntas abiertas y en formato de papel, y la segunda, en 2013, con preguntas cerradas de respuesta múltiple y en formato electrónico) y, en ninguna de ellas, recibimos respuesta por su parte. En dicho cuestionario, como puede verse en la copia que incluimos en los anexos, les solicitábamos datos sobre su experiencia y formación, así como su opinión con respecto a las ventajas e inconvenientes que puede plantear este tipo de interpretación, especialmente en comparación con la presencial, o las dificultades añadidas que se pueden presentar al interpretar telefónicamente en el ámbito sanitario.

\subsubsection{Documentos sobre los servicios de mediación intercultural disponibles en el sistema de salud aragonés}

Por lo que se refiere a los servicios de mediación intercultural que se ofertan en territorio aragonés y, más concretamente, aquellos disponibles para los profesionales y usuarios del 
sistema de salud, cabe destacar la labor del Servicio de Apoyo a la Mediación Intercultural (SAMI), el cual desarrolla su actividad desde el año 2003 con el fin último de lograr la integración de la población extranjera residente en esta comunidad autónoma.

El SAMI forma parte de los servicios ofertados por la Fundación Adunare, organización compuesta por ocho asociaciones y entidades sin ánimo de lucro con sede en la ciudad de Zaragoza. Los principios sobre los que se asienta la Fundación Adunare son, entre otros, la consolidación de lo público, la generación de procesos de desarrollo comunitario, la globalidad de las intervenciones (sanidad, vivienda, educación y tiempo libre), la sensibilización, la discriminación positiva, la solidaridad y el voluntariado. Cuenta con diversos programas, centrados en los sectores de infancia, juventud, adultos, inserción y mediación. Y es precisamente dentro de este último sector en el que se insertan las actividades del SAMI.

El SAMI, financiado por la Administración pública a través de la Dirección General de Inmigración y Cooperación al Desarrollo, tiene como finalidad asesorar a organizaciones públicas o privadas que deseen adecuar o mejorar su oferta de servicios y sus resultados con respecto a la población inmigrante de Aragón. Persigue, además, que los inmigrantes puedan utilizar los servicios y recursos de esas organizaciones en las mismas condiciones que la población autóctona, y que se tengan en cuenta aquellos elementos de índole cultural y/o derivados del hecho migratorio que puedan dificultar dicha utilización, dentro de la legalidad existente. Asimismo, entre sus objetivos, se encuentra la sensibilización de la población autóctona sobre los efectos positivos de la inmigración, mediante la eliminación de los estereotipos y prejuicios que dificultan la convivencia y la integración de las personas de otros países y culturas en la sociedad de acogida. Paralelamente, actúa a demanda en situaciones de conflicto originadas por la diversidad cultural.

En concreto, el SAMI ofrece los siguientes servicios:

1. Asesoramiento técnico para las organizaciones e interpretación de claves culturales.

2. Formación intercultural e interpretación de claves culturales.

3. Mediación intercultural.

4. Edición de materiales y documentación dirigidos tanto a los usuarios de origen extranjero como a los profesionales de los servicios públicos.

5. Proyectos de investigación sobre el fenómeno de la inmigración y sus repercusiones en las organizaciones.

EI SAMI está compuesto por un equipo de trabajo multidisciplinar cuyos miembros, procedentes de distintos países y culturas, disponen de amplia experiencia en proyectos relacionados con la inmigración y la interculturalidad. La mayoría de estos profesionales realizaron un curso de formación que, con una duración de 475 horas, se impartió a lo largo de cuatro meses del año 2003, y que finalizó con un periodo de prácticas. De hecho, una de las metas que se perseguían con este curso consistía en ofrecer perspectivas de futuro laboral a los participantes, de manera que se consolidara un equipo humano motivado, formado y estable que pasaría a integrar el servicio de mediación intercultural. Esta preparación intensiva 
inicial ha sido complementada y ampliada en los años sucesivos con un plan de formación continuada que los mediadores simultanean con su actividad profesional.

Los contenidos del curso de formación inicial se asentaban sobre cuatro pilares:

> Generalidades: las temáticas tratadas no se estudiaron a nivel superficial, sino que se pretendía ofrecer una preparación profunda desde una perspectiva teórico-práctica.

$>$ Habilidades y destrezas: se centraba en la provisión de herramientas técnicas, psicológicas y de comportamiento.

$>$ Recursos sociales: se perseguía el conocimiento de los recursos sociales de los principales ámbitos de protección social.

$>$ Ejes transversales: se incluían una serie de ejes transversales (en concreto, derechos humanos, relaciones norte-sur, pensamiento crítico y reflexivo, desarrollo comunitario, educación para la paz, y resolución de conflictos) que conformaban la base de las distintas áreas de los contenidos formativos.

En cuanto a la metodología del curso, estaba basada en el método investigación-acción participativa, e incluía tres líneas de implementación de las actividades formativas: la explicación de la realidad, la aplicación de los datos a dicha realidad, y la implicación mediante la organización de acciones que fomentaran la participación.

El cuerpo docente que impartió el curso estaba formado por profesionales expertos de las diferentes áreas de trabajo, así como por miembros de instituciones y agentes sociales.

El diseño curricular del curso estaba compuesto por seis grandes áreas y, en cada una de ellas, se perseguía desarrollar determinados conceptos, procedimientos y actitudes. A modo de resumen, expondremos a continuación algunos de los contenidos y objetivos tratados en las diferentes áreas. ${ }^{219}$

\section{Interculturalidad}

En esta área, se analizó el concepto de cultura y de identidad sociocultural, se estudiaron las diferencias entre multiculturalidad, pluriculturalidad e interculturalidad y se ahondó en la idea de sociedad intercultural como proyecto. Asimismo, se estableció una tipología de los prejuicios y los estereotipos, y se determinaron los componentes de los mismos. Se examinaron, además, las posibles causas de la exclusión social, el racismo y la xenofobia, así como los conceptos de etnocentrismo y relativismo. Igualmente, se incluyeron contenidos relacionados con la comunicación y el diálogo entre culturas, y con los modelos de integración, asimilación y adaptación.

En cuanto a los procedimientos, se trabajó sobre los mecanismos psicológicos de percepción de la realidad y sobre el proceso de reflexión sobre la propia identidad cultural.

Por lo que respecta a las actitudes, se trató de desarrollar una actitud de empatía y de análisis crítico de los propios patrones culturales, así como de despertar el interés por el conocimiento de otras culturas.

\footnotetext{
${ }^{219}$ Para mayor información sobre los contenidos detallados del curso, véase el programa formativo completo que se encuentra en los anexos.
} 


\section{Migraciones}

En esta área, se estudió el proceso y las causas de las migraciones, las políticas migratorias de Europa y España, así como las características sociodemográficas de las personas inmigrantes y su integración social. Se analizó, además, la legislación nacional e internacional en materia de inmigración, la evolución de la normativa referida a los extranjeros, y los derechos de las minorías.

Por otro lado, se examinaron los procedimientos fundamentales del sistema legislativo español, se llevó a cabo una valoración del inmigrante en situación administrativa irregular (con especial atención a su invisibilidad y a la denominada economía sumergida), y se realizó una clara diferenciación entre racismo y xenofobia.

Con respecto a las actitudes, se trató de potenciar actitudes de lucha contra la discriminación, se estimuló la reflexión en torno al modelo de acogida propuesto desde los diferentes servicios sociales, y se fomentó la actitud crítica hacia las leyes de extranjería y sus consecuencias discriminatorias.

\section{Mediación intercultural}

En esta área, se analizaron el concepto, los principios, las funciones, los modelos y las metodologías de trabajo de la mediación intercultural. Asimismo, se presentaron las partes implicadas y las fases del proceso, y se examinaron las técnicas de prevención y resolución de conflictos, los distintos ámbitos de actuación y los principios éticos que deben regir la labor del mediador intercultural.

En referencia a los procedimientos, se estudiaron los distintos modos para facilitar la comunicación intercultural (interpretación sociolingüística, interpretación sociocultural y apoyo personal a usuarios y profesionales). Se trataron, además, los mecanismos de cohesión social mediante la dinamización de la participación comunitaria, las estrategias de promoción de la autonomía y de inserción en la sociedad, y las pautas interculturales del conflicto.

Con relación a las actitudes, esta área se centró especialmente en aquellas relativas a la manera de situarse frente al mundo, ante sí mismo y ante el Otro, así como en las favorecedoras de la convivencia y la coexistencia en un mismo contexto de personas pertenecientes a distintas culturas.

\section{Planificación sociocultural}

En esta área, se trataron las diversas fases en las que se podría dividir una planificación sociocultural: análisis y conocimiento de la realidad; programación; organización de las acciones; ejecución e implementación de dichas acciones; y evaluación.

En cuanto a los procedimientos, se trabajó la planificación estratégica, se realizaron ejercicios de elaboración de árboles de problemas, de objetivos y de alternativas, se analizaron las causas y los posibles efectos de los conflictos socioculturales, y se estimuló la búsqueda de estrategias de resolución de dichos conflictos. 
En relación con las actitudes, se trató de promover la solidaridad y la tolerancia, mediante la superación de las inhibiciones y los estereotipos, el reconocimiento y la valoración crítica de la diversidad, y el rechazo a la discriminación basada en las diferencias de origen, sexo, clase social, creencias u otras características socioculturales.

\section{Comunicación interpersonal e intergrupal}

En esta área, se estudió el papel de la expresión corporal en la comunicación humana, los actos de habla, y la importancia de la escucha activa para mejorar la interpretación de los mensajes y de la intención.

Por otro lado, por lo que se refiere a los procedimientos, se examinó el papel de los sentimientos y los estados de ánimo en los intercambios comunicativos, y se trataron algunas técnicas de comunicación (como la interpretación lingüística y la asertividad).

Con respecto a las actitudes, se fomentó, por una parte, la empatía basada en el reconocimiento de todas las partes implicadas y, por otra, el desarrollo de mecanismos para llegar a un buen nivel de comprensión de los mensajes verbales y no verbales.

\section{Sistemas de organización social}

En esta área, se analizaron los factores clave del bienestar social como política, los sistemas de protección social y el papel de las asociaciones.

Se trabajaron, además, las fases del proceso de organización (programación, ejecución, coordinación, control y valoración), así como los aspectos organizativos de los ámbitos en los que actuarían los mediadores (educación, sanidad, servicios sociales de base, justicia, vivienda, participación vecinal y ámbito laboral), y se estudiaron el tejido y las estructuras asociativas.

Por último, por lo que se refiere a las actitudes, se promovió el trabajo en equipo y la cooperación, la implicación personal en la interacción grupal, así como la coordinación de esfuerzos y la integración de los resultados.

Hemos querido incluir los principales contenidos del diseño curricular del curso organizado por el SAMI porque consideramos que, por su exhaustividad y pertinencia, reúnen los requisitos indispensables para proporcionar los conocimientos, habilidades, destrezas y actitudes necesarios para que los profesionales que pasarían a formar parte del equipo de mediación intercultural pudieran desarrollar su labor con éxito.

A continuación, vamos a analizar las principales actividades desarrolladas por el SAMI en el contexto aragonés en el periodo comprendido entre 2008 y $2011 .{ }^{220}$ Atendiendo a los fines de nuestra investigación, nos centraremos en las actividades que estén relacionadas con nuestro ámbito de estudio, es decir, con la salud y la atención sanitaria de la población inmigrante.

Por lo que respecta al año 2008, los mediadores del SAMI organizaron y pusieron en marcha actividades de formación, de asesoramiento y de intervención.

${ }^{220}$ Desde el año 2012, por falta de presupuesto, se han reducido considerablemente las actividades llevadas a cabo por el SAMI, así como el número de mediadores que trabajan en el servicio. Además (o, en consecuencia), la última Memoria de actividades editada se corresponde al año 2011, por lo que no disponemos de datos más recientes. 
En cuanto a las actividades de formación en general, tal y como puede observarse en el gráfico que mostramos a continuación, el mayor número de seminarios impartidos ( $58 \%$ de un total de 271 seminarios) se centró en el sector sanitario. Además, fue en los seminarios dedicados a este sector donde hubo un mayor número de participantes $(65 \%$ de un total de 3.367 participantes). Si sumamos estos porcentajes a otro de los ámbitos de nuestra investigación (las mujeres), vemos cómo suman el $73 \%$ del total de seminarios realizados y el $74 \%$ de los participantes.

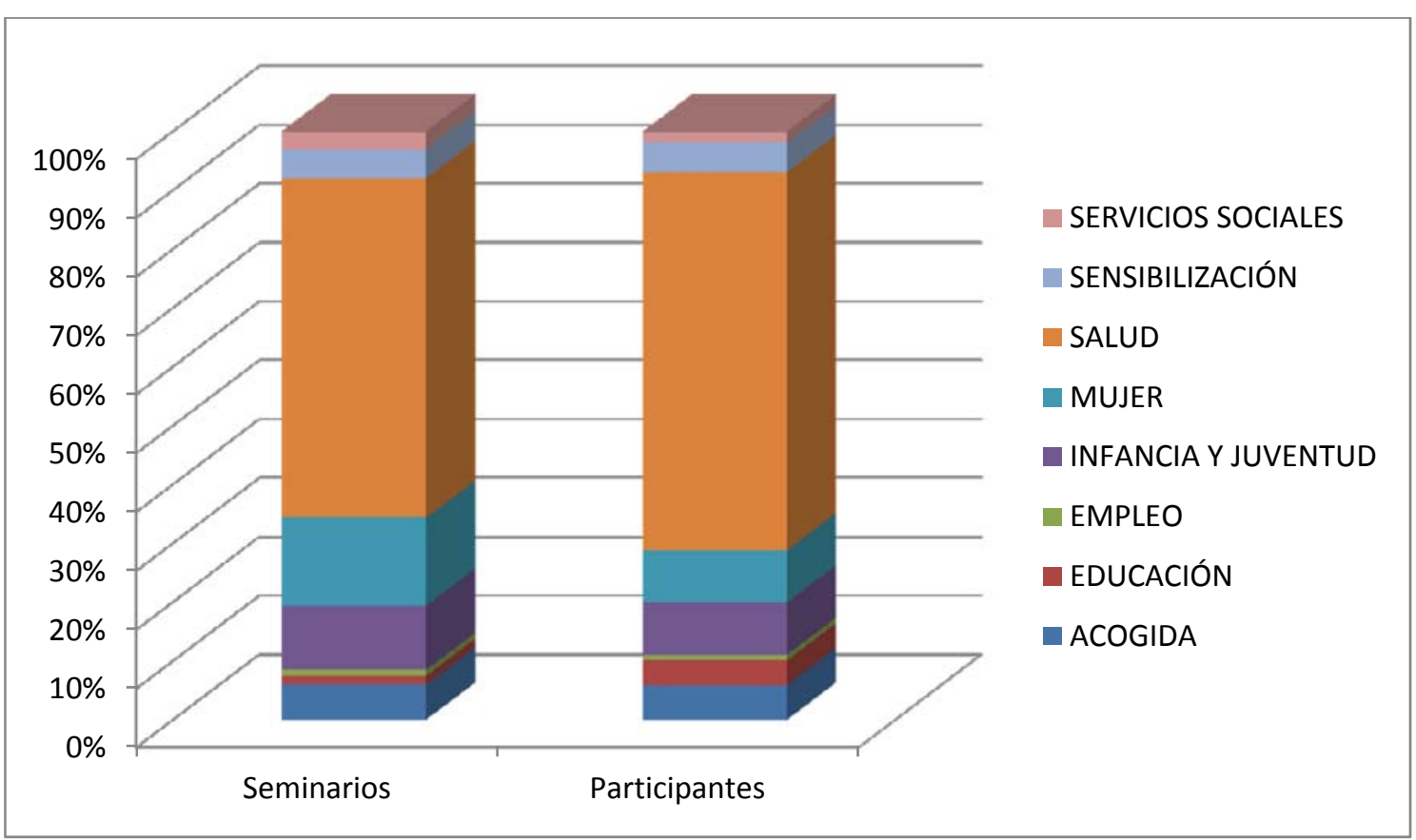

Gráfico 6.9. Seminarios del SAMI y participantes por sector (2008)

Por un lado, se realizaron catorce seminarios centrados en el desarrollo de la competencia intercultural para profesionales (sanitarios y no sanitarios) que trabajasen en el Sistema de Salud de Aragón. En concreto, siete de estos seminarios se destinaron al personal de atención especializada de los hospitales aragoneses, y otros siete a profesionales encargados de atención primaria en los centros de salud.

Los objetivos principales de estos seminarios consistían en:

$>$ Dar a conocer el contexto sanitario del que provienen los principales colectivos de usuarios extranjeros residentes en Aragón.

$>$ Identificar las principales diferencias culturales que pueden dificultar la atención (tanto sanitaria como no sanitaria) que se presta a estos usuarios.

$>$ Eliminar prejuicios y estereotipos que dificultan la relación profesional-paciente.

$>$ Conseguir que los profesionales de atención especializada tengan una visión diferenciada del usuario extranjero que permita ofrecerle un trato personalizado según su cultura de origen.

Entre los contenidos que se abordaron en dichos seminarios, se encontraban los siguientes: competencia comunicativa intercultural, claves culturales que influyen en la atención especializada a colectivos de usuarios extranjeros (con especial atención a aspectos como el 
encuentro con el sistema sanitario español, la exploración médica, el grado de cumplimiento de los tratamientos, la automedicación, las consultas de obstetricia y ginecología, la salud mental, etc.), discusión de casos prácticos sobre posibles situaciones de conflicto cultural o religioso, y recomendaciones y consejos en el trato a los usuarios de origen extranjero.

En total, los seminarios para profesionales de atención especializada contaron con la participación de 1.533 asistentes, los cuales trabajaban en los hospitales que se indican en el siguiente gráfico: ${ }^{221}$

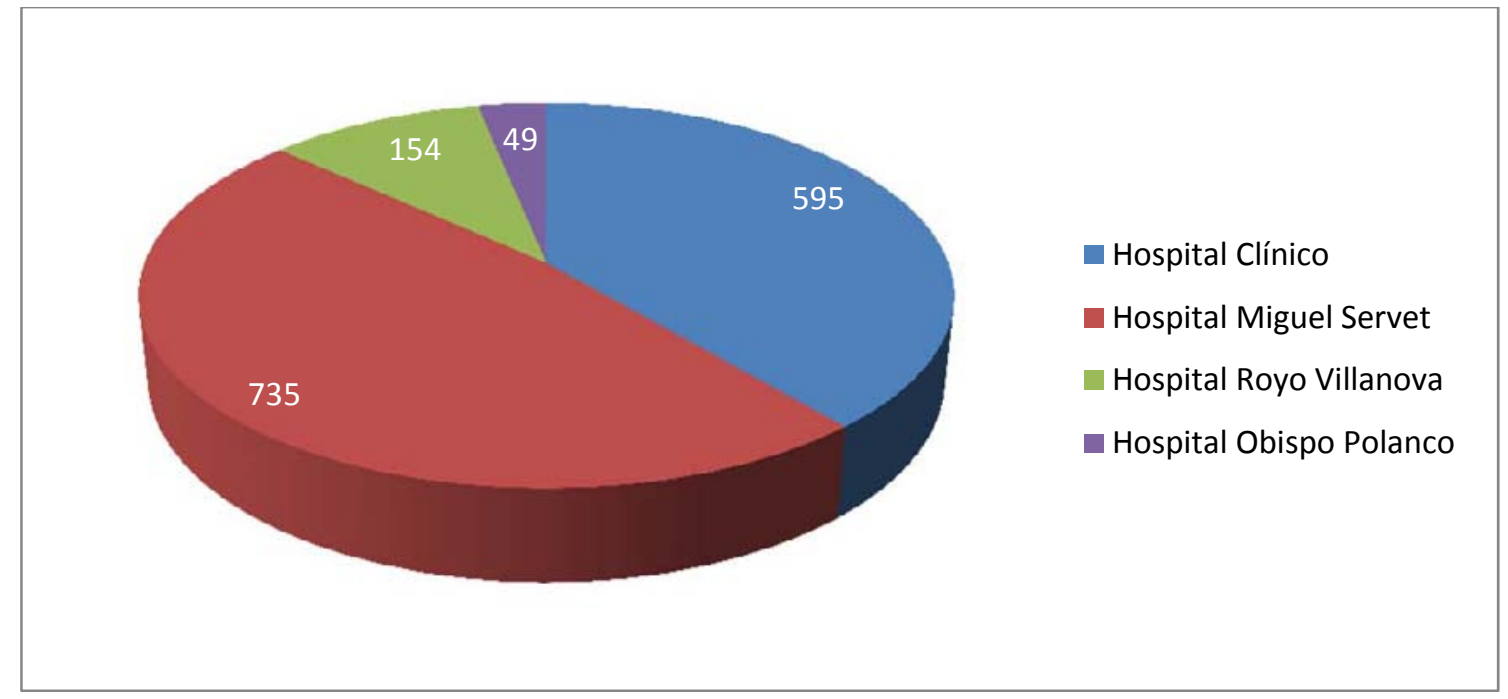

Gráfico 6.10. Participantes de los seminarios del SAMI para profesionales de atención especializada (2008)

El grado de satisfacción de los profesionales de atención especializada que participaron en estos seminarios fue bastante alto, como demuestra la valoración media que realizaron de los mismos que, de acuerdo con los resultados de los cuestionarios de evaluación que cumplimentaron al finalizar la actividad de formación, fue de 4,3 sobre 5.

\footnotetext{
${ }^{221}$ Se trata en todos los casos de hospitales situados en la ciudad de Zaragoza, excepto el Hospital Obispo Polanco, que se encuentra en Teruel.
} 
Por lo que se refiere a los profesionales de atención primaria, el número de participantes fue menor, 343 en total, y estos trabajaban a los centros de salud que aparecen en el gráfico que mostramos a continuación: ${ }^{222}$

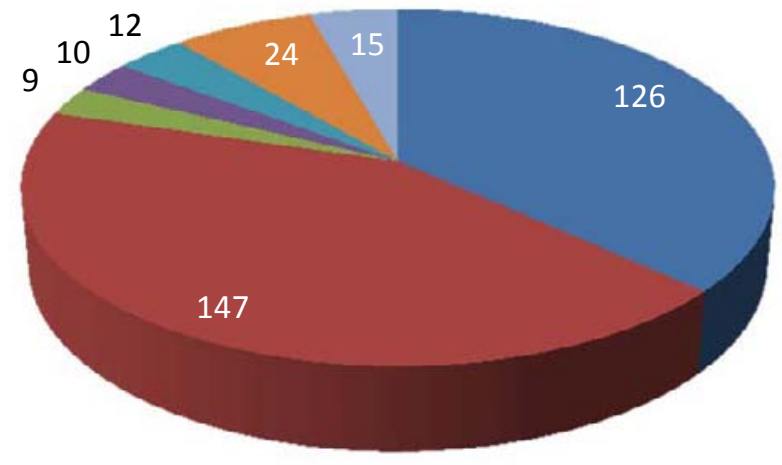

Centros de salud de Huesca

- Centros de salud de Barbastro

C.S. Actur

C.S. Bujaraloz

C.S. Casablanca

C.S. Torreramona

C.S. Universitas

Gráfico 6.11. Participantes de los seminarios del SAMI para profesionales de atención primaria (2008)

También en este caso, los participantes en los seminarios mostraron un alto grado de satisfacción; su valoración de la actividad formativa media fue, de hecho, de 4,24 sobre 5.

Por otro lado, los mediadores del SAMI proporcionaron formación a los miembros de la Federación Española de Religiosas Sanitarias (FERS) de Aragón, así como a los equipos de soporte de atención domiciliaria de Teruel. En el caso de este último grupo, el seminario impartido se centraba en las claves culturales y religiosas que pueden influir en los cuidados paliativos ofrecidos a pacientes procedentes del Magreb, Latinoamérica y Europa del este y, en concreto, sus contenidos se centraban principalmente en costumbres asociadas al fallecimiento, el entierro y el duelo por parte de dichos colectivos.

Entre las actividades de formación realizadas durante 2008, cabe destacar también los seminarios para los profesionales de la Dirección Provincial de Salud Pública de Zaragoza encargados de las vacunaciones internacionales y del tratamiento de enfermedades infecciosas (centrados en el contexto sanitario, los determinantes de salud y los factores culturales de los colectivos procedentes de África Subsahariana, el Magreb, Latinoamérica y Europa del este que influyen en el tratamiento de determinadas enfermedades infecciosas y tropicales), los seminarios para inspectores de Salud Pública sobre las características de los establecimientos de restauración internacionales de la EXPO Zaragoza que se celebró ese año (en los que se trató, entre otros contenidos, el perfil de los trabajadores del sector de la restauración, las peculiaridades de la cocina y la alimentación de los países analizados y el etiquetado internacional de los productos alimenticios), y los seminarios destinados a enfermeros del Banco de Sangre y Tejidos de Aragón (en los que se trataron los aspectos

\footnotetext{
${ }^{222}$ Nótese que la mayoría de los asistentes a los seminarios para profesionales de atención primaria procedían de la provincia de Huesca (centros de salud de Huesca y Barbastro), y solo el $16 \%$ del total de participantes en estos seminarios trabajaba en la provincia de Zaragoza.
} 
culturales que influyen en la atención a los donantes de sangre de los colectivos magrebí, subsahariano, europeo del este, latinoamericano y chino).

Por lo que se refiere a otro tipo de actividades en las que participaron mediadores del SAMI, nos gustaría resaltar, en primer lugar, su colaboración docente con la Facultad de Medicina de la Universidad de Zaragoza, impartiendo la asignatura optativa "Salud e inmigración" en la licenciatura de Medicina y en la diplomatura de Enfermería.

La última actividad del SAMI en el ámbito sanitario durante el año 2008 se centró en el área de la donación de órganos. En particular, por una parte, los mediadores ofrecieron asesoramiento a los coordinadores de trasplantes de los centros hospitalarios aragoneses mediante un taller en el que se trataron, entre otros, los siguientes contenidos: factores culturales que influyen en los procesos de donación de órganos de personas de origen extranjero, aspectos culturales en la comunicación del fallecimiento y en la solicitud de donación, y claves para ganarse la confianza de las familias del fallecido y obtener su autorización. Por otra parte, a petición del coordinador autonómico de trasplantes de Aragón, un grupo de mediadores (que habían recibido formación sobre la legislación española en materia de donación de órganos, así como sobre los aspectos médicos relativos a la muerte encefálica y los protocolos de actuación asociados) intervinieron dando apoyo en los procesos de donación de órganos en los que intervenían personas de origen extranjero.

Por lo que respecta al año 2009, las actividades formativas organizadas y puestas en marcha por los mediadores del SAMI comenzaron a descender, tanto en relación con el total de sectores, como, específicamente, por lo que se refiere al ámbito de la salud, tal y como puede verse en el gráfico que mostramos a continuación. De hecho, de los 199 seminarios impartidos, solo el $26,1 \%$ se centraban en dicho ámbito (frente al $58 \%$ del año anterior), y los profesionales sanitarios supusieron el $14,3 \%$ del total de 2.481 participantes. Durante dicho periodo, se trataron de fomentar, por el contrario, las acciones de sensibilización dirigidas a la población autóctona joven y adulta, así como aquellas relacionadas con la convivencia vecinal (sector Acogida) y la igualdad de género (sector Mujer).

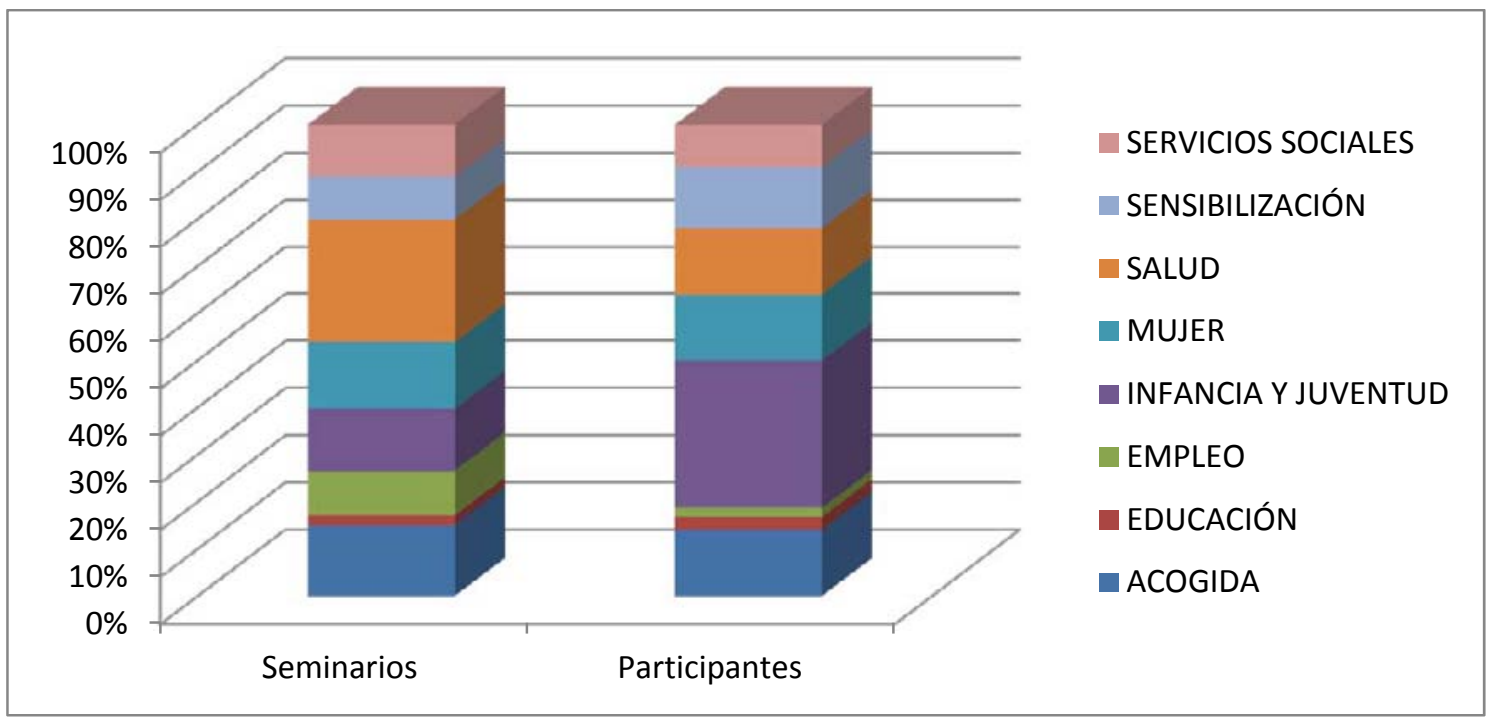

Gráfico 6.12. Seminarios del SAMI y participantes por sector (2009) 
Durante este periodo, se realizaron de nuevo los siete seminarios para profesionales (sanitarios y no sanitarios) de atención especializada, con los mismos contenidos y objetivos que los celebrados el año anterior. Todos los profesionales que participaron en estos seminarios trabajaban en hospitales de la ciudad de Zaragoza, tal y como puede observarse en el siguiente gráfico:

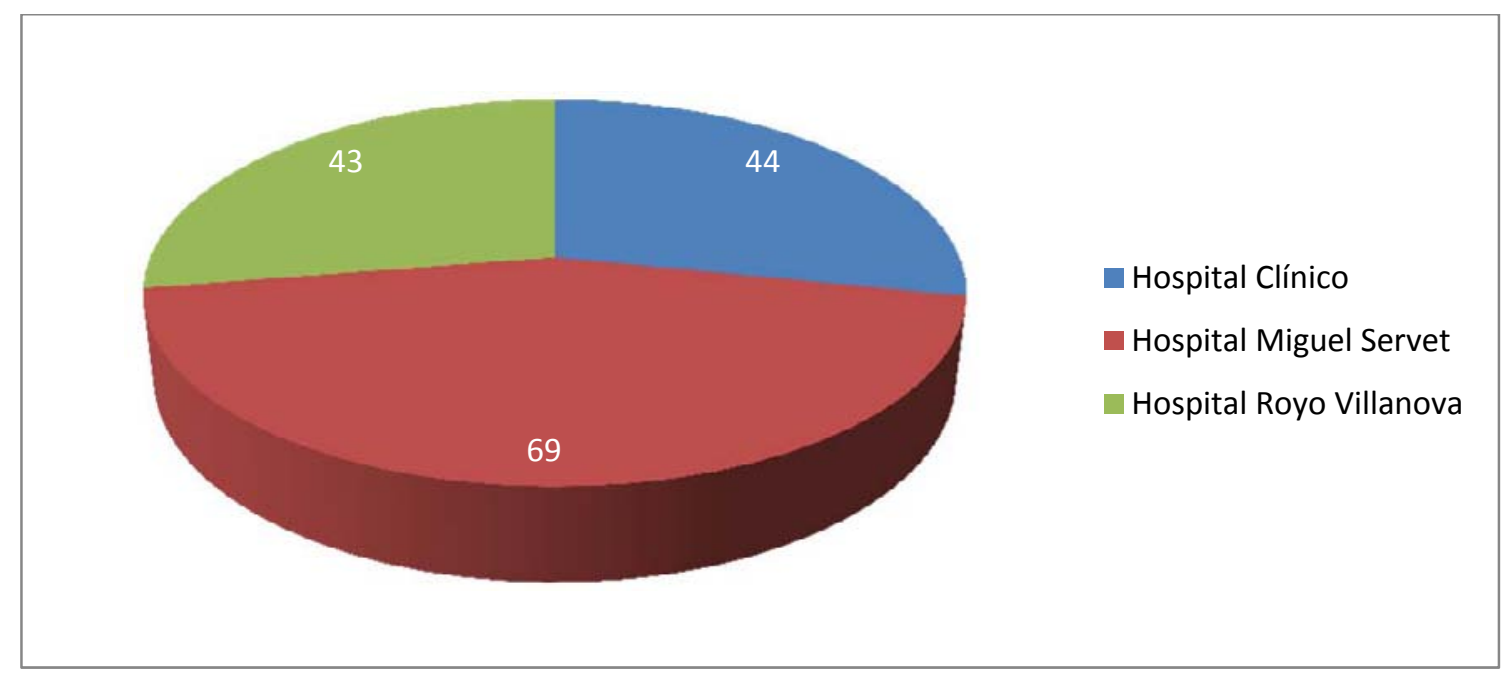

Gráfico 6.13. Participantes de los seminarios del SAMI para profesionales de atención especializada (2009)

El grado de satisfacción con respecto a la formación recibida por parte de estos profesionales de atención especializada fue, una vez más, bastante elevado, siendo la valoración media de los cuestionarios de evaluación de 4,63 sobre 5 .

Se continuó, asimismo, la colaboración con la Facultad de Medicina de la Universidad de Zaragoza, impartiendo de nuevo en este curso la asignatura optativa "Salud e inmigración".

Por otro lado, los mediadores del SAMI organizaron, junto con la Unidad Docente de Matronas de Zaragoza, una jornada de formación teórico-práctica para las enfermeras residentes del Hospital Clínico y del Hospital Miguel Servet de esta ciudad, con el objetivo de proporcionarles herramientas y metodologías para desarrollar la competencia comunicativa intercultural necesaria a la hora de atender a las usuarias de origen extranjero.

Además, impartieron dos seminarios sobre las claves culturales y religiosas que influyen en la labor de apoyo y acompañamiento de los enfermos oncológicos de origen magrebí y latinoamericano, cuyos destinatarios eran los voluntarios de la Asociación Española contra el Cáncer en Teruel.

Otras actividades formativas realizadas por los mediadores del SAMI durante 2009 fueron, por una parte, las destinadas a los agentes de Control Oficial de Seguridad Alimentaria, con el fin de facilitar las tareas de inspección de los establecimientos de restauración regentados por ciudadanos de origen magrebí, latinoamericano o chino y, por otra, las destinadas a algunos técnicos de farmacia de la ciudad de Huesca, cuyo objetivo consistía en analizar las claves culturales de los colectivos magrebí y subsahariano para permitir a dichos técnicos ofrecer un trato personalizado a estos usuarios de acuerdo con su cultura. 
En el año 2010, descendió ulteriormente el número de actividades formativas totales realizadas por el SAMI (pasando, en cuestión de un año, de 199 a 26); en particular, en el sector de la salud, la reducción de estas actividades fue significativa (pues se pasó del $26 \%$ del total de actividades del año anterior, al $4 \%$ en 2010). El mayor número de actividades y de participantes en las mismas durante este periodo se concentraron, como puede verse en el gráfico que presentamos a continuación, en los sectores de Acogida, Infancia y Juventud, y Mujer. Cabe señalar, además, que dejaron de impartirse seminarios para los sectores de Empleo y Educación.

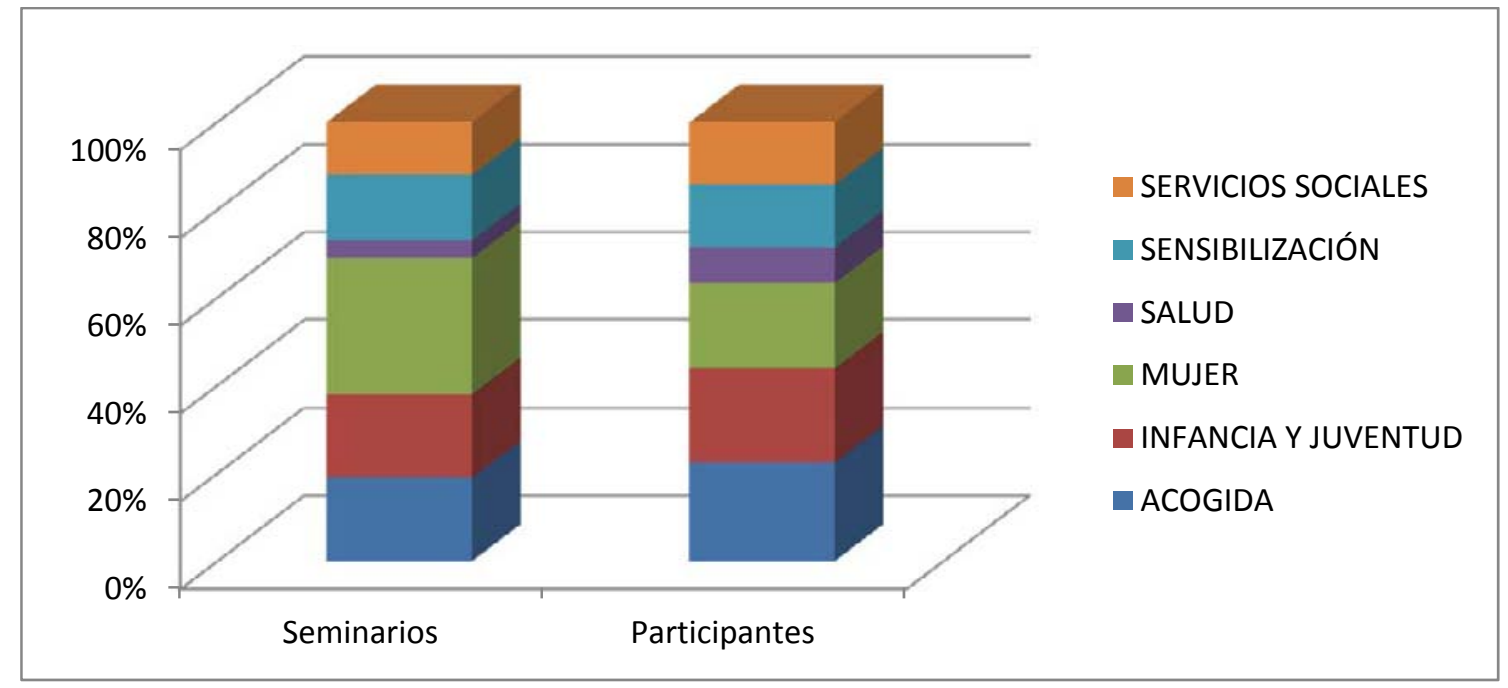

Gráfico 6.14. Seminarios del SAMI y participantes por sector (2010)

Concretamente, por lo que respecta al ámbito de la salud, solo se realizó un seminario sobre desarrollo de la competencia comunicativa intercultural para profesionales de atención primaria del municipio zaragozano de La Almunia de Doña Godina. 
Para finalizar el análisis de las actividades formativas organizadas por los mediadores del SAMI, por lo que se refiere al año 2011, volvió a disminuir el número total de seminarios, con un total de 14 durante todo ese año, aunque, en el caso de aquellos destinados al sector de la salud, se experimentó un ligero ascenso con respecto al año anterior (pues pasaron de suponer el $4 \%$ del total a representar el $9 \%$ ). Como puede observarse en el gráfico que presentamos a continuación, el mayor número de actividades de este periodo se concentró en los sectores de Acogida, Servicios Sociales y Mujer.

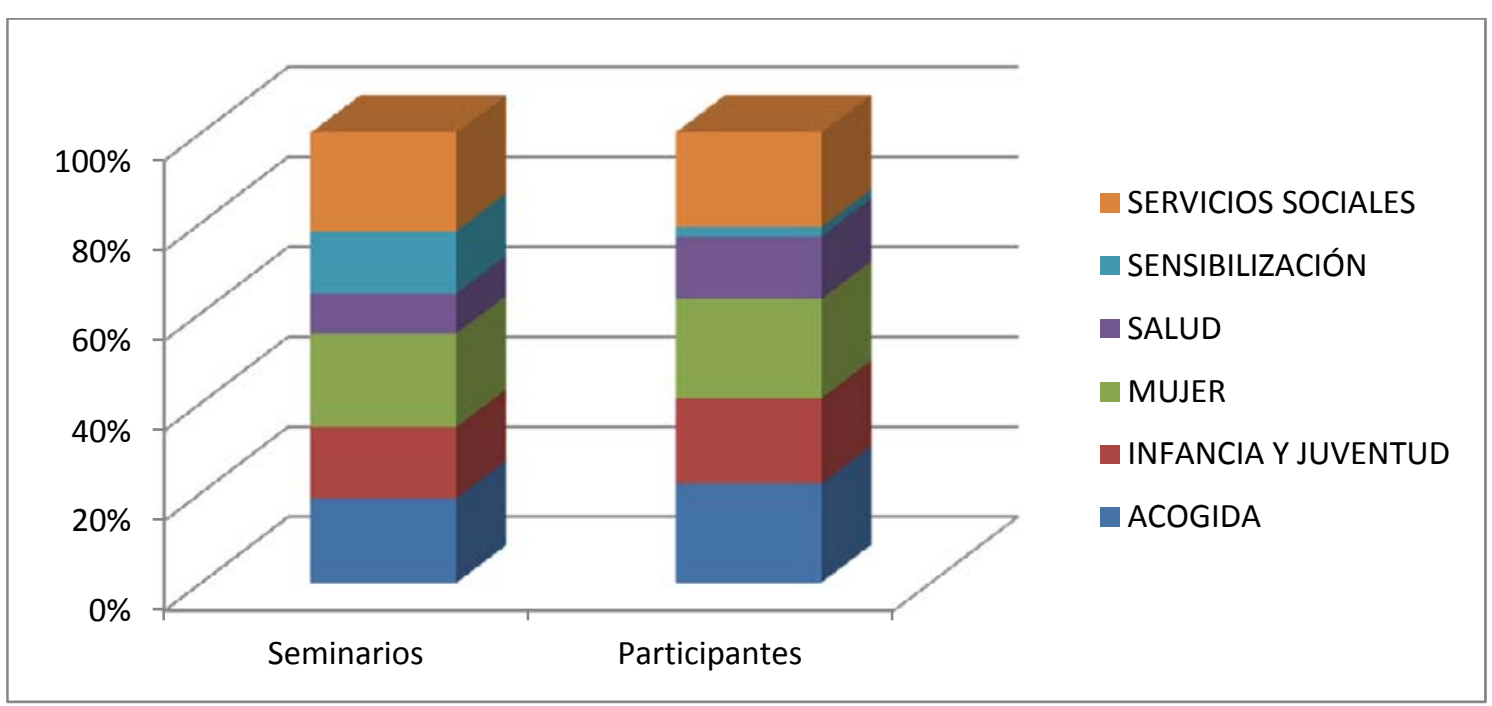

Gráfico 6.15. Seminarios del SAMI y participantes por sector (2011)

Las actividades formativas relacionadas con el ámbito de la salud organizadas durante este año fueron en total tres.

La primera de ellas estaba destinada a alumnos del grado en Psicología de la Escuela Superior de Estudios Aplicados Arké, situada en Zaragoza, y pretendía asesorarles y formarles sobre los factores culturales que influyen en la salud mental y en la atención a pacientes de origen extranjero.

La segunda se llevó a cabo en la Universidad San Jorge, universidad privada de esta misma ciudad, y los participantes fueron alumnos del grado en Traducción y Comunicación Intercultural. En concreto, el seminario se insertó dentro de los contenidos de la asignatura de "Mediación intercultural", y su objetivo principal consistía en analizar las claves culturales que pueden influir en la asistencia sanitaria a pacientes de origen extranjero y en desarrollar la competencia intercultural de los participantes.

Por último, se volvió a colaborar con la Unidad Docente de Matronas, organizando una actividad formativa similar a la que se había realizado con estos mismos profesionales en el año 2009.

Hay una serie de aspectos relacionados con todas estas actividades formativas descritas que quisiéramos destacar en positivo. En primer lugar, cubren las tres provincias de Aragón, así como un amplio espectro de los distintos sectores y áreas del ámbito de la salud. Asimismo, cabe señalar la adaptación de los contenidos formativos a las necesidades y prácticas de los diferentes profesionales que trabajan en este ámbito. Además, como demuestra la celebración 
de actividades también en contexto universitario, integran nuevos contenidos formativos en los planes de estudio $y$, por tanto, se imparten para profesionales tanto presentes como futuros. Por último, ponen énfasis en las pautas culturales de los colectivos inmigrantes con un mayor número de residentes en Aragón.

La última cuestión que vamos a analizar sobre las actividades desarrolladas por el SAMI se refiere a la investigación y la difusión de los resultados de dicha investigación. En concreto, de las distintas publicaciones que a lo largo de estos años han editado los mediadores de este servicio, nos centraremos, atendiendo a los fines de nuestro estudio, en la titulada Las claves que influyen en la atención sanitaria especializada a las personas de origen extranjero y técnicas para abordarlas con éxito (2007), de la cual se distribuyeron unos 300 ejemplares en el SARES (Sistema de Asesoramiento y Recursos en Educación para la Salud), ${ }^{223}$ en el Servicio Aragonés de Salud, y en algunas oficinas de inmigración.

La publicación se divide en tres grandes bloques. En el primero, a modo introductorio, se presenta el Servicio de apoyo a la mediación intercultural (SAMI), indicando las entidades que lo promueven, los principios por los que se rige, los servicios que ofrece y algunos ejemplos de actividades realizadas en el ámbito de la salud. En el segundo, centrado en la competencia intercultural en ámbito sanitario, se abordan los siguientes contenidos: el concepto de cultura y las relaciones interculturales; la comunicación intercultural y estrategias de desarrollo de la competencia intercultural; y los mecanismos y estrategias para eliminar o reducir las consecuencias negativas de los estereotipos y prejuicios. El tercer bloque y, a nuestro parecer, el más interesante, analiza de manera exhaustiva las claves culturales de los usuarios de origen extranjero. Se centra en apartados diferenciados en los colectivos procedentes de África Subsahariana, Asia, el Magreb, Latinoamérica y Europa del Este, ${ }^{224}$ y en él se ofrecen, por una parte, datos sobre el contexto sanitario de la zona de origen, la medicina tradicional, el concepto de salud y enfermedad, los determinantes de salud, y los factores culturales que influyen en su atención (con especial referencia al área de la ginecología y la obstetricia) y, por otra, algunas recomendaciones a la hora de tratar a estos usuarios.

Otra organización que se encarga de proveer servicios de mediación intercultural en ámbito sanitario en Aragón es Médicos del Mundo. La sede aragonesa de esta organización trabaja desde el año 1996 en el desarrollo de proyectos de atención integral a todos los colectivos que se encuentran en situación de riesgo o de exclusión social. En concreto, por lo que respecta a la salud de la población inmigrante, posee un Centro de atención socio-sanitaria (CASSIM), un programa de atención a la salud mental, y un programa de mejora de la salud sexual y reproductiva.

\footnotetext{
${ }^{223}$ El SARES, dependiente del Departamento de Sanidad, Bienestar Social y Familia del Gobierno de Aragón, tiene sede en las tres provincias aragonesas, y se ocupa de proporcionar asesoramiento para la puesta en marcha y desarrollo de programas de educación para la salud, así como de ofrecer para consulta y/o préstamo documentos relacionados con la promoción de la salud. Para mayor información, puede consultarse la página web: [http://www.aragon.es/DepartamentosOrganismosPublicos/Departamentos/SanidadBienestarSocialFamilia/AreasT ematicas/SanidadProfesionales/SaludPublica/PromocionSalud/ci.02_Sistema_Asesoramiento_Recursos_SARES.deta lleDepartamento] (última consulta: 18 de abril de 2013).

${ }^{224}$ Cabe señalar que se trata de los colectivos más representativos entre la población inmigrante residente en Aragón. Serán, además, los colectivos que estudiaremos en nuestro trabajo de campo.
} 
En cuanto a este último programa mencionado, los mediadores interculturales de Médicos del Mundo-Aragón (en su mayoría, mujeres), por una parte, realizan talleres de formación en materia de salud sexual y reproductiva, los cuales se imparten a demanda en distintos centros (asociaciones, colegios, servicios sanitarios, etc.), y cuyos destinatarios son tanto usuarias como profesionales. Los contenidos de dichos talleres se centran principalmente en la utilización de los servicios de obstetricia y ginecología, la planificación familiar y los cuidados durante el embarazo, aunque pueden ampliarse si los centros así lo solicitan.

Por otra parte, los mediadores interculturales de Médicos del Mundo-Aragón participan en un programa de prevención de prácticas perjudiciales para la salud, que, en especial, se ocupa de intervenir tanto a título individual como comunitario con el fin de erradicar la mutilación genital femenina. ${ }^{225}$ Este programa concreto tiene una incidencia significativa en nuestra investigación, ya que, tal y como podrá comprobarse en el análisis de los resultados de la misma, el hospital contexto de estudio forma parte del mismo. La participación del hospital se concreta en un protocolo de actuación según el cual, siempre que da a luz una mujer procedente de África Subsahariana (tanto si presenta mutilación como si no), se avisa a Médicos del Mundo y, durante los días que dicha usuaria permanece ingresada tras el parto, un mediador de la organización la visita y le informa de los riesgos que puede conllevar esta práctica.

Por último, la organización Médicos del Mundo-Aragón publicó en el mes de julio de 2013 una oferta de empleo para el perfil de mediador socio-sanitario. Las funciones a desempeñar por el mismo serían, de acuerdo con esta oferta, las siguientes:

- Tareas para el fortalecimiento de las asociaciones de inmigrantes y de la población inmigrante en general como actores de prevención y promoción de la salud.

- Labores de sensibilización dirigidas a las personas inmigrantes sobre la importancia de los cuidados y sobre la necesidad de adoptar una postura activa en la defensa de su derecho a la salud, a través de la organización de talleres, charlas y reuniones.

- Difusión entre las asociaciones de inmigrantes y la población inmigrante en general de la normativa vigente en materia de asistencia sanitaria y del Programa Aragonés de Protección Social a la Salud Pública.

- Desarrollo de acciones de traducción lingüística y de mediación intercultural sociosanitaria en los casos en que sea pertinente.

- Elaboración de informes de seguimiento y evaluación.

Los candidatos a postularse a esta vacante deben contar con una titulación media, formación en mediación (preferiblemente socio-sanitaria e intercultural) o experiencia demostrable en estos campos, y conocimiento de la situación de la población inmigrante con respecto al acceso a la atención sanitaria pública en Aragón. Asimismo, deben cumplir con los siguientes requisitos: habilidades sociales y comunicativas, conocimiento del tejido asociativo aragonés, y

\footnotetext{
${ }^{225}$ En los anexos incluimos el tríptico elaborado por Médicos del Mundo destinado a los colectivos de inmigrantes procedentes de los países donde se practica mayoritariamente la mutilación genital femenina (concentrados en especial, aunque no únicamente, en África Subsahariana). En dicho tríptico se informa resumidamente de las principales consecuencias que tiene esta práctica sobre la salud de la mujer y sobre la legislación española al respecto.
} 
dominio del castellano, del inglés y/o francés. Se valorará, además, el conocimiento de lenguas africanas.

Para finalizar este subapartado, siempre en relación con el ámbito de la mediación intercultural, cabe señalar la Proposición no de ley núm. 28/12, sobre la mediación intercultural y apoyo a profesionales y colectivos, que fue presentada en marzo de 2012 en las Cortes de Aragón por parte del Grupo Parlamentario de Izquierda Unida, y que fue aprobada por unanimidad.

Dicha Proposición no de ley, en primer lugar, daba respuesta a la demanda presentada por algunos profesionales sanitarios, los cuales manifestaban que tenían dificultades a la hora de atender a usuarios de origen extranjero. Asimismo, partía de la base de que, hasta el momento de su presentación, diversas entidades sociales sin ánimo de lucro habían estado llevando a cabo con éxito proyectos de mediación intercultural que, por un lado, facilitaban el acceso de la población inmigrante al sistema de salud público y, por otro, ofrecían formación al personal sanitario tanto en materia de interculturalidad como en relación con las especificidades culturales de los colectivos a los que debían atender.

Partiendo de estos antecedentes y esta justificación, la Proposición no de ley constaba de dos puntos: primero, proponía estudiar y analizar las memorias de actuación de las entidades sociales que, como se ha comentado, se habían ocupado hasta el momento de poner en marcha proyectos de mediación intercultural; segundo, planteaba la adopción de medidas y actuaciones con el fin de garantizar que los proyectos de mediación y formación en interculturalidad se siguieran desarrollando durante el año 2012.

Se establecieron, además, las funciones que le corresponden al mediador intercultural, las cuales, de acuerdo con la representante del grupo que presentó la Proposición, serían las siguientes:

- Mejorar la accesibilidad de la población inmigrante a los servicios sociales, fundamentalmente a los de salud.

- Fomentar la comunicación, el acercamiento, la comprensión mutua y el encuentro entre la población inmigrante y la comunidad sanitaria, con el objeto de prevenir la aparición de posibles conflictos.

- Informar, interpretar o traducir recursos materiales que permitan tomar decisiones y aplicar soluciones propias.

- Acompañar y asesorar a las personas de forma individual o grupal.

- Apoyar a los profesionales (trabajadores sociales, médicos, psicólogos y otros profesionales sanitarios).

- Realizar actividades de prevención y sensibilización.

Antes de concluir, quisiéramos resaltar los comentarios de dos representantes de otros grupos parlamentarios presentes en las Cortes de Aragón el día en que se planteó la Proposición, que, a nuestro parecer, resumen las dificultades que pueden surgir en la atención sanitaria a la población inmigrante y justifican ulteriormente la aprobación por unanimidad que esta Proposición tuvo. 
El primero de ellos fue realizado por el representante del Partido Aragonés, el cual recordó que la interculturalidad ${ }^{226}$ es un tema pasado, presente y futuro, y que los conflictos derivados de las diferencias en las costumbres, los hábitos, las creencias religiosas, etc. se siguen y se seguirán produciendo. Por este motivo, este representante parlamentario destacó la importancia de seguir adoptando aquellas medidas que pudieran contribuir a hacer que "esta interculturalidad sea cada vez menos un problema y más una realidad en una comunidad integrada" (2012:30).

Por su parte, el representante del Grupo Parlamentario Popular sostuvo que seguía existiendo una "brecha cultural" importante en el ámbito sanitario, que afectaba principalmente a las mujeres y niños inmigrantes, y que, para los profesionales de la salud, la atención a esas personas era en ocasiones "dificultosa o complicada", debido principalmente a las diferencias en el idioma, las tradiciones y las creencias religiosas (2012:30).

\subsubsection{Documentos traducidos a varios idiomas disponibles en los servicios sanitarios de Aragón}

Entre los recursos y estrategias empleados en el ámbito sanitario aragonés para facilitar tanto el acceso y el uso del sistema de salud público como la comunicación entre los profesionales y los usuarios de origen extranjero, se encuentran, además de los servicios de interpretación y mediación intercultural analizados, numerosos documentos traducidos a los idiomas de las principales comunidades inmigrantes residentes en Aragón.

Con el fin de acotar el análisis documental de las publicaciones editadas o traducidas a otros idiomas, nos centramos, dentro del contexto sanitario, en aquellas que están relacionadas con la salud reproductiva, ámbito principal de nuestro estudio.

En primer lugar, quisiéramos señalar la publicación Cuídame: guía para padres y madres. Se trata de una guía informativa elaborada por el Departamento de Salud y Consumo de Aragón y editada en español, árabe, francés y rumano, ${ }^{227}$ en la cual se ofrecen consejos y recomendaciones relacionados con el estado físico y la salud de las puérperas y los recién nacidos. Entre otros datos, proporciona información relativa a la inscripción del recién nacido, los cuidados y controles durante el puerperio, la alimentación aconsejada, etc. Por un lado, nos llama la atención el hecho de que, entre las lenguas a las que esta guía fue traducida, no se encontraran otras igualmente necesarias en el contexto de estudio, como puede ser el chino o el inglés. Por otro lado, hemos accedido a la guía a través de Internet, pero desconocemos si existe la publicación en formato de papel y, en caso afirmativo, de qué manera se distribuyó a los potenciales (padres y madres) destinatarios. Cabe considerar que, entre la población inmigrante, puede haber personas que no dispongan acceso a Internet, por lo que, si la guía solo contara con este medio de difusión, no podría disponer de ella un segmento de la

\footnotetext{
226 Partiendo de la definición de los términos "multiculturalismo" e "interculturalidad" propuestos por Miquel Rodrigo Alsina (1999), de acuerdo con el cual, el primero se referiría a la coexistencia de distintas culturas en un mismo espacio real, mediático o virtual, mientras que el segundo se aplicaría a las relaciones que se dan entre las mismas, creemos que, cuando el representante en cuestión emplea el término "interculturalidad" en este contexto, se está refiriendo en realidad al concepto de multiculturalismo, es decir, a la configuración de las actuales sociedades en las que residen personas procedentes de diversos países y culturas.

${ }^{227}$ En los anexos incluimos la portada y el índice de la publicación "Cuídame: guía para padres y madres" en cada uno de los idiomas mencionados.
} 
población inmigrante. Tampoco sabemos de qué modo se dan a conocer este tipo de recursos, por lo que es probable que una parte considerable de los potenciales destinatarios no tengan noticia de los mismos.

En segundo y último lugar, por lo que respecta concretamente al hospital contexto de nuestro estudio, este dispone de diversos documentos traducidos. En concreto, por una parte, cuenta con dos documentos informativos editados por el propio hospital y disponibles en diversos idiomas (en concreto, en español, árabe, chino, francés, inglés y rumano), ${ }^{228}$ que se encuentran en las plantas de puerperio. Uno de ellos proporciona información básica sobre el funcionamiento del servicio de obstetricia, como, por ejemplo, el nombre del personal sanitario (jefe de servicio, jefes de sección, médicos adjuntos y responsable de enfermería), el teléfono de contacto, los horarios de visitas y comidas, el procedimiento de alta hospitalaria, etc. El otro, recoge una serie de pautas y recomendaciones para el cuidado de los recién nacidos. Consideramos que, en ambos casos, la traducción de estos documentos a las lenguas maternas de las principales comunidades de usuarias favorecerá el conocimiento por su parte de información relevante durante su estancia hospitalaria, promoviendo, además, la equidad en el acceso a esta información. Sin embargo, cabe señalar que nosotros accedimos a estos documentos gracias a la responsable de planta, quien nos los proporcionó, pero en ningún momento observamos durante el trabajo de campo que las usuarias inmigrantes que participaron en nuestra investigación dispusieran también de ellos, ni los mencionaron cuando tratamos el tema de los documentos traducidos a otros idiomas y disponibles en el hospital contexto de estudio. Por tanto, no sabemos si se está realizando un adecuado uso de este recurso disponible.

Por otra parte, el hospital cuenta con consentimientos informados traducidos a los mismos idiomas mencionados previamente (árabe, chino, francés, inglés y rumano), ${ }^{229}$ que se encuentran en la zona de paritorios. Como veremos en el análisis de los resultados de nuestra investigación, estos consentimientos son mencionados en numerosas ocasiones por los profesionales sanitarios, especialmente aquellos que los emplean a menudo (como es el caso de los anestesistas), y consideran en su mayoría que se trata de un recurso muy útil. Sin embargo, también plantean algunos inconvenientes que el uso de este recurso puede conllevar, entre los que destacan los siguientes: en primer lugar, la traducción de los consentimientos no tiene ninguna utilidad en el caso de las usuarias que, al ser analfabetas, no pueden leerlos; en segundo lugar, de acuerdo con algunos profesionales, los consentimientos traducidos no siempre se encuentran a su alcance o desconocen a quién recurrir para obtenerlos; además, el hecho de que estén editados en un solo idioma impide que se diferencien los diferentes consentimientos (para el suministro de la anestesia epidural, para el parto por cesárea, etc.), o incluso que el profesional pueda saber si la usuaria ha firmado en el lugar destinado a autorizar la intervención o a no autorizarla; asimismo, tanto algunos

\footnotetext{
${ }^{228}$ La inclusión en los anexos de estos documentos nos planteó ciertas dudas de carácter ético, ya que, por la información que contienen, se podría identificar cuál es el hospital contexto de estudio. Finalmente decidimos incluir en los anexos copias de estos documentos informativos traducidos, pero, con el fin de preservar la confidencialidad del hospital, hemos eliminado los datos que pudieran ayudar a identificarlo.

${ }^{229}$ En los anexos incluimos los consentimientos informados para el suministro de la anestesia epidural en todos los idiomas disponibles. Cabe señalar que, si bien se nos indicó en el hospital que también disponían de consentimientos informados para los partos por cesárea, ningún profesional de los varios a los que solicitamos estos documentos, pudo encontrar en ese momento copias de los mismos.
} 
profesionales como algunas usuarias reconocen que, por el estado anímico en que se encuentran las mujeres antes de dar a luz, en ocasiones ni siquiera leen los consentimientos antes de firmarlos, por lo que, aparte de entregarles este documento para que lo firmen, se deberían añadir ulteriores explicaciones verbales sobre la intervención que se va a efectuar, así como sobre los efectos y riesgos que esta conlleva. Cabe añadir, igualmente, que este recurso, en todo caso, resulta insuficiente, principalmente porque la usuaria alófona no podrá plantear sus dudas tras haberlo leído, ni el profesional podrá ofrecerle ulteriores indicaciones o aclaraciones.

\subsection{Análisis de las entrevistas}

Nuestro propósito principal con el empleo de esta técnica consistía, tal y como hemos comentado anteriormente, en obtener información detallada sobre las experiencias y puntos de vista de los entrevistados en relación con los temas o preguntas que les íbamos planteando.

Antes de exponer nuestro análisis de los datos obtenidos mediante las entrevistas, deberíamos realizar una serie de consideraciones previas. Por una parte, aunque en la selección de los entrevistados hemos seguido criterios de representatividad y de pertinencia, cabe tener en cuenta que la participación de carácter voluntario en el estudio ha hecho que contáramos solo con aquellos sujetos que estuvieran dispuestos a participar y que quedaran excluidos aquellos que, por uno u otro motivo, no hubieran mostrado interés en colaborar.

Por otra parte, como hemos comentado en el capítulo 2, somos conscientes de que existe la posibilidad de una cierta "falsificación de los hechos" por parte de los sujetos entrevistados, ya que estos pueden haberse visto influidos por la propia presencia de la investigadora y no corresponderse lo que relatan con lo que realmente hacen o piensan.

Además, en el caso de las usuarias entrevistadas, cabe considerar que el hecho de que su origen cultural no se corresponda con el de la investigadora podría influir en la interpretación de sus respuestas. Así, tal y como sostienen Howard S. Becker y Blanche Seer (1957: 28-29, citados en Berg, 2009: 116),

\footnotetext{
Although we speak one language and share in many ways in another culture, we cannot assume that we understand precisely what another person speaking as a member of such a group means by a particular word. In interviewing members of groups other than our own, then, we are in somewhat the same position as the anthropologist who must learn a primitive language, with the important difference that we often do not understand that we do not understand and thus likely to make errors in interpreting what is being said to us.
}

Una vez presentadas estas consideraciones, que conllevan una interpretación crítica de los datos obtenidos mediante las entrevistas, por una parte, y el empleo posterior de otras técnicas que nos permitan ampliar y corroborar estos datos, por otra, pasamos a comentar los rasgos generales del análisis de los mismos.

Tal y como hemos indicado previamente, las entrevistas realizadas a los participantes en esta fase del estudio han sido grabadas en audio y transcritas literalmente, para, posteriormente, introducir estas transcripciones como fuentes de análisis en un proyecto elaborado con el programa NVivo 10. 
En el análisis de los datos obtenidos mediante las entrevistas hemos seguido los siguientes pasos (Kvale, 2007: 107): primero, hemos leído varias veces las transcripciones íntegras para tener una visión de conjunto de los datos; en segundo lugar, hemos fragmentado los datos en unidades de análisis; en tercer lugar, hemos ido codificando dichas unidades de análisis de acuerdo a la estructura de nodos previamente elaborada; ${ }^{230}$ a continuación, hemos agrupado los nodos en los temas relevantes para nuestro estudio; y, por último, hemos descartado aquellos elementos que, por alejarse de los fines de nuestra investigación, no fueran relevantes.

La estructura general de la clasificación por nodos es la siguiente:

1. Categorías contextuales

2. Categorías generales demográficas

3. Categorías conceptuales o teóricas

Asimismo, hemos creado un nodo general denominado "Excellent quotes" en el que hemos ido incluyendo aquellas citas que resultaran de especial relevancia, independientemente del tema con el que estas estuvieran relacionadas, para incluirlas más tarde verbatim en este capítulo de análisis.

\subsubsection{Datos contextuales y demográficos}

Presentamos en primer lugar las categorías contextuales y demográficas, a pesar de que somos conscientes de que estas no forman parte del análisis propiamente dicho. La razón por la que hemos decidido incluir estas categorías en este capítulo es para facilitar la lectura y comprensión de los datos recolectados y permitir que, siempre que sea pertinente, se puedan relacionar las características del contexto y de los sujetos investigados con las respuestas ofrecidas por los mismos.

En primer lugar, por lo que respecta a los datos contextuales, cabe señalar que, antes de comenzar las entrevistas propiamente dichas, anotábamos una serie de datos contextuales, principalmente relacionados con el lugar y la fecha de realización de las mismas.

En total, realizamos 49 entrevistas en el periodo comprendido entre el 9 de mayo de 2012 y el 17 de octubre de 2012.

Por lo que respecta al lugar de realización, todas ellas excepto una se efectuaron en el hospital materno-infantil contexto de estudio. La única que realizamos fuera de este recinto tuvo lugar en un despacho de la Universidad San Jorge (Zaragoza), institución en la que trabajan tanto la investigadora como el entrevistado en cuestión, que compagina su labor de docente con la de matrón.

Podemos dividir los lugares de realización de las entrevistas en dos grandes bloques. Por una parte, a los profesionales sanitarios se les entrevistó en su unidad o departamento habitual de

\footnotetext{
${ }^{230}$ Cabe señalar que, aunque la estructura de nodos se elaboró previamente a la codificación de las diferentes unidades de análisis, esta estructura fue ampliándose y modificándose a medida que avanzaba el análisis de los datos, de acuerdo al diseño metodológico emergente que hemos seguido. Asimismo, quisiéramos recordar que, en algunas ocasiones, hemos codificado una misma unidad de análisis en diferentes nodos, ya que esta hacía referencia a diferentes temas analizados.
} 
trabajo y, más concretamente, en salas de reuniones, salas de descanso, salas de consulta, salas de baño de bebés, o despachos y puntos de información para usuarios, situados en las plantas baja, primera, quinta y séptima del hospital o en el área de urgencias o la de paritorios. Por otra parte, a todas las usuarias se les entrevistó en las zonas de puerperio situadas en las plantas quinta y séptima del hospital y, más concretamente, en la habitación en la que estaban ingresadas tras el parto. No efectuamos ninguna entrevista a las usuarias ingresadas en la zona de puerperio situada en la sexta planta, pues allí se encontraban las usuarias durante los primeros días tras un parto con complicaciones $y$, de acuerdo con la opinión de los propios profesionales sanitarios, por lo general su estado de salud no les hubiera permitido contestar a las preguntas planteadas en las entrevistas.

Asimismo, durante las entrevistas, anotábamos en nuestro diario de campo otros datos contextuales que pudieran resultar de interés para la investigación, centrados principalmente en la presencia de otras personas en el contexto de estudio (profesionales sanitarios, familiares y acompañantes o el recién nacido) o en situaciones o interacciones inesperadas que se dieran durante la realización de las entrevistas. Presentaremos estos otros datos contextuales más adelante, en el análisis de los datos obtenidos mediante la técnica de la observación no participante.

Por último, una vez finalizadas las entrevistas, registrábamos la duración de las mismas, que estaba comprendida entre 7 minutos y 25 segundos (la más breve) y 48 minutos y 30 segundos (la de mayor duración). Cabe destacar que, aunque el número de preguntas planteadas era similar en todos los casos, por lo general, las entrevistas realizadas a profesionales sanitarios solían durar más que las efectuadas a usuarias, con una duración media de 27 minutos y 30 segundos y de 15 minutos y 46 segundos respectivamente. Esta diferencia en la duración de las entrevistas entre los dos grupos de sujetos se preveía antes de la realización de las mismas por diferentes motivos, y quedó confirmada cuando estas se realizaron. Aparte del mayor dominio del idioma empleado en la entrevista por parte de los profesionales sanitarios, cabe añadir otros factores, como la situación psico-emotiva en la que se encontraba cada grupo (las usuarias en un contexto "extraño" y con la situación añadida de haber dado a luz unas horas antes, los profesionales sanitarios en su lugar habitual de trabajo), y como el hecho de que las usuarias hablaran de su propia, breve y única experiencia en el contexto del hospital, y los profesionales comentaran sus experiencias con múltiples usuarias y durante largos periodos de tiempo.

Tras la anotación de los datos contextuales, comenzábamos la entrevista propiamente dicha con una serie de preguntas relacionadas con los datos demográficos generales de los entrevistados. ${ }^{231}$

Los datos demográficos se presentan divididos en los dos grupos principales de entrevistados, es decir, profesionales sanitarios, por un lado, y usuarias inmigrantes, por otro. Ambos grupos compartían algunas de las cuestiones planteadas (como edad, lengua materna y lenguas habladas) y se diferenciaban en otras (como el sexo, que en el caso de las usuarias era siempre

\footnotetext{
${ }^{231}$ Véanse en los anexos las tablas que resumen los principales datos demográficos de los sujetos participantes en las entrevistas.
} 
femenino, o el lugar de procedencia y el tiempo de permanencia en España, datos relevantes solo en el caso de estas últimas).

Asimismo, en este bloque de datos demográficos se preguntaba a los informantes por su nombre y se les solicitaba un teléfono o dirección de correo electrónico de contacto. Obviamente, estos dos últimos datos no se revelarán por cuestiones de anonimato y confidencialidad.

\section{a) Profesionales sanitarios}

Entrevistamos en total 24 profesionales sanitarios, divididos en los siguientes perfiles profesionales: anestesistas (5), enfermeros (6), matrones (7), obstetras (3) y profesionales socio-sanitarios (3). Este último grupo estaba compuesto por la trabajadora social del hospital y por dos auxiliares de enfermería encargadas de labores de información a las usuarias y a sus familias. ${ }^{232}$

La mayoría de los profesionales entrevistados (16 del total de 24), tal y como se puede observar en el gráfico que aparece a continuación, eran mujeres, excepto en el caso de los anestesistas, que eran casi todos ellos hombres. Como comentaremos en el posterior análisis de los datos, la predominancia de mujeres entre los profesionales sanitarios entrevistados puede haber determinado en cierto sentido algunas de las respuestas obtenidas.

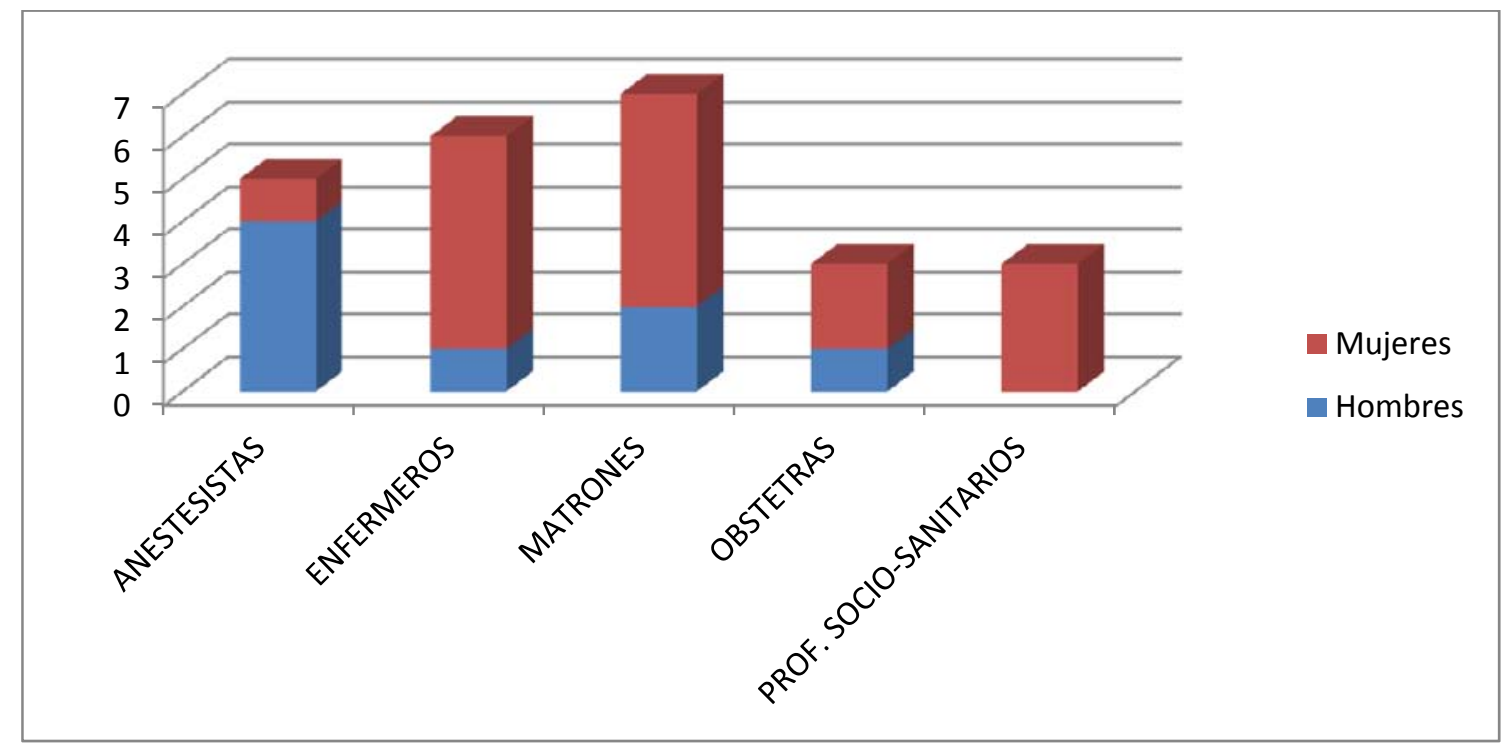

Gráfico 6.16. Perfil profesional y sexo de los profesionales participantes en las entrevistas

\footnotetext{
${ }^{232}$ A pesar de que todos los profesionales que han participado en el estudio podrían englobarse dentro de la categoría "profesionales socio-sanitarios", hemos incluido en este grupo solo a los tres últimos sujetos indicados con el fin de preservar su anonimato, pues se trataba de perfiles muy concretos (o únicos dentro del hospital contexto de estudio, como es el caso de la trabajadora social).
} 
En referencia a la edad de los profesionales entrevistados, esta estaba comprendida entre los 26 y los 61 años. La mayoría de ellos tenía entre 26 y 45 años, siendo la edad media de todos los profesionales relativamente joven, de 42 años. En concreto, estaban distribuidos por edad tal y como figura en el siguiente gráfico:

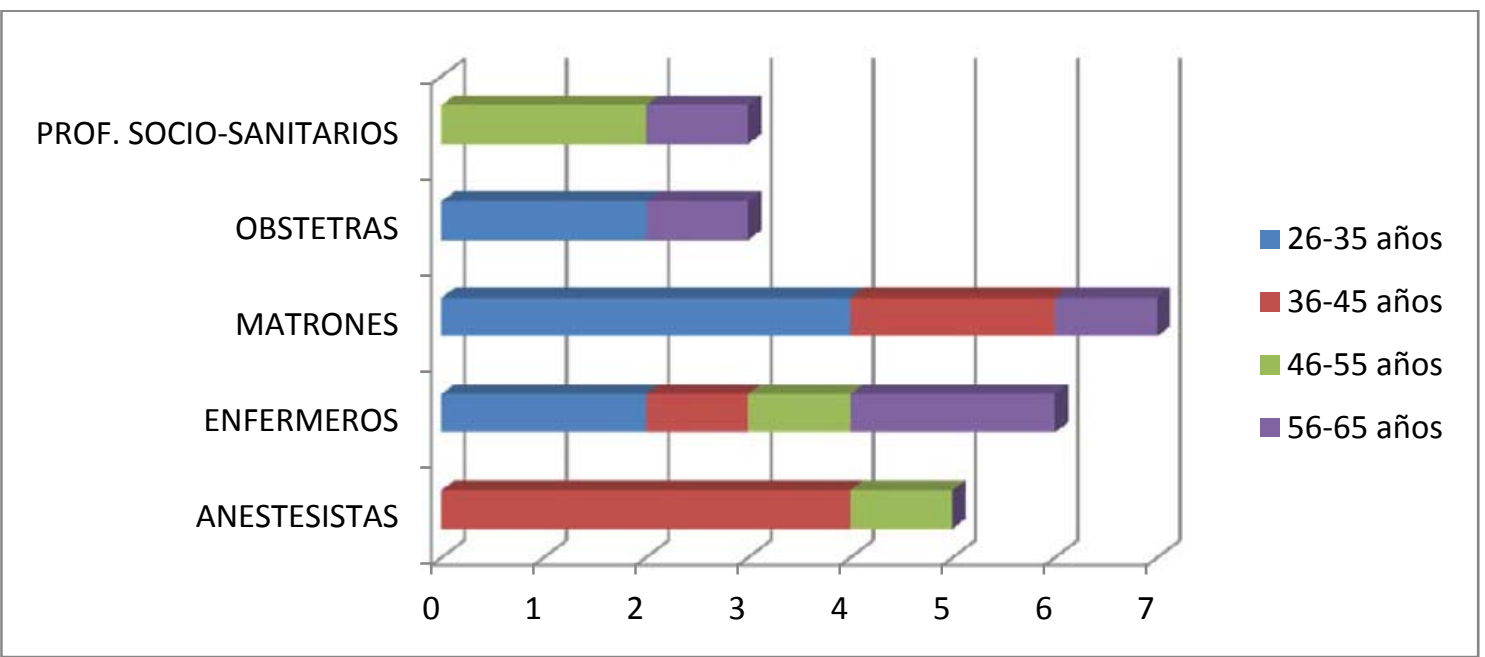

Gráfico 6.17. Perfil profesional y edad de los profesionales participantes en las entrevistas

Por lo que respecta a la lengua materna de los profesionales entrevistados, esta era en todos los casos el español. En cuanto a las lenguas extranjeras habladas, un gran número de profesionales (17) afirmó conocer el inglés, un número considerable (8) conocía el francés, algunos (4) hablaban italiano y, en menor medida, árabe (2), alemán (1) y catalán (1). Por otro lado, cuatro de los profesionales entrevistados no tenían ningún conocimiento de lenguas extranjeras.

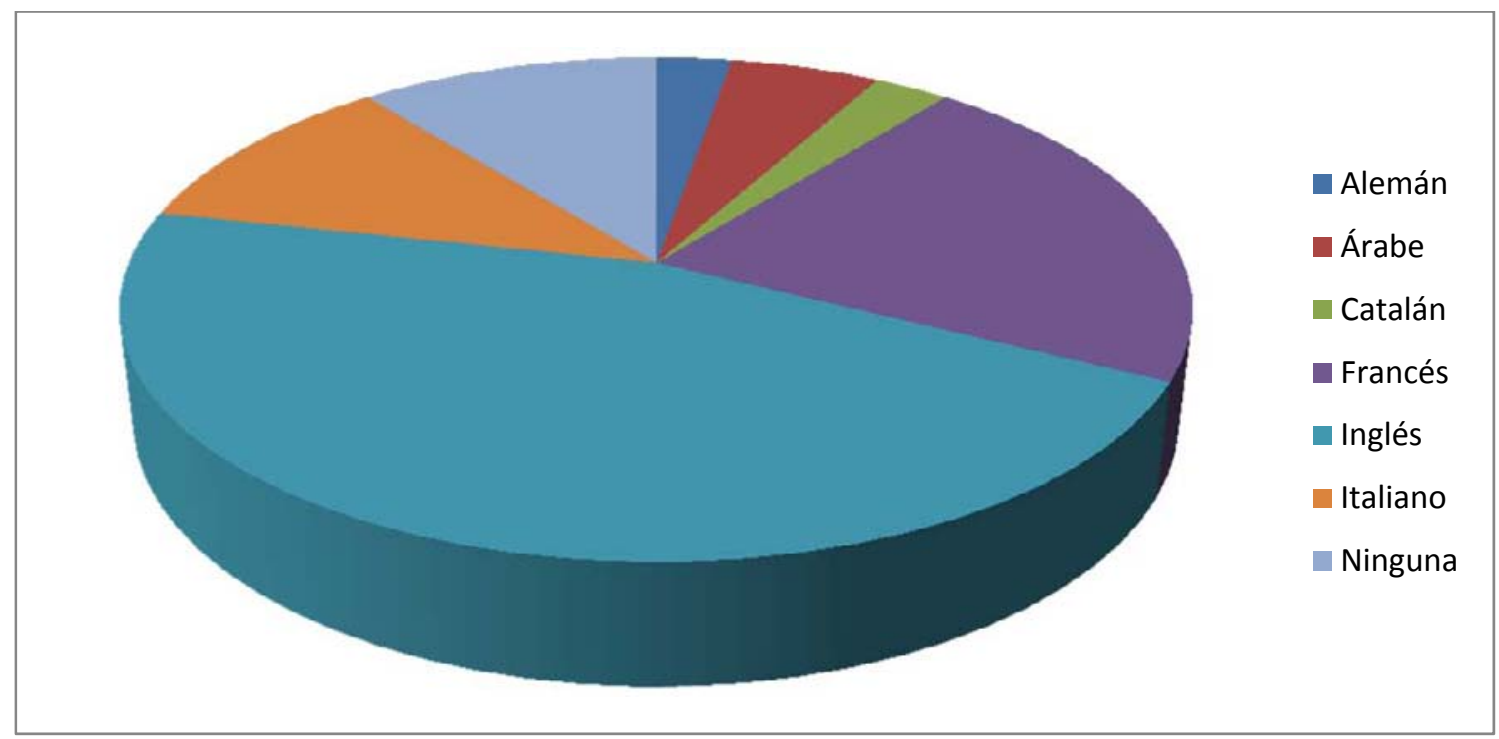

Gráfico 6.18. Lenguas extranjeras habladas por los profesionales participantes en las entrevistas

Cabría destacar que estos conocimientos lingüísticos, de acuerdo con los propios profesionales entrevistados, eran en algunas ocasiones a nivel básico, especialmente por lo que respecta al árabe. Asimismo, las lenguas extranjeras habladas por los profesionales no se correspondían 
en la mayoría de los casos con las lenguas maternas de las principales comunidades de usuarias inmigrantes residentes en la ciudad donde se lleva a cabo el estudio.

\section{a) Usuarias}

Entrevistamos en total 25 usuarias inmigrantes, las cuales se agruparon por procedencia en cinco grandes zonas: África Subsahariana (5), Asia (4), Europa del este (6), Latinoamérica (5) y Magreb (4). Asimismo, aunque su origen no era extranjero, entrevistamos también a una usuaria de la comunidad gitana, ya que los profesionales sanitarios entrevistados habían mencionado hasta el momento en diversas ocasiones a las usuarias de este colectivo, especialmente en relación con los problemas derivados de los excesivos acompañantes o del incumplimiento de las normas del hospital.

En concreto, las usuarias procedían de los siguientes países:

África Subsahariana: Camerún (1), Ghana (1), Nigeria (2) y Senegal (1)

Asia: China (3) y Pakistán (1)

Comunidad gitana: España (1)

Europa del este: Rumanía (5) y Ucrania (1)

Latinoamérica: Brasil (1), Colombia (1), Ecuador (2), Honduras (1)

Magreb: Argelia (2), Marruecos (1) y Mauritania (1)

Por lo que se refiere a la edad de las usuarias, esta estaba comprendida entre los 20 y los 40 años, estando la mayoría de ellas en la franja de edad entre los 26 y los 35 . Las usuarias que, de media, presentaban una edad más joven eran las procedentes de Asia y de Latinoamérica, con una edad media de 27 y 26 años respectivamente, y las que presentaban una edad media mayor eran las procedentes de África Subsahariana y de Magreb, en ambos casos con una edad media de 34 años. Su distribución por franjas de edad era la que figura en el siguiente gráfico:

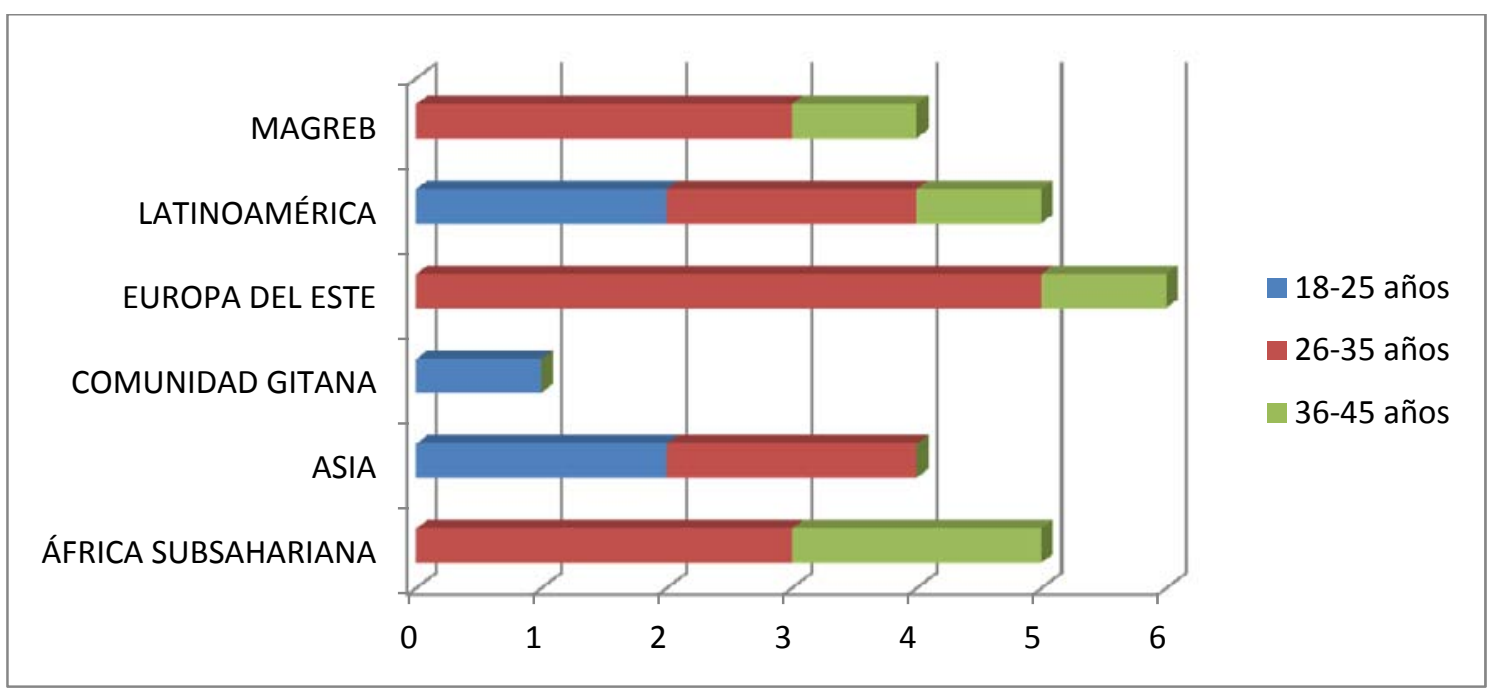

Gráfico 6.19. Colectivo inmigrante y edad de las usuarias participantes en las entrevistas 
En cuanto al tiempo de permanencia en España, la usuaria que menos tiempo llevaba residiendo en este país había llegado hacía aproximadamente un año, y la que más tiempo llevaba residía en España desde hacía 18 años. La mayoría de las usuarias entrevistadas llevaba en España entre 6 y 10 años, tal y como figura en el gráfico que se muestra a continuación, en el que se observan las diferentes franjas de permanencia del total de las usuarias, sin distinción por colectivos. Cabe comentar que, aunque resulta evidente que el proceso de aculturación es de carácter personal y depende de múltiples factores, el hecho de que la mayoría de las usuarias llevara residiendo en España un periodo de tiempo considerable (6-10 años) puede haber contribuido a facilitar tanto el acceso y uso por parte de estas usuarias de los servicios sanitarios, como, más concretamente, su comunicación con los profesionales que trabajan en dichos servicios.

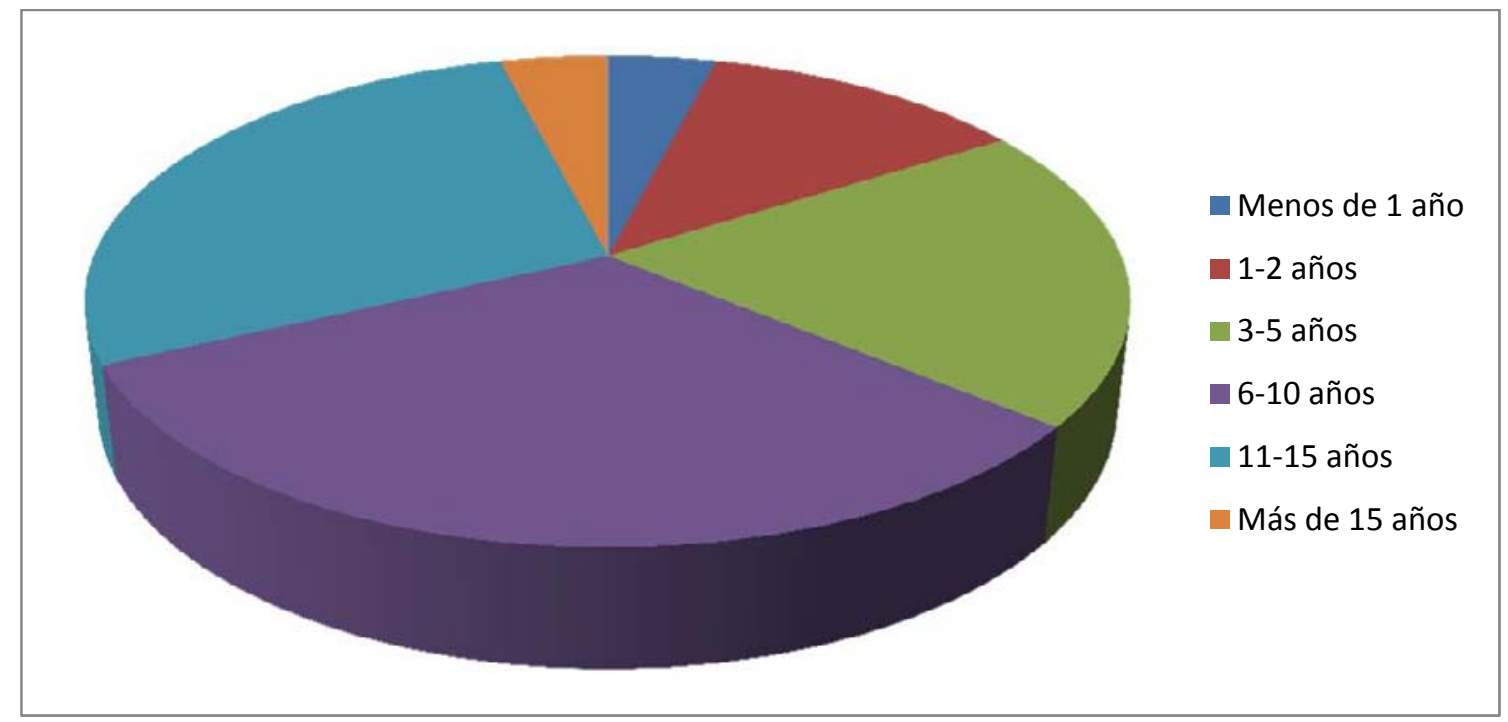

Gráfico 6.20. Usuarias participantes en las entrevistas y tiempo de permanencia en España

Por lo que se refiere a la lengua materna de las usuarias, el total de lenguas era de trece, distribuidas como figura a continuación:

Árabe: usuarias procedentes de Magreb (4)

Beni: usuaria procedente de África Subsahariana (1)

Chino mandarín: usuarias procedentes de Asia (3)

Español: usuaria de etnia gitana (1) y usuarias procedentes de Latinoamérica (4)

Fanti: usuaria procedente de África Subsahariana (1)

Francés: usuaria procedente de África Subsahariana (1)

Inglés: usuarias procedentes de África Subsahariana (2)

Panjabi: usuaria procedente de Asia (1)

Portugués: usuaria procedente de Latinoamérica (1) 
Rumano: usuarias procedentes de Europa del este (5)

Ucraniano: usuaria procedente de Europa del este (1)

Urdu: usuaria procedente de Asia (1)

Wolof: usuaria procedente de África Subsahariana (1)

Cabe destacar, de todos modos, que algunas de las usuarias señalaron dos lenguas maternas, sin indicar de cuál de ellas tenían un mayor dominio o si empleaban una u otra lengua en determinados contextos comunicativos.

Como se puede observar en la enumeración precedente, la lengua materna de las usuarias entrevistadas no se correspondía con ninguna lengua suficientemente conocida por los profesionales sanitarios como para poder emplearla de manera fluida al comunicarse con ellas, excepto en el caso de la mayoría de las usuarias latinoamericanas y la de la comunidad gitana (cuya lengua materna era el español) o en el caso de tres usuarias subsaharianas (cuyas lenguas maternas eran inglés o francés).

En relación con los conocimientos de la lengua del país de acogida, todas las usuarias, excepto la procedente de Pakistán, afirmaron conocer el español, aunque su nivel de conocimientos de esta lengua era en algunos casos muy bajo, tal y como se pudo constatar al realizar la posterior entrevista. Las usuarias con un mayor dominio de esta lengua eran las procedentes de Europa del este. Cabe, además, señalar en este punto que, como se ha comentado previamente en el capítulo 2, no fue posible realizar la entrevista a algunas usuarias a las que se propuso porque no tenían conocimientos mínimos de español o de alguna lengua vehicular, como inglés o francés.

Con referencia al conocimiento de otras lenguas extranjeras, algunas de las usuarias señalaron el inglés (4), el francés (5), el polaco (1) y el ruso (1), aunque en el caso de las dos primeras lenguas indicadas dichos conocimientos eran, de acuerdo con las propias usuarias entrevistadas, muy básicos.

\subsubsection{Datos conceptuales o teóricos}

Tras la presentación de los datos contextuales y los datos demográficos de los sujetos entrevistados, pasamos al análisis de las categorías conceptuales o teóricas. Hemos estructurado los nodos perteneciente a estas categorías, en primer lugar, en los siguientes nodos generales:

1. Introducción

2. Asistencia sanitaria general

3. Embarazo, parto y puerperio

4. Barreras lingüísticas y soluciones

5. Interacción

6. Actitudes sociales

A su vez, hemos dividido los nodos conceptuales generales en diferentes nodos específicos o subnodos, que determinarían el análisis de los subtemas relacionados con cada nodo general. 
Esta clasificación general nos ha servido para analizar posteriormente los datos recolectados mediante el uso de las otras técnicas empleadas en nuestra investigación.

Por otra parte, hemos creado un nodo independiente denominado "Comentarios sobre comunidades inmigrantes específicas", en el que hemos incluido todos aquellos comentarios realizados por parte de los profesionales sanitarios entrevistados en los que se hiciera referencia a algún grupo particular de usuarias procedentes de un determinado país o zona, de manera que pudiéramos extraer algunas características o casuísticas comunes a un determinado colectivo.

Con el fin de facilitar la exposición de los resultados, por razones hermenéuticas, hemos dividido el análisis en diferentes áreas correspondientes a cada uno de los nodos generales mencionados. Sin embargo, cabría tener en cuenta que dichas áreas no se encuentran realmente tan delimitadas o diferenciadas como figuran en el análisis, sino que existe una estrecha interrelación entre las mismas, por lo que los datos deberían ser entendidos como un conjunto.

Antes de iniciar el análisis de las diferentes áreas, vamos a realizar un estudio de carácter más general de las respuestas ofrecidas en las entrevistas por parte de los dos grupos de sujetos entrevistados (los profesionales sanitarios, por una parte, y las usuarias inmigrantes, por otra).

En primer lugar, tal y como figura en las tablas que aparecen a continuación, en las que se comparan los diferentes nodos generales y específicos creados con el número de unidades de análisis que han sido codificadas en cada uno de ellos y en las que el tamaño mayor de algunos recuadros indica que existen más unidades de análisis codificadas en los respectivos nodos, es posible concluir que los profesionales han dedicado un gran espacio en sus respuestas a comentar cuestiones relacionadas con las barreras lingüísticas y la interacción con las usuarias de origen extranjero, mientras que las usuarias entrevistadas se han centrado especialmente en aspectos relacionados con la interacción con los profesionales.

Nodes compared by number of coding references

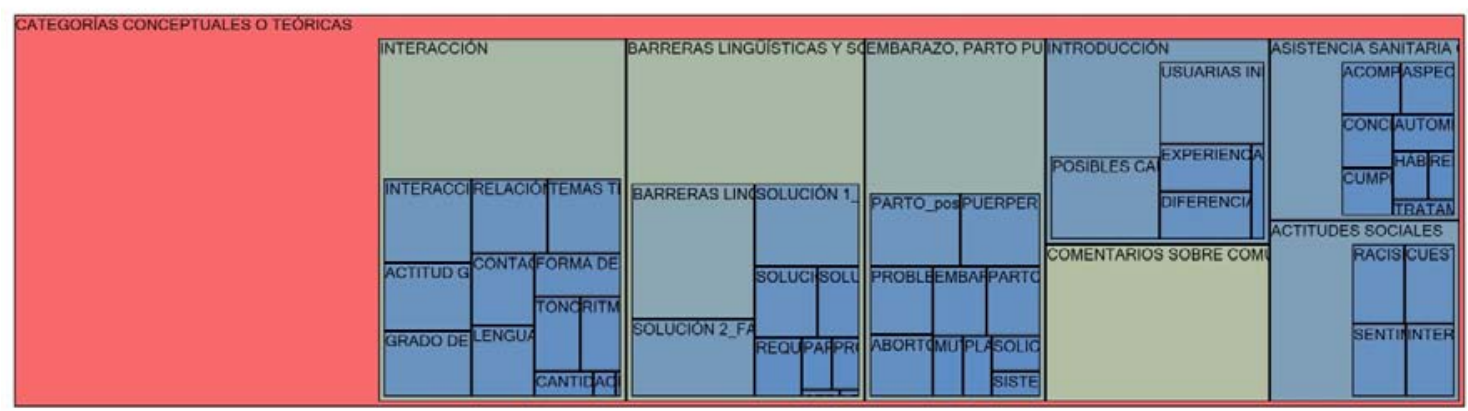

Gráfico 6.21. Análisis de los temas más mencionados por parte de los profesionales sanitarios entrevistados 


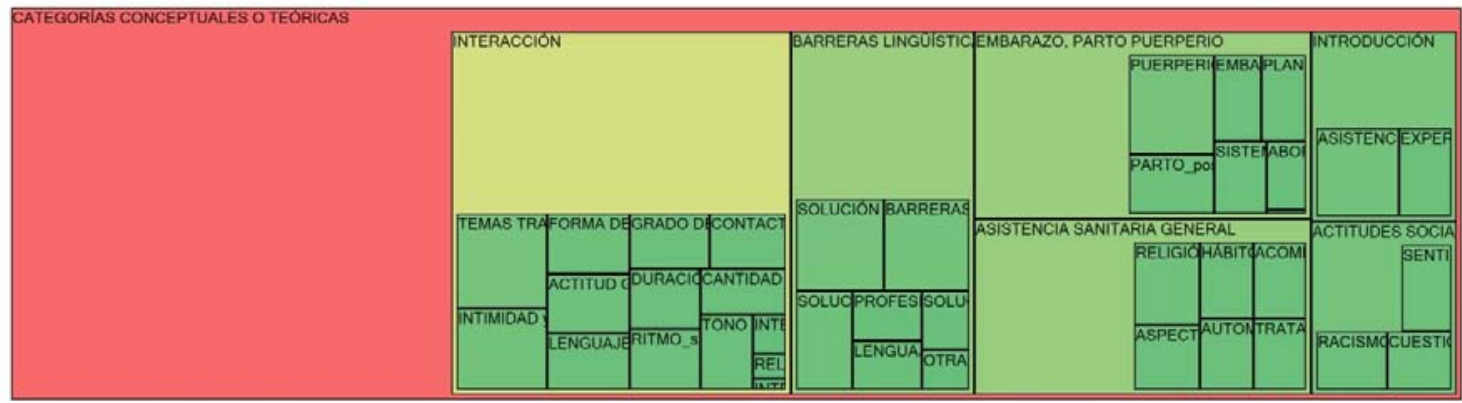

Gráfico 6.22. Análisis de los temas más mencionados por parte de las usuarias inmigrantes entrevistadas

Puede llamar la atención el hecho de que las usuarias entrevistadas no hayan dedicado mucho espacio en sus respuestas a las barreras lingüísticas (de hecho, el recuadro que indica las respuestas sobre este nodo o tema es menor que, por ejemplo, el que indica las respuestas en relación con el embarazo, el parto y el puerperio o con la asistencia sanitaria general). Esto se debe probablemente al hecho de que un gran número de usuarias entrevistadas llevan residiendo en España durante bastantes años y, por tanto, sus conocimientos del español les permiten actualmente desenvolverse en la vida cotidiana y no perciben las barreras lingüísticas como un obstáculo. Además, cabe recordar que la lengua materna de algunas de las usuarias es el español (en concreto, en el caso de las usuarias procedentes de Latinoamérica y el de la usuaria de la comunidad gitana), por lo que, en principio, parece que no deberían enfrentarse a dificultades de comunicación provocadas por la diversidad lingüística.

En segundo lugar, en base al análisis de las palabras que aparecían con mayor frecuencia en las respuestas de ambos grupos, ${ }^{233}$ en el que el tamaño de las palabras indica el número de veces que estas han sido empleadas por los sujetos entrevistados, podemos deducir que los profesionales han empleado muy a menudo los términos "usuarias", "inmigrantes" y "problemas", mientras que entre los términos más mencionados por las usuarias se hallan "personal", "sanitario" y "problema/s".

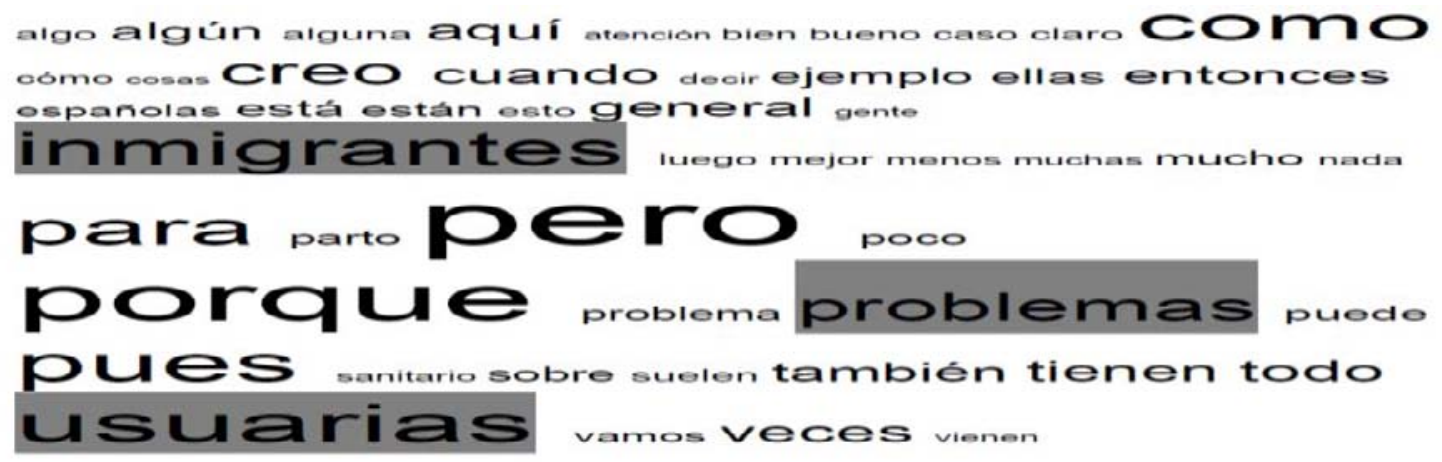

Gráfico 6.23. 50 palabras más usadas por los profesionales sanitarios entrevistados

\footnotetext{
${ }^{233}$ Hemos extraído la frecuencia de uso mediante una búsqueda a través del programa NVivo 10 de las cincuenta palabras de más de cuatro letras más empleadas por ambos grupos en sus respuestas a las preguntas planteadas en las entrevistas.
} 


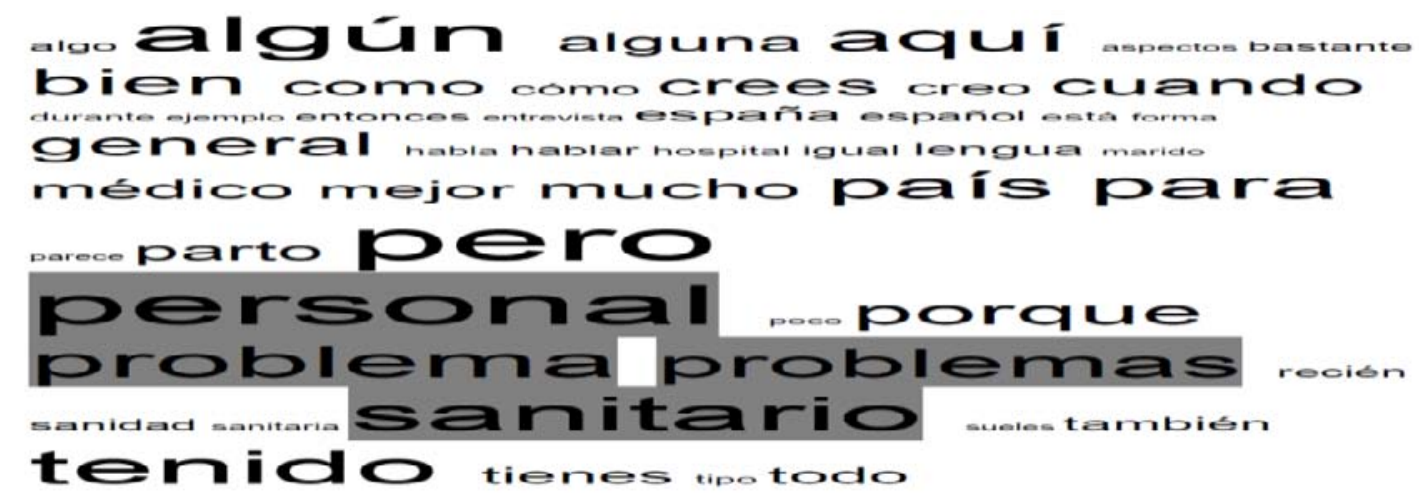

Gráfico 6.24. 50 palabras más usadas por las usuarias inmigrantes entrevistadas

El hecho de que cada uno de los grupos mencione al otro tan frecuentemente en sus respuestas va en sintonía con los fines de nuestra investigación, ya que es precisamente la interacción y la comunicación entre profesionales y usuarias lo que nos interesa estudiar y, por tanto, nuestras preguntas se centran en las relaciones e intercambios comunicativos entre ambos.

Por otra parte, por lo que respecta al uso del término "problema" (o su plural "problemas"), si bien es cierto que en las preguntas formuladas se mencionaba en quince ocasiones esta palabra, este número de veces en comparación con el número de preguntas formuladas en las entrevistas (40 en el caso de las usuarias, y entre 39 y 29 en el caso de los profesionales, dependiendo del perfil) tampoco es tan significativo como para que este término aparezca mencionado en tantas ocasiones por ambos grupos de informantes. Podemos concluir, en principio, que es posible que tanto los profesionales como las usuarias consideren problemática la relación e interacción entre ellos mismos.

Pasamos, a continuación, a realizar el análisis de cada uno de los nodos conceptuales generales.

\subsubsection{Introducción}

El nodo general de Introducción, centrado en la experiencia en el sistema sanitario por parte de las usuarias inmigrantes o en la percepción a grandes rasgos de estas por parte de los profesionales, está compuesto por los subnodos o subtemas que se muestran en esta captura de pantalla de nuestro proyecto con NVivo $10:^{234}$

\footnotetext{
${ }^{234}$ En las columnas que aparecen a la derecha del nombre de los diferentes nodos y subnodos se presenta la siguiente información proporcionada por el programa NVivo 10: en la primera columna numérica se indica el número de fuentes de análisis (entrevistas) que han sido codificadas en el respectivo nodo o subnodo; en la segunda columna numérica se señala el número de unidades de análisis codificadas; la tercera columna muestra la fecha de creación del nodo o subnodo; y, por último, la sigla AN que aparece en la última columna se corresponde con las iniciales de la investigadora, autora de la estructura de los nodos y la subsiguiente codificación. NVivo 10 ofrece esta última información sobre la autoría de un determinado nodo o subnodo porque es posible realizar proyectos colaborativos con este programa $y$, de este modo, sería posible identificar quién de los distintos investigadores involucrados ha propuesto determinadas partes del análisis.
} 


\begin{tabular}{|c|c|c|c|c|}
\hline O CATEGORIAS CONCEPTUALESO TEORICAS & 49 & 1746 & $02 / 02 / 201312.31$ & AN \\
\hline EO INTRODUCCION & 49 & 154 & $02 / 02 / 201312.51$ & AN \\
\hline O USUARIAS INMIGRANTES VS ESPANOLLS & 21 & 72 & $04 / 02 / 20136: 37$ & AN \\
\hline POSIBLES CAUSAS DELOS PROBLEMAS & 24 & 73 & $04 / 02 / 20136: 38$ & AN \\
\hline O EXPERIENCIA GENERAL & 47 & 68 & $04 / 02 / 20136.37$ & AN \\
\hline DIFERENCIACION SEGUNN ORIGEN USUARIAS & 18 & 35 & $04 / 02 / 20136: 38$ & AN \\
\hline O ASISTENCIA SANITARIA ORIGEN vs ESPANA & 31 & 61 & $04 / 02 / 20136: 41$ & AN \\
\hline
\end{tabular}

Gráfico 6.25. Subnodos del nodo INTRODUCCIÓN

Analizamos a continuación las respuestas obtenidas en relación con cada uno de estos subtemas. Puesto que las preguntas formuladas a los dos grupos de sujetos entrevistados en este bloque presentaban notables diferencias, dividimos nuestro análisis en esos dos grupos (profesionales y usuarias), aunque tratamos de comparar en la medida de lo posible las respuestas ofrecidas por ambos.

De acuerdo con los datos recolectados en las entrevistas a profesionales sanitarios, el contacto y la asistencia a usuarias inmigrantes es frecuente en todos los casos, pues el número de mujeres inmigrantes que van a controlar su embarazo o dar a luz al hospital contexto de estudio es bastante elevado (tal y como hemos podido comprobar también durante el trabajo de campo realizado).

Algunos de los entrevistados califican esta asistencia como "normal"235 y no dicen observar grandes diferencias con respecto a la asistencia a usuarias españolas, especialmente en los últimos años, a medida que el fenómeno migratorio se ha ido consolidando en España y la población inmigrante ha ido conociendo, bien personalmente o a través de sus propias redes sociales, los recursos a su disposición y el modo de acceder a los mismos. De hecho, hay entrevistados que opinan que es posible hallar dificultades en la asistencia a todas las usuarias, independientemente de su origen, y que simplemente lo que varía es la causa o la tipología de la dificultad en cuestión.

Pues depende, hay de todo. Yo pienso que eso va con la persona. Hay gente que es muy activa y enseguida se pone a hacer lo que se le dice y hay quien no. Yo pienso que en eso son como cualquier española. [Enfermera 2]

¿En general? Más o menos como con las (usuarias) españolas. Cada una tiene unas características, hay gente de todas las formas en españolas y en extranjeras. [Enfermera 6]

Yo creo que hay diferencias en casos puntuales, pero no en general, yo creo que tampoco hay muchas diferencias... [Matrona 2]

(En cuanto a las dificultades que puede presentar la asistencia a usuarias inmigrantes), cada vez presentan menos. El fenómeno de la inmigración se ha ido tranquilizando, es decir, las que han conseguido quedarse están mucho más estabilizadas, han aprendido el idioma, tienen recursos y tal. Al principio sí que tenían más dificultades que las españolas, fundamentalmente por problemas de tipo social, falta de recursos. [Profesional socio-sanitario 1]

Sin embargo, hay profesionales que definen desde el principio la asistencia a las usuarias inmigrantes como difícil o problemática y aducen, sin que se les pregunte explícitamente, diferentes motivos: falta de recursos o desconocimiento del funcionamiento de los servicios

235 Este término aparece entrecomillado no porque se trate de un término empleado literalmente por los profesionales, sino porque consideramos que la concepción de lo que es "normal" puede variar no solo de una cultura a otra, sino incluso de una a otra persona. 
sanitarios por parte de la población inmigrante, cuestiones de índole cultural y, especialmente, barreras lingüísticas. Observamos, por tanto, desde un primer momento que las dificultades de comunicación con las usuarias de origen extranjero se perciben como un obstáculo importante por parte de la mayoría de los profesionales sanitarios.

Además, ya en esta primera parte, algunos profesionales comienzan a realizar comentarios que se repetirán en otros puntos de las entrevistas, en particular en la sección dedicada a las actitudes sociales, en los cuales señalan la actual situación de crisis por la que está atravesando el país como una de las razones que han modificado la actitud de la sociedad española en general hacia los inmigrantes. ${ }^{236}$

[...] tienen el hándicap añadido de la actitud de la sociedad española ante el inmigrante... Además, por esta situación en la que estamos ahora en España, yo creo que esta actitud se ha acentuado todavía más. Por esta situación de crisis que estamos viviendo, pues al inmigrante lo vemos quizás como una sombra mayor de lo que era hasta ahora. [Matrona 5]

En el momento en que se les pregunta de manera directa a los profesionales sobre las posibles causas de los problemas que pueden encontrar en la asistencia sanitaria a embarazadas y puérperas de origen extranjero, la gran mayoría menciona en primer lugar las barreras lingüísticas derivadas del desconocimiento del idioma del país de acogida (en nuestro caso, el español). Por el gran número de respuestas que se centran en este aspecto ya desde el inicio de las entrevistas, empezamos a deducir que las barreras lingüísticas y la consecuente dificultad o ausencia de comunicación con este tipo de usuarias son percibidas por parte de los profesionales sanitarios como el mayor obstáculo a la hora de ofrecerles asistencia.

Los profesionales que hablan de las barreras lingüísticas presentan, en principio, dos tipos de actitud ante las mismas: algunos opinan que, aunque dificultan, no impiden la comunicación, pues creen que pueden lograr que exista entendimiento a través de otros medios (por ejemplo, recurriendo a la "comunicación" mediante gestos o a familiares de las usuarias que hacen labores de interpretación), mientras que otros consideran que el hecho de que el profesional y la usuaria no hablen el mismo idioma puede suponer para los profesionales un gran obstáculo para explicar los procedimientos que se van a seguir durante el parto (especialmente en relación con el suministro de la anestesia epidural), o para dar indicaciones durante el puerperio (por lo que respecta, por ejemplo, a la lactancia materna), y van a impedir que las usuarias puedan plantear las dudas que les vayan surgiendo.

Sin embargo, algunos consideran que, para determinar el diagnóstico o hacer determinadas analíticas, no es necesario que exista una comunicación efectiva. Quizás en estos casos, aunque no se mencione específicamente en las respuestas, podríamos considerar que se está practicando un tipo de medicina basada simplemente en las evidencias extraídas de análisis y pruebas sin contar con la opinión del paciente.

\footnotetext{
${ }^{236}$ Hemos considerado reseñable mencionar estos comentarios desde un primer momento en la fase de análisis de las entrevistas, ya que a lo largo del estudio, tanto en el uso de esta técnica como durante la observación, detectamos que la actual crisis económica había en efecto modificado la actitud de los españoles en general y de los profesionales sanitarios en particular con respecto a los inmigrantes, especialmente a partir de los últimos meses del año 2012 a raíz de los recortes aplicados en materia presupuestaria de los centros de salud y hospitales.
} 
Pero, vamos, el desconocimiento del idioma no supone un problema a la hora de realizar pruebas. En cualquier prueba analítica funcional, como las ecografías y demás, lo único que se requiere es el consentimiento por parte de la paciente. $Y$, en esto, en el pasado colaboró la Casa de las Culturas, hace muchos años que les pedimos colaboración, y nos tradujeron los consentimientos a varios idiomas. Entonces, el que la mujer no domine un idioma no es un problema para realizar pruebas y detectar las patologías, porque los consentimientos ya están en su idioma materno. [Matrona 7]

Al respecto de esta última cita, quisiéramos comentar que, aunque la traducción de los consentimientos informados de los que disponen los centros de salud es un recurso adecuado para facilitar el entendimiento de los procedimientos a los que se va a someter al usuario alófono, como comentaremos más adelante en el análisis de las barreras lingüísticas, resulta insuficiente, principalmente porque el usuario no podrá plantear sus dudas tras haber leído el documento si no está presente un intermediario (un intérprete) que facilite la comunicación entre el profesional y dicho usuario.

Algunos de los profesionales entrevistados mencionan también las diferencias culturales entre las causas de las dificultades en la asistencia a usuarias inmigrantes. Aquí señalan distintas cuestiones, algunas relacionadas con patrones culturales de carácter más general y otras que se refieren más concretamente a lo que se conoce como cultura sanitaria. Por ahora, nos limitamos a señalar estas posibles diferencias culturales y analizaremos exhaustivamente los factores relacionados con la cultura general o la cultura sanitaria de las usuarias más adelante.

Por lo que respecta al primer grupo, se indican especialmente las costumbres religiosas, por una parte, y las relaciones y roles de género propios de las culturas de origen de las usuarias, por otra. En relación con la denominada cultura sanitaria, los profesionales dicen haber detectado diferencias en cuanto a la consideración del embarazo, el parto y el puerperio en los países de origen de las usuarias y en España, creen que existe desconocimiento del funcionamiento del sistema sanitario español, y aluden además a un menor control del embarazo por parte de algunos colectivos de usuarias o a costumbres relacionadas con la alimentación de la madre después del parto o con la lactancia materna.

Ante estas diferencias de índole cultural, se plantean dos actitudes opuestas por parte de los profesionales. Algunos opinan que deberían ser las usuarias de origen extranjero las que modificasen sus propias costumbres para adaptarse al sistema sanitario español.

Lo que me resulta más curioso es que mantengan sus costumbres y no tengan en cuenta para nada las cosas que se les dicen aquí en el hospital. Porque están aquí y tendrán en cierto sentido que acomodarse a lo que aquí se hace, ¿no? O si no, que se queden en casa para dar a luz. Que yo muchas veces se lo he dicho, que para dar a luz no hace falta venir al hospital. [Enfermera 5]

Mientras que otros consideran que el esfuerzo de cambio debería realizarse por parte de los propios profesionales o que, al menos, debería ser recíproco.

[...] los que tendríamos que cambiar un poco somos nosotros. Yo creo que el mayor problema es nuestro. Deberíamos intentar cambiar la mirada, e intentar pensar que un día nos podemos ver nosotros mismos en esa situación y sobre todo en una situación de... no de enfermedad, porque esto realmente no es ninguna enfermedad, pero el venir a parir sí que es una situación un poco diferente de lo habitual. Es una situación un poco más... ¿cómo te diría yo? Pues, te encuentras con menos herramientas, más vulnerable. [Matrona 5] 
[...] yo creo que cada vez se van integrando más y que cada vez es menor la incidencia de... no de problemas, más bien de cosas diferentes... Pero vamos, se tienen que adaptar y nosotros nos tenemos que adaptar. [Profesional socio-sanitario 1]

Por lo que respecta a las diferencias que los profesionales entrevistados han observado en las usuarias inmigrantes dependiendo de su origen, unos pocos opinan que no existen diferencias, sino que todo depende de los conocimientos que estas tengan de español.

Yo creo que es indistinto, que depende sobre todo de la capacidad que tienen de entender el idioma. [Anestesista 2]

$Y$ es precisamente en base a los conocimientos lingüísticos de las usuarias donde los profesionales encuentran mayores diferencias entre las mismas y señalan algunas comunidades (especialmente la magrebí y la china) como aquellas con las que la comunicación resulta más complicada.

En la comunidad árabe la barrera idiomática es más importante. Quizás todo lo que es inmigración del este, pues, hablan más castellano y entonces es más fácil comunicarte con ellas. Pero hay mucha mujer árabe a la que le cuesta. [Matrona 2]

A ver, por ejemplo, los del este sí que la mayoría son muy espabilados y saben más que... más que nosotros. Con los sudamericanos evidentemente no hay barrera lingüística. Ahí, estupendamente. Y los marroquíes, los argelinos... vienen algunos que no entienden absolutamente nada, sobre todo las que han pasado allí el embarazo y vienen a parir aquí. [Matrona 5]

Algunos profesionales entrevistados van más allá y sostienen que estas barreras lingüísticas son la causa de un comportamiento distinto observado en las usuarias.

Yo creo que sí que varía. Por ejemplo, las chinas, cuando vienen a parir, vienen más nerviosas, con más miedo, y entonces eso les hace estar mucho más agresivas o mucho más reticentes. Las árabes no habla casi ninguna español, el noventa por cien no lo habla, y entonces están muy alerta, tienen mucho miedo, necesitan a su pareja para que les permita ponerse una epidural, para que les permita ponerse un gotero... Están con más miedo. Y, luego, las rumanas vienen mucho más tranquilas, porque nos entienden. Y las senegalesas y de otros países del África negra también parece que están más tranquilas, son más suaves, igual es porque llevan más años, no lo sé... [Profesional socio-sanitario 3]

Solo hay dos profesionales entrevistados que dudan de que las diferencias observadas en las usuarias inmigrantes dependan del país de procedencia, y opinan que quizás podrían deberse a su nivel socio-económico o a una cuestión generacional.

[...] es que también pasa con las nacionales. No creo que sea nada racial ni cultural, sino que va por edades. Me explico: las abuelas de antes gestionaban esto de una manera y las jóvenes de ahora lo gestionan de otra. $\mathrm{Y}$ ahora nadie quiere sufrir, y ahora creo que nos estamos pasando. Antes lo aguantaban todo y ahora no quieren aguantar ni una caricia. [Anestesista 3]

No sé si depende de su comunidad de origen o también de su nivel socio-económico. No lo sé si puede depender de su país de procedencia o más bien de su situación. [Matrona 3]

Por último, otros dos de los profesionales entrevistados describen algunas patologías que se presentan más frecuentemente en determinadas usuarias, especialmente en aquellas procedentes del África subsahariana, aunque no determinan si dichas patologías podrían ser la consecuencia de características genéticas o podrían derivarse de sus estilos de vida. 
[...] porque las pacientes de raza negra son más proclives a problemas de hipertensión arterial y eclampsia. ${ }^{237}$ Pre-eclampsia o eclampsia en su caso, porque si esto no se corrige, puede derivar en un ataque de eclampsia, que es una patología muy grave ya, severa. [Matrona 7]

Desde un punto de vista científico, lo que nos dice la evidencia es que hay algunos colectivos que tienen mayor prevalencia de ciertos problemas perinatales. Por ejemplo, los líquidos teñidos que pueden indicar un riesgo de pérdida de bienestar fetal, pues pienso que se da con mayor frecuencia en las gestantes del África negra. Problemas como la pre-eclampsia también hay algunos colectivos que lo presentan o que tienen una prevalencia mayor que el de las autóctonas. La diabetes gestacional pasa lo mismo. No sé si es por sus costumbres o sus estilos de vida, porque genéticamente tienen esa problemática, o porque se controlan menos el embarazo, que también puede ser. Por lo que sea, sí que hay problemas que, bueno, pues son más frecuentes en estas poblaciones. [Matrona 1]

Así como los profesionales sanitarios señalan desde el primer momento una serie de barreras que dificultan la asistencia a usuarias inmigrantes, por el contrario, la gran mayoría de las usuarias entrevistadas califican su experiencia en la asistencia sanitaria general en España como "buena" y, aunque más tarde iremos comprobando que, en realidad, sí que se han enfrentado a problemas al acudir a los centros de salud $u$ hospitales, en principio no parecen presentar pegas o quejas en cuanto a la asistencia recibida. Cabe considerar que las usuarias se hallan en un entorno para ellas desconocido y que nos encontramos al principio de las entrevistas, lo que puede haber conllevado cierta cautela en las usuarias a la hora de exponer abiertamente sus críticas.

En cuanto a la comparación entre el sistema sanitario de sus países de origen y el de España, casi todas las usuarias, independientemente de su procedencia, opinan que la asistencia en el país de acogida es mejor, y aducen, como se puede observar en las citas que se incluyen a continuación, diferentes motivos: la rapidez en la concertación de citas y en el diagnóstico, los medios de los que disponen los centros de salud, la gratuidad de los servicios prestados o la atención recibida.

Aquí es mejor que en Nigeria, porque, tú sabes, aquí en España es más... como tener más experiencia, como... y en África no tener muchas cosas como en Europa. Me parece que en Europa tener más, eee, eee... máquinas. [África subsahariana 2]

Uy, dónde vamos a parar. Aquí es mucho mejor, sí, sí, mucho mejor. Pues, no solamente la atención y los medios... Porque allí hay que pagar todo, para todo, por ejemplo, que te pinchen y todo eso lo tienes que pagar tú. Y luego la rapidez también. $O$ sea, el diagnóstico y todo eso es más rápido aquí, y además los aparatos son más modernos. [África subsahariana 3]

A ver... Diciendo la verdad, sí que es mejor que en mi país, porque yo no tenía dificultad para ir a la sanidad allí, porque si tienes el dinero para pagar y esas cosas, entonces bien, te puede salir mejor que aquí, pero no es para todo el mundo. [África subsahariana 4]

Mejor. Pero... todos son mejor, pero mi país, diferente. Aquí más limpio y... todo mejor: la operación, el médico, todo mejor. Me gusta. [Asia 1]

\footnotetext{
${ }^{237}$ La eclampsia consiste en la presencia de crisis epilépticas en una mujer embarazada que no tienen relación con una afección cerebral preexistente. Se presenta después de una pre-eclampsia, es decir, de una complicación grave del embarazo caracterizada por hipertensión arterial, así como excesivo y rápido aumento de peso. Ocurre en aproximadamente 1 de cada 2.000 o 3.000 casos y, entre los factores que pueden determinarla, se señalan la edad mayor de 35 años y el pertenecer a la raza negra, como es el caso de las usuarias señaladas por este profesional sanitario entrevistado. Fuente de la definición:
} [http://www.nlm.nih.gov/medlineplus/spanish/ency/article/000899.htm] (última consulta: 23 de mayo de 2013) 
Aquí, mejor, sí. Porque... Cuando está aquí, cuando nace se puede usar epidural, que hace no doler mucho. $Y$ en China no tienes eso. $Y$ en hospital de China, familia traer la comida. Y aquí dan todo, también merendar, y comer, y cenar. [Asia 2]

Aquí es mejor, porque como ya tienes todos los servicios, pues... Puedes optar a todo, con que tengas un trabajo y tengas la seguridad social, puedes optar a todo. $Y$, sin embargo, en mi país te lo tienes que pagar tú y si te atienden bien, bien, y si no... La mayoría de los servicios se pagan. Si les das lo que se conoce como la propina, te atienden bien; si no, te pueden tener ahí horas sin hacerte caso. O sea, que aquí es mucho mejor. [Europa del este 4]

¿La diferencia cuál es? Por ejemplo, allí, como ya te lo he dicho, como tienen pocos recursos, hay una costumbre que está heredado del sistema comunista, que era dar propina. Antes se daba propina con regalos, como un paquete de café o de cigarrillos o algo, y ahora se da dinero, porque es la moda. Entonces sí que te pide... Aunque tú no lo das... No te atiende bien. Es que es un poco tabú, puede que no te lo pide directamente. Pero tú sabes que cuando entras, para que te atienden bien, tú tienes que... Pagar. (Le pregunto si hay una cantidad estipulada o si cada uno da su voluntad). Es que ya lo sabe, toda la gente ya lo sabe. Cuanto más vas a pagar, mejor serás atendido. [Europa del este 5]

La sanidad pública aquí es mejor seguramente. Por todo, por los medios, porque tardan menos, porque la gente te presta más atención... Por todo. [...] en general el noventa y nueve por cien de las personas aquí son muy amables y... No sé, también creo que aquí les pagan mejor por lo que hacen. En Brasil yo creo que les pagan menos. No tanto a los médicos, pero a los enfermeros y tal ya es otra cosa. [Latinoamérica 2]

En comparación con mi país, te atienden mucho mejor aquí. Aquí es mejor. Sobre todo por el personal. Aquí, por ejemplo, en el parto, te atienden seis, siete u ocho personas, depende de cómo sea el parto, si es normal, si es provocado o qué sé yo... [Latinoamérica 5]

Aquí es mejor, mucho mejor. Mira, para mi primer hija, cuando tuve en Argelia, tenía mucho dolor y me fui al hospital y me dijeron "Es tu primera hija. No sabes los dolores, no sabes cómo es el parto...", y me dejaron ahí en una cama hasta que la niña salió. Y había una compañera conmigo que vio la cabecita de la niña y se fue corriendo y dijo "Que la señora que está conmigo ya va a salir la niña". Y vienen y me dijeron de andar y de cerrar las piernas para que no caiga y... (Le pregunto si en Argelia la sanidad es pública o privada). Hay pública, pero privada es muy cara para mí. No todo el mundo puede permitir. [Magreb 3]

Aquí mejor, mejor servicio, todo mejor, todo, todo. (Pregunto si en Mauritania es necesario pagar para ir al hospital. La usuaria se queda en silencio e interviene contestando su marido). Se paga el hospital privada. Hay también pública, pero los medios allí... Es que Mauritania es un país de África y España es un país de Europa y el nivel entonces se nota. [Magreb 4]

\subsubsection{Asistencia sanitaria general}

El nodo de Asistencia sanitaria general estaba dedicado a cuestiones relacionadas, por una parte, con la cultura sanitaria (como, por ejemplo, el concepto de cuerpo y de enfermedad o el recurso a la medicina tradicional) y, por otra, con el comportamiento de las usuarias en el hospital (especialmente por lo que respecta a las visitas, los hábitos alimentarios, el cumplimiento de las normas, o los aspectos burocráticos), sin entrar todavía en temas más específicos relativos a la salud reproductiva. 
En concreto, este nodo estaba compuesto por los subnodos o subtemas que se muestran en esta captura de pantalla de nuestro proyecto con NVivo 10:

7 CATEGORIAS CONCEPTUALES O TEÓRICAS
ACTITUDES SOCIALES
ASISTENCIA SANITARIA GENERAL
ACOMPANAMIENTO y VISITAS
ASPECTOS BUROCRATICOS
AUTOMEDICACIÓN Y MEDICINA TRADICIONAL
CONCEPTO CUERPO Y ENFERMEDAD
CUMPLIMIENTO NORMAS HOSPITAL
HABITOS ALIMENTARIOS
RELIGION y OTRAS COSTUMBRES
TRATAMIENTOS_comprensión y seguimiento

\begin{tabular}{|l|l|}
\hline 49 & 171 \\
\hline 49 & 240 \\
\hline 47 & 62 \\
\hline 49 & 54 \\
\hline 39 & 45 \\
\hline 37 & 23 \\
\hline 18 & 21 \\
\hline 10 & 43 \\
\hline 38 & 51 \\
\hline 36 & 33 \\
\hline 32 & \\
\hline
\end{tabular}

\begin{tabular}{l|l|l}
\hline 1711 & $02 / 02 / 201312: 31$ & AN \\
\hline 151 & $02 / 02 / 201312: 52$ & AN \\
\hline 240 & $02 / 02 / 201312: 51$ & AN \\
\hline 62 & $04 / 02 / 20136: 44$ & AN \\
\hline 54 & $04 / 02 / 20136: 44$ & AN \\
\hline 5 & $04 / 02 / 20136: 45$ & AN \\
\hline 23 & $04 / 02 / 20136: 46$ & AN \\
\hline 21 & $06 / 02 / 20139: 54$ & AN \\
\hline 43 & $04 / 02 / 20136: 45$ & AN \\
\hline 51 & $04 / 02 / 20136: 46$ & AN \\
\hline 33 & $04 / 02 / 20136: 45$ & AN \\
\hline
\end{tabular}

Gráfico 6.26. Subnodos del nodo ASISTENCIA SANITARIA

Al contrario que en el análisis del anterior nodo, en esta ocasión no dividimos los datos en los dos grupos de sujetos entrevistados, sino que tratamos cada uno de los temas relacionados con la cultura sanitaria, por una parte, y con el comportamiento en el hospital, por otra, comparando, siempre que resulte posible, las respuestas ofrecidas por los profesionales y las usuarias en cada uno de estos temas.

En primer lugar, por lo que respecta a la cultura sanitaria y más específicamente al concepto de cuerpo y enfermedad, hay muy pocos profesionales entrevistados que hayan observado en las usuarias inmigrantes conceptos del cuerpo o de la enfermedad distintos a los conceptos propios de la sanidad occidental.

En concreto, la pregunta relativa a este tema se centraba en la expresión verbal de estos conceptos por parte de las usuarias inmigrantes $y$, por las respuestas ofrecidas por los profesionales, podemos deducir que las usuarias inmigrantes no han expresado diferencias a este respecto, probablemente por las barreras lingüísticas con las que estas se encuentran y por su propia posición de inferioridad en la relación asimétrica entre ellas y los profesionales. Quizás esperábamos que los profesionales, aunque no se les hubiera expresado abiertamente, habrían sido capaces de detectar las diferencias en el concepto de cuerpo y enfermedad de las usuarias inmigrantes mediante la observación y la asistencia a las mismas, siempre y cuando existieran estas diferencias, algo que no hemos podido verificar con el empleo de esta técnica.

No, yo creo que en general las pacientes extranjeras son bastante sumisas. No te llevan la contraria, ni... Vamos, yo creo que en general son obedientes y se dejan tratar bien. No me he encontrado a ninguna que me lleve la contraria, ni que me aclare conceptos o quiera reinterpretarlos. [Anestesista 5]

No... El mayor contraste es lo que te comento, es que probablemente algunos de estos colectivos tienen menor cultura de control del embarazo, pero al margen de eso, a nosotros no nos dicen nada. Puede ser que en principio, con estos problemas idiomáticos y culturales se cierran más de lo que se puede cerrar una gestante española. Entonces yo creo que nos dicen menos de lo que se les pasa por la cabeza, no me cabe duda. [Matrona 1]

Solo uno de los profesionales entrevistados parece ser consciente de la posibilidad de que existan diferencias con respecto a los conceptos de cuerpo y enfermedad en las distintas culturas, e incluso propone alternativas para averiguar si la usuaria ha padecido una determinada enfermedad. 
[...] o luego con enfermedades de aquí, o las llaman de otra manera, o no saben qué ha sido, qué han tenido, o ni siquiera lo consideran enfermedad... A veces hay que preguntarles " $¿ Y$ has estado ingresada por algo?". Porque a veces no saben lo que han tenido, pero sí que recuerdan que estuvieron ingresadas y eso es importante... [Anestesista 4]

En referencia al recurso a la medicina tradicional y a la automedicación, es el colectivo chino el que aparece mencionado por parte de la mayoría de los profesionales entrevistados. Unos hablan de "bulo", "rumor" o "leyenda", aunque dicen no poseer datos que demuestren sus suposiciones.

El rumor o la leyenda urbana dice que, por ejemplo, el colectivo chino sí que toma algo de cara al parto, pero eso es una leyenda urbana que yo no puedo... no puedo afirmar categóricamente. En cuanto a otros colectivos, nosotros no lo comentamos. En ese sentido, no... no tenemos esa idea. [Matrona 1]

Hombre, yo creo que los chinos... vamos, que hay rumores. Luego, ¿qué lo hagan? Pues supongo que lo harán, porque ellos tienen una tradición, una medicina tradicional muy, muy, muy arraigada y muy antigua. Entonces, algo harán, supongo. Y, saberlo, pues, chica, a ciencia cierta yo no lo sé, porque además ellos no te lo dicen. [Matrona 4]

Algunos comentan haberlo preguntado directamente a las usuarias, y que estas han eludido dar una respuesta o han mentido al respecto.

[...] además de tener una cultura diferente en general, también tienen una cultura sanitaria muy distinta. Y eso hay que preguntarlo, porque son muy reservados, yo creo que nunca sabremos lo que toman. Pero, en general, los chinos no cuentan que vienen con un tratamiento de casa de medicina alternativa. Te dicen que no. [...], pero las matronas suelen recordarte que puede que hayan tomado algo, hierbas, brebajes y cosas, y nunca lo sé. Yo les pregunto y nunca me dicen que sí. [Anestesista 5]

Sí que corre el bulo de que ellas se hacen una especie de... mejunje, no sé cómo describirlo, para provocar las contracciones. Y normalmente paren muy bien y muy rápido, entonces siempre se ha dicho que... Pero ellas se niegan bastante en rotundo, cuando les intentas preguntar, te salen por peteneras, te cuentan la historia que les parece... (Risas), pero no te dicen exactamente qué se toman ni qué no. [Matrona 3]

Y otros exponen las evidencias que les llevan a pensar que las usuarias de origen chino recurren a la medicina tradicional y la automedicación.

Porque muchas veces te encuentras una mujer que viene a parir, que es primípara, y llega con muy mala pinta en cuanto al parto, y al rato te la encuentras en completa pariendo, y dices "Pero, ¿esto cómo puede ser?". Y sí que sabemos que a veces algo utilizan. [ Matrona 5]

Eso sí que depende de las culturas. Las chinas yo creo que sí. Nosotras no lo sabemos, porque no nos lo dicen, pero por cómo va el proceso, nosotras sabemos que han tomado algo. Nosotras lo sabemos porque no es normal que... Es que ellas tienen la medicina tradicional china, que no tiene nada que ver con la nuestra, que normalmente tiene otros principios. Y sí que vemos que a veces viene la mujer empezando su parto, con una dilatación de dos centímetros, y a la siguiente exploración está en dilatación completa. Eso no es normal, y menos con el primer hijo. Sospechamos, pero ellas desde luego no lo dicen. [Matrona 7]

Los profesionales que mencionan estas sospechas sobre el recurso a la medicina tradicional y la automedicación por parte de las usuarias de origen chino no expresan por lo general ni acuerdo ni descuerdo al respecto, y solo un profesional entrevistado reconoce que, por desconocimiento, no puede entrar a valorar si la medicina tradicional es más o menos válida que la medicina occidental. 
(En cuanto al uso de la automedicación) en principio, el colectivo que más dudas nos generaría sería el chino. Ya sabes que tienen un tipo de medicina muy distinto al nuestro, que no digo que sea menos eficaz, igual es más eficaz, pero nosotros lo desconocemos. $Y$ entonces, en ese sentido no sabemos... en fin. [Matrona 1]

Cabe resaltar la opinión de otro de los profesionales entrevistados en relación con este tema, el cual sí que defiende la validez y complementariedad de diferentes tipos de medicina.

\begin{abstract}
Porque, claro, ellos están habituados a otro tipo de medicina, que para mí no es ni mejor ni peor, todas las medicinas son buenas si sirven para ayudar. Y si la acupuntura y la medicina oriental les han servido a ellos durante siglos y siglos, pues tienen que ser buenas. [...] Para mí, todas las medicinas son complementarias. La nuestra quizás se basa más en la tecnología y podemos diagnosticar mejor, pero tratar, a veces no podemos tratar, nos limitamos a tratamientos todavía de hace cincuenta años o más. Y, sobre todo la medicina oriental, porque el resto... Hombre, el que se hagan sus brebajes algunos otros, pues, lo veo muy bien. Si les va bien, para qué les vas a dar un preparado hecho por un laboratorio, si ellos en su país tomándose una infusión de determinadas hierbas les funciona lo mismo. Pues, iadelante! [Obstetra 1]
\end{abstract}

Además, otros profesionales entrevistados creen que el recurso por parte de la población de origen chino a la medicina tradicional provoca en esta comunidad un menor acceso a los servicios sanitarios y desconfianza.

[...] hacen mucho caso a su medicina tradicional. $\mathrm{Y}$ eso hace que a veces muestren como mucha desconfianza con respecto a nosotros, como si... "Este me está poniendo, no sé qué". [Matrona 5]

Los que menos acceden son los chinos. Yo no sé si es porque son autosuficientes y utilizan sus medicinas tradicionales, o porque son muy desconfiados. [Obstetra 3]

Por último, solo uno de los profesionales entrevistados menciona otra comunidad de usuarias inmigrantes que podría recurrir a la automedicación, en este caso en relación con un medicamento para provocar el aborto.

Sí, eso sobre todo las chinas. Otros grupos, no. Lo único, sí que es frecuente, por ejemplo, en la población africana, sí que veo que se compran ellas por su cuenta o les venden en sus tiendas o lo que sea pastillas de Cytotec, que son pastillas como para provocar el aborto. Pero si me preguntas estrictamente por medicina tradicional, que yo sepa, las chinas son las únicas que la usan. [Obstetra 2]

Por su parte, las respuestas de las usuarias entrevistadas en relación con la automedicación y el recurso a la medicina tradicional parecen confirmar la opinión de los profesionales sobre la escasa utilización de medicamentos (especialmente aquellos asociados a la medicina tradicional) por parte de las usuarias inmigrantes, excepto en el caso mencionado de las usuarias de origen chino. De hecho, solo dos de las usuarias entrevistadas, concretamente procedentes de China, reconocen abiertamente haber adquirido medicamentos $u$ otros remedios procedentes de su país de origen, aunque sus respuestas al respecto son muy breves $y$, por la incomodidad que parecía provocar este tema en estas usuarias, no insistimos en continuar tratándolo.

Sí, algunas cosas China. Tú puedes encontrar. [Asia 2]

Sí, a veces, algunas cosas. Se puede encontrar y hemos traído de China. A mí me gusta más medicina tradicional. [Asia 4]

El resto de usuarias entrevistadas dicen no recurrir a la automedicación o solo en los casos en los que se trata de malestares o dolencias leves. En dichos casos, suelen tomar medicamentos 
de uso común en España (aspirina, paracetamol, ibuprofeno, etc.) y que son también habituales en sus respectivos países de origen.

Sí, por ejemplo, si yo tener dolor de cabeza, yo tener aspirina en casa o paracetamol... Sí, yo puedo tomar. Y si yo no tengo, yo puedo pasar a mi médico para que me da receta. [África subsahariana 1]

No, no uso (la automedicación). Creo que sí que hay cosas como paracetamol y amoxicilina y eso que sí que se pueden encontrar. Pero me imagino que eso estará en todos lados, ¿no? [Europa del este 2]

Así, tomo alguna aspirina o cosas así, pero no... Y la verdad es que no tomo nada de la medicina de mi país. [Latinoamérica 1]

Uso pocas veces la automedicación, pocas. Por ejemplo, para algunas cosas que son más leves, como dolor de cabeza o de tripa o así, sí, pero para las cosas que son más... que son más graves, más delicadas, ahí ya no, ahí ya voy al médico. [Latinoamérica 3]

Bueno, a veces tomo medicamentos para el dolor de cabeza, ibuprofeno y eso. Tomo también aspirina, pero yo creo que eso lo venden tanto aquí como allí. [Latinoamérica 4]

Por ejemplo, si duele la cabeza, toma paracetamol. En Mauritania hay lo mismo, lo único que aquí hay polvo y allí en pastilla. Pero, bueno, no hay muchas diferencias, no... [Magreb 4]

Sobre si observan diferencias significativas entre los medicamentos de sus países de origen y los comercializados en España, la mayoría de las usuarias entrevistadas (excepto, como se ha comentado, algunas de origen chino) creen que no existen grandes diferencias $y$, de hecho, no suelen comprar medicamentos $u$ otros remedios procedentes de sus respectivos países.

En Nigeria es parecido, la gente toma, por ejemplo, paracetamol. Y también tomar otras cosas, pero aquí no he visto. (Le pregunto que, si cuando algún amigo o pariente visita su país, le pide que a la vuelta le traiga algún producto). No, no, no se puede. [África subsahariana 1]

Yo, desde que estoy aquí no compro ningún producto de Camerún, porque no es lo mismo o no se vende. Aun así, no compraría, pero aquí en Zaragoza no puedo encontrar, así que... [África subsahariana 3]

No, yo la verdad es que no... La medicina que me tomo aquí es la misma que podría comprar allí. Por lo que sé de mis hermanas que están allí, toman los mismos medicamentos que se toman aquí en España. Vamos, por mi experiencia, de lo que he visto yo, del resto, no sé... [África subsahariana 4]

No suelo tomar nada sin que me receten. Y no, productos de mi país no utilizo. [Europa del este 1]

Uso lo mismo que allí, paracetamol, ibuprofeno y esas cosas. Bueno, tampoco hay muchas diferencias. En Rumanía hay alguna cosa de tratamiento naturista, pero no... No sé, igual hay algunas plantas que no existen aquí. Pero lo que son antibióticos y medicamentos básicos son iguales, se encuentran aquí y allí. [Europa del este 3]

En España sí que creo que hay medicamentos que son iguales a los que encuentras en Brasil. Los nombres comerciales son distintos, pero las composiciones son iguales. [Latinoamérica 2]

Los medicamentos son casi iguales aquí y en Marruecos. La diferencia es el precio. Allí es más caro, porque aquí pagamos Seguridad Social y cuesta menos. [Magreb 1]

La única diferencia que señalan algunas usuarias entrevistadas en cuanto a los medicamentos es que en algunos países, al contrario de lo que ocurre en España, los antibióticos pueden ser vendidos sin receta, por lo que parece que su uso por parte de la población de estos países está más extendido. 
Sí, sí, sí. Por ejemplo, en Rumanía tú puedes comprar por ejemplo antibióticos en la farmacia. Sin receta ni nada. Y, por ejemplo, mira, toda la vida yo recuerdo que en invierno me enfermaba aquí en la garganta, de amigdalitis o algo y... [...] Bueno, y me venía la fiebre y eso y me iba a la farmacia y me compraba algo que sabía yo que era un antibiótico, algo que era a base de penicilina, pero que era un poco menos fuerte que penicilina, u otros derivados, pero que eran para eso. Pues bien, como te digo, iba una vez, me lo prescribía el médico, y sabía que cada vez que me enfermaba de la misma cosa, me podía tomar eso. [...] Yo respetaba la misma dosada, lo tomaba cada ocho horas, porque sabía que era mejor cada ocho horas, y siempre me lo podía comprar. Pero aquí, en España, si me enfermo, o mi esposa, o mis hijos, ninguno nos dan antibióticos. Si vas al médico, sí. Tienes que ir al médico, tienes que esperar un montón de días, porque puede que no tienes cita, y cuando llego en tres días, igual el hijo ya está curado. O está peor... [Europa del este 5] $]^{238}$

En Brasil hay mucha gente que toma medicamentos sin consultar al médico, muchísima. Además, ahora está prohibido vender antibióticos sin receta médica, pero antes se podían vender libremente, y entonces la gente tenía acceso. [Latinoamérica 2]

Sí, sí que he visto diferencias. Porque, para una infección, allá compramos sin receta, la amoxicilina, los antibióticos en general. Y aquí sin receta no se venden. [Latinoamérica 5]

Por último, algunas usuarias (concretamente procedentes de Latinoamérica y el Magreb) mencionan algunos remedios naturales que emplean para preservar o recuperar su estado de salud en el caso de malestares de carácter leve.

Sí, en Honduras hay hierbas. Y aquí se pueden comprar, en el mercado se vende muchísimo. Bueno, algunas, algunas... Por ejemplo, la manzanilla para el dolor de estómago, y la canela para calmar los nervios. Esos son los más tradicionales. [Latinoamérica 5]

A mí... No me gusta, por ejemplo, me duele la cabeza y voy al médico. Prefiero hacer una cosa natural que tomar medicamentos. Pero si te vas (al médico) te tratan bien, sí. (Le pregunto a qué se refiere cuando habla de remedios naturales). Tomo infusiones, o pongo un poco de limón aquí (se señala la frente), o duermo un poco y luego me levanto mejor. [Magreb 1]

A veces sí uso la miel, el aceite de oliva, también hay una... no sé, son granos negros, se llaman (pronuncia una palabra en árabe). Estos están en el Corán y los usamos también. (Le pregunto para qué sirven estos granos negros). Son mejor para la defensa, para estar más fuerte. Y estos granos con miel son buenos, sí. [Magreb 3]

En cuanto a las creencias religiosas y las costumbres y comportamientos relacionados con dichas creencias, nos centramos ahora en los comportamientos que resulten llamativos o que puedan influir en el estado de salud de las usuarias. No entramos en este punto del análisis a comentar otros posibles comportamientos relacionados de algún modo con las creencias religiosas (como puede ser, por ejemplo, la prohibición de comer carne de cerdo, o la preferencia de personal sanitario de sexo femenino por parte de algunas usuarias o incluso el rechazo a ser tratadas por personal sanitario de sexo masculino), ya que analizaremos estos aspectos detalladamente en otros puntos de nuestro análisis.

Tanto los profesionales como las usuarias mencionan la religión musulmana como aquella en la que pueden encontrarse mayores diferencias en cuanto al comportamiento de sus creyentes con respecto a las usuarias autóctonas.

\footnotetext{
${ }^{238}$ Cabe señalar que el fragmento que se analiza no corresponde a las palabras de la usuaria entrevistada, sino a las de su marido, el cual, tal y como puede observarse en la transcripción de esta entrevista en los anexos, intervino en la entrevista llegando a solaparse con las respuestas de la usuaria entrevistada o incluso a contestar en su lugar.
} 
Los profesionales sanitarios asocian esta religión principalmente al ayuno durante el Ramadán. Por lo que se refiere a este aspecto, parece que los profesionales están informados de que el Islam exonera a las gestantes de realizarlo y en general no ven adecuado el ayuno, especialmente en algunos periodos del año como el verano. ${ }^{239}$

Yo considero que todas las religiones, todas, son muy válidas para quien las necesite. Lo malo son los fanatismos en una religión o en otra. Ahí sí que ya está el problema. O sea, que uno pueda tener su cultura y su religión, me parece muy bien, pero todo lo que sea fanatismo ya no lo veo tan bien, porque ya, desde mi punto de vista, está fuera de lo razonable. Por ejemplo, como lo que nos encontramos más es el Islam, pues, en esta época que hemos pasado ahora, el Ramadán, los musulmanes saben que la embarazada no tiene obligación de seguir el ayuno, al igual que las personas mayores o las que tienen problemas de salud. Sin embargo, hay algunas musulmanas que dicen "Sí, sí, yo, a pesar de todo, lo sigo". Pues, hombre, allá usted, no se le aconseja, pero luego será ella... Entonces, cuando ya entra a formar parte del fanatismo, no te puedes meter. [Obstetra 1]

En cuanto a las prácticas religiosas, nosotros lo que sí que vemos es cuando el embarazo es en el periodo del Ramadán, y sí que hay muchas que lo hacen y, entonces, claro, pues vienen a urgencias con síncopes y cosas de este estilo. [Obstetra 2]

Hombre, siempre se ha dicho, que el Ramadán no tienen por qué cumplirlo las mujeres embarazadas, pero yo creo, así por percepción, que al menos un $80 \%$ lo deben de cumplir, creo yo. Y que les afecte... bueno, yo no creo que esté demostrado, más que nada que sí que te puede dar problemas dependiendo de cuándo caiga el Ramadán. Si cae en invierno no hay problema, porque puedes comer antes y tal. Pero si cae en verano, como por ejemplo este año, pues sí que puede ser un problema, porque se pegan atracones y, claro, una embarazada no puede hacer una digestión... Pero, vamos, no creo que a un embarazo normal le ocasione problemas el Ramadán, eso yo no lo he visto... Tendemos a decirles siempre que da problemas y tal, pero yo creo que es más bien porque nos sabe malo que hagan algo que no tendrían que hacer porque ni siquiera lo dice su religión, ¿̇no? [Obstetra 3]

Además, algunos profesionales sanitarios asocian la religión musulmana a un mayor pudor en las usuarias que practican esta religión o a la importancia otorgada a la virginidad antes del matrimonio.

[...] hay algunas... ¿cómo lo digo esto?... de religión musulmana que tienen algún problema más, se nota que están un poco más cohibidas [...] creo que tienen algo más de vergüenza, suelen ir más tapadas. [Matrona 1]

$\mathrm{Y}$, en cuanto a las cuestiones religiosas, antes del embarazo, con el tema de la virginidad sí que incide, sí. Sobre todo en las pacientes marroquíes, o las árabes. En ese caso sí que a veces me han consultado, bueno, a mí y a más gente, seguro, para que compruebe la integridad del himen y esas cosas, pero eso es antes de quedarse embarazadas. [Obstetra 3]

Uno de los profesionales entrevistados, sin hacer referencia explícita a la religión musulmana, aunque por su descripción deducimos que se refiere a la misma, habla de la costumbre de sus creyentes de orar en varios momentos del día, y cree que esta podría ocasionar sorpresa, falta de entendimiento o incluso malestar en las usuarias que no practiquen la misma religión.

Porque hay gente que tiene que orar todos los días, y el español no para para orar, y hay extranjeros que paran todo, se sientan en el suelo y se ponen a orar. Y eso, pues, si te toca al lado una española, a lo mejor no lo entiende, y puede incluso molestarle que te tires al suelo y... Y entonces, claro. [Anestesista 5]

${ }^{239}$ En principio, el cumplimiento del ayuno durante el Ramadán por parte de las mujeres embarazadas no es preceptivo; sin embargo, algunas ramas o escuelas del Islam determinan que solo se puede evitar el ayuno en caso de embarazo problemático, y otras lo siguen como opción personal, como una forma de extremar el seguimiento de las normas de la religión musulmana. 
Solo dos de los profesionales señalan otro tipo de costumbres asociadas a las creencias pero no relacionadas directamente con la religión musulmana.

Lo que sí notamos, sobre todo en las senegalesas, es que vienen todas con un cordón. Eso me explicaron que se lo ponía su madre cuando se venían a España, como para protegerlas. [Enfermera 6]

[...] es más una cuestión de creencias o psicológica. Pero bueno, sí que veíamos a algunas negras, no te sé decir de qué país, que se colocaban en la cintura una especie un collar, rodeando toda la cintura, y eso las protegía de que a lo mejor el bebé saliera mal o de que contrajese alguna enfermedad... Era como una especie de amuleto. [Matrona 7]

Por lo que respecta a las usuarias inmigrantes entrevistadas, la mayoría considera que las creencias religiosas no han implicado ningún tipo de problema para ellas estando en el hospital, bien porque no practican ninguna religión, bien porque su religión no dicta comportamientos concretos durante el embarazo y el parto, o porque es la misma o no difiere mucho de la religión predominante en el país de acogida (el catolicismo).

Yo soy evangélica. Pero la religión no dice nada de embarazo, ni niños... [África subsahariana 2]

No, es que yo no tengo ninguna religión, así que no... [África subsahariana 3]

Nosotras somos cristianas. Como mucha gente en España. En China hay muchas religiones, porque hay mucha gente. [Asia 4]

No, porque yo... somos católicos, soy católica, pero tampoco soy creyente... Quiero decir, que yo al chico sí que lo voy a bautizar y todo eso. [Europa del este 1]

Sí, tengo religión pero no hay costumbre de religión con el embarazo, ni nada... Es ortodoxa, pero tampoco tan... practicante. [...] Es más espiritual que ir a la iglesia o asuntos de esos... Sé que hay religiones que a lo mejor no permiten trasfusiones de sangre y cosas así, pero nosotros tampoco... [Europa del este 3]

Yo soy ortodoxa, pero no creo que esto puede causar problemas aquí, porque mi religión está muy parecida con el catolicismo. Y ya lo sabe la gente, los españoles lo saben, que está muy parecida. [Europa del este 5]

Soy católica, pero eso no ha sido ningún problema aquí en el hospital. [Latinoamérica 4]

Por su parte, las usuarias inmigrantes que dicen ser musulmanas sí que mencionan algunos problemas con los que se han encontrado en el hospital a causa de sus creencias religiosas, especialmente con respecto a la comida o al trato por parte de personal sanitario de sexo masculino, temas de los cuales, como ya hemos comentado, nos ocuparemos más adelante.

Por último, solo una de las usuarias, concretamente procedente de Senegal, señala una costumbre propia de su país de origen basada en sus creencias.

Solemos poner al niño una pulsera de plata, y lo solemos poner porque según dicen es para las malas habladurías y esas cosas... Yo también llevo uno, y por el embarazo me lo quité, uno que es medio de plata, que lo llevo muchos años, que me lo dio mi madre y lo llevo por costumbre. Suele ser de plata, porque dicen que es bueno para protegerte de las malas habladurías, de las personas que te miran mal y esas cosas, y eso suelen decir en mi país. [África subsahariana 4] 
En relación con la comprensión y el seguimiento de los tratamientos por parte de las usuarias de origen extranjero, tanto por las respuestas de estas como por las de los profesionales, parece que estos dependen en gran parte de los conocimientos lingüísticos de las usuarias.

En principio, todas las usuarias entrevistadas dicen seguir (y comprender) los tratamientos, aunque en muchos casos, por los conocimientos de español que demuestran poseer durante las entrevistas, esta afirmación nos genera ciertas dudas.

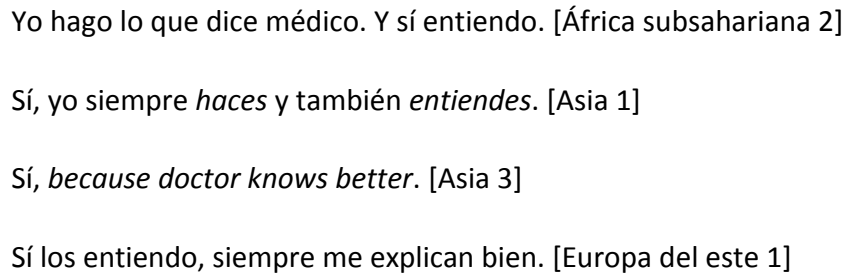

Son pocas las usuarias que reconocen que no siempre entienden las explicaciones relativas a los tratamientos que se les recomienda seguir.

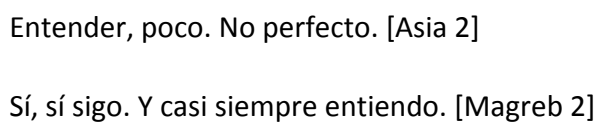

Otras usuarias dicen seguir los tratamientos, pero solo si ven que estos "funcionan", y afirman abandonar el tratamiento antes de lo prescrito por el personal sanitario.

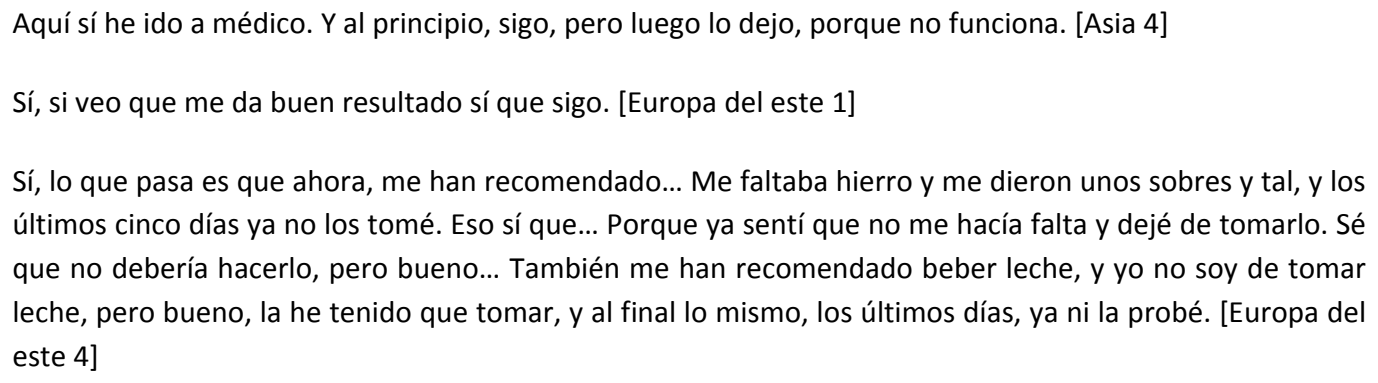

Además, algunas usuarias parecen reforzar la comprensión de los tratamientos mediante la lectura de recetas y prospectos.

\footnotetext{
No he ido nunca al médico, a la farmacia, sí. Sí, entiendo días y eso. Además, como siempre me lo apuntan... [Europa del este 3]

Sí los sigo y entiendo bien, me lo explican bien, sí. Y leo también la receta y el papel del medicamento (el prospecto). Me gusta leer esto, sí. [Magreb 3]
}

Al respecto del apoyo en documentos escritos para comprender los tratamientos indicados, uno de los profesionales entrevistados señala acertadamente uno de los problemas que puede plantear el uso de documentos si estos no están escritos en la lengua materna de las usuarias inmigrantes.

Todo esto depende mucho del idioma. Es difícil comprender, por ejemplo, "Cada ocho horas se toma el Laflón” y luego llegar a tu casa y acordarte. Y se preguntan “¿Era esto cada ocho horas o era lo otro?”. Y 
aunque se lo dejes escrito, pues está escrito en español, no en su idioma, y si no lo entienden, pues... por eso hay más probabilidades de que se hagan un poco de lío. [Enfermera 1]

En relación con la dificultad por parte de las usuarias alófonas de leer documentos escritos en español, otro de los profesionales entrevistados comenta la existencia en el hospital de algunos documentos traducidos a diferentes idiomas, a los que nos hemos referido en el apartado de análisis documental.

Creo que sí que lo entienden, porque se les intenta explicar. Y además me parece que hasta hay folletos en diferentes idiomas. No sé si los habrás visto, pero están escritos en árabe, en chino, en rumano... Son folletos de información y sobre cuidados del bebé. [Obstetra 1]

La mayoría de los profesionales entrevistados opinan que las usuarias de origen extranjero suelen seguir los tratamientos indicados, aunque algunos señalan que el cumplimiento de dichos tratamientos depende de los conocimientos lingüísticos de las usuarias $y$, por consiguiente, de su capacidad para entenderlos.

\begin{abstract}
No, yo pienso que aquí volvemos a lo mismo, es decir, el problema es que se les intenta explicar, pero no es posible que se les queden las cosas lo mismo. Si yo estuviera en otro país y me intentaran explicar un tratamiento, podría entenderlo, pero seguro que no de la misma manera que si me lo explicaran en mi idioma. Es muy difícil a veces el nombre y la toma de los medicamentos, y hay gente incluso española que se le olvida y te pregunta "¿Estas pastillas me las tengo que tomar...?”. Y eso que se lo has explicado a la hora de la comida. Y si eso les pasa incluso a las españolas, pues las otras... y muchas veces, a lo mejor por no molestar, o porque se sienten incómodas, pues no preguntan. [Enfermera 1]
\end{abstract}

A ver, yo creo que cumplimiento sí que hay. Si lo entienden, en general sí que siguen el tratamiento. Pero, claro, el problema es que muchas veces no lo entienden. $Y$ te dicen que sí, pero luego no... no lo han entendido. [Obstetra 2]

Uno de los profesionales resta importancia a la posibilidad de que las usuarias inmigrantes no comprendan los tratamientos, aduciendo que la mayoría de los tratamientos indicados en el caso de un embarazo, un parto y un puerperio "normales" son muy sencillos.

El problema, quizás, sería para explicar la forma en que se toman los medicamentos, aunque realmente aquí se da poca cosa, si es un puerperio normal, hay poco que dar, así que, si existe la barrera idiomática... Aunque, bueno, con todo, es muy sencillo explicar cómo tomar la medicación. [Enfermera 3]

Asimismo, otro profesional considera que, a menos que las capacidades de memorización, retención de información y comprensión de las usuarias estén mermadas por algún motivo (como es el caso de los ancianos), es responsabilidad de estas recordar y seguir los tratamientos tal y como se le haya indicado. Parece que este profesional no considera motivos suficientes como para que a una usuaria alófona le resulte difícil seguir un determinado tratamiento el hecho de que esta usuaria no posea conocimientos lingüísticos suficientes $y$, por tanto, no sea capaz de comprender las explicaciones del personal sanitario ni de plantear las dudas que le puedan surgir.

De todos modos, ellas, tanto pacientes nacionales como extranjeras, tienen que tener unos niveles de autocuidados básicos. Entonces, si tú les explicas que se tienen que tomar esta pastilla, en mi opinión, son ellas las que se deben encargar de realizar esta labor, deben... (Risas) llevársela a la boca, y tomarla, y saber a qué hora, y... tú les explicas, por ejemplo, que a la hora del desayuno y de la cena, les traeremos una pastilla y se la dejaremos en la mesilla... Y creo que no tenemos que ir más allá, pues no son pacientes que tengan... no sé, como pacientes ancianos, que no son capaces de realizarse el más mínimo 
autocuidado, como tomarse la medicación. En esos casos deberíamos estar más atentos, pero ellas, yo creo que sí lo pueden hacer. [Enfermera 3]

Por último, solo un profesional señala la imposibilidad de saber a ciencia cierta si las usuarias comprenden y siguen un tratamiento, y resalta que la función del personal sanitario es la de "informar" y "aconsejar", pero que no le corresponde verificar si las usuarias tienen en cuenta dichas informaciones y consejos.

Vamos a ver, nosotros, antes de dar el alta, se les aconseja un tratamiento que tienen que seguir, y se lo apuntamos en el informe de alta, pero no sabemos si lo siguen (Risas). Porque aquí nosotros podemos informar, aconsejar, si me apuras, pero no... no podemos estar detrás de ellos. [Obstetra 1]

Siempre dentro del nodo de Asistencia sanitaria general, por lo que respecta al comportamiento de las usuarias en el hospital y, más concretamente, al cumplimiento de las normas establecidas en el mismo, algunos profesionales entrevistados opinan que son mayoritariamente las usuarias españolas las que las incumplen.

No, yo diría que en ese aspecto sí que son los españoles los que se comportan un poco más a la... a la brava. Los inmigrantes, por ejemplo, cuando les pides por favor que dejen la habitación, pues normalmente sí que salen. [Enfermera 1]

No, si ya te digo que los horarios, como es en general... (Risas). El problema de los horarios es igual o peor en españolas que en inmigrantes. [Enfermera 2]

Por el contrario, otros profesionales creen que el cumplimiento de las normas no depende tanto del origen de la usuaria, sino de cada usuaria particular.

Yo creo que en general respetan las normas del centro. [Enfermera 3]

En general las normas las cumplen. Es que tampoco... No sé, es que lo mismo que se le puede llamar la atención a ellas se le puede llamar también a las españolas. [Enfermera 4]

¿Sabes lo que pasa? Que en estas cosas normalmente la gente se porta bien. Luego, se te quedan casos que son los de las que dan la lata. Pero en dar la lata da igual que sean de aquí, que de allá. [Enfermera 6]

De hecho, hay uno de los profesionales que piensa que el comportamiento de las usuarias se debe más al estado fisiológico (embarazo o puerperio) por el que todas ellas, independientemente de su origen, se encuentran ingresadas en este hospital.

Veo que la maternidad es muy atípica, no es como un hospital general con unas normas, es que no se puede, porque un parto es algo muy especial. Si tú has dado a luz, sabrás que te vuelves loca, con las hormonas y con todo, no sabes por dónde te da el aire, y es que es normal, es que no se puede... [Enfermera 5]

Otro de los profesionales entrevistados comenta que el cumplimiento de las normas a veces está en función del conocimiento de los derechos que poseen las usuarias.

Hay, por ejemplo, alguna de las del este que tiene más cultura, y entonces se sabe mejor sus derechos, ¿sabes? Y como les digas que no a una cosa, pues entonces se te rebrincan de mala manera. Pues posiblemente porque saben más sus derechos que todas las otras. Y se saben tanto sus derechos que a veces se piensan que son las reinas del mambo, y a veces tienes que pararles los pies. Y les dices "No, no, señora, no. Usted estaba la última y entrará la última". [Enfermera 6] 
Por otra parte, algunos profesionales señalan que las diferencias culturales que presentan las usuarias de origen extranjero podrían ser la causa de que estas presenten un comportamiento "Ilamativo" o incumplan en ocasiones las normas del hospital. Además, un profesional añade que este "choque de culturas" (como él mismo lo denomina) hace que el trabajo del personal sanitario se acentúe.

Lo que sucede es que, claro, esas culturas, al chocar con nuestra cultura, ya no tanto en el vis a vis, sino en cuestión de protocolos del hospital... Nosotros trabajamos con unos protocolos y ellos no se ajustan, no se ajustan para nada, con lo cual el trabajo se acentúa, aumenta mucho. [Enfermera 5]

Igual... me imagino que eso será algo cultural, pero a la negrita le estás diciendo cosas y está a lo suyo, que piensas "Esta está pasando de mí". Por ejemplo, le dices que respire y no te hace ni caso, o sales ahí fuera y le dices "Pero, siéntese bien, no se tire al suelo" y es como si hablaras con la pared. Posiblemente sea su manera de hacer las cosas, su manera de actuar, e igual piensan "Y esta por qué me dice que me siente", si a lo mejor están mucho más cómodas, mucho mejor tiradas ahí. $Y$, entonces, cuando no me hacen caso, yo digo "Pues bueno". [Enfermera 6]

Resulta curioso el hecho de que ningún profesional se plantee el hecho de que quizás las usuarias inmigrantes incumplen las normas porque no las conocen o no las comprenden. Solo uno de ellos opina al respecto $y$, en concreto, duda sobre si el desconocimiento del idioma y la falta de entendimiento puede ser el origen del incumplimiento.

\footnotetext{
Sí, se puede decir así... en tono jocoso, que a veces abusan del desconocimiento del idioma para decir que no se han enterado cuando están incumpliendo una norma. [...] Cuando no entienden el idioma, pues a veces ocurre eso, que incumplen una norma y muchas veces no sabes si no lo están entendiendo o... [...] a veces, cuesta discernir, si es que no se enteran o si es que lo incumplen, porque son incumplidores como podría ser una madre que entendiera perfectamente lo que le estás diciendo. [Profesional socio-sanitario 1]
}

En cuanto a las diferencias que pueden existir entre las normas de los centros de salud del país de acogida y el de los centros de los países de los que proceden las usuarias inmigrantes, un profesional cree que deberían ser estas usuarias las que se adaptasen.

Yo creo que, si vienen aquí, ya saben que tienen que aceptar lo que hay aquí, ¿̇abes? Quiero decir que ya aceptan que aquí hay hombres y mujeres y aceptan que aquí se hacen las cosas así, que se tienen que comportar de una determinada manera, que, por ejemplo, se tienen que quitar la ropa o seguir unas normas... Vamos, a mí me parece que eso lo tienen claro o, al menos, asumido. [...] Ya una vez están aquí, pues tienen que hacer lo que hay aquí y, si no, pues no vendrían al hospital, claro, sobre todo para una cosa que se puede hacer en casa, porque estamos hablando de un parto, que a priori lo podrían hacer en casa, por lo que al venir aquí... es decir, si estás en una sociedad en la que normalmente se pare en el hospital, pues al venir tú también al hospital quiere decir que aceptas un poco todo. [Anestesista 2]

Sin embargo, hay otro profesional que aboga por la flexibilidad y el respeto, y opina todo lo contrario, que debería ser el hospital el que se adaptase en cierta medida a las características de cada usuaria/persona.

En general yo creo que sí que se cumplen las normas, pero vamos, como antes, te diría que hay de todo. También a veces nosotros deberíamos ser un poco más flexibles, ¿eh? [...] Y, luego, nosotros tenemos una rutina de trabajo y pretendemos que todo el mundo haga las cosas según esta rutina. $Y$ yo veo que se trabaja... pues, con muy poca humanidad. Muy poca humanidad, esa es la palabra, humanidad. $Y$, a veces, falta educación, la simple educación, porque a veces oyes unos gritos, unos portazos, unos chillidos... No mantenemos el respeto. Y, sobre todo, cuando son cosas que van saliendo. Porque las normas, muy bien, 
están ahí. Pero ni blanco ni negro, cada paciente es un paciente, y cada persona es una persona, es que... [Enfermera 5]

Por lo que se refiere al tema del acompañamiento y las visitas, ninguna de las usuarias entrevistadas ha tenido problemas porque les hayan acompañado al hospital o por recibir demasiadas visitas.

Casi siempre voy sola, pero si me acompañan, si me acompaña mi marido, nunca he tenido problemas. [África subsahariana 3]

No, no me han dicho nunca nada porque me acompaña alguien al médico o por las visitas... [Comunidad gitana]

No, nunca es problema si me acompañan. [Europa del este 3]

Sí, suelo venir con mi marido normalmente, o con mis suegros. Porque mi familia no vive aquí, y entonces no tengo más que a mi marido y a mis suegros. $Y$ nunca me han puesto problemas porque ellos me acompañasen. [Europa del este 4]

Vengo normalmente acompañada. Y no, nadie me da problemas por esto o por las visitas, ha venido la gente tranquilamente. [Europa del este 6]

Suelo ir acompañada de mi marido. Y no, no he tenido problemas con eso o con las visitas. [Latinoamérica 5]

No, no hay mucha gente. Viene visita, mi amigo, mi familia, y no molesta, no es problema, es normal que haber visita. [Magreb 4]

Solo una de ellas ha recibido un comentario al respecto por parte del personal sanitario, pero, como ella misma afirma, ha sido "simplemente un comentario".

No, lo único que me han dicho, porque el chico lloraba mucho el primer día y sí que me han dicho "A lo mejor es porque has tenido muchas visitas y tal", pero tampoco es... es simplemente un comentario. [Europa del este 1]

La mayoría de las usuarias entrevistadas dicen ir al médico a veces solas y otras acompañadas, tanto por sus maridos como por otros familiares, dependiendo de diferentes factores: la gravedad de la dolencia por la cual acuden al médico, si la persona que les va a acompañar está trabajando en esos momentos, o si necesitan la ayuda de alguien que conozca el idioma o el funcionamiento del hospital.

Sí, pero yo siempre vengo con alguien de mi país que me explica todo, porque tiene más tiempo aquí. Me acompaña mi marido y no es ningún problema. [África subsahariana 1]

Depende, cuando mi marido no está en trabajo, me acompaña y, cuando está en trabajo, yo venir solita. Y no tener ningún problema con las visitas, no. [África subsahariana 2]

Es que depende de las horas. Si son horas que mi marido está trabajando, pues voy sola. Y si puede, pues vamos los dos acompañados. Y no, no he tenido problemas, y con las visitas tampoco, no. [África subsahariana 4]

Al centro de salud a veces va con mi hijo. Él ayuda a entender... [África subsahariana 5]

Me acompaña mi marido y... a veces mi padre. Y no problema. [Asia 2]

I go with marido... with my husband. [Asia 3] 
A veces acompañada de mi mamá o de mi... mi marido. [Asia 4]

Depende. Al médico de cabecera suelo ir sola. Pero si he venido a urgencias, he venido acompañada. Y nunca me han puesto ningún problema por venir acompañada. [Europa del este 2]

¿Al médico? Pues depende cómo estoy. Si no estoy muy mal, voy sola. Cuando me encuentro en estado grave, me acompaña mi marido al médico. Con los chicos, como yo no trabajo, cuando ellos están mal, les acompaño yo siempre. Por ejemplo, ahora con el embarazo, que tuvimos que venir dos veces porque me dolía la tripa, me ha acompañado mi marido, pero si es algo menor, no, me voy sola. [Europa del este 5]

Si es una cosa que yo no sé cómo explicar, voy con mi marido. Pero si es una visita simple, no, voy sola. [Magreb 2]

(Responde el marido directamente) Va con su marido, es decir, yo. Si ella quiere ir sola, no es problema... (Se dirige a la usuaria y le pregunta en árabe si ella prefiere ir sola o con su marido). Con mi marido, yo con mi marido. [Magreb 4]

El hecho de que las usuarias inmigrantes vayan más o menos acompañadas o que reciban más o menos visitas no parece depender, al menos por sus respuestas, del país de origen de las mismas. Además, podemos observar que, en general, las usuarias no afirman que les acompañe o les visite un gran número de personas.

Tampoco los profesionales sanitarios entrevistados han notado que las usuarias de origen inmigrante vayan acompañadas de demasiadas personas o reciban excesivas visitas. Por el contrario, comentan que les sorprende el hecho de que una gran parte de estas usuarias acudan al hospital solas o acompañadas de personas que no forman parte de su círculo familiar o íntimo. ${ }^{240}$

Al respecto, los profesionales opinan que el hecho de que muchas usuarias inmigrantes acudan solas puede deberse a distintos motivos, y no presentan una opinión concordante en cuanto a si el número de acompañantes o visitas puede depender del origen de las usuarias.

Y con respecto a los tipos de etnia, o de cultura, sí que he observado, aunque no sé si es estadísticamente significativo, que hay madres que vienen sin acompañante, sin marido, sobre todo sudamericanas, el resto, no. O sea, las mujeres que vienen solas a dar a luz o con su madre son fundamentalmente sudamericanas. [Anestesista 5]

Sí que alguna vez viene sola alguna mora, o alguna china que viene con otra persona que no es de la familia que le hace de traductor... [Enfermera 6]

Yo no... no más que con gente española. Muchas es verdad que vienen incluso solas, al revés de los demás, yo creo que vienen con menos gente. Por ejemplo, esta mañana hemos tenido el parto de una nigeriana que venía sola porque el marido estaba con las tres niñas que tenía en casa y ella estaba sola. 0 sea, que te quiero decir que más bien por lo contrario, es decir, por el poca gente, que por el mucha gente. [Matrona 3]

No, excesivos acompañantes, yo tampoco... No he notado así... Al contrario, hay muchas veces que vienen solas. Ellos muchas veces tiran de los miembros de su comunidad. Y hay comunidades que sí, que están muy unidas y se ayudan mucho unos a otros... Pero, en general, hay muchas mujeres que llegan solas, porque el marido no puede venir porque está con los críos o trabajando. Las inmigrantes, más que con mucha gente, se ve más que vienen solas. [Matrona 4]

\footnotetext{
${ }^{240}$ Hemos corroborado también este mismo dato (el hecho de que un gran número de usuarias inmigrantes acuden solas al hospital o no reciben apenas visitas) durante los periodos de observación del trabajo de campo. Daremos más detalles al respecto en el análisis de los datos obtenidos mediante esa técnica.
} 
Muchas inmigrantes sí que vienen solas, por ejemplo, las árabes. Porque a lo mejor tienen un niño o dos pequeños, lo colocan donde pueden, con la hermana o quien sea mientras el marido está trabajando y se tienen que venir solas a parir, ¿̇eh? [Matrona 5]

Lo que sí que me ha llamado la atención es que muchas veces vienen solas. Por ejemplo, las mujeres árabes muchas veces vienen solas, pues porque el marido está trabajando o porque no está en el país... Sí, solas sí que vienen más que otro tipo de pacientes, sobre todo destacaría las árabes. [Obstetra 2]

Excesivos acompañantes, en general, no. Las que vienen de Sudamérica sí que pueden venir con más acompañantes. Pero las mujeres árabes, aquí las que vienen son de Marruecos principalmente, y deben de tener el círculo íntimo más reducido, y normalmente vienen con el marido. Algunas veces vienen con otra persona que no es el marido porque el marido está trabajando, pero no, no vienen con muchos acompañantes. [Obstetra 3]

Nos llama la atención el hecho de que dos de los profesionales entrevistados opinen que los maridos de las usuarias procedentes de Magreb no las acompañan o las visitan por falta de interés o "pasotismo".

Pero, vamos, esto igual sucede más con las españolas. Es que los inmigrantes, para empezar, no suelen tener tanta familia. Muchas veces vienen con ellas amigos, o vecinos, o conocidos. No están tan arropados, su situación no tiene nada que ver. Y, a lo mejor, viene el marido, la deja aquí y se va, porque tiene otros niños pequeños en casa, y al no estar tan arropados y tener menos ayudas... Y lo que sí que he visto es muchos maridos pasotas, así coloquialmente hablando, que las dejan, se van a casa a dormir pensando que ya les llamarás... Eso sí que lo he visto, sobre todo en los marroquíes. Vamos, como que no va con ellos, como que el parto es algo de ella y ellos están tranquilos y se van a casa. Y a mí eso me duele mucho. Igual me fijo más porque me da pena. Ves a la pobre mujer que está ahí sola. Y nosotras no le podemos decir nada al marido, nada más que, si se va, que nos deje el teléfono para que le llamemos si tenemos algún problema. $Y$ algunos se van a casa y ni siquiera llaman más tarde para saber cómo va... [Matrona 7]

Y los moros tampoco se comportan muy bien con sus mujeres, porque son capaces de dejarlas aquí, se marchan, y luego te pueden aparecer lo mismo por la tarde que por la noche a preguntar si ya han parido o no han parido, que igual ni te aparecen... Que también es... porque a lo mejor, ellos tienen tres o cuatro hijos más en casa, pero, vamos, yo dudo de que estén con los hijos. La verdad es que yo veo ahí una problemática... Porque luego que no digan que trabajan, que yo veo que no trabajan, porque yo soy quien relleno los papeles y por esto les tienes que preguntar. [Profesional socio-sanitario 2]

Las usuarias inmigrantes que, de acuerdo con algunos profesionales, acuden más acompañadas o reciben más visitas son las latinoamericanas.

¿Problemas? Pues quizás más con el colectivo latinoamericano, en cuanto a que viene demasiada gente a visitarlos. En principio, son los que más problemas pueden ocasionar en ese sentido. [Matrona 1]

El problema de que vengan con muchos acompañantes en todo caso es con los que proceden de Sudamérica. [Obstetra 3]

Pero las usuarias más mencionadas en relación con el tema del acompañamiento y las visitas son, con gran diferencia, las de la comunidad gitana, a pesar de no estar incluidas en principio, por no tener origen extranjero, en nuestro estudio. ${ }^{241}$

\footnotetext{
${ }^{241}$ A pesar de que no hubiéramos considerado incluir a usuarias de la comunidad gitana en nuestro universo de estudio, desde que comenzamos el trabajo de campo en el hospital, fueron numerosas las referencias a las personas de esta comunidad, especialmente cuando se preguntaba a los profesionales por las molestias que pueden ocasionar las usuarias por sus excesivos acompañantes. De hecho, la mayoría de los profesionales entrevistados mencionaban a las personas de esta comunidad como ejemplo de incumplimiento de las normas del
} 
(Se pregunta al entrevistado si hay alguna comunidad que destaque por el número de acompañantes o visitas que recibe). Pues, hombre, la etnia gitana trae mucho acompañante. Pero el acompañante yo no lo valoro, porque en la zona donde yo pongo epidurales solo dejan estar a uno. Lo que sí que ves cuando vas por los pasillos es mucho volumen de gente cuando tienes pacientes gitanas, que no son extranjeras... [Anestesista 5]

Pero bueno, esto no veo que sea con ninguna comunidad en particular, es que no te sabría decir exactamente de dónde... Sí que lo he vivido con toda esta gente... ¿cómo te puedo decir?, con los del género gitano, que tienden a venir muchísima gente y pasan muchos en tropel, y les tienes que decir que se moderen, que salgan unos y entren otros, pero... En ellos es en los que más me llamaba la atención. [Enfermera 4]

$Y$ ya no te digo los gitanos, que ya sabes que esos vienen con toda la familia, dalo por seguro. Es verdad que no son inmigrantes, pero sí que tienen diferencias culturales. Lo que pasa es que en este caso las diferencias ya las sabes: son unas personas probablemente más familiares que nosotros, o como no trabajan, igual les da hacer la tertulia en el bar de enfrente que en la sala de espera del hospital, donde además están calientes en invierno y frescos en verano. $Y$ es que les dices "Oiga que no pueden estar tantos", y no te hacen caso. [Enfermera 6]

No, yo no he observado que vengan con excesivos acompañantes. Si hablamos de inmigración, no, si hablamos de otros colectivos, sí. Me refiero especialmente a la etnia gitana. [Matrona 2]

El tema de muchos acompañantes no se ve en los inmigrantes, se ve más en la etnia gitana. El resto... yo creo que están dentro de lo normal o incluso menos acompañantes que los que vienen con los de aquí. [Matrona 4]

Muchas vienen solas. Y los que más vienen acompañados son los gitanos y son nuestros, o sea que... [Matrona 5]

$\mathrm{Y}$, luego, los gitanos, esos son los que más, pero claro, no son inmigrantes. Aunque es un colectivo muy aislado, llevan aquí generaciones $y$, entonces, aunque haya diferencias no los considero como inmigrantes. Pero, vamos, las que más, las que más vienen acompañadas sin duda son las gitanas. [Obstetra 3]

Otra de las cuestiones que resaltan los profesionales en sus respuestas es el hecho de que muchas usuarias de origen inmigrante acudan acompañadas por niños menores de edad, algo que, en principio, incumple las normas establecidas en el hospital.

Y entre las extranjeras... pues bueno, los sudamericanos pues sí que son bastante gregarios, y a lo mejor si tienen una familia aquí bien estructurada, pues a lo mejor sí que viene a verla toda la familia, incluyendo los niños pequeños. Eso me llama la atención. Porque a lo mejor está dando a luz a altas horas de la noche y vienen niños pequeños. $Y$ otra familia que también suele venir con niños pequeños, pero yo creo que por otro motivo, son los eslavos, la gente del este. Porque son familias que tienen todo lo contrario, están disgregadas, y a los hijos de otras edades no saben qué hacer con ellos, y se los tienen que traer, porque no tienen familiares con los que dejarlos. Y entonces a veces ves por el pasillo al padre con dos críos y la mujer está pariendo al tercero. [Anestesista 5]

hospital o por el acompañamiento por parte de demasiados familiares y/o amigos. De todos modos, asociaban siempre estos comentarios a la idea de que, aun pudiéndoles considerar como miembros de otra cultura, cabría diferenciarlos de los inmigrantes. Además, en alguna ocasión, incluso mencionaron a las personas de la comunidad gitana en alguna broma o chiste prejuicioso. Fueron precisamente los numerosos comentarios, así como el hecho de que un grupo de enfermeras durante el trabajo de campo nos hablaran de una usuaria de la comunidad gitana que se hallaba ingresada ese día en la planta, los que propiciaron que realizáramos una entrevista a una usuaria de esta comunidad. 
También es que normalmente tienen una problemática, que a lo mejor no tenemos los de aquí, que es que no tienen dónde dejar a los niños. Si sus maridos trabajan, no tienen dónde dejarlos. $Y$ aunque les digas que aquí no pueden venir con niños, te dicen que no tienen dónde dejarlos. [Enfermera 6]

Muchas veces es porque tienen más críos y no tienen con quién dejarlos. No tienen todo el apoyo que tenemos nosotros. Ellos no tienen, por ejemplo, a la abuela, para dejarle al niño... [Matrona 4]

En el caso de los inmigrantes, depende de la gente que tengan aquí en España o en Zaragoza, ¿no? Generalmente, los senegaleses, los africanos en general, suelen venir también con mucha gente, vienen con niños... Por ejemplo, las mujeres vienen casi siempre con niños, porque no tienen con quien dejarlos. [Profesional socio-sanitario 3]

La presencia de menores en el hospital como acompañantes y, por consiguiente, el incumplimiento por parte de algunas usuarias de una de las normas del hospital, no parecen en general preocupar excesivamente al personal sanitario. Esta es una muestra, junto con el carácter laxo de los horarios de visitas y del número de acompañantes en las plantas de puerperio, u otras que iremos señalando más adelante, de la flexibilidad que se adopta en el hospital objeto de estudio con respecto a determinadas normas.

Pero eso es a nivel de todo el mundo. Igual da españoles que... Proporcionalmente, a lo mejor, los españoles reciben más acompañantes que los inmigrantes. $Y$ el horario de visitas no lo respeta nadie. [Enfermera 2]

Sí, sí. Eso es un día a día. Cuando estaba en la quinta, en puerperios, eso era una lucha constante, porque había mucha gente y tenías que moderar las visitas, pero no te hacían caso y... [Enfermera 4]

Entonces, a mí los visitantes no me molestan para nada, los acompañantes, ya puede haber treinta, es que me da igual. Me da igual porque si yo tengo que decirle algo a la paciente, voy directamente donde está ella y le digo "Escúchame un momento", y ya está. [Enfermera 5]

En el hospital tenemos un sistema de visitas bastante laxo. No hay un celador en la entrada que les diga "tú no puedes entrar, tú sí" o "necesito el pase". No existen los pases en la maternidad. [Matrona 1]

A lo mejor, alguna vez, nos ha ocurrido que no estaba el marido, pero estaba la hermana. Entonces nos decían que si por el momento entraba la hermana y, luego, cuando llegara el marido, podía también pasar... Pero, bueno, es que lo normal es que, si no está el marido, pues que pase alguien con ella, quien ella quiera que pase, vamos... Yo creo que en eso sí que tenemos manga ancha, no para que pasen dos a la vez, pero si quieren ir turnándose... Vamos, por lo menos, por mí, yo no tengo ningún problema, ninguno. [Matrona 6]

De hecho, solo uno de los profesionales entrevistados manifiesta abiertamente que el excesivo número de acompañantes puede dificultar su trabajo.

Porque cuando dan a luz, aquí es un circo, en el caso de las españolas viene su padre, su madre, su tía, su prima y pasan treinta o cuarenta personas en dos días. Y entonces, además de estar lleno de gente, pues es que la movilidad en el paso... pues es que es un estorbo si hay gente tirada en el suelo. Vamos, pero que no es otra cosa, ¿eh? Vamos, que puedo entender... [Anestesista 5]

Un último aspecto que nos gustaría señalar en relación con la cuestión de los acompañantes y las visitas es la importancia que dan algunos profesionales a que sea la propia usuaria la que decida quién le va a acompañar durante el parto o si desea que sus acompañantes estén presentes durante las visitas.

Nosotras somos las que preguntamos a la señora, siempre es a su voluntad, ¿ंeh?, pues le preguntamos “¿Quién quieres que suba?", y ella responde "Pues, mi pareja” o “Mi marido" o "Mi hermana”, o "Mi 
madre"... Y entonces la mujer decide en todo caso y lo que la mujer ha decidido es lo que nosotras transmitimos a la auxiliar, para que ella pueda informar. [Matrona 7]

No. Bueno, es que yo, normalmente, si hay muchos acompañantes, les invito a que nos dejen en más intimidad, porque la paciente yo creo que lo necesita y lo quiere en el fondo. Porque si tiene que decirte algo... Hay cosas que a lo mejor para mí no tienen ninguna importancia, pero para ellas sí. Entonces, yo prefiero que esté la señora sola, conmigo y con la enfermera. Y si, por ejemplo, está el marido, y no hay ninguna otra paciente en la habitación, no me importa que se quede el marido, pero siempre le pido permiso a la interesada. Le pregunto si le importa que se quede su marido y respeto lo que ella decida. Ella es la interesada. [Obstetra 1]

Otro de los aspectos en los que el hospital objeto de estudio presenta cierta flexibilidad y adaptación es en los hábitos alimentarios de las usuarias. Los profesionales sanitarios son conscientes de las diferencias que pueden existir en relación con estos hábitos, especialmente por lo que respecta a las comunidades china y musulmana.

En cuanto a los hábitos alimentarios, sí, claro, sí que hay diferencias, sobre todo con pacientes árabes. Y también con pacientes chinas, que suelen traer su propia comida. En este aspecto hay incluso más barrera todavía que con las árabes, no solo barrera idiomática, sino que van más a su aire y sí, se traen su propia comida. [Enfermera 3]

Me imagino que aquí te refieres a los árabes, que no pueden comer carne de cerdo... Eso nos hacían hincapié, pero sobre todo en los últimos años, ¿eh? Porque al principio, cuando vinieron, no te decían nada, pero parece que con los años iban cogiendo confianza, o conocían más sus derechos y, entonces, ya nos exigían, pero... [Enfermera 6]

Los chinos sí que es curioso, porque hasta cuando están ingresadas en la sexta planta, antes de parir, les traen la comida ellos. $Y$, luego, en el puerperio también toman una comida aparte, con hierbas y con no sé qué, que probablemente les ayuda... Que dices tú “iFíjate! iQué cosas!”... [Matrona 5]

$Y$, también, por ejemplo, en cuanto a la alimentación nosotros vemos que, cuando están en planta, los maridos, después de haber parido, les llevan una especie de fiambreras en un hato y les traen la comida, es decir, que tampoco comen lo nuestro. [Matrona 7]

Sin embargo, a pesar de que algunas usuarias incumplen las normas del hospital relacionadas con los hábitos alimentarios (por ejemplo, no respetando el ayuno o trayéndose sus propias comidas), no parece que esto sea algo que preocupe excesivamente al personal sanitario. Además, los profesionales comentan que el hospital cuenta con diferentes menús para adaptarse a las características de las usuarias.

Sí que es verdad que a veces les cuesta entender, por ejemplo, cuando les dices "Pues, no puedes comer", y puede ser que por cuestiones de raza o culturales, pues no entiendan que tienen que estar en ayunas y las pillas comiendo porque alguien les ha traído comida, pero bueno... [Anestesista 4]

Pero, lo que no respetan mucho son las comidas. Volvemos a lo mismo, es por sus tradiciones. Se les intenta explicar que una mujer recién dada a luz es más normal que tome una dieta un poquito más sencilla y, en cambio, a lo mejor, suben alimentos con olores superfuertes, con un montón de especias... que tú dices "iPero, hombre! Probemos primero con un zumito, a ver qué tal le sienta"... (Risas). [Enfermera 1]

Aquí hay diferentes menús. Por ejemplo, si una paciente hay algo que no le guste, independientemente de que tenga alergias y demás, pues se le intenta pedir una dieta que no tenga lo que a ella no le gusta. [Enfermera 3] 
Pues bueno, los chinos se traen sus potingues, eso está claro, y lo de aquí no lo comen y se acabó. Pero vamos, allá ellas... [Enfermera 5]

En cuanto a ya la estancia en el hospital, pues sí que hay cosas que son llamativas. Por ejemplo, que llenen las ventanas de alimentos y ese tipo de cosas que, hombre, no es la logística habitual del hospital, pero en sus casos generalmente se les permite. [Matrona 1]

Algunos profesionales creen que, aunque el hospital cuenta con un menú específico para usuarias musulmanas, muchas de ellas no se fían de que este menú siga los preceptos propios de su religión, por ejemplo, en relación con la carne de cerdo.

A veces sí, a pesar de que tienen dietas adecuadas en el hospital para ellas, pero en general no se fían. Por ejemplo, en el hospital hay una dieta musulmana, pero no toda paciente se fía de que lo que le están dando sea realmente una dieta musulmana. [...] ya te digo, aunque está hecha para musulmanes, normalmente no se fían. $Y$ no solo por la carne, porque hay gente que nos dice que no quiere comer carne, y entonces nosotros le ponemos pescado, porque para dos días que están en el hospital, pues aunque no coman carne, tampoco es problemático. [Enfermera 3]

Pues, sobre todo con los musulmanes, que te recalcaban mucho lo de la carne, y aunque tú les decías "Que no, que esto no tiene carne de cerdo", aun así tenías que pedir la dieta de ellos pero sin carne. Vamos, que tú les insistías en que no se preocupasen, pero parece que no te creían. [Enfermera 4]

Hombre, a veces, yo sí que he notado más, cuando están en las plantas ingresadas, por ejemplo pues sí que dicen con el tipo de comida "Pues quiero tal, pero que no lleve carne". Porque no se fían de que es carne no sea cerdo y prefieren que no lleve carne. [Matrona 5]

Con las árabes hay dos extremos: uno que no comen nada de lo que les dan, solamente verduras, por si acaso la carne que les dan es... porque no se fían, y a las otras que les da vergüenza decir que... que no comen cerdo. [Obstetra 3]

Quizás estas usuarias tengan ciertos motivos para no confiar en que el menú que les ofrecen efectivamente no contiene carne de cerdo, pues, de acuerdo con dos de los profesionales entrevistados (e incluso algunas usuarias, como veremos más tarde), en alguna ocasión (por descuido o por desconocimiento, no podemos saberlo a ciencia cierta) les han ofrecido comidas que contenían este tipo de carne.

Mira, para eso, los árabes, los musulmanes, son muy... muy extremos, sobre todo los hombres. Ellas se comen todo lo que les des, porque tienen un hambre que se mueren, pero ellos... Yo sí que tuve una vez un percance con un señor, que me quería pegar, porque le había dado a su mujer una tortilla con... no recuerdo qué llevaba, creo que era jamón de york... [Enfermera 5]

Y me acuerdo que un día había una señora que había pedido sin carne y le dieron unas croquetas. Y eran croquetas de jamón y entonces se puso... Lo dijo muy educadamente, pero lo dijo. Dijo "¿Para qué me preguntas si me vas a poner lo que quieras?". Y, en realidad, tenía razón, pero nosotras también habíamos hecho bien, le habíamos pedido esa dieta, lo que pasa es que en cocina se liarían o lo que fuese y para esa señora le pusieron, precisamente, icroquetas de jamón! ilmagínate! Le pedimos disculpas también, y dijo que bien, que lo entendía, que vale, pero que para qué preguntábamos. Yo me imagino que para esa persona sería como una tomadura de pelo, como si no nos importara ni tres ni cuarenta lo que ella... [Matrona 5]

Por otra parte, la opinión de las usuarias entrevistadas con respecto a la comida del hospital es muy variada. Algunas están muy contentas con la comida que les han dado en el hospital.

La comida pienso que es muy bien, pensaba que igual me quedo con hambre, pero no, ha sido bien. La verdad es que a mí me ha gustado... [África subsahariana 3] 
La comida de aquí del hospital está muy buena, me encantó. La verdad es que superó mis expectativas la comida de aquí. [Latinoamérica 2]

Otras, a pesar de no gustarles tanto, creen que se trata de comidas adecuadas para las mujeres durante el puerperio.

Comida del hospital es bien, pero me parece que es comida de médico, ¿isabes? Como que una persona necesita esta comida para este momento. [África subsahariana 2]

La comida no la cambiaría, porque me supongo que nos dan según nos... es decir, según la dieta que tenemos que seguir, y entonces, yo no la cambiaría. Creo que lo hacen bien. [Latinoamérica 3]

Con respecto a los hábitos alimentarios después de haber dado a luz, hay un grupo de usuarias de distintos orígenes (concretamente de China y de Honduras) que mencionan algunas diferencias en cuanto a las costumbres durante el puerperio en sus países de origen y en España.

La comida me gusta, está muy bien. (Le pregunto si es cierto que en China se prefiere tomar alimentos calientes después del parto). Sí, sí, verdad. En China dan y aquí creo que también. [Asia 1]

Comida, bien. Normal. Madre no puede beber agua fría, pero España diferente. Nosotros hay cosas que no podemos comer. [Asia 4]

La comida aquí en el hospital es distinta, pero no la cambiaría, porque aquí sí que llevan buen orden. Y, allí, sin embargo, nosotros podemos... Venimos del paritorio y, cuanto más comemos para que nos salga la leche, mucho mejor. Nosotros solemos comer mucho, y aquí es ya una dieta blanda o semi-blanda, depende de cómo sea el parto. Sí, esa es la diferencia. [Latinoamérica 5]

Cabe señalar, además, en este punto, que algunas de las usuarias entrevistadas comentan, sin que se les pregunte explícitamente, que se han adaptado a los hábitos alimentarios españoles.

Comida está bien para mí, yo comer comida de España. En Nigeria la comida es diferente, pero yo mucho tiempo aquí y yo saber cocinar todo y yo saber comer todo. [África subsahariana 2]

Por ejemplo, la comida la hago española, como le gusta a mi marido y tal... Y como ya me he acostumbrado tanto... Antes el aceite de oliva, pues claro, a mí me costaba mucho. Es que el sabor es buena, pero a mí no me... Pero, luego, lo he ido probando y probando y ya coges el sabor y... iestá buenísimo! (Risas). [Europa del este 1]

La comida está bien. Yo no tengo problemas con eso. Es que ya me he acostumbrado a la comida de aquí después de tantos años. Como más comida de aquí que de Rumanía. (Le pregunto si hay muchas diferencias entre los hábitos alimentarios de España y Rumanía). Es que en Rumanía se usan como más especias y eso. [Europa del este 2]

Sin embargo, la opinión de las usuarias en cuanto a la comida suministrada en el hospital no siempre es positiva y esto se debe a diversos factores.

Algunas de ellas simplemente señalan que consideran que los alimentos servidos llevan poca sal (algo que se suele comentar también entre usuarios autóctonos).

La comida de aquí no me gusta. (Le pregunto qué cambiaría). Hay muchas cosas que te las dan sin sal, son muy sosas... [Comunidad gitana]

(La usuaria habla directamente en rumano dirigiéndose a su hermano, quien realiza después labores de interpretación al español). Dice que falta sal. Es sin sal, sin sal. (Risas) [Europa del este 3] 
La comida está bien. (Le pregunto si echa algo en falta o cambiaría algo con respecto a la comida del hospital) Le añadiría un poquito de sal... (Risas). [Latinoamérica 4]

En otras ocasiones, la opinión negativa de las usuarias con respecto a la comida se debe a gustos meramente personales.

Me gusta comida del hospital, pero no todo. Yo aquí como comida de mi país, que es diferente. Aquí puedes encontrar de todo y yo como como en mi país. Es que aquí no es comida de mi religión, cristiana, y me cuesta. Además no me gustan por ejemplo las gambas, eso no me gusta. [África subsahariana 1]

Uy, comida... (Risas). Es que a mí solo me gusta mi comida. Yo, por ejemplo, me gusta mi comida de casa, pero bueno, aquí está bien. Tampoco está tan mal del todo, pero es que yo... prefiero mi comida. [Europa del este 1]

Es que a mí en general no me gusta todo de comer. (Le pregunto si suele comer más platos típicos de España o de Rumanía). Como de los dos, pero no me gusta todo, tampoco de mi país me gusta todo, ¿eh? [Europa del este 6]

Asimismo, algunas usuarias comentan que, de acuerdo con su religión, no pueden comer carne de cerdo.

La comida es buena, yo solo no comer cerdo. (Se le pregunta si es musulmana) No, yo no ser musulmana, pero mi tradición es no comer cerdo, solo eso. Yo digo a las enfermeras y no traen cerdo. [África subsahariana 5]

Sí, I like it. Food... because we are Muslims, food... we eat pollo, ternera, pescado, verduras... [Asia 3]

No me gusta mucho. Solo me dan pescado. A mí gustaría comer por ejemplo carne halal. En el colegio de los niños si hay comida para musulmanes. [Magreb 2]

La comida está bien. Como yo... Nosotros musulmanes no comemos cerdo y todo eso y lo dijimos aquí y me han traído otra cosa. [Magreb 3]

La comida, bien. Nosotros somos musulmanes y entonces no cerdo. Pero ningún problema, nosotros decir y no traen cerdo. [Magreb 4]

Por último, tal y como habíamos anticipado previamente, un par de usuarias entrevistadas señalan percances que han experimentado en relación con la prohibición de comer cerdo y las comidas servidas en el hospital.

A ver, sí, eso sí que te lo diría que sí. Bueno, esto pasó antes de ayer, el martes. Porque cuando me ingresaron en esta planta el lunes me preguntaron lo que puedo comer y lo que no puedo. $Y$ yo les dije que no puedo comer cerdo, y luego al pescado azul y a la cabra le tengo alergia. $Y$ el martes me trajeron un plato que es lentejas y le pusieron trocitos de jamón. Los llamé y no era un reclamo, solo que si se habían olvidado y esas cosas que no me lo traigan más. Y la que vino a atenderme empezó a decirme cosas que realmente no me gustaban. Me dijo que mis jefes cuando vienen aquí comen cerdo, y yo le respondí que yo realmente no tengo jefe. No tengo jefes y no me tiene que hablar de esa gente, porque no tengo nada que ver con ellos, no son familia mía, y a mí me da igual el presidente de España o de Senegal ni nada. Yo soy jefa mía, yo no tengo jefes. E insistió "No, es que los ricos lo comen", y eso es como si me trata de pobre, y a ella le da igual que yo sea rica o pobre o lo que sea... E insistió "Antes se pagaba aquí la comida. Los que lo pagan comen y los que no lo pagan no comen". Y lo que le respondí es "Por eso yo pago la seguridad social". Yo estoy pagando la seguridad social y mi marido también, porque estamos trabajando los dos, así que la comida no la tengo que pagar, ni los tratamientos. Yo sé que es una cosa que... sé que es esa persona que me atendió, porque estoy ingresada desde el viernes, estuve en la planta sexta, y allí me atendieron muy bien, perfectamente, pero aquí... Pero bueno, hoy me voy a casa y no se hable más. [África subsahariana 4] 
Y ayer me dan pescado con jamón y eso yo no puedo comer. [Magreb 2]

El último subnodo del nodo de Asistencia sanitaria general se refiere a los aspectos burocráticos. Las respuestas de los profesionales sanitarios con respecto a este tema, en primer lugar, nos proporcionan cierta información básica con respecto a qué áreas y profesionales del hospital se ocupan de estas cuestiones o qué procesos dentro del hospital pueden requerir de un mayor dominio del idioma por parte de las usuarias.

\begin{abstract}
Lo que pasa es que aquí, quieras que no, pues tampoco nos encontramos con tanto... Yo creo que esos temas se dan más a lo mejor en las plantas. Porque aquí vienen ya vienen con la pegatina puesta, que es lo que a nosotros nos interesa, y burocracia tenemos poca o ninguna. $Y$ nosotros nos centramos más en lo físico, en cómo va la dilatación, en poner un gotero, en ver si pares o no pares. Y me imagino que cuando ya están ingresadas puede ser que se encuentren con algún problema más de registro: dónde estás empadronado, cómo se inscribe al recién nacido, y temas de ese tipo. Por eso será más en planta o en la ventanilla donde se encuentren con ese tipo de problemas. Es que aunque llegue de la calle un parto en curso. Pues es que nosotros nos dedicamos a lo que nos dedicamos, no te ves haciendo papeles. [Matrona 5]
\end{abstract}

Es que, mira, hay dos estadios. El primero es cuando la mujer te viene de urgencias, ves que la mujer está embarazada, y supones por su cara que te dice que está sangrando o... y, entonces, la diriges a la zona de urgencias. Ahí no hace falta entenderte, enseguida hay una comunicación no verbal. El problema surge cuando ya ha dado a luz esta señora y le tienes que explicar que hay unos papeles para registrar a ese bebé. Y ahí es imposible, es imposible porque no te entienden. Incluso para un español es complicado, entonces para ellos más. [Profesional socio-sanitario 3]

Además, uno de los profesionales entrevistados señala que son normalmente los maridos de las usuarias quienes se encargan de estas cuestiones, algo que corroboran también, como veremos más adelante, las usuarias entrevistadas en sus respuestas.

De los temas de papeleos para el registro de los niños y demás se ocupa el marido, vamos, el marido o la pareja, porque si no están casados, también puede hacerlo la pareja. [Profesional socio-sanitario 2]

Algunos profesionales opinan que la burocracia en el hospital es excesiva, algo que afecta tanto a usuarias inmigrantes como autóctonas.

El tema burocrático ya sabes cómo es, todos los papeles y eso es que es una barbaridad. [Matrona 4]

En cambio, uno de los profesionales entrevistados opina que las exigencias relacionadas con aspectos burocráticos que reciben los inmigrantes y, en concreto, aquellos que no proceden de países europeos, son mucho mayores con respecto a las que reciben los españoles o los inmigrantes procedentes de países como, por ejemplo, Alemania. Además, opina que el endurecimiento de estas exigencias puede provocar una actitud de miedo o agresividad por parte de las usuarias inmigrantes.

Cuando estaba en las plantas no me resultaba tan difícil como ahora, ahora más. Sí, porque cada vez ellos tienen menos medios, y cada vez hay una exigencia mayor por parte del Estado para que tengan todo regularizado, y entonces es mucho más complicado, para ellos y para nosotras. $Y$, además, también están más de uñas, tienen miedo, y eso yo traducen en agresividad hacia ti. Piensan "A ver qué me va a pedir esta señora o qué me va a decir". Esto lo he notado mucho, mucho... [Profesional socio-sanitario 3]

Yo veo que a ellos concretamente se les ponen muchísimas más trabas que a cualquiera de nosotros o que a cualquier extranjero de Holanda o de Alemania que venga... Se les ponen muchísimas más trabas. Y eso a mí me fastidia, porque a veces teniendo todo lo que hace falta, todo lo que nos piden a nosotros, aparte aún les piden documentación especial. Y tú piensas “¿A santo de qué, si hace poco ha parido aquí una 
alemana y no le han pedido todos estos requisitos?". Entonces, me parece injusto total. Tan extranjeros son los unos como los otros, pero no, a ellos a nivel burocrático se les pide mucho más. Y digo a nivel burocrático, ¿̇eh?, porque a nivel... pues, mira, cada uno tiene una manera de pensar. Pero que a nivel burocrático, a nivel estatal, se les trate a cada uno de una manera, me parece injusto. Si eres extranjero, eres extranjero, tengas pasta o no la tengas. Pero, no, se hace la diferencia, y mucho. [Profesional sociosanitario 3]

Cabe señalar que la mayoría de los profesionales indican que las dificultades que encuentran las usuarias inmigrantes en relación con los aspectos burocráticos son mayores que los de las usuarias autóctonas, y señalan diferentes motivos posibles para esta mayor dificultad.

Por un lado, algunos consideran que las diferencias culturales en cuanto al control del embarazo en sus países de origen y en España puede disminuir la comprensión de estos aspectos por parte de las usuarias inmigrantes.

El mayor problema que nos solemos encontrar es que se controlan generalmente peor el embarazo. No sé si es porque la burocracia es excesiva para ellos, si es porque tienen otras costumbres en cuanto a control del embarazo en su tierra de origen, o porque... pero ese es el mayor de los problemas. [Matrona 1]

A lo mejor para otras cosas, si en su país funcionan de manera diferente, les cuesta más enterarse. [Matrona 3]

Y luego, a lo mejor, en el país del que vienen ellas tampoco se llevan los mismos controles que se puedan llevar aquí. Entonces, claro, si ellas vienen de un país en el que te ven durante el embarazo dos veces como mucho, como era en España antes, que te hacían una ecografía y ya está... Entonces, pasan de la situación de su país a aquí, donde te hacen cincuenta ecografías, y cincuenta visitas... [Matrona 4]

En cuanto a las posibles diferencias culturales relacionadas de algún modo con los aspectos burocráticos, otros profesionales sanitarios señalan también problemas relacionados con las costumbres en cuanto a los nombres propios o en cuanto a la documentación.

Y basta con que vengan con los carnets de identidad y ya está. Eso es importante, porque a veces podemos tener problemas con los nombres, porque por ejemplo, los rumanos, cuando se casan el nombre lo cambian y se ponen el apellido del marido y, claro, si los papeles no están bien rellenados, pues puede haber problemas luego con los niños, porque no están bien inscritos... Y, entonces, siempre hay que pedirles el carnet de identidad o el pasaporte, que hay muchos que no tienen carnet y vienen con el pasaporte, y da gracias... [Profesional socio-sanitario 2]

Muchas veces te das cuenta de que no saben leer ni escribir. Y, sobre todo, los musulmanes, los árabes, son supercomplicados, porque ellas no se enteran de nada, y ellos intentan entender, pero hay cosas, como la cartilla de la Seguridad Social, que no se dan cuenta de lo importantísima que es, no le dan valor. O los gitanos, aunque no sean inmigrantes, pero también tienen diferencias culturales. Y ellos tampoco le dan importancia a ese trámite de la Seguridad Social, que en realidad es super, superimportante, y ellos pues no... no se enteran. [Profesional socio-sanitario 3]

Por otro lado, un gran número de profesionales sostienen que el desconocimiento del idioma es la causa principal de la falta de comprensión de los aspectos burocráticos por parte de las usuarias de origen extranjero.

Y el decirles, por ejemplo, "Tienes que ir a tal sitio y citarte para tal día. Y en tal sitio te darán tal papel y me lo tienes que traer, y luego tienes que ir no sé dónde con otro papel que te dé yo, y entonces ya te dirán qué día tienes que venir". Eso, si a una persona que le hablas en su idioma no se entera, pues imagínate cómo será con un idioma que no entiendes, o que entiendes lo justo para pasar las situaciones 
de la vida diaria. Yo creo que el problema vuelve a ser el idioma. El tema de la burocracia y todo eso es difícil para todos. [Matrona 4]

A veces no acuden a la consulta porque no se han dado cuenta, o porque no han entendido bien. También las chinas, hay alguna que tiene también problemas para comunicarse $y$, a lo mejor, no viene a la ecografía... O ves la cartilla del embarazo y faltan cosas, porque no se han enterado... [Matrona 6]

Supongo que a los subsaharianos les costará más, pero yo creo que será por el idioma, o por... sí, la burocracia, muchas veces tienes que ir de aquí a allá, y se lo explican, pero a lo mejor los subsaharianos, siempre por problemas lingüísticos, pues a lo mejor no lo entienden, porque no entienden el idioma. [Matrona 6]

Pero en este caso es un problema de comunicación, porque no lo entienden, porque a lo mejor no lo han entendido bien. [Matrona 7]

Yo creo que, salvo si no entienden bien, por problemas de idioma, no (presentan este tipo de problemas). [Profesional socio-sanitario 1]

Y otros profesionales indican que, en el caso de las usuarias inmigrantes que no se encuentran regularizadas, el miedo a ser denunciadas, o el hecho de pensar que no las van a atender por su situación irregular, hacen que estas no acudan a los controles del embarazo o que incurran en prácticas inadecuadas, como el uso de la tarjeta sanitaria de otra usuaria.

Algunas veces sí que tienen desconocimiento a la hora de realizar una consulta por asistencia médica, porque a lo mejor no tienen los papeles en regla. Y, bueno, yo siempre atiendo a embarazadas, y a veces piensan que por no tener los papeles en regla no se les va a atender, o se les va a hacer una persecución, o un seguimiento, y entonces, sí, sí que tienen problemas. [Obstetra 3]

Por ejemplo, la utilización de la tarjeta de otra persona, que se da mucho en la comunidad china, pese a que les expliques cincuenta veces los riesgos que conlleva y que no es necesario, que a una embarazada la ven igual, pues no se fían. Se creen que les vas a cobrar o que no les vas a atender y vienen con la tarjeta de una acompañante. Entonces, yo creo que son los que más evitan usar nuestros servicios. [Profesional socio-sanitario 1]

Al respecto de esta cuestión, algunos profesionales señalan la legislación vigente, según la cual, como hemos visto en el apartado de este capítulo centrado en el análisis documental, se debe atender a todas las mujeres embarazadas, independientemente de si cuentan con tarjeta sanitaria o no.

He hecho también de mediadora con los centros de salud, porque muchas veces, como los consideran como desplazados, pues no los quieren ver, y les tengo que aclarar que la Ley de protección jurídica del menor dice que les tienen que ver sí o sí... Que vale, que hay algunos anárquicos que no hacen los papeles y no tienen ninguna excusa, pero que los bebés no tienen la culpa de vivir en una familia de anárquicos, y entonces hay que verlos. [Profesional socio-sanitario 1]

Además, un profesional comenta que su misión es principalmente atender a las usuarias, las cuales, en su opinión, "deberían estar por encima de la burocracia".

Bueno, yo en eso sí que no te puedo ayudar mucho, porque nunca me he preocupado demasiado de los papeleos. Considero que las personas deberían estar por encima de la burocracia. Es necesaria, de acuerdo, porque sin una burocracia no podríamos estar en la sociedad en la que vivimos, pero para eso están las personas que se dedican a estos temas, como son las secretarias, por lo que yo nunca me he preocupado si una persona está inscrita en la seguridad social o no está inscrita, o si ha rellenado el formulario número tal o no lo ha rellenado. Me da igual. Necesita una atención y, si se la puedo ofrecer, se la ofrezco, y ya está. [Obstetra 1] 
En referencia a estas posibles barreras a las que deben enfrentarse las usuarias inmigrantes con respecto a la burocracia, los profesionales entrevistados indican diversas soluciones posibles.

Algunos consideran que las usuarias inmigrantes logran comprender los aspectos burocráticos gracias a la información proporcionada por sus propias redes sociales.

[...] pero en cuestión del embarazo ellas, claro, en su entorno se mueven, y además normalmente son mujeres con mucha... que procrean mucho, y entonces entre ellas se cuentan y se orientan y... Yo creo que sí que están informadas. [Matrona 3]

Lo conocen porque tienen gente que se lo ha explicado. Porque nosotros intentamos explicárselo, les subrayas, les escribes, pero no... [Profesional socio-sanitario 3]

Otro profesional señala la ayuda de un "traductor" (aunque más bien sería un intérprete) en el caso de las usuarias, en concreto de origen chino, que no conocen el idioma.

Con los papeleos los chinos son los que tienen menos problemas, esos sí que saben más y... son más espabilados que la leche (Risas). Es verdad, ¿eh? Se comunican mejor porque siempre vienen con alguien que entiende más que ellos y les hace como de traductor. [Profesional socio-sanitario 2]

Por último, algunos profesionales comentan que ellos mismos ponen de su parte personalmente para que la comprensión y el cumplimiento de las exigencias burocráticas por parte de las usuarias inmigrantes sean efectivos.

Y muchas veces sí que la enfermera o la auxiliar les acompañan abajo, para que tomen cita y se aseguran de que la toman bien, y con que sepan día, hora y lugar, aunque no sepan lo que se van a hacer, por lo menos saben que tienen que venir. [Obstetra 3]

Y el incumplimiento de las normas, si es que no las incumplen, es que no se enteran. No se enteran porque esto es una burocracia horrorosa. Así que, por ejemplo, si yo lo que necesito en concreto es este papel, pues intento hacerlo el primer día, y vale. Y si veo que una persona, porque hay muchas veces que están solas, que las dejan aquí y se van, muchísimas, muchísimas... pues, ¿qué vas a hacer? Pues lo que hago yo, que le digo "Llama por teléfono, que te den este papel, que te lo traigan y yo te lo bajaré"... 0 sea, lo que ya hablábamos. [Enfermera 5]

Por lo que se refiere a las usuarias inmigrantes entrevistadas, la gran mayoría de ellas, independientemente de su origen, opina que hay suficiente información relativa a los aspectos burocráticos en el hospital.

Sí hay información, está bien explicado, entonces no tener muchos problemas. [África subsahariana 2]

Sí, creo que hay bastante información, yo no he tenido problemas. [África subsahariana 3]

Sí hay información. Si no estoy bien, pido cita. [Asia 1]

No, no es difícil. Sí dan información. [Asia 2]

Sí, sí enough information. [Asia 3]

No, no es difícil. Sí hay información. [Asia 4]

No, la verdad es que no he tenido ningún problema con esto. Sí que creo que hay bastante información, vamos, por ahora no me he quejado, todo ha ido bien. [Comunidad gitana] 
No, nunca. Yo creo que hay bastante información y además es que son amables al trato. Hay muy poca gente que... siempre me han tratado muy bien. [Europa del este 1]

No, no he tenido problemas con esto. Y sí que creo que hay bastante información, sí. [Europa del este 2]

En mi caso, sí me han dado mucha información. Me han informado desde el primer momento de todo y la verdad es que no me puedo quejar. [Europa del este 4]

No he tenido problemas de este tipo. Yo creo que hay bastante información y todo va muy organizado. [Latinoamérica 1]

No, no he tenido ningún problema de este tipo. Yo creo que las cosas son bien claras. [Latinoamérica 2]

No, no he tenido problemas de este tipo. Y, sí, sí que creo que hay bastante información. Para todo hay mucha información. [Latinoamérica 4]

No, todo bien. Yo sí creo que hay suficiente información, sí. [Magreb 1]

No, todo está claro. Creo que hay bastante información. [Magreb 2]

Sí hay información, explican todo muy bien y no he tenido problemas. [Magreb 3]

Vemos que las usuarias, al menos las que hemos entrevistado, por lo general no perciben problemas en cuanto a la burocracia, a diferencia de lo que indican en sus respuestas los profesionales entrevistados. Cabe recordar que el desconocimiento del idioma es, de acuerdo con el personal sanitario, la causa principal de la falta de comprensión y cumplimiento de los aspectos burocráticos y, como la mayoría de las usuarias entrevistadas tienen cierto dominio del español, puede ser que a ellas no les resulte tan difícil entender estos aspectos.

No obstante, algunas de ellas concuerdan con los profesionales en la opinión de que la burocracia es excesiva y complicada, y también señalan que normalmente son sus maridos los que se ocupan de estas cuestiones.

Yo creo que hay mucha información, demasiada, buff... (Risas). Pero es mi marido el que hace todos los documentos. [África subsahariana 2]

Es que... al final te pierdes un poco. Y aunque sea el segundo hijo, mi marido ha tenido que preguntar, hemos tenido que informarnos, porque te pierdes un poco los pasos, y tienes que informarte más y pierdes más tiempo. Esto lo hace todo él (su marido), pero como han pasado cuatro años, pues tenemos que preguntar, porque te olvidas... [África subsahariana 3]

Bueno, es que hay muchos papeleos. Hay muchos papeleos que hacer y... Pero a mí no me ha tocado hacerlos, los ha llevado mi marido desde que estoy ingresada, y lleva un mareo... Tiene que ir de un sitio a otro y esas cosas. [África subsahariana 4]

Asimismo, algunas usuarias opinan que su condición de inmigrantes y el endurecimiento de los requisitos que por dicha condición se les exigen dificultan aún más todo este proceso burocrático.

El tema de registro es un lío. La verdad es que nosotros que somos extranjeros tenemos un lío que... Mi marido me contó que fue ayer y que le han pedido tantos documentos, que no los necesitaba, no sé si es para verificar que realmente tenemos todos los documentos o no sé... Vamos, un lío, que le hicieron volver en casa y todo... Por ejemplo, le pidieron certificado de matrimonio de mi país, aunque en la libreta ya figura que estamos casados. $Y$, además, si el primero lo registraron con el certificado y con todo, yo creo que para el segundo no es necesario otra vez. Luego se fue a la Seguridad Social para inscribirlo y la mujer que le atendió lo primero que le pidió fue el pasaporte y volvió a casa para coger el pasaporte. 
Volvió a la Seguridad Social y le tocó otro chico, y este chico le dijo “¿Para qué necesito el pasaporte?”. Que es un lío, es que un lugar donde trabajan dos personas y una te pide una cosa y la otra te pide otras. [África subsahariana 4]

Hombre es que el sistema burocrático ahora es más difícil, en España también, se ha puesto más... Por todas las normativas europeas ahora te dan más papeles que antes. Por ejemplo, cuando hemos venido con el otro niño, no pedían tantos papeles como ahora. Ahora te piden más formularios para rellenarlos, más datos, no sé por qué, pero bueno... [...] Es que me han dicho en el hospital que ahora se pide más, se está controlando más todo. Es que yo me acuerdo, por ejemplo, con los papeles, que la otra vez no eran tantos, y ahora miro que me piden unos datos. [...] Algo conocemos de la vez anterior que hemos tenido un niño, aunque ahora hay más burocracia con los papeles. No sé por qué, a lo mejor es por una normativa europea. Porque ahora te piden más papeles para todo. [Europa del este 5]

Además, algunas usuarias también señalan como posibles obstáculos para entender y cumplir con los aspectos burocráticos el desconocimiento del idioma o del funcionamiento del servicio sanitario.

En Nigeria es diferente, es más fácil. Tú sabes que en mi país es en inglés, y entonces tú puedes leer y no hay muchos documentos, pero aquí sí hay muchos, para empresa y para todo, es muchos... [África subsahariana 2]

No, no, es muy claro, todo muy claro. Sí hay bastante información, pero a veces el español... Es que yo no entiendo bien el idioma, si entiendes el idioma, no hay problemas. Es un sistema muy bien lo que hacer. [Europa del este 3]

Por ejemplo, me piden que algunas fechas las escriba con las letras, que antes no era así, ponías los números y ya está. Ahora te obligan que lo escribes con las letras. Y esto es un poco difícil para los que no saben bastante bien español. Por ejemplo, a lo mejor no sabes si la hora "Diecinueve y cincuenta y siete minutos", a lo mejor no sabes si se escribe junto o separado. Hay algunos que no lo saben...Y te puedes equivocar. $Y$ tienes una hoja amarilla que no puedes escribir erróneo, porque tiene las huellas de la madre y el niño, y entonces no te puedes equivocar, porque ese papel es único, no hay otro. [Europa del este 5]

Sí que creo que hay bastante información, lo que pasa es que nosotros, como no conocemos mucho, pues nos hacemos problemas nosotros, pero de ahí a haber, pues sí, sí que la hay. [Latinoamérica 3]

Y para salvar estos obstáculos, tal y como indicaban también los profesionales entrevistados, las usuarias dicen recurrir a sus propias redes sociales.

Sí, pero yo siempre vengo con alguien de mi país que me explica todo, porque tiene más tiempo aquí. [África subsahariana 1]

Yo ahora he pedido mi cuñada, mi cuñada es española, que rellenar todo y ella ayuda. [África subsahariana 2]

(Le pregunto a quién se dirige cuando hay algo del sistema sanitario que no conoce). Pues pregunto a algún conocido, a alguna señora, a alguna persona que sea de aquí, de España, que como ya sabe las costumbres y todo eso, pues le pregunto y... [Latinoamérica 3] 


\subsubsection{Embarazo, parto y puerperio}

El siguiente nodo analizado se centra ya en aspectos específicos de la salud reproductiva y, concretamente, está compuesto por los subnodos o subtemas que se muestran en esta captura de pantalla de nuestro proyecto con NVivo 10:

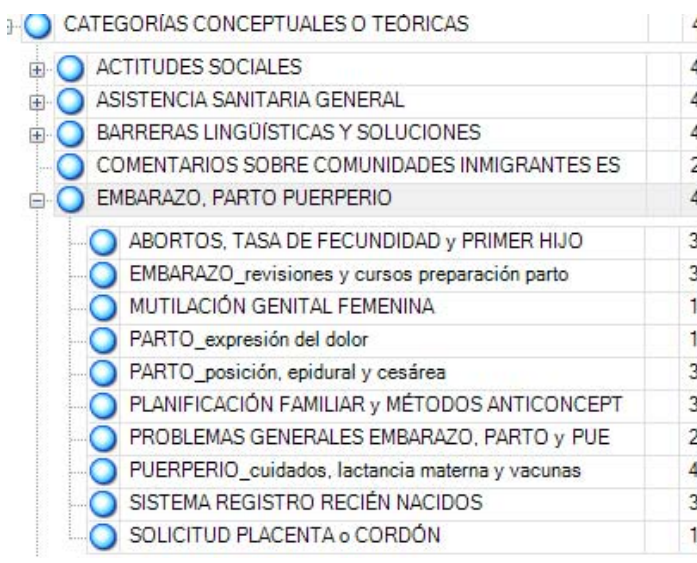

\begin{tabular}{|l|l|l|l|}
\hline 49 & 1711 & $02 / 02 / 201312: 31$ & AN \\
\hline 49 & 151 & $02 / 02 / 201312: 52$ & AN \\
\hline 47 & 240 & $02 / 02 / 201312: 51$ & AN \\
\hline 46 & 372 & $02 / 02 / 201312: 52$ & AN \\
\hline 24 & 240 & $04 / 02 / 20137: 08$ & AN \\
\hline 48 & 331 & $02 / 02 / 201312: 51$ & AN \\
\hline 36 & 66 & $04 / 02 / 20136: 51$ & AN \\
\hline 35 & 56 & $04 / 02 / 20136: 48$ & AN \\
\hline 13 & 15 & $04 / 02 / 20136: 52$ & AN \\
\hline 17 & 30 & $04 / 02 / 20136: 52$ & AN \\
\hline 39 & 86 & $04 / 02 / 20136: 48$ & AN \\
\hline 36 & 43 & $04 / 02 / 20136: 47$ & AN \\
\hline 20 & 34 & $04 / 02 / 20137: 21$ & AN \\
\hline 46 & 114 & $04 / 02 / 20136: 49$ & AN \\
\hline 36 & 38 & $04 / 02 / 20136: 48$ & AN \\
\hline 10 & 13 & $04 / 02 / 20136: 52$ & AN \\
\hline
\end{tabular}

Gráfico 6.27. Subnodos del nodo EMBARAZO, PARTO y PUERPERIO

Dividimos nuestro análisis en una parte introductoria, en la que se tratan aspectos como la tasa de fecundidad de las usuarias inmigrantes, la edad a la que tienen su primer hijo, o el recurso a la planificación familiar y, a continuación, tratamos los aspectos relacionados con las diferentes fases de la reproducción, es decir, con el embarazo, el parto y el puerperio.

En primer lugar, casi todos los profesionales opinan que las usuarias inmigrantes suelen tener el primer hijo a una edad más temprana. Algunos no especifican el origen de estas usuarias primíparas y otros se refieren a comunidades concretas, como las de Latinoamérica, las de África Subsahariana o las de la comunidad gitana.

Más temprana, bastante más temprana. Yo diría que sí... [Matrona 2]

Mucho más temprana, mucho, mucho más temprana. Yo creo que en general es así. A lo mejor las chinas no tanto, no son tan jóvenes, y las rumanas tampoco porque utilizan mucho el aborto, pero las madres sudamericanas y africanas son muy, muy, muy jóvenes. [Matrona 3]

Generalmente más temprana. Generalmente más temprana porque... no sé, al menos a mí me viene a la cabeza que la mayoría se casan antes y, entonces, tienen los hijos a una edad más temprana que las nacionales. [Matrona 5]

Pues, es que la idea es como que todas van a tener hijos mucho más jóvenes, pero luego, a la hora de la práctica, las magrebíes no tienen su primer hijo tan jóvenes como yo pensaba en un principio, los tienen ya con veintiocho, treinta o treinta y tantos... Las del este, tampoco. Y las africanas subsaharianas sí que igual a lo mejor... Pero hay de todo, yo creo que no... Quizás las sudamericanas, sí, por ejemplo, hoy hemos tenido una con diecinueve, y sí que puede ser que sean el grupo más joven, sí. Y en la etnia gitana, aunque esto no entraría dentro del colectivo inmigrante, también es algo habitual. Por ejemplo, te encuentras mujeres que con treinta años igual tienen ya seis o siete hijos. En la etnia gitana, sí. [Matrona 6]

Más temprana, generalmente. Depende de los países, pero, en general, sí, más temprana. [Matrona 7]

Normalmente, por ejemplo, las sudamericanas, a una edad más temprana. Las africanas, si pueden, también. Y, sin embargo, las de los países del este los tienen ya más mayores. [Obstetra 1] 
Más temprana. Sí, eso sí que está claro. [Obstetra 2]

Las que tienen su primer hijo más jóvenes son las mujeres de América del Sur. En este caso, desde los trece o catorce años, hemos tenido niñas embarazadas. Colombianas, peruanas... [Profesional sociosanitario 1]

El otro día vino a parir una gitana rumana que tenía catorce años, y el novio creo que tenía quince, que por cierto estaba tranquilamente durmiendo en casa y ella aquí sola... Pero, vamos, entre ellos parece que eso es lo normal. Y las sudamericanas, también con quince o dieciséis ya tienen hijos. [Profesional sociosanitario 2]

Este hecho parece estar corroborado por un estudio del que nos habla uno de los profesionales entrevistados, en el que analizaron y compararon la edad a la que concebían su primer hijo las usuarias extranjeras y las autóctonas del hospital contexto de nuestro estudio.

Pues mira, de esto te puedo hablar objetivamente. Hicimos un estudio no hace mucho y eran algo más jóvenes, o la edad media era algo menor en las primíparas extranjeras que en las españolas, por lo menos en este hospital. (¿En general o en algún colectivo en particular?) En general, era estadísticamente significativo en... prácticamente todos los colectivos. [Matrona 1]

Solo uno de los profesionales entrevistados considera que en el pasado las usuarias inmigrantes que iban a dar a luz al hospital eran más jóvenes, pero que ahora la edad media de las primíparas autóctonas e inmigrantes se está equiparando.

Pues depende de la raza, ¿̇h? Aunque yo ahora estoy viendo muchas más embarazos más tardíos. Que tengan el primero a una edad más joven... pues podría ser, sí, podría ser. Pero hace unos años se veía más, sí. Yo cuando empecé sí que veía más jóvenes, no sé, chavalitas de veintipocos que iban a tener su primer hijo y, sin embargo, el primer hijo de las españolas llegaba ya más tirando hacia los veintiocho o treinta. $Y$ ahora esto a veces sigue siendo un poco así, pero ya ves que ellas ya también tardan más en tener el primero. Yo creo que es porque hay algunas que están viviendo aquí desde hace tiempo, ya hay algunas de las que están empezando a parir ahora que vinieron siendo adolescentes con sus padres, igual llevan diez años viviendo aquí, y están teniendo su primer hijo pero con unos veintiséis años, que españolas también hay que tienen a esa edad su primer hijo. [Matrona 4]

Como no se encontraba entre las preguntas realizadas a las usuarias a qué edad tuvieron su primer hijo, no podemos saber si eran más o menos jóvenes cuando esto sucedió, si bien es cierto que algunas de las entrevistadas, a pesar de no haber cumplido los treinta años, ya tienen más de un hijo (como veremos en el siguiente subnodo, centrado en la tasa de fecundidad), y esto en parte puede ser porque tuvieron su primer hijo siendo bastante jóvenes.

La tasa de fecundidad de las usuarias inmigrantes, de acuerdo con los profesionales entrevistados, es superior a la de las autóctonas, especialmente en el caso de las latinoamericanas y las africanas.

Sí que hay que ver que la pirámide poblacional es muy distinta en españoles y en inmigrantes; por ejemplo, en su caso nacimientos hay el doble o el triple... $Y$ hay algunos compañeros que se indignan un poco. Y es para decirles “iPues tenlos tú!”. [Enfermera 1]

Y luego las grandes multíparas, pues es más fácil encontrar una gran multípara, es decir alguien que se ha planificado menos, en una magrebí o una sudamericana que en una española. [Matrona 1]

Las chinas, bueno, vamos a decir las orientales, porque siempre decimos chinas y, a lo mejor, no solo son de China, pues, las orientales, no. Normalmente tienen uno o dos chicos y, a veces, no los tienen ni con 
ellas, porque después del parto, los envían a China. Las de países del este, de Rumanía y de toda esa zona, tienen un número de hijos como las españolas, más o menos, uno o dos. Las sudamericanas, si me apuras, a lo mejor alguno más. Y las que sí que tienen muchos chicos son las africanas, las marroquíes... [Obstetra 1]

Pues eso no lo sé, porque aparentemente puede parecer que sí, pero, claro... Brrrr. Porque, claro, tampoco podemos saber... A lo mejor las que vienen aquí son las que tienen más hijos, más problemas de recursos... [Obstetra 2]

Hombre, sí, tienen más hijos pero más que nada porque el inicio de la reproducción es mucho anterior. [Obstetra 3]

Esta opinión de los profesionales parece concordar con el número de hijos que presentan las usuarias entrevistadas. De hecho, solo tres de estas usuarias se hallaban en el hospital porque habían dado a luz a su primer hijo y el resto tenían ya dos, tres o incluso cuatro hijos. Al respecto, una de las usuarias entrevistadas, en particular procedente de Paquistán, comenta que en su país de origen lo habitual es tener un gran número de hijos.

In Pakistan todos... commonly we have cuatro, cinco, seis... even ocho children. [Asia 3]

En relación con la tasa de fecundidad, cabe señalar también el comentario realizado por una usuaria procedente de China, que parece referirse a la política del hijo único que se implantó en dicho país en los años 70 como medida de control poblacional.

Sí conoces sistema, pero en China diferente. En China, primero niña, sí. Pero si primero niña, el segundo no puede. Aquí puedes. Pero en China, primero niño, el segundo nacido muerta. Es bastante una niño y ya está. [Asia 1]

También podría incluirse en el grupo con una mayor tasa de fecundidad a las usuarias de la comunidad gitana. De hecho, este colectivo es señalado por uno de los profesionales entrevistados.

Y en la etnia gitana, aunque esto no entraría dentro del colectivo inmigrante, también es algo habitual. Por ejemplo, te encuentras mujeres que con treinta años igual tienen ya seis o siete hijos. En la etnia gitana, sí. [Matrona 6]

Además, la usuaria de esta comunidad entrevistada, a pesar de su joven edad (en concreto, 21 años), ya tiene tres hijos.

El mayor número de hijos en las usuarias inmigrantes puede deberse a un menor uso de los servicios de planificación familiar y de los métodos anticonceptivos en general, pues, en efecto, un gran número de las usuarias entrevistadas dice no haber utilizado nunca estos servicios $y$, de estas, algunas tampoco han usado métodos anticonceptivos y otras los han empleado sin consultar al personal sanitario.

No, no, yo no usa anticonceptivos, pero yo controla tiempo con mi marido. [África Subsahariana 2]

No, yo no uso planificación. Antes de tener a mi primer hijo, sí, tomaba la píldora, y luego ya nada. [África Subsahariana 3]

Esto no entiendo. (Trato de explicarlo con otras palabras y ejemplos). No, yo no utilizo. [Asia 1]

No, no usa, no. [Asia 2] 
No, nunca he usado anticonceptivos. Todo natural. Pero ahora ya voy a empezar a usar. Me voy a poner el dius (dispositivo intrauterino), porque tres hijos ya son muchos. [Comunidad gitana]

No, no he ido a planificación. ¿Si uso métodos anticonceptivos? Sí, usaba las pastillas, los anticonceptivos. [Europa del este 2]

(Por su reacción, especialmente por su expresión facial y el silencio inicial ante esta pregunta, le recuerdo que no está obligada a responder a aquello que le parezca demasiado personal o no le apetezca contestar. A continuación, intercambia unas breves palabras en rumano con su acompañante). ¿Pero si los he usado antes o...? No, no nunca, nunca usado. [Europa del este 3]

El servicio de planificación familiar no lo he usado nunca, no. He usado los preservativos y, cuando tenía 20 o 21 años tomé las pastillas. [Europa del este 4]

No, no he utilizado ese servicio y tampoco uso anticonceptivos. [Europa del este 5]

¿Planificación familiar? (La usuaria parece no comprender a qué se refiere exactamente este servicio y trato de explicarle en qué consiste). No, alguien me ha explicado con la primera niña y ya está, no he usado. Antes sí que tomaba pastillas (anticonceptivas), pero ahora ya no. [Europa del este 6]

No, no he usado el servicio de planificación y tampoco métodos anticonceptivos, y por eso estoy aquí... (Risas). (Le pregunto si cree que hay bastante información sobre los métodos anticonceptivos para la gente joven). Sí, pero a veces no hacemos caso de esa información. Yo creo que sí hay información, otra cosa es que nosotros no hacemos caso y... [Latinoamérica 1]

No, no he usado ni el servicio (de planificación) ni anticonceptivos. Y por eso... (Risas) [Latinoamérica 4]

No, aquí no lo he usado (el servicio de planificación familiar), porque aquí no se puede... Así como hay allá, que hay cursos de planificación familiar, entonces uno dice que quiere planificar de tal forma y va al tratamiento. Pero aquí, si no es con un médico, no, no se puede. Por eso me he embarazado aquí, porque aquí, si no hay cita, no te recetan nada y entonces... Sí que uso métodos anticonceptivos, pero preservativos nomás, no uso métodos hormonales, como las pastillas y eso. [Latinoamérica 5]

No, no uso servicio ni métodos para no estar embarazada, no. [Magreb 1]

(La usuaria parece no entender qué significa "planificación familiar" o "métodos anticonceptivos" e interviene el marido) ¿̇Entre nosotros? No, no, natural. [Magreb 4]

Cabe resaltar de las citas que acabamos de incluir el caso de dos de las usuarias entrevistadas, concretamente de Latinoamérica, que reconocen que el hecho de no usar métodos anticonceptivos les ha llevado a tener un embarazo no planificado, aunque de acuerdo con una de ellas, esto no se ha debido a falta de información, sino a una decisión personal. De hecho, muchas usuarias comentan también que se les ha informado sobre la existencia de los servicios de planificación familiar, pero que han sido ellas mismas las que han decidido no usarlos.

Estos servicios de planificación familiar se ofrecen en los centros de salud; por este motivo, algunos profesionales entrevistados señalan que no pueden opinar sobre si las usuarias inmigrantes los utilizan o no.

No tenemos demasiado contacto nosotros con la planificación familiar, al menos desde el punto de vista de evitar el embarazo. [Matrona 1]

Yo no sé si lo utilizan o no, pero la tasa de embarazos es mayor que en las autóctonas. Ya no sé si es por cultura, o porque no utilizan la planificación, o porque realmente quieren tener hijos... pero, vamos, 
tienen más hijos. Y luego es que en paritorio ya temas de planificación no se tocan, eso es más en primaria. [Matrona 2]

Me imagino que algunas sí que utilizan los servicios de planificación, pero como ya eso es fuera del hospital, pues entonces eso ya nosotras lo desconocemos. Como no estamos metidas en ese servicio, pues desconocemos qué porcentaje de usuarias inmigrantes hay. [Matrona 4]

Eso ya no te lo puedo decir, porque yo no he estado en planificación familiar. [Obstetra 3]

Tres profesionales creen que las usuarias inmigrantes sí que recurren a la planificación familiar, aunque no podemos saber si ofrecen esta información en base a su propia experiencia en estos servicios.

Sí, yo creo que sí lo usan... [Matrona 6]

El servicio de planificación muchas sí lo usan, muchas sí, pero si lo hacen todas, pues eso no lo sé. [Matrona 7]

Sí, yo creo que sí emplean bastante el servicio de planificación, sí. [Obstetra 2]

Otro profesional, al contrario, comenta que las usuarias de origen extranjero no suelen emplear los servicios de planificación familiar y opina que esto se debe a cuestiones culturales, en concreto, al rechazo por parte de los maridos de las usuarias a usar métodos anticonceptivos.

Yo creo que una minoría, pocos, poquitos. Además, culturalmente también, yo creo que hay más... como barreras para ellas. A veces el marido no les deja utilizar métodos anticonceptivos. Hay gente que sí, que ya vemos que están más actualizados en esto y para ellos no pasa nada, pero hay otros que tienen como... [Matrona 5]

Solo uno de los profesionales afirma haber trabajado en los servicios de planificación familiar y sostiene que el número de usuarias inmigrantes en dichos servicios era considerable.

Sí, eso sí que lo utilizan. Mira, aquí, en Zaragoza, en los centros de planificación que nosotros llevamos, porque yo también me he encargado durante muchos años de esto y sigo todavía atendiéndolos, pues sí, sí que te encuentras tanto orientales, como occidentales, como africanas... De todo, sí, sí, sí. [Obstetra 1]

Para finalizar esta parte introductoria del nodo centrado en la salud reproductiva, en cuanto a los abortos que las usuarias inmigrantes han podido tener, un gran número de profesionales entrevistados mencionan a las usuarias procedentes de Europa del este.

Sí, por ejemplo, en la cultura rumana prácticamente todas las mujeres han tenido alguna interrupción voluntaria del embarazo, parece que es el anticonceptivo propio de ese país. En los países del este, sobre todo en los países del este de la época soviética, utilizaban las IVEs que se llaman, la interrupción voluntaria del embarazo, como método anticonceptivo. Y entonces cuando tú les vas a preguntar porque te interesa sobre todo saber cuántas veces han sido anestesiadas, por saber la región, los productos anestésicos o si han sido intubadas, que son las cosas que te interesan, que tú valoras como importantes, lo obvian. $Y$ entonces tú les tienes que insistir, y preguntar por otro lado, ya directamente si han tenido legrados, o abortos o si alguna vez han estado embarazadas. [Anestesista 5]

A las del este, que ya sabes que hay muchos casos de aborto y todo eso, pues hablar de anticonceptivos no les cuesta nada. [Enfermera 6]

Yo lo que veo en las historias, o en la cartilla de la embarazada es que, por ejemplo, el colectivo de las rumanas... pues, ha utilizado, al menos en su país, el IVE, la interrupción voluntaria del embarazo, como 
método anticonceptivo, porque tienen muchísimos IVEs. Yo no sé si... por supuesto, en España no pueden hacer eso. Pero... pues tienen otras costumbres, eso sin duda. [Matrona 1]

Por ejemplo, ahora, con las rumanas nos encontramos con que allí el aborto es un método de planificación como otro cualquiera, entonces muchas de ellas tienen un historial de abortos... ique tela! [Matrona 3]

Y también las rumanas, aunque esto ya era un problema de su país, por costumbres de ellas. Porque yo a alguna le he preguntado "Oye, ¿cómo puede ser que tengas cinco abortos?", y te explican que en su país era más barato para ellas abortar que tomar anticonceptivos, porque no se los proporcionaban, o a lo mejor los tenían que comprar en el mercado negro. Entonces, las rumanas sí que tienen abortos repetidos, muchos. [Matrona 7]

Por ejemplo, las rumanas, que aquí tenemos tantas, pues ten en cuenta que en su país, como en otros países comunistas, como Cuba, son países en los que no había una planificación familiar, sino que la solución era abortar. Es decir, que me quedo embarazada, y aborto y punto. Y todavía te encuentras casos aquí en los que, cuando haces la historia clínica, tienen tres, cuatro, cinco abortos, y algunas muchos más, ¿eh? Te encuentras con una gran cantidad de abortos, y te explican simplemente "Pues, sí, me quedaba embarazada y al mes siguiente iba a abortar y ya está". [Obstetra 1]

Sí, eso fundamentalmente la gente del este, es decir, las rumanas y tal, tienen muchísimos más abortos. Sobre todo son las de los países del este. [Obstetra 2]

En las rumanas, sí se observa un gran número de abortos. Es su método anticonceptivo. [Obstetra 3]

La opinión de los profesionales sanitarios a este respecto parece estar en cierto sentido confirmada por algunas usuarias procedentes de Europa del este, que hablan del recurso personal a la píldora anticonceptiva de emergencia (conocida como la pastilla del día después) o del alto precio de los anticonceptivos en sus países de origen.

Hombre, con veintiún años que me quedé embarazada, por los anticonceptivos que me fallaron, el médico mío de cabecera, el problema que tuve con él es que no me quería dar la pastilla del día después. Por sus ideologías, como tenía derecho a decirme que no... Entonces, el único problema que tuve con él fue ese. Y ya me tuve que cambiar de médico y ya... Pero ya de lo demás, nada que... [Europa del este 4]

(Le pregunto si es muy común en Rumanía el uso de métodos anticonceptivos). Bueno, no sé ahora, pero cuando estaba yo allí, no. Hombre, la gente sí que lo usa, quien quiere. Allí (en Rumanía), no sé... Hay dos tipos de puntos de vista: hay quien no quiere gastar dinero, porque... hombre, cuesta un poquito, y entonces no lo usa por este motivo, por el punto de vista financiero; pero hay quien sí que invierte dinero en esto, y se compra un condón o se compra unas pastillas. Ya te digo que depende del punto de vista financiero, porque hay gente que no puede gastarse para comprar un condón que cuesta... seis euros o nueve euros. Entonces, para uno que no tiene dinero... [Europa del este 5]

Pasamos, a continuación, a analizar las diferentes fases de la reproducción. Empezaremos hablando del embarazo y, en concreto, de los controles durante el mismo y la asistencia a cursos de preparación al parto.

Algunos profesionales sanitarios opinan que la gran mayoría de usuarias inmigrantes suelen realizar controles durante el embarazo.

Yo creo que muchas sí, ¿eh? Sí, la gran mayoría, sí. Las que tienen un embarazo normal, pues acuden al centro de salud, o al centro de especialidades, donde está el tocólogo de cupo y las lleva allí. Pero si es un embarazo de riesgo, el control se lleva aquí en el hospital. Y yo creo que la gran mayoría hacen las revisiones, tanto si están llevadas aquí como allí. Porque cuando vemos las cartillas vemos que los datos de las revisiones los suelen llevar. [Matrona 4] 
Yo creo que la gran mayoría, sí, la gran mayoría sí. Pero también tenemos gente de aquí, nuestra, que no las hace. O sea, hay un tanto por ciento de mujeres que, independientemente de si son de aquí o de allá, que no las hacen. [Matrona 5]

$Y$ algunas no se controlan, simplemente vienen a que se les haga la prueba de embarazo y, luego, vienen a urgencias a controlarse cuando les parece, o cuando tienen problemas, y vienen tropecientas veces. Pero estos casos son mínimos, son las menos, la mayoría sí que se controlan. [...] Yo veo que las marroquíes, las magrebíes en general, sí que cumplen con las visitas, y con la analítica y todas las pruebas que se les piden. Y las rumanas yo veo que también. $Y$ ahora se ven más polacas y ucranianas, y están también son cumplidoras. Estas son mujeres muy inteligentes y muy colaboradoras, sí. [Matrona 7]

Normalmente, sí. Y, si no lo hacen, no creo que sea porque no quieran, sino porque a lo mejor puedan tener alguna dificultad aparte. Pero sí, normalmente son embarazos que están bastante controlados. [Obstetra 1]

Por el contrario, otros profesionales sostienen que el control del embarazo en las usuarias inmigrantes es menor con respecto a las autóctonas.

Por ejemplo, a veces vienen con el embarazo sin controlar, aunque si todo va bien y el embarazo está sin controlar, tampoco pasa nada, como si quieren dar a luz en la calle. [Enfermera 5]

El mayor problema que nos solemos encontrar es que se controlan generalmente peor el embarazo. No sé si es porque la burocracia es excesiva para ellos, si es porque tienen otras costumbres en cuanto a control del embarazo en su tierra de origen, o porque... pero ese es el mayor de los problemas. [Matrona 1]

Por su estilo de vida, hay algunas que, bueno, si hablamos así en líneas generales, sí que el control gestacional es peor que en las pacientes españolas. [...] Si hablamos en general, y comparamos a las pacientes inmigrantes con las españolas, pues yo creo que sí, que el cumplimiento es peor. [Obstetra 2]

Las marroquíes, no, como te comentaba. $Y$ las chinas muchas veces vienen con un control tardío, empiezan tarde a controlarse. $\mathrm{Y}$, en general, si no son españolas, o bueno, occidentales, tienen un concepto más laxo del cumplimiento de las visitas, faltan mucho más a las visitas que las occidentales, no le dan tanta importancia. En general, ¿eh? Es en general, desde las que vienen de Ecuador, aunque igual esas no tanto, porque están más integradas, pero bueno... Subsaharianas, marroquíes, rumanas, chinas... son todas mucho más laxas a la hora de cumplir las visitas. [Obstetra 3]

Y las que sí que fallan mucho a la hora de controlar el embarazo son las rumanas, pero las rumanas gitanas, que casi directamente te llegan aquí sin más, sin controles previos. Puede que pase también con alguna sudamericana, pero por... por dejadez. [Matrona 4]

Estos profesionales exponen diferentes motivos por los cuales el control gestacional en las usuarias de origen extranjero es peor. Algunos señalan el caso de aquellas inmigrantes que llegan a España en un estado de embarazo avanzado y no han realizado previamente los controles pertinentes en sus respectivos países de origen.

El único problema que puedo destacar, que no sé si será lo que tú estás buscando, es que a veces vienen mal controladas, es decir, se produce un inicio tardío del control del embarazo. Eso es lo único que... sí, creo que sucede en general. Y no sé a qué se puede deber, principalmente yo creo que es porque vienen tarde del país a aquí. Todavía hay, cada vez menos, pero todavía hay gente que viene a pasar el final del embarazo y a parir aquí. Y entonces el control inicial no lo tienen, y cuando vienen aquí es ya a mitad del embarazo. [Matrona 2]

$Y$, luego, están las que te vienen directamente, eso sí que se da mucho, las que te vienen directamente cuando ya están a punto de parir, que te vienen aquí a parir. Que directamente es que no lo tienen controlado el embarazo allí y vienen... En Senegal se da mucho, sí, las de Senegal algunas vienen 
directamente cuando ya están con el bombo que dicen "Esto está ya a punto". Y muchas llevan aquí tres o cuatro días, y vienen directamente aquí a eso. [Matrona 4]

Y también es verdad que algunas vienen directamente a parir aquí. Ha pasado el embarazo y ha hecho las revisiones o lo que sea en su país de origen y viene a parir aquí. [Matrona 5]

Dos profesionales indican que podrían ser las barreras lingüísticas causadas por el desconocimiento del español por parte de algunas usuarias las que podrían desembocar en una falta de control del embarazo.

Pero, desde luego, en el parto se ve mucho embarazo mal controlado o sin controlar. Y yo creo que es por el problema del idioma, porque, claro, si hay mucho control y, a veces, por el idioma no se enteran, o porque hay mucha diferencia con los controles en sus países de origen. [Matrona 4]

También las chinas, hay alguna que tiene también problemas para comunicarse y, a lo mejor, no viene a la ecografía... O ves la cartilla del embarazo y faltan cosas, porque no se han enterado... [...] No, sobre todo las chinas y las subsaharianas. Sobre todo cuando hay barrera lingüística, cuando no entienden lo que les explicas, pues entonces es cuando siempre hay alguna falta de asistencia a las revisiones o a alguna prueba. Pero yo creo que es la barrera lingüística la que marca la diferencia. Porque, por ejemplo, las sudamericanas, por lo general, hay un seguimiento bueno del embarazo, las del este también, que hablan bien el idioma... O sea, que yo creo que es más bien un problema lingüístico. No es que sea algo cultural y que digan "No, mi embarazo es algo normal y no voy al médico". Porque yo creo que el colectivo inmigrante sí que va al médico, lo ve como algo necesario, vamos, es mi percepción, ¿̇eh? [Matrona 6]

Resulta curioso el hecho de que precisamente estos dos profesionales presenten una opinión discordante en cuanto a si, además de las barreras lingüísticas, podrían ser también las diferencias culturales de las usuarias inmigrantes en cuanto al concepto de embarazo y el comportamiento durante el mismo las que contribuyeran a que estas no realicen las revisiones durante el embarazo.

Otros dos profesionales señalan las estancias periódicas de algunas usuarias inmigrantes en sus países de origen durante el embarazo como una posible causa de la falta de realización de todos los controles.

O puede ser que algunas vayan a su país algunos meses para estar con su familia, y en ese entretanto no se controlan el embarazo. Tienen ese tipo de problemas... Pero, vamos, normalmente las que se controlan y acuden a las citas y eso, pues no. Por ejemplo, las marroquíes acuden regularmente y cumplen con todo lo que se les... con los controles y demás. [...] Si algunas están aquí, pero se van a ver a la familia, pues durante ese tiempo no realizan controles. [Matrona 7]

Y durante el embarazo, por ejemplo, las marroquíes, durante el periodo vacacional, si se tienen que ir a Marruecos, pues se van a Marruecos y ahí te dejan todas las pruebas que se tienen que hacer, y luego te vienen en septiembre, que es cuando vuelven, con todas las pruebas que se tenían que hacer que no se han hecho. Eso, sí. [Obstetra 3]

$Y$ un profesional señala el miedo a ser denunciadas por no encontrase en situación regular, del que hemos hablado en el subapartado relativo a la burocracia, como el motivo de que las usuarias en dicha situación no acudan regularmente a realizar las revisiones.

Y sí que me he encontrado con pacientes a las que tienes que reprender, y les dices “¿Cómo es que no has venido antes" o ¿Por qué no te has controlado el embarazo?", y te contestan que es porque no tenían papeles y, entonces, tú ya les explicas que en su situación les vamos a visitar aunque no tengan papeles. [Obstetra 3] 
La opinión de estos profesionales sanitarios relativa al menor control gestacional en las usuarias inmigrantes parece contrastar con las respuestas recibidas de las usuarias entrevistadas, pues todas ellas afirman haber realizado las revisiones prescritas durante el embarazo. Algunas de estas usuarias añaden que el número de controles les parece excesivo.

Sí, sí, revisiones he hecho. Son muchas. [África Subsahariana 3]

Sí que he ido a las revisiones, a todas. (Le pregunto si opina que son muchas o pocas las revisiones prescritas durante el embarazo). Hombre, lo hace bien, lo hace bien que lo ha puesto cada mes o así, pero como yo no he tenido complicaciones, pues para mí estaba un trabajo ir a hacer todo el rato análisis o hacer tu cita y... Pero hay personas que tienen problemas y lo tienen que hacer todos los meses, les viene bien. [Europa del este 5]

Sí hago revisiones, sí. Son muchas (Risas). [Magreb 3]

En cuanto a la asistencia a los cursos de preparación al parto por parte de las usuarias inmigrantes, son pocos los profesionales entrevistados que tienen información de primera mano, pues estos cursos se realizan en los centros de salud y no en los hospitales.

Pues, sobre los cursos de preparación al parto no sé. No sé porque no he trabajado en primaria y, entonces, no te puedo decir. [Matrona 2]

Lo de los cursos de preparación al parto, es que aquí no se hacen. Se hacen en los centros de primaria, así que yo a eso no te sé contestar. [Matrona 7]

Aquellos profesionales que en el pasado han trabajado en atención primaria comentan que la proporción de usuarias inmigrantes en los cursos de preparación al parto era menor en comparación con el número de estas usuarias que acuden al hospital a dar a luz. Uno de estos profesionales cree que la falta de asistencia a los cursos puede deberse a la insuficiente información y al desconocimiento de este servicio por parte de las usuarias de origen extranjero, algo que, de acuerdo con uno de ellos, se soluciona en el caso de las usuarias autóctonas a través de sus propias redes sociales.

Proporcionalmente... la gran cantidad de gestantes extranjeras que dan a luz en nuestro hospital no se corresponde con el porcentaje de mujeres extranjeras que van a las sesiones maternales en el centro de salud, es decir, no hay tanto porcentaje. (Si van solas o acompañadas) lo desconozco, porque yo ahora en primaria... Entiendo que van menos y es difícil que vayan acompañadas también. [Matrona 1]

A los cursos de preparación, no, no suelen asistir. Hay un problema, porque la preparación al parto la dan las matronas en los centros de salud, y eso va diferente, como por dos vías distintas, yuxtapuestas completamente con las visitas prenatales del tocólogo. No hay ningún tipo de comunicación entre las dos cosas. Entonces, a las visitas prenatales sí que van, porque les hacen la ecografía, les hacen la analítica... pero a las visitas de las matronas no van, a lo mejor porque tampoco el médico las deriva a la matrona. Entonces, si no te las deriva alguien, en concreto, sobre todo el médico de cabecera, si nadie te dice que existen estas clases de preparación al parto, pues tú no las puedes captar. Si nadie te informa de que está eso, pues claro... A lo mejor, las autóctonas de aquí con el tú a tú, o porque mi hermana o mi prima las han hecho... pues ya sabes de estas clases de preparación, y le preguntas al médico o en la ventanilla del centro de salud, y pides cita con la matrona. Pero ellas, si no lo saben y nadie las deriva o les propone... [Matrona 5]

Otros profesionales, a pesar de no haber trabajado en atención primaria, creen que las usuarias inmigrantes no acuden a los cursos de preparación al parto, bien porque no se les 
informa, o porque ellas mismas no preguntan al respecto. Esto puede deberse a que ni siquiera saben que existen o a que ellas mismas consideran que no los necesitan.

Los cursos de preparación al parto, sin embargo, son de primaria, entonces, se ve en atención primaria más que aquí. Yo cursos de preparación al parto no doy, y entonces no sé, no te sabría decir... Pero yo creo que no van, porque aquí les preguntamos si han ido y, a no ser que lleven aquí tiempo y estén más integradas en lo que es la dinámica que se lleva de seguimiento del embarazo... Y es que muchas veces ni las propias españolas no, porque si nadie les informa... Pues, imagínate entonces estas pobres, que encima tienen cinco críos enganchados a la bata, pues a ver cómo lo hacen. [Matrona 4]

Y lo de los cursos de preparación al parto, no lo sé, no sé si los hacen, la verdad. Lo que sí que es cierto es que, preguntar por las clases de preparación al parto, preguntan mucho menos. A lo mejor no preguntan porque no saben que existen o... si ya son multíparas, pues puede ser que piensen que no los necesitan. [Obstetra 2]

Efectivamente, son pocas las usuarias inmigrantes entrevistadas que afirman haber asistido a los mencionados cursos y, de estas, un par de ellas empezaron a asistir pero los abandonaron por diversos motivos.

Y cursos de preparación, esta vez no. Pero con el primer hijo, sí. [África Subsahariana 3]

Y cursos de preparación al parto, también, con la matrona del centro de salud. Y estos cursos me han parecido muy bien, muy bien. A lo mejor es por la matrona, que me ha ayudado con el primer embarazo y con el segundo. Me ha atendido la misma y muy bien. Me enteré de estos cursos en el primer embarazo, por una señora que me vio en la revisión del tocólogo, a los dos meses o así. Yo no hablaba español en esos tiempos, ni nada. Entonces se lo dije a mi marido, fuimos al centro, pedimos cita con la matrona, me revisó y todo y me habló de los cursos y vamos los dos, desde el primer hijo. Y en el segundo, como ya lo sabía, pues fui a pedir cita y empecé los cursos. [África Subsahariana 4]

Cursos, también. Cursos por parto están bien. [Asia 1]

A los cursos para el parto sí he ido, solo que como me mareaba tanto, hay veces que no podía ir. Entonces no he asistido a todos, pero la verdad es que sí que son interesantes y siempre aprendes alguna cosilla y tal... Lo que pasa es que me mareaba mucho, no sé, siempre tenía que tener agua para beber y un caramelo o algo así... No sé, me faltaba el aire, me encontraba mal... Y, entonces, la médica me decía, la matrona, pues... "Vete a casa, que...". Porque, claro, salía y entraba y yo pensaba "Si estoy molestando a las compañeras y no me encuentro a gusto, pues...". [Europa del este 1]

Y también he ido a los cursos de preparación al parto. [Europa del este 2]

A cursos de preparación al parto he ido varios días, pero luego es que me aburría. Como hacíamos todo el rato lo mismo y tal... Me dije "Bueno, como cuando vaya al hospital lo tendré que pasar igual...", así que ya dejé de ir. [Europa del este 4]

También he ido al curso de preparación al parto. [Latinoamérica 2]

Estas usuarias solían ir solas a los cursos, bien por elección propia o bien porque el horario de los mismos coincidía con el horario de trabajo de sus maridos.

No me acompañaba nadie, mi marido no ha ido nunca... Iba sola. [África Subsahariana 3]

(A estos cursos), yo venía sola, porque a ver, para venir me encontraba bien, podía andar sola y eso... [Europa del este 1]

A la preparación iba sola. Yo prefería ir sola y, además, mi marido trabajaba, así que tampoco podía venir conmigo. [Europa del este 2] 
Iba sola, porque estos cursos eran de 9 a 11 y, como mi marido trabajaba y tal, pues, claro, no podía ir. [Europa del este 4]

A este curso iba sola, porque solo había mujeres y mi marido sí que quería ir, pero por no sentirse ahí el único hombre y tal... [Latinoamérica 2]

Por el contrario, la gran mayoría de las usuarias entrevistadas no ha asistido a ningún curso de preparación al parto debido a diversos motivos: algunas no conocían su existencia, y otras simplemente no tenían interés en asistir o pensaban que, al haber tenido ya otros hijos, no los necesitaban.

No he hecho cursos de preparación. Esta hija es tercera, entonces no necesito. [África Subsahariana 1]

Cursos no he hecho, porque yo no sabía, si yo sabía, iba, pero no me han dicho. Yo no sabía... [África Subsahariana 2]

Cursos no. Yo prefiero no ir. [Asia 2]

No courses, because... este es el cuarto, so I am an expert. [Asia 3]

Cursos, no, no he hecho. Sí sabía que había, pero no me interesaban... Como ya he tenido más hijos. Y la primera vez tampoco fui, me estuvo ayudando mi madre. [Comunidad gitana]

Cursos, no. (Le pregunto si no ha ido a los cursos porque no los conocía o porque no le interesaban). Tampoco me han informado. Me atendió una matrona una vez, me habló un poco del tema de las respiraciones y eso y ya... me quedó claro y eso y ya... [Europa del este 3]

A los cursos (de preparación al parto) no he ido. Me ha preguntado la matrona, pero como ya he tenido más hijos... No sabía todo perfectamente, pero creo que estaba bastante bien lo que sabía. [Europa del este 5]

A cursos para el parto no he ido, porque no me han dicho, no sabía que había, pero tampoco podría venir, por tiempo y eso... [Europa del este 6]

A los cursos (de preparación al parto) no he ido. Sí que me han informado, pero no he querido ir. [Latinoamérica 1]

A cursos de preparación al parto no he ido, no, porque la verdad, no... Sí sabía que había, pero yo creo que no me hacían falta. (Le pregunto si en Ecuador este tipo de cursos se suelen hacer). No, en Ecuador, no. [Latinoamérica 3]

A los cursos (de preparación al parto) no he ido, no, porque ya había tenido otro embarazo y, entonces, ya lo tenía claro. [Latinoamérica 4]

Cursos (de preparación al parto) no he seguido, porque creo que no me hacían falta, porque ya tenía mi... mi experiencia previa. [Latinoamérica 5]

Cursos (de preparación al parto) no he hecho. El primero hacer cesárea y luego, cuando decir segundo normal, no... Es que antes no sabes español y entonces no sabes que hay cursos. Yo busco en Internet en árabe y así sé cada mes cómo cambiar. [Magreb 2]

No he hecho cursos. Sí que sabía que había, pero como he tenido más hijos, pensaba que no necesitaba. [Magreb 3]

Y cursos, no, no ido. Yo te explico, nosotros no vivimos en Zaragoza, vivimos en un pueblo, y hay poca gente y... y no hay cursos. [Magreb 4] 
Analizamos ahora la siguiente fase de la reproducción, en concreto, el parto.

En cuanto a la postura adoptada durante el parto, la mayoría de los profesionales sanitarios entrevistados afirman que se sigue en todos los casos un protocolo estándar ${ }^{242}$ y no se da opción a que sean las propias usuarias quienes escojan cómo colocarse.

No se les da opción, porque aquí dentro del hospital se siguen una serie de protocolos y realmente no hay posibilidad de realizar un parto distinto al estándar, y entonces, en ese sentido, no... [Anestesista 1]

Tampoco creo que haya muchas diferencias porque aquí todas paren igual, no se da opción a parir de otra manera, entonces... [Anestesista 2]

En cuanto a lo que hacemos nosotros, no muestran preferencias durante el parto, porque yo creo que tampoco les damos opción, ¿eh?, las cosas como son. Les decimos "Ponte así o asá", "Yo te hago tal cosa"... y se acabó. [Anestesista 3]

La verdad es que en lo que a nosotros nos atañe, les dices que tienen que ponerse así, y se ponen, les cueste más o menos. Puede ser que en sus países tengan la costumbre de parir a cuatro patas o yo qué sé... Pero aquí no suele haber muchas diferencias, por razones asistenciales, si se tienen que sentar, se sientan, y hacen lo que tengan que hacer, aunque les cueste más... [Anestesista 4]

En cuanto a la posición, tampoco se les da mucha opción porque actualmente la posición que se adopta, a menos que sea un parto precipitado y den a luz en la cama, es la litotomía. ${ }^{243}$ [Matrona 1]

$Y$, luego, yo creo que alguna también tiene preferencias en cuanto a las posiciones. Es verdad que a algunas les gustaría estar, pues... en cuclillas. Pero aquí tampoco hay opción. [Matrona 4]

Pues, es que aquí no lo expresan. No sé si es porque no les dejamos o porque ellas también sienten timidez o no se ven seguras de... Pero, no lo expresan, no, no expresan preferencias en cuanto a la posición durante el parto. [Matrona 5]

Pero, claro, es que tampoco damos mucha opción, la verdad. (Risas) De todos modos, en cuanto a las posturas, tampoco creo que sea... no creo que tengan ellas preferencias distintas. Igual es más, pues eso, su relación con el recién nacido y cosas de esas, no sé. [Obstetra 1]

Como se puede observar en las respuestas ofrecidas por los profesionales, algunos de estos ni siquiera son conscientes de que quizás las usuarias podrían preferir dar a luz en otra posición diferente a la establecida por el hospital o que esto pueda tener relevancia para ellas, por tradición y expectativas. Otros, sin embargo, señalan preferencias observadas en algunas comunidades concretas, aunque destacando que no siempre es posible atender a estas demandas, especialmente una vez se ha suministrado la anestesia epidural.

No, aunque quizás a la mujer de África sí que le gustaría a lo mejor parir en otras posturas, pero esta posibilidad no se ofrece. Igual preferirían en cuclillas o... pero vamos, no hay opción. [Matrona 2]

Nos intentamos adaptar un poco dentro de las condiciones del hospital. Este hospital no está preparado para atender diferentes tipos de partos, como si estuviéramos en un hospital mucho más pequeño, con

\footnotetext{
${ }^{242}$ Este protocolo se corresponde con las recomendaciones incluidas en el documento Estrategia de atención al parto normal en el Sistema Nacional de Salud (2007), examinado en el apartado de análisis documental de este capítulo.

${ }^{243}$ La posición de litotomía es "la que adopta el paciente en decúbito supino, apoyado sobre la cabeza, torso y nalgas, con las piernas levantadas y apoyadas sobre los complementos de la mesa quirúrgica o de exploración. Es la posición más empleada para la exploración ginecológica y el parto, para las intervenciones en el ano y periné y para la cirugía transuretral." Fuente de la definición: [http://www.definicionesdemedicina.com/posicion-de-litotomia/] (última consulta: 18 de mayo de 2013)
} 
más tiempo... Aquí lo que hay es lo que hay, los espacios ya los ves, tampoco podemos hacer mucha cosa, pero bueno, lo que se puede sí que se hace, ¿eh? Pero bueno, en el momento en que se pone la epidural, evidentemente ya no te puedes levantar, la postura es la que se puede también, porque las piernas muchas veces con la epidural se quedan completamente dormidas y no hay manera de moverlas, casi ni para que empujen, así que... lo que te quiero decir, que se hace un poco lo que se puede. [Matrona 3]

Y una vez puesta la epidural no hay opciones, hay muy pocas opciones. Porque sentir, sientes, pero no se te puede pedir una estabilidad de piernas. Es que no le puedes decir a una mujer con epidural que se ponga de pie, nos da miedo, porque probablemente no se va a tener. [Matrona 4]

Hombre, yo creo que las negras, a lo mejor, tienen más reticencia a estar en la cama. Es que, a ver, si se ponen epidural, ya no pueden deambular, porque se pueden caer, ya no controlan las piernas igual. Pero, hasta que se ponen la epidural, yo por lo menos, a veces... Hombre, depende de la situación, si la situación y el bebé lo permiten, pues entonces, si están muy retrasadas, sí que a veces les quito los captores y las dejo levantarse al baño, o estar sentadas en la sillica... Sí que se puede, pero llega un momento en que eso sí que entraña más dificultad, porque a lo largo del parto el bebé hace bajadas, y a veces hay que poner un monitor interno, pero al principio... Además, en la planta, están todo el tiempo levantándose, vamos, que hacen vida normal, se levantan, se sientan... En la planta lo que sí que les enseñamos es a mover las caderas, a ponerse de cuclillas, que eso alivia mucho... Se les explica para que se les haga más llevadero. Aquí el problema es la epidural, que la suelen querer a medio parto. $Y$, entonces, con la epidural, uno ya no se puede, por ejemplo, poner de pie. [Matrona 7]

Las chinas, pero por el mero hecho de que no se ponen la epidural, pues van un poco más a la suya, y les gusta caminar más. Y tampoco se da mucha opción en el tema de las posturas y tal, pero vamos... Todo este movimiento de que yo quiero parir de una forma o de otra está más desarrollado en pacientes escandinavas o, bueno, o españolas que se han informado mucho y que del embarazo y del parto hacen una profesión, y se han informado mucho y está muy... y entonces sí que demandan ese tipo de cosas. Pero que sea por la etnia, eso no te lo sabría decir. [Obstetra 2]

Las paquistaníes, que en Barcelona cuando yo estaba había muchas, y hay muchas, por lo menos donde yo estaba, que vienen que son multíparas, que tienen muchos hijos, y esas hacen el parto como ellas quieren, no les puedes... A pesar de que viene el marido y parece que el que dirige es el marido, son ellas las que... Es el cuarto parto, por ejemplo, ha tenido tres en Paquistán y el cuarto pare en cuclillas o en el baño porque ella quiere. De eso sí que me he encontrado. Que no hay forma de hacerles subir a un potro, y es que no. Además, no hablan, no dicen nada, pero te hacen así (hace un gesto como apartando con las manos), como si dijeran "iDéjame! Yo me las apaño", y como que te enseñan ellas que van a hacer lo que ellas quieren, eso es lo que hacen. [Obstetra 3]

En relación con la postura durante el parto, todas las usuarias entrevistadas dicen adaptarse a los protocolos del hospital, a pesar de que algunas de ellas comentan que sus costumbres al respecto varían en cierto sentido en comparación con las costumbres propias de los hospitales españoles.

Yo hago como me diga la matrona, no tengo preferencias, no. [África Subsahariana 4]

Me gusta tumbada como estoy. [Asia 1]

Yo querer como normal, como aquí. [Asia 2]

Yo hago como me dicen los médicos. [Asia 4]

Y la posición me pareció la adecuada, porque como me pusieron la epidural, pues no me quedaba otra. [Europa del este 2]

La postura creo que está muy bien, así sale mejor. [Latinoamérica 4] 
Nosotros sí que tenemos la costumbre, en vez de estar en cama, de caminar mucho, para que así baje mejor. [Latinoamérica 5]

Aquí el modo del parto es un poco diferente, pero yo me encuentro cómoda. [Magreb 3]

Cabe destacar la respuesta de una de las usuarias entrevistadas, en concreto procedente de Paquistán, quien nos cuenta cómo en su país de origen antes era habitual dar a luz en casa, pero que, con el fin de disminuir el número de muertes en recién nacidos, son cada vez más las mujeres paquistaníes que acuden a los hospitales $y$, de hecho, ella afirma preferir que le asistan el parto en el hospital.

In Pakistan, ten years ago, women commonly do it at home, but now they go to the hospital. I prefer hospital. Because dead children is common in Asia, you know... And now almost every woman want to go hospital. [Asia 3]

En referencia a los acompañantes de las usuarias durante el parto, los profesionales sanitarios presentan dos opiniones discordantes. Uno de los profesionales entrevistados opina que, por lo general y especialmente en el último periodo, las usuarias inmigrantes son acompañadas por sus maridos.

Durante el parto las acompañan normalmente sus parejas, los maridos. Antes estaban más solas. Y, además, en todas estas de... de Marruecos y todo eso, he notado mucho el cambio. Yo cuando empecé veía muchas familias, no sé, como muy hechas, como si tu familia te hubiera casado con tal familia, y en cambio hay veces ahora que no... que veo amor. (Risas) Y ese cambio lo he notado de un tiempo a esta parte, desde hace unos años, que no se ven tantas familias como de conveniencia, que se hubieran casado porque esta familia se tiene que casar con esta otra por lo que sea. Se les ve más implicados en la relación, y también se interesan más... Se les ve que las quieren, se preocupan, las atienden... [Matrona 4]

En cambio, hay otro profesional que sostiene que los maridos de las usuarias (sean estas inmigrantes o autóctonas) no presentan mucho interés en estar presentes durante el parto y que, si lo hacen, es casi por imposición de sus parejas.

\footnotetext{
Allí los maridos no suelen implicarse mucho, pero ni en el embarazo, ni en el parto, ni... Y, por lo general, los de las españolas, sí, a lo mejor por demanda de la mujer, pero sí que se implican más. Por lo menos en el estar, el que figuren. Sí que les acompañan a las clases de preparación al parto, los maridos de las españolas, y vienen aquí, a paritorios... Pero las inmigrantes suelen ir más a su aire. También porque yo creo que consideran que es una cosa de mujeres, ¿eh? Los maridos están ausentes no porque se lleven mal o nada de eso, sino porque consideran que estar presentes es como no respetar el proceso de las mujeres. De todos modos en España la implicación de los maridos no es de hace tanto. Y ahora muchos hombres vienen obligados por la demanda de su mujer, quiero decir que a ellos no es que les apetezca especialmente. Sí que hay a algunos que sí, pero hay otros que vienen simplemente por eso, porque les toca, porque tienen que pasar, y ya está. [Matrona 3]
}

Por su parte, la mayoría de las usuarias comentan que durante el parto les ha acompañado su pareja o marido, aunque en otros casos, de acuerdo con sus respuestas, ha sido su madre o algún otro familiar e incluso, en caso de no contar con el apoyo de familiares o amigos que se queden al cuidado del resto de hijos de la familia, cuentan que han tenido que estar solas durante el parto. No parece existir un patrón de comportamiento por colectivos, sino que probablemente la elección del acompañante durante el parto es más una cuestión personal.

Yo he entrado sola, porque mi marido está con otras hijas en casa. [África Subsahariana 2]

Estaba conmigo mi marido. [Asia 1] 
Durante el parto quiero que esté conmigo mi marido, claro. Y sí, él estaba conmigo. [Europa del este 1]

(Durante el parto) He estado con mi marido, así que muy bien. [Europa del este 2]

Me acompañó su mujer (refiriéndose a la mujer de su hermano, quien está presente en este momento en la habitación), es decir, mi cuñada. [Europa del este 3]

En el parto me acompañó mi pareja, estuvo allí conmigo todo el tiempo. [Europa del este 4]

En el parto me acompaña mi marido. Yo prefiero eso. [Europa del este 6]

Durante el parto estaba con mi madre. Bueno, mi chico también estaba, pero fuera. Yo prefería estar con mi madre, me inspiraba más confianza. (Risas). [Latinoamérica 1]

Me acompaña mi esposo siempre. [Latinoamérica 4]

Mi marido me acompañó durante todo el embarazo y todo el parto. Y mi hermana, también. [Latinoamérica 5]

Prefiero estar acompañada por mi marido. [Magreb 1]

Me acompaña mi marido, porque mi madre no está aquí. Estoy sola aquí con mi marido que ahora está con dos hijos en casa. [Magreb 2]

Al respecto del acompañamiento durante el parto, llama la atención la opinión de una de las usuarias entrevistadas, concretamente de China, quien afirma que hubiera preferido que el número de acompañantes durante el parto hubiera sido mayor (recordemos que solo se permite un acompañante durante el parto), pues ella considera importante que estén presentes otros miembros de su familia para que "le den fuerza". Quizás el carácter colectivista de la cultura china ha podido influir en cierto sentido en esta opinión.

Pero para parto, sola. Familia toda está fuera. Solo una entrar para ver niña nacida. Esto muy mal me parece. (Le pregunto si hubiera preferido que entraran más miembros de su familia durante el parto). Sí, pero no puede. Solo entrar uno. Si puede entrar toda la familia, más fuerte me parece. [Asia 1]

Por lo que se refiere al uso de la anestesia epidural, los profesionales sanitarios señalan diferentes cuestiones, en algunos casos relativas a determinadas comunidades.

Algunos profesionales comentan que se respeta la elección de las usuarias sobre el suministro de la anestesia epidural, y que simplemente hay usuarias que lo aceptan y otras no.

Y ya la gente luego decide si se la quiere poner o no. Hay gente que lo tiene muy claro, como ya ha pasado mucho tiempo desde la epidural, puede que hace siete u ocho años no supieran lo que es, pero ahora casi todo el mundo, incluso las extranjeras, aunque no sepan exactamente qué es, pero te dicen directamente "Epidural, ino!". Y puedes explicarles, pero a muchas tampoco puedes sacarlas de su idea, aunque a veces puedas creer que es necesario o que es mejor tener la epidural puesta que no tenerla, ellas ya saben que existe la epidural y que no la quieren. $\mathrm{O}$, al revés, que la quieren a toda costa y te dicen "Epidural. ¡Dolor, dolor! ¡Quitar dolor!", que es lo único que te pueden decir, pero tú no puedes explicarles ni qué es, ni los riesgos, ni por qué no se la puedes poner. [Anestesista 4]

Otros opinan que hoy en día la mayoría de las usuarias (independientemente de su origen) suelen recurrir a la anestesia epidural.

Sí, yo creo que la mayoría sí se la ponen. [Anestesista 2] 
Pues eso, que creo que hay cosas que van mucho con la cultura o con las modas de los momentos. Yo estoy convencido de que hace cuatro años el 99,99\% quería la epidural y ya entraba pidiéndola, y ahora hay un mínimo, aunque siguen siendo pocos casos, en el que hay incluso españolas, que vienen mentalizadas a intentar parir sin epidural. [Anestesista 4]

Pero... en cuanto al periodo de dilatación, pues sí que se ponen algo menos la epidural que las de aquí. Se ponen algo menos la epidural, pero sigue siendo una técnica estrella, la gran mayoría de las mujeres se la acaba poniendo. (Las usuarias inmigrantes) la aceptan, a lo mejor se tienen que leer varias veces o lo tienen que consultar con los maridos, cosa que con las autóctonas no sucede, quienes se la ponen independientemente de lo que diga él, pero... pero, sí que es bastante bien aceptada. [Matrona 1]

Y en cuanto a la anestesia epidural, creo que se la pone la mayoría. [Matrona 2]

Además, al final, la gran mayoría acaba poniéndose la epidural. Se les da el consentimiento y, bueno, se lo leen y la verdad es que la gran mayoría se la acaba poniendo. [Matrona 4]

Porque, por ejemplo, antes la gran mayoría no quería ponerse la epidural, sobre todo las árabes, y ahora nos estamos encontrando con que está creciendo bastante el número de mujeres inmigrantes que se ponen la epidural. [Matrona 5]

Algunos profesionales entrevistados sostienen que en algunas ocasiones son las diferencias en cuanto a las costumbres durante el parto y el miedo a lo desconocido los que provocan que algunas usuarias, especialmente las procedentes de África subsahariana, se nieguen a que se les suministre la anestesia epidural.

Podía ser también por miedo a lo desconocido, por ejemplo sucedía mucho con las mujeres de raza negra que eran más reacias, ya dejando el tema del machismo y demás, que eran más reacias a ponérsela, pero últimamente ya la piden. [Anestesista 4]

A lo mejor a las de África subsahariana les cuesta un poquito más, pero en este caso yo creo que no es porque estén influenciadas por su pareja, sino porque están más acostumbradas, no sé, han visto más el parto natural, son más de parto natural. [Matrona 2]

El tema de la epidural, porque muchas de ellas tienen miedo a ponerse la epidural, sobre todo las africanas. Las africanas tienen mucho miedo a ponerse la epidural, no les gusta, y ya te la piden cuando ya no se puede poner, que están muertas de dolor, entonces recurren, pero... [Matrona 3]

Hombre, alguna... le tienen más miedo a la epidural, le tienen miedo, sobre todo yo creo que por desconocimiento. [Matrona 4]

Y a las subsaharianas les cuesta un poco; no entienden, no saben, no entienden qué es la epidural. Algunas no la conocen, han tenido hijos sin epidural y no, no conocen la técnica. [Matrona 6]

En relación con el desconocimiento y el miedo que este puede provocar, uno de los profesionales relata un suceso en el que se suministró la anestesia epidural a una usuaria y esta, no entendiendo los efectos provocados por la misma, interpretó que esta técnica era inadecuada o, en sus propias palabras, "mala".

Sí, yo me acuerdo una negrita, que no sé de dónde era, que hablaba poco español, pero algo hablaba. Era su tercer hijo y había parido a los otros dos en su país sin anestesia epidural ni nada. Total, que aquí, también por la presión asistencial que hay o porque somos un poco comodones y nos gusta que los partos sean lo más sencillos para nosotros, como estamos acostumbrados nosotros. $Y$, entonces, me acuerdo que era un parto que se estaba dilatando, que le queríamos ya poner oxitocina, pero no se quería poner la epidural. Hasta que al final dijo "Bueno, si me estáis poniendo ya esto, pues ponerme también la epidural". Y entonces empezó a decir "Medicina mala. Esta medicina mala. No funciona. ¡Parad! ¡No, no, no! Esto malo, malo, malo. ¡No pongáis a más mujeres!”. Y estuvo todo el rato así. [...] Y ella lo percibía 
como algo malo, decía "Medicina mala. Esto que me estáis poniendo a mí, no, no pongáis a nadie más". (Risas) [Matrona 5]

Por otra parte, numerosos profesionales señalan el caso de las usuarias de origen magrebí (aunque en ocasiones se refieren a las mismas simplemente como musulmanas o árabes), y afirman que estas suelen necesitar el permiso de sus respectivos maridos a la hora de decidir si se les suministra o no la anestesia epidural.

Muchas de las veces, por no decir en la gran mayoría de los casos, están supeditadas a la decisión del marido o de la pareja y, sobre todo los musulmanes, no suelen ser favorables a la epidural, sobre todo porque tienen esa concepción de que el parto tiene que ser con dolor, porque igual lo han vivido desde la niñez, que su madre, sus hermanas o las mujeres de su tribu han parido en la choza con dolor y entonces por qué aquí no se va a poder, si esto es algo invasivo y además hay una serie de problemas que pueden aparecer, mínimos, pero bueno... entonces sí que hay una limitación impuesta por sus familiares. [Anestesista 1]

Pero también hay casos en los que es el marido el que dice que no. Yo creo que eso son sobre todo casos en los que la mujer no se puede expresar. El marido dice que no y como tú solo te entiendes a través de él... Y nosotros desde luego tampoco forzamos ninguna situación, porque si dicen que no y con ella no te puedes entender. [...] Es que hay algunas comunidades, pues no sé, marroquíes o... pues en las que el hombre es el que dice y decide que la epidural no se pone y la mujer está ahí que se muere de dolor, pero él dice que no y es que no. Eso por un lado; y luego, a la hora de tú informarle, pues lo que veo es que si tienen interés en que sí que se la ponga, pues modifican un poco la información hacia... ¿sabes? Me refiero en nuestro caso solo a lo que es la epidural y la anestesia para parir en el caso de las cesáreas y tal. O sea que, si el hombre no quiere no se pone, y luego si ellas sí... [Anestesista 2]

Y también me llama la atención de las magrebíes que no se ponen la epidural si el marido no quiere, y muchas veces es el marido el que decide si se pone o no. $Y$ en otras comunidades no ocurre eso, con los chinos no ocurre, con los senegaleses tampoco... [...] Sí, las magrebíes cuando no está el marido son unas y cuando está el marido son otras. De hecho, hay veces que consigues convencerla para que se ponga la epidural y al rato te dice que no porque al marido no le parece bien. Y cuando está el marido, en el caso de las magrebíes, la mirada siempre se dirige hacia él. [Anestesista 5]

Aquí ya no te hablo como experiencia profesional, sino por lo que me han comentado otras compañeras, que la mujer marroquí quería la anestesia epidural y el marido no quería, y entonces estaba un poco influenciada por el marido. Y entonces lo que hacían era dejar al marido fuera y ella decidía y casi todas se ponían la anestesia. [Matrona 2]

Hombre, pues depende un poco de... los maridos, sobre todo, depende un poco de lo arraigada que tengan su cultura. Porque hay culturas muy machistas. Por suerte, en España, no tenemos una cultura machista. Sin embargo, hay muchas zonas por ahí en las que domina el hombre, está clarísimo. Y se ve que se hace lo que él diga y hay mujeres, sobre todo con el tema de las epidurales, que te dicen “¿Puede pasar mi marido?". Y cuando les preguntas que para qué, te dicen que es para preguntarle a él si se la ponen. $Y$ le tienen que pedir permiso. [Matrona 4]

Luego, tenemos diferentes tipos de inmigración, claro. Por ejemplo, la mujer árabe es muy diferente a nosotros, es algo cultural. $Y$ eso nos molesta y nos choca. Porque a veces, por ejemplo, para el consentimiento de la epidural, te dicen "Pero, ¿yo firmo? ¿Y mi marido?”. Y yo pienso "¿Quién se va a poner la epidural? ¿Tú? ¿Quién tiene el dolor? ¿Tú o tu marido?”. [...] Y eso depende también, tenemos que diferenciar, porque no todas las inmigrantes árabes son iguales. Depende del país que vengan, y me imagino que también influirá el nivel de educación que tengan, y las ves que son más independientes o menos. [Matrona 5]

Con la anestesia epidural son reticentes, sobre todo las árabes. Aunque ya las estamos empezando a ver, que empieza a haber alguna que sí, pero la mayoría no quiere, no quiere. O ellas querrían, pero cuando viene el marido dice "No, no, no". [Matrona 5] 
Con la anestesia epidural a las magrebíes les cuesta, hasta que no está el marido delante, les cuesta tomar la decisión. Con las del este y con las sudamericanas no hay ningún problema. [Matrona 6]

Y, luego, la población árabe, pues que siempre están pendientes de lo que les dice el marido, a ver si le parece bien o no que se la pongan. [Obstetra 1]

Otro problema que yo me he encontrado es con las pacientes subsaharianas o las marroquíes que vienen son su marido, y es su marido el que decide sobre cómo se le tiene que analgesiar durante el parto y eso. Ese es otro de los problemas. [Obstetra 2]

Observamos la sorpresa o incluso en algunos casos la indignación que experimentan algunos profesionales sanitarios con respecto al hecho de que, en algunas culturas, sea el marido de la usuaria quien decida si esta se pone o no la anestesia epidural durante el parto. ${ }^{244}$ Algunos incluso afirman tratar de convencer a la usuaria para que recurra a esta técnica o comentan que se excluye al marido (dejándolo fuera del paritorio) para que sea la usuaria quien decida libremente si quiere que se le suministre la anestesia. Además, solo uno de los profesionales que mencionan este tema es consciente de que, dentro de la comunidad magrebí, puede haber diferencias entre usuarias y que no todas dejan esta decisión en manos de sus maridos, sino que esto puede depender de factores como el lugar concreto de origen o la educación que hayan recibido.

Por lo que respecta a comportamientos de determinados colectivos en relación con el parto, otros profesionales mencionan la reticencia de las usuarias de origen chino con respecto a la anestesia epidural, aunque uno de ellos comenta que esta tendencia parece estar cambiando.

\footnotetext{
Chinas, no sé en qué porcentaje estaremos, pero hay poquitas. Yo llevo dos años de residente aquí, y se ven muy pocas. Sí que es verdad que igual antes venían mucho más avanzadas, muy dilatadas de casa y ya no daba tiempo para la epidural, y entonces era todo más rápido, o parían en casa, y últimamente se ven algo más. Con ellas el mayor problema suele ser el idioma, pero sí que es verdad que las chicas jóvenes suelen hablar más español que antes, y hablan peor casi los maridos... Entonces, últimamente sí que se puede hablar con ellas, y normalmente sí que se ponen la epidural. Yo creo que es que antes venían más avanzadas, y parece que van cambiando ellas también. Aunque ya te digo, el tanto por ciento no es tan grande, como para poder reafirmar una cosa u otra. [Anestesista 4]

Sí, las que vienen de China, intentan venir tarde a la hora de asistir al parto y no quieren la analgesia que les ofrecemos nosotros, como puede ser la epidural. Ese es el problema, porque cuando les tienes que poner la epidural por otra cuestión que no es para calmar el dolor, pues te encuentras con ese problema. [Obstetra 2]
}

La anestesia epidural las pacientes chinas no la suelen aceptar. [Obstetra 3]

Son diversos los profesionales que señalan la dificultad con la que se suelen encontrar a la hora de explicar a las usuarias alófonas en qué consiste la anestesia epidural, por qué es recomendable su uso y cómo se van a sentir tras el suministro de dicha anestesia.

Yo creo que el problema principal es la comunicación, el no poder expresar, a pesar en este caso de que se les haya aplicado una técnica epidural que funcione a nuestro entendimiento perfectamente, pero ellas esa sensación de presión que se tiene continuamente aunque se les haya aplicado la epidural no la saben

\footnotetext{
244 Tratándose de un tema que parece preocupar a los profesionales sanitarios y, con el fin de verificar si efectivamente es algo común que los maridos de las usuarias magrebíes sean quienes deciden si se les administra la anestesia epidural y, en caso afirmativo, conocer la opinión de las usuarias al respecto, decidimos plantear esta cuestión en el grupo de discusión de las usuarias procedentes del Magreb. Por tanto, abordaremos este tema más ampliamente en el análisis de esa otra técnica.
} 
o no la pueden expresar. Porque ellas no entienden completamente lo que nosotros les decimos y a lo mejor piensan que con la epidural no van a notar absolutamente nada, que la mitad del cuerpo se les va a dormir y... yo creo que eso es lo que más cuesta que entiendan. [Anestesista 1]

Yo creo que sí. El problema es que te dicen... pues eso, estilo a la mecagüen diez, que quieren algo, pero luego no hay manera de comunicar. Yo creo que muchas se piensan que es una inyección sin más, y no saben lo que se les está haciendo y se ponen ahí para que les quiten el dolor. Y el resto... prrrr (hace un gesto con la mano a modo de trompetilla junto a los labios mientras emite este sonido). [Anestesista 3]

Y el mayor problema es la comunicación, o sea, la diferencia de idioma. Entonces es muy difícil explicar lo que vas a hacer, o las opciones que hay si no utilizas esa técnica, sobre todo explicarles que aquí la técnica estándar es la epidural, aquí en el hospital de maternidad, que es una técnica que tiene muchos beneficios, y los beneficios casi siempre son mayores que el riesgo, pero que tiene sus particularidades y ya es algo difícil de hacérselo entender a una española, como para hacérselo entender a alguien que no habla tu idioma. Así que el mayor problema es el idioma, y luego ya un poco el cultural, pero principalmente para llegar al cultural ya has tenido que pasar la barrera del idioma. [Anestesista 4]

La anestesia epidural les suele dar más miedo. Pero también yo creo que es por el problema idiomático. [Obstetra 1]

Con el fin de superar estas barreras lingüísticas y hacer comprender a las usuarias que no hablan español en qué consiste la técnica de la anestesia epidural, los profesionales afirman haber recurrido a diversas soluciones, en particular al uso de intérpretes o a la traducción de los consentimientos informados. Trataremos más exhaustivamente el tema de las soluciones adoptadas para facilitar la comunicación con usuarias alófonas en el subapartado incluido más adelante dedicado a las barreras lingüísticas.

En general, si alguien ha hecho de traductor, esa experiencia ha ido bien, porque al final, logras comunicarte con la paciente, que es lo que deseas: expresarle que todo va bien, que lo que siente es lo habitual, que sí que podrá tener un poco adormecidas las piernas, pero que eso es un efecto colateral, indeseable a lo mejor, pero que le evita tener dolor, el dolor de la contracción del parto. [Anestesista 1]

Ha ayudado mucho a esto que tenemos consentimientos en todos los idiomas, bueno en todos los idiomas más frecuentes y... pues, hombre, les ayuda a entenderlo un poquito mejor. [Matrona 1]

Pues, por ejemplo, la epidural es muy difícil que entiendan lo que es. Se arman mucho lío. Me imagino que eso a los que más preocupará será a los anestesistas. Y eso que están muy preparados, porque tienen los consentimientos en varios idiomas, pero, claro, luego tienen también que explicarle a la paciente cómo ponerse, cómo moverse y todo eso. [Matrona 6]

Con respecto a la opinión de los profesionales en relación con la anestesia epidural, cabe señalar la tendencia que presentan algunas usuarias españolas, de acuerdo con dos de los profesionales, a preferir el parto natural. Uno de ellos se refiere a dicha tendencia como "una moda actual".

Se ve que hay cambios de tendencia; por ejemplo ahora el noventa por ciento de españolas se ponen la epidural, pero con el bombo del parto natural y demás, hay un porcentaje que en principio no la quiere. Es decir, que te encuentras que gente que antes no la pedía o eran más reacias y la van conociendo y ahora no tienen tantos problemas en ponérsela, y gente en cambio que aguanta mucho más, aguanta todo lo que pueda para tener el parto sin que le pongan la epidural. No es un porcentaje muy significativo, pero ahora sí que te encuentras algunas españolas que piensan que el dolor del parto es el dolor del parto y que van a intentar aguantar mientras se encuentren bien. Luego, al final, si ya no aguantan, tampoco tienen ningún reparo en pedirla. [Anestesista 4] 
Las diferencias, más que en el parto, son en la dilatación. Pero, vamos, ahí ya entramos en lo de epidural o no epidural. Si no demandan epidural, pues sí que a veces evidentemente solicitan estar en posturas que les haga soportar el dolor de un modo más fácil. Pero, bueno, eso pasa también con las españolas. Ahora está muy de moda lo del parto natural y todas estas cosas y también hay españolas que lo demandan. [Matrona 3]

En cuanto a la opinión de las usuarias inmigrantes con respecto a la anestesia epidural, podemos establecer dos grupos, sin que la pertenencia a uno u otro grupo esté determinada por el origen de las usuarias en cuestión: aquellas que no la han empleado, normalmente por elección propia, y otras que sí que han recurrido a la misma.

Incluimos a continuación las respuestas de aquellas usuarias a las que no se ha suministrado la anestesia, entre las que destacan las usuarias procedentes de África Subsahariana:

La inyección, ¿̇no? No, no poner porque yo no quiero. [África Subsahariana 1]

No he usado anestesia. De dos hijos yo sí quería, pero ahora no quería, porque cuando tenía, me duele la espalda. Como ya de dos hijos he tenido, ahora no quería. Yo ha dicho la médico que no quería, que voy a aguantar. [África Subsahariana 2]

(Risas) Es que a mí no me ha dado tiempo. Han salido siempre rápido. No me han podido anestesiar, aunque me hubiera gustado. Por el dolor, ya sabes, porque si te pinchan dicen que sientes relajación, pero a mí no me ha dado tiempo, o sea que... [África Subsahariana 3]

No, a mí no me ponen ninguna inyección, yo no quiero, no. [África Subsahariana 5]

No, no anestesia. I prefer everything is natural, prefiero. [...] I do not like injection aquí (se señala la parte baja de la espalda). Natural way I prefer. Because if you do not feel pain, we effort much. [Asia 3]

No es que no esté de acuerdo con la epidural, porque cada uno tiene su nivel de dolor que puede aguantar, ¿no? Entonces creo que es algo muy personal, muy individual. Pero yo, si pudiera, preferiría todo natural. [Latinoamérica 2]

Yo no he usado anestesia, yo no he querido. [Magreb 1]

La anestesia epidural esta vez no la he usado, porque ha venido rápido, muy rápido. [Magreb 3]

Entre este grupo de usuarias a las que no se les ha suministrado la anestesia epidural, cabe señalar el caso de una usuaria procedente de Rumanía, en el que parece que ha sido más bien la elección de su marido (o, al menos, la influencia) la que ha hecho que esta usuaria optara por un parto natural.

Yo, por ejemplo, no estoy de acuerdo con anestesia epidural. No la he usado nunca, prefiero natural. (Interviene el marido de la usuaria) Es que si tú sabes la información... Porque yo he leído algunos artículos científicos que hay médicos que dicen que están contra porque puede afectar al feto, por eso no la usamos. Porque dicen que puede afectar al niño, y entonces es mejor aunque te duele... Date cuenta que hay mujeres que he visto que no les duele cuando sale el niño, porque usan anestesia, pero les duele mucho más después. Es una cosa personal... Por ejemplo, ves, ella (la usuaria) tuvo muchos dolores cuando salió el niño y ahora los dolores con respecto al parto... (La usuaria interrumpe a su marido, aunque él enseguida retoma la palabra) Hombre, sí que me duele ahora. Bueno, sí que le duele, pero me refiero que después de pasar dolores tan fuertes, esto es nada. En comparación con las mujeres que usaron epidural, que después, cuando los nervios empiezan a entrar en activo, empiezan a sentir dolores que para ellas... les molesta mucho. Pero depende de cada uno, si prefieres que te duele antes o que te duele después. Yo creo también que no usar la anestesia es mejor para los niños, pero para las madres es peor. Entonces, tú tienes que elegir, ¿’para quién quieres que te queda mejor, para la madre o para el 
niño? No lo sé, ya te digo, cada uno elige. Es personal, porque muchas mujeres quieren que lo hacen. Es que cuando tienes el primer niño, como no sabes, entonces es como una incógnita, entonces puede ser que muchas mujeres aceptan la epidural. Pero si has tenido ya un parto natural, no veo por qué en el siguiente parto tienes que usar anestesia. Y ella (la usuaria) como ya había tenido partos naturales, por eso ha dicho que no. (Finalmente parece que la usuaria puede expresar su opinión) Me han preguntado dos o tres veces, pero yo siempre decía "No, no, no. Que no quiero, no quiero". Aunque sé que voy a tener muchos dolores, pero no... [Europa del este 5]

El grupo de usuarias que, por el contrario, han decidido usar la anestesia epidural es, como se puede observar en las siguientes citas, más numeroso que el de las que han preferido no usarla.

Por lo de la anestesia, yo las dos veces sí que la he utilizado. [África Subsahariana 4]

Sí, poner inyección, yo prefiero. [Asia 1]

Aquí, mejor, sí. Porque... Cuando está aquí, cuando nace se puede usar epidural, que hace no doler mucho. Y en China no tienes eso. [Asia 2]

Y yo poner epidural. Antes yo pienso, si no duele mucho, no echarlo. Pero... duele mucho, entonces, mejor epidural. Entonces yo preguntar a la señora si puede ser, y ella dice que si tardar mucho no puede ser. Entonces yo dicho "Quiero epidural". Pero, a veces, tienes una problema, que quieres echar epidural y tienes una problema. Pero yo estoy bien, entonces firmar yo y mi marido. [Asia 2]

Sí uso epidural, sí. Así, duele menos. [Asia 4]

Sí, sí me la han puesto (la epidural). [Comunidad gitana]

Yo sí que estoy a favor de la anestesia epidural, porque... porque te agotan mucho las contracciones, te agotan tanto, que dices "Es que necesito que me...". Y, entonces, sí, yo sí que la he usado. [Europa del este 1]

Yo estoy de acuerdo con la anestesia epidural. [Europa del este 2]

Epidural sí he usado. La pido yo, y me la ponen. (Le pregunto si en Rumanía suelen usar la anestesia epidural y responde directamente el hermano de la usuaria en español y, a continuación, ella comenta algo en rumano). No, no, en Rumanía, no. No es tan frecuente. [Europa del este 3]

Y sí que usé la epidural, porque llegó un momento que ya no podía, y dije "Por favor, que me la pongan ya, porque vamos...". [Europa del este 4]

Sí que me ponen anestesia epidural. (Le pregunto si la solicitó ella misma). Me han preguntado y yo he querido, he dicho que sí. [Europa del este 6]

Estoy totalmente de acuerdo con la anestesia epidural y me la pusieron. (Le pregunto si la solicitó ella o se la ofrecieron). A ver, ya me lo habían dicho, desde que empecé el embarazo me lo habían preguntado y, entonces, desde el primer momento dije que sí. [Latinoamérica 1]

Sí que me han puesto anestesia epidural, la pedí yo. [Latinoamérica 4]

Y sí que he usado la epidural, sí. Es que ahora tuve el parto complicado. Tuve el parto muy complicado, de cuatro días estar aquí. [...] Casi me muero, de verdad, lo estoy contando porque está ella (la hija) también aquí, pero... Lo importante es que he estado bien atendida, bien atendida, sí. Estuve con un doctor que me aguantó todo el día ahí... Sí, sí, eso sí. [Latinoamérica 5]

Sí he usado anestesia, así menos dolor. [Magreb 2]

Sí, sí, inyección, sí, yo digo “Dolor, dolor” y ponen. [Magreb 4] 
Por lo que respecta al parto por cesárea, los profesionales presentan opiniones variadas. Algunos sostienen que normalmente las usuarias inmigrantes no suelen poner pegas a este tipo de parto, es más, hay quienes afirman que algunas usuarias, especialmente del colectivo latinoamericano, demandan el parto por cesárea.

Y pegas al parto por cesárea no hemos tenido, no, incluso muchas lo piden de entrada, pues porque también tienen la concepción de que te recuperas más rápidamente. Tienen la sensación de que el niño va a sufrir menos y de que, al ser mucho más rápido, pues te recuperas más rápidamente, lo cual no es cierto, pero bueno... existe ese cuento que van diciendo por ahí "No, si te recuperas mejor, y el niño sale más sonrosadito y...". [Anestesista 1]

Y en cuanto al parto por cesárea, yo creo que no suelen oponerse. Si no hay otra opción de que sea por cesárea... [Anestesista 2]

El parto por cesárea no le suele gustar a nadie, pero vamos... no me suena que haya... Ha habido casos en los que ha habido que correr un poquillo, pero por lo general si se les explica que hay que hacerlo, lo aceptan, aunque a nadie, ni a españolas ni a extranjeras, le guste. A lo mejor los ginecólogos te pueden decir si son más reacias en cesáreas programadas, pero en nuestro caso, que trabajamos mucho la urgencia, se les explica que hay que hacerlo, que es necesario, y se quedan un poco así, pero tampoco ponen excesivas pegas. [Anestesista 4]

Sobre si ponen pegas o no al parto por cesárea, no, en esto no he apreciado diferencias. [Anestesista 5]

¿Si ponen pegas al parto por cesárea? No especialmente. No, no especialmente. Es más, algún colectivo incluso lo demanda mucho, como es el de las sudamericanas, porque es muy frecuente la cesárea allí, es muy frecuente. [Matrona 1]

Pues, para el parto por cesárea, a mí nunca me han puesto pegas, no. [Matrona 2]

Al parto por cesárea no suelen poner pegas, no. [Matrona 3]

Yo, personalmente, no me he encontrado con ninguna que haya puesto pegas al parto por cesárea. Se les intenta explicar y, a veces, si es una cesárea urgente, te la llevas de la camilla y yo creo que ni se entera. Pero las de aquí tampoco se enteran tampoco a veces, ¿eh? [Matrona 5]

Y al parto por cesárea nunca me han puesto pegas, no. [Matrona 6]

El parto por cesárea, por evitar, yo creo que todas. Bueno, las sudamericanas, no, las sudamericanas simplemente por el hecho de no pasar por un dolor de parto, muchas te piden que le hagas la cesárea ya. Además, vienen de una cultura donde te hacen la cesárea a la mínima, en Ecuador, por ejemplo, la tasa de cesáreas es muy alta, en Brasil, también. Y entonces ellas sí que aceptan. [Obstetra 3]

Por el contrario, algunos profesionales comentan que, en algunas ocasiones, las usuarias inmigrantes, en especial las procedentes de África subsahariana, han presentado reticencias a que se les practique el parto por cesárea. Esto se debe, según algunos profesionales, a la creencia de que este tipo de parto puede provocar una disminución en la fertilidad.

Y lo del parto por cesárea, alguna sí, sí que ha puesto pegas, sí. Pero es que no sé decirte de dónde son. Sé que son de África. Y algunas se disgustan mucho, pero mucho, mucho, como que no se sienten mujer. Y ha habido algunas que cuando les dices... En concreto, tuve un caso que, cuando se lo dije, es que daba gritos desgarradores, y decía "Que no, que no, que no, que no". Y es que no había otra forma, es que era imposible. Y tenía un disgustazo la pobre mujer, pero algo increíble. [Matrona 4]

Hay algunas que sí que lo rechazan, pero no te sabría decir de qué raza. Yo creo que, en general, se confía mucho en el personal sanitario, en los médicos y las matronas, y como ellas y el marido si está presente ven la evolución y, si hay algún problema, se les dice, y se les comunica "Pues, le vamos a dar tantas horas 
de plazo" o "Hay que hacer una cesárea, porque el bebé no está bien y hay que sacarlo, tiene que nacer", pues yo creo que lo comprenden y no muestran reticencias. Pero alguna vez, sí, sí que te dicen que prefieren parto, porque lo ven natural, pero, vamos, no insisten mucho porque hay mucha información al respecto. Se les dice que el bebé está en peligro y que, si no le hacemos la cesárea, no sabemos cómo va a nacer, y entonces lo entienden y no muestran grandes reticencias. [Matrona 7]

Y otro problema que alguna vez me he encontrado, aunque no es muy habitual, es cuando hay que hacer una cesárea y el marido se niega, o es ella misma la que no quiere, y te encuentras con muchos problemas a la hora de intentar hacerla, porque tiene que firmar el consentimiento y... Ellos tienen la creencia de que una cesárea disminuye la fertilidad posterior, y claro, una mujer de esos ámbitos, que no tiene la fertilidad al $100 \%$, es como que vale menos, ¿no? Y entonces, por eso, ellos son más reticentes con la cesárea. [Obstetra 2]

Pero las subsaharianas lo ven como un drama, un drama, porque luego no se sabe qué le va a decir su marido, porque tienen el concepto de que en ese caso la fertilidad es menor y no la van a valorar igual... $Y$ yo creo que es al revés, en los países subsaharianos si te hacen una cesárea, es porque has tenido un problema gordo, muy gordo, porque en ese caso es probablemente por un problema materno, porque allí partos con fetos muertos hay bastantes. $Y$ entonces cuando te hacen una cesárea es porque has tenido un problema muy gordo, como una hemorragia muy fuerte, y en ese caso, puedes tener problemas en el siguiente embarazo. $Y$ es a eso a lo que se asocia. Porque una cesárea en condiciones normales no es un problema en sí, pero en el contexto en el que se hace en esos países es mucho más extremo que aquí. [Obstetra 3]

Incluso uno de los entrevistados menciona un caso en que, ante la negativa de la usuaria a que se le practicase el parto por cesárea y la posibilidad de que esto afectase negativamente a la salud de la madre y del niño, fue necesario llamar al juez para que ordenara que se llevara a cabo este tipo de parto.

A los partos por cesárea me han puesto pegas sobre todo las africanas, la población negra con eso... Una vez tuvimos que llamar al juez, porque no quería la mujer que le hiciéramos la cesárea. Y el asunto acabó... pues, que se la hicimos, claro. (Risas) Bueno, el juez dijo que sí, y se hizo y tal. Es que claro, en caso de que esté en juego su vida y la del bebé, y ella se niega, pues no te queda más remedio y te tiene que dar la orden el juez, que siempre te dice que sí, claro. Sobre todo a ellas les dan mucho miedo las operaciones, a la población negra, eso es lo que he observado yo. [Obstetra 1]

De nuevo en este aspecto un profesional señala las barreras lingüísticas y la dificultad de explicar a las usuarias alófonas en qué consiste la técnica que se les va a aplicar, en este caso el parto por cesárea, y el estado de ansiedad que se puede dar en las usuarias al no comprender qué se les está haciendo.

Por ejemplo, a mí hace poco me tocó una chica que estaba sola, no te puedo decir exactamente de dónde era... No sé si era de... Hungría, no de Hungría, no... Bulgaria. Y vino una conocida de la paciente, que se supone que era la que traducía y te das cuenta de que tampoco se está enterando muy bien de lo que hay... (Risas). Y, por ejemplo, es que luego esa fue cesárea, y tampoco la señora puso ningún problema. Pero, claro, es un problema para nosotros, porque una vez tú estás en el quirófano, le tienes que explicar lo que va a notar, lo que no, que diferencie el tacto con el dolor y, claro, si tú no sabes qué es lo que te están haciendo, no sabes lo que está pasando, pues lo único que tienes es gritar, que es lo que pasó con esta chica. [Anestesista 2]

Por su parte, la mayoría de las usuarias, a pesar de preferir un parto natural, parecen comprender que es necesario recurrir a la cesárea en algunas circunstancias.

Y el parto por cesárea, yo no lo he tenido, pero si hay que hacerlo, se hace, si es para salvarme o salvar mi bebé. [África Subsahariana 4] 
Y el parto por cesárea no me parece mal; es mucho más larga la recuperación, pero si era necesario, no hubiese sido ningún problema. [Europa del este 2]

No tengo nada en contra del parto por cesárea. Cada uno que haga lo que cree que tiene que hacer y... [Europa del este 4]

El parto por cesárea... Yo prefiero natural, pero si no se puede... [Europa del este 6]

Y el parto por cesárea, pues, la verdad, si es necesario, pues bien, pero si se puede parto natural, mejor. [Latinoamérica 1]

Sí, yo quería... la verdad es que tuve una cesárea, porque ya había roto aguas y tuve complicaciones, pero yo quería un parto normal y poder caminar y tal... Me hubiera gustado que fuera lo más natural posible $\sin$ medicación, pero no ha podido ser. [Latinoamérica 2]

Pues, preferencias... Es que yo, como tuve una cesárea, pues ahí hay poco que decir. (Le pregunto su opinión sobre el parto por cesárea, si hubiera preferido que fuera natural). Pues, si es necesario es que no... no queda más. [Latinoamérica 3]

Y la cesárea... Yo prefiero todo normal, pero depende de médicos... [Magreb 1]

Y yo no cesárea, parto normal. Pero si el médico lo dice, yo hago, si no hay otra cosa, salir cualquier maneras, parto normal o con el... [Magreb 4]

Entre las usuarias que prefieren que no se les practique el parto por cesárea, algunas basan esta preferencia en el hecho de que el malestar en este tipo de parto y la duración de la recuperación de la madre son mayores.

Y la cesárea no me gusta, prefiero natural. Con las cesáreas tienes más molestias y tardas más en recuperarte. [Comunidad gitana]

El parto por cesárea creo que debe de ser doloroso. Prefiero que sea natural. [Latinoamérica 4]

(Le pregunto si, vistas las complicaciones del parto, al final le practicaron la cesárea). Gracias a dios, no. Porque... como le digo, había tres matronas, tres doctores, dos anestesistas... había como doce personas en la sala. Es que ya se me estaba pasando demasiado, y los dolores me daban, pero no bajaba, no bajaba, es que la tenía igual, igual como estuvo los nueve meses, los nueve y la semana que se alargó. [...] Pero, por último, a cinco minutos de que me hicieran una cesárea, pudo salir. Y yo prefiero que haya nacido así, no estoy muy a favor de la cesárea, porque... se lo pasa muy mal uno. Aunque en algunos casos sí se necesita, pero yo, ¿cesárea?, no, no. Si puedo evitarlo, no... Porque además luego tardas mucho más en recuperarte, y uno necesita trabajar también. [Latinoamérica 5]

Otras usuarias, sin embargo, se oponen al parto por cesárea y algunas atribuyen al mismo posibles consecuencias basadas más en comentarios de otras personas que en la evidencia científica.

Con lo del parto por cesárea, la gente dice que es mejor no usar cesárea... Pero, vamos, a ver, yo tengo mis hermanas que son enfermeras y me dicen que tampoco... vamos, que no es una cosa de otro mundo, que si te toca, te toca. Yo prefiero natural, pero tengo amigas que dicen que prefieren cesárea porque es más rápido y menos doloroso que natural... Pero, bueno, yo tampoco... Hay gente que lo ve como, iuy, la cesárea!, como que has fallado, que te ha fallado algo y te han abierto, pero es que... cuando se lo digo a mis hermanas dicen "Pero, iqué antigua!", si eso no depende de la madre... [África Subsahariana 3]

El parto por cesárea, si no hay otra opción, pues entonces, sí. Por ejemplo, mi madre me tuvo con cesárea, pero también porque ya era más mayor y no sé qué cosas tenía, entonces se la tuvieron que hacer. Yo tenía un poco miedo de que me iban a hacer cesárea, más que nada porque quiero tener más hijos, pero 
ya me han comentado que hay mujeres que han tenido un primer parto con cesárea y luego un parto normal. Yo más que nada no quería que me cortaran tantas veces (Risa nerviosa). Pero bueno... [Europa del este 1]

(Le pregunto qué opina sobre el parto por cesárea). Bueno, no sé... Hombre, eso se usa en los casos en los que no se puede... vamos, cuando es necesario. Aunque hay casos de mujeres que no quieren dolores y no quieren que se estropea la vagina o algo y entonces lo piden. Ahora cada uno lo hace en función de su mentalidad, yo creo, y entonces hay algunas que no quieren estropearse el cuerpo y, entonces... [Europa del este 5]

El siguiente aspecto que analizamos en relación con el parto es la expresión del dolor durante el mismo por parte de las usuarias inmigrantes, aspecto sobre el que solo preguntamos a los profesionales, ya que nos parecía difícil que las usuarias inmigrantes entrevistadas nos pudieran ofrecer verbalmente su propia opinión sobre cuánto dolor sienten al dar a luz y cómo lo expresan.

La opinión de los profesionales sanitarios al respecto podría dividirse por comunidades de usuarias inmigrantes. De hecho, muchos sostienen que la expresión del dolor depende del país de origen de las usuarias y algunos consideran que, en general, las inmigrantes lo suelen expresar más enfáticamente.

Pues la expresión del dolor depende un poquillo también de sus comunidades. [Anestesista 4]

Y por lo que respecta a la expresión del dolor, buenooooo, ahí sí que te desgloso claramente por comunidades. [Anestesista 3]

En cuanto a si son más o menos enfáticas las inmigrantes en la expresión del dolor durante el parto, generalmente más. Sí, generalmente más. [Matrona 1]

La expresión del dolor cambia muchísimo de unas a otras, depende un poco de dónde vengan. [Matrona 2]

En cuanto a la expresión del dolor, yo creo que las inmigrantes son más enfáticas. [Matrona 3]

Lo de que sean más o menos enfáticas depende. Claro, es que yo creo que eso depende más de la mujer y también de dónde procede. [Matrona 4]

En la expresión del dolor son diferentes, depende, va por comunidades también. [...] Depende un poco de qué países. Porque hay algunas que dices "Bffff... Esto está todo perdido con esta mujer". Pero hay otras que también son muy valientes, muy echadas p'alante... [Matrona 5]

El que sean más o menos expresivas en el dolor también depende de las culturas. [Matrona 7]

Y en la expresión del dolor, ahí sí que hay una gran variedad, ¿eh? Hay una gran variedad. Normalmente, las inmigrantes se quejan bastante más que, por ejemplo, una española, o que una europea. [Obstetra 1]

Hombre, la expresión del dolor depende de las razas. [Obstetra 2]

La mayoría señala entre las que expresan el dolor de manera más enfática principalmente a las usuarias latinoamericanas, y, además, a las de la comunidad gitana o a las procedentes del Magreb, aunque al respecto de estas últimas usuarias los profesionales presentan opiniones variables, como expondremos más adelante.

Son más enfáticas (en la expresión del dolor), especialmente, yo diría que las magrebíes, que son mucho más expresivas. [Anestesista 1] 
Dentro de las nacionales, e incluso dentro de las rumanas, las gitanas son muy escandalosas. Bueno, escandalosas, entiéndeme... vamos, que son muchísimo más enfáticas. [Anestesista 3]

Las sudamericanas expresan muchísimo el dolor, gritan más o hacen más aspavientos. [Anestesista 4]

Me acuerdo también de otro caso... Viene una sudamericana con contracciones, y bueno, parece que va a parir allí mismo, y le empezamos a preguntar “¿Cada cuánto son las contracciones?” y el marido se pone a contestar en lugar de la otra, y tú le dices "No, oiga, déjele contestar a ella". Y, entonces, le dijimos que no estaba de parto y quería que la ingresáramos. Y le dijimos que si no estaba de parto no se le podía ingresar y bueno... Esto suele pasar un poquitín más con las sudamericanas, son las más quejosas, mucho más expresivas.. Pero tampoco podemos generalizar. [Enfermera 6]

Las mujeres latinoamericanas exageran un poco más el dolor, no digo que no tengan dolor, pero su forma de... o el umbral del dolor lo exageran muchísimo. [...] Y las mujeres españolas, pues hay de todo, aunque no suelen gritar tanto como... como las latinoamericanas, por ejemplo. Las latinoamericanas no es que griten, es que exageran mucho el dolor, el umbral es... es menor. [Matrona 2]

Las mujeres árabes, pues sí, sí que gritan bastante. [Matrona 2]

Pero, por ejemplo, es que las sudamericanas se quejan mucho, a cualquier... esto no lo soportan. El nivel del dolor lo tienen mucho más bajo. Las sudamericanas se quejan de verdad mucho. [Matrona 3]

Las magrebíes son más exageradas, por lo general, hay de todo, pero sí que son más de gritar. [Matrona 6]

Por ejemplo, las sudamericanas siempre son más, no sé... a ver, que no sé si está bien decirlo, pero sí que expresan más el dolor. No es que les duela más o menos, pero a lo mejor las sudamericanas se expresan más. [Obstetra 2]

$Y$ respecto a la tolerancia del dolor, las marroquíes y las sudamericanas normalmente tienen una tolerancia más baja, un umbral de dolor más bajo, entonces se quejan mucho, mucho más, o al menos antes que las pacientes de otros orígenes. [Obstetra 3]

En referencia a las usuarias de la comunidad magrebí, como habíamos anticipado, hay opiniones discordantes $\mathrm{y}$, al contrario de otros profesionales, algunos sostienen que estas usuarias suelen ser bastante estoicas a la hora de expresar el dolor durante el parto. Asimismo, otros profesionales opinan que el énfasis en la expresión de este dolor depende de si sus respectivos maridos se encuentran presentes o no.

Me llama la atención la comunidad marroquí, que muchas veces la queja por dolor, eeee.... tengo la impresión de que es algo cultural. Que cuando yo creo que la analgesia es completa y eficaz, tienen queja y tengo la duda de si esa queja es parte del ámbito del parto, si es parte de la expresión que ellas deben hacer, porque normalmente van acompañadas del marido, y esta expresión me llama la atención. [Anestesista 5]

Aunque, por ejemplo, las moras llaman a su madre, suelen llamar a su madre, sí. Y también son como más sufridas. Las ves que piensas "Madre mía, tiene que estar teniendo unos dolores y están ahí que cierran los ojos, pretan los labios y no dicen ni esta boca es mía". Y, luego, tienes como el otro extremo, en las moras también, ¿eh?, que son como muy... como muy demandantes, muy quejicas, incluso más de... quiero decir, desmesurado, que piensas que para tanto no puede ser. [Matrona 4]

Las menos enfáticas son las árabes, para mí, son las árabes. Y alguna árabe expresa así el dolor, como con sumisión. Parece como si se involucionan un poco. [Matrona 5]

Y es curioso porque en países como pueden ser sudamericanos, o africanos, en los que en teoría no tienen tantos medios como nosotros, sí que exteriorizan más, se quejan más, porque lo están pasando fatal, sobre todo si está el marido delante. Como para, entre comillas, "culpabilizarlo" un poco. Es una cosa cultural, como para decir "Mira, por tu culpa, lo mal que lo estoy pasando". Y, entonces, claro, ¿qué le vas 
a hacer? Pero es una cuestión psicológica, ¿eh? Y que, a veces, las miman mucho. Les dicen "Ay, mi amor" (Risas). [Obstetra 1]

La comunidad de usuarias que es mencionada más a menudo por los profesionales entrevistados en relación con la expresión del dolor durante el parto es, sin duda, la procedente de África Subsahariana. De hecho, numerosos profesionales describen el comportamiento de estas usuarias durante el parto a la hora de expresar o mitigar el dolor que sienten porque les resulta especialmente llamativo.

Y, en cambio, las de los países subsaharianos parece que intentan contener mucho más el dolor. [...] Las pacientes del África subsahariana sobre todo expresan mucho el dolor en la cara. Es tremendo, porque tú ves que tienen dolor y lo aguantan, por pues culturalidad o porque realmente no quieren expresarlo y se ve, se ve el dolor en la cara. [Anestesista 1]

A lo mejor, culturalmente, sí que es verdad que hay pacientes, como las de raza negra, que viven de otra manera el dolor y cuando ya no pueden más es imposible hacer que se estén quietas, aguantan, pero se quejan y tienen una forma de moverse... o se mueven mucho, pero vamos, problemas así... [...] Determinadas comunidades negras o africanas ves que hacen rituales o lo que sea, que siguen sus costumbres y algunas parece que gritan un poquillo más o expresan más el dolor, aunque tampoco podría generalizar. [Anestesista 4]

Me llama la atención que para las negras, por ejemplo, una manera de expresar el dolor es hacer esto (chasquea los dedos repetidamente). Y también en las negras otra cosa que veo es que a veces salimos fuera a pedir la cartilla, por ejemplo, cuando les van a hacer una cesárea, y tienes que ver si es urgente, porque si es urgente tienes que llamar enseguida a la matrona, y sales y a veces te encuentras a las negras tiradas por el suelo. $Y$ perdona si digo negras, que no lo digo despectivamente, es la manera de expresar... porque es que no sé de dónde son, si son senegalesas, de Mali, o de dónde sea... [...] Bueno, pues sales, y las ves como tiradas, y es su manera de expresar el dolor. $Y$ tú dices "Pero si esta gente, cuando están en el desierto y por ahí, se van al árbol a parir ellas solas. ¿Cómo es que aquí hacen tantos aspavientos?”. [Enfermera 6]

Sí, sobre todo la manera de... bueno, de expresar el dolor. Por ejemplo, en, esto claro en la grabación no se verá, pero bueno, las mujeres del África negra hacen mucho así (chasquidos de dedos) con el dolor, y tienen como una especie de mantra que ahora no te lo podría reproducir, que sería algo así como "Ay madre, ay madre, ay madre...". Algo así, ¿eh? No quiere decir que digan eso, pero un poco así, y lo acompañan del chasquido de los dedos. Y la verdad es que eso es muy llamativo. [Matrona 1]

Las mujeres subsaharianas hacen muchos gestos, gesticulan mucho... (Chasquea los dedos repetidamente). Hacen mucho así con las manos. Hacen los típicos "Tic, tic, tic" (Vuelve a chasquear los dedos). [Matrona 2]

$\mathrm{Y}$, sin embargo, las africanas, son todo lo contrario, o sea, a la hora de expresarlo, te tocan pitos, te cantan... no sé. Me llama la atención porque no estamos acostumbrados, pero no lo veo ni bien ni mal, quiero decir, que no... es su manera de vivirlo. [Matrona 3]

Las africanas lo que sí que intentan, a lo mejor, a la hora de mitigar el dolor, más que tomarse cosas es, no sé, recurren a sus cantos, a sus... pero nada más. Más que quejarse, es que ellas el dolor lo expresan. [Matrona 4]

Las africanas sí que empiezan con su chasquido, así. (Chasquea repetidamente los dedos). Y dicen "Urur, uuurur, urur". Y otras, sin embargo, son calladas (Baja el tono de voz), que dices "Jo, qué capacidad tiene esta mujer". [...] Luego están los gestos. Por ejemplo, los gestos así (chasquea los dedos) de las africanas cuando están dilatando. Eso sí que me llama la atención. [Matrona 5] 
En cuanto a sí son más o menos enfáticas, yo creo que las subsaharianas aguantan mucho, yo creo que su actitud es más... musical. Son más de hacer ruidos con la lengua y con los dedos. Es su forma de expresar el dolor. Y... las del este, normal, tampoco... [Matrona 6]

Por ejemplo, las subsaharianas son más expresivas, se quejan más, canturrean. A veces, muchas no querían epidural, sobre todo hace años, y entonces, pues eso, se quejan más, muestran más el dolor y... [...] Y algunas también, hay algunas que cantan, expresan a lo mejor esas emociones con cantinelas. Nosotras no entendemos lo que dicen, pero yo lo intuyo por la entonación. Porque es algo repetitivo, ¿no?, como un mantra, siempre las mismas palabras y siempre la misma entonación, ya te digo, es como un mantra. Es que yo he visto muchas cosas, es que llevo aquí muchos años ya... [Matrona 7]

Las africanas como que el dolor lo llevan ellas... no sé, son menos expresivas. [...] Las africanas cuando tienen dolor, sí que hacen determinados movimientos, no sé, es otra manera de expresarlo, con las manos sí que hacen más gestos, con los dedos así (chasquea los dedos), sí que lo expresan más de esa manera. [Obstetra 2]

Entre las usuarias menos enfáticas a la hora de expresar el dolor durante el parto, de acuerdo con algunos profesionales entrevistados, se encuentran las procedentes de China.

En general, yo creo que las que menos enfáticas con respecto a la expresión del dolor son las chinas, no sé, a mí me da esa impresión, por las que he tratado... [Anestesista 2]

En cambio, las chinas, normalmente, no expresan mucho. Y tienes que tener cuidado, porque igual... igual te pare aquí. (Risas). [Enfermera 6]

Quizás las chinas sean más estoicas, si se puede hablar así, ¿eh? Que no lo digo en plan... Menos enfáticas, vamos a decirlo así. [Matrona 1]

Bufff... pues no sé. Ya te he dicho antes, a las chinas yo las veo muy sumisas y su gesto de dolor está como reprimido hacia dentro, que no se note. [Matrona 3]

Bueno, las chinas son más sumisas, las chinas no suelen quejarse. [Matrona 4]

Las orientales demuestran que les molesta, pero normalmente no se quejan. [Obstetra 2]

Y también se menciona dentro del grupo de usuarias que son menos expresivas en cuanto al dolor a las que provienen de Europa del este.

Y en cambio, las de Europa del Este, son como más sufridas, puede que con el dolor hagan alguna mueca y demás, pero aguantan más o lo expresan menos. [Anestesista 4]

$\mathrm{Y}$, en cambio, las ucranianas, las polacas, las rumanas, las del este en general, son mujeres más sufridas, más fuertes, y como que aguantan más. [Matrona 7]

Las europeas, pues no, normalmente aguantan mucho más, o por lo menos, oye, lo tienen más asumido. [Obstetra 2]

Por último, en relación con la expresión del dolor, un par de profesionales señalan que, en el caso de las usuarias autóctonas, es cada vez menor la capacidad para soportar dicho dolor, debido a la edad a la que se tiene el primer hijo o, simplemente, a una cuestión de diferencias entre generaciones.

No creo que sea nada racial ni cultural, sino que va por edades. Me explico: las abuelas de antes gestionaban esto de una manera y las jóvenes de ahora lo gestionan de otra. $Y$ ahora nadie quiere sufrir, $y$ ahora creo que nos estamos pasando. Antes lo aguantaban todo y ahora no quieren aguantar ni una caricia. ¿Entiendes lo que te quiero decir? [Anestesista 3] 
Y también esto está pasando ahora con las españolas, ¿eh? Yo creo que las españolas cada vez tenemos menos preparación para lo que supone parir. A lo mejor porque nos pilla más mayores y ya pensamos "Mira, qué bien. Que me ayuden, que me saquen, que me...", pero como si no fuera contigo, que te lo hagan las demás. Entonces, yo sí que creo que las españolas se abandonan también un poco. [Matrona 3]

Otro aspecto relativo al momento del parto planteado a los profesionales se refiere a si, en alguna ocasión, se han enfrentado a la solicitud de la placenta o el cordón umbilical por parte de las usuarias tras haber dado a luz.

La mayoría de los profesionales entrevistados afirma no haberse enfrentado nunca a ningún caso de este tipo.

A mí particularmente, no, ni extranjeras ni españolas, y no es algo frecuente, ni mucho menos. [Matrona 1]

A mí no, no me lo han pedido nunca. [Matrona 2]

A mí no me ha ocurrido nunca. O sea, enseñarla y tal, lo he hecho muchas veces, pero tanto como que se la lleven, eso nunca me ha pasado. [Matrona 3]

A mí, no, pero sí que he oído que a alguna compañera... [Matrona 4]

No, a mí no me ha pasado. [...] Es que, además, como parece que son pocos los casos en los que se pide, si se hubiera dado algún caso en este hospital, yo creo que se hubiera difundido mucho, que la gente diría “¿Sabes lo que pasó el otro día?". Vamos, como que una cosa así yo creo que quedaría en el recuerdo durante mucho tiempo, y a mí nadie me ha contado nada... [Matrona 6]

Estos profesionales a los que nunca les han solicitado la placenta o el cordón umbilical tras el parto desconocen si el hospital presenta un protocolo al respecto, y la mayoría comentan que consultarían a sus supervisores en caso de que esto les sucediera.

Si ocurriera, lo tendría que preguntar, por lo menos a mi supervisora, a ver qué me decía. No lo sé, supongo que... pensándolo bien, tendría derecho a tenerlo. Pienso que sí, pero, no lo sé con seguridad, legalmente no sé cómo está el tema. [Matrona 1]

Y no tengo ni idea de cómo se actuaría en estos casos. Enseñársela, sí, pero para dársela tendría que preguntar si es posible. [Matrona 2]

Y si me pasara... yo creo que no se da, pienso, ¿̇eh? Pero, vamos, me pillas totalmente... [Matrona 3]

No tengo ni idea de cuál es la política del hospital en estos casos, pero yo supongo que no sería posible que se lo dieran, porque es un resto biológico, y yo creo que los restos biológicos no pueden salir del hospital. [Matrona 4]

Si me lo pidieran, preguntaría que para qué y, dependiendo de lo que me dijeran, no sé, si tiene mucho interés... [...] Pero vamos, preguntaría, preguntaría a la supervisora si eso se puede hacer o no se puede hacer. Porque antes sí que creo que se podía hacer, pero ahora me parece que no, no estoy segura, y entonces yo tampoco puedo... Es un tejido y, aunque sea de ella, pues igual según las leyes es potestad del hospital, yo qué sé. Entonces preguntaría si se podría hacer o no. Y si se pudiera hacer, pues a mí no me importa... [Matrona 5]

No sé cómo se actúa en esos casos. Es que... ¿̇la placenta? Pues, hombre, yo creo que no... porque aquí las tiramos, así que yo creo que no se debería... Y si quieren un trocito de cordón, ipues bueno! (Risas) No sé. Nunca se me ha dado el caso, la verdad es que no sé cómo actuaría. Yo creo que hablaría con el ginecólogo, a ver qué le parece a él, pero bueno... A ver, es su placenta, evidentemente, pero no sé si está permitido sacarla del hospital. Es que, claro, eso va incinerado todo. [Matrona 6] 
Los pocos profesionales que se han enfrentado en el pasado a casos de este tipo dan a entender que la política del hospital al respecto antes era algo más laxa, pero que en la actualidad no se permite extraer del hospital ni la placenta ni el cordón umbilical, pues se consideran restos biológicos. Además, algunos señalan que esta petición se da más en usuarias españolas que en inmigrantes. Pero, vamos, no sé ahora cómo está la cosa. Yo sí que sé que antes, compañeras te hablan de ello además,
que antes se las llevaban si querían, incluso había quien se la ponía por aquí, porque se decía que
regeneraba la piel del cutis o no sé qué, pero ahora es que ya directamente las tiramos. [Matrona 5]

Sí, sí que ha ocurrido alguna vez. Yo, si me lo han pedido, se lo hado. Esto hace años, porque es que aquí las placentas se tiran. Y lo del cordón sí que ahora se ha puesto de moda que el padre quiere cortar el cordón, pero esos no son extranjeros, son más españoles, pasa sobre todo con algunos modernillos. Y, claro, eso implica que hay que esterilizarlo, que se tiene que poner unos guantes estériles, y entonces ya... Que es que es una tontada el cordón, porque eso ya está pinzado, lo pinzamos nosotras, o sea que eso de cortar el cordón es una chorradica. [Matrona 7]

Sí, la placenta alguna vez sí que nos la han pedido. Pero yo no recuerdo que fueran inmigrantes, eso también lo piden algunas españolas. Pero que me lo hayan pedido por tradición y cosas de esas no tengo recuerdo. Y nosotros la placenta no la damos, porque se considera un material orgánico de aquí, del hospital, y no se la pueden llevar. [Obstetra 2]

Sí, una vez, me sucedió en Barcelona. Pero no era inmigrante, era una paciente española naturista. Y, que yo sepa, no había ningún protocolo en el hospital, y hubo un follón. No me acuerdo bien cómo acabó, pero se consideró un producto biológico que, por riesgo de... de contaminación, no se le permitió sacar del hospital. Al final, no lo sacó, no se le permitió por riesgo biológico, que no sé yo si eso es verdad o no, pero bueno. $Y$ yo recuerdo que se montó un poco de follón porque no era algo habitual. Y, luego, me han contado que ha habido más casos, pero yo solo lo presencié esa vez. [Obstetra 3]

Solo un profesional entrevistado reflexiona sobre el hecho de que quizás esta solicitud viene determinada por creencias y comportamientos propios de una determinada cultura y que la dificultad de comprensión de los mismos no implica que los patrones de una cultura sean más o menos válidos que los propios de otra cultura.

Hombre, pues me imagino que para ellos será algo muy importante. Hay veces que dices "No lo puedo llegar a entender", pero bueno, ellos tampoco me entenderán a mí, ¿no? Es que yo he nacido aquí, pero podría haber nacido allí. Yo prefiero esto, pero ¿̇y lo otro?, ¿por qué no? [Matrona 5]

Una última cuestión planteada en el subnodo del parto, aunque no está directamente relacionado con este, pero probablemente es en ese momento cuando se detecta, es la mutilación genital femenina que puede haberse practicado a las usuarias de origen extranjero.

La mayoría de los profesionales entrevistados afirman haberse encontrado con casos en los que la usuaria había sido sometida a este tipo de mutilación, aunque algunos sostienen que dichos casos son muchos y otros consideran que son pocos y que en el último periodo han ido disminuyendo.

En infantil sí que nos hemos encontrado con algunos casos de niñas mutiladas, pero aquí en urgencias, desde que estoy, yo no he visto ningún caso, o al menos de labios mayores y menores, esos casos más exagerados, no. [Enfermera 6] 
Muchísimas veces nos encontramos con mujeres mutiladas. Continuamente. [Matrona 1]

Sí, algún caso ha habido. [Matrona 2]

Sí que hay mujeres sometidas a la mutilación. [Matrona 3]

Sí, sí que me he encontrado con algún caso. [Matrona 4]

Aunque son pocas, cada vez menos, pero siguen viniendo con mutilaciones. [Matrona 5]

Sí, yo sí que me he encontrado con algún caso, sí. [Matrona 6]

Sí, sí, yo he visto muchas. [Matrona 7]

Luego, te encuentras, y es una lástima, muchas subsaharianas, de Senegal, Gambia y demás, que cuando eran pequeñas les han hecho una ablación, y cuando lo ves te sabe muy mal. [Obstetra 1]

Sí, muchas veces. [Obstetra 2]

La verdad es que yo he trabajado en Madrid, y en Madrid, por la zona, no teníamos casos de mujeres con mutilación genital. Y trabajé también en Barcelona, y en Barcelona algún caso había, pero la verdad es que muy pocos. Cuando me he puesto un poco, digamos, a enterarme del tema, ha sido aquí. $Y$ aquí he visto ya dos pacientes, pero eran parciales, y ya estaban diagnosticados. O sea, yo nunca he sido la que se lo ha diagnosticado, porque yo estoy en urgencias y, como mucho, en hospitalización, y estos diagnósticos no los he hecho yo de primeras, o sea, ya venían diagnosticadas. [Obstetra 3]

En relación con si existe algún tipo de protocolo que se sigue en el hospital contexto de estudio con las usuarias a las que se detecta una mutilación genital, algunos profesionales, en concreto las matronas, nos hablan de un programa de mediación que se lleva a cabo en coordinación con la organización no gubernamental Médicos del Mundo. ${ }^{245}$

En estos casos tenemos en maternidad un protocolo, entonces se recogen los datos de esa gestante. Nosotros en el momento de la dilatación, en el paritorio, etc. no les decimos nada, pero recogemos los datos y los remitimos a... a mediación cultural, y ya se encargan ellos de hablar con la mujer, etc. Independientemente de que tengan hijo o hija, que yo creo que eso es importante también, que es una cuestión de prevenir. [Matrona 1]

Sé que aquí existe... bueno, la verdad es que no te puedo hablar mucho del programa porque hace poco que me han explicado lo que había que hacer. Sé que hay una asociación contra la mutilación genital femenina $y$, entonces, cuando se localiza a una mujer de un país africano y que se pueda sospechar que pueda existir mutilación, tanto si el niño que nace es varón como si es mujer, se hace un protocolo y se llama a esta asociación para que ellos sean los que hablen con ella. Nosotros no le comentamos absolutamente nada; sin embargo, son los mediadores los que vienen al día siguiente o mientras la mujer está ingresada en el hospital. [Matrona 2]

De hecho, aquí hay un programa que, cuando viene una mujer inmigrante, eeeee... de raza negra, africana, nos ponemos en contacto con unos mediadores culturales para que estén al tanto de estas cosas y... les hagan un seguimiento, aparte de informarlas de todas las cosas que hay, para que les hagan un seguimiento y para evitar eso. Porque sí que vemos mujeres mutiladas y que piensan seguir con estas prácticas con sus hijas, entonces... eso sí que se ve. Tenemos unos teléfonos, entonces llamamos allí y les dejamos el mensaje de, pues, que ha parido tal, y entonces ellos se vienen, les dan la información y... yo

\footnotetext{
245 Durante el trabajo de campo, tal y como se comentará en el apartado de análisis de la observación no participante, fuimos testigos en primera persona de la actuación de un mediador de Médicos del Mundo en el caso de una usuaria procedente de África Subsahariana que se encontraba ingresada en la planta de puerperio. Hablamos con dicho mediador y, además, visitamos la sede de la organización para que nos informaran sobre este programa de mediación.
} 
creo que está bastante bien que haya un seguimiento, porque, claro, es que aquí les pierdes la pista muy rápido. [Matrona 3]

Ahora ya realmente lo que hacemos es apuntar los datos de la mujer, la habitación a la que va, y entonces vienen los mediadores y ellos cogen todos los papelicos y ya se ponen en contacto con ellas. Yo, la verdad, es que tampoco he sido de las que ha estado dentro del proyecto, y entonces tampoco... Sé que hacen un seguimiento de cara a evitar que, si tiene una niña, pues que no... ¿Tú sabes si gracias a este programa están disminuyendo los casos de mutilación? Porque yo me imagino que sí, ¿no? Que quieras que no, les tiene que dar miedo, porque hacen con ellas barbaridades. Pero, claro, esto es algo completamente cultural... [Matrona 4]

Y tenemos aquí... bueno, ya lo sabrás. Solo por ser de determinados países ya las consideramos mujeres en riesgo y más si ya nace una niña. Entonces, aunque nosotros no observemos que físicamente o exteriormente haya una mutilación, solo por ser de determinados países, pues hay unas mediadoras, y aquí tenemos un sobrecito, ponemos una pegatina y luego las mediadoras vienen cada cierto tiempo y se ponen en contacto en ellas o llamas a la planta y les dices que si va por allí alguna mediadora que le digan que tenemos una señora que... que tal. [Matrona 5]

Y, luego, ya son los de Médicos del Mundo, creo que son ellos los que se encargan de organizar cursillos y hacer un seguimiento. [Matrona 6]

En esos casos, nosotras tomamos nota y transmitimos las notas fundamentales relativas al parto $y$, entonces, hacemos un informe y lo pasamos a los mediadores culturales. Hay varios, ellos se van turnando, y periódicamente vienen a recoger todas las notas y se encargan de visitar a la señora, sobre todo para prevenir que se repita la conducta en el futuro. [Matrona 7]

Por las respuestas ofrecidas por otros profesionales sanitarios con respecto a este programa de mediación coordinado con Médicos del Mundo, nos damos cuenta de que probablemente las únicas que conocen y participan en este programa dentro del hospital son las matronas.

Sí, claro, sí que nos hemos enfrentado a casos. Pero no seguimos ningún tipo de protocolo, ya está hecho, o sea, cuando vienen aquí es a parir, y quizás eso se lo hicieron cuando tenían tres o cuatro años, vete a saber. [Obstetra 1]

Y no hacemos gran cosa en estos casos. Porque es que aquí... Yo sí que sé que hay un grupo de matronas, no sé si lo siguen realizando ahora, pero había un grupo de matronas que les hacía un seguimiento, cuando detectaban estos casos en el parto, en el puerperio les hacían un seguimiento. $Y$ yo simplemente lo que hacía era comentárselo a ellas cuando detectaba un caso. Pero, vamos, nosotros, aparte de eso, no tenemos ningún protocolo. [Obstetra 2]

No, a mí nunca han venido a presentarme ese programa los de Médicos del Mundo. Sí que vino una trabajadora social de Sanidad. Nos explicaron que hicieron una especie de programa, creado por ellas, en el que informaban a las mujeres, incluso les daban una especie de credencial, para en su país acreditar que no podían hacer eso, porque a la vuelta tal... Pero, con Médicos del Mundo, no. No he hablado con ellos de este tema. Los de Sanidad aprovechaban el momento en que iban a vacunarse porque iban a viajar a su país como momento de enganche. Pero los de Médicos del Mundo no sé cómo lo hacen, no sé qué momento aprovechan, si es al nacimiento o... [Profesional socio-sanitario 1]

La última fase de la reproducción que vamos a analizar se refiere al puerperio y, dentro de este subnodo, vamos a abordar diferentes aspectos.

En primer lugar, por lo que respecta a la atención ofrecida al recién nacido, algunos profesionales sanitarios opinan que este aspecto no depende tanto de la cultura de origen de la usuaria, sino de cada usuaria en particular y que, por tanto, no se debería generalizar. 
Yo creo que esto depende de la madre. Porque, por ejemplo, yo veo que hay chinas que pasan mucho del bebé $y$, en cambio, hay otras que se desviven. Entonces, yo... bueno, creo que todo depende de la persona. [Enfermera 2]

Pues en esto hay un poco de todo. Porque yo también tengo experiencia en el área infantil. Y en maternidad sí que veo que ellas y las madres de ellas se suelen ocupar de los niños, pero en las plantas de infantil hemos tenido madres que no han aparecido en todo el ingreso del bebé. Pero bueno, yo creo que esto no depende tanto de la cultura, sino de la madre en sí. [Enfermera 4]

Pero, bueno, es que a veces te llama la atención un caso particular. Te encuentras con un caso concreto que dices "Fíjate tú. Con el problema que tiene el crío y la madre no hace más que mirar otras cosas y al crío no le hace caso". Pero, claro, ¿̇eso son todas las rumanas? ¿O son todas las sudamericanas? Es que no se puede generalizar. En general no tenemos un patrón. [Enfermera 5]

Es que yo creo que ahí no se puede generalizar, que cada mujer responde de una manera diferente. Así como con las españolas, que algunas son muy efusivas y otras menos. [Matrona 6]

Por el contrario, algunos profesionales mencionan comportamientos observados en las usuarias de determinados orígenes durante el puerperio. Por lo que se refiere a las usuarias de África Subsahariana, algunos profesionales comentan que parecen estar especialmente dotadas para la maternidad y que actúan de manera muy natural durante los primeros días tras el nacimiento.

Y luego los negritos sí que son más... no sé. Así como a los españoles los veo demasiado protectores, la gente de color son más... no sé, que lo llevan con mucha más soltura, ¿̇sabes? Yo veo que en los españoles hay como una excesiva protección del bebé, en mi opinión. [Enfermera 1]

$\mathrm{Y}$, además, las inmigrantes tienen todavía muy arraigado el instinto de maternidad. Por ejemplo, las negras, es que cogen y le dan el pecho que es una maravilla. [...] Las mujeres de raza negra lo hacen muy bien, muy bien. Y eso que se van occidentalizando, ¿eh? Yo veía que al principio, cuando empezaron a venir, te chocaba más. Las negras, por ejemplo, cogían así al bebé, como si fuera un orangután, y ahora eso ya no se ve tanto, ya no es igual. [Enfermera 5]

Y también veo que, por ejemplo, las subsaharianas parece que están dotadas especialmente para la maternidad, porque las ves... Es que no hay que explicarles, ellas directamente sacan el pecho y lo hacen de una manera que parece que lo estén haciendo todos los días durante toda su vida, y los niños se agarran perfectamente. Esas mujeres parece que están especialmente dotadas para la maternidad. [Matrona 7]

Otros profesionales, sin embargo, resaltan porque les resulta sorprendente o, por lo menos, llamativo, el hecho de que algunas mujeres procedentes de África Subsahariana no demuestran afecto por sus bebés en las primeras horas de vida, y algunos ofrecen explicaciones al respecto de este comportamiento asociadas a posibles creencias propias de la cultura de estas usuarias.

Sí, esto yo lo he visto más en paritorio o en el puerperio inmediato, durante las primeras veinticuatro horas, antes de que las traigan a planta. En su relación con el recién nacido, hay mujeres subsaharianas que no quieren tener mucho contacto en un primer momento con el recién nacido e incluso no lo quieren ni mirar; desvían la mirada y, claro, tú lo que intentas es que al recién nacido lo veas, y lo cojas y lo tengas, y te llama la atención que estas mujeres no lo quieren ver. [Enfermera 3]

Sí que te puedo decir, a lo mejor, que la negrita está normalmente más asustada y como que... no acaricia tanto al niño. [Enfermera 5] 
Ahí hay muchas, muchas diferencias... Es que, hay tantos. Te acuerdas de algunos casos, te pueden llamar la atención cosas. Por ejemplo, el que a ti te puedan parecer despegadas, es que a lo mejor ellas expresan sus sentimientos así. Esto pasa por ejemplo en las negras, que igual no muestran tanto sus sentimientos. [Enfermera 6]

Pues... depende mucho de las mujeres. Las del África negra hay bastantes de ellas que no le hacen prácticamente nada de caso a sus recién nacidos. No sé, en algún curso nos dijeron que podría ser algo así como para evitar mal de ojos y demás, pero... el caso es que es frecuente, pues eso, que te quedas incluso parado, porque casi apartan la cara. [Matrona 1]

Yo sí que creo que en algún país africano, no sabría decirte cuál, hacen algo que a mí me ha llamado la atención, que es que, cuando acaban de dar a luz, no quieren que le pongas encima al niño. Es como si los malos espíritus estuvieran por ahí rondando y, si ven que le prestas demasiada atención, se te puede llevar al bebé. Entonces, a veces, no quieren ni mirarlo. No es que sean todas las africanas, no te sé decir de qué país son, pero esto sí que lo vemos, es verdad. [Matrona 3]

Y en África, no sé exactamente de dónde son, pero hay algunas que no miran a los bebés. A mí me dijeron es que culturalmente como que daba mala suerte, que en las primeras horas no había que mirarlo, porque el niño podía morir o no sé qué. Son creencias que tienen ellos. Te llama la atención que ni los miran. Que tú dices "iMadre mía!". Y es que a mí personalmente me parecen tan majicos, los negros son preciosos, son de verdad... cuando nacen, son los bebés más guapos que hay. Y yo pienso "iQué lástima que no lo mires! iCon lo precioso que es!". [Matrona 4]

Y las africanas, las de Nigeria y demás, pues a veces cuando nacen los bebés no los quieren coger, ni los miran. Y claro, cuando tú te metes en este mundo, es que... no lo entiendes. Piensas "Pero, dios mío, ¿pero cómo puede no mirar a su bebé? ¿Cómo no lo puede coger?". Hasta que coges y preguntas y ellas o alguna compañera te explican "Pues es por sus creencias religiosas, porque piensan que si los cogen o los miran, los espíritus malignos que están ahí se los pueden llevar. Y hasta que pasan unas horas hago como que no le hago caso, no me importa, y así no se lo van a llevar". [Matrona 5]

Hay algunas culturas en las que las madres no quieren tocar al recién nacido al principio, aunque luego por ejemplo las ves... Es que puede cambiar completamente, que aquí, sobre todo las negritas, que nace el bebé y no lo tocan, no lo miran, casi no les quieren dar el pecho... Y luego las ves en la planta al día siguiente, y las ves que están con ellos, que les dan la teta perfectamente... [Matrona 5]

Lo que sí que alguna vez me ha llamado la atención es que con el grupo de las subsaharianas hay un poquito como una desconexión. Yo, personalmente, solo lo he visto una vez, tampoco quiero generalizar, pero me llamó tanto la atención... porque era una niña preciosa, guapísima, que todo el mundo íbamos a la habitación a verla, y la mujer la tenía al lado y no le hacía ni caso. Y luego nos enteramos de que era por el miedo a que los espíritus se la llevaran. Y, sí, me llamó mucho la atención. [Matrona 6]

Sí, en las mujeres de algunos países se ve muchísima diferencia. A una madre española, si, por ejemplo, su hijo está ingresado en neonatos, cuesta sacarla de neonatos. Les dices "Vete a descansar, que no es necesario que pases aquí la noche" y tal... Y las madres de otras culturas son muchísimo más despegadas. Ese apego, lo que siente una madre española que se lo pegaría con pegamento Imedio, una madre de otras culturas, no. Vienen lo justito, lo justito. Los africanos, concretamente, son los más despegados... [Profesional socio-sanitario 1]

Este mismo patrón de comportamiento se asocia por parte de algunos profesionales a las usuarias procedentes de China y del Magreb.

Las chinas no les hacen ni caso, pero ni caso, igual son sus creencias... [Enfermera 5]

En el momento inmediatamente después del parto, las árabes, al nacer, no muestran ese apego, no parece que quieran estar con el hijo, no digo que no quieran estar, pero no se les nota tanto como... Parece que si te lo llevas les haces un favor, que ya se lo devolverás, pero en ese primer momento no... [Matrona 2] 
Por ejemplo, cuando nace el bebé, generalmente no quieren tenerlo. Nosotras enseguida, inmediatamente, si el parto ha sido normal, los colocamos encima de ellas, para que sientan calorcico, piel con piel, pegados a su cuerpo, y estas, por ejemplo, decían "Ay, no", como que no querían... Pero eso no es porque no los quieran, sino porque es cultural. Aunque últimamente a las chinas yo las veo que ya lo cogen, ya siguen ese... tipo de comportamiento. Las chinas son las únicas que he notado como si no quisieran acercarse al niño. [Matrona 7]

Por ejemplo, la población china sí que he notado que no suele querer ver al recién nacido inmediatamente [Obstetra 2]

En relación con las usuarias de estos dos últimos colectivos mencionados, los profesionales entrevistados realizan otros comentarios aislados relativos al comportamiento de las madres de estos orígenes que les han llamado la atención.

Pues, yo veo que las madres en general son muy atentas con el recién nacido y tal. Pero, por ejemplo, sí que noto que parece que tienen más arraigo cuando estos son varones que cuando tienen niñas. Y esto pasa sobre todo en el caso de los chinos y los musulmanes. [Enfermera 2]

Luego, las chinas tienen eso de que no se pueden mover en no sé cuántos días. No pueden moverse y no pueden tocar al niño, no le dan el pecho, le dan agua de arroz, ellas no comen nada de aquí... [Enfermera 5]

Pero, vamos, no es que den mucha guerra los chinos. Solamente los padres, que veo que yo están como recelosos, están siempre mirando qué haces con el bebé, ¿sabes? Te lo traes y vienen detrás, y cuando vuelves, lo vuelven a mirar. Yo los veo con miedo, como con miedo. A veces me choca y me digo "Fíjate, este hombre, acabo de sacar al bebé y va detrás de mí", que aún les digo “¿Quieres verlo?"... [Enfermera 5]

En el caso de los árabes, en cambio, ellas expresan mucho los sentimientos hacia el bebé, y ellos no tanto... [Enfermera 6]

En los pocos casos en los que los profesionales aluden a usuarias de otros orígenes, en concreto procedentes de Latinoamérica y de Europa del este, comentan que el comportamiento de las madres procedentes de estas áreas es bastante similar al de las madres autóctonas, y solo en dos ocasiones se alude a comportamientos llamativos por ser diferentes a lo habitual.

En esto las sudamericanas son muy miedosas, muy miedosas, sí. Enseguida se creen que al niño le pasa algo, son más... Las rumanas, prácticamente igual que nosotras, muy parecidas. [Enfermera 5]

Los niños también es muy curioso cómo los arropan, y cómo los colocan. Eso también lo pregunté y creo que son las rumanas, que los ponen de otra manera, mirando hacia no sé dónde. No sé si son las rumanas o eran otras, yo creo que eran las rumanas... Y también les ponen debajo dinero, sí, porque eso quiere decir que va a tener suerte. $Y$, por ejemplo, las rumanas, ahora ya menos, pero al principio, los envolvían "estilo bizantino", ¿sabes?, el clásico así y así (Cierra una toalla que tiene delante a modo de sobre), que el pobre bebé no se podía ni mover. Y, entonces, les tienes que explicar que eso no es conveniente hacerlo. [Enfermera 5]

Las mujeres de Sudamérica y las de los países del este son más como nosotras, más o menos. [Matrona 4]

Con respecto a las diferencias culturales detectadas por los profesionales en la atención que ofrecen las usuarias inmigrantes al bebé tras el nacimiento, algunos de estos llegan a varias conclusiones: que la adaptación ante estas diferencias debería ser mutua (por parte tanto de los profesionales como de las usuarias), que el desconocimiento de los patrones culturales no 
debería conducir a críticas, y que es necesario antes de juzgar un determinado comportamiento ponerse en el lugar de la persona sobre la que se va a opinar.

$\mathrm{Y}$, bueno, pues claro, eso tienes que ir tanteándolo. Y tienes que ver que el niño está aquí, es decir, en España, y se tiene que amoldar... Pero, claro, tampoco puedes ir con un látigo, no se trata de eso. El trabajo es que hay que personalizar, y como prácticamente solo tenemos inmigrantes, deberíamos ponernos ya manos a la obra. [Enfermera 5]

Pero a lo mejor eso son cosas culturales y nosotros eso no lo sabemos, y a veces criticamos sin más... [Enfermera 6]

Claro es una manera totalmente diferente la que tenemos en esta cultura de entender el nacimiento. Por eso, a veces, hay que pararse a pensar un poco, y ponerse en la situación de la persona que estás atendiendo en ese momento, para poder... no sé, no juzgar, no juzgar en principio. [Matrona 5]

Por su parte, la mayoría de las usuarias inmigrantes entrevistadas no creen que se le deba prestar a los recién nacidos ninguna atención o trato especial, sino simplemente los cuidados necesarios por su condición de bebés.

No sé, lo cuido normal, como a todos los bebés. [África Subsahariana 2]

¿Algún trato especial? Pues, la verdad, no te sabría decir. [África subsahariana 4]

Hombre, especiales (los recién nacidos) ya son, así que claro que deben recibir algún trato especial. [Europa del este 2]

¿Algún trato especial? ¿Desde qué punto de vista? ¿Por ser de otra cultura? No. [Europa del este 3]

Hombre, claro, los recién nacidos tienen que tener más atención. [Latinoamérica 1]

No, no creo que deba recibir ningún cuidado especial, no. [Latinoamérica 2]

(Silencio durante unos segundos) Pues creo que sí. Porque hay niños que nacen malitos y otros que nacen normal. Entonces sí que deberían dársele cuidados especiales. [Latinoamérica 5]

¿Dónde? ¿En España? (Le explico que me refiero a su propia opinión en cuanto al cuidado del bebé). No, el trato es normal. [Magreb 2]

¿De parte de quién? ¿De la madre? Pues, sí. (Le pregunto si me podría explicar cómo se ocupa ella del recién nacido). Con mucho cariño. Es un bebé, ¿no? Entonces... [Magreb 3]

Solo algunas usuarias, en especial aquellas que proceden de Asia, mencionan creencias y patrones de comportamiento propios de su cultura que difieren en cierto sentido de los que suelen presentar las usuarias autóctonas tras dar a luz.

Solemos poner al niño una pulsera de plata, y lo solemos poner porque según dicen es para las malas habladurías y esas cosas... Yo también llevo uno, y por el embarazo me lo quité, uno que es medio de plata, que lo llevo muchos años, que me lo dio mi madre y lo llevo por costumbre. Suele ser de plata, porque dicen que es bueno para protegerte de las malas habladurías, de las personas que te miran mal y esas cosas, y eso suelen decir en mi país. [África Subsahariana 4]

Por... por ejemplo, yo luego poner pendientes. Pero en China, si pones pequeña niña un pendiente, dicen "Aaaaah... ¿Por qué poner una pequeña niña pendiente?". [Asia 1]

Vale. Eeee... Costumbre de país, porque... cuando nace la niña no se puede duchar. Solo cuando traen a la madre y entonces se puede duchar. $Y$ aquí duchan antes. Esto no parece bien. $Y$ entonces madre duchar niño con agua caliente. [Asia 2] 
Sí... Por ejemplo, cuando nace la niña, la ropa es de manga larga. Porque cuando nace hace frío, entonces mejor primero mes que te ponen manga larga, no importa si es verano, y no salir a la calle. (Le pregunto si, tal y como he leído en libros sobre medicina tradicional china, las mujeres después de dar a luz deben permanecer durante aproximadamente un mes sin prácticamente realizar ninguna actividad, ni lavarse, especialmente con agua fría). Bueno, lo que poner los libros tampoco perfecto, porque cada una persona es diferente. Muchas cosas diferentes... Yo no hago. Cuando puedo yo trabajar. [Asia 2]

Sí. Because mother is a gift for baby and baby is a gift for mother. We take care of each other. [Asia 3]

Madres un mes tienen que estar tranquilas, o cuarenta días. Y mucho cuidado con las comidas. [Asia 4]

En cuanto a quién se ocupa de los cuidados del bebé, los profesionales entrevistados consideran que por lo general es la madre quien se encarga de los cuidados básicos, aunque en ocasiones puede también intervenir su familia, y para determinadas cuestiones cuentan con la ayuda del personal sanitario.

En general se ocupan ellas de los recién nacidos. Aquí los bañamos y demás, pero luego cosas como cambiarles los pañales y demás se ocupan ellas. Y si les dan biberón, que hay también un porcentaje muy alto de chinas, más que las otras, que les dan biberón, pues se los dan ellas también. [Enfermera 2]

Y en general suele ser la madre la que se ocupa de los cuidados. Normalmente en el cuidado de los niños es muy raro que aparezca más el hombre que la mujer, en todos los casos, ¿eh?, en los españoles también. [Enfermera 6]

En los cuidados, cuando son más jóvenes, pues a lo mejor sí que puede intervenir un poco más la familia, pero bueno. [Matrona 6]

Con respecto a estas ayudas externas que pueden recibir las usuarias en el cuidado de sus hijos, dos profesionales mencionan una escuela de padres creada en el hospital contexto de estudio y un programa denominado "Maternaje"246 y del que se ocupa el Centro provincial de Promoción de la Salud de Zaragoza, cuidad en la que se enmarca nuestra investigación.

Teníamos una escuela de padres montada aquí en el hospital, vamos, ahora en vacaciones vamos peor, y también te cansas y lo dejas por temporadas, pero teníamos es una idea muy buena que consistía en meter a los padres y las madres cuando bañábamos al bebé, que estuvieran aquí, y les explicábamos, y nos decían ellos sus dudas, sus miedos... Porque, es eso, o sea, es en los primeros días cuando tienes que estar de apoyo... [Enfermera 5]

Hay un servicio del Ayuntamiento, que se llama "Maternaje", que está en la Plaza Añón, y ellas se encargan, pues si más o menos ellos pueden tirar, con un poco de ayuda o con un poco de habilidades, o sea, enseñar a la madre habilidades y tal, pues este equipo lo hace muy bien, y de paso, van viendo lo que va ocurriendo. [Profesional socio-sanitario 1]

Ante esta misma cuestión, algunas usuarias entrevistadas, ${ }^{247}$ entre las que destacan aquellas procedentes de Europa del este, comentan que se ocupan ellas solas de los cuidados del bebé, aunque una de ellas señala que le gustaría que su marido la apoyara.

\footnotetext{
${ }^{246}$ El denominado "Programa de Maternaje" es gestionado por el Centro provincial de Promoción de la Salud, situado en la Plaza Añón, 3 y 5 de Zaragoza. Aborda principalmente temas relacionados con la salud sexual y reproductiva y la atención materno-paterno infantil. Para mayor información puede consultarse la siguiente página web: [http://www.zaragoza.es/ciudad/encasa/detalle_Tramite?id=21207] (última consulta: 13 de mayo de 2013).

247 Durante el trabajo de campo en las plantas de puerperio del hospital, pudimos también observar el comportamiento de las usuarias y sus acompañantes relativo al cuidado de los recién nacidos, por lo que trataremos también este tema en el apartado dedicado al análisis de los datos recolectados mediante observación no participante.
} 
Me ocupo yo sola. [África Subsahariana 2]

Me ocupo yo, pero, hombre, si me puede ayudar mi marido, más o menos, para que él también tenga una idea y sepa, yo qué sé, cambiar el pañal o... porque si un día yo no puedo... Lo único, yo, darle el pecho y también todo, pero vamos, al menos las primeras semanas que me ayude. [Europa del este 1]

Sí, me ocupo yo sola del bebé. (Interviene el hermano de la usuaria) Le ayudamos, pero ella no quiere que... que intervengan muchos estilos, digamos. [Europa del este 3]

Me ocupo sobre todo yo. (Interviene el marido de la usuaria) Bueno, yo la ayudo cuando no puede. Pero como ella tiene más experiencia y está más cariñosa... (Vuelve a tomar la palabra la usuaria) Los chicos siempre piden que se quedan con la madre, siempre. Están más apegados a la madre. Él (su marido) quiere hacer algo, pero si empieza a llorar con él, lo tengo que coger yo. Están más acostumbrados y hasta los ocho o diez años están pegados con la madre. [Europa del este 5]

Aquí me han ayudado a limpiarlo y ya está. En casa me ocuparé yo sola. (Le pregunto si en Rumanía es habitual que los maridos se ocupen también de los cuidados del recién nacido). Depende, depende del marido (Risas). [Europa del este 6]

Me ocupo yo misma, por supuesto. [Latinoamérica 2]

Me ocupo yo misma de los cuidados, sí. No creo que tenga que ayudarme nadie. [Latinoamérica 4]

Por el contrario, otras usuarias afirman que les ayudan sus maridos o sus hijos mayores.

Mi marido me ayuda. [África Subsahariana 1]

Nos ocupamos los dos, con el primero también me ayudó. (Se le pregunta que, en caso de que viviera en Camerún en lugar de en España, si su marido también le ayudaría en los cuidados del bebé). Lo que pasa es que se estigmatiza un poco todo. En África hay familias muy tradicionales donde los hombres son machistas, como aquí, y te dicen "Yo al bebé no lo toco, es tu trabajo". Y hay otros que son diferentes. Por ejemplo, mis padres, mi padre es un poco machista, no voy a mentir... (Risas). Pero, luego, veo a mis hermanos y ellos sí que colaboran, yo he visto a mis hermanos ayudar y ocuparse de sus hijos, entonces... Es que las cosas van cambiando. No sé, igual si me hubiera casado con un camerunés, tendría que haber luchado si fuese machista... [África Subsahariana 3]

Me ocupo yo del bebé y, bueno, en mi caso, es mi caso, ¿eh?, mi marido se ocupa los primeros días, porque yo lo veo tan chiquitito que... Aparte de darle el pecho, el resto se lo dejo a él, porque él tiene más experiencia, porque se ocupó de sus hermanas, de las más pequeñas y eso, así que es como si hubiera sido padre antes. [África Subsahariana 4]

Me ocupo de sus cuidados yo misma y ahora mismo también me ayuda el chico, mi hijo, hasta que venga mi esposo. (La usuaria señala al que parece el mayor de sus dos hijos previos). [Latinoamérica 3]

(Del bebé) Me ocupo yo y mi pareja, nos ocupamos los dos. [Europa del este 2]

(Pregunta el marido de la usuaria, quien está realizando labores de intérprete) ¿Cuándo han nacido los niños? Yo explico en árabe, ¿va bien? (La usuaria responde en árabe y su marido traduce al español) Se ocupa madre y padre, los dos. [Magreb 4]

En relación con esta ayuda por parte de los maridos en el cuidado de los bebés, cabe señalar el caso de una usuaria, concretamente procedente de Honduras, la cual señala un ejemplo de adaptación cultural al país de acogida, pues dice contar con el apoyo de su marido por estar residiendo en España, y asegura que en su país de origen este comportamiento por parte de los maridos no es nada habitual y que se suele ocupar del recién nacido la madre sola. Además, también recalca que considera importante que los maridos se den cuenta de cuánto 
cuesta dar a luz, aspecto que algún profesional también había observado en las usuarias de Latinoamérica y nos lo había comentado durante las entrevistas.

Allá se ocupa la madre, pero, por ejemplo, si un niño nace de siete meses, va a incubadora, igual que aquí [...]. Pero si ya es parto normal, nosotros nos hacemos cargo de ellos. Los hombres no suelen ayudar mucho en Honduras. El cuidado es cuestión de las madres. Se la tira uno todo el tiempo cuando lo tienen en el hospital sola. Y, sin embargo, aquí, tengo a mi marido las veinticuatro horas. Las veinticuatro horas está él aquí, aunque sea solo para acompañarme. Y allá es que... hay mucho machismo, allá es la madre la que se debe ocupar sola. (Le pregunto si su marido es hondureño). No, mi marido es de Ecuador, y en Ecuador en este tema es muy parecido a como sucede en Honduras. Lo que pasa es que al venir aquí... Yo prefiero que me ayude y esté conmigo, porque creo que es importante que también él se ocupe, que vea cómo se cambia el pañal, y que vea lo que cuesta dar a luz. Eso es lo principal, que vea qué es lo que cuesta. [Latinoamérica 5]

Por último, otras usuarias, en particular aquellas que proceden de Asia y del Magreb, sostienen que cuentan (o les gustaría contar si estuvieran en España) con el apoyo de sus madres o suegras. Algunas hablan también de otras figuras femeninas que les apoyan en el cuidado de los recién nacidos, bien familiares $u$ otras mujeres conocidas a las que presuponemos que contratan.

Cuando yo trabajando, yo buscar a alguien que se ocupa del bebé. Una amiga o los hijos mayores. Mi marido, no, él trabaja como soldador. Entonces, yo buscar a alguna mujer que me ayuda. [África Subsahariana 5]

Para cuidar ayudan, ayuda mi tía. Y luego yo... yo coger una señora cuidado mi niña. Hasta que yo estar fuerte, cuidando la señora. [Asia 1]

Me ayuda mi mamá. [Asia 4]

Y también mi suegra me ayudó mucho, estuvo con nosotros dos días, porque el otro (refiriéndose a su marido), pobre, casi no durmió y entonces mi suegra ha estado aquí los dos primeros días y ahora, que ya es el tercero, nos iremos a casa. [Europa del este 1]

Sí, como le quiero dar el pecho, pues por lo menos hasta los cuatro meses me ocuparé yo, y luego, pues, la suegra. Ella me ayudará, claro. [Europa del este 4]

Si estás... Mejor te ayuda alguien. A mí ayuda mi madre, esto es normal en mi país. [Magreb 1]

En Argelia cuando sales del hospital vas a casa de tu madre para descansar. A veces ayuda la madre, ¿cómo se dice?, la abuela, pero como no está... [Magreb 2]

Me ayuda también mi hija mayor, que tiene quince años. (Le pregunto si también los hombres se suelen involucrar en el cuidado de sus hijos en Argelia). Hay algunos que ayudan, no sé, depende del hombre. [Magreb 3]

Por lo que se refiere a la lactancia materna, una de las cuestiones que señala uno de los profesionales sanitarios entrevistados es que, en el momento en que las mujeres han dado a luz, estas pasan a ocupar una posición secundaria y su mayor preocupación es la alimentación de sus bebés.

Yo creo que, una vez han parido, ya ellas se quedan en un segundo plano, y lo que más les preocupa es el bebé, y sobre todo, la alimentación del bebé. La principal duda que tienen cuando están unos días aquí ingresadas durante el puerperio inmediato es cuando el bebé no come, que si quieren dar el pecho, no pueden hacerlo, porque no tienen todavía leche, ni tienen calostro o como quieran ellas llamarlo... Sobre 
todo, yo creo que lo que más les preocupa es la alimentación, por ellas mismas se preocupan poco. [Enfermera 3]

Por lo general, los profesionales consideran que la mayoría de las usuarias inmigrantes recurren a la lactancia materna, excepto en el caso del colectivo de usuarias chinas, las cuales, de acuerdo con los entrevistados, son las que más suelen recurrir a la lactancia artificial.

La mayoría, sí. Los que menos, sobre todo, son los chinos; en su caso, es artificial casi, casi siempre. Siempre les preguntas y te dicen "No, no, materna", pero nada, duran horas, y enseguida pasan a lactancia artificial. [...] También noto que la gente china es muy reservada. Y, por ejemplo, cuando les hablas de la lactancia materna, pues tú les hablas, pero notas que no... no les interesa mucho. [Enfermera 1]

Muy pocas chinas dan el pecho. Y el resto, por lo general, sí. A veces se les ayuda, porque no tienen la subida de leche y tal, pero, vamos, normalmente, excepto las chinas... [Enfermera 2]

Sí, en general, sí, salvo las chinas, que quieren biberón la inmensa mayoría. [Enfermera 3]

En cuanto a la lactancia materna, aparte del caso de las chinas, del que te hablaba antes, el resto, igual que las españolas, a algunas les cuesta más y a otras menos. [Enfermera 5]

Sí, en general recurren a la lactancia materna, sí. [Matrona 2]

Las chinas, por lo general, no. Alguna sí que recurre, esporádicamente, y te dice "Sí, yo, pecho", pero generalmente, no. Y el resto de los grupos varía, como en las españolas. [Matrona 6]

Los motivos por los cuales las usuarias procedentes de China no dan el pecho a los recién nacidos son, según los profesionales, porque las madres deben reincorporarse pronto al trabajo tras el parto o porque envían a sus hijos a su país de origen al poco de nacer. No sabemos si esta información la conocen los profesionales de primera mano o se trata de un rumor que se ha ido difundiendo en el hospital, pues solo uno de ellos comenta haber preguntado directamente a una usuaria china por qué las mujeres de su mismo colectivo suelen preferir la lactancia artificial.

Con las chinas tenemos que insistir, porque ellas dan casi siempre lactancia artificial. Yo no sé cuál es el motivo, yo pensaba que era porque se los llevaban a China, aunque también puede ser por el trabajo, para que mientras están trabajando, alguien les enchufe el biberón. [Enfermera 5]

Nosotros las perdemos de vista a los tres días, porque a los tres días, si todo va bien, se les da el alta, a los partos normales, partos vaginales, pero... pienso, pienso que las gestantes chinas mandan a sus hijos a China con mucha frecuencia y, por eso, en este caso hay mucha lactancia artificial. [Matrona 1]

Pues con el tema de la lactancia materna, las chinas también son muy propensas a dar el biberón porque, según dicen, mandan a los hijos a sus países, a que se críen allí, entonces, claro, no van a instaurar una lactancia, para luego, a las tres semanas, interrumpirla. [Matrona 3]

Generalmente, estas mujeres de China después del parto no les suelen dar lactancia materna. Las que ya llevan muchos años aquí y están más adaptadas a nuestra cultura, pues sí. Pero estas generalmente, no. Yo pienso que es un problema laboral, porque tienen que empezar a trabajar inmediatamente, y trabajan muchas horas. $\mathrm{Y}$, además, a estos niños enseguida cuando pueden los mandan a China y los crían los abuelos. [Matrona 7]

Por ejemplo, con las chinas yo había notado que no daba el pecho casi ninguna, y entonces me dijo una que hablaba bastante bien español que ella sí que le daba. Y yo le dije "Cuéntame por qué las de tu país no les suelen dar el pecho", y ella me comentó que se los llevaban allí a los niños. Yo me quedé alucinado y pensé "iQué desarraigo!". Y ella me explicó que así van con los abuelos y aprenden el idioma, o la 
cultura y tal... Vamos, que esta madre igual no ve a su hijo en años y años o no lo ve más. $Y$, entonces, le pregunté "Y si no tiene abuelos, ¿qué? ¿Se hace cargo el estado?", y me comentó que no, que la señora coge y alquila unos abuelos allí, o sea, paga a alguien para que se haga cargo. Entonces, claro, imagínate. [Obstetra 1]

Además, uno de los profesionales entrevistados cree que la decisión de dar el pecho en las usuarias de China depende del sexo del bebé.

Lo que sí que me llama la atención es que me dijeron que las pacientes chinas, si el bebé era niña, nunca daban el pecho, nunca. Eso era una cosa que siempre... No sé si era casualidad o no, pero sí que lo he notado. $Y$, además, las compañeras de la planta, cuando estás empezando y tal, pues sí que te comentan "Pues, mira, esto es curioso". Y una de las curiosidades en este caso es que, si eran niñas, a los niños, sí, pero si eran niñas, nunca les daban el pecho. [Enfermera 4]

De todos modos, algunos profesionales señalan que cada vez es menor el rechazo por parte de las usuarias de origen chino a la lactancia materna.

Luego, ahora cada vez menos, pero en las chinas era muy frecuente que no quisieran dar el pecho a los recién nacidos, porque la idea era mandarlos de vuelta a China para que su infancia la pasaran allí. Ahora, ya no los mandan tanto, pero por supuesto, si los mandan, pues no les dan el pecho. [Matrona 1]

Las chinas ahora ya suelen dar más lactancia materna natural, antes daban solo artificial, vamos, era algo que directamente... En los chinos, ya te digo que yo he observado mucho el tema de la lactancia. Hace unos años, si era china sabías directamente que no iba a dar el pecho, y ahora yo creo que la gran mayoría lo da. [Matrona 4]

En los chinos he visto un pelín de cambio, porque antes a todas las chinas que les hablabas de lactancia materna te decían directamente que no, y era no, no, no, no. Y ahora empiezan a darla, la lactancia materna. Y eso a mí me demuestra como un poco más de apego. O sea, no es que no quieran a los niños, pero antes nacían y les daban el biberón, y a lo mejor así, en cuanto pudieran, lo mandaban allá con sus familiares. $Y$ ahora parece que... como que están cambiando también un poco las costumbres, que también empiezan a quedarse los bebés aquí. [Matrona 5]

Algunos profesionales mencionan el caso de otras comunidades de usuarias que presentan creencias y comportamientos en cierto sentido atípicos relativos a la lactancia materna.

Hay mujeres... nosotros porque aquí tenemos pocas mujeres de la comunidad hindú, pero ellas se niegan por ejemplo a dar el calostro, porque piensan que es malo. [Enfermera 3]

Por ejemplo, te puedo decir, en el tema de la lactancia, muchas madres africanas piensan que el dar leche artificial a sus bebés es síntoma de riqueza, entonces, lo que intentan es que a sus niños también les nutran, digamos, con esa leche. Como aquí hay una organización que se llama "La Gota de la Leche"248, no sé si la conoces, que les proporciona leche, pues en el caso de muchas inmigrantes tienes que luchar con ellas para que entiendan que, al revés, que su leche es mejor que la que le puedan dar, pero eso es difícil. [Matrona 3]

Las subsaharianas, a lo mejor, son el grupo que tiene más consciencia de que hay que dar el pecho, que funciona, es como que tienen más arraigado que la lactancia materna es lo habitual, ¿no? Pero, a lo mejor, otros grupos, como ocurre con las españolas, pueden pensar que puede no funcionar. Y, en cambio, las

\footnotetext{
${ }^{248}$ El programa La Gota de Leche (que no "Gota de la leche") se propone ofrecer atención fisiológica y dietética para los niños que lo necesiten, desde su nacimiento hasta los catorce meses de edad. La Fundación "El Refugio", situada en la Calle Crespo de Agüero, 1-5 de Zaragoza, la cual tiene como objetivo general actuar en favor de los menores necesitados y de sus familias, colabora en dicho programa. Para mayor información sobre el mismo, véase la siguiente página web: [http://hermandaddelrefugio.es/wp-content/uploads/gl.pdf] (última consulta: 15 de mayo de 2013).
} 
subsaharianas lo ven como algo normal el que funcione, no se llegan a plantear que no pueden dar lactancia. [Matrona 6]

Al respecto de la lactancia (materna o artificial), uno de los profesionales presenta mayor flexibilidad que sus compañeros y destaca el hecho de que en el hospital se tratan de imponer unos horarios para las tomas que no considera adecuados, pues cree que la leche se debería dar a demanda, bien de la madre o del bebé.

$\mathrm{Y}$, sobre todo, en esta maternidad, y si queremos favorecer la lactancia materna, porque yo creo que los horarios no se pueden seguir a rajatabla, no se puede, y esto no lo entiende el personal, de ninguna manera. Mira, en el tema de la lactancia mixta, o en el de la lactancia artificial, aún trabajamos con horarios. Y no sé por qué, porque qué más da, si debería ser cuando te lo pide ella, la madre, o se lo pide el bebé. Qué ganas tenemos de imponer... Porque se ha decidido que tiene que ser cada tres horas. Y a mí, que soy la protestona de la planta, como te habrás dado cuenta, que llevo la contraria a todo dios, pues me canso de decir que el biberón, por favor, hay que darlo cuando lo pida. Y que si ven un biberón que no está terminado, no pasa nada, que ya vigilamos al niño con el peso y ya sabemos lo que hay que hacer en cada caso. Es que se hacen muchos comentarios fortuitos, que no tienen ningún sentido. [Enfermera 5]

Por su parte, la gran mayoría de las usuarias afirman que han recurrido a la lactancia materna.

Sí, sí doy pecho. [África Subsahariana 1]

Sí, sí, prefiero el pecho. Yo, si puedo, le doy el pecho. [África Subsahariana 3]

Sí, sí, yo le doy el pecho. [África Subsahariana 4]

Sí, all children drink my milk. [Asia 3]

Sí, sí doy pecho. [Asia 4]

Sí, sí le doy el pecho. [Europa del este 2]

Sí, sí, ahora solo pecho. [Europa del este 3]

Sí, sí doy pecho. [Europa del este 6]

Sí, le voy a dar el pecho. [Latinoamérica 1]

Sí, sí le doy el pecho. [Latinoamérica 2]

Sí, claro que sí le doy el pecho. [Latinoamérica 3]

Sí, sí le doy el pecho. [Latinoamérica 4]

Sí, sí doy pecho, lo prefiero. [Magreb 1]

Sí, sí doy pecho. [Magreb 2]

Sí, sí, yo doy leche de la madre. [Magreb 4]

Algunas usuarias añaden matices $y$, por ejemplo, una de ellas comenta que va a combinar la lactancia materna con la artificial, u otras explican durante cuánto tiempo darán el pecho a sus hijos, bien por elección propia o por tradición y creencias religiosas.

Yo doy el pecho, pero uso los dos. Cuando le da solo pecho, no es suficiente, porque hay poquito leche y, entonces, uso los dos, también biberón. [África Subsahariana 2]

Sí, pero solo tres meses. Es tradición solo tres meses. [África Subsahariana 5] 
Sí, sí, sí le doy el pecho. Y pienso dárselo al menos hasta un año, si se puede. Pedí una excedencia en mi trabajo para poder hacerlo. Porque, claro, es que mi trabajo es muy... Tengo que ir mañana y tarde, domingos y festivos y, entonces, es que así no puedo darle el pecho. Entonces yo prefiero darle el pecho, aunque tenga que estar uno o dos años sin trabajar. Y mi marido también dice que lo prefiere y... [Europa del este 1]

Sí, sí doy el pecho. En el Corán dice dos años, mejor dos años. [Magreb 3]

Una de las usuarias comenta que la elección de recurrir o no a la lactancia materna puede deberse a cuestiones culturales o personales.

\begin{abstract}
Por ejemplo, a mí también me han preguntado si le voy a dar el pecho o no, porque sé que hay mujeres que no quieren, pero yo sí que se lo doy. Es que, ya te digo, cada uno en función de su educación, de su mentalidad, de su cultura, de las costumbres de donde viene... Hombre, pero si la mujer no tiene leche o tiene problemas y el niño no puede chupar... [Europa del este 5]
\end{abstract}

Por último, de las usuarias que han recurrido a la lactancia artificial, en dos casos se han visto forzadas a ello porque físicamente no producían leche, y solo una de ellas (precisamente procedente de China) afirma directamente preferir dar a su hijo el biberón.

\author{
No, yo preferir biberón. [Asia 1] \\ Yo intento dar leche, pero no salir. [Asia 2]
}

Sí, sí le voy a dar el pecho. En esas estoy, pero no me ha bajado todavía la leche. Y es que como mi hija pesa poco, pues tiene que comer mucho. Me está costando. Ha salido el líquido este que sale primero, pero parece que todavía no me baja la leche. Cuando parece que ella ya se va agarrando y se va alimentando, me baja muy poco. [Latinoamérica 5]

Otra de las cuestiones que planteamos a los profesionales en relación con el puerperio se refiere a si las usuarias inmigrantes suelen seguir los programas de vacunación infantil. Por sus respuestas, descubrimos que en el hospital tan solo se ocupan de suministrar la primera vacuna a los recién nacidos y que el resto ya se suministran en los centros de salud, por lo que los profesionales entrevistados nos pueden ofrecer poca información con respecto a esta cuestión.

\footnotetext{
Si siguen los programas de vacunación infantil, yo supongo que sí, pero eso bueno, es más en los centros de salud. Es que aquí solo se les pone la primera vacuna contra la hepatitis B cuando llegan y se les pregunta y, por lo general, aceptan ponerla. [Enfermera 2]
}

Y la vacunación, aquí solo les ponemos la primera vacuna y luego ya... [Matrona 2]

Pues, de la vacunación, como aquí solo se hace la primera vacuna, pues no te sabría decir. [Matrona 7]

Solo uno de los profesionales entrevistados menciona a las usuarias de la comunidad china porque opina que son las que más se suelen negar a que se les suministren las vacunas a sus hijos.

Y en cuanto al tema de las vacunas, aquí les ponemos la primera. Y volvemos a lo mismo, en españoles o en gente musulmana y gente de color, pues normalmente no te ponen ningún impedimento. Por regla contraria, la gente oriental, que además son los que más riesgo tienen de hepatitis $B$, son los que más se niegan a ponerla. [Enfermera 1] 
Esta información de la que no podíamos disponer entrevistando a los profesionales nos la proporcionan las usuarias, las cuales afirman en su totalidad que sí que siguen o van a seguir los programas de vacunación infantil.

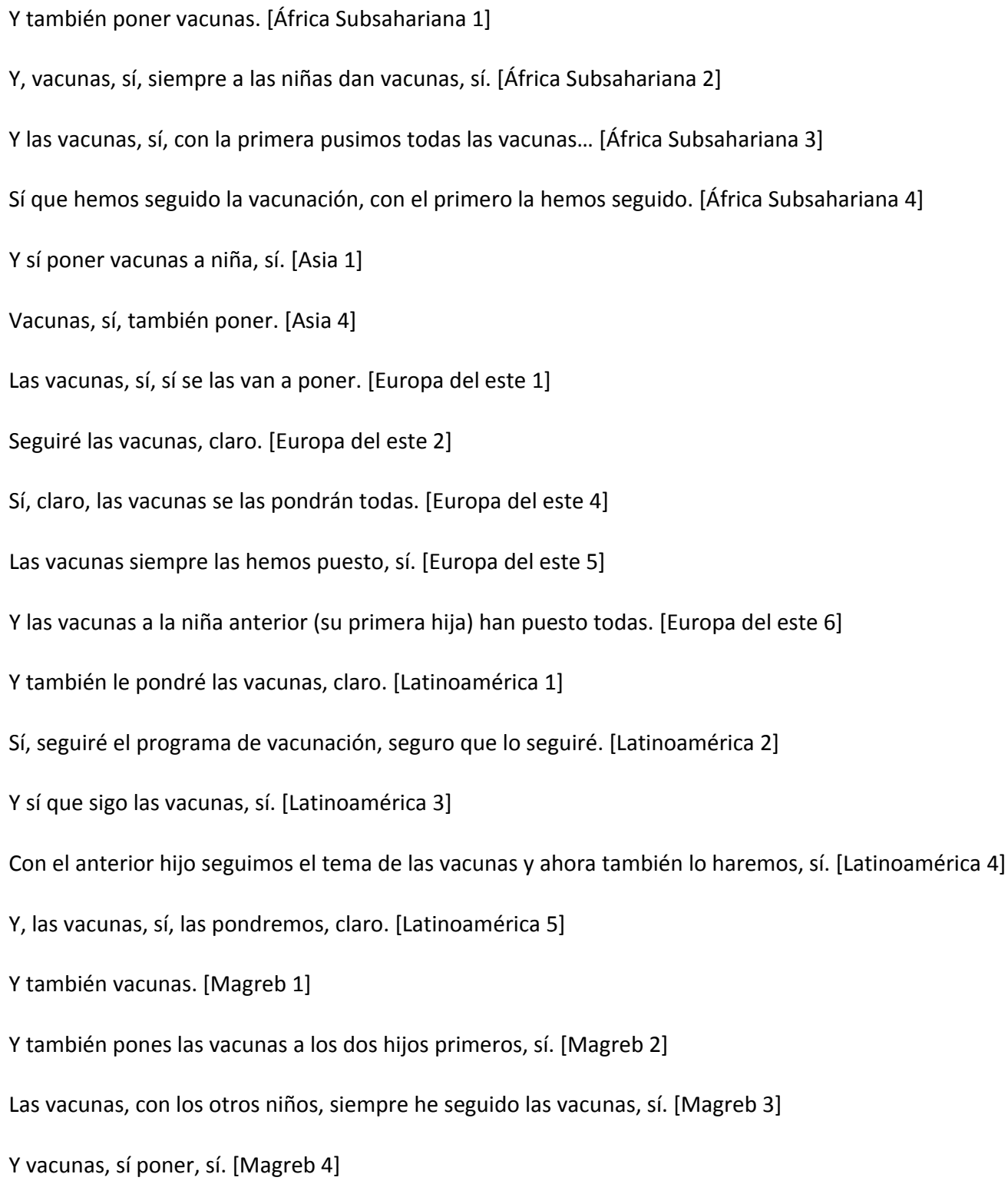

El último aspecto relacionado con el puerperio que vamos a analizar se refiere al sistema de registro de los recién nacidos. De nuevo en este caso la mayoría de los profesionales entrevistados pueden ofrecernos poca o ninguna información al respecto, porque son los profesionales socio-sanitarios encargados de información los que se ocupan de estas cuestiones. ${ }^{249}$ No obstante, algunos profesionales creen que las usuarias inmigrantes no suelen tener problemas con el registro de sus hijos.

Yo creo que, en un principio, no, pero tampoco las mujeres españolas lo conocen demasiado bien. Se les explica... hay una compañera de información que, un poquito después del parto, les explica, bueno le

\footnotetext{
${ }^{249}$ Cabe recordar que, dentro del grupo de profesionales entrevistados en nuestra investigación, se encuentran dos profesionales socio-sanitarios encargados precisamente de labores de información, entre las cuales se incluye el sistema de registro de los recién nacidos.
} 
explica generalmente a la pareja todos los trámites que tienen que llevar a cabo. No es difícil, así que no... no suele haber problemas. [Matrona 1]

No sé si los conocen, porque las matronas no los explican, sino que es la de información cuando da los papeles. Entonces, no te puedo decir. [Matrona 2]

Pues la verdad es que sobre esto no te sabría decir, porque como siempre es la persona de información la que habla con los maridos, pues no te sé decir. Ella es la que se encarga de mantener la comunicación entre los familiares que están abajo y aquí. [...] Y va un poco entre nosotras y la familia dando información. Luego, cuando acaba el parto, ella se lleva el papel del juzgado y es la que se pone en contacto con el marido para decirles cómo tienen que hacer. [Matrona 3]

Pues no sé, esto no te lo sabría decir, porque aquí no... [Matrona 4]

Pero es que eso... nosotras ya no... Nosotras lo que hacemos es rellenar el documento en el que ponemos las huellas del bebé y de la madre, y les explicamos que eso es para el registro civil, y luego ya la persona que está en información se encarga de que lo entiendan bien, del plazo que tienen para ir, les hace firmar en el libro como que han recogido el papel... Y, vamos, yo creo que con eso no hay problemas, que lo entienden perfectamente. [Matrona 7]

Además, algunos profesionales opinan que el entendimiento del sistema de registro dependerá de si las usuarias han tenido previamente otros hijos en España, de la información que les proporcionen sus redes sociales, o de sus conocimientos del español.

Depende. Me imagino que las que hayan tenido hijos anteriores sí que lo conocerán. Y las que no, pues aquí hay siempre una señora en información y les explica cómo funciona. Pero yo creo que a veces sí que vienen un poco desorientadas. Pero vamos, yo creo que los de aquí, si se trata de su primer hijo, tampoco saben cómo se hace. [Matrona 5]

Pues, de eso... ni idea. Supongo que a los subsaharianos les costará más, pero yo creo que será por el idioma, o por... sí, la burocracia, muchas veces tienes que ir de aquí a allá, y se lo explican, pero a lo mejor los subsaharianos, siempre por problemas lingüísticos, pues a lo mejor no lo entienden, porque no entienden el idioma. [Matrona 6]

Lo conocen porque tienen gente que se lo ha explicado. Porque nosotros intentamos explicárselo, les subrayas, les escribes, pero no... Muchas veces te das cuenta de que no saben leer ni escribir. [Profesional socio-sanitario 3]

Esta opinión de los profesionales coincide con la información que nos ofrecen las usuarias inmigrantes entrevistadas. Aquellas que han tenido previamente un hijo en España o tienen redes sociales que les ayudan con los trámites parecen no haber tenido grandes problemas a la hora de registrar a sus bebés.

Yo ahora he pedido mi cuñada, mi cuñada es española, que rellenar todo y ella ayuda. [África Subsahariana 2]

Sí, sí lo conozco, como ya es el tercero... [Comunidad gitana]

Bueno, lo conoce mi cuñada, lo va a hacer ella. [Europa del este 3]

Sí conozco, porque este es tercer hijo. [Magreb 2]

Sí conozco, sí. Este es el tercer hijo que nace en España. [Magreb 3]

Sí, sí, ya conocer por otra hija. Me dan todo aquí esta mañana y ahora tener que ir al registro civil. [Magreb 4] 
Sin embargo, otras usuarias consideran que el sistema de registro de los recién nacidos es complicado, bien porque la burocracia es excesiva ${ }^{250}$ o porque no cuentan con conocimientos suficientes de español.

Yo creo que hay mucha información, demasiada, buff... (Risas). En Nigeria es diferente, es más fácil. Tú sabes que en mi país es en inglés, y entonces tú puedes leer y no hay muchos documentos, pero aquí sí hay muchos, para empresa y para todo, es muchos... [África Subsahariana 2]

Es que... al final te pierdes un poco. Mi marido ha tenido que preguntar, hemos tenido que informarnos, porque te pierdes un poco los pasos, y tienes que informarte más y pierdes más tiempo. [África Subsahariana 3]

El tema de registro es un lío. La verdad es que nosotros que somos extranjeros tenemos un lío que... [África Subsahariana 4]

I find it difficult, it is hard. Because of the language. [Asia 3]

No, no conoce. Es difícil. Hay muchos papeles. [Asia 4]

Al respecto de la dificultad en los trámites para registrar a sus hijos, una de las usuarias entrevistadas, concretamente procedente de Nigeria, cuenta un episodio vivido por su marido en el que ni siquiera las personas encargadas del registro parecían estar de acuerdo en qué documentos eran necesarios en el caso de los niños nacidos de padres inmigrantes.

Mi marido me contó que fue ayer y que le han pedido tantos documentos, que no los necesitaba, no sé si es para verificar que realmente tenemos todos los documentos o no sé... Vamos, un lío, que le hicieron volver en casa y todo... Por ejemplo, le pidieron certificado de matrimonio de mi país, aunque en la libreta ya figura que estamos casados. Y, además, si el primero lo registraron con el certificado y con todo, yo creo que para el segundo no es necesario otra vez. Luego se fue a la Seguridad Social para inscribirlo y la mujer que le atendió lo primero que le pidió fue el pasaporte y volvió a casa para coger el pasaporte. Volvió a la Seguridad Social y le tocó otro chico, y este chico le dijo "¿Para qué necesito el pasaporte?". Que es un lío, es que un lugar donde trabajan dos personas y una te pide una cosa y la otra te pide otras... [África Subsahariana 4]

La mayoría de las usuarias entrevistadas afirman que son sus maridos quienes se suelen encargar de registrar a sus hijos. De hecho, algunas no conocen el sistema de registro.

Mi marido hace todos los documentos. [África Subsahariana 2]

Esto lo hace todo él (la usuaria señala a su marido). [África Subsahariana 3]

Va mi marido a registrar bebé. Eso hace mi marido, yo no sé... [África Subsahariana 5]

Eso todo lo hace mi marido. [Europa del este 1]

La verdad es que no lo conozco. Está haciendo todos los papeles mi esposo ahora mismo, pero no... no lo sé. [Latinoamérica 3]

Sí, aunque eso lo lleva mi esposo, que siempre está... [Latinoamérica 4]

No sé cómo funciona, pero ya lo hemos hecho. Aquí, abajo, le explicaron a mi marido lo que tenía que hacer y ya está todo hecho. Le explicaron que hay que ir aquí a la planta baja, y luego al registro, a la Seguridad Social... Justo anda en eso, en la Seguridad Social, ahora. [Latinoamérica 5]

\footnotetext{
${ }^{250}$ En relación con el tema de la burocracia, véase también el subnodo dedicado a esta cuestión dentro del nodo de Asistencia sanitaria general presentado previamente.
} 
La última cuestión relativa a este tema se refiere a si el sistema de registro de los recién nacidos es igual en España que en el país de origen de las usuarias entrevistadas. Algunas, principalmente las procedentes de Europa del este, desconocen esta información, pues residen en España desde hace mucho tiempo o no han tenido ningún hijo en sus respectivos países.

Y no sé si es igual o diferente al de mi país, porque yo el de ahí no sé cómo es... [Europa del este 1]

No sé si es igual o distinto al registro en mi país, no tengo ni idea. Es que mi hermana tuvo una hija también el año pasado, pero lo tuvo aquí en España, así que no sé cómo funciona en Rumanía. [Europa del este 2]

No sabemos si es igual en Rumanía, no sabemos... [Europa del este 3]

Y no sé si es distinto o igual en Rumanía. [Europa del este 4]

Sí, sí conozco y no sé si en Rumanía es diferente, no lo sé. [Europa del este 6]

Me he leído unos papeles que me han dado y, sí, me ha quedado todo claro. No sé si es igual o diferente al de mi país, porque yo vine muy pequeña y... [Latinoamérica 1]

No sé si el sistema (de registro) es igual o diferente en Ecuador, eso no lo sé. [Latinoamérica 4]

Las usuarias procedentes de Magreb opinan que el sistema es sencillo y similar al que existe en sus países de origen.

Sí, conozco, sí. Creo que este sistema es igual que en Marruecos. [Magreb 1]

En Argelia pienso es igual. [Magreb 2]

Creo que este sistema es sencillo y es parecido al sistema en Argelia. [Magreb 3]

En Mauritania es así también. Cuando ha nacido un chico o una chica, tener que ir al registro civil para los papeles. [Magreb 4]

Por el contrario, algunas usuarias procedentes de África Subsahariana, Asia y Latinoamérica exponen diferencias en cuanto al registro de los recién nacidos, principalmente relacionadas con el nombre que va a recibir el bebé (por ejemplo, cuándo se decide dicho nombre, si incluye o no los apellidos de ambos padres, a quién se debe comunicar y a quién no, etc.)

En mi país es diferente. Cuando yo estar en mi país, ahora yo no sé, cuando nace un hijo no se pone la huella. También se pone nombre y se hace certificado de nacimiento y todo, pero la huella no se pone. Ahora yo no sé, puede ser cambiado. [África Subsahariana 1]

(Le pregunto cómo hacen para registrar al bebé si, tal y como me ha contado al inicio de la entrevista, no le suelen poner el nombre hasta el octavo día). No, pero para los papeles sí que damos el nombre, lo que no hacemos es darlo en público, pero para los documentos, sí, para las cosas administrativas y esas cosas, sí. Hasta en mi país también se hace. Cuando nace, a la Administración sí que damos el nombre, pero al resto, no. (Le pregunto si deciden el nombre mientras está embarazada). Sí, sí, si sabemos el sexo, sí. Solemos dar el nombre de una persona querida, puede ser un amigo, tus papas, tus abuelos, puede ser de quien sea... [África Subsahariana 4]

En China yo no hecho nunca, pero pienso es igual. La diferencia es que en China puedes decir nombre después de unos días y apellido solo por su padre. [Asia 2]

Pakistan is not like this. Solo apuntar el nombre and date. [Asia 3] 
Es diferente al de mi país, en el sentido en que los apellidos, por ejemplo, en Brasil puedes poner los apellidos que quieres, puedes poner el primero y el segundo, solo el primero, solo el del padre, solo el de la madre... Y aquí no, ¿verdad? Aquí tienes que poner el del padre y el de la madre. A mí me gustaría, si se puede, ponerle a mi hijo primero mi apellido. $Y$ el sistema de nombres creo que también es diferente. Porque me han dicho que aquí no se pueden poner algunos tipos de nombres, ¿no? En Brasil se puede poner el tipo de nombre que quieras. Y esto es un problema también, porque, por ejemplo, en Brasil, han tenido casos como el de un niño que los padres se conocieron por el Facebook, y le han puesto al niño Facebook's son y entonces... (Risas). Es que yo creo que eso es ofensivo al niño, ¿no? Pero, por otro lado, no creo que sea un problema poner al niño un nombre, por ejemplo, extranjero, y yo creo que aquí tienes que poner el nombre correspondiente que hay en España y eso... Es que yo no creo que sea un problema poner al niño un nombre que es extranjero; el problema es poner un nombre que es ofensivo al niño o que le puede causar algún problema y tal, pero... Hay que respetar la individualidad, ¿̇no? [Latinoamérica 2]

Y no sé si es igual o diferente al de mi país. Me parece que es diferente, porque, por ejemplo, aquí, el día que nacen ya necesitan el nombre, en cambio, en mi país, hasta el día que nacen no sabemos si es niña o niño, entonces el nombre no lo has podido decidir. Se decide una vez nace, cuando uno ya lo va a inscribir. Y aquí yo me enteré ya a los cinco meses que tenía una niña, entonces... [Latinoamérica 3]

En Honduras es distinto, sí. Allá uno se va a casa cuando le dan el alta y va al registro cuando quiere. $Y$ pasa un año, dos años, y hay niños que no los inscriben. Aquí, tres días creo que dan. Tres u ocho días al máximo. Allá uno puede escoger el nombre hasta el año, es decir, puede parir y al año decidir, y aquí, no. Aquí a uno le piden el apellido del papá, si lo tiene, y si no, el de la madre, y sí lo exigen aquí, y está muy bueno eso. [Latinoamérica 5]

\subsubsection{Barreras lingüísticas y soluciones}

A continuación, pasamos a analizar las barreras lingüísticas que pueden existir en la comunicación entre los profesionales sanitarios y las usuarias inmigrantes, así como las soluciones adoptadas por el hospital contexto de estudio para superar dichas barreras. Dividimos el análisis de este nodo en los subnodos o subtemas que se muestran en esta captura de pantalla de nuestro proyecto con NVivo 10:

CATEGORIAS CONCEPTUALESO TEÓRICAS
INTRODUCCIÓN
INTERACCIÓN
EMBARAZO, PARTO PUERPERIO
COMENTARIOS SOBRE COMUNIDADES INMIGRANTES ESPECIFI
BARRERAS LINGOISTICASY SOLUCIONES
OSOLUCION 4 _INTERPRETACION TELEFONICA
SOLUCION 3 _INTERPRETES PRESENCIALES
SOLUCION 2_FAMILIARES Y AMIGOS
SOLUCION 1_GESTOS Y DOCS TRADUCIDOS
REQUISITOSBUEN INTERPRETE
PROFESIONALES Y DOMINIO OTROS IDIOMAS
PAPEL Y FUNCIONES DEL INTERPRETE
OTRAS SOLUCIONES
LENGUAJE ESCRITO

\begin{tabular}{|l|l|}
\hline 49 & 1746 \\
\hline 49 & 15 \\
\hline 49 & 3 \\
\hline 48 & 2 \\
\hline 24 & 3 \\
\hline 46 & 3 \\
\hline 20 & 4 \\
\hline 32 & 1 \\
\hline 43 & 1 \\
\hline 43 & 2 \\
\hline 20 & 3 \\
\hline 28 & 12 \\
\hline 10 & 14 \\
\hline 11 & 22 \\
\hline 19 & 1 \\
\hline 52 & \\
\hline
\end{tabular}

\begin{tabular}{l|l|l}
\hline 1746 & $02 / 02 / 201312: 31$ & AN \\
\hline 154 & $02 / 022201312: 51$ & AN \\
\hline 530 & $02 / 02 / 201312: 52$ & AN \\
\hline 331 & $02 / 02 / 201312: 51$ & AN \\
\hline 240 & $04 / 02 / 20137: 08$ & AN \\
372 & $02 / 02 / 201312: 52$ & AN \\
\hline 34 & $04 / 02 / 20136: 27$ & AN \\
\hline 41 & $04 / 02220136: 26$ & AN \\
\hline 127 & $04 / 02 / 20136: 26$ & AN \\
\hline 102 & $04 / 02 / 20136: 26$ & AN \\
\hline 21 & $04 / 02 / 20136: 27$ & AN \\
\hline 34 & $04 / 02 / 20136: 41$ & AN \\
\hline 12 & $04 / 02 / 20136: 27$ & AN \\
\hline 14 & $18 / 022201317: 09$ & AN \\
22 & $04 / 02220136: 40$ & AN \\
\hline 192 & $04 / 02220136: 25$ & AN \\
\hline
\end{tabular}

Gráfico 6.28. Subnodos del nodo BARRERAS LINGÜÍSTICAS y SOLUCIONES

Antes de iniciar el análisis propiamente dicho de este nodo, cabe recordar que las barreras lingüísticas constituyen un tema de preocupación para los sujetos estudiados, especialmente para los profesionales sanitarios, los cuales, como hemos señalado previamente, dedican un 
gran espacio desde el inicio de sus entrevistas a hablar de esta cuestión. ${ }^{251}$ De hecho, como hemos visto en el análisis de los nodos anteriores, numerosos profesionales consideran que estas barreras son la causa de la gran mayoría de los problemas a los que deben enfrentarse en la asistencia a usuarias inmigrantes, y opinan que el desconocimiento del idioma por parte de algunas de ellas impide que comprendan los tratamientos a seguir, que conozcan el funcionamiento y las normas del centro, que sean capaces de seguir los procedimientos burocráticos (como el sistema de citas o el de registro de los recién nacidos), o que entiendan algunas de las técnicas que se les van a aplicar (como es el caso de la anestesia epidural).

Asimismo, partiendo de los datos demográficos de los profesionales entrevistados que hemos presentado en páginas anteriores, cabe recordar que la lengua materna de todos ellos es el español, y que las lenguas extranjeras habladas por los profesionales sanitarios no se corresponden en la mayoría de los casos con las lenguas maternas de las principales comunidades de usuarias inmigrantes residentes en la ciudad donde se lleva a cabo el estudio. Además, a pesar de que muchos afirman presentar conocimientos de inglés y francés, así como algunos de otras lenguas (como el alemán, el árabe, el catalán o el italiano), en la mayoría de los casos se trata de conocimientos básicos, por lo que probablemente no serían suficientes para mantener una comunicación fluida y efectiva con las usuarias alófonas.

De hecho, y pasando ya al análisis de las respuestas de los profesionales en relación con este tema, vemos cómo son ellos mismos los que opinan que sus conocimientos de lenguas extranjeras no son una solución para superar las barreras lingüísticas presentes en la comunicación con algunas usuarias inmigrantes.

Mi inglés no es que sea algo maravilloso, pero si te viene una persona que hable inglés $y$, así, te puedes comunicar, aunque sea diciendo "Yo gran jefe indio ser", más o menos así te puedes comunicar. [Anestesista 3]

$Y$ es que a una española, aunque también depende a veces del nivel cultural que tengan, pero normalmente se lo puedes hacer llegar a entender, pero aunque tú hables algo de un idioma, si no lo conoces perfectamente, a duras penas vas a poder explicarle la técnica en un lenguaje llano. [...] Entre que nosotros no somos un país muy ducho para los idiomas y, a veces, por ejemplo, vienen del norte de África y saben francés, y justo aquí no hay nadie que hable francés, solo inglés y a duras penas... [Anestesista 4]

La gente más joven tenemos el inglés, pero claro, según también su nivel cultural, es muy difícil comunicarse en inglés, porque en árabe, evidentemente, nosotras vamos más bien justitas. $Y$ entonces, en inglés lo puedes llegar a intentar, pero... [Enfermera 1]

También es verdad que estos últimos (refiriéndose a los pacientes "árabes y de color" que acaba de mencionar) a veces se desenvuelven en francés, que nosotros los más jóvenes lo tenemos un poco más perdido, porque nos hemos centrado más en el inglés... [Enfermera 1]

Por ejemplo, cuando el paciente sabe inglés, pues puedes buscar a alguien, porque aquí las jovencitas todas saben algo de inglés. [Enfermera 6]

Porque a veces tú puedes saber un idioma, hablarlo medio decente, pero a nivel sanitario no saber decir nada. Por ejemplo, a mí ahora me pasa algo en Estados Unidos, y me llevan al hospital y se me ponen a hablar en inglés, y yo te digo "Sí, sí. Claro, claro"... [Matrona 4]

\footnotetext{
${ }^{251}$ Véase, por ejemplo, la tabla que aparece en la introducción del apartado en el que presentamos los datos conceptuales o teóricos de las entrevistas, en la cual se observa, por el tamaño del recuadro centrado en las barreras lingüísticas, que estas son uno de los nodos en el que más unidades de análisis han sido codificadas.
} 
Pues le preguntas si habla inglés, aunque no sea mucho, pero con unas poquitas palabras... O si habla algo de árabe... [Matrona 6]

Porque, a ver, si viniera gente de según qué países que hablan inglés y tal, pues no tendríamos tanto problema. Pero la gente que viene normalmente no habla inglés. Entonces, no... es muy difícil entenderte con ellas. [Obstetra 2]

Igualmente, la mayoría de las usuarias entrevistadas comentan que los profesionales sanitarios no suelen emplear sus respectivas lenguas maternas a la hora de comunicarse con ellas, y que solo en algún caso emplean alguna palabra concreta en dichos idiomas.

Que yo sepa, no... Siempre me han hablado en español. [África Subsahariana 4]

No, no... Hablan español. [África Subsahariana 5]

No, nada chino. [Asia 1]

No, no sabe chino. [Asia 2]

Saben poco. Dicen "Ni hao". Solo eso. [Asia 4]

Sí, el médico que viene sabe decir "Hola" y luego... ¿Qué más ha dicho? Creo que ha dicho "¿Qué tal?". Bueno, lo ha dicho en ruso, pero es casi igual. [Europa del este 1]

Sí, ayer en la sala de dilatación sí que me dijo alguna palabra en rumano la matrona, como "Empuja" y "Respira". [Europa del este 2]

Sí, hay una tocóloga que sabe algo... algunas palabras. [Europa del este 4]

No, no creo. No tiene ningún sentido para aprender. Aunque hay tantos extranjeros, el rumano no es una lengua importante. Hombre, puede ser que con el tiempo a lo mejor por el trabajo, pues sí que hay gente que puede aprender algunas palabras, por ejemplo, "Buenos días". Hombre, el médico que ha venido antes sí que dice algunas palabras. Probablemente como ha atendido a tantos rumanos, pues ha aprendido dos o tres palabras, pero... Hablar rumano, no, no creo. [Europa del este 5]

Yo nunca les he oído decir nada en rumano. [Europa del este 6]

No, antes, sí estuve ingresada y había una mujer que hablaba un poco de árabe, pero aquí, no. [Magreb 1]

Yo no he visto médicos que hablan francés o árabe. [Magreb 2]

En árabe, no. El árabe es difícil. Me dijeron que en el pasado había médicos que estudian árabe, porque venía gente del norte de África para operarse de los ojos. Si alguien habla tu lengua, facilita el trabajo. [Magreb 3]

¿Médico aquí? ¿̇ enfermeras? No, no, no árabe y no francés. Solo español. [Magreb 4]

Algunas de las usuarias entrevistadas comentan al respecto que en ocasiones se recurre al inglés o al francés como lenguas vehiculares en la comunicación con ellas, tal y como habían señalado también algunos profesionales sanitarios. No obstante, cabe recordar que estos últimos reconocen que sus conocimientos de estas dos lenguas tampoco son siempre tan amplios como para poder comunicarse eficazmente con las usuarias alófonas.

En beni no saber nada, en inglés, algunos sí. [África Subsahariana 1]

Aquí nadie habla en inglés, no sabe. Pero mi médico del centro (de salud), él sí sabe. [África Subsahariana 2] 
And some doctors speak some English, so I can speak English. No Urdu. But English, sí. Young doctors can speak English. They don't know Urdu or Punjabi. They are new for them. [Asia 3]

Por ejemplo, el médico que ahora pasa estaba también cuando tuve mi anterior hija en 2007, y él habla francés. [Magreb 3]

Pasamos a continuación a analizar la opinión de los profesionales y las usuarias en cuanto a las barreras lingüísticas que pueden encontrarse a la hora de comunicarse entre ellos. Como ya habíamos comentado con anterioridad, los profesionales sanitarios en general presentan dos opiniones discordantes.

Por una parte, algunos profesionales restan importancia a estas barreras y consideran que actualmente son muy pocas las usuarias que no hablan nada de español y que siempre, en uno u otro modo, han conseguido comunicarse.

De todos modos, la verdad es que encontrarte con una paciente que no sepa nada, nada, nada de español es difícil. Todas saben alguna palabra. [Anestesista 5]

Yo, sobre todo, he tenido problemas de comunicación. Aunque cada vez tengo menos, porque cada vez hablan más. [Enfermera 4]

Y ellos, además, se arreglan, raro es el caso en que no saben decir nada en español. [Enfermera 5]

Es que, claro, yo no creo que la comunicación de la paciente con la matrona sea solamente lingüística, a veces es más importante la comunicación visual. Vamos, para simplemente entenderte, yo creo que te puedes entender con cuatro palabras, que son las que te sirven para saber si hay alguna patología o si todo entra dentro de la normalidad. Y para acompañarla, pues no hace falta... A veces es más la empatía que puedas crear. [Matrona 2]

Mi experiencia es amplia, por supuesto, porque llevo mucho tiempo con ellas y... en general, no he tenido ningún problema de ningún tipo. O sea, no he tenido ningún problema a la hora de relacionarme con ellas, pero de comunicación sí, muchas veces sí. Pero, a pesar de eso, siempre hemos llegado a un... no sé, a una especie de acuerdo a la hora de comunicarnos, de entendernos, por gestos o como sea nos hemos llegado a entender siempre. [Matrona 4]

Pero aquí, si ni ella entiende ni el acompañante tampoco, pues entonces... Me parece raro que nadie entienda. [Matrona 5]

La dificultad con las usuarias inmigrantes únicamente estaría en la comunicación, pero realmente para hacerle un control de constantes a una paciente embarazada o para hacerle un test basal, tampoco necesitas grandes comunicaciones. [...] Pero, vamos, el desconocimiento del idioma no supone un problema a la hora de realizar pruebas. [Matrona 7]

Yo diría que siempre de algún modo esa barrera la hemos conseguido superar. Y, fíjate, que hemos tenido gente de todas partes, y nunca he tenido problema para comunicarme. Yo creo que la comunicación depende de cada uno, si uno quiere comunicarse, por un medio o por otro lo conseguirá. [Obstetra 1]

Pues el tema del entendimiento, del idioma quiero decir, no es fundamental, no. El idioma, no. Porque ellos lo entienden, yo creo que son más espabilados que nosotros, vamos que te entienden... $Y$, además, normalmente entre ellos se ayudan y se pasan la información y, si tienen algún problema, pues van a ver a la trabajadora social. [Profesional socio-sanitario 2]

De todas formas, ellos siempre hay alguna que otra palabra que la entienden. Son pocos, muy pocos los casos en los que no dicen ni una palabra. [Profesional socio-sanitario 2]

Son pocos los casos en que los que vienen no hablan nada, nada de español. [Profesional socio-sanitario 3] 
Al respecto de estas observaciones realizadas por algunos profesionales, cabe señalar que, al contrario de lo que estos opinan, tanto durante la observación no participante como en el proceso de selección para las entrevistas, sí se hallaron casos de usuarias cuyos conocimientos de español eran mínimos, por no decir inexistentes. Además, como veremos a continuación en las respuestas ofrecidas por otros profesionales, sí que se han dado en el hospital contexto de estudio casos de usuarias con poco o nulo dominio de la lengua del país de acogida.

Por otra parte, están aquellos profesionales (una gran mayoría) que consideran que las barreras lingüísticas suponen un obstáculo importante, incluso el mayor obstáculo al que deben hacer frente en la asistencia a usuarias inmigrantes, ya que el hecho de no conocer el español impide que estas entiendan las explicaciones del personal sanitario o que ellas mismas se puedan expresar.

Hay un problema de idioma importante. [...] Yo creo que el problema principal es la comunicación, el no poder expresar, [...] ellas esa sensación de presión que se tiene continuamente aunque se les haya aplicado la epidural no la saben o no la pueden expresar. Porque ellas no entienden completamente lo que nosotros les decimos [...] yo creo que eso es lo que más cuesta que entiendan. [Anestesista 1]

Los problemas con estas usuarias son mayores. Sobre todo con aquellas que no entienden español y no hablan. Pero sobre todo con las que no entienden, porque no les puedes explicar nada de lo que les vas a hacer. Nosotros necesitamos que ellas colaboren y nos den una serie de datos y poder explicarles un poco en qué consiste lo que les vamos a hacer. [Anestesista 2]

Buffff... En la parte que nos compete a nosotros, el $99 \%$ de los casos para mí se debe a problemas de comunicación, porque si tienen algunas enfermedades o algunas cosas que tú no conoces, pues hay muchas veces que no hay manera humana de saberlo, entonces dices “¿Qué hago?” y “¿Cómo lo hago?”. [...] El desconocimiento de la lengua creo que es, al menos para mí, una cosa fundamental. El prestar una atención correcta a una persona que no sabes con qué te puedes enfrentar, esto es como irte... yo que sé... como irte a la sabana y decir "Vamos a ver si tengo a los lobos ahí esperándome". [Anestesista 3]

Pero es que hay gente que les preguntan "¿Hablas castellano?” Y es que no hablan nada de nada, y entonces, ¿con esas personas qué haces? ¡Es que no hay manera! [Anestesista 3]

Te dicen "Epidural. ¡Dolor, dolor! ¡Quitar dolor!”, que es lo único que te pueden decir, pero tú no puedes explicarles ni qué es, ni los riesgos, ni por qué no se la puedes poner. [...] El mayor problema es la falta de comunicación, yo creo. [Anestesista 4]

El problema es que se les intenta explicar, pero no es posible que se les queden las cosas lo mismo. Si yo estuviera en otro país y me intentaran explicar un tratamiento, podría entenderlo, pero seguro que no de la misma manera que si me lo explicaran en mi idioma. [...] y muchas veces, a lo mejor por no molestar, o porque se sienten incómodas, pues no preguntan. [Enfermera 1]

Pues hay algunas que no hablan español, vamos, que no te entienden. [Enfermera 4]

Yo me he encontrado muchos casos, muchísimos, de pacientes que hablaban poco o nada de español. [Enfermera 6]

El idioma, total, en general. En muchas ocasiones es muy difícil comunicarse. [Matrona 1]

La asistencia a estas usuarias sí que es más difícil por lo general con respecto a las autóctonas. El idioma es una barrera importante. [Matrona 4]

Es que sobre todo es la barrera del idioma... No tanto aquí, pero cuando vienen al tocólogo a las consultas prenatales, sobre todo vienen muy anémicas todas. $Y$ tú les dicen que se tomen el hierro, pero, a veces, a lo mejor es que, como no te entienden, pues no se lo toman. [Matrona 5] 
La imposibilidad para comunicarse con determinadas usuarias puede provocar sentimientos de hastío, enfado y frustración en los profesionales, tal y como podemos observar en las siguientes citas:

Yo, en estos casos, me enfado mucho conmigo mismo. Porque lo primero que pienso es si eso me va a conllevar a mí un problema que yo no quiero que tenga. Entonces, con eso, ¿qué haces? [Anestesista 3]

Yo creo que hemos llegado a una situación ya de hartazgo, que estamos hartos ya de lidiar todos los días con las mismas situaciones... Particularmente, en mi caso, para mí lo peor es la barrera idiomática, porque es doble esfuerzo... Ya con el trabajo físico que haces, más el psicológico, porque nuestro trabajo como matronas requiere mucha implicación... de mente. Requiere mucha atención, porque tienes que estar pendiente de la salud de la madre y de la salud del que está dentro, por lo que requiere muchísima atención. $Y$ a todo eso sumarle el esfuerzo de entenderte con una persona que no entiende tu idioma, y que encima culturalmente es distinta... Y entonces hay días que dices "No puedo más", es verdad... $Y$, entonces, eso creo que ha llevado... sobre todo a la gente más mayor, que han llegado a un punto en el que dicen "Oye, que paso ya"... [Matrona 4]

Porque, claro, hablar con ellas para mí es un esfuerzo adicional, el tener que intentar que te entiendan. Porque tú te comunicas y supones que el feedback con la otra persona es bueno, y que la comunicación verbal también, pero a veces ves que te están diciendo que sí y es que no... Y es que son unos papeles que yo no me conformo con darlos y ya te buscarás la vida, porque es importante que sepan hacerlos, entonces... Para mí es muy complicado, lo es. [...] Por ejemplo, hay personas que te vienen no por el tema de los papeles, sino buscando a una persona, y les dices "Dime el apellido", y te contestan "Jacamelán", y tú te quedas con una cara y les dices "¿Lo sabes escribir?", y te dicen "No"... Y, entonces, yo me agobio, ¿eh?, me agobio en el sentido en que dices "Buffff". Es que no son dos minutos lo que te cuesta encontrar así a un paciente, te puede llevar diez o quince minutos, y es más, se enfadan, porque dicen "Pues tal paciente está aquí". Y seguramente está, pero como nuestro medio para encontrarlo es el ordenador, y no te sale, pues entonces, es... complicado. Es... frustrante, esa es la palabra, frustrante. [Profesional sociosanitario 3]

No obstante, algunos profesionales señalan que existen situaciones y áreas del hospital en las que la comunicación con las usuarias cobra mayor relevancia que en otras, ya que en estas últimas parece que consiguen desempeñar su labor a pesar de no poder comunicarse adecuadamente con las usuarias alófonas.

Problemas (de comunicación) durante el parto... no. Porque realmente hablamos muy poquito con ellas durante el parto, una vez les has puesto la epidural, vas entrando de vez en cuando para ver si todo va bien, y al final con gestos o por ahí, si no te entienden mucho, te dicen “iBien!” (hace un gesto de OK con la mano), o te dicen que no, que les duele, y entonces intentas solucionar el problema... [Anestesista 4]

Claramente no en la urgencia, pero cuando algo no es estrictamente necesario, aunque sea altamente recomendable para el confort de la madre y del niño, pues no puedes hacérselo entender, principalmente por el idioma, y también por la cultura médica. [Anestesista 4]

Y eso, lo que más te asusta, vamos, donde siempre llamamos al traductor, es con el tema de las alergias, las alergias de medicamentos y demás... Y en general, intentar no dañar, por ejemplo, en el caso de que ella tenga que tomar algún tipo de decisión y no pueda hacerlo por no entendernos, ¿̇abes? [Enfermera 1]

El primordial problema de este tipo que tendríamos sería nada más llegar la mujer a su ingreso en la planta, cuando ya han dado a luz, para explicarles las normas y funcionamiento del servicio: qué es lo que hay que hacer, cómo hacerlo, gestión de los papeles del bebé y de la mamá... Eso sería en un principio. Y, luego ya, toda la educación sanitaria que quieras realizar con la mujer y con el recién nacido, pues también te supone una barrera el explicar cómo actuar. [Enfermera 3] 
Pues hay cosas que sí que es importante que te digan, por ejemplo, si eres alérgica. Hay otras cosas que, bueno, si soy incapaz de que me entiendas, siento mucho que no me puedas entender, pero hay que hacerlo. Pero cuando es una cosa que tu actuación puede perjudicarte, pues, claro, aquí ya es más importante que haya comunicación. [Matrona 2]

Es que, mira, hay dos estadios. El primero es cuando la mujer te viene de urgencias, ves que la mujer está embarazada, y supones por su cara que te dice que está sangrando o... y, entonces, la diriges a la zona de urgencias. Ahí no hace falta entenderte, enseguida hay una comunicación no verbal. El problema surge cuando ya ha dado a luz esta señora y le tienes que explicar que hay unos papeles para registrar a ese bebé. $Y$ ahí es imposible, es imposible porque no te entienden. Incluso para un español es complicado, entonces para ellos más. [Profesional socio-sanitario 3]

La imposibilidad de comunicación entre profesionales y usuarias alófonas puede desembocar, de acuerdo con algunos profesionales, en graves consecuencias médicas o incluso legales, especialmente referidas al suministro de la anestesia epidural.

\footnotetext{
Para mí la mayor barrera es la lingüística. Mira, yo soy una persona que soy muy cuadriculado, me gusta tenerlo todo muy controlado y andar dos pasos por delante, y el tener que ir y no poder preguntarle a una persona qué enfermedades... es que, lo que yo estoy haciendo, o sea te puedes cargar a una persona si no lo haces bien. Es que una epidural... Bueno, tú no conoces las técnicas y estas cosas. Pero es que en una anestesia epidural, con el volumen de anestésico que yo estoy poniendo, si lo pongo en el sitio erróneo, es que te cargas a una persona, es que te la cargas, así de sencillo, ¿vale? Entonces, tienes que tener unos métodos para intentar comprobar que tú lo estás haciendo bien, y los métodos son no solo farmacológicos, sino que yo tengo que preguntar a la gente cómo se siente, qué es lo que nota, si se le duermen las piernas, si está todo bien... Y si yo no tengo una comunicación que sea fluida, pues... [Anestesista 3]
}

En teoría según la legislación que existe en nuestro país, la paciente tiene que entenderlo y tenemos además que contarle todas las opciones que hay, cómo funcionan y lo que puede pasar con cada una de ellas. Y ella es libre de decir si quiere, cuándo quiere... pero con las que no hablan tu idioma a veces esto es muy difícil de hacerlo. [Anestesista 4]

A ver, hay un problema legal. Realmente, en otros hospitales donde he trabajado, si tú no te entiendes con el paciente, no deberías hacer ninguna técnica eee.... vital, o sea, perdón, no vital. Por ejemplo, la epidural es no vital, puedes parir con o sin epidural. Si nos ponemos estrictos, si tú no puedes mantener una conversación normal con la paciente, no deberías aplicarle técnicas que ella puede no entender. [...] Es como si hubiera un vacío legal, porque tú no puedes, o no deberías hacer determinadas cosas si no te aseguras de que todo se entiende, pero bueno, miramos para otro lado y ponemos epidurales. [Anestesista 5]

$Y$, entonces, por ejemplo, para poder ponerle la epidural y que la mujer colaborase... porque, claro, para el anestesista es un problema si no le entiende. De hecho, en otros sitios, no la ponen si la mujer no sabe español, porque puede ser un problema si la mujer se mueve. A ver, si están poniendo un catéter epidural y pinchan un espacio que no deben, las consecuencias pueden ser graves, muy graves. [Matrona 7]

Al hablar de las barreras lingüísticas, en ocasiones los profesionales realizan una diferenciación entre las usuarias dependiendo de su país de origen, y opinan que la comunicación suele ser más fluida con las usuarias latinoamericanas y las procedentes de Europa del este, mientras que las usuarias de Asia, de África Subsahariana y del Magreb suelen presentar mayores problemas de comunicación. Además, creen que el uso de una lengua vehicular (como el francés o el inglés) podría facilitar la comunicación, aunque, como hemos visto previamente en este mismo nodo cuando hemos hablado de los idiomas que dominan los profesionales, los conocimientos de estas lenguas por su parte, al no ser en la mayoría de los casos muy profundos, no garantizarían una comunicación fluida y eficaz. 
Esto pasa sobre todo con las que no son francófonas, porque con las que proceden del África francófona sí que es más fácil, pero hay un área en la que no hablan ni francés ni inglés, sino que tienen idiomas propios, y sí que con ellas es muy difícil. [...] Yo diría que lo más complicado es con las que proceden de áreas de África que no son francófonas ni anglófonas. Y luego, también, las del Magreb. [Anestesista 1]

Yo, por lo que veo, te diría que quizás las de raza negra. No sé si es porque quizás son las que hablan... Bueno, que con raza negra, entiéndeme, que luego por religiones tienes islámicas o tal... pero yo, personalmente, por lo que veo, creo que las de raza negra son con las que más problemas tienes de comunicar. [Anestesista 3]

Hombre... Más o menos en cuanto al idioma, todas parecido. A lo mejor con determinadas mujeres es más fácil hablar, o entenderse o dialogar, mujeres a lo mejor de países más afines o más cercanos a nuestra cultura, los países mediterráneos o que son más europeos. [Anestesista 4]

Con ellas (las chinas) el mayor problema suele ser el idioma, pero sí que es verdad que las chicas jóvenes suelen hablar más español que antes, y hablan peor casi los maridos... Entonces, últimamente sí que se puede hablar con ellas. [Anestesista 4]

Porque cuando es una cirugía programada el nivel de usuarias extranjeras disminuye, no sé por qué, pero disminuye. $Y$ las extranjeras que hay programadas son sobre todo sudamericanas. $Y$ bueno, también alguna brasileña, pero bueno, las brasileñas, suelen hablar español. Y las rumanas que se operan de programada llevan ya años también no son las últimas o recién llegadas, y entonces ya hablan español, y te entiendes más o menos. [Anestesista 5]

A veces las magrebíes te están diciendo que sí cuando no entienden nada absolutamente, pero vamos no es porque son magrebíes, es porque desconocen el idioma. Las del este son bastante más listas, son más rápidas para aprender el idioma, quizás porque su idioma no es tan diferente al español, pero se les ve más... más rápidas. [Anestesista 5]

Y también según... digamos la... no sé cómo decirlo, según la raza, ¿̇sabes?, o el origen, pues es mucho más difícil la comunicación, por ejemplo a la hora de preguntar por las alergias y tal. Los chinos sí que siempre traen un acompañante, normalmente nunca están solas. Las rumanas y tal sí que se desenvuelven muy bien en español. Así que normalmente este tipo de problemas pues son más con árabes y con gente de color. [Enfermera 1]

Yo, particularmente, pienso que los chinos son los que menos español conocen. [Enfermera 2]

En la comunidad árabe la barrera idiomática es más importante. Quizás todo lo que es inmigración del este, pues, hablan más castellano y entonces es más fácil comunicarte con ellas. Pero hay mucha mujer árabe a la que le cuesta. [Matrona 2]

A ver, por ejemplo, los del este sí que la mayoría son muy espabilados y saben más que... más que nosotros. Con los sudamericanos evidentemente no hay barrera lingüística. Ahí, estupendamente. Y los marroquíes, los argelinos... vienen algunos que no entienden absolutamente nada, sobre todo las que han pasado allí el embarazo y vienen a parir aquí. [Matrona 5]

Barreras lingüísticas, con las rumanas, por ejemplo, no, porque las rumanas entienden bastante, se desenvuelven muy bien. El problema es sobre todo con las chinas y las marroquíes, principalmente. Chinas hay dos extremos: unas que no entienden nada, y otras que te entienden muy bien; o sea, está muy desequilibrado. Y las marroquíes te das cuenta que igual llevan aquí diez años y no hablan (español), igual que algunas chinas. [Obstetra 3]

Algunos consideran que el desconocimiento de español por parte de estas usuarias podría deberse a su escasa relación con la sociedad de acogida, por hallarse "recluidas" en sus hogares o en sus comunidades. 
Porque además yo creo que la mujer sí que está... tienen menos facilidad para aprender porque están un poco más recluidas. [Anestesista 1]

Y luego... según qué cultura tengan, pues o están tan metidos en su comunidad, que solo se relacionan con los de su comunidad, y tampoco las dejan relacionarse con los demás... [Matrona 4]

Asimismo, son diversos los comentarios por parte de los profesionales con respecto a la posible relación entre, por una parte, la dificultad de comunicación y entendimiento y, por otra, determinados sentimientos de miedo, desconfianza, aislamiento, etc. que observan en algunas usuarias inmigrantes.

Por ejemplo, a mí hace poco me tocó una chica que estaba sola, no te puedo decir exactamente de dónde era... No sé si era de... Hungría, no de Hungría, no... Bulgaria. Y vino una conocida de la paciente, que se supone que era la que traducía y te das cuenta de que tampoco se está enterando muy bien de lo que hay... (Risas). Y, por ejemplo, es que luego esa fue cesárea, y tampoco la señora puso ningún problema. Pero, claro, es un problema para nosotros, porque una vez tú estás en el quirófano, le tienes que explicar lo que va a notar, lo que no, que diferencie el tacto con el dolor y, claro, si tú no sabes qué es lo que te están haciendo, no sabes lo que está pasando, pues lo único que tienes es gritar, que es lo que pasó con esta chica, que gritaba y gritaba... [Anestesista 2]

Pues yo creo que esto va en proporción a la capacidad que tienen de entenderte. Que las que no se pueden expresar y no te entienden yo creo que se aíslan más y no interaccionan tanto. Sin embargo, las que tienen la capacidad de expresarse y de entender, sí, yo creo que sí... a lo mejor, hay de todo, pero creo que estas últimas sí que interaccionan más. [Anestesista 2]

Sí, yo creo que son más inexpresivas. Las que no entienden, con las que hay más dificultad para comunicar, son más inexpresivas. Se meten en sí mismas, se aíslan, responden lo justo... [Anestesista 2]

Sí colaboran, lo que pasa es que, yo creo que hay un componente que no se puede controlar, que es el miedo. El miedo porque... no es lo mismo dar a luz en tu país natal que dar a luz en un país extranjero, en el que el idioma no lo controlas. Entonces, lo que podríamos entender como no colaboración yo creo que es más bien miedo y ansiedad. [Anestesista 5]

Yo pienso que, en general, (las usuarias inmigrantes) son más rígidas, pero porque de alguna manera el no comunicarte bien, al ser la comunicación más escasa, pues yo pienso que están como un poco más rígidas. [Enfermera 1]

Sí, te desvían la mirada, les impone mucho el sanitario... Impone mucho el sanitario me imagino que por ser sanitario, y a veces también por ser hombre, como en mi caso, e impone mucho porque no están entendiendo lo que les estás diciendo y, entonces, igual desconectan de lo que les estás comentando porque no te están entendiendo, creo yo. [Enfermera 3]

Porque todos ellos tratan de entenderte, y si no te entienden, es porque tienen miedo, porque están asustados, porque este no es su país, y, bueno, es normal que se sientan así. [Enfermera 5]

Las que llevan aquí tiempo y no han aprendido a hablar el idioma, en el momento en que llegan a una situación así, se dan cabezazos. Porque las ves que lo pasan mal, ves que les estás hablando y se agobian porque no te entienden. $Y$ yo creo que algunas se dan cabezazos, ¿ंeh? [Matrona 4]

[...] en una situación de... no de enfermedad, porque esto realmente no es ninguna enfermedad, pero el venir a parir sí que es una situación un poco diferente de lo habitual. Es una situación un poco más... ¿cómo te diría yo? Pues, te encuentras con menos herramientas, más vulnerable. Y súmale a eso que no te entiendes con la persona que está. Por eso a veces incluso ellos se cierran un poco más. [Matrona 5]

A veces, a lo mejor, a lo mejor las puedes tachar de más pasivas, pero es porque es que no te están entendiendo, es que no saben por qué, es que no... Entonces, ¿qué iniciativa esperas? [Matrona 5] 
Bueno, a veces, yo considero que, cuando un inmigrante no comprende muy bien tu idioma, eso puede condicionar a que se cree en su mente una desconfianza. Porque, claro, si no entiendes, pues piensas “¿Qué me querrá decir? ¿Me querrá engañar?”. Hay gente que ya es muy desconfiada de por sí, y otros, no, otros son muy confiados. Y sí que hay algunos que piensas "Qué lástima", porque tú vas con toda tu buena intención y, como no te entiende, pues está receloso. Pero es más una cuestión de entendimiento, y el encontrarse en un lugar en el que para ellos es todo nuevo. Es lógico. Porque, claro, yo me imagino que, por ejemplo, yo voy a China, y me pasa algo y tengo que ir al hospital, y me encuentro allí con extraños, no porque tengan el tono de la piel más amarillito y los ojos rasgados, sino porque hablan " $U a$ Sai Sai", y tú dices "iOstras! Yo aquí no entiendo nada"... Y tienes que confiar, porque tú estás enfermo y te sientes impotente, te sientes ya desvalido, porque si no, no estarías en el hospital, porque has tenido una enfermedad, o una lesión, o algo... Y te sientes tan vulnerable... Porque aunque yo, por mi manera de ser, me diga que tengo que confiar en ellos, son los profesionales, que no tengo que pensar mal, porque no me van a fastidiar, sino que creo que intentarán ayudarme como yo intentaría hacer con ellos. Pero, claro, si no entiendes... [Obstetra 1]

¿En los pacientes extranjeros? Hombre, que se fijan mucho en todo lo que haces. Siempre los ves muy atentos a lo que haces... Porque, claro, también desconfían. Pero yo pienso que es algo normal, porque si tú te vas a un país extranjero donde no entiendes mucho... pues igual te piensas que te están engañando, o... yo qué sé, ¿̇sabes? Yo creo que desconfían más. Y miran si subes más, si subes menos, a quién avisas... vamos, están en todo. Parece que no, pero eso sí que lo hacen, se fijan mucho. Sobre todo los que entienden menos, los otros, como tienen menos problema, pues... [Profesional socio-sanitario 2]

Y la barrera lingüística también puede ser una causa, aunque cuando tú vas a pedir algo, siempre vienes, o vamos, con las orejas gachas. Por lo tanto, ellos siempre vienen con una posición más de... de miedo, ¿no? $Y$, claro, al no saber expresarse, eso se acentúa. Y la economía cada vez más dura también les hace estar más indefensos y, por lo tanto, con más miedo y, al mismo tiempo, más agresivos. O sea, que se junta todo. [Profesional socio-sanitario 3]

Numerosos profesionales mencionan además la posibilidad de que las usuarias inmigrantes recurran en ocasiones a lo que se conoce como "mentiras sociales" y digan que no son capaces de hablar español, cuando en realidad sí que cuentan con conocimientos de este idioma o viceversa. Creen que esto puede deberse, especialmente en el caso de las usuarias magrebíes, a la presencia de sus maridos, ante los cuales, de acuerdo con los profesionales entrevistados, no suelen demostrar que conocen el idioma del país de acogida por diversos motivos, bien para ocultarles esta habilidad o bien para que se les permita que ellos, los cuales normalmente sí hablan español, las acompañen durante todo el proceso y faciliten su comunicación con el personal sanitario.

Las del Magreb, por esa cultura que tienen en la que la mujer está en un segundo plano, por lo que sí que es más difícil, porque muchas veces entienden español, pero por miedo, por ese sometimiento, piden que esté delante el marido para que sea él el que conteste, incluso el marido hace de traductor. [Anestesista 1]

Pues sobre todo el problema es el entendimiento y, también, les es más difícil expresarse, unas porque no lo hablan realmente, y otras porque están supeditadas a lo que diga su marido. Nos encontramos con muchos casos de mujeres que dicen que no entienden y, en cambio, te están entendiendo perfectamente. $Y$ esa es una barrera que hay que salvar, muchas de las veces porque no está indicado en ese caso administrar la epidural, porque ya está muy avanzado el parto, y nos cuesta conectar con ella y explicarle y hacerle entender... [Anestesista 1]

Y muchas veces yo creo que ellas dicen que entienden, pero no entienden. [Anestesista 2]

Cada vez menos, pero antes con la gente de países del mundo islámico o países tradicionalmente más machistas o donde la mujer está subordinada al marido, no solo tienes que convencer, bueno, no convencer, sino decírselo no solo a la mujer, sino también al marido. Ahora igual han cambiado un 
poquito las cosas, pero antes te decían "No, no, habla con mi marido", y yo les respondía "No, no, a quien se lo tengo que explicar es a ti, te la voy a poner a ti". Pero aun así, miran al marido, y realmente harán lo que quiera el marido. Si el marido dice que sí, ellas dirán que sí. $\mathrm{O}$ a mí me ha pasado que ella me diga que no y luego, llegar el marido y decir que sí, a lo mejor porque lo ha hablado con ella o qué se yo... vamos, que el que tiene que decirlo por último es el marido. Y casos en los que ellas te han dicho que no hablan español, y luego descubres que lo hablan, pero como el marido no lo sabe, delante de él tienen que fingir. E incluso hemos vivido situaciones extrañas y peligrosas, porque a veces ha habido complicaciones o lo que sea, y has intentado explicarles y cuando no estaba el marido le decías "Mira, hay cosas que te han pasado que tienes que saberlas. Es mejor sí me dices la verdad..." y entonces te enteras de que sí que hablan español. Es decir, ya de primeras te engañan, porque asumes riesgos sin tener que asumirlos o gente que se queda sin poder optar a determinados servicios porque tú crees que no habla tu idioma cuando sí que lo habla. [Anestesista 4]

Sí, hay veces que maridos o familiares quieren estar presentes cuando la rutina y el funcionamiento del hospital indican lo contrario, ¿vale? Entonces eso también les choca. Se amparan muchas veces en que la paciente no entiende y que, por eso, tienen que estar presentes. Pero también la experiencia te demuestra que muchas veces la paciente sí que entiende y utilizan ese sistema, es decir, esa dificultad en el idioma, el no entendimiento, para ellos estar presentes y controlar la situación, para ver qué se les está haciendo en ese momento. [Enfermera 3]

A veces también me ha resultado curioso que no te entendían en determinadas ocasiones y, luego, les decías otra cosa y veías que sí que te había entendido perfectamente. Entonces te preguntabas "Pero, ¿entiende o no entiende?"... [Enfermera 4]

Luego hay algunas que saben hablarlo, pero cuando llegan por miedo o por lo que sea, te dicen que no, para que enseguida pases a su pareja y no estar solas.... [Matrona 4]

Porque, por ejemplo, con las subsaharianas, a veces no sabes si te han comprendido o no. Te dicen que sí, que sí, que sí, y tú piensas "No sé si me está diciendo que sí porque sí o si realmente...". No sabes si te comprenden o no te comprenden, a veces puedes llegar a dudar. [Matrona 6]

$\mathrm{Y}$, luego, después de parir, en el postparto, y esto lo hemos observado todas en general, pues sí que hay algunas que, cuando estaban en dilatación, no querían hablar, decían que no sabían. "No entiendes, no entiendes" te dicen. No te dicen "No entiendo", sino "No entiendes"... (Risas) Y yo pienso que no quieren hablar, porque una vez han parido y todo ha salido bien y están confiadas, empiezan a hablar. Luego, algún miedo deben de tener. $O$ no están legales y no quieren que investiguemos y, así, las asistes y no pasas a intimar más con ellas. [...] Yo, en general, creo que son sinceras. Lo que veo es lo que hablábamos antes, que a veces te dicen que no hablan español y luego, una vez ganan confianza, te das cuenta de que sí que entienden. [Matrona 7]

Luego, están las que sí que se han preocupado de aprender un poco, y entonces intentas ayudarlas lo máximo posible, aunque a veces parece que te entienden, te dicen "Sí, sí, sí", y tú piensas "Me parece que esta vez el sí tenía que haber sido que no". Y a veces les haces preguntas para ver si te han entendido o no te han entendido. Pero, bueno, son barreras que tenemos que enfrentarnos a ellas e intentar corregirlas con los medios de los que disponemos. [Obstetra 1]

Basta que te digan, y aquí volvemos al tema de la cultura, y en este caso a las moritas, que el marido dice "No, ella no habla nada, no entiende", y cuando no está el marido delante, yo hablo con ella y me entiende en castellano, o en francés, o en inglés, o por signos... Vamos, me entiende. Pero, claro, si está el marido delante, no, se queda calladita, mudita, "Yo soy tonta. No saber"... Esto es algo cultural, cultural totalmente. [Obstetra 1]

Es que... la actitud ante la incomprensión es distinta. Por ejemplo, los chinos, los asiáticos, sobre todo los chinos, muchos tienen miedo, dicen a todo que sí sin saber a qué dicen que sí... [Obstetra 2]

Y luego muchas veces ellas dicen que no, sobre todo los moros y demás, el marido dice que no entienden y luego ellas sí que entienden. Son más espabilaícos... No les interesa decirte que te entienden, porque así 
ellos las tienen controladas y dicen que no entienden, pero yo veo que ellas sí que entienden. [Profesional socio-sanitario 2]

No será esta la única ocasión en la que se mencione el rol de la mujer y la relación con su marido en el caso de las usuarias magrebíes, tal y como veremos en el siguiente nodo, dedicado a la interacción social. De hecho, por la importancia que otorgan los profesionales sanitarios a esta cuestión, tratamos de obtener más información al respecto en el grupo de discusión con las usuarias procedentes del Magreb.

Por otro lado, hay profesionales que consideran que la relevancia de las barreras lingüísticas es mayor que la de las barreras provocadas por las diferencias culturales, o que estas últimas no se pueden percibir si no existe una comunicación eficaz entre ellos y las usuarias inmigrantes.

La principal causa es la barrera lingüística. Porque yo creo que ya si ellas nos entendieran, podrían saber también si hay otro tipo de barreras culturales, o de que acepten o no acepten que nosotros intervengamos dentro de todo el proceso del parto. Pero, claro, si no nos pueden entender, tú no te puedes explicar y, a lo mejor, ellas creen algo que no es, o no puedes aclarar dudas o... [Anestesista 2]

El idioma yo diría que es la barrera principal. Porque, luego, la cultura, pues cada uno tiene su cultura y... es cuestión de conocerla por lo que vas viendo en ellas y entenderla un poco, ¿no?, respetarla. Yo creo que el mayor problema es la comunicación, sí, la comunicación. [Matrona 4]

Y entonces, ahí la barrera lingüística es tan fuerte, que la cultural, al menos en urgencias, no llegas a valorarla. En las consultas sí que puedes ver una barrera cultural que es ya más... más distinta. Pero en las urgencias es más la cuestión idiomática, porque además es una visita muy dinámica, muy rápida, y en la obstetricia es que es "Sota, caballo y rey". Tienes cuatro patologías y casi siempre son de embarazo y no requieren mucha explicación y... Pero lo principal es el idioma, sí, sí... Y en las consultas, no. Cuando hablas de educación, das más consejos a la hora de cuidarse el embarazo y eso, sí que se nota que es más cultural. [Obstetra 3]

Por lo que respecta a las usuarias inmigrantes entrevistadas, cabría realizar un inciso antes de comenzar el análisis de sus respuestas en relación con el tema de las barreras lingüísticas. Como hemos señalado en páginas anteriores, concretamente en el subapartado de las características demográficas de los sujetos entrevistados, de las 25 usuarias que participaron en las entrevistas, solo 5 (procedentes de Latinoamérica y de la comunidad gitana) tienen como lengua materna el español. A estas usuarias en concreto no se les realizaron algunas de las preguntas relativas a las barreras lingüísticas, pues resultaba obvio que en su caso los problemas de comunicación serían, al menos en principio, menores que los que debían afrontar las usuarias alófonas.

El resto de usuarias entrevistadas presentaban por lo general lenguas maternas de las cuales ni los profesionales sanitarios ni la propia investigadora teníamos conocimientos. Por este motivo, cuando el dominio de español por parte de la usuaria no era suficiente para llevar a cabo la entrevista adecuadamente, recurrimos en algunos casos a sus acompañantes, que realizaron labores de interpretación, o al uso de lenguas vehiculares, especialmente el inglés. Trataremos este tema de manera más exhaustiva en el análisis de las notas de nuestro diario de campo.

Asimismo, aun en los casos en los que las usuarias declaraban conocer el español, no siempre la comunicación entre la investigadora y las entrevistadas era fluida, y quizás este conocimiento no era suficiente como para que no fuera necesario en ocasiones realizar 
aclaraciones y reformulaciones o para que no surgieran malentendidos. Asimismo, consideramos que las respuestas breves ofrecidas por algunas usuarias también se pueden deber en algunos casos a sus escasos conocimientos de español. Por último, cabe recordar que no fue posible realizar entrevistas a algunas usuarias inmigrantes ingresadas en el hospital contexto de estudio pues sus conocimientos de español (o de alguna lengua vehicular) eran muy escasos o presentaban un desconocimiento total.

Por todos estos datos aportados, podemos deducir que hay usuarias inmigrantes que se enfrentan a barreras lingüísticas. De hecho, algunas de las usuarias entrevistadas reconocen tener problemas de comunicación con los profesionales sanitarios. En este grupo se encuentran principalmente usuarias de África Subsahariana, Asia y Magreb, dato que coincide con las respuestas ofrecidas por los profesionales entrevistados, ya que estos señalaban precisamente a las usuarias de estas zonas como las que presentaban un mayor desconocimiento de español.

A veces no entiendo, entonces el médico me explica despacito para que entiendes. [África Subsahariana 2]

Sí, a veces no entender, es difícil entender... Yo digo que no entiendo y médico repite... Y a veces médico habla muy rápido y yo no entiendo... [África Subsahariana 5]

Siíi, hablar español... (Parece muy dubitativa y, con sutileza, trato de reformular la pregunta). Bueno... regular. Yo no sabes español perfecto... Es difícil. Si alguien explica en chino es mejor. [...] Y cuando no entiendes, díselo a médico. Pero ellos no dar solución. [Asia 1]

Mmmmm, sí, un poco. A veces alguna palabra no entiendes. Las cosas que son de enfermedad no entiendo mucho. [Asia 2]

Sí, lengua is a problem. [Asia 3]

A veces es difícil, porque yo no hablo mucho español. Sí, a veces es difícil. Por ejemplo... no sé. Sí, pero a veces es difícil. Por culpa de la lengua y porque son temas que... [Asia 4]

No hablo mucho español, sí entiendo, pero no hablo mucho. Dal context... (palabras pronunciadas en rumano por la usuaria y reproducidas fonéticamente). (Interviene el hermano de la usuaria) Sí, más o menos lo entiende, un resumen lo puede hacer, pero ya los detalles... [Europa del este 3]

Sí, muchos problemas... Cuando no sabe y pregunta no me entienden nada (Risas). Si sabes el... ¿Cómo se dice? Si sabes el tema es más fácil. [Magreb 2]

Sí, sí, sí. Pero antes de esto problema, no es mucha información. Entonces yo tener miedo. Para médico es una cosa normal, pero yo no tiene información y entonces... Con el médico de mi país es más fácil por idioma. En esto estoy muy mal y yo decir a mi marido "Yo voy a mi país y así explicar bien y...". Es importante entender bien. [Magreb 2]

Sí, a veces no entiendo a los médicos. [Magreb 3]

En referencia a las usuarias procedentes del Magreb, dos de ellas afirman que no tienen problemas de comunicación, a pesar de que durante la entrevista pudimos comprobar que sus conocimientos de español no eran suficientes como para que pudieran expresarse plenamente y entender las palabras de los profesionales sanitarios.

No, no tengo problemas en general. Y para hablar con médicos, tampoco. Siempre los entiendo. [Magreb 1] 
(Responde directamente a la pregunta formulada el marido de la usuaria) ¿Si tiene problemas? No, no, no, no, ella habla y las enfermeras entiende. Sí, sí, tardará mucho para entender, pero al final, las enfermeras entiende. (Contesta en ese momento la usuaria) No, no, yo entiendo y, si no, pido que repetir. [Magreb 4]

Otras comentan que al llegar a España tenían más problemas de comunicación, pero que el tiempo de permanencia en el país de acogida ha conllevado un mayor conocimiento del idioma y, por tanto, una disminución de dichos problemas. Recordemos que, de acuerdo con los datos demográficos presentados previamente, la mayoría de las usuarias entrevistadas llevan residiendo en España entre 6 y 10 años.

Ahora tener menos problemas, pero al principio no saber español y entonces no comprender médicos. [África Subsahariana 1]

Yo ahora ya hablo español, pero con el primer hijo, como te he dicho, no lo hablaba y, cuando mi marido no podía ir en las consultas, cualquier cosa que yo necesitaba preguntar, él me lo apuntaba en un papel, y lo que hacía el médico siempre era volver a apuntar las respuestas y eso... Y yo también iba con un diccionario de francés-español para algunas cosas. Ahora ya no, ahora ya entiendo bastante bien, la verdad... [África Subsahariana 4]

Sí, sí, a los médicos les he entendido todo. Es que el problema también es que yo ya pienso en español y, entonces, a mí me cuesta ya más hablar con mi madre en ucraniano, por ejemplo. [Europa del este 1]

Ahora, no, ya no. Es que, claro, depende de lo que me preguntes. Si me preguntas algo de política, igual... (Risas). Pero cosas así simples, cosas de todos los días, no tengo problemas. [Europa del este 1]

Es que yo ya he vivido más años aquí que en Rumanía. Para mí la lengua no es un problema. [...] No, no, los entiendo bien. [Europa del este 2]

Es que yo a los tres meses ya hablaba... Vamos, que ya todo lo entendía. Porque yo empecé a trabajar limpiando en una casa, y la chica me enseñaba a escribir, a leer... Y luego ya cogía periódicos, la tele la veía mucho, y preguntaba mucho... Y a los tres meses o así, ya... Y al año me puse a trabajar de camarera y la gente me entendía ya muy bien. Entonces no recuerdo así una situación en que tuviera problemas con la lengua. [Europa del este 4]

Bueno, al principio tenía más problemas, pero más o menos siempre hemos conseguido entendernos. [Europa del este 5]

Antes sí, pero ahora ya no. No, no ahora ya no tengo problemas por la lengua. [Europa del este 6]

Ahora ya tengo menos. Pero, cuando llegamos, no sabía nada de español. Antes no entendía casi nada, pero ahora comprendo mejor. [Magreb 3]

El único grupo de usuarias entrevistadas que casi en su totalidad afirma que no ha tenido problemas de comunicación con los profesionales sanitarios es, junto con la usuaria de la comunidad gitana, el de las usuarias latinoamericanas, a pesar de que una de ellas, procedente de Brasil, tiene como lengua materna el portugués, y no el español.

No, no he tenido problemas por la lengua, no. $Y$ con los términos médicos tampoco, porque, al ser veterinaria, los términos médicos no son nuevos para mí. Además, los términos en español son prácticamente igual que los que usamos en portugués y entonces... La única cosa que a lo mejor puede ser un poco más difícil es si el médico tiene un acento un poco más cerrado o tiene ese acento un poco más de pueblo que tienen algunas personas aquí. Y en esos casos tienes que estar más atento, pero por la lengua en sí no he tenido ningún problema. [Latinoamérica 2]

Así problemas en general con la lengua no he tenido, no, como hablamos el mismo idioma, pues... [Latinoamérica 3] 
A los médicos sí que los entiendo. No han usado palabras así más médicas, no. Y me explicaban todo cómo iba, lo que tenía que hacer, y sí que los entendía sin problemas. [Latinoamérica 3]

No, yo nunca he tenido problemas para comunicarme, ni aquí ni en la calle. Como hablamos la misma lengua, todo es más fácil. [Latinoamérica 5]

Solo una de las usuarias latinoamericanas entrevistadas señala que, a pesar de hablar la misma lengua que se habla en el país de acogida, por tratarse de variedades diatópicas del español, pueden existir diferencias que le dificulten la comunicación con los autóctonos.

Bueno, en general no he tenido ningún problema. Aunque a veces, como usamos palabras distintas, tengo que decir que me expliquen bien, porque si no, no lo entiendo. Y además hay palabras que en mi país significan otra cosa, tienen otro significado... Pero, vamos, problemas, lo que se dice problemas de comunicación, nunca he tenido. [Latinoamérica 4]

Este mismo dato fue aportado en una conversación informal con uno de los profesionales participantes en el estudio, quien nos contó, como veremos más adelante en el apartado de análisis de la observación no participante, que, por su experiencia, en ocasiones la comunicación con las usuarias procedentes de Latinoamérica no era tan fluida como cabría esperar. Partiendo de estos dos datos discordantes con el resto de opiniones, incluso con la nuestra propia, pues en principio consideramos que las barreras lingüísticas no afectarían a las usuarias hispanohablantes, decidimos tratar de corroborarlos en el grupo de discusión a usuarias latinoamericanas.

Por último, cabe señalar que una de las usuarias procedentes de Europa del este, junto con su marido, quien estaba presente durante la entrevista, comentan que la similitud entre su lengua materna y el español puede facilitarles el aprendizaje de esta última lengua y el entendimiento con la población autóctona, aunque también son conscientes de que la semejanza fonética entre algunas palabras en los dos idiomas que, sin embargo, presentan significados diferentes, puede conducirles a malentendidos.

Bueno, ahora no hablo español correctamente y cuando nació aquí mi otro hijo aún hablaba menos... (Interrumpe la conversación el marido de la usuaria y la contradice). No, no, no. Sí que lo dominaba, porque de eso hace ya cuatro años y cuando nació ya llevábamos cinco años en España. Y como el español es una lengua parecida al rumano, porque es una lengua latina, que está enraizada en el latín, para nosotros es fácil aprender español. Lo único que no te sale el acento y hay algunas palabras que no sabes bien el sentido... Esto puede pasar porque si son palabras que no usas en cada día, aunque me digas qué significa, si no la uso, se me olvida. Pero en general, no es difícil. Date cuenta que los romanos conquistaron Iberia y también conquistaron Francia, y por eso se formaron lenguas distintas pero parecidas. Por ejemplo, cuando nos vamos en Italia, hablamos español, y los italianos casi todos entienden español. (Interviene de nuevo la usuaria) Pero hay palabras que parecen iguales y no significan lo mismo. (Vuelve a participar su marido) Por ejemplo, en Rumanía si tú dices "Estoy constipado", la gente te dice “¿Cómo? ¿Constipado?" Porque esa palabra para nosotros tiene otro sentido. Constipado para nosotros significa estreñido. [Europa del este 5]

En cuanto al uso de la terminología médica, prácticamente todos los profesionales entrevistados comentan que tratan de evitar el uso de lenguaje especializado y que suelen emplear un lenguaje lo más sencillo posible en la comunicación con las usuarias, tanto autóctonas como inmigrantes, a pesar de que, de acuerdo con la opinión de algunos profesionales, en el caso de estas últimas, a veces ni siquiera es posible hacerles entender determinados matices incluso empleando un lenguaje llano. 
En el momento en que parece que pueden comunicarse, los problemas con la terminología médica son los mismos que con las usuarias españolas. [Anestesista 1]

Pues yo creo que de lenguaje técnico poco les puedes decir. [Anestesista 2]

Vamos a ver, con la terminología médica, es que las usuarias... es que al ser cosas médicas, pues realmente, tendrías que explicarle de una manera muy llana lo que les vas a hacer, pero el problema es que muchas de las inmigrantes tampoco hay manera, ni con un lenguaje llano, de que te entiendan lo que les quieres decir. $\mathrm{Y}$, entonces, explicar simplemente, cuando estamos con la epidural, "¿Sientes hormigueo?" o “¿Sientes que se duermen las piernas?", o sea... Son cosas que no hay que dominar mucho el lenguaje, pero tienen un matiz, y entonces como no entienden ese matiz, pues muchas veces pensarán “¿Y este qué dice?”. Ves claramente que no saben lo que les estás preguntando. [Anestesista 3]

Normalmente solemos emplear las dos, primero lo dices en terminología médica y luego lo explicas en terminología llana. Le puedes decir "Te vamos a pinchar en un canal que se encuentra en el espacio epidural" y luego le explicas "Te vamos a pinchar en una membranita que es por donde va la médula espinal". Vamos, para que te entiendan un poco, y después les explicas "Esa membrana se puede infectar...". [...] Pero, vamos, la terminología médica es difícil a veces tanto para españolas como para extranjeras. [Anestesista 4]

No, hombre, no, la terminología médica no la usamos. Para las extranjeras concretamente, es que... a ver, las africanas, por ejemplo, algunas hablan inglés, y las magrebíes, las que tienen cierta cultura, hablan francés. Porque, en Marruecos, por ejemplo, quien ha vivido en Casablanca o en ciudades grandes, pues normalmente sí que ha estudiado algo de francés, el resto, no. Y entonces, cuando intento utilizar el inglés o el francés, pues uso nombres muy básicos, no... para nada anatómicos, o sea, un lenguaje casi, casi nativo, con "Hola" y "Mover" y "Dolor" y poco más. No, porque tampoco tienen la actitud como para aprender anatomía, yo creo que vienen a dar a luz y ya está, no... [Anestesista 5]

Pienso que (con la terminología médica) tienen un poco más de problemas que las españolas. Aparte que muchas veces la gente sanitaria pecamos un poco del uso de términos (especializados). [Enfermera 1]

Pues en esto yo creo que, a veces, incluso algunos españoles no te entienden, y entonces tienes que darle la vuelta, y ya está. Tampoco es complicado, es buscar ejemplos y explicaciones fáciles, como si fueran un chico pequeño. [Enfermera 2]

No solemos emplear la terminología médica. Si ya no te entienden, intentas hablar del modo más sencillo posible. [Enfermera 3]

Es que en estos casos la terminología médica procuramos no usarla, la verdad. [Enfermera 4]

No, no, no empleamos la terminología médica para nada, imposible. No, no, no, no... (Risas). [Enfermera 5]

Hombre, con todas las pacientes, inmigrantes y españolas, tratamos de hablar lo más sencillo posible, no solemos usar terminología médica. [Enfermera 6]

Hombre, pues... si añadimos terminología médica a un idioma que no entienden, pues ya es... es el final. Intentamos ser muy llanos, muy llanos con el leguaje, también con las españolas, soltar poco tecnicismo, etc. [Matrona 1]

No, hombre, no usamos terminología médica. Se intenta explicar para que te entiendan. Sí, se hace con palabras cortas, con signos, o incluso que hay algún gráfico, aunque yo no he llegado a utilizarlo todavía, pero no usamos términos médicos, no. [Matrona 2]

Se intenta usar un lenguaje más sencillo, pero es que hay cosas que no se pueden hacer de otra manera. Se intenta explicar las cosas, pero es que... lo que es es lo que es. [...] Hay momentos en que... porque también españolas hay con un nivel cultural muy básico y tampoco te queda otro remedio que explicarles las cosas. [Matrona 4] 
Yo creo que problemas con la terminología médica puede tener cualquiera, españolas y no. [Matrona 5]

No, claro, la terminología médica en estos casos no la usamos. Hablamos lo más sencillo posible para que nos puedan entender. [Matrona 6]

Con ellas no empleamos terminología médica, no. Es que hay que ponerse a la altura de la mujer, a su mismo nivel, de manera que te entienda... [Matrona 7]

Noooo, noooo. Normalmente no tengo costumbre, pero no ahora sino de toda la vida, de utilizar terminología médica con pacientes que no son, digamos, que no utilizan nuestra jerga. No porque... Es que es absurdo, si ya bastante dificultad tienes para que te contesten para saber si han hecho pipí... $\mathrm{O}$ algunas dicen "Pipí, no. Caca, no. Pipí, sí", vamos, que no saben ni siquiera lo que es, como para empezar a decir “¿Ha miccionado usted?”, y ella pensará “¿Y esto qué puñetas es?” (Risas) [Obstetra 1]

Es que la terminología médica en estos casos no la usamos. Intentamos explicarles las cosas de un modo más sencillo, más sencillo, sí, porque es que si no, no... no lo entienden. [Obstetra 2]

No, terminología médica no usamos, bajamos bastante el registro. [Obstetra 3]

Por lo que se refiere al lenguaje escrito, la gran mayoría de las usuarias opina que le resulta más fácil entender los mensajes en español de este modo que cuando se reproducen oralmente o, en su defecto, que si cuentan con el mensaje escrito, siempre pueden recurrir a alguien que domine el español para que se lo explique o se lo traduzca.

Si no entiendo, pedir a alguien que lo lee. [África Subsahariana 1]

Si el médico me da papel, yo puedo leer, yo lo entiendo, lo leo en español, sí... [...] Escrito es más fácil. Si no entender, pregunto a mi hijo... [África Subsahariana 5]

Sí, hay cosas, muy pocas, que no entiendo, pero normalmente sí que entiendo lo que está escrito. [...] Yo siempre lo leo en español, porque parece que lo entiendo mejor. (Risas). También, como te acostumbras ya, pues dices "Esto es muy fácil". [Europa del este 1]

Tampoco el lenguaje escrito es un problema. Ya te digo que yo hablo y comprendo perfectamente. [Europa del este 2]

(El hermano de la usuaria le traduce la pregunta al rumano y ella responde en esa misma lengua, tras lo cual él interpreta al español sus palabras). Sí, lo escrito lo entiende perfectamente, bueno, lo entiende mejor. [Europa del este 3]

No, yo diría que escrito es más fácil. [Europa del este 5]

No, no, tampoco lo escrito es problema. [Europa del este 6]

No, no, entiendo todos los documentos. [Latinoamérica 2]

Con los documentos tampoco he tenido nunca ningún problema. [Latinoamérica 3]

Sí, sí entiendo. [Magreb 1]

No, escrito es bien. [Magreb 2]

Escrito es más fácil. [Magreb 3]

Mi marido me ayuda y, si no entender, traducir. [Magreb 4] 
Solo tres de las usuarias entrevistadas, en concreto procedentes de China y Paquistán, reconocen que se enfrentan a dificultades a la hora de entender los mensajes escritos en español.

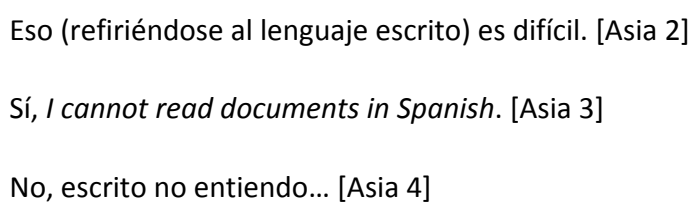

En relación con esta cuestión, los profesionales sanitarios parecen presentar serias dudas sobre si las usuarias inmigrantes pueden entender los mensajes escritos en español y, además, uno de ellos comenta que en ocasiones las usuarias inmigrantes no saben leer ni escribir, lo cual les impedirá entender cualquier mensaje escrito, tanto en su propia lengua materna como en español. Retomaremos el tema del analfabetismo de algunas usuarias cuando hablemos de los documentos traducidos a otros idiomas presentes en el hospital contexto de estudio.

\footnotetext{
Y aunque se lo dejes escrito, pues está escrito en español, no en su idioma, y si no lo entienden, pues... por eso hay más probabilidades de que se hagan un poco de lío. [Enfermera 1]

¿Si entienden los mensajes escritos? Pues, pues depende, hay de todo... Depende sobre todo de si saben bien español o no. [Obstetra 2]

Nosotros intentamos explicárselo, les subrayas, les escribes, pero no... Muchas veces te das cuenta de que no saben leer ni escribir. [Profesional socio-sanitario 3]
}

Tras haber descrito las barreras lingüísticas con las que se encuentran los profesionales sanitarios y las usuarias inmigrantes a la hora de comunicarse entre ellos, pasamos ahora a analizar las diferentes soluciones que se adoptan o se han adoptado en el pasado en el hospital contexto de nuestro estudio para tratar de superar dichas barreras.

La primera solución que vamos a estudiar es el recurso al lenguaje no verbal para la comunicación entre los profesionales sanitarios y las usuarias alófonas.

Prácticamente todos los profesionales entrevistados afirman recurrir al lenguaje no verbal cuando las barreras lingüísticas les impiden comunicarse con las usuarias inmigrantes.

Sí, sí, (el lenguaje no verbal) lo uso muchas veces, sí. [Anestesista 2]

Yo suelo emplear los gestos. [Enfermera 2]

Si ya no te entienden, intentas hablar del modo más sencillo posible y yo, en mi caso, incluso gesticular mucho, y hacer mucha parafernalia con las manos, los gestos, la cara, ¿vale? Indicando posiciones en el pecho, también, vamos, para intentar que comprendan. [Enfermera 3]

Sí, claro, (el lenguaje no verbal) a veces sí que lo empleamos. [Enfermera 4]

Pues, yo, personalmente, sí, gesticulo mucho. Nos comunicamos como podemos, hablamos, si es en francés, pues en francés, y si no, gesticulando. [Enfermera 5]

Pero la comunicación es verdad que a veces es muy muy complicada, de hecho a veces es gestual. [Matrona 1]

Los gestos los empleo a todas horas, sí, a todas horas. [Matrona 4] 
Sí, sí claro. Haces "Empuje", "Grrrr...", o "Contracción”... (Mientras pronuncia esos términos hace gestos y expresiones faciales). Sí, sí. (Risas) Hay que recurrir a eso muchas veces. [Matrona 6]

Si no te puedes entender con ellas verbalmente, lo haces por gestos. [...] Pues si alguna mujer no sabe ningún idioma y no nos podemos entender, entonces lo hacemos con gestos. Le dices "Empuja. A ver...", y con gestos y eso, y le doblas las piernas y ya... Pues le dices "Empuja" o "Respira" y lo haces con gestos. (Mientras pronuncia estas últimas palabras gesticula y hace como que respira fuertemente.) Cuando no hay ninguna manera de comunicarte, pues... De todos modos, cuando tienes una contracción te entra un deseo irresistible de empujar, que es que la naturaleza te dice lo que tienes que hacer. [Matrona 7]

Bueno, pues, en un principio, intentas comunicarte con gestos, o con palabras así, sencillas. [Obstetra 2]

Uy, yo los gestos los utilizo mucho. Y también me pongo a chillar como si fueran sordos, no sé por qué... (Risas). Pero, vamos, eso yo creo que lo hacemos todos. Y luego piensas "Pero, ¿por qué le estoy chillando, si no está sordo?" (Risas). [Profesional socio-sanitario 2]

Muchos opinan que los gestos, las expresiones faciales o señalar partes del cuerpo les resultan útiles para hacer llegar sus mensajes a estas usuarias, y consideran que mediante el lenguaje no verbal consiguen comunicarse "perfectamente". Probablemente estos profesionales no son conscientes de la diversidad cultural que, tal y como hemos explicado en el capítulo 3, existe en el uso y la interpretación de los elementos no verbales.

Sí, sí, sí, de hecho, es vital ese tipo de lenguaje. [Anestesista 1]

Pues con gestos. Yo recurro mucho a los gestos. Señalas partes del cuerpo, y haces así como si te produce picor (se rasca el brazo mientras dice esto), o cosas así. Yo creo que el lenguaje no verbal es bastante importante. [Enfermera 1]

Uy, ilos gestos! Utilizamos todo. Es como cuando te vas al extranjero. Yo no hablo idiomas, y me he pateado Asia, África y... al final, nos solemos entender. [...] Cuando ha habido algún caso que no nos entendíamos nada, nada, como a lo mejor no era algo tan importante y con gestos y con cosas nos entendíamos perfectamente. [Enfermera 6]

Si hay problemas lingüísticos los resolvemos con gestos, o con palabras cortas [...] Sí, sí que empleo los gestos y me resulta útil para poderme comunicar. [Matrona 2]

Sí, claro. Los gestos como comunicación dicen mucho. Yo creo que ellas también lo reciben así. Todo cuenta: el tono de voz, si me tratan más suave o me están gritando, eso se percibe. [Matrona 3]

Siíi, claro, los gestos se usan internacionalmente. ¡Dolor, dolor, dolor! (Mientras pronuncia estas palabras se aprieta la zona del estómago y realiza expresiones faciales) iTú, gmmmmm! (Hace un gesto como si estuviera empujando). [Matrona 5]

Sí, sí, muchísimas veces. Y sí que creo que me ayuda. Vamos, el lenguaje de los signos te ayuda muchísimo. Como a mí me ha ayudado estando en el extranjero, pues a ellas también les ayuda. [Obstetra 1]

Yo sí que utilizado alguna vez los gestos, y diría que me han funcionado... [Obstetra 2]

Mucho, pero es que yo uso mucho los gestos, sí, sí, sí. Y yo creo que sí que me ayudan en la comunicación, sí, yo creo que sí. [Obstetra 3]

Síií, sí, sí. Muchísimas veces. Y con los gestos nos comunicamos mejor, sí, sí, sí. [Profesional socio-sanitario 3]

Solo unos pocos profesionales manifiestan que sienten cierta incomodidad al emplear el lenguaje no verbal y dudan de si la comunicación en estos casos es realmente efectiva. 
Y eso, ¿cómo lo soluciono yo? Pues, a veces, haciendo el indio, porque no se puede decir de otra manera, pues eso, con señas y cosas raras, pero que no, que no, que no. [...] Hacemos el idiota todo lo que quieras. Porque yo a veces tengo que hacer cosas muy raras para intentar que la otra persona entienda lo que le estoy diciendo. [Anestesista 3]

Sí, claro, "Ponte así, baja los hombros, baja la cabeza, no te muevas, o te pincho en la espalda" (Mientras pronuncia estas palabras realiza gestos y adopta posturas). Yo qué sé, haces el tonto, y además te preguntas “Pero, ¿̇me estará entendiendo?" y piensas "Que sea lo que dios quiera” y ya está. [Anestesista 4]

Sí, sí, el lenguaje no verbal lo empleamos mucho. Hacemos gestos... llegamos a hacer gestos que dices, si me vieran, se reirían de mí. O sea, hacer como que empujas tú también, de todo, de todo... (Risas) [...] Pues, en muchas ocasiones nos comunicamos mediante gestos. $Y$ hay veces que no se les puede explicar todo lo que nos gustaría explicar. [Matrona 1]

Sí recurrimos a los gestos. Y la comunicación en estos casos es más complicada en estos casos, principalmente por eso, por la incertidumbre de que se hayan enterado bien de lo que les estás diciendo. [Profesional socio-sanitario 1]

Por su parte, la mayoría de las usuarias inmigrantes entrevistadas afirma que no suele recurrir a los gestos ni en sus intercambios comunicativos en general ni para comunicarse con los profesionales sanitarios.

Yo no uso gestos, no. [África Subsahariana 1]

No, no, no uso gestos, no. [África Subsahariana 2]

Bueno, a lo mejor al principio... pero es que yo normalmente no uso mucho los gestos... [África Subsahariana 4]

No, gestos no usas. [Asia 2]

No, no gestos, no. [Asia 3]

No, no gestos. [Asia 4]

No, no empleo gestos normalmente. [Europa del este 6]

Únicamente algunas de ellas, principalmente las usuarias procedentes del Magreb, señalan que emplean el lenguaje no verbal en el contexto objeto de estudio. Tal vez tampoco estas usuarias, al igual que sucedía con algunos de los profesionales entrevistados, son conscientes de que el uso de este tipo de lenguaje en una interacción comunicativa intercultural podría conducir a malentendidos.

Sí, sí, sí, por ejemplo, yo muevo las manos así... (Risas) [África Subsahariana 5]

A veces, hace una mano. [Asia 1]

Yo los gestos los uso siempre, pero no es porque no me entienden, es que los uso yo... [Europa del este 1]

A veces uso gestos, o palabras en otros idiomas. [Europa del este 3]

Bueno, los gestos los he usado poquito, pero los españoles he visto que los usaban conmigo. Es que al llegar yo no hablaba casi nada. Y me acuerdo que una vez alguien me ha dicho algo de cocina y me ha dicho cómo se escribe, que para mí se pronunciaba "cochina" y en Rumanía esto significa "la casa de los cerdos" y entonces yo no entendía nada. Hombre, es que si yo te digo "Uang chu on tu", no entiendes casi 
nada, entonces sí que tienes que usar los gestos, los signos, la mímica de la cara para entendernos. [Europa del este 5]

Sí que empleo a veces gestos, pero como los emplearía en mi país. Los gestos normales que acompañan a lo que estás diciendo y tal... [Latinoamérica 2]

Sí, también uso gestos, sí. [Magreb 1]

Sí, a veces, sí uso gestos. [Magreb 2]

Sí, a veces también uso gestos. [Magreb 3]

¿Las manos para hablar? Sí, sí, yo uso para decir "Me duele aquí" o "Me duele allí". [Magreb 4]

Otro de los recursos de los que dispone el hospital contexto de estudio para facilitar la comunicación con las usuarias alófonas consiste en documentos traducidos a otros idiomas. ${ }^{252}$

Al respecto de estos documentos, parece existir bastante desinformación entre los profesionales sanitarios.

En primer lugar, muchos profesionales señalan la existencia de consentimientos informados (especialmente por lo que se refiere al suministro de la anestesia epidural) en las lenguas maternas más frecuentes en las usuarias inmigrantes.

[...] luego, hay, en nuestro caso, creo que también consentimientos informados, pero en este caso creo que solo en árabe, rumano y chino, por población, vaya, por volumen de partos. [Anestesista 1]

Nosotros no, lo único que tenemos es el consentimiento en varios idiomas, pero solo eso. [Anestesista 2]

Los consentimientos informados están traducidos. [Anestesista 5]

Tenemos consentimientos en todos los idiomas, bueno en todos los idiomas más frecuentes y... pues, hombre, les ayuda a entenderlo un poquito mejor. [Matrona 1]

Sí, sí que hay. El consentimiento para la anestesia está en francés y creo que también en árabe. [Matrona 2]

Sí, los consentimientos de epidural, por ejemplo, están en todas las lenguas, eso sí. [Matrona 3]

Pues tenemos, como te decía, los consentimientos en varios idiomas: el consentimiento para la epidural, para la cesárea y todo eso. [Matrona 7]

Es que solemos tener documentos traducidos. (Los consentimientos) Para la epidural, por ejemplo, están traducidos. [Obstetra 3]

Yo creo... yo creo que sí. Vamos, yo creo que arriba sí que algo tienen, como lo de la epidural en otros idiomas. Vamos, creo que sí, que algo hay... [Profesional socio-sanitario 2]

Otros profesionales entrevistados indican que existen también guías multilingües sobre el parto o sobre cuidados neonatales, pero algunos comentan que la edición de estas guías se ha visto reducida por la actual situación de crisis económica.

\footnotetext{
252 En los anexos se incluyen todos aquellos documentos traducidos que nos ha proporcionado el hospital contexto de nuestro estudio, en concreto, consentimientos informados para el suministro de la anestesia epidural y folletos informativos sobre cuidados a los recién nacidos traducidos al árabe, el chino, el francés, el inglés y el rumano.
} 
Sí, que yo sepa, hay materiales en rumano, chino, árabe, francés e inglés por supuesto, e italiano creo que también. Se trata de un documento general sobre el parto. [Anestesista 1]

Había... hasta ahora estábamos dando un libro que estaba editado en varias lenguas: estaba en español, estaba en árabe, estaba en chino creo que también... era sobre los cuidados del recién nacido en los primeros meses de vida. Y yo pienso que sí que era para ellos de bastante utilidad. [Enfermera 1]

Sí, sí que hay algunos documentos traducidos. Y, anteriormente a todo esto de la crisis también había un libro que editaba el Gobierno de Aragón, una guía en los diferentes idiomas que se entregaba a las mujeres. [Enfermera 3]

Sí que sé que había folletos informativos traducidos a varios idiomas. Y entonces tú pensabas "Te doy esto que está en tu idioma y lo vas a entender", y ya si tenemos alguna duda más... pues ya intentaremos resolverla. [Enfermera 4]

Sí, hay muchos folletos traducidos por ahí. Aunque ahora menos, ahora ha bajado todo eso. [Enfermera 5]

Y luego las cosas de los niños yo creo que en las plantas sí que las tienen en diferentes idiomas. La cartilla de información que se les da sobre cuidados del recién nacido yo creo que también está. [Matrona 3]

Me parece que hasta hay folletos en diferentes idiomas. No sé si los habrás visto, pero están escritos en árabe, en chino, en rumano... Son folletos de información y sobre cuidados del bebé. [Obstetra 1]

$\mathrm{Y}$, luego, en el ambulatorio, a pesar de que son de propaganda, pues tenemos documentos de consejos $\mathrm{Y}$ esas cosas en varios idiomas. [Obstetra 3]

Sí, hemos traducido, pues eso, los consentimientos informados, las informaciones de las plantas... [Profesional socio-sanitario 1]

Asimismo, algunos profesionales sostienen que cuentan también con listados de expresiones comunes en varios idiomas.

Tenemos hojas que están... Bueno, aparte de los consentimientos, que los tenemos escritos en varias lenguas, tenemos hojas con frases ya hechas relacionadas con nuestro trabajo en varios idiomas. Y si no lo sabemos decir nosotros, pues por lo menos vamos con la hojica y les señalamos. Yo ha habido veces que los he utilizado y sí, me han servido. [Matrona 4]

Sí, en la planta sí que hay unas fichas en las que pone en diferentes idiomas "Cuándo tuvo la última regla", "Si hay sangrado", "Si hay dolor". Están en francés, en árabe, en rumano... no sé, están en cuatro o cinco idiomas. [Matrona 6]

Cabe señalar que parece ser que no todos los profesionales entrevistados son conocedores del recurso de las guías o listados multilingües, a pesar de que algunos de ellos consideran que podrían resultarles útiles para comunicarse con las usuarias alófonas.

Que yo sepa, no. Sé que tienen los consentimientos traducidos, pero allá dentro. Pero aquí, nada. Lo único que tenemos aquí son unos documentos sobre la ablación, con unas fotografías y explicaciones. [Enfermera 6]

Aparte de los documentos informativos en varias lenguas que se entregan a las pacientes, nosotros no tenemos nada. No hay documentos con listados o expresiones para el personal sanitario, no. [Obstetra 1]

Yo sé que están los consentimientos en varios idiomas, pero aquí no tenemos ningún otro material traducido, no... [Obstetra 2]

Aquí donde estamos nosotros no tenemos nada escrito en otras lenguas. [Profesional socio-sanitario 3] 
También algunos de ellos realizan propuestas de otros documentos (como los registros de los recién nacidos) cuya traducción a otros idiomas podría facilitarles su labor.

No, otros documentos traducidos no tenemos, pero deberíamos tener. Aunque fuese algún tríptico, o algún... para decir "Sí, dolor", como han hecho por ejemplo, vi una noticia que había unas enfermeras de Andalucía, me parece, no recuerdo de dónde, que han hecho un material para poder decir "Nauseas" o "Fiebre", y le señala el pictograma, el dibujo... y, por lo menos, lo más básico... [Matrona 5]

Lo que estaría bien es que los papeles del registro civil estuvieran en varios idiomas. Eso estaría muy bien. [Profesional socio-sanitario 3]

Por último, algunos profesionales indican los inconvenientes que observan en el uso de documentos traducidos. Principalmente, señalan, como hemos comentado previamente, el analfabetismo de algunas usuarias y la consecuente imposibilidad para estas de leer los documentos traducidos, así como el hecho de que, al estar editados en una sola lengua, resulta imposible para el profesional saber, por ejemplo, de qué tipo de documento se trata o dónde debe firmar. Además, algunos consideran que las traducciones son un recurso insuficiente, pues indican que, a pesar de que las usuarias inmigrantes entiendan los documentos escritos en sus respectivas lenguas maternas, estas no pueden posteriormente plantear sus dudas a los profesionales, ni estos últimos pueden ofrecerles ulteriores explicaciones.

Lo único que hay traducido a otros idiomas son los consentimientos, eso sí que por lo menos... Pero hay veces que son personas que son analfabetas, y entonces es que te da igual, te hacen una cruz y eso no vale absolutamente para nada... [Anestesista 3]

Lo único, los consentimientos informados, que no siempre los encuentras, y la pega es que solo aparece un idioma, es decir, que por ejemplo, te sacan el árabe, y tú no sabes lo que pone en el árabe, por lo que podría ser por ejemplo el consentimiento de la cesárea y no el de la epidural. Vamos, que no aparece en la misma hoja el consentimiento en castellano y el idioma correspondiente. $Y$ a veces incluso no sabes dónde pone "Firma", y no sabes dónde tienes que firmar, y la paciente me dice "Aquí" y yo firmo, pero no sé si pone "Consiento" o "No consiento". [Anestesista 4]

Aunque tengamos un consentimiento informado en su idioma, al final de todo consentimiento informado dice que aclares las dudas con el médico que te atiende. $Y$ si esas dudas no puedes expresarlas en tu idioma, pues no las puedes aclarar. [Anestesista 5]

(Los anestesistas) tienen los consentimientos en varios idiomas, pero, claro, luego tienen también que explicarle a la paciente cómo ponerse, cómo moverse y todo eso. [Matrona 6]

Yo sé que los consentimientos sí que los tienen en francés, en musulmán, bueno, quiero decir, en árabe, y en otras lenguas. Pero es que las mujeres que van a parir muchas veces no saben leer. $Y$, en ese caso, pues entra el hombre $y$, si tiene la suerte de saber leer, pues entonces se lo lee y lo entienden. [Profesional socio-sanitario 3]

Por lo que se refiere a las usuarias inmigrantes, cabe señalar que parece existir un desconocimiento generalizado por su parte de la existencia de documentos traducidos a sus lenguas maternas.

Yo no he visto (documentos traducidos). [África Subsahariana 1]

No, no, en los centros no tenían nada escrito en francés, y mucho menos en wolof, no... [África Subsahariana 4] 
Todo en español, los documentos son en español, mira. (La usuaria saca de su bolsa una carpeta de documentos. Le explico que no es necesario que me los muestre). [África Subsahariana 5]

Yo no visto papeles en chino. [Asia 1]

I do not know if documents for Pakistanis... I think there is not anything in Urdu. [Asia 3]

¿Aquí? No, no he visto... Lo he visto por la ciudad, me refiero por sitios. Hay sitios que sí que tienen. Y, en algún departamento, por en ejemplo, para niños y eso, sí que algún documento tienen. [Europa del este 1]

Documentos escritos en rumano no he visto, no. [Europa del este 2]

Pues documentos traducidos... no lo sé, esto no lo sé. [Europa del este 6]

Yo creo que no hay documentos traducidos, bueno, no lo sé, no me han dicho nada... [Latinoamérica 2]

No, yo no he visto, no. [Magreb 1]

Yo no he visto. [Magreb 4]

De hecho, solo a 7 de las 25 usuarias entrevistadas se les han entregado dichos documentos, pese a que muchas de ellas, como ya hemos comentado anteriormente, no presentan amplios conocimientos de español.

Sí, sí, sí, hay una vez que yo vengo para ecografía y el médico explicar, pero yo no entiendo y él me da un papel en inglés. [África Subsahariana 2]

Papel de epidural es en chino, eso sí he visto. [Asia 2]

Sí, sí tienen, documento de epidural es en chino. [Asia 4]

(El hermano de la usuaria le traduce la pregunta al rumano y ella responde en esa misma lengua, tras lo cual él interpreta al español sus palabras). Sí, la hoja esa... para entrar a la sala (de partos). Esa está también en rumano. Hay en varios idiomas. [Europa del este 3]

¿Aquí en el hospital? Yo no he visto, no. Lo único que nos han dado con David, nuestro hijo de cuatro años, fue un documento en rumano con las instrucciones para las embarazadas. Antes sí que nos han dado ese libro que decía cómo cuidar a los niños, pero ahora no nos han dado. [Europa del este 5]

Sí, abajo (se presupone que es en el paritorio, que se encuentra en la primera planta del hospital) me dan algún documento escrito en árabe. [Magreb 2]

Sí, esto de la anestesia que tienes que firmar está en árabe. [Magreb 3]

Pasamos a continuación a analizar otra de las soluciones adoptadas en el hospital contexto de estudio, en concreto, el recurso a familiares o amigos de las usuarias alófonas para realizar labores de interpretación $y$, de este modo, facilitar la comunicación entre estas y los profesionales sanitarios. Se trata sin lugar a dudas del recurso más empleado en el hospital contexto de estudio en los casos en los que las usuarias inmigrantes no hablan español, aunque, como veremos más adelante, presenta numerosos inconvenientes y posibles consecuencias negativas.

Son los pacientes los que generalmente traen a alguien que les traduzca. Suele ser alguien de la comunidad o un familiar que lleva más años en el país y un poco controla el idioma. [Anestesista 1] 
Normalmente cuando no hablan, suelen venir acompañadas. Yo no sé qué implicaciones tiene, pero yo si la paciente no habla nada de español y quien le acompaña sí que lo habla, pues él es el que le traduce y luego les hago firmar a los dos, a una como usuaria y al otro como traductor. [Anestesista 4]

A veces también lo que haces es llamar al acompañante si sabe idiomas. Entonces yo lo utilizo como traductor y le hago que se quede durante la punción. Normalmente el marido o el acompañante se salen fuera cuando entramos nosotros, porque hay que... las condiciones de esterilidad se buscan, no se consiguen siempre, pero se buscan cuando pones una epidural. Entonces, cuanta menos gente haya en el lugar, menos contaminación. Pero hay veces en que utilizas al acompañante de traductor. [Anestesista 5]

Pero sí que hemos tenido a veces que depender de que no se vaya el marido o el acompañante, porque si no, ella ya no entiende. [Enfermera 4]

A veces traen a alguien que les traduzca, sí. Y en esos casos, pues va bien, tú le dices que le traduzca y le traduce. [Enfermera 2]

Suelen venir con familiares, amigos... que saben más o menos hablar español, y entonces con la gran mayoría no tenemos ningún problema en que pasen, y les expliquen las cosas y estén con ellas. [Matrona 4]

Pues, a veces, si el acompañante tampoco traduce, le preguntamos si tiene a alguien aquí en el hospital que, por lo menos, entienda. $Y$ en esos casos se hace una pequeña excepción y dejas entrar a un intérprete de su familia, para, por lo menos... [Matrona 5]

Pues le preguntas si habla inglés, aunque no sea mucho, pero con unas poquitas palabras... Y si no, pues paso a alguien, a algún familiar que hable español o... [Matrona 6]

Bueno, pues si las usuarias tienen alguna duda, se supone que está el marido, y te sirve de traductor. [Obstetra 3]

En estos comentarios de los profesionales sanitarios sobre el empleo de familiares o amigos para que actúen como intérpretes entre ellos y las usuarias inmigrantes, se destacan especialmente el colectivo magrebí y el chino.

$\mathrm{Y}$ a veces traen ellas mismas gente que conocen para que les traduzca. Es que normalmente, por regla general, en los matrimonios chinos, si ninguno de los dos sabe español, pues se traen a una persona. En el caso musulmán, él suele saber siempre español, ella no, pero él sí. Los rumanos sí que se defienden muy bien, tanto él como ella. La gente de color, pues... también, aunque recurren mucho más al francés. Pero, vamos, en general, todos cuando les dices que por favor llamen a alguien, o hablas con ellos por teléfono y tal, pues sí que... nos solemos poner de acuerdo. [Enfermera 1]

Pues muchas veces se recurre a familiares, porque muchas veces vienen acompañadas de gente que sí que tiene un conocimiento del idioma. Por ejemplo, las pacientes chinas casi siempre vienen acompañadas de alguien que tiene un buen control. Las árabes suelen venir acompañadas de su pareja, y entonces la pareja sí que se defiende un poquito mejor y puedes comunicarte a través de ella. [Enfermera 3]

La verdad es que normalmente suelen venir con alguien que entiende. [...] Entonces, casi siempre vienen acompañadas. Sobre todo hay muchas chinas. Chinas que se ve que acaban de llegar. Deben de estar llegando remesas enteras en poco tiempo. Porque esas sí que vienen siempre con alguien. [Enfermera 6]

[...] si está la pareja, como el mayor problema lo tienes con las marroquíes y los hombres marroquíes no suelen tener problemas con el idioma, pues te comunicas a través de él. [Matrona 2]

Cuando hay problemas lingüísticos, pues los resolvemos intentando que alguien te traduzca. Porque muchas veces los maridos sí que hablan mucho mejor castellano que las mujeres. Por ejemplo, en el caso 
de los árabes, muchas mujeres no hablan castellano, otras sí, ¿̇eh?, pero hay muchas que no. Entonces, en esos casos, se intenta que los maridos te traduzcan. [Matrona 3]

Porque a lo mejor las magrebíes no saben tanto el idioma, pero el marido, sí. Porque generalmente primero vienen los maridos a trabajar y, cuando ya están estabilizados, se traen a la mujer. Entonces, en esos casos, el marido está presente, y les explica para que colaboren. [Matrona 7]

Los chinos son los que tienen menos problemas, esos sí que saben más y... son más espabilados que la leche (Risas). Es verdad, ¿eh? Se comunican mejor porque siempre vienen con alguien que entiende más que ellos y les hace como de traductor. [...] Porque ellos ya se buscan sus intérpretes, por ejemplo, yo con los chinos siempre veo a la misma que les hace de traductor... [Profesional socio-sanitario 2]

La mayoría de los profesionales ven ventajas en el empleo de familiares o amigos como intérpretes, como su amplia disponibilidad horaria o la cercanía de estos con la usuaria, y opinan que les facilitan o permiten la comunicación con esta en aquellos casos en los que las barreras lingüísticas por desconocimiento del idioma les impiden comunicarse.

Hay ocasiones en que te da la sensación de que las usuarias no se enteran y hay otras en que sí. Y lo que hacemos, porque normalmente cuando les pinchamos y eso el familiar se va fuera, pero en estos casos, yo les dejo dentro, para que ellas tampoco no se sientan tan... tan aisladas. Aparte de que a ti te facilita tu trabajo, porque tú tienes que interactuar, interaccionar con la señora para poder trabajar. [Anestesista 2]

Y cuando traen a alguien que les traduzca, pues, bueno, no es lo ideal, pero a ti te solventa por lo menos las cosas que a ti te preocupan. Aquello que tú crees importante que le tienes que preguntar, lo puedes hacer. Entonces, por lo menos lo gordo, lo descartas. No es lo ideal, pero... [Anestesista 3]

[...] con las que no hablan nada, nada, nada, desde luego el acompañante sirve de traductor. Y la experiencia con el acompañante que hace de traductor es útil, yo creo que sirve, sí. [Anestesista 5]

Pues, a ver, lo que yo veo es que si la persona (el acompañante que hace de intérprete) está aquí, siempre en algún momento, cuando tengas una duda, pues siempre puedes recurrir a ella. $Y$, aunque la comunicación no sea muy fluida, siempre está ahí, ¿̇abes? [Enfermera 1]

Cuando algún familiar o algún amigo han hecho de intérpretes, la verdad es que nunca he tenido ningún tipo de problema. Él traducía lo que la mujer decía y lo que decíamos nosotros, y yo no he tenido ningún tipo de problema. Hombre, sería mejor que tú pudieras comunicarte con esa persona sin tener ningún problema ni tener que depender de nadie. Porque, claro, si resulta que esa persona se ha tenido que ir por cualquier motivo y tú pasas con el médico y esta persona no está, pues no va a haber manera de saber si la paciente está bien, si le duele o... Entonces, es preferible, pues eso, poder no depender de nadie. Pero, vamos, por mi experiencia con terceras personas yo nunca he tenido problemas, al revés. [Enfermera 4]

Cuando es un familiar, un amigo, un conocido o lo que sea que hace de traductor, normalmente nos ayuda a comunicarnos, sí. Incluso, fíjate, con los árabes, que les tienes que decir "Pregúntale cuándo fue la regla. Pregúntale cómo la tiene...". Y tú ya sabes los árabes cómo son para esas cosas... Y le tiene que preguntar el varón a la mujer, porque normalmente, los árabes ellos saben español, pero ellas no suelen hablar, porque claro, como las tienen... [...] Y, en cambio, te diriges a ellos y les dices "Pregúntale que tal...", y, oye, les preguntan. [Enfermera 6]

Yo, en los casos que me he encontrado, yo creo que ha ido bien, ha sido positivo. Incluso yo creo que mejor, ¿no? Porque estamos todos mejor, sabemos de lo que hablamos... Tú te encuentras mejor también, porque no te encuentras tan limitada y ves que alguien te entiende y está receptivo y entonces estamos los dos en la misma sintonía. Y yo creo que ellos también, ¿no? Se enteran de por qué hago esto o aquello, saben si está yendo bien o mal... [Matrona 5] 
Cuando el marido o un familiar hacen de intérprete, generalmente, sí que se solucionan los problemas de comunicación. Porque él les explica y así... [Matrona 7]

Muchas veces sí que hemos utilizado como intérprete a algún familiar o amigo que hablara español y la lengua de la paciente. Si vemos que entre ellos hay una buena relación, casi es preferible, porque si es un familiar íntimo, que a la paciente no le importe que se entere de cosas, entonces, pues casi es mejor... [Obstetra 1]

La experiencia con familiares o amigos que hicieran de intérpretes a mí me ha ido bien. [Obstetra 2]

Muchas veces vienen con un acompañante que sabe algo de español, y eso nos ayuda en la comunicación totalmente, sí, totalmente. Para mí es una liberación. [Profesional socio-sanitario 3]

Además, algunos ven incluso como una obligación de las propias usuarias el acudir al hospital acompañadas por alguien que les ayude a comunicarse en caso de que desconozcan la lengua propia de los profesionales sanitarios.

En general (las usuarias) no vienen con alguien que les traduzca, no vienen preparadas, lo que pasa es que aquí se les dice que, hombre, sería mejor, ¿no? Pero yo no creo que tengan la concepción de que tengan que buscar a alguien que les traduzca y eso, simplemente vienen, y vienen, sin preocuparse de si les entienden o no. Eso creo, ¿̇eh? [Anestesista 2]

Porque, claro, muchas veces a ellas (las usuarias inmigrantes) les dices "¿Puede venir alguien a traducirnos?" y te responden "No, es que está trabajando". [Enfermera 1]

(Si traen las usuarias a alguien que les traduzca) en algunas ocasiones sí y en otras no. Normalmente, los maridos suelen hablar mejor que las mujeres, no sé si es porque han venido a trabajar antes, o por el proceso migratorio, sin más, porque digamos que hacen más vida social. Pero, eso es solo en ocasiones, ¿eh? No siempre traen los traductores. Sería estupendo... [Matrona 1]

Bueno, claro, hay muchas señoras, muchas mujeres, que cuando llegan aquí no tienen ni idea de nuestro idioma, y entonces les aconsejamos siempre que se busquen a alguien que les haga de intérprete. [Obstetra 1]

$Y$ yo he trabajado tanto en consulta como en urgencias, y las dificultades, yo... sobre todo en las urgencias, porque no planifican la visita muchas veces, y vienen solas, o como mucho con el marido, y pocas veces con un intérprete. Y luego también en las consultas. Lo que pasa que en las consultas ya sí que vienen casi siempre o con el marido que habla (español) o, por ejemplo, los chinos igual vienen con algún compañero o con algún familiar que les hace de intérprete. Pero sobre todo es en las urgencias donde es más complicado, porque no vienen con intérpretes. [Obstetra 3]

Yo también me hice un cartel que pone "Por favor, vengan acompañados de alguien que hable nuestra lengua", porque acudían a las consultas sin decir ni media palabra, ni acompañante, ni habiéndolo solicitado previamente, con lo cual no daba tiempo de solicitarlo y tal... [Profesional socio-sanitario 1]

Pues, hombre, pocos son los que no hablan nada de nada. $Y$ en esos pocos casos, pues vienen con alguien, o si no, intentamos que vengan con alguien, se les dice que vengan con alguien... [Profesional sociosanitario 2]

Sin embargo, otros profesionales son conscientes de los problemas que puede ocasionar la falta de preparación y formación de los familiares y amigos de la usuaria para ejercer como intérpretes. Al respecto, algunos señalan la falta de conocimientos lingüísticos generales, o el desconocimiento de la terminología y los conceptos básicos propios del ámbito sanitario. 
Normalmente te traduce el marido, [...] que tampoco es gente que tenga unos conocimientos... o sea, que tiene que ser todo como muy casero, vamos, tenemos que explicárselo a él para que se lo pueda explicar. [Anestesista 2]

Y es que la comunicación no es la misma. Porque tú estás con una persona que le está contando bien, se supone, lo que tú quieres decir, pero es que hay muchas ocasiones en las que, hablando con esa persona, te das cuenta de que tampoco te entiende al cien por cien lo que tú le estás diciendo. Entonces dices, muchas veces dices “¿Le estará diciendo lo que yo quiero que le diga?” [Anestesista 3]

Por otro lado, pues claro, pues siempre te queda la duda de si lo habrá entendido bien. Y entonces, como que hay mucha repetición “¿Seguro” ¿Seguro que... esto?”. Y entonces con el intérprete (profesional) pues sí que te sientes más seguro tú, a la hora por ejemplo de preguntar por alergias. Como con los familiares o conocidos es un poco chapurreao, por decirlo de alguna manera... [...] Sí que tienes la facilidad de eso, de que siempre tienes el móvil o lo tienes ahí, por lo que te da comodidad, por así decirlo, pero esa comodidad hay veces que te da inseguridad. Porque siempre te quedas "¿Seguro que me habrá entendido?". Porque hay mucha gente que te dice "Sí, sí", pero en su cara estás viendo que es que no, por mucho que te estén diciendo que sí. Y entonces, como no te terminas de fiar, por miedo también a... por cubrirte un poco también tus espaldas, porque si yo a una persona le doy algo a lo que es alérgico, pues imenuda faena! Tanto para ella, como para mí profesionalmente. Por eso hay veces que sí que te intentas asegurar por varias vías familiares de que lo que has preguntado sí que lo están entendiendo. [Enfermera 1]

Porque hay veces que aunque te venga un familiar y tú le expliques que está dilatando muy despacio y que le estás poniendo una medicación, si él no se lo puede decir porque sus conocimientos no le dan para explicarle eso, pues tampoco sirve de mucho... [Matrona 4]

Algunas sí que vienen acompañadas, o saben ellas mismas el idioma, pero muchas vienen acompañadas de una que habla todavía menos. Y te dicen "Sí, sí, sí" y "Sí, sí, yo entender", pero, vamos, que no te han entendido. [Matrona 5]

Siempre y cuando el familiar hable bien tu idioma, claro, porque si te encuentras que habla igual de mal que la paciente, pues, entonces, no sirve de nada. [Obstetra 1]

[...] porque si el intérprete es un familiar, a lo mejor, según qué palabras ya más especializadas, pues a lo mejor, no sabe explicárselas o decírselas en su idioma. Me refiero a términos médicos y cosas de esas... [Obstetra 2]

Asimismo, diversos profesionales entrevistados muestran preocupación con respecto al posible incumplimiento de los principios de fidelidad e imparcialidad, y presentan dudas acerca de si existen omisiones, ampliaciones, condensaciones o intercambio de roles por parte de estos intérpretes ad hoc. En relación a esta cuestión, mencionan especialmente a las usuarias de origen magrebí, pues algunos profesionales opinan que, cuando sus maridos realizan funciones de intérprete, no siempre son fieles a la hora de transmitir el mensaje que intercambian los interlocutores (la usuaria, por un lado, y el profesional sanitario, por otro).

Aunque muchas veces se queda algún familiar, que normalmente suele ser el marido, que hace de traductor, y ahí sí que puede haber una influencia de tipo más cultural, por las creencias religiosas y tal. Porque muchas veces es el marido el que dirige un poco el cotarro, y ya no sabes si él te dice lo que la señora está diciendo o lo que él quiere que diga. [Anestesista 2]

Muchas veces tienes que insistir "No, pero pregúntale si...". Porque también a veces pasa que, si quien traduce es la pareja o el acompañante, que se supone que es el marido, te contesta él sin hablar con ella. Y tú: “No, pero pregúntale". Y tú qué sabes lo que le está diciendo, no lo puedes saber. [Anestesista 2]

Y normalmente si alguien no habla, suele venir con el familiar que sí entiende, muchas veces las mujeres árabes dicen que no entienden, o no entienden de verdad, porque son las que más están en casa, y el 
marido sí que habla español. Y se han dado casos en los que no sabes lo que se está traduciendo, porque ves perfectamente que una quiere y el otro no quiere, y yo realmente no sé cómo se le está traduciendo o si se le está condicionando, es decir, qué le está contando, lo bueno, lo malo o las dos cosas... porque lo ves muy claro, que su comportamiento va dirigido. [Anestesista 4]

Cuando el marido hace de traductor, yo doy por hecho que le está contando todo lo que le estoy diciendo, y luego ya si aceptan o no aceptan es cosa de ellas. Las cuestiones culturales, o cómo las dirijan a ellas, eso yo ya no puedo controlarlo... Simplemente damos un servicio y yo tengo que hacerlo lo mejor posible. Por eso, voy a explicar lo que tenga que explicar, los inconvenientes, ayudarles si tienen dudas, pero que ya cómo actúen ellos yo ya no... [Anestesista 4]

Si un familiar o conocido hace de intérprete, pues ayudar sí que te ayuda, pero claro, siempre te queda la duda de... de lo que realmente le está transmitiendo, si realmente le está diciendo toda la información que tú quieres o cómo la está transmitiendo. [Enfermera 3]

(Cuando traen a alguien que les traduzca) es casi una liberación, porque te permite trabajar con mucha más facilidad. Y bueno, si confías en que se lo esté traduciendo bien... Por lo menos, es una forma de comunicarte. [Matrona 1]

Cuando el marido o un familiar hacen de intérpretes a veces sí que puedes tener el problema de que no sabes si lo que le estás diciendo se lo está traduciendo tal cual o le está cambiando la versión. Aquí no lo he vivido porque no tengo mucha experiencia aquí, pero hice la residencia en Lérida, y allí había mucha marroquí, y entonces ahí sí que es verdad que a veces con el tema de la anestesia pues tú no sabías lo que te estaba diciendo ella, porque lo estaba diciendo en su idioma, el marido te lo traducía a ti, pero no sabías si lo que te decía era la verdad o no era la verdad. [Matrona 2]

Pues, a veces, esta experiencia es... desagradable. Porque no te permite interactuar directamente con la mujer en condiciones. Muchas veces dependes del feeling que tengas con el marido. O sea, si, por ejemplo, te parece un tío, así, como un poco dictador, estás pensando “¿Qué le estará diciendo?”. Porque muchas veces los árabes no dejan que sus mujeres se pongan epidural. Entonces tú le estás explicando, y él está traduciendo, y tú estás pensando "No sé lo que le está diciendo". Ahí sí que no llegamos, ahí nos quedamos... [Matrona 3]

Por otra parte, algunos profesionales desconfían de que, al emplear a familiares o amigos como intérpretes, se mantenga la confidencialidad o la intimidad necesarias en este contexto.

[...] o te los pasan por teléfono y te explican que es el primo de... que realmente te preguntas hasta qué punto se respeta la protección de datos o de la intimidad del paciente. [Enfermera 1]

Cuando un familiar hace de intérprete es más fácil. Lo que pasa es que, claro, también depende un poco de la relación que tenga esa mujer con el intérprete, porque estás en un momento muy importante, ¿no?, muy significativo. $Y$, a lo mejor, estar con una persona que es la primera vez que la ves o que es algún amigo de la familia, pero que... Pues, hombre, es que es momento muy íntimo, muy particular... Y, entonces, a lo mejor hay cosas que la mujer no expresa porque no se las va a decir a él para que te las diga... O puede haber situaciones que te resultan un poco... un poco violentas. Vamos, que depende de la relación que tengan. [Matrona 4]

Por último, algunos profesionales entrevistados afirman haber recurrido a la comunicación telefónica con algún familiar o amigo, así como a otras usuarias ingresadas en el mismo hospital o incluso a niños, para que realizaran labores de interpretación, sin ser muchas veces conscientes de las consecuencias que esto podría acarrear, especialmente en el caso de los menores, pues tener que actuar como intérpretes podría suponer para ellos un gran impacto emocional, por su cambio de roles en el contexto familiar y por recibir información de carácter demasiado grave para su grado de madurez. 
Que yo he llegado a pedir a una persona que no tenía nada que ver con la paciente que me hiciera de traductor, que dices tú "Es que... es que esto no tiene sentido lo mires por donde lo mires". [Anestesista 4]

[...] puede ser una prima, una hermana, incluso alguna vez hemos tenido a las hijas de pacientes que se operaban. (Se pregunta al entrevistado si en alguna ocasión se ha recurrido a menores). Sí, si hemos utilizado a menores para hacer de traductor. $Y$, a veces, incluso he utilizado el teléfono móvil para hablar con familiares y explicarles a ellos las cosas. Pues el sobrino sabe español y chino, y traduce a su tío español y chino. [Anestesista 5]

Y entonces muchas veces estás a la espera. "Espera un momento, que te paso a mi prima, que sabe español o que sabe inglés", y tú esperas para hablar con ella... [...] no he tenido nunca ningún problema, como te comentaba, para hablar con algún familiar que me han pasado al teléfono. Así que no, en este aspecto, pues bien... [Enfermera 1]

Pues, ya te digo, te intentas hacer entender con palabras, gestos, o en inglés, de alguna forma y tal, y si no, dependemos de algún familiar o de los hijos más mayores, que ya igual tienen amigos aquí y saben más español, y entonces te traducen ellos. Porque si no, tampoco... [Enfermera 4]

Según qué personas hay, las uso de intérpretes yo. Les digo "¿Tú eres rumana y hablas rumano y español? Pues, vente conmigo que me vas a ayudar a preguntarle a esta paciente". Vamos, hago como conjuntos. Con los árabes, también. Y ellos colaboran muy bien. [Enfermera 5]

$\mathrm{Y}$, a veces, cuando pasamos en los puerperios por el tema de las lactancias, con muchas no te entiendes $\mathrm{y}$, con el teléfono móvil, pues te comunicas con una amiga o una hermana, o a quien te pasen y le explicas... Pero, bueno, eso no es un servicio oficial, aunque sí que es algo que se hace. [Matrona 3]

Generalmente es el marido. Pero alguna vez sí que ha pasado que se recurre a la hermana pequeña. Por ejemplo, en el caso de algunas chinas, se ha pasado a la hermana pequeña. $Y$, claro, son situaciones en las que tienes que explicarle a una persona más jovencita, no sé, si sangra o algo de eso. $Y$, claro, se puede montar en su cabeza una película que no es, ¿no? Y, entonces, sí que se puede dar alguna situación algo más tensa. Pero, por lo general, pasa el hermano o la hermana, o pasa el marido y, si dominan bien el idioma, no hay problema... [Matrona 6]

Muchas veces vienen con un acompañante, o les preguntamos si puede venir algún familiar. O incluso alguna vez hemos tenido que hablar por teléfono con algún familiar o algún amigo. [Obstetra 2]

Aquí, cuando me ha pasado, pues le he pedido que llame la paciente por teléfono a alguien. Sobre todo los chinos eso sí que lo hacen mucho, y te pasan con alguna amiga o con algún compañero de trabajo que habla chino y español. Eso es lo que consigo... [Obstetra 3]

Yo, cuando ha hecho mucha falta, incluso he buscado, por ejemplo, persona que habla un dialecto africano, pues me he recorrido las plantas buscando a algún negro que sea capaz de traducir. [Profesional socio-sanitario 1]

Se recurre muchas veces a parientes, amigos, o incluso compatriotas que se encuentran en el hospital. ¿Y niños? ¿Para interpretar a sus padres? Sí, los hemos utilizado muchas veces. Los críos son más hábiles aprendiendo los idiomas y hay fundamentalmente mujeres que no hay forma de que lo aprendan y sus hijos les traducen. [Profesional socio-sanitario 1]

Por su parte, las usuarias inmigrantes no hispanohablantes entrevistadas también cuentan haber recurrido, actualmente o en el pasado, en su periodo inicial de residencia en España, a familiares o amigos para que realizaran labores de interpretación y les ayudaran a entender las palabras de los profesionales sanitarios. ${ }^{253}$ Estos intérpretes ad hoc han sido principalmente los

253 De la misma manera, cabe además recordar que, durante la realización de las entrevistas a determinadas usuarias, en algunos casos empleamos a los acompañantes de estas para que actuaran como intérpretes entre ellas y la investigadora. 
maridos de las usuarias, sus hijos o algún otro familiar o amigo con un mayor dominio del español que ellas.

Al principio era muy difícil, y cuando yo tener problemas de este, yo siempre venir con alguien. [África Subsahariana 1]

Cuando no entiendo, me voy con mi cuñada y ella me ayuda. [...] Y al principio iba al médico con alguien, con una amiga que está mucho tiempo aquí y hablar bien español. Y ella me traducía. [África Subsahariana 2]

Al principio, sí, me acompañaba mi marido que ya sabía español. Porque él vino antes, vino en el 99, y yo en el 2005. [África Subsahariana 4]

Al centro de salud a veces vas con mi hijo. Él ayuda a entender... [...] Y a veces yo vengo al médico con algún amigo, siempre que puedo traer amigos, sí, yo traer amigos... [África Subsahariana 5]

Cuando no entiendo, llamar a mi marido y preguntar. [Asia 2]

Si no entiende, llamo mi marido, entonces él explica y está bien. [Asia 2]

My marido comes sometimes, and he knows Spanish better. [Asia 3]

A veces difícil, pero está mi novio, que entiende todo porque está mucho tiempo aquí. [Asia 4]

(Le pregunto si le acompaña alguien para hacerle de intérprete y responde directamente el hermano de la usuaria). A veces le acompaño yo, depende del problema. [Europa del este 3]

Antes, cuando tenía problemas, venía conmigo mi prima, que llevaba más años aquí. Por ejemplo, ella me acompañaba siempre cuando nació la primera niña. Y entonces ella me traducía lo que decía el médico. Y así podía entender. [Europa del este 6]

Sí, alguna vez he venido con alguien, sí, y me ha ayudado, claro. [Magreb 1]

Me acompaña antes siempre mi marido para traducir. Él habla mejor español. Cuando tener mi primer hijo, él cambia cada día el trabajo para yo no estar sola. [Magreb 2]

A veces, mi hija primera, que vino cuando tenía tres años y habla muy bien español, me ha traducido. [Magreb 3]

Mi marido me ayuda y, si no entender, traducir. [...] (Interviene el marido de la usuaria) Y cuando llega aquí, su primero tiempo, una amiga de familia nos acompaña, pero hace ya mucho tiempo. Ahora, a médico del pueblo vamos solos los dos. [Magreb 4]

Algunas señalan diferentes situaciones comunicativas en las que, dependiendo de la importancia que atribuyan a los asuntos tratados, consideran más necesario el emplear a familiares o amigos como intérpretes.

Cuando era revisiones, yo pasa sola. La médica explícalo y eso son cosas fáciles. Pero cuando nace la niña, como yo necesita, porque son cosas importantes, entonces va mi marido. [Asia 2]

Hay también amigos, depende de... Depende de problema. Depende del problema o de dónde vas y... Al mercado voy sola o al cine o... Pero al médico sí me acompañan. [Europa del este 3]

Por lo general, la mayoría de las usuarias que han recurrido a estos intérpretes ad hoc opinan que les ha resultado útil y que, de este modo, han conseguido comunicarse con los 
profesionales sanitarios. Ninguna de ellas parece ser consciente de que, en los casos en los que los conocimientos de español por parte de dichos familiares o amigos tampoco son demasiado amplios, o su falta de formación en interpretación podrían derivar en pérdidas de información, malentendidos u otros problemas de comunicación.

Pues bien, cuando alguien traduce, es bien. [África Subsahariana 1]

Cuando me acompañaba mi amiga, ella me ayudaba, ella traducía y yo entiendo, sí. [África Subsahariana 2]

Cuando me acompañaba mi marido y traducía, la experiencia era mucho mejor. [África Subsahariana 4]

Cuando viene un amigo, me ayuda. Comprendo mejor si viene amigo... [África Subsahariana 5]

Sometimes I go with marido. Good, it is good. Like this you understand. [Asia 3]

A veces me ayuda mi novio. Ayuda mucho, sí, mucho. [Asia 4]

Cuando acompañan, sí me ayudan, ayuda mucho. [Europa del este 3]

Bien, cuando vienes con alguien, siempre bien, a mí ayuda. [Magreb 1]

Bien, cuando él (su marido) traduce, está bien. Yo entiende mejor. [Magreb 2]

Cuando traduce mi hija, me ha ayudado mucho. [Magreb 3]

Bien, bien, cuando llega aquí, dos meses o tres meses, amiga acompaña y ella ayuda a comprender médico, sí. [Magreb 4]

La siguiente solución adoptada por el hospital contexto de estudio que vamos a analizar consiste en el recurso a servicios de interpretación proporcionados por entidades externas. Cabe recordar en este punto que, tal y como hemos comentado en el apartado de análisis documental, los servicios sanitarios de Zaragoza han contado en los últimos años con servicios de interpretación tanto presencial como telefónica, provistos respectivamente por la Casa de las Culturas, por un lado, y por las empresas Interpret Solutions y Dualia, por otro.

De las respuestas ofrecidas por los profesionales sanitarios entrevistados, la primera cuestión que podríamos resaltar en relación con estos servicios es el gran desconocimiento y la infrautilización de los mismos.

No lo sé. La verdad es que los que hay no sé de quién dependen, si es un servicio oficial o si es algo voluntario. [...] El centro, propiamente, yo creo que no cuenta con intérpretes. Hay intérpretes, o mediadoras interculturales que llaman, que creo que si se les llama, vienen. Pero que trabajen aquí y eso, no. [Anestesista 2]

No, no, el centro no cuenta con intérpretes. [Anestesista 3]

Sé que hay forma de resolver los problemas lingüísticos, parece ser que con teléfonos y tal, pero yo no lo he utilizado, no, no lo he utilizado. Porque en realidad mi intervención con extranjeras es principalmente de urgencias. [Anestesista 5]

Por ejemplo, yo con los chinos sí que he hablado a través de un traductor. Al principio, venía el traductor aquí, y ahora sí que creo que hay un servicio de interpretación por teléfono, aunque no sé de quién depende. [Enfermera 5]

Yo no he utilizado nunca el servicio que teníamos llamando al número ese. [Enfermera 6] 
(Tras observar en preguntas anteriores la desinformación por parte de la entrevistada, se le pregunta directamente si conoce el servicio de interpretación telefónica y si lo ha empleado alguna vez) No, no lo conozco y, por supuesto, no lo he empleado nunca. [...] Pero traductores presenciales, creo que sí que hay. Creo que hay mediadoras en el hospital. No sé de dónde son las que trabajan aquí, pero en otros hospitales había del mundo árabe, y alguna que hablase creo que rumano. [Matrona 2]

Ay, no lo sé, corazón, no tengo ni idea. (Risas) Supongo que aquí en la Unidad de Asistencia Social, si no los tiene el hospital aquí presentes, sí que puede contactar con intérpretes. [Obstetra 1]

Hasta ahora existía un servicio de... guía telefónica, que podías hablar, les llamabas y decías "Oye, este es ruso, o es senegalés"... Pero creo que llevamos ya varios meses que ya no existe ese móvil con el que te ponías en contacto con los traductores. [Profesional socio-sanitario 3]

Por otra parte, numerosos profesionales sanitarios no ven la necesidad de emplearlos y algunos afirman, por ejemplo, que consiguen comunicarse usando otros métodos, principalmente el recurso a familiares y amigos de las usuarias para que realicen labores de interpretación.

Pues no sabía que había un servicio de interpretación telefónica, pero si no lo usan, será porque siempre hay alguien de la familia o del entorno de la paciente que les puede ayudar. [Anestesista 2]

Claro, es que yo creo que recurres a ello cuando ya... cuando la comunicación es nula, pero si te vas apañando con lo poco que puedan saber ellas, con lo que te cuenta el marido, o con lo que sea, pues por eso igual no se utiliza... [Matrona 3]

Sé que existe un servicio de interpretación telefónica, pero no lo he usado nunca. Porque como siempre ha habido alguien que ha solucionado el problema de la comunicación, no ha hecho falta. [...] Pero aquí no contamos con ningún intérprete oficial. Lo que sí que se hace, como te decía antes, es recurrir a algún familiar o a un amigo que hable español. [Matrona 6]

Sí, yo siempre he visto, al menos en las plantas, unos teléfonos a los que podemos llamar en caso de problemas de comunicación. Pero yo nos los he usado nunca, porque no he tenido necesidad de usarlos. Pero vamos, si tuviera la necesidad, no tendría ningún problema en usarlos, la verdad, están para eso. [Enfermera 4]

Sé que hay un servicio de interpretación, sé que hay un teléfono al que puedes llamar, pero en el tiempo que llevo aquí yo no lo he usado [...] porque en la consulta suelen venir con alguien que les traduzca y, como es más o menos básico lo que digo y se lo pongo por escrito... [Obstetra 3]

Aparte del servicio de interpretación telefónica, o antes de la Casa de las Culturas, se recurre muchas veces a parientes, amigos, o incluso compatriotas que se encuentran en el hospital. [Profesional sociosanitario 1]

Además, algunos aducen que desconocían la existencia de estos recursos, a pesar de que nos consta que en el hospital se han realizado campañas informativas sobre los mismos.

En el hospital no contamos con ningún traductor, y el servicio de traducciones (telefónicas) ni nos dicen muy bien cómo funciona, ni sabes a qué horas está disponible, ni dónde está.... Vamos, que a mí nadie me ha dicho dónde tengo que llamar, ni cómo tengo que hacerlo, ni a qué hora, ni a qué empresa, ni si esas conversaciones quedan grabadas o no quedan grabadas, no sé si lo que se está diciendo... sí, sé que me tengo que fiar porque es un traductor, pero lo que no sé es cómo funciona eso... Ni si es algo oficial que depende del SALUD. La verdad es que no nos han informado. [...] Está el traductor, pero realmente los que firman sois tú y el paciente. ¿Queda registrado que se llamó, el nombre del traductor que tradujo...? [Anestesista 4] 
Yo sé que había por ahí un papel circulando que decía que se puede llamar a un intérprete que te ayuda por teléfono. Pero, chica, a mí eso no me ha llegado, ni sé cómo funciona, ni... Yo sé que las compañeras de admisión lo leyeron en la revista, que lo iban a poner y tal, pero ni siquiera sé si finalmente lo han puesto o... [Profesional socio-sanitario 2]

Concretamente en relación con el servicio de interpretación presencial, no todos los profesionales sanitarios entrevistados parecen estar al corriente de que dicho servicio se ha eliminado.

Pues, hasta hace poco, y me imagino que ahora con los recortes se habrá eliminado, había un servicio en el que personas de las mismas comunidades, había un servicio para rumanos, para chinos, etc., que hacían de intérpretes y dependían de algún organismo oficial y muchas veces podían venir cuando no se les necesitaba en ese organismo y... pero vamos, me imagino que con los recortes este tipo de servicios habrán desaparecido. [Anestesista 1]

Hemos tenido muchísimo, incluso había un servicio de intérpretes con la Casa de las Culturas, con los que te podías poner en contacto. [Enfermera 5]

Y también creo que podemos llamar a la Casa de las Culturas cuando tenemos un problema. Aquí teníamos un cartel que decía dónde podíamos llamar cuando teníamos un problema, pero creo que lo han quitado estos días. Nos han dicho que lo han eliminado. Lo que hay ahora no lo sé. [Enfermera 6]

Antiguamente, hace unos años, colaboraba con nosotros la Casa de las Culturas. Y, entonces, por ejemplo, para poder ponerle la epidural y que la mujer colaborase... [...] Entonces, antiguamente, sí que venían de la Casa de las Culturas y les explicaban en su idioma y tal, y con el intérprete presente la ponían. Y ahora, pues... tenemos el teléfono de la Casa de las Culturas, que si queremos se puede llamar... [Matrona 7]

Asimismo, algunos profesionales apuntan como desventajas la limitación horaria de este servicio y el hecho de que se tuviera que solicitar con antelación y no se pudiera contar con la presencia del intérprete de manera inmediata.

Para mí, los dos sistemas valen. Hombre, el telefónico es muy rápido, el problema del otro es que tardaba en venir. [Enfermera 5]

Hombre, yo creo que el hospital sí que tiene traductor. Yo creo que sí que hay, en las plantas creo que sí que lo utilizan más, porque tienen como un horario determinado. Aquí no lo utilizamos, vamos, yo no lo he utilizado nunca. [Matrona 3]

Pues creo que sí que hay intérpretes, pero, claro, no están las veinticuatro horas, y muchas veces tampoco los utilizamos, porque como suelen traer siempre a algún familiar... [Matrona 4]

El problema de los profesionales es su horario limitado. Por ejemplo, en urgencias, cuando los necesitas, a veces no coincide con el horario del intérprete. [Obstetra 3]

Antes, cuando trabajábamos con la Casa de las Culturas, se solicitaba el servicio de traducción previamente, tenían que avisar de que iban a venir, y entonces lo pedíamos a la Casa de las Culturas. Pero, inmediatamente, era imposible, porque ellos tenían que contactar con el traductor y que viniera. [Profesional socio-sanitario 1]

$\mathrm{Y}$, en cuanto al servicio de interpretación telefónica, muchos profesionales la ven como un recurso incómodo, complicado, con el que se pierde cercanía con la usuaria o que requiere que empleen más tiempo del habitual para comunicarse con las usuarias, siendo el tiempo algo que escasea en su rutina laboral diaria.

Y también había en un inicio eso de los... traductores por teléfono. Y eso es como si te abanicas, porque no vale para nada. [...] Lo que sí que sé es que había, o hay, un servicio de interpretación telefónica, pero yo 
no lo he usado nunca, jamás. Sé que existe porque mi mujer es enfermera y ellos sí que lo han usado a veces y dicen que es horrible, que no vale para nada. [Anestesista 3]

Es que si el hospital no pone traductores, porque con el servicio (de interpretación telefónica) se pierde mucho tiempo, si estás al teléfono yo creo que en consulta lo que son 15 minutos te cuesta una hora y pico, y eso es inviable... Así que el acompañante hace de traductor y ya está. [Anestesista 4]

Con el intérprete (profesional) te puedes sentir más segura, aunque no es tan cómodo, pero realmente es más seguro. Y no lo veo tan cómodo por el tema del teléfono. Porque si tuviéramos un intérprete en el hospital sería maravilloso. Podrías avisarle y decirle "Oye, por favor, ¿puedes subir, que me pasa esto?" ¡Madre mía! No te tendrías que comer la cabeza. [Enfermera 1]

Sé que hay un servicio de interpretación telefónica, pero yo nunca lo he utilizado. A veces... yo creo que es complicado y, además, hacerlo... no sé, a través del teléfono yo creo que también se pierde un poquito de... de intimidad, de cercanía con la mujer, con lo que te está diciendo a través del teléfono la otra persona... [Enfermera 3]

No creo que se tan complicado utilizarlo, lo que pasa es que tienes que perder tiempo, entonces también depende de cómo estés. Porque ahora estamos muy tranquilas, pero de repente puede subir una curva de partos y... ya no tienes tiempo de nada, o sea, es un poco sobre la marcha. [Enfermera 5]

Creo que hay un servicio como de traducción... simultánea telefónica, pero no usa prácticamente nada, y las veces que se ha intentado usar ha sido un fracaso, o sea que... Lo hemos descartado. [Matrona 1]

Y si no te entiendes nada, nada, nada, pues hay un teléfono en urgencias con el que te puedes poner en contacto con algún traductor. Pero, claro, no es tan fácil tampoco a veces... Digamos que lo del teléfono para ponerse en contacto con un traductor yo lo uso ya como último recurso. Yo creo que es un poco por el tiempo. Pensamos que con el teléfono vamos a perder más tiempo o... Como que te intentas apañar, y no sé si no lo usamos por tiempo o por intentar solucionar tú mismo la cosa. [Obstetra 2]

Y, luego, además que tienes treinta y tantos pacientes y ya si te pones a llamar, pues vas con un poco más de presión, por el tiempo y tal. [Obstetra 3]

Ahora, como te decía, contamos con un servicio de interpretación telefónica, que, para mi gusto, tiene todas las ventajas. Lo que ocurre es que es imprescindible la rapidez, porque si un médico la pide desde la consulta y tiene cincuenta esperando y le tienen al teléfono seis minutos, cuando el tiempo de consulta medio es cinco, pues no lo puede utilizar. [Profesional socio-sanitario 1]

Además, uno de los profesionales entrevistados muestra preocupación por el hecho de que no quede constancia de que se ha empleado este servicio para comunicarse con una determinada usuaria ni se registre el nombre de la persona que realizó la interpretación.

Está el traductor, pero realmente los que firman sois tú y el paciente. ¿Queda registrado que se llamó, el nombre del traductor que tradujo...? Porque nadie nos ha explicado si esto queda registrado o si debemos apuntarlo en la hoja y preguntar, por ejemplo, el nombre del traductor para que aparezca en el consentimiento. Porque, por ejemplo, cuando es un familiar del paciente el que hace de traductor o firma en nombre de un paciente porque es menor o lo que sea, aparece su nombre y su DNI en el consentimiento, y tiene que firmarlo. $Y$ yo no sé en este caso del traductor, que es el que tiene que dar fe de que ha traducido todo lo que he dicho y ha hablado con la paciente tal y como yo lo he hecho, si tengo que ser yo el que apunte "He llamado a la empresa de traducción y...". [Anestesista 4]

Por el contrario, los pocos profesionales que han recurrido al servicio de interpretación telefónica afirman por lo general sentirse satisfechos con los resultados comunicativos obtenidos. 
Aquí, no, lo he empleado una vez en consulta general, que vino un paciente para un pre-operatorio para una intervención y no sabía nada de español. Y entonces llamamos a la empresa y estuvimos hablando por teléfono. El paciente creo que era árabe... [Anestesista 4]

Sí, hay un servicio de interpretación telefónica. Y yo lo he usado a veces, sobre todo cuando viene el partograma de debajo de paritorios y ya indica que han tenido problemas, y vemos que ya han pasado varias horas y todavía no ha venido nadie y hay que tomar decisiones como, por ejemplo, porque hay que vacunar al niño, o tenemos que hacer la historia y tal... y entonces sí que conectamos, en el teléfono tienes como una doble clavija, y entonces ella habla con el intérprete y a la vez escuchas tú. Y entonces sí que es mucho más fácil, porque tú le dices “Oye, pregúntale esto" y tal... [...] Yo las veces que he recurrido a ella (la interpretación telefónica) la experiencia ha sido estupenda, porque evidentemente todas las dudas que tenía me las ha resuelto y muy bien. [Enfermera 1]

Hay en el hospital un teléfono con el que se puede llamar a un traductor, pero yo... bueno, una vez o dos lo he usado, pero con las compañeras. [...] es un teléfono que se conecta a este (señala el teléfono de la habitación) y hablamos los dos a la vez. El traductor está al otro lado de la línea y entonces le va preguntando a la paciente y, a la vez, lo oímos nosotras lo que dice el traductor. [Enfermera 2]

Yo el servicio de interpretación telefónica sí que lo he usado alguna vez. Y la experiencia ha ido bien. [...] Y no creo que se tan complicado utilizarlo, lo que pasa es que tienes que perder tiempo, entonces también depende de cómo estés. [Enfermera 5]

Hay un servicio de interpretación telefónica. Y yo lo he usado a veces [...] en el teléfono tienes como una doble clavija, y entonces ella habla con el intérprete y a la vez escuchas tú. Y entonces sí que es mucho más fácil, porque tú le dices "Oye, pregúntale esto" y tal... [Profesional socio-sanitario 1]

Por lo que respecta a las usuarias inmigrantes entrevistadas, solo una de ellas (en concreto, procedente del Magreb) ha empleado el servicio de interpretación y opina que le resultó de utilidad.

Sí, yo he usado una vez, sí. (La usuaria se refiere al servicio de interpretación telefónica). Y a mí ayuda, sí. [Magreb 1]

Por el contrario, por las respuestas ofrecidas al preguntarles si saben si el hospital cuenta con intérpretes, deducimos que el resto de usuarias entrevistadas no conoce la existencia de estos servicios, algo que, en nuestra opinión, resulta cuanto menos preocupante, ya que no solo los profesionales no los han empleado para comunicarse con ellas, sino que, además, ellas mismas, por desconocimiento, no los han podido solicitar.

No sé, creo que no. [África Subsahariana 1]

No sé, yo creo que no, yo no he visto... [África Subsahariana 2]

Esto no lo sé. Yo creo que no... Al menos yo nos los he visto. [África Subsahariana 4]

No, no, yo no ver intérpretes aquí. [África Subsahariana 5]

No sé, yo no visto. [Asia 1]

No, creo que no. [Asia 2]

This I do not know. [Asia 3]

No sé, esto no sé. [Asia 4]

Pues esto, no lo sé, la verdad. [Europa del este 1] 
No sé, yo no he visto. [Europa del este 3]

Esto no sé, la verdad. [Europa del este 5]

Yo no los he visto. [Europa del este 6]

Pues, no sé, no tengo ni idea, la verdad. [Latinoamérica 2]

Yo no he visto. [Magreb 2]

Yo no he visto. No sé. [Magreb 3]

No sé, no sé, creo que no... [Magreb 4]

Por otro lado, cabe además destacar en relación con los servicios de interpretación mencionados el desconocimiento o confusión por parte de algunos profesionales sanitarios con respecto a la terminología adecuada para referirse a los intérpretes y a la labor ejercida por los mismos. Nótese al respecto el uso indistinto por su parte de vocablos como "mediadora", "traductor", "traductor telefónico", o "traducción simultánea telefónica".

Dicho desconocimiento o confusión por parte de los profesionales sanitarios se aplica también en relación al papel y funciones del intérprete. La mayoría de los profesionales entrevistados opinan que su única labor consiste en traducir literalmente lo que dicen los interlocutores. De ello podemos deducir que ven al intérprete como un agente externo al acto de comunicación que se limita a reproducir automáticamente el mensaje en una y otra lengua.

Porque si es un traductor, yo espero que haga una traducción fiel de lo que yo estoy diciendo. No creo que haya problemas. [Anestesista 3]

[...] a lo mejor con que te traduzca... es decir, con saber que le está diciendo exactamente lo que tú quieres decirle, a lo mejor es suficiente. [Matrona 3]

No hay que interpretar, porque hacer de intérprete no significa interpretar lo que el otro quiere decir, sino que si el otro dice "Pipí, sí", el intérprete dice "Ha dicho: Pipí, sí". Como un notario. [Obstetra 1]

Solo uno de los profesionales entrevistados añade otras funciones a la labor del intérprete y afirma que, cuando ha recurrido a sus servicios, este le ha transmitido información de carácter personal o cultural de las pacientes.

[...] te interpretaba también un poco la situación de la paciente. O sea, ella te traducía literalmente lo que te decía la paciente y luego te explicaba [...] te decía un poco sobre la paciente, te explicaba de qué etnia era, su situación familiar o qué solía hacer. [Obstetra 3]

Además, algunos no observan grandes diferencias entre el empleo de familiares y amigos como intérpretes ad hoc y el recurso a intérpretes profesionales, y simplemente señalan que el recurso a la interpretación profesional puede ofrecerles mayores garantías sobre la fidelidad del mensaje transmitido. No mencionan, sin embargo, otros de los principios por los que se debe regir un intérprete profesional (como puede ser la imparcialidad o la confidencialidad), ni la formación que este habrá recibido para desempeñar su labor, hechos que constituyen factores diferenciadores entre los profesionales y los intérpretes ad hoc.

$Y$, luego, también pasa que con el intérprete (profesional) sabes que se lo va a traducir todo tal cual, y el familiar también se lo puede contar un poco como él quiera. Eso lo he pensado muchas veces, sí. [Obstetra 2] 
No veo diferencias, para lo que yo los he utilizado, entre recurrir a un intérprete profesional o a una persona que simplemente conoce las dos lenguas. No, porque vamos, normalmente la gente pone interés en traducir. Lo único es que con uno profesional te queda la tranquilidad de que está haciendo la trascripción literal de lo que tú estás diciendo, que no interpreta ni pone nada de su cosecha. Es la única diferencia, porque con la otra forma te queda la duda de... "¿Pero le has dicho? ¿Te ha entendido claramente?". Y con un profesional no te hace falta. [Profesional socio-sanitario 1]

Otra diferencia señalada por uno de los profesionales entrevistados consiste en que él considera al intérprete profesional como un aliado en comparación con los familiares y amigos que realizan labores de interpretación, los cuales, en su opinión, parecen estar del lado del paciente.

Cuando el intérprete es profesional está como de tu lado, y cuando el intérprete es un familiar del paciente, está como en el otro lado y la barrera es mayor. Cuando era un profesional yo le preguntaba “Bueno, ¿y tú qué crees? ¿Es normal que haga esto o aquello?". En esos casos el intérprete era más como tu aliado. Esa es la única diferencia que veo. [Obstetra 3]

Por lo que respecta a los requisitos necesarios para llevar a cabo labores de interpretación, algunos profesionales sanitarios entrevistados señalan que es suficiente con que conozca las dos lenguas de trabajo.

(Por su experiencia, ¿̇cree que cualquier persona con conocimientos lingüísticos de ambas lenguas puede ejercer de intérprete?) Sí, sí, sí, por supuesto. [Anestesista 1]

Sí, yo creo que con que tengan conocimientos lingüísticos es suficiente, sí. [Anestesista 2]

Si tiene un buen conocimiento de las dos lenguas, yo creo que sí (es suficiente). [Anestesista 3]

(Por su experiencia, ¿cree que cualquier persona con conocimientos lingüísticos de ambas lenguas puede ejercer de intérprete?) Pues para lo que aquí se usa, sí. Porque no se habla de cosas raras, son todas muy fáciles y simples. [Enfermera 2]

Yo creo que sí, ¿no? Vamos, si sabe español y el otro idioma creo que es suficiente... [Enfermera 4]

Yo creo que es suficiente con que (el intérprete) conozca las dos lenguas. [Enfermera 6]

Por supuesto, claro. Por ejemplo, si una señora viene de Marruecos y el intérprete habla árabe y español, pues ya... [Matrona 7]

Bueno, eeeee, ahí... Podríamos hablar de eso largo y tendido. Tú fíjate, el intérprete, bajo mi punto de vista estoy hablando, ¿eh?, ojo, que yo no siento cátedra... Considero que si sabes los dos idiomas perfectamente, puedes hacer de intérprete. [...] Por eso digo, para la cosa digamos... nuestra, médica, hablando así, a mí me basta con que sepa los dos idiomas. [Obstetra 1]

Otros profesionales consideran que los conocimientos lingüísticos no son suficientes y añaden la necesidad de que el intérprete posea también conocimientos culturales, de terminología médica, o del funcionamiento de los servicios sanitarios.

Tu traductor tiene que conocer muy bien la terminología médica y la técnica que vas a usar para luego saber traducir lo que les estás diciendo. [Anestesista 4]

Primero, debería ser alguien vinculado con el trabajo que está haciendo. Es decir, yo creo que si hay tanta multiculturalidad, debería haber traductores del hospital acostumbrados a trabajar en el medio y familiarizados con las técnicas que se emplean en ese medio. [Anestesista 4] 
Hombre, (usar como intérpretes a personas con conocimientos de ambas lenguas) mejora la situación en principio, aunque no sé si la solución es la ideal. [Anestesista 5]

Claro, una cosa es el conocimiento de la lengua, y otra sería el conocimiento que tenga de la... de la cultura, de las costumbres... Y, me imagino, que con ambas cosas pues sí que serviría. [Enfermera 3]

No es que crea que con conocer las dos lenguas ya se sabe traducir, no idealmente, pero es mejor que nada. [Matrona 1]

Yo creo que para hacer de intérprete harían falta más requisitos que simplemente conocer las dos lenguas. Habría que conocer la cultura. [Matrona 2]

Hombre, no sé. Si ya supiera un poco de qué va la cosa en el embarazo y el parto, pues ya sería estupendo. [...] Eso a nivel de idioma, porque a nivel cultural, para entender las costumbres de cada uno, requeriría tener una traductora por cada... por cada raza, ¿no?, por decirlo de alguna manera. Vamos, puestos a pedir... [Matrona 3]

\begin{abstract}
Hombre, a ver, lo ideal sería que el intérprete tuviera conocimientos a nivel sanitario. Porque a veces tú puedes saber un idioma, hablarlo medio decente, pero a nivel sanitario no saber decir nada. Por ejemplo, a mí ahora me pasa algo en Estados Unidos, y me llevan al hospital y se me ponen a hablar en inglés, y yo te digo "Sí, sí. Claro, claro"... Así que, si los intérpretes pudieran tener también conocimientos a nivel sanitario, pues sería estupendo. [Matrona 4]
\end{abstract}

Con solo conocer el idioma te vas a entender lo justo, básico y necesario, pero no llegas [...] como para quedarte satisfecho con la atención, no. Es necesario conocer culturalmente más y un poco tener ganas también por ambas partes de entender. [...] No sé, tener algo más de relación que simplemente te miro, te exploro y me salgo. [Matrona 5]

Yo creo que habría que tener conocimientos médicos también, o al menos una noción de cómo funciona el sistema sanitario español, o sea, debería estar bien integrado en lo que es la cultura sanitaria. [Matrona 6]

La terminología médica básica tendrá que conocerla también. $Y$, bueno, me imagino que si conoce el idioma, también conocerá un poco sus costumbres, su cultura... [Obstetra 2]

Echamos en falta entre los requisitos señalados otras habilidades, conocimientos y aptitudes necesarios para que el intérprete desempeñe adecuadamente su labor, tales como el conocimiento de los principales patrones comunicativos de las personas implicadas (aspecto que trataremos en el próximo nodo analizado), la capacidad de análisis y escucha activa, el conocimiento y aplicación de los principios éticos inherentes a esta profesión o, en el ámbito específico que nos ocupa, el conocimiento de los conceptos de salud y enfermedad en las comunidades implicadas, o de los comportamientos y costumbres relacionados con el embarazo, el parto y el puerperio en las culturas de origen de las usuarias.

Por lo expuesto hasta el momento, podemos afirmar que existe una falta de conocimiento por parte de la mayoría de los profesionales entrevistados sobre las condiciones de trabajo de los intérpretes sanitarios, así como sobre el papel y las funciones que estos deben cumplir para facilitar la comunicación intercultural eficaz entre los profesionales y las usuarias.

Para finalizar el análisis del nodo dedicado a las barreras lingüísticas y las soluciones adoptadas para eliminarlas, cabe señalar que, aparte de los recursos mencionados hasta el momento que se han empleado en el hospital contexto de estudio para facilitar la comunicación entre los profesionales sanitarios y las usuarias alófonas, algunos entrevistados mencionan otras soluciones. 
Por lo que se refiere a los profesionales sanitarios, dos de ellos señalan el recurso a pictogramas, ${ }^{254}$ y uno de estos nos habla además de aplicaciones de traducción a través de telefonía móvil, aunque son conscientes de que estos recursos no permiten una comunicación completamente eficaz o de que hay situaciones (como es el caso de las urgencias) en las que es difícil emplearlos.

O incluso ahora con los móviles hay aplicaciones que se pueden usar para traducir: tú introduces palabras concretas, como "Dolor" o "Vómito" y la aplicación te habla, te da la traducción oralmente, y, por ejemplo, en chino, te aparece incluso la palabra escrita en chino en la pantalla. Y entonces eso también sirve, aunque sea para lo básico, porque para nada más. [Anestesista 5]

Y luego tenemos unas fichas que son pictogramas, copiadas me parece de un servicio gallego de salud, con las que puedes sin saber el idioma más o menos entender lo que quiere decir: por ejemplo, de cuántas semanas estás, si tienes fiebre, si tienes dolor. Eso lo manejan sobre todo las matronas, no sé si las has llegado a ver... Yo sé que están en la zona de dilatación, creo que las trajo un matrón, y no sé si se hace uso diario, pero están muy bien, y para la gente que no sabe nada, nada, nada de español y viene sin acompañante, que también las hay, pues para esos casos las fichas van bien. [Anestesista 5]

Hay algún pictograma. También lo que te he comentado del consentimiento en varios idiomas. Por ejemplo, un pictograma que te representa gráficamente lo que es una rotura de bolsa, dolor, sangrado, ese tipo de cosas, pero quizás sea más útil para la urgencia, cuando vienen de la calle, desde su domicilio. Pero ya en el paritorio, pues ya no es tan útil, y se utiliza poco. [Matrona 1]

Por su parte, las usuarias inmigrantes entrevistadas mencionan otras soluciones que ellas mismas han adoptado cuando no podían comunicarse en español o no conseguían entender las palabras de los profesionales sanitarios. Entre estas soluciones, algunas usuarias afirman que solicitan a los profesionales que se les repita y explique la información transmitida de otra manera, o señalan haber recurrido al uso de diccionarios o haber llevado los mensajes que querían transmitir escritos en un papel en español por otra persona antes de acudir a las consultas.

Yo ahora ya hablo español, pero con el primer hijo, como te he dicho, no lo hablaba y, cuando mi marido no podía ir en las consultas, cualquier cosa que yo necesitaba preguntar, él me lo apuntaba en un papel, y lo que hacía el médico siempre era volver a apuntar las respuestas y eso... Y yo también iba con un diccionario de francés-español para algunas cosas. [...] Ya te digo, me acompañaba mi marido cuando podía, o iba con mi diccionario y las preguntas escritas. [África Subsahariana 4]

Pues, es que, a lo mejor, si no entiendo les digo que me lo expliquen de otra forma y así sí que ya... [Europa del este 1]

Cuando hay algo que no entiendo, le pido que me lo explique y, con otras palabras y eso, pues al final más o menos se entiende. Y, además, como decía, el rumano es bastante parecido al español. [Europa del este 5]

Pido repetir, si no entiendo, digo "Repetir". [Magreb 1]

Pregunto para que me explicar de otra manera. [Magreb 2]

\footnotetext{
${ }^{254}$ En el ámbito aragonés, cabe destacar la labor desempeñada por ARASAAC (Portal Aragonés de la Comunicación Aumentativa y Alternativa) en cuyo portal de internet es posible descargar o incluso crear el propio usuario sistemas gráficos y gestuales SAAC (Sistemas Aumentativos y Alternativos de Comunicación). Los SAAC son formas de expresión distintas al lenguaje hablado, que tienen como objetivo aumentar (aumentativos) y/o compensar (alternativos) las dificultades de comunicación y lenguaje de muchas personas con problemas comunicativos, como discapacitados o inmigrantes. Para mayor información, visítese la página web: [http://www.catedu.es/arasaac/index.php] (última consulta: 19 de julio de 2013).
} 
Primero, pregunto si hablan francés. Y si no, busco en diccionario, en Internet, o pregunto a mi hija. A mí me gusta bien aprender. [Magreb 3]

No, no, yo entiendo y, si no, pido que repetir. Si no entiende, pido preguntas. O si médico no entiende, yo repito. Al final los dos entiende. [Magreb 4]

\subsubsection{Interacción}

El siguiente nodo en el que centramos nuestro análisis se refiere a la interacción entre los sujetos principales de nuestra investigación: profesionales sanitarios y usuarias inmigrantes. Estudiamos las semejanzas y diferencias que existen en los modelos conversacionales de estos dos grupos, por lo que respecta tanto a los elementos verbales como a los no verbales. Asimismo, incluimos algunas cuestiones relativas a la relación entre las usuarias inmigrantes y sus maridos dentro del hospital contexto de estudio.

El análisis se centra en los subnodos o subtemas que aparecen en esta captura de pantalla de nuestro proyecto con NVivo10:

\begin{tabular}{|c|c|c|c|c|}
\hline \multicolumn{5}{|l|}{ Nodes } \\
\hline Name & $\checkmark$ S Sources & References & Created On & Created By \\
\hline E CATEGORIAS CONCEPTUALES O TEORICAS & 49 & 1746 & $02 / 02 / 201312: 31$ & AN \\
\hline$\oplus$ O INTRODUCCION & 49 & 154 & $02 / 02 / 201312.51$ & AN \\
\hline E O INTERACCIÓN & 49 & 530 & $02 / 02 / 201312: 52$ & AN \\
\hline O TONO DEVOZ & 53 & 59 & $04 / 02 / 20136.54$ & AN \\
\hline TEMAS TRATADOS_personales y tabues & 48 & 94 & $04 / 02 / 20136.56$ & AN \\
\hline RITMO_silencios, interrupciones y solapamientos & 51 & 52 & $04 / 02 / 20136: 55$ & AN \\
\hline RELACION PROFS-USUARIAS & 25 & 55 & 05/02/20137:12 & AN \\
\hline LENGUAJE NO VERBAL_gestos, contacto visual y cercania & 49 & 63 & $04 / 02 / 20136.57$ & AN \\
\hline INTIMIDAD y CONFIDENCIALIDAD & 24 & 45 & $04 / 02220136: 58$ & AN \\
\hline INTERACCIÓN USUARIA-MARIDO & 30 & 69 & $05 / 02 / 20136: 18$ & AN \\
\hline INTERACCION ENTRE USUARIAS & 3 & 3 & $18 / 02 / 201317: 32$ & AN \\
\hline GRADO DE SINCERIDAD & 48 & 71 & $04 / 02 / 20136: 54$ & AN \\
\hline O FORMA DE HABLAR & 50 & 61 & $04 / 02 / 20136.57$ & $A N$ \\
\hline DURACION CONSULTA & 25 & 26 & $04 / 02 / 20136: 57$ & AN \\
\hline CONTACTO FISICO. DESNUDEZ y EXPLORACIÓN & 47 & 62 & $04 / 02 / 20136.58$ & AN \\
\hline CANTIDAD DE INFO & 33 & 37 & $06 / 02 / 201310: 39$ & AN \\
\hline ACTITUD GENERAL USUARIAS & 25 & 51 & $04 / 02 / 20136.54$ & AN \\
\hline OC ACTITUD GENERAL PROFESIONALES & 31 & 38 & $04 / 02 / 20136.54$ & $\Delta N$ \\
\hline
\end{tabular}

Gráfico 6.29. Subnodos del nodo INTERACCIÓN

En primer lugar, abordamos una serie de cuestiones generales relativas a la interacción.

Por lo que respecta a la actitud de las usuarias inmigrantes de acuerdo con los profesionales entrevistados, la mayoría opina que dichas usuarias suelen colaborar con el personal sanitario.

No, no, no, colaboran, colaboran porque les interesa a ellas mismas también. [Anestesista 1]

Yo creo que sí que colaboran. [Anestesista 3]

Yo creo que en general las pacientes extranjeras son bastante sumisas. No te llevan la contraria, ni... Vamos, yo creo que en general son obedientes y se dejan tratar bien. No me he encontrado a ninguna que me lleve la contraria, ni que me aclare conceptos o quiera reinterpretarlos. [Anestesista 5]

Sí, sí, en general colaboran. [Enfermera 1]

Colaboran, yo diría que colaboran, sí. [Matrona 6]

Pues hay de todo, pero generalmente sí que colaboran. Hay de todo. Las hay pasivas, que parece que pasan y no quieren parir, pero son las menos. La mayoría sí que colabora. [...] Ellas confían mucho en la 
matrona, en el personal sanitario en general, pero sobre todo en la matrona, y yo veo que, claro, ellas lo que quieren es parir bien, y sobre todo si ya tienen la epidural, pues ya están tan tranquilas. $Y$ entonces son gente que, en general, colabora. [Matrona 7]

¿Que si suelen colaborar con el personal sanitario? Pues, yo creo que sí. Aunque, a veces, son muy exigentes, lo cual te llama la atención, porque piensas "Si de donde vienes tú no disponéis ni de la décima parte de lo que tenemos aquí, y se te ofrece y, sin embargo, que me estés exigiendo...". La verdad es que llama la atención. Pero, vamos, sí, normalmente colaboran. [Obstetra 1]

Pues... depende, pero vamos, en general, yo creo que son educados y colaboran. Vamos, ellos vienen preocupados con esto del parto y, lo demás, no les preocupa mucho... [Profesional socio-sanitario 2]

Hay de todo, aunque generalmente colaboran. [Profesional socio-sanitario 3]

Incluso uno de los profesionales entrevistados cree que el grado de colaboración de las usuarias inmigrantes suele ser mayor que el de las autóctonas. En su opinión, esto puede deberse al agradecimiento que sienten por poder acceder a unos servicios sanitarios de mayor calidad que los que se prestan en sus respectivos países de origen.

Pero, en general, yo creo que se esfuerzan más, por intentar comunicarse, y por intentar entablar una relación de cooperación con el personal sanitario, más que las de aquí. Porque las de aquí lo tienen ya todo hecho, y muchas veces piensan que estamos aquí para atenderlas y ya está. Sin embargo, las de fuera, muchas están como muy agradecidas. Y, claro, supongo que más si la asistencia en su país es mala, o es más deficitaria que aquí. Entonces, el llegar aquí y que les den todo, pues claro, tiene que ser increíble. [Matrona 4]

Otros profesionales indican que, en caso de que algunas usuarias muestren una actitud poco colaborativa, esto se deberá principalmente a las circunstancias específicas que estas experimentan, por los problemas de comunicación a los que deben enfrentarse o por encontrarse en un contexto que les resulta extraño, todo lo cual puede derivar en miedo o desconfianza, tal y como habíamos señalado en el análisis de nodos anteriores.

Pues yo creo que esto va en proporción a la capacidad que tienen de entenderte. Que las que no se pueden expresar y no te entienden yo creo que se aíslan más y no interaccionan tanto. Sin embargo, las que tienen la capacidad de expresarse y de entender, sí, yo creo que sí... a lo mejor, hay de todo, pero creo que estas últimas sí que interaccionan más. [Anestesista 2]

Es que todas, o casi todas, suelen estar bastante asustadas, da casi igual de dónde vengan. Están casi todas como a la expectativa, pensando "Me duele mucho. Quiero que me quiten el dolor" y preguntándose “¿Qué es esto?”. Sí que hay mucho miedo. [Anestesista 4]

Sí colaboran, lo que pasa es que, yo creo que hay un componente que no se puede controlar, que es el miedo. El miedo porque... no es lo mismo dar a luz en tu país natal que dar a luz en un país extranjero, en el que el idioma no lo controlas. Entonces, lo que podríamos entender como no colaboración yo creo que es más bien miedo y ansiedad. Cuando a veces dices "Estate quieta, estate quieta, estate quieta", y no se está quieta a pesar de entenderte, pues yo no lo consideraría como una desobediencia, sino que yo creo que es miedo... Y encima con dolor, con lo que no todo el mundo piensa bien. Vamos, yo creo que una vez ya analgesias al paciente se convierte en otra persona. [Anestesista 5]

Yo pienso que quizás (las usuarias inmigrantes) son un poquito más desconfiadas. [Enfermera 1]

Hay de todo, hay de todo. Yo, más que pasivas, diría que están como a la expectativa. Yo creo que están mareadas, porque se marea hasta una española, porque no hacemos más que dar vueltas, es un sistema horroroso, es catastrófico, porque entramos, salimos, ahora la matrona, ahora no sé quién, por la noche 
me despiertan, me ponen el termómetro, un calmante, no sé qué... Vamos, que no es el sistema adecuado, es normal que estén mareadas. [Enfermera 5]

Tienen una actitud algo más pasiva que la autóctona, pero yo creo que es por... pues porque están en un sitio extraño, en general. Y si añades lo que te digo siempre, los problemas de comunicación, pues es que es normal que estén un poco más pasivas. [Matrona 1]

A veces, a lo mejor, a lo mejor las puedes tachar de más pasivas, pero es porque es que no te están entendiendo, es que no saben por qué, es que no... Entonces, ¿qué iniciativa esperas? [Matrona 5]

Pues, es que hay de todo, no sé. Hay gente que colabora un montón, y que no se queja nunca y que... Pero, vamos, yo creo que eso, muchas veces el problema es por miedo de ellas, o porque no entienden, o porque están solas en una situación... Sí que hay gente que es poco colaboradora, pero, bueno, también hay gente que colabora mucho, no... [Obstetra 2]

Algunos profesionales consideran que la falta de colaboración no depende del país de origen de las usuarias, sino que dentro de un mismo colectivo puede haber usuarias que colaboren más y otras menos.

Pues depende, hay de todo. Yo pienso que eso va con la persona. Hay gente que es muy activa y enseguida se pone a hacer lo que se le dice y hay quien no. Yo pienso que en eso son como cualquier española. [Enfermera 2]

No creo que sea cultural el que colaboren más o menos, depende más del carácter de la persona. A veces ha habido que recordarles varias veces las normas de la planta... Pero, vamos, en general, no tengo así ningún ejemplo concreto de falta de colaboración. [Enfermera 4]

Depende. No sabría decirte si hay algunas que colaboran más que otras. Yo creo que depende de las personas. [...] Si te toca una persona inmigrante, que encima no habla, y te exige mucho, y está enfadada, pues no es porque sea de Marruecos o sea de Rumanía, es porque su carácter es así y ya está. [Matrona 2]

Depende, depende... Y ya no de la etnia, ¿eh? Depende un poco de la mujer. ¿Colaborar? Pues yo creo que muchas se esfuerzan [Matrona 4]

Chica, no sé, hay de todo. Pero también las de aquí, ¿eh? Te encuentras gente supermaja y colaboradora y te encuentras gente... [Matrona 5]

Es que en eso ya creo que hay una gama muy amplia también. A lo mejor, hay algunas que si no estás encima y casi empujas más tú que ella, a base de tu esfuerzo y de insistir e insistir, y de decir "Venga. Empuja, Coge aire. Haz así"..., pues no lo hacen. Y, en cambio, hay otras que rápidamente captan y colaboran. [Matrona 7]

Al cincuenta por ciento. Hay gente muy, muy, muy callada, que lo mismo, tampoco sabes por qué están tan calladas, que intuyes que entienden más de lo que confiesan, pero que no eres capaz de hacerlo tangible... Y hay otras muy, muy, muy colaboradoras. [Profesional socio-sanitario 1]

Por el contrario, otros profesionales realizan comentarios, tanto positivos como negativos, referidos a la actitud de colectivos concretos de usuarias. Sin embargo, consideramos que se trata de comentarios poco significativos, pues no son comunes, y probablemente se corresponden más bien con percepciones personales de cada profesional basados en experiencias determinadas que, quizás, les llevan a generalizar.

Lo intentan. Yo creo que todo el mundo intenta colaborar. A lo mejor, les cuesta un poco más ponerse a las sudamericanas o a las de raza negra. Cuando les dices "Siéntate" o "Muévete", parece que les cuesta... [Anestesista 4] 
[...] las sudamericanas sí que es verdad que a veces parece que no son conscientes de las situaciones peligrosas, no son conscientes, no, cuando las cosas se complican, no... no consigues empatizar con ellas. Cuando hay un cambio en el registro, cuando hay una situación que era normal y ahora es urgente, pues las sudamericanas, a veces, no todas, pero a veces no son conscientes de que la situación es urgente, y hay que hacer una cesárea y hay que dormirla entera... [Anestesista 5]

Y luego, a los que no les cojo el punto es a los chinos, porque no... no sé, no les cojo el punto. Porque esos hasta hace poco no venían al hospital, pero ahora están empezando a venir. Y son curiosos, ¿eh?, son muy curiosos. Es que tienen una cultura totalmente diferente. Entonces, ha habido chinos que están en Zaragoza de toda la vida, y no sé por qué no pasaban por el hospital, ni para nacer ni para morir, no me preguntes por qué, y ahora van viniendo. Y son gente muy amable también, ¿eh? Son exquisitos, vamos, de trato. [Anestesista 5]

La gente de la cultura gitana, en teoría mientras tú a ellos les das lo que te piden, pues muy bien, pero en el momento en que les niegas algo, icon la iglesia hemos topado! Tienen muchas leyes, muchos derechos, pero muy pocas obligaciones. Es la etnia con la que más cuesta tratar, por lo menos, para mí, sí. [Enfermera 1]

Te diría que depende del grupo cultural al que pertenezcan. Incluso dentro del mismo grupo cultural, del acompañante que tengan. Por ejemplo, las árabes están muy poco receptivas si están acompañadas por la pareja. En el momento en que la pareja desaparece de la acción pueden estar más receptivas, colaboran más, incluso prestan más atención y están más activas. [Enfermera 3]

¿Colaboran, con el parto te refieres? Pues, depende también. Por ejemplo, las sudamericanas paren muy bien, por el tipo de pelvis que tienen, que es una maravilla, pero les cuesta mucho colaborar. Son como un poco... eso, que a mí que me lo hagan. Pero las demás razas sí que suelen colaborar. [Matrona 3]

Por ejemplo, por mi experiencia, yo diría que las mujeres del este son muy colaboradoras, muy trabajadoras y muy eficaces. [Matrona 7]

Las paquistaníes, que en Barcelona cuando yo estaba había muchas, y hay muchas, por lo menos donde yo estaba, que vienen que son multíparas, que tienen muchos hijos, y esas hacen el parto como ellas quieren, no les puedes... A pesar de que viene el marido y parece que el que dirige es el marido, son ellas las que... Es el cuarto parto, por ejemplo, ha tenido tres en Paquistán y el cuarto pare en cuclillas o en el baño porque ella quiere. De eso sí que me he encontrado. Que no hay forma de hacerles subir a un potro, y es que no. Además, no hablan, no dicen nada, pero te hacen así (hace un gesto como apartando con las manos), como si dijeran "iDéjame! Yo me las apaño", y como que te enseñan ellas que van a hacer lo que ellas quieren, eso es lo que hacen. [Obstetra 3]

Yo diría que los peores son los rumanos, qué quieres que te diga, a mí los rumanos me parecen muy maleducados. Y si son rumanos gitanos, ya, para darles de comer aparte. [Profesional socio-sanitario 2]

Por lo que se refiere a la opinión de las usuarias sobre la actitud de los profesionales sanitarios, la gran mayoría los considera amables y cercanos, y parecen estar muy satisfechas con la atención recibida.

Son muy cariñosos y muy buena gente. [África Subsahariana 1]

Son bien, bien, yo creo que son bien. [África Subsahariana 2]

Sí, sí, son todos amables... [África Subsahariana 5]

Amable, sí. Habla muy bien. Todo está bien, muy simpática. [Asia 1]

They are kind. They are nice. [Asia 3]

Amables, son amables. Me tratan bien. [Asia 4] 
Es que son amables al trato. Hay muy poca gente que... siempre me han tratado muy bien. [Europa del este 1]

¿En general? En general son... Especial, son humanos. [Europa del este 3]

No, amables, son amables. Sobre todo las matronas se han portado superbien. Los médicos que han venido a verme, lo mismo. Así que no... Tampoco pido mucho más. [Europa del este 4]

Sí, sí, son amables. No solo conmigo, con el chico también. Si no me ayudaban, no sabía qué hacer. Y ayer también, he tenido dos o tres chicas que se han quedado desde el principio hasta que el niño nacía. Me han ayudado mucho. Por ejemplo, antes de ponerme en la mesa, aunque lo sabes de antes y te explican... pero luego, cuando llega el momento, ya no sabes cómo hacer, porque estás nerviosa. Así que me han ayudado mucho. [Europa del este 5]

Son amables, en general, son amables. [Europa del este 6]

Yo diría que su actitud es muy buena, son muy amables y atentos. [Latinoamérica 1]

Son amables, para mí, son amables. [Latinoamérica 4]

Son amables. Todos los que a mí me han atendido son amables, todos, todos. [Latinoamérica 5]

Son amables, muy amables. [Magreb 1]

No, no, no, no fríos, son amables. [Magreb 2]

Creo que son amables. [Magreb 3]

Muy amables, sí, son muy amables. [Magreb 4]

Otras usuarias, sin embargo, consideran que la actitud de los profesionales puede variar de persona a persona. Al respecto, cabe destacar que ninguna usuaria muestra una opinión negativa generalizada relativa a todo el personal sanitario. Lo que no podemos saber es si la respuesta de las usuarias en relación con la actitud de los profesionales podría haber variado en el caso de que se les hubiera entrevistado en otro contexto, pues es probable que puedan sentirse en cierto modo cohibidas a la hora de expresar una opinión negativa hallándose todavía ingresadas en el hospital a la hora de realizar la entrevista.

Hay de todo, yo creo que depende de la persona... Hay de todo, sí. [África Subsahariana 3]

Es que hay de todo. Hay personas muy majas. Por ejemplo, yo diría que la matrona que me tocó en este parto es majísima, la verdad es como si me conociera de toda la vida. Nada más entrar, se presenta, me dice su nombre y tal y está ahí con bromas y todo eso... La verdad es que el parto no lo sentí tan... estaba muy relajada por su actitud. [...] Bueno, eso depende de la persona que te toca. Hay algunos muy educados y hay otros que parece que están... no sé, como si "Venga, que yo me tengo que ir a casa". Es que eso depende de la persona también, no depende de profesión ni nada, depende de la persona. Depende de cómo eres, no depende de que seas español o senegalés o lo que sea... [África Subsahariana 4]

Algunos son... hay muchos que son amables, pero hay muchos también que son fríos. [Comunidad gitana]

En general, son amables. Puede haber alguna persona, una o dos... pero, bueno, no puedo decir que... No, en general, son amables. [Europa del este 1]

Yo diría que hay de todo. Habrá de todo como en todos lados. Yo no he tenido ningún problema. [Europa del este 2] 
Pero con la obstetra con la que tenía citas durante el embarazo y tal sí que... No sé, veía un poco de prejuicios tal vez, no sé... Era una persona muy seria y nunca me miraba a la cara y tal y... Pero, bueno, en general, muy bien. [...] Por eso te digo, tuve este problema con la obstetra, pero en general el noventa y nueve por cien de las personas aquí son muy amables y... [Latinoamérica 2]

Hay de todo, hay de todo. O sea, hay personal que es muy buena gente y te tratan bien, pero también hay personal que... que es muy frío. Sí, hay de todo. [Latinoamérica 3]

En cuanto a la interacción entre usuarias dentro del hospital contexto de estudio, disponemos de poca información, ya que los datos recolectados mediante el uso de la técnica de las entrevistas en relación con este tema es bastante escasa.

Las dos únicas usuarias que ofrecen información al respecto, comentan que no han tenido ningún problema en su interacción con otras usuarias en el hospital.

No, no tener malas experiencias con otras madres. [África Subsahariana 1]

No, no hemos tenido problemas con personal sanitario ni con otras pacientes. [Europa del este 3]

Sin embargo, hay un dato relacionado con este tema que nos ha llamado la atención y del que nos hizo partícipes uno de los profesionales sanitarios entrevistados. En concreto, nos comentó que, a la hora de distribuir a las usuarias en la zona de paritorios o en las plantas de puerperio, suelen basarse en el origen de las mismas, y suelen poner juntas a aquellas que comparten una misma cultura. En primer lugar, observamos que esta distribución es bastante aleatoria, pues no se centra en el país de origen específico de las usuarias, sino más bien en rasgos físicos compartidos o en cuestiones como las creencias religiosas. Además, aunque probablemente se realice con buena voluntad, no vemos la necesidad de llevar a cabo esta disposición y consideramos que podría tratarse incluso de una cierta forma de discriminación o marginación. Si bien el compartir la misma lengua con la compañera de habitación de la planta de puerperio puede ayudar a superar la soledad e incomunicación que sienten las usuarias alófonas que no reciben muchas visitas, desde nuestro punto de vista, separar a las usuarias autóctonas e inmigrantes puede suponer una guetización de estas últimas y, al mismo tiempo, puede acarrear problemas de privacidad en comunidades de inmigrantes muy cerradas, en las que pasar unos días compartiendo habitación puede suponer que determinada información de carácter personal sobre una o ambas usuarias se revele al resto de la comunidad.

También, bueno, si coincide que las dos culturas son iguales, pues es muy tranquilizador para la paciente. Encontrarse, por ejemplo, una mujer árabe con otra mujer árabe, es muy agradable. Yo creo que para ellas... Igual que las senegalesas, que aunque tampoco son muchas, pero yo creo que dentro de las africanas lo que más hay es de Senegal. Y tendrán otra forma de hacer las cosas, otra religión también. Porque hay gente que tiene que orar todos los días, y el español no para para orar, y hay extranjeros que paran todo, se sientan en el suelo y se ponen a orar. Y eso, pues, si te toca al lado una española, a lo mejor no lo entiende, y puede incluso molestarle que te tires al suelo y... [Anestesista 1]

Por lo que respecta a la interacción entre las usuarias inmigrantes y sus maridos dentro del hospital, ya hemos comentado en el análisis de nodos anteriores algunos aspectos relativos a la opinión de los profesionales sanitarios, especialmente referidos a quién decide si se suministra o no la anestesia epidural. Por este motivo, simplemente incluimos en este punto algunos comentarios que nos han resultado llamativos y que corroboran el hecho de que, de acuerdo con los profesionales, las usuarias de religión musulmana están en ocasiones supeditadas a sus maridos o estos se implican poco en el proceso del parto. Notamos que a 
estos profesionales les resulta difícil entender (o incluso respetar) las diferencias en cuanto al rol atribuido a mujeres y hombres en las distintas culturas. Con el fin de presentar la opinión al respecto de los dos grupos implicados (los profesionales sanitarios, por una parte, y las usuarias magrebíes, por otra), trataremos este tema más en profundidad, pero desde el punto de vista de las usuarias, en el análisis del grupo de discusión en el que estas participaron.

[...] las del Magreb, por esa cultura que tienen en la que la mujer está en un segundo plano, por lo que sí que es más difícil, porque muchas veces entienden español, pero por miedo, por ese sometimiento, piden que esté delante el marido para que sea él el que conteste. [Anestesista 1]

Porque muchas veces es el marido el que dirige un poco el cotarro, y ya no sabes si él te dice lo que la señora está diciendo o lo que él quiere que diga. [...] Sí que hay algunas comunidades, pues no sé, marroquíes o... pues en las que el hombre es el que dice y decide que la epidural no se pone y la mujer está ahí que se muere de dolor, pero él dice que no y es que no. [Anestesista 2]

En cambio, cada vez menos, pero antes con la gente de países del mundo islámico o países tradicionalmente más machistas o donde la mujer está subordinada al marido, no solo tienes que convencer, bueno, no convencer, sino decírselo no solo a la mujer, sino también al marido. Ahora igual han cambiado un poquito las cosas, pero antes te decían "No, no, habla con mi marido", y yo les respondía "No, no, a quien se lo tengo que explicar es a ti, te la voy a poner a ti". Pero aun así, miran al marido, y realmente harán lo que quiera el marido. Si el marido dice que sí, ellas dirán que sí. $\mathrm{O}$ a mí me ha pasado que ella me diga que no y, luego, llegar el marido y decir que sí, a lo mejor porque lo ha hablado con ella o qué se yo... vamos, que el que tiene que decirlo por último es el marido. [...] Creo que es con la gente de países sobre todo islámicos, o aquellos en los que las mujeres están subordinadas al marido con la que puede haber algún problema. [Anestesista 4]

Sí, las magrebíes cuando no está el marido son unas y cuando está el marido son otras. De hecho, hay veces que consigues convencerla para que se ponga la epidural y al rato te dice que no porque al marido no le parece bien. Y cuando está el marido, en el caso de las magrebíes, la mirada siempre se dirige hacia él. [Anestesista 5]

Y, luego, según qué cultura, pues si no está el marido, a la hora de preguntar por las vacunas o según qué cosas, pues no puedes preguntarlas hasta que no te da permiso el marido. [...] La causa es totalmente cultural, sus costumbres, sus tradiciones, que son diferentes a las nuestras, por ejemplo, les cuesta mucho aceptar que nos dirijamos a las mujeres para que ellas tomen las decisiones, por decirlo de alguna manera. Parece que tiene que ser él el que hable siempre, cuando la que ha dado a luz es ella, la que tiene que decirme sus dolencias o su estado anímico es ella, el cómo se siente, si quiere lactancia materna o la prefiere artificial... Yo pienso que en ese aspecto hay veces que se sienten cohibidas tanto ellas como nosotras, porque vemos que tenemos una limitación con ellos. [Enfermera 1]

Pienso que hay diferencias entre la cultura europea y la de las otras mujeres. Porque estas no tienen esa soltura, ni esa independencia, ni nada. Creo que están como más arraigadas al marido, o a la familia, y están en un segundo plano totalmente. [...] Sí, sí, a mí hay veces que me molesta que las aíslen de esa manera, me molesta el no poder tratar con ellas, o que les hagas una pregunta a ellas y lo miren a él. $Y$ digo esto como mujer, no ya como enfermera. Como mujer, me molesta muchísimo. [Enfermera 1]

[...] porque normalmente, los árabes ellos saben español, pero ellas no suelen hablar, porque claro, como las tienen... Que yo les digo "Pero, tienes que aprender, no seas boba". Porque yo voy a un sitio, a una fundación, y allí dan clases de español, y yo les digo "Id a la fundación, que allí os darán clases de español, porque estos no quieren que aprendáis...". [Enfermera 6]

Aquí ya no te hablo como experiencia profesional, sino por lo que me han comentado otras compañeras, que la mujer marroquí quería la anestesia epidural y el marido no quería, y entonces estaba un poco influenciada por el marido. Y entonces lo que hacían era dejar al marido fuera y ella decidía, y casi todas se ponían la anestesia. [Matrona 2] 
Hombre, pues depende un poco de... los maridos, sobre todo, depende un poco de lo arraigada que tengan su cultura. Porque hay culturas muy machistas. Por suerte, en España, no tenemos una cultura machista. Sin embargo, hay muchas zonas por ahí en las que domina el hombre, está clarísimo. [Matrona 4]

Por ejemplo, la mujer árabe es muy diferente a nosotros, es algo cultural. Y eso nos molesta y nos choca. [...] Sí, las árabes, sobre todo las árabes. Y si está el marido hay veces que está un poco como receloso. Pero ellas lo aceptan. O sea, yo creo que vienen aquí como un poco... como un poco sumisas. [Matrona 5]

Y lo que sí que he visto es muchos maridos pasotas, así coloquialmente hablando, que las dejan, se van a casa a dormir pensando que ya les llamarás... Eso sí que lo he visto, sobre todo en los marroquíes. Vamos, como que no va con ellos, como que el parto es algo de ella y ellos están tranquilos y se van a casa. Y a mí eso me duele mucho. Igual me fijo más porque me da pena. Ves a la pobre mujer que está ahí sola. Y nosotras no le podemos decir nada al marido, nada más que, si se va, que nos deje el teléfono para que le llamemos si tenemos algún problema. Y algunos se van a casa y ni siquiera llaman más tarde para saber cómo va... [Matrona 7]

Basta que te digan, y aquí volvemos al tema de la cultura, y en este caso a las moritas, que el marido dice "No, ella no habla nada, no entiende", y cuando no está el marido delante, yo hablo con ella y me entiende en castellano, o en francés, o en inglés, o por signos... Vamos, me entiende. Pero, claro, si está el marido delante, no, se queda calladita, mudita, "Yo soy tonta. No saber"... Esto es algo cultural, cultural totalmente. [Obstetra 1]

Y los moros tampoco se comportan muy bien con sus mujeres, porque son capaces de dejarlas aquí, se marchan, y luego te pueden aparecer lo mismo por la tarde que por la noche a preguntar si ya han parido o no han parido, que igual ni te aparecen... [Profesional socio-sanitario 2]

Algunos profesionales entrevistados opinan, sin embargo, que este comportamiento de las mujeres ha ido cambiando en los últimos tiempos y que, poco a poco, han ido asimilando los patrones de comportamiento propios de la sociedad de acogida.

Y luego las tendencias han ido un poco cambiando; te das cuenta de que hay mujeres, incluso del mundo islámico, que ahora sí la quieren, cuando antes, como te decía, sí que querían pero parece que estaban subordinadas al marido. [Anestesista 4]

Y las islamistas ${ }^{255}$ hablan poco si está el marido delante, pero sí que se nota que las cosas están cambiando... Parece que ahora hay más diálogo, están como más españolizadas, da igual que esté el marido delante, pero puedes dialogar normalmente con los dos. [Anestesista 4]

En todas estas de... de Marruecos y todo eso, he notado mucho el cambio. Yo cuando empecé veía muchas familias, no sé, como muy hechas, como si tu familia te hubiera casado con tal familia, y en cambio hay veces ahora que no... que veo amor. (Risas) Y ese cambio lo he notado de un tiempo a esta parte, desde hace unos años, que no se ven tantas familias como de conveniencia, que se hubieran casado porque esta familia se tiene que casar con esta otra por lo que sea. Se les ve más implicados en la relación, y también se interesan más... Se les ve que las quieren, se preocupan, las atienden... [Matrona 4]

Este cambio de comportamiento y la asimilación de los patrones de la sociedad de acogida en cuanto a la relación entre hombres y mujeres también son comentados por algunas de las usuarias inmigrantes entrevistadas.

\footnotetext{
${ }^{255}$ Nótese el uso incorrecto que este profesional sanitario entrevistado realiza del término "islamista", pues parece confundirlo con el término "musulmán", cuando en realidad "islamista" es aquel que es partidario del integrismo musulmán y no se refiere a aquel que simplemente profesa la religión islámica. Este mismo profesional usará de nuevo este término incorrectamente en una cita que aparece posteriormente este capítulo.
} 
(Se le pregunta que, en caso de que viviera en Camerún en lugar de en España, si su marido también le ayudaría en los cuidados del bebé). Lo que pasa es que se estigmatiza un poco todo. En África hay familias muy tradicionales donde los hombres son machistas, como aquí, y te dicen "Yo al bebé no lo toco, es tu trabajo". Y hay otros que son diferentes. Por ejemplo, mis padres, mi padre es un poco machista, no voy a mentir... (Risas). Pero, luego, veo a mis hermanos y ellos sí que colaboran, yo he visto a mis hermanos ayudar y ocuparse de sus hijos, entonces... Es que las cosas van cambiando. No sé, igual si me hubiera casado con un camerunés, tendría que haber luchado si fuese machista... [África Subsahariana 3]

Los hombres no suelen ayudar mucho en Honduras. El cuidado es cuestión de las madres. Se la tira uno todo el tiempo cuando lo tienen en el hospital sola. $Y$, sin embargo, aquí, tengo a mi marido las veinticuatro horas. Las veinticuatro horas está él aquí, aunque sea solo para acompañarme. Y allá es que... hay mucho machismo, allá es la madre la que se debe ocupar sola. (Le pregunto si su marido es hondureño). No, mi marido es de Ecuador, y en Ecuador en este tema es muy parecido a como sucede en Honduras. Lo que pasa es que al venir aquí... Yo prefiero que me ayude y esté conmigo, porque creo que es importante que también él se ocupe, que vea cómo se cambia el pañal, y que vea lo que cuesta dar a luz. Eso es lo principal, que vea qué es lo que cuesta. [Latinoamérica 5]

En cuanto a la relación que se establece entre los profesionales sanitarios y las usuarias inmigrantes, la información que hemos podido obtener con el empleo de esta técnica es limitada. De hecho, ofreceremos más detalles sobre esta cuestión en el análisis de los datos recolectados con la observación no participante. Sin embargo, sí que hay algunos datos concretos recopilados en las entrevistas sobre dicha relación que nos gustaría destacar.

En primer lugar, algunos profesionales nos indican que, sea por el perfil profesional que desempeñan, sea por el corto periodo de tiempo que suelen pasar las usuarias ingresadas (pues, si se trata de un parto normal, no suelen permanecer en el hospital más de dos o tres días), no les resulta posible establecer una relación muy intensa con las usuarias.

Es que nosotras con ellas no tenemos mucha conversación, ¿eh? Hablamos solamente a lo mejor mientras les haces la cama, luego les das las comidas... Tampoco es un sitio donde... como no son patologías, pues no estás mucho rato con ellas. [Enfermera 2]

Aquí en esta planta nuestra labor como enfermería es muy corta, es muy corta, porque aquí todo es normal. Puede ocurrir algún día algo, pero no es lo habitual. [Enfermera 5]

Ten en cuenta que todo aquí es un proceso muy rápido; a lo mejor, si te pasas ingresado quince días... pero es que aquí es como... claro, ingresas, te bajan, pares, te quedas un par de días y... vamos, que no estás en un mismo sitio con la misma gente, que va todo muy... y eso también dificulta de alguna manera el que te puedas integrar con ellos, el que puedas preocuparte de sus problemas. [Matrona 3]

Sin embargo, hay perfiles profesionales, como es el caso de las matronas, que, por las funciones que les corresponden, quizás sí que dedican más tiempo a la atención de las usuarias embarazadas en las distintas fases de la asistencia sanitaria e interactúan más con ellas, tal y como se puede observar en la siguiente cita:

A ver, es que en los centros de salud las ven durante el embarazo, y las matronas, en el área nuestra las vemos en el servicio de urgencias, donde a veces controlamos las constantes 0 , si tienen problemas de mamas, les echamos una mano, o cuando nos llaman de urgencias porque una señora tiene algún problema, para ver qué le aconsejamos y entonces vamos a urgencias a darle esa asistencia. Y, luego, sí, en la planta sexta, donde están las embarazadas de alto riesgo, es un área de patologías obstétricas. $Y$, entonces, ahí sí que están todas embarazadas y nos relacionamos con ellas administrándoles los tratamientos, y realizando vigilancia y exploraciones hasta que están de parto y las mandamos bajar a paritorio. Y, aquí, en paritorios, las vemos durante la dilatación, que es el periodo que antecede al parto, las acompañamos y asistimos en el parto. Porque el parto lo puede llevar en ese momento otra 
compañera y yo puedo estar para asistirle, en el sentido de manejar medicación, darle un masaje uterino o... lo que la compañera me pida, y apuntar y registrar, y lo de las huellas... Y, luego, una vez han parido, durante el periodo postparto inmediato que se llama, realizamos el control de la mujer y del bebé, que no sangre, que estén dentro de la normalidad las constantes vitales... Porque el primer periodo del postparto es el más peligroso, y entonces hay que vigilarlos estrechamente. También les enseñamos a mamar, porque ahora la lactancia es precoz, lo más precoz posible. Y también estamos ahí para aclararle las dudas que te pregunte. [Matrona 7]

Esta diferenciación entre la atención recibida dependiendo de los perfiles profesionales también es realizada por una de las usuarias entrevistadas, quien opina que el trato recibido por las enfermeras y las matronas es más personal que el que suele recibir de los médicos.

Es que los médicos tienen eso a veces, de ser un pocooooo... de ser poco personales y de tratar al enfermo... no al enfermo como persona, y sí como enfermedad. Lo que es distinto, por ejemplo, con las matronas aquí, que son personas, y las enfermeras también, son personas que están ahí pendientes de ti, y que son más cercanas. [Latinoamérica 2]

Y es precisamente uno de los obstetras entrevistados el que nos da una posible justificación de esta actitud más distante mantenida por algunos profesionales sanitarios.

Claro, como las que vienen, normalmente, vienen de países en teoría subdesarrollados, o menos desarrollados que el nuestro, pues a veces esto nos hace sentir que nosotros somos dioses. Y no, no, no somos ningún dios. (Risas). O sea, tenemos también nuestras limitaciones y nuestras posibilidades de error, ¿no? [Obstetra 1]

De todos modos, por lo general observamos predisposición a ayudar y voluntad de establecer una relación lo más cercana posible en la gran mayoría de los profesionales sanitarios, sin que ello presuponga, tal y como indica uno de los entrevistados, que se adopte una actitud paternalista o que las usuarias no deban tener autonomía y responsabilizarse de unos autocuidados mínimos.

De todos modos, ellas, tanto pacientes nacionales como extranjeras, tienen que tener unos niveles de autocuidados básicos. Entonces, si tú les explicas que se tienen que tomar esta pastilla, en mi opinión, son ellas las que se deben encargar de realizar esta labor, deben... (Risas) llevársela a la boca, y tomarla, y saber a qué hora, y... tú les explicas, por ejemplo, que a la hora del desayuno y de la cena, les traeremos una pastilla y se la dejaremos en la mesilla... Y creo que no tenemos que ir más allá, pues no son pacientes que tengan... no sé, como pacientes ancianos, que no son capaces de realizarse el más mínimo autocuidado, como tomarse la medicación. En esos casos deberíamos estar más atentos, pero ellas, yo creo que sí lo pueden hacer. [Enfermera 3]

Pasamos a continuación a analizar las interacciones comunicativas entre los profesionales sanitarios y las usuarias inmigrantes. En concreto, examinamos diferentes aspectos de los modelos e intercambios comunicativos de ambos grupos, clasificando las distintas cuestiones tratadas en dos apartados: usos verbales y usos no verbales. ${ }^{256}$ Vemos, además, cómo las diferencias culturales con respecto a estos usos entre los dos grupos estudiados podrían desembocar en malentendidos o problemas de comunicación.

Antes de iniciar el análisis de las interacciones comunicativas, cabe señalar la dificultad para obtener información relativa a los usos verbales y no verbales por parte de los sujetos

\footnotetext{
256 Para el análisis de las interacciones comunicativas interculturales nos basaremos principalmente en la clasificación propuesta por Francisco Raga (2003; 2006a), a la que ya hemos hecho referencia en el capítulo 3, dedicado a la comunicación intercultural.
} 
participantes en el estudio, ya que, tal y como hemos comentado en el capítulo 3, lo que realmente aumenta la gravedad de los problemas comunicativos entre interlocutores procedentes de diferentes culturas es el carácter semi-inconsciente de los mismos. De hecho, en la mayoría de las interacciones interculturales, es posible que los participantes en la conversación sientan cierto malestar, incomodidad o frustración porque la comunicación no está siendo efectiva, pero probablemente serán incapaces de identificar la causa concreta de los problemas comunicativos.

Por lo que se refiere a los usos verbales, basamos nuestro análisis en el principio de cooperación y las máximas de Grice (1975: 45-47).

En primer lugar, con respecto a la máxima de cantidad, solicitamos a los profesionales sanitarios y las usuarias inmigrantes entrevistados que nos indicaran si la cantidad de información que les proporcionaban habitualmente sus interlocutores en el hospital contexto de estudio era mayor o menor de la que ellos esperaban, y si a ellos mismos se les permitía dar toda la información deseada durante sus intercambios comunicativos.

En relación con estas cuestiones, algunos profesionales sanitarios opinan que las usuarias inmigrantes por lo general suelen proporcionar poca información o que los datos aportados por estas son suficientes, no excesivos.

$\mathrm{Y}$, al contrario, que te ofrezcan mucha información, con las inmigrantes yo diría que no nos ha pasado. Con las nacionales, sí. (Risas). [Anestesista 3]

Pues... con ellas... No, en general, hablas tú. La verdad es que, realmente, te suelen dejar hablar. [Anestesista 4]

Información no dan en exceso, no, no sé, no... [Anestesista 5]

No, en esto yo no he tenido ningún problema. Yo creo que ofrecen suficiente información. [Enfermera 2]

Al revés, es decir, que te den demasiada información, en principio, no. [Matrona 1]

Otros consideran que la cantidad de información proporcionada o la capacidad de escucha pueden estar relacionadas con el origen de las usuarias, con la información de la que estas disponen o incluso con las personas que están presentes durante la interacción.

Bueno, las chinas no hablan casi, o muy bajito. La raza negra tampoco es muy dada a hablar. [Anestesista 4]

Y las islamistas hablan poco si está el marido delante [...] hay gente que pregunta más, pero yo creo que depende también de lo claro que lo tengas todo. Por ejemplo, con las sudamericanas tienen claro todo y saben que quieren la epidural, por lo que con ellas hay poco que hablar. Las árabes y las del este sí que quizás preguntan algo más y tratan de resolver más dudas... Y entre las españolas, pues hay un poco de todo... [Anestesista 4]

¿Si saben escuchar? Hombre, es que en esto yo creo que son muy diferentes. [...] las de los países del este sí que hablan mucho, a veces hablan incluso más que tú, o dirigen la conversación. Pero, claro, todo esto es generalizar. Y las árabes sí que son más pacientes, escuchan más... [Obstetra 2]

Silencios, con las subsaharianas. Pueden estar... son muy parcas en palabras. Sí, esas, sí. Y eso es lo que más me llama la atención, en las demás yo creo que depende de la persona. [Obstetra 3] 
Por otro lado, dos de los profesionales entrevistados comentan que, en caso de que los temas planteados por las usuarias no les resulten relevantes, suelen interrumpirlas o redirigir la conversación.

Es que, aunque se cree que nuestra figura es, o tiene que ser, muy cercana, muy cercana, también creo que debemos mantener un pelín las distancias. Y si en algún momento vemos que la conversación deriva en algo que no tiene que derivar, intentamos redirigirla o reconducirla de alguna manera. No creo que sea conveniente tampoco una relación demasiado, demasiado afectuosa. [Matrona 1]

Con las sudamericanas a veces sí que es difícil mantener una conversación, porque les preguntas una cosa y ellas te hablan, se van por otro tema, te cuentan cosas que no tienen nada que ver... Pero, claro, yo que sé, es que eso igual es algo... algo propio. $\mathrm{Y}$, entonces, claro, a veces te resulta algo violento, pero les tienes que cortar, les tienes que interrumpir. [Obstetra 2]

Por lo que respecta a las usuarias inmigrantes entrevistadas, la mayoría de ellas considera adecuada y suficiente la cantidad de información intercambiada por los dos interlocutores.

Sí hablan y dejan que yo hablar. [África Subsahariana 1]

Yo creo que habla lo normal. Entra, te mira, te ayuda a relajarte, y también pregunta dudas y esas cosas. Y sí, me dejan hablar lo suficiente, sí, bueno, los que me tocaron a mí... [África Subsahariana 4]

Habla muy bien. Todo está bien, muy simpática. Y, sí, yo hablas también. [Asia 1]

Médico habla bien. Primero pregunta qué problemas y luego... pasar ya a verte y eso, pero primero te pregunta qué problemas. [Asia 2]

Dan suficiente información. Porque si les vuelves a preguntar, te contestan. Si algo no te has... no te has comunicado, te lo vuelven a explicar con todo... Y yo hablo también suficiente, sí. [Europa del este 1]

Es que te dicen lo que te tienen que decir y ya te preguntan qué tal estás... O sea, que se ve que están interesados en tu caso, que no te miran por encima y no te dicen "Toma esto y vete a tu casa". Vamos, por lo menos en mi caso. [Europa del este 4]

Hablan bien. Y a mí me dejan hablar lo que necesito. [Europa del este 5]

Habla normal. Yo también hablo normal. [Europa del este 6]

Yo creo que hablan lo justo. Dicen lo que tienen que decir y ya está. Y yo... pues también hablo lo justo. [Latinoamérica 1]

El médico habla bien, lo normal. Y yo también hablo lo normal, vamos, digo lo que necesito decir. [Latinoamérica 4]

Habla lo debido, ni más ni menos. Y a mí me dejan hablar lo que necesito. [Latinoamérica 5]

Sí hablan suficiente y yo también. [Magreb 1]

El médico habla lo normal. A mí me dejan hablar, pero yo no pregunto. (Risas). (Le pregunto si no realiza preguntas porque no las tiene o porque hay algo que le impide realizarlas). Porque no tengo, no sé... [Magreb 3]

Hablan bien, explican todo. [Magreb 4]

Otras, en cambio, consideran que uno o ambos interlocutores deberían transmitir mayor información. Opinan que esta falta de información puede deberse, entre otros factores, principalmente a su desconocimiento de español o a la rapidez con la que se desarrollan las 
consultas, tema este último que trataremos con mayor profundidad en el análisis de los usos no verbales.

Ellos, los médicos, hablan mucho. Y yo quiero hablar más, pero, tú sabes, hay gentes que cuando tú no es del mismo, que quiere hacer rápido, pero tú no entiendes, y tienes que ir rápido afuera. Cuando hay una persona que habla bien español, cuando atenta, cuando bien, habla mucho, habla otras cosas, pero tú no entiendes y no tener tiempo para ti. [África Subsahariana 2]

Poco, poco, yo creo que hablan poco. Por ejemplo, ha venido el médico hoy y prácticamente ha entrado y ha salido. Y yo... bueno, si tienes una pregunta y tal, preguntas y te contestan. $O$ sea, que tampoco va más allá. Tú tienes una duda y preguntas, y te contestan lo que te tengan que contestar, pero va todo bastante rápido. Es como... que no tienes tiempo y entonces tampoco le preguntas muchas cosas, porque hay gente esperando y... [África Subsahariana 3]

Habla bien. Yo no hablo mucho porque no sé mucho español. [Asia 4]

Yo creo que el médico habla poco. Y yo no hablo todo lo que me gustaría, hablo también poco, lo justo. [Comunidad gitana]

Yo creo que hablan poco. Yo desearía que hablaran más. [...] Yo hablo lo normal durante la consulta, normal. [Latinoamérica 2]

Yo creo que hablan poco. Preferiría que hablaran más, que nos explicaran más. Depende del caso que vayan a tratar, pero sí que creo que deberían hablar un poco más, sí. Y en cuanto a mí, pues sí, también me gustaría que me dejaran que me explique, y que explicaran ellos más, sí, sí que me gustaría. [Latinoamérica 3]

Habla mucho si es especialista de una cosa, pero el médico general habla poco. Si me escuchan más, es mejor... [Magreb 2]

Por último, hay dos usuarias que creen que la cantidad de información que se les transmite puede variar de un profesional sanitario a otro.

Depende. Depende de... de médico. Cuando hay una, hablas más, cuando hay otra, hablas menos. Por ejemplo, cuando el médico habla inglés y tú hablas inglés, entonces quieres hablar más cosas. [África Subsahariana 2]

Depende. Hay médicos que te cuentan más cosas y hay médicos que te cuentan lo justo. Y yo... hay veces que también te callas cosas. [Europa del este 2]

Por otra parte, siempre en referencia a la máxima de cantidad, recopilamos información relacionada con los temas tratados durante los intercambios comunicativos entre los dos grupos estudiados. Concretamente, deseábamos saber si las usuarias inmigrantes sentían incomodidad al tratar determinados temas que para ellas pudieran resultar demasiado personales o incluso tabúes en sus culturas de origen.

Al respecto de este tema, hay unos pocos profesionales sanitarios (especialmente del perfil profesional de los anestesistas) que consideran que las preguntas que ellos suelen realizar a las usuarias están estrechamente relacionadas con la asistencia y no suelen ser delicadas, por lo que no han percibido que las usuarias inmigrantes se sintieran incómodas ante el planteamiento de determinados temas.

Nosotros no hacemos ese tipo de preguntas, no. Solamente entramos en temas puramente médicos, de enfermedades y operaciones previas y poco más. [...] Es que yo creo que nosotros, con las preguntas que hacemos, no nos metemos en temas delicados. [Anestesista 2] 
Es que nosotros de eso no preguntamos. En anestesia vamos a ir directamente a lo que son antecedentes médicos. Entonces, cosas de ese tipo, sobre las que me estás preguntando, es que ni las valoramos. A mí me interesa si eres alérgico a algo, si tienes tal enfermedad, para saber si a mí me puede condicionar el que te pinche o no te pinche, o si tienes tal cosa que yo tengo que valorar para... es que lo nuestro es muy específico. [Anestesista 3]

Es que... tampoco soy yo el médico, que pregunta su historia completa. Yo no hago la historia del paciente, yo hago unas preguntas dirigidas para mi interés. Pues a mí, si ha tenido IVEs o relaciones con uno o con otro, eso a mí no me importa, a mí me interesa saber si ha pasado por quirófano previamente. Yo no le pregunto si ha tenido más o menos parejas o si su hábito de vida es este o el otro. Yo necesito saber si está en ayunas, si ha pasado por quirófano y si es alérgica a algo, o sea, no... no pregunto mucho más. [Anestesista 5]

Es que tampoco las preguntas que les hacemos aquí son... Les preguntas cuándo fue la última regla, les dices que no tengan relaciones sexuales cuando tienen amenaza de aborto o, a lo mejor, alguna te comenta que le duele cuando tiene relaciones sexuales... pero, vamos, todo eso más delicado es también más de consulta, que no de aquí de urgencias. [Enfermera 6]

Aquí es que tampoco hay preguntas muy... muy comprometidas. Entonces no les cuesta hablar. [Matrona 2]

Hombre, tampoco hablamos de temas muy profundos. Nos limitamos, nuestra labor o, en este caso, la mía... pues, nos limitamos a hacer nuestro trabajo, que a veces puede resultar algo rutinario, pero, claro, no investigamos ni nos metemos demasiado en temas más profundos... Tampoco tenemos tiempo. (Risas). [Obstetra 1]

Por el contrario, la mayoría de los profesionales entrevistados señalan algunos temas sobre los cuales las usuarias inmigrantes procedentes de determinados países se muestran reacias a hablar. Por ejemplo, algunos comentan que resulta difícil obtener información sobre enfermedades contraídas, especialmente si se trata de enfermedades infecciosas.

Suelen mentir, sí, ocultan información, y yo te lo digo por situaciones que se han vivido, como por ejemplo, alguna punción accidental, que de acuerdo con los protocolos del hospital hay que hacer en estos casos serologías, tanto a la paciente, previo consentimiento informado de ella, y al profesional que se ha pinchado, y nos hemos encontrado casos en los que la paciente no ha dicho que presentaba serología positiva frente a algún tipo de virus y ha habido enfermedades en profesionales del área. [Anestesista 1]

Pero bueno, puede suceder que, al preguntarle por enfermedades y eso, pues que hayan tenido alguna cosa y que nos lo oculten porque para ellos puede ser algo negativo o... [Anestesista 2]

De enfermedades y demás yo creo que a veces no... Porque a mí sí que me ha pasado, por ejemplo, que un VIH vayan a decírselo al ginecólogo y a mí no. Claro, te enteras, porque estás en comunicación con el ginecólogo, pero la otra se calla y... ¿Cómo se dice? ¿Que qué atrevida es la ignorancia? Pues eso. Que te estás guardando una información que yo la tengo que saber, porque eso puede conllevar no ya peligro para mí, que soy el profesional que está trabajando y me puedo pinchar, sino que yo puedo hacer cosas que a ella la puedo fastidiar. Y entonces, a veces, ellas dentro de... a ver, ¿cómo puedo decirlo? Dentro de su cortedad de conocimientos, pues no lo pueden valorar. Yo siempre les digo a ellas y a todo el mundo "Dime todas las enfermedades que tú sepas que tienes o problemas de tipo médico, que yo valoraré lo que es importante y lo que no". Porque es que hay gente que no te puedes ni imaginar. [Anestesista 3]

La mayoría de la gente, con respecto a las enfermedades, casi tienes que sacárselas, y ya no sabes si es porque se les olvida o... [...] Pero yo creo que eso es un poco en general. Y luego a la gente también se le suele olvidar mucho las enfermedades infecciosas o.... Que hay gente que no, porque para ellos todavía es tabú, o por vergüenza o porque se les olvida de verdad... Y hay veces que casi tienes que sacárselo tú, 
preguntándole "¿Y qué enfermedades tienes?” No te lo niegan, pero tampoco te lo dicen de primeras... [Anestesista 4]

A la gente en general le cuesta hablar de las enfermedades, algunas veces por desconocimiento, porque piensan que ya no están malos, o por vergüenza... Pero bueno, aquí donde nosotros trabajamos, como es un pre-operatorio, lo que no te cuenta el paciente afortunadamente lo tienes en las historias, y hoy en día, con las historias electrónicas puedes saber si antes lo ha visto su médico de cabecera, o si ha estado antes en el hospital, o le ha visto el cirujano...entonces antes de hablar con él, ya conoces todos los antecedentes que él tiene... [...] Y sí que a la gente en general se le olvida este tipo de cosas mucho, aunque no sabría decirte si sucede más con alguna comunidad. Puede ser que con la negra, o gente de África, que no han estado tan controladas, por lo que no saben ni lo que han tenido, y encima no te puedes comunicar con ellas, como para enterarte de lo que les ha pasado... [...] o luego con enfermedades de aquí, o las llaman de otra manera, o no saben qué ha sido, qué han tenido, o ni siquiera lo consideran enfermedad... A veces hay que preguntarles "¿Y estás estado ingresada por algo?". Porque a veces no saben lo que han tenido, pero sí que recuerdan que estuvieron ingresadas y eso es importante... [Anestesista 4]

Sí que viene alguna con vaginitis, pero eso es tan delicado tanto para la española como para la extranjera. $Y$ en esos casos te dicen que no, que no, que no, que no quieren que las miren ni las toquen. Pero, bueno, yo he visto dos casos de vaginitis, es un $1 \%$ de los casos, y no recuerdo si eran españolas o extranjeras, pero vamos, son casos raros. [Enfermera 6]

\section{Otros profesionales indican casos en los que no se les proporciona información sobre operaciones quirúrgicas, interrupciones voluntarias del embarazo o embarazos previos.}

Sí, por ejemplo, en la cultura rumana prácticamente todas las mujeres han tenido alguna interrupción voluntaria del embarazo, parece que es el anticonceptivo propio de ese país. En los países del este, sobre todo en los países del este de la época soviética, utilizaban las IVE's que se llaman, la interrupción voluntaria del embarazo, como método anticonceptivo. Y entonces cuando tú les vas a preguntar porque te interesa sobre todo saber cuántas veces han sido anestesiadas, por saber la región, los productos anestésicos o si han sido intubadas, que son las cosas que te interesan, que tú valoras como importantes, lo obvian. Y entonces tú les tienes que insistir, y preguntar por otro lado, ya directamente si han tenido legrados, o abortos o si alguna vez han estado embarazadas. [Anestesista 5]

Y luego hay un grupo cultural, que es el de las sudamericanas, que no considera la cirugía estética como cirugía, y no la valora como tal. Y entonces pues lo mismo, pasa por quirófano para operarse por ejemplo los pechos, o el tabique nasal, o para quitarse cartucheras, y no te lo cuentan como una experiencia quirúrgica. $Y$ tienes que repreguntar, o buscarle la vuelta, para que... Y hay gente incluso que lo niega $y$, cuando llegas a quirófano y las duermes y tienes que abrir la tripa... pues ves las cicatrices y dices "Pero, bueno, ¿por qué no ha querido decirme...?". [Anestesista 5]

Hombre, pues, por ejemplo, el otro día nos encontramos con un caso, que a unas compañeras que habían estado en otros hospitales también les había pasado. En este caso era una sudamericana, y nos dijo que era su primer hijo y, cuando tuvo que trasladarse más tarde a quirófano y se hizo una ventosa y tal, pues vimos que había tenido una cesárea anterior. Con lo cual el primer hijo no era. Y tampoco se le notaba tanto. Yo pensé “¿Cómo no nos hemos podido dar cuenta?". Es que, claro, con la tripa tan gordita, pues no se veía bien la cicatriz, pero nos dimos cuenta justo después de haber parido en quirófano que tenía otra cicatriz de cesárea anterior. Y es que era igual, no podía coincidir con una laparotomía o... vamos, era claramente una cesárea. $Y$ entonces contaron las compañeras que se estaban dando casos, sobre todo en las sudamericanas, casadas con un señor de aquí... pues soltero, mayor, que encuentra pareja y tal y... y luego al final en algún caso sí que han llegado a confesar que sí que habían tenido otro hijo en su país, que vive o que ha muerto y tal... [Matrona 5]

Sí, esto me ha sucedido muchas veces, principalmente cuando hablamos de los abortos previos. Es que tampoco indagamos mucho más. No les preguntamos, por ejemplo, sobre su primera relación, porque 
tampoco médicamente es interesante para según qué cosas. No les solemos poner en un aprieto. Pero en el caso de los abortos, tanto si son provocados como no, sí que se nota bastante que... [Obstetra 3]

También parece que en ocasiones resulta difícil que determinadas usuarias inmigrantes den información relacionada con sus órganos genitales, la menstruación, las relaciones sexuales o la mutilación genital femenina.

Yo sí que he visto algunas veces que a las mujeres musulmanas les resulta vergonzoso el tema de su aparato genital y esas cosas en general. Si le preguntas la fecha de su última regla, por ejemplo, eso se lo sabe el marido, todas esas cosas se las sabe él, y entonces te las cuenta él. No sé si es por vergüenza o por qué, pero sí que veo que son más reacias a dar ese tipo de información. [Enfermera 4]

Incluso, fíjate, con los árabes, que les tienes que decir "Pregúntale cuándo fue la regla. Pregúntale cómo la tiene...". Y tú ya sabes los árabes cómo son para esas cosas... [Enfermera 6]

¿Te refieres por ejemplo al tema de las relaciones sexuales? Puede ser que las árabes sí, pero es que también ha cambiado mucho la cosa. Por ejemplo, las sudamericanas para hablar de esto no tienen ningún problema. [Enfermera 6]

Pero es que, claro, es que, por ejemplo, si yo veo una mutilación, creo que no debo indagar, ni preguntar, más allá de... Pienso que ese tema ya bastantes consecuencias ha tenido para esa mujer. $Y$, entonces, yo no le voy a preguntar, por ejemplo, si disfruta teniendo relaciones sexuales con su pareja. Porque ese tipo de cosas que no me tiene por qué contestar yo no las pregunto. Yo le pregunto solo cosas que me importan a mí para el parto, y para que colabore conmigo, para su bienestar y el de su hijo. [Matrona 7]

Por último, otros profesionales mencionan la incomodidad o la indiferencia que perciben en algunas usuarias inmigrantes al tratar temas como la lactancia materna, el número de hijos previos, la preferencia por hijos de sexo masculino o femenino, el estado civil u otras cuestiones que dichas usuarias pueden considerar de carácter demasiado personal.

También noto que la gente china es muy reservada. Y, por ejemplo, cuando les hablas de la lactancia materna, pues tú les hablas, pero notas que no... no les interesa mucho. [Enfermera 1]

Es que en años anteriores ha habido una encuesta, que nosotros nos negábamos a hacer, en la que preguntaban por hábitos de drogas y otras cuestiones, y eso era... Yo no sé si todavía se hace en algún servicio, porque todo esto va cambiando... Y ahí sí que había reticencias a responder, porque es que, claro, se hacían unas preguntas... Era para saber un poco el tipo de paciente que estabas manejando, pero claro, según qué preguntas... [Enfermera 5]

Yo no he tenido así ningún problema, no... Bueno, a lo mejor, sí que cuando intentas enterarte un poco más de cosas de su cultura, hay temas que... Por ejemplo, el tema de los moros, que prefieren tener niños que niñas, y cuando les preguntas a ellas por qué, te dicen "Bueno, bueno", como que no quieren explicarte por qué. [Matrona 4]

Hombre, alguna vez sí, cuando por ejemplo les preguntas cuántos hijos tienen... Y hay quien les dice "Pero, ¿vas a tener más hijos? Pues, cuídate". Y, a lo mejor, ellas igual no tanto, pero al marido... a lo mejor te mira como diciendo "Y esta por qué se tiene que meter". [Matrona 5]

Son reticentes en dar alguna información, sí. Su información personal a veces no entienden por qué se la estás preguntando. Por ejemplo, yo que pregunto cosas semi-confidenciales, ¿no?, como “¿Con quién vives? ¿Cuánto cobras? ¿Por qué este niño no ha ido al cole? ¿Por qué no has venido? ¿A qué te dedicas? ¿De dónde tal?" $y$, a veces, me miran diciendo "Pero esta mujer, ¿Por qué me pregunta a mí...?”. Y eso que les explico que necesito saber en qué situación están para ver qué ayudas se les puede ofrecer. [Profesional socio-sanitario 1] 
Mira, hay una pregunta que la haces, y que yo ya no sé cómo hacerla, y es si están casados. Yo ya no les pregunto si están casados, porque ya hay muchas parejas de hecho. [...] Y, entonces, yo ya he pasado de preguntarles si están casados y les pregunto simplemente por el libro de familia. $O$ sea, si tienes un registro civil, si estás casado, pues figura en el libro de familia, si no, no. Y, entonces, ya les pregunto directamente "¿Tenéis libro de familia?". [...] Vamos, que este tipo de preguntas sí que ves que les resultan un poco incómodas y, entonces, claro, ya no sabes cómo hacerlas. Y tampoco digo ya "Tu mujer" o "Tu marido", sino que digo "Tu pareja", porque además no solamente puede haber parejas hetero(sexuales), sino que también pueden ser homo(sexuales). Y eso varias veces me ha pasado, el decir "El marido de tal...", y es una mujer, y entonces dices "Bueno, la pareja", y te echas a reír, porque es gracioso, es cómico, y además las chicas mismas también lo ven como algo gracioso, ¿no? $\mathrm{Y}$, además, seguro que están acostumbradas a que les pase esto, seguro. Así que ya hace tiempo que no hay maridos, hay parejas, que como es neutro vale para todos. [Profesional socio-sanitario 3]

Por lo que se refiere a las usuarias inmigrantes entrevistadas, cabe señalar que sus respuestas parecen no coincidir plenamente con las de los profesionales sanitarios que acabamos de presentar, pues prácticamente todas opinan que los temas por los cuales les suelen preguntar los médicos no son personales, sino que se suelen centrar casi exclusivamente en su estado físico y en el del recién nacido.

Preguntan si estar bien. No preguntan por familia. En Nigeria tampoco preguntar por familia cuando iba al médico. [África Subsahariana 1]

(¿Te preguntan por temas muy personales que crees que no deberían preguntarte?) No entiendo bien. (Trato de explicárselo de otro modo). No, no, es normal lo que preguntan. [África Subsahariana 2]

No, no, temas así personales, no... [...] Es que tampoco te preguntan mucho, solo si tienes alguna molestia y cosas de esas. En el parto, por ejemplo, me preguntaban solo si tenía dolores y todo eso, pero tampoco... [África Subsahariana 3]

No, no suelen preguntar por temas familiares y esas cosas. Te dicen si te duele o no te duele o cómo te encuentras y cosas así... [África Subsahariana 4]

No preguntan por familia o trabajo. No hacen esas preguntas... [África Subsahariana 5]

No, preguntas no personal. [Asia 1]

No me parece, pregunta temas normales. [Asia 2]

Preguntan si está todo bien. [Asia 4]

No, no me preguntan nada de eso... [Comunidad gitana]

No, no me han preguntado nada personal. No, yo creo que hablan lo que tienen que hablar. [Europa del este 2]

Sí, preguntan sobre todo por cosas físicas. [Europa del este 3]

Me preguntan cómo me encuentro y esas cosas, pero yo si me quejaba de algo, no me daban mucha atención y no... Bueno, es que ya sabía que todo lo que te quejas tú es algo que luego se te pasa. Pero... primero el chico, siempre preguntaban por él. Todo estaba relacionado con él, los análisis... todo. [Europa del este 5]

No, no me parece que pregunten temas personales, no... Preguntan lo que tienen que preguntar. [Europa del este 6]

No, no, no me han preguntado nada personal. No, la verdad es que yo creo que tienen que centrarse más en eso, en los aspectos físicos, ¿no? A mí... está bien de la forma que hacen. [Latinoamérica 2] 
No, no me han preguntado por nada personal, no. [Latinoamérica 5]

No, esto (que le pregunten por temas personales) no me ha pasado. Sí me preguntan por aspectos físicos, sí. Con eso es suficiente, no me preguntan otras cosas de mi vida. [Magreb 1]

¿El médico? No, no pregunta nada personal. Preguntan las mismas cosas: si el niño come bien, si hay algo que te duele... Son las cosas normales que tienes que preguntar. [Magreb 2]

¿Preguntas personales? ¿Te refieres relaciones o algo así? No, no, médico no pregunta. Solo pregunta cómo encontrar, si todo bien y eso... [Magreb 4]

Algunas también afirman que se les ha preguntado por sus familias, especialmente por el número de hijos previos.

\author{
También preguntan por familia y esas cosas, sí. [África Subsahariana 2] \\ Sí, también preguntan por familia. [Asia 2] \\ Sometimes they ask about the family. [...] They ask me how many children. [Asia 3]
}

No, solo me preguntan por los niños, cuántos niños tengo, pero otros temas familiares, no. [Comunidad gitana]

Sí, sí, han preguntado siempre preguntas así... Por ejemplo “¿Tiene más hijos?” y ese tipo de cosas. [Latinoamérica 5]

Al respecto de esta pregunta, encontramos dos opiniones discordantes en las respuestas de las usuarias entrevistadas. Algunas de ellas consideran que no les deberían preguntar por ningún aspecto relacionado con su vida personal fuera del hospital.

¿Aquí? ¿En el hospital? No, no me preguntan por nada personal. [...] Creo que no tienen por qué interesarse por mi familia, o mi vida fuera del hospital. [Europa del este 1]

No, no me han preguntado por nada personal. Me preguntan cómo me encuentro y esas cosas. No creo que me tengan que preguntar nada más. [Latinoamérica 1]

No, nunca me han preguntado por nada personal. No, solo me preguntan por aspectos físicos. Y yo creo que no deberían interesarse por nada más, no. [Latinoamérica 4]

Sí me preguntan por aspectos físicos. No creo que tienen que hacer otras preguntas. [Magreb 3]

$\mathrm{Y}$, por el contrario, una usuaria piensa que deberían interesarse por otras cuestiones no estrictamente relacionadas con los aspectos físicos.

Pues, no, esto (que le pregunten por temas personales) no me ha pasado, no. Pues sí, me preguntan por aspectos físicos, y yo creo que deberían preocuparse un poco más por otras cosas. [Latinoamérica 3]

Solo dos de las usuarias entrevistadas, concretamente procedentes de China, señalan que les resulta difícil en ocasiones responder a las preguntas de los profesionales sanitarios, no solo por su desconocimiento del español, sino también por los temas tratados, aunque no especifican a qué temas concretos se refieren.

Sí, físico y otras que no sabe. A veces familia, trabajo, pero no sabe, y pido que hace otra pregunta. [Asia 1]

Sí, a veces es difícil. Por ejemplo... no sé. Sí, pero a veces es difícil. Por culpa de la lengua y porque son temas que... [Asia 4] 
La tercera cuestión relativa a la máxima de cantidad se centra en la confidencialidad de los datos aportados. En referencia a este tema, algunos profesionales sanitarios, tal y como hemos comentado en el análisis del nodo anterior (dedicado a las barreras lingüísticas y las soluciones adoptadas), presentan ciertas dudas sobre si se mantiene la confidencialidad de la información intercambiada en las conversaciones con las usuarias cuando, por su desconocimiento de español, debe intervenir un intermediario que actúe como intérprete, bien ad hoc o bien profesional, o a través del teléfono. Por su parte, todas las usuarias inmigrantes entrevistadas consideran que en el hospital contexto de estudio hay suficiente confidencialidad con respecto a sus datos, como se puede observar en las citas que se incluyen a modo de ejemplo a continuación.

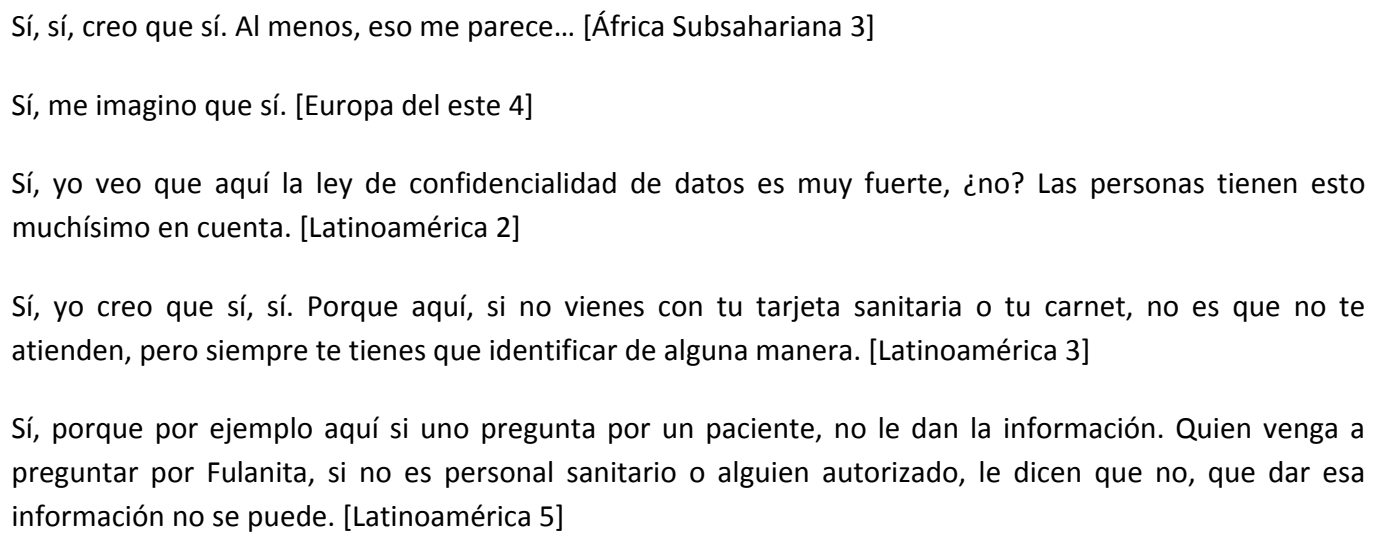

Sin embargo, por las respuestas y las expresiones faciales de algunas usuarias al responder a esta cuestión, no tenemos total certeza de que realmente hayan comprendido el concepto de "confidencialidad".

Sí... (Tono muy dubitativo; me pregunto si habrá comprendido mis palabras). [Asia 3]

Sí, está bien... (Por su expresión facial y su tono de voz, no estoy segura de que haya entendido esta pregunta). [Comunidad gitana]

No entiendo. (El marido le traduce al árabe y, entonces, ella responde). Sí, sí, creer que sí. [Magreb 4]

En cuanto a la máxima de calidad, preguntamos a ambos grupos si confiaban en sus interlocutores y presuponían que estos les hablaban con sinceridad.

Por lo que respecta a los profesionales sanitarios entrevistados, podemos dividir sus respuestas sobre este tema en dos grupos.

En primer lugar, hay algunos profesionales que opinan que las usuarias inmigrantes pueden ocultar la verdad cuando se refieren, como ya hemos comentado en el análisis de nodos anteriores, a sus conocimientos de español, o en cuanto a enfermedades, embarazos o abortos previos. A estos temas, añaden las mentiras relativas a hábitos y estilos de vida, al uso de una tarjeta sanitaria ajena o al seguimiento de tratamientos médicos recomendados, aunque no realizan distinciones dependiendo del origen de las usuarias.

Eso lo ves... no todo el mundo te dice toda la verdad. Pero eso lo hemos hecho un poco todos, es como una forma de... me ha mandado el médico que me tome esto y yo le digo que me lo he tomado y no es verdad. Pero bueno ahí el primero que se engaña es el paciente. Tú intentas decirle que te lo cuente todo, que te diga la verdad, por su bien... Es como cuando le preguntas “¿Fuma?" y te dice "Sí, pero muy poco", 
y “¿Y cuántos cigarrillos fumas, unos ochenta al día?, y te responde "No, no, solo fumo dos paquetes al día"... Vaya que quitándole importancia, puedes conseguir que te diga la verdad... (Risas) [Anestesista 4]

Yo creo que sí, que pueden mentir. Porque hay veces que te lees las historias y hay cosas que les han hecho en su país que no cuadran con luego cosas de aquí... [Enfermera 1]

De hábitos, pues, a veces sí que pueden contar alguna mentirijilla. Pero, vamos, exactamente igual que las usuarias españolas. [Enfermera 4]

Por supuesto en cuanto a hábitos o estilos de vida no deseables, como el tabaquismo y demás, pues las mujeres... mienten un poco. $\mathrm{Y}$ hay veces que te encuentras unas placentas que están totalmente envejecidas, calcificadas, infartadas, que se nota a la legua que se han fumado todo lo que había y más y... (Risas) y te dicen "No, no he fumado. Bueno, me fumé un cigarro hace cinco meses". Y tú te das cuenta de que es mentira. Sobre todo esas cosas que, hombre, que les podrían hacer sonrojar un poco, pues sí, a veces mienten. Pero esto es independiente, yo creo, de la procedencia. [Matrona 1]

Porque aquí se colaba de todo, claro, y algunas mujeres no tenían seguridad social. Y, por ejemplo, hace muchos, pero muchos años, se dieron casos de mujeres que venían a parir con el nombre de otra, lo cual nos acarreaba muchísimos problemas. Nos dábamos cuenta porque venía una mujer, fulanita de tal, pedíamos la historia, y a lo mejor esa mujer no hacía ni un año que había parido. Entonces, no podía ser, porque era un primer hijo, entonces... Lo que no entiendo es que... Quizás esto tenía alguna implicación legal, a lo mejor no querían que supiéramos más datos por lo que fuera, que no les hiciésemos preguntas. Pienso que era un problema de este tipo, no porque no confiasen en nosotras. [Matrona 7]

No son sinceras (Risas). No, así de fácil. Nunca te fíes de ninguna paciente. Había una serie televisiva, no me acuerdo cómo se llamaba, es que yo veo muy poca televisión... Pero, bueno, da igual, es una serie de un médico, y alguna vez he visto algún fragmento de algún capítulo, y este médico decía que los pacientes siempre mienten, y normalmente es así. (Risas). No es que digo que siempre mientan, pero, vamos, sinceras... Sinceras no son. Pero aquí no haría distinciones, ahí sí que ni españolas, ni inmigrantes, ni... Te dicen lo que quieren. Y allá ellas, yo ahí no me voy a meter. [Obstetra 1]

Depende. Bueno, puedo ver que algunas cosas sean... no sé, que las oculten, que no te den información, puede ser... Pero, creo que esto puede pasar también con las españolas. [Obstetra 3]

Otros profesionales hablan de la falta de sinceridad de colectivos concretos de usuarias, y se refieren especialmente a las usuarias procedentes de China.

Además de tener una cultura diferente en general, también tienen una cultura sanitaria muy distinta. Y eso hay que preguntarlo, porque son muy reservados, yo creo que nunca sabremos lo que toman. Pero, en general, los chinos no cuentan que vienen con un tratamiento de casa de medicina alternativa. Te dicen que no. Antes me preguntabas si alguna vez me habían mentido y ahora me viene a la cabeza esto... A veces te dicen que no, pero las matronas suelen recordarte que puede que hayan tomado algo, hierbas, brebajes y cosas, y nunca lo sé. Yo les pregunto y nunca me dicen que sí. [Anestesista 5]

Por ejemplo, la utilización de la tarjeta de otra persona, que se da mucho en la comunidad china, pese a que les expliques cincuenta veces los riesgos que conlleva y que no es necesario, que a una embarazada la ven igual, pues no se fían. Se creen que les vas a cobrar o que no les vas a atender y vienen con la tarjeta de una acompañante. [Profesional socio-sanitario 1]

Entre las causas que pueden provocar esta falta de sinceridad, algunos profesionales sanitarios señalan las barreras lingüísticas o el miedo que pueden sentir estas usuarias por comportarse de manera diferente a la habitual en la sociedad de acogida.

Yo creo que igual alguna vez ocultan información. No sé, es una sensación que... Pero yo creo que no es porque no lo quieran contar, sino por pereza de explicarse o por la barrera en la comunicación. [Anestesista 2] 
Hombre, pues, a lo mejor, sí puede ser que alguna vez mientan. Pues, a lo mejor, por miedo, por miedo a ser diferentes o... No creo que lo hagan conscientemente, como para engañar, sino que para que no nos extrañemos si hacen tal o cual cosa, o si se toman tal hierba... Yo creo que alguna cosa sí que nos ocultarán. Pero, bueno, como una española, que te puede decir que no fuma, y luego fuma... Vamos, que no creo que digan "Voy a hacerlo para...", sino que yo creo que es más por miedo. [Matrona 6]

Por el contrario, hay un segundo grupo de profesionales sanitarios que consideran que las usuarias inmigrantes suelen ser sinceras $y$, además, algunos opinan que no se encuentra entre sus funciones el determinar el grado de veracidad de la información que estas les transmiten.

No, no creo que mientan. Yo creo que son sinceras. [Enfermera 3]
De enfermedades, no creo que mientan, la verdad. [Enfermera 4]

Ay, no sé, yo en eso no entro, no tengo ni idea. Para mí, todo el mundo me dice lo que piensa, yo no sé si es verdad o no, pero vamos a mí me dice lo que piensa, o lo que no piensa, o lo que le dé la gana. Y yo hago caso a eso, no estoy ahí para ver si me ha mentido. [Enfermera 5]

Hombre, yo me imagino que son sinceras. Vamos, eso espero. [Enfermera 6]

Ay, no lo sé, yo... confío en que digan la verdad. Tampoco me puedo estar planteando que me puedan estar mintiendo. Va en su propio beneficio, ¿no? No veo el interés en... Hombre, a lo mejor pueden ocultar que... Pero, vamos, no me lo planteo que me mientan. Me lo creo todo. (Risas). [Matrona 3]

No, yo creo que son sinceras, ¿eh? Porque al fin y al cabo... entienden que lo que llevan dentro es su hijo. Lo entienden y le quieren. $Y$, entonces, yo creo que sí, que te dicen las cosas, yo creo que sí. $O$ yo me fío de ellas y me lo creo, no sé. Luego, también te lo reconozco, que dices “Mira, si me estás mintiendo, es tu problema. Es tu hijo, ¿'sabes? Eres tú y tu hijo. Si luego esto sale mal, pues tú verás". O sea, si yo te estoy explicando por activa y por pasiva cómo hay que controlar una diabetes, por ejemplo, y tú sigues comiéndote esos pasteles que llevan miel y piñones... Pues, mira, hija, es tu problema. [Matrona 4]

Hombre, yo creo que sí son sinceras. Y, si en algún caso mienten, pues tampoco lo podemos saber... Eso es cosa de ellas. [Obstetra 2]

Por lo que se refiere a las usuarias inmigrantes, todas las entrevistadas confían en que los profesionales sanitarios son sinceros cuando hablan con ellas.

Sí, yo pienso dicen la verdad. [África Subsahariana 1]

Sí, sí, creo que sí... [África Subsahariana 5]

Sí, I trust them. [Asia 3]

Sí, confío. [Asia 4]

Sí, sí, sí que confío... [Comunidad gitana]

Yo creo que son sinceros. No tienen por qué mentir. Si hay algo mal, pues es que, mira... no puede estar todo perfecto. Entonces, yo creo que sí, que sí que me dicen la verdad, por mi punto de vista... [Europa del este 1]

Sí, sí que confío, sí. [Europa del este 2]

Sí, sí pienso son sinceros, sí confío. [Europa del este 3]

Yo creo que sí, que son sinceros. Yo, sí. [Europa del este 5]

Esto no lo sé... (Risas). Pero espero que sí. [Europa del este 6] 
Sí, sí, claro que confío. [Latinoamérica 1]

Sí, sí, sí confío en ellos, sí. [Latinoamérica 2]

Creo que sí, porque si no... todos estaríamos muertos, creo. (Risas). [Latinoamérica 5]

Claro, sí, sí dicen la verdad. [Magreb 1]

Sí, sí que confío, sí. [Magreb 3]

Un par de usuarias, además, asocian este grado de sinceridad al perfil profesional, es decir, consideran que un médico no puede (o no debe) nunca mentir.

Bueno, yo creo que sí, porque si son médicos realmente, creo que no me dirían una cosa que no es cierto. [África Subsahariana 4]

Sí. Es que... Igual lo que digo suena mal, o suena como que soy ignorante, pero yo creo que si son médicos te tienen que informar, te tienen que decir lo que hay. [Europa del este 4]

Para finalizar el análisis del grado de sinceridad, cabe añadir el relato de una de las usuarias, concretamente de la comunidad gitana, según la cual le acusaron de mentir en cuanto al robo de una toalla del hospital. Consideramos que, quizás, esta acusación podría estar basada en prejuicios y estereotipos que a menudo se atribuyen a las personas de la comunidad gitana.

Por ejemplo, a mi hija me la trajeron envuelta en una toalla, y se la han llevado esta mañana para ducharla y, al volver, me la han traído sin toalla. Entonces, han venido luego y me han dicho "¿Dónde está la toalla?". Y yo le he explicado que me la habían devuelto sin toalla. Y no sé cómo lo ha dicho, pero ha dicho algo así como "No puede ser. Siempre el mismo cuento. Es que no me lo creo... “. ¿Pero qué voy a hacer yo con una toalla, una toalla pequeña?. O sea, que son cosas que tienen algunas, que piensan que... [Comunidad gitana]

Y, para concluir el análisis de los usos verbales, por lo que respecta a la máxima de manera, analizamos si los profesionales sanitarios y las usuarias inmigrantes consideraban que la forma de hablar de sus interlocutores seguía ciertas normas asociadas a la cortesía verbal.

La mayoría de los profesionales sanitarios entrevistados opina que en general las usuarias inmigrantes son respetuosas y educadas cuando se comunican con ellos.

No, no, en general son corteses a la hora de hablar. [Anestesista 1]

Yo creo que en general son bastante respetuosas. [Anestesista 4]

No, en general son corteses, a mí no me parecen maleducadas. [Anestesista 5]

Sí, sí, en general son respetuosas, sí. [Enfermera 1]

Normalmente son educadas, sí. [Enfermera 2]

Sí, sí, son corteses y respetuosas, respetuosas también. [Enfermera 3]

No son más informales, no, no me parece que sean más informales, no. En ese sentido, ni peor educación ni nada, no, no. [Matrona 1]

No, qué va, qué va... Son muy respetuosas y educadas. [Matrona 6]

Normalmente son bastante respetuosas. De todo hay también, pero yo diría que en general son más respetuosas. Se encuentran en un país extraño y... Sí, normalmente son respetuosas. [Obstetra 1] 
Normalmente son respetuosas y educadas. [Profesional socio-sanitario 1]

Son corteses, son corteses, sí. [Profesional socio-sanitario 3]

Yo me encuentro poca gente que me hable de uñas, ojo, poca gente inmigrante. Te hablan mucho peor los españoles que los inmigrantes. [Profesional socio-sanitario 3]

Otros consideran que en todos los colectivos (tanto de usuarias inmigrantes como autóctonas) se puede encontrar personas cuya forma de hablar sea más o menos cortés.

No sé, hay de todo. [Anestesista 2]

Pues no lo sé, sinceramente, porque tienes un poco de todo también. [Anestesista 3]

Yo, desde mi experiencia, yo no he tenido así... Porque las veces que he visto descortesía o informalidad, como lo he visto en general en todas, para mí es algo más de la persona. Porque he tenido, pues eso, desde musulmanas que son muy, muy, muy educadas a musulmanas que nada, y lo mismo con las españolas y todas en general. No te sabría decir si son en concreto de alguna comunidad. [Enfermera 4]

Pues, hay de todo. Hay gente educada y respetuosa, y hay otros que vienen con muchas exigencias. [...] Pero, vamos, hay de todo. Como con los españoles, hay personas de una manera y de otra. [Enfermera 5]

No, igual que todo el mundo, quiero decir, hay de todo. Hay gente que es educada y cordial y hay gente que no, pero, vamos, como en España también. [Matrona 3]

Por último, algunos profesionales señalan determinados colectivos de usuarias inmigrantes que, según su parecer, son más directas y descorteses cuando se dirigen a ellos. Dentro de estos colectivos, destacan especialmente a las usuarias procedentes del este de Europa o a las de la comunidad gitana.

Posiblemente la gente del este sea más brusca, porque creo que su carácter es así, y posiblemente su forma de hablar sea algo más brusca, pero no creo que sean descorteses, sino que son así. [Anestesista 5]

$Y$, luego, me ha pasado alguna vez encontrarme con mujeres maleducadas, que son de Portugal, pero gitanas. Con ellas sí que alguna vez hemos tenido algún problema, pero vamos son casos especiales... [Enfermera 6]

Las más informales cuando hablan quizás sean las del este. [Matrona 2]

Las rumanas, las rumanas son muy maleducadas. (Risas). [Matrona 4]

Algunas son respetuosas, y otras... Las gitanas, a veces, a lo mejor contestan con desaires, o dicen “iCállate ya! ¡Que me pongan la epidural! ¡Que no puedo más!”, y tú le dices "Pues, mira, espera un poquito, porque en este momento no conviene, porque tienes que esperar a tener contracciones más rítmicas". [Matrona 7]

En cuanto a las causas de esta forma directa de hablar, dos profesionales entrevistados señalan que puede deberse a que no son hablantes nativas de español y quizás hayan aprendido este idioma en contextos donde el registro habitualmente empleado sea muy coloquial.

También puede ser por su forma de hablar, porque hay veces que no han aprendido bien español y entonces su forma de hablar puede resultar directa... Alguna vez se te encaran, alguna vez, sí. Si no les dices lo que ellas quieren, o les dices "¿Por qué ha venido en ambulancia?" o "Esto no es de urgencias", se te encaran, sí. [Enfermera 5] 
A ver, no, no quería decir maleducadas. Yo creo que la gente del este aprende muy rápido nuestro idioma, pero como vienen aquí y trabajan en sectores que son a lo mejor culturalmente como más bajos, entonces aprenden a hablar como muy coloquial. Y, entonces, claro, ¿qué pasa? Pues que a veces te sueltan cada barbaridad... Porque la española aquí te habla de vagina y tal, y llega la rumana y te dice "Es que me duele el coño". Y te quedas como diciendo... (Risas). Pero es que es lo que han aprendido. A lo mejor, son distintas a la hora de tratar con ellas, pero es porque la forma en la que han aprendido a vivir y a relacionarse aquí, a lo mejor, no es... Porque una persona española que sea culturalmente inferior, que no haya ido a la universidad, a lo mejor coloquialmente puede ser la más burra del mundo, con sus amigos, pero cuando va a un sitio que sabe que tiene que guardar unas formas, pues las sabe guardar. Y el español que ha recibido una cultura más normalica, más normalica, porque no ha podido recibir más, se esfuerza por tener una educación en ese contexto. Pero es que ellas, las rumanas, no. Sobre todo ya te digo que son las del este, que aprenden el idioma coloquial de aquí y son brutas como ellas solas, de verdad, son una pasada. (Risas). [Matrona 4]

Por su parte, casi todas las usuarias inmigrantes entrevistadas creen que, por lo general, los profesionales sanitarios se dirigen a ellas de forma respetuosa y educada.

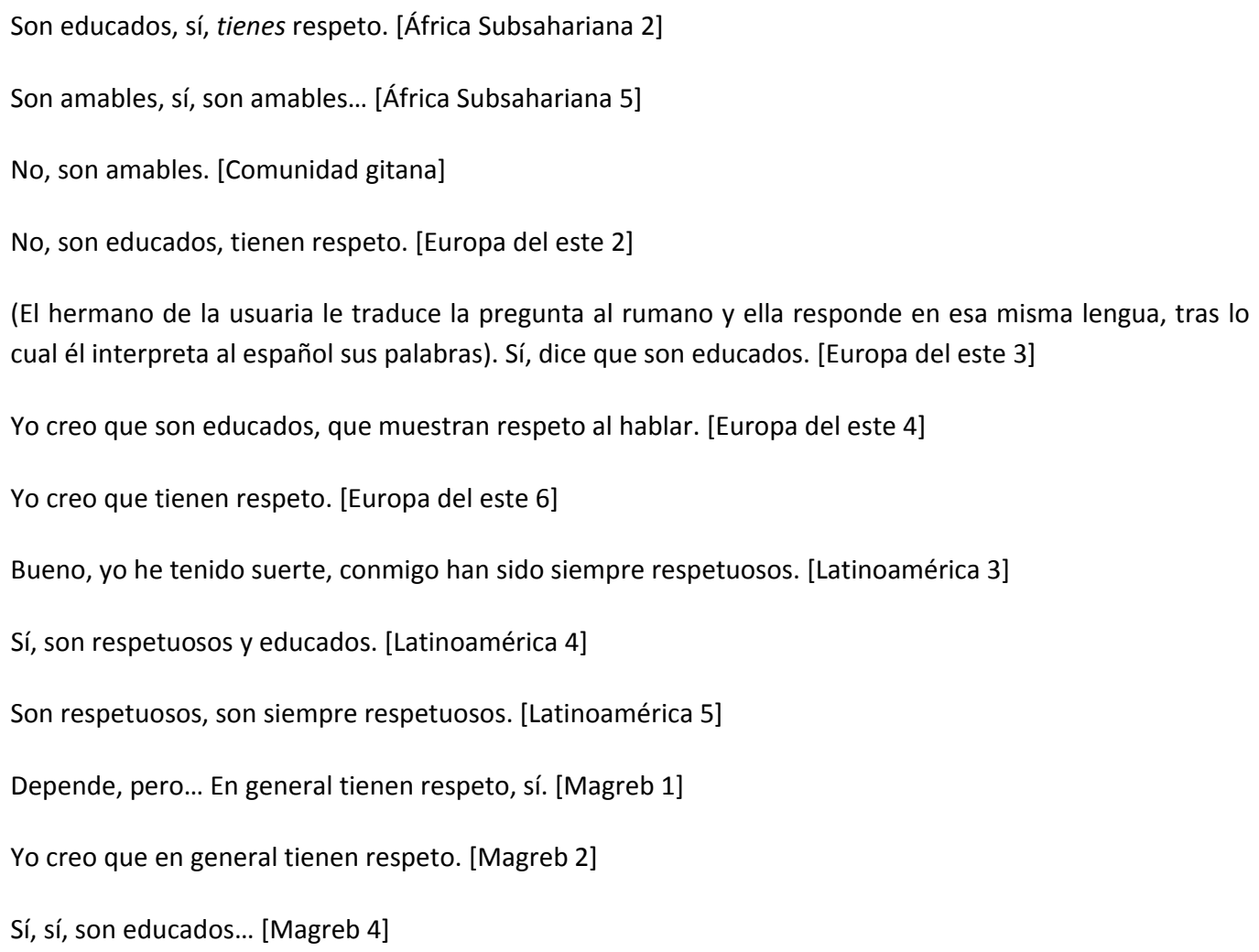

Al respecto, una de estas usuarias, concretamente procedente de Nigeria, opina que tanto en España como en su país de origen el modo de hablar suele estar determinado por el nivel educativo de las personas.

Hablan normal. Pero depende. En Nigeria también la gente habla diferente. Por ejemplo, cuando tú estás en una oficina, tú sabes que allí la gente tiene diplomas, y habla diferente, habla más despacito y educado que la gente cuando trabaja en la calle. [África Subsahariana 2]

Además, otra usuaria añade que no ha notado diferencias determinadas por su origen cuando los profesionales sanitarios se han comunicado con ella, es decir, que considera que se han dirigido a ella con el mismo respeto con el que se dirigirían a una usuaria autóctona. 
Son educados. No piensan que estás de fuera. Te tratan como la gente normal. A mí me tratan así los nueve meses. No me han preguntado si estás de fuera, si eres extranjero, o... si estás de aquí. A mí me han acogido como a la gente normal, como a los otros. [Europa del este 5]

También hay algunas usuarias que, al igual que comentaban los profesionales, creen que la forma más o menos educada de hablar depende de cada persona y que no es posible generalizar.

Es que depende de la persona. Como te decía antes, hay de todo... [África Subsahariana 3]

Bueno, eso depende de la persona que te toca. Hay algunos muy educados y hay otros que parece que están... no sé, como si "Venga, que yo me tengo que ir a casa". Es que eso depende de la persona también, no depende de profesión ni nada, depende de la persona. Depende de cómo eres, no depende de que seas español o senegalés o lo que sea... [África Subsahariana 4]

No, sometimes there are people who are unkind, and others... usually they are kind. [Asia 3]

Solo tres de las usuarias entrevistadas, procedentes de distintos países, piensan que los profesionales sanitarios son demasiado serios o directos cuando hablan con ellas.

Hablan normal, pero mucho serio. [Asia 2]

Los españoles en general son más bien directos, en general. En Brasil sí que las personas tienden a hablar de una forma más... ¿Sabes? Y los españoles son más directos, pero eso no me parece mal. [Latinoamérica 2]

Son directos, sí. [Magreb 3]

A continuación, pasamos a analizar algunas cuestiones relacionadas con los usos no verbales de las interacciones entre usuarias inmigrantes y profesionales sanitarios. Dividimos este análisis en tres secciones, dedicadas respectivamente a la distribución del tiempo, la distribución del espacio y el paralenguaje.

En cuanto a la distribución temporal, comenzamos con un análisis más general del tiempo de las interacciones, relativo en concreto a la duración de las consultas. Ya hemos adelantado en el estudio de nodos anteriores que algunas usuarias consideran que durante las consultas ocurre todo muy rápido, y así lo corroboran tres de ellas cuando se les pregunta directamente sobre este tema.

\footnotetext{
Pues, corta... Es todo muy rápido, sí. [África Subsahariana 4]

Son cortas, a mí me parecen cortas. [Comunidad gitana]
}

Yo creo que son muy rápidas, sí. Pero eso es en todos los sitios. [Latinoamérica 2]

Sin embargo, la gran mayoría opina que la duración es adecuada y no creen que las consultas sean excesivamente cortas o largas.

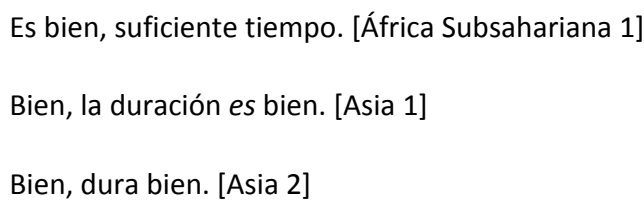


Está bien, duran bien. [Europa del este 3]

Bien, duran lo que tienen que durar. [Europa del este 4]

Duran bien. Yo no quiero que duran más, no (Risas). [Europa del este 5]

No son cortas, no, son suficiente. [Europa del este 6]

La duración, sí, está bien. [Latinoamérica 1]

Duran bien, sí, me parece bien. [Latinoamérica 4]

Duran suficiente. [Latinoamérica 5]

Duran normal, bien. [Magreb 1]

Normal, duran lo normal. [Magreb 3]

(Por su expresión, parece no entender mis palabras. El marido le traduce al árabe y, entonces, ella responde). Tiempo, bien, no mucho, no poco. [Magreb 4]

Por lo que respecta a la estructura global de la conversación y la distribución de los turnos de palabra, preguntamos tanto a los profesionales sanitarios como a las usuarias inmigrantes si habían percibido demasiados silencios, solapamientos o interrupciones al comunicarse entre ellos.

La opinión de los profesionales sanitarios entrevistados relativa a esta cuestión podría dividirse en dos grupos. Por una parte, están aquellos que no perciben dificultades o diferencias relativas al ritmo de la conversación cuando esta tiene lugar entre ellos y las usuarias inmigrantes, y consideran que estas les suelen escuchar.

Suelen escuchar, sí, la mayor parte suelen escuchar. No suele haber solapamientos, sino que escuchan y, después, la mayoría preguntan si algo les angustia mucho. [Anestesista 1]

No, no, normalmente te escuchan. Otra cosa es que luego te entiendan, pero vamos, que lo intentas. [Enfermera 2]

No, no especialmente, no me parece que en este tema haya un problema excesivo. [Matrona 1]

Pues, no sé, en esto yo no he notado nada que las diferencie, la verdad. [Matrona 2]

Pues, yo de esto, no sabría qué decirte. No hay nada que me llame la atención, no. [Matrona 7]

No, de eso (silencios, solapamientos, interrupciones, etc.) no he notado nada, la verdad... [Profesional socio-sanitario 2]

Por otra, algunos profesionales señalan que no se suelen producir interrupciones o solapamientos, pero que sí han notado que las conversaciones con las usuarias inmigrantes no son fluidas, pues presentan un ritmo lento o muchos silencios (quizás debidos, de acuerdo con alguno de estos profesionales, a sus escasos conocimientos de español). Algunos indican colectivos específicos de usuarias con las que esto sucede, pero no deberían considerarse significativos, pues no son comunes.

Yo creo que hay muchos silencios. A veces les dices algo y no contestan, no te dicen nada. Y no sabes si es que no entienden lo que les dices o no te quieren decir. [Anestesista 3] 
Sí, vamos, yo creo que hay silencios. [Enfermera 3]

Hombre, no sé si es por el idioma, pero por ejemplo, con las musulmanas sí que por lo general cuando he hablado con ellas eran conversaciones muy lentas, les hacías la pregunta y te contestaban al tiempo. Y, en cambio, las africanas, ellas te decían todo y te cortaban a veces y tal. Pero esto es lo único que he observado, porque el resto... [Enfermera 4]

Eso (los silencios, solapamientos o interrupciones) depende más del manejo que tengan del idioma, más que de su cultura. Sí, sí, yo creo que sí. [Matrona 4]

Hay muchos silencios. Yo creo que es lo que más hay de todo lo que me has nombrado ahora. Interrumpir, pocas veces. Muy pocas veces. Yo creo que hay más silencio. [Matrona 5]

Interrumpir, no. Silencios, a lo mejor... [Matrona 6]

Normalmente se te quedan mirando e intentan escuchar, intentan indagar... o sea, intentan entender lo que les estás diciendo. Por eso, yo creo que hay más bien silencios. [Obstetra 1]

Silencios, con las subsaharianas. Pueden estar... son muy parcas en palabras. Sí, esas, sí. Y eso es lo que más me llama la atención, en las demás yo creo que depende de la persona. [Obstetra 3]

Por lo que se refiere a las usuarias inmigrantes entrevistadas, todas ellas consideran que no se producen interrupciones o solapamientos cuando hablan con los profesionales sanitarios y que normalmente estos las suelen escuchar.

Sí escuchan. [África Subsahariana 1]

Sí, sí escuchan. [África Subsahariana 2]

No, they listen. [Asia 3]

Saben escuchar y me dejan hablar. [Asia 4]

No, me escuchan. [Comunidad gitana]

En la consulta, no te interrumpen, no, te escuchan. [Europa del este 1]

(El hermano de la usuaria le traduce la pregunta al rumano y ella responde en esa misma lengua, tras lo cual él interpreta al español sus palabras). Sí, bueno, cuando empieza a hablar, la dejan, pero... como no la entienden... [Europa del este 3]

Pues no me he fijado... No sé, si no hay nada que me haya llamado la atención, me imagino que sí que me escuchan... [Europa del este 4]

Sí que me han escuchado todo lo que he dicho yo. No sé si he dicho tonterías o no. Porque a veces dices cosas pequeñitas que para ellos no valen o saben que no tienen importancia, pero te escuchan. [Europa del este 5]

Sí, sí saben escuchar. [Europa del este 6]

No, es lo que te digo, siempre son muy atentos, escuchan lo que digas y al instante ya te responden... [Latinoamérica 1]

No, no me interrumpen, normalmente me escuchan. [Latinoamérica 2]

No, sí que me han escuchado. [Latinoamérica 3]

No, siempre me escuchan. [Latinoamérica 4] 


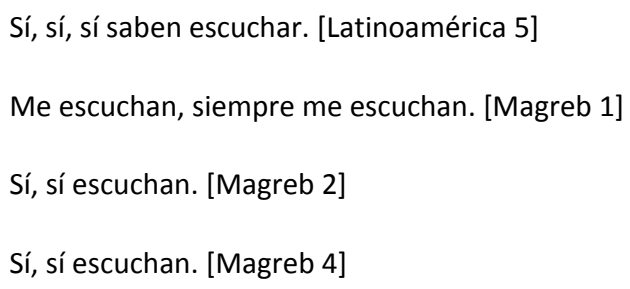

Una de ellas, procedente de Camerún, nos comenta, además, que en su país de origen existen ciertas normas según las cuales no se considera adecuado interrumpir mientras se está hablando con otra persona, especialmente si el interlocutor es una persona de mayor edad.

Normalmente te escuchan, no veo en esto ningún problema. En Camerún sí que nos dicen, por ejemplo, que no hay que interrumpir, sobre todo, si las personas mayores están hablando, pues tú te callas y no te interrumpes. Pero bueno, en general, yo no he tenido problemas porque me interrumpan y eso... [África Subsahariana 3]

En cuanto a la distribución espacial de las interacciones comunicativas entre profesionales sanitarios y usuarias inmigrantes, dividimos el análisis en dos secciones.

La primera de ellas se centra en el macroespacio y en ella analizamos dos aspectos concretos. Por una parte, preguntamos a las usuarias inmigrantes si creían que había bastante intimidad durante las consultas. La gran mayoría opina que sí la hay, tal y como se puede observar en las citas que se presentan a modo de ejemplo a continuación.

Sí, sí, yo creo que sí. [África Subsahariana 2]

No, no es un problema, porque hay biombos y tú te quitas la ropa y ya está. No es un problema, no... [África Subsahariana 3]

Sí, sí creo que hay bastante intimidad, sí. [Europa del este 1]

Sí que hay intimidad, sí. [Latinoamérica 3]

Sí, sí, porque cuando uno va... Por ejemplo, aquí te dicen que hay que tocar antes de entrar o que se debe esperar a ser llamado antes de entrar a la consulta. Así que... sí, sí. [Latinoamérica 5]

Está bien, yo prefiero que no entra mucha gente. [Magreb 1]

No, no hay mucha gente. Viene visita, su amigo, su familia, y no molesta, es normal que haber visita. [Magreb 4]

Solo una de las usuarias entrevistadas comenta que dicha intimidad se ve violada en los casos en los que, durante las consultas, están presentes estudiantes en prácticas del área de la salud.

Pues... cuando no hay estudiantes en prácticas, sí, sí que hay intimidad, pero si te toca con estudiantes... [África Subsahariana 3]

Sin embargo, como sucedía en el análisis de la confidencialidad de los datos presentado previamente, por las expresiones faciales y las respuestas ofrecidas al plantearles esta cuestión a algunas usuarias, nos surge la duda de que todas ellas hayan comprendido perfectamente el concepto de "intimidad".

¿Intimidad con los pacientes? Es que como ellos (los profesionales sanitarios) están tan acostumbrados, pues para ellos es lo normal... [Europa del este 4] 
¿Qué es intimidad? (Trato de explicarle el significado de este concepto). Está bien, porque estoy sola en la habitación. Pero puede ser que no hay mucha gente, ¿no? No sé si en verano hay menos gente. $\mathrm{O}$ a lo mejor es la crisis... [Magreb 3]

Por otra parte, siempre en relación con el macroespacio, analizamos si los profesionales sanitarios consideraban que el modo de vestir de algunas usuarias podía suponer un obstáculo para la asistencia sanitaria, y si las usuarias inmigrantes podían sentirse incómodas por la desnudez requerida en ocasiones durante dicha asistencia.

En cuanto al modo de vestir de las usuarias inmigrantes, algunos profesionales sanitarios opinan que no supone ningún problema y que, en todo caso, el que algunas usuarias lleven muchas prendas puede simplemente conllevar que empleen más tiempo para desvestirse antes de la exploración o que estas usuarias pasen más calor durante su estancia en el hospital.

En cuanto a su modo de vestir, aquí ningún problema, porque van prácticamente sin nada, como mucho con bata... Y ya saben a lo que vienen. [Anestesista 2]

Y el modo de vestir para nosotros no es ningún problema, porque cuando nosotros llegamos están ya... con su bata al máximo y ya está. [Anestesista 3]

Pero los atuendos, eso sí, el tema de los atuendos... porque al ser una planta maternal, de niños, pues hace calor, y viene gente musulmana con mucha ropa, y con turbantes en la cabeza, y entonces pues a veces presentan una décimas (de fiebre) e intentas hablar con ellas para que no se abriguen tanto y para explicarles que la fiebre no viene de nada infeccioso, sino que entre los esfuerzos del parto y tantas capas de ropa... Pero es muy difícil que lo entiendan, por su tradición y su cultura. [Enfermera 1]

Y en cuanto a su modo de vestir, yo creo que no supone ningún problema, no, ninguno. [Enfermera 3]

Sí que la manera de vestir, por ejemplo, las negras que llevan la saya esta que se la envuelven así dos veces y normalmente no llevan bragas, no, no, no... Te digo esas que tienen el culo tan prieto, que llevan esos vestidos tan vistosos, pues esas la mayoría no llevan bragas. Pero, vamos, que a nosotros nos da igual. Y las árabes llevan más refajos que yo qué sé; porque llevan la braguita, luego llevan esos pantalones que son como... como pololos, después llevan como enagua y encima la chilaba. Pero vamos, que eso suponga un problema... Se tarda más tiempo, pero vamos, eso es como cuando yo llego y me voy a cambiar, que en invierno me tengo que quitar el abrigo, el jersey y no sé qué, y ahora, en verano, llego y en un momento me quito el vestido. [Enfermera 6]

Y en cuanto a su modo de vestir, sí que en la cama cada una lleva sus "uniformes". Las islámicas van con el velo en la cabeza, con cincuenta refajos, o sea, con un montón de ropa, y, en cambio, por ejemplo, las del este, pues, no, van como nosotros. Pero, vamos, a mí eso no me crea ningún problema, el problema lo tendrán ellas que tendrán más calor. (Risas). [Obstetra 1]

Y el modo de vestir no resulta..., porque se quitan la ropa o se levantan el vestido, y no... a mí eso no me ha causado problemas. [Obstetra 2]

En cuanto a la ropa, claro, yo cuando las miro se quitan la ropa siempre, entonces, si no se dejan mirar... Es que o se quitan la ropa o no se las puede explorar. [...] Y su modo de vestir, no es que cree ningún obstáculo, pero hay algunas que llevan más ropa y tardas más en verlas, según qué origen... (Risas) [Obstetra 3]

Otros profesionales, sin embargo, sí que consideran que el no retirarse determinadas prendas, como puede ser el velo en las mujeres musulmanas, especialmente durante el parto, puede ser contraproducente por la falta de asepsia que es requerida en dicho contexto. La mayoría 
de los profesionales indica que, en estos casos, se trata de hacer sentir cómodas a estas usuarias colocándoles un gorro en lugar del velo antes de entrar a la zona de paritorios.

El modo de vestir sí que crea algún obstáculo, especialmente, y en esto creo que habremos coincidido todos, seguro que los ginecólogos te lo podrán decir, que esto es un problema especialmente con las mujeres musulmanas, incluso alguna de ellas no se quiere quitar el velo para nada. Y, claro, esta es un área en la que la paciente tiene que entrar con gorro al quirófano, pero no con ropa que traen de fuera, porque es un área estéril y... [Anestesista 1]

Y en cuanto a su modo de vestir, ¿si crea algún obstáculo? Sí, claro. Sí, por ejemplo, a mí los gorros no me gustan, ni en quirófano, ni con la epidural, me parece que es una falta de higiene llevar un pelo tocado con algo, o incluso llevar postizos en el pelo, prolongaciones y demás. Entonces, en estos casos, si se puede quitar se quita y, si no, se pone un gorro, pero a mí me sigue pareciendo un inconveniente. Por el resto, no. Porque, por ejemplo, lo típico, mujeres con calcetines en el quirófano hay de todos los colores, y tampoco me parece higiénico. Y lo demás, no. Y con el velo, pues lo mismo, a mí no me gusta, me parece también poco higiénico. Yo, personalmente, les pregunto si se puede quitar el velo, si tienen algún problema, y si las veo un poco así, si les molesta despojarse de algo, pues les pongo un gorro encima, un gorro quirúrgico, que bueno, sí, en principio, lo más limpio sería no llevarlo, pero a veces, su situación personal, pues no.... o sea, les angustia más el quitárselo que otra cosa. Y entonces, pues, claro, como tampoco entiendo muy bien por qué lo llevan, pero sí que asimilo la ansiedad que les produce quitárselo, pues se lo dejo y le pongo un gorro. [Anestesista 5]

Tampoco entendemos que lleven el chador a todas horas. Ese es un tema que parece que... como mujer, parece que te hiere, ¿no? Aunque ellas sabemos que es su religión, que lo hacen muy a gusto, que patatín, que patatán... Pero, claro, en un hospital tenemos el tema de la limpieza, y el velo tampoco es muy aséptico, y se ponen tanta ropa que... claro, no hay limpieza. [Enfermera 5]

Y el modo de vestir sí que puede crear obstáculos, muchos. Claro que es muy complicado con todas las vestimentas que llevan. Es muy complicado para un parto, para otra cosa no lo sé, pero para el parto es muy complicado. $Y$ en ese contexto hay que tener una limpieza, una asepsia, y entonces... [Enfermera 5]

Porque el velo, por lo general, se lo quitan, ¿eh? Y lo que sí que les ofrecemos es un gorro, un gorro de los de quirófano. Se le da un gorro y... y ya está. [Matrona 4]

Nooo, los problemas varían, varían mucho según su país de origen. Mira, por ejemplo, las árabes, eeee... Aquí cuando vienen las señoras, las despojamos de todo, y nos olvidamos muchas veces y les quitamos también su pañuelo. $Y$ a veces, ponerle un gorro, es tan sencillo como ponerle un gorro, que ellas ya sienten una relajación y un... Eso es una cuestión, yo creo, más bien cultural. [...] Y con lo del pañuelo, a lo mejor, eso es superimportante. Porque a lo mejor no caes tú y le pones el gorrito de la epidural y se lo vas a quitar y te dice "No, por favor" (Voz lastimera). Y entonces tú dices "Claroooo". Están más cómodas, para ellas es muy importante. [Matrona 5]

Por otro lado, algunos profesionales entrevistados señalan que hay determinados colectivos de usuarias que muestran más reticencias a la hora de desnudarse, provocadas a veces porque el profesional sanitario es de sexo masculino o porque está presente el marido de la usuaria.

Sí, les cuesta desnudarse, especialmente a las mujeres musulmanas. [Anestesista 1]

Hay algunas, como las de raza negra, las chinas, o las islamistas, que quizás se tapan algo más, pero tampoco... Al resto, yo creo que no... que no les preocupa. [Anestesista 4]

$Y$ en general notas que no les gusta mucho que las miremos, que las miremos en el sentido de que... como las ayudamos para levantarse e ir al baño, o si les tenemos que cambiar la bata... Y ahí ves que se ponen un montón de refajos, o se ponen fajas para disminuir la tripa... Y ahí intentas hablar con ellas para decirles que es un proceso biológico, que todo lleva su tiempo y tal... En este sentido sí que son un poco arraigadas. [Enfermera 1] 
Hay algunas... ¿cómo lo digo esto?... de religión musulmana que tienen algún problema más, se nota que están un poco más cohibidas, pero nunca he tenido yo, como chico, grandes problemas con ellas. A mí nunca se me han negado, aunque sé que ha habido casos, pero bueno, tampoco es algo tan frecuente. Pero sí que creo que tienen algo más de vergüenza, suelen ir más tapadas. [Matrona 1]

Ah, bueno, sí, por ejemplo, hay culturas, sobre todo las magrebíes, que son reticentes a que el marido les vea los genitales desnudos. Tú estás allí con los dos y rápidamente te das cuenta. El marido se da la vuelta, e incluso quiere salir, pero, claro, no puede salir, porque si están las salas de dilataciones llenas y están pasando mujeres que van al paritorio, pues no pueden estar los maridos en los pasillos. Entonces, a estos maridos, o los metes en los servicios, que están aquí al lado, o les dices que se den la vuelta y... Y, vamos, yo respeto en todo caso la voluntad de la mujer. [Matrona 7]

Otros consideran que el pudor ante la desnudez no depende del origen de las usuarias, sino que puede variar de persona a persona, y comentan que, en todo caso, cuando se observa que una usuaria se siente incómoda por dicha desnudez, se trata, en la medida de lo posible, de mantenerla tapada.

A lo mejor sí que tienen, como todas las mujeres, un poco de cuidado para mantenerse el camisón, pero bueno, eso es en todas las mujeres. [Anestesista 2]

Y lo de desnudarse depende de la gente, pienso yo. Porque hasta entre las nacionales, hay gente que para cualquier cosa se destapa rápidamente y otras que se tapan hasta las pestañas. [Anestesista 3]

Normalmente están sentadas, las procuramos tapar por delante, y hay algunas que, si se les cae el camisón, tienden a subirlo rápidamente, para que no se le vean a lo mejor los pechos, pero yo la verdad es que no he tenido problemas con destaparle o tocarle la espalda a alguien. [Anestesista 4]

( $Y$, en cuanto a desnudarse,) yo pienso que hay igual españolas que son más retraídas y eso a la hora de desnudarse... pero vamos, que hay lo mismo españolas, ¿eh? Eso dependerá de la educación que les dan, nada más. [Enfermera 2]

Y el tema del pudor, yo creo que pudor tenemos mucha gente... Yo, por ejemplo, cuando se echan y se les dice que pongan una pierna a cada lado, yo siempre cojo la sabanita y se la pongo encima. Sí que hay alguna que hay que decirle que por favor quite las manos, porque se tapan y, si no, no las podemos mirar. Pero yo creo que eso depende más de la persona. [Enfermera 6]

Y en cuanto a desnudarse, es que aquí tampoco las hacemos... es decir, se ponen el camisón cuando vienen y, luego, intentamos, en la medida de lo posible, claro, cuando estás empujando y eso igual no, pero, en la medida de lo posible, sí que intentas cubrirlas un poco, y entonces no... [Matrona 3]

Hombre, es que aquí, si vienen de urgencias, cuando llegan, se les retira la ropa y se les pone el camisón. Y si llegan de la planta, pues se les dice que se quiten las bragas, la ropa interior, quiero decir. Y no suelen tener reticencias. Sí que algunas se tapan, algunas tienen mucho pudor. Pero es que, claro, yo creo que también... somos pudorosas. Vamos, si tienen que empujar, pues las tienes empujando al aire, pero es normal que durante las primeras exploraciones y eso seamos pudorosas. Llega un momento que la mujer se confía y ya pasa de eso y no le da la menor trascendencia, ya ve que es lo normal. [Matrona 7]

Por su parte, algunas usuarias inmigrantes entrevistadas comentan que no les supone un gran problema desnudarse, y otras, aunque afirman que sienten pudor, especialmente cuando están presentes profesionales sanitarios del sexo masculino, comprenden que en este contexto es necesario que se despojen de su ropa para que les puedan proporcionar asistencia.

No, no es un problema, porque hay biombos y tú te quitas la ropa y ya está. No es un problema, no... [África Subsahariana 3] 
La verdad es que no ha sido un problema. Si estoy embarazada, pues ese es un paso que tengo que dar... porque no voy quitándome la ropa por ahí, pero si voy al médico... [África Subsahariana 4]

No, if doctor says, I have to do it. [Asia 3]

No... (Se ríe tímidamente) Si hay que hacer, se entiende. [Asia 4]

Con la primera hija sí que me daba un poco de cosa, sobre todo si eran chicos, pero ahora ya no, ya estoy acostumbrada. [Comunidad gitana]

No, no, no es un problema quitarme la ropa, no. [Europa del este 3]

No, a mí no me da vergüenza eso. [Europa del este 4]

No, no es un problema. Ahora ya estoy acostumbrada. Pero la primera vez que yo vengo aquí, me han dicho que me bajo toda la ropa y me pongo esta cosa (Señala la bata del hospital). Y esta cosa no estaba cerrada, lo tenía que poner así, y yo pensaba que estaba sin nada... Pero, ahora, ya... [Europa del este 5]

No, no es un problema quitarme la ropa, no. [Latinoamérica 1]

No es un problema. También, por ejemplo, cuando voy a la revisión médica de la empresa para la que trabajo, pues me tenía que quitar a lo mejor la camiseta o... Y no ha sido nunca ningún problema. [Latinoamérica 3]

No, no es problema quitarme la ropa aquí. En mi país también pasa cuando vas al médico. [Magreb 1]

Bueno, como ahora, que ha venido el médico y me ha dicho de quitar la braga y esto es incómodo... Si es una mujer, es mejor. [Magreb 3]

No, no, no es problema. Si el médico quiere quitar la ropa, el médico manda. El médico no puede saber tu enfermedad y te dice de quitar esto para ver o... a pinchar o... [Magreb 4]

La segunda sección relativa a la distribución espacial se centra en el microespacio y contiene diferentes aspectos a analizar.

El primero de estos aspectos está muy relacionado, tal y como nos indica uno de los profesionales sanitarios entrevistados, con el tema del pudor ante la desnudez que acabamos de presentar, y se refiere exactamente a la posible incomodidad sentida por algunas usuarias por el contacto físico durante la exploración.

Entonces, normalmente las que se niegan a ser exploradas son las que no se quieren quitar la ropa. [Obstetra 3]

La mayoría de los profesionales sanitarios señala a las usuarias magrebíes o a las de religión musulmana como aquellas que sienten mayor incomodidad al ser exploradas, especialmente si el profesional sanitario es de sexo masculino o si está presente el marido de la usuaria. No obstante, parece no existir un acuerdo entre los profesionales entrevistados sobre si esta incomodidad y la petición de ser tratadas por personal sanitario de sexo femenino se dan con mucha o poca frecuencia, pues algunos indican que esto no les ha sucedido casi nunca y otros que ha ocurrido en numerosas ocasiones. Trataremos este tema con mayor profundidad en el siguiente subapartado, relativo a las actitudes sociales $y$, más concretamente, cuando hablemos de cuestiones de género. 
Son muy pudorosas, sobre todo las magrebíes, en cada una de las exploraciones que les tienen que hacer, los tactos vaginales, para ver cómo va evolucionando el parto. Y en algunas ocasiones, la pareja ha pedido que la exploración la haga una mujer. [Anestesista 1]

¿Al contacto físico...? Sí, a veces les sorprende cuando llegan a la habitación y hay que explorarlas para ver si hay sangrado o altura uterina... les sorprende otra vez que las vuelvas a descubrir, que les levantes el camisón, que les vuelvas a tocar la tripa, a mover las piernas, y... me imagino también que les sorprende si eres hombre. [Enfermera 3]

Sobre todo... sí, esto ha pasado con las musulmanas sobre todo. Especialmente cuando el médico es un varón, pues sí que a lo mejor... No es una imposición, pero sí que ves que tienen cierto recelo, hasta que dicen "Esto es lo que me toca y, entonces, me tiene que ver el médico. No hay más remedio". Entonces sí que ya ceden, pero al principio les cuesta un poco, tienen un poco de reparo. [Enfermera 4]

A las árabes ves que les cuesta mucho que las explore el médico, para ellas es muy complicado, muy difícil. [...] Esto las árabes, sí. Como te decía, para ellas es un problema. Han pedido muchas veces que las explore una ginecóloga. [Enfermera 5]

Lo que sí que les cuesta a veces es que las explores delante del marido, incluso a veces el marido se da la vuelta y está ahí, sin mirar. [Matrona 2]

Durante la exploración, sí. El contacto físico no les... Hay sobre todo problemas con el género masculino, por ejemplo, si tienes un ginecólogo de guardia, no les gusta que les explore, no les gusta en general que haya hombres en el proceso del parto. Esto también depende de su origen, claro. [Matrona 3]

Sí, pero sobre todo hemos tenido casos en urgencias que se han negado a la asistencia por parte de hombres, por parte de ginecólogos. Y aquí supongo que a alguno de los compañeros matronas también les habrá pasado. [Matrona 4]

Sí, las árabes, sobre todo las árabes. Y si está el marido hay veces que está un poco como receloso. Pero ellas lo aceptan. $\mathrm{O}$ sea, yo creo que vienen aquí como un poco... como un poco sumisas. [Matrona 5]

A las magrebíes, si está la figura masculina, sí que les cuesta muchísimo. Siempre prefieren que se marche el marido, o la pareja, y entonces no hay ningún problema. $Y$ a las subsaharianas el tema del contacto... puede que les cueste un poquito más a la hora de que tú le vayas a tocar. Se quedan como un poquito más frías. Y el resto de grupos no pone ningún impedimento. [Matrona 6]

Yo he tenido solamente tres casos en once años en los que me dijeron que querían solamente que las explorara una mujer, y como en esos casos no había, pues no pudimos hacer nada... [Obstetra 1]

Eso las árabes también. A la hora de hacer tactos vaginales son las que más problemas tienen, más miedo, más... [Obstetra 2]

Son pocos los profesionales sanitarios que nunca se han encontrado con reticencias a la hora de explorar a las usuarias.

A mí nunca me han puesto pegas con respecto al contacto físico. [Anestesista 3]

Impedimentos para el contacto físico yo no he tenido, no. A veces existe el mito de que si eres hombre no vas a tocar a una magrebí, pero a mí nunca me ha pasado, no, jamás. [Anestesista 5]

Para la exploración no hemos tenido ningún problema. [Enfermera 1]

No, a mí nunca me ha ocurrido que me pongan pegas al contacto físico. [Enfermera 2]

No, a mí, no, eso no me ha pasado nunca, quizás por ser mujer. [Matrona 2] 
Además, uno de los profesionales entrevistados sostiene que el pudor ante la exploración se da indiferentemente en usuarias de distintos orígenes.

Sí, sí, a veces no quieren ser exploradas. Pero me las he encontrado por igual, de diferentes países de origen. [Obstetra 3]

Por lo que respecta a las usuarias inmigrantes, tal y como se puede observar en las citas que se incluyen a continuación a modo de ejemplo, casi todas afirman que el ser exploradas no supone para ellas ningún problema, pues parecen comprender que la exploración y el contacto físico por parte de los profesionales sanitarios es necesario a la hora de recibir asistencia.

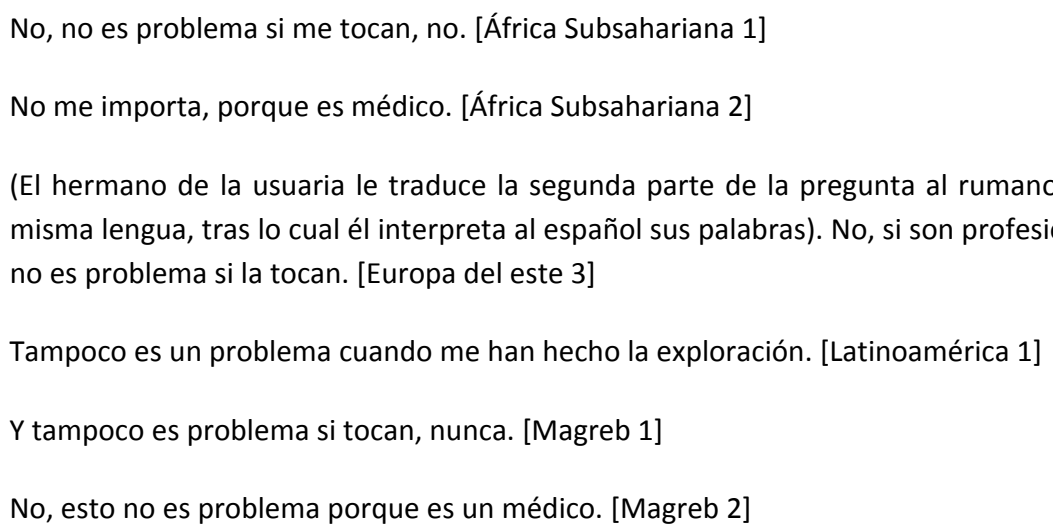

Solo dos de las usuarias entrevistadas comentan que se han sentido incómodas, una de ellas porque era la primera vez que era explorada y la otra porque no le explicaban previamente qué tipo de exploración le iban a realizar.

Primero no sabe, entonces primera vez no gusta mucho. [Asia 2]

No, no es un problema, no. Lo único es que a veces la obstetra de la que te hablaba antes iba a examinarme y no me decía lo que iba a hacer, y esto me molestaba un poco, porque además, con el tema de que es obstetra o ginecóloga, pues hay algunos exámenes que son más molestos, y si no te dice qué va a hacer, tú estás ahí y... [Latinoamérica 2]

El siguiente aspecto a analizar relacionado con el microespacio se refiere al contacto visual, los gestos y la cercanía física entre los interlocutores.

Por lo que se refiere a los profesionales sanitarios, cabe señalar dos aspectos que ya han sido mencionados en el análisis de nodos anteriores. Por una parte, estos destacan los gestos, expresiones faciales y posturas que presentan las usuarias de África Subsahariana a la hora de expresar o mitigar el dolor que sienten durante el parto.

Las pacientes del África subsahariana yo creo que sí que son más enfáticas y, sobre todo, expresan mucho el dolor en la cara. Es tremendo, porque tú ves que tienen dolor y lo aguantan, por pues culturalidad o porque realmente no quieren expresarlo y se ve, se ve el dolor en la cara. [Anestesista 1]

No sé, yo a las africanas las veo muy expresivas. A lo mejor de estas cosas no te das cuenta cuando estás trabajando, pero ahora que me preguntas, yo sí que las veo que son... no sé, muy expresivas. Hacen, por ejemplo, muchos gestos con las manos, sí. [Enfermera 4]

Me llama la atención que para las negras, por ejemplo, una manera de expresar el dolor es hacer esto (chasquea los dedos repetidamente). Y también en las negras otra cosa que veo es que a veces salimos fuera a pedir la cartilla, por ejemplo, cuando les van a hacer una cesárea, y tienes que ver si es urgente, 
porque si es urgente tienes que llamar enseguida a la matrona, y sales y a veces te encuentras a las negras tiradas por el suelo. Y perdona si digo negras, que no lo digo despectivamente, es la manera de expresar... porque es que no sé de dónde son, si son senegalesas, de Mali, o de dónde sea... Aunque, bueno, las senegalesas, normalmente acertamos si son de allí, porque suelen tener unos tipazos que te cagas... (Risas). Son altas, guapas, y con unos tipazos, que las ves por detrás y no dirías que están embarazadas... Bueno, pues sales, y las ves como tiradas, y es su manera de expresar el dolor. Y tú dices "Pero si esta gente, cuando están en el desierto y por ahí, se van al árbol a parir ellas solas. ¿Cómo es que aquí hacen tantos aspavientos?". [Enfermera 6]

Sí, sobre todo la manera de... bueno, de expresar el dolor. Por ejemplo, en, esto claro en la grabación no se verá, pero bueno, las mujeres del África negra hacen mucho así (chasquidos de dedos) con el dolor, y tienen como una especie de mantra que ahora no te lo podría reproducir, que sería algo así como "Ay madre, ay madre, ay madre...". Algo así, ¿eh? No quiere decir que digan eso, pero un poco así, y lo acompañan del chasquido de los dedos. Y la verdad es que eso es muy llamativo. [Matrona 1]

Luego están los gestos. Por ejemplo, los gestos así (Chasquea los dedos) de las africanas cuando están dilatando. [Matrona 5]

Hombre, las africanas cuando tienen dolor, sí que hacen determinados movimientos, no sé, es otra manera de expresarlo, con las manos sí que hacen más gestos, con los dedos así (chasquea los dedos), sí que lo expresan más de esa manera. [Obstetra 2]

Por otra parte, algunos profesionales entrevistados sostienen que las usuarias de origen magrebí suelen evitar el contacto visual, rehúyen la mirada del profesional o la dirigen exclusivamente hacia sus maridos si estos se encuentran presentes.

Y cuando está el marido, en el caso de las magrebíes, la mirada siempre se dirige hacia él. [Anestesista 5]

Eeeee... las moras rehúyen más la mirada. Sí, rehúyen más el contacto visual. Sin embargo, el contacto físico, no. Enseguida te van a coger la mano cuando tienen dolor, enseguida... Pero lo que es la mirada, la rehúyen más, sí. [Matrona 4]

[...] hay como una barrera. Lo notas en la mirada, en los ojos, le estás diciendo algo que tú crees que es importante, te estás esforzando en explicarlo y, a lo mejor, a veces, te cambian la mirada o miran a su acompañante... Que dices tú "Jolín, no estamos llegando a... a un entendimiento". Y alguna árabe expresa así el dolor, como con sumisión. Parece como si se involucionan un poco. [Matrona 5]

La mirada, la mirada sobre todo. En el grupo de las magrebíes, es más difícil que te miren a la cara directamente. Son como más... no más sumisas, sino que lo hacen como por educación, ¿no? [Matrona 6]

Y las árabes no suelen mirar mucho a los ojos, como que rehúyen la mirada. Hombre, y si está el marido, habla el marido y ellas le miran. [Obstetra 2]

Además, algunos profesionales opinan que en general es posible percibir inexpresión, rigidez o falta de contacto visual en las usuarias inmigrantes, sin distinciones por su origen, y algunos creen que esto puede deberse al miedo que sienten o a su dificultad para comunicarse en español.

Sí, yo creo que son más inexpresivas. Las que no entienden, con las que hay más dificultad para comunicar, son más inexpresivas. Se meten en sí mismas, se aíslan, responden lo justo, [Anestesista 2]

Es que todas, o casi todas, suelen estar bastante asustadas, da casi igual de dónde vengan. Están casi todas como a la expectativa, pensando "Me duele mucho. Quiero que me quiten el dolor" y preguntándose “¿Qué es esto?". Sí que ves en sus expresiones mucho miedo. [...] Lo ves en sus caras, la mayoría de la gente está tensa, y con miedo a lo que les vas a hacer. Pero vamos, nadie ha salido corriendo... [Anestesista 4] 
Yo pienso que, en general, (las usuarias inmigrantes) son más rígidas, pero porque de alguna manera el no comunicarte bien, al ser la comunicación más escasa, pues yo pienso que están como un poco más rígidas. [Enfermera 1]

Sí, te desvían la mirada, les impone mucho el sanitario... Impone mucho el sanitario me imagino que por ser sanitario, y a veces también por ser hombre. [Enfermera 3]

Son mucho más huidizas, sobre todo las mujeres. Yo miro siempre a los ojos además y, entonces, ellas lo pasan mal, ellas, si pueden eludirte, te eluden. [Profesional socio-sanitario 3]

Por lo que respecta a las usuarias inmigrantes entrevistadas, y en relación concretamente con su opinión sobre los gestos empleados por los profesionales sanitarios al comunicarse con ellas, podemos establecer dos grupos.

En primer lugar, algunas usuarias consideran que el personal sanitario emplea pocos gestos, o no han notado nada relevante ni que les llame la atención en cuanto al uso de los mismos en sus interacciones dentro del hospital contexto de estudio.

No, no me parece que usen mucho los gestos, no. [África Subsahariana 3]

Si hacen gestos, no me he fijado, la verdad, realmente... [África Subsahariana 4]

No, not much gestures. [Asia 3]

¿Gestos? No sé, no hay nada que me ha llamado la atención. [Comunidad gitana]

No, para mí no hacen muchos gestos, no. [Europa del este 1]

No, no me parece que gesticulan demasiado. [Europa del este 2]

No, no creo que usan mucho los gestos, lo normal. [Europa del este 5]

No, no me parece que usen muchos gestos. [Latinoamérica 1]

¿Si usan gestos? Pues, normal, me parece normal. [Magreb 1]

Usan los gestos normal. [Magreb 2]

Usan gestos lo normal. [Magreb 3]

No, no creo mueven mucho las manos, no. [Magreb 4]

Otras, en cambio, sostienen que los profesionales emplean muchos gestos en sus intercambios comunicativos, aunque algunas consideran que este uso puede variar de persona a persona.

Sí, sí, mueven mucho las manos. [África Subsahariana 2]

No, aquí mueven mucho las manos [...] pero en China mueve mucho no está bien. Bueno, en China yo ya mucho tiempo no estar, y ya no sabe seguro... [Asia 1]

Hombre, no todos son iguales, unos usan más gestos que otros, pero no le veo nada malo a eso. [Latinoamérica 1]

Depende, eso también depende. Hay personas que sí que usan muchos gestos y hay personas que no, o sea... Eso digo, hay de todo. [Latinoamérica 3] 
Al respecto, además, dos de las usuarias entrevistadas, concretamente procedentes de Latinoamérica, creen que el uso de gestos por parte de los profesionales sanitarios les ayuda a entender mejor los mensajes que estos desean transmitir.

Sí que utilizan los gestos, pero así se entiende mejor. Por lo menos, yo, así, lo entiendo mejor. [Latinoamérica 4]

Sí que creo que usan gestos, pero de esta manera le entienden mejor a uno. [Latinoamérica 5]

En cuanto al contacto visual, algunas usuarias inmigrantes afirman que los profesionales sanitarios suelen mirarles a los ojos cuando hablan con ellas. Dentro de este grupo, hay algunas que nos cuentan que en su país también se suele mantener el contacto visual con el interlocutor, y otras que, en cambio, añaden matices o diferencias relativas a este contacto en sus respectivos países de origen, dependiendo de factores como la edad o el sexo de los interlocutores o el contexto en el que se desarrolla la interacción.

Sí miran, sí. (Le pregunto si en su país se suele mirar a los ojos cuando se habla). No sé, ya no sé... (Se ríe de forma nerviosa). [África Subsahariana 1]

[...] también te miran en los ojos. En Nigeria también miramos en los ojos. [África Subsahariana 2]

Y sí que suelen mirarme a los ojos. En Camerún, a veces, por temas de respeto y todo eso, no se mira a los ojos. Pero si es una conversación normal, sí que miras a los ojos, sí. [África Subsahariana 3]

Y sí que me miran a los ojos cuando hablan. En Senegal, si miras o no miras a los ojos depende de con quién estás hablando. Por ejemplo, con el médico sí que le miras a los ojos cuando estás hablando, pero cuando es por tema familiar, depende, porque a veces hay más respeto, depende de la edad y esas cosas. Por ejemplo, a una persona mayor que encuentras en la calle, pues a lo mejor no le miras a los ojos, por respeto, porque lo consideras como tus papas o como tus abuelos, y eso es el respeto que llevamos. [África Subsahariana 4]

También miran ojos. Mirar ojos es un poco como mi país, pero mirar parte de abajo, eso no gusta. [Asia 2] They usually look at my eyes. In Pakistan you do if there is a woman, we are shy from... from men. [Asia 3]

¿Si me miran a los ojos? Pues, no sé, la verdad es que no me he fijado, pero me imagino que sí, sí me miran. [Europa del este 1]

Y sí me miran a los ojos. Eso me parece bien, en Rumanía también se mira a los ojos. [Europa del este 2]

[...] mirarte a los ojos, sí. (Le pregunto si en Rumanía es habitual que los profesionales sanitarios miren a los ojos del paciente). Es que como ya me fui con dieciocho años, y allí solo fui una vez al dentista a que me sacaran una muela, que lo hicieron con la mano casi, pues... Ya todo lo demás no sé cómo lo hacen. [Europa del este 4]

Siempre me miran a los ojos, sí. (Le pregunto si en Ecuador se suele hablar mirando a los ojos). No, pocas, veces, impone respeto. No sé, yo lo veo algo diferente. [Latinoamérica 4]

¿Si miran a los ojos? Algunos sí, creo, no sé. (Le pregunto si en Argelia se suele mirar a los ojos al interlocutor). A veces, depende. Si es hombre y mujer y no se conocen o a la gente mayor no se mira a los ojos. [Magreb 3]

Sí me miran a los ojos, sí. [Magreb 3] 
¿Qué si miran en ojos? Sí, ¿no? (Le pregunto si en Mauritania se suele mirar a los ojos cuando se habla con la gente y responde el marido de la usuaria) Es que también depende, hay mucha gente que te mira a los ojos y hay mucha gente que no... Depende también si es hombre o mujer. [Magreb 4]

Cabe destacar las respuestas de dos de las usuarias entrevistadas, que proceden de Rumanía, las cuales interpretan la falta de contacto visual como una señal de que el interlocutor tiene algo que ocultar o está mintiendo. Mientras que esta misma interpretación podría coincidir con la interpretación realizada por una persona autóctona, observamos por las respuestas ofrecidas por otras usuarias que acabamos de presentar que existen diferencias relacionadas con el contacto visual (o la ausencia del mismo), pues en otros países y culturas este está relacionado con el pudor o el respeto.

Y sí miran a los ojos. (Le pregunto si en Rumanía se suele mirar mucho a los ojos). Depende, los que son profesionales sí que... Porque ahí, los que son más corruptos son el personal auxiliar, y esos no miran mucho. Y los médicos sí que suelen mirar. [Europa del este 3]

No me fijado si me miran a los ojos, no me he dado cuenta. Sí que te miran, pero... Es que nosotros no somos como los árabes, que para ellos es un insulto. Nosotros somos europeos, como vosotros, como en Francia, lo mismo... Yo creo que es algo a nivel mundial. Cuando estás sincero, miras a la cara, cuando tienes algo que esconder o que tienes vergüenza, no miras a la cara. Eso pasa también con el médico. Cuando tiene algo que esconder al paciente, será mejor que no le mira a la cara, porque es posible que algunos ven en la expresión o en la mirada que hay algo que esconde. Eso pasa en todos los sitios, no solo en el hospital, también en los negocios, o en algunos tipos de trabajo, o... Es que siempre se ve en la cara si estás mintiendo o no. Por ejemplo, mi hija, si yo la miro en la cara cuando me dice una cosa, yo puedo saber si me miente. [Europa del este 5]

Por el contrario, otras usuarias entrevistadas, aunque este grupo es menos numeroso, creen que los profesionales sanitarios, en determinadas ocasiones o contextos, no suelen mirarlas a los ojos.

A veces no miran mucho a los ojos. En Ghana yo miro a los ojos cuando hablo. [África Subsahariana 5]

Y a los ojos, no siempre miran, miran a veces. Hay veces que están a lo suyo y, mientras hacen esto o aquello, te hablan. [Comunidad gitana]

La mayoría me miran a los ojos cuando me hablan, pero los médicos, menos. Los médicos son más... Aquí, no, aquí en este hospital fui muy bien atendida, los médicos sí que me miraban y tal, pero en los centros de salud me he dado cuenta de que es más impersonal. (Le pregunto si en Brasil se suele mirar a los ojos del interlocutor cuando se habla). Sí, sí miramos, sí. [Latinoamérica 2]

No, no miran. En China depende, a veces no, por respeto. No tienes que mirar a los ojos cuando tienes que hablar. [Asia 4]

No me miran a los ojos, no. (Risa nerviosa). (Le pregunto si prefiere que le miren a los ojos cuando le hablan y se produce un breve silencio, tras el cual la usuaria responde tímidamente) No, no. [Magreb 1]

Dentro de este grupo de usuarias entrevistadas que sostienen que los profesionales sanitarios no les suelen mirar a los ojos, hay una que, además, corrobora una de las afirmaciones que estos habían hecho. En concreto, comenta que, cuando no entiende el mensaje, ella misma desvía la mirada.

No miran a los ojos, no. Cuando sabes bien de qué habla él, miras. Si no entiendes, miras a otro lado. [Magreb 2] 
Por último, por lo que se refiere a la cercanía que mantienen los profesionales sanitarios cuando se comunican con las usuarias entrevistadas, algunas señalan que se han sentido cómodas o que no han percibido diferencias entre la distancia que se mantiene en este contexto en España y en sus países.

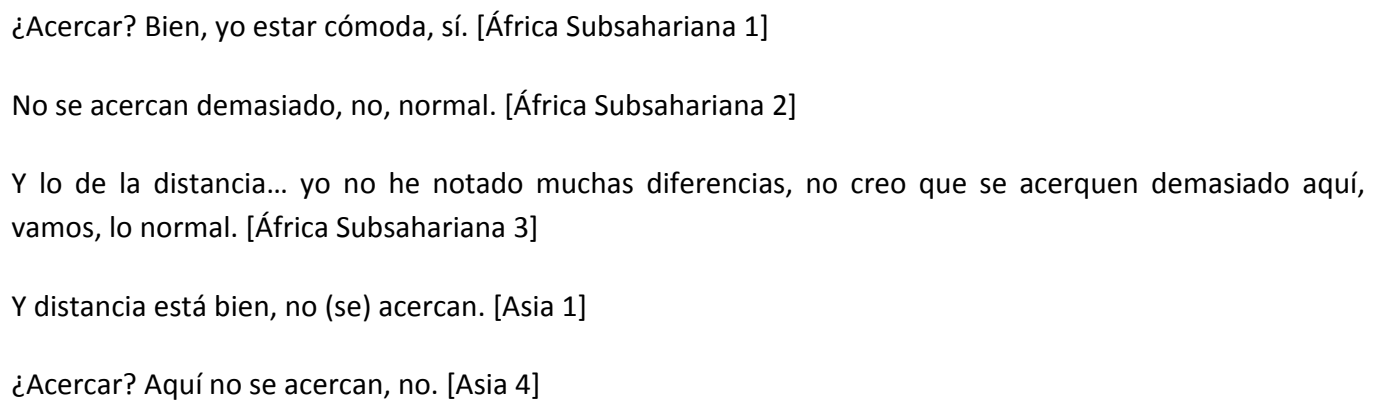

Además, una usuaria magrebí, concretamente procedente de Argelia, aunque parece no haber percibido diferencias en cuanto a la distancia mantenida entre los interlocutores en España, comenta que en su país de origen dicha distancia varía dependiendo de si estos son del mismo sexo y que, por tanto, entre mujeres hay mayor cercanía y, cuando la conversación transcurre entre un hombre y una mujer, la distancia suele ser mayor.

No sé si se acercan mucho o poco. En Argelia si es un hombre, te pones lejos. Si estás entre mujeres es más cerca. [Magreb 3]

Otras, aunque sí que han observado diferencias, no consideran que esto suponga ningún problema. Aquí destacan especialmente las respuestas ofrecidas por algunas usuarias procedentes de Rumanía, que afirman que el trato recibido por parte de los españoles en general a la hora de entablar una conversación suele ser más familiar y cercano que el que se suele dar en su país, y valoran este hecho como algo positivo.

Y aquí veo que se acercan más que en Rumanía, es mucho más cercano. Para mí es mejor así, prefiero que se acerquen. [Europa del este 2] 
¿Si se acercan en conversación? (La usuaria intercambia unas palabras en rumano con su hermano y responde él en español). Sí, sí se acercan, sí. (Le pregunto si en Rumanía se mantiene una distancia mayor a la que ha observado en España y responde directamente su hermano). Es que depende del carácter, son cosas de cada carácter. Yo... yo me peleo con ellos, o sea que no... que tengo otro carácter y no soporto que... pero tampoco... (La usuaria comenta algo en rumano y parece que su hermano traduce sus palabras al español). Si comparamos España con Rumanía, aquí se acercan más. Pero, bueno, es el ambiente caluroso, eso es bueno. [Europa del este 3]

¿Si la distancia entre las personas es mayor en Rumanía? Por lo que yo recuerdo es mayor. Es que nosotros, por nuestra cultura, somos bastante fríos, y sobre todo los hombres. Los hombres son machistas y... Es que el trato es diferente al de aquí. Aquí de buenas a primeras, aunque tengan cierta desconfianza porque te ven extranjero y aún hay ciertas barreras, pero aun así aquí el trato es más familiar, la gente es más abierta. Y, sin embargo, allí (en Rumanía) cuesta mucho, y con los hombres sobre todo. [Europa del este 4]

Para finalizar con el análisis del microespacio, cabe señalar que solo una de las usuarias entrevistadas, concretamente procedente de China, sostiene haber sentido "miedo" (palabras textuales) por los excesivos movimientos y la cercanía mantenida por el personal sanitario al comunicarse con ella.

Mueven y se acercan mucho. Y yo tengo miedo. [Asia 2]

Por último, analizamos una de las cuestiones relativas a lo que se conoce como paralenguaje, el cual incluye todos los aspectos sonoros sin valor fonológico, como el tempo, el volumen, el tono de voz, la modulación, etc. En concreto, nuestro análisis se centra precisamente en si los profesionales sanitarios o las usuarias inmigrantes han percibido diferencias o les ha llamado la atención el tono de voz empleado por sus interlocutores en las interacciones comunicativas dentro del hospital contexto de estudio.

Por lo que se refiere a los profesionales sanitarios, algunos de los entrevistados afirman que no han observado diferencias en cuanto al tono de voz entre las usuarias inmigrantes y las autóctonas. Dentro de este grupo, algunos consideran que el tono de voz varía de una persona a otra y no depende de su origen cultural, y otros opinan que todas las usuarias, independientemente de dónde procedan, emplean un tono de voz elevado cuando están enfadadas por algún motivo.

No, no, no hay nada en esto (el tono de voz) que me llame la atención. [Anestesista 5]

Pues, la verdad, es que no lo sé. Yo es que como... al revés, peco de hablar alto, pues... [Enfermera 2]

(¿Hay algo de su tono de voz que llame la atención, hablan de una forma muy enfática o muy poco enfática?) No, la verdad es que no... [Enfermera 4]

Pues, en esto te diría lo mismo, que de todo hay. Hay gente que grita que es de aquí, y hay gente que grita y es de allá. [Enfermera 5]

¿En cuanto al tono? (Largo silencio). No sé, estoy pensando y ahora no... De momento, no sé. A lo mejor, si me pongo a pensar... Pero... ahora así, chica, no me sale nada, no sé. [Matrona 5]

Las chinas cuando se enfadan gritan mucho, y su tono de voz... Y las rumanas a veces son más agresivas cuando se enfadan... Pero vamos, como todos, que cuando te enfadas... [Obstetra 3] 
Pues igual que los castellanoparlantes. Cuando están más enfadadas elevan el tono, cuando están más apesadumbradas lo bajan. Yo creo que en eso no hay diferencia con el idioma castellano. [Profesional socio-sanitario 1]

Sin embargo, hay otros profesionales sanitarios que sí que han notado diferencias en el tono de voz de determinadas usuarias y las dividen por colectivos. En general (aunque hay excepciones) creen que el tono de voz empleado por las usuarias de África Subsahariana, de Europa del este y de Latinoamérica suele ser más alto y, por el contrario, el que usan las usuarias magrebíes y las asiáticas suele ser más bajo, siempre en comparación con el tono habitual en las usuarias autóctonas.

Sí, las de África subsahariana hablan con un tono de voz muy alto y, sin embargo, las magrebíes hablan en un tono de voz muy bajito, como escondiéndose... Y bueno, las sudamericanas son también muy enfáticas. [Anestesista 1]

Yo creo que las sudamericanas hablan como muy fuerte. Y las demás, no, son más suaves, más... [Anestesista 2]

Hombre, quizás el tono más alto lo tengan las del este a lo mejor. [Enfermera 6]

Bueno, hablan más alto, las magrebíes y las mujeres del África negra hablan más alto. Y hablan más meloso y más bajito las latinoamericanas. Y más como nosotros las mujeres rumanas. [Matrona 1]

Las marroquíes, sí, las marroquíes hablan en un tono más bajo. [Matrona 2]

Yo creo que el tono de voz es más alto, bueno, por ejemplo, en las africanas es más alto. Pero en otras no, por ejemplo, en las sudamericanas, no, en las árabes, no, en las chinas, tampoco... [Matrona 3]

En las subsaharianas el tono es más elevado. Bueno, tanto en ellos como en ellas el tono es más elevado. En el resto de los grupos, el tono es más normal. [Matrona 6]

Pues, por ejemplo, las que son negritas negritas, de Gambia, de Senegal y así, pues hablan más alto. Las chinitas, las orientales, te hablan muy bajito. Y las otras, pues... como nosotros. [Obstetra 1]

Las árabes sí que hablan con un tono de voz más bajo. Y en las demás no ha habido nada que me haya... [Obstetra 2]

Asimismo, algunos profesionales entrevistados piensan que, cuando las usuarias se comunican entre ellas, por lo general presentan un tono de voz más elevado y, en cambio, este desciende al dirigirse al personal sanitario.

El tono es menos elevado en el caso de las árabes cuando se dirigen a ti. Luego, entre ellas, cuando están en la habitación, solas, el tono cambia, es más elevado, sí. Cuando se dirigen a ti, lo hacen como con miedo o con mucha prudencia. Las pacientes sudamericanas también se dirigen con mucha prudencia, también incluso te pueden desviar la mirada... [Enfermera 3]

Hombre, los chinos ya sabes que hablan como con cánticos cuando hablan entre ellos, pero aquí los pobres, es que ni respiran. Porque tengo entendido que ellos, según la entonación, pues quiere decir una cosa o quiere decir otra... [Enfermera 5]

Uy, los chinos hablan muy alto, sí, sí, chillan cosa mala, sobre todo cuando hablan entre ellos no hablan normal, es que chillan... [Profesional socio-sanitario 2]

Cabe también señalar los comentarios realizados por algunos profesionales entrevistados, quienes sostienen que, a pesar de las diferencias lingüísticas y culturales, es posible percibir el 
trato recibido y establecer una relación más o menos armoniosa dependiendo del tono de voz que se emplee.

Todo cuenta: el tono de voz, si me tratan más suave o me están gritando, eso se percibe. [Matrona 3]

Claro, es que por la entonación se sabe. Eso es como los animales. Un animal te entiende por la entonación, es decir, no entiende lo que le dices, pero, por la entonación, sabe si lo estás aplaudiendo, o estás riñéndole o... ¿sabes? A ver, una mujer puede que no te entienda, pero si tú le dices con cariño "Vuélvete. Cógete la piernita y empuja así" (todo esto lo dice en un tono muy dulce), pues es que son muy colaboradoras en general. [Matrona 7]

Por su parte, la gran mayoría de las usuarias inmigrantes entrevistadas afirma que no ha percibido nada que le llame la atención en el tono de voz empleado por los profesionales sanitarios, y algunas añaden que este puede variar de persona a persona.

No, el tono es normal. [África Subsahariana 1]

Pues, no, realmente en el tono de voz no hay nada que me haya llamado la atención. [África Subsahariana 4]

El tono normal me parece. [Asia 1]

Yo, siempre muy bajo. Ellos siempre son normal. [Asia 2]

No, hablan normal. [Asia 4]

No, no hay nada en el tono de voz que me llame la atención. [Europa del este 2]

Depende de la persona, pero en general hablan normal. [Europa del este 3]

No, el tono es normal. Es que ya me he acostumbrado. (Le pregunto si recuerda algo en el tono de voz de los españoles/zaragozanos que le llamara la atención cuando llegó, y si en Rumanía normalmente el tono de voz empleado es más alto o más bajo con respecto al empleado aquí). Es que no recuerdo ya si cuando llego a España... Ha pasado mucho tiempo. Y en Rumanía... no sé si es más alto, creo que depende, depende de las personas... [Europa del este 6]

No, para nada, no me llama la atención el tono de voz. [Latinoamérica 1]

No, yo creo que no hablan muy alto, no... No sé, para mí, no. [Latinoamérica 3]

No, para mí hablan normal. [Latinoamérica 4]

No, me parece que hablan normal. [Latinoamérica 5]

No, no hay nada que llama mi atención en el tono. [Magreb 1]

Normal, el tono me parece normal. (Le pregunto si cuando llegó de Argelia había algo en el modo de hablar de los españoles que le llamara la atención). Los españoles hablan mucho y muy rápido. Cuando voy en el autobús, digo a mi marido "Los españoles hablan mucho". Pero ahora ya estoy costumbre. [Magreb 3]

Depende de la persona. En Mauritania también hay gente que habla alto y otros, bajo. Varía. [Magreb 4]

Otras usuarias sostienen que el personal sanitario suele emplear un tono de voz elevado al dirigirse a ellas. Además, dentro de este grupo, una usuaria duda sobre si dicho tono denota enfado o es el tono habitual que usan los profesionales, y otra cree que quizás estos elevan el 
tono de voz porque creen que, de este modo, aumentará la comprensión por parte de las usuarias alófonas.

Médicos hablan alto, muy alto... [África Subsahariana 5]

They speak too loud, normally it is loud. [Asia 3]

Hay algunas que te hablan muy alto, pero no sabes si es que te están contestando mal o si es que es la forma de hablar de ellas. No sé si será normal o... [Comunidad gitana]

No, hay gente que a lo mejor se piensa que nosotros no entendemos y al hablar alto (sube el tono de voz al pronunciar estas palabras), lo vamos a entender... Pero lo entiendo aunque me hablen bajo. (Risas). No, es sobre todo la gente del pueblo que te empiezan a gritar pensando que así la vas a entender, pero hablando alto o bajo la entiendes igual. [Europa del este 1]

Bueno, aquí hablan más alto, sí. [Latinoamérica 2]

Solo dos de las usuarias entrevistadas consideran que el tono de voz de los profesionales sanitarios es, por lo general, bajo, y una de ellas, concretamente procedente de Camerún, lo compara con el tono elevado que se emplea en su país de origen.

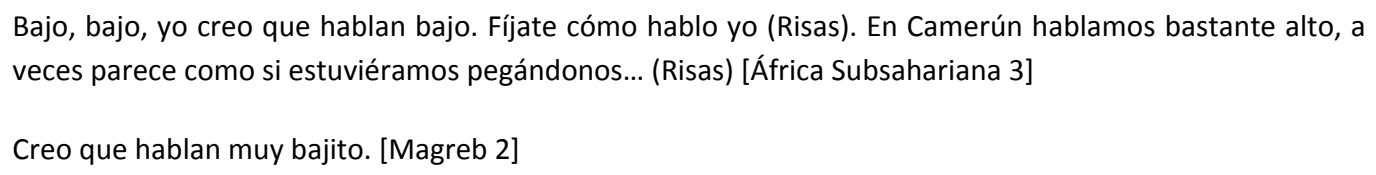

\subsubsection{Actitudes sociales}

Analizamos a continuación el último nodo de datos recolectados con la técnica de las entrevistas, centrado en las actitudes sociales. Como hemos comentado en el capítulo 2, relativo al diseño metodológico de nuestro estudio, las preguntas planteadas mediante esta técnica siguen una progresión de menor a mayor complejidad y, de hecho, las cuestiones que estudiamos en este nodo presentan un carácter más delicado y afectivo con respecto a las presentadas previamente. En concreto, se refieren a cuestiones de género, la interacción de los profesionales sanitarios con los maridos y familiares de las usuarias inmigrantes, el posible sentimiento de discriminación de estas últimas, o la manifestación de actitudes racistas o xenófobas por parte de los profesionales sanitarios. 
El análisis se centra en los subnodos o subtemas que aparecen en esta captura de pantalla de nuestro proyecto con NVivo 10:

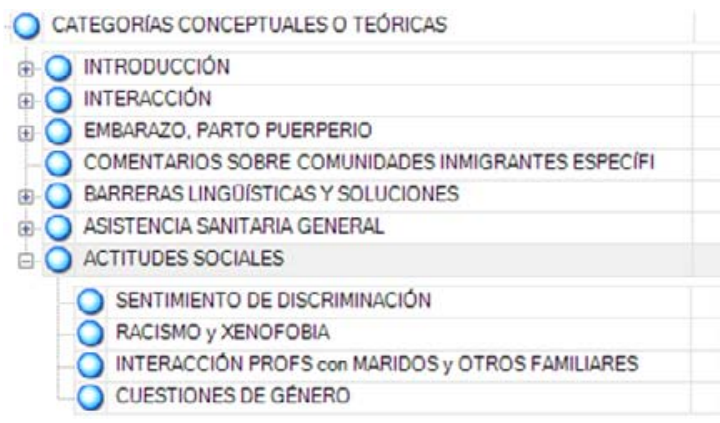

\begin{tabular}{|l|l|l|l|}
\hline 49 & 1746 & $02 / 022201312: 31$ & AN \\
\hline 49 & 154 & $02 / 02201312: 51$ & AN \\
\hline 49 & 530 & $02 / 02 / 201312: 52$ & AN \\
\hline 48 & 331 & $02 / 02 / 201312: 51$ & AN \\
\hline 24 & 240 & $04 / 02 / 20137: 08$ & AN \\
\hline 46 & 372 & $02 / 02 / 20131252$ & AN \\
\hline 47 & 240 & $02 / 02 / 201312: 51$ & AN \\
\hline 49 & 151 & $02 / 02 / 201312: 52$ & AN \\
\hline 49 & 64 & $04 / 02 / 20137: 00$ & AN \\
\hline 51 & 67 & $04 / 02 / 20137: 01$ & AN \\
\hline 21 & 30 & $04 / 02 / 20137: 00$ & AN \\
\hline 46 & 60 & $04 / 02 / 20137: 00$ & AN \\
\hline
\end{tabular}

Gráfico 6.30. Subnodos del nodo ACTITUDES SOCIALES

El primer tema que analizamos se centra en cuestiones de género y, más concretamente, en el planteamiento de impedimentos a ser tratadas por profesionales sanitarios hombres por parte de las usuarias inmigrantes o en la posible existencia de dificultades de interacción cuando el profesional que atiende a estas usuarias es de sexo masculino.

En primer lugar, cabe señalar que, aunque planteamos una pregunta específica sobre posibles problemas de género en el último bloque de las entrevistas, ya habían ido surgiendo referencias a estos problemas en otros puntos del análisis de las mismas, como por ejemplo, cuando tratamos las cuestiones relativas a la interacción entre los sujetos investigados y, en particular, aquellas relacionadas con el pudor manifestado por algunas usuarias inmigrantes (en especial las de origen magrebí) ante el contacto físico y la exploración o al tratar determinados temas que podrían considerarse tabúes en su cultura de origen. Se ponen de manifiesto en este caso las líneas difusas y la interrelación existentes entre los diferentes temas analizados en nuestro estudio, cuestión que ya habíamos planteado al principio del análisis.

Además, debemos tener en cuenta que existe un predominio de mujeres tanto en general en los servicios de obstetricia de este hospital como entre los profesionales sanitarios entrevistados, ${ }^{257}$ lo cual puede haber condicionado en cierto modo las respuestas obtenidas en relación con este tema. De hecho, algunos de los sujetos entrevistados afirman no haber vivido la experiencia de que se les solicitara un cambio de profesional sanitario (por ser mujeres) o confirman que en los servicios de obstetricia la mayoría del personal es de sexo femenino.

\footnotetext{
Porque, claro, también tienes que tener en cuenta una cosa, y es que aquí somos casi todo mujeres. Por ejemplo, de doce residentes, hay dos chicos y diez chicas. Entonces, ese problema se plantea muy pocas veces. [Enfermera 6]

Como matrona, con la mujer que está de parto, pues aquí sí que puede surgir algún problema más cultural a lo mejor si eres un hombre, pero, claro, siendo mujer, pues eso no lo sufro yo. [Matrona 2]

A mí, claro, como mujer, no me ha pasado, pero sí que a algún compañero... [Obstetra 2]
}

\footnotetext{
${ }^{257}$ Tal y como hemos indicado en la presentación de los datos demográficos de los sujetos entrevistados, de los 24 profesionales sanitarios que participaron en esta fase del estudio, solo 8 eran hombres, y las 16 restantes, mujeres.
} 
Por algunas de las respuestas obtenidas, parece ser que el impedimento por parte de las usuarias inmigrantes a ser tratadas por personal sanitario de sexo masculino suele darse más en urgencias o en los centros de salud.

A mí... aquí, no, no me ha pasado. Cuando trabajaba en urgencias, sí [...] Pero la verdad es que aquí en este servicio, si lo piensan, desde luego no lo han manifestado, al menos en mi caso. Yo creo que no sé si se mentalizan, o ven tanto hombre que... pero vamos, aquí no nos han pedido que venga una chica. [Anestesista 4]

Sí, pero sobre todo hemos tenido casos en urgencias que se han negado a la asistencia por parte de hombres, por parte de ginecólogos. Y aquí supongo que a alguno de los compañeros matronas también les habrá pasado. [Matrona 4]

A mí no me ha tocado un caso así. Pero sí que he oído casos, también de los centros de salud, en los que han dicho "No, no, yo hombre no quiero". También sé que en urgencias alguna vez les han dicho "No, no, yo médico hombre no". Pero, vamos, a mí aquí no me ha tocado nunca tenerle que cambiar a un compañero la señora que le tocaba por estos problemas. [Matrona 5]

En cuanto a cómo reacciona el hospital contexto de estudio ante este tipo de peticiones, podemos observar dos opiniones diferenciadas, tanto entre aquellos profesionales sanitarios que lo han vivido en primera persona como entre los que saben que se han dado estos casos por los relatos que les han contado sus compañeros.

Un primer grupo de profesionales entrevistados considera que las usuarias deben adaptarse a las condiciones y al personal que esté presente en el hospital en el momento de ofrecerles asistencia.

Yo creo que, si vienen aquí, ya saben que tienen que aceptar lo que hay aquí, ¿sabes? Quiero decir que ya aceptan que aquí hay hombres y mujeres y aceptan que aquí se hacen las cosas así, que se tienen que comportar de una determinada manera, que, por ejemplo, se tienen que quitar la ropa o seguir unas normas... Vamos, a mí me parece que eso lo tienen claro o, al menos, deberían tenerlo asumido. [Anestesista 2]

Yo, personalmente, no me he encontrado ningún caso en el que la paciente se negara a ser tratada porque el personal fuera hombre, pero sí que me han comentado las compañeras que alguna vez ha pasado, y no era ya la paciente, sino el marido. Yo no lo he vivido, pero a mí me han contado que sí que ha pasado algún caso, y ha sido como... "Bueno, lo siento, pero es que es lo que hay". [Enfermera 4]

Alguna vez eso nos ha pasado con alguna árabe y le hemos dicho que eso era lo que había. [Enfermera 6]

A algún compañero sí que le ha pasado, sí. Conozco un caso, que me explicaron, en el que la matrona era un hombre, un compañero mío que estaba haciendo la residencia, y le dijeron que preferían que le tratara la matrona que estaba como de profesora de él, y se le dijo que no, que él era un compañero como otro cualquiera y que la iba a explorar sí o sí. [Matrona 2]

Yo creo que te tienes que aguantar un poco con lo que hay. En muchas ocasiones es que no se puede elegir. Es que si te baja un pediatra que está de guardia, es que le toca a él estar de guardia, o si te viene un ginecólogo... Quizás se puede intentar, pero, bueno, tampoco lo suelen pedir en plan de "A mí me gustaría que...", sino que se rechaza, por ejemplo, cuando eso, diciendo "No, no, no...", pero es que les dices "Bueno, este es el médico que está de guardia y ya está. Es que te tiene que mirar", y tampoco... [Matrona 3]

Otros, sin embargo, se esfuerzan porque la usuaria se encuentre cómoda y, si es necesario y hay posibilidades dependiendo de los profesionales disponibles en ese momento, atienden a la 
petición de algunas usuarias inmigrantes de cambiar a un profesional de sexo femenino o, en todo caso, no la obligan a ser atendida por un hombre.

[...] en estos casos, pues actuamos dependiendo de cómo esté la guardia compuesta: si son dos ginecólogos hombres, pues no hay opción, no hay otro remedio, y si realmente es un problema que puede acarrear mayores problemas, pues yo creo que, si se puede, entre ellos, se dicen "Pues, mírala tú, que eres mujer". Pero, claro, depende de quién esté ese día en la guardia. [Anestesista 1]

[En urgencias] sí que había personas de origen árabe o africano que sí que te lo han pedido y lo intentabas o directamente en esos casos mandabas a una chica o iba la chica o lo que sea... [Anestesista 4]

Sí, pero esto me pasó solamente con una magrebí una vez. Dijo que no quería un hombre y que no quería un hombre, que quería una mujer. Y hubo un revuelo... Porque, claro, allí había matronas, y algunas me decían "Que no, que tienes que ser tú, que tienes que ser tú". Y yo les dije "Mira, es que realmente lo va a pasar mal”. La situación era muy tensa, así que al final vino una compañera y ya está. Pero, vamos, me ha ocurrido una sola vez. [Matrona 6]

Aquí lo único, aunque muy rara vez, porque en los once años que llevo aquí ha sucedido muy pocas veces, pues, solamente me he encontrado con tres señoras, creo que eran del Magreb, que no querían que las visitara un varón. Pero, vamos, de todas las que tenemos, las miles, solamente hubo tres, vaya, ha habido tres en estos once años. $Y$ en esos casos... Pues yo le ofrezco lo que hay. Si solo estamos varones y no quiere que la visitemos, pues, no pasa nada. O sea, cuando ella quiera, se va, y ¿qué quiere que le haga yo? No la puedo forzar, ni mucho menos... (Risas). [Obstetra 1]

Muchas veces les ha sucedido a compañeros, sí, muchas veces... Ha habido mujeres árabes que su marido se niega a que le atienda durante el parto un ginecólogo hombre, entonces, pues... A mí me ha pasado en mi equipo y entonces lo que se ha decidido es que le atienda una ginecóloga, buscas una ginecóloga que le atienda. Raro es que el equipo sea todo de hombres. Entonces, bueno, se ocupa una mujer. Hombre, si es en la consulta, pues ellas mismas ya lo eligen, si el primer día se encuentran con que es un hombre, pues igual ese día pasan un mal rato, igual no se dejan explorar, pero yo creo que, incluso el mismo ginecólogo está de acuerdo en que el próximo día la visite una ginecóloga. Al principio veía que los compañeros se intentaban enfrentar, como para intentar educar a la gente, y decían "Pues si le toca, le toca". Pero yo creo que últimamente, de un tiempo a esta parte, yo no veo que los compañeros se enfrenten. Cambias a que le vea una ginecóloga mujer y ya está. [Obstetra 3]

Por último, dos de los profesionales sanitarios opinan que puede suceder todo lo contrario, es decir, que algunas usuarias prefieran ser tratadas por personal de sexo masculino, bien porque los hombres las suelen atender de forma más delicada o porque a veces las usuarias asocian la figura masculina con una mayor preparación. Veremos a continuación cómo esta misma opinión es manifestada por algunas de las usuarias inmigrantes entrevistadas, algo que, en principio, no preveíamos entre las hipótesis iniciales de nuestro estudio.

No sé... Yo creo que ellos tienen incluso más tacto que nosotras cuando tratan con las puérperas. Porque, quieras que no, cuando tú vas a ver a una mujer, como se supone que tienes lo mismo, pues a veces pecas de no tener ese tacto que los hombres tienen. [Enfermera 1]

Por lo general, consideran al personal sanitario como alguien muy bien preparado y que te va a ayudar, entonces... Luego, puede pasar también que a la figura del hombre se la relacione más con un médico, es una visión algo más machista. $Y$, entonces, en el caso de las matronas hombre, pues lo consideran algo más superior, como por encima, como que va a saber más, como que confían más y piensan "Pues, mira, me ha tocado hombre, entonces la cosa va a ir muy bien". [Matrona 6]

Por lo que respecta a las usuarias inmigrantes entrevistadas, la gran mayoría afirma que no les importa si el personal sanitario que las trata es hombre o mujer, y algunas añaden que confían en que, independientemente de su sexo, será un buen profesional quien las atienda. 
Eso, ya me da igual, si es buen médico, no importa hombre o mujer. [África Subsahariana 1]

Me da igual, es médico. Lo importante es que trabajar bien, me da igual hombre o mujer. [África Subsahariana 2]

No, no me importa que sea hombre. Porque por ejemplo el primero que me tocó es un hombre, Roberto, y la verdad, por confianza y esas cosas, me hubiera gustado que me atendiera él hasta el final... Si es buen médico, me da igual que sea hombre o mujer. [África Subsahariana 4]

Igual (si es hombre o mujer), solo si es simpático, todo igual. (Risas). [Asia 1]

Me da igual, porque harán lo mismo unos que otros. Da igual que sea hombre o mujer, la verdad. [Europa del este 2]

No, si es profesional no importa si es hombre o mujer. [Europa del este 3]

No, eso me da igual. Mientras lo hagan bien, me da igual que sea hombre o mujer. [Europa del este 4]

No, no, no es un problema si es hombre o mujer. Si me tratan bien y son capaces, da igual si es hombre o mujer. [Europa del este 5]

Es igual, mientras te atiende bien, me da igual. [Europa del este 6]

No es un problema, no. Siempre da vergüenza, pero bueno... Si es un ginecólogo, si es hombre o mujer da igual. A mí no me importa... Ellos están acostumbrados, porque ven no solo a una sino a miles de mujeres, o sea que... [Latinoamérica 5]

Me da igual. En mi país también hay médicos hombres y mujeres. [Magreb 1]

Por la respuesta ofrecida por una de las usuarias que no ponen impedimentos a ser tratadas por un profesional sanitario de sexo masculino, en concreto una usuaria de China, podemos deducir que esta actitud puede haber cambiado en su comunidad de origen con respecto a la generación anterior, ya que afirma que su madre, quizás por falta de costumbre, prefería que quien le ofreciera asistencia fuera mujer.

Da igual. Porque a mí da igual. Siempre he visto, entonces es normal. Pero para mi madre, no. (Risas). Ella prefiere mujer. [Asia 2]

Por otra parte, algunas usuarias, en especial las procedentes de Asia, de Latinoamérica y, sobre todo, del Magreb, sostienen que prefieren ser tratadas por personal sanitario femenino, aunque ninguna de ellas afirma haberse negado cuando el profesional que las ha atendido era un hombre. Cabe destacar el caso de las usuarias magrebíes, algunas de las cuales dicen preferir que les ofrezca asistencia una mujer en determinados contextos o para tratar determinados temas, considerados más "de mujeres" (palabras textuales de una de las entrevistadas).

No importa si es hombre o mujer, pero prefiero mujer, sí, yo prefiero mujer... [África Subsahariana 5]

No, solo... we Muslim woman don't want to treat a man... Si, I prefer nurse or doctor to be a woman. We are shy from... men. [Asia 3]

Yo prefiero mujer. Si es hombre... eeee... (Se ríe nerviosamente). Si es hombre, yo aguanta. [Asia 4]

Hombre, por confianza, prefiero mujer, pero no porque haya tenido ninguna mala experiencia ni nada, sino que, por confianza, me inspira más. Pero si es un hombre, no pasa nada, no me importa, no. [Latinoamérica 1] 
Bueno, en ciertas cosas sería mejor mujer, pero bueno, por ejemplo, ahora que he tenido una niña, he estado con médicos varones y no ha sido ningún problema, no. [Latinoamérica 3]

Prefiero mujer, pero sea hombre o mujer siempre me han tratado con respeto. [Latinoamérica 4]

Depende del caso. Un caso de parto si está mujer o está hombre es normal. Pero médico de familia yo prefiero mujer. [Magreb 2]

Bueno, como ahora, que ha venido el médico y me ha dicho de quitar la braga y esto es incómodo... Si es una mujer, es mejor. [Magreb 3]

Yo prefiero si es mujer. Especialmente por ciertos temas, es mejor si es mujer, sí. [Magreb 3]

Es lo mismo, son iguales... pero, si es posible, mejor mujer, porque mujeres entienden más cosas de mujeres. [Magreb 4]

Por último y, como anticipábamos en el análisis de las respuestas de los profesionales sanitarios en relación con este tema, dos de las usuarias entrevistadas (con diferentes orígenes, concretamente de Camerún y de Ucrania), sostienen que prefieren ser tratadas por personal de sexo masculino, pues consideran que son más delicados y suaves en el trato.

La verdad es que a mí al principio me daba igual que el médico fuera hombre o mujer. Pero, luego, con el tiempo, me parece que los hombres son más delicados. Las chicas son más frías y a veces... no sé. Por ejemplo, con mi primer parto, cuando las enfermeras me tenían que hacer el tacto y todo eso, pues me hicieron mucho daño. Parece que los chicos son de otra manera, te dicen "Tranquila, relájate", son más... como más delicados. El que me atendió en este parto era una matrona hombre y era como más tranquilo, simpático... La verdad es que cuando das a luz, que estás un poco sensible, se agradece que te traten bien. [África Subsahariana 3]

No, yo casi prefiero que sea hombre. Porque los ginecólogos hombres son más... No sé, o por tener más... Que son más suaves. Porque a mí me tocó una ginecóloga mujer y otro hombre, y como casi mejor el hombre. He preferido que fuera el hombre el que me atendió en el parto. No es por nada, es que no sé... los hombres como que siempre saben tratar, parecen más delicados los médicos. [Europa del este 1]

La siguiente cuestión que analizamos en relación con las actitudes sociales se refiere a la interacción con los maridos y familiares de las usuarias inmigrantes. Este tema solo fue planteado en esta última parte de las entrevistas a los profesionales sanitarios, pues en preguntas anteriores (relativas, por ejemplo, a las visitas y al acompañamiento durante el parto) ya se había indagado sobre la interacción de los maridos y familiares con las propias usuarias.

En particular, preguntamos a los profesionales sanitarios si habían hallado algún tipo de dificultad a la hora de relacionarse con los maridos y familiares de las usuarias inmigrantes. Al respecto, la gran mayoría nos comentaron que, en su opinión, era más difícil la relación en el caso de las usuarias autóctonas.

Pues, de todo hay. Con algunos, sí, pero realmente, en este caso, los mayores problemas no son con inmigrantes, sino con nacionales, especialmente son muy comunes con la etnia gitana. [Anestesista 1]

Yo creo que no... Aunque, bueno, en la planta sí, es más habitual. A veces, cuando pasan muchas horas y no se ponen de parto, les parece como que no las estás atendiendo. Y los familiares te dicen "¿Qué pasa? ¡Esto es infrahumano! ¿Cómo puede estar aguantando estos dolores en el siglo XXI?” Y situaciones así... Pero esto con la población inmigrante no sucede tanto, quizás más con la española. Yo creo que el inmigrante, por lo general, es más cauteloso, o más respetuoso... [Matrona 6] 
La verdad es que la mayoría de las veces es una situación muy positiva, el bebé sale bien, y entonces todos están contentos, que es de lo que se trata. Pero algunas veces hay algunos maridos que se impacientan. Porque hay partos muy largos, y ellos tampoco se han formado para saber que el parto es un proceso muy largo, que el periodo de dilatación y el expulsivo pueden durar varias horas. Entonces, si el parto va muy lento, y se atascan, y a lo mejor las aguas están teñidas y... porque se les explica todo, tienen toda la información, no se les oculta nada. Y, a veces, se impacientan, se ponen muy nerviosos y dicen "Que se lo saquen ya, que le hagan la cesárea, porque esto no va". O, a veces, como van abajo a informar a la familia, en los casos en los que la mujer está doce o trece horas, pues la familia se pone nerviosa. Los padres, los suegros, los abuelos se ponen nerviosos, y empiezan a decir "Pues a tu hermana le fue mejor. Fueron menos horas", y entonces ellos se impacientan, se ponen muy nerviosos. Pero, vamos, esto igual sucede más con las españolas. Es que los inmigrantes, para empezar, no suelen tener tanta familia. Muchas veces vienen con ellas amigos, o vecinos, o conocidos. No están tan arropados, su situación no tiene nada que ver. [Matrona 7]

No, generalmente... no. En general con los inmigrantes, no, hay más con los nacionales que con los inmigrantes. Ellos se quedan en un ladico, y no dicen ni "mu", de verdad, ¿eh? [Profesional socio-sanitario 3]

Tal y como señalan algunos de los entrevistados, el mayor número de quejas o problemas de interacción con maridos y familiares de las usuarias autóctonas se deba probablemente al hecho de que las usuarias inmigrantes y sus familiares conocen menos sus derechos y el funcionamiento del proceso de parto hospitalario en España y a que normalmente cuentan con menos redes de apoyo. A estos factores podríamos sumar, aunque no lo mencionen en este punto los entrevistados, la posible falta de dominio del idioma que les impide expresar quejas.

Son pocos los profesionales sanitarios entrevistados que afirman haber tenido mayores problemas en la interacción con los maridos y familiares de las usuarias inmigrantes y, en estos casos, sostienen que estos problemas se deben principalmente a su desconocimiento del idioma y las consecuentes barreras lingüísticas.

Sí que es verdad, como te comentaba antes, que a veces con los maridos puede haber más problemas o no, pero yo ya he aprendido a no meterme, o sea, es que realmente yo estoy trabajando, estamos dando un servicio y no estoy aquí para convencer a nadie. Intentaré ver qué es lo mejor para ella, y podré perder más el tiempo para explicarles las cosas por los problemas de comunicación, pero desde luego no me voy a meter en si quieres o no quieres... [Anestesista 4]

Con familiares y maridos tenemos los problemas del idioma y, en principio, nada más. Nada más, no, no veo especial problema, no. [Matrona 1]

Yo tengo mucha experiencia con inmigrantes aquí, con el tema de los partos, pero me relaciono más con los maridos. Nosotros tratamos sobre todo con los maridos, porque tenemos que subirlos cuando nos avisan de dilatación para que estén con ellas y, después, una vez han dado a luz las mujeres, informamos a los maridos de todos los pasos que tienen que dar para registrar al niño. [...] Yo creo que la relación con ellos es más difícil que con los españoles. Porque, de todas maneras, te dicen que no te entienden y, en realidad, igual te entienden, y luego hacen lo que quieren. A lo mejor lo hacen por eso, que una ya no es tonta... [Profesional socio-sanitario 2]

Solo uno de los profesionales sanitarios opina que, por diferentes motivos, resulta más difícil la relación con los maridos y familiares de algunas usuarias inmigrantes, y destaca en concreto el caso de los maridos de las usuarias procedentes de Marruecos y Rumanía.

Sí, con maridos de marroquíes. Porque deciden ellos el tipo de tratamiento que tienen que tener las mujeres, independientemente de lo que tú digas, porque no les parezca bien que la tenga que mirar, o 
que se tenga que quedar o... [...] También, los maridos de las rumanas, porque muchas veces les mandas a casa, mientras están preparándose para el parto, y se van con dolor, y ellos no quieren hacerse responsables de tener a su mujer con dolor en casa. Tienen miedo o lo que sea, pero en lugar de decir "Tengo miedo, por favor, doctora, no sé qué hacer con mi mujer", te grita, o porque tenga contracciones en casa, te hecha a ti la... la peste. [Obstetra 3]

Para concluir el análisis de los datos recolectados mediante la técnica de las entrevistas, estudiamos dos de las cuestiones más delicadas de tratar en relación con las actitudes sociales que se dan en los encuentros interculturales. En concreto, analizamos si, de acuerdo con los entrevistados, hay profesionales sanitarios que presentan actitudes racistas o xenófobas al proporcionar asistencia a las usuarias inmigrantes, y si estas últimas han manifestado sentimientos de discriminación durante su permanencia en el hospital contexto de estudio.

Por lo que respecta a los profesionales sanitarios entrevistados, la primera cuestión que nos gustaría destacar es que, a pesar de que en principio habíamos presupuesto que las respuestas recibidas serían más bien breves o evasivas, precisamente por el carácter delicado de las preguntas planteadas, nos sorprendió recibir contestaciones muy extensas, detalladas y aparentemente sinceras en relación con estos temas.

En primer lugar, en referencia a las posibles actitudes racistas o xenófobas por parte de sus compañeros, un escaso número de profesionales sanitarios afirma que no ha observado dichas actitudes. Entre estos, uno de ellos sostiene que la profesionalidad y la ética les impiden tratar de manera diferenciada a las usuarias, independientemente de su origen, algo que repetirán también más adelante otros profesionales que, sin embargo, sí han presenciado episodios de discriminación a usuarias inmigrantes.

\footnotetext{
Yo creo que no. Con todo lo que pasa por ahí, podemos tener todos nuestras ideas y nuestra manera de pensar: que si el sistema sanitario, que si los derechos universales, o que deberían regular todo esto, que qué está pasando con la sanidad, parece que aquí no hay dinero para nadie y... pero en el momento en que alguien entra por la puerta, no te planteas si hay que atenderlo o no hay que atenderlo, es un paciente como cualquier otro y le haces lo que le harías a otros, y utilizas los mismos medios y los mismos criterios que usarías con otros. Es que yo creo que los problemas políticos no van ni con la sanidad ni contigo, tú estás aquí para lo que estás y da igual que se llame Mohammed, que se llame Ana, o que se llame Chu Li... Yo creo que en ese aspecto... no. Yo creo que aquí la gente es profesional y yo creo que... vamos, sé perfectamente que no se discrimina a nadie. Otra cosa es que se diga que los que no tienen papeles parece que tienen más derechos que... Pero vamos, una cosa es lo que se diga y otra... porque en cuanto alguien entra, estoy convencido al cien por cien de que no se le discrimina. Es verdad que hoy, por la coyuntura o los problemas que hay, pues lo puede decir todo el mundo y en las noticias y tal, pero, independientemente de todo eso, ese no es nuestro problema, que en el momento en que alguien entra por la puerta, somos profesionales y que no se discrimina, se trata exactamente igual a todo el mundo, y se le hace a todo el mundo lo que necesita, no te planteas ni que sea de un sitio u otro, o de la tarjeta sanitaria y demás... [Anestesista 4]
}

No. Yo creo que la única actitud xenófoba, que en realidad no es xenófoba, simplemente es que hay gente con la que creas empatía y hay gente con la que no la creas. Pero más que tratar de uno u otro modo porque es fulanita que viene de tal sitio, las tratamos porque es fulanita y porque es así. Y lo mismo nos podría pasar con una de Madrid, o con una de Zaragoza. [Matrona 2]

Además, otro profesional dentro de este primer grupo señala que, en todo caso, los comentarios de carácter racista pueden escucharse más en la calle que en el hospital, donde cada vez están más acostumbrados a tratar a usuarios de diferentes países y culturas. 
También es verdad que cada vez la gente estamos más concienciados. Aunque a veces me da rabia, porque vas por la calle o mismo en los pueblos, por ejemplo, yo ahora vengo de las fiestas de mi pueblo, y allí la gente siempre está con lo mismo "Que si los extranjeros, que si se nos van a llevar las pensiones, que se lo están comiendo todo... “. Y es que en la calle se piensa mucho más en el extranjero como el culpable de todos los males que nos pasan en este país, que bueno, eso es lo que cree alguna gente, que te lo dice tan descaradamente y tan así... Yo, por ejemplo, en las fiestas de mi pueblo, que no han parado, y les he dicho "¿Y lo que nos han robado los ricos?". Llegas a enfadarte, porque piensas en que todo lo que nos han robado todos los directivos, todos los ricos y todos los políticos no es ni una parte de lo que gastan los extranjeros. [...] Pero yo pienso que en la calle hay más problema que aquí. Y aquí la gente joven, a menos que haya algún extranjero que dé la nota, normalmente, todas las residentes y todo eso es muy, muy, muy raro que alguien diga una palabra desagradable. Y si dices una palabra desagradable, se la dirías también a la española que es la típica jeta, que dices "Oiga, que no...". Pero no lo haces, no usas una palabra desagradable porque sea extranjera. [Enfermera 6]

Al respecto, otros matizan que, aunque no se manifieste ninguna actitud racista, es posible que, por las dificultades que entraña la asistencia a determinados colectivos de usuarias, se exprese por parte de algunos profesionales cierto recelo o preocupación previos cuando tienen que atender a estas usuarias.

No, yo creo que actitudes xenófobas, no. Lo que sí que haces a veces, porque ya te digo, que los problemas los presentan casi siempre unos determinados grupos, no sé si porque son acrecentados también por alguien de esos grupos que los estimulan, por así decirlo, y entonces algunos profesionales vienen como muy vigilantes. Pero que los profesionales sean xenófobos, yo creo que no. [Anestesista 1]

No, yo, de todos los que conozco, sinceramente, pienso que no. Pero lo que sí te digo, y a mí me pasa también, es que yo nunca he sido racista, jamás, ni creo que ahora lo sea, pero es verdad que cuando te encuentras con situaciones de estas constantemente, pues al final cuando ves que te viene una inmigrante, lo primero que haces es pensar "iHorror! ¿A ver con qué me encuentro?". Yo lo primero que pregunto es si habla castellano, eso es lo primero que les pregunto a las matronas, y cuando me dicen que sí, pues ya, me quedo tranquilo. [Anestesista 3]

Asimismo, uno de los profesionales sanitarios opina que, aunque el trato que se da a las usuarias es siempre bueno, es posible que a sus compañeros más mayores les resulte más difícil (o, en sus palabras, "les choque más") dar asistencia a usuarias inmigrantes.

Hombre, yo pienso que... a lo mejor, la gente que somos más joven y que nos ha tocado interactuar ya con gente de otras culturas, pues estamos algo más hechos. Y hay gente que a lo mejor, pues... llevamos poco tiempo de democracia en España y... También depende bastante de la zona, porque hay zonas como Madrid o Barcelona que son más interculturales, y entonces allí no cuesta tanto. Pero sí que pienso que hay gente mayor a la que le cuesta un poco más adaptarse. Sí que hay que ver que la pirámide poblacional es muy distinta en españoles y en inmigrantes; por ejemplo, en su caso nacimientos hay el doble o el triple... Y hay algunos compañeros que se indignan un poco. Y es para decirles "iPues tenlos tú!". [...] No es que luego las traten mal, porque normalmente las tratan bien y, si necesitan algo, pues siempre ayudan, porque por su experiencia, al ser más mayores, pueden saber más... Pero sí que se ve que al principio pues les produce una especie de choque. $Y$ es que ahora casi por cada española tenemos en planta a cuatro inmigrantes, y esto a la gente mayor puede producirle algo de choque. Pero bueno, las tratan bien igualmente, sí, yo pienso que al final las tratan bien. [Enfermera 1]

Por el contrario, la gran mayoría de los profesionales sanitarios entrevistados afirma que sus compañeros han presentado en alguna ocasión comportamientos racistas o xenófobos. ${ }^{258}$

\footnotetext{
${ }^{258}$ En el análisis de los datos recolectados durante la observación no participante presentaremos episodios en los que fuimos testigos en primera persona de alguno de estos comentarios o actitudes racistas.
} 
Casi todos opinan que se trata de comentarios, y que la actitud y el trato por parte de los profesionales no se ven influenciados por el hecho de que la usuaria provenga de uno u otro país.

(Le cuesta responder inmediatamente). ¿Te refieres a algún comentario? Pues, hombre, algún comentario sí, pero yo creo que también se oye sobre gente de aquí... Pues porque hay mucha carga de trabajo, hay mucha presión asistencial, y cada vez nos están apretando más, también últimamente las condiciones para nosotros y... pues esto hace que disminuya un poco el aguante que tú puedas tener. A mí, de todos modos, me molesta oír ese tipo de comentarios, como me molesta oírlos también de la gente de aquí. Al final es que la presión que tú tienes puede influir en el trato. En general, sí que es verdad que se puede oír algún comentario, pero que nunca, o casi nunca es delante de la paciente. [Anestesista 2]

Hombre... Hombre, no creo que sean tan así, pero de vez en cuando sí que algún comentario hay, sí que te llega... Pero, vamos, tampoco es que sea una actitud de estar constantemente haciendo críticas o comentarios despectivos, ni nada de eso. Pero, de vez en cuando sí que se suelta algún comentario así... esporádico. [Enfermera 4]

Sí. Xenófobas no de quizás demostrarlo hacia ellas, sino más bien del critiqueo por ahí, que digo yo. O sea, yo creo que aquí se trata a todo el mundo con respeto, que no es que haya un maltrato hacia ellas, pero a lo mejor pues sí que se comenta "Pues fíjate" y "No sé qué" y "No sé cuántos", "Si vienen con el móvil y luego no tienen dinero" y "No sé qué"... Cosas de ese tipo, juicios de ese tipo, sí que se pueden comentar en el pasillo. Pero, se trata bien, ¿̇eh? Yo creo que ellas no lo pueden percibir en ese sentido. [Matrona 3]

Sí. (Con rotundidad) Pero son más comentarios; acción, no. Yo creo que hasta ese punto... Porque hay que estar muy tarado, de verdad, para... Y, entonces, yo creo que son más comentarios. [...] Yo creo que hemos llegado a una situación ya de hartazgo, que estamos hartos ya de lidiar todos los días con las mismas situaciones... Pero, vamos, yo creo que son más comentarios, porque acción, pasar a la acción... no. Porque al fin y al cabo son todos iguales. [...] Por lo general, yo creo que todos nos esforzamos y que, si hay comportamientos xenófobos, yo creo que son más comentarios... Es que por ética no las puedes tratar ni diferente ni mal. Es que no te sale tratar a una persona mal. Si te dedicas a la salud, se supone que tienes un carácter que te lleva a ayudar a los demás, que no has acabado aquí por casualidad, que has seguido un camino... $\mathrm{Y}$, entonces, pues bueno, se supone que te cuesta tratar mal a la gente. Por muy harto que estés, por ética y por ti mismo, no puedes, no, no puedes tratar mal a la gente. [Matrona 4]

Además, por esta situación en la que estamos ahora en España, yo creo que esta actitud se ha acentuado todavía más. Por esta situación de crisis que estamos viviendo, pues al inmigrante lo vemos quizás como una sombra mayor de lo que era hasta ahora. [...] Sí, oyes comentarios sobre todo. Pero yo creo que acción, lo que se dice acción... Aunque, bueno, yo creo que dejar a una chica sola todo el día... en una ocasión lo vi yo, pero más no. Ahora, comentarios, muchos. [Matrona 5]

Pues sí, yo creo que el personal sanitario es racista, sí. Claro, estamos en una situación de crisis y se intenta echar la culpa al más desfavorecido. Entonces se le echa al inmigrante, porque es el que está allí abajo, aunque no tenga la culpa. $Y$, a pesar de que somos un grupo social privilegiado, porque tenemos trabajo, sí que parece como que nos van a quitar el trabajo. Cuando en realidad nos están dando trabajo, gracias a dios. $Y$, entonces, yo en los dos hospitales en los que he estado sí que he notado sentimientos, y comentarios como "Anda, más sudamericanas" o "Más no sé qué". Es un sentimiento... un poco... racista. Son comentarios, a comportamientos no trasciende. [Matrona 6]

Sí, a veces subo por las plantas y el $99,9 \%$ no, pero siempre hay alguno que te dice "Oye, ¿y a mí cuándo me vas a dar alguna ayuda? ¿Y a mí cuándo me vas a dar un recurso? Pues mi hijo también está en el paro..." y esas cosas. [...] Pero son más bien comentarios, acción ninguna, ¿eh? Acción ninguna, en absoluto, pero comentarios, sí. Que a lo mejor en la práctica es justo lo contrario de lo que manifiestan verbalmente, ¿eh?, es decir, que luego las tratan fenomenal, pero en un primer momento te dicen "Este despliegue de medios a ver cuándo lo vemos con una española". Vamos, en ese plan... [Profesional sociosanitario 1] 
Otros, sin embargo, sostienen que el racismo y la xenofobia están presentes no solo en los comentarios, sino también a veces en el modo de actuar de algunos profesionales al tratar a las usuarias inmigrantes.

Sí (con mucha rotundidad). Tanto en comentarios como en su modo de actuación. Sí, sí. Eso... vamos, yo creo que seguro. La manera de dirigirse a la paciente, la manera de explorar a la paciente, eeee... la forma en que repartes la medicación, o la comida, tu modo de actuar cuando suena un timbre, el ver que la habitación está llena de gente y cómo reaccionas, ver que se trae su propia comida y cómo reacciona el personal sanitario. $Y$ hay gente que yo creo que sí que puede dar contestaciones fuera de tono o tener actuaciones muy bruscas... (Mientras va pronunciando estás últimas frases, va bajando el tono de voz, quizás porque teme que le escuchen los compañeros que están en la planta, fuera de la sala en la que nos encontramos). [Enfermera 3]

(Largo silencio antes de responder). Hombre, estamos en tiempos de crisis. Puede que algún.... comportamiento sí que se pueda ver. Pero no es algo extendido, ¿eh? Es algo más bien puntual, muy puntual. Pero creo que en tiempos de crisis, bueno creo que este comportamiento se ha acentuado un poco ahora, antes era mucho más bien escaso, pero... es puntual. [Matrona 1]

A ver, yo creo que en la atención no, el orden de entrada siempre es el mismo, se les trata a todas igual, los procedimientos son iguales... Es decir, que en todo eso, no. Pero igual el trato personal, a la hora de hablar con ellas, pueden tener algún prejuicio o alguna contestación más así, pues... yo qué sé, puede ser. [Obstetra 2]

(Largo silencio). Hombre, prejuicios, sí, muchos, muchos, pero de ahí a que se les trate mejor o peor... Hmmmm. En cuanto a los resultados finales, yo creo que no, pero igual a la hora de tratar a las pacientes, sí. Con menos respeto, igual, en función del origen, o... Sí, sí, puede ser. [Obstetra 3]

Cabe destacar dentro de este grupo el comentario realizado por uno de los profesionales sanitarios, quien nos expresa su opinión al respecto de un modo de actuar que se da en el hospital contexto de estudio a la hora de distribuir a las usuarias en las plantas de puerperio y que, a su juicio, podría denotar cierta xenofobia. ${ }^{259}$

Sí. Son comentarios y son acciones. Bueno, xenófobas... Marcan la diferencia. Simplemente el hecho de poner a las extranjeras juntas en las habitaciones aunque no compartan la nacionalidad es una actitud muy normal, habitual y diaria. A las españolas con las españolas, y a las extranjeras con las extranjeras. Que puede coincidir o no el idioma, pero bueno, a mí me parece un poco raro esa forma de mezclar, pero bueno... Y, de hecho, en las habitaciones de dilatación, cuando estamos con muchas mujeres que van a dar a luz, también se busca compartir española con española y extranjera con extranjera. Porque bueno, en principio, se piensa que con el idioma, pues la española puede hablar con la española, y en el caso de la extranjera, igual el idioma puede coincidir... pero vamos, no sé qué decir, yo es una cosa que veo, que no comparto, pero que tampoco me da para criticarlo, o sea... ¿Por qué se hace? Pues, se hace de toda la vida, o sea, yo lo he conocido así. [Anestesista 5]

Algunos de estos profesionales que comentan haber sido testigos de episodios en los que se haya hablado o tratado de forma discriminatoria a las usuarias inmigrantes manifiestan su total desacuerdo con esta actitud y demuestran una clara empatía con las usuarias de origen inmigrante.

Sí, sí es que se ve claramente. Se oyen comentarios como "es que esta negra, es que no sé qué...". Luego ya no sé si las tratan de manera distinta o no, pero a mí sí que me han dicho alguna vez "Pues esta como

\footnotetext{
${ }^{259}$ Al respecto de la distribución de las usuarias según sus orígenes en el hospital contexto de estudio, véase también, en el subapartado de análisis de la interacción entre usuarias de este capítulo, tanto la respuesta ofrecida por otro de los profesionales sanitarios entrevistados como nuestros propios comentarios en relación con dicha distribución.
} 
es mora, o es no sé qué... pues oye, que se aguante". De eso sí que hay. Y yo no pienso que sea en general, pero hay unas cuantas que sí. Y yo creo que están contra todos los inmigrantes, no contra estas, sino contra todos... [...] A veces veo el comportamiento de algunas compañeras y... se me llevan los demonios. Y ya veremos si el día de mañana si no tenemos que vivir de las pensiones de ellos... Y tampoco se les ocurre que a lo mejor ellos mismos un día se tienen que ir a vivir al extranjero, eso no se les ocurre... En fin, paciencia. [Enfermera 2]

En general, no, así de fuerte, no. Pero, yo he observado que... Esto no va a trascender a ninguna parte, ¿no? Yo sí que he observado que a casi todo el mundo no le gusta... no le gusta una gitana, ni trata igual, con la misma exquisitez, digamos, entre tú y yo, a una española que a una negrita, o una marroquí. Yo, personalmente, lo tengo clarísimo. Para mí es una mujer que está de parto, es una mujer que está doliente, y tiene el mismo derecho a la asistencia que la de al lado, que puede ser una médico, o una periodista o lo que sea. $Y$ ese hijo que va a nacer tiene los mismos derechos a nacer en las mismas condiciones y tener el nivel de inteligencia máximo que podamos alcanzar en la vida. Porque nosotros no sabemos qué nivel va a alcanzar. A lo mejor el de la española es infinitamente más torpe por genética o... Para mí, tiene el mismo derecho. [...] Yo pienso que tienen los mismos derechos, tanto ella, que está en una situación doliente, que está en trabajo de parto, que es una situación especial, y que tiene derecho a la misma asistencia, a la mejor asistencia, como el hijo que va a nacer. Exactamente igual. Tienen los mismos derechos. Y me da igual que se quede en España o que se vaya a su país. Y cuanto más inteligente y más listo sea, y menos patologías tenga, y más sano esté, como recién nacido, y como niño y como todo, mejor para él, mejor le va a ir en la vida. Pero no todo el mundo piensa igual. Yo lo he observado, pero, claro, esto es tabú, y yo no me puedo meter en cómo piensan los demás. Eso no se puede evitar, cada uno es como es. Pero yo sí que he visto gente que no les hace el mismo caso, pues... eeee... ¿sabes? Pero, claro, yo no me puedo meter en cómo trabaja mi compañera o mi compañero. [Matrona 7]

Sí, sí, sí. Son comentarios y son actitudes, de las dos cosas hay. Y te sientes mal, yo, personalmente, me siento mal, porque para mí son personas... Y, por ejemplo, ahora, todo esto de la tarjeta sanitaria me parece una discriminación, y un abuso de poder y un genocidio. Te lo digo de verdad, ¿eh? Porque, vamos a ver, yo por tener la suerte de nacer en esta parte del mundo soy una privilegiada, y por nacer un metro más abajo no tienen derecho a nada... Y es que son personas. Bastante tienen con venir aquí. Porque, ¿quién quiere irse de su país, de su tierra, de su familia, de todo lo que ha vivido, y marcharse fuera? Es que es muy duro... Y, entonces, eso la gente no lo entiende, mis compañeras no lo entienden. ¿Y por qué? Porque lo han tenido todo siempre, no se han tenido que ir nunca a ningún sitio. $Y$ no es que yo haya tenido que hacerlo, pero al menos soy capaz de ponerme en el lugar del otro, y no me creo que yo por vivir aquí debo tener todo y los demás no tienen que tener nada... Pues no. Yo creo que todo el mundo deberíamos tener todo: educación, sanidad... Además, la sanidad en teoría es un derecho universal, y está visto que ahora no... Y el que quiera atender a estas personas deberá hacerlo en su tiempo libre. Y eso me parece también horroroso. Un médico no tiene por qué alargar, o un sanitario no tenemos por qué alargar nuestra jornada cuando un paciente, negro, blanco, o lo que sea, necesita una atención médica. Ahí estás discriminándolos a los dos, al sanitario y al paciente, a los dos. [Profesional socio-sanitario 3]

Solo tres de los profesionales sanitarios entrevistados declaran haber experimentado en primera persona sentimientos racistas hacia las usuarias inmigrantes y, en los tres casos (como también se puede observar en algunas de las respuestas incluidas anteriormente en el análisis de esta cuestión), consideran que estos sentimientos pueden estar causados por la actual situación de crisis económica y el empeoramiento de sus condiciones de trabajo, con una mayor carga asistencial. Además, también creen que, por lo general, las ayudas que se ofrecen a la población extranjera suelen ser mayores que las que reciben los autóctonos (algo que, de acuerdo con los datos oficiales, no se corresponde con la realidad o, al menos, debería matizarse), y es este sentimiento de discriminación por parte de los profesionales el que quizás les hace experimentar cierta hostilidad hacia los inmigrantes.

Pues, sí. Y cada día más. Esta situación de crisis nos estando afectando un poco a todos. E incluso, yo misma, a veces, me doy cuenta de que me cuesta más, que a veces los problemas son tantos que la pagas 
con... Pero vamos, son más comentarios entre compañeros, pasar a la acción, como si dijéramos, son raras las ocasiones en que se pasa... [Enfermera 5]

Bueno... Mira, vamos a ver (Risas). Las actitudes xenófobas, te puedo decir que yo, que siempre me he considerado ciudadano del mundo, en toda mi vida en mi relación con los demás nunca he tenido ni la mínima idea de xenofobia, pues te puedo decir que ahora, a mi vejez, me está dando pena porque a veces tengo sentimientos de xenofobia. Y me está dando pena de mí mismo, porque, aunque yo las voy a tratar igual de bien, me revienta un poco que en nuestro país, por las situaciones políticas que ha habido, se haya hecho tanto efecto llamada. Porque cuando se puede, adelante, a ayudar siempre que podamos a todos, pero cuando no podemos ayudarnos ni siquiera a nosotros... Que no llamemos a tanto turismo sanitario. Y ya me da igual que sean orientales, negritas, sudacas... ${ }^{260}$ No, no, no. Da igual que sean ingleses, americanos, alemanes... O sea, no hagamos ese turismo sanitario, ¿eh? ¡Hala, que España lo da todo! Pues sí, me siento un poco xenófobo con todo esto, pero no con las personas en sí, sino por la estragada política que hemos llevado hasta ahora. $\mathrm{Y}$, entonces, eso sí que se puede ver, lo que estoy sintiendo yo, pues a veces sí que lo... lo palpo en el ambiente. Esta sensación que dices... porque antes, cualquier compañero mío hacía lo mismo que yo, que nos entregábamos totalmente... Y, ahora, te sigues entregando, pero dices “iPuñetas! Que ya es demasiada invasión. Que mi hijo o mi hija que son de aquí, y yo que soy de aquí, que llevamos toda la vida cotizando y estamos en el paro, y que tengamos una serie de desventajas frente al que viene de fuera...". Tenemos que ser muy buenos, claro que sí, pero la caridad empieza por uno mismo. Pero vamos, son sensaciones y sentimientos, nunca se va a pasar... [Obstetra 1]

Pues cada día más, sí. Por ejemplo, yo no era tanto, pero te digo que cada día lo soy más. También ellos hacen mucho, ¿eh? Y es que hay algunos, me da igual de dónde sean, que son unos pesados, y tú se lo dices igual, no porque son de una u otra parte, y entonces te dicen "Es que eres racista"... Y sí que te lo dicen, sí, pero a mí me da igual. ¿Qué quieres que te diga? Porque yo hay cosas que tampoco las entiendo, hay cosas que las veo muy injustas. Porque primero vienen los de casa y, luego, los demás, ya está, y ahora más... Y es por la situación, porque influye todo, ¿sabes? Mientras está todo bien, pues está todo bien, y está todo bien para todo el mundo. Pero ya es otra cosa que a los que vienen aquí, que son de fuera, se les da todo, y tú, siendo de aquí, no tienes nada... Pues yo entiendo a la gente, ¿eh? Porque es que a ellos les dan todo y a nosotros, muchas veces, nada. Por ejemplo, lo del comedor y todas estas ayudas van siempre para ellos antes que para una persona "normal"... Pregúntaselo a la trabajadora social, pero estoy segura de que las ayudas si eres gitano o eres extranjero, pues tienes más facilidad. Por lo menos antes, porque yo creo que ahora... pues no sé lo que harán. [Profesional socio-sanitario 2]

Por otra parte, en cuanto a si las usuarias inmigrantes se sienten discriminadas y han expresado en algún momento este sentimiento, casi la mitad de los profesionales entrevistados opina que no o que, al menos, a ellos en concreto no se lo han manifestado.

No, no creo, no me da la sensación de que ellas se sientan discriminadas. [Anestesista 5]

No, la verdad es que nunca me han hecho ningún comentario de... como que se las tratara con algún tipo de discriminación. [Enfermera 4]

Yo no creo que se sientan discriminadas, al menos a mí, no... [Enfermera 5]

No, no me han dicho a mí nunca nada de eso, ¿eh? Intentamos tratarlas igual de bien que a cualquiera, sí, sí, sin ningún tipo de distinción. [Matrona 1]

Yo no creo que se sientan discriminadas, porque a la hora del comportamiento, yo creo que el trato siempre es agradable. Es más, a veces algunos pecamos más de... de exceso de ayudar, porque sabes que es inmigrante y le cuesta, o porque va a tener más problemas con respecto a la española. [...] Las rumanas

\footnotetext{
${ }^{260}$ Aunque "sudaca" es un término despectivo para referirse a los sudamericanos en España, no creemos que este profesional sanitario entrevistado lo esté empleando conscientemente con intención despreciativa, sino que quizás cree que se trata simplemente de un uso coloquial o eufemístico (como es el caso del adjetivo "negritas" que él mismo usa en esa frase).
} 
están encantadas. Tanto ellas como ellos se van encantados del trato, porque comparan con su país, y dicen que la atención aquí es muchísimo mejor que en su país. Y el resto tampoco creo que se sientan discriminadas. Y eso a pesar de que el personal sanitario es racista... [Matrona 6]

¿Discriminadas con respecto a otras mujeres? ¿Con respecto a las españolas? Pues, mira, yo no me he encontrado ningún caso, o no me lo han dicho, por lo menos. [Matrona 7]

En cuanto a la expresión manifiesta del sentimiento de discriminación, como apunta uno de los profesionales entrevistados, esta puede estar relacionada con un dominio del idioma y un conocimiento más profundo del sistema y de los derechos de acceso y uso de los servicios, capacidades de las que carecen algunas usuarias inmigrantes.

\begin{abstract}
No. Ummmm... yo creo que no, yo creo que quien realmente lo expresa es quien tiene un control del idioma y llevan ya años dentro del sistema, bueno, dentro de la sociedad y saben cómo funciona el sistema sanitario. Y con el conocimiento del idioma y del funcionamiento pueden ejercer más presión, su fuerza o mostrar su disconformidad. Las pacientes que llevan poco tiempo, que no conocen el sistema o tienen la barrera idiomática, yo creo que se evaden más, no protestan, no dicen nada, o te pueden decir que sí, que sí, que lo entienden todo, que lo van a cumplir y tal, aunque luego hagan lo que quieran, pero no muestran su disconformidad o ningún tipo de queja. [Enfermera 3]
\end{abstract}

Por el contrario, hay otro grupo dentro de los profesionales entrevistados a los que las usuarias inmigrantes sí que han expresado en algún momento que se sienten discriminadas (bien verbalmente o mediante su actitud).

No lo dicen, pero hay muchas actitudes, el modo en que hacen las cosas, que te puede al menos dar a pensar que sí, que se siente discriminadas. [Anestesista 3]

Pues, a lo mejor, alguna (se siente discriminada)... Pero bueno, yo pienso que también les pasa a las españolas. Suponemos que es la hormona... (Risas). [Enfermera 2]

Algunas yo creo que sí (se sienten discriminadas). Las veo como muy exigentes en cuanto a derechos... Sí, yo creo que sí. [Matrona 4]

Hombre, puede ser, sí que puede ser (que se sientan discriminadas). Porque a veces sí que hacen algún comentario cuando hay que esperar a las pruebas, o cuando les dices que les duele y es normal... $O$ alguna vez sí que he tenido problemas cuando han tardado en llamarlas en urgencias porque había gente, y se han quejado y han dicho "Claro, como yo soy de otro país...". Y, sí, sí, eso sí que lo he oído muchas veces. Como que nos echan en cara que les tratamos peor. Pero, ahora, yo creo que esto pasa cada vez menos, se quejan menos, no sé... [Obstetra 2]

Algunos de ellos opinan que puede tratarse de un modo empleado por estas usuarias para recibir mayor atención, pero que realmente no sienten dicha discriminación o que, si la perciben, esta en realidad no se da, puesto que los profesionales intentan tratar a todos las usuarias por igual (o incluso, tal y como sostiene alguno de los entrevistados, tratan mejor a las usuarias inmigrantes que a las autóctonas, por la situación desfavorecida que suelen vivir las primeras con respecto a las segundas).

Pues, yo ya no lo sé, si se sienten discriminadas o juegan a hacer ver que se sienten discriminadas para que las atiendas de otra manera o para que las atiendas antes... Porque con eso sí que se juega o se ha jugado. [...] Yo creo que en parte sí que lo pensarán, y a veces incluso te lo dicen, pero cuando te lo dicen ya no sabes si es porque realmente se sienten discriminadas o lo hacen para jugar contigo y para que las veas antes, en servicios como urgencias y demás... Y te dicen "No, es que como soy negra....". Pero es que eso ya está cambiando tanto, porque ahora incluso los españoles te dicen al revés "Claro, si fuera negro, me atenderíais". Y entonces ya, llegamos a un punto que... [Anestesista 4] 
Yo sí que pienso que hay veces que ellas se creen que somos más racistas de lo que somos realmente. Cuando a lo mejor le dirías lo mismo a un español, ¿sabes? Lo que pasa es que a veces por decir lo que piensas, aunque se lo dirías a un español igualmente, pues ya piensan que eres xenófoba, o racista o... Cuando yo creo que, al contrario, ipara nada! [Enfermera 1]

Alguna hay (que puede sentirse discriminada), pero cada vez menos. [...] Y te dicen "Eso es porque soy extranjera", y no es porque sean extranjeras... Por ejemplo, si tenemos cinco pacientes para ver, solemos llamar antes a las de toco(logía) que a las de gine(cología), porque si viene una de gine(cología) muy mal ya te avisan los celadores. Es que el celador, parece que no, pero es un baremo el que te indica, porque llevan muchos años... Y, entonces, la de gine(cología) te dice "Oiga, porque yo estaba antes...", y se piensan que tienen derecho y no saben que nosotros seguimos un turno establecido... [Enfermera 6]

Y yo pienso que muchas veces es el arma, cuando ellas... no sé, en los casos concretos en que están enfadadas por algún motivo, lo utilizan como arma, es decir, que te dicen que se sienten discriminadas cuando a lo mejor no es así. Eso es lo único que... Pero, vamos, yo creo que realmente sentirse discriminadas no se sienten, porque no tienen por qué, aquí se trata a todos por igual. Pero el hecho a lo mejor de que no se les trate como quieren ellas o como piensan que se las tiene que tratar, pues lo consideran una discriminación, cuando no lo es, porque aquí se hace con todo el mundo igual. [Matrona 2]

Pero vamos, son sensaciones y sentimientos, nunca se va a pasar... No, eso no, por lo menos, no creo. Eso sí que no lo he visto. Se intenta tratar a todas por igual. Es más, precisamente tratamos mejor a estos pobres, y digo a estos pobres como si nosotros fuéramos ricos... (Risas). Es decir, a estas personas más necesitadas siempre se les trata, bajo mi punto de vista, creo que mucho mejor que a nosotros mismos. Que no es que a nosotros nos tratemos mal... Vamos, yo creo que la sensación que deben o que deberían de tener es de que se les ayuda, más incluso de lo que nos ayudamos nosotros. [Obstetra 1]

No, en ese sentido yo sí que a veces creo que lo utilizan. Cuando no tienen ningún argumento, dicen "Porque claro, como soy inmigrante...". [...] Pero en el fondo de la cuestión, yo no creo que se sientan discriminadas, de hecho hay gente con la que entablas una relación semi-personal y te dicen que se han sentido muy bien tratadas, que a veces piensan que en su propio país esto no sería así ni por casualidad... Vamos, que yo creo que no, que no se sienten discriminadas. [Profesional socio-sanitario 1]

Ellos igual te dirán que sí (se sienten discriminados). Pero, vamos, yo con todos me comporto igual, si se portan bien... Porque hay algunos que se comportan fatal, pero eso da igual extranjeros que nacionales, eso depende de la persona... Lo que sí que noto es que antes se decía más entre españoles que a los extranjeros se les daba más que a los españoles... Pero, no sé, yo creo que ahora lo dicen menos, que antes al principio cuando venían lo decían más. Pero, bueno, yo los trato igual a todos, a mí me da igual, basta con que se comporten bien y yo no voy a estar mirando... de dónde vienen, vamos. [Profesional socio-sanitario 2]

El hecho de que algunos profesionales consideren que, aunque haya usuarias inmigrantes que se sientan discriminadas, no deberían hacerlo, resulta llamativo, puesto que, precisamente en la pregunta anterior, algunos han declarado haber presenciado comentarios o actitudes racistas por parte de algunos compañeros, con lo cual este sentimiento de discriminación podría estar en cierto sentido justificado.

También en referencia a este tema, como ha ocurrido en el caso de otros temas analizados previamente, algunos profesionales entrevistados indican colectivos concretos de usuarias que expresan más quejas por el trato recibido, y señalan dentro de estos colectivos a las usuarias latinoamericanas, a las magrebíes (o los maridos de estas) y a las de la comunidad gitana.

Yo creo que, en general, están bastante contentas y no se sienten discriminadas. Lo que sí que es verdad es que determinados grupos, en este caso, sudamericanos, y determinadas nacionalidades, sí que vienen con un exceso de... enseguida que la decisión que tomas va en contra de lo que ellos prevén, sí que dicen 
"Claro, es que como yo no soy de aquí...". Pero, desde luego, las pacientes africanas y las musulmanas no se suelen quejar. Es algo, no sé si diría específico, pero sí muy común en las sudamericanas y, además, de determinadas nacionalidades. [Anestesista 1]

Ummm, no sé. A lo mejor, eso más que los inmigrantes a mí me parece que lo hacen los gitanos. Que son muy exigentes, enseguida te dicen "Es que, como soy gitano...". Sí, son muy exigentes, muy demandantes y muy... protestones, diría yo. Piensan que si algo no va bien, es porque son gitanos, y eso no es así. Es porque sí, ya está, le podría pasar a cualquiera, pero ellos son como muy... muy poco transigentes con lo que pueda pasar. [Anestesista 2]

Cuando tienes una cesárea no programada en quirófano, te dicen "¿Y cómo que no voy a entrar?". Eso me ha pasado solo con árabes. El marido podría estar si no fuera una zona quirúrgica. ¿O cuando te operan de apendicitis hay alguien en el quirófano? No, ¿verdad? Pues ese es el motivo, no es porque seas racista, ni... Yo creo que igual ellos interpretan que se les deja fuera por algún motivo, no sé, porque son extranjeros y no... Y solo me ha pasado con árabes. [Anestesista 5]

Sí, algunas incluso sin motivo se sienten discriminadas. Las sudamericanas, por ejemplo, muchas veces dicen que se les trata mal por ser inmigrantes. Las chinas, no, no dicen nada de eso. Son las sudamericanas y las árabes. Sí, sí, muchas se quejan. Y, sobre todo, los maridos, te dicen "Eso es porque soy inmigrante". Es un poco como los gitanos, que te dicen "Pues, eres una racista". [Obstetra 3]

En relación con la posible discriminación sentida por las usuarias inmigrantes, cabe señalar la respuesta recibida por parte de uno de los profesionales sanitarios entrevistados en referencia al nuevo Real Decreto-ley que priva del uso de los servicios sanitarios por parte de la población inmigrante en situación irregular y que entró en aplicación durante la realización de nuestro trabajo de campo. ${ }^{261}$ En concreto, este profesional opina que no han recibido suficiente información sobre la nueva normativa y que, en todo caso, no le corresponde al personal sanitario decidir a quién debe o no debe atender.

\begin{abstract}
Así que aquí, nosotros no... Es que aquí no ha lugar que se sientan discriminadas. Porque aquí se atiende a todo el mundo. Llegan, te dicen "Buenas, mire que sangro" o "Que hace tres meses que no...", y como aquí hasta ahora se atendía a todo el mundo... (Se pregunta a la entrevistada si sabe si con la nueva ley que elimina la cobertura sanitaria gratuita para los extranjeros no registrados se seguirá atendiendo a las embarazadas). Eso estaba hablando yo ahora con las compañeras. Porque creo que la ley se puso en vigor el 1 de septiembre y, desde entonces, yo he pasado aquí solo dos noches. Las que han venido a urgencias en esas noches eran todas de toco(logía), de gine(cología) precisamente en esas dos noches creo que no he tenido nada. Pero, bueno, también puede ser una coincidencia, es que de solo dos noches no puedes sacar una conclusión. Yo sé que las urgencias de las que van a ser madres, las de toco(logía), las tenemos que seguir atendiendo, entonces... La ley pone que a las embarazadas y a los niños hay que atenderlos, pero la gine(cología)... eso ya... Estamos a día cinco, yo llevo desde el día uno aquí, y desde luego a nosotros no nos han pasado nada, debería haber más información al respecto, no nos han pasado ninguna circular diciendo a quién debemos atender y a quién no. Desde luego, yo no voy a ser quien me ponga aquí como el guardia con la porra y diga "Oiga, yo a usted no la miro". ¿Pero quién soy yo? Eso tendrá que hacerlo la administración o quien sea, pero nosotros, no. Yo me niego a ser yo la que diga... Porque además creo que no es nuestra labor, y tampoco nos han informado de quién tiene que ser. Han dicho que se atenderá a madres, es decir, a embarazadas, y a niños, pero no han dicho dónde está el corte. Sí que me han comentado que fuera, donde recogen las cartillas, que ahora les hacen firmar un papel, eso me dijeron, pero si eso les frena, no lo sé. $\mathrm{O}$, a lo mejor, los primeros días, están un poco a la espera a ver qué pasa. Y, también, luego hay muchos extranjeros que tienen cartilla, ¿̇eh? [Enfermera 6]
\end{abstract}

\footnotetext{
${ }^{261}$ Para mayor información sobre el mencionado Real Decreto, así como para conocer nuestra opinión al respecto de las consecuencias previsibles de su aplicación, véase el apartado del presente capítulo dedicado al análisis documental.
} 
Por lo que se refiere a las usuarias inmigrantes, analizamos conjuntamente las respuestas recibidas en relación con el posible racismo o xenofobia de los profesionales sanitarios y el propio sentimiento de discriminación que las mismas entrevistadas han podido experimentar.

La gran mayoría de las usuarias entrevistadas no cree que los profesionales sanitarios presenten actitudes racistas y afirman que no se han sentido discriminadas. Resulta llamativo el hecho de que, al contrario de lo manifestado por los profesionales sanitarios, los cuales, como hemos visto, opinan que algunos de sus compañeros presentan actitudes $y$ comportamientos discriminatorios, las usuarias sin embargo no lo hayan percibido o, al menos, no lo manifiesten en las respuestas ofrecidas durante las entrevistas. No podemos saber si realmente estas usuarias no son conscientes del posible racismo y xenofobia de una parte del personal sanitario o si, a pesar de las garantías de confidencialidad aportadas, consideran que esta cuestión es demasiado comprometida para tratarla abierta y sinceramente en las entrevistas (y menos quizás estando todavía ingresadas en el hospital).

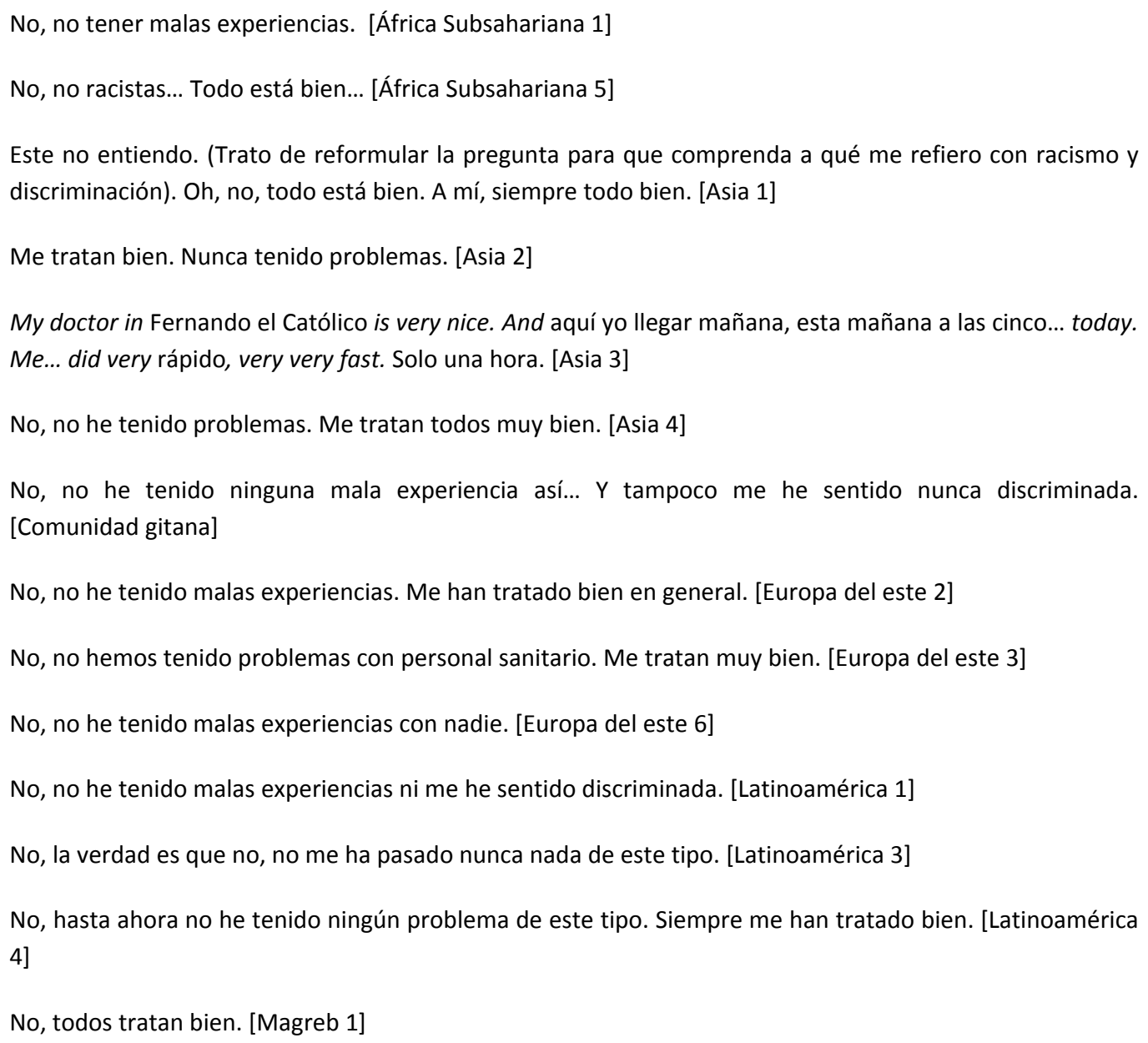

Entre estas, algunas añaden que se han sentido tratadas de la misma manera que el resto de gestantes y puérperas, independientemente de si su origen era autóctono o inmigrante.

La verdad es que no he tenido problemas. Yo creo que no, que me tratan igual que si soy española, porque claro, también depende de cómo te comportes tú. Porque tú si con esa persona estás bien, te va a tratar bien. [Europa del este 1] 
Son educados. No piensan que estás de fuera. Te tratan como la gente normal. A mí me tratan así los nueve meses. No me han preguntado si estás de fuera, si eres extranjero, o... si estás de aquí. A mí me han acogido como a la gente normal, como a los otros. [Europa del este 5]

Asimismo, tres usuarias manifiestan abiertamente al realizarles estas preguntas su satisfacción con los servicios y el trato recibidos, los cuales son, de acuerdo con una de ellas procedente en concreto de Argelia, de mayor calidad que los que recibiría en su país de origen.

No, nunca me he sentido discriminada. A mí no me ha pasado, ni en el hospital ni en el centro de salud. Sí que estoy contenta porque le atienden a uno muy bien aquí, bien, bien. [Latinoamérica 5]

Normal, como cualquier madre. No he notado que me tratan mal o diferente. Como he dicho del principio, aquí es mucho mejor. Ahora viene una de limpieza y me dice que hay una pieza que está rota y tengo que tener cuidado, pero en Argelia no hacen así. Si estamos así en Argelia, yo no estaba aquí en este país. [Magreb 3]

No, no, médico bueno, buen servicio, muy amable y... todo bien. [Magreb 4]

Son pocas las usuarias inmigrantes que relatan algún episodio en el que un profesional sanitario se haya comportado de manera racista o xenófoba, y todas ellas resaltan que se ha tratado de casos puntuales, y evitan realizar generalizaciones relativas a todo el personal sanitario.

Sí, hay médicos que, cuando he dicho me duele ahí, me mirar, pero poner guantes, y no hace con todos igual, porque piensa tú es morena y pone guantes. Depende de médico, pero hay otro que piensa que todos somos igual. [África Subsahariana 2]

No es que me hayan tratado mal, pero muchas veces a lo mejor las contestaciones no son las adecuadas... Esta segunda vez, la verdad es que no tengo quejas, pero con mi primer hijo a lo mejor... Por ejemplo, me trajeron la comida y yo estaba con una visita y entraron al rato y me dijeron "Oye, que te vamos a quitar la comida, que se acaba el tiempo de comer". Vamos, que no se puede generalizar, a veces te tratan mejor y otras peor... [África Subsahariana 3]

Por ejemplo, en el caso que te he contado antes, con el tema de la comida, no me trataron muy bien. ${ }^{262}$ Pero por el resto, ha ido bien, me han tratado bien. Lo único es que al final del embarazo, no sé por qué lío, nos cambiaron de médicos, de tocólogos, y el que me tocaba hasta el séptimo mes lo cambiaron, y en esos dos últimos meses me han tocado tres personas diferentes... Así que era llegar sin saber quién te iba a tocar, y te encontrabas con uno, luego con otro, y eso... [África Subsahariana 4]

No, pero en el hospital tiene personas buenas y tiene personas malas... No sé... Cómo decir... racismo. No pasa a mí, pero a mi amiga. Una vez una enfermera no dejar que ella... y hacer esto (hace un gesto como si le hubieran dado un golpe con la mano) y decir “¿Tú quieres dar parto en España?”. No lo sé cómo decir... Pero tiene malo y tiene bueno. También hay gente buena. [Magreb 2]

Pero con la obstetra con la que tenía citas durante el embarazo y tal sí que... No sé, veía un poco de prejuicios tal vez, no sé... Era una persona muy seria y nunca me miraba a la cara y tal y... Pero, bueno, en general, muy bien. [...] Solamente con esta obstetra de la que estábamos hablando. Pero no creo que fuera nada personal contra mí, yo creo que ella es así... Pero con el resto del personal ha ido todo muy bien. [Latinoamérica 2]

\footnotetext{
${ }^{262}$ Para recordar el episodio al que se refiere esta usuaria entrevistada, relativo a las contestaciones recibidas por parte de un profesional sanitario al protestar porque le habían servido comida con carne de cerdo a pesar de que hubiera advertido antes que no podía comerla por motivos religiosos, véase el anterior subapartado de análisis de las entrevistas centrado en los hábitos alimentarios.
} 
Para finalizar, cabe comentar que dos de las usuarias inmigrantes, tal y como había señalado también uno de los profesionales entrevistados, consideran que en el hospital contexto de estudio no se dan actitudes discriminatorias, sino que es más bien fuera de él donde la población autóctona las puede presentar. De acuerdo con estas usuarias esta discriminación puede estar motivada principalmente por la apariencia física o por estereotipos o generalizaciones. En particular, una de estas usuarias sostiene además que los comentarios y comportamientos racistas y xenófobos se dirigen más hacia algunos colectivos de inmigrantes (magrebíes, subsaharianos y latinoamericanos) que a otros (por ejemplo, procedentes de Europa del este).

\footnotetext{
Más que aquí, en hospital, es que luego con la gente en la calle... Es que te miraban un poco extraño al principio. Pensaban "Esta es rumana y viene a lo que viene y...". Como trabajaba también en un bar, pues... No sé, parecía que, por cómo me vestía y tal, y al ser de fuera, pues parecía que quería algo más que trabajar. Pero, luego ya, cuando se me conoce y me hago respetar, porque yo vine aquí a trabajar y punto, o sea no... [Europa del este 4]
}

No, no he tenido malas experiencias, no. A mí aquí me han tratado como a los demás. Pero en realidad, vamos a ver, hay gente que sí que discrimina. Bueno, aquí, no. En el hospital, no, pero fuera hay gente que sí que discrimina. En el hospital yo no he visto... Es que aquí como se trata de los hijos, yo pienso que para ellos todos los chicos son igual, y como yo he venido en el hospital solamente cuando he tenido a los chicos, se han comportado normal, pero no sé si esto es siempre así. La discriminación yo creo que la hace sobre todo la gente que tiene poca cultura, yo así lo veo. Se trata de personas que tienen poca cultura o, vamos a ver, también puede ser por otra cosita, puede ser gente que tienen poca espiritualidad, no solamente cultura. Por ejemplo, hay gente que discrimina, porque aunque no te conoce, te mira en la cara, y si tienes una cara negra o morena o no sé qué, piensa "Este no está de mi país, es extranjero", y entonces... Es algo como inconsciente, debido a la publicidad que se hace de los extranjeros, debido a que hay gente que son malos, ¿me entiendes? Entonces, te asocia con otros, entonces te trata mal. $Y$ es algo inconsciente que lo ves cómo te habla. Hombre, los rumanos como tenemos la cara blanca, pues si tú no hablas, a lo mejor no se dan cuenta que estás extranjero. Bueno, pero si hablas, se nota el acento del este. Lo único es que cuando dices que eres de Rumanía, Rumanía se ve como al margen de Europa, entonces sí que te pueden clasificar, y hay algunos que hacen como un cuadro y si no entras en ese cuadro y estás fuera, sí que hay un poco de discriminación. Pero de todas formas, hay menos discriminación para los rumanos, que para los moros, los negros, o los latinoamericanos. Pero hablamos de fuera, aquí en los hospitales es menos. Porque aquí como... es la etiqueta profesional que te impide comportarte de esta manera, pero cuando estás en la calle, sí que se comportan de esta manera. [Europa del este 5]

Antes de concluir el análisis de los datos recolectados mediante la técnica de las entrevistas, cabe recordar que las cuestiones más relevantes presentes en dicho análisis se retoman en el apartado de conclusiones generales del estudio de caso, en el que se comparan además con los datos obtenidos mediante otras técnicas y con la literatura publicada sobre nuestros intereses de investigación.

Asimismo, nos gustaría señalar que, al ser nuestro diseño metodológico emergente y en cascada, tratamos de ampliar con la técnica de los grupos de discusión los temas que hubieran resultado ambiguos, no suficientemente desarrollados o contradictorios en el análisis de los datos recolectados con las técnicas empleadas previamente, es decir, con las entrevistas y con la observación no participante. 


\subsection{Análisis de la observación no participante}

Nuestro propósito principal con el empleo de esta técnica consiste, como hemos comentado anteriormente, en observar de manera no intrusiva los fenómenos y situaciones que se dan entre los sujetos investigados (profesionales sanitarios y usuarias inmigrantes) en su vida cotidiana dentro del hospital contexto de estudio.

Entre las ventajas que nos ha proporcionado el uso de esta técnica, se encuentra el contacto directo con el entorno social estudiado y la consecuente posibilidad de analizar e interpretar las interacciones observadas en un contexto real. Por el contrario, también ha conllevado ciertas desventajas, entre las que destacan la dificultad para obtener mediante la observación datos relacionados con hechos pasados, opiniones y percepciones de los participantes (lo cual se suple con la complementariedad de los datos aportados mediante el uso de otras técnicas) y la imposibilidad de acceder, por falta de autorización, a todos los espacios en los que nos gustaría haber estado presentes.

Asimismo, cabe tener en cuenta que, tal y como sucedía con el empleo de la técnica de las entrevistas, es posible que los sujetos estudiados hayan modificado (ligera o sustancialmente) su actitud y comportamiento por el hecho de que estuviéramos observando, ya que, como se ha comentado en el capítulo 2, centrado en el diseño metodológico, tanto nuestra presencia en el hospital como los fines que perseguíamos con nuestra investigación en ningún momento han sido encubiertos.

Los datos recolectados mediante la observación no participante se dividen en dos grupos. El primero se refiere a los datos registrados en notas de campo inscritos en fichas siguiendo un esquema predeterminado con categorías excluyentes, aunque relacionadas entre sí. El segundo consiste en las notas tomadas en el diario de campo de forma asistemática mientras permanecíamos en el hospital durante el trabajo de campo.

Como en el caso de los datos recolectados mediante las entrevistas, hemos empleado el programa NVivo 10 para analizar los datos obtenidos con la observación. 
Dichos datos se han incluido en las categorías previamente establecidas para el análisis de las entrevistas (categorías contextuales, categorías demográficas y categorías conceptuales o teóricas) y se han codificado en los nodos generales que se resaltan en la siguiente captura de pantalla de nuestro proyecto:

\begin{tabular}{|c|c|c|c|c|}
\hline \multicolumn{5}{|l|}{ Nodes } \\
\hline Name & 8 Sources & References & Created On & Create \\
\hline$\boxminus$ CATEGORIAS CONCEPTUALES O TEÓRICAS & 57 & 1788 & 02/02/2013 12:31 & AN \\
\hline$\oplus \bigcirc$ ACTITUDES SOCIALES & 49 & 151 & $02 / 02 / 201312: 52$ & AN \\
\hline$\oplus \bigcirc$ ASISTENCIA SANITARIA GENERAL & 47 & 240 & $02 / 02 / 201312: 51$ & AN \\
\hline$\oplus$ BARRERAS LINGUISTICASY SOLUCIONES & 46 & 372 & $02 / 02 / 201312: 52$ & AN \\
\hline COMENTARIOS SOBRE COMUNIDADES INMIGRANTESE & 24 & 240 & $04 / 02 / 20137: 08$ & AN \\
\hline † EMBARAZO, PARTO PUERPERIO & 48 & 331 & $02 / 02 / 201312: 51$ & AN \\
\hline$+\bigcirc$ INTERACCION & 49 & 519 & $02 / 02 / 201312: 52$ & AN \\
\hline$\oplus$ INTRODUCCIÓN & 49 & 154 & $02 / 02 / 201312: 51$ & AN \\
\hline O OBSERVACIÓN PARTICIPANTE & 8 & 77 & $11 / 07 / 20139: 03$ & AN \\
\hline † DIARIO DE CAMPO & 4 & 26 & $11 / 07 / 20139: 04$ & AN \\
\hline 由 $\bigcirc$ FICHAS_NOTAS DE CAMPO & 4 & 51 & $11 / 07 / 20139: 04$ & AN \\
\hline$\because$ CATEGORIAS CONTEXTUALES & 60 & 190 & $05 / 02 / 20135: 57$ & AN \\
\hline Datos contextuales OBSERVACIÓN & 4 & 5 & $11 / 07 / 20139: 02$ & AN \\
\hline Duración entrevista & 49 & 49 & 05/02/2013 5:57 & AN \\
\hline Entidades colaboradoras & 1 & 4 & $18 / 02 / 201320: 19$ & AN \\
\hline Fecha entrevista & 49 & 50 & $05 / 02 / 20135: 57$ & AN \\
\hline Lugar entrevista & 49 & 49 & $05 / 02 / 20135: 57$ & AN \\
\hline Notas de campo & 8 & 37 & $18 / 02 / 201320: 08$ & AN \\
\hline Otros datos contextuales & 9 & 31 & $05 / 02 / 20135: 58$ & AN \\
\hline$\square$ CATEGORIAS GENERALES DEMOGRAFICAS & 55 & 265 & $02 / 02 / 201312: 29$ & AN \\
\hline$\oplus$ C COLECTIVO & 50 & 51 & $02 / 02 / 201312: 37$ & AN \\
\hline O DATOS SUJETOS OBSERVADOS & 4 & 8 & $11 / 07 / 20139: 02$ & AN \\
\hline
\end{tabular}

Gráfico 6.31. Nodos de la OBSERVACIÓN NO PARTICIPANTE

Igualmente, hemos codificado los datos registrados en el diario de campo y en las fichas en los siguientes subnodos o subtemas que determinarán el análisis posterior:

\begin{tabular}{|c|c|c|c|c|}
\hline \multicolumn{5}{|l|}{ Nodes } \\
\hline Name & Sources & References & Created On & Created By \\
\hline EO OBSERVACIÓN PARTICIPANTE & 8 & 77 & $11 / 07 / 20139: 03$ & AN \\
\hline$\because$ O DIARIO DE CAMPO & 4 & 26 & 11/07/20139:04 & AN \\
\hline Acompariantes & 2 & 24 & $11 / 07 / 20139: 09$ & AN \\
\hline Barreras lingüisticas & 3 & 16 & $11 / 07 / 20139: 08$ & AN \\
\hline Comentarios y actitudes racistas & 2 & 4 & 11/07/20139:11 & AN \\
\hline Costumbres y creencias en embarazo, parto y puerper & 2 & 10 & 11/07/20139:08 & AN \\
\hline Establecimiento inicial del rapport & 2 & 21 & $11 / 07 / 20139: 07$ & AN \\
\hline Interacción profesional-usuaria & 2 & 3 & $11 / 07 / 20139: 11$ & AN \\
\hline Predisposición a participar en el estudio & 3 & 9 & $11 / 07 / 20139: 07$ & AN \\
\hline Presencia otras personas & 1 & 1 & 11/07/20139:09 & AN \\
\hline Profesionales y dominio otros idiomas & 1 & 3 & $15 / 07 / 201320: 24$ & AN \\
\hline Relación madre-hijo & 2 & 7 & 11/07/2013 9:09 & AN \\
\hline Relación profesionales-investigadora & 2 & 2 & $11 / 07 / 20139: 11$ & AN \\
\hline Ritmo y tono de voz usuarias & 1 & 6 & $11 / 07 / 20139: 10$ & AN \\
\hline$\because O$ FICHAS_NOTASDECAMPO & 4 & 51 & $11 / 07 / 20139: 04$ & AN \\
\hline Acompañantes & 4 & 9 & $11 / 07 / 20139: 44$ & AN \\
\hline Actitudes sociales & 1 & 3 & $11 / 07 / 20139: 41$ & AN \\
\hline Barreras lingüisticas & 4 & 8 & $11 / 07 / 20139: 04$ & AN \\
\hline Comentarios finales a destacar & 4 & 6 & $11 / 07 / 20139: 06$ & AN \\
\hline Cuestiones culturales & 3 & 4 & $11 / 07 / 20139: 05$ & AN \\
\hline Introducción intervención & 4 & 5 & $11 / 07 / 20139: 34$ & AN \\
\hline Problemas de interacción & 4 & 13 & $11 / 07 / 20139: 05$ & AN \\
\hline Valoración de la intervención & 4 & 15 & $11 / 07 / 20139: 05$ & AN \\
\hline
\end{tabular}




\subsubsection{Datos contextuales y demográficos}

Con el fin de facilitar la lectura y comprensión de las notas registradas en las fichas y en el diario de campo, antes de iniciar el análisis de las mismas, presentamos los datos contextuales de la observación y los datos demográficos de los sujetos observados.

Por lo que respecta a los datos contextuales, tal y como hemos comentado previamente en el capítulo 2, la observación tuvo lugar en diversas zonas del hospital, aunque se centró especialmente en las plantas de puerperio y, dentro de las mismas, en las habitaciones donde estaban ingresadas las usuarias, así como en las zonas de descanso para personal sanitario y las salas de baño de los recién nacidos situadas en dichas plantas.

Esta observación llevada a cabo en las plantas de puerperio se desarrolló entre el 26 de julio y el 19 de septiembre de 2012, periodo en el cual se observaron en concreto 14 consultas a usuarias inmigrantes que habían dado a luz bien ese mismo día o el día anterior en el hospital contexto de estudio. Dichas consultas tenían una duración aproximada de entre 5 y 15 minutos cada una, por lo que, si sumamos el tiempo durante el cual estuvimos presentes en todas ellas, esta observación presenta una duración total de 2 horas y 40 minutos.

Por otro lado, el 30 de agosto de 2012 se realizó una tentativa de observación en la planta baja del hospital, concretamente en la sala de espera de las consultas a gestantes. Permanecimos en dicho contexto una hora y media. Los resultados de esta observación, como veremos más adelante, fueron bastante escasos, por la dificultad de acceso a dicho entorno.

Tanto los datos observados en las consultas a puérperas como el intento fallido de observación en las consultas prenatales se anotaron en las fichas mencionadas y aportadas en los anexos.

Por último, también se empleó la técnica de la observación en el periodo en el que se llevaron a cabo las entrevistas, es decir, entre el 9 de mayo de 2012 y el 17 de octubre de 2012. No nos resulta posible contabilizar el número exacto de horas de las que consta esta observación, pero teniendo en cuenta el número de días que acudimos al hospital (unos 25) y el número de horas aproximadas que permanecimos en el mismo cada uno de esos días (6), podemos afirmar que esta observación tuvo una duración aproximada de entre 125 y 150 horas. Durante dichas horas, observamos y tomamos nota en nuestro diario de campo de interacciones y situaciones que surgían bien durante las entrevistas o en los lapsos de tiempo intermedios, y que considerábamos que podían resultar interesantes para los fines de nuestro estudio.

Por lo que se refiere a los datos demográficos de los sujetos observados durante nuestro trabajo de campo, nos gustaría realizar una serie de aclaraciones previas. Por un lado, a diferencia de lo que ocurría con los sujetos que participaron en las entrevistas, en este caso no contamos con datos exhaustivos de todas las personas observadas, ya que, en ocasiones, no nos resultó posible solicitarlos tras la observación. Por este motivo, no podemos aportar datos demográficos, por ejemplo, sobre los maridos o familiares presentes durante las consultas o sobre algunos profesionales que, mientras estábamos en un determinado contexto en calidad de observadores, realizaban algún comentario o interactuaban brevemente con las usuarias. Por otro lado, cabe señalar que los datos demográficos de los sujetos observados coincidirán 
en ocasiones con los datos de los sujetos a los que hemos realizado entrevistas, ya que, por ejemplo, algunas de las usuarias presentes durante la observación llevada a cabo en las consultas a puérperas (en concreto tres de ellas), accedieron a ser entrevistadas posteriormente, lo cual sucedió también en el caso de uno de los obstetras encargados de dichas consultas.

Presentamos los datos demográficos divididos en tres grupos: en primer lugar, nos referimos a los sujetos observados durante nuestra presencia en las consultas a puérperas; en segundo lugar, nos centramos en aquellos sujetos presentes durante nuestro intento fallido de observar las consultas a gestantes; $y$, en tercer lugar, describimos a los sujetos observados durante nuestra permanencia en el hospital antes, durante o en el lapso de tiempo intermedio entre las diferentes entrevistas. A su vez, dividimos cada uno de estos grupos en tres subgrupos: usuarias inmigrantes, profesionales sanitarios, y otros sujetos (familiares o acompañantes de las usuarias y otras personas ajenas al hospital). ${ }^{263}$

\section{a) Consultas a puérperas}

Por lo que respecta a las consultas a puérperas en el hospital contexto de estudio, en primer lugar, cabe señalar que los encargados de realizarlas son siempre dos obstetras que se turnan y van por lo general acompañados de algún enfermero o, en ocasiones, de algún residente. Ambos obstetras accedieron a que empleáramos la técnica de la observación durante su ronda de consultas y, en total, observamos a 7 profesionales sanitarios, entre los cuales, además de los dos obstetras mencionados, se encontraban cuatro enfermeros y una residente. Dentro de este grupo, tal y como se puede observar en el siguiente gráfico, 3 son hombres y 4 mujeres.

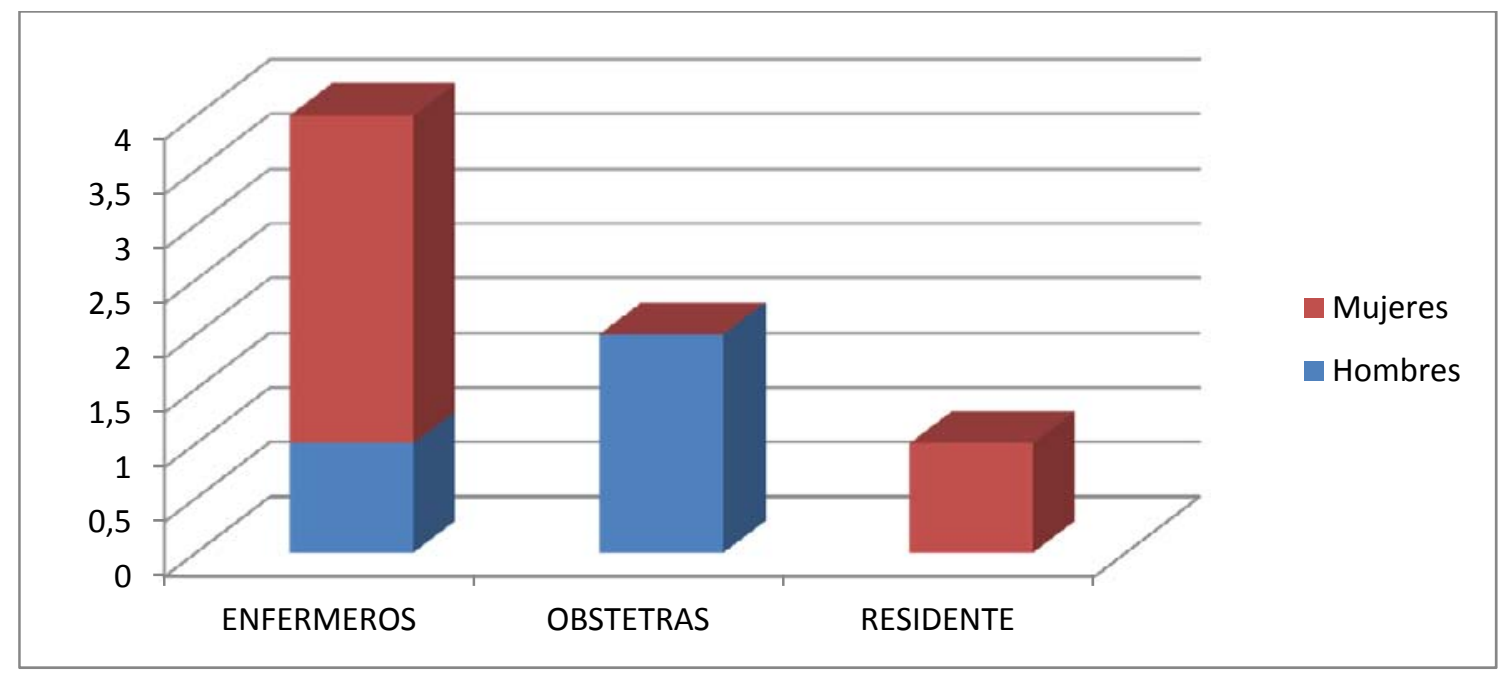

Gráfico 6.33. Perfil profesional y sexo de los profesionales observados en las consultas a puérperas

\footnotetext{
${ }^{263}$ En los anexos se incluye un documento con tablas en las que se resumen los principales datos demográficos de los sujetos de la observación no participante.
} 
La edad de estos profesionales, como figura en el gráfico que presentamos a continuación, era mayor en el caso de los obstetras (con una media de edad de 58 años) y menor en el caso de los enfermeros (con una media de edad de 35 años). También era bastante joven la residente presente durante algunas de las observaciones, la cual tenía 25 años.

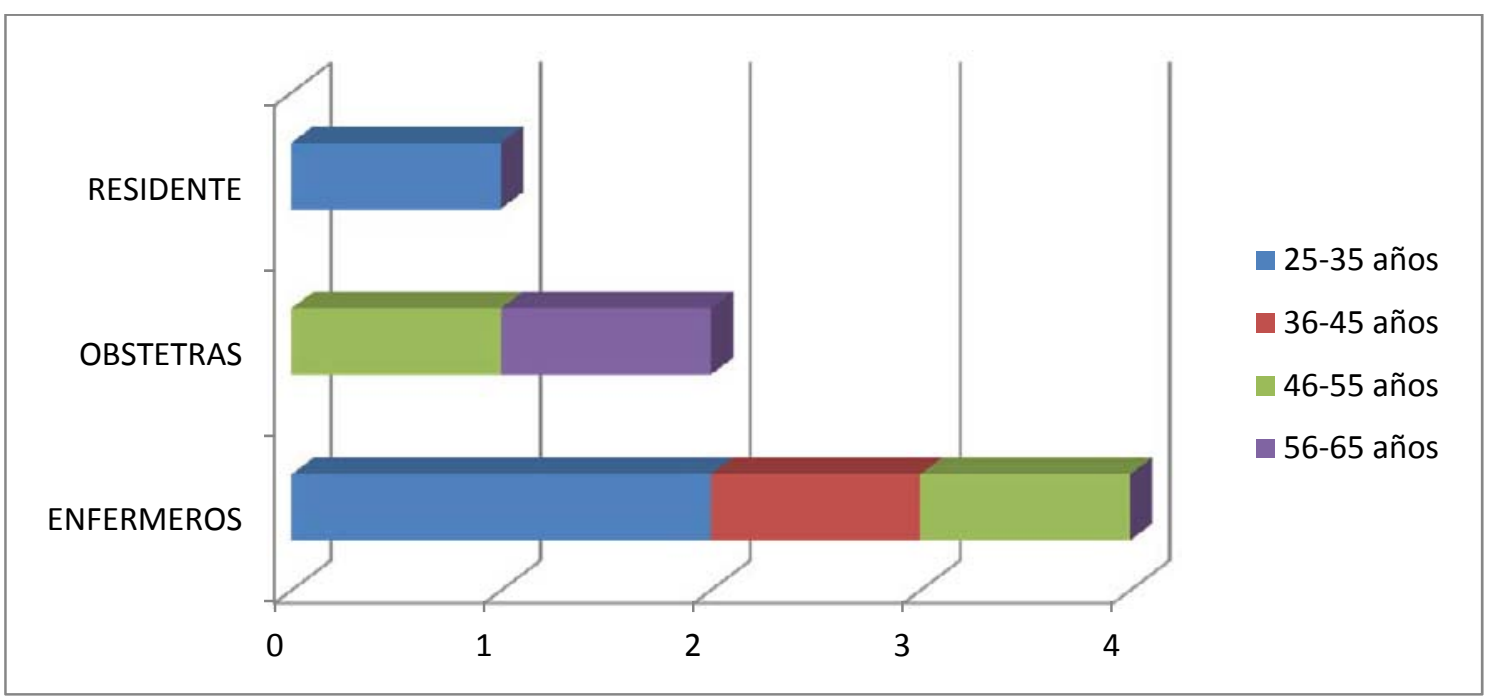

Gráfico 6.34. Perfil profesional y edad de los profesionales observados en las consultas a puérperas

La lengua materna de 6 de los 7 profesionales sanitarios sujetos de la observación en las plantas de puerperio era el español y la del profesional restante era el árabe. ${ }^{264}$ En cuanto a las lenguas extranjeras habladas por los profesionales sanitarios, solo disponemos de los datos relativos a los dos obstetras, quienes eran en realidad los que interactuaban con las usuarias durante las consultas, pues, como se puede ver en las fichas que figuran en los anexos, los enfermeros y la residente no se comunicaron en ninguna ocasión directamente con las usuarias inmigrantes observadas. En concreto, uno de ellos hablaba francés, inglés, alemán e italiano, y conocía además ciertas expresiones (por ejemplo, los saludos y algunos términos de cortesía, como "por favor" y "gracias") en otras lenguas extranjeras, entre ellas, el rumano y el árabe. Tal y comentaremos más adelante en el análisis de los datos de la observación, este obstetra en particular usaba estas expresiones en la lengua materna de algunas usuarias inmigrantes como un modo de acercamiento, demostrando al mismo tiempo cierta empatía con las mismas.

Por otra parte, las usuarias inmigrantes que participaron en la observación mientras se les realizaba la consulta en las plantas de puerperio fueron en total 14, y las zonas de procedencia de las mismas eran las siguientes: África Subsahariana (3), Asia (1), Europa del este (5), Latinoamérica (1), y Magreb (4).

En concreto, las usuarias procedían de los siguientes países:

África Subsahariana: Gambia (1), Ghana (1) y Senegal (1)

Asia: China (1)

\footnotetext{
264 Dicho profesional era de origen sirio, aunque llevaba residiendo en España más de 20 años y, de hecho, no se percibía acento extranjero cuando este hablaba español.
} 
Europa del este: Polonia (1), Rumanía (3) y Ucrania (1)

Latinoamérica: Guatemala (1)

Magreb: Argelia (2) y Marruecos (2)

Por lo que se refiere a la edad de las usuarias, esta estaba comprendida entre los 20 y los 40 años, estando la mayoría de ellas en la franja de edad entre los 26 y los 35 . Las usuarias que, de media, presentaban una edad más joven eran las procedentes de Asia y de Latinoamérica, con una edad aproximada de 20 y 25 años respectivamente, y las que presentaban una edad media mayor eran las procedentes de África Subsahariana y de Europa del este, con una edad media de 33 y 34 años aproximadamente. Su distribución por franjas de edad es la que figura en el siguiente gráfico:

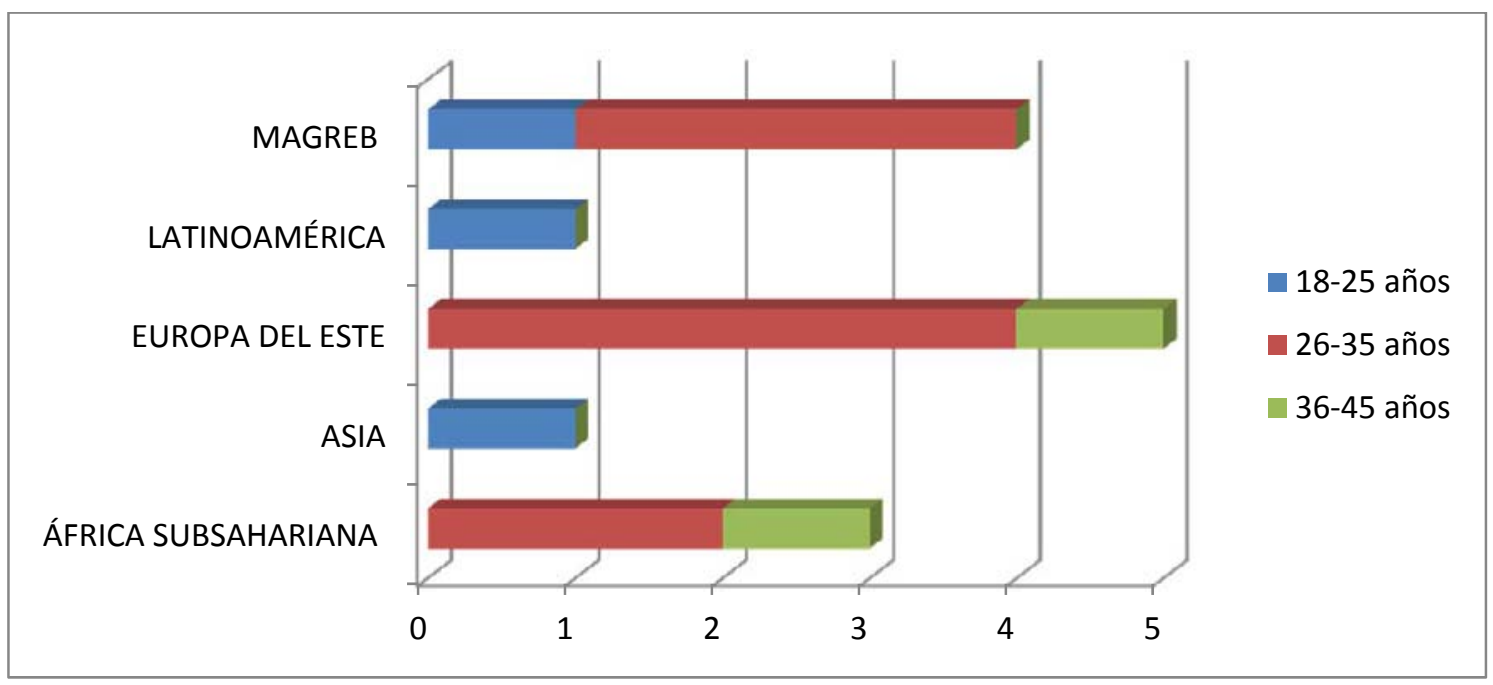

Gráfico 6.35. Colectivo inmigrante y edad de las usuarias observadas en las consultas a puérperas 
En cuanto al tiempo de permanencia en España, la que menos tiempo llevaba residiendo en este país era la usuaria procedente de Ucrania, con 2 años de permanencia. Por el contrario, la mitad de las usuarias inmigrantes observadas, tal y como se puede observar en el gráfico que presentamos a continuación, llevaba residiendo en España un periodo de tiempo considerable, entre 3 y 5 años. Como hemos comentado en la presentación de los datos demográficos de las usuarias inmigrantes entrevistadas, su relativamente larga permanencia en España conllevará, probablemente, un mayor dominio de la lengua y un mayor conocimiento del funcionamiento de los servicios sanitarios. ${ }^{265}$

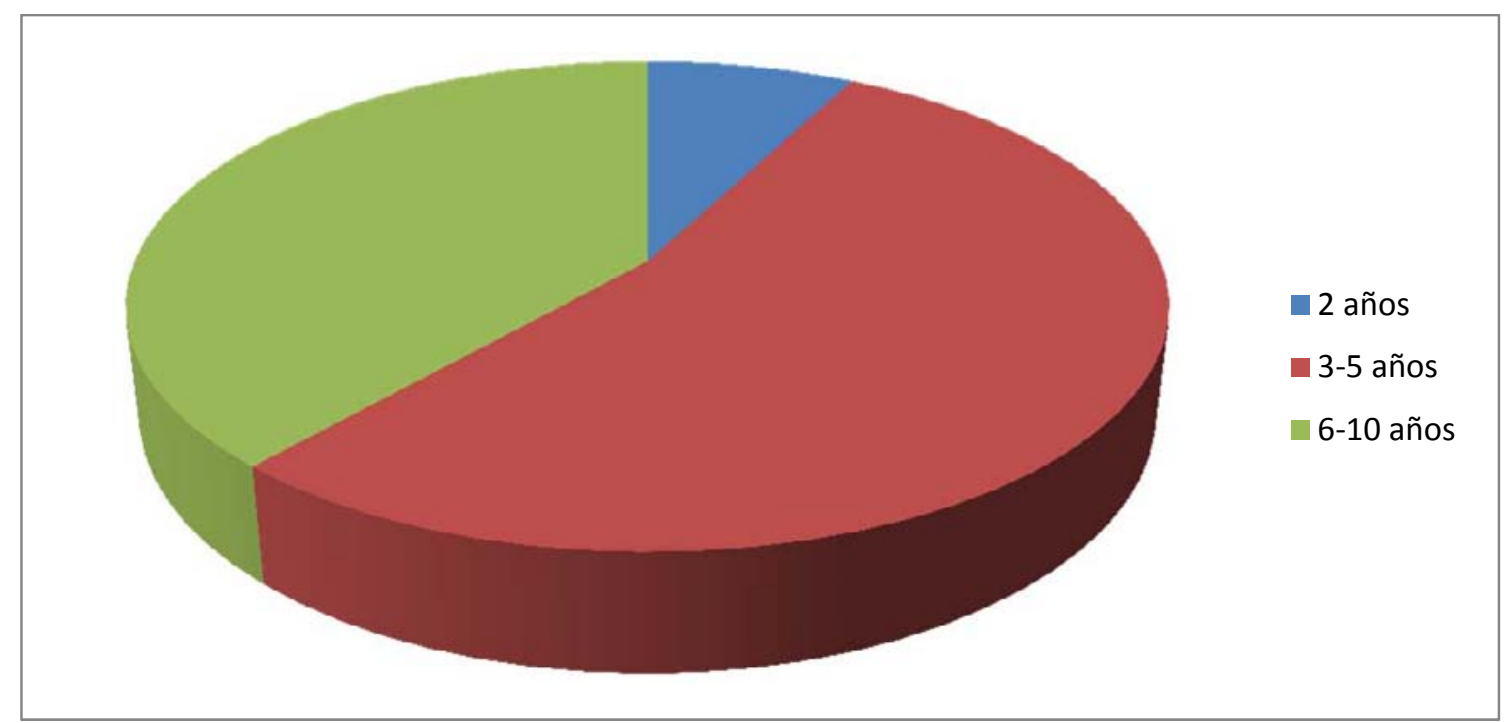

Gráfico 6.36. Usuarias inmigrantes observadas en las consultas a puérperas y tiempo de permanencia en España

\footnotetext{
${ }^{265}$ No disponemos de los datos relativos al número de hijos previos nacidos en España de todas las usuarias inmigrantes observadas durante las consultas a puérperas, pero sabemos por aquellos de los que sí disponemos que algunas de ellas ya habían dado a luz previamente en este país (algunas incluso en este mismo hospital), lo cual probablemente también habrá incrementado su conocimiento sobre el funcionamiento de los servicios de atención al embarazo, el parto y el puerperio.
} 
Y por lo que respecta a sus conocimientos de español, la mitad de las usuarias inmigrantes poseía conocimientos bajos o nulos de esta lengua, una poseía conocimientos medios, y cinco presentaban un dominio alto (todo ello sin contar con la usuaria de Latinoamérica, cuya lengua materna era el español). Podemos observar en el siguiente gráfico que el colectivo de usuarias que presentaban mayores conocimientos de español eran las procedentes de Europa del este. Asimismo, si cruzamos estos datos con los del tiempo de permanencia en España, podemos concluir que, a diferencia de lo que preveíamos, no siempre existe una relación entre un mayor periodo de residencia en el país y un mayor dominio de la lengua. De hecho, las tres usuarias con un desconocimiento casi total del español, procedentes concretamente de China, Marruecos y Senegal, llevaban residiendo en España entre 3 y 5 años.

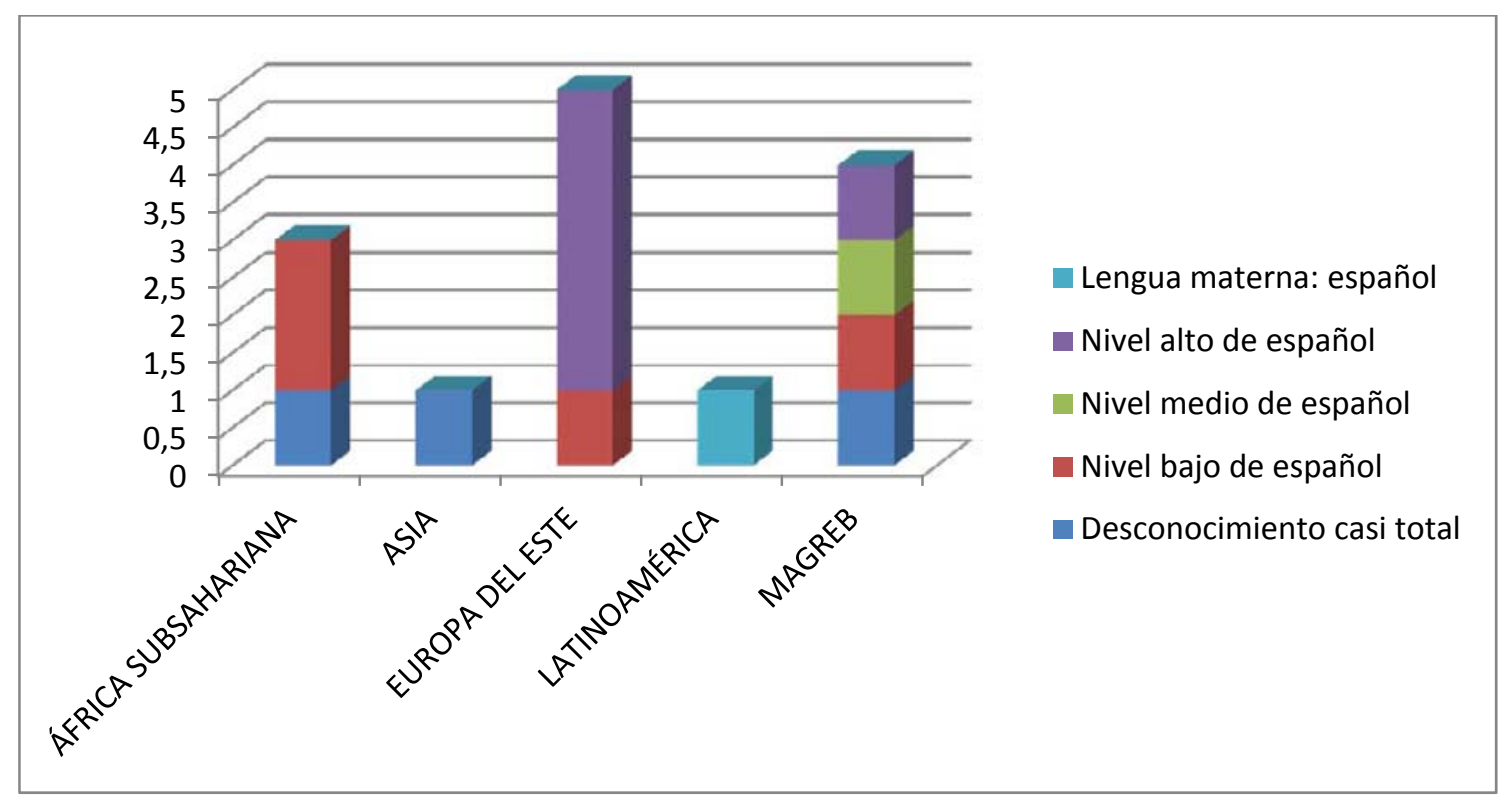

Gráfico 6.37. Colectivo inmigrante y dominio del español de las usuarias inmigrantes observadas en las consultas a puérperas

Por lo que se refiere a los acompañantes de las usuarias presentes durante las consultas, cabe señalar que 8 de las usuarias inmigrantes observadas en las plantas de puerperio se encontraban solas. Aportamos a continuación los pocos datos de los que disponemos en relación con las 6 usuarias que sí que se encontraban acompañadas, indicando el país de origen de cada una de estas usuarias. Los países de origen de los acompañantes coinciden con los de las usuarias, excepto en los casos en los que se indica entre paréntesis que los acompañantes eran autóctonos.

Gambia: amiga

Marruecos: marido

Marruecos: marido

Polonia: marido y suegra (ambos españoles)

Rumanía: marido (español)

Ucrania: marido 


\section{b) Consultas a gestantes}

En relación con la única observación realizada en las consultas a gestantes, son pocos los datos demográficos de los sujetos observados que podemos aportar.

El único profesional sanitario que participó en esta observación fue una obstetra, mujer, de 35 años.

En cuanto a las usuarias inmigrantes presentes, estas procedían de los siguientes países:

España (padres originarios de Cabo Verde) ${ }^{266}$

China

Malí

Bulgaria

Los conocimientos de español de estas usuarias, excepto en el caso de la que había nacido en España, eran bajos (en el caso de la usuaria procedente de Malí) o prácticamente nulos (en los casos de la usuaria procedente de China y la procedente de Bulgaria). De hecho, nos comunicamos con estas dos últimas usuarias gracias a las labores de interpretación realizadas por sus acompañantes (su pareja y su madre, respectivamente). Por el contrario, la usuaria nacida en España y la procedente de Malí se encontraban solas.

\footnotetext{
${ }^{266}$ Basándonos en el aspecto físico de esta usuaria, nos dirigimos a ella mientras esperaba en la sala de espera para presentarle nuestra investigación y solicitarle si podíamos estar presentes como observadores durante su consulta. Tal y como nos comentó, aunque sus padres eran originarios de Cabo Verde, ella había nacido en España, por lo que no cumplía con los requisitos para incluirla dentro del grupo de usuarias inmigrantes sujetos de nuestro estudio.
} 


\section{c) Diversas zonas del hospital}

El grupo de profesionales sanitarios a los cuales hacemos referencia en nuestro diario de campo son en total 13, divididos por perfiles de la siguiente manera: auxiliares de enfermería (2), anestesista (1), enfermeros (5), obstetras (3) y profesional socio-sanitario (1). La mayoría de ellos eran mujeres, tal y como es posible observar en el siguiente gráfico:

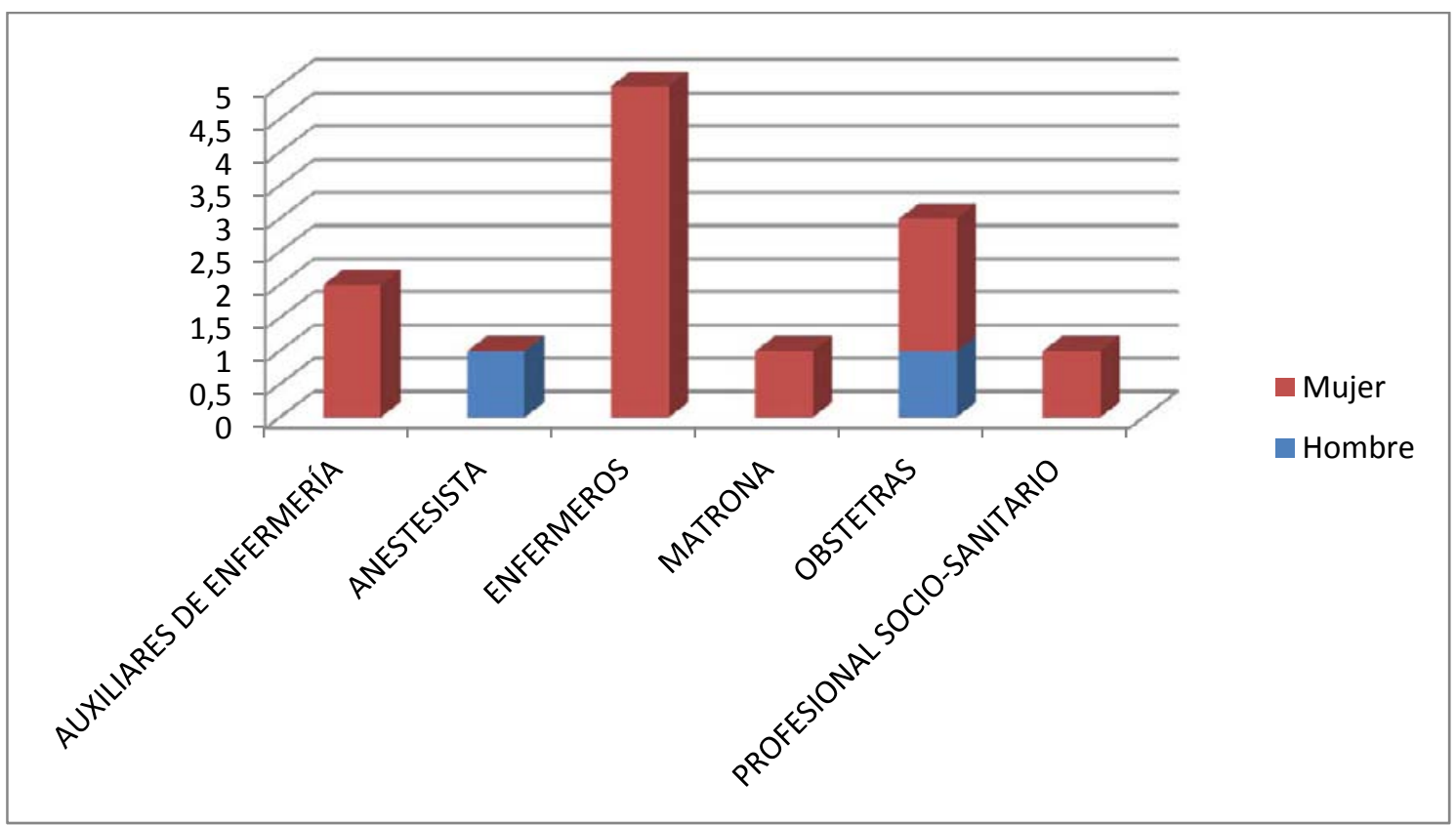

Gráfico 6.38. Perfil profesional y sexo de los profesionales observados en diversas zonas del hospital

Por lo que respecta al resto de datos demográficos de estos profesionales, solo contamos con información relativa a la edad y los conocimientos de lenguas extranjeras en el caso de 8 de los 13 sujetos observados. La edad media de estos profesionales (47 años aproximadamente) era algo más alta en relación con la edad media de los profesionales participantes en otras observaciones o en las entrevistas, y esta estaba comprendida entre los 31 y los 61 años.

Su lengua materna era el español en todos los casos. En cuanto a sus conocimientos de lenguas extranjeras, algunos de ellos afirmaron tener conocimientos de inglés (4), algunos de francés (4), un profesional tenía conocimientos de alemán e italiano, y otro de árabe. Cabe resaltar que, como en el caso de los entrevistados, los profesionales sanitarios mencionados en nuestro diario de campo reconocieron tener en muchos casos un nivel bajo de conocimientos de estas lenguas extranjeras y, además, estas lenguas no se correspondían en la mayoría de los casos con las lenguas maternas de las principales comunidades de usuarias inmigrantes.

En relación con las usuarias inmigrantes de las cuales aportamos datos en nuestro diario de campo, este grupo está constituido por las 25 usuarias entrevistadas. Por este motivo, los datos demográficos de las mismas pueden consultarse en el subapartado de este capítulo relativo a los datos demográficos de las usuarias que participaron en las entrevistas. 
Por último, en nuestro diario de campo hacemos referencia a otros sujetos observados (principalmente acompañantes de las usuarias). Indicamos a continuación el país de origen de las usuarias y los acompañantes que estaban presentes durante la observación.

Brasil: dos amigas

Camerún: marido

China: madre

China: tía

Ecuador: dos hijos adolescentes

Mauritania: marido

Nigeria: mediador de Médicos del Mundo

Rumanía: hermano

Rumanía: marido

\subsubsection{Datos conceptuales o teóricos}

Tras la presentación de los datos contextuales y los datos demográficos de los sujetos observados, pasamos al análisis de las categorías conceptuales o teóricas. A pesar de que los subnodos o subtemas de la observación no participante no coinciden plenamente con los de las entrevistas, con el fin de facilitar el análisis contrastivo de los datos recolectados con las diferentes técnicas, hemos seguido la misma clasificación general empleada en el análisis de las entrevistas:

1. Introducción

2. Asistencia sanitaria general

3. Embarazo, parto y puerperio

4. Barreras lingüísticas y soluciones

5. Interacción

6. Actitudes sociales

Asimismo, dividimos el análisis de los datos recolectados mediante la observación en dos grupos: el primero incluye los datos obtenidos en la observación en las consultas a puérperas y en las consultas a gestantes, y el segundo reúne los datos registrados en el diario de campo.

\subsubsection{Datos registrados en fichas}

Por lo que respecta a los datos relativos a la observación llevada a cabo en las consultas, cabe realizar una serie de consideraciones previas. Los datos obtenidos mediante esta técnica se han anotado en las fichas que figuran en los anexos numeradas del 1 al 4 (consultas a puérperas) y 5 (consultas a gestantes). En cada una de las fichas recogemos las observaciones realizadas en un mismo día, y las usuarias observadas se identifican con el número de la ficha seguido de otro número que indica el orden en el cual tuvo lugar la consulta. ${ }^{267}$

\footnotetext{
${ }^{267}$ En la tabla de los datos demográficos de los sujetos presentes durante la observación no participante que figura en los anexos, es posible hallar más información en relación con la forma escogida para identificar a dichos sujetos.
} 


\subsection{Introducción}

En este subapartado, a falta de datos sobre la percepción de la asistencia sanitaria a usuarias inmigrantes por parte de los profesionales sanitarios y sobre la valoración de estas usuarias de la asistencia recibida (ya que mediante la observación no resulta posible conocer los pensamientos de los sujetos observados), comentamos de qué manera accedimos al contexto objeto de estudio para actuar como observadores durante las consultas.

En el caso de las consultas a puérperas, la observación tiene lugar durante las visitas médicas que suelen realizarse a primera hora de la mañana en las plantas de puerperio. Unos días antes de iniciar la observación, nos reunimos con los dos obstetras encargados de realizar estas visitas para solicitar su consentimiento para participar como observadores durante aquellas en las que se atienda a usuarias no autóctonas. Los obstetras no plantean ningún inconveniente, siempre y cuando las usuarias estén de acuerdo con que estemos presentes. Acudimos a la planta antes del comienzo de la ronda de visitas médicas y solicitamos a la responsable que nos indique el número de las habitaciones donde se encuentran ingresadas usuarias de origen extranjero y la nacionalidad de las mismas. Desde el primer momento, nos llama la atención el hecho de que, por lo general, las usuarias inmigrantes se encuentren ingresadas en el mismo pasillo ${ }^{268}$ en habitaciones contiguas, cuestión que comentaremos más detalladamente en el subapartado del análisis de la observación relativo a las actitudes sociales.

Por lo que se refiere a las consultas a gestantes, nuestro propósito con la observación era completar el estudio y observar la interacción de los profesionales sanitarios no solo con puérperas, sino también con usuarias embarazadas. En primer lugar, nos dirigimos a los obstetras que se ocupan de las consultas durante el embarazo en el hospital contexto de estudio. Cabe señalar que estas consultas atienden a usuarias con embarazos que plantean algún tipo de riesgo, ya que, en caso contrario, se realizarían en el centro de salud que le corresponda a cada usuaria por lugar de residencia. Solo una integrante del grupo de obstetras accede a participar en el estudio, pero nos indica que deberemos permanecer en la sala de espera y preguntar a las usuarias antes de que entren a la consulta si aprueban que estemos presentes durante la misma. Con estas condiciones, debemos prácticamente "adivinar" por el aspecto físico de las usuarias quiénes son de origen extranjero y, a diferencia de lo que ha ocurrido con la observación y con las entrevistas realizadas en las plantas de puerperio, notamos desde el principio bastante recelo y desconfianza por parte de las usuarias. De hecho, por falta de consentimiento por parte de las usuarias o sus acompañantes, solo conseguimos estar presentes como observadores en una consulta a gestantes (en concreto, en el caso de la usuaria 5.3.).

Al respecto de la observación en este contexto, cabe añadir que hablamos con la obstetra a última hora de la mañana, cuando ha finalizado su ronda de consultas, y nos anima a continuar realizando la observación en las plantas de puérperas, y no en la sala de espera de las consultas prenatales. Aunque ella se ha mostrado colaboradora, insiste en que no es posible

\footnotetext{
${ }^{268}$ Cada planta de puerperio se divide en un pasillo con habitaciones pares y otro con habitaciones impares, separados por una zona central en la que se encuentra el despacho de la supervisora, el almacén con material sanitario y la sala de descanso para profesionales sanitarios.
} 
que estemos presentes en las consultas a gestantes si previamente estas no han dado su consentimiento. Sostiene, además, que deberíamos tener en cuenta que estas consultas van dirigidas a mujeres cuyos embarazos presentan algún tipo de riesgo, por lo que es normal que se muestren más recelosas de lo habitual. Y puntualiza: "Todas las mujeres se tranquilizan una vez han nacido sus hijos y todo ha ido bien". Por los motivos expuestos, decidimos continuar el trabajo de campo en otras zonas del hospital y tratar de obtener los datos sobre la interacción profesional-usuaria o sobre cuestiones relativas al embarazo (como, por ejemplo, el control gestacional) mediante las otras técnicas empleadas en nuestro estudio.

\subsection{Asistencia sanitaria general}

Presentamos a continuación los datos relativos a la asistencia sanitaria general recolectados mediante la observación llevada a cabo en las consultas a puérperas y gestantes. Por los lugares concretos en los que se llevó a cabo esta observación, no incluimos datos relativos a la asistencia sanitaria en cualquier circunstancia (como habíamos hecho, por el contrario, en el análisis de los datos de las entrevistas), sino que nos referimos a aquella ofrecida durante el embarazo, el parto y el puerperio.

Uno de los datos que podemos aportar en relación con este aspecto se refiere a los acompañantes de las usuarias durante las consultas. De las 18 usuarias mencionadas en las fichas, menos de la mitad (en concreto, 8) se encuentran acompañadas, 6 de ellas (usuarias 1.3., 2.1., 3.3., 3.7., 4.2. y 5.2.) por sus maridos o parejas (en uno de los casos junto con la suegra de la usuaria), una usuaria (5.4.) por su madre y, por último, otra usuaria (3.2.) por una amiga. Este dato, junto con la presencia de numerosas visitas por parte de familiares y amigos de las usuarias autóctonas observada durante el trabajo de campo, confirman la opinión expresada por los profesionales sanitarios en las entrevistas, según la cual las usuarias inmigrantes suelen recibir menos visitas que las autóctonas, quizás debido a que cuentan con redes sociales menos numerosas.

Por el contrario, hay un dato aportado por los profesionales sanitarios entrevistados que no parece corroborarse en la observación durante las consultas a puérperas. En concreto, algunos profesionales comentaron en las entrevistas que los maridos de las usuarias magrebíes no solían acompañar a sus mujeres en el proceso de parto o puerperio. Sin embargo, las dos usuarias procedentes de Marruecos mencionadas en las fichas estaban acompañadas por sus maridos. Somos conscientes de que se trata de un número demasiado exiguo para llegar a conclusiones, pero por el carácter contrastante de este hecho con la opinión manifestada por algunos profesionales en las entrevistas, hemos pensado que merecía la pena mencionarlo.

Por lo que respecta a los acompañantes de las usuarias inmigrantes observadas, podemos también añadir ciertos datos relativos a la interacción entre estas usuarias y sus maridos. En el caso de las consultas a puérperas, el obstetra suele solicitar a los acompañantes que abandonen la habitación antes de iniciar la visita médica. Solo en dos ocasiones permanece el marido durante la visita para facilitar la comunicación entre la usuaria y el obstetra, en el primer caso (usuaria 2.1.) porque esta presenta escasos conocimientos de español y, en el segundo (usuaria 3.7.), porque la usuaria se encuentra muy mareada y, por tanto, le resulta difícil responder a las preguntas planteadas por el obstetra. En dichos casos, los maridos se 
muestran bastante colaboradores y tratan de facilitar, en la medida de sus posibilidades, la comunicación entre el obstetra y la usuaria.

Además, cabe señalar en este punto que son precisamente dos de los maridos de las usuarias los que deciden, cuando volvemos a entrar en las habitaciones tras la ronda de visitas para tomar los datos demográficos de las usuarias observadas, que estas no participen en las entrevistas que les proponemos hacer. En concreto, se trata de una usuaria procedente de Ucrania (2.1.) y otra procedente de Marruecos (4.2.). En el primer caso, en principio la usuaria parece acceder a participar en la entrevista, pero, cuando vamos a iniciarla, mira a su marido, que está sentado a su lado, y este nos pregunta qué tipo de preguntas le vamos a hacer a su mujer. Le explicamos los contenidos y objetivos de la entrevista y él responde rotundamente "No, no va a hacer ninguna entrevista". La usuaria baja la mirada, sonríe como avergonzada y nos dice en un tono muy suave "Lo siento". En el segundo caso, tras plantearle a la usuaria la posibilidad de participar en una entrevista personal, esta dirige la mirada hacia su marido, y él afirma que no tienen nada que contar y que no su mujer no va a responder a más preguntas.

En cuanto a las consultas a gestantes, interactuamos con los acompañantes de las usuarias (5.2. y 5.4.) en la sala de espera y, puesto que estas no hablan español, son ellos los que nos indican que no están de acuerdo con que entremos como observadores a la consulta.

Otro aspecto que cabe mencionar en este subapartado de asistencia sanitaria general se refiere a los hábitos alimentarios. Concretamente, al entrar en la habitación de la usuaria de origen chino (3.4.) notamos que hay un fuerte olor extraño, y observamos que en el alféizar de la ventana hay unos recipientes de plástico que parecen contener comida, que probablemente le habrán traído sus familiares. Este hecho parece corroborar, por una parte, la costumbre en la medicina tradicional china de ingerir determinados alimentos tras el parto y, por otra, la permisividad en el hospital contexto de estudio por lo que respecta a la introducción de alimentos por parte de los familiares de las usuarias. Este último aspecto demuestra que, en cierto sentido, en este hospital se trata de respetar los hábitos alimentarios de las usuarias, al igual que se hace incluyendo diferentes tipos de menús (como es el caso de los menús específicos para usuarias de religión musulmana).

El último dato que nos gustaría comentar en relación con la asistencia sanitaria en general se refiere a los aspectos burocráticos. Una de las usuarias procedentes de Rumanía (3.1./Europa del este 5) accede a realizar la entrevista personal tras haber participado en la observación. Durante la entrevista, esta nos habla de la dificultad que le supone rellenar los documentos referentes al registro del recién nacido. Al día siguiente nos cuentan las enfermeras que esta usuaria se ha marchado sin entregar dichos documentos. Consideramos que es probable que este incumplimiento de las normas del hospital se deba precisamente a la dificultad de la que nos había hablado la usuaria. También en las entrevistas, tal y como se puede observar en el análisis de los datos recolectados mediante esa técnica, tanto algunos profesionales como algunas usuarias habían comentado que las dificultades idiomáticas y el desconocimiento del funcionamiento del sistema sanitario español por parte de algunas usuarias inmigrantes podían contribuir a que estas incumplieran las normas establecidas en el hospital. 


\subsection{Embarazo, parto y puerperio}

Existen diferentes factores que nos han impedido recolectar información relacionada con las primeras fases de la salud reproductiva, en concreto, el embarazo y el parto, mediante la observación en las consultas. En primer lugar, cabe señalar la falta de autorización o las dificultades para acceder a determinadas zonas del hospital, como, por ejemplo, los paritorios o las consultas a gestantes previamente mencionadas. Asimismo, por la imposibilidad de obtener mediante la observación datos relativos a hechos y sucesos pasados, no podemos aportar información referente al embarazo y el parto que haya sido observada durante las consultas a puérperas.

Por otro lado, tampoco nos ha resultado posible recabar información sobre la relación entre la madre y el hijo durante los primeros días del puerperio en la observación llevada a cabo en las consultas a puérperas, pues en ningún caso se hallan presentes los recién nacidos, a quienes, a primera hora de la mañana, cuando tienen lugar las consultas, se suelen realizar los baños y controles de rigor. Por ello, tampoco podemos saber mediante la observación en este contexto si estas recurren a la lactancia materna. Sin embargo, en las notas registradas en nuestro diario de campo sí que incluimos algunos datos al respecto, como se verá más adelante.

Una cuestión que sí podemos comentar brevemente en este subapartado se refiere a la tasa de fecundidad de algunas de las usuarias presentes durante la observación (en concreto, aquellas cuyos datos se incluyen en las fichas 2 y 3). Por la información de la que disponemos, relativa a 5 usuarias, nos consta que algunas usuarias inmigrantes cuentan con experiencia previa en los servicios de obstetricia españoles; de hecho, en el caso de dos de las usuarias observadas (3.5./Europa del este 6 y 3.7.), este es su segundo hijo y ambos han nacido en España, y otra usuaria (3.6.) ha tenido tres hijos, de los cuales uno nació en su país de origen y los dos siguientes en España. Sin embargo, en el caso de dos usuarias observadas, es la primera vez que dan a luz en un hospital español, una (2.1.) porque es primípara, y la otra (2.2.) porque tuvo a su primer hijo en su país de origen. En principio, podemos afirmar que aquellas usuarias con experiencia previa en los servicios de obstetricia españoles tendrán probablemente menos dificultades para acceder y usar estos servicios, aunque no contamos con datos que corroboren esta afirmación.

En relación con la tasa de fecundidad de las usuarias inmigrantes, cabe señalar además un comentario recogido en una de las fichas de la observación. En todas las ocasiones en las que estuvimos presentes como observadores en el hospital, había usuarias inmigrantes ingresadas, pero uno de los días el número de estas usuarias nos parece incluso mayor que de costumbre, y comentamos esta percepción a las enfermeras con las que nos encontramos en la sala de descanso. ${ }^{269}$ Una de ellas responde a nuestra observación diciendo "Ya estamos acostumbradas. Normalmente más de la mitad de las habitaciones están ocupadas por

\footnotetext{
${ }^{269}$ Como se ha comentado en el apartado dedicado a los datos contextuales de la observación no participante, una de las zonas en las que recolectamos datos mediante esta técnica fue precisamente en las salas de descanso de las plantas de puerperio. Desde los primeros días de nuestra presencia en el hospital, las enfermeras de dichas plantas nos invitaron a tomar un café con ellas en estas salas a primera hora de la mañana, antes de que iniciara la ronda de consultas. Nuestra presencia en este contexto, entre otros factores por el carácter "relajado" de la situación, nos permitió obtener datos de primera mano (verbales y actitudinales) con respecto al funcionamiento del hospital contexto de estudio y sobre la experiencia y la opinión de los profesionales sanitarios en relación con la asistencia a usuarias inmigrantes.
} 
usuarias extranjeras". Aunque, como se ha comentado en el apartado de este capítulo dedicado al análisis documental, no disponemos de datos sobre el número de partos atendidos en el hospital contexto de estudio en los que se indique el país de origen de las usuarias que han dado a luz, si consideramos los datos obtenidos en nuestro trabajo de campo y les sumamos el hecho de que el porcentaje de mujeres autóctonas en edad fértil en nuestro contexto de estudio es mayor que el de mujeres inmigrantes, podemos afirmar, por tanto, que la tasa de fecundidad de estas últimas debe de ser más elevada con respecto a la de las autóctonas. ${ }^{270}$

\subsection{Barreras lingüísticas y soluciones}

De las 18 usuarias observadas en las consultas a puérperas y gestantes, 10 presentan escasos conocimientos de español o incluso un desconocimiento casi total de este idioma. Este hecho parece contrastar con la opinión de algunos de los profesionales sanitarios entrevistados, los cuales sostenían que los casos de usuarias con conocimientos escasos o nulos de español eran prácticamente inexistentes.

Asimismo, nos llama la atención, tal y como hemos comentado previamente en el subapartado de datos demográficos de las usuarias observadas, el hecho de que algunas de estas usuarias con conocimientos escasos o nulos de español que han participado en la observación lleven residiendo en este país entre 3 y 5 , o incluso entre 6 y 10 años. No disponemos de datos que corroboren esta opinión, pero cabe recordar que algunos de los profesionales sanitarios entrevistados consideraban que, si a pesar de residir en España tantos años, las usuarias inmigrantes no hablaban español, esto podía deberse a que estas se relacionasen casi exclusivamente con miembros de su colectivo de origen.

Por otra parte, cabe señalar dos cuestiones en relación con los conocimientos de español de las usuarias inmigrantes que hemos detectado mediante la técnica de la observación.

La primera de ellas se refiere a la presuposición de que las usuarias de origen latinoamericano, al compartir la lengua materna con los profesionales sanitarios, no deberían tener problemas de comunicación. Al respecto, uno de los obstetras que están presentes durante la observación en las consultas a puérperas nos comenta que las usuarias de Latinoamérica (como, por ejemplo, la usuaria 1.2.), a pesar de que su lengua materna sea el español, en ocasiones no comprenden las explicaciones ofrecidas por los profesionales sanitarios, aunque no suelen admitir su falta de entendimiento. Por ello, afirma que frecuentemente debe explicarles las cosas varias veces a estas usuarias, parafraseándose a sí mismo para mejorar la comprensión. Tratamos de verificar esta cuestión, que se había planteado tanto durante la observación como durante las entrevistas, en el grupo de discusión con usuarias latinoamericanas.

En segundo lugar, en una de las observaciones parece corroborarse el hecho comentado por algunos profesionales sanitarios en las entrevistas de que algunas usuarias de origen magrebí sostienen que no conocen el español mientas están presentes sus maridos $y$, $\sin$ embargo,

\footnotetext{
270 Este dato queda también corroborado con los datos más recientes disponibles en la página web del Instituto Nacional de Estadística, según los cuales, en el año 2011, la tasa de natalidad de las extranjeras residentes en Aragón era del 17,7 por cada 1000 habitantes, mientras que la de las autóctonas era del 8,21.
} 
cuando estos están ausentes, demuestran cierto dominio de la lengua. Es el caso de una de las usuarias procedentes de Marruecos (4.2.), quien afirma no hablar prácticamente nada este idioma, pero luego, durante la consulta, sí que parece ser capaz de comunicarse con el obstetra.

Antes de pasar a analizar las soluciones adoptadas para eliminar las barreras lingüísticas entre profesionales y usuarias durante las consultas observadas, cabe mencionar que, tal y como nos habían señalado los profesionales entrevistados, en general estos huyen del empleo de terminología médica y suelen usar un lenguaje lo más sencillo posible. Uno de los obstetras observados, como comentaremos más detalladamente en el subapartado dedicado a la interacción, usa incluso un registro informal, y recurre frecuentemente al empleo de diminutivos y expresiones coloquiales o infantiles.

Por lo que respecta a las soluciones adoptadas durante las consultas a puérperas para comunicarse con las usuarias alófonas son, en nuestra opinión, inadecuadas, aunque también queremos destacar que uno de los obstetras encargados de las consultas parece preocuparse más de establecer una comunicación efectiva que el otro. De hecho, en los casos en los que el dominio del español por parte de algunas usuarias es bajo o muy bajo, este obstetra emplea términos muy sencillos y frases muy breves, se parafrasea a sí mismo cuando percibe que no le están entendiendo, o incluso se ofrece a hablar con las usuarias en otros idiomas (inglés, francés o alemán), pero estas suelen rechazar este ofrecimiento; en concreto, la paciente procedente de Gambia (3.2.) dice preferir hablar español, y la paciente procedente de Argelia (3.6.) afirma que, al hablar, confunde o alterna el español y el francés.

En ocasiones observamos que las usuarias con dificultades para expresarse en español emplean los gestos (por ejemplo, asintiendo con un movimiento vertical de la cabeza) para transmitir sus mensajes. En otro momento de la observación vemos cómo a veces estas usuarias alófonas responden señalando partes del cuerpo. Es el caso de la usuaria procedente de Senegal (2.2.), quien, al preguntarle el médico en qué lugar del cuerpo siente dolor, contesta señalando con la mano la parte baja de la espalda, sin pronunciar ni una sola palabra y manteniendo la mirada baja. Asimismo, a veces son los profesionales quienes recurren a movimientos corporales para comunicarse, como en la consulta a la usuaria procedente de Ghana (4.1./África Subsahariana 5), en la cual, al entrar en la habitación, es la enfermera quien se dirige a la usuaria y le solicita que se tumbe. Esta parece no entender muy bien sus palabras $y$, acto seguido, ante su falta de reacción, la enfermera parece impacientarse, realiza un movimiento simulando el acto de tumbarse y, finalmente, la ayuda ella misma a hacerlo.

Otra de las soluciones adoptadas es el recurso a los acompañantes para que hagan de intérpretes. En concreto, en una de las observaciones en las consultas a puérperas, se recurre al marido de la usuaria (2.1.) para que realice labores de interpretación y facilite de este modo la comunicación entre esta y el obstetra. La función de intérprete por parte del marido de esta usuaria no resulta efectiva, ya que él tampoco parece poseer conocimientos muy amplios de español, e incluso en ocasiones contesta en lugar de la usuaria. Sin embargo, no se recurre a la acompañante de la usuaria procedente de Gambia (3.2.) para que realice labores de interpretación, cuando en este caso la acompañante, tal como descubrimos al entrar en la habitación tras la ronda de visitas para tomar los datos demográficos de esta usuaria, sí que 
hubiera estado capacitada, al menos por sus amplios conocimientos de español, para hacer de intérprete entre la usuaria y el obstetra.

Por lo que se refiere a las usuarias observadas en la sala de espera de las consultas a gestantes, las dos que presentan un desconocimiento casi total del español (5.2. y 5.4.) se encuentran acompañadas por su pareja y su madre, quienes sí que parecen conocer este idioma. Como no nos permiten entrar con ellos a las consultas, no podemos saber cómo se solucionan en estos casos las barreras lingüísticas, aunque suponemos que se recurre a los acompañantes para que estos realicen labores de intérpretes.

Por tanto, verificamos mediante la observación un dato que ya había aparecido previamente en las entrevistas, consistente en el hecho de que en el hospital contexto de estudio se recurre con frecuencia a familiares y amigos de las usuarias alófonas para interpretar las palabras de los profesionales sanitarios y las usuarias, y para facilitar de este modo la comunicación entre ambos. Sin embargo, no se tienen en cuenta los conocimientos de español por parte de los intérpretes ad hoc, ni la falta de formación de estos para actuar como intérpretes, lo cual puede conllevar que no se respeten los principios de fidelidad o confidencialidad, o puede derivar en que el intérprete no traduzca las palabras de la usuaria, sino que responda por esta.

Además, en ninguna de las consultas a usuarias alófonas en las que estuvimos presentes como observadores se recurre al servicio de interpretación telefónica que se encuentra disponible en el hospital contexto de estudio, a pesar de que en el ámbito de las consultas, contando con antelación con los datos de las usuarias y disponiendo de un aparato telefónico tanto en el despacho de consultas a gestantes como en las habitaciones de las puérperas, el empleo de este servicio no habría sido complicado. Se verifica, por consiguiente, mediante la observación en las consultas, que el servicio de interpretación telefónica en el hospital contexto de estudio está infrautilizado.

\subsection{Interacción}

En relación con las interacciones observadas, cabe comentar, en primer lugar, que, en todo lo referido al análisis de los intercambios comunicativos, hay una parte subjetiva a la que no se puede acceder mediante la simple observación, ya que, por una parte, sería necesario conocer los pensamientos de los sujetos observados para saber, por ejemplo, si la cantidad de información o la manera en que esta se les presenta les parecen adecuadas. Además, por otra parte, las interacciones presentan un carácter efímero y orquestal, y en ellas se presentan múltiples datos simultáneamente, por lo que muchos de ellos pueden pasar desapercibidos por parte de un observador.

Pasando ya al análisis, tal y como hemos hecho en el caso de los datos recolectados mediante las entrevistas, dividimos el subapartado de interacción en tres bloques.

El primero de ellos se refiere a cuestiones generales de la interacción entre los profesionales sanitarios y las usuarias inmigrantes. En este caso no son los propios sujetos estudiados de uno u otro grupo (profesionales y usuarias) los que opinan sobre la actitud de sus interlocutores, como sucedía en el caso de las entrevistas, sino que somos nosotros mismos los 
que extraemos una serie de conclusiones sobre la actitud de estos dos grupos observando las interacciones entre los mismos.

Por lo que respecta a las consultas a puérperas, principalmente son los obstetras quienes interactúan con las usuarias. Los enfermeros también presentes, por el contrario, observan y toman notas, pero apenas interactúan con ellas. En las consultas en las que está presente también una residente, es ella quien se ocupa de la exploración a las usuarias. Observamos una actitud en los dos obstetras encargados de estas consultas que difiere bastante en uno y otro caso. Uno de ellos presenta un trato cercano (incluso cariñoso), y se adecúa a las condiciones y características de cada usuaria. El otro, en cambio, mantiene una actitud bastante distante, apenas se dirige directamente a las usuarias, sino que se centra en la exploración u orienta a la residente cuando es esta quien se ocupa de realizarla. Si contrastamos estos datos con los obtenidos mediante las entrevistas, podemos corroborar el hecho de que, a pesar de que en general las usuarias inmigrantes califican la atención recibida por parte de los profesionales sanitarios como amable y cercana, es cierto que, tal y como nos comentaron algunas de las usuarias entrevistadas, esta actitud puede variar de uno a otro profesional.

Por su parte, las usuarias inmigrantes observadas durante las consultas a puérperas generalmente se muestran colaboradoras, si bien es cierto que, en los casos en los que su dominio del español es más escaso, obedecen las instrucciones del obstetra, pero presentan un comportamiento algo más pasivo. Este hecho también se había mencionado en las entrevistas, en las que algunos profesionales sostenían que la pasividad observada en algunas usuarias podía deberse a sus escasos conocimientos de español, así como a los sentimientos de miedo o desconfianza por hallarse en un contexto que les resulta extraño o, cuanto menos, novedoso.

Por lo que se refiere a la única consulta a gestantes en la que podemos estar presentes, tanto la actitud de la profesional como la de la usuaria son bastante colaboradoras y cercanas. La obstetra le comenta los resultados de una ecografía y unos análisis que le habían realizado unos días antes y le da algunas recomendaciones para asegurar que el embarazo llegue a buen término. La usuaria responde a las preguntas realizadas por la obstetra y plantea ella misma algunas dudas. No hay ningún aspecto en la interacción (cantidad de información, temas tratados, gestos, contacto visual, ritmo y tono de voz, malentendidos lingüísticos o culturales, etc.) que llame nuestra atención.

El segundo bloque que analizamos en este subapartado se refiere a los usos verbales observados durante la interacción entre los obstetras y las usuarias inmigrantes. Hacemos solo referencia tanto en este bloque como en el siguiente a los datos recolectados en la observación durante las consultas a puérperas, ya que, como hemos comentado previamente, son escasos los datos obtenidos en la única observación en las consultas a gestantes, y no hay ningún aspecto en relación con los usos verbales y no verbales de los interlocutores en dicha consulta que nos llame la atención durante dicha consulta.

Para el análisis de los usos verbales nos basamos, tal y como hemos hecho en el análisis de las entrevistas, en el principio de cooperación y las máximas de Grice (1975: 45-47). 
En referencia a la máxima de cantidad, y más concretamente en relación con la cantidad de información intercambiada durante las interacciones observadas, cabe destacar que las usuarias inmigrantes por lo general se limitan a responder brevemente a las preguntas planteadas por los obstetras y solo dos de ellas (1.3. y 3.3.), procedentes de Polonia y Marruecos, realizan ellas mismas preguntas, centradas principalmente en su estado físico y en el de sus hijos. El hecho de que estas dos usuarias en concreto posean conocimientos medios o altos de español puede haber favorecido el que estas realizaran preguntas y, por el contrario, los escasos conocimientos de este idioma por parte de numerosas usuarias inmigrantes observadas pueden haber impedido que estas ofrezcan mayor información o planteen sus dudas e inquietudes a los profesionales sanitarios.

Por lo que respecta a los temas tratados durante las consultas, estos se centran casi exclusivamente en el estado físico de las usuarias (si sienten dolores, si se encuentran mareadas, si han podido orinar o defecar, etc.). Desconocemos si estos temas pueden resultar delicados o tabúes en las culturas de origen de las usuarias observadas, pero en ningún momento observamos incomodidad a la hora de tratarlos, e incluso nos llama la atención el hecho de que una usuaria (1.1.), procedente de Argelia, hable de manera muy directa sobre excrementos.

No hemos podido detectar durante la observación en las consultas a puérperas si, en relación con la máxima de calidad, se ha producido algún incumplimiento de la misma y si, en consecuencia, los profesionales o las usuarias no han sido sinceros a la hora de transmitir información. Solo cabe señalar con respecto a esta cuestión la duda que se nos plantea (ya mencionada previamente) sobre si una de las usuarias (4.2.), procedente de Marruecos, es sincera cuando afirma, estando presente su marido, que no tiene conocimientos de español, ya que, una vez comienza la consulta y este ya no está presente, la usuaria sí que demuestra tener cierto dominio de este idioma. Este hecho coincide con las opiniones manifestadas por algunos profesionales sanitarios durante las entrevistas, los cuales sostenían que en ocasiones las usuarias de origen magrebí, a pesar de afirmar en un principio que no hablan español, más tarde demuestran que sí les resulta posible comunicarse en esta lengua.

En cuanto a la máxima de manera, observamos que tanto las usuarias inmigrantes como los profesionales sanitarios observados se dirigen a sus interlocutores en todo momento de manera respetuosa y educada. No obstante, cabe señalar ciertas diferencias en la forma de hablar de los dos obstetras estudiados. Uno de ellos emplea un lenguaje familiar, en el que predominan los diminutivos, los apelativos cariñosos, los términos coloquiales y las expresiones tranquilizadoras (por ejemplo, en una ocasión, se dirige a la usuaria y trata de calmar el temor que puede sentir antes de ser explorada diciendo "Tienes suerte, porque hoy es jueves, y los jueves no hacemos daño a nadie"). Por el contrario, el otro obstetra usa un lenguaje más neutro y quizás algo más formal, y se dirige a las usuarias de un modo bastante directo, sin circunloquios ni amplias explicaciones.

El tercer bloque de este subapartado de interacción se refiere a los usos no verbales, y se divide a su vez en tres grandes temas: la distribución del tiempo, la distribución del espacio y el paralenguaje. 
La primera cuestión relativa a la distribución temporal de las interacciones observadas se centra en la duración de las consultas. En general, como ya se ha comentado, las consultas suelen tener una duración breve, de entre 5 y 15 minutos, dependiendo del estado físico de la usuaria atendida $y$, por tanto, de la necesidad de realizarle más preguntas o ampliar la exploración. La rapidez a la hora de efectuar las consultas se ve aumentada uno de los días en concreto en los que realizamos observación. Ese día el obstetra acude a la ronda de consultas más tarde de lo que acostumbra a hacer, y nos avisa desde un primer momento de que en esa ocasión todo va a suceder más rápido de lo habitual. Ello va a influir inevitablemente en el ritmo de la conversación mantenida entre el obstetra y las usuarias. De hecho, si bien el ritmo de las conversaciones entre estos interlocutores suele ser bastante lento y presentar bastantes silencios por parte de las usuarias (especialmente en el caso de aquellas con escasos o nulos conocimientos de español), ese día en que las consultas son más breves, se acelera considerablemente el ritmo, e incluso se dan algunos solapamientos e interrupciones por parte del obstetra cuando las usuarias tardan en contestar a sus preguntas o se alargan en sus respuestas más de lo que este desearía.

Con respecto a la distribución global de la conversación y la gestión de los turnos de palabra, por lo general son los obstetras quienes dirigen la interacción comunicativa, formulando preguntas que las usuarias responden, como ya hemos comentado, brevemente. Ambos interlocutores demuestran capacidad de escucha, excepto en la ocasión de la cual acabamos de hablar, en la que el obstetra interrumpe a las usuarias debido a la rapidez con que deben producirse las consultas.

En relación con la distribución espacial y, en concreto, por lo que se refiere al macroespacio, la primera cuestión que podemos señalar y de la cual no nos había resultado posible obtener mucha información mediante la técnica de las entrevistas se centra en la intimidad durante las consultas. Por lo general, si el número de usuarias ingresadas lo permite, se realiza un uso individual de las habitaciones de puérperas. Además, como ya hemos mencionado, se suele solicitar a los acompañantes de estas que abandonen las habitaciones antes de comenzar las visitas médicas. Por tanto, por lo general, podemos afirmar que se suele respetar la intimidad de las usuarias, pues el número de personas presentes durante las consultas se limita al estrictamente necesario (la usuaria, el obstetra y un enfermero). Solo uno de los días en los que realizamos observación se encuentra presente, además de las personas indicadas, una residente. Este hecho podría relacionarse con la opinión de una de las usuarias entrevistadas, según la cual, la intimidad en el hospital contexto de estudio podía verse en cierto sentido comprometida en ocasiones por la presencia de estudiantes en prácticas.

En referencia al modo de vestir de las usuarias, este no ha supuesto en ninguno de los casos observados ningún impedimento para efectuar la consulta. Todas ellas están vestidas con la bata proporcionada por el hospital y, ni siquiera en el caso de las usuarias magrebíes observadas, estas llevaban ninguna otra prenda de ropa adicional (como, por ejemplo, el pañuelo que emplean algunas mujeres de religión musulmana). Ninguna de estas usuarias muestra reticencias a la hora de tener que desnudarse para que los profesionales realicen la exploración, a pesar de que los obstetras presentes sean en ambos casos de sexo masculino. Es posible que las usuarias sientan pudor ante la desnudez exigida, pero ninguna de ellas lo manifiesta abiertamente, quizás porque, como las usuarias entrevistadas nos habían 
manifestado, comprenden la necesidad de despojarse de la ropa para que se lleve a cabo la exploración. Resaltamos el caso de una de las usuarias observadas (2.1.), de origen ucraniano, que nos sorprende precisamente por todo lo contrario, ya que, cuando entramos en la habitación, se encuentra completamente desnuda, y no se tapa ni se muestra incómoda ante nuestra presencia.

Estrechamente relacionado con el tema de la desnudez está el tema de la exploración y el contacto físico durante la misma. Ninguna de las usuarias observadas plantea problemas con respecto a esta cuestión, no obstante los obstetras sean hombres, ni siquiera las usuarias de origen magrebí, las cuales, de acuerdo con algunos profesionales entrevistados, son las que mayores reticencias suelen mostrar cuando quienes las exploran son de sexo masculino.

Por lo respecta al contacto visual entre los interlocutores, por lo general las usuarias observadas suelen evitarlo, tal vez por sus dificultades comunicativas debidas a su desconocimiento del español, por el miedo provocado por encontrase en un contexto extraño, o porque la ausencia de contacto visual es el patrón habitual en las interacciones médicopaciente en su cultura. Por su parte, los obstetras presentan dos comportamientos distintos: uno de ellos mira directamente a los ojos de las usuarias, y el otro dirige su mirada a un cuaderno que lleva en las manos o incluso les da la espalda mientras habla con ellas. No nos resulta posible saber cómo habrán valorado las usuarias atendidas la presencia o ausencia de contacto visual por parte de los obstetras, aunque cabe recordar que, de acuerdo con la opinión de algunas de las usuarias entrevistadas, la falta de contacto visual se asocia en algunas culturas (como la rumana) como una señal de que se está mintiendo o se está ocultando información, y en otras culturas (especialmente en África Subsahariana y en el Magreb) como una señal de respeto hacia el interlocutor.

En cuanto a la cercanía entre los interlocutores, normalmente las usuarias se encuentran tumbadas en la cama durante la consulta, y son los obstetras los que se acercan a ellas para realizar la exploración. Por nuestra parte, no observamos que exista una excesiva cercanía, si bien nuestra percepción estará influida por el hecho de que compartimos patrones culturales con los profesionales objeto de la observación. Aunque somos conscientes de la dificultad de percibir las sensaciones o sentimientos de las usuarias con respecto a la cercanía mantenida por los obstetras, no notamos a primera vista malestar o incomodidad por el hecho de que estos se acerquen demasiado a ellas.

Por último, por lo que se refiere al paralenguaje y, más concretamente, al volumen y el tono de voz, en general las usuarias inmigrantes observadas emplean un tono de voz bastante suave, y no percibimos distinciones al respecto por colectivos. Por su parte, en el caso de los obstetras, observamos también en relación con esta cuestión ciertas diferencias entre ellos. En concreto, el tono empleado por el obstetra cuya forma de hablar es más familiar y cercana es más delicado y denota cierto afecto, lo cual puede haber influido, tal y como se comentaba en el análisis de las entrevistas, en el establecimiento de una relación más armoniosa entre este profesional y las usuarias por él atendidas, y quizás en una mayor tranquilidad por parte de estas usuarias. 


\subsection{Actitudes sociales}

En este último subapartado de análisis de los datos registrados en las fichas tratamos, como en el caso del análisis de las entrevistas, temas que presentan un carácter más delicado. Nos centramos únicamente en los datos recolectados en las consultas a puérperas, ya que no disponemos de datos relevantes relacionados con las actitudes sociales observados durante la única consulta a gestantes en la que se nos permitió estar presentes.

El primer tema se refiere a cuestiones de género, en concreto, a la posible incomodidad sentida por las usuarias inmigrantes al ser tratadas por profesionales de sexo masculino. Como hemos comentado anteriormente en el análisis de los usos verbales (en particular, de los temas tratados durante las consultas) y de los usos no verbales (concretamente, en relación con la desnudez y el contacto físico durante la exploración), ninguna de las usuarias presentes en las consultas a puérperas observadas manifiesta abiertamente incomodidad o rechazo por el hecho de que los obstetras que las atienden sean hombres. Cabe recordar que la mayoría de las usuarias inmigrantes que habían participado en las entrevistas afirmaba que no suponía para ellas ningún problema el hecho de que el personal sanitario fuera de sexo femenino o masculino, que lo importante en su opinión era que se tratase de buenos profesionales. $\mathrm{Ni}$ siquiera las usuarias de origen magrebí observadas en las consultas a puérperas, dos de Marruecos (3.3. y 4.2.) y dos de Argelia (1.1. y 3.6.) parecen sentirse incómodas a la hora de ser tratadas por los obstetras encargados de las consultas $y$, si bien no podemos saber si preferirían que estos fueran mujeres, tampoco solicitan que sea otra persona quien las atienda.

El segundo tema abordado se centra en la interacción entre los profesionales sanitarios y los maridos o familiares de las usuarias. Durante la observación en las consultas a puérperas se produce poca interacción entre estos sujetos, ya que, como hemos explicado previamente, normalmente se solicita a los acompañantes que abandonen la habitación antes de iniciar la visita médica. Solo dos de ellos permanecen con el fin de facilitar la comunicación entre el obstetra y las usuarias (2.1. y 3.7.) y, en ambos casos, como ya hemos señalado, se muestran muy colaboradores. Un dato que nos gustaría resaltar es el hecho de que solo en el caso de una de las usuarias inmigrantes (1.3.), procedente de Polonia, sus acompañantes, concretamente su marido y su suegra, ambos españoles, se dirigen al obstetra cuando, al finalizar la consulta, este sale de la habitación, y le formulan numerosas preguntas en relación con el estado físico de la usuaria y el recién nacido. Este dato parece coincidir con la opinión de algunos de los profesionales entrevistados, los cuales sostenían que la interacción con los maridos y familiares de las usuarias autóctonas (o, como en este caso, cuando se trata de acompañantes autóctonos) solía ser más difícil, probablemente porque estos no debían afrontar barreras lingüísticas y conocían mejor sus derechos como familiares de las usuarias de los servicios sanitarios.

En tercer lugar, por lo que respecta al sentimiento de discriminación por parte de las usuarias inmigrantes, solo podemos señalar un caso, del cual no somos testigos directamente, sino que se basa en un relato que nos ofrece una de las usuarias observadas al entrar a tomar sus datos demográficos tras la ronda de consultas. Concretamente, se trata de una de las usuarias de origen argelino (1.1.), la cual nos comenta que ha recibido un trato negativo por parte de las 
enfermeras de la planta. Afirma que le han gritado y le han dicho bruscamente que ni ella ni su hijo tienen ningún problema de salud, por lo que no entienden que se queje. Opina que se le ha infravalorado y juzgado sin conocerla, y nos cuenta que ella, a diferencia de lo que los profesionales pueden creer, cuenta con un alto nivel de estudios. Por el contrario, sostiene haber recibido un trato excelente por parte de las matronas. Vemos cómo aquí se verifica uno de los datos ya presentados en el análisis de las entrevistas, consistente en el hecho de que, si alguna usuaria inmigrante se ha sentido en algún momento discriminada, no suele asociar la discriminación a todo el personal sanitario indistintamente, sino que es consciente de que se trata de casos puntuales, que dependen de la actitud variable de uno a otro profesional. Antes de marcharnos, la usuaria que nos había hecho partícipes de este episodio de discriminación nos dice que nos ha comentado todo esto para desahogarse y nos agradece que la hayamos escuchado.

Para finalizar, en referencia a las posibles actitudes racistas o xenófobas de los profesionales sanitarios, durante la observación en las consultas no fuimos testigos de comentarios ni comportamientos de este tipo por parte de los obstetras, los enfermeros ni la residente presentes en dichas consultas. Si bien el comportamiento de uno y otro obstetra varía considerablemente en algunos aspectos ya comentados, no podemos calificar la actitud de ninguno de ellos como racista o discriminatoria, sino que creemos que los rasgos que diferencian a uno y a otro se deben probablemente al carácter y al modo habitual de actuar de cada uno de ellos, independientemente de si la usuaria a la que atienden es inmigrante o autóctona.

Una cuestión que hemos corroborado mediante la observación y que cabe resaltar en relación con los posibles comportamientos racistas o xenófobos en el hospital contexto de estudio es el hecho de que se distribuya en los pasillos de las plantas de puerperio a las usuarias según sean autóctonas o inmigrantes. Esta cuestión ya la había sacado a relucir uno de los profesionales sanitarios entrevistados y la hemos podido verificar como observadores. Consideramos que la distribución de las usuarias dependiendo de su origen manifiesta en cierto sentido discriminación en la organización y funcionamiento del hospital, y contribuye a la marginación o guetización de las usuarias de origen inmigrante.

\subsubsection{Datos registrados en el diario de campo}

Pasamos a continuación a analizar los datos recolectados mediante la observación en diversas zonas del hospital y registrados en nuestro diario de campo. Clasificamos estos datos, tal y como hemos comentado previamente, en los mismos bloques en los hemos clasificado los datos recolectados con las entrevistas.

Antes de iniciar el análisis propiamente dicho, nos gustaría recordar que la mayoría de los datos anotados en el diario de campo se centran en aspectos observados durante la realización de las entrevistas o en los lapsos de tiempo intermedios y, por tanto, se corresponden principalmente con cuestiones observadas en las usuarias o en los profesionales entrevistados (de ahí que el modo de identificar a estos sujetos sea el mismo que el empleado en el análisis de las entrevistas), o con comportamientos y comentarios de otros sujetos (acompañantes, otros profesionales sanitarios o personas ajenas al hospital) que aparecen en el contexto en el que nos hallamos mientras realizamos las entrevistas. 
Asimismo, cabe señalar que en este segundo subapartado de análisis de la incuimos textualmente las notas contenidas en el diario de campo, indicando entre corchetes, como hemos hecho en el análisis de los datos recolectados mediante las entrevistas, el sujeto al que nos referimos en cada una de estas notas.

\subsection{Introducción}

En esta sección introductoria, como sucede en el caso de las notas contenidas en las fichas, no disponemos de datos sobre la opinión que tienen los profesionales sanitarios en relación con la asistencia a usuarias inmigrantes ni sobre la valoración de estas últimas de la asistencia recibida. Por este motivo, comentamos fundamentalmente dos aspectos.

El primero de ellos se refiere a la predisposición de los sujetos estudiados a participar en la investigación.

Por lo que respecta a las usuarias inmigrantes, son pocos los casos en los que estas se niegan a participar y, si se produce una negación, esta viene casi siempre determinada por los escasos o nulos conocimientos de español por parte de algunas usuarias o por la oposición manifestada por sus maridos a que estas participen en el estudio, tal y como se ha comentado en el análisis previo de las fichas. De hecho, algunas usuarias acceden a participar y se muestran muy colaboradoras, a pesar de la presencia de barreras lingüísticas o aun cuando su estado físico no es óptimo, como se puede observar en los siguientes fragmentos de nuestro diario de campo:

\footnotetext{
La usuaria se encuentra en la habitación con su hermano, que lleva más años que ella residiendo en España y, a diferencia de ella, habla un español bastaste fluido. Desde el primer momento parecen ambos muy colaboradores y él interviene activamente en la toma de contacto inicial. [Europa del este 3]
}

La usuaria accede a realizar la entrevista, no obstante haga solo unas horas que dio a luz. [Europa del este 4]

La usuaria está en la habitación con su marido. Son ambos exquisitamente educados y colaboradores. [...] En un momento dado, la usuaria se comunica con su marido en árabe y parece que se queja de dolor. Le comentamos que, si se encuentra mal, podemos dejar la entrevista, que no hay ningún problema, pero dice que puede seguir. [Magreb 4]

Otras usuarias, en cambio, pese a que muestran su consentimiento a participar en el estudio, presentan una escasa implicación, y sus respuestas a las preguntas planteadas son más bien breves.

\footnotetext{
Aunque la usuaria afirma estar dispuesta a colaborar, sus respuestas son bastante escuetas, y no suele ofrecer muchos detalles ni opiniones personales. [Europa del este 2]

Desde el principio resulta difícil que la usuaria se implique. Suele responder a las preguntas planteadas con frases breves y concisas, y con un tono firme, que no da pie a realizar ulteriores indagaciones. [Europa del este 6]
}

La predisposición a participar en el estudio por parte de los profesionales sanitarios es por lo general menor con respecto a la manifestada por las usuarias inmigrantes, y nos resulta más difícil encontrar voluntarios que accedan a ser entrevistados. Sin embargo, destaca el caso de tres de los profesionales que, desde el principio, muestran un gran interés por nuestra investigación. 
Desde el primer contacto, este profesional sanitario demuestra un gran interés por participar en el estudio. Antes de iniciar la entrevista, comenta que la asistencia a usuarias inmigrantes es un tema que le tiene muy preocupado, pues la falta de comunicación con las mismas, como se verá en sus respuestas, le provoca un gran estrés y ansiedad. [Anestesista 3]

Desde que iniciamos el estudio de campo, esta profesional estaba de baja, por lo que no se había tenido ningún contacto previo con ella. Es ella misma la que el primer día que nos encontramos en la planta se dirige a nosotros para interesarse por el motivo de nuestra presencia. Desde el primer momento, muestra un gran interés en el estudio y no tiene ningún problema en participar cuando se le ofrece. [Enfermera 5]

Este profesional es uno de los obstetras que se ocupan de pasar visita en las plantas de puerperio (5a y 7ạ), donde están ingresadas durante dos días las usuarias que han tenido un parto sin complicaciones. Los dos obstetras encargados de las consultas a puérperas se han mostrado disponibles para participar en el estudio, tanto por lo que respecta a la observación no participante, como, en el caso de este profesional en concreto, en la realización posterior de la entrevista personal. [Obstetra 1]

El segundo aspecto que analizamos en esta introducción se refiere al establecimiento inicial del rapport en las entrevistas realizadas a usuarias inmigrantes. Tal y como se ha comentado en el capítulo 2, concretamente en el apartado de diseño metodológico de las entrevistadas, para garantizar que los entrevistados se abran al investigador, es necesario crear un clima de confianza inicial que, en nuestro caso, se obtuvo mediante la formulación de preguntas relacionadas con la propia entrevistada que demostraran que teníamos interés en conocer su historia personal. Estas preguntas se referían, como se puede observar en los fragmentos del diario de campo incluidos a continuación, a aspectos como su lugar exacto de procedencia, su lengua materna, el número de hijos previos, o el nombre que habían dado al recién nacido. Consideramos que, aparte de servir para ganarnos la confianza de las entrevistas, estas preguntas aportan datos que enriquecen considerablemente los resultados de la investigación, aunque no estén siempre directamente relacionados con los fines perseguidos en la misma.

La usuaria nos cuenta que su lengua materna es el beni. Por nuestra dificultad para entender el nombre de este idioma, es la propia usuaria quien lo escribe en un papel. No se corresponde con ninguno de los idiomas más difundidos (inglés -idioma oficial-, yoruba, hausa e ibo) en su país de origen, Nigeria, aunque en dicho país, según aprendemos más tarde, se hablan unas quinientas lenguas. [África Subsahariana 1]

Nos cuenta la usuaria antes de comenzar la entrevista que esta es su segunda hija. La mayor está en este momento al cuidado de sus suegros. Dice no querer tener más hijos, que así ya es suficiente. [África Subsahariana 3]

La usuaria nos comenta que tiene tres hijos más (dos niños y una niña), de los cuales uno nació en España, en este mismo hospital. [Asia 3]

Son las propias enfermeras de la planta las que nos han hablado de esta usuaria, pues consideran que se trata de un caso "curioso", por ser la madre gitana y el padre latinoamericano, concretamente de Ecuador. La usuaria, muy joven (21 años), nos cuenta que esta es su tercera hija, que ya tiene otra de cinco años y un niño de tres. Dice no querer tener más hijos, y afirma que sus padres la apoyan en esta decisión. Al finalizar la entrevista, la usuaria comenta (off the record) que sus familiares no se han opuesto a su matrimonio con un ecuatoriano, pues no es el primer caso de este tipo en la familia, ya que tiene una prima casada con un venezolano y otra casada con un dominicano. [Comunidad gitana]

La usuaria nos cuenta, antes de iniciar la entrevista, que su marido es español y que este es su primer hijo. [Europa del este 1]

La usuaria nos cuenta que es su primer hijo y que su nombre es Andrei. [Europa del este 3] 
La usuaria nos cuenta que su marido es español y que este es su primer hijo. [Europa del este 4]

La usuaria nos comenta que este es su cuarto hijo, y el segundo que nace en España. [Europa del este 5]

La usuaria se encuentra sola en la habitación con el recién nacido (que es su segundo hijo y al que han llamado Peter, según nos cuenta). [Europa del este 6]

Al principio de la entrevista, la usuaria nos cuenta que es veterinaria y que se encuentra en España haciendo un Master. Este es su primer hijo y dice que, por ahora, cree que no tendrá más, pues desea realizar estudios de doctorado y piensa que no tendrá tiempo de ocuparse de más de un hijo. [Latinoamérica 2]

La usuaria se encuentra en la habitación con la recién nacida y con sus dos hijos mayores, ya adolescentes, los cuales miran la televisión, que se encuentra encendida, mientras realizamos la entrevista. Nos cuenta que los dos primeros hijos nacieron en Ecuador. [Latinoamérica 3]

La usuaria nos comenta antes de iniciar la entrevista que esta es su segunda hija y que la anterior nació en su país de origen, Honduras. [Latinoamérica 4]

La usuaria nos comenta que este es su tercer hijo y que los dos anteriores nacieron también en España, pero en otro hospital de esta misma ciudad. [Magreb 2]

La usuaria nos comenta que este es su cuarto hijo y que la primera fue una niña, la cual nació en su país de origen, Argelia. También nos cuenta que procede de la segunda ciudad más grande su país, Orán. [Magreb 3]

La usuaria y su marido también presente nos explican que este es su segundo hijo, que primero tuvieron una niña que tiene cuatro años y que ahora han tenido un niño. [Magreb 4]

Uno de los datos más significativos que nos aportan estas preguntas iniciales es que son pocos los casos de usuarias inmigrantes primíparas, puesto que la mayoría de ellas ya tienen hijos previos, algunos nacidos en sus respectivos países de origen y otros en España. Coincide este dato con la información aportada previamente sobre la alta tasa de fecundidad de las usuarias inmigrantes.

Cabe además resaltar la existencia de matrimonios mixtos, como es el caso de dos usuarias de Europa del este casadas con españoles, o el de la usuaria de la comunidad gitana (autóctona) casada con un ecuatoriano.

\subsection{Asistencia sanitaria general}

La primera cuestión a analizar en este subapartado de asistencia sanitaria general se refiere a los acompañantes de las usuarias inmigrantes mientras se encuentran ingresadas en el hospital. También en este caso, por el contexto en el que nos hallamos mientras tomamos notas en nuestro diario de campo (principalmente en las plantas donde se encuentran ingresadas las puérperas), los datos analizados relativos a la asistencia sanitaria no se centran en la asistencia en general, sino en aquella recibida específicamente durante el puerperio.

En primer lugar, cabe señalar que son numerosas las usuarias inmigrantes que, como se puede observar en los extractos del diario de campo que incluimos a continuación, se encuentran solas en las plantas de puerperio, dato que corrobora la información presentada anteriormente, según la cual es menor el número de visitas que reciben estas usuarias con 
respecto a las que reciben las autóctonas. Dentro de este grupo de usuarias que se encuentran solas, destacan las procedentes de Europa del este, de Latinoamérica y del Magreb.

La usuaria se encuentra sola en la habitación. Al finalizar la entrevista, llama a su marido para que venga a recogerla, porque le han dado el alta. [África Subsahariana 4]

La usuaria se encuentra sola en la habitación. Me comenta que su marido está en casa, cuidando de sus otros tres hijos. [Asia 3]

La usuaria se encuentra sola en la habitación, junto a la recién nacida. [Comunidad gitana]

La usuaria se encuentra sola en la habitación con el recién nacido, que duerme en su cuna. [Europa del este 1]

La usuaria se encuentra sola en la habitación. No está con ella tampoco el recién nacido, pues le están realizando unas pruebas rutinarias. [Europa del este 2]

La usuaria se encuentra en la habitación con el recién nacido. [Europa del este 4]

La usuaria se encuentra sola en la habitación con el recién nacido. [Europa del este 6]

La usuaria se encuentra sola en la habitación con el recién nacido. [Latinoamérica 1]

La usuaria se encuentra sola en la habitación. Se han llevado al bebé para hacerle unas pruebas de rigor.

[Latinoamérica 4]

La usuaria se encuentra sola en la habitación con la recién nacida. [Latinoamérica 5]

La usuaria se encuentra sola en la habitación. Se han llevado hace un momento a su hijo para lavarlo y

realizarle algunas pruebas de rigor. [Magreb 1]

La usuaria se encuentra sola en la habitación con el recién nacido. [Magreb 2]

La usuaria está sola en la habitación con el recién nacido. [Magreb 3]

Otras usuarias inmigrantes, por el contrario, se encuentran acompañadas, principalmente por sus maridos u otros miembros de su familia. En los fragmentos del diario de campo que presentamos a continuación se incluye información sobre la relación de estos acompañantes con las usuarias, su actitud general y su implicación (en ocasiones no deseada) en las entrevistas.

El marido, de origen español, está en la habitación mientras realizamos la entrevista, pero no interviene en ningún momento. Cuando el bebé llora, se ocupa de él y, como les han dado el alta, va recogiendo las cosas de la habitación mientras su mujer y yo hablamos. [África Subsahariana 3]

La usuaria se encuentra en la habitación con otra mujer más mayor, también de origen chino. Esta última parece no hablar español; durante la entrevista, no dice ni una sola palabra, solo nos observa y, en alguna ocasión, sonríe tímidamente. Además, se ocupa del bebé cuando este se mueve en la cuna o emite algún sonido. Se trata, como sabremos más tarde, de la tía de la usuaria, quien, según esta, siempre la acompaña al médico. [Asia 1]

La usuaria se encuentra en la habitación con su madre. [Asia 4]

La usuaria se encuentra en la habitación con su hermano, que lleva más años que ella residiendo en España y, a diferencia de ella, habla un español bastaste fluido. Como el nivel de conocimientos de español por parte de la usuaria es bastante bajo, su hermano le va traduciendo algunas preguntas e 
incluso realiza él mismo labores de intérprete entre la usuaria y la investigadora. A veces interviene respondiendo él mismo a las preguntas. [Europa del este 3]

La usuaria se encuentra en la habitación con su marido y el recién nacido. Al principio el marido se distancia físicamente de nosotros y parece no estar prestando atención a la entrevista, pero, ya en la segunda pregunta, interviene, interrumpe e incluso contesta en ocasiones en lugar de la usuaria, la cual intenta intercalarse a las respuestas de su marido, solapándose. Aunque intentamos evitar la intervención del marido en las preguntas sucesivas, formulando directamente a la usuaria las preguntas y dirigiendo la mirada exclusivamente hacia ella, este se inmiscuye en la conversación y a veces actúa como si la entrevista se centrara en él en lugar de en la usuaria. De hecho, como se puede observar en la transcripción, la participación de la usuaria es menor que la de su marido. En un momento dado, el recién nacido se pone a llorar y la usuaria da indicaciones a su marido para que se ocupe de él. En concreto, le dice "Le tienes que coger de ahí, en brazos, para que no llore". [Europa del este 5]

Al principio de la entrevista, la usuaria se encuentra sola en la habitación con el recién nacido. Cuando se encuentra contestando a la pregunta número 13, llaman a la puerta de la habitación y entran dos mujeres, que parece que vienen a hacerle una visita. La usuaria les dice que pasen y se sienten, y permanecen con nosotros hasta el final de la entrevista en silencio, escuchando atentas nuestras preguntas y sus respuestas. [Latinoamérica 2]

La usuaria se encuentra en la habitación con la recién nacida y con sus dos hijos mayores, ya adolescentes, los cuales miran la televisión, que se encuentra encendida, mientras realizamos la entrevista. [Latinoamérica 3]

La usuaria está en la habitación con su marido. Aunque al principio ella nos dice que habla español, su marido debe traducirle al árabe muchas preguntas, incluso a veces contesta por ella. Llegado un punto, se comunica con él en árabe y parece que se queja de dolor. Este le acaricia el pelo y la ayuda a incorporarse un poco en la cama. [Magreb 4]

De la información que acabamos de presentar nos gustaría resaltar dos cuestiones. La primera de ellas se refiere a la presencia de familiares de sexo femenino que acompañan a dos de las tres usuarias de origen chino, quizás motivada por el hecho de que en dicha cultura se suele recurrir a mujeres de la familia para ayudar a las madres que acaban de dar a luz y permitir que estas guarden el periodo de reposo habitual tras el parto. La segunda consiste en el hecho de que algunos de los acompañantes de las usuarias de Europa del este (concretamente el marido y el hermano de dos de ellas) intervienen excesivamente durante las entrevistas y, a menudo, responden en lugar de estas a las preguntas planteadas.

Mención aparte merece el caso de una de las usuarias de África Subsahariana, concretamente procedente de Nigeria, la cual, tal y como se ha comentado en el subapartado de análisis de las entrevistas relativo al tema de la mutilación genital femenina, recibe mientas estamos realizando la entrevista la visita de un mediador de la organización Médicos del Mundo.

En ese momento entra en la habitación un hombre preguntando por la usuaria. Se presenta y dice que es un mediador de Médicos del Mundo. Le explicamos los motivos por los que nos encontramos con la usuaria y nos deja a solas en la habitación para que terminemos la entrevista. Más tarde nos cuenta, al salir de la habitación, que en Médicos del Mundo tienen un programa para evitar la mutilación genital femenina y que le han avisado del hospital para que venga a hablar con esta usuaria, tal y como hacen cuando dan a luz otras mujeres procedentes de África Subsahariana. [África Subsahariana 1]

Otro aspecto a tratar en este subapartado de asistencia sanitaria general se refiere al cumplimiento por parte de las usuarias inmigrantes de las normas del hospital contexto de estudio. Por lo general, en nuestra permanencia en el hospital durante el trabajo de campo, no 
hemos observado incumplimiento de las normas o problemas de convivencia en los que estuvieran implicadas usuarias inmigrantes. Una vez más, cabe destacar que el hospital en el que centramos nuestra investigación presenta cierta permisividad en cuanto a algunos aspectos, como el carácter relativamente laxo de los horarios de visitas, el consentimiento tácito de que se introduzcan alimentos por parte de los familiares de las usuarias, o la presencia de menores en las habitaciones (como es el caso de una de las usuarias latinoamericanas que se encuentra acompañada por sus dos hijos adolescentes). El único caso de incumplimiento de las normas, del cual ya hemos hablado en el análisis previo de las fichas, se refiere a la falta de entrega de los documentos para el registro del recién nacido por parte de una de las usuarias procedentes de Europa del este. Incluimos a continuación información adicional relativa a este caso que había sido anotada en nuestro diario de campo.

El día anterior a la realización de esta entrevista, habíamos estado en esta misma planta llevando a cabo labores de observación no participante y entrevistas. Estuvimos casi una hora y media dentro de una de las habitaciones con una usuaria rumana, algo que extrañó a las enfermeras, pues las entrevistas con usuarias no suelen tener una duración tan extensa. Al día siguiente, dan el alta a esta usuaria y se marcha sin entregar los documentos de inscripción del recién nacido, por lo que las enfermeras nos preguntan algo enfadadas si sabemos algo al respecto, visto que habíamos pasado tanto tiempo con ella. Por supuesto, les contestamos que no sabemos nada y que, en cualquier caso, todo lo tratado en las entrevistas tiene carácter confidencial. De ahí se genera un debate acalorado entre distintas enfermeras y auxiliares de enfermería sobre el cumplimiento del protocolo de registro de los bebés por parte de las usuarias inmigrantes. [Europa del este 5]

\subsection{Embarazo, parto y puerperio}

En este subapartado incluimos algunos fragmentos de nuestro diario de campo que se refieren a comportamientos y creencias de las usuarias inmigrantes relativos a las distintas fases del proceso reproductivo.

La primera cuestión a analizar se refiere al escaso uso por parte de algunas usuarias latinoamericanas de métodos anticonceptivos, lo cual las conduce a embarazos que previamente no habían planificado. Ahondaremos más en esta cuestión que nos ha resultado llamativa en el análisis del grupo de discusión con usuarias procedentes de Latinoamérica.

Es una de las usuarias más jóvenes a las que he entrevistado y, como descubriremos más adelante en la entrevista, no había planificado previamente este embarazo, sino que se ha producido por la falta de uso de métodos anticonceptivos. [Latinoamérica 1]

A pesar de su corta edad (20 años) este es su segundo hijo. Nos da a entender más adelante en la entrevista que el embarazo no estaba programado, que se ha producido por no usar ningún tipo de método anticonceptivo. [Latinoamérica 4]

Otro aspecto a destacar se refiere a una creencia sobre el momento del parto, que repercute en un comportamiento posterior durante el puerperio. En concreto, según la literatura al respecto, las madres de origen chino consideran que se produce una pérdida considerable de calor al dar a luz. Con el fin de recuperar dicho calor y, por tanto, el equilibrio perdido, estas usuarias suelen ingerir alimentos considerados calientes $y$, como vemos en el extracto del diario de campo que incluimos a continuación, mantener su cuerpo tapado. 
La usuaria se encuentra tapada (literalmente) de los pies a la cabeza, incluso lleva una especie de cinta ancha que le cubre la frente, y se vuelve a tapar siempre que, al moverse, queda alguna parte de su cuerpo al descubierto. [Asia 4]

Entre las cuestiones relativas al puerperio, cabe señalar también la preferencia de algunas de las usuarias inmigrantes entrevistadas por hijos de uno $\mathbf{u}$ otro sexo. De hecho, dos de las usuarias a las que se hace referencia en los fragmentos del diario de campo que incluimos a continuación, habían tenido previamente hijas, pero esperaban con mucho ahínco que el siguiente hijo fuera varón. Por el contrario, otra usuaria comenta que deseaba que el bebé que acaba de tener fuera niña, visto que sus hijos previos eran todos de sexo masculino.

\footnotetext{
Antes de iniciar la entrevista, la usuaria me habla del recién nacido, cuyo nombre es Samuel. Dice que es su cuarto hijo. Antes ha tenido tres niñas, todas nacidas en España, y afirma que tenía muchas ganas de tener un hijo varón. [África Subsahariana 2]
}

Llega en ese momento un enfermero con la bebé recién nacida. Cambia completamente la expresión de la cara de la usuaria, sonríe, parece más tranquila, y rápidamente coge a la niña para acercarla a su pecho y amamantarla. Le preguntamos si está contenta y responde "Sí, sí, muy contenta". Nos explica que es su primera niña, que el resto de sus hijos son varones y que quería tener una hija. [África Subsahariana 5]

Cuando ya nos estamos marchando, traen al bebé (varón) al que sus padres todavía no habían vuelto a ver desde su nacimiento. La expresión de la madre cambia radicalmente, se le ilumina el rostro, desaparece el cansancio y sonríe. Alarga rápidamente los brazos hacia el bebé y repite numerosas veces una expresión breve en árabe dirigida al niño. [Magreb 4]

Una de estas usuarias que acabamos de mencionar nos hace partícipes, además, de una costumbre propia de su país de origen, Nigeria, según la cual no se da nombre a los recién nacidos hasta que han transcurrido ocho días desde su nacimiento. Esta costumbre puede estar en cierto sentido motivada por el alto índice de mortalidad infantil que presenta este país.

Le preguntamos antes de iniciar la entrevista si ya le han puesto nombre al bebé, y nos cuenta que es costumbre no darle el nombre al bebé hasta que no han pasado ocho días desde su nacimiento. [África Subsahariana 2]

Una última cuestión que nos llama la atención relacionada con la protección a los recién nacidos se refiere a una costumbre de carácter religioso que observamos en el caso de una usuaria procedente de Mauritania.

\footnotetext{
Nada más entrar, observamos que bajo la almohada hay una especie de rosario con cuentas verdes. Según nos cuenta más tarde el marido, se trata de un objeto que emplean para rezar, dar gracias por el nacimiento y pedir que se proteja a su bebé. [Magreb 4]
}

\subsection{Barreras lingüísticas y soluciones}

En este subapartado de barreras lingüísticas incluimos comentarios relativos a los dos grupos de sujetos estudiados.

Por lo que respecta a las usuarias inmigrantes, cabe señalar aquellos casos en los que las usuarias, en el momento de realizar las entrevistas, presentan amplios conocimientos de la lengua del país de acogida y a las que, por consiguiente, no efectuamos las preguntas relativas a las barreras lingüísticas. 
No se plantean las preguntas del bloque Barreras lingüísticas y soluciones, porque en el momento en que se realiza la entrevista, la usuaria habla perfectamente español. Cuenta, sin embargo, que cuando llegó a España no lo hablaba tan bien. En esa primera época, nunca tuvo que ir al médico, aunque afirma que se encontraba con dificultades y barreras comunicativas en su vida cotidiana, por ejemplo, a la hora de ir a comprar. En esas situaciones se hacía acompañar por una amiga, que, según ella, le traducía y le explicaba todo. [África Subsahariana 3]

La usuaria, de 23 años de edad, lleva doce años residiendo en España. Por tanto, ha vivido en este país más tiempo que en Rumanía, ha asistido a la escuela aquí y sus conocimientos de español son muy elevados. Por este motivo, no se le formulan las preguntas 19, 20, 23, 24 y 25 del bloque de Barreras lingüísticas y soluciones. [Europa del este 2]

Por la respuesta recibida en la primera pregunta del bloque de Barreras lingüísticas y soluciones, se deduce que resulta innecesario plantear a la usuaria el resto de preguntas de este bloque. [Europa del este 4]

No se formulan las preguntas de este bloque (Barreras lingüísticas y soluciones), por tratarse de una usuaria de origen latinoamericano que, además, lleva viviendo en España más de la mitad de su vida. Nos comenta que nunca se ha encontrado con problemas de comunicación, ni con el lenguaje escrito ni con el oral. [Latinoamérica 1]

Por las respuestas ofrecidas por la usuaria a las primeras preguntas, no se formula el resto de preguntas de este bloque (Barreras lingüísticas y soluciones). [Latinoamérica 3]

No se formulan las preguntas de este bloque (Barreras lingüísticas y soluciones), por tratarse de una usuaria de origen latinoamericano. Además, ella misma reitera que nunca se ha encontrado en España con "problemas para comunicarse con nadie" (palabras textuales empleadas por la usuaria). [Latinoamérica 4]

Al responder la usuaria a la primera pregunta que nunca ha tenido ningún problema de comunicación, no se formula el resto de preguntas de este bloque (Barreras lingüísticas y soluciones). [Latinoamérica 5]

Nos gustaría destacar distintos aspectos relacionados con estos fragmentos de nuestro diario de campo. En primer lugar, por lo que se refiere a la usuaria procedente de África Subsahariana, se corrobora el hecho de que, cuando las usuarias inmigrantes se enfrentan con problemas por su desconocimiento del español o del funcionamiento de la sociedad de acogida, suelen recurrir a la ayuda por parte de familiares y amigos con mayor experiencia. En segundo lugar, las usuarias latinoamericanas entrevistadas dicen no haber tenido ningún problema a la hora de comunicarse, aspecto que tratamos de corroborar, como ya hemos comentado previamente, en el grupo de discusión en el que participaron usuarias de esta procedencia.

Por otro lado, en el caso de aquellas usuarias con un escaso dominio de español, según puede observarse en los extractos del diario de campo que presentamos a continuación, fueron varias las soluciones adoptadas. En concreto, tuvimos que recurrir al empleo de otras lenguas o a los acompañantes presentes, quienes actuaron como intérpretes para facilitar la comunicación entre la investigadora y la usuaria.

Se pregunta a la usuaria si prefiere realizar la entrevista en español o en inglés. Contesta que para ella es mejor hablar en español. Sin embargo, a lo largo de la entrevista, en algunas ocasiones, recurrimos al inglés cuando, tras reformular la pregunta de diferentes maneras en español, sigue resultando incomprensible para la usuaria. [África Subsahariana 5] 
La usuaria habla muy poco español, por lo que la entrevista se desarrolla alternando el inglés (usado siempre en la formulación de preguntas) y el español (idioma que emplea en ocasiones la usuaria en sus respuestas). [Asia 3]

Como el nivel de conocimientos de español por parte de la usuaria es bastante bajo, su hermano le va traduciendo algunas preguntas e incluso realiza él mismo labores de intérprete entre la usuaria y la investigadora. [Europa del este 3]

Su nivel de español no es muy alto y, en numerosas ocasiones durante la entrevista, afirma que no entiende las preguntas y se le ofrecen explicaciones mediante paráfrasis o se emplean términos en francés para aumentar su comprensión. [Magreb 2]

Aunque ella dice al principio que habla español, su marido debe traducirle al árabe muchas preguntas. [Magreb 4]

Por lo que se refiere a los profesionales sanitarios, nos gustaría destacar tres cuestiones incluidas en nuestro diario de campo.

La primera de ellas se refiere al dominio por parte de los profesionales sanitarios de lenguas extranjeras, que en principio les podrían facilitar su comunicación con algunas usuarias alófonas. En concreto, en el siguiente fragmento del diario de campo se hace referencia a uno de los obstetras encargados de las consultas a puérperas, quien, como se ha comentado en el análisis de las fichas, es de origen sirio y su lengua materna es el árabe. Al respecto, nos surge la duda de si el hecho de tener esta lengua materna garantizará una comunicación plenamente efectiva con las usuarias con las que comparta la misma lengua materna, pero que procedan de otros países y culturas.

\footnotetext{
La profesional entrevistada nos cuenta "[...] también tenemos otro ginecólogo, que es árabe, con lo cual él con las mujeres que hablan árabe se maneja muy bien". Se refiere a uno de los obstetras que realizan las visitas en las plantas de puerperio, quien es de origen sirio, aunque lleva décadas residiendo en España. Creemos que el hecho de que la lengua materna de este profesional sea el árabe no garantiza un total entendimiento (lingüístico y cultural) con las usuarias con esa misma lengua materna. En este caso, la entrevistada no tiene en cuenta las variedades del árabe ni los posibles conflictos de índole cultural que pueden existir previamente entre sus países de origen. [Enfermera 5]
}

La segunda está relacionada con el presumible aumento de la capacidad de ponerse en el lugar de las usuarias alófonas cuando los propios profesionales han vivido en primera persona la experiencia de enfrentarse con dificultades de comunicación al encontrarse trabajando en países extranjeros.

\footnotetext{
Antes de iniciar la entrevista, nos comenta que ha estado trabajando en Barcelona y en Madrid y, además, ha realizado estancias durante distintos veranos en Líbano y en Japón. A propósito de esta última estancia, cuenta sus propias dificultades en dicho país a la hora de comunicarse, por no conocer la lengua japonesa. [Obstetra 3]
}

Por último, cabe señalar una observación que anotamos en nuestro diario de campo en relación con las dificultades de comprensión a las que deberán probablemente hacer frente las usuarias cuando reciban explicaciones de una de las profesionales socio-sanitarias encargadas de informarles sobre el protocolo de registro de los recién nacidos.

Le pedimos a esta profesional que nos explique el funcionamiento del protocolo de registro de los recién nacidos. Sus explicaciones resultan muy confusas $y$, aun compartiendo la misma lengua materna con la 
entrevistada, no nos queda nada claro cómo funciona este protocolo. ¿Cuánto más difícil puede ser para una usuaria con escasos conocimientos de español comprenderlo? [Profesional socio-sanitario 2]

\subsection{Interacción}

No son muy numerosos los datos relativos a la interacción recolectados mediante la observación llevada a cabo durante las entrevistas o en los lapsos de tiempo intermedios.

Por una parte, anotamos en nuestro diario de campo aquellas interacciones breves entre los dos grupos de sujetos estudiados cuando, estando entrevistando a alguna usuaria inmigrante, entraba un profesional sanitario en la habitación y se dirigía a esta por uno u otro motivo. En este punto, incluimos aquellos casos en los que la comunicación entre ambos interlocutores ha sido efectiva y armoniosa, principalmente por la actitud cercana y cariñosa del profesional en cuestión. Dejamos para el siguiente subapartado, relativo a las actitudes sociales, aquellas situaciones en las que el profesional sanitario presentase comportamientos o actitudes que podrían considerarse racistas o xenófobas.

\footnotetext{
En un momento dado, entra una enfermera a la habitación, se acerca al bebé, que está tomando el pecho plácidamente, y le hace unas carantoñas, diciendo que le parece muy bonito. Pregunta a la madre cómo se llama y se preocupa por si ha comido y si se ha cogido bien el pecho. La enfermera coge al niño para hacerle una prueba de azúcar. Le pincha en el talón, tras lo cual el bebé se pone a llorar, y la enfermera trata de tranquilizarle diciendo "No llores, no llores, pero si somos amigos...". Explica a la madre que la prueba ha salido muy bien, que cuando ingresó, como "es tan gordito" (palabras textuales), tenía el azúcar muy bajo, pero ahora sus niveles son correctos. La madre, que se había alarmado al oír el llanto del bebé, parece tranquilizarse por estas últimas palabras de la enfermera y el tono empleado por la misma. [África Subsahariana 2]
}

Entra en este momento una auxiliar de enfermería y le pregunta a la usuaria si, cuando se han llevado al bebé, le estaba dando el pecho. La usuaria parece no entender y la auxiliar se lo repite con otras palabras. La usuaria responde "No, desde ducharme no he dado el pecho". La auxiliar le comenta "Es que el bebé ha tenido una arcadilla, ha vomitado un poco. Y eso pasa a veces cuando le estás dando el pecho. Pero nada, no te preocupes, que no es nada grave. ¿Quieres que te limpie la camica?". La usuaria no había comentado nada, pero tiene la cama mojada, así que interrumpimos la entrevista mientras le cambian las sábanas. [Magreb 1]

Mientras realizamos la entrevista, entra en la habitación una enfermera para darle el alta a la usuaria. Se dirige a ella en modo muy cariñoso y cercano y utiliza diminutivos para referirse tanto a la madre como a la niña. [Comunidad gitana]

Por otra parte, también registramos en nuestro diario de campo un aspecto relacionado con los usos no verbales del estilo comunicativo de las usuarias inmigrantes entrevistadas. En particular, anotamos aquellos casos en los que el tono de voz de la usuaria nos llamase la atención por ser muy bajo o suave, o aquellas en las que el ritmo de la conversación nos pareciese más lento de lo habitual. Cabe destacar que, como puede observarse en los fragmentos del diario que incluimos a continuación, son principalmente las usuarias procedentes de Asia (3) y del Magreb (2) las que presentan rasgos relativos al paralenguaje que nos han resultado más llamativos, quizás porque se alejan más de nuestros propios patrones comunicativos.

Nos llama la atención su modo de hablar, con un ritmo lento y un tono bastante bajo. [África Subsahariana 2] 
El tono de voz de la usuaria es bastante bajo. A veces, desciende tanto que debemos subir hasta el máximo el volumen de la grabación al realizar la transcripción de la entrevista. [Asia 1]

El tono de voz de la usuaria es muy bajo, y su timbre es dulce, a veces incluso como infantil. [Asia 2]

El tono de voz de la usuaria es suave y dulce, el ritmo es lento, en ocasiones, dubitativo, y realiza numerosas pausas. [Asia 3]

Desde el principio nos llama la atención su tono de voz, muy bajo y suave, y el ritmo pausado y, en ocasiones, con algunos silencios prolongados entre fragmentos. [Magreb 2]

El tono de voz de la usuaria es bastante bajo y suave durante toda la entrevista. [Magreb 3]

\subsubsection{Actitudes sociales}

En este último subapartado incluimos aquellas situaciones descritas en nuestro diario de campo en las que, estando entrevistando a un profesional sanitario o una usuaria inmigrante, fuimos testigos de un comportamiento o comentario por parte de algún profesional que nos pareciera en cierto sentido racista o xenófobo. El hecho de que en el diario incluyéramos ejemplos de actitudes del personal sanitario tanto negativas como positivas (véase subapartado anterior) en relación con su interacción con las usuarias inmigrantes demuestra una vez más que no resulta posible generalizar, ya que el trato que reciben las usuarias por parte de los profesionales puede variar notablemente, tal y como afirmaban las usuarias inmigrantes entrevistadas, de una a otra persona.

Desde que comenzamos el trabajo de campo en el hospital, han sido numerosas las referencias a las personas de la comunidad gitana, especialmente cuando se preguntaba por las molestias que pueden ocasionar las usuarias por sus muchos acompañantes. La mayoría de los profesionales entrevistados mencionaban a las personas de esta comunidad como ejemplo de incumplimiento de las normas del hospital o por el acompañamiento por parte de excesivos familiares y/o amigos. De todos modos, asociaban siempre estos comentarios a la idea de que, aun pudiéndoles considerar como miembros de otra cultura, cabría diferenciarlos de los inmigrantes. En alguna ocasión, incluso mencionan a las personas de la comunidad gitana en alguna broma o chiste prejuicioso. [Comunidad gitana]

En el momento en que íbamos a empezar el último bloque de la entrevista, entra en la habitación una auxiliar de enfermería y nos interrumpe para contarnos que una usuaria de origen chino, a quien le acaban de dar el alta, se estaba llevando la camiseta y la mantita del bebé que proporciona el hospital durante la estancia hospitalaria. Se reproduce a continuación un fragmento de su intervención: "Estos han venido a hacerse ricos. Y, seguro, seguro, que por mucho que hayan pagado, no habrán pagado ni la mitad de lo que han gastado. Esto, que conste. Contando que estos estén cotizando a la Seguridad Social, que tampoco lo tengo claro... Y tienen unas ventajas que aprovechan, eso sí que es verdad. Vamos, que vienen aquí a mesa puesta, que me consta que no trabajan, que ponen así la mano y... Me consta, no lo sé. A lo que íbamos, estos chinos han visto que la camiseta y la manta eran de algodoncico bueno y han dicho "Mira, esto me lo voy a llevar también»". Iniciamos entre las tres un debate sobre lo (in)adecuado que resulta generalizar. La entrevistada le pregunta a la auxiliar qué ocurriría entonces si, porque hay españoles que se llevan objetos de los hoteles, se generalizara y se dijera que lo hacemos todos los españoles. Las últimas palabras de la auxiliar antes de abandonar la habitación son: "Bueno, yo me voy de aquí. No quería interrumpir, quería comentar. Que el otro día vi en la tele un reportaje en el que se veía que en el desierto, ahí en su país, con una sequía de años, iban tapados como vienen aquí en pleno mes de agosto. Que yo quisiera saber si los bisabuelos de estos islamistas ${ }^{271}$ que vienen se tapaban tanto como

${ }^{271}$ No es esta la única ocasión en la que algún profesional sanitario emplea el término "islamista" de manera equivocada y se confunde presumiblemente con el término "musulmán". Véase la nota a pie de página incluida en el apartado de análisis de las entrevistas en la que comentamos que se produce esta misma confusión por parte del Anestesista 4. 
se tapan ellos. A mí que no me digan que es cultura, porque eso es... Esto es como si yo mañana vengo a trabajar vestida de baturra, porque, mira, mis abuelos, se ponían esa ropa. Y si no puedo venir a trabajar así, pues que me den el sueldo sin trabajar". [Enfermera 5]

Mientras hago la entrevista, entra una auxiliar de enfermería, y la usuaria y su marido le preguntan tímidamente algo sobre el gotero que lleva puesto la usuaria. La auxiliar responde de forma grosera, con un tono de voz muy alto y como recriminándoles: "Ya os he dicho que..." (palabras textuales). [Magreb 4]

La profesional finaliza la entrevista sacando a relucir estereotipos y prejuicios sobre determinadas comunidades inmigrantes que no estaban directamente relacionados con la pregunta planteada. [Profesional socio-sanitario 2]

Para concluir el análisis de los datos registrados en las fichas y en el diario de campo, cabe destacar que el empleo de la observación no participante nos ha permitido contrastar la información obtenida mediante el uso de otras técnicas. Asimismo, nos gustaría señalar de nuevo que las cuestiones más relevantes presentes en dicho análisis se retoman en el apartado de conclusiones generales del estudio de caso, en el que se comparan además con los datos obtenidos mediante el resto de técnicas empleadas y con la literatura publicada sobre las cuestiones estudiadas en nuestra investigación.

\subsection{Análisis de los grupos de discusión}

Los grupos de discusión presentan un carácter dinámico y permiten obtener significados construidos socialmente mediante el debate. En ellos, como se ha comentado en el capítulo 2, centrado en el diseño metodológico de nuestro estudio, los temas planteados se abordan desde los puntos de vista de los diferentes participantes, los cuales estimulan con sus respuestas la intervención del resto, de manera que dichos temas pueden ser confrontados y analizados más profundamente que con el uso de otras técnicas de investigación. En efecto, hemos podido comprobar que, en los grupos de discusión celebrados, se produjo un "efecto sinérgico" (Stewart et al. 2006; Sussman, Burton, Dent, Stacy y Flay, 1991, citados en Berg, 2009: 163), que conllevó que, en general, los participantes fueran extensos en sus respuestas y los encuentros tuvieran un carácter muy dinámico.

En el presente estudio, mediante los grupos de discusión, tal y como hemos señalado previamente, tratamos de ampliar los temas que hubieran resultado ambiguos, no suficientemente desarrollados o contradictorios en el análisis de los datos de las entrevistas y de la observación no participante.

De hecho, el objetivo principal que perseguíamos con la realización de estos grupos era precisamente corroborar, contrastar y ampliar los datos recolectados con otras técnicas, de manera que la combinación de los datos obtenidos mediante todas ellas pudiera aportar mayor fiabilidad a nuestra investigación.

\subsubsection{Datos contextuales y demográficos}

Tal y como hemos hecho en apartados anteriores, antes de pasar al análisis de los datos proporcionados por los participantes en los grupos de discusión y, con el fin de facilitar la lectura y comprensión de dichos datos y permitir que, siempre que sea pertinente, se puedan relacionar las características del contexto y de los sujetos investigados con las respuestas 
ofrecidas por los mismos, presentamos los datos contextuales y demográficos relativos a esta técnica.

Por lo que se refiere a los datos contextuales de los grupos de discusión y, más concretamente, en cuanto al lugar de realización de los mismos, cabe señalar que tratamos de que fuera un ambiente lo más neutral posible, para no inhibir la participación de los miembros del grupo. Asimismo, permitimos que fueran estos últimos, una vez seleccionados para colaborar en el estudio, quienes escogieran el lugar concreto donde nos íbamos a reunir. En particular, los grupos de discusión se celebraron en una sala del hospital contexto de estudio (grupo con profesionales sanitarios), en la casa particular de la investigadora (grupo con usuarias latinoamericanas), y en una escuela de árabe (grupo con usuarias magrebíes).

Otra de las características que perseguimos con el fin de facilitar la producción del discurso y la interacción fue que el lugar permitiera una buena acústica y que los participantes estuvieran dispuestos físicamente de manera que pudiera producirse el contacto visual entre ellos $\mathrm{y}$, al mismo tiempo, con la moderadora. Además, colocamos distintivos con el nombre de los participantes sobre la mesa, delante de cada uno de ellos, de modo que pudieran interpelarse mutuamente durante la discusión.

Con respecto a las fechas de celebración, los grupos de discusión tuvieron lugar durante los meses de junio y julio de 2013, cuando, respetando los criterios de nuestro diseño metodológico emergente y en cascada, y basado en la inducción analítica, habíamos ya analizado los datos recolectados mediante las otras técnicas.

En referencia a la duración, en principio, estimamos que el encuentro duraría entre una hora y una hora y media, aunque tuvimos en cuenta que las características de cada grupo y la predisposición de los participantes a debatir sobre los temas propuestos, impedía, tal y como sostiene Jesús Ibáñez (2003: 274), establecer unos límites temporales predeterminados. Por ello, avisamos a los participantes de que dicha duración podía verse modificada en función de su disponibilidad, y las sesiones se dieron por terminadas en el momento en que se dejó de aportar información nueva con respecto a los temas planteados. Finalmente, los grupos de discusión duraron 42 minutos y 18 segundos (grupo con profesionales sanitarios), 55 minutos y 43 segundos (grupo con usuarias latinoamericanas), y 1 hora, 4 minutos y 42 segundos (grupo con usuarias magrebíes).

Con relación a los datos demográficos de los informantes, ${ }^{272}$ en primer lugar, cabe indicar que el número de los participantes en los grupos de discusión realizados osciló entre 4 y 6 . Nuestra intención inicial era que los grupos no estuvieran conformados por menos de 5 ni más de 10 participantes, tal y como recomiendan algunos autores cuyas publicaciones se centran en el uso de esta técnica (Ibáñez, 2003: 272; Debus y Novelli, 1998: 22; Krueger, 1991: 97). Sin embargo, en el caso concreto de uno de los grupos (usuarias latinoamericanas), dos de las convocadas no se presentaron, por diversos motivos personales, el día en que celebramos el grupo de discusión. A pesar de que el número de participantes fue menor de lo previamente estipulado, el debate fue igualmente dinámico y rico en contenidos.

\footnotetext{
${ }^{272}$ En los anexos se incluyen unas tablas que resumen los datos demográficos de los participantes en los grupos de discusión.
} 
Un excesivo tamaño de la muestra habría multiplicado los canales de comunicación y habría podido resultar en divisiones de los participantes por subgrupos formados por aquellos que estuvieran más próximos. Además, habría dificultado no solo la participación de todos los sujetos en la discusión, sino también el control de dicha discusión por parte de la moderadora. Por el contrario, si el grupo hubiera presentado un tamaño más reducido, consideramos que la interacción se habría visto mermada y la discusión no hubiera sido lo suficientemente activa.

Tras estas consideraciones iniciales, a continuación, presentamos los datos demográficos de los participantes en los grupos de discusión divididos en los dos grupos principales sujetos de nuestro estudio: profesionales sanitarios, por una parte, y usuarias inmigrantes, por otra. 


\section{a) Profesionales sanitarios}

El grupo de discusión con profesionales sanitarios estaba compuesto, tal y como hemos señalado en el capítulo 2, por sujetos con diferentes perfiles, en particular, tres obstetras, dos matronas y una enfermera. Todos excepto uno, tal y como puede observarse en el siguiente gráfico, eran mujeres.

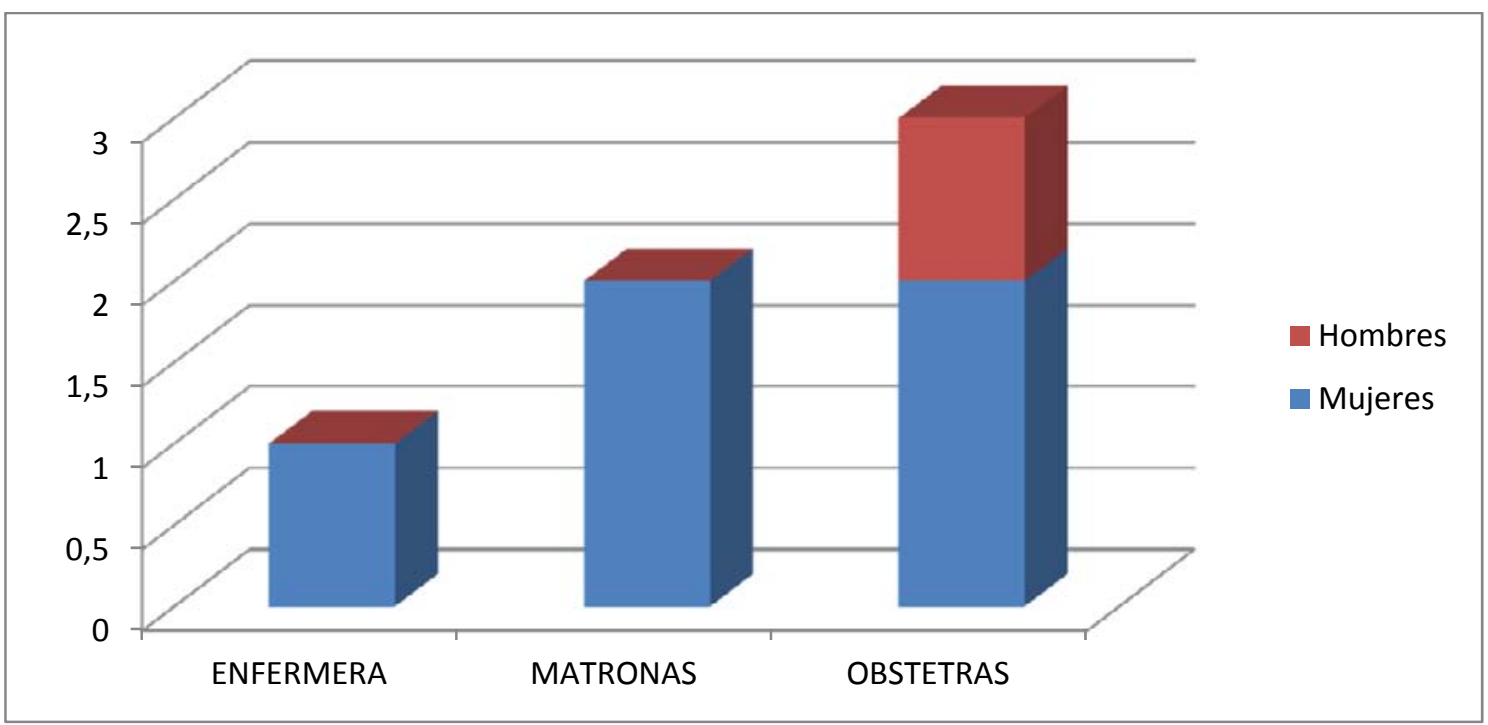

Gráfico 6.39. Perfil profesional y sexo de los profesionales participantes en el grupo de discusión

Por lo que se refiere a la edad, los participantes en este grupo presentaban una edad media joven (32 años), siendo el mayor de ellos de ellos de 58 años, y la menor de 24 años. En concreto, su distribución por edad y perfil profesional queda reflejada en el gráfico que mostramos a continuación.

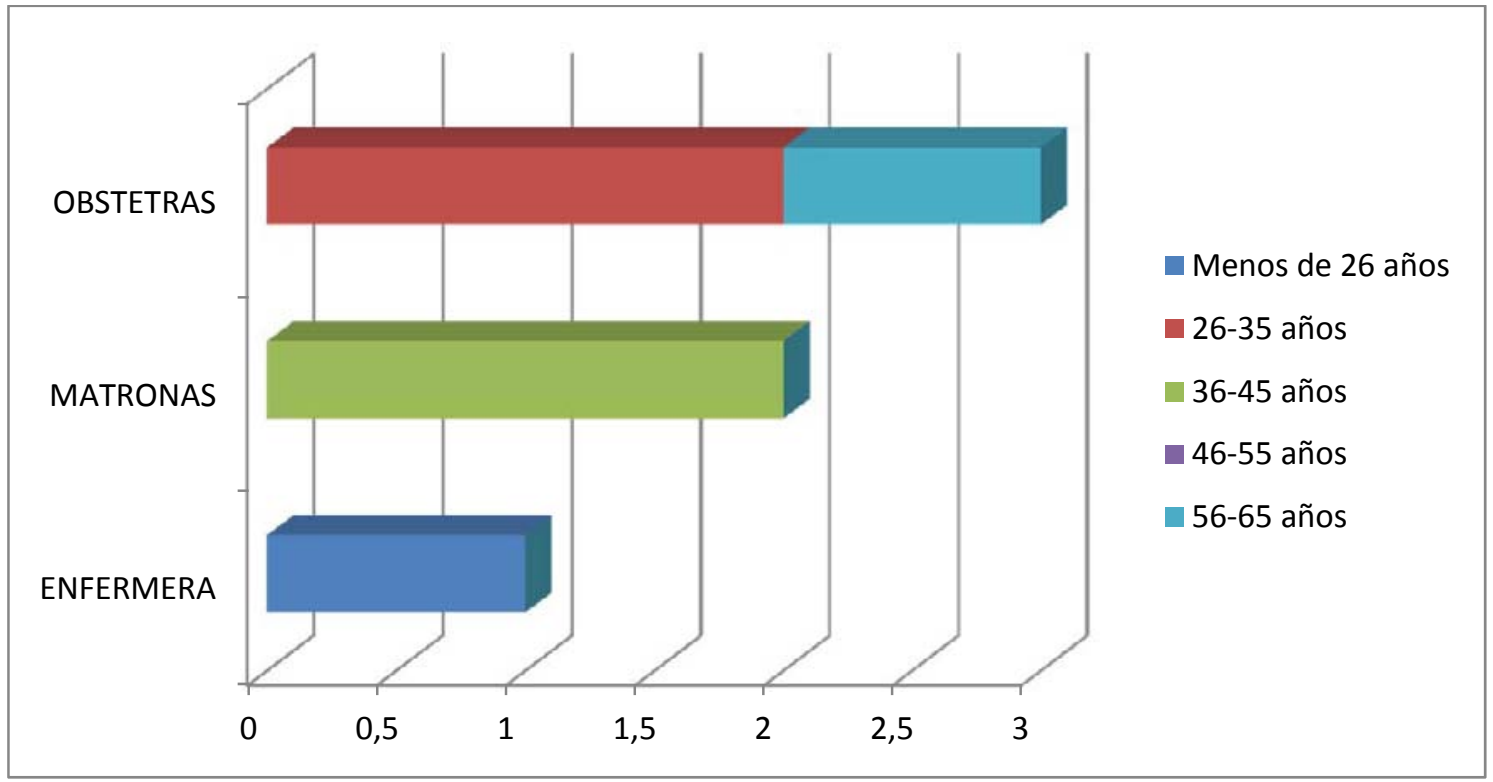

Gráfico 6.40. Perfil profesional y edad de los profesionales participantes en el grupo de discusión 
La lengua materna de todos los profesionales sanitarios era el español y algunos presentaban, además, conocimientos de lenguas extranjeras, principalmente inglés (3) y francés (2), como puede verse en el siguiente gráfico:

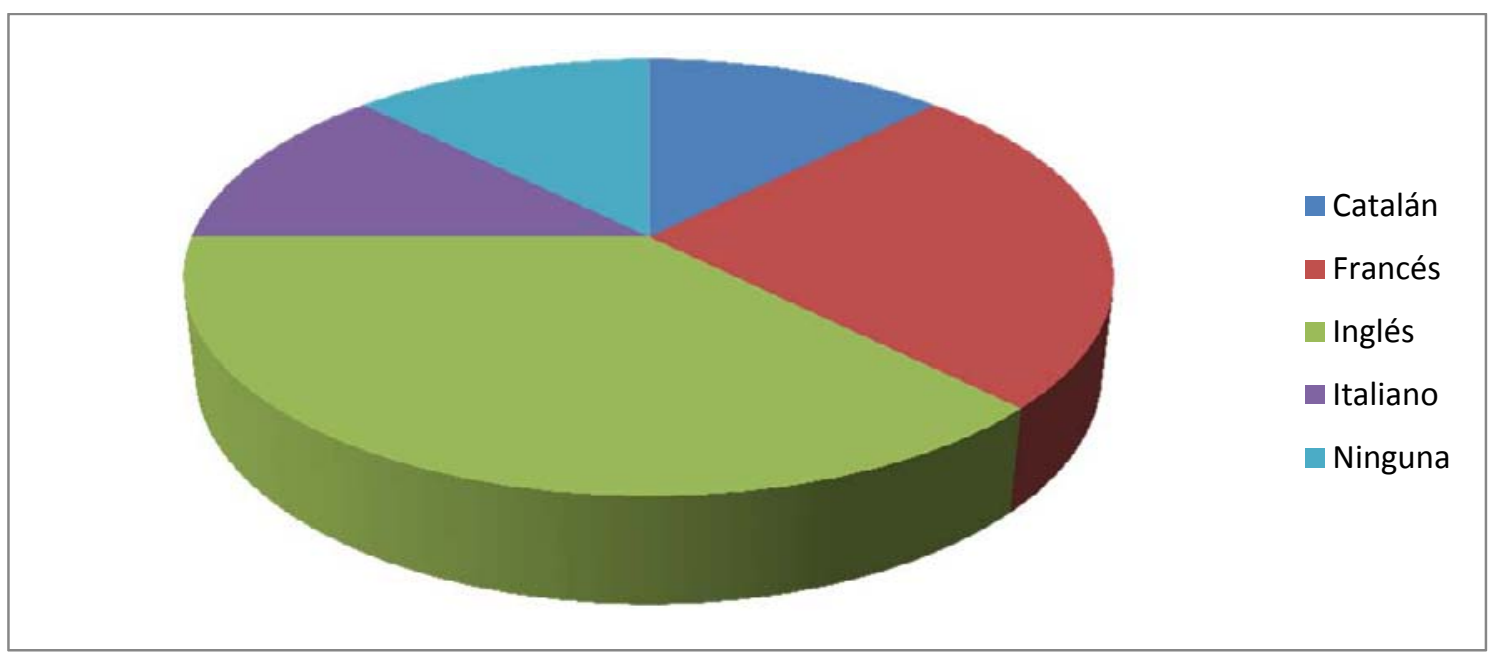

Gráfico 6.41. Lenguas extranjeras habladas por los profesionales participantes en el grupo de discusión

De nuevo en esta ocasión, como en el caso de los profesionales sanitarios participantes en las entrevistas y en la observación, vemos cómo las lenguas extranjeras que estos dominan no se corresponden con la lengua materna de las principales comunidades inmigrantes presentes en el territorio contexto de nuestro estudio.

Por último, en cuanto al tiempo que llevaban trabajando profesionales en el ámbito de la obstetricia, este era en casi todos los casos relativamente amplio (36 años en el caso del profesional con mayor experiencia, y 3 años en el caso de las dos profesionales con menos experiencia), de manera que quedara garantizado que estos disponían de suficiente información como para participar en el grupo de discusión. Es posible conocer su distribución por perfil profesional y tiempo trabajado, tanto en el hospital contexto de estudio como en otros centros, en el siguiente gráfico que aparece a continuación.

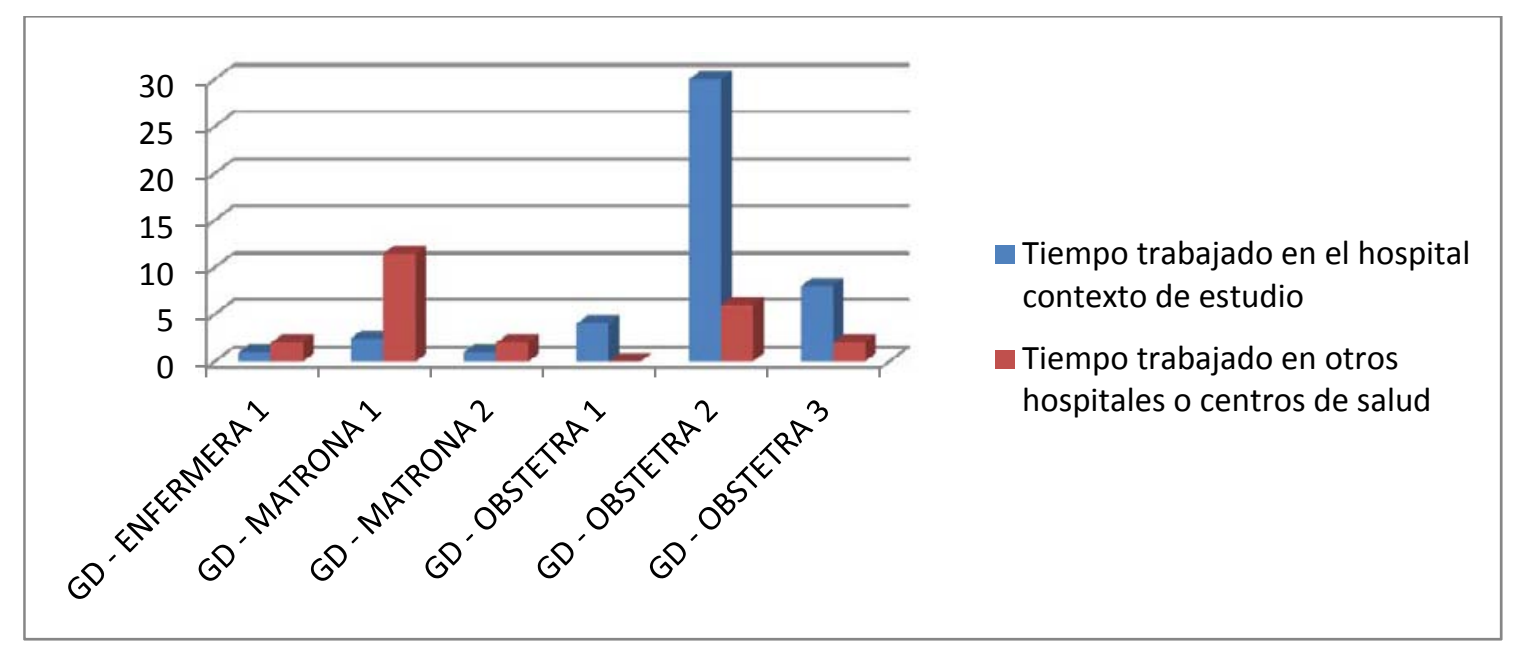

Gráfico 6.42. Perfil profesional y experiencia en el ámbito de la obstetricia de los profesionales participantes en el grupo de discusión 


\section{b) Usuarias inmigrantes}

Las usuarias inmigrantes participantes en los grupos de discusión procedían, como hemos comentado previamente, de Latinoamérica y del Magreb. En concreto, los países de origen de dichas usuarias eran los siguientes:

Latinoamérica: Ecuador (1), Colombia (2) y Perú (1)

Magreb: Marruecos (5)

Ambos grupos de usuarias presentaban una edad media bastante joven (29 años aproximadamente en el caso de las latinoamericanas, y unos 32 años en el caso de las magrebíes), que oscilaba entre los 18 y los 37 años. Puede observarse su distribución según colectivo de origen y edad en el gráfico que se presenta a continuación:

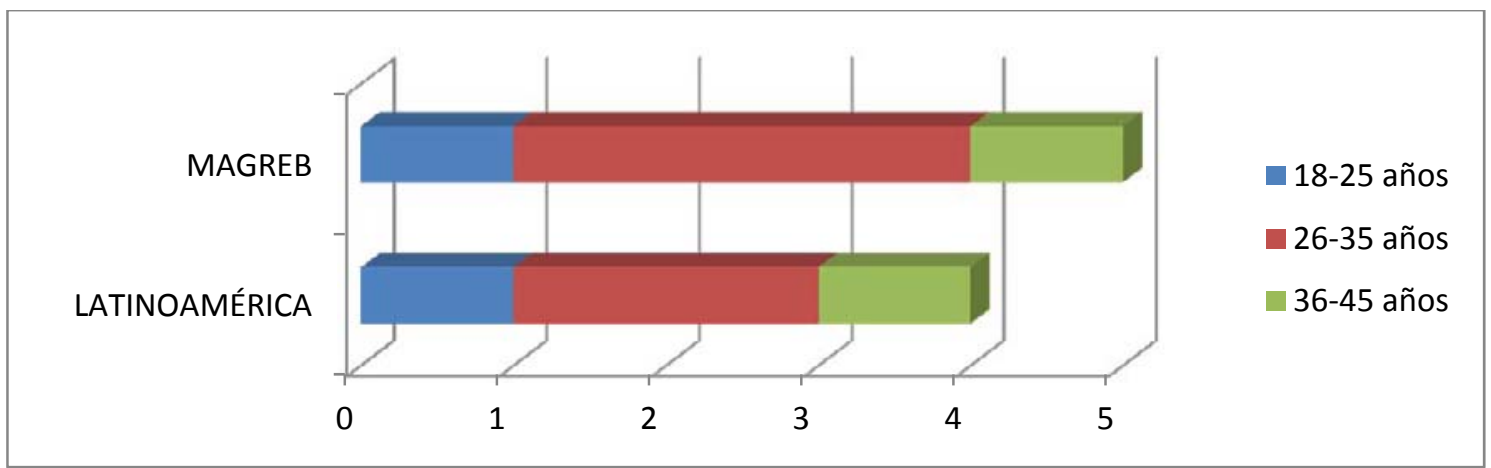

Gráfico 6.43. Colectivo inmigrante y edad de las usuarias participantes en los grupos de discusión

Por otra parte, todas ellas llevaban residiendo en España un periodo de tiempo relativamente amplio, en ningún caso inferior a los 6 años. Este hecho, junto con la exigencia de que hubieran tenido algún hijo en este país (dato que expondremos a continuación), nos garantizaba que las participantes tuvieran la suficiente experiencia en el contexto de estudio (tanto en sentido amplio -en el país- como en sentido más concreto -en el ámbito de la obstetricia) como para poder aportar datos significativos durante la discusión. En el siguiente gráfico queda reflejado el tiempo de permanencia en España de las usuarias, sin distinción por colectivo de origen.

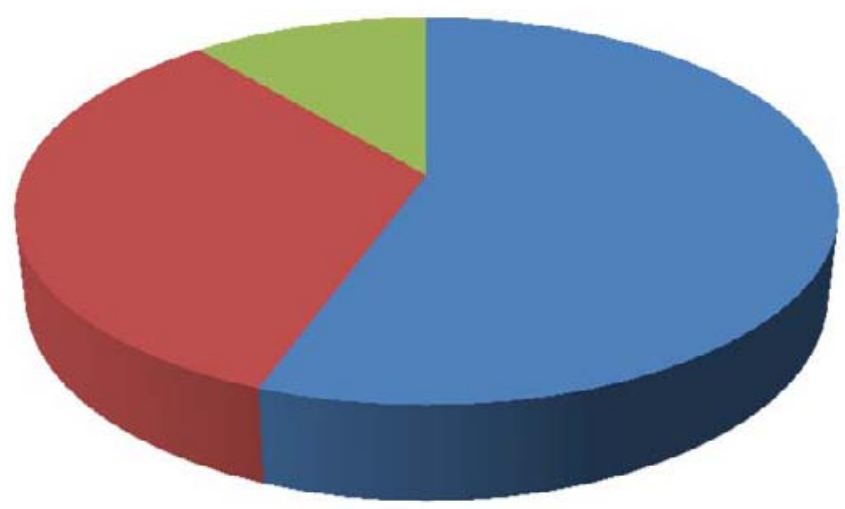

6-10 años

11-15 años

Más de 15 años

Gráfico 6.44. Usuarias participantes en los grupos de discusión y tiempo de permanencia en España 
Con respecto al número de hijos de las usuarias, podemos ver en los gráficos mostrados a continuación que la tasa de fecundidad media (a diferencia de lo que habíamos supuesto previamente) no era excesivamente alta (1,8 en el caso de las latinoamericanas y 2,4 en el caso de las magrebíes). ${ }^{273}$ Asimismo, el hecho de que algunas de ellas hubieran dado en luz también en sus respectivos países de origen permitió que estas contrastaran la atención recibida en dichos países y en España durante el embarazo, el parto y el puerperio.

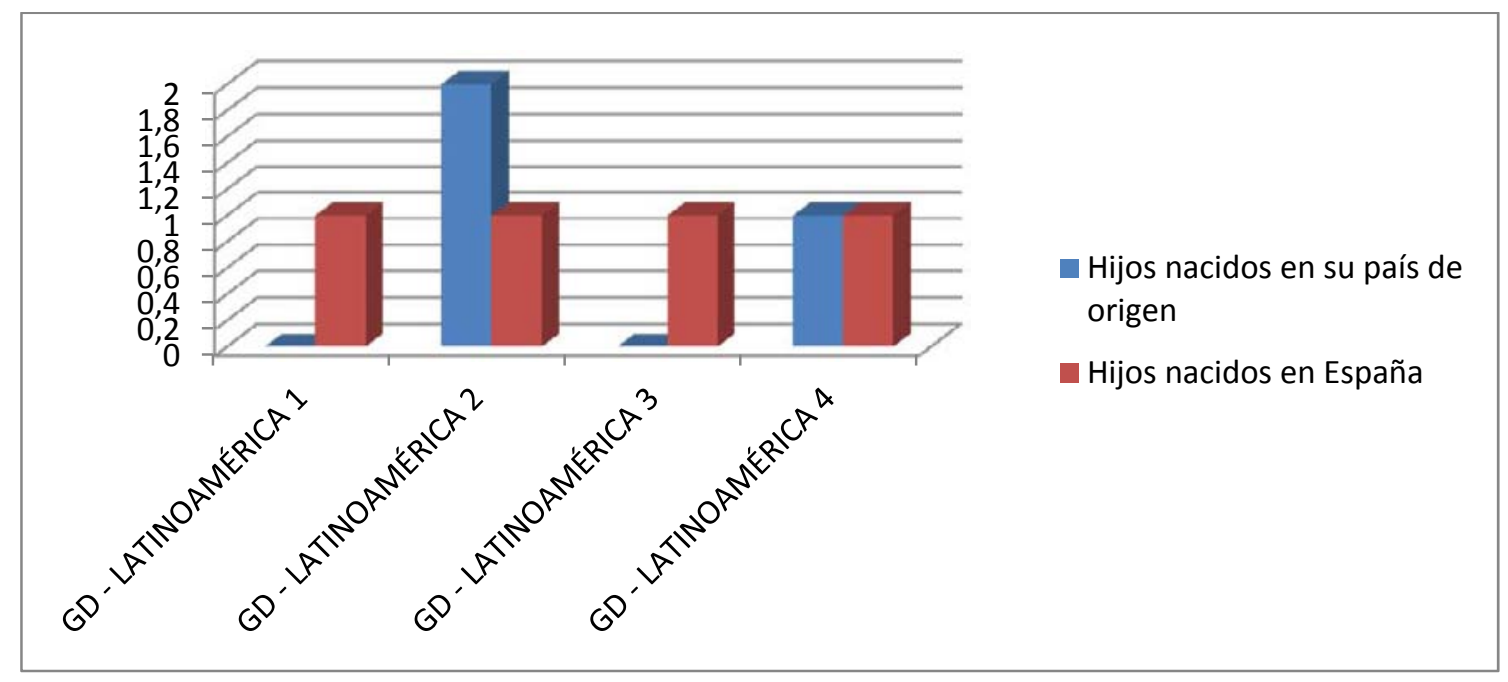

Gráfico 6.45. Usuarias latinoamericanas participantes en el grupo de discusión y número de hijos

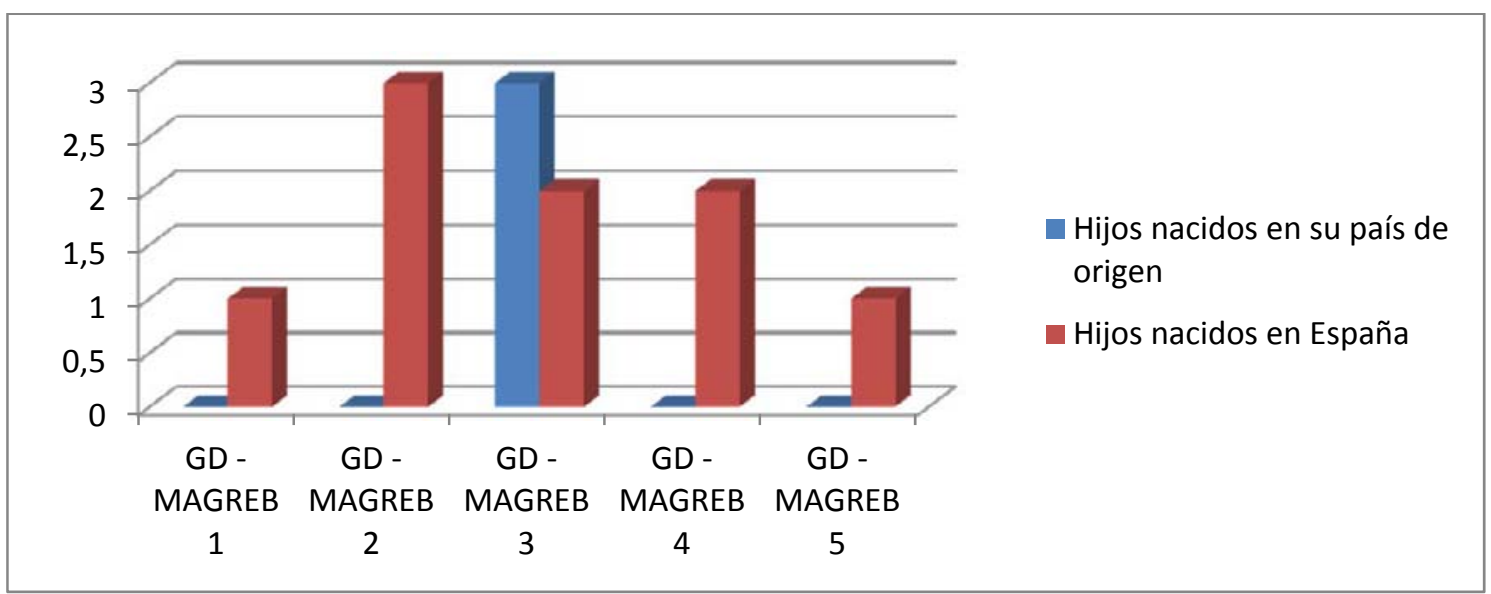

Gráfico 6.46. Usuarias magrebíes participantes en el grupo de discusión y número de hijos

Nos gustaría destacar un dato que nos ha resultado llamativo en las usuarias participantes de ambos grupos, relativo a la edad en la que algunas de estas tuvieron a su primer hijo. En concreto, dos usuarias (una procedente de Ecuador y otra procedente de Marruecos) fueron primíparas a los 17 años, y la edad media a la que tuvieron su primer hijo, tanto en el caso de las latinoamericanas como en el de las magrebíes, era bastante joven, 22 y 23 años respectivamente.

Por último, por lo que respecta a la lengua materna de las participantes, esta era el español en el grupo de usuarias latinoamericanas, y el árabe en el grupo de las usuarias magrebíes. En el

\footnotetext{
${ }^{273}$ No hemos considerado en estos datos el caso de una de las usuarias procedente de Marruecos quien, durante la celebración del grupo de discusión, nos reveló que estaba embarazada de su segundo hijo.
} 
caso de estas últimas, establecimos como requisito indispensable para participar en el grupo que poseyeran conocimientos medio-altos de español, de manera que pudieran participar activamente en la discusión.

\subsubsection{Datos conceptuales o teóricos}

Tras la presentación de los datos contextuales de los grupos de discusión y los datos demográficos de los participantes en los mismos, pasamos a analizar los datos conceptuales o teóricos recolectados mediante esta técnica. Dividimos el análisis en las mismas categorías o áreas previamente consideradas en los subapartados de este capítulo centrados en las entrevistas y en la observación no participante:

1. Introducción

2. Asistencia sanitaria general

3. Embarazo, parto y puerperio

4. Barreras lingüísticas y soluciones

5. Interacción

6. Actitudes sociales

Antes de iniciar el análisis de las diferentes áreas, realizamos un estudio de carácter más general de las respuestas ofrecidas por los participantes en los grupos de discusión. En concreto, en base al análisis de las palabras que aparecían con mayor frecuencia en las respuestas de los tres grupos, ${ }^{274}$ en el que el tamaño de las palabras indica el número de veces que estas han sido empleadas por los participantes, podemos deducir que, entre los términos más mencionados, se hallan "Latinoamérica", "Magreb" y "obstetra".

ahora algún antes bueno claro Cuando decía dicen dicho durante ejemplo ellas embarazo entonces estaba estás gente había hacer hasta hombre hospital latinoamérica wego mater magreb marido marruecos matrona médico menos meses muchas mucho mujer obstetra parto porque risas también tener tengo tenía tiempo tiene tienes todas veces verdad

Gráfico 6.47. 50 palabras más usadas por los participantes en los grupos de discusión

\footnotetext{
${ }^{274}$ Hemos extraído la frecuencia de uso mediante una búsqueda a través del programa NVivo 10 de las cincuenta palabras de más de cuatro letras mayormente empleadas por parte de los participantes en los grupos de discusión en sus respuestas a los temas planteados.
} 
El hecho de que los términos más empleados en los grupos de discusión se refieran a los participantes en los mismos o a su zona de origen no se aleja de los fines de nuestra investigación, ya que lo que nos interesa estudiar es precisamente la interacción y la comunicación entre profesionales y usuarias y, por tanto, nuestras preguntas se centran en las relaciones e intercambios comunicativos entre ambos.

Cabe recordar que, al realizar este mismo análisis pero con los datos recolectados mediante las entrevistas, habíamos detectado que uno de los términos que tanto los profesionales como las usuarias habían empleado más frecuentemente era "problema" y su plural "problemas". Hemos querido comprobar si los participantes en los grupos de discusión también mencionaban este término en sus respuestas, pero esta vez hemos evitado conscientemente por nuestra parte usarlo en el planteamiento de los temas a debatir. El resultado es que, en este caso, los términos "problema/s" no aparecen entre los más utilizados por los participantes en los grupos, por lo que podemos deducir que quizás se hallaban presentes en las respuestas de los entrevistados porque, en cierto sentido, el empleo de dichos términos en las preguntas planteadas podría haberles conducido a mencionarlos con mayor frecuencia.

Pasamos, a continuación, a realizar el análisis de cada uno de los nodos conceptuales generales en los que hemos codificado las respuestas ofrecidas en los grupos de discusión. Junto a los datos grabados y transcritos proporcionados verbalmente por los participantes, exponemos también los resultados de los cuestionarios individuales que estos completaron tras haber finalizado el encuentro.

En esta ocasión no mostramos las capturas de pantalla de nuestro proyecto con el programa NVivo 10 en las que aparecen los subnodos específicos en los que hemos clasificado nuestro análisis, puesto que coinciden con los creados para el análisis de los datos recolectados con las entrevistas. 


\subsubsection{Introducción}

En este subapartado introductorio incluimos, en primer lugar, la opinión general de los profesionales sanitarios en cuanto a la asistencia a las usuarias inmigrantes.

De acuerdo con las respuestas proporcionadas por estos profesionales en los cuestionarios individuales que completaron tras concluir el grupo de discusión, dicha asistencia es ciertamente difícil, ya que, en una escala de 1 a 10 (siendo 10 la puntuación correspondiente a una mayor complicación), la mayoría de ellos, tal y como puede observarse en la siguiente tabla, indicaron que el grado de dificultad era 7.

\begin{tabular}{|l|l|l|l|l|l|l|l|l|l|l|}
\hline & $\mathbf{1}$ & $\mathbf{2}$ & $\mathbf{3}$ & $\mathbf{4}$ & $\mathbf{5}$ & $\mathbf{6}$ & $\mathbf{7}$ & $\mathbf{8}$ & $\mathbf{9}$ & $\mathbf{1 0}$ \\
\hline Enfermera 1 & & & & & & & $\mathrm{X}$ & & & \\
\hline Matrona 1 & & & & & & & $\mathrm{X}$ & & & \\
\hline Matrona 2 & & & & & & & $\mathrm{X}$ & & & \\
\hline Obstetra 1 & & & & & & & & $\mathrm{X}$ & & \\
\hline Obstetra 2 & & & & & & $\mathrm{X}$ & & & & \\
\hline Obstetra 3 & & & & & & $\mathrm{X}$ & & & & \\
\hline
\end{tabular}

Tabla 6.1. Grado de dificultad de la asistencia sanitaria a usuarias inmigrantes de acuerdo con los profesionales participantes en el grupo de discusión (10 "Muy complicada"; 1 "Muy sencilla”)

Al respecto, como puede observarse en los fragmentos del grupo de discusión que se muestran a continuación, ${ }^{275}$ los profesionales consideran que, por su parte, tratan de ofrecer la misma asistencia a todas las usuarias, independientemente de su origen. Sin embargo, sí que perciben ciertas dificultades y desconfianza por parte de las usuarias inmigrantes, aunque uno de los profesionales participantes en el grupo opina, al igual que habían manifestado algunos compañeros suyos en las entrevistas, que estos problemas son cada vez menores y descienden a medida que las usuarias se van integrando en la sociedad de acogida. Quizás lo que no tienen en cuenta estos profesionales es que, a medida que algunas usuarias se van integrando, van llegando nuevos flujos migratorios. Asimismo, podemos observar cómo desde el principio se señalan las barreras lingüísticas como uno de los principales obstáculos con los que se enfrentan los profesionales sanitarios a la hora de atender a las usuarias inmigrantes.

Vamos a ver, yo pienso que, por parte de nosotros, los profesionales, la asistencia a usuarias inmigrantes es la misma, porque seguimos unos protocolos, hacemos con todas un poquito lo mismo. $\mathrm{Y}$, no sé si estaréis de acuerdo, pero creo que llevamos una coordinación y se hace para todas lo mismo. Pero, de cara de ellas hacia nosotros, sí que creo que la asistencia es diferente. [...] Que también pasa con las de aquí, ¿eh?, que de todo hay, pero sí que seguramente hay una cierta dificultad y como una desconfianza,

275 Tratándose el grupo de discusión de una especie de entrevista grupal en la que los participantes dialogan y debaten entre sí, en la mayoría de los casos, no incluiremos las intervenciones particulares de los participantes, sino que mostraremos fragmentos de la interacción entre los mismos. 
aunque en estos últimos años cada vez menos. Yo veo que... como que se van integrando cada vez más. [GD - Obstetra 2]

Yo opino parecido. Que la asistencia intentamos que sea a todas por igual. Lo que pasa es que en la asistencia a inmigrantes podemos tener dificultades, con el idioma fundamentalmente, y de seguimiento. [GD - Obstetra 3]

Uno de los participantes considera, además, que la asistencia a las usuarias inmigrantes puede variar en función del país de origen de las mismas, ya que cree que algunas usuarias en concreto (como, por ejemplo, las procedentes de China) se muestran más "cerradas" y presentan un mayor y más prolongado desconocimiento del español.

Y, por supuesto, también va a depender mucho del grupo. No es lo mismo las sudafricanas de la zona ecuatorial, que son musulmanas, pero son mucho más abiertas, o las rumanas o las de la zona de Eslovenia, que te aprenden enseguida el idioma, que otros grupos que hay que viven más cerrados, como las chinas y por ahí... Vienen al quinto embarazo y, bueno, ya te tienen confianza, pero con el idioma y demás estamos como el primer día. Esa es mi impresión personal, ¿eh? [GD - Obstetra 2]

Igualmente, también de acuerdo con las respuestas de los profesionales a los cuestionarios individuales, existen diferencias dependiendo del país de origen de las usuarias. Tal y como puede comprobarse en la tabla presentada a continuación, consideran que los colectivos cuya asistencia presenta mayores dificultades son, en este orden, los conformados por las usuarias asiáticas, las de la comunidad gitana, las magrebíes, y, en último lugar, las subsaharianas. No señalan, sin embargo, como dificultosa la asistencia a otros colectivos de usuarias inmigrantes, como las latinoamericanas o las procedentes de Europa del este, tal vez porque en estos casos, como señalaron algunos profesionales sanitarios en las entrevistas, la comunicación suele ser más sencilla por su dominio del español.

\begin{tabular}{|c|c|c|c|c|c|c|c|c|c|}
\hline & NO & sí & $\begin{array}{l}\text { Usuarias } \\
\text { asiáticas }\end{array}$ & $\begin{array}{l}\text { Usuarias } \\
\text { autóctonas }\end{array}$ & $\begin{array}{l}\text { Usuarias } \\
\text { gitanas }\end{array}$ & $\begin{array}{c}\text { Usuarias } \\
\text { de Europa } \\
\text { del este }\end{array}$ & $\begin{array}{l}\text { Usuarias } \\
\text { magrebíes }\end{array}$ & $\begin{array}{c}\text { Usuarias } \\
\text { latinoamericanas }\end{array}$ & $\begin{array}{c}\text { Usuarias } \\
\text { subsaharianas }\end{array}$ \\
\hline Enfermera 1 & & $\mathrm{X}$ & $\mathrm{X}$ & & & & $x$ & & $x$ \\
\hline Matrona 1 & & $x$ & $x$ & & $x$ & & & & \\
\hline Matrona 2 & & $x$ & $x$ & & $x$ & & & & $X$ \\
\hline Obstetra 1 & & $x$ & $\mathrm{X}$ & & $x$ & & & & \\
\hline Obstetra 2 & & $x$ & $x$ & & & & $x$ & & \\
\hline Obstetra 3 & & $X$ & & & $x$ & & $x$ & & \\
\hline
\end{tabular}

Tabla 6.2. Mayores dificultades en la asistencia a determinados colectivos de usuarias inmigrantes de acuerdo con los profesionales participantes en el grupo de discusión

Entre las causas de las dificultades en la asistencia a usuarias inmigrantes, aparte de las barreras lingüísticas ya mencionadas, los profesionales participantes en el grupo de discusión también señalan el menor control del embarazo por parte de algunas de estas usuarias y el mayor recurso a los servicios de urgencias. 
No todas, pero sí que es verdad que hay un porcentaje pues... que tienen un control irregular. [GD Obstetra 3]

Pues yo no sé aquí qué percepción tenéis. Yo he estado diez años trabajando en comarcales, y lo que eran era muy demandantes de urgencias. [GD - Matrona 1]

Sí, esa también es otra característica. [GD - Obstetra 3]

Me refiero a que lo del control de embarazo era un poco al azar, y dependía de si les venía bien o si estaban aquí, pero, sin embargo, de urgencias sí que te venían con un montón de hojas de atención. [GD Matrona 1]

Sí, totalmente de acuerdo, porque sí que te vienen con... [GD - Obstetra 2]

Es como si tuvieran otro... otro concepto, no lo sé. [GD - Obstetra 3]

Es que son, no sé, para entendernos, como más desorganizadas. [GD - Obstetra 2]

Bueno, hablamos en general, ¿eh? Igual hay cosas que nosotros no conocemos tampoco... [GD - Obstetra 3]

Sí, pero en general, se saltan más las citas y... luego, te aparecen. Pero, también, excepcionalmente, te llevas alguna sorpresa, que te viene algún marido y te dice "Que teníamos hoy cita, pero acabamos de tener al niño y queríamos avisarle de que todo ha ido muy bien". Pero eso es muy, muy excepcional. Lo normal es que pasen un poco... Van a su bola $y$, como saben que tienen el problema en urgencias resuelto... Eso sí, las ecografías, perfectas, esas sí que las hacen. Es decir, no es un problema de que se les pase, sino que ellas utilizan los servicios sanitarios a su conveniencia, porque si no, se les pasarían también las ecografías. [GD - Obstetra 2]

Cabe señalar varias cuestiones en relación con estos últimos datos aportados. Por una parte, los profesionales sanitarios (excepto uno de ellos que reconoce no disponer de suficiente información y se plantea la posibilidad de que el concepto del embarazo sea diferente en algunos colectivos) consideran que el control irregular del embarazo por parte de algunas usuarias inmigrantes se debe a su desorganización o al uso que realizan de los servicios sanitarios según su disponibilidad o conveniencia. Por otra parte, resulta llamativo el hecho de que, a pesar de no acudir a todas las citas programadas durante el embarazo, las usuarias inmigrantes sí que suelan realizar todas las ecografías prescritas. Veremos más adelante cómo las usuarias participantes en los otros dos grupos de discusión nos comentan que, para ellas, son muy convenientes las ecografías para detectar posibles complicaciones en el embarazo o problemas en el feto durante su desarrollo, y quizás por este motivo sí que, por lo general, las realizan.

Además, uno de los profesionales participantes indica otro tipo de causas de carácter religioso o cultural que pueden dificultar la asistencia a usuarias inmigrantes y que pueden afectar a cuestiones como los hábitos alimentarios, la higiene o el seguimiento de los tratamientos prescritos.

$Y$, luego, a la hora de seguir las normas y tal, pues, la verdad es que tenemos que combatir bastante con temas religiosos y culturales. Por ejemplo, ahora estamos en el Ramadán. Pues, el Ramadán, la higiene, esto, lo otro, las pautas de comida, que no te hacen caso con la medicación y hacen lo que les da la gana... [GD - Obstetra 2]

En los cuestionarios individuales parecen corroborarse estos datos, ya que, como figura en la siguiente tabla, los profesionales señalan como la causa principal de las dificultades en la 
asistencia a usuarias inmigrantes las diferencias lingüísticas, seguidas por las diferencias culturales generales, y sitúan en el mismo y último lugar las diferencias que pueden existir en cuanto a la cultura sanitaria y los problemas que suelen encontrar a la hora de relacionarse con los maridos y familiares de las usuarias. Aunque no disponemos de datos suficientes como para afirmarlo con rotundidad, podemos deducir que, por la escasa importancia que parecen dar a las diferencias relativas a la cultura sanitaria, quizás estos profesionales, tal y como sucedía en el caso de los entrevistados, no son plenamente conscientes de que, en las diferentes culturas, existen distintos conceptos de salud y enfermedad (o, en nuestro caso, distintos conceptos del embarazo, el parto y el puerperio).

\begin{tabular}{|l|c|c|c|c|c|}
\hline & $\begin{array}{c}\text { Diferencias } \\
\text { culturales } \\
\text { generales }\end{array}$ & $\begin{array}{c}\text { Diferencias cultura } \\
\text { sanitaria }\end{array}$ & $\begin{array}{c}\text { Diferencias } \\
\text { lingüísticas }\end{array}$ & $\begin{array}{c}\text { Interacción con } \\
\text { maridos y } \\
\text { familiares }\end{array}$ & Otras \\
\hline Enfermera 1 & 2 & 4 & 1 & 3 & 3 \\
\hline Matrona 1 & 4 & 2 & 1 & 2 & 4 \\
\hline Matrona 2 & 4 & 3 & 1 & 4 & \\
\hline Obstetra 1 & 2 & 3 & 2 & 3 & \\
\hline Obstetra 2 & 1 & 3 & 1 & & \\
\hline Obstetra 3 & 2 & 4 & & & \\
\hline
\end{tabular}

Tabla 6.3. Causas de las dificultades para tratar a usuarias inmigrantes de acuerdo con los profesionales participantes en el grupo de discusión (1 "Causa principal”; 4 "Causa menor") 
Por lo que respecta a las usuarias inmigrantes participantes en los grupos de discusión, en general valoran positivamente la asistencia recibida en España durante el embarazo, el parto y el puerperio, tal y como puede observarse en la tabla que mostramos a continuación.

\begin{tabular}{|l|l|l|l|l|l|l|l|l|l|l|}
\hline & $\mathbf{1}$ & $\mathbf{2}$ & $\mathbf{3}$ & $\mathbf{4}$ & $\mathbf{5}$ & $\mathbf{6}$ & $\mathbf{7}$ & $\mathbf{8}$ & $\mathbf{9}$ & $\mathbf{1 0}$ \\
\hline Latinoamérica 1 & & & & & & & & $\mathrm{X}$ & & \\
\hline Latinoamérica 2 & & & & & & & & & $\mathrm{X}$ & \\
\hline Latinoamérica 3 & & & & & & & & $\mathrm{X}$ & & \\
\hline Latinoamérica 4 & & & & & & & & $\mathrm{X}$ & & \\
\hline Magreb 1 & & & & & & & & & $\mathrm{X}$ & \\
\hline Magreb 2 & & & & & $\mathrm{X}$ & & & & & \\
\hline Magreb 3 & $\mathrm{X}$ & & & & & & & & & \\
\hline Magreb 4 & & & & & & & & $\mathrm{X}$ & & \\
\hline Magreb 5 & & & & & & & & $\mathrm{X}$ & & \\
\hline
\end{tabular}

Tabla 6.4. Valoración de la atención recibida durante el embarazo, el parto y el puerperio de acuerdo con las usuarias participantes en los grupos de discusión

(10 “Excelente atención”; 1 “Muy mala atención”)

En referencia a los aspectos negativos percibidos en dicha asistencia, las participantes en ambos grupos nos relatan experiencias personales en las que algún miembro del personal sanitario no las ha tratado adecuadamente. En concreto, comentan casos en los que algunos profesionales no les han respondido correctamente, no han mostrado empatía o sensibilidad, o no han sabido comprender que sus quejas estaban motivadas por los fuertes dolores padecidos. De todos modos, vemos que, junto a estas experiencias negativas, algunas usuarias también mencionan a aquellos profesionales sanitarios que, a diferencia de algunos de sus compañeros, las han tratado bien, como si intentaran matizar sus críticas o comprendieran que la asistencia puede depender de cada profesional concreto y del carácter o estado emocional del mismo en el momento de la interacción. Cabe señalar que esta variabilidad en el trato por parte de los profesionales sanitarios también la habíamos encontrado en las opiniones manifestadas por algunas usuarias entrevistadas o durante la observación.

¿Te refieres en cuanto al personal o al centro? (Le aclaro que me refiero a ambas cosas). Bueno, pues a mí, en cuanto al personal, en algunos, la experiencia ha sido negativa $y$, en otros, positiva; pero bueno, digamos que en cuanto al personal, la experiencia ha sido más bien negativa. [GD - Latinoamérica 4]

Pues... Yo aquí con la Seguridad Social sí que tuve un problema cuando me hicieron la primera ecografía, porque me hicieron doler muchísimo. Y yo pregunté si era normal, ¿no? Vamos, si era normal que me doliera cuando me hicieron la ecografía a los tres meses, y no me contestaron. $O$ sea, tuve una mala experiencia. Pero, luego, en la privada sí que me atendieron muy bien. $Y$, entonces, decidí hacerme los controles por la privada. Como tenía un seguro particular, ya tú sabes que ahí es una atención más 
personalizada, y me atendieron de lujo. Y también me hicieron una cesárea en la Quirón ${ }^{276}$ y me trataron muy bien. [...] Fue aquí donde tuve esa... esa pequeña riña con la ecografista que... que no me quiso responder las preguntas y tenía como un aire de superioridad y me miraba... un poco mal. [GD Latinoamérica 2]

Pues a mí me pasó, a mí me hicieron una cesárea, porque mi hijo nació con 4 kilos 200 gramos, y entonces, claro, al levantarme... Bueno, que me hicieron la cesárea, y yo ya estaba estupenda y, al levantarme, pues una de ellas me chilla, o sea, me protegieron demasiado, y yo no quería que fuera así, porque yo ya me quería duchar y tal... Pero, del resto... Solo quisiera que no nos protejan tanto, que no nos vamos a morir. (Risas). [GD - Latinoamérica 3]

Pues... Yo tengo tres niños, pero uno diferente de los dos. Por ejemplo, el mayor yo he dado la luz en el hospital $X$, el segundo en el hospital $Y$, y el tercero otra vez en $X .{ }^{277}$ Entonces, en $Y$ fue mal. Fue fácil, para dar la luz fue fácil, pero el comportamiento fue mal. En cambio, el primero fue muy difícil, pero los médicos... no tengo palabras, muy bien, me tratan muy bien. Y el segundo, que fue fácil, solo una hora dar la luz, pero no me tratan bien. [GD - Magreb 2]

Yo, en cambio, en $\mathrm{X}$, como durante el embarazo tenía problema de diabetes, que tenía el nivel de azúcar muy alto, tenía que pincharme con insulina. $Y$ justo una semana antes de dar a luz, fui al hospital para que me hicieran la ecografía, y yo fui a las diez y me dijeron "No, tú tienes que dar a luz hoy, porque el niño está seco, no tiene el agua". Y me han dicho que tengo que esperar un poco, y yo estaba ahí sin comer ni nada. Y me quedé ahí en el pasillo esperando hasta las tres. Tenía la cita a las diez y me quedé ahí esperando hasta las tres, y no vino nadie a... Y yo, como no pregunto mucho, pero tengo hambre, que tengo que comer... Gracias a dios que vino el médico que me trataba durante el embarazo, que tenía este día la guardia ahí, y me dijo "¿Qué estás haciendo aquí?", y le digo todo y se enfadó y fue a hablar con las enfermeras y, desde ahí, ha cambiado un poco el comportamiento. Bueno, luego, me quedé ahí dos días antes de dar a luz y probaron varios métodos para provocar el parto, y el día del parto vino el dolor muy fuerte, y yo llevaba dos días con pastillas y con suero, y no me imaginaba que voy a gritar mucho, pero, con el dolor que tenía, no puedo soportar, y las enfermeras me trataron muy mal. Me decían "¿Por qué gritas?". Y es que no es una cosa en mis manos para controlarla, es que es un dolor... [...] Y había una, una enfermera sola, que estaba en todo momento a mi lado, que me acariciaba así y me dice... Pero las otras, no. [GD - Magreb 4]

Yo, con el primero, como fue muy difícil, estaba ingresada tres días antes de dar la luz, porque ya llevaba embarazada diez meses y no tenía ni dolor ni nada. Y, además, el niño también está arriba, no baja, ni cambia, ni nada. Pero el médico que encuentro era muy majo, y se queda conmigo hasta que doy la luz. Lo que pasa es que las enfermeras, después de dar la luz, me pasa a mí también que... Porque, después de dar la luz, la tripa te duele. El dolor que tienes en la tripa no lo puedes soportar. Y, cuando viene la enfermera, te tiene que tocar, te tiene que tocar fuerte $y$, entonces, con el dolor, tú no puedes, y yo empiezo a llorar. Y me dice “¿Por qué tú te quejas? ¿Por qué tú lloras? ¡No te duele nada! ¡Ay, qué quejicas!". Y claro que yo siento dolor. Yo no quiero llorar. Y, en cambio, en el segundo, fue muy fácil, pero una doctora me trata muy mal y me dice "No, aún no, no te toca". Y yo, cuando me vienen contracciones, yo llamo y digo "Ahora, ahora, viene ahora", y me dice "Mentira. Eso es mentira. Eres tú que estás haciendo... que estás provocando". [...] Y, entonces llega una doctora y me ha dicho "Mira, te digo una manera muy buena para tener parto fácil". Y esto no me habían dicho antes. Y ella me ha dicho "Si quieres empujar, cierra la boca, para que las fuerzas salen de debajo, porque si estás abriendo la boca, el aire sale por arriba y no haces fuerza". Entonces, cuando me ayuda esta doctora, sale muy fácil. [GD - Magreb 2]

\footnotetext{
${ }^{276}$ Se refiere a un hospital privado situado en la ciudad de Zaragoza que pertenece al Grupo Hospitalario Quirón. La primera clínica de este Grupo fue fundada en 1959 en esta misma ciudad y, hoy en día, cuenta, además, con centros en Valencia, San Sebastián y Barcelona.

${ }^{277}$ La usuaria se refiere a dos hospitales de la ciudad de Zaragoza, cuyo nombre no mencionamos para preservar la confidencialidad de estos centros hospitalarios. Otras usuarias magrebíes harán referencia a ellos, y siempre los identificaremos con $\mathrm{X}$ e $\mathrm{Y}$.
} 
Tal y como comentan algunas de estas usuarias, desearían, por tanto, que estos profesionales fueran más humanos y las trataran de manera igualitaria, a pesar de no compartir con ellas determinados rasgos culturales o las creencias religiosas.

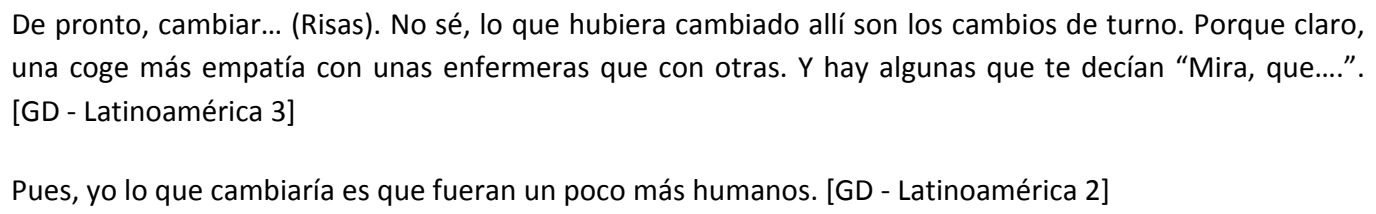

Pues yo haría que las personas no piensen igual. Porque aunque tenemos una religión y una cultura diferente, pues somos iguales todos. O sea, que ni la religión ni la cultura nos pueden... Es que no sé cómo decirlo... Es que si te tratan diferente, sufre el bebé, y tú más, porque eres más consciente. Es que estás en una situación que no te pueden tratar mal. Es que estás en un periodo que necesitas un tratamiento psíquico más... porque estás más sensible, más... [GD - Magreb 1]

Por el contrario, entre los aspectos positivos también señalan el trato recibido por parte de algunos profesionales, que les han aconsejado y atendido con amabilidad. Además, tanto en el caso de las usuarias latinoamericanas como en el de las magrebíes, algunas de ellas consideran que las instalaciones y los medios de los que disponen los servicios sanitarios españoles son aspectos a destacar positivamente.

En mi caso, en cambio, todo ha ido bien. Las instalaciones eran muy buenas, y el personal me ha tratado muy bien, o sea, han sabido tratarme adecuadamente, y me han ayudado mucho, porque con la edad que tengo, ellos me han aconsejado y me han dicho, pues... cómo tengo que comportarme como madre. Así que todo bien. [...] Yo, no. Yo, como te dije que a mí me fue todo bien, que me han atendido bien y tal, y yo no cambiaría nada. [GD - Latinoamérica 1]

Porque la atención aquí... son personas muy amables, y yo no tengo ninguna queja del hospital, y sobre todo mi doctor es un encanto. Así que yo valoro mucho la atención y cómo me acogieron de bien allí. [GD - Latinoamérica 3]

En cuanto a las instalaciones, mi experiencia es muy positiva, porque se cuenta con los medios para atenderlo a uno. [GD - Latinoamérica 4]

Para mí, que he dado la luz con gemelos y fue en el hospital Y, me han tratado bien. Porque todo el tiempo del embarazo me han tratado allí en el hospital, los análisis, las ecografías y todo, y me han tratado muy bien. Lo provocaron para que yo dar la luz y me han tratado muy bien. Ha venido el médico para verme y, además, las matronas también me han tratado muy bien, al menos para mí. [GD - Magreb 3]

Pues yo di a luz... Bueno, fui al hospital para revisión, pero me han cogido, porque el niño se había quedado sin agua. Entonces yo le digo a la persona, al médico, que yo me voy a mi casa para traer mi ropa, y él me dice "No, si tú sales de la puerta, pues tú asumes tu responsabilidad, porque tu niño puede morir dentro de una hora o de dos, o no sé...". Y allí me han tratado muy bien. [GD - Magreb 1] 
Hombre, algo bueno sí que hay. Por ejemplo, a nivel de material, siempre, siempre, siempre, ha habido más cosas que en nuestro país. $\mathrm{O}$ a la hora de las revisiones durante el embarazo, o también durante el parto, pues la atención es buena. [GD - Magreb 5]

Bueno, a mí, me pasó al revés que a ella (se refiere a GD - Magreb 2). Yo tuve dos niños, uno en el hospital $X$ y otro en $Y$. $Y$ yo de $Y$ la verdad es que no tengo nada negativo. Todo era muy bien, perfecto, el comportamiento de la gente y todo. [GD - Magreb 4]

Para concluir este subapartado, vamos a analizar las respuestas ofrecidas por parte de las usuarias participantes en los grupos de discusión sobre las diferencias existentes entre la asistencia durante el embarazo, el parto y el puerperio en los servicios sanitarios de sus países de origen y la recibida en España.

Algunas participantes admiten que desconocen si existen diferencias, ya que solo han dado a luz en España. Sin embargo, una de estas participantes, aunque ella personalmente no ha pasado un embarazo en su país de origen, afirma que la asistencia, de acuerdo con la opinión de familiares suyos que sí que cuentan con dicha experiencia o que trabajan en el ámbito sanitario allí, es mejor en España.

Yo de esto no sé qué decirte, porque como apenas tuve a mi primer hijo y fue aquí... [GD - Latinoamérica 1]

Yo, a ver, yo valoro mucho... Es que mi familia ha trabajado en hospitales en Colombia y mis primas han dado a luz allí, y todos dicen que es mejor aquí. [GD - Latinoamérica 3]

Esta opinión la corroboran otras participantes con experiencia en cuanto a salud reproductiva en ambos países, las cuales sostienen que las principales diferencias residen en la mayor calidad de las instalaciones y en el mayor número de controles prescritos durante el embarazo en España. Al respecto de estos controles, comentan que en sus respectivos países de origen son menos numerosos y, además, comienzan a realizarse cuando el estado de gestación se encuentra más avanzado. El hecho de que las pautas de seguimiento del embarazo sean distintas en uno y otro país puede ser la causa de que algunas usuarias inmigrantes, como sostenían los profesionales sanitarios entrevistados y los participantes en los grupos de discusión, acudan a los controles con escasa regularidad.

Yo, bueno... En cuanto a las instalaciones, sí que he notado un poco de diferencias. Y, en cuanto al personal... (Largo silencio). Es que, como casi no tenía contacto, porque acá es más periódico el tema de las revisiones, allí, no. Allí, la primera ecografía me la hicieron a los ocho meses. Entonces, cuando iba al control era algo... Porque no es como aquí, que le hacen a uno muchos controles y muchos exámenes y... [GD - Latinoamérica 4]

Pues, a mí, en Colombia, por lo que me han dicho mis primas, las ecografías se hacen ahora a los seis y a los nueve meses. Y aquí me hicieron las ecografías mes a mes. Las hacían mensualmente. [GD Latinoamérica 3]

Es la diferencia entre aquí y Marruecos. Porque allí te dicen que estás embarazada y, si no vas a un especialista que pagas, pues no te hacen los controles hasta que das la luz. Si no vas a hospital grande y eso, pues no te hacen revisión. Yo tuve mi primer hijo en Marruecos, y diferencias... he notado un poco, no mucho, porque también en Marruecos me han tratado muy bien. Pero la diferencia es de... creo que es de material y eso. Los medios aquí en los hospitales son un poco más... [GD - Magreb 3] 
Y allí las visitas que te indican son menos. Aquí, mientras el embarazo, te envían cartas y, como te avisan, pues dices "Tengo que ir". Pero, en Marruecos, no. [GD - Magreb 5]

La mayoría de las usuarias consideran que iniciar los controles más pronto y realizarlos periódicamente, tal y como se hace en España, puede dar a conocer con antelación si existen problemas de salud en la madre o en el feto $y$, por tanto, pueden ayudar a prevenir posibles enfermedades futuras o permitir que la madre decida si desea continuar con el embarazo.

No, yo creo que los controles son buenos. Pero allá, no. Imagínate, la primera ecografía a los ochos meses, y si hubiera algún problema con el niño es muy tarde para... [GD - Latinoamérica 4]

(Les pregunto si les parecen pocas o muchas las revisiones prescritas.)

Muchas, muchas, son muchas. (GD - Magreb 1 y GD - Magreb 5 a la vez.)

A mí, también me parecen muchas. Sobre todo con el segundo, son muchas. (GD - Magreb 4)

Pues a mí me parece bien así, porque estás más controlada. (GD - Magreb 2)

Por ejemplo, yo con una hija tuve un problema, porque no estaba aquí durante el embarazo y no me hicieron muchas revisiones. Y si estoy aquí, no me va a salir como ahora, que tiene problemas de corazón y todo eso. Porque en Marruecos solo me vio dos veces el médico y la niña estaba mal, pero como no ven dentro, pues no lo sabían. Y, luego, la niña nace aquí y, nada más nacer, la tienen que operar del corazón. Así que yo veo bien que aquí se hacen muchas revisiones. [GD - Magreb 3]

Asimismo, algunas usuarias magrebíes cuentan que existen diferencias entre los servicios sanitarios de las zonas urbanas y de las zonas rurales en su país de origen, Marruecos. Asimismo, afirman que, si desearan realizar un seguimiento más periódico de su embarazo en dicho país, deberían pagar por ello, lo cual supone otra diferencia con respecto a la gratuidad de este servicio en España.

(Les pregunto si ellas en Marruecos vivían en una ciudad o en una zona rural, y contestan todas que en una ciudad. Les comento que he leído que, en Marruecos, hay muchas diferencias entre los servicios sanitarios de las zonas rurales y los de las zonas urbanas.)

Sí, sí, esto es así. [GD - Magreb 1]

Es la diferencia entre aquí y Marruecos. Porque allí te dicen que estás embarazada y, si no vas a un especialista que pagas, pues no te hacen los controles hasta que das la luz. Si no vas a hospital grande y eso, pues no te hacen revisión. [GD - Magreb 2]

¿Sabes por qué? Porque en Marruecos tenemos hospital grande privado y hospital público. $Y$, entonces, en público, no dan importancia a hacer revisión, por ejemplo. Entonces, tienes que pagar. [GD - Magreb 3]

Sí, si quieres un seguimiento perfecto, tienes que pagarlo. [GD - Magreb 1]

\subsubsection{Asistencia sanitaria general}

Por lo que se refiere al nodo de Asistencia sanitaria general, dividimos el análisis de los datos recolectados en los grupos de discusión en los mismos subnodos o subtemas presentes en este mismo subapartado del análisis de los datos de las entrevistas, es decir, hablamos, por un lado, de cuestiones relacionadas con la cultura sanitaria de las usuarias inmigrantes $y$, por otro, del comportamiento de las mismas durante su estancia en el hospital. Sin embargo, tal y como ha 
sucedido en el análisis de la observación no participante, centramos el análisis de estos temas en la asistencia durante el embarazo, el parto y el puerperio. No podemos incluir en este subapartado cuestiones más generales relativas a la asistencia sanitaria en cualquier circunstancia, puesto que los temas a debatir durante los grupos de discusión, siendo más restringidos en comparación con los que se pudieron plantear durante las entrevistas, se centraron exclusivamente en la atención ofrecida o recibida en relación con la salud reproductiva, ámbito principal de nuestra investigación.

En referencia a la cultura sanitaria, no pudimos saber mediante el empleo de esta técnica si las usuarias inmigrantes tienen un concepto diferente del cuerpo y la enfermedad. La única referencia explícita a esta cuestión la realiza una de las participantes latinoamericanas, quien, al relatarnos un conflicto que tuvo con un profesional sanitario, nos da a entender que, tal y como sucede en España, ella tampoco considera que el embarazo sea una enfermedad, aunque opina que, si las condiciones del lugar de trabajo no son adecuadas, como era en su caso, se le debería conceder la baja durante el periodo de gestación.

\begin{abstract}
Yo les conté "Mire, es que las condiciones de trabajo son... Estoy trabajando en un sitio donde no hay aire. Es que se me baja la tensión". Porque en verano no había aire acondicionado y trabajábamos en un salón, en el bar donde me tocaba a mí, y en ese bar no entra viento por ninguna parte, ¿sabes? Y el techo era muy bajito y, entonces, el calor era insoportable. $Y$, encima, había que subir y bajar gradas y el piso de donde trabajábamos era muy resbaloso, eso era como andar en patines todo el tiempo. Entonces yo le explicaba a ella, a mi médico, cuáles eran las condiciones de trabajo, y ella me decía que eso era lo que había y que el embarazo no era una enfermedad. Y yo le decía "Es que yo no estoy diciendo que sea una enfermedad". Y ella contestaba "No, no, no, no. Que el embarazo no es una enfermedad". Y ahí se quedaba con eso. Esto me pasó en los controles que hacía en el centro de salud. Y a la chica la notaba como si tuviera algo personal conmigo y yo no entendía por qué... [GD - Latinoamérica 4]
\end{abstract}

Encontramos otras referencias al concepto de embarazo y puerperio, o a los cuidados que se deben suministrar en estos estados, cuando las usuarias participantes en el grupo de discusión con latinoamericanas nos hablan del recurso a la medicina tradicional y la automedicación para, por ejemplo, aumentar la producción de leche materna, evitar la aparición de gases en los recién nacidos, o recuperar el calor perdido durante el parto.

Ah, pues sí te dicen, ¿no?, que, por ejemplo, el agua de cacao te ayuda a tener más leche. Entonces, te
preparan agua de cacao y te la dan para... para que tengas más producción. (Risas). Bueno, en teoría...
Pues, ese tipo de cosas sí que hay, sí que hay mucho, bueno, allá en mi país por lo menos, ese tipo de
cosas se usan. Se usan también muchas plantas, como la manzanilla, o el anís, para los gasecitos. Te dicen
que tienes que tomar anís y, como das de lactar, pues así alivias un poco los cólicos de gases a los niños...
Se dicen muchas cosas, ¿no? [GD - Latinoamérica 2]
Yo estoy pensando... estoy pensando... Por ejemplo, para la leche, se toma maduro, ${ }^{278}$ maduro cocinado
con cáscara, con panela ${ }^{279}$ y hojas de nacedero. ${ }^{280}$ Eso para la leche. Y, después, le hacían a uno, después

278 En Colombia, Ecuador y Bolivia se denomina "maduro" al que en España se conoce como "plátano macho" o "plátano guineo", que es el "fruto de otra musácea del mismo género que el plátano, procedente de una especie originaria de la India y muy cultivada en América Central y las Antillas". Fuente: Diccionario on-line de la Real Academia Española. [http://lema.rae.es/drae/?val=maduro] (última consulta: 24 de julio de 2013).

${ }^{279}$ La panela es, como nos explica más tarde otra de las usuarias participantes en el grupo de discusión, un derivado de la caña de azúcar. En concreto, este término se usa en Colombia, El Salvador y Honduras para referirse al "azúcar mascabado en panes prismáticos o en conos truncados". Fuente: Diccionario on-line de la Real Academia Española. [http://lema.rae.es/drae/?val=panela] (última consulta: 24 de julio de 2013).

${ }^{280}$ El nacedero (Trichanthera gigantea) es una especie de planta arbórea, de la familia de las acantáceas, que se usa principalmente para la alimentación de animales y que crece en países como Colombia, Bolivia, Panamá y 
de los cuarenta días, eee... pues te dan muchas hierbas, que todas eran calientes. Pero es que no sé el nombre de las hierbas, porque tú vas donde venden y te dan ya todas las hierbas unidas y, cuando llegas a casa, esas hierbas las cocinan y, con esa agua, te tienes que bañar, y es para sacar todo el frío que tienes. [GD - Latinoamérica 4]

Sí, es verdad, durante los cuarenta días está también lo de la dieta, ¿no? [GD - Latinoamérica 2]

Sí, eso de los cuarenta días a mí también me pasó. En el pueblo en el que yo vivo hay un grupo de colombianos que llevan muchos años acá, y me han dicho que... bueno, hay una señora que me cuidó la dieta durante los cuarenta días, y también me dijo que me tapase con unos algodoncillos los oídos, porque si me entraba aire por los oídos, podía quedar loca... Bueno, eran cosas de... de la yaya. Y me hizo tomar una cosa que se llama panela, que es un elaborado sacado de la caña de azúcar, y eso es como café, y me hizo una especie de... de infusión con una cáscara de plátano, pero plátano macho, no el plátano de Canarias, ese no, era plátano macho, y ese plátano estaba más malo que... (Risas). Ya estaba de tirar. Y me hizo eso como en una infusión y me lo dio a tomar. Y me salía leche como nunca en mi vida yo creo que... Porque era para producir leche. $Y$ eso fue lo que más me marcó, porque yo... (Risas), yo no tenía conocimiento, porque mis primas sí decían que se tomaban todo eso, pero yo decía "¡Bah, tonterías!". Y ya cuando llegué aquí, pues... Porque mi mamá tampoco era muy dada a hacer cosas así, sino que fue gente de mi propio país que vive aquí y... Y también con lo de cuidarle el ombligo al niño con Betadine, que ahí en Colombia se llama yodo, y le aplicaban yodo, y el médico me decía "No, tú aplícale alcohol 96 únicamente". Y claro, ella me decía "No, que se le va a pudrir el ombligo al niño, que se te va a morir...". O sea, mucha cosa rara, pero... [GD - Latinoamérica 3]

En relación con los posibles remedios naturales empleados por las usuarias inmigrantes, cabe señalar que los profesionales sanitarios entrevistados solo habían mencionado al colectivo chino. Sin embargo, la respuesta de una de las usuarias entrevistadas (en concreto, procedente de Honduras) sí que coincide con las de las participantes en el grupo de discusión con latinoamericanas, pues, en la entrevista, dicha usuaria comentaba que recurría a la medicina tradicional (principalmente a la ingestión de infusiones de hierbas) para tratar lo que consideraba dolencias leves.

Un último aspecto relacionado con la automedicación y que confirma uno de los datos aportados por las usuarias entrevistadas concierne a una mayor medicalización del embarazo en España con respecto a los países de origen de algunas usuarias. De hecho, una de las participantes en el grupo de discusión de usuarias latinoamericanas nos cuenta los tratamientos que le han recomendado en España durante el embarazo, los cuales, a su juicio, a pesar de ser más de los que se recomiendan en su país de origen, son adecuados.

Y con una atención... que tú ibas y te decían "Toma la Natal-B"281 o "Toma esto a aquello para que te produzca leche"... O sea, aquí hay muchos medicamentos que allí en mi país no se ven. Y, para mí, eso es muy positivo. [GD - Latinoamérica 3]

El siguiente subnodo que analizamos se centra en las creencias religiosas de las usuarias inmigrantes y los comportamientos asociados a dichas creencias. Los profesionales sanitarios entrevistados habían mencionado principalmente a las usuarias musulmanas como aquellas cuya asistencia podía presentar mayores problemas derivados de sus creencias religiosas, en

Venezuela. [http://pastosyforrajesieavm.blogspot.com.es/2009/11/nacedero.html] (última consulta: 25 de julio de 2013).

${ }^{281}$ Se refiere la B-Natal, un compuesto de vitamina B6 y glucosa que se receta a las embarazadas para aliviar las náuseas y los vómitos de lo que se conoce como "enfermedad de la mañana" (por el momento del día en que los trastornos asociados a dicha enfermedad se producen con mayor intensidad). [http://www.nutrivea-es.com/bnatal.htm] (última consulta: 25 de julio de 2013). 
especial por lo que se refiere a su preferencia por personal sanitario de sexo femenino (tema que abordaremos en el subapartado centrado en las actitudes sociales) y en relación con el ayuno prescrito en esta religión durante el Ramadán. Al respecto, los profesionales entrevistados eran conocedores del hecho de que las mujeres embarazadas están exoneradas de ayunar, y consideraban que no era recomendable el ayuno, sobre todo en los periodos estivales. Esta exoneración queda confirmada por las usuarias participantes en el grupo de discusión con magrebíes, las cuales, como puede observarse en el fragmento que incluimos a continuación, decidieron personalmente si ayunar o no durante el Ramadán cuando estaban embarazadas.

(Les pregunto qué dice el Corán acerca del seguimiento, mientras se está embarazada, del ayuno prescrito durante el Ramadán.)

Dicen que, si ves que lo estás haciendo y ves que estás bien, pues lo haces. Si ves que no puedes aguantar todo el día sin comer, puedes comer. O sea, que no es obligación nada que no podemos hacer. [GD Magreb 5]

No están obligadas las personas enfermas o muy ancianas. Tampoco las embarazadas o la mujer que da la leche a su hijo. Esos no están obligados. [GD - Magreb 2]

Yo, por ejemplo, me coincidió Ramadán con el embarazo de mi primer hijo y yo no hice ayuno. [GD Magreb 4]

Pues yo estoy ahora embarazada y lo estoy haciendo. Lo estoy haciendo y me siento fenomenal. No me encuentro mal, así que, ¿por qué no lo voy a hacer? Y si algún día me siento mal, pues no lo hago, y ya está. [GD - Magreb 5]

Otra cuestión asociada a las creencias religiosas se refiere a la costumbre de orar. Ya uno de los profesionales entrevistados había comentado que la oración durante la permanencia en el hospital podía conllevar problemas de convivencia. Este hecho parece confirmarse en el relato que nos ofrece en el grupo de discusión una de las usuarias magrebíes, según la cual, cuando se encontraba rezando y pidiendo a su dios que la protegiera y le ayudara con los dolores del parto, había recibido una reprimenda por parte de un profesional sanitario, el cual, por su actitud, no parecía comprender o respetar que la usuaria rezara en esos momentos, y mucho menos que lo hiciera en su lengua materna, el árabe.

Y, luego, yo estaba hablando en árabe, le estaba pidiendo a dios, y me dice “¿Qué dices en árabe?”. Y es que el tiempo del parto, pues claro que hablas en tu idioma. Y ella dice "Pero, ¿qué hablas en árabe?". Y yo le he dicho que estoy pidiendo a dios, y ella responde "Sí, sí, pide a dios, pide a dios" y me da un golpe con la mano, así (hace un gesto como golpeando) y sale. [GD - Magreb 2]

El último tema relacionado con la cultura sanitaria concierne a la comprensión y seguimiento de los tratamientos por parte de las usuarias inmigrantes. Ya hemos comentado en el subapartado anterior, por lo que no lo volveremos a incluir en este subapartado, que uno de los profesionales participantes en el grupo de discusión sostiene que algunas usuarias no siguen los tratamientos prescritos, aunque no indica si esto se da más en algún colectivo en particular, ni menciona las posibles causas de la falta de adhesión al tratamiento. Recordemos que, según algunos profesionales entrevistados, esta podía deberse a la incomprensión de los mismos por los escasos conocimientos de español que presentaban algunas usuarias inmigrantes. 
Por lo que respecta al comportamiento de las usuarias inmigrantes mientras se encuentran en el hospital, ni los profesionales ni las usuarias participantes en los grupos de discusión hacen referencia al cumplimiento de las normas de los servicios sanitarios por parte de estas últimas. Cabe recordar que los profesionales entrevistados sostenían que las usuarias que menos respetaban dichas normas eran las autóctonas, y consideraban que esto podía deberse a que generalmente estas conocen mejor sus derechos como pacientes que las usuarias inmigrantes. Tampoco durante la observación habíamos detectado ningún caso en el que alguna usuaria inmigrante hubiera incumplido las normas, excepto el de la familia que se había marchado del hospital sin entregar los documentos del registro del recién nacido. Por consiguiente, por los datos de los que disponemos a partir del uso de las diferentes técnicas, podemos deducir que estas usuarias no destacan por ser incumplidoras y que, en las ocasiones en las que no respetan las normas, puede deberse a que las desconocen o no las comprenden.

En cuanto al acompañamiento y las visitas, en las entrevistas y en la observación ya habíamos detectado que no son muchos los acompañantes de las usuarias inmigrantes, tanto en las consultas como durante su ingreso en el hospital. Tampoco las usuarias participantes en los grupos de discusión comentan que las acompañen muchas personas a los servicios sanitarios, por lo que este dato puede considerarse corroborado. De todos modos, en el siguiente subapartado, centrado en el análisis de las respuestas relativas al embarazo, el parto y el puerperio, añadiremos más detalles sobre los acompañantes de las usuarias inmigrantes en las diferentes fases de su proceso reproductivo.

Una última cuestión a señalar en relación con los acompañantes se refiere a un dato que nos habían aportado algunos profesionales sanitarios durante las entrevistas. En concreto, estos afirmaban que les resultaba llamativo que, en ocasiones, las usuarias estuvieran acompañadas por personas que no pertenecían a su círculo familiar o íntimo. Este hecho queda verificado en las respuestas de las usuarias participantes en los grupos de discusión, algunas de las cuales comentan que, en alguna ocasión, especialmente al principio de su estancia en España, han acudido a los servicios sanitarios con personas no pertenecientes a su familia, ya que estas personas conocían mejor el idioma o el funcionamiento de dichos servicios. La escasa presencia de familiares, junto con el desconocimiento del idioma o del funcionamiento de los servicios, pueden ser, por tanto, las causas que obligan a algunas usuarias inmigrantes a recurrir a sus redes sociales no estrictamente familiares para que las acompañen a las consultas o durante su ingreso en el hospital. Incluiremos los fragmentos de los grupos de discusión relativos a esta cuestión en el subapartado posterior de análisis de las barreras lingüísticas, ya que, cuando las usuarias magrebíes mencionan a estos acompañantes que no son de sus familias, se están refiriendo en especial al recurso a estos para que realicen funciones de intérpretes ad hoc.

El siguiente tema relacionado con el comportamiento de las usuarias inmigrantes se refiere a los hábitos alimentarios de las mismas. En las entrevistas y en la observación se había hecho referencia a las posibles diferencias con respecto a la alimentación considerada más adecuada durante el embarazo y el puerperio que presentaban algunas usuarias inmigrantes, en especial las procedentes de China, con respecto a las autóctonas. También una usuaria latinoamericana entrevistada nos había comentado que, en su país de origen, Honduras, después del parto, se solían ingerir determinados tipos de alimentos, y que se comía más de lo que se hace 
habitualmente en España durante el puerperio. Y esta diferencia se observa también en los comentarios de algunas usuarias de Latinoamérica participantes en el grupo de discusión, como puede observarse en el fragmento incluido previamente en el subapartado relativo a la medicina tradicional en el que las usuarias hacían referencia a los hábitos alimentarios favorables para obtener una mayor producción de leche materna o para evitar los gases en los recién nacidos.

Por el contrario, las usuarias magrebíes dicen no haber seguido ningún tipo de dieta especial durante el embarazo o en el puerperio.

\footnotetext{
(Les pregunto si durante el embarazo han seguido algún tipo de dieta o si, en general, ha cambiado en algo su alimentación durante el puerperio)

Yo no sigo dieta. [GD - Magreb 2]

Yo tampoco, yo como igual. Bueno, a lo mejor, como un poco más. [GD - Magreb 1]

Pues yo, durante el embarazo, bajo el peso (Risas). Sí, porque todo lo que como, durante nueve meses, lo vomito. [GD - Magreb 3]

Pues yo también vomito, pero me engordé mucho. [GD - Magreb 2]

Yo, con el primero, me engordé diecisiete kilos. Y, con el segundo, ni un kilo, porque con lo de la diabetes estaba muy controlada. [GD - Magreb 4]
}

El último aspecto relativo al nodo de Asistencia sanitaria general que tratamos se centra en los aspectos burocráticos. Al respecto, cabe recordar que los profesionales sanitarios participantes en el grupo de discusión señalaban que las usuarias inmigrantes, por lo general, suelen realizar un control irregular del embarazo y no siguen de manera estricta las visitas prescritas. Tanto algunos profesionales como algunas usuarias nos habían comentado en las entrevistas que esto podía deberse a diferencias en cuanto a los controles efectuados durante la gestación en España y en sus respectivos países de origen, algo que, como hemos señalado en el subapartado introductorio de análisis de los datos de los grupos de discusión, queda corroborado mediante el uso de esta técnica.

\subsubsection{Embarazo, parto y puerperio}

Tal y como hemos hecho en el análisis de los datos recolectados mediante las entrevistas, dividimos este el nodo de Embarazo, parto y puerperio en dos partes: en la primera, a modo de introducción, abordamos cuestiones relativas a la tasa de fecundidad, la edad a la que tienen el primer hijo y el recurso a la planificación familiar por parte de las usuarias inmigrantes $\mathrm{y}$, en la segunda, presentamos las creencias, comportamientos y actitudes de estas con respecto a las distintas fases del proceso reproductivo.

En relación con la edad a la que tienen el primer hijo, ya hemos comentado en los datos demográficos de las usuarias participantes en los grupos de discusión que, tanto las usuarias latinoamericanas como las magrebíes, de media, habían dado a luz la primera vez cuando eran bastante jóvenes (22 y 23 años respectivamente). Asimismo, cabe recordar que dos de las usuarias participantes en los grupos de discusión habían sido primíparas a la edad de 17 años. Estos datos parecen corroborar la opinión manifestada por los profesionales sanitarios en las 
entrevistas, los cuales sostenían que las usuarias inmigrantes y, en particular, las procedentes de Latinoamérica y África Subsahariana, así como las pertenecientes a la comunidad gitana son las que presentan una edad menor al dar a luz por primera vez. De todos modos, quizás estas tendencias, de acuerdo con algunos profesionales entrevistados y algunas usuarias participantes en los grupos de discusión, como veremos más adelante, estén cambiando y, poco a poco, la edad media a la que tienen su primer hijo las usuarias autóctonas y las inmigrantes se está equiparando. ${ }^{282}$

En cuanto a la tasa de fecundidad, si bien en el momento en que celebramos los grupos de discusión las usuarias participantes no tenían un gran número de hijos (de media, 1,8 en el caso de las usuarias latinoamericanas, y 2,4 en el caso de las magrebíes), la gran mayoría de ellas, tal y como puede observarse en los fragmentos que incluimos a continuación, desearía tener más hijos, por lo general, tres o cuatro. ${ }^{283}$

Nosotros lo que estamos pensando es ya no tener más hijos... Porque con tres ya... ya es suficiente. [GD Latinoamérica 2]

(Pregunto a las demás si ellas desean tener más hijos.)

Yo no, la verdad, por ahora, no. [...] digo yo "iMadre mía!”. Si así es como se tiene un hijo, yo lo digo, hoy por hoy lo puedo decir, y lo puedo asegurar, yo un hijo me lo pensaría para volverlo a tener. ${ }^{284}$ [GD Latinoamérica 3]

Yo, ahora mismo, creo que no, pero si estoy abierta a la... a tener más hijos más adelante. Sí, sí, sí. [GD Latinoamérica 4]

Yo sí, que ha sido el primero, y todavía soy muy joven. Me gustaría tener uno o dos más. Vamos, unos tres en total. [GD - Latinoamérica 1]

(Le pregunto si, visto que su primer hijo ha sido niño, si ahora le gustaría tener una niña.)

Pues, la verdad, si es niño o niña me da igual. Con que esté bien y tal... [GD - Latinoamérica 1]

(Les comento que, de acuerdo con la literatura, en Latinoamérica la tasa de fecundidad es más alta que en España, y les pido que me confirmen si esto es así.)

Bueno, ahora eso está cambiando. En las ciudades grandes, por ejemplo, en mi ciudad, las chicas no quieren ya tener tantos hijos $y$, si tienen, tienen uno. $Y$ yo soy un conejo para ellas. $Y$ mis amigas de la universidad hay muchas que no... que no están casadas y siguen solteras y no tienen hijos. Es que ha cambiado muchísimo. Ha cambiado muchísimo también porque la mujer se ha integrado a la vida laboral, cosa que antes no era así. [GD - Latinoamérica 2]

Y ya se educa más... O sea, la mujer ya no está solo en la casa. [GD - Latinoamérica 4]

Sí, sí, la mujer ya no está ya solo en la casa. Ahora ya... [GD - Latinoamérica 2]

\footnotetext{
282 Según los últimos datos disponibles ofrecidos por el Instituto Nacional de Estadística, relativos a 2012, la edad media de maternidad de las usuarias autóctonas se sitúa en 32,15 años, y la de las usuarias inmigrantes, en 28,9 años. No hemos podido obtener datos más exhaustivos en cuanto al país de origen de las usuarias inmigrantes, ya que no se encuentra disponible la disgregación por nacionalidades posterior al año 2002.

${ }^{283}$ Aun no presentando una tasa de fecundidad media tan alta como esperábamos, las usuarias participantes en el grupo de discusión superan la media nacional que, de acuerdo con los últimos datos disponibles del Instituto Nacional de Estadística, relativos al año 2012, presentan tanto las usuarias inmigrantes $(1,7)$ como las autóctonas $(0,9)$.

${ }^{284}$ Esta usuaria en concreto, como veremos más adelante, ha tenido una muy mala experiencia en el primer parto y parece ser que, por este motivo, no desea tener más hijos.
} 
Es que ya salir, conocer y estudiar ya te da... te da otra mentalidad. [GD - Latinoamérica 4]

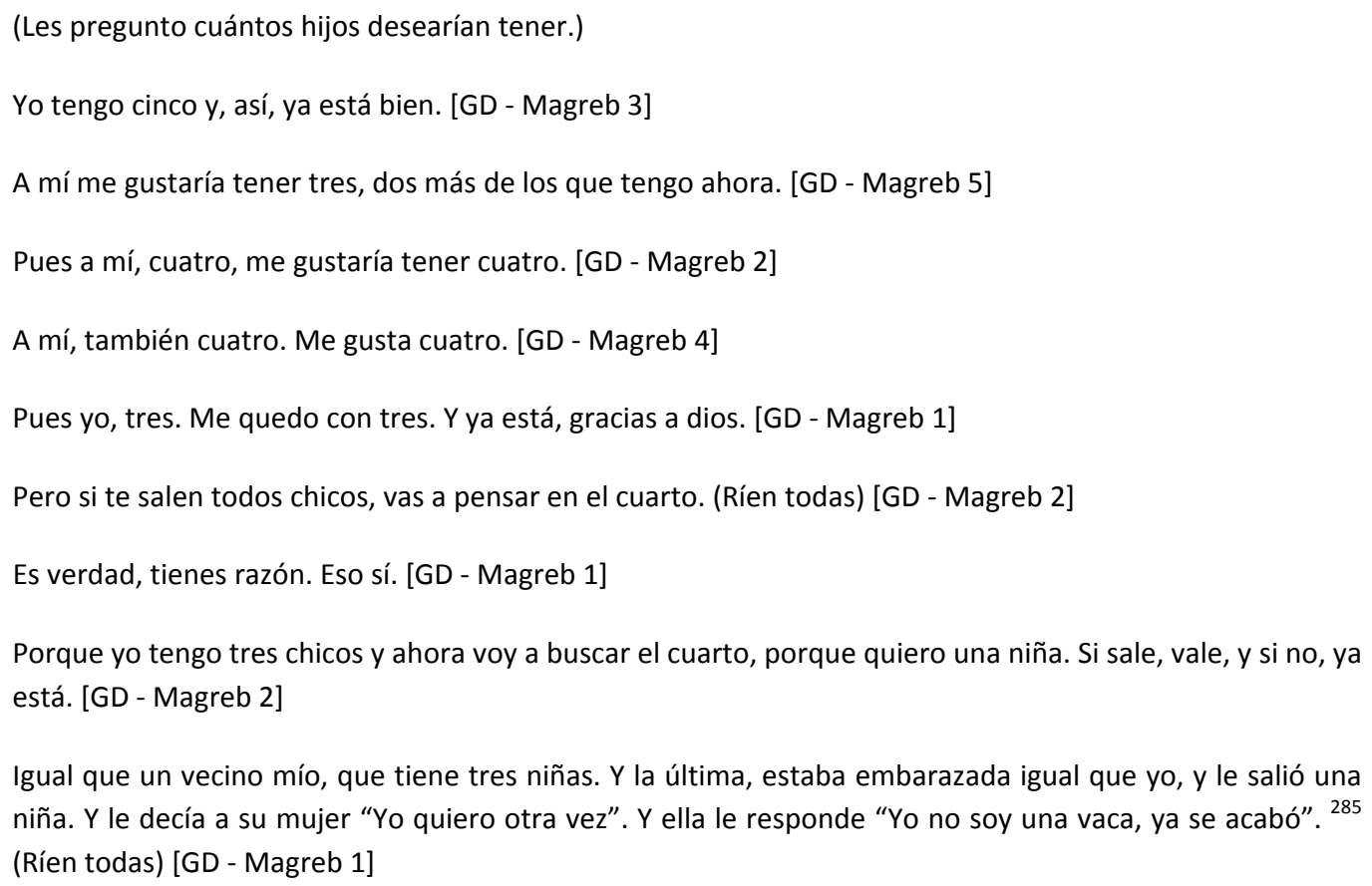

De estos últimos fragmentos incluidos, por una parte, cabe señalar que, de acuerdo con las participantes en los grupos de discusión, tanto en sus respectivos países de origen como en el caso de las usuarias procedentes de dichos países que residen en España, el número de hijos por mujer está descendiendo, principalmente por el mayor acceso a la educación y la incorporación de la mujer al mundo laboral.

Por otra parte, a diferencia de lo que opinaban algunos profesionales en las entrevistas, por los datos obtenidos tanto en los grupos de discusión como en la observación no participante, parece ser que las usuarias inmigrantes no presentan una clara preferencia por hijos de sexo masculino o femenino, sino que, en algunas ocasiones, cuando todos sus hijos son exclusivamente de uno u otro sexo, suelen desear que el siguiente que nazca rompa con esta supremacía y, en todo caso, su principal preocupación es que el bebé goce de buena salud.

Pasamos a continuación a analizar los datos relativos a los servicios de planificación familiar y los métodos anticonceptivos.

Por lo que se refiere a las participantes en los grupos de discusión, todas las usuarias magrebíes afirman haber acudido a los servicios de planificación familiar y, entre los métodos anticonceptivos más usados, señalan, como puede verse en el fragmento incluido a continuación, el DIU y la píldora anticonceptiva, métodos que, además, tanto por la literatura al respecto como por sus respuestas, parecen ser los más empleados en su país de origen, Marruecos. Además, una de ellas menciona un remedio natural que se empleaba en el pasado en su país para evitar los embarazos.

\footnotetext{
285 Nos llama la atención el hecho de que en ambos grupos de discusión se asocie la figura de la mujer gran multípara con un animal de granja, un conejo, en el caso de las latinoamericanas, y una vaca, en el de las magrebíes.
} 
(Les pregunto si, en los periodos transcurridos entre un embarazo y el siguiente, han usado algún método de planificación familiar, y responden prácticamente todas "Sí, sí" o "Sí, claro".

Sí, yo, por ejemplo, llevo el DIU. Al principio usaba las pastillas, pero ahora llevo el DIU siete años. [GD Magreb 4]

Pues, yo tomo las pastillas. [GD - Magreb 1]

Yo, también. [GD - Magreb 2]

Sí, y yo. Yo, también pastillas. [GD - Magreb 5]

(Les pregunto si esos son los métodos anticonceptivos más comunes en su país, si se utiliza también algún otro método, o si conocen algún remedio natural para evitar los embarazos.)

Lo que más se usa en Marruecos son las pastillas. Bueno, y el DIU, también. [GD - Magreb 4]

Para prevenir, no, no hay hierbas. [GD - Magreb 1]

Yo tampoco he oído nunca que están hierbas naturales para prevenir. Eso no lo he oído nunca. [GD Magreb 3]

El contrario, sí. O sea, sí que hay hierbas que hacen al revés, que te ayudan a quedar embarazada. [GD Magreb 5]

Ahora me recuerdo una cosa. Sí que me recuerdo una vez que nos decían que nuestras abuelas, para no quedarse embarazadas, toman siete... siete... ¿cómo se llama? (Pronuncia una palabra en árabe.) [GD Magreb 4]

Pimienta negra, se dice pimienta negra. [GD - Magreb 1]

Pues, eso, tomaban pimienta negra. Eso me recuerdo. [GD - Magreb 4]

En cuanto a las usuarias latinoamericanas, nos interesaba especialmente plantear este tema en el grupo de discusión, ya que, tanto en las entrevistas a usuarias como en las notas del diario de campo, habíamos manifestado nuestra sospecha de que el uso de métodos anticonceptivos por parte de algunas usuarias de este colectivo (o más bien la no utilización de dichos métodos) les hubiera conducido a un embarazo no planificado. Todas las usuarias participantes en este grupo excepto una (de la que hablaremos más adelante) afirman haber acudido a los servicios de planificación familiar y, además, aparte de los métodos de barrera, hablan de métodos anticonceptivos innovadores o no tan empleados o conocidos en España, como la vasectomía, el parche, la Liofora ${ }^{286}$ o métodos naturales para evitar el embarazo.

Bueno, pues yo sí, hace poco que estuve en planificación familiar. Pero es que el método que estábamos buscando, que era la vasectomía, nos han dicho que desde el año pasado en los hospitales públicos ya no la practican, que la han sacado, que desde abril del año pasado no se hace ninguna operación de este tipo. $Y$, sin embargo, pregunté "¿Y la ligadura de trompas", y me dijeron "Ah, la ligadura de trompas, sí". ¿Y la vasectomía no? O sea, a la mujer, sí, y al hombre, no. Me quedé un poco... O sea, es lo que pasa. ¿Que a la mujer si la pueden ligar y a los hombres, no? ¿Por qué? Nosotros buscábamos algo con carácter ya

\footnotetext{
${ }^{286}$ La usuaria que ha empleado este método nos comenta, como puede verse en el fragmento del grupo de discusión, que se trata de un método hormonal. En concreto la LIOFORA DIARIO ${ }^{\circledR}$ (Química Farmacéutica Bayer) es el nombre comercial de un anticonceptivo combinado compuesto por dos hormonas femeninas diferentes, denominadas drospirenona y etinilestradiol. Fuente de la definición: Agencia Española de Medicamentos y Productos Sanitarios, Ministerio de Sanidad, Servicios Sociales e Igualdad, Gobierno de España. [http://www.aemps.gob.es/cima/especialidad.do?metodo=verFichaWordPdf\&codigo=68026\&formato=pdf\&formul ario=PROSPECTOS] (última consulta: 7 de agosto de 2013).
} 
semipermanente. Y, claro, la vasectomía es una operación más simple que una ligadura de trompas. Y, ya ves, nos dijeron que desde el año pasado, concretamente desde abril de 2012, ya no se practicaba ninguna. Y por ahí ya estuve escuchando que cuesta unos 1500 euros hacerte la vasectomía. Y, nada, mientras tanto, pues usamos un método de barrera. [GD - Latinoamérica 2]

Y, de los métodos anticonceptivos que hablábamos, pues yo... Yo estuve con el parche. Me recomendaron el parche $y$, la verdad, es que me fue muy bien. Pero, después de tener a mi última hija, ya ahorita estamos usando un método de barrera. $Y$, además, yo ahora estoy yendo a unas sesiones de capacitación sobre métodos naturales para planificar. Me la están dando en el centro de orientación familiar diocesano. Y es un curso teórico-práctico. Tengo que estar llevando un control, y ella, la que nos da el curso, después, con diapositivas, según lo que yo le voy llevando y las prácticas que voy haciendo, pues ella me va explicando. $Y$, fíjate, yo ya con 37 años y dos hijos y es ahora cuando me vengo a enterar que en mi cuerpo pasa esto por esto. $Y$ la verdad es que muy bien. Nos dicen que tenemos que tener en cuenta el flujo, el ciclo menstrual y la temperatura; esas tres cosas. $Y$ me parece muy bien que se aprenda uno a conocerse y saber cuándo es fértil y cuándo no lo es. Y, así, sabes cuándo puedes quedar embarazada y cuándo no, sin necesidad de tomar nada, es decir, sin usar ningún anticonceptivo. [GD - Latinoamérica 4]

Pues yo he usado la Liofora. (Es la primera vez que oigo este término y le pregunto qué es). Pues son unas pastillas anticonceptivas, que son una píldora, que te la mandan para tomar todo el mes y es de tipo hormonal. [GD - Latinoamérica 3]

Por el contrario, una de las usuarias latinoamericanas, como había sucedido en dos casos de usuarias entrevistadas, parece, tanto por su corta edad como por su respuesta relativa al uso de métodos anticonceptivos, que no había planificado previamente su embarazo.

\footnotetext{
(La usuaria GD - Latinoamérica 1 es la única que no ha respondido todavía esta pregunta. Cabe señalar que tiene 18 años, tuvo a su hijo a los 17 , y no sabemos si fue o no un embarazo planificado. Me dirijo a ella y se la formulo de nuevo directamente.)

Bueno, pues yo... He usado la... no sé cómo se dice. (Le pregunto “¿Te refieres a la píldora?”). Sí, eso, perdona que no me venía el nombre. Ese es el método que por ahora yo prefiero... (Por el tono de voz dubitativo y su expresión facial, me surgen ciertas dudas sobre el grado de sinceridad de esta usuaria al responder esta pregunta). [GD - Latinoamérica 1]
}

Los datos que acabamos de presentar no siempre coinciden plenamente con los ofrecidos por estas mismas usuarias en los cuestionarios individuales posteriores a los grupos de discusión, ya que, en estos últimos, algunas señalan preferencias de uso no mencionadas durante el encuentro. Por ejemplo, algunas usuarias magrebíes dicen en los cuestionarios que el segundo método anticonceptivo más valorado por ellas es el preservativo, cuando ninguna había indicado en la discusión haberlo empleado. Además, la usuaria latinoamericana que nos había comentado que estaba muy interesada en la vasectomía, afirma en el cuestionario preferir en segundo lugar (tras los preservativos) un nuevo método no mencionado anteriormente, en particular, el anillo vaginal. Por último, la usuaria de la cual dudábamos que hubiera planificado su embarazo y que, en la discusión, había afirmado que la píldora era su método anticonceptivo preferido, en el cuestionario, sostiene valorar más el preservativo. 


\begin{tabular}{|c|c|c|c|c|c|c|}
\hline & DIU & $\begin{array}{c}\text { Métodos } \\
\text { naturales/Ningún } \\
\text { método }\end{array}$ & $\begin{array}{c}\text { Píldora } \\
\text { anticonceptiva }\end{array}$ & $\begin{array}{l}\text { Píldora del } \\
\text { día después }\end{array}$ & Preservativos & Otros \\
\hline Latinoamérica 1 & 3 & 4 & 2 & 5 & 1 & \\
\hline Latinoamérica 2 & 5 & & 4 & 3 & 1 & $\begin{array}{l}2 \text { (anillo } \\
\text { vaginal) }\end{array}$ \\
\hline Latinoamérica 3 & & & 1 & & & \\
\hline Latinoamérica 4 & & & & & 1 & \\
\hline Magreb 1 & & & 1 & & 2 & \\
\hline Magreb 2 & & & 1 & & 2 & \\
\hline Magreb 3 & & & 1 & & & \\
\hline Magreb 4 & 1 & & 2 & & & \\
\hline Magreb 5 & 3 & 5 & 1 & 4 & 2 & \\
\hline
\end{tabular}

Tabla 6.5. Clasificación de los métodos anticonceptivos de acuerdo con las usuarias participantes en los grupos de discusión

(1 "El más valorado/utilizado"; 5 "El menos valorado/utilizado")

No podemos conocer a ciencia cierta los motivos por los cuales las respuestas ofrecidas por algunas usuarias en la discusión y en el cuestionario individual no siempre coinciden. Dichos motivos pueden ser muy variados (desde el pudor a manifestar una cierta opinión en público, hasta la imposibilidad de profundizar más en este tema durante la discusión por la dinámica de la misma) y, quizás, podríamos haber resuelto esta duda reuniéndonos posteriormente con las usuarias para ahondar individualmente en sus respuestas.

Por lo que respecta a los profesionales sanitarios, cabe recordar que la gran mayoría de los entrevistados disponía de escasa información en cuanto a la utilización de los servicios de planificación familiar por parte de las usuarias inmigrantes, ya que dichos servicios se ofrecen fuera del hospital contexto de estudio, en concreto, en los centros de salud. Por el contrario, algunos de los profesionales participantes en los grupos de discusión sí que cuentan con experiencia en estos servicios y opinan que las usuarias inmigrantes suelen emplearlos.

\footnotetext{
(Las consultas de planificación familiar suelen tener lugar en los centros de salud. Por este motivo, les pregunto si, en los periodos trabajados fuera del hospital contexto de estudio, alguno de ellos ha estado presente en estas consultas.)

Yo, por ejemplo, ahora he estado pasando veinte días la consulta de planificación familiar y sí que vienen, sí. [GD - Obstetra 1]
}

Asimismo, en cuanto a los métodos anticonceptivos más empleados por las usuarias inmigrantes, de acuerdo con los profesionales participantes en el grupo de discusión, estas utilizan mucho el DIU (especialmente si se las compara con las usuarias autóctonas) y, últimamente, también la píldora. Algunos sostienen que el mayor uso actual de este último método mencionado puede deberse a la reciente financiación del mismo. Además, mencionan un método muy frecuente en las usuarias latinoamericanas; se trata del implante, cuyo uso, 
por lo visto, es bastante común en los países de origen de estas usuarias y menos conocido en España. Cabe señalar que ninguna de las usuarias latinoamericanas, ni las entrevistadas ni las participantes en los grupos de discusión, ha señalado el método del implante entre aquellos que usan o han usado en el pasado, por lo que no podemos saber si esta tendencia señalada por los profesionales en el grupo de discusión es real.

(Les pregunto si saben si las usuarias inmigrantes suelen preferir un método anticonceptivo en lugar de otro.)

Hombre, igual, el DIU sí que lo solicitan más extranjeras que españolas. Pero, bueno, ahora ya, yo creo que, como antes no había anticonceptivos financiados y eso, pero ahora que sí que hay, pues, a lo mejor, sí que hay algunas que utilizan pastillas. Pero, vamos, lo que es el DIU sí que lo demandan más extranjeras que españolas. [GD - Obstetra 1]

Bueno, aquí los implantes que se suelen poner en la planta casi todos son a sudamericanas. [GD - Matrona 1]

Sí, es verdad, los implantes son más de sudamericanas. [GD - Obstetra 3]

Hombre, porque es un método cómodo y... [GD - Matrona 2]

Y porque lo tienen oído ellas... [GD - Obstetra 3]

No, y porque allí se utiliza mucho. [GD - Obstetra 2]

Por eso ellas lo conocen más. [GD - Obstetra 3]

A una española le explicas el implante y lo ves, que te va poniendo una cara y va abriendo así los ojos... (Adopta una expresión facial de sorpresa mientras va pronunciando estas palabras). ¿Entiendes lo que te quiero decir? Ya, luego, le dices que realmente no es tanto, y algunas aceptan ponérselo, pero... [GD Obstetra 2]

Mientras debaten sobre los métodos anticonceptivos más empleados por las usuarias inmigrantes, surge de nuevo un tema que ya se había planteado durante las entrevistas. En concreto, se habla del caso de las usuarias procedentes de Europa del este, las cuales, también de acuerdo con los profesionales participantes en el grupo de discusión, emplean con frecuencia el aborto como método anticonceptivo, aunque mencionan que dicha tendencia parece estar cambiando.

Y las del este, DIUs. [GD - Obstetra 1]
Sí, es verdad, las del este... [GD - Obstetra 3]

Bueno, es algo un poco cultural, yo creo... Porque tienes el grupo de las rumanas, que ellas, como el aborto lo usan como método anticonceptivo... [...] Así que esas van menos a planificación familiar, aunque sí que es verdad que, como habéis dicho, ahora parece que usan más las pastillas y tal. Quizás sea por eso, por lo de la financiación, porque así les resulta más... [GD - Obstetra 2]

Otra de las cuestiones relativas al aborto que los profesionales sanitarios habían mencionado en las entrevistas se refería al uso de determinadas pastillas por parte de algunas usuarias africanas para provocarse una interrupción del embarazo. En el caso de los grupos de discusión, son las usuarias de origen magrebí las que comentan que en su país se emplean remedios naturales para abortar, aunque señalan que esta práctica está prohibida de acuerdo con el Islam. 
Y sí que hay unas hierbas, pero no son para evitar, son cuando ya están embarazadas... Yo creo, no estoy segura, pero creo que hay unas hierbas que las mujeres las toman cuando ya están embarazadas, para que se baja el niño. Creo que se usaba antes, pero esto está prohibido en el Islam. Está prohibido, porque matar a... [GD - Magreb 1]

También una de las usuarias latinoamericanas nos comenta que, en su país de origen, Perú, está prohibida la interrupción voluntaria del embarazo, en este caso, por la legislación vigente en dicho país, según la cual, no le resultaría posible abortar aun en el caso de que peligrara la salud del futuro hijo.

Y, además, nosotros tampoco tenemos legalizado el aborto. Aquí, al menos, te dan la opción de abortar, por ejemplo, si el niño tiene alguna malformación. ${ }^{287}$ Allá, no... Por ejemplo, si tiene alguna malformación, pues lo tienes y ya está. [GD - Latinoamérica 2]

Una vez finalizada la parte introductoria de este subapartado, vamos a analizar, en segundo lugar, los datos recolectados mediante los grupos de discusión referidos a las distintas fases del proceso reproductivo.

Por lo que se refiere al embarazo, ya hemos abordado el tema de los controles en el subapartado anterior, centrado en la asistencia sanitaria general. Por ello, no incluimos aquí fragmentos de los grupos de discusión y, simplemente, recordamos que, por un lado, los profesionales participantes en los grupos sostenían que el seguimiento de dichos controles suele ser más irregular en las usuarias inmigrantes. Estos datos coinciden con los recolectados en las entrevistas, en las cuales los profesionales también habían señalado la irregularidad en el seguimiento del embarazo por parte de las usuarias inmigrantes. Sin embargo, por otro lado, los datos ofrecidos tanto en las entrevistas como en los grupos de discusión por parte de las usuarias contradecían la opinión de los profesionales, ya que, aunque consideran que en España, a diferencia de en sus países de origen, los controles del embarazo son muchos, la gran mayoría dice acudir a todos ellos y los considera positivos.

En cuanto a los cursos de preparación al parto, la mayoría de los profesionales entrevistados no disponía de información al respecto, ya que se informa de dichos cursos en los centros de salud y no en los hospitales, como es el caso de nuestro contexto de estudio. Por el contrario, algunos de los profesionales participantes en los grupos de discusión han trabajado en otros centros de salud y, por tanto, sí pueden ofrecernos datos relativos a esta cuestión. Como se puede observar en el fragmento que se incluye a continuación, opinan que, aunque suelen acudir a la primera charla informativa, no es muy alta la asistencia a dichos cursos por parte de usuarias inmigrantes, a excepción quizás de algunas latinoamericanas. Además, nos informan de que la participación es voluntaria.

Yo no tengo datos concretos, pero, por lo que hablo con las matronas, sí que suelen ir, ¿eh? Bueno, suelen ir a la charla y tal y luego... un poco a su aire, ¿no? [GD - Obstetra 2]

Yo... Lo que pasa es que no es de aquí, del hospital, porque los cursos se hacen en los centros de salud, pero cuando yo estaba en Huesca, en los cursos de preparación no había ni una extranjera, eran todo autóctonas y, si acaso, extranjeras de lengua española, es decir, latinoamericanas, pero... [GD - Matrona 2]

\footnotetext{
${ }^{287}$ La usuaria parece desconocer la existencia del proyecto de ley propuesto por el actual partido en el gobierno de España, que, en caso de ser aprobado, modificaría la legislación actual sobre los casos en los que es aborto estaría despenalizado.
} 
(Les pregunto de qué manera se informa a las usuarias en general sobre la existencia de los cursos de preparación al parto.)

Con la primera visita con la matrona en los centros de salud, se las cita para los cursos de preparación al parto. Y son voluntarios, es decir, asiste quien quiere. [GD -Matrona 1]

Precisamente por el carácter voluntario de estos cursos y por las explicaciones exhaustivas ofrecidas por las usuarias inmigrantes en las entrevistas sobre las causas que motivaban la no asistencia a los mismos, no preguntamos sobre este tema a las usuarias en los grupos de discusión. Recordemos que, entre dichas causas, eran pocas las usuarias entrevistadas que habían aducido falta de información, y que la gran mayoría había manifestado que no le interesaban los cursos o que, al haber tenido hijos previos, no consideraba que los necesitara.

Con respecto a los cuidados durante el embarazo, solo disponemos de datos concretos en el caso de las usuarias participantes en el grupo de discusión con latinoamericanas, las cuales, como se muestra en el siguiente fragmento, consideran que tanto la pareja como la familia en general deben implicarse en dichos cuidados desde un primer momento. Retomamos el tema de la implicación de los maridos y las familias cuando analizamos un poco más adelante en este mismo subapartado los cuidados durante el puerperio.

(Les pregunto si se implican sus maridos o sus familias en los cuidados durante el embarazo, y responden todas más o menos a una y dicen "Sí, sí...". Entonces, les pregunto si consideran importante esta implicación.)

Yo creo que la pareja se tiene que implicar muchísimo. Además, que le hace mucho bien al bebé, porque está demostrado que el bebé siente desde que está en el útero, y le hace mucho bien crear vínculos con el padre. Y, además, que le viene muy bien también emocionalmente a la madre. A mí, me vino de lujo. [GD Latinoamérica 2]

Yo también creo que sí, la familia se tiene que implicar, porque... En mi caso fue sobre todo mi padre el que estuvo más conmigo y, claro, ahora mi hijo está más con mi padre, es con el que más afecto tiene y tal. Porque mi madre, sí vive con nosotros, y el niño la quiere y eso, pero no es el mismo afecto que tiene con mi padre, porque él se implicó más desde el principio. [GD - Latinoamérica 1]

En mi caso, con mi primer hijo, cuando aún estaba en Colombia, también me ayudó mi familia, tanto la paterna como la materna, de los dos lados. Y sí que creo que es importante, porque es un apoyo... [GD Latinoamérica 4]

En referencia al parto, no planteamos específicamente en los grupos de discusión ninguna pregunta relativa a la postura adoptada durante el mismo. Sin embargo, mientras las usuarias magrebíes discuten sobre otros temas relacionados, surgen espontáneamente cuestiones relacionadas con este tema, como la frecuencia de los partos en casa (por otra parte, cada vez menor) en las zonas rurales de Marruecos, o la preferencia por caminar antes de dar a luz.

Sí, por ejemplo, hace tiempo se da la luz en casa, y eso era la gente del pueblo, porque no les daba tiempo a llegar al hospital. Pero eso hace tiempo, ahora ya todos en el hospital. [GD - Magreb 2]

Pero aún queda mucha gente pobre y están muy lejos de los centros. La gente de las montañas y eso. Y, a veces, vemos en la tele que los llevan a los hospitales en helicóptero, pero no siempre es así. Aunque, gracias a dios, ahora estamos mejor que antes. [GD - Magreb 1]

Yo me recuerdo hace doce años, por ejemplo, las mujeres de mis tíos, prefieren dar a luz en casa, y dan a luz en casa. Pero, ahora, ya no sé... Entonces, ayudaban las mujeres, parteras creo que se llaman en español, ¿no? Había muchas, y ayudaban a dar a luz en casa. [GD - Magreb 4] 
Ahora aquí también hay muchas mujeres que quieren tener hijos de manera natural, ¿no? [GD - Magreb 1

(Hablan todas a la vez y se solapan unas a otras, por lo que no resulta posible saber quién dice qué, pero comentan "Sí, sí, yo vi hace poco un programa en la tele en el que las señoras daban a luz en casa", y otra contesta "Sí, sí, y algunas en el agua". A lo que otra responde "Es que son como modas...".)

Pues cosas así se podrían hacer en el hospital, ¿no? Porque a la hora de dar a luz, yo entiendo que hay que dar opción que facilite que pueda hacerse en la forma que la madre quiere hacerlo. Para facilitarle que tenga su momento más fácil y más cómodo... [GD - Magreb 3]

Sí, porque con el dolor... Por ejemplo, yo que ya tengo tres chicos, pues yo prefiero andando, porque sentada y con el dolor, no puedes... no puedes mover, no puedes ayudar, ¿̇entiendes? Pero, si estás de pie hasta el momento de dar la luz, pues así es mejor. [GD - Magreb 2]

Por las respuestas ofrecidas por los profesionales sanitarios en las entrevistas, sabemos que no es posible en el hospital contexto de estudio atender a estas preferencias y propuestas manifestadas en el grupo de discusión por las usuarias magrebíes, ya que se sigue un protocolo estándar igual en todos los casos y, una vez suministrada la anestesia epidural, se restringen todavía más las opciones durante el proceso de parto.

En cuanto a la anestesia epidural, se verifican en los grupos de discusión los datos recolectados en las entrevistas, en las cuales, tanto los profesionales como con las usuarias entrevistadas habían comentado que la aceptación de su suministro era bastante frecuente en las usuarias inmigrantes. En concreto, a tres de las cuatro usuarias latinoamericanas participantes en los grupos de discusión se les suministró esta anestesia en sus partos, bien porque lo solicitaron o bien porque, antes de practicarles la cesárea, se les recomendó.

A mí me pusieron la epidural las tres veces. Porque claro, en las tres fue cesárea, entonces, primero me tuvieron que poner la epidural. [GD - Latinoamérica 2]

El mío no fue cesárea, pero a mí también me pusieron epidural. (Le pregunto si fue ella quien la pidió). Me explicaron todo bien y sí, yo la pedí. Fue una decisión propia, porque... (Risas). Es que me dolía mucho. [GD - Latinoamérica 1]

Pues yo nunca la he usado, he hecho todo siempre natural, sin epidural. [GD - Latinoamérica 4]

Pues a mí también, antes de hacerme la cesárea, primero me pusieron la epidural. Es que lo que pasó es que yo rompí aguas en casa, porque el niño tenía que nacer el 27 de mayo, y se me adelantó 14 días, lo tuve el 13. Y es que eché un tripón, que la gente me decía “¿Pero, ¿tú, cómo haces, con tu estatura, para cargar ese tripón?". Y, entonces, claro, yo comencé con un dolorcico como de... como menstrual. Y yo decía "¡Ay, qué raro!", y le decía yo a mi chico "Llévame al hospital”. Porque vivíamos muy cerca del hospital de mi pueblo, a unos 200 metros. Y, aunque no era un hospital donde se hicieran normalmente partos, porque era más un centro de alta resolución para accidentes de montaña, al menos allí me podían ver para saber que todo iba bien. Y le decía "Llévame al hospital”, y él me decía "No, cariño, mañana a las nueve te llevo". Pues, a las nueve no me dio tiempo. Eso fue el día... 12, no, no, el día 11, cuando me ingresaron en el hospital del pueblo porque reventé aguas. Porque claro, mi chico me dio paracetamol, y me frenó la dilatación, y entonces no pasaba de dos (centímetros), y me aplicaron... me metieron como una especie de un... de un lazo por dentro para... para apurar los dolores y tal, y no... Entonces, me tomaron una ecografía y vieron que mi hijo venía con mucho peso, y que yo no tenía la capacidad... Entonces, no sabían qué hacer, porque no había anestesiólogo, porque compartían anestesiólogo con la ciudad más cercana y el tío estaba de vacaciones, y no se percataron de que, si surgía algo, no tendrían a quién recurrir. $Y$ desplazarse hasta la capital son 45 minutos $y$, entonces, no... Pensaron "No llega". Y estuvieron el médico y la matrona monitoreándome, porque el niño se puso muy inquieto, porque ya 
quería salir. Y, claro, yo trataba de... pero no pasaba sino de dos, dos y medio, dos, dos y medio (centímetros)... Y de ahí no pasé y, siendo tan grande, no iba a salir. Entonces, llamaron y me iban a mandar a la capital. Y yo pensaba que no me iba a dar tiempo. Pero, como en el hospital en el que yo estaba, la hija del alcalde había muerto en marzo, dos meses antes de que yo diera a luz... Hacía dos meses que se había muerto la hija del alcalde (mientras pronuncia las últimas palabras eleva el tono de voz, recalcándolas), y yo le decía "iDoctor, por favor, no me vaya a dejar morir!". (Esta última frase la pronuncia con voz lastimera). Decía "iMándenme a la capital, mándenme a la capital!”, porque ahí sí yo tenía mucho miedo. Y las enfermeras se portaron fenomenal, me decían "Tranquila, no te vamos a dejar morir". Y lo que más me marcó fue eso, que a pesar de ser un pueblo, no tener anestesiólogo me parece una pasada, porque yo ahí sí que lo vi un poco fuerte. Y finalmente me trasladaron y pude dar a luz a mi hijo el día 13 a las cinco y media de la mañana. [GD - Latinoamérica 3]

También a la mayoría de las usuarias magrebíes participantes en el grupo de discusión, tal y como puede observarse en el fragmento que incluimos a continuación, se les suministró la anestesia epidural, bien por decisión propia o bajo recomendación del personal sanitario.

Pero, cuando te ponen epidural, ya no puedes andar... [GD - Magreb 3]

Pero la epidural te la ponen ya a lo último, cuando ya estás... [GD - Magreb 5]

No, no, a mí me la han puesto a lo primero, que yo no siento nada desde primer momento. [GD - Magreb 3]

Pues, a mí, me la ponen cuando quedan dos horas. [GD - Magreb 1]

(Pasamos a hablar de la epidural y les pregunto si al resto se la suministraron en sus partos y qué opinan del uso de esta anestesia.)

Yo, me gusta (Risas). [GD - Magreb 1]

A mí, en el primero, como está difícil, sí que uso epidural, porque me han dicho que me tienen que provocar, pero, con el segundo, no. Porque, con el primero, yo no podía soportar y, además, he perdido mucha sangre... Luego, me tuvieron que poner tres bolsas de sangre, porque he perdido mucha sangre. $Y$ fueron ellos que me han dicho "Has perdido mucha sangre y tienes que hacer epidural". Con el tercero, también he hecho epidural, y la doctora me trata muy bien y se queda conmigo hasta el final. [GD Magreb 2]

Siempre en relación con la anestesia epidural, abordamos dos temas debatidos durante las entrevistas. El primero de ellos se refiere a la opinión de numerosos profesionales entrevistados, los cuales consideraban que, a la hora de decidir si se les suministraba esta anestesia, las usuarias de origen magrebí estaban supeditadas a sus maridos. Esta opinión queda desmentida por las usuarias magrebíes participantes en el grupo de discusión, las cuales sostienen que no son sus maridos quienes deciden, sino que les consultan, como hacen mutuamente en pareja para otras cuestiones consideradas importantes, y al final son ellas las que escogen si optar por ponérsela no.

(Les cuento que, en las fases previas de mi investigación, los profesionales sanitarios me han comentado que creen que no son las mujeres magrebíes las que deciden si se les suministra o no la anestesia epidural, sino que dependen de lo que decidan sus maridos. Ríen todas a una.)

Dicen que los maridos mandan, ¿̇no? (Risas) [GD - Magreb 1]

Es la mujer la que tiene que aguantar el dolor, por eso, ella decide. [GD - Magreb 5] 
Igual es que se confunden. Es que la mayoría de los magrebíes, cuando quieren hacer algo, se consultan, tanto la mujer al hombre como el hombre a la mujer. Por ejemplo, a mí, cuando me han dado la hoja de firmar para la anestesia, yo he dicho “¿Me puedes llamar a mi marido, que tengo que consultar con él?”. Y me han dicho "Vale". Pero quien decide soy yo, soy yo. Igual que él, cuando te ve sufriendo, te dice "Si te va a ayudar un poco para mejorar, pues hazla". Te ayuda a decidir, pero te obliga, no. [GD - Magreb 4]

Pues yo, cuando he firmado la hoja, no estaba mi marido conmigo, porque ha salido un momento y no estaba. Pero a mí me han dicho que tengo que hacerla, me han dicho "Como son gemelos, si tienes que operar, así estás preparada". Me han dicho "Te dejamos elegir, pero mejor tienes que poner". [GD Magreb 3]

Es que las decisiones importantes nosotros las tomamos entre los dos, nos consultamos. Por ejemplo, cuando se habla de la educación de los niños. [GD - Magreb 5]

Eso es con todas las cosas importantes... [GD - Magreb 3]

(Les pregunto a qué se refieren cuando hablan de "cosas importantes", puesto que lo que para ellas es importante puede no serlo para otras personas.)

Pues... ¿Podría ser un ejemplo el venir hoy aquí? Yo, sí, por ejemplo, hoy sí que he consultado, porque él tenía que cuidar a mi niño (Risas). Porque si yo vengo hoy con mi niño aquí, para estar charlando de esto, el niño no me deja, ¿ंverdad? [GD - Magreb 1]

Pues mi marido no está en Zaragoza, está de viaje, así que ni se ha enterado de que yo estoy hoy aquí... [GD - Magreb 3]

El segundo tema relativo a la anestesia epidural abordado con las usuarias magrebíes en el grupo de discusión y ya tratado en las entrevistas concierne a las explicaciones ofrecidas por el personal sanitario sobre los efectos y los riesgos de suministrar dicha anestesia. Por la información que nos ofrece una de las usuarias, parece ser que en ocasiones firman los consentimientos sin apenas leerlos. Queda demostrada una vez más la insuficiencia de los consentimientos informados traducidos como recurso para explicarles el procedimiento de la anestesia epidural a las usuarias alófonas, pues el mensaje debería reforzarse con indicaciones verbales por parte del personal sanitario, algo que, en el caso de algunas usuarias, por las barreras lingüísticas, resulta prácticamente imposible.

(Les pregunto si les explicaron bien en qué consistía la anestesia y qué efectos podía tener.)

Te dan una hoja donde pone todo, pero tú estás con el dolor y no te puedes concentrar. Con el dolor, tú firmas rápido. (Risas). No lees bien y, luego, te mueves, y te dicen "No, no puedes caminar. Si te mueves, tú puedes quedar minusválida para siempre". [GD - Magreb 1]

En referencia al parto por cesárea, solo preguntamos su opinión al respecto a las usuarias participantes en el grupo de discusión de latinoamericanas, ya que habían sido las más mencionadas en las respuestas sobre este tema en las entrevistas. De hecho, algunos profesionales entrevistados sostenían que estas usuarias, incluso sin que hubiera una causa de fuerza mayor que obligara a realizar este tipo de parto, lo demandaban. Dos de las cuatro usuarias latinoamericanas, como se muestra en el siguiente fragmento, han tenido partos por cesárea y, por sus relatos, parece ser que en todos los casos era estrictamente necesario. $\mathrm{Ni}$ estas dos usuarias ni las otras dos participantes en este grupo, a las que no se les ha practicado este tipo de parto, ven en él ningún inconveniente, y parecen estar preocupadas únicamente porque el niño salga bien y a ellas les desaparezca el dolor. 
Porque yo sufrí mucho, lo que no sufrí en todo el embarazo lo sufrí en el parto. Porque yo tuve un parto... Por ejemplo, contracciones, yo sentí todas las contracciones, y yo me pegaba del techo... Y me decía la matrona (emite un sonido como si estuviera respirando fuertemente) "iRespiración! iRespiración!”, que yo decía "¿Cuál respiración?”. Que yo no podía hacer nada (Risas). Y al final me tuvieron que hacer parto por cesárea. Y... iTe puedes imaginar! Con el parto que yo tuve, a mí cuando me dijeron que me hacían cesárea, yo dije (Risas) "Bueno, ahora ya...". Yo lo que le dije a la doctora fue "Sáqueme a este bicho ya, porque no lo aguanto más..." (Risas). Porque el niño se me subía así (se señala la parte alta del abdomen), y es que él quería salir y se estiraba, se estiraba, y se estiraba, y se estiraba... Y yo sentía la tripa que... [GD - Latinoamérica 3]

Yo en la cesárea también soy experta, porque me la hicieron las tres veces, como dije. (Le pregunto si en los tres casos le practicaron una cesárea por complicaciones en el parto). Es que se ve que genéticamente hago los bebés, los fetitos, muy grandes y, entonces, me hicieron aquí muchos exámenes, para ver si era por diabetes gestacional, pero no. $Y$, menos mal, porque luego los niños pueden tener problemas con el azúcar... Pero, gracias a dios, ese no era mi caso. Y yo pensaba que sí, ¿̇eh? Y decía "iMadre mía, ahora va a salir que tengo diabetes!". Entonces me dijeron que era algo genético y, por eso, los niños me salían, pues, con cuatro kilos y medio y hasta cinco kilos. (Efectivamente, está con nosotras su último hijo, de dos meses, y su tamaño es bastante más grande de lo habitual en un bebé de esa edad. Además, se pasa durante todo el tiempo que dura el grupo de discusión tomando el pecho). Lo que sí me dijo el médico es que los latinoamericanos normalmente también hacíamos los niños más grandes por la alimentación o algo así... Y, entonces, para sacar a los niños, es que yo no puedo, no puedo, incluso dilatando, no... Porque con el primero sí que lo intenté, pero no pude, me tuvieron que hacer una cesárea también. Dilaté, pero no salía, no salía, debo de ser superestrecha, porque no había manera. Y, entonces, sí, la cesárea a mí me parece un método que... primero, revolucionario, porque tú imagínate un niño tan grande, yo no sé cómo lo harían antes. Igual también antes había más mortalidad, ¿no? Pero, a mí, la cesárea me parece una buena opción, dependiendo de cómo esté la madre. [GD - Latinoamérica 2]

(Pregunto a las otras dos usuarias _ GD - Latinoamérica 1 y GD - Latinoamérica 4_si ellas también tuvieron un parto por cesárea. Responden negativamente, y les pregunto si, de todos modos, tienen una opinión al respecto.)

No sé, no le veo problemas... [GD - Latinoamérica 1]

No, no, con que salga y se quite el dolor. (Ríen todas acaloradamente). Con eso es suficiente, sí, sí. [GD Latinoamérica 4]

En relación con este tema cabe también citar la cuestión de la expresión del dolor durante el parto. En las entrevistas, un gran número de profesionales sanitarios habían mencionado a las usuarias latinoamericanas como uno de los colectivos que expresaban más enfáticamente el dolor durante el parto y se quejaban más. 
De acuerdo con los cuestionarios individuales que las usuarias participantes en los grupos de discusión completaron y que se muestran a continuación, el dolor percibido durante el parto por las usuarias procedentes de Latinoamérica ha sido, en algunos casos, muy fuerte $y$, en otros, leve o soportable. Sin embargo, en los fragmentos que hemos incluido hasta el momento sobre su vivencia del parto, sí parecían expresar de modo bastante elocuente cuánto habían sufrido dando a luz. No podemos saber si estos relatos detallados de las complicaciones del parto y de los dolores percibidos se deben a que estas usuarias presentan un mayor dominio del idioma y, por tanto, pueden expresarlos mejor o si, por el contrario, son la señal de que tienen un umbral del dolor menor que otras usuarias.

\begin{tabular}{|c|c|c|c|c|c|c|c|c|c|c|}
\hline & 1 & 2 & 3 & 4 & 5 & 6 & 7 & 8 & 9 & 10 \\
\hline Latinoamérica 1 & & & & & & & & & $\mathrm{x}$ & \\
\hline Latinoamérica 2 & & $\mathrm{X}$ & & & & & & & & \\
\hline Latinoamérica 3 & & & & & & & & & & $\mathrm{x}$ \\
\hline Latinoamérica 4 & $x$ & & & & & & & & & \\
\hline Magreb 1 & & & & & & & & & & $\mathrm{x}$ \\
\hline Magreb 2 & & & & & & $\mathrm{x}$ & & & & \\
\hline Magreb 3 & $x$ & & & & & & & & & \\
\hline Magreb 4 & & & & & & & $\mathrm{x}$ & & & \\
\hline Magreb 5 & & & & & & & & $\mathrm{X}$ & & \\
\hline
\end{tabular}

Tabla 6.6. Valoración del dolor percibido durante el parto de acuerdo con las usuarias participantes en los grupos de discusión

(10 “Dolor muy fuerte/insoportable"; 1 “Dolor leve/soportable")

Las respuestas de las magrebíes, como puede verse en la anterior tabla con los resultados de los cuestionarios, también son bastante variadas, y van desde el dolor máximo ("muy fuerte o insoportable"), al mínimo ("leve o soportable"). Recordemos, de todos modos, que, en las entrevistas, algunos profesionales habían manifestado que la expresión del dolor durante el parto por parte de las usuarias magrebíes era mayor cuando estaban presentes sus maridos.

Enlazando con esta última cuestión apuntada, pasamos a analizar el tema de los acompañantes de las usuarias inmigrantes durante el parto. Por las respuestas ofrecidas por las usuarias entrevistadas al respecto, no parecía haber un patrón de comportamiento por colectivos en cuanto a los acompañantes que accedían a paritorios, sino que, indistintamente, estas estaban acompañadas, a veces, por sus maridos $y$, otras, por sus madres $u$ otros familiares, comúnmente de sexo femenino.

Esta variedad de acompañantes queda verificada en el caso de las usuarias latinoamericanas participantes en el grupo de discusión, tal y como puede verse en el siguiente fragmento:

(Les pregunto si sus parejas estaban con ellas durante el proceso de parto.)

Yo tuve que entrar sola, porque, como fue cesárea... [GD - Latinoamérica 3] 
Pues mi pareja sí que entró y cortó el cordón umbilical, y fue muy bonito. Como dije, como fue cesárea y es una cirugía, pues, en principio, te dicen que no, porque allá dentro es una carnicería, pero hablamos con el médico y, al final, accedió. Al final, accedió a que entrara mi pareja y cortara el cordón y... Fue una suerte, sí, sí. (Le pregunto si para ella tiene algún valor el hecho de que el padre cortara el cordón.) Yo creo que más simboliza para él. Él quería tener ese vínculo con su hijo y vivirlo desde el primer momento $y$, bueno, le dije "Pues vamos a plantearlo al médico". Y el médico finalmente aceptó. [GD - Latinoamérica 2]

Pues, a mí me acompañó mi madre, que yo si no... (Risas). Me dieron la opción y yo preferí que fuera mi madre. [GD - Latinoamérica 1]

A mí me acompañó mi pareja también. [GD - Latinoamérica 4]

Sin embargo, no se verifica en los grupos de discusión un dato aportado por algunos profesionales entrevistados, los cuales sostenían que los maridos de las usuarias procedentes del Magreb no solían acompañar a las usuarias y mostraban un comportamiento "pasota" (palabras textuales) con respecto a la atención ofrecida a sus mujeres durante el embarazo, el parto y el puerperio. Ya comentamos en el subapartado relativo a este aspecto en el análisis de la observación que este hecho parecía no ser del todo cierto y, de nuevo, en los grupos de discusión, por las respuestas de las usuarias magrebíes, comprobamos que sus maridos sí que se suelen implicar en el proceso de salud reproductiva ya que, en la mayoría de los casos, las acompañaron durante el parto.

En el parto, está el marido, me acompaña mi marido. [GD - Magreb 2]

A mí también me acompaña mi marido. [GD - Magreb 5]

Pues yo, al principio, estaba todo el tiempo mi marido conmigo, pero luego, como eran gemelos, tenía que entrar al quirófano. Aunque todo fue bien, no me ponen ni puntos, con gemelos y... ini puntos! Pero me han dicho "Tienes que entrar al quirófano, porque, como son gemelos, por si pasa algo, tienes que estar preparada". Y, claro, ahí no ha entrado mi marido. [GD - Magreb 3]

Es que al quirófano no dejan entrar. Al paritorio, sí. [GD - Magreb 5]

Por otra parte, existe otro aspecto concerniente al acompañamiento durante el parto que se había mencionado en las entrevistas y que vuelve a aparecer en los grupos de discusión. En concreto, algunos profesionales entrevistados afirmaban que dejaban que fuese la usuaria la que decidiese quién la acompañaría durante el parto. Por el contrario, algunas usuarias participantes en el grupo de discusión con magrebíes comentan que la posibilidad de entrar al paritorio con alguien diferente al marido es algo reciente.

$\mathrm{Y}$ ahora lo han facilitado. Porque antes dicen "Solo puede entrar tu marido", y ahora han cambiado. Ahora entra quien tú quieres. Por ejemplo, cuando da la luz mi cuñada, que mi hermano es un poco miedoso, y a mí me han dejado entrar con ella. Antes decían que no, que solo el marido. [GD - Magreb 5]

Sí, solo el marido, sí. [GD - Magreb 2]

Y le ha pasado a una amiga hace tiempo. Que quería entrar con su madre, y le han dicho que no, que tiene que estar solo el marido. [GD - Magreb 5]

No disponemos de datos que confirmen o desmientan este hecho, aparte de la opinión manifestada por los profesionales en las entrevistas y por las usuarias en el grupo de discusión, 
de modo que no podemos saber con certeza si en el pasado no estaba permitido que el acompañante durante el parto fuera alguien distinto al marido de la parturienta.

Un dato obtenido en uno de los grupos de discusión y que también habíamos detectado previamente consiste en que las usuarias procedentes del Magreb, al igual que habíamos descubierto mediante las entrevistas y la observación no solo en cuanto a las usuarias magrebíes sino también en el caso de las chinas, parecen preferir que las acompañen familiares de sexo femenino (principalmente sus madres) durante el proceso reproductivo, aunque encontrándose la mayoría de sus familiares en sus países de origen, no han podido contar con su acompañamiento, sino que, por ejemplo en el parto, como hemos señalado en párrafos anteriores, han sido sus maridos los que han estado presentes.

Como no tenemos ni familia ni nada, ¿quién nos va a acompañar? Si estarían aquí nuestras madres, eso sería... [GD - Magreb 5]

(Todas asienten, como confirmando que también ellas hubieran preferido estar acompañadas por sus madres.)

Es que se puede... o, al menos, eso escuché, se puede en el caso de todas, se puede pedir que venga la madre. Pero yo no lo sabía hasta hace poco. Me he enterado por el caso de una amiga, que está en Madrid, y está solita, y el marido tampoco está aquí. Y le dieron un permiso a la madre para que está aquí... dos meses, me dijo. [GD - Magreb 1]

Pero habrá que tener unas condiciones. Ella estaba trabajando, ¿no? [GD - Magreb 5]

No, no estaba trabajando. Y el marido estaba en Marruecos todavía. Pregunta, porque igual tú podías pedirlo. (Se dirige en árabe a la compañera que está embarazada en este momento.) [GD - Magreb 1]

Pero, bueno, no nos queda más remedio. Porque no tenemos mucha familia ni nada. $\mathrm{O}$ a lo mejor te toca a las tres de la mañana y... ¿cómo te vas a buscar a tu prima o a tu hermana? [GD - Magreb 4]

Cuando planteamos el tema de los cuidados de los recién nacidos durante el puerperio, las usuarias magrebíes participantes en el grupo de discusión también sostienen que prefieren la ayuda por parte de familiares de sexo femenino, especialmente sus madres. De hecho, tal y como se muestra en el fragmento que se incluye a continuación, cuentan que en España han sido sus maridos quienes las han ayudado o, en algunos casos, familiares de sexo femenino que están viviendo en este mismo país, pero que, si hubieran permanecido en su país de origen, Marruecos, se habrían ocupado sus madres o las mujeres de la familia de ellas y de sus hijos. Además, nos hacen partícipes de otra costumbre propia del periodo postparto, según la cual, la madre suele guardar un tiempo de reposo (total durante siete días y parcial durante cuarenta) tras dar a luz, costumbre que algunas de ellas, por sus obligaciones y por la falta de redes familiares en el país de acogida, tampoco han podido respetar aquí.

Nos ayuda el marido. (Ríen todas y dicen "Sí, sí, el marido".) [GD - Magreb 1]

(Les pregunto que, si, en caso de que hubieran tenido a sus hijos en Marruecos, también les habrían ayudado sus maridos en el cuidado de los niños.)

Ahí nos ayudaría la familia. Por ejemplo, si doy a luz en Marruecos, ahí estaría mi madre, que me cuidaría de maravilla. (Risas) [GD - Magreb 2]

Es que en Marruecos la mujer se queda durante cuarenta días sin hacer nada, solo cuidando del bebé. [GD -Magreb 1] 
Sí, sí, y se queda siete días en la cama, no se levanta de la cama y la familia le cuida. Pero aquí, por ejemplo, mi hijo salió del hospital, descanso el domingo, y el lunes ya tenía que ir a hacer todos los papeles. [GD - Magreb 2]

Yo aquí, cuando nacen los gemelos, al día siguiente de volver a casa tengo que llevar a los niños al colegio. [GD - Magreb 3]

Yo, por ejemplo, en mi caso, estuve en el hospital diez días, porque me pusieron veinticuatro puntos, y me dijo el médico que es mejor que no me voy a mi casa hasta que se cierran los puntos. $Y$, en esos diez días, menos mal que las enfermeras duchaban a mi bebé, porque yo tenía mucho miedo. Y, cuando llora, me decían “No lo cojas de ahí. Déjalo en la cuna. Porque cuando tú estás en casa sola...”. (Risas). [GD - Magreb 5]

Pero, bueno, aquí maridos ayudan, cambian los pañales y todo. [GD - Magreb 1]

Mi marido no me ayuda a cambiar pañales, porque mi hija tiene dieciséis años, entonces me ayuda ella. Y tenía también aquí una hermana que también me ayuda. [GD - Magreb 3]

El mío también me ayuda. Si estás en Marruecos, te ayudan mujeres de la familia, pero aquí, si no tienes a nadie, él tiene que ayudar. [GD - Magreb 2]

También los maridos de las usuarias latinoamericanas, de acuerdo con sus respuestas, las han ayudado durante el puerperio, bien por voluntad propia, o porque no tenían más remedio, ya que, al no residir en España las madres o familiares de las usuarias, los maridos eran los únicos que podían colaborar en los cuidados de los recién nacidos. Al respecto, como veremos en el siguiente fragmento, algunas opinan que esta implicación sería menor si continuaran viviendo en sus respectivos países de origen, donde, por motivos como el machismo imperante o los horarios de trabajo, parece ser que los hombres no suelen ayudar en los cuidados.

Yo llevé a mi hijo a cuestas, pero también me echaban una mano. Porque con una cesárea... Así que me ayudaban mucho. Por ejemplo, el papá me lo cambiaba, me lo duchaba... Y es que mi hijo nació con 4 kilos y 200 (gramos), y yo no sabía ni cómo cogerlo. Pero si me hubiera nacido con 2500 (gramos) o hasta con 3000 (gramos), yo no hubiera sido capaz de maniobrarlo, porque me daba... Yo decía "iAy, lo voy a partir!". Y eso que él era tan... Es que no se me puso ropa de bebé, llevaba ya nada más nacer ropa de un niño de 4 o 5 meses. [GD - Latinoamérica 3]

En mi caso, mi madre se ocupó de él hasta los... los doce años. [GD - Latinoamérica 4]

(Aprovecho esta intervención para preguntarles si creen que el tema de los cuidados de los niños es más una cuestión femenina, masculina, o se deben ocupar los dos).

Puede ser cosa de los dos también. [GD - Latinoamérica 1]

No, es cosa de los dos, es cosa de los dos. [GD - Latinoamérica 4]

Sí, es verdad que es cosa de los dos. Lo que pasa es que al principio las mamás... Bueno, a mí me pasa, ¿eh?, que el papá quería cambiarle el pañal, quería bañarlo, quería limpiarlo... Y yo estaba como una leona, y le decía "No, no lo hagas asi". Nosotras siempre como que pensamos que lo vamos a hacer mejor que ellos, ¿no? O igual lo podemos hacer mejor que ellos porque tenemos más experiencia, pero... ellos aprenden y lo hacen muy bien. Al final parece como... como que te ganen. (Risas). [GD - Latinoamérica 2]

En mi caso me ayudaba mi madre sobre todo. Lo duchaba y tal... Porque ella tenía más experiencia, y yo lo veía tan pequeñito que me daba miedo que se me cayese o algo. [GD - Latinoamérica 1]

Pues a mí, en el caso de mi última hija, estando aquí, hemos sido sobre todo su papá y yo los que nos hemos ocupado. Porque como no tenemos familia cerca, pues nos ha tocado a los dos solos. Pero, con el 
primero, sí que estuvo mi mamá ahí... Porque, cuando lo tuve, yo tenía diecinueve años y, entonces, la mamá siempre... como que tú eres... como que no tienes experiencia y, entonces, todo lo quieren hacer ellas. Bueno, me enseñaba, me decía "Mira, lo bañas así...". Y ya con la última, el papá me decía "Pero, ¿̇i ya has tenido un hijo, cómo no vas a saber bañarla?". Y yo le decía "Pero si es que yo no bañaba al primero, lo bañaba mi mamá". [GD - Latinoamérica 4]

Y, además, es que no te acuerdas. Porque mi último hijo nació siete años después que su hermanita, y yo no me acordaba de nada, ni de bañarlo, ni de cómo lo cogía... Es que se olvida uno. [GD - Latinoamérica 2]

Sí, total, totalmente. El papá me decía “¿Pero, ¿cómo no sabes esto o lo otro?”. Y yo decía "Es que yo no lo hacía, lo hacía mi madre”. [GD - Latinoamérica 4]

Yo, al principio, sí que me hacía mucho lío. Pero, bueno, ahora ya sí que le digo al papá "Toma, toma, cámbialo" o "Báñalo, báñalo". [GD - Latinoamérica 2]

(Les pregunto si creen que, si vivieran todavía en su país, sus parejas se implicarían en los cuidados de los hijos).

Es que aquí es muy normal, pero en mi país, no. Por ejemplo, en mi familia en Colombia, yo a los hombres nunca los he visto ocuparse... Y hablo de ellos porque son a los que he visto, porque, como no he tenido hijos allí... Por ejemplo, muchas de mis primas han sido madres solteras, porque en el embarazo le cogen fastidio al marido y, entonces, optan por separarse, y ya después tienen el hijo y, como cada uno lleva su vida, pues mira... Cada quien a su rollo. Pero las que más se implican son las yayas. [GD - Latinoamérica 3]

Yo creo que depende, depende del padre. Porque allí también hay mucho machismo, al menos en mi país. Yo creo que esto pasa en casi todos los países de Sudamérica, que los chicos son muy machistas. [GD Latinoamérica 2]

\section{Sí, sí, eso es verdad. [GD - Latinoamérica 1]}

Y aparte que los horarios de trabajo tampoco son como aquí, que aquí trabajas ocho horas y luego, chao, te vas a tu casa, ¿no? Y, luego, si quieres, haces horas extras o qué se yo, pero allá trabajas de sol a sol. Si tienes suerte, pues sí que trabajas ocho horas y, luego, a casa, pero es más difícil. Por lo menos, en mi caso, fue más difícil. Porque mi primer niño tuvo dermatitis, y no podía usar pañales desechables $y$, entonces, teníamos que ponerle pañales de tela, y me pasaba todo el día lavando, y yo, al final, me cansé, me cansé y le dije a mi marido que tenía que ayudarme, a lavar los pañales y a todo. $Y$, entonces, el ya venía del hospital, se sacaba la bata y se ponía a lavar los pañales. Pero fue difícil, fue difícil convencerlo de que me tenía que ayudar, porque los han educado de otra manera y... [GD - Latinoamérica 2]

(Al oír estas últimas palabras, asienten todas.)

Bueno, yo como... Mi pareja no tenía problemas en ayudarme, pero... [GD - Latinoamérica 4]

Es que varía de persona a persona. Depende de las mentalidades. [GD - Latinoamérica 1]

Sí, sí, sí. Porque el padre de mis hijos, de los dos primeros, era machista que... iMadre mía! [GD Latinoamérica 2] 
Las respuestas ofrecidas en cuanto a la implicación de maridos y familiares en todo el proceso reproductivo, tanto en el caso de las usuarias magrebíes como en el de las latinoamericanas, sí que parecen confirmarse en los cuestionarios individuales que completaron tras los grupos de discusión, tal y como puede observarse en la siguiente tabla:

\begin{tabular}{|l|c|c|l|}
\hline & NO & Sí & \multicolumn{1}{c|}{ (En caso afirmativo), de qué manera } \\
\hline Latinoamérica 1 & & X & $\begin{array}{l}\text { Desearía que su pareja le acompañara a los } \\
\text { controles del embarazo y le ayudara más en el } \\
\text { cuidado del bebé. }\end{array}$ \\
\hline Latinoamérica 2 & X & X & $\begin{array}{l}\text { Desearía que su pareja le ayudara a cambiar } \\
\text { pañales y en el cuidado del bebé y le diera } \\
\text { masajes. }\end{array}$ \\
\hline Latinoamérica 4 & & X & $\begin{array}{l}\text { Considera la implicación del padre importante } \\
\text { para el desarrollo emocional tanto del bebé } \\
\text { como de la pareja. }\end{array}$ \\
\hline Magreb 1 & & X & $\begin{array}{l}\text { Desearía que le hubiera podido ayudar en los } \\
\text { cuidados su madre. }\end{array}$ \\
\hline Magreb 2 & & X & $\begin{array}{l}\text { Desearía que le hubiera podido ayudar en los } \\
\text { cuidados su madre. }\end{array}$ \\
\hline Magreb 3 & X & $\begin{array}{l}\text { Desearía que le hubiera podido ayudar en los } \\
\text { cuidados su madre. }\end{array}$ \\
\hline Magreb 4 & & $\begin{array}{l}\text { Desearía que le hubiera podido ayudar en los } \\
\text { cuidados su familia. Está muy satisfecha con la } \\
\text { ayuda proporcionada por su marido. }\end{array}$ \\
\hline Magreb 5 & & $\begin{array}{l}\text { Desearía que le hubiera podido ayudar en los } \\
\text { cuidados su familia y, en concreto, su madre. }\end{array}$ \\
\hline
\end{tabular}

Tabla 6.7. Deseo de mayor implicación de los maridos y familiares en los cuidados durante el embarazo, el parto y el puerperio por parte de las usuarias participantes en los grupos de discusión

El último aspecto relativo al puerperio que abordaremos en este subapartado se refiere a una cuestión que había planteado una usuaria magrebí entrevistada y que no habíamos podido verificar. Concretamente, esta usuaria había comentado que, de acuerdo con los preceptos del Islam, la madre debía optar por la lactancia materna y, a ser posible, durante dos años. Vemos en el siguiente fragmento del grupo de discusión con usuarias magrebíes cómo confirman este dato y cómo, incluso, una de ellas comenta que se disgustó enormemente cuando, por causas ajenas a su voluntad, no le resultó posible continuar dándoles el pecho a sus hijos.

(Les pregunto si están a favor de la lactancia materna y, en caso afirmativo, durante cuánto tiempo les gustaría mantenerla. Todas afirman haber dado el pecho a sus hijos.)

Yo lo di durante un año y seis meses. [GD - Magreb 4]

Por ejemplo, yo, a los dos primeros les doy cuatro meses, y se va la leche. $Y$ al tercero, dos meses y medio, y se va la leche. Y, cuando me pasó con el primero, yo fui llorando a la doctora y le pedí "Por favor, hazme algo", y me dice "No, para quitar leche sí que hay, pero para poner no hay". Hay pastillas para que se va la leche, pero para poner, no. [GD - Magreb 2]

(Les pregunto si el Corán dice algo sobre la lactancia materna y todas dicen que sí.)

El Corán dice que, si se puede, hay que dar leche durante dos años, porque la leche de la madre es la mejor, sirve para proteger al niño, porque así sale fuerte. [GD - Magreb 4] 
También creo que es por el tiempo que hay que esperar entre un niño y otro. Porque tienes que esperar dos años antes de tener un niño otra vez. [GD - Magreb 5] $]^{288}$

\subsubsection{Barreras lingüísticas y soluciones}

En este subapartado, analizamos las barreras lingüísticas que, de acuerdo con los participantes en los grupos de discusión, pueden existir en la comunicación entre los profesionales sanitarios y las usuarias inmigrantes, así como las soluciones que estos participantes han adoptado para superar dichas barreras.

Puesto que pueden haber influido en las respuestas de los participantes, antes de iniciar el análisis propiamente dicho, cabe recordar algunos datos demográficos de los mismos que hemos presentado en páginas anteriores. La lengua materna de todos los profesionales es el español, lengua que comparten con las usuarias del grupo de latinoamericanas. Por el contrario, las usuarias del grupo de magrebíes presentan como lengua materna el árabe, aunque todas ellas poseen conocimientos medio-altos de español. Asimismo, algunos profesionales afirman conocer otras lenguas, en particular, inglés, francés, catalán e italiano. Desconocemos si el nivel de conocimientos de estas lenguas extranjeras es suficiente como para permitir que los profesionales del grupo de discusión los puedan emplear como lengua vehicular para establecer una comunicación efectiva con las usuarias alófonas. Además, se trata también en este caso, como en el de los profesionales que hemos mencionado en el análisis de los datos recolectados con otras técnicas de investigación, de lenguas extranjeras que no coinciden con las lenguas maternas de las principales comunidades de inmigrantes residentes en la ciudad contexto de nuestro estudio.

Pasamos a continuación a presentar las barreras lingüísticas detectadas por los participantes en los grupos de discusión.

Por lo que se refiere a los profesionales sanitarios, estos señalan desde el principio estas barreras como la causa principal de las dificultades que encuentran en la asistencia sanitaria a usuarias inmigrantes. Además, como los profesionales entrevistados, comentan que los problemas comunicativos, junto con la presión asistencial a la que están sometidos, en ocasiones, generan en ellos nerviosismo y frustración, y hacen que la información transmitida a las usuarias alófonas sea menor que la que se ofrece a las usuarias que dominan el español.

(Les pregunto si creen que existen barreras lingüísticas al comunicarse con las usuarias inmigrantes.)

Esta es la barrera principal, sí. [GD - Obstetra 3]

(El resto asiente con un movimiento de cabeza.)

A veces reconozco que me pongo un poco de los nervios. Y le explicas, a lo mejor, menos de lo que le explicarías a otra mujer... [GD - Obstetra 2]

Claro, pero por falta de tiempo. [GD - Obstetra 3]

\footnotetext{
${ }^{288}$ Cabe señalar que organizaciones como la OMS y UNICEF también recomiendan seguir amamantando a partir de los seis meses, al mismo tiempo que se va ofreciendo al bebé otros alimentos complementarios, hasta un mínimo de dos años. Asimismo, los mismos beneficios de la lactancia materna señalados por las usuarias magrebíes en el grupo de discusión fueron indicados en la Cumbre sobre Promoción y Desarrollo, en 1994, en la que se presentó la recomendación de recurrir a la lactancia materna como herramienta para mejorar la salud de la madre y del bebé y para espaciar los embarazos.
} 
Los profesionales participantes en el grupo no mencionan específicamente ningún colectivo con el que estas dificultades de comunicación sean mayores, a diferencia de los profesionales entrevistados, que habían indicado que las usuarias con mayores problemas comunicativos eran las procedentes de Asia, África Subsahariana y el Magreb. Un dato en el que sí que coinciden tanto con las respuestas ofrecidas por sus compañeros en las entrevistas como con las notas registradas en una de las fichas de observación durante las consultas a puérperas se refiere al hecho de que, en ocasiones, las usuarias inmigrantes pueden afirmar conocer el español cuando no es así y viceversa, como señala el profesional cuyas palabras reproducimos en este fragmento.

(Interpelo directamente a GD - Enfermera 1, pues ha transcurrido ya casi la mitad del grupo de discusión y es la única participante que todavía no ha intervenido. Le pregunto si ella se ha encontrado con barreras lingüísticas y, en caso afirmativo, cómo las ha tratado de resolver.)

Sí, sí, a mí me ha pasado muchas veces, muchas. Porque, por ejemplo, cuando les vas a hacer el ingreso, aunque les haces cuatro preguntas, cuando ves que a todo te dicen que sí... iMalo! (Risas). Y piensas "Esta no se está enterando...". [GD - Enfermera 1]

Todo ello puede conducir a situaciones en las que los profesionales se enfrentan en cierto sentido a un dilema ético, ya que pueden dudar de si las usuarias alófonas han comprendido sus mensajes y de si, por tanto, habrán tomado decisiones estando debidamente informadas, tal y como puede observarse en el siguiente fragmento:

Es que, a veces, ves que hay información que no llega, por la falta de comunicación. Sobre todo cuando deciden algo que se sale de la norma, que hemos tenido casos en los que el pronóstico fetal era nefasto y, por ejemplo, han querido seguir con el embarazo, y hasta cierto punto te preguntas si esta mujer lo estará decidiendo porque realmente quiere o porque se ha enterado de la misa, la mitad, ¿̇sabes? Cuando, por ejemplo, una española, pues habría decidido interrumpir el embarazo precozmente porque el pronóstico era pésimo, no, lo siguiente. Entonces, esas situaciones, además de que te crean a ti como profesional algo de conflicto, pues también dices “¿Se habrán enterado bien?” [GD - Matrona 2]

También en este caso, como en el de los profesionales entrevistados, los participantes indican que hay contextos y áreas del hospital en las que quizás los problemas comunicativos son mayores, por el carácter complejo de las situaciones que se viven en ellos.

Es que en una situación de urgencias es más difícil, pero, en una consulta, que es sota, caballo y rey, pues es más fácil, ¿̇no? [GD - Obstetra 2]

Además, puede tratarse de situaciones en las que, dependiendo del modo en que la información se transmite y llega a la usuaria, esta puede experimentar un incremento notable de ansiedad, con los consecuentes perjuicios para su propia salud o la del feto.

Y a ver cómo le explicas, por ejemplo, a una china, que hay un retraso en el crecimiento del feto y que hay que hacer una ecografía a los quince días para ver si crece lo que está estipulado o menos, y que si no, hay que cambiar de restaurante (Risas). Y, sobre todo, a ver cómo se lo explicas para que no se angustie, porque, claro, si se angustia, estamos haciendo lo contrario. $O$ sea, en el crecimiento restringido, el que la madre te colabore, y coma bien, y esté tranquila, eso es muy importante, mucho más de lo que pensamos, porque la ansiedad y la angustia todavía reducen más el calibre de las arterias que llevan sangre a la placenta. [GD - Obstetra 2] 
En cuanto a las usuarias inmigrantes participantes en los grupos de discusión, en un primer momento, ninguna de ellas afirma enfrentarse en el momento de celebración del encuentro con graves problemas para comunicarse con los profesionales sanitarios. Así queda también reflejado en el cuestionario individual que estas completaron, tal y como puede verse en la siguiente tabla:

\begin{tabular}{|l|l|l|l|l|l|l|l|l|l|l|}
\hline & $\mathbf{1}$ & $\mathbf{2}$ & $\mathbf{3}$ & $\mathbf{4}$ & $\mathbf{5}$ & $\mathbf{6}$ & $\mathbf{7}$ & $\mathbf{8}$ & $\mathbf{9}$ & $\mathbf{1 0}$ \\
\hline Latinoamérica 1 & & & & & & & & & $\mathrm{X}$ & \\
\hline Latinoamérica 2 & & & & & & & $\mathrm{X}$ & & & \\
\hline Latinoamérica 3 & & & & & & & & & & $\mathrm{X}$ \\
\hline Latinoamérica 4 & & & & & & & $\mathrm{X}$ & & & \\
\hline Magreb 1 & & & & & & & & & & $\mathrm{X}$ \\
\hline Magreb 2 & & & & & & & & $\mathrm{X}$ & & \\
\hline Magreb 3 & & & & & & & & $\mathrm{X}$ & & \\
\hline Magreb 4 & & & & & & & & $\mathrm{X}$ & & \\
\hline Magreb 5 & & & & & & $\mathrm{X}$ & & & & \\
\hline
\end{tabular}

Tabla 6.8. Valoración de la comunicación con los profesionales sanitarios de acuerdo con las usuarias participantes en los grupos de discusión

(10 “Comunicación totalmente efectiva”; 1 “Comunicación muy complicada/ineficaz”)

Por lo que se refiere a las usuarias procedentes del Magreb, recordemos que era un requisito indispensable para poder participar en el grupo que poseyeran amplios conocimientos de español, de manera que pudieran manifestar abiertamente sus opiniones sobre los temas planteados y debatir entre ellas. Sin embargo, estas usuarias sí que admiten que, en el pasado, su escaso dominio de esta lengua no les permitió mantener una comunicación efectiva con los profesionales sanitarios durante el embarazo, el parto y el puerperio.

(Les pregunto si, cuando dieron a luz, hablaban español, y todas parecen responder que no o que, al menos, no tenían tantos conocimientos de este idioma como ahora.)

Yo entendía bien, pero a la hora de contestar me costaba más. Porque, cuando tuve a mi hija, tenía aquí un año y cuatro meses, o sea, que ya entendía más o menos todas las palabras, pero para contestar no podía. [GD - Magreb 5]

Pues yo, justo al poco de venir a España, me quedé embarazada. Y yo ya sabía español en mi país, o sea, que las palabras las entendía, pero me daba vergüenza hablar. [GD - Magreb 4]

Yo, con mi primer hijo, no conozco... [GD - Magreb 2]

En el caso de la usuarias de Latinoamérica, nuestra intención principal al plantearles el tema de las barreras lingüísticas era principalmente verificar, como hemos comentado en apartados previos, si el hecho de compartir la lengua materna con los profesionales sanitarios garantizaría la comunicación efectiva con estos, o si, por el contrario, y tal y como habían comentado tanto un profesional como una usuaria latinoamericana entrevistados, podían 
surgir problemas comunicativos en la interacción. Al respecto, las participantes en el grupo de discusión opinan que existe una comprensión mutua y que no se han enfrentado a problemas de tipo lingüístico. No obstante, sí que reconocen que el estilo comunicativo puede ser diverso en sus respectivos países y en España, y esto podría conducir a interpretaciones erróneas tanto del mensaje como de la intención de su interlocutor.

Yo, en mi caso, creo que lo que pasa es que malinterpretamos las formas. Es que en nuestros países todo es más con diminutivos. Hablamos... como que más cariñoso y qué sé yo. Y aquí es como más... [GD Latinoamérica 2]

Seco, es seco, ¿no? [GD - Latinoamérica 4]

Sí, sí. [GD - Latinoamérica 2]

Es serio, serio. [GD - Latinoamérica 1]

Sí, entonces, a veces malinterpretamos y pensamos "Oye, me ha hablado mal", ¿no?, o "Me ha mirado mal" o... O "Me ha dicho esto y, para mí, es una grosería". Pero, luego, en el idioma, no, en el idioma, no... [GD - Latinoamérica 2]

Se entiende igual. [GD - Latinoamérica 1]

Sí, se entiende muy bien. [GD - Latinoamérica 2]

Sí, puede ser que sean las formas, pero yo no he notado... Respecto a eso, no tuve... Me entendí siempre muy bien. [GD - Latinoamérica 4]

Yo es que llevo casi doce años aquí y, entonces, ya he vivido más acá que allá, entonces no noto tampoco... [GD - Latinoamérica 1]

Por un lado, comentan que algunos términos de uso común en España son considerados groseros en sus países de origen y, además, que el hecho de hablar diferentes variedades diatópicas del español puede conllevar que en uno y otro país se usen palabras idénticas en su forma, pero con diferentes significados.

Pues, sí, por ejemplo, en mi ciudad decir "culo" es una grosería, es una barbaridad. [GD - Latinoamérica 2]

Sí, sí. [GD - Latinoamérica 1

Allá le dices, el pompito, o el chanchito... Pero, ¿el culo? Escucharle a un niño decir esa palabra es una grosería. Y, aquí, es normal. [GD - Latinoamérica 2]

(Les pregunto si puede que en sus países y en España haya palabras distintas para referirse a los mismos conceptos.)

No, a mí esto no me pasó, pero he conocido gente que sí que le ha pasado. Aunque, bueno, sí que cuando llegué, hace muchos años, me acuerdo que me enfermé, no recuerdo exactamente qué tenía, pero me dieron muchas fiebres, y fui al ambulatorio, y me dice el médico: "Bájate el vaquero y para el culo, que te van a pinchar". Y, claro, yo decía... Es que en Colombia «pinchar» es como decir que te van a follar. Y yo le decía al médico "iQue no, que no, que no!". (Risas). Y él me decía "Pero, chavala, ¿cómo es que no te has desvestido? Bájate el pantalón, que te van a pinchar", y yo decía, “No, no, no, doctor, no, no, no". Y ya, al final, me explicaron y lo entendí. Es que nosotros, aquí, por más que hablemos el mismo español, pero metemos cada... Porque usamos palabras distintas. (Le pregunto si, aparte de los malentendidos lingüísticos, ha notado ella también que el modo de hablar de los españoles es más serio o más directo que el que se usa en su país). Pues, a mí, esto no me marcó, porque yo venía ya preparada psicológicamente por mi madre. Ella me dijo "Prepárate, porque te vas a encontrar allí un mundo 
totalmente diferente. Tú allí no te vas a poder escandalizar, por ejemplo, si ves a una persona fumándose un porro por la calle". En Colombia eso es... Buff. Vamos, en Colombia eso es como decir en qué mundo vamos a estar. Y aquí eso es... Por ejemplo, aquí se ve un crío en el botellón, y allí si vas al botellón, te meten una paliza, te llevan a casa y no sales... Vamos, ien meses! Entonces... Y aquí lo que más me marcó fue con el trabajo de mi papá. Porque mi papá es chapista. Y me invitaron a una cena de despedida antes de las vacaciones con los compañeros de trabajo del papá de mi hijo. Entonces, yo llego allí, y me dicen "Ay, morena, guapa", tú ya sabes cómo hablan los madrileños... Y me dicen "Cuéntanos de tu familia", y no sé qué... Porque yo estaba recién llegada, tenía aquí tres o cuatro meses. Y me preguntan "¿Y qué hace tu familia?”. Y yo les cuento "Pues, mi madre trabaja aquí, trabaja en la hostelería”. “¿Y tu padre?”. "Pues, mi padre está en Colombia”. "¿Y qué hace tu padre?”. Y yo dije "Pues mi padre es chapero”. (Risas). Entonces, claro, ellos, como yo lo dije con tanta naturalidad, pues me preguntaban "¿Y cómo le va a tu padre siendo chapero en Colombia?". Y yo "Le va estupendamente. A veces le va muy, muy, muy bien, y otras, no tanto". Y, claro, ellos se cortaron, porque me veían hablando con tanta naturalidad, que pensaban "iQué bien lleva esta chica que su padre sea... sea homosexual!". Yo sí que veía que me miraban muy raro. Entonces se para mi compadre y me dice "Ven al baño". Y me pregunta "Pero, ¿cómo les has dicho que tu padre es chapero?". Y yo le digo "Sí, es que es chapero". Y él me pregunta "Pero, a ver, ¿qué hace tu padre?". Y, entonces, le cuento "Pues repara las abolladuras a los coches". Y me dijo, "Ven acá, que te voy a dar una colleja. Que no se dice "chapero", que se dice "chapista»". Y ya todos "Aaaaaaah, vale". Así que es algo que te marca. Y ya cada vez que tenía que decir algo, yo me lo pensaba, porque creía que me iban a decir algo... Y todavía, aunque llevo dieciséis años, pues me cuesta. [GD - Latinoamérica 3]

Tal y como puede observarse en el fragmento que acabamos de incluir, estos términos homónimos pueden llevar a situaciones en las que se producen malentendidos de mayor o menor gravedad. Asimismo, es probable que las usuarias latinoamericanas que hayan experimentado episodios de este tipo sientan cierto reparo a la hora de comunicarse, por temor a que no se las comprenda adecuadamente.

Por otro lado, una de las usuarias latinoamericanas manifiesta la dificultad añadida a la que deben enfrentarse por el hecho de que en España se hablen diferentes idiomas y variedades dialectales del español.

[...] porque, aquí, cada comunidad tiene su propio idioma, y así digamos que todos somos España, no. Por ejemplo, los del pueblo donde yo vivo tienen una manera diferente de hablar de los madrileños o los andaluces, o incluso de los zaragozanos. Por ejemplo, yo aquí a Zaragoza llegué y todo era "Maña, maña, maña, maña". Y yo, vale. Y, en el pueblo, eso no se usa. Y es que se encuentra uno con diferentes culturas. Por ejemplo, cuando estuve en Andalucía de vacaciones, me dicen " $\mathrm{i} A y$, chiquilla, pero es que tú eres muy salá!". (Cuando pronuncia esta última frase intenta imitar el acento andaluz). Y yo pensaba "Pero, ¿por qué me dicen "salá», si yo tengo muy buena suerte?" (Ríen todas). Porque para ellos "salá» significa una persona muy divertida, muy graciosa, y para mí, en cambio, es una persona que tiene muy mala energía. (Ríen todas de nuevo). De estas me pasaban cada dos por tres. Así que es un lío, porque piensas “¿Cómo hablo? ¿Cómo digo? ¿Lo digo o no lo digo?”. [GD - Latinoamérica 3]

Vemos, por tanto, que, a pesar de que resulta innegable que las usuarias latinoamericanas se enfrentarán a menos barreras lingüísticas a la hora de interactuar con los profesionales sanitarios con respecto a otras usuarias inmigrantes, no podemos afirmar rotundamente que estén exentas de dificultades comunicativas, bien por las diferencias en algunos usos verbales y no verbales, bien por las diferencias culturales.

No incluimos en los grupos de discusión preguntas relativas al empleo de terminología médica, ya que con las técnicas de las entrevistas y la observación había quedado suficientemente claro que los profesionales suelen emplear un lenguaje estándar, huyendo del uso de tecnicismos en su comunicación tanto con usuarias autóctonas como inmigrantes. 
Tampoco planteamos el tema del lenguaje escrito, puesto que prácticamente todas las usuarias entrevistadas habían manifestado que este les resultaba bastante más sencillo que el oral y, además, en caso de no comprenderlo perfectamente, siempre podían recurrir al uso de diccionarios o solicitar a alguien con un mayor dominio del español que se lo tradujera. Al respecto, sí que cabe recordar que los profesionales entrevistados habían señalado en sus respuestas la posibilidad de encontrarse con usuarias analfabetas que, por consiguiente, no podrían leer los documentos escritos, pero ninguna de las participantes en nuestro estudio reunía esta condición (lo cual no quiere decir que no haya usuarias inmigrantes en todo nuestro contexto de estudio que sí que la reúnan), por lo que no hemos podido hallar ningún caso en el que, por su imposibilidad para leer y escribir, alguna usuaria se encontrara con esta barrera añadida.

A continuación, analizamos las soluciones adoptadas por los participantes en los grupos de discusión para eliminar o disminuir las dificultades de comunicación. No incluimos información relativa al grupo de discusión con latinoamericanas, pues al sostener que no se habían enfrentado a particulares barreras lingüísticas, no tratamos con ellas el tema de las soluciones.

La primera solución que presentamos es el recurso al lenguaje no verbal como modo para facilitar la comunicación. Prácticamente todos los profesionales entrevistados habían reconocido que lo empleaban habitualmente al comunicarse con usuarias alófonas, y así había quedado también confirmado durante la observación. Igualmente, uno de los profesionales participantes en el grupo de discusión dice haber recurrido en ocasiones a los gestos y, como sucedía con sus compañeros mencionados en el análisis de las otras técnicas, tampoco parece ser consciente de las posibles diferencias en el uso y la interpretación del lenguaje no verbal en las diferentes culturas.

$Y$, luego, ya lo normal, con gestos te vas a entendiendo. Porque, claro, al final, te acostumbras. $Y$ les dices “¿Fumas?” o “¿Bebes?” (Mientras plantea estas dos preguntas hace gestos con las manos simulando fumar y beber.) E igual la señora se pone "iUuuuuu, uuuuuu!" (Hace aspavientos con las manos y adopta una expresión facial que denota entre sorpresa y pudor.) ${ }^{289}$ [GD - Obstetra 2]

Otra de las soluciones mencionadas por los profesionales participantes en el grupo se refiere a los documentos traducidos de los que dispone el hospital contexto de estudio.

\footnotetext{
$\mathrm{Y}$, luego, como tenemos instrucciones para dar en varios idiomas. De hecho, las instrucciones que damos en lengua árabe, están traducidas al "árabe básico", lo que va a entender todo el mundo, o en el caso del chino... Vamos, que no incluimos todos los dialectos, sino que vamos a los más usados y, así, más o menos todo el mundo lo entiende. Vamos, yo creo que tener los documentos traducidos es importante. [GD Obstetra 2]

Hombre, pues sí. [GD - Obstetra 3]

Y también hay un cuadernito por ahí con las preguntas típicas, pues sobre la menarquia (se refiere, como sabré más tarde, a la aparición de la primera menstruación), el sangrado, esto, lo otro... Pues, están en varios idiomas y te facilita, pero hay que perder tiempo. Y es para preguntas muy... muy estandarizadas, ¿eh? [GD - Obstetra 2]
}

\footnotetext{
${ }^{289}$ No podemos saber si la sorpresa que, de acuerdo con este profesional, manifiesta la usuaria está provocada por una malinterpretación de los gestos que este ha empleado o por considerar vergonzoso que se dude de si ha fumado y bebido durante el embarazo.
} 
Ya, pero aquí tenemos una cantidad de casos que sería imposible tener papeles para todas las situaciones que se nos presentan. De hecho, para la epidural, que es ya más una cosa universalizada, pues sí que tenemos los consentimientos en muchos idiomas. Pero, bueno, como todas se la quieren poner, te firman cheques en blanco, que, aunque no lo entiendan, te lo firman. Pero, aquí, por ejemplo, en la planta de alto riesgo, que hay tantas posibles situaciones, no puedes tener papeles para todas. Porque aunque sea el mismo tipo de patología, hay un abanico inmenso de posibilidades... [GD - Matrona 2]

Al respecto de estos documentos, cabe señalar algunas limitaciones y desventajas que los propios profesionales indican. Por una parte, los documentos están traducidos solo a determinados idiomas, por la imposibilidad de tener versiones en el amplio abanico de lenguas y dialectos de toda la población de usuarias. Por otra, los listados de expresiones multilingües solo pueden emplearse para formular preguntas estandarizadas $y$, en consecuencia, no cubren todas las posibles situaciones en las que deberán comunicarse los profesionales con las usuarias alófonas.

Los profesionales participantes en el grupo de discusión solo mencionan de pasada el recurso a los consentimientos informados traducidos, aunque ya habíamos comentado en el anterior subapartado, concretamente cuando hablábamos del suministro de la anestesia epidural, que, por el estado anímico en el que se encuentran las usuarias justo antes de dar a luz, parece ser que en muchos casos ni siquiera se los leen antes de firmarlos. Por consiguiente, para un perfecto entendimiento de la técnica que se les va a practicar y las consecuencias de la misma, los consentimientos deberían acompañarse de explicaciones por parte de los profesionales sanitarios. Además, cabe tener en cuenta que, de acuerdo con los datos recolectados mediante las entrevistas, los consentimientos traducidos presentan otros inconvenientes, como, por ejemplo, la imposibilidad por parte del profesional sanitario de saber exactamente qué ha firmado la usuaria, por estar estos documentos editados en una sola lengua, o el hecho de que, tras su lectura, ni la usuaria alófona puede formular preguntas al respecto, ni el profesional puede añadir aclaraciones ulteriores.

Por último, recordamos que un gran número de usuarias entrevistadas desconocía la existencia de documentos traducidos en el hospital contexto de estudio y, de hecho, este recurso tampoco es señalado por las usuarias participantes en el grupo de discusión con magrebíes, por lo que podemos intuir que probablemente tampoco eran conocedoras del mismo.

El recurso a familiares y amigos de las usuarias alófonas para que realicen labores de interpretación es, sin duda, la solución más empleada, tanto de acuerdo con los profesionales como con las usuarias participantes en los grupos de discusión, al igual que habíamos detectado con el empleo del resto de técnicas.

Tal y como puede observarse en el fragmento que incluimos a continuación, los profesionales son conscientes de que, a pesar de ser una solución a la que recurren con frecuencia, no garantiza que la comunicación sea efectiva, ya que es posible que estos intérpretes ad hoc no presenten suficientes conocimientos lingüísticos y, por su falta de formación en interpretación, pueden incumplir algunos principios (como la fidelidad al mensaje) o responder en lugar de la usuaria, quedando esta última excluida de la conversación.

Y, entonces, esas veces le preguntas “¿Y va a venir alguien a acompañarte?”. Pero... poco más. Y, luego, ya si viene el acompañante, se habla con él, pero... Es difícil, es difícil. [GD - Enfermera 1] 
$Y$, normalmente, les pides si pueden entrar con alguien que entienda o que hable español más que ellas. Lo que pasa es que a veces, yo que sé... [GD - Matrona 2]

(Les pregunto si, cuando han usado como intérpretes a parientes o amigos, la comunicación ha resultado eficaz.)

A veces te encuentras con que el intérprete sabe menos que ellas. [GD - Obstetra 2]

Exacto, que el intérprete sabe menos, o no estás realmente convencida de todo lo que se está traduciendo, ¿no? O que no sabes lo que le está llegando, porque, claro, como tú no tienes ni idea, ni tienes mucha confianza... [GD - Matrona 2]

A veces, es verdad, que no te quedas del todo convencido. $Y$, luego, también depende de qué grado de familiaridad o de relación tiene con la paciente. Porque si es la madre $y$, como pasa a veces con las españolas, que es la madre la que sabe y la que te contesta cuándo tiene su hija la regla y no sé cuántos, pues... Te la lía, esa sí que te la lía, porque ahí sí que intuyes que la mujer se ve apurada y no está entendiendo qué... Pero, bueno, normalmente, el intérprete sí que es de una gran ayuda y suele ser bastante ágil. [GD - Obstetra 2]

Asimismo, reconocen que en ocasiones son los propios hijos de las usuarias los que actúan como intérpretes para facilitar la comunicación entre sus madres y los profesionales sanitarios. Aunque les preguntamos directamente si ven adecuado que menores de edad se ocupen de estas labores, parecen eludir el tema y pasan a hablar de otras situaciones, en las que, además, se pone en duda si el grado de familiaridad entre la usuaria y el intérprete ad hoc es adecuado para que este esté presente en la consulta obstétrica.

O con un niño pequeño que te vienen alguna vez... [GD - Obstetra 1]

Sí, eso también. [GD - Matrona 1]

¡Hombre, los niños...! Bueno, yo digo "niño", porque me refiero a una situación en la que me acuerdo que me vino un chavalillo más vivo que el hambre. [GD - Obstetra 2]

(Le pregunto si considera que una consulta médica es un lugar adecuado para que un niño esté realizando labores de intérprete.)

Bueno, nos pasa de todo, ¿eh? A mí me ha pasado de venir una chica acompañada de un chico y, a la hora de explorar, ponerse el chico al lado de la puerta con la silla en la esquina, así (mientras pronuncia estas palabras, se cubre la cara con las manos) (Risas). Y decirme "Es que no es mi mujer" (Risas). Entonces, se puso cara a la pared, claro, como no se podía salir... Te juro que se puso ahí en esa esquina, que yo pensaba "Cómo ahora abran la puerta, me lo van a chafar...". (Risas.) [GD - Obstetra 2]

Por su parte, también la mayoría de las usuarias magrebíes participantes en el grupo de discusión sostienen haber recurrido a familiares, amigos y conocidos, especialmente en el primer periodo de su estancia en España, para que les acompañaran a los servicios sanitarios. Vemos en el fragmento que se incluye a continuación que no siempre eran familiares directos de dichas usuarias $y$, además, que estos acompañantes no se limitaron a realizar labores de interpretación, sino que también ayudaron a las usuarias a conocer el funcionamiento de los servicios y se implicaron en los cuidados durante el embarazo, el parto y el puerperio. Cabe señalar que incluso, en uno de los casos, la acompañante ni siquiera conocía la lengua de la usuaria, sino que se comunicaba con ella hablando lentamente y ofreciéndole múltiples explicaciones de los mensajes que no había comprendido. 
Y las revisiones me tocaban de lunes a viernes, y mi marido tenía vacaciones sábado y domingo, y entonces iba al médico con unas familiares de parte de mi marido, por ejemplo, con mi cuñada, y ella me traducía. [GD - Magreb 5]

Y, al venir aquí, mi marido tenía amigos, y esos amigos tenían novias. Y yo hice contacto con ellas y nos hicimos amigas, y ellas venían a casa y me enseñaron toda Zaragoza y todo. Y ellas me ayudaron durante todo el embarazo. Por ejemplo, una de ellas se encarga de... Porque mi marido trabajaba siempre y estaba fuera de casa toda la semana y, entonces, ella venía a dormir conmigo, me acompañaba a todas las revisiones y todo. Entonces, como ellas me entienden, yo hablaba con ellas y ellas me traducen. [GD Magreb 4]

Yo, con mi primer hijo, no conozco... Es que yo vine aquí en 1999 y, en esa época, gente de Marruecos hay muy pocos. No hay extranjeros de mi país. Y yo conozco una matrona jubilada aquí, y es ella quien me ayuda y me explica todo, y viene conmigo a los médicos y todo eso. Está conmigo hasta la hora del parto. Ella habla en español, pero explica despacio y, si no entiendo, me explica de otra manera. Y también pregunta a los médicos de mi situación. Como el parto fue largo y fue difícil, ella espera durante todo el parto y pregunta a los médicos para luego explicarle a mi marido por qué estoy tanto tiempo. Y sale mi chico con fiebre y tuvo que quedarse siete días en el hospital, y yo cada tres horas tengo que ir para darle el pecho, y mi marido estaba fuera trabajando y, como tenía que ir andando al hospital, aunque estaba cerca, como he tenido doce puntos, pues no podía ni andar. Y ella siempre me acompañaba. La verdad es que esta mujer era muy maja, muy maja. [GD - Magreb 2]

En referencia al servicio de interpretación telefónica disponible en el hospital contexto de estudio, también en este caso, como habíamos detectado con las entrevistas y la observación, cabe señalar su desconocimiento e infrautilización por parte de los participantes en los grupos de discusión.

Por lo que respecta a los profesionales, como puede verse en el fragmento que presentamos a continuación, solo uno de ellos reconoce haber usado este servicio y parece satisfecho, aunque no sabía que podía recurrir a él las veinticuatro horas del día y, además, señala que, al tener que introducir numerosos códigos antes de iniciar la comunicación con el intérprete, se debe disponer de tiempo para poder emplearlo. El resto nunca lo ha utilizado $y$, entre los diferentes motivos de esta falta de uso, mencionan no saber cómo funciona, no contar con tiempo para usarlo, considerarlo impersonal, o adoptar otras soluciones (principalmente el recurso a intérpretes ad hoc) para comunicarse con las usuarias alófonas.

Si no, recurrimos al traductor del hospital. [GD - Obstetra 3]

Ya, pero depende de cómo te pille... Porque yo reconozco que si me pilla en el ambulatorio, con un montón de mujeres esperando y tal, pues... [GD - Obstetra 1]

(Le pregunto a GD - Obstetra $3 \mathrm{si}$, cuando ha hablado del traductor del hospital, se refería a un servicio de traducción/interpretación en concreto.)

Me refiero al de urgencias. Ese es el que yo he utilizado. El servicio de interpretación por teléfono. [GD Obstetra 3]

(Le solicito, visto que tiene experiencia empleando el servicio de interpretación telefónica (ialeluya!), cómo le ha resultado, si lo ve complicado o sencillo.)

No, bien. Bueno, yo lo he usado dos o tres veces y... siempre me ha ido bien. Lo he usado siempre por el día, ¿eh? (Le comento que el servicio está disponible veinticuatro horas al día.) Ah, ¿está veinticuatro horas? No lo sabía... Pues, bueno, por el día, bien, a mí me ha funcionado bien. Ahora sí, hay que tener 
tiempo para usarlo, porque, por ejemplo, hay que poner muchos códigos y... Pero sé que se usa poco, e incluso hay profesionales que no saben ni que existe, o que no saben cómo se usa... [GD - Obstetra 3]

Por ejemplo, yo no sé cómo se usa. [GD - Obstetra 1]

(Pregunto al resto de participantes si algún otro ha usado este servicio y todos niegan, verbalmente o mediante un movimiento de cabeza, haberlo empleado.)

No, normalmente se recurre a algún pariente o amigo de la paciente y... [GD - Obstetra 2]

(Les pregunto qué inconvenientes ven a la interpretación telefónica y por qué creen que no se usa.)

Hombre, es que es muy impersonal, ¿no? Estás ahí a través del teléfono... Vamos, a mí no me gusta. [...] la verdad, es que a lo que más recurrimos es al intérprete que es pariente y amigo. Porque, a mí, cuando me vienen con un teléfono y le tienes que contar a un tercero al que no estás viendo... [GD - Obstetra 2]

Por su parte, solo una de las usuarias participantes en el grupo de discusión con magrebíes, aunque no lo ha empleado, conocía el servicio de interpretación, pero no porque el personal sanitario le hubiera informado, sino porque ella misma, estando en el hospital, había visto un cartel en el que se informaba de su existencia. El resto, como sucedía en el caso de prácticamente todas las usuarias entrevistadas, desconocía la disponibilidad del servicio y el derecho a solicitarlo en caso de tener dificultades para comunicarse con los profesionales, tal y como puede observarse en el siguiente fragmento:

Yo, cuando estaba en el hospital, he visto un cartel que ponía que había un servicio de traducción, pero no me han informado, y yo nunca tampoco he pedido para que me lo traen o algo. [GD - Magreb 5]

(Las demás comentan que ellas ese cartel no lo han visto y que no sabían que podían pedir un servicio de interpretación.)

Yo he visto, pero no he pedido. [GD - Magreb 5]

Perdona, una cosa, a mí me han contado que en Andalucía hasta en los centros de salud, ahí tú entras y dices que no hablas español y te ponen una máquina para traducir. ¿Y aquí eso no hay en Aragón? [GD Magreb 1]

(Les explico que en los hospitales aragoneses también hay un servicio de interpretación telefónica.)

¿Y por qué no se usa? [GD - Magreb 1]

Presentamos la posibilidad a los profesionales sanitarios de que planteen otras propuestas que puedan facilitar la comunicación con las usuarias alófonas, y algunos parecen decantarse, tanto en el grupo de discusión como en el cuestionario individual posterior, por la interpretación presencial, como puede comprobarse en el fragmento y en la tabla que incluimos a continuación.

(Sigo insistiendo en el planteamiento de nuevas propuestas. Visto que una de las participantes lo había mencionado, saco a relucir el servicio de interpretación telefónica, comentando que, de acuerdo con los resultados preliminares de mi investigación, este servicio se usa poco, y les pregunto si les resultaría más cómodo un servicio de interpretación presencial.)

Sí, es verdad que el servicio de interpretación telefónica se usa muy poco. [GD - Obstetra 3]

El presencial sería bastante más cómodo. [GD - Matrona 2]

Yo también creo que sería más cómodo y, además, te daría más confianza porque... [GD - Enfermera 1] 
¿Pero eso (refiriéndose a la interpretación presencial) es factible? [GD - Obstetra 1]

Es que no es lo mismo una consulta, como la de planificación, o la de embarazo, o cuando tienes que hacer una citología, que todo es "Bien, bien, bien, bien", que una consulta donde hay problemas y, además, problemas que angustian mucho $y$, hasta cuando se los explicamos a las españolas, lo entienden al revés o la mitad. $\mathrm{Y}$, claro, estas mujeres llevan ahí una sobrecarga $\mathrm{y}$, en esos casos, sí que sería importante tener a alguien presencial y que, además, pudieras tú explicarle para que luego se lo reexplique. Porque tú ya sabes el problema de la gente cuando va al médico, que se queda ahí como atontada y, luego, no se han enterado de nada. [GD - Obstetra 2]

Eso es, se bloquean. [GD - Matrona 2]

Como no te vengan ahí con la listica y se vayan apuntando "Tacatacatacataca"... (Hace un gesto con la mano, como si estuviera apuntando algo en un cuaderno.) [GD - Obstetra 2]

Entonces, yo creo que un traductor presencial sí que te puede transmitir mejor que tirando de un teléfono. [GD - Matrona 2]

\begin{tabular}{|l|c|c|l|}
\hline & \multicolumn{1}{|c|}{ Sí } & NO & Otras propuestas \\
\hline Enfermera 1 & & $\mathrm{X}$ & $\begin{array}{l}\text { Interpretación } \\
\text { presencial }\end{array}$ \\
\hline Matrona 1 & & $\mathrm{X}$ & $\begin{array}{l}\text { Interpretación } \\
\text { presencial }\end{array}$ \\
\hline Matrona 2 & & $\mathrm{X}$ & $\begin{array}{l}\text { Interpretación } \\
\text { presencial y mayor } \\
\text { difusión de los } \\
\text { recursos existentes }\end{array}$ \\
\hline Obstetra 1 & $\mathrm{X}$ & $\mathrm{X}$ & $\begin{array}{l}\text { Interpretación } \\
\text { presencial } \\
\text { traducción y de } \\
\text { documentos }\end{array}$ \\
\hline Obstetra 2 & & & $\begin{array}{l}\text { Interpretación } \\
\text { presencial }\end{array}$ \\
\hline Obstetra 3 & & $\mathrm{X}$ & \\
\hline
\end{tabular}

Tabla 6.9. Suficiencia de los instrumentos y estrategias para facilitar la comunicación con usuarias inmigrantes de acuerdo con los profesionales participantes en los grupos de discusión

Con relación a las respuestas de los profesionales participantes en el grupo de discusión relativas a la interpretación presencial, cabe señalar, por una parte, que opinan que este recurso sería más cómodo y les inspiraría más confianza que la interpretación telefónica. Además, lo ven más adecuado que esta última en las consultas no rutinarias que presenten un carácter más complejo y en las que haya que explicar a las usuarias algún tipo de problema.

Por otra parte, consideramos importante resaltar que el único profesional que, de acuerdo con la tabla presentada, opina que los recursos para comunicarse con las usuarias alófonas de los que dispone el hospital son suficientes es aquel que, como hemos indicado previamente, ha empleado el servicio de interpretación telefónica en alguna ocasión.

Para finalizar este subapartado, exponemos otras soluciones a las que los profesionales o las usuarias participantes en los grupos de discusión han recurrido o a las que podrían recurrir, algunas de las cuales coinciden con las respuestas ofrecidas en las entrevistas. Entre dichas soluciones, se encuentran, como aparece en los fragmentos incluidos a continuación, el dominio de lenguas extranjeras por parte del personal sanitario, el uso de aplicaciones de 
traducción a través de teléfonos móviles, o la solicitud de apoyo a personas ajenas al hospital, para que, por ejemplo, ayuden a las usuarias a completar los historiales médicos o les escriban en español las preguntas a formular posteriormente en las consultas.

(Trato de reconducir la conversación y vuelvo a insistir en si se les ocurre algún modo para facilitar la comunicación con las usuarias inmigrantes.)

Sí, aprender idiomas. [GD - Obstetra 2]

(El resto de participantes asienten con la cabeza y ríen.)

Que los profesionales supiéramos idiomas. [GD - Obstetra 2]

(Les hago notar que, por lo general, los idiomas que los profesionales sanitarios conocen -inglés, francés, italiano, etc.- no se suelen corresponder con las lenguas maternas de las comunidades inmigrantes más numerosas en este territorio.)

Sí, claro, es verdad, claro. [GD - Obstetra 3]

Si no, yo, cuando la mujer sí que viene sin intérprete o realmente no llegamos a entendernos, pues yo le entrego una historia que yo tengo en papel, que es un auto-cuestionario, y le digo que se dirija a.... ¿Cómo se llama? La Casa de las Culturas o... la Casa de la Mujer... No me acuerdo ahora cómo se llama. Que ahí van y las ayudan y, así, yo sí que tengo la historia clara y bien. [GD - Obstetra 2]

Ahora, muchas veces vienen ellas con la aplicación del teléfono, es decir, lo escriben en el móvil, y lo ponen y te lo enseñan. Y si lo que utilizan hace una buena traducción, pues, puede estar bien, pero... Si aparece algún término médico, no sé yo cómo lo traducirá. Así que, claro, eso es para lo más básico, pero, bueno, todo puede ser útil. [GD - Obstetra 3]

Y hay veces que sí que vienen con las preguntas escritas, que se las ha escrito alguien antes y... [GD Obstetra 1]

\subsubsection{Interacción}

En este subapartado analizamos las intervenciones de los participantes en los grupos de discusión referidas a la interacción y a los modelos conversacionales de los profesionales sanitarios y las usuarias inmigrantes. No es muy abundante la información al respecto recolectada mediante esta técnica, ya que los temas planteados estaban centrados en otros aspectos que deseábamos corroborar. Sin embargo, como se verá a continuación, de las respuestas ofrecidas tanto por los profesionales como por las usuarias participantes en los grupos se desprenden algunos datos de interés.

Comenzamos con un bloque introductorio en el que estudiamos cuestiones generales relativas a la interacción y, más concretamente, nos centramos en la actitud de profesionales y usuarias, así como en la relación entre los mismos.

La opinión manifestada tanto por las usuarias magrebíes como por las latinoamericanas sobre la actitud del personal sanitario que las ha atendido es variada, como se ha visto en el análisis 
de los nodos de Introducción y de Asistencia sanitaria general, y se basa en las múltiples experiencias que estas han vivido en los servicios sanitarios. No volveremos a incluir los fragmentos en los que expresan dicha opinión; simplemente recordaremos que, a pesar de que la mayoría de estas usuarias participantes en los grupos de discusión consideran que, en general, los profesionales son amables y cercanos, y valoran positivamente la atención recibida, también nos hacen partícipes de algunos episodios en los que, a su juicio, los profesionales no las han tratado adecuadamente.

Al respecto, cabe resaltar dos cuestiones. Por un lado, al analizar las respuestas de las usuarias entrevistadas nos había surgido la duda de si el hecho de que las entrevistas se llevaran a cabo en el mismo hospital contexto de estudio había podido condicionarlas y, por tanto, habrían reprimido la expresión de juicios negativos por temor a que esto pudiera conllevar para ellas algún tipo de represalia durante su estancia hospitalaria. Sin embargo, las respuestas de los grupos de discusión con usuarias, los cuales, como hemos comentado, se celebraron en otros contextos, no se distancian mucho de las ofrecidas en las entrevistas, y la única diferencia destacable consiste en que, en los grupos de discusión, el relato de los sucesos vividos por estas es quizás más extenso y detallado. De los datos obtenidos mediante esta técnica, como había sucedido con los datos de las entrevistas, podemos deducir que las usuarias consideran que la actitud del personal sanitario no es generalizada, sino que depende del profesional concreto que las atiende e incluso del estado de ánimo en el que este se encuentre.

Por otro lado, sí que hay un dato en los grupos de discusión sobre la actitud del personal sanitario que difiere en cierto sentido de los datos recolectados con las entrevistas. En concreto, las usuarias entrevistadas habían comentado que veían como más cercanos a los profesionales del perfil de matronas y enfermeras en contraposición con los obstetras y, por el contrario, las usuarias magrebíes participantes en el grupo de discusión califican a las enfermeras como "duras" y ven, sin embargo, a los obstetras como una figura más amable. No podemos saber si esta opinión se basa en experiencias personales o en la visión estereotipada que pueden tener las usuarias magrebíes de uno y otro perfil.

Los propios profesionales participantes en los grupos de discusión también opinan sobre la actitud del personal sanitario con respecto a las usuarias inmigrantes $y$, como puede observarse en el fragmento que incluimos a continuación, consideran que, en todo caso, discriminan positivamente a estas usuarias, pues comprenden la situación de vulnerabilidad por la que están pasando y sienten hacia ellas cierta empatía.

Vamos, te dan a entender que no están pasando un buen momento, que les está pasando de casi todo, y tú dices "iMadre mía!". Si con las de aquí, que por lo menos te entiendes, ¿no?, y aun así te surgen dudas, y lo pasas mal, pues piensas "Con esta pobre mujer que no sé ni de lo que se está enterando, que la han sacado de dónde sea y la han traído aquí, y encima está hospitalizada...". Brrrrr. [GD - Matrona 2]

Hombre, pero tiras más de recursos que con las españolas no utilizas, ¿eh? Como el contacto físico, mantener la mirada, la sonrisa... Eso es cierto. Que aquí hemos tenido gente con ingresos hospitalarios muy prolongados por patologías graves, y les coges mucho cariño. Porque, como no puedes comunicarte con ellas verbalmente, tiras más de la sonrisa, o la caricia... [GD - Matrona 1]

Sí, se hace más discriminación positiva. Y si no se entera de nada, se coge a la enfermera, se la levanta, se la lleva de las orejas a las habitaciones, luego aquí, luego allá... [GD - Obstetra 2] 
Eso es cierto, sí. Pero siempre piensas que claro, la que acaba de llegar, que encima se encuentra en un lugar extraño y en una situación vulnerable, porque probablemente no se encuentra bien... Es como si yo, ahora, me voy de vacaciones, me rompo no sé qué, en China, y acabo en un hospital en China y... (Risas) ¡Bffff! ¡Estás vendido! Ves entrar y salir gente, te tocan, te hacen, y tú no sabes ni qué está pasando... [GD - Matrona 2]

En cuanto a la actitud de las usuarias inmigrantes, cabe destacar los comentarios realizados por dos profesionales participantes en el grupo de discusión que mostramos en los siguientes fragmentos:

Yo sí que quisiera hablar de la sensación o, al menos, el comentario que yo creo que en algún momento, al menos aquí en las plantas, sí que se ha producido de "Claro, como yo soy extranjera ...". [GD - Matrona 2]

Yo, como hombre, pues me puedo encontrar a alguna que me dice "No, no, yo no quiero desnudarme delante de un hombre. Yo quiero a una mujer". De alguna manera ellas hacen una exclusión, ¿no? [GD Obstetra 2]

Por el primer comentario deducimos que el profesional que lo hace cree que algunas usuarias inmigrantes se amparan en su condición de extranjeras $\mathrm{y}$, a veces, la emplean para manifestar que, en cierto sentido, se sienten discriminadas.

Del segundo comentario se desprende que el profesional considera que algunas usuarias inmigrantes excluyen a los profesionales de sexo masculino al expresar su deseo de ser tratadas únicamente por mujeres.

No ahondamos más en este subapartado en estos dos temas, pues las cuestiones de género y los sentimientos de discriminación se tratan en el siguiente subapartado, relativo a las actitudes sociales.

Por lo que respecta a la interacción entre usuarias, tampoco con esta técnica, al igual que había sucedido con las entrevistas y con la observación, hemos sido capaces de recolectar datos. Cabe simplemente destacar que, por la ausencia de opiniones al respecto por parte de los sujetos participantes en el estudio, y no habiendo sido testigos de ningún episodio relacionado con esta cuestión durante la observación, podemos concluir que quizás no se producen graves problemas de convivencia entre las usuarias durante su permanencia en el hospital.

En referencia a la interacción entre las usuarias y sus maridos, el único dato obtenido en los grupos de discusión que quisiéramos resaltar se centra en el hecho de que, tal y como hemos comentado en el análisis del nodo de Embarazo, parto y puerperio, las usuarias participantes en el grupo con magrebíes desmienten la opinión manifestada por los profesionales entrevistados, según la cual, estas estaban supeditadas a sus maridos, en especial, cuando debían decidir si se les suministraba o no la anestesia epidural.

También cabe señalar otro dato habíamos obtenido en las entrevistas y que, en este caso, se corrobora mediante el empleo de esta técnica, consistente en el hecho de que los maridos de algunas usuarias inmigrantes han modificado en cierto sentido su comportamiento $y, a$ 
diferencia de lo que tal vez harían en sus respectivos países de origen, ayudan a sus parejas en el cuidado de los hijos, porque no cuentan en España con el apoyo de sus familias y porque probablemente han ido asimilando algunos patrones de comportamiento propios del país de acogida.

Pasamos a continuación a analizar los datos recolectados en los grupos de discusión referentes a las interacciones comunicativas entre los profesionales sanitarios y las usuarias inmigrantes. Antes de presentar dichos datos, cabe recordar que, tal y como hemos comentado en el análisis de las otras técnicas, resulta complicado obtener información fidedigna concerniente a las interacciones comunicativas, en primer lugar, por el carácter semi-inconsciente de los elementos que intervienen en una conversación, que impide que los interlocutores tengan pleno conocimiento de los usos verbales y no verbales que tanto ellos mismos como el resto de sujetos participantes en la conversación están empleando y, además, por la subjetividad inherente a la interpretación de dichos elementos, tanto por parte de los interlocutores como por nuestra parte.

Tras estas aclaraciones previas, nos centramos en los usos verbales y, como en el análisis de las entrevistas y la observación, nos basamos en el principio de cooperación y las máximas de Grice (1975: 45-47).

En cuanto a la máxima de manera, no se hace referencia en los grupos de discusión a si la cantidad de información que ofrecen profesionales y usuarias es adecuada o supera por exceso o por defecto la cantidad que desean expresar ellos mismos o que esperan que proporcione su interlocutor. Un dato que sí que podríamos extraer de los grupos de discusión y que corrobora información obtenida con el resto de técnicas consiste en que, si las usuarias poseen conocimientos suficientes de español, como es el caso de las participantes en los grupos, suelen manifestar más abiertamente sus pensamientos y opiniones. Este hecho lo habían comentado tanto las usuarias como los profesionales en las entrevistas, y también habíamos podido verificarlo mientras realizábamos observación en las consultas a puérperas. Así, en aquellas consultas en las que se hallaban presentes usuarias con un mayor dominio de la lengua del país de acogida, observamos que la información expresada por dichas usuarias era mayor que en aquellas en las que las usuarias tenían escasos conocimientos de esta lengua.

Por lo que respecta a los temas tratados durante los intercambios comunicativos, los profesionales participantes en el grupo de discusión, al igual que habían afirmado sus compañeros en las entrevistas, consideran que los temas que se plantean en las consultas no presentan un carácter personal o delicado, ya que creen que no profundizan demasiado en las cuestiones íntimas de las usuarias, sino que, en parte por la presión asistencial a la que están sometidos y la consecuente falta de tiempo, se centran casi exclusivamente en aspectos relacionados con el estado físico de la madre y el hijo.

(Les pregunto si hay temas sobre los que algunas usuarias inmigrantes pueden sentir incomodidad al hablar.)

Pues, no lo sé. [GD - Obstetra 3]

Yo no sabría qué decirte, no... [GD - Obstetra 1] 
Es que... Bueno, no sé, yo en mis historias tampoco profundizo mucho en la sexualidad. Cuando yo estuve hace muchos años en planificación familiar, sí que teníamos unos cuestionarios que eran la repera, porque le preguntabas hasta si se ponía... ropa sexy cuando... (Risas generalizadas). Eeeee... El número de coitos, la satisfacción... Todo eso se valoraba, hasta que, claro, el exceso de trabajo impedía entrar en esos detalles, con lo cual, todo el mundo estaba más contento. Pero en las consultas generales, habitualmente... Bueno, yo ahora soy una excepción, porque a mí me han "robado" a casi todas mis pacientes y vivo muy tranquilo. Me han reducido el $57 \%$ el número de población a asistir, pero hasta ahora... Te puedo decir que a la hora de hacer las historias, generalmente, vamos muy presionados. Por ejemplo, las compañeras que han venido ahora a hacer mi trabajo van de culo. [GD - Obstetra 2]

Ves muchas, entonces no... [GD - Obstetra 1]

Entonces, realmente no... O sea, vas a lo esencial y, entonces, yo no he notado tampoco que... [GD Obstetra 2]

Recordemos que las únicas cuestiones que, de acuerdo con los profesionales entrevistados, podían suscitar cierta incomodidad en algunas usuarias inmigrantes se referían a enfermedades contraídas y embarazos o abortos previos, o estaban relacionadas con sus órganos genitales, las relaciones sexuales, la menstruación o la mutilación genital femenina. Cabe señalar, de todos modos, que no nos resulta posible saber con certeza si los temas planteados pueden considerarse personales o tabúes en las culturas de origen de determinadas usuarias, puesto que ni las usuarias entrevistadas ni las participantes en los grupos de discusión han indicado explícitamente ningún tema específico del cual les resulte molesto hablar en los servicios sanitarios. Asimismo, es probable que la expresión de malestar por parte de algunas usuarias al tratar determinados temas haya resultado imperceptible a los ojos de los profesionales que estuvieran interactuando con ellas en ese momento.

Por nuestra parte, aunque somos conscientes de que podemos haber interpretado subjetiva y quizás erróneamente el comportamiento de las usuarias, nos gustaría comentar un episodio vivido en el grupo de discusión con usuarias latinoamericanas. En concreto, al plantear el tema de los métodos anticonceptivos, tenemos la sensación de que nuestra pregunta incomoda en cierta medida a las participantes, quizás porque les resulta demasiado personal, ante lo cual les recordamos que deben sentirse siempre libres de responder o no, tal y como puede observarse en el siguiente fragmento:

(Les pregunto si han usado algún método de planificación familiar. Se produce un silencio prolongado y, a diferencia de lo que ha sucedido con el resto de temas planteados, tardan bastante en contestar. Les informo de nuevo de que, si hay alguna pregunta que les parece demasiado personal o a la que les resulta incómodo responder, no tienen por qué hacerlo.)

En referencia a la máxima de calidad, solo hay una ocasión en la que surge este tema durante la celebración de los grupos de discusión, y es nuevamente en relación con el uso de métodos anticonceptivos por parte de las usuarias latinoamericanas. Tal y como hemos comentado en el subapartado relativo al embarazo, el parto y el puerperio, por los datos recolectados mediante las entrevistas, nos había surgido la duda de si algunas usuarias procedentes de Latinoamérica podían haber tenido embarazos no planificados. Y, precisamente, al tratar esta cuestión con las participantes en el grupo, una de ellas, cuyo embarazo se había producido cuando esta tenía 17 años, parece no ser del todo sincera al indicar los métodos anticonceptivos que más emplea y valora, como puede verse en el fragmento que reproducimos a continuación. 
(La usuaria GD - Latinoamérica 1 no ha respondido todavía a esta pregunta. Cabe señalar que tiene 18 años, tuvo a su hijo a los 17 , y no sabemos si fue o no un embarazo planificado. Me dirijo a ella y le formulo de nuevo la pregunta directamente.)

Bueno, pues yo... He usado la... no sé cómo se dice. (Le pregunto “¿Te refieres a la píldora?”). Sí, eso, perdona que no me venía el nombre. Ese es el método que por ahora yo prefiero... (Por el tono de voz dubitativo y su expresión facial, me surgen ciertas dudas sobre el grado de sinceridad de esta usuaria al responder esta pregunta). [GD - Latinoamérica 1]

Cabe, además, recordar que la respuesta de esta usuaria que acabamos de mostrar y los datos que esta misma incluyó en el cuestionario individual tampoco eran coincidentes, por lo que se añade otro factor que parece demostrar que probablemente ha incumplido la máxima de calidad, quizás por sentir cierto pudor a la hora de admitir que su embarazo no había sido planificado.

Con relación a la máxima de manera y, más concretamente, a la forma de hablar de los profesionales y las usuarias inmigrantes, las participantes en el grupo con latinoamericanas, como hemos señalado en el subapartado de barreras lingüísticas y soluciones, mencionan diferencias que, a su modo de ver, existen entre el estilo comunicativo propio de España y el de sus respectivos países de origen. Comentan que, en Latinoamérica, se suele emplear un modo de hablar más cercano y cariñoso, mientras que el modo de hablar español les parece textualmente más "seco" o "serio". Ello puede conducir, en su opinión, a malinterpretaciones del mensaje y la intención del interlocutor en los intercambios comunicativos entre hablantes latinoamericanos y españoles, a pesar de que estos compartan la misma lengua materna. Presentamos de nuevo parte del fragmento referido a esta cuestión.

\footnotetext{
Yo, en mi caso, creo que lo que pasa es que malinterpretamos las formas. Es que en nuestros países todo es más con diminutivos. Hablamos... como que más cariñoso y qué sé yo. Y aquí es como más... [GD Latinoamérica 2]

Seco, es seco, ¿̇no? [GD - Latinoamérica 4]

Sí, sí. [GD - Latinoamérica 2]

Es serio, serio. [GD - Latinoamérica 1]
}

Sí, entonces, a veces malinterpretamos y pensamos "Oye, me ha hablado mal", ¿no?, o "Me ha mirado mal" o... O "Me ha dicho esto y, para mí, es una grosería". Pero, luego, en el idioma, no, en el idioma, no... [GD - Latinoamérica 2]

En cuanto a los usos no verbales, la primera cuestión que nos gustaría resaltar se refiere a la distribución temporal y el paralenguaje empleado por las usuarias magrebíes en el grupo de discusión. A diferencia de las usuarias entrevistadas de este mismo colectivo, observamos que, cuando las usuarias interactúan entre sí, se producen numerosas interrupciones y solapamientos (que, además, dificultaron la posterior labor de transcripción de este grupo de discusión), y el tono de voz empleado es bastante más alto que el usado por las usuarias procedentes del Magreb mencionadas tanto en el análisis de las entrevistas como en las notas de nuestro diario de campo. Es posible que el carácter distendido del encuentro haya hecho que las participantes en el grupo de discusión interactuaran entre ellas como lo harían en una conversación informal, y puede que se confirme así con este hecho la opinión manifestada por uno de los profesionales entrevistados, el cual sostenía que, cuando las usuarias conversaban 
entre ellas, empleaban un tono de voz más elevado que cuando se dirigían al personal sanitario.

Y, por lo que respecta a la distribución espacial, en los grupos de discusión, nuevamente los profesionales, como habían hecho sus compañeros en las entrevistas, señalan el pudor que estos perciben en las usuarias musulmanas ante el contacto físico y la exploración, tal y como puede verse en el siguiente fragmento:

Yo lo único diría es que las musulmanas, con el tema de la exploración, son muy pudorosas y parece que les resulta muy violento. [GD - Obstetra 3]

El tema del pudor físico, sí. [GD - Matrona 2]

Este tema está directamente relacionado con la preferencia de las usuarias magrebíes a ser tratadas por profesionales de sexo femenino, de la cual hablamos más detalladamente en el siguiente subapartado, relativo a las actitudes sociales.

\subsubsection{Actitudes sociales}

Para concluir el análisis de los datos recolectados mediante los grupos de discusión, nos centramos, como en el análisis de las técnicas presentadas previamente, en las cuestiones que presentan una mayor complejidad y un carácter más delicado y afectivo. En concreto, analizamos, por una parte, si las usuarias prefieren ser tratadas por personal sanitario de uno $u$ otro sexo y, por otra, si los profesionales han podido presentar actitudes racistas o xenófobas y si las usuarias inmigrantes se han sentido discriminadas cuando las han atendido durante el embarazo, el parto y el puerperio.

En cuanto a las cuestiones de género, los profesionales participantes en el grupo de discusión, como hemos señalado previamente, sostienen que, en ocasiones, las usuarias magrebíes manifiestan ciertas reticencias a ser tratadas por personal de sexo masculino. Al preguntarles cómo se actúa en dichos casos, al igual que habían comentado sus compañeros en las entrevistas, estos afirman que, si es posible, solicitan a profesionales de sexo femenino que atiendan a estas usuarias en lugar del profesional hombre, y que, en todo caso y si este cambio no es factible, la mujer puede decidir no ser atendida, siempre y cuando, como señala uno de los participantes en el fragmento que incluimos a continuación, no peligre la salud de la madre o del hijo.

Yo, como hombre, pues me puedo encontrar a alguna que me dice "No, no, yo no quiero desnudarme delante de un hombre. Yo quiero a una mujer". De alguna manera ellas hacen una exclusión, ¿no? [GD Obstetra 2]

(Aprovecho que se plantea esta cuestión para preguntarles si se han encontrado con algún impedimento a la hora de realizar la exploración, o si algunas usuarias se han mostrado reticentes cuando quien las tenía que atender era un hombre.)

Sí, sí. Eso, mucho. Y todo musulmanes, sí. [GD - Obstetra 3]

Sí, eso es habitual. [GD - Obstetra 1]

(Les pregunto qué se ha hecho en esos casos.) 
No sé, yo como soy mujer... [GD - Obstetra 3]

Depende... Pero yo sí que he estado presente, por ejemplo, en urgencias y, a veces, si al compañero le ponen pegas y tal, pues, a lo mejor, te llama para que le explore una mujer. Y otras veces le dice "Estoy yo, y mi compañera está ocupada, así que, si quieres que te explore yo, bien, y si no, te vas". (Le pregunto si se ha dado algún caso en el que la usuaria se haya ido y haya renunciado a ser atendida.) Sí, sí, claro. [GD Obstetra 1]

A mí, personalmente, como soy mujer, nunca me ha pasado. $Y$ tampoco que me pida un compañero que la atienda yo. $Y$, en los comarcales, como solo estaba uno, pues, vamos, es que se tenían que quedar, porque no había otra. [GD - Matrona 1]

Pero, vamos, yo te puedo decir lo que le pasó a una amiga mía, que es matrona, en Málaga, que tuvieron un follón... Fue en Ronda, concretamente, en una guardia, y estaba de parto una mujer y solo había un ginecólogo varón, y exigía el marido que viniera la ginecóloga mujer que estaba en casa descansando. Estaba descansando o de retén, no me acuerdo ahora exactamente.... Y se puso borde el señor $y$, entonces, vino una matrona fuerte y tal y le dijo "Mira, macho, como le pase algo a tu mujer, sales disparado". Entonces... Y, a mí, sí que me ha pasado, y yo les digo "Pues, lo siento, porque... te pierdes una buena cosa" (Risas). A ver, les remites a atención al paciente y... y ven si les pueden cambiar de cupo y.... [GD - Obstetra 2]

Además, preguntamos a los profesionales si estas reticencias mencionadas conllevan un número considerable de solicitudes de cambio de cupo por parte de estas usuarias inmigrantes, a lo cual nos responden que estas peticiones no son tan numerosas como para ser significativas y causar desequilibrios en el número de usuarias atendidas por cada médico en los centros de salud. Al respecto, nos gustaría señalar que tampoco podemos saber si no se han solicitado más cambios de médico porque las usuarias inmigrantes afectadas no disponían de suficientes conocimientos de español, del funcionamiento de los servicios sanitarios o de sus derechos como usuarias de dichos servicios.

(Les pregunto si esto lo que conlleva es que las profesionales tengan en su cupo un mayor número de mujeres musulmanas que sus compañeros hombres.)

Bueno, tampoco es algo tan habitual que pidan un cambio de médico. Habrá algún caso, pero tampoco lo veo yo que... no sé, que repercuta tanto. [GD - Obstetra 3]

Yo soy hombre y sigo teniendo bastantes... árabes. [GD - Obstetra 2]

Las usuarias participantes en el grupo de magrebíes, por el contrario, no confirman la opinión manifestada por los profesionales, pues aunque algunas de ellas sí que sostienen preferir ser tratadas por personal sanitario de sexo femenino, parecen comprender que, en ocasiones, no es posible atender estas preferencias, tal y como puede observarse en el siguiente fragmento:

(Les pregunto si prefieren que el personal sanitario sea hombre o mujer y si les supone algún problema tener que desnudarse o que las exploren durante las consultas si el profesional sanitario es de sexo masculino.)

Para mí, mujer es mejor. [GD - Magreb 3]

Pues, en mi caso, yo habría preferido hombre. Porque, cuando entré a una sala que era más grande que esta y ahí estábamos seis mujeres que íbamos a dar a luz de urgencia, y ha entrado una médico en prácticas para romperme la bolsa y me ha mucho, mucho, mucho daño. Y yo estaba gritando, hacía “¡Aaaaaaaa!”, que las otras mujeres decían “¿Pero, ¿qué le pasa a esta mujer?”. Y yo le he dicho a esta médico en prácticas "Tú no me tocas más, porque me has hecho mucho daño". Y yo prefería al médico hombre y no a esta médico mujer que estaba en prácticas. [GD - Magreb 1] 
Yo creo que los hombres son más delicados. Porque, como yo pasé varios días en el hospital, pues ahí me han tocado todos. Y los hombres eran siempre más delicados. [GD - Magreb 5]

Yo prefiero mujer. Aunque hay algunos que entienden la religión. Porque, por ejemplo, a mí el médico que me ha tocado durante el embarazo para las revisiones y tal es un hombre. Y nunca me ha tocado ahí abajo, porque lo entiende que yo me siento mal. Si es mujer, me da igual que me toca, pero si es hombre, me molesta. $Y$ yo intenté varias veces cambiarlo, pero en ese centro no había mujer. Y, entonces, me dijo "Tranquila, que no te voy a tocar yo. Cuando tenemos que tocar ahí abajo, pues la enfermera se encarga de eso". Y esto lo veo yo que entiende un poco nuestra religión. [GD - Magreb 4]

Pues yo... (Se queda largo rato en silencio). Es que yo no lo sé. En el embarazo de mi hija me ha tocado un hombre y no... No veo que... Porque es algo que tienes que hacer, entonces no sientes que... porque es un médico. Entonces, si es hombre o mujer me da igual, lo que importa es el trato. [GD - Magreb 5]

Asimismo, cabe destacar dos cuestiones planteadas por estas usuarias en sus respuestas. Por un lado, una de las usuarias nos relata su experiencia con el profesional que la ha atendido durante el embarazo, el cual ha evitado en todo momento realizar él mismo la exploración, respetando de este modo los preceptos de su religión. Por otro lado, se confirma un dato que no preveíamos al inicio de nuestro estudio, pero que otras usuarias inmigrantes habían manifestado en las entrevistas, según el cual algunas de estas prefieren ser tratadas por hombres, a lo cual una de ellas añade que los considera más delicados en el trato.

No tratamos directamente en los grupos de discusión el tema de la interacción de los profesionales con los maridos y familiares de las usuarias inmigrantes, ya que, en las entrevistas, la mayoría de ellos nos había comentado que dicha interacción es más complicada en el caso de las autóctonas, los maridos y familiares de las cuales, bajo su punto de vista, al disponer de mayor información sobre sus derechos y sobre el funcionamiento de los servicios, suelen presentar más quejas.

Por lo que se refiere a las posibles actitudes racistas o xenófobas por parte de los profesionales sanitarios y la expresión de sentimientos de discriminación por parte de las usuarias inmigrantes, como se ha podido observar en apartados anteriores del análisis de los grupos de discusión, algunas de las respuestas obtenidas en dichos grupos corroboran parte de los datos recolectados previamente con el resto de técnicas, y otras desmienten o añaden matices a dichos datos.

En primer lugar, algunos profesionales participantes en el grupo de discusión, tal y como habían manifestado algunos de sus compañeros en las entrevistas, sostienen que la atención ofrecida a las usuarias inmigrantes es incluso mejor que la que se proporciona a las autóctonas, ya que intentan en cierto modo compensarlas por la situación de indefensión y vulnerabilidad en la que estas se encuentran.

Sin embargo, a diferencia de los entrevistados, ningún profesional del grupo señala explícitamente casos en los que haya presenciado comportamientos o modos de actuar inadecuados o discriminatorios hacia las usuarias inmigrantes.

Por el contrario, estos casos sí son descritos por algunas usuarias participantes en los grupos de discusión, las cuales, como hemos podido observar en los datos presentados con anterioridad, han vivido situaciones en las que no se les ha tratado adecuadamente. A pesar de que no podemos afirmar rotundamente que estos comportamientos hayan estado motivados 
por sentimientos racistas por parte de los profesionales sanitarios, ni saber si, en caso de estar atendiendo a usuarias autóctonas, estos habrían actuado de la misma manera, los comentarios de las usuarias que los relatan sí que parecen denotar cierto sentimiento de discriminación por su parte. Incluimos, a continuación, breves fragmentos aislados de estos episodios ya analizados en apartados anteriores.

Y a la chica la notaba como si tuviera algo personal conmigo y yo no entendía por qué... [GD Latinoamérica 4]

Fue aquí donde tuve esa... esa pequeña riña con la ecografista que... que no me quiso responder las preguntas y tenía como un aire de superioridad y me miraba... un poco mal. [GD - Latinoamérica 2]

Cuando se cambió el turno, vino otro médico, que es una matrona, que era un hombre, y estaba muy enfadado, porque esa noche tenía el cumpleaños de su hijo y le escuché comentando al amigo, bueno, al compañero, que él estaba enfadado, porque tiene que ayudarme en el paritorio y, cuando sacó a mi niño, le rompió la mano. Y mi marido quiere poner denuncia, pero yo le digo que no. Y, gracias a dios, así, somos musulmanes y dios quiere eso que me pasa malo. [GD - Magreb 1]

Lo que pasa es que las enfermeras, después de dar la luz, me pasa a mí también que... Porque, después de dar la luz, la tripa te duele. El dolor que tienes en la tripa no lo puedes soportar. Y, cuando viene la enfermera, te tiene que tocar, te tiene que tocar fuerte $y$, entonces, con el dolor, tú no puedes, y yo empiezo a llorar. Y me dice “¿Por qué tú te quejas? ¿Por qué tú lloras? ¡No te duele nada! ¡Ay, qué quejicas!". Y claro que yo siento dolor. Yo no quiero llorar. $Y$, en cambio, en el segundo, fue muy fácil, pero una doctora me trata muy mal y me dice "No, aún no, no te toca". Y yo, cuando me vienen contracciones, yo llamo, y digo "Ahora, ahora, viene ahora", y me dice "Mentira. Eso es mentira. Eres tú que estás haciendo... que estás provocando". Y, luego, yo estaba hablando en árabe, le estaba pidiendo a dios, y me dice "¿Qué dices en árabe?". Y es que el tiempo del parto, pues claro que hablas en tu idioma. Y ella dice “Pero, ¿qué hablas en árabe?". Y yo le he dicho que estoy pidiendo a dios, y ella responde "Sí, sí, pide a dios, pide a dios" y me da un golpe con la mano, así (hace un gesto como golpeando) y sale. [GD - Magreb 2]

Bueno, luego, me quedé ahí dos días antes de dar a luz y probaron varios métodos para provocar el parto, y el día del parto vino el dolor muy fuerte, y yo llevaba dos días con pastillas y con suero, y no me imaginaba que voy a gritar mucho, pero, con el dolor que tenía, no puedo soportar, y las enfermeras me trataron muy mal. Me decían “¿Por qué gritas?”. Y es que no es una cosa en mis manos para controlarla, es que es un dolor... Y, además, como he tardado mucho, mucho en dar a luz, pues me han puesto la inyección esta, la epidural y no me ha hecho efecto. [GD - Magreb 4]

De estos relatos nos llama la atención, por una parte, que dos usuarias del grupo de magrebíes, al igual que habían comentado dos usuarias entrevistadas de su mismo colectivo, hayan recibido una reprimenda por parte del personal sanitario por quejarse del dolor percibido. Aun en el caso de que estas usuarias estuvieran expresando enfáticamente dicho dolor o exagerándolo, a nuestro juicio, no se las debería recriminar por este motivo.

Además, cabe señalar que, aunque las usuarias magrebíes y las latinoamericanas han hablado en los grupos de discusión de experiencias negativas que han vivido en los servicios sanitarios, 
la mayoría de ellas opina que no es posible generalizar, que estos casos puntuales dependen de la persona concreta que las ha atendido, y han quedado ensombrecidos por el trato amable y cercano que han recibido de otros profesionales.

Pues yo sí que quisiera decir que en el centro de salud me encontré con gente así, como negativa, pero que, al final, me... hicieron un cambio y me asignaron otras personas y me encontré con una calidad humana total. [...] Y ya cuando me atendieron en el hospital, también fue excelente la atención. Se presentaba cada uno, me explicaban todo lo que iban a hacer, y trataban siempre de que yo estuviera bien, que mi pareja también estuviera bien, que me pudiera acompañar en todo momento... Así que, al final, todo eso negativo que me pasó al principio se borró con lo positivo que vino después. [GD Latinoamérica 4]

Aunque a nivel de tratamiento de la gente, depende también de tu suerte. Hay veces que caes en personas muy buenas y otras que caes en unas racistas y... (Risas) No te cuento nada más. Además, como te ven con el pañuelo y eso, pues te tratan un poco diferente de a los demás. Eso lo notamos cuando estamos los tres días en el hospital, ahí eso lo notas más. [GD - Magreb 5]

(Les pregunto si todas han notado en el hospital que les tratan de manera diferente.)

Sí, sí, sí. [GD - Magreb 1]

Bueno, todos no, todos no son así. [GD - Magreb 3]

(Les pregunto si este tratamiento diferente lo han notado por los comentarios o si son más comportamientos hacia ellas.)

Es que... Lo sientes que el tratamiento es un poco... Mira, por ejemplo, la primera noche que tuve a mi hija, yo estaba con siete u ocho puntos, que no podía ni moverme para coger a la niña y darle el pecho. Entonces, llamé a la enfermera para decirle que la niña estaba llorando y yo no podía moverme para cogerla y darle el pecho. $Y$, entonces, llegó la enfermera y me dice "¿Qué quieres?", y le digo "Por favor, ¿me puedes pasar a la niña, que no puedo cogerla de la cunita?". Y me ha dicho "Cógela tú", y me la ha dado de una manera, que es que... casi me la tira. Y, como yo casi no hablaba español, pues he cogido a la niña y ya está. Es verdad que depende de las personas, no todas son así, pero una o dos o tres te caen así. [GD - Magreb 5]

Una de las usuarias latinoamericanas comenta, por otro lado, que el racismo parece ser más patente fuera de los servicios sanitarios o en las localidades pequeñas, opinión que coincide con las respuestas tanto de algunos profesionales como de algunas usuarias que hemos presentado previamente en el análisis de los datos recolectados con la técnica de las entrevistas.

Te tienes que ir adaptando a cada lugar y, por ejemplo, a mí, adaptarme al pueblo me costó mucho, porque la gente de allí son muy cerrados. Son muy, muy cerrados. $Y$ en el hospital no hay tanto racismo como hay en el ambulatorio del pueblo, porque en el pueblo hay mucho racismo. Y te miran así... A mí directamente no me pasó, pero yo veía cómo se miraba a los extranjeros y... Por ejemplo, en el pueblo, tú no ves negros, no es como en Zaragoza que ves negros a punta y pala. Allí, no, allí todos somos mulatos, pero negros, negros, negros, no. No lo vemos. ¿Por qué? Pues, porque la policía los agobia y los acecha tanto, que se van a otro sitio. Por ejemplo, yo, cuando llegué al pueblo, cada dos por tres tenía a la policía tocándome al timbre. Y venían, y me entraban, y me decían que tenían una orden y... Porque sacaban una orden del juez o lo que fuese, y decían "Venimos a hacer un chequeo". Y te miraban y te pedían que sacaras esto o lo otro. $Y$ eso que yo estaba viviendo con un español y estaba casada con un español... Y yo pensaba "Pero, ¿qué es esto?". Y me decían los que llevaban trece o catorce años "Es que todos, cuando llegamos, tuvimos que pasar por esto". Y da la casualidad que la inspectora de extranjería es la misma 
desde hace muchos años y, entonces, ya la conocen, y me decían "Uy, esa, esa es el demonio". Pero, vamos, que al final lo dejan a uno en paz... [GD - Latinoamérica 3]

Cabe destacar que las usuarias participantes en los grupos han sido bastante más extensas a la hora de manifestar su opinión sobre los profesionales sanitarios y describir algunas situaciones discriminatorias de lo que lo habían sido las usuarias entrevistadas. Las razones pueden ser, entre otras, que las primeras presentan por lo general un mayor dominio del español con respecto a las entrevistadas y que, al hallarse fuera del hospital contexto de estudio, probablemente se han sentido más libres a la hora de expresar abiertamente su parecer.

Por su parte, los profesionales participantes en el grupo de discusión creen que la manifestación del sentimiento de discriminación por parte de las usuarias inmigrantes se produce con mayor frecuencia en determinados contextos (como en el área de urgencias). Además, sostienen que no se puede atribuir este sentimiento a un colectivo determinado y que, de todos modos, la expresión explícita del mismo es cada vez menor.

(Les pregunto si, en alguna ocasión, las usuarias inmigrantes han manifestado algún sentimiento de discriminación o han comentado que, en su opinión, al ser extranjeras, se las trata de manera diferente.)

Sí, sí, eso sí. Bueno, para mí, ese es un comentario bastante habitual. (Le pregunto si esto sucede más con algún colectivo inmigrante en concreto.) No sé. Hombre es de cara más a la atención en urgencias, que no en consultas. Pero, en la urgencia, sí, aunque no sabría decirte qué colectivos. [GD - Obstetra 1]

A veces se quejan de que se pasa a otros usuarios antes, o de que no les haces caso, o yo qué sé... [GD Obstetra 3]

Hombre, muy excepcionalmente, sí que ha sucedido que alguna en la sala de espera se han puesto a decir “¡Racistas!" o no sé qué, o no sé cuántos... Y yo he salido y les he dicho "Oye, de eso nada, ¿eh?”. [GD Obstetra 2]

Pero, ahora, cada vez menos. [GD - Obstetra 1]

Sí, esto pasa cada vez menos, antes yo creo que más. [GD - Obstetra 2]

Para finalizar tanto este subapartado como el análisis de los datos recolectados en los grupos de discusión, quisiéramos incluir un fragmento del encuentro con las usuarias magrebíes que, a nuestro juicio, resume de manera muy acertada la actitud ante el inmigrante en la sociedad de acogida.

Es que aquí me parecen racistas. Lo digo siempre y lo voy a decir hasta que me voy de Zaragoza. [GD Magreb 5]

(Las demás responden al unísono "No, no todos, no todos son racistas".)

Bueno, es verdad, nosotros siempre decimos que, en el mundo, en cada ciudad, en cada país, hay personas buenas y personas malas y... ¿Cómo decimos? Que hay como rocas y... y harinas. O sea, que hay gente dura y gente suave, es así. Así decimos nosotros en un proverbio marroquí. Yo no digo que discriminan, pero no son buena gente, porque aquí te sientes extranjera al ciento por ciento. [GD Magreb 5]

Mira, yo he notado una cosa. Cuando yo vine, cuando no había muchos extranjeros, la gente nos trata bien, nos saluda por la calle... Pero, ahora, que ha venido tanta gente de fuera, ahora ya no nos tratan tan bien. Y tampoco entiendo por qué a la gente de Rumanía los tratan bien, cuando los rumanos roban y los españoles lo saben. En cambio, nunca encuentran un marroquí que roba, pero los rumanos roban mucho, 
en los mercados, en los autobuses... Por ejemplo, no tienen confianza en una rumana para dejarla en su casa trabajando, pero sí que los tratan bien. ¿Y por qué a mí, que respeto mi religión, y sé que no tengo que robar, y tengo que trabajar bien y tengo que cobrar justo de mi trabajo, pero no nos tratan bien como a los demás? [GD - Magreb 2]

Yo, desde mi punto de vista, creo que la gente aquí te juzgan dependiendo de tu aspecto. Por ejemplo, si te ven que vas medio desnuda, piensan que eres más libre, que eres más abierta... Y si te ven que vas más tapada y respetas unas reglas que en la vida tienes que respetar, piensan que tú eres retrasada, ignorante, que no tienes derechos, que tu marido manda y eres esclava... Y eso no es así. [GD - Magreb 5]

Es que piensan que, por ejemplo, los maridos nos obligan a poner el pañuelo y que son... ¿Cómo dicen? Machistas, eso dicen, que son machistas. Y nos preguntan "¿Y por qué tu marido viste así y tú así?". Pues, es que eso es nuestra religión. [GD - Magreb 4]

Yo puedo asegurarte que ningún marido marroquí obliga a su mujer a hacer ninguna cosa que ella no quiere hacer. [GD - Magreb 1]

Es que no pueden entender que una mujer musulmana, cuando toma una decisión, lucha hasta que lo consigue. Por ejemplo, yo estoy haciendo las prácticas de monitora de tiempo libre, y yo he hecho el curso y todo y, un día, nos dieron una hoja para valorar el curso, y me dijo el profesor "Pero... ¿tú llevas el tema de escribir bien?". Y yo me quedé con una cara que... Y le dije "Pues, claro, ¿qué te parece? Voy a probar $y$, si te parece bien, sigo y, si no..." (Risas). Y me preguntó “¿Y vas a algún taller de escritura o algo?”. Y yo le conté que yo en mi país estudié, estudié francés y español también... [GD - Magreb 4]

Es que piensan que somos todas ignorantes y que está prohibido en nuestro país que las mujeres estudian. No piensan que las mujeres también pueden estudiar y pueden trabajar en los ministerios, y tenemos médicos mujeres, y profesoras... [GD - Magreb 2]

Pero es que también los medios de comunicación no cuentan estas cosas. Por ejemplo, yo sé que uno de los puentes que se construyeron aquí en la Expo lo hizo una mujer que creo que era iraní, pero la publicidad no se ha hecho. [GD - Magreb 3]

Es verdad. Yo llevo aquí seis años y no he visto nunca, pero nunca, alguna cosa en la televisión que habla de Marruecos. Como mucho hablan de las mujeres que llevan pañuelo, pero nada más, nunca. [GD Magreb 5]

Es que los medios de comunicación hacen papel muy importante. Hay una televisión que hace unos documentales de Marruecos y sacan siempre los camellos y el desierto y la gente que vive en tiendas. (Risas). Así, luego, los españoles piensan que todo Marruecos es así. Por ejemplo, tengo una amiga que iba a viajar en coche hasta Marruecos y una española le pregunta si allí tenemos caminos para ir en coche, porque piensa que nosotros vivimos todos en el Sáhara, y no hay caminos ni ciudades ni... [GD - Magreb 1]

Pero si Marruecos parece también como España. Si la gente va a Casablanca, o a Agadir, o a Marraquech, la gente se volvería loca ahí. La gente de España que va a Marruecos hablan bien, porque saben. Pero los que se quedan con la imagen que da la televisión o los periódicos... [GD - Magreb 2]

Como se puede observar en el fragmento presentado, en primer lugar, estas usuarias afirman que, a pesar de que algunos autóctonos manifiestan actitudes y comportamientos racistas, no es posible generalizar. Además, una de ellas, que reside en España desde hace casi quince años, opina que el progresivo aumento de población inmigrante ha conllevado un incremento del sentimiento negativo hacia esta población. Consideran que la percepción del extranjero varía dependiendo del país del que este proceda, algo que también habían señalado algunas usuarias entrevistadas, y que, por ejemplo, hay mayor discriminación hacia los magrebíes con respecto a la que se da hacia los originarios de Europa del este. Asimismo, creen que, en ocasiones, se les juzga por su aspecto, y que se tiene un concepto de la mujer musulmana que 
no se corresponde con la realidad. En su opinión, existen numerosos prejuicios y estereotipos sobre los musulmanes en general, y sobre los magrebíes en particular, y las usuarias tratan de desmontar estas imágenes estereotipadas aportando datos sobre su sociedad de origen. La influencia de los medios de comunicación es, a su juicio, bastante negativa, ya que en dichos medios no se suele ofrecer una imagen completa de la realidad, sino solo información "exótica" o distorsionada. Concluyen afirmando que esta imagen que se muestra en la prensa o en la televisión se ve modificada y sustancialmente mejorada en el caso de aquellas personas que han visitado su país, es decir, que el conocimiento en primera persona puede aportar un acercamiento y una mejor comprensión del Otro y de la sociedad en la que este vive. 


\section{CAPÍTULO 7}

Conclusiones 


\section{CONCLUSIONES}

En el capítulo anterior hemos presentado de manera descriptiva y exhaustiva la información recabada mediante las diferentes técnicas empleadas en nuestro estudio de caso y, una vez hemos alcanzado la saturación de datos y los hemos analizado separadamente, pasamos a continuación a exponer las conclusiones a las que hemos llegado. Cabe recordar brevemente que nuestro análisis ha seguido una progresión emergente y en cascada y, en líneas generales, se ha dividido en las siguientes fases:

1. El primer estadio de la investigación, tras la revisión bibliográfica pertinente, consistió, por una parte, en el proceso de solicitud de autorizaciones al hospital contexto de estudio y, por otra, en el análisis documental. Este último, pese a tratarse de una técnica secundaria o complementaria, nos ofreció valiosos datos contextuales, y nos ayudó a detectar cuestiones de interés a incluir en el estudio. A medida que avanzábamos, fuimos seleccionando otros documentos relacionados con los objetivos de investigación, que incluimos entre las fuentes a analizar.

2. Una vez recibimos las autorizaciones necesarias, comenzamos a realizar el trabajo de campo, el cual, en un primer momento, se centró en el uso de la técnica de las entrevistas y de la observación no participante. Los datos recolectados mediante estas técnicas se fueron trascribiendo, segmentando en unidades de análisis, codificando y analizando a medida que se recopilaban, en base a la inducción analítica, consistente en la búsqueda de información que nos permitiera verificar o refutar nuestras hipótesis iniciales. ${ }^{290}$

3. Tras analizar y contrastar los datos obtenidos con las técnicas mencionadas, llevamos a cabo, en una tercera fase, los grupos de discusión, cuyo fin consistía principalmente en profundizar en aquellos temas que, hasta el momento, hubieran resultado ambiguos, no suficientemente desarrollados o contradictorios. Tras la finalización de los mismos, solicitamos a los participantes que rellenaran un cuestionario individual, lo cual nos permitió corroborar ulteriormente determinados datos.

4. En esta cuarta y última fase, presentamos las conclusiones del estudio de caso. En ellas, recurrimos al contraste y la triangulación de los datos obtenidos en el trabajo de campo, y los cotejamos y relacionamos con anteriores investigaciones o publicaciones que versan sobre esta área de estudio, con el fin de tratar de responder a las preguntas que nos planteamos inicialmente como objetivos de investigación.

Nuestro propósito con este último capítulo consiste, por consiguiente, en realizar un análisis descriptivo-interpretativo de la comunicación intercultural que tiene lugar entre los profesionales sanitarios y las usuarias inmigrantes que acuden al hospital contexto de estudio. En concreto, señalamos las dificultades que pueden impedir que dicha comunicación sea efectiva y cuáles podrían ser las causas de dichas dificultades. Estudiamos, asimismo, qué soluciones se han adoptado hasta el momento para garantizar la eficacia de la comunicación con las usuarias inmigrantes y, en última instancia, favorecer el acceso y uso de los servicios del hospital por parte de las mismas. El análisis de las soluciones adoptadas persigue el fin de

\footnotetext{
${ }^{290}$ Cabe recordar que, en esta fase y en la siguiente, nos apoyamos en el programa de análisis de datos cualitativos NVivo 10. Para mayor información, véanse los capítulos 2 y 6 , en los que presentamos, respectivamente, el diseño metodológico de nuestro estudio y los datos recolectados en el mismo.
} 
comprobar si estas son suficientes y si se están aplicando adecuadamente. En estos primeros apartados de las conclusiones del estudio de caso, van surgiendo, inevitablemente, una serie de recomendaciones por nuestra parte que podrían aplicarse en la práctica diaria del hospital. Sin embargo, es en el siguiente apartado en el que planteamos una serie de propuestas de mejora que podrían implantarse tanto en el ámbito específico del hospital como, por extensión, en los servicios sanitarios aragoneses. Para finalizar, en un último apartado, proponemos una serie de acciones de mejora que, a nuestro parecer, podrían aplicarse en el ámbito nacional, a las cuales hemos podido llegar a través del estudio de un microespacio (el contexto específico de nuestro estudio). El objetivo principal que perseguimos con el planteamiento de todas estas propuestas consiste en contribuir a la mejora de la comunicación y de la relación entre los profesionales sanitarios y las usuarias (refiriéndonos no solo las inmigrantes sino también, en cierto sentido, a las autóctonas), lo cual, a su vez, aumentaría la calidad de la asistencia sanitaria prestada.

\subsection{Conclusiones generales del estudio de caso}

\subsubsection{Opiniones e impresiones iniciales de los grupos implicados}

De acuerdo con los datos que hemos recolectado con las diferentes técnicas empleadas, por lo general, los profesionales sanitarios suelen percibir la asistencia sanitaria a las usuarias inmigrantes como más dificultosa que la de las usuarias autóctonas, a pesar de que consideran que, con el paso del tiempo, a medida que aquellas se han ido integrando en la sociedad de acogida, han ido aprendiendo la lengua y han adquirido mayores conocimientos sobre el sistema sanitario y su funcionamiento, los problemas en su atención han ido disminuyendo. Si bien es cierto que un mayor grado de integración supone un mejor acceso y uso de los servicios sanitarios, como hemos comentado en el capítulo 1, concretamente en el apartado de contextualización, es más que probable que España continúe recibiendo flujos migratorios en un futuro, por lo que seguirá habiendo usuarias cuyo conocimiento de la lengua y del funcionamiento del sistema de salud no sea suficiente como para permitir que su utilización de los servicios sanitarios sea plenamente satisfactoria para todos los implicados y cumpla con unos requisitos mínimos de calidad y equidad. Asimismo, cabe recordar que las mujeres, por lo general, y las inmigrantes, en particular, son uno de los colectivos que presentan un mayor riesgo de exclusión social y que, a menudo, sus condiciones socio-económicas y personales en la sociedad de acogida las llevan a una situación de aislamiento y marginación, la cual no les permite adquirir la autonomía necesaria para desenvolverse con éxito en la sociedad y hacer uso de los recursos que esta pone a su alcance.

A pesar de las dificultades que la asistencia sanitaria a las usuarias inmigrantes puede entrañar, cabe señalar que, de todos modos, la gran mayoría de los profesionales que han participado en nuestro estudio afirma que, excepto en casos aislados, la actitud de las usuarias inmigrantes es colaboradora, respetuosa y educada y, en las ocasiones puntuales en las que dicha actitud no ha sido tan positiva, consideran que probablemente esto se ha debido al carácter de la usuaria en cuestión, a su desconocimiento del español, o al hecho de sentir miedo y desconfianza por encontrarse en un contexto que le resulta extraño o, cuando menos, novedoso. 
Los profesionales participantes opinan que existen diferencias por colectivos en relación con las dificultades presentadas por las usuarias. Así, en general, señalan que aquellas cuya asistencia es más compleja suelen ser las procedentes de Asia (principalmente de China), las del Magreb y las de África Subsahariana. Por el contrario, creen que aquellas cuya asistencia suele ser más sencilla o, al menos, más similar a la que se presta a las usuarias autóctonas, son las procedentes de Europa del este y de Latinoamérica.

Las razones que aducen para estas diferencias en la complejidad de la asistencia por colectivos enlazan directamente con lo que estos profesionales perciben como las mayores causas de los obstáculos en la atención a las usuarias inmigrantes, que son, por este orden, las diferencias lingüísticas, las diferencias en cuanto a la cultura general y, por último, las diferencias relativas a la cultura sanitaria y la relación con los maridos y familiares de las usuarias. Cabe señalar que, pese a que los problemas comunicativos, como veremos a lo largo de la exposición de nuestras conclusiones, constituyen un obstáculo importante a la hora de atender a las usuarias de origen extranjero, no podemos limitar el origen de las dificultades en la asistencia a estas usuarias a una cuestión meramente lingüística, como así demuestran, por ejemplo, las complicaciones que surgen con las usuarias de origen latinoamericano o con aquellas procedentes de otras áreas que presentan un dominio considerable de español.

Otro punto que merece ser destacado es el hecho de que los profesionales perciben las diferencias relativas a la cultura general (asociadas con frecuencia a cuestiones referentes a las costumbres religiosas, los hábitos alimentarios, el rol del hombre y de la mujer o las relaciones de género, etc.) $y$, sin embargo, no son tan conscientes de las diferencias que existen en relación con la cultura sanitaria. Esto puede responder a dos motivos principales. Por una parte, probablemente a los profesionales sanitarios les resulta más sencillo observar aquellos aspectos de la cultura que son perceptibles a simple vista (los elementos culturales que, de acuerdo con estudiosos de las relaciones interculturales, como Michael Paige, 1993, se encuentran "por encima de la superficie del iceberg") y, por el contrario, no son capaces de apreciar las conexiones intrínsecas que existen entre estos elementos culturales más superficiales y otros elementos menos visibles referidos a cuestiones como las creencias, los sistemas de valores o las relaciones intraculturales. Por otra parte, desde una visión etnocéntrica y anclada en la consideración de superioridad de los principios propios de la biomedicina hegemónica, la mayoría de los profesionales sanitarios no se plantea ni siquiera que puedan existir diferencias culturales en cuanto al concepto de salud y enfermedad o, en referencia a nuestro ámbito específico de estudio, con relación al concepto y la vivencia del embarazo, el parto y el puerperio.

Una de las cuestiones que sí comienzan a plantearse los profesionales sanitarios es que pueden existir diferencias relativas al funcionamiento de los servicios sanitarios en los países de origen de las usuarias inmigrantes y los españoles, lo cual, sumado a su desconocimiento general sobre el sistema de salud en el país de acogida, las conduce a efectuar un uso inadecuado de los servicios sanitarios. Al respecto, a menudo señalan que las usuarias inmigrantes suelen presentar una asistencia irregular a las visitas programadas o que recurren con asiduidad a los servicios de urgencias, y consideran que esto se debe principalmente a una falta de organización y a una utilización de los servicios de acuerdo con su disponibilidad y conveniencia. Por el contrario, en nuestra opinión, estas pautas de comportamiento por lo que 
se refiere al uso de los servicios sanitarios están causadas fundamentalmente por las dificultades de acceso provocadas por las barreras lingüísticas y culturales, el desconocimiento sobre el funcionamiento de los servicios, o la situación socio-económica y personal, que, a menudo, impide a las mujeres inmigrantes disponer del tiempo suficiente como para abandonar sus numerosas obligaciones (laborales y familiares) y ocuparse de sus problemas de salud. Cabe recordar, además, que la gran mayoría de las mujeres inmigrantes no disponen de redes sociales y de apoyo que les faciliten información sobre el sistema sanitario, las acompañen a las visitas médicas o durante sus ingresos hospitalarios, o las ayuden atendiendo a sus hijos cuando estas deben acudir a los centros de salud, de ahí que, por ejemplo, suelan acudir a las consultas solas o acompañadas de menores, cuestión que han señalado diversos profesionales sanitarios y que nosotros mismos hemos podido observar en nuestro trabajo de campo. Del mismo modo, quisiéramos señalar que, de acuerdo con algunos estudios, entre los cuales podríamos citar el documento "Inmigración y salud en Aragón", que fue elaborado en 2007 por el Grupo de trabajo Inmigración y salud de la SEMFYC (Sociedad Española de Medicina de Familia y Comunitaria), y del cual hemos hablado en el apartado de análisis documental del anterior capítulo, las pautas de comportamiento a la hora de usar los servicios sanitarios no son tan diferentes en los usuarios autóctonos y en los de origen extranjero, especialmente en el caso de aquellos que presentan un conocimiento "aceptable" de la lengua del país de acogida y del funcionamiento del sistema de salud. Así, por ejemplo, en dicho documento se indica que el mayor recurso a los servicios de urgencias se debe en ambos casos a motivos similares, como pueden ser el deseo de evitar la espera y agilizar los trámites burocráticos, o la posibilidad de acudir a los mismos sin que esto interfiera con sus horarios de trabajo.

Igualmente, cabe resaltar que, a pesar de que la asistencia sanitaria a las mujeres embarazadas y los menores y a aquellas personas que necesitan atención médica de urgencia está garantizada incluso después de la aprobación del Real Decreto-ley 16/2012, de medidas urgentes para garantizar la sostenibilidad del Sistema Nacional de Salud y mejorar la calidad y seguridad de sus prestaciones, como hemos señalado previamente, existe un gran desconocimiento sobre las disposiciones de esta nueva normativa, tanto por parte de los profesionales sanitarios como de los propios usuarios, lo cual podría conllevar un menor uso y acceso de los servicios por parte de la población inmigrante, por falta de información sobre su derecho a emplearlos y por miedo a que, en caso de no encontrarse en situación regular, se les denuncie a las autoridades al acudir a los centros de salud.

Antes de pasar a analizar la opinión de las mujeres inmigrantes sobre la asistencia sanitaria en España, quisiéramos señalar una idea que, por su especial relevancia, iremos retomando en otros puntos de nuestro análisis. En concreto, consideramos que, tanto si la asistencia a las usuarias inmigrantes resulta más dificultosa como si es similar a la de las usuarias autóctonas, cabe recordar que todos los ciudadanos deberían gozar del derecho a la salud y a una asistencia sanitaria de calidad y equitativa, independientemente de características personales, como la nacionalidad, el credo, etc., tal y como se afirma en documentos como la Declaración Universal de los Derechos Humanos, la Constitución española o el Estatuto de Autonomía de Aragón. 
Por lo que respecta a las usuarias inmigrantes que han participado en nuestro estudio, la gran mayoría valora positivamente los servicios sanitarios españoles y, en general, muestran una actitud de reconocimiento y agradecimiento por la atención recibida en los mismos. Los principales aspectos que destacan son los medios y las instalaciones de las que disponen y la gratuidad de las prestaciones, así como el trato recibido, en general, por los profesionales sanitarios. En relación con este último aspecto, algunas de las participantes en la investigación nos han relatado episodios en los que un profesional sanitario concreto no las ha tratado adecuadamente $y$, por ejemplo, ha realizado comentarios despectivos o las ha recriminado por haber expresado abiertamente sus dolencias. Al respecto, nos han llamado la atención dos cuestiones. La primera se refiere al hecho de que las críticas al trato recibido por parte de algunos miembros del personal sanitario o los relatos de episodios puntuales en los que se las hubiera discriminado han sido mayores en los grupos de discusión celebrados fuera del contexto del hospital que en las entrevistas individuales llevadas a cabo dentro del mismo, lo cual, unido a la posibilidad de interacción que caracteriza a las entrevistas grupales, puede haber conllevado una manifestación más explícita de las opiniones de las propias usuarias. Por consiguiente, consideramos que, para futuras investigaciones, se debería dar peso al empleo de esta técnica que nos ha ofrecido excelentes resultados. Por otra parte, quisiéramos resaltar que las propias usuarias inmigrantes, por lo general, han mostrado una actitud abierta y comprensiva, e incluso aquellas que en algún momento habían recibido un trato inadecuado por parte de algún profesional sanitario han sabido contextualizar este problema y evitar las generalizaciones, afirmando que la actitud de cada profesional depende fundamentalmente de cuestiones como su carácter o el estado de ánimo que este presente en el momento de la interacción.

El trato negativo recibido en ocasiones puntuales es prácticamente el único aspecto que critican algunas usuarias en relación con la asistencia sanitaria en España. Por el contrario, las cuestiones positivas indicadas (medios, instalaciones, gratuidad) ${ }^{291}$ son aquellas en las que estas usuarias observan mayores diferencias con respecto al sistema de salud de sus países de origen. Así, algunas usuarias, principalmente procedentes de Europa del este, de África Subsahariana o del Magreb, nos hacen partícipes de la falta de medios y de personal, la deficiencia de las instalaciones o la obligación de pagar las prestaciones sanitarias en sus respectivos países, aunque algunas de ellas matizan que estos aspectos pueden variar dependiendo de si se procede de una zona urbana o rural, ya que en esta última el acceso y la existencia de servicios sanitarios suele ser más limitado, mientras que en las ciudades es posible hallar centros de salud y hospitales con unas condiciones más similares a los que se encuentran en España.

\footnotetext{
${ }^{291}$ Cabe recordar que la gratuidad de los servicios sanitarios, a partir de la aprobación del Real Decreto-ley 16/2012, deja de ser universal y que, por tanto, un número considerable de los usuarios inmigrantes residentes en España deberán pagar por la asistencia recibida, tal y como ocurre en algunos de sus países de origen, eliminándose esta diferencia. Lo peor, a nuestro parecer, es que, mientras que, en algunos de los países de los que proceden los usuarios de origen extranjero, el pago por los servicios sanitarios prestados se aplica a toda la población por igual, la nueva normativa implantada en España el pasado año, aplica la gratuidad a algunos ciudadanos (principalmente a los españoles y a aquellos que reúnen ciertas condiciones estipuladas por la ley) y, por el contrario, les niega este derecho a otros ciudadanos (algunos inmigrantes) por el mero hecho de no haber nacido en este país, no hallarse en situación administrativa regular, y no contribuir a la Seguridad Social.
} 
Para finalizar este apartado, cabe resaltar que, cuanto mayores sean las diferencias en cuanto a la organización y el funcionamiento del sistema de salud de los países de origen de las usuarias inmigrantes y el de España, más aumentarán las dificultades que estas encuentren para acceder y usar los servicios sanitarios en la sociedad de acogida. Así, por ejemplo, resultará más complicado comprender los trámites burocráticos, las estructuras y las funciones de las diferentes figuras profesionales socio-sanitarias, el sistema de citas o el de elección del médico de cabecera para una usuaria que provenga de un país donde estas cuestiones funcionan diversamente (como puede ser China), que para una en cuyo país de origen los servicios presenten más similitudes con los españoles (como puede el caso de las usuarias de Europa del este).

\subsubsection{Barreras que dificultan la comunicación y la asistencia a las usuarias inmigrantes}

Las mayores dificultades a las que se enfrentan las usuarias inmigrantes a la hora de acceder y usar los servicios sanitarios españoles suelen estar causadas, como hemos afirmado en numerosas ocasiones a lo largo de este trabajo, principalmente (aunque no únicamente) por barreras culturales y lingüísticas. En concreto, en el presente apartado analizamos con más detalle las cuestiones relacionadas con la cultura y con la lengua que pueden obstaculizar la comunicación y la relación entre los profesionales de los centros de salud y hospitales, por un lado, y las usuarias de origen extranjero, por otro. Asimismo, presentamos una serie de actitudes ante la diversidad cultural que podrían ser fuente de malentendidos y conflictos $y$, por tanto, impedir o dificultar la comunicación entre los dos grupos de sujetos mencionados.

\subsubsection{Barreras culturales en el ámbito de la salud}

En este subapartado estudiamos las diferencias culturales relacionadas con la salud que pueden existir entre los profesionales sanitarios autóctonos y las usuarias inmigrantes a las que estos atienden. Si bien centramos nuestro análisis en cuestiones relativas a la salud reproductiva, área principal de nuestra investigación, entendemos que un gran número de los temas aquí planteados podrían hacerse extensibles a otros ámbitos de la salud. Asimismo, quisiéramos recordar una vez más que los elementos culturales están interrelacionados y, por tanto, pese a que estructuramos nuestro análisis en diversos temas (clasificados en las diferentes fases del proceso reproductivo) y lo centramos en el concepto de cuerpo y salud, los modos de prevención y cura, etc. propios de cada cultura, consideramos que otros aspectos más generales (como el concepto del tiempo, el rol atribuido a la familia o a los distintos sexos, las creencias religiosas, etc.) propios de cada comunidad influyen notablemente en lo que se conoce como cultura sanitaria.

Del mismo modo, además del hecho de que la cultura no está conformada por compartimentos estancos, cabe señalar que esta no es inmutable, sino que varía a lo largo del tiempo (como puede hacerlo, entre otras circunstancias, por el hecho de emigrar a otro país), y que no todos los miembros de una misma comunidad presentan los mismos patrones culturales, sino que cada uno de ellos posee una única e irrepetible identidad personal y unos condicionantes sociales específicos. Por este motivo, aunque presentamos una serie de características asociadas a la cultura sanitaria de algunas comunidades concretas, nuestro propósito no consiste en establecer generalizaciones aplicables a todos los miembros de dichas comunidades, sino en "dar pistas" sobre cuál podría ser su pauta de comportamiento y 
las posibles causas que lo motivan. En consecuencia, en la valoración de los patrones culturales que afectan al concepto y el modo de actuar de las usuarias en relación con su salud, los profesionales sanitarios deberían tener en cuenta lo que autores como George Estes y Darryl Zitzow (1980) y Rachel E. Spector (2003) denominan "modelo de la consistencia hereditaria", el cual se refiere al grado en que una determinada persona combina las creencias y las prácticas asociadas a la medicina tradicional con otros elementos más propios de la modernidad y la biomedicina.

\section{Cuestiones generales sobre la salud reproductiva}

Antes de comenzar el análisis de las cuestiones culturales que atañen a cada una de las fases del proceso reproductivo, quisiéramos exponer una serie de consideraciones generales que se deberían tener en cuenta a la hora de estudiar la asistencia sanitaria a las mujeres inmigrantes por lo que respecta a su salud reproductiva.

En primer lugar, cabe señalar que factores como la feminización de los flujos migratorios y el hecho de que las mujeres inmigrantes que residen en España sean mayoritariamente jóvenes $y$, por tanto, se encuentren en edad fértil, han conllevado, en los últimos años, un aumento notable de su presencia en los servicios de obstetricia y ginecología. De hecho, tanto por lo que señalan algunos estudios publicados ${ }^{292}$ como de acuerdo con nuestra propia experiencia en el contexto investigado, se puede constatar que el uso por parte de las mujeres de origen extranjero de los servicios sanitarios relacionados con la salud reproductiva es considerable, llegando a ser similar o, en proporción con el porcentaje de población total, incluso mayor que el de las autóctonas.

Del mismo modo, quisiéramos recordar que, a partir de la revisión que se realizó en el año 2000 de la definición de salud ofrecida por la Organización Mundial de la Salud, el derecho a la salud abarca no solo la atención sanitaria, sino también una serie de factores determinantes relacionados con "el acceso a la educación e información sobre cuestiones relacionadas con la salud, incluida la salud sexual y reproductiva", los cuales deberían considerarse como prioritarios dentro de las políticas sanitarias.

El enfoque de dichas políticas de atención a la salud reproductiva debería realizarse desde un punto de vista antropológico, teniendo en consideración que cuestiones como el embarazo, el parto y el nacimiento, como señala María Isabel Blázquez (2005:2), están moldeadas culturalmente "dándose de diferentes maneras en cada sociedad y en los diferentes grupos sociales". Asimismo, consideramos oportuno que estas políticas adopten también un enfoque de género, ya que los comportamientos y las creencias relacionados con el proceso de reproducción son, en cierto sentido, indicadores de los roles atribuidos a los hombres y a las mujeres en las distintas sociedades, como puede comprobarse al analizar las distintas representaciones de la mujer gestante o los modelos de maternidad y paternidad comúnmente aplicados en las diferentes culturas.

\footnotetext{
292 Al respecto, véase por ejemplo el mencionado informe "Inmigración y Salud en Aragón" (2007), en el que se señala que las mujeres inmigrantes suponían, en el año de su publicación, entre un 10 y un $37 \%$ del total de ingresos hospitalarios relacionados con el embarazo, el parto y el puerperio.
} 
Otra cuestión a señalar se refiere a la progresiva medicalización que se ha producido en las sociedades occidentales en cuanto a la asistencia durante el embarazo, el parto y el puerperio. Ello ha conllevado que, lo que hasta el momento era considerado mayoritariamente como un proceso fisiológico pasara a describirse como un proceso patológico, justificando de este modo la intervención sanitaria que recibe. A pesar de que son innegables algunas de las ventajas que esta medicalización del proceso reproductivo ha conllevado (como la reducción de las enfermedades y la mortalidad maternal y prenatal, o la resolución de algunos problemas de infertilidad), la intervención médica (que a veces puede resultar incluso excesiva en los casos en los que la gestación sigue un curso "normal") convierte a la mujer en un ser pasivo, y le hace perder el protagonismo que merece en su proceso reproductor. La gestación pasa a ser un "problema de salud" aislado, en el cual a menudo se pierden de vista las características psicosociales y culturales de la mujer gestante, tan relevantes, como veremos en las próximas páginas, a la hora de proporcionar una asistencia sanitaria que resulte exitosa y satisfactoria para todos los implicados.

Comúnmente, se asocian con las mujeres inmigrantes, en general, o con aquellas pertenecientes a algunos colectivos, en concreto, determinados patrones de comportamiento con respecto a la fecundidad. Así, por ejemplo, los datos oficiales disponibles señalan que las mujeres inmigrantes suelen presentar una edad más joven con respecto a las autóctonas a la hora de tener su primer hijo. ${ }^{293}$ En parte, este hecho queda constatado en nuestra investigación, con las debidas consideraciones y cautelas que, por el carácter reducido de su alcance y del universo estudiado, deben aplicarse a sus resultados. Así, como puede desprenderse del análisis de los datos presentados en el capítulo 6, un número considerable de las usuarias inmigrantes que han participado en nuestro estudio fueron primíparas a una edad muy temprana, incluso algunas de ellas (en su mayoría procedentes de Latinoamérica) eran menores de edad cuando su primer hijo nació. En nuestra investigación, tratamos de comprobar si este último hecho relatado estaba relacionado con el conocimiento y el acceso que estas mujeres tenían de los métodos anticonceptivos a su alcance, como comentaremos más adelante.

Otro de los patrones atribuidos a las mujeres inmigrantes es su alta tasa de fecundidad con respecto a las autóctonas. ${ }^{294}$ También en este caso los datos oficiales y los resultados de nuestro estudio parecen coincidir, ya que la mayoría de las usuarias inmigrantes o bien tiene en el momento de su participación en el estudio más de dos hijos o manifiesta desear tener en un futuro tres o incluso cuatro. Este hecho puede estar relacionado con la importancia de la fecundidad y el rol atribuido a las mujeres como madres en determinadas culturas, en las que se valora en positivo tener un elevado número de hijos y se considera negativamente la infertilidad (la cual, dicho sea de paso, suele atribuirse a la mujer).

En consecuencia, el aumento de la presencia de mujeres inmigrantes residentes en nuestro país, unido a su elevada tasa de fecundidad, han contribuido a incrementar la tasa de natalidad

\footnotetext{
293 La edad media de maternidad de las usuarias autóctonas, de acuerdo con los datos ofrecidos por el Instituto Nacional de Estadística relativos a 2012, se sitúa en 32,15 años, mientras que la de las usuarias inmigrantes es de 28,9 años. No se dispone de datos disgregados por nacionalidad, por lo que no nos resulta posible saber si dicha edad media es superior o inferior en las mujeres procedentes de un determinado país.

294 De acuerdo con los datos proporcionados por el Instituto Nacional de Estadística, en el año 2012, la tasa de fecundidad de las mujeres en España era de 0,9 para las autóctonas y 1,7 para las extranjeras.
} 
media nacional, la cual, desde los años ochenta del pasado siglo hasta principios del presente, había ido disminuyendo, debido principalmente a la incorporación de las mujeres al mercado laboral, y a su acceso a la educación y a los métodos anticonceptivos. De todos modos, cabe señalar que los dos patrones analizados (la edad a la maternidad y la tasa de fecundidad) presentan valores cada vez más similares en las mujeres autóctonas y en las de origen extranjero. En el caso de las mujeres que han emigrado a nuestro país, es posible que su asimilación de las pautas de comportamiento de la sociedad de acogida, unido a sus condiciones socio-económicas y familiares en el país receptor, por un lado, las hayan obligado a postergar el momento de tener a su primer hijo y, por otro, hayan reducido sus posibilidades o sus deseos de tener un alto número de hijos. Sin embargo, las modificaciones en estas pautas se están observando también en los países de origen de estas mujeres, tal y como nos comentan algunas de las participantes en nuestra investigación, y como queda también patente en algunos estudios, como por ejemplo, en el que presenta Yolanda Aixelà (2010:251), en el cual se indica que, en países como los pertenecientes al Magreb, donde la tasa de natalidad era bastante elevada hasta hace unos años, diversos factores (como las migraciones, tanto internas como externas, los procesos de industrialización, la escolarización femenina, y la incorporación de las mujeres al mercado laboral) han contribuido a que se redujera dicha tasa, modificando al mismo tiempo las estructuras familiares.

Otra de las cuestiones que quisiéramos resaltar se refiere a la preferencia de las mujeres de determinados colectivos por tener hijos de un determinado sexo. Esta opinión, infundada y únicamente basada en las impresiones de algunos de los profesionales que han participado en el estudio, queda refutada por algunas de las usuarias entrevistadas o participantes en los grupos de discusión, las cuales manifiestan el deseo de tener hijos de ambos sexos, e indican que lo que les preocupa mayormente es que su hijo (sea niño o niña) goce de buena salud.

Entre los aspectos incluidos en nuestra investigación, se encuentra también el análisis de la presencia de las mujeres inmigrantes en los servicios de planificación familiar. La información que hemos podido recabar por parte de los profesionales sanitarios ha sido más bien escasa, debido a que este tipo de servicios no se suelen ofrecer en los hospitales, como es el caso de nuestro contexto de estudio, sino en los centros de salud, de modo que la mayoría de los profesionales participantes no contaba con experiencia suficiente para poder responder a nuestras preguntas al respecto. Los pocos que sí han trabajado anteriormente en estos servicios consideran que, por lo general, las usuarias inmigrantes suelen acudir a este tipo de consultas, aunque no presentan datos concretos al respecto.

Por lo que respecta a las usuarias inmigrantes que han participado en el estudio, no hemos podido establecer ningún tipo de clasificación por lo que se refiere al uso de los servicios de planificación, y el empleo de los mismos no parece depender tanto de patrones culturales como de cuestiones personales. Así, por ejemplo, mientras que en las entrevistas la mayoría de las usuarias inmigrantes (de diferentes nacionalidades) manifiesta no haber empleado nunca estos servicios (algunas por desconocimiento y otras por decisión propia), casi todas las usuarias participantes en los grupos de discusión (procedentes, recordemos, de Latinoamérica y del Magreb) sí los han utilizado. En la bibliografía consultada se señala que la elección sobre si acudir o no a las consultas de planificación familiar puede estar determinada por cuestiones culturales y religiosas. El hecho de que los temas relativos a la salud sexual y reproductiva 
(como la menstruación, los aparatos genitales o las relaciones sexuales) sean considerados tabú en determinadas sociedades (como las de religión musulmana) puede ser una de las causas por las que las mujeres de dichas sociedades no acuden con tanta frecuencia a los servicios de planificación. Asimismo, este problema se verá ulteriormente agravado si estas mujeres, por su desconocimiento del español, deben ir a las consultas acompañadas por familiares (incluidos hijos menores) o amigos, quienes les ayudan a comunicarse con el personal sanitario, como veremos más adelante, realizando labores de interpretación, y ante los cuales pueden sentirse todavía más cohibidas al tratar temas considerados muy íntimos. De todos modos, por la ausencia de datos concluyentes, opinamos que este tema podría ser objeto de futuras investigaciones centradas en los centros de salud donde se ofrecen servicios de planificación familiar, con el fin de conocer el patrón de uso por parte de las usuarias inmigrantes de dichos servicios y averiguar si este puede estar relacionado con un mayor o menor número de hijos o con la presencia de embarazos no planificados.

Con respecto al uso de métodos anticonceptivos, en nuestra investigación hemos detectado, tanto por las respuestas de los profesionales sanitarios como por las de las usuarias inmigrantes, algunos patrones de comportamiento que se dan en determinados colectivos. Así, por ejemplo, sin ánimo de generalizar, podríamos decir que la mayoría de las mujeres magrebíes que han participado en el estudio manifiestan decantarse por el empleo de dispositivos intrauterinos y la píldora anticonceptiva (hecho que parece contrastar con los datos presentados en diversos estudios), ${ }^{295}$ mientras que las latinoamericanas presentan dos comportamientos diferenciados: por un lado, se encuentran aquellas que conocen y emplean una gran variedad de métodos contraceptivos (como el parche, la vasectomía o incluso métodos naturales) y, por otro, algunas que, a pesar de disponer en ciertos casos de información, no han empleado ningún método, lo cual a veces las ha conducido a embarazos no planificados.

Los embarazos no planificados son también muy frecuentes, tanto por lo que señalan estudios al respecto, ${ }^{296}$ como por los resultados de nuestra investigación, en las mujeres provenientes de Europa del este, colectivo que presenta un gran número de interrupciones voluntarias del embarazo. Por lo que se refiere a los datos obtenidos en nuestro trabajo de campo, este hecho es comentado por un gran número de profesionales sanitarios, aunque esta información la han obtenido a través de conversaciones con las usuarias de esta procedencia, y el hospital no dispone (o al menos no nos ha facilitado) de datos sobre el número de IVEs practicadas. La causa principal, de acuerdo tanto con algunos profesionales como con algunas usuarias provenientes de Europa del este, reside en el elevado precio que tienen los anticonceptivos en

\footnotetext{
295 De acuerdo con Yolanda Aixelà (2010:257), el uso de métodos anticonceptivos en el área del Magreb, si bien se fomenta por parte de los gobiernos con el fin de contener el crecimiento demográfico del país, solo está justificado desde el punto de vista religioso si está en peligro la vida de la madre, mientras que se acepta el recurso a otros métodos de contracepción naturales, como el método Ogino o el amamantamiento tardío. Sin embargo, cabe recordar que, como sostienen María Isabel Oliver, Pilar Baraza y Encarnación Martínez (2007:87), el uso de los métodos anticonceptivos en las mujeres magrebíes dependerá también de su nivel de estudios y de su grado de islamización, por lo que a la hora de interpretar los datos que hemos obtenido, deberíamos pasarlos por el tamiz de estos (y otros) factores. Cabe, además, considerar que el hecho de que las magrebíes analizadas en nuestro estudio ya no vivan en sus respectivos países de origen también puede haber provocado cambios en sus comportamientos relativos al empleo de métodos anticonceptivos.

${ }^{296}$ En el estudio previamente citado "Inmigración y Salud en Aragón" se indicaba que las mujeres inmigrantes representaban el $47 \%$ de las interrupciones voluntarias del embarazo en un periodo de seis meses del año 2007 y, dentro de este porcentaje, se destacaba especialmente al colectivo de las rumanas, las cuales suponían un $15 \%$.
} 
su país de origen, lo cual las conduce frecuentemente a recurrir al aborto como si se tratase de un método contraceptivo más. Quizás el precio más bajo y la financiación de determinados anticonceptivos en España, unido a una labor de información y educación para la salud, podría modificar sustancialmente este comportamiento y reducir el número de interrupciones del embarazo en las mujeres de este colectivo que residen en nuestro país.

Enlazando con este último punto, quisiéramos destacar que consideramos fundamental que las familias puedan disponer de información adecuada que les permita decidir libremente el número de hijos que desean tener, qué espacio de tiempo prefieren esperar entre uno y otro embarazo, y qué métodos anticonceptivos quieren utilizar, ajustándose a sus valores, sus creencias y sus necesidades. Esta labor de información, como se indica en el fragmento extraído del "Libro Blanco sobre la percepción de los anticonceptivos en las mujeres españolas" ${ }^{\prime 297}$ (2012) que presentamos a continuación, debe realizarse desde los centros de salud.

El Ginecólogo es el medio a través del cual las mujeres españolas obtienen más información sobre métodos anticonceptivos, siendo igualmente el que más influye en su toma de decisiones. Cabe destacar la influencia que ejercen también la matrona y el farmacéutico, así como la información que les aportan principalmente los folletos en las salas de espera, más incluso que la televisión, la radio, la prensa o las redes sociales.

Cabe señalar que la información proporcionada en esta cita se refiere a un estudio (presumiblemente) centrado en mujeres autóctonas, y que se debería verificar con otras investigaciones, como hemos indicado previamente, si las mujeres de origen extranjero también acuden a las consultas de planificación familiar a la hora de decidir si emplear o no métodos anticonceptivos, o si, por el contrario, recurren más a las redes familiares y sociales, en cuyo caso, con el fin informar sobre los métodos disponibles, se deberían poner en marcha iniciativas de carácter comunitario. De todos modos, queda patente una vez más la necesidad de realizar estudios más exhaustivos sobre las pautas asociadas a la salud reproductiva disgregados por nacionalidades para detectar las necesidades específicas de las usuarias inmigrantes $y$, de este modo, poder responder a las mismas adecuadamente.

Asimismo, quisiéramos recordar que las personas excluidas del acceso a la sanidad pública de conformidad con lo establecido en el Real Decreto-ley 16/2012 no podrán ser destinatarias de medidas de salud preventivas, como las actividades de educación para la salud, entre las que se encuentran los servicios de planificación familiar.

\footnotetext{
${ }^{297}$ Esta publicación presenta los resultados de un estudio que llevó a cabo la consultora Kantar Health para la empresa farmacéutica Janssen durante el mes de junio de 2012, en el cual realizó 1.000 entrevistas telefónicas a mujeres de 18 a 49 años, residentes en el territorio nacional. Si bien ofrece datos sociodemográficos sobre las entrevistadas (como la edad, el nivel de estudios o el estado civil) no indica si su nacionalidad era en todos los casos española, aunque el título de la publicación así parece darlo a entender. Para mayor información, puede consultarse la página web: [http://www.sec.es/area_cientifica/estudiosyencuestas/LIBROBLANCO.pdf] (última consulta: 2 de octubre de 2013).
} 


\section{El embarazo}

En las últimas décadas, en España, el embarazo, a pesar de ser un proceso fisiológico, ha experimentado, como otras fases de la reproducción, una progresiva medicalización, por lo que se han visto notablemente incrementados el seguimiento y los controles que se suelen realizar durante el mismo. Al respecto, los profesionales sanitarios que han participado en nuestro estudio, sostienen que la asistencia a las visitas de seguimiento y control por parte de las usuarias de origen inmigrante es, por lo general, bastante irregular. Los motivos principales de dicha irregularidad, en su opinión, se refieren a las barreras lingüísticas, la excesiva burocracia, y las diferencias de funcionamiento existentes entre los servicios destinados al cuidado de la salud reproductiva españoles y los de los países de origen de estas usuarias. Sin embargo, prácticamente todas las usuarias participantes en el estudio afirman haber realizado estas visitas periódicamente.

Una de las causas de esta diferencia de opiniones puede basarse en el hecho de que las usuarias que han participado en nuestra investigación, en su mayoría (con excepciones, tal y como hemos señalado en el capítulo anterior), presentan ciertos conocimientos de español y llevan residiendo en España un tiempo relativamente largo. Por este motivo, probablemente, al acudir a realizar las visitas de control del embarazo en el periodo de nuestro trabajo de campo, no han debido enfrentarse a todas las barreras señaladas por los profesionales.

Además, algunas usuarias inmigrantes nos han hecho partícipes de las diferencias que existen en relación con el control del embarazo en sus respectivos países de origen, comentando que en ellos dichas visitas suelen ser menos frecuentes y se inician cuando la gestación se encuentra en un estado más avanzado. Esta diferencia puede ser una de las causas que provocan un seguimiento que podría considerarse escaso, siempre desde nuestra propia percepción del número de controles que deben realizarse durante el embarazo.

A pesar de haber efectuado todos los controles prescritos (especialmente las ecografías, que parecen ser la "técnica preferida" de control del embarazo para algunas usuarias), algunas de las participantes en el estudio manifiestan que estos les parecen excesivos. No obstante, por lo general, parece que las usuarias de origen extranjero valoran positivamente que se realice un seguimiento exhaustivo durante la gestación, y reconocen que este seguimiento puede resultar muy útil para detectar o prevenir posibles enfermedades en la madre o en el feto.

Junto a las barreras lingüísticas y las diferencias en cuanto a las costumbres relacionadas con el control del embarazo, cabe destacar otros factores que pueden condicionar la presencia limitada o irregular por parte de las usuarias de origen extranjero en las visitas de seguimiento del embarazo. Entre dichos factores, podemos señalar, por una parte, aquellos relacionados con la situación socio-económica en la que se encuentran algunas mujeres inmigrantes, la cual no les permite ocuparse de su propia salud o contar con las redes sociales y familiares que les informen sobre cómo acceder a los servicios sanitarios o les sirvan de apoyo a la hora de acudir a los mismos.

Por otra parte, la falta de asistencia a las mencionadas visitas puede estar también determinada por las creencias que, como hemos comentado en el capítulo 4, están relacionadas con el concepto de cuerpo, salud y enfermedad característico de las diferentes 
culturas $y$, en base a las cuales, se atribuye un determinado origen a las enfermedades. De hecho, entre las cinco áreas del ámbito de la salud que, de acuerdo con Nolan E. Penn et al. (1995), están influenciadas por la cultura, se encuentra la solicitud de asistencia, la cual está determinada, entre otros factores, por las creencias relacionadas con el origen de las enfermedades y con el concepto mismo de enfermedad. Mientras que, en las sociedades occidentales, se sostiene que las enfermedades pueden estar originadas por alteraciones fisiológicas (trastornos genéticos, desequilibrios bioquímicos, y organismos infecciosos) (Luckman, 2000:44), en otras culturas, en las que estas se tratan de manera holística y desde un punto de vista social, el origen puede atribuirse a distintas causas, como la posesión por parte de espíritus o fuerzas malignas, la pérdida del equilibrio entre el calor y el frío, o entre conceptos como el yin y el yang, la falta de armonía con el entorno natural y social, etc. Por ejemplo, en determinadas culturas, como señala Geri-Ann Galanti (2008:21), se cree que el mundo es un escenario dominado por fuerzas supernaturales y que, en ocasiones, la enfermedad es un castigo por un determinado comportamiento trasgresor, y que el sufrimiento causado por la misma es algo inevitable. ${ }^{298}$ ¿Qué importancia tendrá entonces para las mujeres de dichas culturas controlar el embarazo desde un punto de vista médico si creen que las enfermedades que pueden surgir a lo largo de la gestación están provocadas por factores que no pueden evitarse o que dependen de cuestiones que los profesionales sanitarios no pueden controlar?

Igualmente, cabe señalar que estas creencias culturales y religiosas también determinarán una serie de comportamientos durante el embarazo, ${ }^{299}$ entre los cuales, en nuestra investigación, el más comentado ha sido el relativo al ayuno prescrito para los musulmanes durante el Ramadán. Dicho ayuno, del cual las embarazadas (al igual que las personas con problemas de salud, los ancianos y los niños) están exoneradas, para la gran mayoría de los profesionales sanitarios, debería evitarse durante la gestación, especialmente en los periodos estivales, y así lo recomiendan a las mujeres musulmanas que atienden. Por lo que respecta a las usuarias musulmanas entrevistadas y aquellas que han participado en los grupos de discusión, la decisión sobre ayunar o no en estas circunstancias en las que no están obligadas a hacerlo parece depender de factores personales, y hemos hallado casos tanto de mujeres que lo habían realizado durante el embarazo como de otras que habían decidido no ayunar. Vemos, por tanto, una vez más, que no es posible atribuir pautas de comportamiento generalizadas a todas las personas de un determinado grupo cultural, sino que, dentro de cada grupo existen diferentes modos de pensar, sentir y actuar.

Para finalizar este subapartado, por lo que se refiere a los cursos de preparación al parto, tampoco disponemos de información exhaustiva al respecto por parte de los profesionales sanitarios, ya que, como sucede con las consultas de planificación familiar de las que hemos

\footnotetext{
${ }^{298}$ Al respecto de la consideración de la enfermedad como algo inevitable, nos llamó la atención que, en el grupo de discusión celebrado con mujeres magrebíes, se emplearan a menudo expresiones como "gracias a dios..." o "si dios quiere...", para referirse a determinadas complicaciones en la salud de la madre y el hijo que a estas mujeres les parecían difíciles de controlar o prever. Es cierto que este tipo de expresiones son también bastante comunes en el lenguaje coloquial español, incluso entre personas no creyentes, pero, en este caso, lo sorprendente fue la alta frecuencia con la que se emplearon.

${ }^{299}$ Así, por ejemplo, en algunos países de Latinoamérica, se cree que las mujeres gestantes no deben realizar ningún esfuerzo físico o deben evitar ingerir determinados alimentos, como la miel, para evitar que la placenta "se pegue" (Mendoza, 2009:318).
} 
hablado anteriormente, estos se realizan en los centros de salud. Aquellos profesionales (especialmente matronas) que sí han colaborado en el pasado en dichos cursos sostienen que la asistencia a los mismos por parte de las usuarias inmigrantes es bastante menor que la de las autóctonas. En su opinión, esta escasa presencia por parte de las usuarias de origen extranjero puede deberse a que no disponen de suficiente información y desconocen la existencia de estos cursos. De acuerdo con los datos ofrecidos por las usuarias participantes, esta no es siempre la causa de su falta de asistencia, puesto que muchas de ellas, a pesar de haber recibido información sobre los cursos de preparación al parto (bien en los centros de salud o a través de sus redes sociales y familiares), han decidido libremente no asistir, porque sostienen no necesitarlos o porque sus circunstancias personales se lo impiden. Cabe recordar que la participación en estos cursos no deja de ser voluntaria y no es estrictamente necesaria, por lo que, en todo caso, debería respetarse la decisión de no asistir a los mismos en los casos en los que, aun disponiendo de información, se opta por no acudir. Por el contrario, vemos conveniente que se produzca una mayor difusión de información sobre estos cursos y una coordinación entre el personal sanitario y las redes sociales, de manera que todas las usuarias conozcan la existencia de los mismos, y sean ellas mismas quienes decidan, en última instancia, si desean o no participar.

\section{El parto}

En relación con el parto, existen diversos documentos que, tanto a nivel nacional como autonómico, proponen una serie de pautas que se deberían seguir durante el mismo, entre los cuales, se encuentran la "Estrategia de atención al parto normal en el Sistema Nacional de Salud" (EAPN) (2007), el documento "Maternidad responsable. Estándares y Recomendaciones" (2009) o, por lo que respecta a la comunidad autónoma de Aragón, el "Plan de atención a la salud de la mujer 2010-2012". ${ }^{300}$ Cabe señalar que dichas pautas no dejan de ser recomendaciones, las cuales, en muchos casos, no pueden seguirse por las infraestructuras con las que cuentan los hospitales, los protocolos y las rutinas de trabajo, o la formación y capacitación de los profesionales que trabajan en los mismos.

Algunas de las cuestiones de carácter general que se establecen en dichos documentos se refieren a la consideración del nacimiento como un proceso fisiológico, por lo que se recomienda que, durante el parto, se instaure un clima de confianza, seguridad e intimidad, en el que se respete la privacidad y la dignidad de las parturientas. De estas cuestiones generales se desprenden otras más específicas, relativas al derecho a la información, el impulso de la participación de las mujeres y sus familias, y el reconocimiento de su derecho a elegir libremente el modo en el que, dentro de las posibilidades y siempre que no existan riesgos para la madre o el hijo, se desea dar a luz.

Cabe recordar que el parto, al igual que otras fases del proceso reproductivo, ha experimentado una progresiva medicalización; de hecho, en nuestra opinión, es quizás la fase de la reproducción que recibe una mayor atención médica, ajustada, además, en numerosas ocasiones, a las demandas y las necesidades de los profesionales sanitarios y de las instituciones en las que estos trabajan. Por el contrario, en algunos de los países de origen de

\footnotetext{
300 Para mayor información sobre estos documentos, véase el apartado del capítulo 6 dedicado al análisis
} documental. 
las usuarias inmigrantes, el parto continúa produciéndose con relativa frecuencia (cada vez menor) en el ámbito doméstico, y en él participan, junto a la parturienta, principalmente familiares de sexo femenino y figuras sanadoras tradicionales (entre las cuales, se encuentran las conocidas como parteras).

Por lo que respecta a la postura adoptada durante el expulsivo, la práctica común en los hospitales españoles, así como en el hospital contexto de nuestro estudio, es que esta sea horizontal, y que la parturienta se encuentre tumbada sobre una mesa quirúrgica, apoyada sobre la cabeza, el torso y las nalgas y con las piernas levantadas. Sin embargo, algunas mujeres (no solo aquellas de origen extranjero) preferirían que se les permitiera adoptar otras posturas (verticales o en cuclillas), preferencia que la mayoría de los hospitales públicos en España, por las infraestructuras y los medios de los que disponen, no pueden contemplar. Se sigue, por tanto, un protocolo estándar, y no se atiende a las recomendaciones presentadas por los documentos citados, de acuerdo con los cuales, se debería, por un lado, permitir que las mujeres adoptasen la postura que espontáneamente prefirieran y, por otro, capacitar a los profesionales de la atención al parto para que pudieran trabajar estando la mujer en diferentes posiciones, así como estudiar las percepciones de las mujeres y los factores que influyen en la elección de las posiciones que adoptan (EAPN, 2007:40). ${ }^{301}$

Otra de las cuestiones que hemos tratado en nuestro estudio en relación con el parto se refiere al suministro de la anestesia epidural como método para aliviar el dolor. En general, por la información ofrecida tanto por los profesionales sanitarios como por las usuarias inmigrantes participantes en nuestra investigación, estas últimas suelen aceptar su aplicación, bien por decisión propia o porque el personal sanitario se lo recomienda, aunque esta, en última instancia, dependerá, entre otros factores, de los conocimientos previos que las usuarias tengan sobre esta técnica, de la percepción personal del dolor, y de la ausencia de barreras lingüísticas que permita a los profesionales explicar en qué consiste. No podemos afirmar rotundamente que se aliente a las mujeres a emplear este método, pero, por los datos de los que disponemos, ${ }^{302}$ en los últimos diez años se ha producido en el hospital contexto de estudio un importante incremento en su suministro, pasando del 73,7\% en el año 2001 al $88,7 \%$ en el año 2011. Cabe señalar al respecto que, de acuerdo con las recomendaciones de la EAPN (2007:38), este tipo de anestesia no se debería suministrar de manera rutinaria.

En relación con este tema han surgido en nuestra investigación dos cuestiones importantes a estudiar. La primera de ellas concierne a la información sobre este tipo de anestesia que toda mujer debería recibir antes de que se le suministrase, en la cual se deberían incluir los efectos y los riesgos que conlleva. Los profesionales sanitarios participantes en nuestro estudio, así como el centro hospitalario como institución, muestran una considerable preocupación por transmitir esta información a las usuarias, en parte por las consecuencias legales que podrían derivarse de alguna complicación que surgiera a raíz de su suministro. Como muestra de dicha preocupación, con el fin de superar las barreras lingüísticas que presentan algunas usuarias

\footnotetext{
301 Incluimos principalmente las recomendaciones del documento "Estrategia de atención al parto normal", ya que el resto de documentos citados, así como el plan de parto del propio hospital contexto de estudio, recogen dichas recomendaciones.

${ }^{302}$ Recordemos que los datos aportados por el hospital contexto de estudio no presentan disgregación por nacionalidad $u$ origen (autóctona/extranjera), por lo que no podemos saber si el recurso a la anestesia epidural como método de alivio del dolor durante el parto es más frecuente en las usuarias españolas o en las inmigrantes.
} 
inmigrantes por su desconocimiento del español, el hospital dispone de consentimientos informados sobre la anestesia epidural traducidos a las principales lenguas de las usuarias de origen extranjero. Si bien la traducción de estos documentos supone una actitud de (cierto) acercamiento a las necesidades de las usuarias, resulta, como comentaremos más adelante en el apartado dedicado a las barreras lingüísticas, un recurso insuficiente y, además, a nuestro parecer, está ampliamente motivado por un deseo de protección de los propios profesionales. ${ }^{303}$

Cabe realizar aquí un inciso y recordar de qué manera se instaura en los servicios sanitarios occidentales el empleo de los consentimientos informados. En el sistema biomédico, los profesionales de la salud han pasado de adoptar un enfoque paternalista al relacionarse con el enfermo, de acuerdo con el cual era el profesional quien, por los conocimientos de los que disponía, decidía según su criterio qué información necesitaba el paciente y cuáles eran las medidas terapéuticas más adecuadas en su caso, a incorporar el paradigma autonomista, con el que surge un nuevo perfil de enfermo, que cuenta con la capacidad de decidir, consentir o rechazar la propuesta de tratamiento que le plantee el profesional. Nace, de este modo, lo que se conoce como el derecho al consentimiento informado, el cual se ha ido configurando como una obligación legal en la mayoría de los países occidentales. Al respecto, cabe destacar que, el derecho a la información ( $y$, por ende, a tomar decisiones informadas), así como los tratamientos que enfatizan el rol del individuo en la recuperación de la salud propios del sistema médico occidental pueden entrar en conflicto con las expectativas de aquellos pacientes que consideran que la familia debe implicarse en dicha recuperación.

Enlazamos así con la segunda de las cuestiones que han surgido en nuestra investigación al tratar el tema de la anestesia epidural. En concreto, una gran mayoría de los profesionales entrevistados afirma que, a la hora de decidir si esta anestesia se va a suministrar o no, en el caso de las mujeres magrebíes (o, por extensión, las musulmanas), es el marido quien normalmente toma esta decisión, lo cual no le parece "correcto" (por llamarlo de algún modo) al personal sanitario que las atiende durante el parto. En su opinión, la parturienta, siendo ella la que percibe el dolor, es, por tanto, quien debe decidir si desea aliviarlo mediante este método o si, por el contrario, prefiere rechazarlo y dar a luz de un modo más natural. Para poder llegar a una conclusión en relación con este tema, era necesario que las propias implicadas (las mujeres magrebíes) pudieran expresar su opinión al respecto, de modo que se lo hemos planteado en el grupo de discusión celebrado con ellas. Su respuesta ante esta cuestión ha sido que, efectivamente, sus maridos participan a la hora de tomar esta decisión, pero que, en última instancia, son ellas quienes escogen optar por la aplicación de la anestesia o no. Su explicación de este comportamiento se basa en el hecho de que, en su cultura, las decisiones consideradas importantes se consultan y se toman en el seno de la familia. Por un lado, en este patrón cultural vemos la influencia de una cultura predominantemente colectivista, en la que el individuo basa su identidad en relación con su grupo (familiar o comunitario) de pertenencia. Por otro lado, este comportamiento se basa también en la asignación de unos roles determinados a las mujeres y a los hombres en cada cultura.

\footnotetext{
${ }^{303}$ De hecho, como se afirma en la "Estrategia de atención al parto normal" (2007:48-49), "la conformidad libre, voluntaria y consciente luego de recibir información (mediante el consentimiento informado) es utilizada habitualmente como instrumento jurídico, y no garantiza la participación activa de las usuarias en la toma de decisiones".
} 
Cabe destacar, en este caso, que, tanto si las mujeres magrebíes se apoyan en sus maridos a la hora de tomar decisiones de este tipo como si son ellos los que deciden, por la información y la actitud mostrada por las participantes en nuestro estudio, no parece que ellas estén en desacuerdo con este patrón de comportamiento, por lo cual, en nuestra opinión, deberíamos abandonar la posición etnocentrista que nos lleva a valorar como "justo/injusto", "adecuado/inadecuado" o "bueno/malo" los comportamientos y actitudes ajenos y permitir, siempre dentro de ciertos límites, que sean los propios miembros de cada cultura los que decidan de qué manera desean actuar en los casos en los que deben tomar decisiones que les afectan a ellos directamente. Dicho en otras palabras, si las mujeres desean usar la anestesia epidural o no, o si quieren tomar esta decisión autónomamente o teniendo en cuenta la opinión de sus maridos o familiares, se deberá, como recomienda la EAPN (2007:38-39), informar a las parturientas sobre los diferentes métodos de alivio del dolor existentes y, en todo caso, y siempre que no haya complicaciones que lo impidan, respetar la decisión que tome la mujer, quien es la principal implicada/afectada en el proceso de parto.

Siempre en relación con la anestesia epidural, por los relatos de las usuarias inmigrantes participantes en nuestro estudio, hemos sabido que algunas de ellas desearían poder caminar durante el proceso de dilatación anterior al parto, ya que opinan que esto podría ayudarles a acelerar el expulsivo. Sin embargo, de acuerdo con los profesionales sanitarios, una vez les suministran la anestesia, la posibilidad de poder caminar, o incluso de estar de pie, se elimina. Se desatiende, de este modo, la recomendación de contemplar la aplicación de la anestesia epidural sin bloqueo motor (EAPN, 2007:39), que permitiría a las mujeres que así lo deseasen conservar la movilidad mientras están dilatando.

Por lo que respecta a la expresión del dolor durante el parto, la gran mayoría de los profesionales sanitarios participantes en nuestra investigación señalan diferencias por colectivos. Así, opinan que las usuarias que manifiestan más abiertamente el dolor padecido son las mujeres procedentes de Latinoamérica y del Magreb. Además, algunos de ellos creen que, cuando el marido de estas usuarias está presente durante el parto, la expresión del dolor por su parte es más enfática. Al respecto, no hemos podido comprobar mediante la observación (por tratarse el parto de un momento tan íntimo que ni siquiera contemplamos la posibilidad de solicitar autorización para estar presentes durante el mismo) si efectivamente la presencia de los maridos provoca un mayor énfasis en la expresión del dolor en determinadas usuarias $y$, en dicho caso, cuáles son las causas que subyacen tras este comportamiento. Por otra parte, según los profesionales sanitarios, las usuarias que son menos expresivas o, al menos, se asemejan más al patrón español, son las procedentes de Europa, dentro de las cuales, destacan especialmente a las mujeres de Europa del este, las cuales, a su parecer, son muy "estoicas". Esta actitud menos enfática puede estar directamente relacionada con los patrones comunicativos propios de esta cultura concernientes al lenguaje no verbal, aspecto que trataremos en el próximo apartado, centrado en el estudio de las barreras que surgen en las interacciones interculturales en ámbito sanitario. Asimismo, una cuestión que ha señalado un gran número de profesionales sanitarios ha sido el hecho de que las usuarias procedentes de África Subsahariana presentan un comportamiento durante el parto que a ellos les resulta llamativo. En concreto, de acuerdo con los profesionales, estas mujeres suelen chasquear los dedos rítmicamente y repetir una letanía durante el parto $y$, aunque no saben dar una explicación de este comportamiento, creen que puede deberse a una intención de calmar el 
dolor padecido. Por los relatos de los profesionales sanitarios, podemos deducir que el comportamiento durante el parto por lo que se refiere a la expresión del dolor puede estar condicionado por factores culturales y sociales, a los que nosotros sumaríamos los factores personales, ya que la vivencia de este momento es sobre todo una cuestión individual.

Por otra parte, en relación con los tipos de parto, en general, en España, se ha producido un aumento del número de cesáreas en los últimos años, debido, entre otros factores, al aumento de la edad de las madres, el mayor número de partos múltiples y las demandas personales de algunas usuarias. Con relación a este último factor, algunos de los profesionales sanitarios participantes en nuestro estudio comentan que son especialmente las usuarias procedentes de Latinoamérica las que más suelen demandar que se les efectúe este tipo de parto. Desconocemos si este hecho relatado por los profesionales se da con tanta frecuencia como ellos sostienen, pues no disponemos de datos al respecto y, en caso de que así fuera, no sabemos los motivos que podrían conducir a estas usuarias a solicitar la cesárea, ni si son ellas quienes realizan más a menudo esta petición porque, al no deber enfrentarse a barreras lingüísticas, tienen mayores posibilidades de expresarse. Por el contrario, más que mostrar predilección por el parto por cesárea, la gran mayoría de las usuarias inmigrantes afirman que, a pesar de no haberse negado a que se la practicaran en caso de que los profesionales les hubiesen indicado que era necesario, preferían que el parto fuera normal, aduciendo diversas razones como, por ejemplo, que la recuperación y el malestar tras el parto por cesárea era mayor o, en el caso de las usuarias de África Subsahariana, por la creencia de que este tipo de parto, del que además se suele culpabilizar a la parturienta, puede causar problemas de infertilidad (cuando la fecundidad es un aspecto muy valorado en las mujeres procedentes de esta zona). Sin embargo, quisiéramos precisar que una de las entrevistadas de esta área de procedencia ha manifestado que se trataba de una creencia antigua, que poco a poco se había ido abandonando en su lugar de origen, lo cual es muestra, una vez más, del carácter cambiante de las culturas.

En referencia a los acompañantes durante el parto, en el hospital contexto de estudio, se suele aceptar la decisión al respecto que tome la parturienta, tal y como recomienda la "Estrategia de atención al parto normal" (2007). No obstante, el hecho de aceptar dicha decisión no siempre implica que se entienda o se respete, ya que algunos profesionales sanitarios manifiestan abiertamente su incomprensión (o incluso, en ocasiones, su desacuerdo) con la misma. Así, les resulta extraño el hecho de que algunas mujeres estén acompañadas por personas de fuera de su entorno familiar o íntimo. En este sentimiento de extrañeza está implícito un desconocimiento de las causas culturales, sociales y personales que pueden conducir a las usuarias inmigrantes a elegir a una determinada persona para que las acompañe durante el parto. Por ejemplo, en los casos de las usuarias inmigrantes cuyos conocimientos de español sean limitados, estas pueden decidir que sea alguien que domine este idioma (aunque no pertenezca a su familia) quien las acompañe, con el fin de facilitar su comunicación con los profesionales. En otras ocasiones, la falta de redes familiares en el país de acogida que posibilita que algunas personas las acompañen o se ocupen de otros hijos de la familia puede limitar sus opciones a la hora de elegir al acompañante, o incluso hacer que tengan que enfrentarse solas a este momento. 
Otra cuestión que provoca cierto asombro en los profesionales sanitarios se refiere al hecho de que los maridos de algunas usuarias musulmanas, en su opinión, muestran desapego hacia sus mujeres, y parecen no sentirse cómodos en el contexto del paritorio. Este comportamiento puede deberse al sentido del pudor y a los roles de género propios de esta cultura. De todos modos, cabe recordar que la implicación de los maridos en el proceso del parto es también bastante reciente en la cultura española, en la cual, hasta hace unas décadas, la vivencia de este proceso se asociaba a las figuras femeninas de la familia. En relación con este rol asignado a las mujeres, son numerosas las usuarias inmigrantes (de diferentes procedencias) las que han afirmado que habrían preferido estar acompañadas por sus madres o algún miembro femenino de sus familias durante el parto, pero que, al encontrarse estas en sus países de origen, no han podido contar con esta opción.

Un último aspecto en relación con el proceso del parto que investigamos en nuestro trabajo de campo concierne a la posible solicitud de la placenta o del cordón umbilical por parte de algunas usuarias inmigrantes. De acuerdo con los datos obtenidos, no se han dado prácticamente casos de mujeres de origen extranjero que los hubieran solicitado en el hospital contexto de estudio, lo cual puede deberse a que se trata de una costumbre que no comparten las comunidades de origen más frecuentes en el contexto de nuestra investigación. En caso de que se solicitara la placenta o el cordón umbilical, la gran mayoría de los profesionales sanitarios entrevistados afirma que no sabría exactamente cómo deberían comportarse, y unos pocos manifiestan que no podrían aceptar esta solicitud, puesto que, al tratarse de residuos biológicos, el hospital está obligado a eliminarlos. Algunos de ellos, por otra parte, comentan que este tipo de solicitudes se están viendo incrementadas no en las mujeres inmigrantes, sino en algunas autóctonas, que parecen decantarse por procesos de parto y costumbres en relación con el mismo más tradicionales o naturales y, por ello, acuden a dar a luz a hospitales privados donde las infraestructuras y la normativa les permiten cumplir con sus deseos y expectativas.

De estas respuestas podemos extraer dos conclusiones: en primer lugar, el desconocimiento sobre qué se debe hacer cuando una usuaria solicita la placenta o el cordón umbilical tras el parto puede provocar que, a discreción del profesional que lo atienda, se permita o se niegue a la usuaria que los solicita disponer de ellos. Por otro lado, el hecho de deber acudir a un hospital privado para poder tener un parto diferente al estándar excluye de esta posibilidad a un gran número de mujeres inmigrantes, considerando la situación socio-económica en la que se encuentran la mayoría de ellas. En ambos casos se trata, a nuestro parecer, de una forma de discriminación. Por último, de cara a futuro, cabría analizar si este tipo de solicitudes de un parto más natural/tradicional por parte de las usuarias autóctonas puede en cierto sentido empujar a los hospitales a comenzar a plantearse la posibilidad de adecuar sus infraestructuras y capacitar a su personal para que se pueda atender a las peticiones de las parturientas, algo de lo cual podrían beneficiarse también las usuarias inmigrantes que así lo desearan. ${ }^{304}$

\footnotetext{
${ }^{304}$ Recordemos que, como hemos señalado en el capítulo anterior, ya existe un número limitado de hospitales españoles que cumplen con las recomendaciones de la Estrategia Nacional de Atención al Parto Normal y que han sido acreditados con la certificación iHan (Iniciativa para la Humanización de la Asistencia al Nacimiento y la Lactancia), promovida por la Organización Mundial de la Salud y UNICEF. Para mayor información, visítese la página web: [http://www.ihan.es/index1.asp] (última consulta: 16 de agosto de 2013).
} 


\section{El puerperio}

La primera cuestión relativa al puerperio analizada en nuestro estudio se refiere a los momentos inmediatamente posteriores al parto. De acuerdo con las recomendaciones de los diferentes documentos relativos al parto y el nacimiento que hemos mencionado previamente, se debe favorecer el contacto prematuro (piel con piel) entre la madre y el recién nacido, puesto que dicho contacto estrecha el vínculo madre-hijo, reduce el estrés de este último tras el nacimiento y fomenta la lactancia materna. Sin embargo, por los relatos ofrecidos por los profesionales participantes, algunas usuarias inmigrantes, especialmente las procedentes de África Subsahariana y Asia, parecen no desear que se establezca este contacto, lo cual es interpretado por el personal sanitario como una falta de cariño, algo que, en muchas ocasiones les resulta incomprensible. Solo algunos de estos profesionales, en el afán de comprender este comportamiento diferente, han tratado de averiguar las causas subyacentes al mismo, y nos relatan que, de acuerdo con lo que les han comentado en algunos cursos de formación sobre patrones culturales o lo que les han contado otros compañeros, este puede deberse a un deseo de protección del recién nacido por parte de las madres, por ejemplo, para evitar el mal de ojo o tratar de no llamar la atención de espíritus malignos.

Efectivamente, en algunas culturas, se cree que determinados comportamientos tras el parto (como evitar el contacto con el recién nacido, no expresar abiertamente sus características positivas o colocarle amuletos) son un modo de protección del recién nacido. Observamos de nuevo cómo, cuando las pautas comportamentales difieren de las comunes en el seno de la sociedad de acogida, suelen producirse malinterpretaciones motivadas por la valoración de los comportamientos ajenos desde los referentes de la propia cultura. Así, por ejemplo, estas actitudes se consideran una falta de interés y de amor maternal, o una falta de higiene en el caso de los amuletos mencionados.

En primer lugar, cabe señalar que el amor maternal, por mucho que se opine lo contrario, no es algo innato y, sobre todo en los momentos inmediatamente posteriores al parto, por el estrés postraumático que este puede provocar o por la situación novedosa en la que se encuentran las madres, es posible que dicho amor no se manifieste tan abiertamente como cabría esperar. Asimismo, un acercamiento a los patrones propios de otras culturas nos haría comprender que, en algunos casos, más que una falta de interés o amor por el recién nacido, estos comportamientos se originan por todo lo contrario, es decir, por un deseo de protección. En resumen, consideramos que se debería informar a las madres de los efectos beneficiosos que conlleva el contacto prematuro, pero, en todo caso, y como recomienda la EAPN (2007:44), permitir y respetar que sea la propia madre quien decida qué tipo de contacto desea establecer con el recién nacido en el momento inmediatamente posterior al parto.

Una vez las mujeres dan a luz, suelen permanecer en el hospital un periodo breve de tiempo, que va desde uno o dos días en el caso de las madres cuyo parto ha sido normal, a unos cuatro o cinco días en los casos en los que se han producido complicaciones durante el parto y, por ejemplo, se ha debido practicar una cesárea, o cuando las condiciones de salud de la madre o el niño exigen que estos reciban asistencia y cuidados médicos. En nuestra investigación, hemos estudiado algunas cuestiones relativas al comportamiento y las actitudes de las 
usuarias inmigrantes durante dicho periodo de tiempo, de cuyo análisis nos ocupamos a continuación.

En primer lugar, con relación a las visitas que las usuarias reciben durante el puerperio, se plantean dos tipos de comportamiento que resultan llamativos para algunos profesionales sanitarios. Por un lado, de acuerdo con los profesionales sanitarios, algunas mujeres inmigrantes (las menos) reciben numerosas visitas, en ocasiones incluso por parte del resto de hijos de la familia. La presencia de menores en el hospital no siempre es comprendida por el personal sanitario, quizás porque no son capaces de ponerse bajo la piel del Otro y comprender que puede estar originada por la imposibilidad de dejar a sus hijos al cuidado de otras personas al carecer de redes sociales y familiares de apoyo. Las numerosas visitas que reciben las puérperas de determinadas comunidades (algo que se produce, de acuerdo con los profesionales, especialmente en el caso de las mujeres procedentes de Latinoamérica o aquellas pertenecientes a la comunidad gitana) pueden responder al carácter colectivista de sus culturas, en las que se espera que la familia (entendida no solo en sentido nuclear, sino como familia extensa) participe y acompañe cuando se dan este tipo de acontecimientos tan significativos como puede ser el nacimiento. Sin embargo, lo más común, tanto por los datos que nos han proporcionado profesionales y usuarias como por lo que hemos podido observar en el trabajo de campo, es que las mujeres inmigrantes se encuentren solas durante su estancia hospitalaria, precisamente porque carecen de extensas redes familiares y sociales en el país de acogida, y los familiares que sí residen aquí deben atender sus obligaciones laborales y disponen, por tanto, de poco tiempo para poder dedicarlo a sus familias.

Precisamente esta ausencia de redes familiares provoca un cambio de roles en el seno de la familia del que nos han hecho partícipes algunas de las usuarias inmigrantes. En concreto, estas relatan que, en sus respectivos países de origen, es habitual que sean las figuras femeninas de la familia (especialmente las madres) las que se encarguen de ayudar a las mujeres que acaban de dar a luz en sus propios cuidados y en los del recién nacido. Sin embargo, por la ausencia de estas figuras femeninas, quienes normalmente continúan residiendo en el país de origen, en numerosos casos, ha debido ser el padre de familia quien se ocupara en el país de acogida de estos cuidados, modificando su comportamiento con respecto a los roles más comúnmente atribuidos al hombre en su cultura.

Además del tema de los cuidados y la ayuda por parte de la familia, existen otras costumbres que se siguen durante el puerperio en determinadas culturas. Usuarias de diferentes procedencias (Asia, el Magreb, Latinoamérica, África Subsahariana) nos relatan diferentes comportamientos que, en sus comunidades de origen, se suelen producir en el periodo posterior al nacimiento. Entre ellas, citan la costumbre de evitar el frío para recuperar el calor perdido durante el parto (manteniendo, así, el equilibrio perdido), de modo que las madres evitan ducharse, permanecen tapadas (aun cuando sea verano y la temperatura ambiental sea bastante elevada, como pudimos comprobar durante la observación), y evitan ingerir determinados alimentos o consumen preferentemente otros. En relación con los hábitos alimentarios, las usuarias citan algunos alimentos que las madres suelen comer tras el parto con el fin de obtener beneficios adicionales, como aumentar la producción de leche materna o evitar que se produzcan gases en los niños. Es tan breve el espacio de tiempo que pasan las mujeres ingresadas en el hospital tras el parto que, por lo general, los menús que les ofrecen 
en el mismo no suelen ser un problema. Además, cabe señalar que el hospital ha realizado un esfuerzo por adaptarse a las particularidades de las usuarias, ofreciendo diferentes alternativas dentro de los menús, entre las cuales, por ejemplo, se encuentra la posibilidad de escoger un menú que no contenga carne, algo de lo que pueden beneficiarse las mujeres musulmanas. Sin embargo, la falta de un conocimiento profundo de los patrones culturales, en algunas ocasiones, ha causado algún conflicto. En concreto, tal y como nos relatan tanto algunas usuarias musulmanas como algunos profesionales, se han dado casos en los que, a pesar de que la madre había elegido un menú que no contuviese carne (en especial si esta era de cerdo), le habían dado platos que sí la contenían (como croquetas, lentejas o tortilla con jamón, ese alimento tan typical Spanish que nos resulta difícil comprender que no se aprecie).

En nuestra investigación, nos hemos ocupado también de analizar, en relación con el puerperio, la cuestión de la lactancia materna. Por los datos ofrecidos tanto por los profesionales sanitarios como por las usuarias inmigrantes, la gran mayoría de estas últimas suele optar por amamantar al recién nacido, algo que en el hospital contexto de estudio se trata de favorecer, por los beneficios que este tipo de lactancia, de acuerdo con estudios científicos y de conformidad con las recomendaciones que se ofrecen en los documentos sobre parto y nacimiento citados, puede proporcionar al recién nacido. La única comunidad que, según los profesionales, es más reacia a dar el pecho a los recién nacidos es la procedente de China. En su opinión, esto se debe a que la mayoría de las madres de esta procedencia suelen enviar a sus hijos al país de origen poco después del nacimiento, dato que no hemos podido corroborar en nuestro estudio. Otra de las causas del recurso a la lactancia artificial en este colectivo podría ser la imposibilidad de las madres de origen chino de dar el pecho a los recién nacidos, por sus horarios y cargas laborales y su incorporación casi inmediata al trabajo tras el parto. De todos modos, según nos relatan algunos profesionales, esta pauta de comportamiento está cambiando en los últimos tiempos, y las madres de origen chino optan cada vez más por la lactancia materna, equiparándose de este modo al resto de usuarias inmigrantes, quienes se muestran muy favorables a este tipo de lactancia. Para algunas de estas madres, el poder amamantar a sus hijos es incluso algo de vital importancia, y nos comentan que les afectaría muy negativamente el hecho de no poder hacerlo. Además, algunas usuarias inmigrantes afirman que han prolongado en el pasado o piensan prolongar con el recién nacido la lactancia materna durante un periodo de hasta los dos años, algo recomendado, por ejemplo, en el Islam, pero también en documentos publicados por la Organización Mundial de la Salud y UNICEF, en los que se aconseja alargar este tipo de lactancia por los beneficios que aporta a la salud de la madre y el hijo, y como herramienta para espaciar los embarazos. En nuestra opinión, en el caso de las madres que desconozcan estos beneficios, es labor de los profesionales sanitarios informarles sobre los mismos y ayudarles en la medida de lo posible, si desean optar por la lactancia materna, a que esta se produzca, pero respetando en todo caso y como se sugiere en la EAPN (2007:45-46) la decisión de aquellas madres que deseen optar por la lactancia artificial, algo, que, según hemos podido comprobar en nuestro trabajo de campo, se cumple en el caso del hospital contexto de estudio.

En cuanto al periodo de estancia hospitalaria de las puérperas, hemos analizado otros dos aspectos en nuestra investigación. El primero de ellos se refiere al (in)cumplimiento de las normas del hospital. De acuerdo con los profesionales sanitarios participantes en el estudio, 
en general, las usuarias inmigrantes suelen cumplir las normas establecidas en el centro, y la mayoría son conscientes de que, en caso de no hacerlo, esto puede deberse a su desconocimiento del funcionamiento del hospital. Por el contrario, los profesionales opinan que son principalmente las gestantes y puérperas autóctonas quienes suelen ser más "incumplidoras", quizás porque conocen más los derechos de los que, como usuarias, se pueden beneficiar. Tampoco durante el trabajo de campo hemos podido observar episodios en los que se hubiera producido algún conflicto por el incumplimiento de las normas del hospital por parte de alguna usuaria inmigrante, excepto algún caso aislado. Cabe, de todos modos, señalar, que el hospital contexto de estudio presenta unas normas de funcionamiento bastante flexibles en cuanto a cuestiones como los horarios de visitas o el número de acompañantes, algo de lo que se pueden beneficiar todas las usuarias en su conjunto, independientemente de la procedencia de las mismas.

Para finalizar, una última cuestión de la que se deben ocupar las usuarias antes de abandonar el hospital se refiere al registro de los recién nacidos. ${ }^{305}$ Son numerosas las usuarias inmigrantes que se deben enfrentar a obstáculos a la hora de cumplir con este trámite administrativo: por un lado, se encuentran las barreras lingüísticas, en el caso de las usuarias alófonas; por otro, existen barreras culturales, en el caso de las usuarias que proceden de países en los que el sistema de registro funciona diversamente, o en los que las costumbres en cuanto uno de los datos que se deben aportar en dicho registro (el nombre y los apellidos del recién nacido) difieren de las propias de la sociedad de acogida. Así, por ejemplo, en algunas comunidades solo se utiliza el apellido del padre, los apellidos se colocan en un orden diferente al que suele seguir en España, o los nombres que se pueden dar al recién nacido se alejan bastante del "modelo tradicional" en las sociedades occidentales o europeas. ${ }^{306}$

Aparte de estas cuestiones relativas a los datos que se deben aportar en el documento para registrar al recién nacido, existen otras costumbres que pueden contrastar con la normativa propia de nuestro país en cuanto al registro. En concreto, de acuerdo con algunas usuarias inmigrantes (principalmente procedentes de África Subsahariana), se suele dar el nombre a los recién nacidos transcurridos unos días después del nacimiento (unos ocho días, según nos relataron algunas usuarias), costumbre que no les resulta posible seguir en la sociedad de acogida, al deber incluir el nombre en el documento de registro que se debe entregar antes de abandonar el hospital.

Antes de pasar a analizar las barreras que surgen en las interacciones interculturales en el ámbito de la salud reproductiva, para concluir este apartado relativo a la cultura sanitaria y, en especial, a los patrones asociados al proceso de reproducción, quisiéramos resaltar la gran

\footnotetext{
${ }^{305}$ Cabe mencionar que, en principio, pensamos en incluir también el estudio de los patrones de comportamiento de las usuarias inmigrantes con relación a la vacunación de sus hijos y, de hecho, fue uno de los temas planteados en las entrevistas en relación con la fase del puerperio. Sin embargo, hemos descubierto que la vacunación tiene lugar en los centros de salud, por lo que prácticamente ningún participante en la investigación ha podido proporcionar información al respecto, excepto algunas usuarias inmigrantes que sostienen haber seguido los programas de vacunación con sus hijos previos. Esta cuestión podría incluirse en futuras investigaciones centradas en el contexto de los centros de salud, al igual que el tema de la planificación familiar y los cursos de preparación al parto de los que hemos hablado anteriormente.

${ }^{306}$ Recordemos el caso de una usuaria procedente de Brasil que nos comentó como, en su país de origen, se habían dado casos de padres que habían elegido para sus hijos nombres muy "originales", como Facebookson, por haberse conocido la pareja a través de esta red social.
} 
influencia que los factores culturales, sociales y personales de cada madre ejercen sobre su percepción y su vivencia del embarazo, el parto y el puerperio. Solo un acercamiento humano, personalizado $\mathrm{y}$ en el que se permita que las usuarias participen y tomen decisiones informadas, y se respeten estas últimas, hará que la asistencia a las gestantes, las parturientas y las puérperas responda a sus necesidades $y$, en definitiva, sea satisfactoria para todas las partes implicadas.

\subsubsection{Barreras en las interacciones comunicativas en el ámbito de la salud}

Tal y como hemos comentado repetidamente en anteriores capítulos, nuestra investigación se centra en el estudio de la comunicación intercultural entre profesionales sanitarios y usuarias inmigrantes. La primera cuestión a señalar en relación con la comunicación intercultural, entendida como la interacción comunicativa cara a cara que se da entre personas procedentes de diferentes países y culturas, es que en ella entran en juego numerosos aspectos, entre los que se encuentran la cultura, los sistemas de valores, las diferentes percepciones del tiempo y el espacio, las creencias, los ritos, las costumbres y, por supuesto, la lengua y los modelos conversacionales de los interlocutores.

En todo acto comunicativo, incluso en aquel que se establece entre personas procedentes de una misma cultura, pueden surgir malentendidos y conflictos, pero la probabilidad de que esto ocurra es mayor cuando quienes entablan una conversación presentan referentes culturales diferentes.

En relación con el ámbito que nos ocupa, el ámbito sanitario, la comunicación intercultural presenta una serie de características adicionales en comparación con la comunicación en contextos coloquiales, que están determinadas, entre otros factores, por el entorno específico en el que la interacción comunicativa tiene lugar, por las particularidades de los interlocutores, y por la relación que se establece entre los mismos.

Por lo que respecta al entorno, el ámbito sanitario abarca diferentes áreas destinadas al cuidado de la salud, en las que las interacciones se suelen encuadrar dentro de un complejo cuadro de malestar físico y psicológico y, en ocasiones, cargado de sentimientos de miedo, padecimiento y dolor. Cabe resaltar, de todos modos, que el contexto específico en el que se ha desarrollado nuestra investigación presenta características que lo diferencian de otros ámbitos hospitalarios, ya que, si no surgen complicaciones y tanto la madre como el niño gozan de buena salud (lo cual suele ser lo más habitual en embarazos controlados y que han seguido una progresión normal), los acontecimientos que en este contexto tienen lugar suelen ser recibidos positivamente.

En cuanto a los implicados en las interacciones comunicativas en ámbito sanitario, se debe tener en cuenta que, por lo general, se establece una relación asimétrica entre los profesionales de la salud y los pacientes, en la cual los profesionales se encuentran en una posición de mayor poder, principalmente por los conocimientos de los que disponen (tanto por lo que se refiere a los conocimientos científicos, como por lo que respecta a los conocimientos del medio en el que tiene lugar la interacción). ${ }^{307}$ Esta posición de superioridad

\footnotetext{
307 Quisiéramos destacar que esta asimetría, según las usuarias inmigrantes y los profesionales participantes en nuestro estudio, así como de acuerdo con los datos que hemos podido recoger durante la observación, es menor en
} 
puede conducir a los profesionales sanitarios a tratar de imponer sus patrones de comportamiento (incluido el comportamiento comunicativo) y a interpretar el patrón comportamental ajeno según los parámetros institucionales y/o personales.

Si a estas características del entorno y los participantes en la interacción comunicativa en ámbito sanitario sumamos las barreras lingüísticas y culturales que pueden surgir en el caso de los pacientes de origen extranjero, "el plato de la incomunicación intercultural", como veremos a continuación, está servido.

Las barreras que se suelen presentar en las interacciones comunicativas entre los profesionales sanitarios y las pacientes inmigrantes están causadas principalmente por dos tipos de factores: la ausencia de una lengua común, por un lado, y las diferencias en los modelos conversacionales de los interlocutores, por otro.

Desde el principio de nuestro trabajo de campo, la dificultad más señalada por lo que respecta a la asistencia sanitaria a usuarias inmigrantes ha sido, sin duda, aquella provocada por las barreras lingüísticas causadas por la ausencia de una lengua común. De ahí deriva el hecho de que la mayoría de las soluciones implantadas hasta el momento en el hospital contexto de estudio, como veremos en el próximo apartado, persigan superar dicha barrera.

Además, cabe recordar que, de acuerdo con la Ley General de Sanidad 14/1968, de 25 de abril, todo paciente tiene derecho a "que se le dé en términos comprensibles información completa y continuada, verbal [sic] y escrita, sobre su proceso, incluyendo diagnóstico, pronóstico y alternativas de tratamiento", por lo que, desde un punto de vista legislativo, se debería hacer todo lo posible para garantizar que los usuarios de los servicios sanitarios españoles, independientemente de su origen, pudieran disfrutar de este derecho.

Por los datos obtenidos en nuestra investigación, son numerosos los casos en los que los profesionales sanitarios y las usuarias inmigrantes no comparten una lengua común. Por lo que respecta a las usuarias, algunas de ellas presentan escasos o nulos conocimientos de español, por lo cual a menudo deben recurrir a familiares o amigos para que realicen tareas de interpretación y les ayuden a comunicarse con el personal del hospital, con las consecuencias nefastas que, como veremos en el próximo apartado, el recurso a estos intérpretes ad hoc puede conllevar. De acuerdo con los profesionales participantes en nuestro estudio, son las usuarias procedentes de Asia, África Subsahariana y el Magreb las que suelen presentar un mayor desconocimiento del español, especialmente en los casos de las usuarias que residen en España desde hace relativamente poco tiempo o el de aquellas que, por sus condiciones socioeconómicas o por sus patrones culturales, viven en una situación de aislamiento $y$, por consiguiente, establecen pocas relaciones con los ciudadanos de la sociedad de acogida y disponen de escasas posibilidades para asistir a cursos de español. Los profesionales sanitarios comentan, sin embargo, que con las usuarias de Latinoamérica y las de Europa del este este tipo de barrera no se suele presentar, en el caso de las primeras, por compartir la misma lengua $y$, por lo que se refiere a las segundas, porque estas, por lo general, aprenden rápidamente el español (en parte porque las semejanzas entre este idioma y sus lenguas

el caso de determinadas figuras profesionales (como las matronas y las enfermeras), las cuales suelen presentar una actitud más cercana y empática con las usuarias. 
maternas). De todos modos, como analizaremos con más detalle en las siguientes páginas, compartir una lengua no es sinónimo de éxito en la comunicación intercultural, ya que en ella intervienen también, entre otros factores, las diferencias culturales y las relativas a los modelos conversacionales de los interlocutores.

Ante el escaso o nulo conocimiento de español por parte de algunas usuarias inmigrantes, los profesionales sanitarios podrían recurrir al empleo de lenguas extranjeras para comunicarse con ellas. Sin embargo, las lenguas extranjeras que los profesionales participantes en nuestro estudio "dominan" no se corresponden con las lenguas maternas de las principales comunidades inmigrantes residentes en el contexto de estudio y, en el caso de otras lenguas, como el inglés o el francés, los conocimientos de las mismas por parte de los profesionales son insuficientes para garantizar que la comunicación sea efectiva.

En general, podemos decir que los profesionales sanitarios presentan dos actitudes diferentes en relación con las barreras provocadas por la ausencia de una lengua común. Por una parte, algunos consideran que estas barreras no constituyen un obstáculo importante, ya que opinan que pueden emplear otras estrategias para comunicarse con las usuarias alófonas, como el empleo a los gestos y expresiones faciales o el recurso a familiares y amigos de las usuarias para que realicen labores de interpretación. Por otra parte, un gran número de profesionales sanitarios creen que la ausencia de una lengua común, sumada a la presión asistencial a la que se ven sometidos y que les obliga a que las consultas se desarrollen de un modo muy rápido, les impiden establecer una comunicación efectiva con estas usuarias, ante lo cual muestran gran preocupación. Este segundo grupo de profesionales piensa que resulta muy difícil que las usuarias en estas condiciones puedan expresar claramente su malestar, sus inquietudes y sus dudas. Opinan, además, que para ellos resulta complicado (por no decir imposible) poder explicar las técnicas y los tratamientos aconsejados y los riesgos que estos conllevan, todo lo cual puede repercutir muy negativamente en la asistencia sanitaria prestada. Así lo confirman también numerosos estudios sobre comunicación intercultural en el ámbito sanitario, entre los cuales podríamos citar aquellos que sostienen que sin un uso efectivo de la lengua, la relación entre el médico y el paciente se ve considerablemente perjudicada (Woloshin et al., 1995:727); que el profesional de la salud debe comunicarse con el paciente para conocer sus problemas, sus necesidades y sus preocupaciones, así como para informarle y ofrecerle recomendaciones en cuanto a sus cuidados (Hornberger et al., 1996:846); que está ampliamente reconocida la importancia de la comunicación entre el paciente y el médico a la hora de establecer el diagnóstico y asegurar el cumplimiento de las terapias (Jacobs et al., 2001:468); y que la comunicación efectiva entre el paciente y el médico es fundamental para garantizar los buenos resultados asistenciales (Collins et al., 2002:9).

Igualmente, estas dificultades en la comunicación provocan en ambos interlocutores (los profesionales sanitarios y las usuarias inmigrantes alófonas) sentimientos de hastío, frustración, desconfianza y enfado, que conllevan mayores problemas en su relación.

De todos modos, cabe mencionar que la presencia de este tipo de barreras lingüísticas, según los participantes en nuestro estudio, puede resultar más grave en situaciones y áreas del hospital en las que la importancia de la comunicación efectiva entre los profesionales y las 
usuarias es mayor, como, por ejemplo, en las urgencias o cuando se van a aplicar técnicas que pueden conllevar ciertos riesgos, como es el caso del suministro de la anestesia epidural.

Existen otras cuestiones de carácter lingüístico que pueden conllevar dificultades en la comunicación en ámbito sanitario. La primera de ellas concierne a lo que autores como Salvatore Geraci y Riccardo Colasanti (1995:71) denominan nivel pre-lingüístico, el cual se refiere a la incomprensión que puede derivar de la dificultad de manifestar y comunicar las sensaciones internas. Este obstáculo no se presenta exclusivamente en las relaciones interculturales, ya que la dificultad de reconocer y expresar este tipo de sensaciones es más bien una experiencia difundida; no obstante, en el ámbito intercultural, se agrava, en parte porque la relación con la propia interioridad puede variar de una cultura a otra.

La terminología médica es otro aspecto lingüístico que puede dificultar la comunicación en ámbito sanitario. No obstante, por los resultados de nuestra investigación, en el contexto estudiado no suele suponer un problema, ya que se recurre con poca frecuencia al empleo de tecnicismos $y$, en caso de que su utilización sea necesaria, se suelen acompañar de explicaciones en un lenguaje estándar para facilitar su comprensión.

En nuestro estudio hemos hecho también referencia al lenguaje escrito, por considerar inicialmente que para las usuarias inmigrantes podía resultar difícil la comprensión del mismo. Sin embargo, la mayoría de las participantes afirman que este les resulta más fácil de entender, algo que no puede aplicarse al caso de las usuarias inmigrantes analfabetas que, evidentemente, no podrán entender los mensajes que los documentos escritos contengan. De todos modos, por los relatos ofrecidos por las participantes en la investigación, tanto las usuarias que no saben leer y escribir como aquellas que presentan un desconocimiento de español cuentan con la posibilidad de consultar a personas de su comunidad que dominan este idioma o de apoyarse en otras estrategias que faciliten la comprensión de los documentos escritos, como el uso de diccionarios bilingües.

En anteriores párrafos hemos analizado de qué manera puede afectar la ausencia de una lengua común a la comunicación intercultural en ámbito sanitario. Nuestra pregunta ahora es la siguiente: ¿Solo surgen problemas comunicativos cuando los interlocutores no hablan una misma lengua 0 , por el contrario, podrían otros elementos implícitos en la comunicación plantear obstáculos para conseguir la plena eficacia de la misma? Trataremos de responder a estas cuestiones en el análisis de los modelos conversacionales que realizamos a continuación.

En primer lugar, cabe considerar que, al comunicarnos, no solo transmitimos mensajes verbales, sino que en la interacción intervienen una serie de elementos lingüísticos y extralingüísticos, a los que se suman los valores psicológicos, emotivos, individuales y sociales de los interlocutores. Por otro lado, del mismo modo en que cada comunidad organiza sus relaciones sociales, también regula sus interacciones mediante una serie de normas que comparten los miembros de la misma, y que establecen, dependiendo de la situación y el contexto comunicativos, quién puede hablar, en qué momento puede hacerlo, de qué, cómo y con quién. En el proceso de enculturación, por tanto, no solo aprendemos una lengua, sino también una serie de pautas que nos indican qué se espera de nosotros y qué podemos esperar de nuestros interlocutores en una determinada situación y, en base a dichas pautas, 
optaremos por emplear una lengua, una variedad y unos usos específicos, y seguiremos un modelo conversacional concreto.

Son diversas las clasificaciones o taxonomías de los modelos conversacionales que estudiosos de la comunicación intercultural han propuesto, ${ }^{308}$ en las cuales se ofrecen definiciones y categorizaciones de los patrones comunicativos y culturales, y se explica la interrelación que existe entre dichos patrones. Por otro lado, pese a que asocian determinados modelos comunicativos a algunas culturas, los autores de estas taxonomías suelen coincidir en que el modelo conversacional adoptado dentro de una misma cultura variará dependiendo de la situación comunicativa y de las características individuales de los participantes en la interacción. Al mismo tiempo, cabe recordar que las culturas son interiormente plurales, y precisamente un ejemplo de la diversidad intracultural es el estilo comunicativo propio de cada uno de los individuos de una misma comunidad. De hecho, la comunicación en general, incluso aquella que se establece entre personas que comparten un mismo origen cultural, no siempre fluye con facilidad y, a menudo, se genera cierto malestar entre los interlocutores, surgen malentendidos, incomprensiones o conflictos que pueden impedir que esta sea eficaz. Sin embargo, como hemos comentado previamente, en los casos en los que los interlocutores proceden de culturas diferentes, es más probable que se den estas situaciones; como sostiene Miquel Rodrigo Alsina (2000:7), en la comunicación intercultural se debe asumir que "el malentendido puede ser la norma y no la excepción".

La gravedad de los problemas comunicativos en las interacciones interculturales reside principalmente en el carácter inconsciente de los mismos, en el hecho de que percibimos el malestar o la frustración que estos problemas nos provocan, pero no somos capaces de identificar la causa de los mismos (Raga, 2006b:222). Así, mientras nos resulta evidente que, ante la ausencia de una lengua común, existen enormes dificultades para podernos comunicar, no solemos apreciar o considerar las posibles diferencias en los modelos conversacionales, las cuales se refieren a cuestiones relativas, por una parte, a los usos verbales (como, por ejemplo, las formas de hablar directas o indirectas, el grado de formalidad, o la cantidad y tipo de información que se intercambia) y, por otra, a los usos no verbales (como, por ejemplo, la distribución de los turnos de palabra, o el contacto físico y visual entre los interlocutores).

Las interacciones comunicativas tienen un carácter efímero y orquestal y, además, en ellas se presentan una gran multitud de datos simultáneamente, por lo que muchos de ellos pueden pasar desapercibidos ante los ojos de los propios interlocutores. Ese carácter inconsciente de los diferentes elementos que intervienen en la comunicación, unido a la interpretación subjetiva que puede realizarse de dichos elementos, conlleva que los datos relativos a los modelos conversacionales que hemos recogido en nuestra investigación (tanto mediante las entrevistas y los grupos de discusión como durante la observación) no siempre sean exhaustivos y deban ser considerados con cautela. Para futuras investigaciones, creemos que podríamos enriquecer el análisis de los usos verbales y no verbales presentes en las interacciones comunicativas entre profesionales sanitarios y usuarias inmigrantes mediante la

\footnotetext{
${ }^{308}$ Véase el capítulo 3, centrado en el estudio de la comunicación intercultural, para obtener mayor información sobre la clasificación de los modelos conversacionales propuesta por autores como Edward T. Hall (1976), Geert H. Hofstede (1991) y Francisco Raga (2006a).
} 
grabación (audio)visual de dichas interacciones, lo cual, si bien no eliminaría la subjetividad inherente en la interpretación, al menos permitiría un análisis reiterativo y más pausado. ${ }^{309}$

Tras esta breve introducción, pasamos a continuación a presentar las conclusiones que hemos podido extraer en relación con las diferencias existentes en los modelos conversacionales de los profesionales sanitarios y las usuarias inmigrantes sujetos de nuestro estudio.

Por lo que respecta a los usos verbales, basamos nuestro análisis en el principio de cooperación y las máximas conversacionales propuestos por Paul H. Grice (1975). De acuerdo con dicho principio, al instaurar una conversación, adecuamos nuestra contribución comunicativa a un contexto, una situación y un interlocutor (o interlocutores) concretos, de acuerdo con las normas (o máximas) que hemos interiorizado en el seno de una comunidad cultural. En consecuencia, adaptamos nuestro comportamiento comunicativo ofreciendo la información que, a nuestro parecer, resulta justa, pertinente, veraz y clara, de manera que se garantice el éxito de la comunicación. El grado de aplicación de dichas máximas puede variar de una cultura a otra, lo cual, sumado al hecho de que normalmente interpretamos el comportamiento de nuestro interlocutor de acuerdo con las normas conversacionales de nuestra propia cultura, conllevará que en las interacciones interculturales se produzcan con frecuencia las situaciones de malestar, frustración e incomprensión de las que hemos hablado anteriormente.

Con respecto a la máxima de cantidad y, más concretamente, a la cantidad de información que ofrecen las usuarias inmigrantes al entablar conversaciones con los profesionales sanitarios, tanto por la opinión de estos últimos como por lo que hemos podido observar, en general, estas usuarias no suelen ofrecer mucha información, debido a los escasos conocimientos de español que poseen algunas de ellas y, quizás, también en parte a la rapidez con la que se suelen producir las consultas. De hecho, hemos observado que, en los casos de aquellas usuarias cuyos conocimientos de español son "aceptables", estas suelen manifestar más abiertamente sus pensamientos, dudas y opiniones. Por otra parte, la cantidad de información transmitida puede estar igualmente fundamentada en la relación asimétrica que se establece entre las usuarias inmigrantes y el personal sanitario, así como en los valores sociales implícitos en la situación comunicativa. En efecto, son normalmente los profesionales, desde su posición de superioridad, los que transmiten un mayor número de mensajes verbales, realizan más preguntas $u$ ofrecen más explicaciones. Sin embargo, a ninguno de los grupos de sujetos estudiados les parece que no sea justa la cantidad de información que ellos mismos o sus interlocutores proporcionan, probablemente porque la consideran adecuada al contexto y los participantes en la situación comunicativa concreta. Sin embargo, podría darse el caso de una usuaria inmigrante que, en base a los patrones comunicativos propios de su cultura de origen, esperara que el profesional sanitario español le diera más o menos información de la que le ofrece, o que le permitiera a ella misma dar más detalles de los que tiene la posibilidad de aportar. También podría suceder que el profesional sanitario español se sintiera abrumado al recibir por parte de una usuaria inmigrante una cantidad de información, en su opinión, desmesurada 0 , al contrario, que considerase esta información excesivamente escasa y, en

309 Como muestra del enriquecimiento que conlleva la grabación de las interacciones en el análisis de la comunicación intercultural en ámbito sanitario, véanse los trabajos de Claudia V. Angelelli (2004) o de Carmen Valero (2005). 
base a sus propios patrones comunicativos, interpretara esta escasez, por ejemplo, como una muestra del desinterés o de la poca colaboración de su interlocutora.

En referencia a los temas tratados en las interacciones, algunos profesionales sostienen que las cuestiones planteadas a las usuarias se centran exclusivamente en el estado físico de la madre y el hijo, por lo que, en principio, no creen que estas puedan ser consideradas demasiado personales o delicadas. En esta interpretación del carácter de la información, estos profesionales no tienen en cuenta que, en las culturas de origen de las usuarias, los temas considerados íntimos o incluso tabúes no tienen por qué ser los mismos que en la sociedad de acogida. Por el contrario, la gran mayoría de los profesionales participantes afirma que han percibido en algunas usuarias inmigrantes cierta incomodidad o incluso reticencia al tratar determinados temas relacionados, por ejemplo, con las enfermedades infecciosas, los abortos y embarazos previos, la menstruación, los aparatos genitales, las relaciones sexuales o la mutilación genital femenina. Dentro de los diferentes colectivos en los que han observado este tipo de comportamiento, destacan a las mujeres procedentes del Magreb, las cuales, de acuerdo con los patrones comunicativos que suelen aplicar en las interacciones en ámbito sanitario, tal y como hemos señalado en el capítulo 3, por lo general evitan intercambiar información comprometida con los profesionales de la salud, especialmente en el caso de que estos sean de sexo masculino, por el sentido del pudor y la distribución de los roles de género propios de su cultura. Cabe señalar, de todos modos, que, pese a que algunas usuarias inmigrantes pueden sentirse incómodas cuando surgen en las conversaciones en ámbito sanitario temas considerados delicados o tabúes, la gran mayoría, de acuerdo con los datos recabados en nuestro estudio, parece comprender que la situación comunicativa y los fines que se persiguen en la interacción requieren abordarlos.

Por lo que se refiere a la máxima de calidad, los profesionales sanitarios participantes en nuestro estudio consideran que se pueden dar situaciones en las que las usuarias inmigrantes (así como las autóctonas) mientan cuando se refieren, por ejemplo, a embarazos, abortos o enfermedades previas, a cuestiones relativas a los hábitos y estilos de vida, al seguimiento de los tratamientos médicos recomendados, o al empleo de métodos propios de la medicina tradicional. Otra de las situaciones en las que han detectado que se da una ausencia de sinceridad en algunas usuarias inmigrantes concierne a los conocimientos de español que estas dicen poseer. ${ }^{310}$ No obstante, muchos de estos profesionales sostienen que no se encuentra entre sus funciones determinar el grado de veracidad de la información que las usuarias les transmiten. Por el contrario, algunos comentan el dilema ético que se les plantea cuando sospechan que las usuarias inmigrantes afirman entender el mensaje que se les está transmitiendo $y$, sin embargo, ellos perciben ciertas señales de que no existe una completa comprensión, lo cual les puede conducir a tomar decisiones sin estar debidamente informadas.

El recurso a estas mentiras sociales puede asociarse, entre otros factores, al grado de preocupación por el conflicto, que suele ser mayor en las culturas colectivistas, en las que normalmente se evita la expresión explícita de reacciones y opiniones contrarias a las del

\footnotetext{
${ }^{310}$ Cabe recordar que, durante la observación, fuimos testigos de un posible incumplimiento de la máxima de calidad. En concreto, se produjo cuando una usuaria de origen magrebí afirmó, estando presente su marido, que no poseía conocimientos de español y, sin embargo, al ausentarse este, demostró un dominio considerable de esta lengua.
} 
interlocutor. Asimismo, probablemente también recurrirán con relativa frecuencia a este tipo de mentiras las usuarias de determinadas culturas en las que sean más evidentes las distancias de poder y se establezcan jerarquías sociales muy marcadas (Hofstede, 1991), y en las que se atribuya una posición de mayor estatus o superioridad a los profesionales sanitarios.

Al contrario que los profesionales sanitarios, la mayoría de las usuarias inmigrantes que han participado en nuestra investigación opinan que estos suelen ser sinceros, e incluso algunas de ellas consideran, en base al valor social que le atribuyen, que este perfil profesional está intrínsecamente relacionado con la sinceridad, es decir, que un médico (o una enfermera, una matrona, etc.), no puede o no debe mentir.

En relación con la máxima de manera, la mayor parte de los profesionales sanitarios sostiene que las usuarias inmigrantes suelen presentar una forma de hablar respetuosa y educada, y que, en todo caso, la cortesía verbal dependerá principalmente de cuestiones personales, por lo que no creen que se pueda realizar una distinción por colectivos en este sentido, a excepción, de acuerdo con algunos participantes, de las usuarias procedentes de Europa del este, las cuales, en su opinión, suelen presentar una forma de hablar muy directa. El uso de un lenguaje directo en este colectivo puede deberse a los patrones comunicativos propios de su cultura, y también, como señalan algunos profesionales, al hecho de que hayan aprendido el español en contextos en los que el registro empleado es predominantemente coloquial, y donde el grado de formalidad suele ser bastante bajo.

Por lo que respecta a las usuarias inmigrantes, en general, opinan que los profesionales suelen dirigirse a ellas de manera cortés y educada, aunque algunas señalan que la forma de hablar depende de las características y el estado de ánimo de su interlocutor. En la observación, como puede verse en la presentación de los datos recogidos en el diario y las fichas de campo que hemos expuesto en el capítulo anterior, hemos podido verificar que, efectivamente, el modo en el que los profesionales se dirigen a las usuarias inmigrantes puede variar en base a una serie de factores personales, emotivos y psicológicos, y que no es posible establecer generalizaciones al respecto. ${ }^{311}$ Cabe señalar, además, las diferencias en cuanto a la forma de hablar que, de acuerdo con las usuarias procedentes de Latinoamérica participantes en el grupo de discusión, presentan por lo general los españoles y los latinoamericanos. Estas usuarias sostienen que en España se suele hablar de un modo más "serio y seco", mientras que en sus respectivos países de origen es más "cercano y cariñoso", lo cual puede conducir a malinterpretaciones del mensaje y de la intención del interlocutor en las interacciones en las que participan hablantes españoles y latinoamericanos. Se confirma de este modo nuestra hipótesis de que, a pesar de emplear una misma lengua, (lo cual, sin duda, conllevará que las usuarias latinoamericanas, en principio, se enfrenten a menos barreras lingüísticas a la hora de interactuar con los profesionales sanitarios con respecto a otras usuarias inmigrantes), no podemos afirmar rotundamente que estas usuarias estén exentas de dificultades comunicativas, causadas por las diferencias en algunos usos verbales y no verbales, a las que debemos sumar, además, las diferencias culturales.

\footnotetext{
${ }^{311}$ Así, por ejemplo, como hemos señalado en el anterior capítulo, de los dos profesionales responsables de las consultas a puérperas que hemos observado en nuestro estudio, uno presenta generalmente una forma de hablar cercana (recurriendo con frecuencia al uso de diminutivos, apelativos cariñosos, términos coloquiales, etc.), mientras que el otro suele utilizar una forma de hablar distante, neutra y formal.
} 
Por lo que se refiere a los usos no verbales, estos pueden dividirse en tres grupos, concernientes, respectivamente, a la distribución temporal, la distribución espacial, y el paralenguaje.

El primer aspecto relativo a la distribución temporal que hemos tratado en nuestra investigación atañe a la duración de las consultas. La mayoría de los participantes en el estudio sostiene que estas se desarrollan casi siempre muy rápidamente, en parte debido a la presión asistencial propia del ámbito sanitario. Al respecto, es posible que algunas usuarias, especialmente aquellas que suelen recurrir a la medicina tradicional, estando acostumbradas a que el sanitario les dedique el tiempo que sea necesario, consideren que la duración de las consultas en España es demasiado corta en relación con sus expectativas (Sales, 2009:105).

En cuanto a la distribución global de la conversación, por los datos recabados en nuestro trabajo de campo, podemos afirmar que suele ser el profesional sanitario quien dirige los turnos de palabra, y raramente se producen interrupciones o solapamientos por parte de las usuarias inmigrantes. Por el contrario, son frecuentes los silencios por parte de estas usuarias. Dichos silencios, interpretados en ocasiones por los profesionales como miedo o falta de interés, pueden estar causados por diferentes factores. Por un lado, los escasos o nulos conocimientos de español que poseen algunas usuarias inmigrantes conllevan que necesiten cierto tiempo para codificar y comprender los mensajes que los profesionales les transmiten y elaborar la respuesta que les van a ofrecer. Por otro lado, cabe recordar que, en las culturas colectivistas (como puede ser el caso de algunas comunidades de Asia y África Subsahariana), el silencio se emplea para fomentar la armonía y es una muestra de respeto y sensibilidad. Por el contrario, en las sociedades predominantemente individualistas, como podría ser la española, se espera del interlocutor una participación activa, y se considera el silencio como una falta de iniciativa o desinterés (Jandt, 2010:119). Son estas diferencias en la consideración de los silencios las que pueden conducir a errores en la interpretación de los mismos.

El análisis de la distribución espacial puede dividirse en dos tipos de datos, los macroespaciales y los microespaciales (Raga, 2006:31-32). Los primeros se refieren a los elementos del espacio que envuelven a los participantes en la interacción. Una de las cuestiones que hemos analizado con respecto a los mismos concierne a la intimidad de la que pueden disfrutar las usuarias en las habitaciones y en las consultas del hospital contexto de estudio. La mayoría de las usuarias inmigrantes opina que esta intimidad es suficiente, ${ }^{312}$ aunque algunas sostienen que la ven mermada cuando están presentes estudiantes de disciplinas médicas en las consultas y demás áreas del hospital. La observación nos ha permitido corroborar este dato, ya que, por lo general, si el número de usuarias ingresadas lo permite, se efectúa un uso individual de las habitaciones de puérperas, y se suele solicitar a los acompañantes de estas que abandonen las habitaciones antes de comenzar las visitas médicas, reduciendo el número de personas presentes durante las consultas a lo estrictamente necesario (la usuaria, el obstetra y un enfermero). De todos modos, como comentaremos más detalladamente en el apartado sucesivo relativo a la relación entre profesionales sanitarios y usuarias inmigrantes, la distribución que se realiza en el hospital de las puérperas que deben compartir habitación de acuerdo con su origen puede reducir la

\footnotetext{
${ }^{312}$ Cabe señalar que, al plantear la pregunta relativa a la intimidad en las entrevistas individuales a las usuarias, nos surge la duda de que todas ellas hayan comprendido perfectamente el concepto de "intimidad".
} 
intimidad de estas usuarias, por la probabilidad de que se transmita información personal de las mismas en el seno de la propia comunidad.

Otro de los datos analizados con respecto al macroespacio se refiere al modo de vestir de las usuarias inmigrantes. Para la mayoría de los profesionales participantes, el hecho de que algunas usuarias lleven muchas prendas no supone ningún problema, y simplemente puede implicar que empleen más tiempo para desvestirse antes de la exploración o que estas usuarias pasen más calor durante su estancia en el hospital. Por el contrario, algunos profesionales consideran que el uso de determinadas prendas, como puede ser el pañuelo o el velo en las mujeres musulmanas, puede provocar problemas de higiene en determinadas áreas del hospital, como los paritorios, donde es elevado el nivel de asepsia requerido. Al respecto, algunos participantes nos hacen partícipes de cómo se comportan en estos casos, y nos cuentan que procuran hacer sentir cómodas a estas usuarias ofreciéndoles la posibilidad de colocarse un gorro en lugar del pañuelo o del velo. En nuestra opinión, esta actitud es muestra de respeto y sensibilidad cultural, así como de acercamiento a los patrones propios de otras culturas.

Durante la estancia hospitalaria se reducen las diferencias en el modo de vestir, ya que la mayoría de las usuarias llevan únicamente una bata proporcionada por el hospital. Si bien, en principio, consideramos que esta indumentaria, así como el hecho de tener que despojarse de ella durante las consultas, podía suponer para algunas usuarias un problema, tanto por lo que las participantes nos relataron como por lo que pudimos observar, la mayoría de las usuarias no plantean reticencias a llevar las batas o a desnudarse cuando la situación lo requiere, lo cual no quiere decir que no se sientan en cierto sentido intimidadas, por el concepto de pudor que algunas de ellas pueden presentar. Una excepción a este patrón de comportamiento, según los profesionales sanitarios, está constituida por las mujeres de religión musulmana, las cuales, en su opinión, suelen ser reticentes a desnudarse, especialmente en presencia de personal sanitario de sexo masculino o de sus maridos, algo que, por nuestra parte, no hemos podido constatar mediante la observación, pues, en las situaciones en las que estábamos presentes, ninguna usuaria manifestó abiertamente reticencias.

Con relación a este último aspecto examinado $y$, pasando al estudio de los datos microespaciales, según numerosos profesionales sanitarios, se reproduce este mismo patrón de comportamiento en los casos en los que deben establecer un contacto físico con las usuarias musulmanas durante la exploración. Por el contrario, no hemos podido corroborar esta afirmación en la observación y, en base a las respuestas ofrecidas por estas usuarias en las entrevistas y en el grupo de discusión, parecen comprender que dicho contacto es necesario en el ámbito sanitario. Asimismo, a pesar de que nos planteamos la hipótesis inicial de que que probablemente las usuarias musulmanas preferirían ser tratadas por personal sanitario de sexo femenino, esta se ha visto refutada por los datos ofrecidos por algunas de estas usuarias, las cuales sostienen preferir a los profesionales de sexo masculino, por considerar que suelen ser más delicados en el trato que las mujeres. Vemos, por tanto, en estos casos, una excepción a la distribución de roles propia de las comunidades musulmanas, probablemente originada en parte por la valoración del contexto y los participantes que intervienen en el ámbito sanitario. 
Por lo que se refiere al resto de datos microespaciales (los gestos, la distancia física y el contacto visual), no hemos podido extraer datos concluyentes en nuestra investigación, por la gran heterogeneidad de la información obtenida tanto en las interacciones observadas como en las respuestas de los participantes. Cabría reiterar que la rapidez con la que se desarrollan las interacciones y la simultaneidad de los múltiples datos que en ellas se presentan, en numerosas ocasiones, impiden a los interlocutores o a los observadores percibir los elementos no verbales. Un único aspecto que quisiéramos destacar atañe a las diferentes interpretaciones que, de acuerdo con la opinión de los profesionales y las usuarias, pueden darse ante la presencia o ausencia de contacto visual. Así, por ejemplo, el hecho de que las usuarias de determinadas comunidades (como algunas procedentes de Asia, África Subsahariana y el Magreb), en las cuales se suele mantener un modelo distante en las interacciones en ámbito sanitario, no miren a los ojos de los profesionales mientras conversan con ellos, puede ser interpretado por estos últimos como miedo, vergüenza o desinterés, cuando probablemente la falta de contacto visual por parte de estas usuarias es una muestra de respeto o pudor.

Por último, en relación con el paralenguaje hemos analizado dos aspectos concretos. El primero se refiere al tono de voz empleado por los profesionales sanitarios y las usuarias inmigrantes. Al respecto, no hemos podido obtener datos relevantes ni por parte de los propios grupos estudiados ni mediante la observación. La única cuestión que cabe señalar es que hemos observado que el tono de voz de las usuarias magrebíes puede variar dependiendo de la situación comunicativa en la que se encuentren, ya que este era bastante bajo (y suave) durante las entrevistas $o$ al dirigirse al personal sanitario $y$, por el contrario, era considerablemente elevado en el grupo de discusión. Dicha variación puede deberse a que perciben la situación comunicativa del grupo de discusión como más simétrica y coloquial, lo cual es una muestra de que el contexto de la interacción y los interlocutores presentes en la misma influyen en el modelo comunicativo adoptado.

El segundo atañe a la expresión del dolor durante el parto. Como hemos comentado previamente, las diferencias por colectivos en cuanto a esta cuestión percibidas por los profesionales sanitarios pueden deberse a los patrones de comportamiento relativos al lenguaje no verbal de las distintas culturas. Por ello, si las mujeres de una determinada comunidad expresan más abierta o enfáticamente el dolor padecido no significa que dicho dolor sea mayor que en el caso de aquellas que lo expresan en un modo menos evidente (o como lo definen los profesionales participantes en el estudio, más "estoico"), como tampoco significa que sean (siempre empleando las palabras de los profesionales) "más quejicas". Por el contrario, consideramos que la expresión más enfática del dolor de las mujeres de determinados colectivos reproduce los patrones comunicativos propios de su cultura.

\subsubsection{Actitudes ante la diversidad cultural en el ámbito de la salud}

En las relaciones que se establecen entre los profesionales sanitarios y las usuarias inmigrantes, por factores como el desconocimiento mutuo y la presencia de actitudes etnocéntricas, surgen a menudo sentimientos negativos recíprocos de miedo, rechazo, frustración y desconfianza. 
En la aparición de estos sentimientos influye también el tipo de relación que se espera del interlocutor. Así, por ejemplo, la relación entre los profesionales sanitarios y los pacientes suele ser más fría, distante y asimétrica en el caso de las sociedades occidentales, mientras que, en otras culturas, se espera del paciente y del sanador una implicación personal y emocional y una relación mucho más cercana. En consecuencia, los usuarios inmigrantes, en base a sus propios patrones culturales y sus expectativas, podrían interpretar negativamente el comportamiento de los profesionales sanitarios occidentales (Rena C. Gropper, 1996).

Por otro lado, en las relaciones interculturales, como hemos podido observar en nuestro trabajo de campo, son frecuentes los estereotipos y prejuicios que se aplican mutuamente los interlocutores, si bien, con respecto al ámbito de nuestro estudio, quisiéramos destacar que hemos detectado una mayor predisposición a estereotipar y presentar juicios de valor por parte de los profesionales sanitarios que por parte de las usuarias inmigrantes, las cuales, en su mayoría, suelen evitar las generalizaciones al valorar el comportamiento del personal que las atiende.

Estos estereotipos llevan a los profesionales a considerar, por ejemplo, que todas las usuarias de religión musulmana son mujeres sumisas, carentes de independencia y sometidas a la opinión y los designios de sus maridos, cuando, por la opinión que nos han transmitido estas usuarias, no siempre se reproduce este patrón de comportamiento y, en caso de que así sea, cabría interpretarlo con los necesarios matices y desde el punto de vista de su propia cultura. En la difusión de este tipo de estereotipos juegan un importante papel los medios de comunicación de masas, los cuales, como comentan las usuarias magrebíes participantes en el grupo de discusión, suelen presentar una visión distorsionada de las comunidades musulmanas, en general, y de las mujeres de esta religión, en particular.

Además, los prejuicios y la incapacidad de distanciarse de los patrones de la propia cultura llevan a algunos profesionales sanitarios a no comprender ni respetar, por ejemplo, que determinadas usuarias sientan la obligación o el deseo de rezar durante su estancia hospitalaria, o que lleven una vestimenta diversa a la habitual en la sociedad de acogida. Cabe señalar, sin embargo, que no todos los profesionales presentan esta actitud, y muchos de los participantes en nuestro estudio han demostrado interés por conocer los patrones culturales ajenos y capacidad de empatizar con las usuarias inmigrantes.

Uno de los estereotipos y prejuicios que, por los datos recabados en nuestra investigación, se reproducen con mayor frecuencia (no solo en el ámbito del hospital sino también en la sociedad en general), concierne a la creencia de que los inmigrantes "se aprovechan" de su situación de vulnerabilidad y son los destinatarios principales de las ayudas autonómicas y estatales, en detrimento de los autóctonos. Como hemos señalado en anteriores capítulos, son numerosos los estudios que demuestran que esta creencia es infundada, que las ayudas se distribuyen en base a factores como la renta y las necesidades, no en base al origen del destinatario, y que el uso (o abuso) de los servicios sanitarios por parte de la población inmigrante es menor que el que realiza la población autóctona.

Otra de las reacciones comunes ante la diversidad cultural se materializa, como hemos comentado previamente en diversas ocasiones, en comportamientos $\mathbf{y}$ actitudes discriminatorias, racistas y xenófobas. 
Por lo que se refiere al trato recibido en el hospital contexto de estudio, la mayoría de las usuarias participantes no ha percibido que se las discrimine, ${ }^{313}$ a excepción de situaciones puntuales en las que algún profesional sanitario concreto ha mostrado una actitud negativa hacia ellas. De hecho, consideran que el trato que reciben es igual o muy similar al de las usuarias autóctonas.

La opinión de los profesionales sanitarios al respecto presenta dos vertientes. ${ }^{314}$ Por una parte, un número reducido de ellos considera que no se discrimina a las usuarias inmigrantes o que, en todo caso, dicha discriminación es positiva, es decir, que se trata de compensar la situación de vulnerabilidad e indefensión que viven estas usuarias concediéndoles un trato más favorable que a las autóctonas. Por otra parte, numerosos profesionales afirman haber sido testigos de comentarios, actitudes y comportamientos discriminatorios y racistas por parte de algún compañero. La gran mayoría cree que la discriminación y el racismo se manifiestan únicamente mediante comentarios, puesto que la ética profesional (y las leyes) ${ }^{315}$ les impiden tratar de modo diferenciado a los pacientes que atienden dependiendo de cuestiones como su origen, su credo, su sexo, etc. Sin embargo, unos pocos opinan que, en ocasiones, se trascienden los comentarios y se presentan actitudes y comportamientos discriminatorios, muchas veces motivados por la presión asistencial a la que están sometidos y la dificultad que entraña la atención a las usuarias inmigrantes. Estos comportamientos y actitudes se refieren, de acuerdo con algunos profesionales, a cuestiones como el establecimiento del orden de entrada, el reparto de la medicación y la comida, o el modo mismo de dirigirse a las usuarias cuando estas solicitan ayuda.

Por nuestra parte, hemos podido escuchar comentarios discriminatorios (por ejemplo, mediante el uso de términos peyorativos como "moras", "protestonas", "quejicas", 316 etc., o la manifestación de opiniones del tipo "me consta que no trabajan, que ponen así la mano..."). Del mismo modo, hemos presenciado actitudes y comportamientos negativos por parte de algunos profesionales sanitarios (los menos) al tratar a las usuarias inmigrantes, aunque en la mayoría de los casos no podemos saber si habrían actuado de la misma manera al atender a una usuaria autóctona.

Un aspecto que sí ha llamado nuestra atención y que, en nuestra opinión, constituye un claro ejemplo de discriminación y separación se refiere a la distribución de las puérperas en las habitaciones de acuerdo con su origen. Al respecto, hemos observado que dicha distribución es bastante aleatoria, pues no se centra en el país de origen específico de las usuarias, sino

\footnotetext{
${ }^{313}$ Cabe recordar que las mujeres extranjeras sufren una doble discriminación, pues a la discriminación de género padecida también por las mujeres autóctonas- se suma la situación de desprotección que conlleva su condición de inmigrantes, la cual las expone a una situación de precariedad, inseguridad e indefensión, tanto en sus relaciones familiares como con respecto a las instituciones y servicios públicos de la sociedad de acogida (Bedoya, 2000:255).

314 En relación con el planteamiento a los profesionales sanitarios de las preguntas relativas a las posibles manifestaciones de discriminación y racismo, quisiéramos señalar que, a pesar de que, en principio, habíamos presupuesto que las respuestas serían más bien breves o evasivas, precisamente por el carácter delicado de las preguntas planteadas, nos sorprendió recibir contestaciones muy extensas, detalladas y aparentemente sinceras en relación con estos temas.

${ }^{315}$ Con respecto al ámbito que nos ocupa, podemos señalar el Estatuto de Autonomía de Aragón, en el cual se estipula que "Todas las personas tienen derecho a acceder a los servicios públicos de salud, en condiciones de igualdad, universalidad y calidad".

${ }^{316}$ Está claro que estos términos en sí no tienen por qué resultar peyorativos o despectivos, sino que más bien lo eran por el modo y el tono con el que se empleaban por parte de algunos profesionales participantes en el estudio.
} 
más bien en rasgos físicos compartidos o en cuestiones como las creencias religiosas. Además, pese a que probablemente se realice con buena voluntad, no vemos la necesidad de llevar a cabo esta separación. Aunque compartir la misma lengua con la compañera de habitación de la planta de puerperio puede ayudar a superar la soledad e incomunicación que sienten las usuarias alófonas que no reciben muchas visitas, desde nuestro punto de vista, separar a las usuarias autóctonas e inmigrantes puede suponer una guetización de estas últimas y, en última instancia, impide que las relaciones entre las mismas puedan contribuir a que exista un mayor (re)conocimiento y acercamiento recíproco.

Para finalizar esta apartado, quisiéramos comentar que, a pesar de que en las relaciones interculturales son frecuentes los malentendidos y los conflictos, en nuestra opinión, es posible garantizar que la comunicación establecida entre personas culturalmente diversas sea efectiva, lo cual, en el ámbito que nos ocupa, conllevaría una mejora en la asistencia sanitaria a usuarias de origen extranjero. Cabe recordar, sin embargo, que la comunicación intercultural es un "two-way process" (Bennett, 1998), es decir, que la adaptación de los interlocutores debe ser mutua, y que estos deben hallar un marco común y unos objetivos compartidos en el que se tengan en cuenta y se respeten las diversas características de los participantes.

\subsubsection{Análisis (crítico) de las soluciones adoptadas}

La primera cuestión que cabe señalar antes de pasar a analizar las diferentes soluciones adoptadas en el hospital contexto de nuestro estudio se refiere al hecho de que el centro hospitalario como institución y los trabajadores del mismo no presentan una actitud indiferente ante la (elevada) presencia de las usuarias inmigrantes, sino que demuestran un interés relativo por resolver o eliminar las dificultades que surgen en la atención a estas usuarias. De hecho, en el contexto que nos ocupa, se han empleado en la última década diferentes estrategias de forma simultánea o alterna con el fin de mejorar la comunicación intercultural con las usuarias de origen extranjero, algunas de ellas fomentadas por organismos públicos, y otras impulsadas por organizaciones sin ánimo de lucro o por el propio hospital. Sin embargo, como veremos a continuación, ello no significa que las soluciones que se han empleado sean las más adecuadas, o que se apliquen de manera que se pueda extraer el máximo beneficio de las mismas.

Centramos el análisis de las soluciones en dos grupos. El primero concierne a aquellas que se han adoptado con el fin de suprimir las barreras lingüísticas que se plantean en la comunicación con las usuarias alófonas. El segundo engloba tanto las soluciones destinadas a disminuir las barreras de tipo cultural, como otras estrategias generales encaminadas a mejorar la relación y la asistencia a las usuarias de origen extranjero, entre las cuales se encuentran algunas de las cuales se pueden beneficiar también las usuarias autóctonas. El orden y la distribución en dos grupos que hemos adoptado en el análisis de estas soluciones no son aleatorios, sino que responden a la importancia que se ha concedido a cada uno de los grupos, la cual queda patente no solo en el número de estrategias implantadas con uno u otro fin, sino también en los datos y opiniones proporcionados por los participantes en nuestro estudio. 


\subsubsection{Soluciones para superar las barreras lingüísticas}

Como hemos comentado previamente, tanto por la opinión de los profesionales participantes en nuestra investigación como por el número de soluciones adoptadas, parece ser que las barreras lingüísticas son aquellas que preocupan mayormente a la hora de proporcionar asistencia a las usuarias inmigrantes. Con el propósito de reducir o eliminar dichas barreras, se han empleado diferentes estrategias, las cuales no siempre han servido para conseguir que la comunicación con las usuarias alófonas fuera efectiva, tal y como veremos a continuación.

\section{Servicios de interpretación presencial ad hoc}

El recurso más ampliamente utilizado en el contexto de nuestro estudio para facilitar la comunicación entre los profesionales sanitarios y las usuarias con escasos o nulos conocimientos de español consiste, sin lugar a dudas, en el empleo de familiares, amigos o conocidos de las usuarias para que realicen labores de interpretación. ${ }^{317}$ En ocasiones, con este mismo fin, incluso se ha solicitado la ayuda de estas personas por teléfono, o se ha llegado a recurrir a familiares o acompañantes de otras usuarias o a personal socio-sanitario "bilingüe".

Diversos estudios ${ }^{318}$ demuestran que la utilización de estos intérpretes "naturales" es la estrategia más difundida entre los usuarios de origen extranjero que acuden a los servicios sanitarios españoles para superar las barreras lingüísticas con las que se encuentran a la hora de comunicarse con los profesionales sanitarios, lo cual, como expondremos en los próximos párrafos, puede conducir con bastantes probabilidades a incomprensiones, malentendidos e interrupciones en la comunicación, disminuyendo de este modo su eficacia (Valero y Taibi, 2004:3).

Si bien es cierto que el recurso a familiares y amigos puede conllevar algunas ventajas, como por ejemplo, su disponibilidad a cualquier hora, su conocimiento previo de los problemas de salud del paciente, o la tranquilidad que puede transmitir a este último su presencia, el desempeño de labores de interpretación por su parte implica también considerables riesgos. Así, por ejemplo, a causa de su desconocimiento del rol del intérprete, estas personas pueden ofrecer su opinión o su propia versión de los hechos en lugar de ceñirse a la traducción, pueden decidir omitir determinada información para proteger al paciente, o pueden sentirse molestos o violentos (tanto ellos mismos como el propio paciente) al tratar determinada información de carácter más privado o delicado. Asimismo, la intimidad del paciente queda ulteriormente comprometida cuando la interpretación es llevada a cabo no por algún miembro de su familia o círculo de amistades, sino por personal del centro de salud o por acompañantes de otros pacientes.

\footnotetext{
${ }^{317}$ Por parte de los profesionales sanitarios participantes en nuestro estudio, es también bastante frecuente el recurso al lenguaje no verbal (gestos y expresiones faciales) para comunicarse con las usuarias alófonas. La mayoría consideran que les sirve de gran ayuda, probablemente, porque no son conscientes de las diferencias existentes en el uso y la interpretación de estos elementos no verbales en las distintas culturas.

${ }^{318}$ Valgan como ejemplo los estudios llevados a cabo por el grupo de investigación FITISPoS, por lo que se refiere a la zona centro (Madrid y alrededores), o los desarrollados por el Grupo MIRAS, por lo que respecta a Cataluña, y por el Grupo CRIT, en relación con la Comunidad Valenciana.
} 
Un elemento preocupante por lo que se refiere al hospital estudiado concierne al hecho de que no son solo las usuarias alófonas quienes recurren espontáneamente a esos "intérpretes", sino que algunos de los profesionales del centro consideran que es casi una obligación que sean ellas quienes vengan acompañadas por alguien que tenga conocimientos de español y, por tanto, ayude a facilitar la comunicación.

Igualmente, cabe señalar que, en ocasiones, especialmente durante el periodo inicial de su estancia en España, algunas de las usuarias inmigrantes que han participado en el estudio afirman haber recurrido a conocidos (o conocidos de conocidos) para que las ayudaran a comunicarse con los profesionales de los servicios sanitarios, los cuales, a su vez, realizaban otras labores de ayuda, como puede ser la explicación del funcionamiento de dichos servicios. Quisiéramos destacar la pérdida de intimidad y confidencialidad que puede implicar el recurso a estas personas que no son intérpretes profesionales $y$, además, no pertenecen al círculo familiar o íntimo de las usuarias.

Por otra parte, durante diversos años, para facilitar la comunicación con las usuarias alófonas, se ha recurrido a los intérpretes no profesionales miembros del Servicio Permanente de Interpretación, ${ }^{319}$ el cual estaba gestionado por la Casa de las Culturas, un centro social municipal dirigido a inmigrantes y minorías étnicas activo desde el año 1998 en la ciudad de Zaragoza.

El Servicio Permanente de Interpretación se empezó a prestar en el año 1999, fruto de un convenio entre el Ayuntamiento y el Colegio de Abogados de Zaragoza, y dejó de existir en marzo de 2012. ${ }^{320}$ Ofrecía servicios de interpretación en más de veinte idiomas, de las 9:00 a las 21:00 horas, de lunes a viernes, por lo que presentaba una disponibilidad limitada. Los destinatarios eran profesionales y usuarios alófonos de diferentes servicios sociales zaragozanos (institutos, hospitales, o servicios de protección de mujeres y menores), así como entidades sin ánimo de lucro.

El único requisito que debían cumplir los intérpretes inscritos en el registro del Servicio Permanente de Interpretación era, en caso de que fueran inmigrantes, lo cual era bastante común, encontrarse en situación regular. Por el contrario, no se les solicitaba ningún tipo de certificado o acreditación que demostrase sus conocimientos lingüísticos de las lenguas de trabajo ni formación en interpretación. Asimismo, estos intérpretes no se regían por ningún código deontológico ni se efectuaba ninguna valoración posterior de los servicios prestados.

Son considerables las posibilidades de que, al emplear estas dos soluciones descritas hasta el momento, la comunicación entre los profesionales sanitarios y las usuarias inmigrantes no sea efectiva, principalmente por la falta de preparación y formación previas de las personas que actúan como intérpretes ad hoc. De hecho, aparte de sus carencias por lo que respecta al conocimiento de las lenguas implicadas, estos intérpretes probablemente no están preparados para afrontar las dificultades propias del desempeño de esta profesión, especialmente las de

\footnotetext{
${ }^{319}$ Para mayor información, véase el apartado de análisis documental del capítulo 6.

${ }^{320}$ Cabe señalar que no todos los profesionales sanitarios participantes en el estudio parecen estar al corriente de que este servicio ya no se encuentra disponible, a pesar de haber transcurrido un año y medio desde que se suprimió.
} 
carácter psicológico, y desconocen las funciones y principios inherentes al papel que deben ejercer (Wadensjö, 1998:52).

En consecuencia, es bastante elevado el riesgo de que estos intérpretes ad hoc cometan los cinco errores básicos identificados por Carmen Vásquez y Rafael Javier (1991, citados en Hale 2007:48) en el fragmento que incluimos a continuación:

Omission is the process by which an interpreter completely or partially deletes a message sent by the speaker. Addition is the tendency to include information not expressed by the speaker. The tendency to simplify and explain is referred to as condensation, the tendency to replace concepts as substitution. Finally, role exchange occurs when an interpreter takes over the interaction and replaces the interviewer's questions with the interpreter's own, thus assuming the role of interviewer.

Como ejemplo de que estos errores se han producido efectivamente en nuestro contexto de estudio, $y$, en particular, con respecto al intercambio de roles, algunos profesionales sanitarios nos han relatado episodios en los que el amigo o familiar de la usuaria, actuando en calidad de intérprete, ha respondido él mismo a las preguntas planteadas por el profesional, quedando de este modo excluida la usuaria de la conversación.

Asimismo, la falta de formación puede conducir al incumplimiento de determinados principios asociados a esta profesión, como la fidelidad (al, como hemos comentado, omitir, modificar o añadir información), la confidencialidad ${ }^{321}$ o la imparcialidad. ${ }^{322}$ En ocasiones, los propios participantes en el estudio han demostrado su preocupación por que no se estuviera transmitiendo fidedigna o íntegramente el mensaje por parte de los intérpretes ad hoc a los que han recurrido. Además, a algunos profesionales se les plantean dudas sobre si el hecho de que estos intérpretes pertenezcan a la familia o al círculo de amistades de las usuarias no lleva a que estas los vean como "aliados", con la consecuente pérdida de imparcialidad que esta "alianza" podría provocar.

Otra de las consecuencias negativas señaladas con respecto al recurso de intérpretes ad hoc se refiere a la relación entre el profesional sanitario y el paciente, la cual es puesta en riesgo por los factores psico-sociales nuevos que conlleva la presencia de estos intérpretes en la consulta (Angelelli, 2008:22). De hecho, la presencia de una tercera persona no siempre es aceptada por parte de los profesionales sanitarios, quienes ven en ella más un obstáculo que un facilitador de la comunicación y de la relación con la usuaria. Del mismo modo, como hemos

\footnotetext{
${ }^{321}$ Con respecto al principio de confidencialidad, a modo anecdótico, podemos relatar el episodio del que nos hizo partícipes la responsable del Servicio Permanente de Interpretación, en el cual, una intérprete que trabajaba en una casa de acogida para mujeres maltratadas había revelado la dirección de dicha casa al marido de una de estas mujeres, con las posibles consecuencias negativas que el incumplimiento de la confidencialidad podría haber acarreado en este caso.

${ }^{322}$ Cabría señalar que la supuesta imparcialidad/neutralidad del intérprete es uno de los aspectos más ampliamente debatidos por los estudiosos de la interpretación en los servicios públicos, tal y como hemos comentado en el capítulo 5. En concreto y, por lo que respecta al ámbito específico que nos ocupa (los servicios sanitarios), algunos autores sostienen que la "mythological neutrality" del intérprete no resulta tan pertinente como en otros ámbitos. Así, como señala Hanneke Bot (2003, citada en Leanza, 2007:15), el intérprete médico "is not expected to completely maintain the ideal of impartiality and must proceed on the basis of identifying either with the community [...] or with the institution. [...] (It depends on) the setting in which the interpreter works. It may be pertinent in legal settings, but not in medical or social settings, where personal involvement may be in the interest to both patient and care provider".
} 
comentado previamente, es posible que las usuarias se hayan sentido intimidadas por la presencia de familiares y amigos durante la interacción con el profesional y, por ejemplo, hayan mentido $u$ omitido información imprescindible para garantizar que la asistencia es adecuada.

Igualmente, para las personas que carecen de la preparación y la formación necesarias, deber interpretar en ámbito sanitario puede suponer un gran impacto emocional, especialmente en el caso de los menores (frecuentemente empleados en el contexto de nuestro estudio), por el cambio de roles que esto conlleva en el contexto familiar, y por el carácter de la información que se suele intercambiar en este contexto, la cual es demasiado grave, delicada o comprometida para su grado de madurez.

En última instancia, por las carencias descritas, el recurso a la interpretación ad hoc puede conllevar consecuencias negativas relacionadas con la propia asistencia sanitaria prestada, como "reduced trust in physicians, lower patient satisfaction [...], misdiagnosis, inadequate or inaccurate treatment, and reduced quality of care" (Jacobs et al., 2001:469, citados en Angelelli, 2008:23).

Por los datos aportados por los participantes en nuestro estudio, son numerosos los casos en los que se ha verificado (o podría haberse verificado) ${ }^{323}$ alguna de estas consecuencias negativas, y en los que no ha resultado posible instaurar una comunicación satisfactoria con las usuarias alófonas. Sin embargo, la mayoría de los profesionales sanitarios y las usuarias que han recurrido al empleo de intérpretes ad hoc afirman estar satisfechos con los resultados obtenidos, los cuales, a su parecer, si no han sido óptimos, al menos han resultado "aceptables". El motivo de su satisfacción está relacionado con el desconocimiento no solo de las posibles consecuencias que la adopción de esta solución puede implicar (y de los beneficios que conllevaría el recurso a intérpretes profesionales), sino también del papel del intérprete en ámbito sanitario y de los requisitos que este debe poseer para desempeñar con éxito su labor, algo que ha quedado patente en nuestra investigación.

De hecho, en relación con el papel y las funciones del intérprete, la mayoría de los profesionales participantes consideran que su única labor consiste en traducir "literalmente" las palabras de los interlocutores; ven al intérprete como un agente externo al acto de comunicación, el cual se limita a reproducir automáticamente un mensaje en una y otra lengua. Son muy pocos los profesionales que añaden otras funciones a la labor del intérprete y afirman que, cuando han recurrido a sus servicios, este les ha transmitido valiosa información sobre las usuarias de carácter personal o cultural. ${ }^{324}$

\footnotetext{
${ }^{323}$ Afortunadamente, no se ha dado ningún caso en el que la aplicación de la anestesia epidural hubiera presentado complicaciones tras haber accedido a su suministro una usuaria alófona a la que se hubiera explicado el procedimiento y los riesgos que conlleva por medio de un intérprete ad hoc, pero tengamos en cuenta que esto podría suceder.

${ }^{324}$ Otro factor añadido que demuestra el gran desconocimiento de la interpretación en el contexto de nuestro estudio consiste en el mal uso o la confusión por parte de los profesionales participantes con respecto a la terminología apropiada para referirse a los intérpretes y a la labor desempeñada por los mismos. Así, por ejemplo, usan indistintamente términos como "intérprete", "mediador", "traductor", "traductor telefónico" o "traducción simultánea telefónica", y alguno cree que la diferencia existente entre el intérprete y el traductor reside en que el primero "interpreta" a su discreción y libre albedrío lo que la usuaria ha querido decir.
} 
Y esta percepción del rol del intérprete deriva en una considerable limitación de los requisitos que, a su parecer, este debería poseer para desempeñar con éxito su labor. Así, la mayoría de los participantes señala que el único requisito indispensable es que conozca las dos lenguas de trabajo (lo cual se incumple en muchos casos en los que los familiares o amigos que interpretan presentan ellos mismos escasos conocimientos de español). Otros consideran que los conocimientos lingüísticos no son suficientes, y añaden la necesidad de que el intérprete posea también conocimientos culturales, de terminología médica, o del funcionamiento de los servicios sanitarios. Echamos en falta entre los requisitos indicados otras habilidades, conocimientos y aptitudes necesarios para que el intérprete ejerza adecuadamente su papel como, entre otros, el conocimiento de los patrones comunicativos de las personas implicadas, la capacidad de análisis y escucha activa, el conocimiento y aplicación de los principios éticos inherentes a esta profesión o, en el ámbito específico que nos ocupa, el conocimiento de los conceptos de salud y enfermedad en las comunidades implicadas, o de las creencias, los comportamientos y costumbres relacionados con la preservación de la salud y la cura, en general, así como con el embarazo, el parto y el puerperio, en particular.

Todo ello denota una ignorancia por parte de los participantes en el estudio de las condiciones de trabajo de los intérpretes médicos, así como del papel y las funciones que estos deben cumplir para facilitar la comunicación intercultural entre los profesionales sanitarios y las usuarias. Igualmente, lleva a que algunos profesionales participantes no observen grandes diferencias entre recurrir a familiares y amigos para que actúen como intérpretes ad hoc y emplear a intérpretes profesionales. De hecho, consideran que la única ventaja que presentan los intérpretes formados y preparados es que podrían ofrecerles mayores garantías sobre la fidelidad del mensaje transmitido. ${ }^{325}$ No mencionan, sin embargo, la importancia de contar con formación para garantizar otros de los principios por los que se rige esta profesión, los cuales, como hemos señalado al analizar los posibles errores e incumplimientos por parte de intérpretes no preparados, constituyen factores diferenciadores entre los servicios prestados por los intérpretes profesionales y por los intérpretes ad hoc.

Quizás si fueran más conscientes de las implicaciones negativas que presenta el recurso a intérpretes no profesionales y de las ventajas que conllevaría el empleo de intérpretes formados y preparados, recurrirían con menos frecuencia a la interpretación ad hoc.

\footnotetext{
${ }^{325}$ Además, unos pocos participantes sostienen, erróneamente, que el hecho de que el intérprete sea profesional, en contraste con los intérpretes que son familiares o amigos de la usuaria, les garantiza que estos "estarán de su lado" y defenderán los intereses de la institución.
} 


\section{Servicios de interpretación telefónica}

Aparte de las dos soluciones ad hoc mencionadas, desde hace unos años se ofrece en los centros de salud y hospitales de Zaragoza un servicio de interpretación telefónica gestionado por una empresa privada externa a la Administración pública. Dicho servicio se ha atribuido a dos empresas diferentes a través de diversas licitaciones. Actualmente, lo presta la empresa Interpret Solutions, la cual ha trabajado para el Gobierno de Aragón en los periodos comprendidos entre junio de 2009 y diciembre de 2010, y desde marzo de 2012 hasta el momento presente. ${ }^{326}$ En el espacio intermedio entre estos dos periodos, se ocupó del servicio la empresa Dualia.

El objetivo de esta contratación, tal y como figura en el pliego de prescripciones técnicas, consiste en eliminar las barreras lingüísticas a las que se enfrentan los usuarios no hispanohablantes de los servicios públicos aragoneses, con el fin de cumplir con los principios de equidad e igualdad en el acceso a dichos servicios.

En cuanto al ámbito de prestación, pueden solicitar el servicio el Instituto Aragonés de la Mujer, así como los diferentes centros y organismos del Departamento de Sanidad, Bienestar Social y Familia, del Departamento de Educación, Universidad, Cultura y Deporte, del Instituto Aragonés de Empleo, y del Instituto Aragonés de Servicios Sociales.

Con respecto a la disponibilidad, el servicio se puede solicitar de nueve de la mañana a nueve de la noche ininterrumpidamente, excepto en el caso de los centros de salud y hospitales, en los que se oferta las veinticuatro horas durante todos los días del año. Por consiguiente, a diferencia del servicio de interpretación presencial previamente analizado, este no presenta ninguna restricción en cuanto al horario o calendario de disponibilidad en los servicios sanitarios, ámbito de nuestra investigación.

En referencia a los idiomas ofertados, la empresa adjudicataria puede proporcionar servicios de interpretación en más de treinta lenguas, algunas de las cuales se corresponden con lenguas minoritarias poco habituales, pero no por ello menos importantes, de las comunidades inmigrantes actualmente residentes en Aragón (como el bambara, el mandinga o el urdu).

Por lo que respecta a las condiciones técnicas del servicio, la empresa distribuye unos terminales con doble auricular, o dual handset phone (Kelly, 2008:87), a los centros donde este se presta, de manera que es posible establecer una conversación tripartita (en la cual, en todo momento, ambos interlocutores pueden escuchar la conversación y la intervención del intérprete), y se evita la incomodidad de tener que ir pasando el auricular de uno a otro interlocutor.

Cabe mencionar, además, una serie de factores que contribuyen a garantizar unas condiciones mínimas de calidad de los servicios prestados por esta empresa, como los informes anuales que esta redacta, el Manual de Calidad por el que se rige, o la posibilidad automática que ofrece a sus usuarios de valorar la intervención del intérprete.

\footnotetext{
${ }^{326}$ Cabe señalar que, en el último periodo de contratación, se ha incluido también la traducción de documentos oficiales entre las prestaciones que deberá proporcionar la empresa adjudicataria, aunque no se ofrecen datos concretos al respecto, como qué tipo de documentos concretos se traducirán, ni qué combinaciones lingüísticas se ofertarán.
} 
Las principales ventajas de este servicio son, por una parte, el empleo de intérpretes profesionales (los cuales cuentan con una formación reglada en traducción e interpretación o, en su defecto, deben superar una prueba que determina su capacidad de interpretar telefónicamente) y, por otra, y en comparación con la interpretación presencial, la reducción de costes y la inmediatez.

Por lo que respecta a las desventajas, la distancia física entre el intérprete y los interlocutores, con las consecuentes ausencias de un marco de referencia compartido y de visión de los elementos no verbales, pueden conducir a omisiones o malentendidos. Así, como sostiene Cecilia Wadensjö (1999:254), para el intérprete telefónico,

There is an obvious disadvantage in being on the phone compared to being on site when it comes to capturing the communicative cues provided by interlocutors' gestures, posture, mimics, and other nonverbal behavior, all of which have a role in guiding the interpretation.

Por otro lado, se suele afirmar que la ausencia física del profesional responsable de llevar a cabo la interpretación telefónica garantiza que exista mayor confidencialidad en situaciones comprometidas (como podrían ser las consultas en las que se realizan exploraciones) y, al mismo tiempo, puede mitigar la preferencia de un intérprete de un determinado sexo por parte de algunos usuarios (Mikkelson, 2003:260). Sin embargo, los participantes en nuestro estudio muestran opiniones discordantes en cuanto al tema de la confidencialidad: por un lado, algunos parecen sentirse más cómodos que con el intérprete presencial, por la ausencia de contacto visual entre ellos, pero, por otro, algunos manifiestan cierto recelo, precisamente por la incapacidad de reconocer al intérprete, quien, sin embargo, sí que dispone de medios para saber quiénes son los interlocutores. Además, algunos de los profesionales sanitarios que han participado en nuestra investigación incluso se preguntan si existe algún registro en el que se conserven los datos de la intervención y del intérprete, de manera que estos se puedan solicitar en caso de que una interpretación "errónea" contribuya a la inadecuación de la asistencia sanitaria prestada.

De todos modos, el principal problema que presenta este servicio en el contexto que nos ocupa es con diferencia su desconocimiento y su infrautilización. La gran mayoría de los profesionales sanitarios no conocen la existencia de este recurso o no lo emplean, aduciendo falta de tiempo, incomodidad, dificultad de uso y pérdida de cercanía con la usuaria. Además, opinan que disponen de otros recursos (uso de gestos o expresiones faciales, recurso a familiares o amigos con conocimientos de español, etc.) para comunicarse con las usuarias alófonas, y no ven la necesidad de recurrir a intérpretes profesionales, los cuales garantizarían una mayor eficacia de la comunicación. Por lo que respecta a las usuarias, ninguna (o prácticamente ninguna) ${ }^{327}$ conoce la existencia del servicio $y$, por consiguiente, no pueden disfrutar del derecho a solicitar a los profesionales que se emplee en caso de necesidad.

\footnotetext{
${ }^{327}$ Solo una de las participantes en el grupo de discusión con usuarias magrebíes afirma conocer este servicio, no porque lo haya empleado ella misma o le hayan informado los profesionales sanitarios, sino porque vio un cartel en el hospital que informaba de la posibilidad de solicitarlo. Por lo que se refiere al uso, solo una usuaria inmigrante reconoce haberlo empleado y opina que le resultó de utilidad.
} 
Por tanto, resulta evidente que los mecanismos de difusión sobre el servicio actualmente empleados (mediante folletos informativos o carteles) ${ }^{328}$ no son suficientes. Además, si bien la empresa adjudicataria celebró en el primer periodo de contratación una serie de charlas destinadas a los profesionales de los servicios públicos, con el fin de darles a conocer el servicio y su utilización, estas no eran obligatorias y, de acuerdo con los datos proporcionados por la empresa, no contaron con un gran número de asistentes.

Para finalizar el análisis del servicio de interpretación telefónica, quisiéramos resaltar que los pocos profesionales del hospital contexto de estudio que sí lo han empleado para comunicarse con las usuarias alófonas afirman estar satisfechos con los resultados obtenidos. No obstante, cabe señalar que algunos desconocen que el servicio se encuentra activo las veinticuatro horas del día, y otros opinan que deber introducir un gran número de códigos antes de acceder al intérprete hace que se prolonguen en exceso los tiempo de espera (vitales, por ejemplo, en los casos de urgencias o en las consultas sobresaturadas), o que incluso se llegue a perder la conexión telefónica, aspectos que se deberían revisar para la futura prestación de este servicio.

\section{Servicios de traducción}

Aparte de los servicios de interpretación presencial y telefónica previamente analizados, el hospital contexto de estudio, con el fin de superar las barreras lingüísticas a las que se enfrentan las usuarias alófonas, dispone de una serie de documentos traducidos a otros idiomas.

Entre dichos documentos, se encuentra, en primer lugar, la guía "Cuídame: guía para padres y madres", publicada en español, árabe, francés y rumano, en la cual se ofrecen consejos y recomendaciones relacionados con el estado físico y la salud de las puérperas y los recién nacidos. ${ }^{329}$ Asimismo, el hospital cuenta con dos documentos informativos disponibles en diversos idiomas (en concreto, en español, árabe, chino, francés, inglés y rumano) editados por el propio centro hospitalario, los cuales se encuentran en las plantas de puerperio. Uno de ellos proporciona información básica sobre el funcionamiento del servicio de obstetricia, y el otro recoge una serie de pautas y recomendaciones para el cuidado de los recién nacidos.

Consideramos que la traducción de los documentos mencionados a las lenguas de las principales comunidades de las usuarias inmigrantes, sin duda, pueden favorecer que estas dispongan de información relevante durante su estancia hospitalaria y, en consecuencia, facilitará el uso de los servicios sanitarios por su parte. Asimismo, por lo que se refiere a los documentos que contienen algunas pautas aconsejables para el cuidado de las madres y sus hijos durante el puerperio, estos pueden resultar útiles para las primíparas que carecen de redes familiares y sociales que les orienten y apoyen durante el primer periodo tras el nacimiento. Sin embargo, cabe señalar algunas limitaciones y desventajas de estos documentos, algunas de las cuales han sido indicadas, además, por los propios participantes

\footnotetext{
${ }^{328}$ Cabe destacar que, durante nuestro trabajo de campo, no encontramos en el hospital contexto de estudio ningún cartel o folleto sobre el servicio de interpretación telefónica que estuviera a la vista del público.

${ }^{329}$ Como hemos comentado en el capítulo anterior, concretamente en el apartado de análisis documental, nos llama la atención el hecho de que, entre las lenguas a las que esta guía fue traducida, no se encontraran otras igualmente necesarias en el contexto de estudio, como pueden ser el chino o el inglés.
} 
en nuestro estudio. Por una parte, los documentos están traducidos solo a determinados idiomas, por la imposibilidad de tener versiones en el amplio abanico de lenguas y dialectos de toda la población de usuarias. Por otra, creemos que no se está realizando una difusión adecuada de la existencia de estos documentos ni una correcta distribución de los mismos. Así lo demuestra el hecho de que un gran número de profesionales y casi todas las usuarias desconozcan que pueden disponer de ellos o no sepan a quién se los deben solicitar en caso de necesitarlos.

Por otro lado, el hospital cuenta con listados de expresiones multilingües. Si bien pueden ser un recurso de utilidad, solo pueden emplearse para formular preguntas estandarizadas y, en consecuencia, no cubren todas las posibles situaciones en las que los profesionales deberán comunicarse con las usuarias alófonas.

Igualmente, quisiéramos destacar que existen otros documentos de especial relevancia que no se encuentran traducidos (como el plan de parto del hospital, los documentos relativos al registro de los recién nacidos, o documentos informativos sobre diferentes métodos de alivio del dolor, alternativos a la aplicación de la anestesia epidural), y cuya traducción fomentaría que las usuarias alófonas participaran en su proceso de parto y pudieran tomar decisiones debidamente informadas.

Mención aparte merecen los consentimientos informados traducidos de los que dispone el hospital. Se trata, indudablemente, de un recurso de gran utilidad y, de acuerdo con los datos recopilados en nuestra investigación, muy valorado tanto por los profesionales como por las usuarias inmigrantes. No obstante, a nuestro parecer (y como corroboran, además, algunos de los participantes), presenta numerosas limitaciones. En primer lugar, la traducción de los consentimientos no tiene ninguna utilidad en el caso de las usuarias que, al ser analfabetas, no pueden leerlos. En segundo lugar, de acuerdo con algunos profesionales, los consentimientos traducidos no siempre se encuentran a su alcance o desconocen a quién recurrir para obtenerlos. Además, el hecho de que estén editados en un solo idioma impide que se diferencien los diferentes consentimientos (para el suministro de la anestesia epidural, para el parto por cesárea, etc.), o incluso que el profesional pueda saber si la usuaria ha firmado en el lugar destinado a autorizar la intervención o a no autorizarla. Asimismo, tanto algunos profesionales como algunas usuarias reconocen que, por el estado anímico en que se encuentran las mujeres antes de dar a luz, en ocasiones, ni siquiera leen los consentimientos antes de firmarlos, por lo que, aparte de entregarles este documento para que lo firmen, se deberían añadir ulteriores explicaciones verbales sobre la intervención que se va a efectuar, así como sobre los efectos y los riesgos que esta conlleva. Igualmente, como sucedía con los documentos traducidos que hemos mencionado con anterioridad, algunas usuarias ni siquiera conocen la existencia de estos consentimientos $y$, por tanto, no podrán solicitarlos si los necesitan. Por último, cabe señalar que este recurso, en todo caso, resulta insuficiente, principalmente porque la usuaria alófona no podrá plantear sus dudas tras haberlo leído, ni el profesional podrá ofrecerle ulteriores indicaciones o aclaraciones.

Por consiguiente, la traducción de los consentimientos informados no garantiza que las usuarias conozcan el procedimiento de las técnicas que se les van a aplicar, ni los riesgos y beneficios que estas conllevan o qué alternativas tienen para paliar el dolor, de modo que su 
participación en la toma de decisiones se verá limitada, y no se podrá garantizar que, al decidir, estén debidamente informadas. Se incumple, de esta manera, una de las recomendaciones de la "Estrategia de atención al parto normal" (2007:48), según la cual,

[...] las mujeres embarazadas que carecen de información carecen también de la capacidad de opinar, discutir, y decidir conjuntamente con los profesionales de la salud que las atienden. [...] las decisiones sobre las prácticas a utilizarse serán compartidas, consensuadas y asumidas coresponsablemente.

\subsubsection{Soluciones para reducir las barreras culturales y otro tipo de iniciativas}

Aparte de las soluciones adoptadas para tratar de reducir o eliminar las barreras lingüísticas que surgen en la atención a las usuarias con escasos o nulos conocimientos de español, el hospital contexto de estudio ha empleado otras estrategias que podrían servir para mejorar la asistencia sanitaria a las usuarias inmigrantes, algunas de las cuales podrían beneficiar igualmente a las usuarias autóctonas.

Por lo que respecta a los servicios de mediación intercultural de los que pueden disponer los profesionales y los usuarios del sistema de salud aragonés, cabe citar, en primer lugar, el Servicio de Apoyo a la Mediación Intercultural (SAMI), ${ }^{330}$ el cual desarrolla su actividad desde el año 2003 con el objetivo principal de lograr la integración de la población de origen extranjero residente en Aragón.

El SAMI nace con la finalidad de ofrecer orientación y apoyo a aquellas organizaciones públicas o privadas que deseen adecuar o mejorar los servicios proporcionados a usuarios inmigrantes, de manera que se facilite el acceso y uso equitativos de dichos servicios por su parte. Asimismo, persigue sensibilizar a la población autóctona sobre los efectos positivos de la inmigración, y actúa a demanda en situaciones de conflicto causadas por la diversidad cultural. Entre los diferentes servicios de los que se ocupa el SAMI se incluyen el asesoramiento técnico a las organizaciones demandantes, la formación intercultural e interpretación de claves culturales, la mediación intercultural, la edición de materiales y documentación destinados tanto a los profesionales de los servicios públicos como a los usuarios de origen extranjero, y la investigación sobre el fenómeno migratorio y sus repercusiones en las organizaciones.

Uno de los aspectos positivos de este servicio se refiere a las características de los miembros que lo integran. El equipo multidisciplinar de mediadores está compuesto por personas procedentes de diferentes países y culturas, la mayoría de las cuales asistió, en el año 2003, a un curso intensivo de larga duración cuyos contenidos cubrían la adquisición y desarrollo de las competencias fundamentales para llevar a cabo labores de mediación. Asimismo, el curso incluía un periodo de prácticas (fundamental para aplicar los conocimientos adquiridos en un contexto real), y se ha complementado en años sucesivos con un plan de formación continuada que los mediadores compaginan con su actividad laboral.

\footnotetext{
330 El SAMI forma parte de los servicios ofertados por la Fundación Adunare (organización compuesta por ocho asociaciones y entidades sin ánimo de lucro con sede en la ciudad de Zaragoza) y está financiado por la Administración pública a través de la Dirección General de Inmigración y Cooperación al Desarrollo. Para mayor información, véase el apartado de análisis documental del capítulo 6.
} 
Entre las principales actividades puestas en marcha por el SAMI, quisiéramos destacar algunas centradas en el ámbito de esta investigación y que, a nuestro parecer, pueden haber contribuido a mejorar la asistencia sanitaria a las usuarias inmigrantes.

En primer lugar, el SAMI ha celebrado en los últimos años diversas actividades de orientación y asesoramiento y varios cursos de formación dirigidos a profesionales de los centros de salud y hospitales aragoneses, los cuales estaban centrados principalmente en desarrollar la competencia intercultural de dichos profesionales. ${ }^{331}$ Entre los objetivos de estos cursos y actividades, cabe señalar los siguientes: dar a conocer el contexto sanitario de origen de las comunidades inmigrantes residentes en Aragón, identificar las causas de las barreras que pueden dificultar la atención a estas comunidades, eliminar los estereotipos y prejuicios presentes en la relación médico-paciente, y aumentar el conocimiento de los usuarios extranjeros por parte de los profesionales sanitarios, para que estos últimos sean capaces de ofrecer una asistencia personalizada en la que se tengan en cuenta las particularidades culturales de los usuarios.

Asimismo, el SAMI ha participado en otras actividades formativas, como las jornadas organizadas con la Unidad Docente de Matronas de Zaragoza, cuyo objetivo principal consistía en proporcionar a las enfermeras de diversos hospitales de esta ciudad herramientas y metodologías para desarrollar la competencia comunicativa intercultural necesaria a la hora de atender a usuarias inmigrantes. Ha colaborado también con diversas instituciones universitarias aragonesas, como con la Facultad de Medicina de la Universidad de Zaragoza (impartiendo la asignatura optativa "Salud e inmigración"), con el Grado en Psicología de la Escuela Superior de Estudios Aplicados Arké (realizando un curso sobre factores culturales que influyen en la salud mental), y con la Universidad San Jorge (celebrando un seminario sobre claves culturales en la atención sanitaria a pacientes de origen extranjero para los alumnos de la asignatura "Mediación intercultural" del Grado en Traducción y Comunicación Intercultural).

Las actividades formativas organizadas por el SAMI han ido descendiendo en los últimos años (principalmente por problemas de presupuesto) y, con el fin de fomentar su continuidad, quisiéramos destacar en positivo algunas de las características de las mismas, por su aportación al contexto de nuestra investigación: cubren las tres provincias de Aragón, así como un amplio espectro de los diferentes sectores y áreas del ámbito sanitario; sus contenidos están adaptados a las necesidades y prácticas de los diferentes profesionales que trabajan en los servicios y centros de salud; contribuyen a mejorar la formación de los futuros profesionales, al ofertarse también para alumnos de diferentes grados universitarios; $y$, por último, se centran en las pautas culturales de los colectivos inmigrantes con un mayor número de residentes en Aragón.

Por otro lado, en cuanto a las labores de investigación y edición de materiales llevadas a cabo por el SAMI, cabe resaltar la publicación Las claves que influyen en la atención sanitaria especializada a las personas de origen extranjero y técnicas para abordarlas con éxito (2007),

\footnotetext{
${ }^{331}$ Nos consta, por las memorias de actividades que publica anualmente el Servicio de Apoyo a la Mediación Intercultural, que se han celebrado diversas actividades formativas en el hospital contexto de estudio. Sin embargo, desconocemos si los profesionales sanitarios que han participado en nuestra investigación asistieron a dichas actividades, ya que, si bien algunos mencionan haber recibido algún curso de contenidos formativos similares a los descritos por el SAMI, no recuerdan qué entidad lo organizó.
} 
la cual fue distribuida, entre otros organismos y entidades, en los servicios del Sistema de Salud de Aragón. Consideramos que dicha publicación, por los contenidos que la integran, puede resultar de gran utilidad a los profesionales sanitarios a la hora de atender a los usuarios inmigrantes. En concreto, se divide en tres grandes bloques. En el primero, a modo introductorio, se presenta el Servicio de Apoyo a la Mediación Intercultural (SAMI). En el segundo, centrado en la competencia intercultural en ámbito sanitario, se abordan cuestiones como, por ejemplo, el concepto de cultura y las relaciones interculturales; la comunicación intercultural y estrategias de desarrollo de la competencia intercultural; y los mecanismos y acciones para eliminar o reducir las consecuencias negativas de los estereotipos y prejuicios. El tercer bloque y, a nuestro parecer, el más interesante, analiza de manera exhaustiva las claves culturales de los usuarios de origen extranjero procedentes de África Subsahariana, Asia, el Magreb, Latinoamérica y Europa del Este. En este último bloque, se ofrecen, por una parte, datos sobre el contexto sanitario de la zona de origen, la medicina tradicional, el concepto de salud y enfermedad, los determinantes de salud, y los factores culturales que influyen en su atención (con especial referencia al área de la ginecología y la obstetricia) y, por otra, algunas recomendaciones a la hora de tratar a estos usuarios.

Otra de las entidades que provee servicios de mediación intercultural en el ámbito sanitario aragonés es la organización Médicos del Mundo, la cual trabaja desde el año 1996 en proyectos de atención integral a los ciudadanos en riesgo de exclusión social, entre los que se encuentra la población inmigrante. Por lo que se refiere a las actividades dirigidas a este colectivo, posee un centro de atención socio-sanitaria, un programa de atención a la salud mental, y un programa de mejora de la salud sexual y reproductiva. Y, precisamente, dentro de este último programa, se encuentran dos actividades relacionadas con el contexto y los sujetos de nuestra investigación. Por un lado, los mediadores interculturales de Médicos del Mundo organizan talleres de formación sobre salud sexual y reproductiva destinados tanto a profesionales sanitarios como a usuarias, centrados en aspectos tales como la planificación familiar, el uso de los servicios de obstetricia y ginecología, o los cuidados durante el embarazo. Por otro, estos mediadores colaboran en un programa de prevención de prácticas perjudiciales para la salud, en el cual participa el hospital en el que hemos desarrollado nuestra investigación. Este programa se centra especialmente en la intervención individual y comunitaria para erradicar la práctica de la mutilación femenina, y la participación del hospital se concreta en un protocolo de actuación según el cual, siempre que da a luz una mujer procedente de África Subsahariana (tanto si presenta mutilación como si no), se avisa a la Médicos del Mundo y, durante los días que dicha usuaria permanece ingresada tras el parto, un mediador de la organización la visita y le informa de los riesgos que puede conllevar esta práctica. El único inconveniente que vemos en este programa por lo que concierne a nuestro contexto de estudio es que no todos los profesionales del hospital conocen su existencia, por lo que no queda garantizada la inclusión en el programa de todas las potenciales destinatarias.

Consideramos que las dos entidades que acabamos de presentar desarrollan una importante labor en el ámbito de la integración, la mediación y la mejora del acceso y uso de los servicios sanitarios por parte de la población inmigrante residente en Aragón. Por este motivo, creemos que las instituciones públicas aragonesas deberían continuar fomentando sus actividades (a pesar de las limitaciones presupuestarias), favorecer la coordinación entre estas entidades y las organizaciones y centros a los que van dirigidos sus servicios y, por último, ayudar a 
difundir los programas e investigaciones que ponen en marcha, de modo que lleguen al mayor número de interesados posibles. ${ }^{332}$

Aparte de las mencionadas estrategias centradas en la mediación intercultural, el hospital contexto de estudio ha participado o ha organizado otras actividades que pueden contribuir a la mejora de la asistencia sanitaria a usuarias inmigrantes y de las cuales, por extensión, se pueden beneficiar también las usuarias autóctonas. Entre ellas, cabría citar la colaboración del hospital en el programa Gota de leche, impulsado por la Fundación El Refugio, cuyo fin consiste en proporcionar leche a aquellos recién nacidos a los que no sea posible dar lactancia materna y cuyas familias tengan escasos recursos. Los objetivos de dicho programa cumplen con una de las recomendaciones de la "Estrategia de atención al parto normal" (2007:46), referida al "fomento de la donación de leche de madre y la puesta en marcha de bancos de leche".

Asimismo, el hospital creó una escuela de padres, en la cual los participantes estaban presentes durante el baño y los cuidados proporcionados a sus hijos por las matronas y enfermeras, y podían plantear a estas últimas las dudas y dificultades con las que se encontraban en el puerperio. Por la ausencia de redes familiares y sociales de las que a menudo carecen las usuarias inmigrantes, consideramos que la asistencia a esta escuela podría resultarles de utilidad. Sin embargo, en el que momento en que realizamos nuestro trabajo de campo, había dejado de funcionar.

Para finalizar, quisiéramos mencionar otro tipo de iniciativas que favorecen la personalización y humanización de la asistencia a gestantes y puérperas, aspectos tan destacados en los documentos que incluyen recomendaciones sobre el parto y la salud sexual y reproductiva que hemos presentado en el apartado de análisis documental del capítulo anterior. En concreto, como hemos señalado previamente, el hospital contexto de estudio ha realizado un esfuerzo por adaptarse a las particularidades y necesidades de sus usuarias, ofreciendo distintas posibilidades en el menú que se ofrece durante la estancia hospitalaria de las puérperas, brindando la posibilidad de ponerse un gorro en lugar del pañuelo o del velo a las mujeres musulmanas, y siendo bastante flexible en cuanto a los horarios de visitas y el número de acompañantes. No obstante, en nuestra opinión, estas iniciativas se quedan en la superficie, y cabría realizar un ulterior esfuerzo por descubrir las creencias y valores que subyacen a determinados comportamientos, como la elección de un menú concreto o la presencia de muchos, pocos o ningún acompañante. Así, como sostiene John W. Berry (2012:169),

At the most concrete level, cultures can be seen to vary in terms of their housing, dress, food and transportation. However, as we have noted, it may not be these most concrete aspects that are the usual source of intercultural difficulties. Although it is true that all these practical

\footnotetext{
${ }^{332}$ Como muestra del apoyo que reciben las actividades de mediación intercultural desarrolladas hasta el momento en territorio aragonés, cabe señalar, por una parte, la mención del SAMI en los planes estratégicos sobre inmigración de los años 2004-2007 y 2008-2011 y, por otra, la aprobación por unanimidad de la Proposición no de ley núm. 28/12 sobre la mediación intercultural y apoyo a profesionales y colectivos, la cual fue presentada en marzo de 2012 en las Cortes de Aragón. En ella se proponía analizar las actividades que las entidades sociales encargadas de mediación intercultural habían puesto en marcha en los últimos años y se planteaban medidas para garantizar su continuidad. En el momento presente, nos consta que tanto el SAMI como el programa de mediación de Médicos del Mundo siguen funcionando, y esperamos que puedan continuar haciéndolo en un futuro.
} 
issues do pose problems [...], the greatest intercultural problems arise from the more implicit aspects of culture.

Asimismo, como expondremos en el siguiente apartado, la adecuación de los servicios sanitarios debe abarcar otras áreas de la asistencia prestada a las usuarias inmigrantes y a las autóctonas.

\subsection{Propuestas de mejora}

Uno de los objetivos que nos planteamos desde el principio de esta investigación consistía en poder proponer, tras el análisis de la situación estudiada, una serie de acciones y estrategias que contribuyesen, en la medida de lo posible, a mejorar la comunicación entre los profesionales sanitarios y las usuarias inmigrantes $y$, en definitiva, que fomentasen que estas pudieran acceder y usar los servicios de salud (en nuestro caso, los servicios destinados a la salud reproductiva) en condiciones de calidad y equidad. Por ello, en las siguientes páginas, presentamos las propuestas que, a nuestro modo de ver, podrían implantarse en el hospital contexto de estudio con el fin de lograr las mencionadas metas. Consideramos que buena parte de las acciones y estrategias, por extensión, podrían ponerse en marcha en los diferentes servicios y centros del Sistema de Salud de Aragón y, además, que no solo favorecerían a las usuarias inmigrantes, sino también a las autóctonas y, evidentemente, a los profesionales que las atienden.

Seguidamente, a modo de conclusión final, ampliamos el espectro de nuestro análisis, y presentamos una serie de reflexiones y propuestas que se refieren al contexto nacional, especialmente encaminadas a concienciar a la Administración pública de las deficiencias existentes en la asistencia prestada actualmente a los usuarios de origen extranjero que acuden a los servicios sanitarios españoles. En especial, mediante el planteamiento de estas propuestas pretendemos destacar la importante labor que realizan en el ámbito estudiado figuras como los intérpretes en los servicios públicos y los mediadores lingüísticos y culturales $y$, en última instancia, contribuir a que estas alcancen el reconocimiento profesional que merecen.

\subsubsection{Propuestas de mejora para el hospital contexto de estudio}

A lo largo de los capítulos y apartados anteriores, hemos ido analizando las barreras lingüísticas y culturales que surgen en la comunicación y en la relación entre las usuarias inmigrantes y los profesionales sanitarios del hospital contexto de estudio, así como las consecuencias negativas que dichas barreras pueden suponer por lo que respecta a la asistencia a dichas usuarias.

De todos modos, cabe señalar que los fenómenos asociados a la reproducción y a la maternidad que experimentan las mujeres de origen extranjero no pueden atribuirse únicamente a su condición de inmigrantes, a sus conocimientos de la lengua del país de acogida, y a sus patrones culturales, sino que será necesario tener en cuenta la influencia que podrían ejercer otros factores, entre los que se encuentran los siguientes (Oliver, Baraza y Martínez, 2007:82): 
d) Las desigualdades con respecto a la salud que se basan en cuestiones de tipo socioeconómico, y que podrían afectar tanto a la población inmigrante como a la autóctona.

e) Las desigualdades de género, que se pueden dar tanto en los países de origen como en el país de acogida.

f) La situación y el funcionamiento de los servicios sanitarios de sus países de origen, que influirán en la aceptación de los patrones sanitarios propios del país receptor.

En resumen, podemos afirmar que las barreras a las que se enfrentan las usuarias de origen extranjero son de índole muy diversa: lingüísticas, culturales, institucionales o administrativas, y personales (socio-económicas, psico-sociales, etc.). Con el fin de reducir o eliminar dichas barreras, a continuación, planteamos algunas propuestas, las cuales se distribuyen en dos grandes grupos. Por un lado, exponemos una serie de acciones y estrategias que el hospital podría poner en marcha en un periodo de tiempo relativamente breve, algunas de las cuales se encuentran ya en funcionamiento, pero deberían aportarse a las mismas determinadas correcciones y mejoras. Por otro lado, planteamos aquellas iniciativas que, por su envergadura y las personas e instituciones implicadas, requieren mayores esfuerzos y podrían implantarse a medio-largo plazo.

Antes de pasar al planteamiento de las propuestas, cabe realizar algunas matizaciones al respecto. En primer lugar, consideramos que las acciones de mejora deben abarcar todas las fases del proceso reproductivo de las usuarias inmigrantes, desde la información que les permita planificar el tipo de familia que desean formar, así como conocer y tener acceso a diferentes métodos anticonceptivos, hasta la asistencia sanitaria durante el embarazo, el parto y el puerperio, de modo que se garantice la minimización de los riesgos y se ofrezcan las máximas posibilidades para que tanto la madre como el hijo no presenten problemas de salud.

Igualmente, partiendo de los principios establecidos en la Carta de Compromisos del Departamento de Salud y Consumo con los Usuarios del Sistema de Salud de Aragón (los cuales se refieren explícitamente a la información, la accesibilidad, la participación y la calidad), y teniendo en cuenta las recomendaciones ofrecidas en documentos como la "Estrategia de atención al parto normal" (2007), creemos que las acciones de mejora deben encaminarse a cubrir distintas áreas de actuación: la prevención y la promoción de la salud, el acceso, la asistencia de calidad, el derecho a la información (oral y escrita), y la participación de las usuarias en la toma de decisiones.

Una de las preguntas que nos planteamos desde el inicio de nuestra investigación y que volvió a surgir a lo largo de todo el estudio se refería a si las barreras lingüísticas eran más relevantes que las culturales en la comunicación intercultural en ámbito sanitario. No hemos hallado una respuesta concluyente a esta pregunta. Lo único que nos vemos capaces de afirmar al respecto es que, si bien ambas interfieren en la comunicación y pueden dificultar o impedir que esta sea efectiva, consideramos que, si no se superan las barreras lingüísticas, es más difícil que se perciban las culturales. De todos modos, opinamos que se deben aportar soluciones que eliminen ambos tipos de barrera, con el fin de permitir que la comunicación y la relación entre los profesionales sanitarios y las usuarias inmigrantes sean satisfactorias para ambos y que, por tanto, se garantice una adecuada asistencia sanitaria. En consecuencia, nuestras 
propuestas de mejora están encaminadas a tratar de superar tanto las barreras lingüísticas como las culturales. Por lo que respecta al resto de barreras mencionadas (como pueden ser las dificultades de acceso por cuestiones de carácter administrativo, o las condiciones socioeconómicas en las que viven algunas mujeres inmigrantes), a pesar de considerarlas igualmente importantes, creemos que se alejan de los fines de nuestra investigación, y no somos capaces, con los datos, los conocimientos y la experiencia con los que contamos, de plantear propuestas que ayuden a reducirlas o eliminarlas.

\section{Acciones específicas a corto-medio plazo}

El primer bloque de propuestas a implantar en un periodo de tiempo relativamente breve persigue el fin de superar las barreras lingüísticas que surgen en la comunicación entre los profesionales sanitarios y las usuarias alófonas.

Dentro de este bloque, la primera propuesta consiste en la puesta en marcha de un servicio de interpretación presencial. En concreto, consideramos necesario que se reactive el servicio de interpretación que fue eliminado en marzo de 2012, pero introduciendo sustanciales modificaciones. La primera de ellas se refiere a la formación de los intérpretes. Recordemos que los intérpretes del Servicio Permanente de Interpretación gestionado por el centro municipal de la Casa de las Culturas no contaban con ningún tipo de formación para ejercer sus funciones, y ni siquiera debían demostrar sus conocimientos de las lenguas de trabajo. Como ya hemos comentado anteriormente, estas carencias pueden derivar en graves errores de interpretación, así como de actuación, debido al desconocimiento de los principios éticos por los que el intérprete debe regir el desempeño de su labor.

En segundo lugar, no creemos que sea necesario que estos intérpretes presenciales dominen todas (o casi todas) las lenguas de las comunidades inmigrantes residentes en Zaragoza/Aragón, sino que sería suficiente con contar con profesionales que interpretaran en aquellas lenguas de las que existe mayor demanda. Dichas lenguas podrían ser el chino y el árabe, de acuerdo con la opinión de los profesionales sanitarios participantes en nuestro estudio y nuestra propia experiencia durante la observación en el trabajo de campo. Además, según los datos proporcionados por el Servicio de Interpretación Permanente, las lenguas que presentaron una mayor demanda durante los últimos años de su ejercicio, fueron, aparte de las señaladas, el inglés y, en menor medida, el rumano. ${ }^{333}$ Sin embargo, la elección final de las lenguas a ofertar debería estar basada en un estudio riguroso que permitiera establecer en qué combinaciones lingüísticas existe una mayor necesidad real.

Junto al servicio de interpretación presencial, continuaríamos ofreciendo el servicio de interpretación telefónica, el cual, por sus características, puede suplir algunas carencias o problemas que plantea el servicio de interpretación presencial. Por nuestra parte, creemos que, por los datos relativos al lenguaje no verbal y los referentes del contexto de los que dispone el intérprete presencial, es preferible la intervención de este con respecto a la del

\footnotetext{
${ }^{333}$ Cabe señalar, asimismo, que el inglés y el francés son segundas lenguas de gran parte de la población africana y asiática residente en Aragón (con la excepción de la comunidad china).
} 
telefónico, ${ }^{334}$ pero resulta inviable contar con un equipo de intérpretes disponibles en todo momento y que conozcan una amplia variedad de lenguas (entre otros motivos, por los elevados costes que ello implicaría).

De todos modos, cabe considerar, por un lado, que la interpretación telefónica reduce el tiempo de espera necesario cuando el intérprete (que no es omnipresente y, por tanto, no puede estar en todas las áreas del hospital o en todos los hospitales a la vez) se debe desplazar. No obstante, en relación con la "inmediatez" de este servicio, quisiéramos señalar que, con el fin de reducir ulteriormente la espera y evitar que se pierda la conexión telefónica antes de contactar con el intérprete, se debería revisar el actual procedimiento de acceso al servicio, el cual requiere la introducción de numerosos códigos y la intervención de diferentes interlocutores antes de que el intérprete empiece efectivamente a trabajar.

Por otro lado, la interpretación telefónica podría abarcar un mayor número de lenguas y destinarse, por tanto, a aquellas comunidades en las que el número de población inmigrante es, por el momento, menor. Cabría tener en cuenta que los flujos migratorios van variando y, en consecuencia, las lenguas a ofertar en modalidad presencial o telefónica también podrían ir cambiando con el paso del tiempo. Asimismo, quisiéramos recordar que, en ocasiones (como en las consultas en las que se realizan exploraciones), la propia usuaria podría preferir que el intérprete no estuviera presente, y en ellas podría recurrirse a este tipo de interpretación remota.

En ambos casos, y considerando la aceptación y el uso que el servicio de interpretación telefónica ha presentado hasta el momento, creemos que resulta indispensable realizar una labor concienzuda de información y sensibilización del personal sanitario, para fomentar que este recurra a los servicios de interpretación (presencial o telefónica) siempre que la situación lo requiera. En esta labor deberían resaltarse las consecuencias negativas que puede conllevar el recurso a intérpretes ad hoc para comunicarse con las usuarias alófonas (sean estos familiares y amigos de las usuarias o intérpretes no profesionales), así como los beneficios que puede aportar el empleo de intérpretes profesionales. Del mismo modo, como comentaremos más detalladamente en el apartado de acciones a medio-largo plazo, los profesionales sanitarios deberían aprender a interactuar con las usuarias mediante la intervención del intérprete. Una última cuestión en relación con los servicios de interpretación concierne a la difusión de los mismos entre las usuarias inmigrantes, de manera que, aunque ellas no puedan solicitarlos personalmente, conozcan su existencia y, en caso de necesidad, puedan pedir al profesional sanitario que las atiende que sea él quien lo solicite.

Igualmente, siempre con el fin de superar las barreras lingüísticas, proponemos que se recurra a la traducción de documentos. Con respecto a los mismos, se deberían efectuar algunas modificaciones, como, por ejemplo, editar ediciones bilingües (español-lengua extranjera) de los consentimientos informados, de modo que los profesionales sanitarios pudieran discernir de qué consentimiento (para la epidural, para la cesárea, etc.) se trata, o saber si las usuarias han firmado en la sección del documento que autoriza o no autoriza la intervención médica.

\footnotetext{
${ }^{334}$ Quisiéramos recordar que los propios participantes en el estudio también afirman preferir la opción de la interpretación presencial, ya que, en su opinión, les ofrece la posibilidad de tener mayor cercanía con la usuaria y, además, la presencia física del intérprete les inspira mayor confianza.
} 
Del mismo modo, se debería realizar una difusión más adecuada de estos documentos traducidos, que permitiera conocer su existencia y ubicación. Además, aparte de los documentos de los que actualmente dispone el hospital, se deberían traducir otros documentos relevantes para la asistencia sanitaria, como los relativos a los métodos para paliar el dolor alternativos a la anestesia epidural, los de registro de los recién nacidos, ${ }^{335}$ o el plan de parto del hospital. También sería conveniente traducir la señalética y los rótulos de los hospitales a las principales lenguas de las comunidades inmigrantes o, en su defecto, al menos al inglés y el francés.

Un último factor que podría ayudar a reducir las barreras lingüísticas atañe a los listados de expresiones multilingües de los que dispone el hospital. A nuestro parecer, si bien pueden resultar útiles como estrategia "de último recurso", presentan considerables limitaciones. No obstante, cabe señalar la existencia de aplicaciones informáticas multilingües, como, por ejemplo, UniversalDoctor Speaker, que pueden ayudar a facilitar la comunicación entre profesionales sanitarios y usuarios alófonos mediante la traducción (escrita y oral) de las expresiones y términos más comunes que se pueden plantear en las diferentes consultas médicas. ${ }^{336}$

Mediante la adecuada implantación de las propuestas mencionadas se reducirían considerablemente las barreras lingüísticas entre los profesionales sanitarios y las usuarias alófonas. De esta manera, las usuarias podrían expresar sus dolencias, sus opiniones, sus dudas y sus inquietudes, y los profesionales sanitarios conseguirían explicar los diagnósticos, las técnicas y recomendaciones, y los tratamientos, de modo que se mejoraría sustancialmente la asistencia prestada y se fomentaría la participación de las usuarias en el proceso de atención a su salud. Sin embargo, la supresión de las barreras lingüísticas no es suficiente para garantizar una asistencia sanitaria equitativa y de calidad, ya que las diferencias culturales pueden afectar igualmente a la comunicación y la relación entre los profesionales y las usuarias inmigrantes.

Cabe recordar que, además de las diferencias culturales que existen entre las usuarias de origen extranjero y los profesionales autóctonos, estos últimos suelen presentar un desconocimiento de los principales patrones culturales de las comunidades de usuarias, así como una actitud etnocéntrica, que les lleva a valorar los comportamientos ajenos desde el

\footnotetext{
${ }^{335}$ Cabe señalar que, en el momento en que nos hallamos escribiendo estas líneas (octubre de 2013), el actual Consejo de Ministros ha aprobado un anteproyecto de ley (anteproyecto de Ley de medidas de reforma administrativa en el ámbito de la Administración de Justicia y del Registro Civil) que, entre otras medidas, estipula que la inscripción de los recién nacidos se realice directamente en los centros sanitarios, sin necesidad de que los padres se desplacen físicamente al Registro Civil. Para dicha inscripción, los padres, asistidos por los facultativos que hayan atendido el parto, firmarán el formulario oficial de declaración, al que se incorporará el acreditativo del nacimiento, y que será remitido al Registro Civil desde el propio hospital. Aumenta de este modo la responsabilidad del hospital en todo el proceso de registro de los recién nacidos y, por consiguiente, su responsabilidad en eliminar las barreras que dificulten o impidan dicho registro.

${ }^{336}$ La aplicación multimedia UniversalDoctor Speaker, la cual puede descargarse también como aplicación para el teléfono móvil o para el tablet (iPhone o iPad), presenta, hasta el momento en doce lenguas, la fraseología más usual relativa a cuestiones como la sintomatología, los accidentes, o las consultas de especialidad. Cabe destacar, en relación con el ámbito específico de nuestro estudio, que, además de su versión original, recientemente se ha creado una nueva aplicación denominada UniversalWomen Speaker, destinada exclusivamente a la salud reproductiva, y que cubre las principales situaciones que se pueden dar durante el embarazo, el parto y el puerperio. Para mayor información, puede visitarse la página web: [http://www.universaldoctor.com/] (última consulta: 8 de octubre de 2013).
} 
prisma de la propia cultura, y a aplicar estereotipos y prejuicios a los miembros de dichas comunidades. Con el fin de superar estas barreras culturales, proponemos recurrir a la mediación lingüística y cultural. Mediante sus funciones preventivas, resolutivas y transformadoras o creativas, los mediadores lingüísticos y culturales podrían ayudar a mejorar la comunicación, y a evitar o resolver los malentendidos y conflictos que surgiesen en la interacción entre profesionales y usuarias culturalmente diversos. Al mismo tiempo, podrían promover cambios de actitud y pensamiento consistentes en favorecer el acercamiento y el (re)conocimiento mutuo y, en un sentido más amplio, fomentar la integración de las minorías y la convivencia intercultural.

Los mediadores lingüísticos y culturales podrían actuar tanto en los casos en los que interactuaran pocas personas (como, por ejemplo, en las consultas), como a nivel comunitario, realizando labores de formación, información y sensibilización, de las que hablaremos más ampliamente en el próximo apartado.

Como en el caso de los intérpretes, los mediadores deberían ser profesionales debidamente formados, y se debería realizar una correcta difusión de sus servicios y del modo más adecuado para emplearlos. Consideramos que la mediación lingüística y cultural podría seguir a cargo de las entidades sin ánimo de lucro que, hasta el momento, han venido desempeñando diligentemente estas funciones, como el Servicio de Apoyo a la Mediación Intercultural (SAMI) y la organización Médicos del Mundo, cuyos mediadores se encuentran formados y cuentan con experiencia en este ámbito. Sin embargo, estas entidades deberían recibir más apoyo (financiero e institucional) por parte de la Administración pública, y se debería mejorar su coordinación con los servicios públicos, siguiendo de este modo las recomendaciones de la Proposición no de ley núm. 28/12 sobre la mediación intercultural y apoyo a profesionales y colectivos aprobada en Aragón el pasado año que hemos mencionado anteriormente.

Por consiguiente, nuestras propuestas a corto-medio plazo deberían concretarse en la creación de equipos de trabajo multidisciplinares, en los que intérpretes y mediadores se coordinasen, se complementasen, y tuvieran funciones y roles definidos.

\section{Acciones globales a medio-largo plazo}

Mediante la aplicación de las estrategias previamente mencionadas, se mejoraría considerablemente la comunicación entre los profesionales de la salud y las usuarias de origen extranjero a las que estos atienden, de modo que aumentaría la información que estas últimas pueden transmitir y recibir. No obstante, como se señala en la "Estrategia de atención al parto normal" (2007), simplemente informar a las usuarias no es suficiente, sino que, para garantizar la calidad de la asistencia y su participación en todo el proceso de atención a la salud, es igualmente necesario realizar un cambio sustancial en los modelos de actuación e intervención de los servicios de salud. Teniendo en cuenta que la comunicación intercultural requiere la implicación de las dos partes, este cambio debería producirse en todos los afectados, es decir, en los profesionales sanitarios y en las usuarias inmigrantes $y$, por extensión, en las instituciones en las que trabajan los primeros, y en las familias y comunidades a las que pertenecen las segundas. 
Pasamos, a continuación, a exponer una serie de propuestas cuyo fin es que se produzca el citado cambio en los modelos de actuación y prevención, el cual contribuiría a lograr los siguientes objetivos: favorecer el acceso de las usuarias de origen extranjero al hospital contexto de estudio (o a otros servicios sanitarios de Aragón), mejorar la calidad de la asistencia prestada a dichas usuarias, y permitir que estas participen activamente en el proceso de planificación familiar y de atención al embarazo, el parto y el puerperio.

\section{Formación de los profesionales sanitarios}

Por lo que respecta a los profesionales sanitarios, hemos podido constatar que los conocimientos, habilidades y destrezas de los estos disponen actualmente no son suficientes para superar las dificultades que puede entrañar la asistencia sanitaria a las usuarias inmigrantes. En consecuencia, los profesionales deberían capacitarse mediante actividades formativas, a las que podrían asistir estando ya en activo, o que podrían incluirse de cara al futuro en los planes de estudios universitarios de las diferentes disciplinas médicas.

Sería también conveniente que la formación se dirigiera a los responsables de la gestión, organización y toma de decisiones, lo cual podría conllevar cambios en la estructura organizativa que garantizasen la equidad en el acceso y uso de los servicios por parte de la población inmigrante.

Visto que han sido más bien escasas la aceptación y la asistencia que las actividades de formación organizadas hasta el momento han recibido, se debería estimular e incentivar de algún modo a los profesionales sanitarios, de manera que estos apreciaran los beneficios que dichas actividades pueden aportar a su trabajo diario y, en consecuencia, se aumentara su participación en las mismas.

En resumen, la formación debería contribuir a que el personal sanitario adquiriera y desarrollara una serie de competencias que mejorasen la comunicación y la relación intercultural con las usuarias. Concretamente, las actividades formativas deberían estar centradas en la consecución de los objetivos que exponemos a continuación.

En primer lugar, tal y como se desprende de los resultados de nuestro estudio, los profesionales sanitarios presentan limitados conocimientos sobre las comunidades de origen de las usuarias inmigrantes a las que atienden. Por ello, creemos que su formación debería perseguir la adquisición y desarrollo gradual de la competencia cultural. Con dicho fin, entre los contenidos formativos, se debería incluir información sobre las principales pautas y patrones culturales que influyen en la asistencia a las usuarias de origen extranjero. Dicha información debería contener datos tanto de la cultura general como de la cultura sanitaria de las usuarias, y debería alejarse de la presentación de hechos exóticos y anecdóticos, así como resaltar el carácter cambiante y plural de las culturas. Tal y como plantean Berta Artigas-Lelong y Miquel Bennassar-Veny (2009:45), en las actividades formativas dirigidas a profesionales sanitarios debe plantearse "un concepto de cultura flexible y en constante construcción y reconstrucción y que sea capaz de responder a la variabilidad y a la complejidad de las identidades en un universo esencialmente mestizo", de manera que pudieran ofrecer unos cuidados integrales de calidad a una población culturalmente diversa, sin que ello supusiera diferenciar o clasificar en base al origen étnico o cultural. 
La competencia cultural permitiría a los profesionales sanitarios

[essere] in grado di cogliere le determinanti socioculturali della malattia e della cura, di integrare la nostra visione del corpo come universo che obbedisce alle sole leggi biologiche, alla visione del corpo come somma di tecniche e comportamenti culturalmente determinati, per tentare di collocare positivamente tale visione all'interno della relazione terapéutica (Gomma y Orecchini, 2001:188).

De la misma manera, las actividades formativas deberían ayudar a los profesionales a desarrollar su competencia comunicativa, es decir, permitir que estos fueran conscientes de las diferencias que pueden existir en el uso y la interpretación de los usos verbales y no verbales, y de los valores sociales e individuales que pueden transmitir los diversos modelos conversacionales.

Junto a la competencia comunicativa, los profesionales deberían poseer capacidad para metacomunicarse, es decir, mediante la formación, se debería lograr que estos no dieran por sentado que las usuarias entenderán el mensaje y el sentido implícito del mismo y, por tanto, que fueran capaces de explicar el significado y la intención que subyace a sus palabras.

Del mismo modo, los profesionales deberían adquirir y desarrollar una cierta competencia intercultural, la cual, en el contexto de nuestro estudio, se refiere a los comportamientos, actitudes y políticas de los centros de salud y el personal de los mismos que les permitan trabajar adecuadamente en contextos de elevada multiculturalidad (Cross et al., 1989, citados en Brach y Fraser, 2000:182). Esta competencia incluiría un (re)conocimiento y una toma de conciencia tanto de la propia cultura como de las culturas de las usuarias de origen extranjero, lo cual conduciría a eliminar los estereotipos y prejuicios que, como hemos podido observar, se aplican con tanta frecuencia en el ámbito sanitario.

Por otro lado, deberían manifestar una actitud de empatía, que les permitiera identificarse con las usuarias y, mediante la reflexión sobre la propia cultura, comprender los sentimientos y los puntos de vista de las mismas a partir de sus referentes culturales (Rodrigo Alsina, 2000:4). En relación con el ámbito específico de nuestra investigación, la empatía del profesional al tratar a las usuarias permitiría, tal y como se sostiene en documentos como la "Estrategia Nacional de Salud Sexual y Reproductiva" (2011), que se identificaran las opiniones, inquietudes y expectativas de las usuarias $y$, al mismo tiempo, evitaría que estas vivieran situaciones de estrés, las cuales, por la ansiedad que generan en la madre, podrían perjudicar el desarrollo y estado de salud del bebé.

Como sostiene Josep Maria Comelles (2009:8), incluir entre los objetivos formativos de los profesionales sanitarios el desarrollo de la competencia intercultural y de la empatía no significa que estos deban ser antropólogos o sociólogos,

[...] sino que pueden aprender a utilizar esas técnicas y métodos en su trabajo cotidiano del mismo modo que aprenden metodología clínica o técnicas de cuidado, o simplemente siendo sensibles en la interacción con los pacientes y sus familiares y orientando de manera comprensiva las prácticas que se quieren implantar.

Igualmente, teniendo en cuenta que las situaciones en las que intervienen las usuarias inmigrantes implican cierta novedad (aunque, a medida que pasa el tiempo y es mayor el 
número de usuarias de origen extranjero que frecuentan los hospitales y centros de salud, se ve reducido el carácter novedoso de estas situaciones), los profesionales deberían desarrollar tolerancia a la ambigüedad, flexibilidad y capacidad de adaptación. Estas cualidades conllevarían que la incertidumbre que estos experimentan en las interacciones comunicativas interculturales no les provocara un grado tan alto de ansiedad y preocupación.

Asimismo, gracias a la formación, se debería producir un reequilibrio en las posiciones de los interlocutores propias de la relación asimétrica que se suele dar en el ámbito sanitario. Esta relativa igualdad entre los profesionales y las usuarias no debería conducir a "actitudes paternalistas o victimistas" (Rodrigo Alsina, 1999:243), sino que, como sostiene uno de los profesionales participantes en las entrevistas, se debería fomentar la autonomía de las usuarias y su capacidad de responsabilizarse de sus propios cuidados. Esta opinión es respaldada por el marco legal vigente (Ley 41/2002, de autonomía del paciente) y coincide, además, con las recomendaciones ofrecidas en los diferentes documentos analizados en el capítulo anterior en relación con la atención a las gestantes y puérperas, en los que se indica, por ejemplo, que se debe fomentar la autonomía, la implicación y la participación de las usuarias (EAPN, 2011:88).

La búsqueda de una posición más simétrica en las relaciones con las usuarias de origen extranjero debería ampliarse a las comunidades a las que estas pertenecen. Así, los profesionales deberían demostrar un cierto relativismo cultural, huyendo del establecimiento de universales, sin que ello suponga una aceptación de cualquier patrón cultural, sino entendido como una capacidad de escucha, de consideración de los puntos de vista ajenos, y de modificación de los propios comportamientos y patrones culturales (Bacetti, 2001:121).

Cabe señalar que los conocimientos, habilidades y actitudes desarrollados a partir de estas actividades formativas podrían suponer para el personal sanitario una ocasión para convertirse en profesionales mucho más competentes (también en el ámbito isocultural), así como en personas mucho más ricas intelectual y humanamente.

Por último, considerando que en un gran número de ocasiones los profesionales de la salud, al comunicarse con las usuarias de origen extranjero, deberán recurrir a intérpretes y mediadores para que realicen labores de intermediación (lingüística y cultural), creemos conveniente, como hemos apuntado con anterioridad, que se informe a los miembros del personal del hospital (u otros servicios sanitarios) del papel y las funciones de estos intermediarios, del modo y el momento más adecuados para solicitar sus servicios, y de la actitud y el comportamiento que se deben adoptar cuando la conversación pasa de establecerse directamente con la usuaria a ser tripartita.

\section{Actividades de información, educación y sensibilización de las usuarias}

Por lo que se refiere a las usuarias inmigrantes, ya hemos comentado anteriormente que simplemente transmitirles información (a veces, de modo anecdótico, mediante la edición de materiales y guías multilingües) no garantiza que estas puedan acceder y usar los servicios sanitarios y participen activamente en la toma de decisiones que afectan a su proceso de salud. 
Por consiguiente, creemos que resultaría conveniente que se organizasen actividades de información, sensibilización y educación dirigidas a las usuarias de origen extranjero, las cuales deberían incluir contenidos relacionados no solo con el acceso y uso de los servicios sanitarios (el funcionamiento de los mismos, las figuras profesionales que trabajan en ellos, los procedimientos administrativos más comunes, etc.), sino también con aspectos relativos a la prevención y promoción de la salud (métodos de planificación familiar, modos para paliar el dolor durante el parto, pautas recomendables durante el puerperio, etc.). La incorporación de estos contenidos fomentaría la preservación de la salud, promoviendo hábitos saludables, y reduciendo el riesgo de contraer enfermedades, y favorecería, al mismo tiempo, la detección y tratamiento temprano de estas últimas (Kok, van den Borne y Mullen, 1997, citados en Brach y Fraser, 2000:186).

Cabe resaltar que, en la organización de estas actividades, deberían tenerse en cuenta los patrones culturales de origen de las usuarias a las que estas van dirigidas. De hecho, como sostienen Cindy Brach e Irene Fraser (2000:186), "in an attempt to make health-promotion efforts more culturally competent, culture-specific attitudes and values should be incorporated into messages and materials".

Tanto de estas actividades destinadas a las usuarias como de la formación de los profesionales sanitarios podrían encargarse, como han venido haciendo hasta ahora, los mediadores lingüísticos y culturales del SAMI o de Médicos del Mundo, pero estos deberían contar con el apoyo y el respaldo institucional que garantizase el éxito de estas iniciativas.

\section{Adecuación a las necesidades específicas}

Aparte de los directamente implicados (profesionales sanitarios y usuarias), sería necesario que se produjera un cambio en los servicios y el sistema de salud, de manera que estos fueran capaces de atender con las mayorías garantías de calidad y equidad a las usuarias lingüística y culturalmente diversas.

Somos conscientes de que las actuales infraestructuras, prácticas y rutinas del hospital no permiten que se produzca una rápida adecuación a las necesidades específicas de estas usuarias. Estos factores, unidos a las actuales carencias presupuestarias y a la presión asistencial característica de los servicios de salud, implican que la adaptación de los servicios se deba producir de manera relativamente lenta y progresiva, pero consideramos que, no por ello, se debe dejar de lado este objetivo.

Nuestra propuesta consiste en abogar por un sistema mixto, que conjugue las actuales particularidades y prácticas del sistema de salud con la inclusión gradual de nuevas pautas en el funcionamiento de los servicios y en la rutina de trabajo de los profesionales. Al respecto de la posibilidad de conciliar los patrones culturales de origen con los de la sociedad de acogida, estamos de acuerdo con Zuanilda Mendoza (2009:313), cuando sostiene que

Postular la existencia de un sistema mixto nos lleva a aceptar la presencia de diferentes alternativas de atención -no siempre integradas armónicamente-, así como a pensar que todo proyecto o programa (de atención a la salud reproductiva) debe advertir la importancia de la diversidad. 
Entre los cambios a introducir, se deberían ofrecer alternativas concernientes no solo a los aspectos más superficiales (como los menús del hospital), sino también en relación con el proceso de salud reproductiva, abarcando, por consiguiente, aspectos referidos, por ejemplo, a los métodos anticonceptivos, las posiciones adoptadas durante el parto, o las técnicas de alivio del dolor. Cabe destacar que, de estos cambios, no solo se beneficiarían las usuarias inmigrantes, sino también las usuarias autóctonas que así lo deseasen.

La adaptación de los métodos y técnicas sanitarios a las necesidades, valores, creencias, experiencias y hábitos de las usuarias fomentaría la participación de estas, así como su satisfacción con la atención recibida.

Un objetivo a largo plazo que, a nuestro modo de ver, debería plantearse el hospital consiste en alcanzar los requisitos para obtener la certificación iHan (Iniciativa para la Humanización de la Asistencia al Nacimiento y la Lactancia), cumpliendo de este modo con la humanización y personalización del proceso reproductivo postuladas en documentos como la "Estrategia de atención al parto normal” (2007).

\section{Investigación sobre las pautas y las necesidades de las usuarias inmigrantes}

No es posible lograr alcanzar el objetivo de adecuación previamente expuesto sin que se conozcan las necesidades reales de las usuarias. Por consiguiente, creemos que se deberían realizar más investigaciones encaminadas a obtener estos conocimientos. Al respecto, ya hemos comentado que el hospital contexto de estudio carece de datos disgregados por nacionalidad de las usuarias, y consideramos que este debería realizar un estudio del perfil obstétrico y neonatal de las gestantes y puérperas de origen extranjero. Asimismo, creemos que investigaciones como la que hemos desarrollado podrían resultar de utilidad para el hospital en el que esta ha tenido lugar. De hecho, consideramos, desde la humildad y teniendo en cuenta la envergadura limitada de nuestro estudio, que los resultados del mismo podrían contribuir en cierto sentido a que los profesionales sanitarios comprendieran los múltiples factores implícitos en la asistencia a usuarias inmigrantes, y a impulsar cambios en la comunicación y en la relación con dichas usuarias que mejorasen la calidad de la atención prestada.

Por otro lado, como el hospital es una estructura dependiente en muchos sentidos de la Administración pública autonómica, también se deberían realizar estudios de carácter más general sobre los patrones reproductivos de las mujeres inmigrantes residentes en Aragón que dieran a conocer a los responsables de la gestión y las políticas sanitarias las dificultades que se presentan actualmente en la atención a estas mujeres y los patrones culturales que las caracterizan. Las investigaciones deberían abarcar, además, otros ámbitos de la salud, y estar centradas en los diferentes colectivos que conforman la población inmigrante que reside en esta comunidad autónoma, ${ }^{337}$ teniendo en cuenta, como señalan Juan Oliva y Gloria Pérez (2009:2), que

\footnotetext{
${ }^{337}$ Asimismo, cabría estudiar los patrones propios de la comunidad gitana, la cual, pese a no encontrarse entre los colectivos inmigrantes, presenta características culturales que también la diferencian considerablemente del resto de la población autóctona.
} 
Las políticas de salud no deben considerar a los inmigrantes como un colectivo homogéneo, sino que se debe estudiar qué tipo de intervenciones son más adecuadas en función de las características de los ciudadanos a quienes van dirigidas. Establecer e identificar la relación entre la salud de las personas y sus determinantes, como los estilos de vida, las influencias sociales y comunitarias, las condiciones laborales y el uso de los servicios sanitarios, es lo que nos permitirá orientar aquellas políticas destinadas a proteger la salud de la población.

Todos estos estudios permitirían descubrir las necesidades reales de los distintos usuarios de los servicios de salud y poner en marcha (con las limitaciones presupuestarias a considerar) aquellas iniciativas que pudieran favorecer la adecuación de los mismos a dichas necesidades.

\section{Implicación de las familias, los líderes comunitarios y los sanadores tradicionales}

Los profesionales sanitarios y las usuarias no son los únicos implicados en el proceso de atención a la salud (reproductiva), sino que, además, participan dos entidades sociales, respectivamente, la institución sanitaria y la familia o la comunidad a las que pertenecen, las cuales influirán en los comportamientos y creencias de los primeros concernientes al proceso de atención a la salud.

Ya hemos comentado de qué manera deberían implicarse las instituciones sanitarias y los responsables de las políticas en materia de salud. Por su parte, dependiendo de las características culturales de las usuarias, estas podrían preferir una mayor implicación de sus familias en el proceso de atención de la que suele ser usual en nuestro sistema de salud. Así, como señala Anne Fadiman (1997), involucrar a las familias y, en las sociedades con marcadas jerarquías sociales, incluso a los líderes comunitarios, puede resultar de vital importancia para asegurar el consentimiento y la adherencia a las técnicas y los tratamientos propuestos por el personal sanitario.

Por lo que respecta al ámbito específico de nuestro estudio, cabe recordar que, en los documentos que contienen recomendaciones sobre la atención a la salud reproductiva, la implicación de la familia es considerada de notable importancia; de hecho, en la "Estrategia de atención al parto normal" (2007:65) se indica que

La institucionalización y medicalización del parto fue el factor determinante para separar a la familia en el momento del nacimiento. La estructura física de las instituciones y las rutinas hospitalarias fueron diseñadas para atender más a las necesidades de los profesionales de la salud que a las parturientas y sus familias. Existe una contradicción entre lo que la evidencia indica y la manera en que se organizan las prácticas asistenciales. El acompañamiento durante el parto integra la estrategia de humanización del parto.

Del mismo modo, los miembros de las comunidades de las usuarias podrían implicarse en las mencionadas actividades de información y sensibilización a estas dirigidas. De acuerdo con Marisa Ros y Carmen Ollé (2006:93), el recurso a estas personas para que participen activamente en la organización y puesta en marcha de dichas actividades provocaría cambios en el seno de la comunidad, los cuales se producirían, por una parte, a nivel individual, modificando conocimientos, actitudes, creencias y comportamientos de cada uno de los asistentes en particular $y$, por otra parte, a nivel social, ya que conllevarían modificaciones en las normas internas del grupo mediante la acción colectiva. 
Otra forma de implicación de las comunidades estaría constituida por el empleo de los conocidos como agentes comunitarios, definidos por Marisa Ros y Carmen Ollé (2006:95) como

[...] un profesional miembro de la comunidad con la que se trabaja, que se integra dentro del equipo de salud y cuyo objetivo es convertirse en puente entre los servicios informativos y asistenciales, con el fin de mejorar la difusión de la información, de las iniciativas y los recursos entre ambas partes, así como para promover y dinamizar acciones de promoción de la salud para cada uno de los grupos implicados o de forma conjunta.

Por último, cabe recordar que no todas las culturas recurren a las mismas figuras a la hora de solicitar asistencia sanitaria y, de hecho, en los sistemas médicos tradicionales, a diferencia de lo que ocurre en el sistema biomédico, esta responsabilidad recae sobre sanadores que ostentan el poder de curar y que, normalmente, son poseedores de conocimientos y costumbres milenarios. Es, por tanto, bastante frecuente, que los miembros de las culturas en las que se recurre a la medicina tradicional consulten a este tipo de sanadores antes, simultáneamente o en sustitución de los profesionales de la salud occidentales, o escojan a uno $o$ a otro dependiendo de la dolencia específica que padezcan. Por consiguiente, con el fin de garantizar la continuidad de los tratamientos prescritos y evitar que se produzcan complicaciones derivadas de la simultaneidad de terapias incompatibles, sería conveniente implicar también a estos sanadores tradicionales en los cuidados de las usuarias que así lo desearan. El recurso a estas figuras sanadoras, permitiría, asimismo, que se presentaran las explicaciones médicas de los profesionales sanitarios occidentales "in a conceptual framework concordant with cultural beliefs and traditional health practices (which) may increase the chances that patients will concur with and adhere to behavioral and treatment recommendations" (Brach y Fraser, 2000:185).

\section{Empleo de profesionales sanitarios de otras procedencias en los servicios y centros de salud}

Mediante el empleo de profesionales sanitarios procedentes de otros países y culturas sería posible la atención directa en el idioma de las usuarias de su misma procedencia y, al mismo tiempo, se ayudaría al personal sanitario a comprender el comportamiento y las necesidades de las usuarias, los sistemas sanitarios y las terapias de sus países de origen, así como a adquirir la competencia intercultural previamente mencionada. De hecho, se suele afirmar que estos profesionales "because of their shared cultural beliefs and common language, may improve communication, create a more welcoming environment, and structure health systems to better reflect the needs of minority communities" (Cooper-Patrick et al. 1999 y Nickens, 1992, citados en Brach y Fraser, 2000:185).

No obstante, recurrir a profesionales de diferentes orígenes para atender a la población inmigrante no es una panacea, puesto que esta estrategia presenta también sus limitaciones. Así, como sostiene, Antoine Gailly (2010:35), la coincidencia cultural entre el usuario inmigrante y el profesional

[...] genera una especie de sentimiento de "nosotros" y un lenguaje común, por parte del paciente, y tiende a convertirse en una situación intracultural [...]. Algunos afirman que entonces los problemas culturales e idiomáticos tienen menos influencia en el proceso de asistencia, porque profesional y paciente comparten un idioma y una cultura comunes, además 
de experiencias de emigración y discriminación. (Sin embargo) Incluso aquellos con los mismos antecedentes étnicos, muestran diferencias en conocimientos idiomáticos y culturales y en sus experiencias con la emigración y su implicación con la cultura de origen. (comillas del original)

Por lo que respecta al hospital contexto de nuestra investigación, cabe señalar que en él trabajan diferentes profesionales de origen extranjero, pero su número es bastante escaso, por lo que, a nuestro parecer, podría incrementarse. De todos modos, cabe considerar que, como hemos comentado con anterioridad, la contratación de personal sanitario de otros países se ve dificultada por el hecho de que resulta complicado, en muchos casos, convalidar los títulos de estudio obtenidos en el extranjero. Por este motivo, creemos que las autoridades competentes deberían agilizar y simplificar estos procesos de convalidación.

\section{Difusión de los recursos disponibles y coordinación}

Una de las deficiencias de las soluciones implantadas hasta el momento en el contexto de nuestro estudio, tal y como hemos señalado previamente, se refiere al hecho de que no se ha realizado una correcta difusión de los recursos disponibles, de modo que no se conoce su existencia o el modo en el que se pueden solicitar, por lo que se encuentran infrautilizados. Por consiguiente, consideramos que es necesario mejorar la difusión de dichos recursos, de manera que no se desaprovechen y se efectúe un adecuado uso de los mismos.

Con el mismo fin, cabría, además, mejorar la coordinación entre los diferentes profesionales, así como entre las instituciones y entidades para los que estos trabajan, pues con frecuencia la ausencia de coordinación conlleva también un mal uso o una escasa utilización de los recursos y estrategias.

Por otro lado, cabe resaltar la labor llevada a cabo por los creadores de diversos portales web $^{338}$ que albergan catálogos de recursos muy variados (materiales multilingües, enlaces de interés, pictogramas, etc.) que pueden resultar de gran utilidad tanto a los profesionales sanitarios como a los usuarios inmigrantes que estos atienden.

En definitiva, consideramos que se debería realizar un análisis riguroso de los recursos de los que se dispone, seguir avanzando en lo que está funcionando, y modificar o eliminar lo que no está dando buenos resultados.

\footnotetext{
338 Entre dichos portales con catálogos de recursos, podemos citar, por ejemplo, www.saludycultura.uji.es/equipo.php (portal gestionado por el Grupo CRIT de la Universidad Jaume I), www.saludinmigrantes.es (portal puesto en marcha por un grupo de investigadores de diferentes disciplinas, como Medicina, Enfermería o Antropología, de la Universidad de Alcalá), o www.saludentreculturas.es (portal creado por un equipo multidisciplinar que desarrolla proyectos en el ámbito de la promoción de la salud con población autóctona e inmigrante en todo el territorio español). Por lo que respecta a nuestro ámbito de estudio (las mujeres inmigrantes y su salud reproductiva), cabe mencionar, por ejemplo, el blog de la asociación sin ánimo de lucro Amalgama, constituida por mujeres latinoamericanas residentes en España [http://mujeresamalgama.blogspot.com.es/], o el blog del Grupo Lactard, compuesto por madres con diferentes experiencias personales y profesionales que desean compartir sus experiencias con respecto a la maternidad y la crianza [http://grupolactard.blogspot.com.es/] (última consulta: 9 de octubre de 2013).
} 


\section{Análisis de buenas prácticas llevadas a cabo por otros hospitales y aplicación al contexto específico}

Una última estrategia que, en nuestra opinión, podría servir para mejorar la calidad de la asistencia prestada a las usuarias inmigrantes consistiría en el análisis de las buenas prácticas que se están llevando a cabo en hospitales del contexto nacional, para su posterior puesta en marcha en el hospital contexto de estudio, adaptándolas a las características que este presenta.

Por ejemplo, como hemos comentado en el capítulo 5, son diversos los hospitales españoles que han empleado a intérpretes y mediadores lingüísticos y culturales con excelentes resultados. ${ }^{339}$ Así, como afirma Francisco Raga (2006:228),

[...] las experiencias que se vienen desarrollando avalan que la presencia generalizada de mediadores interculturales en ambulatorios, centros de salud y hospitales garantiza una mejora en el acceso de la población extranjera a la sanidad.

Asimismo, el hospital contexto de nuestra investigación ( $y$, por extensión, los servicios sanitarios aragoneses), podrían tener en cuenta la experiencia de los hospitales participantes en la previamente mencionada iniciativa "Hospitales amigos del inmigrante en una Europa etnoculturalmente diversa", así como las recomendaciones de la Declaración de Ámsterdam que surgió de este proyecto, entre las cuales, se indica que se deberían ofrecer servicios más individualizados y orientados a las personas, se deberían producir cambios en la comunicación, en las rutinas organizativas y en la asignación de recursos, y se debería recordar que el estatus del inmigrante, su ascendencia étnica, su origen cultural y su filiación religiosa son solo algunas de las muchas dimensiones de la complejidad del ser humano.

De este modo, el hospital estudiado podría convertirse en un "hospital amigo del inmigrante", en el que se valorara

[...] la diversidad aceptando a personas con diversos orígenes sobre todo como miembros iguales ante la sociedad, identificando las necesidades de personas con distintos orígenes y controlando y desarrollando servicios en relación con estas necesidades y, finalmente, compensando las desventajas debidas a los diferentes orígenes. (Declaración de Ámsterdam, 2004:1)

Para concluir este apartado, cabe señalar que, indudablemente, las usuarias inmigrantes deben adaptarse a los servicios sanitarios y al sistema de salud de la sociedad de acogida, pero dicha adaptación debe ser mutua. Consideramos que solo un acercamiento y un (re)conocimiento mutuo por parte de todos los sujetos implicados, así como el respeto y la búsqueda de objetivos comunes permitirán que exista entre ellos una comunicación intercultural eficaz, mejorando, en consecuencia, el acceso y uso de los servicios de salud por parte de la población inmigrante, y fomentando tanto la calidad y la equidad en la asistencia sanitaria, como el grado de satisfacción global. Por último, quisiéramos subrayar que la adaptación de las estructuras, las prácticas y el funcionamiento del hospital contexto de

\footnotetext{
${ }^{339}$ Recordemos que, entre estos hospitales, se encuentran, por ejemplo, el Hospital Ramón y Cajal de Madrid, el Hospital Punta Europa de Algeciras, el Hospital del Mar y el Hospital Vall d'Hebron (ambos en Barcelona), y el Hospital de Poniente de El Ejido.
} 
estudio y, por extensión, de los servicios sanitarios aragoneses a las particularidades de los usuarios de origen extranjero contribuiría, por supuesto, a la mejora de la asistencia prestada a estos usuarios, pero también ofrecería la posibilidad de reflexionar y modificar positivamente la atención a la salud de los usuarios autóctonos.

\subsubsection{Propuestas de mejora generales y conclusiones finales}

Tras la exposición de las propuestas aplicables al contexto específico de nuestro estudio, pasamos, en este último apartado, a presentar una serie de reflexiones finales centradas en la labor que figuras profesionales como los intérpretes en los servicios públicos y los mediadores lingüísticos y culturales pueden desempeñar en los servicios sanitarios del contexto nacional. Nuestro propósito, en este apartado, consiste principalmente en presentar brevemente las condiciones en las que actualmente deben trabajar estos profesionales, y en exponer los factores que se deberían dar para mejorar su situación. En ambos casos, veremos que los elementos que constituyen la actual situación, por un lado, y los que deberían darse para mejorarla, por otro, están estrechamente interrelacionados e influyen inevitablemente en el resto.

El incremento de la población inmigrante en nuestro país y la incorporación al sistema de salud de unos usuarios con particularidades y necesidades específicas ha propiciado la búsqueda de soluciones que fomentasen la comunicación con estos "nuevos" usuarios y que, en consecuencia, permitiesen que la asistencia prestada a los mismos fuera adecuada. Así, en algunos hospitales y centros de salud españoles, como hemos señalado en anteriores capítulos y apartados, se ha recurrido a intérpretes y mediadores profesionales como medio para alcanzar los objetivos descritos, aunque cabe señalar que el empleo de estas figuras resulta todavía demasiado escaso. De hecho, son numerosas las ocasiones en las que se utiliza a intérpretes y mediadores ad hoc para llevar a cabo funciones de intermediación en las consultas a pacientes de origen extranjero, con las consecuencias nefastas que dicha utilización, como hemos visto, puede implicar.

En primer lugar, quisiéramos destacar una vez más cómo, de acuerdo con diferentes estudios, la adecuación lingüística y cultural de los servicios sanitarios mediante el recurso a la interpretación (ISSPP) y la mediación (MLC) conlleva mejores resultados por lo que se refiere a la salud de los usuarios inmigrantes y en cuanto a la satisfacción de todos los implicados en el proceso de asistencia. Al respecto, por ejemplo, ha quedado demostrado que la intervención de intérpretes y mediadores puede favorecer la disminución del número de visitas, una mayor regularidad en el seguimiento de los tratamientos prescritos, y una reducción en la duración media de las hospitalizaciones (Torre, 2006; De Muynck, 2004, citados en Sandín, Río y Larraz, 2012:39). Del mismo modo, puede implicar un ahorro en pruebas analíticas, cuyo número aumenta en los casos en los que los profesionales no logran comunicarse con los pacientes de origen extranjero. Por consiguiente, estamos completamente de acuerdo con Caminee Blake (2003, citada en Leanza, 2007:12), cuando afirma que "if the goal is the best care possible, it is an ethical imperative to hire such professionals in medical settings".

Pese a las evidencias de que las mencionadas figuras profesionales pueden fomentar la comunicación con los usuarios inmigrantes y mejorar la calidad de la atención sanitaria, ambas se encuentran todavía en un estado poco avanzado por lo que respecta a su desarrollo y 
reconocimiento en España. De hecho, las dos carecen de una denominación unívoca y una definición clara de sus funciones, lo cual conlleva que a menudo exista confusión entre los límites que existen entre ellas y, al mismo tiempo, que se tenga un concepto infravalorado de su labor, el cual se traduce en la opinión generalizada de que cualquier persona con unos mínimos conocimientos lingüísticos y/o culturales puede ejercer como intérprete o mediador.

Asimismo, la percepción social de estas figuras profesionales suele ser bastante baja, debido a la asociación de sus labores con un colectivo de la población (los inmigrantes) por los cuales no se siente un especial interés en general, o incluso a los que se llega a rechazar. Así, de acuerdo con Joseph Tseng (1992, citado en Mikkelson, 1996),

Because foreigners and foreign languages are not viewed favorably [...], and because of the anti-immigrant, anti-criminal defendant sentiment prevailing in many societies today, anyone associated with immigrants is regarded as undesirable. Consequently, providing qualified interpreters (and mediators) [...] is a low priority.

Por otro lado, son todavía limitadas las ofertas formativas en estas disciplinas, y ni la ISSPP ni la MLC cuentan con un título de estudios reconocido, si bien es cierto que la primera se halla algo más consolidada que la segunda, tanto por lo que se refiere a la formación de carácter oficial, como en cuanto a la investigación llevada a cabo.

A su vez, todos estos factores implican que las condiciones laborales de intérpretes y mediadores sean precarias. Esta precariedad, además, aleja de la profesión a personas muy valiosas que deciden dedicarse a otros menesteres mejor considerados y valorados, por lo que frecuentemente acaban ocupándose de desempeñar estas tareas voluntarios con muy buena voluntad, la cual no siempre va acompañada de las debidas formación y preparación. Y, al mismo tiempo, como señala Cecilia Wadensjö (1998:52),

The instability and stress of the labour market has sometimes made community interpreters (and intercultural mediators) refrain from putting effort and time into achieving professional qualification, that is, when and if professional training is available, and affordable.

Por todo lo expuesto hasta el momento, consideramos que intérpretes y mediadores deberían trabajar conjuntamente, colaborar de forma constructiva y complementaria, y aunar fuerzas para alcanzar un objetivo común, consistente en la profesionalización y el reconocimiento de su labor. Con el fin de lograr dicho objetivo, de acuerdo con diversos autores (Corsellis, 2002; Mikkelson, 1996; Roberts, 1994; Wadensjö, 1998), se deben dar una serie de factores, cada uno de los cuales influye sobre el resto, de manera que se deberían producir de manera circular, "with each phase providing feedback and reinforcement to the previous phase" (Mikkelson, 1996). Dichos factores son principalmente los siguientes:

En primer lugar, se debería adoptar una denominación unívoca para referirse a los intérpretes en los servicios públicos y a los mediadores lingüísticos y culturales, lo cual contribuiría, sin duda, a reducir la confusión que existe entre la labor de ambos y evitaría que se les solicitase asumir funciones que no les corresponden. En relación con este último aspecto, resulta necesario que se presente una delimitación de su papel y sus funciones, con el fin de evitar solapamientos y contribuir a que se emplee a estos profesionales del modo más adecuado y provechoso posible. 
Asimismo, se deberían desarrollar programas de formación homogéneos y coherentes, en los que se recogieran las experiencias exitosas de instituciones universitarias y otras entidades que han ofertado hasta el momento titulaciones y cursos centrados en la ISSPP y en la MLC. La formación no debería estar únicamente destinada a los futuros intérpretes y mediadores, sino que también deberían recibirla los usuarios de sus servicios y los responsables de la gestión y las políticas sanitarias. Las actividades formativas dirigidas a estos últimos conllevarían una mayor concienciación y sensibilización con respecto a la conveniencia de utilizar a personas preparadas para facilitar la comunicación entre los profesionales sanitarios y los usuarios inmigrantes, así como en relación con la complejidad inherente a la intermediación lingüística y cultural en ámbito sanitario. Como señala Hans Verrept (2008:200), si los profesionales de la salud y los responsables de la organización de los servicios sanitarios no están debidamente concienciados y sensibilizados sobre estas cuestiones,

[...] there is a real danger that intercultural mediators (and interpreters) will be perceived as low-qualified health workers who hand down information, as dictated by Western biomedicine to the members of their community (which) may seriously hamper the impact of intercultural mediation (and interpretation) on the quality of care.

Igualmente, se debería establecer un código de conducta que guiara a los profesionales de la interpretación y de la mediación en el desempeño de sus labores y, al mismo tiempo, ofreciera una garantía de la actuación de los mismos de conformidad con unos principios éticos básicos.

Sería, además, conveniente que se estableciera un sistema de certificación oficial, lo cual no solo serviría para asegurar la preparación de estos profesionales y la calidad de sus servicios, sino que, simultáneamente, contribuiría a su reconocimiento tanto por parte de las autoridades como por parte de la sociedad en general.

Por último, la constitución de asociaciones de intérpretes y mediadores aumentaría su visibilidad, y constituiría un punto de encuentro en el que estos profesionales podrían poner en común sus experiencias y sus conocimientos.

En la consecución de los factores expuestos deberían participar, como sostiene Ann Corsellis (2002:30), diferentes grupos directa o indirectamente implicados, constituidos por los servicios públicos (o, en nuestro caso, los servicios sanitarios) y los profesionales que en estos trabajan, los propios intérpretes y mediadores, los académicos e investigadores, los gobiernos, los funcionarios y los ciudadanos autóctonos, y los miembros de la población inmigrante.

Como resultado de todo este proceso, tal y como afirma Holly Mikkelson (1996), la ISSPP (y, por extensión, la MLC), sería "[...] a strong and respected profession with a recognized body of knowledge and credentials process, a financially and intellectually rewarding occupation that will attract the most qualified practitioners".

A modo de conclusión final, cabe resaltar que consideramos que la vulnerabilidad de los usuarios de origen extranjero, las dificultades a las que se enfrentan al acudir a los servicios sanitarios, y las posibles consecuencias derivadas de dichas dificultades tienen que ser un factor determinante de movilización de recursos. Las administraciones públicas deben seguir haciendo un gran esfuerzo para situar a nuestros sistemas de salud en una posición que permita responder a los problemas de comunicación que surgen entre los profesionales y los 
pacientes no autóctonos (Bischoff, Loutan y García, 1998:8). En nuestra opinión, un modo adecuado para reducir o eliminar estos problemas comunicativos consiste en el recurso a intérpretes y mediadores profesionales, el cual, unido a las estrategias e iniciativas que hemos descrito en anteriores apartados, contribuiría, sin lugar a dudas, a eliminar las disparidades que se dan en la asistencia sanitaria prestada a la población inmigrante y, en consecuencia, a garantizar la calidad y la equidad de dicha asistencia en una sociedad realmente intercultural. 


\section{BIBLIOGRAFÍA}




\section{BIBLIOGRAFÍA}

ABRIL, María Isabel (2006). La Interpretación en los Servicios Públicos: Caracterización como género, contextualización y modelos de formación. Hacia unas bases para el diseño curricular, Tesis doctoral, Universidad de Granada, Departamento de Traducción e Interpretación. [http://hera.ugr.es/tesisugr/16235320.pdf] (última consulta: 17 de septiembre de 2013).

ABRIL, María Isabel (2008). "La interpretación en los servicios públicos en la Unión Europea: Una selección de panoramas nacionales", III Jornada Internacional de bones pràctiques de gestió del multilingüisme. Els serveis de traducció, interpretació i mediació a les llengües dels immigrants, 2 de octubre de 2008, Barcelona. [http://www10.gencat.cat/casa_Ilengues/binaris/conferencia_abril_tcm302113452.pdf] (última consulta: 28 de septiembre de 2013).

AEP Desenvolupament Comunitari y Andalucía Acoge (2002). Mediación intercultural. Una propuesta para la formación, Madrid: Editorial Popular.

AGUADO, Teresa et al. (2002). Mediación intercultural en el ámbito socioeducativo. Análisis de necesidades de formación y recursos, Madrid: Consejería de Educación.

AGUSTÍ, Jordi (2003). The Complex Plasticity of Mediation. Intercultural Mediators in Catalonia, Tesis doctoral, Stanford University, Stanford Law School. (Inédita).

AIXELÀ, Yolanda (2010). "Mujeres, reproducción y contracepción en Marruecos" en COMELLES, Josep Maria et al. Migraciones y salud, Tarragona: Publicacions de la Universitat Rovira i Virgili, pp. 251-264.

ALEXANDER, Claire et al. (2004). Access to Services with Interpreters: User Views, Londres: Joseph Rowntree Foundation/London South Bank University. [http://www.jrf.org.uk/bookshop/eBooks/1859352294.pdf] (última consulta: 10 de mayo de 2013)

ALONSO, Estanis y Tona LIZANA (2009). "Los sistemas sanitarios en nuestro entorno" en CASAS, Miquel, Francisco COLLAZOS y Adil QURESHI (coords.) Mediación intercultural en el ámbito de la salud. Programa de formación, pp. 31-58. [http://multimedia.lacaixa.es/lacaixa/ondemand/obrasocial/pdf/inmigracion/Mediacio _intercultural_es.pdf] (última consulta: 10 de agosto de 2013). 
ALONSO, Luis (1994). "Sujeto y discurso en la entrevista abierta en las prácticas de la sociología cualitativa" en DELGADO, Juan y Juan GUTIÉRREZ (coords.). Métodos y técnicas cualitativas de investigación en ciencias sociales, Madrid: Síntesis, pp. 277-300.

ALONSO, Marta (2010). "Mujeres inmigrantes marroquíes en el sistema sanitario catalán" en COMELLES, Josep Maria et al. Migraciones y salud, Tarragona: Publicacions de la Universitat Rovira i Virgili, pp. 358-373.

ÁLVAREZ-GAYOU, Juan Luis (2003). Cómo hacer investigación cualitativa: fundamentos y metodología, México: Paidós.

AMEZCUA, Manuel (2000). "El Trabajo de Campo Etnográfico en Salud. Una aproximación a la observación participante" en Index de Enfermería [Index Enferm] (edición digital), 30, pp. 30-35. [http://www.index-f.com/index-enfermeria/30revista/r30_articulo_3035.php] (última consulta: 18 de enero de 2013).

AMEZCUA, Manuel (2003). "La entrevista en grupo. Características, tipos y utilidades en investigación cualitativa" en Enfermería clínica, 13(2), pp.112-17.

AMEZCUA, Manuel y Alberto GÁLVEZ (2002). “Los modos de análisis en investigación cualitativa en salud: perspectiva crítica y reflexiones en voz alta" en Revista Española de Salud Pública, 76, pp. 423-436.

AMEZCUA, Manuel y Antonia CARRICONDO (2000). "Investigación Cualitativa en España. Análisis de la producción bibliográfica en salud" en Index de Enfermería [Index Enferm] (edición digital), 28-29, pp. 26-34. [http://www.index-f.com/index-enfermeria/2829revista/28-29_articulo_26-34.php] (última consulta: 22 de enero de 2013).

ANGELELLI, Claudia V. (2003). "The interpersonal role of the interpreter in cross-cultural communication: Survey of conference, court, community, and medical interpreters in the U.S., Canada and Mexico" en BRUNETTE, Louise et al. (eds.) The Critical Link 3: Interpreters in the Community, Amsterdam/Filadelfia: John Benjamins Publishing, pp. 289-302.

ANGELELLI, Claudia V. (2004). Medical Interpreting and Cross-cultural Communication, Cambridge: Cambridge University Press.

ANGELELLI, Claudia V. (2006). "Validating professional standards and codes. Challenges and opportunities" en Interpreting, 8(2), pp. 175-193.

ANGELELLI, Claudia V. (2008). "The role of the interpreter in the healthcare setting. A plea for a dialogue between research and practice" en VALERO, Carmen y Anne MARTIN (eds.) 
Crossing Borders in Community Interpreting. Definitions and Dilemmas, Amsterdam/Filadelfia: John Benjamins Publishing, pp. 147-163.

ANICH, Rudolf, Tara BRIAN y Frank LACZKO (2013). "Tendencias de la migración: Comparación de las cuatro direcciones" en Organización Internacional para las Migraciones (OIM) Informe sobre las migraciones en el mundo 2013. El bienestar de los inmigrantes y el desarrollo, pp. 54-87. [http://publications.iom.int/bookstore/free/WMR2013_SP.pdf] (última consulta: 15 de septiembre de 2013).

ANTONIN, Monserrat (2011). La mediación intercultural en el sistema de salud de Cataluña, Tesis doctoral, Universitat Rovira i Virgili, Departamento de Antropología, Filosofía y Trabajo Social. [http://www.tdx.cat/bitstream/handle/10803/8442/TESIS.pdf;jsessionid=C9AC977D9D 8677EB2C68767A06BFBB31.tdx2?sequence=1] (última consulta: 24 de septiembre de 2013).

ARBOLEDA, Luz M. (2008). “El grupo de discusión como aproximación metodológica en investigaciones cualitativas" en Revista de la Facultad Nacional de Salud Pública, vol. 26, no 1, pp. 69-77, Medellín, Colombia: Universidad de Antioquía.

ARTIGAS-LELONG, Berta y BENNASAR-VENY, Miquel (2009). "La salud en el siglo XXI: El reto de los cuidados multiculturales" en Index de Enfermería (versión impresa), vol. 18, № 1, pp. 42-46. [http://scielo.isciii.es/scielo.php?script=sci_arttext\&pid=S1132$12962009000100009 \& \operatorname{lng}=e s \& n r m=i s o]$

Asociación Médica Mundial (1948). Declaración de Ginebra. [http://www.wma.net/es/30publications/10policies/g1/] (última consulta: 10 de agosto de 2013).

BABBIE, Earl R. (1979). The Practice of Social Research, 11a edición, Belmont, CA: Wadsworth, 2007.

BACCETTI, Sonia (2001). La comunicazione interculturale in sanità, Milán: Centro Scientifico Editore.

BAHADIR, Şebnem (2001). "The Empowerment of the (Community) Interpreter: The Right to Speak with a Voice of One's Own", Conference papers presented in the Critical Link 3 Conference, 2001, Montreal. [http://criticallink.org/conferences/conferencepapers/critical-link-3] (última consulta: 12 de marzo de 2013). 
BAIXAULI, Lluís (2012). La interpretació als serveis públics des d'una perspectiva ética: La deontologia professional i l'aplicació al context penitenciari, Tesis doctoral, Universitat Jaume I, Departament de Traducció i Comunicació. [http://www.tdx.cat/handle/10803/83723] (última consulta: 10 de agosto de 2013).

BALSAMO, Franca (2003). Famiglie di migranti. Trasformazioni dei ruoli e mediazione culturale, Roma: Carocci Editore.

BARALDI, Claudio et al. (ed.) (2008). Immigrazione, mediazione culturale e salute, Milán: FrancoAngeli.

BARNA, LaRay M. (1998). "Stumbling Blocks in Intercultural Communication" en BENNETT, Milton J. Basic Concepts of Intercultural Communication: A Reader, Boston: Intercultural Press, pp. 173-189.

BAUMAN, Zygmunt (2003). Comunidad. En busca de seguridad en un mundo hostil, 2ª edición, Madrid: Siglo XXI de España Editores, 2006. Traducción de Jesús Alborés.

BEAUCHAMP, Tom L. y James F. CHILDRESS (1979). Principles of Biomedical Ethics, Oxford: Oxford University Press.

BECK, Ulrich (2005). Lo sguardo cosmopolita, Roma: Carocci.

BECKER, Howard S. y Blanche GEER (1957). "Participant Observation and Interviewing: A Comparison" en American Journal of Sociology, 62, pp. 28-32.

BEDOYA, María Helena (2000). “Mujer extranjera: una doble exclusión. Influencia de la Ley de Extranjería sobre las mujeres inmigrantes" en Papers, 60, pp. 241-256.

BEGLEY, Polly A. y Debbie A. OCKEY (1972). "When Cultures Collide: Alternative Medicine, Biomedicine, and the Patients in the Middle" en SAMOVAR, Larry A., Richard E. PORTER y Edwin R. McDANIEL. Intercultural Communication: A Reader, 12ª edición, Boston: Wadsworth CENGAGE Learning, 2009, pp. 324-336.

BENNETT, Milton J. (1986). "A developmental approach to training intercultural sensitivity" en MARTIN, J. (ed.), International Journal of Intercultural Relations. Special Issue on Intercultural Training, vol. 10, no 2, pp. 179-186.

BENNETT, Milton J. (1993). "Towards ethnorelativism: A developmental model of intercultural sensitivity" en PAIGE, Michael R. (ed.), Education for the Intercultural Experience, Yarmouth, ME: Intercultural Press. 
BENNETT, Milton J. (1998). Basic Concepts of Intercultural Communication: A Reader, Boston: Intercultural Press.

BERG, Bruce L. (1989). Qualitative Research Methods for the Social Sciences, 7a edición, Boston: Pearson Education Inc., 2009.

BERRY, John W. (1993). "Fundamental Psychological Processes in Intercultural Relations" en LANDIS, Dan, Janet M. BENNETT y Milton J. BENNETT (eds.) Handbook of Intercultural Training, 3a edición, Thousand Oaks (California): SAGE Publications, 2012, pp. 166-184.

BISCHOFF, Alexander, Louis LOUTAN y Sofía GARCÍA (2009) En otras palabras. Guía para la consulta médica intercultural. Comunicación a través de un intérprete en los servicios de salud, Universal Doctor Project. [http://medecine-internationale.hugge.ch/recherche_publications/En_otras_palabras_2010.pdf] (última consulta: 30 de abril de 2013).

BLANCO, Cristina (2000). Las migraciones contemporáneas, Madrid: Alianza Editorial.

BLÁZQUEZ, María Isabel (2005). "Aproximación a la Antropología de la Reproducción" en Revista AIBR Revista de Antropología Iberoamericana, julio-agosto, 42, Madrid: Antropólogos Iberoamericanos en Red. [http://redalyc.uaemex.mx/src/inicio/ArtPdfRed.jsp?iCve=62304208] (última consulta: 16 de diciembre de 2012).

BLÁZQUEZ, María Isabel (2008). "Una etnografía en la atención sanitaria" en ROMANí, Oriol, Cristina LARREA y José FERNANDEZ (coords.) Antropología de la medicina, metodologías e interdisciplinariedad: de las teorías a las prácticas académicas y profesionales, Donostia: Ankulegi Antropologia Elkartea, pp. 17-30.

BONILLA, Marcelo (2004). "La construcción de la imagen y el estatuto del inmigrante indocumentado en la España de la época de la globalización" en VV.AA. Globalización, migración y derechos humanos, Ecuador: Universidad Andina Simón Bolívar, pp. 47-60.

BOT, Hanneke (2003). "The Myth of the Uninvolved Interpreter in Mental Health and the Development of a Three-Person Psychology" en BRUNETTE, Louise et al. (eds.) The Critical Link 3: Interpreters in the Community, Amsterdam/Filadelfia: John Benjamins Publishing, pp. 27-36.

BRACH, Cindy y FRASER, Irene (2000). "Can Cultural Competency Reduce Racial and Ethnic Disparities? A Review and Conceptual Model" en Medical Care Research and Review, 57 (Supplement 1), pp. 181-217. 
BURON, Andrea (2012). Barreras de acceso de la población inmigrante a los servicios de salud en Catalunya, Tesis doctoral, Universitat Autònoma de Barcelona, Departament de Pediatria, d'Obstetrícia i Ginecologia i de Medicina Preventiva. [http://www.consorci.org/publicacions/cataleg-de-publicacions/tesi-doctorals-itesines/buron-a.-barreras-de-acceso-de-la-poblacion-inmigrante-a-los-servicios-desalud-en-catalunya-tesis-doctoral-.-barcelona-universitat-autonoma-de-barcelona2012] (última consulta: 15 de marzo de 2013).

BUSS THOFEHRN, Maira et al. (2013). "Grupo focal: Una técnica de recogida de datos en investigaciones cualitativas" en Index de Enfermería [Index Enferm] (edición digital), 22 (1-2), pp. 75-78. [http://www.index-f.com/index-enfermeria/v22n1-2/articulo_7578.php] (última consulta: 5 de febrero de 2013).

CÁCERES, Pablo (2003). "Análisis cualitativo de contenido: Una alternativa metodológica alcanzable" en Psicoperspectivas, vol. II, no 1, pp. 53-81. [http://redalyc.uaemex.mx/src/inicio/ArtPdfRed.jsp?iCve=171018074008] (última consulta: 31 de enero de 2013).

CALLEJO, Javier (1998). “Articulación de perspectivas metodológicas: posibilidades del grupo de discusión para una sociedad reflexiva" en Papers, 56, pp. 31-55.

CALLEJO, Javier (2002). “Observación, entrevista y grupo de discusión: El silencio de tres prácticas de investigación" en Revista Española de Salud Pública, 76, pp. 409-422.

CASADEI, Simone y Massimiliano FRANCESCHETTI (2009). Il mediatore culturale in sei paesi europei. Ambiti di intervento, percorsi di acceso e competenze. Report di ricerca del progetto finanziato dal Fondo Sociale dell'Unione Europea, il Ministero del Lavoro, della Salute e delle Politiche Sociali e I'Istituto per lo Sviluppo della formazione $\begin{array}{llll}\text { professionale dei lavoratori } & \text { (ISFOL). }\end{array}$ [http://www.isfol.it/pubblicazioni/Collane/strumenti-isfol-1/strumenti-n.-1] (última consulta: 20 de abril de 2013).

CASAS, Miquel, Francisco COLLAZOS y Adil QURESHI (coords.) (2009). Mediación intercultural en el ámbito de la salud. Programa de formación. [http://multimedia.lacaixa.es/lacaixa/ondemand/obrasocial/pdf/inmigracion/Mediacio _intercultural_es.pdf] (última consulta: 8 de junio de 2013).

CASTELLÓ, Berta (2013). "La Plataforma Salud Universal exige la asistencia sanitaria gratuita para los extranjeros de Aragón" en aragondigital.es, 27 de febrero de 2013. 
[http://www.aragondigital.es/noticia.asp?notid=104952] (última consulta: 1 de marzo de 2013).

CASTIGLIONI, Marta (1997). La mediazione linguistico-culturale. Principi, strategie, esperienze, Milán: Franco Angeli.

CASTIGLIONI, Marta (2001). Percorsi di cura delle donne immigrate, 7ạ edición, Milán: Franco Angeli, 2007.

CASTIGLIONI, Marta (2006). “Uno sguardo da lontano. Riflessioni sull'esperienza di mediazione linguistico-culturale nei servizi sanitari e socio-sanitari", en LUATTI, Lorenzo (ed.) Atlante della mediazione linguistico culturale, Milán: Franco Angeli, pp.144-156.

CASTILLO, Gema S. y Mustapha TAIBI (2005). "El papel del intérprete en el ámbito sanitario" en VALERO, Carmen (ed.) Traducción como mediación entre lenguas y culturas, Alcalá de Henares: Servicio de Publicaciones de la Universidad de Alcalá, pp. 108-113.

CHIARENZA, Antonio (2004). "Intercultural mediation", Hospitals in a culturally diverse Europe", International conference on quality-assured health care and health promotion for migrants and ethnic minorities, Final conference of the European project Migrant-Friendly Hospitals, December 9-11, 2004, Amsterdam. [http://www.mfh-

eu.net/public/files/conference/mfh_paper1_5_intercultural_mediation.pdf] (última consulta: 8 de agosto de 2013).

CICOUREL, Aaron V. (2011). Método y medida en sociología, Madrid: Centro de investigaciones sociológicas.

CODURAS, Pedro y Carlos GÓMEZ (2008). “Inmigración e inclusión en la Comunidad Autónoma de Aragón” en SEVILLA, Rafael y José TUDELA (eds.) Aragón. Interculturalidad y compromiso, Bad Honnef: Horlemann.

COHEN-EMERIQUE, Margalit (2003). "La negociación intercultural y la integración de los inmigrantes", en Políticas sociales en Europa. Mediación Social, 13-14, pp. 27-36.

COLASANTI Riccardo y Salvatore GERACI (1995). "I livelli di incomprensione medico-paziente migrante" en GERACl, Salvatore (ed.) Argomenti di medicina delle migrazioni, Roma: Peri Tecnés, pp. 213-220.

COLLINS, K.S. et al. (2002) "Diverse Communities, Common Concerns: Assessing Health care Quality for Minority Americans. Findings from the Commonwealth Fund 2001". Health Care Quality Survey, New York: Commonwealth Fund. 
COMELLES, Josep Maria (2009). "Inmigración, cultura y salud" en CASAS, Miquel, Francisco COLLAZOS y Adil QURESHI (coords.) Mediación intercultural en el ámbito de la salud. $\begin{array}{llll}\text { Programa de formación, } & \text { 16-30 }\end{array}$ [http://multimedia.lacaixa.es/lacaixa/ondemand/obrasocial/pdf/inmigracion/Mediacio _intercultural_es.pdf] (última consulta: 29 de agosto de 2013).

COMELLES, Josep Maria et al. (comps.) (2010). Migraciones y salud, Tarragona: Universitat Rovira

[http://www.urv.cat/universitat/unitats_administratives/publicacions/cataleg/100/mi graciones-y-salud] (última consulta: 17 de marzo de 2013).

COMELLES, Josep Maria y Ángel MARTÍNEZ (1993). Enfermedad, cultura y sociedad: un ensayo sobre las relaciones entre la Antropología Social y la Medicina, Madrid: Ediciones de la Universidad Complutense de Madrid.

COMINSKY, Sheila (1976). "Cross-Cultural Perspectives on Midwifery" en GROLLING, F. y H. HALEY (eds.) Medical Anthropology, París: Mouton, pp. 229-249.

COMINSKY, Sheila (1992). "La atención del parto y la antropología médica" en CAMPOS, Roberto (comp.) La antropología médica en México, México: Instituto Mora, UNAM.

Consejería de Salud de la Junta de Andalucía (ed.) (2007). Manual de atención sanitaria a inmigrantes.

[http://www.juntadeandalucia.es/salud/sites/csalud/galerias/documentos/p_4_p_2_p romocion_de_la_salud/materiales_publicados_inmigrantes/manualatencioninmigrant es.pdf] (última consulta: 30 de abril de 2013).

CONTRERAS, Jesús (2007). "Alimentación y religión" en HUMANITAS. Humanidades Médicas, 16, pp. 1-22. [http://www.fundacionmhm.org/tema0716/articulo.pdf] (última consulta: 23 de febrero de 2013).

Cortes Generales (1978). Constitución española. [http://www.boe.es/buscar/doc.php?id=BOEA-1978-31229] (última consulta: 12 de agosto de 2013).

CORSELLIS, Ann (2002). "Creating a professional context for public service interpreters" en VALERO, Carmen y Guzmán MANCHO (eds.) Interpretación en los Servicios Públicos: Nuevas realidades para nuevas necesidades / Community Interpreting and Translating: New Needs for New Realities, Alcalá de Henares: Servicio de Publicaciones Universidad de Alcalá, pp. 29-36. 
CORSELLIS, Ann (2003). “Formación de los proveedores de servicios públicos para trabajar con intérpretes y traductores. Habilidades y competencias interculturales" en VALERO, Carmen (ed.) Traducción e interpretación en los Servicios Públicos. Contextualización, actualidad y futuro, Granada: Editorial Comares, pp. 71-89.

CORSELLIS, Ann (2010). Traducción e interpretación en los servicios públicos. Primeros pasos, Granada: Editorial Comares. Traducción de Carmen Valero y Rosa Cobas.

Cortes de Aragón (2012). Proposición no de ley núm. 28/12, sobre la mediación intercultural y apoyo a profesionales y colectivos. [http://bases.cortesaragon.es/bases/original.nsf/\%28BOCA1\%29/2DF95EE437D2F47C C12579C700426D24/\$File/BOCA_53.pdf?OpenElement] (última consulta: 10 de enero de 2013).

CRESSWELL, John W. (1998). Qualitative Inquiry \& Research Design. Choosing Among Five Approaches, 2a edición, Thousand Oaks (California): SAGE Publications, 2007.

CRESSWELL, John W. (2002). Educational Research. Planning, Conducting and Evaluating Quantitative and Qualitative Research, 3a edición, New Jersey: Pearson Prentice Hall, 2008.

DAVIS, Flora (2010). La comunicación no verbal, 11ạ reimpresión, Madrid: Alianza Editorial.

DAVIS-FLOYD, Robbie y Carolyn F. SARGENT (eds.) (1997). Childbirth and Authoritative Knowledge. Cross-Cultural Perspectives, California: University of California Press.

DAVIS-FLOYD, Robbie (2000). "Anthropological Perspectives on Global Issues in Midwifery" en Midwifery Today, no 53. [http://www.midwiferytoday.com/magazine/issue53.asp] (última consulta: 10 de febrero de 2013).

DE LA CUESTA BENJUMEA, Carmen (1997). “Características de la Investigación Cualitativa y su relación con la Enfermería" en Revista Investigación y Educación en Enfermería, XV (2), pp.

13-24.

[http://193.145.233.67/dspace/bitstream/10045/18349/1/De\%20la\%20Cuesta_Caract eristicas\%20de\%20la\%20Investigacion.pdf] (última consulta: 18 de enero de 2013).

DE LA CUESTA BENJUMEA, Carmen (2006). “Estrategias cualitativas más usadas en el campo de la salud" en Nure Investigación. Revista científica de enfermería, 25, noviembrediciembre

06. [http://www.nureinvestigacion.es/FICHEROS_ADMINISTRADOR/F_METODOLOGICA/F Metod_25.pdf] (última consulta: 18 de enero de 2013). 
DE LA CUESTA BENJUMEA, Carmen (2006). "Naturaleza de la investigación cualitativa y su contribución a la práctica de la Enfermería" en Metas de Enfermería, vol. 9, no 5, pp. 50-55.

DE LUCAS, Javier (2009). "Inmigración y diálogo. Hablemos de igualdad, de derechos y de ciudadanía" en GARCíA, Alonso (dir.) El diálogo intercultural, Murcia: Servicio de Publicaciones de la Universidad de Murcia, pp. 26-57.

DE LUISE, Danilo (2005). “¿Mediadores? ¿Intérpretes? ¿Negociadores? La percepción del papel de diferentes profesionales" en VALERO, Carmen (ed.) Traducción como Mediación entre Lenguas y Culturas, Alcalá de Henares: Servicio de Publicaciones de la Universidad de Alcalá, pp. 57-74.

$\begin{array}{llll}\text { Declaración de Ámsterdam } & \text { (2004). } & \text { http://www.mfh- }\end{array}$ eu.net/public/european_recommendations.htm] (última consulta: 6 de octubre de 2013).

DELGADO, María Eugenia, Ingrid VARGAS y VÁZQUEZ, María Luisa (2006). "El rigor en la investigación cualitativa" en VÁZQUEZ NAVARRETE, María Luisa (coord.) Introducción a las técnicas cualitativas de investigación aplicadas en salud: cursos GRAAL 5, Barcelona: Servei de Publicacions de l'Universitat Autònoma, pp. 83-96.

DENBOBA, D.L. et al. (1998). "Reducing Health Care Disparities through Cultural Competence" en Journal of Health Education, 29 (Supplement 5), pp. 47-53.

DENZIN, Norman K. (2009). The Research Act. A Theoretical Introduction to Sociological Methods, New Jersey: Transaction Publishers.

DENZIN, Norman K. e Yvonna S. LINCOLN (1994). Handbook of Qualitative Research, Nueva York: SAGE Publications.

DEY, Ian (1993). Qualitative Data Analysis: A User-Friendly Guide for Social Scientists. Londres: Routledge.

DÍAZ, Magdalena (2009). “Política de inmigración y la población inmigrante en España y la Unión Europea" en Revista de Derecho de la Unión Europea, 17 (2), pp. 69-84.

EFE.Zaragoza (2012). "Aragón deniega la tarjeta sanitaria a 25 inmigrantes con derecho a asistencia", en Heraldo.es, 21 de noviembre de 2012. [http://www.heraldo.es/noticias/aragon/2012/11/21/al_menos_inmigrantes_con_der echo_asistencia_pierden_tarjeta_sanitaria_212573_300.html] (última consulta: 22 de noviembre de 2013). 
EFE.Zaragoza (2012). "Los inmigrantes van la mitad que los aragoneses al centro de salud" en Heraldo.es, 16 de mayo 2012. [http://www.heraldo.es/noticias/aragon/2012/05/16/los_inmigrantes_aragon_van_mi tad_centro_salud_que_los_espanoles_187975_300.html] (última consulta: 18 de mayo de 2012).

ESTEBAN, Mari Luz (2000). "La maternidad como cultura. Algunas cuestiones sobre lactancia materna y cuidado infantil" en PERDIGUERO, Enrique y Josep Maria COMELLES (eds.) Medicina y cultura. Estudios entre la antropología y la medicina, Barcelona: Edicions Bellaterra, pp. 207-226.

ESTEBAN, Mari Luz (2006). "El Estudio de la Salud y el Género: Las Ventajas de un Enfoque Antropológico y Feminista" en Salud Colectiva, vol. 2, № 1, pp. 9-20. [http://www.scielo.org.ar/pdf/sc/v2n1/v2n1a02.pdf] (última consulta: 30 de noviembre de 2012).

Eurostat (2012). "Fertility Statistics", publicado en octubre de 2012. [http://epp.eurostat.ec.europa.eu/statistics_explained/index.php/Fertility_statistics] (última consulta: 30 de julio de 2013).

Eurostat (2013). "Migration and migrant population statistics", publicado en marzo de 2013. [http://epp.eurostat.ec.europa.eu/statistics_explained/index.php/Migration_and_mig rant_population_statistics/en] (última consulta: 5 de junio de 2013).

FABRE, Ernesto (coord.) (2010). MIAS. Mujer inmigrante y asistencia sanitaria. [http://www.programamias.com/images/stories/MIAS_baja.pdf] (última consulta: 30 de abril de 2013).

FABREGA, Horacio Jr. (1973). "Toward a Model of Illness Behavior" en Medical Care, vol. 11, no 6, pp. 470-484.

FADIMAN, Anne (1997). The Spirit Catches You and You Fall Down. A Hmong Child, her American Doctors, and the Collision of Two Cultures, Nueva York: Farrar, Straus and Giroux.

FAVARO, Graziella (2006). "I paradossi della mediazione", en LUATTI, Lorenzo (ed.) Atlante della mediazione linguistico culturale. Nuove mappe per la professione di mediatore, Milán: FrancoAngeli, pp.25-35.

FLORES, Glenn et al. (2003). "Errors in medical interpretation and their potential clinical consequences in pediatric encounters" en Pediatrics, 111 (1), pp. 6-14. 
FLYVBJERG, Bent (2004). "Cinco malentendidos acerca de la investigación mediante los estudios de caso" en Reis, 106, pp. 33-62. [http://www.reis.cis.es/REIS/PDF/REIS_106_041167998142322.pdf] (última consulta: 20 de enero de 2013).

FOUCAULT, Michel (1978). Microfísica del poder, 2a edición, Madrid: Las Ediciones de La Piqueta, 1979. Traducción de J. Varela y F. Álvarez-Uría.

FREDERICKS, Cecilia (1998). "Using Non-Professional Interpreters in a Multi-Ethnic Primary Care Clinic", Conference papers presented in the Critical Link 2, 1998, Vancouver. [http://criticallink.org/conferences/conference-papers/critical-link-2] (última consulta: 20 de agosto de 2013).

FULLER, Jeffrey (2003). "Intercultural Health Care as Reflective Negotiated Practice" en Western Journal of Nursing Research, vol. 25, no 7, pp. 781-797.

Fundación ADUNARE (2008) Memoria Fundación ADUNARE. Año 2008

Fundación ADUNARE (2009) Memoria Fundación ADUNARE. Año 2009

Fundación ADUNARE (2010) Memoria Fundación ADUNARE. Año 2010

Fundación ADUNARE (2011) Memoria Fundación ADUNARE. Año 2011

Fundación ADUNARE (ed.) (2007). Las claves que influyen en la atención sanitaria especializada a las personas de origen extranjero y técnicas para abordarlas con éxito, D.L.: Z/972/2007.

GAILLY, Antoine (2010). "La atención sensible a la cultura" en COMELLES, Josep Maria et al. (comps.) Migraciones y salud, Tarragona: Universitat Rovira i Virgili, pp. 17-54. [http://www.urv.cat/universitat/unitats_administratives/publicacions/cataleg/100/mi graciones-y-salud] (última consulta: 17 de marzo de 2013).

GALANTI, Geri-Ann (1991). Caring for Patients from Different Cultures, 4a edición, Filadelfia: University of Pennsylvania Press, 2008.

GALANTI, Geri-Ann (1999). "Commentary: How to do ethnographic research" en WJM (Western Journal of Medicine), $171 \quad$ (I), $\quad$ pp.19-20. [http://gagalanti.com/articles/ehtnoresearch.pdf] (última consulta: 2 de febrero de 2013).

GALANTI, Geri-Ann (2000). "An introduction to cultural differences" en WJM (Western Journal $\begin{array}{lllll}\text { of } & \text { Medicine), } & 172 & \text { (5), } & \text { 335-336. }\end{array}$ 
[http://www.ncbi.nlm.nih.gov/pmc/articles/PMC1070887/] (última consulta: 16 de julio de 2013).

GARCÍA, Alonso (2009). "Diálogo intercultural. Una introducción” en GARCíA, Alonso (dir.) El diálogo intercultural, Murcia: Servicio de Publicaciones de la Universidad de Murcia, pp. $17-25$.

GARCÍA, Dailys y Zoe DÍAZ (2010). “Perspectiva antropológica y de género en el análisis de la atención al embarazo, parto y puerperio" en Revista Cubana de Salud Pública, vol. 36, no 4 , pp. 330-342.

GARCÍA, F. Javier y Cristina BARRAGÁN (2004). "Mediación intercultural en sociedades multiculturales. Hacia una nueva conceptualización" en Portularia, 4, pp. 123-142. [http://Idei.ugr.es/javiergarcia/wpcontent/uploads/2012/10/GarciaBarragan2004.pdf] (última consulta: 25 de febrero de 2013).

GARCÍA, F. Javier, Antolín GRANADOS y Raquel MARTíNEZ (2006). “Comprender y construir la mediación intercultural" en Portularia; vol. 6, no 1, pp. 7-21. [http://www.redalyc.org/articulo.oa?id=161016087002] (última consulta: 2 de marzo de 2013).

GARCÍA, Francisca (2009). "La interpretación telefónica en el ámbito sanitario: Realidad social y reto pedagógico" en Redit, 3, pp. 18-30.

GERACl, Salvatore (ed.) (1995). Argomenti di medicina delle migrazioni, Roma: Peri Tecnés.

GERACl, Salvatore, Bianca MAISANO y Marco MAZZETTI (2005). "Migrazione e salute. Un lessico per capire" en Studi emigrazione, 157, pp. 7-51.

GERRING, John (2007). Case Study Research, Cambridge: Cambridge University Press.

GIBBS, Graham R. (2007). Analyzing Qualitative Data. Londres: SAGE Publications.

GIBBS, Graham R. (2008). Qualitative Data Analysis: Explorations with NVivo, Berkshire: Open University Press.

GIJÓN, Mạ Teresa (2010). “La comparación demográfica en estudios sobre inmigrantes, salud y diversidad cultural" en COMELLES, Josep Maria et al. (comps.) Migraciones y salud, Tarragona: Publicacions de la Universitat Rovira i Virgili., pp. 90-106.

GIL FLORES, Javier (1993). "La metodología de investigación mediante grupos de discusión" en Revista de enseñanza e investigación educativa, vol. 10, pp. 199-212. 
GIMÉNEZ, Carlos (1997). "La naturaleza de la mediación intercultural” en Migraciones, 2, pp. $125-160$.

GIMÉNEZ, Carlos (2003). “Pluralismo, Multiculturalismo e Interculturalidad. Propuesta de clarificación y apuntes educativos" en Educación y futuro: revista de investigación aplicada y experiencias educativas, 8, pp.9-26.

GIMÉNEZ, Gilberto (2012). "El problema de la generalización en los estudios de caso" en Cultura y representaciones sociales, Año 7, 13, pp. 40-62.

Gobierno de Aragón (2007) Estatuto de Autonomía de Aragón. [http://www.boa.aragon.es/EBOA/pdf/ESTATUTOAUTONOMIA.pdf] (última consulta: 21 de enero de 2013).

Gobierno de Aragón, Departamento Aragonés de Salud y Consumo y Servicio Aragonés de Salud (2010). "Estado de Salud de Aragón: Determinantes y Actuaciones del Departamento de Salud y Consumo". [http://www.aragon.es/estaticos/GobiernoAragon/Temas/Familias/Documentos/Pres entacion.pdf] (última consulta: 21 de enero de 2013).

Gobierno de Aragón, Departamento de Economía, Hacienda y Empleo (2004). Plan Integral para la Inmigración en 2004-2007. [http://aragonparticipa.aragon.es/dmdocuments/Plan_Integral_2004-20071.PDF] (última consulta: 21 de enero de 2013).

Gobierno de Aragón, Departamento de Salud y Consumo (2010). Plan de atención a la salud de la mujer 2010-2012. [http://www.saludinforma.es/opencms/export/SALUD_1/04_Temas_de_salud/Docum entos/Plan_mujer_14_enero_2010-OK.pdf] (última consulta: 21 de enero de 2013).

Gobierno de Aragón, Departamento de Salud y Consumo de Aragón (2005). Cuídame: guía para padres $\quad$ y madres. [http://www.aragon.es/estaticos/GobiernoAragon/00_StaticFiles/GUIA+CUIDAME_esp _0-2.pdf] (última consulta: 10 de febrero de 2013).

Gobierno de Aragón, Departamento de Salud y Consumo. Carta de Compromisos del Departamento de Salud y Consumo con los Usuarios del Sistema de Salud de Aragón [http://bases.cortesaragon.es/bases/NDocumen.nsf/b4e47719711a1d49c12576cd002 660cc/1214c5527eef870ec12576aa0031e135/\$FILE/folleto_compromisos.pdf] (última consulta: 12 de febrero de 2013). 
Gobierno de Aragón, Departamento de Sanidad, Bienestar Social y Familia, Dirección General de Bienestar Social y Dependencia (2012). Plan Estratégico de Servicios Sociales de Aragón

2012-2015.

[http://aragonparticipa.aragon.es/dmdocuments/I\%20Plan\%20Estrat\%C3\%A9gico\%20 de\%20Servicios\%20Sociales\%20de\%20Arag\%C3\%B3n\%202012-2015.pdf] (última consulta: 5 de junio de 2013).

Gobierno de Aragón, Departamento de Servicios Sociales y Familia (2008). Plan Integral para la Convivencia intercultural en Aragón 2008-2011. [http://aragonparticipa.aragon.es/dmdocuments/Planintegralinmigracionaragon1.pdf] (última consulta: 10 de febrero de 2013).

Gobierno de España, Ministerio de Asuntos Sociales y de Cooperación Libro Blanco de la Traducción Institucional, pp. 123-127. [http://www.ritap.es/wpcontent/uploads/2012/11/libro_blanco_traduccion_vfinal_es.pdf] (última consulta: 20 de septiembre de 2013).

GOLDBERG, Alejandro (2003). Ser inmigrante no es una enfermedad. Inmigración, condiciones de vida y de trabajo. El proceso de salud/enfermedad/atención de los migrantes senegaleses en Barcelona, Tesis doctoral, Universitat Rovira i Virgili, Departamento de Antropología, Filosofía $\quad$ y $\quad$ Trabajo [http://www.tdx.cat/bitstream/handle/10803/8418/AGoldbergTESIS1.pdf?sequence=1 ] (última consulta: 15 de marzo de 2013).

GÓMEZ MENDOZA, Miguel Ángel (2000). “Análisis de contenido cualitativo y cuantitativo: Definición, clasificación y metodología" en Revista Ciencias Humanas, 20, Pereira (Colombia): Universidad Tecnológica de Pereira. (Sin paginación).

GÓMEZ-DIAGO, Gloria (2010). “Triangulación metodológica: Paradigma para investigar desde la Ciencia de la Comunicación" en Razón y palabra, 72. [http://www.razonypalabra.org.mx/N/N72/Varia_72/GomezDiago_corr_72.pdf] (última consulta: 19 de enero de 2013).

GOMMA, Gessica y Orecchini, Fabio (2001). "Servizi sanitari e immigrazione in una prospettiva antropologica" en Rivista dell'Istituto Italiano di Medicina Sociale - Immigrazione, salute e partecipazione, no 12 , pp.185-188.

GÓNZALEZ, Juan Luis y Paloma RUIZ (2011). “Investigación cualitativa versus cuantitativa: ¿dicotomía metodológica o ideológica?" en Index de Enfermería (versión impresa), vol. 
20, no 3, pp. 189-193. [http://scielo.isciii.es/scielo.php?pid=s113212962011000200011\&script=sci_arttext] (última consulta: 22 de enero de 2013).

GRACIA-GARCÍA, Roberto A. (2002). "Telephone interpreting: A review of pros and cons" en BRENNAN, Scott (ed.) Proceedings of the $43^{\text {rd }}$ Annual Conference, Alexandria, Virginia: American Translators Association, pp. 195-216.

GREENWOOD, Davydd (2000). "De la observación a la investigación-acción participativa: una visión crítica de las prácticas antropológicas" en Revista de Antropología Social, 9, pp. 27-49.

GREGORIO, Carmen (1998). Migración femenina: su impacto en las relaciones de género, Madrid: Narcea.

GRICE, H. Paul (1975). "Logic and conversation" en COLE, Peter y Jerry L. MORGAN (eds.) Speech Acts, Nueva York: Academic Press, pp. 41-58.

GROPPER, Rena C. (1996). Culture and the Clinical Encounter. An Intercultural Sensitizer for the Health Professions, Londres: Nicholas Brealey Publishing.

Grupo CRIT (2003). Claves para la comunicación intercultural, Castellón de la Plana: Publicacions de la Universitat Jaume I.

Grupo CRIT (2006). Culturas cara a cara. Relatos y actividades para la comunicación intercultural, Madrid: Edinumen.

Grupo CRIT (2009). Culturas y atención sanitaria. Guía para la comunicación y la mediación intercultural, Barcelona: Octaedro.

GUBER, Rosana (2001). La etnografía: método, campo y reflexividad, Bogotá: Grupo editorial Norma.

GUDYKUNST, William B. (1995). “Anxiety/Uncertainty Management (AUM) Theory. Current Status" en WISEMAN, R.L. (ed.) Intercultural Communication Theory, Londres: SAGE Publications, pp. 8-58.

HALE, Sandra Beatriz (2008) "Controversies over the role of the court interpreter" en VALERO, Carmen y Anne MARTIN (eds.) Crossing Borders in Community Interpreting. Definitions and Dilemmas, Amsterdam/Filadelfia: John Benjamins Publishing, pp. 100-122.

HALE, Sandra Beatriz (2010). La interpretación comunitaria. La interpretación en los sectores jurídico, sanitario y social, Granada: Editorial Comares. Traducción de Rosa Cobas y Carmen Valero. 
HALL, Edward T. (1959). The Silent Language, Nueva York: Anchor Books.

HALL, Edward T. (1976). Beyond Culture, Nueva York: Anchor Books.

HALL, Edward T. (1998). "The power of hidden differences" en BENNETT, Milton J. (ed.) Basic Concepts of Intercultural Communication: A Reader, Boston: Intercultural Press, pp.5367.

HALL, Edward T. y Mildred R. HALL (1990). Hidden differences, Nueva York: Doubleday/Anchor Books.

HERAS GONZÁLEZ, Purificación y Anastasia TÉLLEZ INFANTES (2005). “Representaciones de género y maternidad: una aproximación desde la antropología sociocultural" en CAPORALE BIZZINI, Silvia (coord.) Discursos teóricos en torno a la(s) maternidades. Una visión integradora, Madrid: Ed. Entinema, pp. 63-102.

HERMANS, Theo (2001). "Shall I Apologize Translation?" en Journal of Translation Studies, 5, pp. 1-17.

HOFSTEDE, Geert G. (1991). Cultures and Organizations: Software of the Mind, Londres: McGraw-Hill UK.

HORNBERGER, John, Haruka ITAKURA y Sandra R. WILSON (1997). "Bridging Language and Cultural Barriers between Physicians and Patients" en Public Health Reports, vol. 112 (Sept/Oct), pp. 410-417.

HOUNKPATIN, Lucien (2003). "Corps et mediation" en Corpi individuali e contesti interculturali, Turín: L’Harmattan Italia, pp. 17-23.

IBÁÑEZ, Jesús (1979). Más allá de la Sociología. El grupo de discusión: Técnica y crítica, 5ạ edición, Madrid: Siglo XXI de España Editores, 2003.

INFESTA DOMÍNGUEZ, Graziela et al. (2012). "Reflexiones en torno al trabajo con grupos de discusión en ciencias sociales" en Intersticios. Revista Sociológica de Pensamiento Crítico, vol. 6, no 1, pp. 233-244.

Instituto Aragonés de Estadística (laest) (2013). "Datos básicos de Aragón" [http://www.aragon.es/DepartamentosOrganismosPublicos/Organismos/InstitutoArag onesEstadistica/AreasGenericas/ch.DatosBasicos.detalleDepartamento] (última consulta: 20 de agosto de 2013).

Instituto Aragonés de Servicios Sociales (I.A.S.S.) y Asociación de Desarrollo Comunitario en Áreas de Aragón (A.D.C.A.R.A.) (2007) Maternidad responsable: Opciones y recursos 
ante

un

embarazo

no

planificado.

[http://iass.aragon.es/adjuntos/menores/GuiaMaternidadSP.pdf] (última consulta: 3 de julio de 2013).

Instituto Nacional de Estadística (INE) (2012a). "Movimiento Natural de la Población e Indicadores Demográficos Básicos", publicado el 18 de enero de 2012. [http://www.ine.es/prensa/np697.pdf] (última consulta: 20 de febrero de 2013).

Instituto Nacional de Estadística (INE) (2012b). "Movimiento Natural de la Población e Indicadores Demográficos Básicos. Datos definitivos de 2011 y avance del primer semestre de 2012" publicado el 19 de diciembre de 2012. [http://www.ine.es/prensa/np759.pdf] (última consulta: 20 de febrero de 2013).

Instituto Nacional de Estadística (INE) (2013). “Cifras de Población a 1 de enero de 2013 Estadística de Migraciones 2012. Datos Provisionales" publicado el 25 de junio de 2013. [http://www.ine.es/prensa/np788.pdf] (última consulta: 20 de julio de 2013).

JABBAR, Adel (2006). "Disuguaglianza sociale e differenze culturali: per una intercultura democratica" en LUATTI, Lorenzo, Atlante della mediazione linguistico culturale, Milán: Franco Angeli, pp.82-95.

JACOBS, Elizabeth A. et al. (2004). “Overcoming Language Barriers in Health Care: Costs and Benefits of Interpreter Services" en American Journal of Public Health, 94(5), pp. 866869.

JANDT, Fred E. (1995). Intercultural Communication. An Introduction, 6a edición, Londres: SAGE Publications, 2010.

JANSÀ, Josep M. y Patricia GARCÍA DE OLALLA (2004). "Salud e inmigración: nuevas realidades y nuevos retos" en Gaceta Sanitaria, 18 (Suplemento), pp. 207-213.

KAPLAN, Adriana (2004). "Salud y derechos sexuales y reproductivos en la población senegambiana: tradición, identidad e integración social" en CHECA, Francisco, Juan Carlos CHECA y Ángeles ARJONA (eds.) Inmigración y derechos humanos. La integración como participación social, Barcelona: Icaria editorial, pp. 203-228.

KARLINER, Leah S. et al. (2007). “Do Professional Interpreters Improve Clinical Care for Patients with Limited English Proficiency? A Systematic Review of the Literature" en Health $\begin{array}{lllll}\text { Services } & \text { Research, } & \text { 42(2), } & \text { 727-754. }\end{array}$ [http://www.ncbi.nlm.nih.gov/pmc/articles/PMC1955368/] (última consulta: 12 de noviembre de 2012). 
KELLY, Nataly (2008). Telephone Interpreting: A comprehensive guide to the profession, Lowell (Maine): Trafford Publishing.

KIM, Young Yun (1993). "Long-term Cross-cultural Adaptation. Training Implications of an Integrative Theory" en LANDIS, Dan, Janet Marie BENNETT y Milton J. BENNETT (eds.) Handbook of Intercultural Training, 3a edición, Thousand Oaks (California): SAGE Publications, 2004, pp. 337-362.

KNAPP, Mark L. (1982). La comunicación no verbal, Barcelona: Paidós.

KOSHY, Elizabeth et al. (2011). Action Research in Healthcare, Portland: SAGE Publications.

KOTTAK, Conrad Philip (1997). Espejo para la humanidad. Introducción a la Antropología cultural, 10a edición, Madrid: McGraw-Hill, 2003. Traducción y adaptación. José C. Lisón Arcal.

KRUEGER, Richard A. (1991). El grupo de discusión. Guía práctica para la investigación aplicada, Madrid: Pirámide.

KU, Leighton y Glenn FLORES (2005). "Pay Now Or Pay Later: Providing Interpreter Services In Health Care" en Health Affairs, vol. 24, no 2, pp. 435-444.

KVALE, Steinar (2007). Doing interviews, 5a edición, Londres: SAGE Publications, 2011.

LACZKO, Frank y Gervais APPAVE (2013). “Conclusiones” en Organización Internacional para las Migraciones (OIM) Informe sobre las migraciones en el mundo 2013. El bienestar de los $\begin{array}{lllll}\text { inmigrantes } & y & \text { el }\end{array}$ [http://publications.iom.int/bookstore/free/WMR2013_SP.pdf] (última consulta: 8 de septiembre de 2013).

LACZKO, Frank y Rudolf ANICH (2013). "Introducción" en Organización Internacional para las Migraciones (OIM) Informe sobre las migraciones en el mundo 2013. El bienestar de los $\begin{array}{lllll}\text { inmigrantes } & y & \text { el } & \text { desarrollo, } & \text { 30-52. }\end{array}$ [http://publications.iom.int/bookstore/free/WMR2013_SP.pdf] (última consulta: 8 de septiembre de 2013).

LANDIS, Dan, Janet Marie BENNETT y Milton J. BENNETT (eds.) (1993). Handbook of intercultural training, 3a edición, Thousand Oaks (California): SAGE Publications, 2012.

LÁZARO, Raquel (2010). La interpretación en los servicios sanitarios en España. Estudio de la asimetría en las consultas médicas con pacientes de habla extranjera y la repercusión de la presencia de un intérprete ocasional, Tesis doctoral, Universidad de Alcalá de 
Henares, Departamento de Filología Moderna. [http://dspace.uah.es/dspace/bitstream/handle/10017/8067/lazarogutierrezr.tesisdoc toral.pdf?sequence=1] (última consulta: 20 de julio de 2013).

LEANZA, Yvan (2007). "Roles of community interpreters in pediatrics, as seen by, physicians and researchers" en PÖCHHACKER, Franz y SHLESINGER, Miriam (eds.) Healthcare Interpreting. Amsterdam: John Benjamins Publishing, pp. 11-34.

LEDERMAN, Linda (1990). "Assessing Educational Effectiveness: the focus group interview as a technique for data collection" en Communication Education, vol. 39, no 2, pp. 117-127.

LEE, Jieun (2007). "Telephone interpreting -seen from the interpreters' perspective" en Interpreting, 9(2), pp.231-252.

LEE, Sharon M. (2003). "A review of language and other communication barriers in health care", Department of Sociology, Portland State University. [http://faculty.ksu.edu.sa/71640/Publications/COURSES/446\%20CHS\%20Communicati on\%20Skills/8\%20Handout.pdf] (última consulta: 6 de febrero de 2013).

LEWIN, Kurt (1946). "Action Research and Minority Problems" en Journal of Social Issues, vol. 2, no 4, pp. 34-46.

Ley 14/1986, de 25 de abril, General de Sanidad. [https://www.boe.es/boe/dias/1986/04/29/pdfs/A15207-15224.pdf] (última consulta: 15 de enero de 2013).

Ley Orgánica 7/1985, sobre Derechos y Libertades de los Extranjeros en España. [https://www.boe.es/buscar/doc.php?id=BOE-A-1985-12767] (última consulta: 15 de enero de 2013).

Ley Orgánica 4/2000, de 11 de enero, sobre Derechos y Libertades de los Extranjeros en España y su Integración Social. [http://www.boe.es/buscar/act.php?id=BOE-A-2000544] (última consulta: 15 de enero de 2013).

Ley Orgánica 14/2003, de 20 de noviembre, de Reforma de la Ley orgánica 4/2000, de 11 de enero, sobre derechos y libertades de los extranjeros en España y su integración social. [http://www.boe.es/boe/dias/2003/11/21/pdfs/A41193-41204.pdf] (última consulta: 15 de enero de 2013).

LINCOLN, Yvonna S. y GUBA, Egon G. (1985). Naturalistic inquiry, Londres: SAGE Publications. 
LINCOLN, Yvonna S. y GUBA, Egon G. (1999). "Establishing trustworthiness" en BRYMAN, Alan y Robert G. BURGUÉS (eds.) Qualitative Research, Londres: SAGE Publications, pp. 397344.

LÓPEZ, Arantxa et al. (2003). Inmigrantes y mediación intercultural. Materiales para la formación, Bilbao: Universidad de Deusto.

LÓPEZ, Rafaela (coord.) (2007). Las múltiples caras de la mediación. Y llegó para quedarse..., Valencia: Universitat de València.

LUATTI, Lorenzo (ed.) (2006). Atlante della mediazione linguistico culturale, Milán: Franco Angeli.

LUCKMAN, Joan (2000). Transcultural Communication in Health Care, Albany, NY: Delmar Thomson Learning.

LUQUE, Mariola (2008). "La interpretación telefónica en España" en Hermeneus. Revista de Traducción e Interpretación, 10, pp. 313-320.

LUQUE, Miguel Ángel y María Isabel OLIVER (2005). “Diferencias culturales en la percepción y vivencia del parto. El caso de las mujeres inmigradas" en Index de Enfermería [Index Enferm] (edición digital), vol. 48-49, pp. 9-13. [http://www.index-f.com/indexenfermeria/48-49revista/48-49_articulo_9-13.php] (última consulta: 30 de noviembre de 2012).

LUSTIG, Myron W. y Jolene KOESTER (1996). Intercultural Competence: Interpersonal Communication across Cultures, 6a edición, Boston: Pearson Education, 2010.

MALIK, Beatriz y Mercedes HERRAZ (2005). Mediación intercultural en contextos socioeducativos, Málaga: Aljibe.

MARTIN, Anne (2003) "Investigación en interpretación social: estado de la cuestión" en ORTEGA, Emilio (dir.) Panorama actual de la investigación en Traducción e Interpretación, vol. I, Granada: Atrio, pp. 429-446.

MARTíNEZ, Ma Jesús (2007). “Compromisos con la vertiente socioeducativa: Potencialidades y obstáculos para la profesionalización del mediador intercultural" en LÓPEZ, Rafaela (coord.) Las múltiples caras de la mediación. Y llegó para quedarse..., Valencia: Universitat de València, pp. 167-209.

MEJÍA NAVARRETE, Julio (2000). "El muestreo en la investigación cualitativa" en Investigaciones Sociales, Año IV, no 5, pp. 165-180. 
MEJÍA NAVARRETE, Julio (2003). "Sobre la investigación cualitativa. Nuevos conceptos y campos de desarrollo" en Investigaciones Sociales, Año VIII, n¹3, pp. 277-299.

MENDOZA, Zuanilda (2009). "La salud materno-infantil en un contexto intercultural: el proceso reproductivo" en CITARELLA MENARDI, Luca, Alessia ZANGARI y Roberto CAMPOS NAVARRO (eds.) YACHAY TINKUY. Salud e interculturalidad en Bolivia y América Latina, Bolivia: PROHISABA, pp. 311-327.

MENÉNDEZ, Eduardo (1994). “La enfermedad y la curación ¿Qué es medicina tradicional?” en Alteridades, 4 (7), pp. 71-83.

MERCADO MARTÍNEZ, Francisco J. et al. (2000). "Situación actual de la investigación cualitativa en salud. Un campo en consolidación" en Revista de la Universidad de Guadalajara. Dossier 17/Invierno: Investigación cualitativa en salud, Universidad de Guadalajara. [http://www.cge.udg.mx/revistaudg/rug17/1situacion.html]

MEYER, Bernd (1998). "Interpreter-mediated Doctor-Patient Communication", Conference papers presented in the Critical Link 2, 1998, Vancouver. [http://criticallink.org/conferences/conference-papers/critical-link-2] (última consulta: 15 de abril de 2013).

MEYER, Bernd et al. (2003). "Analysing Interpreted Doctor-Patient Communication from the Perspectives of Linguistics, Interpreting Studies and Health Sciences" en BRUNETTE, Louise et al. (eds.) The Critical Link 3: Interpreters in the Community, Amsterdam/Filadelfia: John Benjamins Publishing, pp. 67-78.

MIKKELSON, Holly (1996). "The Professionalization of Community Interpreting", Global Vision: Proceedings of the 37th Annual Conference of the American Translators Association, (sin paginación). [http://www.acebo.com/papers/profslzn.htm] (última consulta: 15 de marzo de 2013).

MIKKELSON, Holly (1999). "Interpreting is Interpreting - Or is It?", Originally presented at the GSTI 30th Anniversary Conference, January 1999, Monterey, California. [http://www.acebo.com/papers/INTERP1.HTM] (última consulta: 7 de noviembre de 2012).

MIKKELSON, Holly (2003). "Telephone Interpreting: Boon or Bane?" en PÉREZ, Luis (ed.) Speaking in Tongues: Language across Contexts and Users. Valencia: Universitat de València, pp. 251-269. 
MILES, Matthew B. y Michael HUBERMAN (1984). Qualitative Data Analysis: A Sourcebook of New Methods, Beverly Hills, CA: SAGE Publications.

Ministerio de Salud y Consumo (2007). "Estrategia de atención al parto normal en el Sistema Nacional de Salud". [http://www.msssi.gob.es/organizacion/sns/planCalidadSNS/pdf/equidad/estrategiaPa rtoEnero2008.pdf] (última consulta: 15 de enero de 2013).

Ministerio de Sanidad y Política Social (2009). "Maternidad Hospitalaria. Estándares y Recomendaciones".

[http://www.msssi.gob.es/organizacion/sns/planCalidadSNS/docs/AHP.pdf] (última consulta: 15 de enero de 2013).

Ministerio de Sanidad, Política Social e Igualdad y Observatorio de Salud de las Mujeres (2011). "Estrategia Nacional de Salud Sexual y Reproductiva". [http://www.msssi.gob.es/organizacion/sns/planCalidadSNS/pdf/equidad/ENSSR.pdf] (última consulta: 15 de enero de 2013).

MONTES, María Jesús (2010). "Transferencia de la maternidad. El itinerario asistencial del embarazo" en MARTORELL, María Antonia, Josep Maria COMELLES y Mariola BERNAL (eds.) Antropología y enfermería, Tarragona: Publicacions de la Universitat Rovira i Virgili, pp. 16-37.

MORELLI, Mara (2009). "Reflexiones sobre el papel del intérprete como mediador" en CARRERAS, María y María Enriqueta PÉREZ (eds.) La mediación lingüistica y cultural y su didáctica. Un nuevo reto para la Universidad, Bolonia: Bolonia University Press, pp. 93-111.

MORENO, F. Javier y María BRUQUETAS (2011). "Las políticas sociales y la integración de la población de origen inmigrante en España" en Anuario de la inmigración en España: la hora de la integración, pp. 158-186.

MORGAN, David L. (1996). Focus Groups as Qualitative Research, 2a edición, Londres: SAGE Publications, 1997.

MORRONE, Aldo (2000). "La salute per tutti: quale ruolo del SSN per gli immigrati?" en La Salute dei Migranti. Web del Istituto Fernando Santi. [http://www.istitutosanti.org/istit/iniziative/conve/morrone.asp] (última consulta: 15 de octubre de 2012).

MORSE, Janice M. (1994). Qualitative Health Research, Newbury Park: SAGE Publications. 
MOUALHI, Djaouida (2000). “Mujeres musulmanas: estereotipos occidentales versus realidad social" en Papers, 60, pp. 291-304.

OFRI, Danielle (2010). Medicine in Translation. Journeys with My Patients, Nueva York: Beacon Press.

OLIVA, Juan y Gloria PÉREZ (2009). “Inmigración y salud” en Gaceta Sanitaria, 23 (Suplemento), pp.1-3.

OLIVER, María Isabel (2002). “Comunicación Intercultural. Comunicándonos con mujeres de otras culturas" en Matronas Profesión, vol. 3, no 9, pp. 21-27. [http://www.federacionmatronas.org/revista/matronas-profesion/sumarios/i/7522/173/comunicacionintercultural-comunicandonos-con-mujeres-de-otras-culturas] (última consulta: 21 de noviembre de 2012).

OLIVER, María Isabel, Pilar BARAZA y Encarnación MARTíNEZ (2007). "La salud y la mujer inmigrante" en Consejería de Salud de la Junta de Andalucía (ed.) Manual de atención $\begin{array}{llll}\text { sanitaria } & a & \text { inmigrantes, } & \text { 77-105. }\end{array}$ [http://www.juntadeandalucia.es/salud/sites/csalud/galerias/documentos/p_4_p_2_p romocion_de_la_salud/materiales_publicados_inmigrantes/manualatencioninmigrant es.pdf] (última consulta: 23 de noviembre de 2012).

OLLÉ, Carmen (2009). "La salud sexual y reproductiva" en CASAS, Miquel, Francisco COLLAZOS y Adil QURESHI (coords.) Mediación intercultural en el ámbito de la salud. Programa de formación, pp.

[http://multimedia.lacaixa.es/lacaixa/ondemand/obrasocial/pdf/inmigracion/Mediacio _intercultural_es.pdf] (última consulta: 18 de agosto de 2013).

Organización de las Naciones Unidas (ONU) (1948). Declaración Universal de Derechos Humanos. [http://www.un.org/es/documents/udhr/] (última consulta: 30 de agosto de 2013).

Organización de las Naciones Unidas (ONU) (2006). "International migration and development. Report of the Secretary-General", 18 de mayo de 2006, A/60/871. [http://www.refworld.org/docid/44ca2d934.html] (última consulta: 14 de enero de 2013).

Organización de las Naciones Unidas (ONU) (2006). La mujer y la inmigración internacional. [http://www.unfpa.org/swp/2006/spanish/introduction.html] (última consulta: 23 de enero de 2013). 
Organización de las Naciones Unidas (ONU), Programa de las Naciones Unidas para el Desarrollo (2013). "Informe sobre Desarrollo Humano 2013. El ascenso del Sur: Progreso humano en un mundo diverso". [http://www.undp.org/content/dam/undp/library/corporate/HDR/2013GlobalHDR/Sp anish/HDR2013\%20Report\%20Spanish.pdf] (última consulta: 30 de septiembre).

Organización Internacional para las Migraciones (OIM) (2006). "Sobre Migración". [http://www.oim.org.co/sobre-migracion.html] (última consulta: 23 de julio de 2013).

Organización Internacional para las Migraciones (OIM) (2013). Informe sobre las migraciones en el mundo 2013. El bienestar de los inmigrantes y el desarrollo. [http://publications.iom.int/bookstore/free/WMR2013_SP.pdf] (última consulta: 8 de agosto de 2013).

Organización para la Cooperación y el Desarrollo Económicos (OCDE) (2013). “Recent developments in international migration movements and policies". [http://www.oecdilibrary.org/social-issues-migration-health/international-migration-outlook2013/recent-developments-in-international-migration-movements-andpolicies_migr_outlook-2013-4-en] (última consulta: 8 de agosto de 2013).

ORTEGA, Emilio (dir.) (2003). Panorama actual de la investigación en Traducción e Interpretación, Granada: Atrio.

ORTÍ, Roberto (2009). "Atención sanitaria a la población de origen magrebí" en Grupo CRIT Culturas y atención sanitaria. Guía para la comunicación y la mediación intercultural, Barcelona: Octaedro, pp.19-52.

ORTÍ, Roberto, Dora SALES y Enric SÁNCHEZ (2006). “Interacción comunicativa en la atención sanitaria a inmigrantes: diagnóstico de necesidades (in)formativas para la mediación intercultural" en GALLARDO, Beatriz, Carlos HERNÁNDEZ y Verónica MORENO (eds.) Lingüística clínica y neuropsicología cognitiva. Actas del Primer Congreso Nacional de Lingüística Clínica, Volumen 3: Lingüística interaccional en ámbitos de salud, Valencia: Universitat de Valencia, pp. 114-139.

OZOLINS, Uldis (2010). "Factors that determine the provision of Public Service Interpreting: comparative perspectives on government motivation and language service implementation" en JoSTrans. The Journal of Specialized Translation, 14, pp. 194-215. [http://www.jostrans.org/issue14/art_ozolins.pdf] (última consulta: 5 de febrero de 2013). 
OZOLINS, Uldis (2011). "Telephone Interpreting: Understanding practice and identifying research needs" en Translation \& Interpreting, vol.3, no 1, pp. 33-47.

PALACIOS, Beatriz et al. (2013). "NVivo 10: Una herramienta de utilidad en el mundo de la comunicación" en VICENTE, Miguel y Tecla GONZÁLEZ (coords.) Investigar la Comunicación hoy. Revisión de políticas científicas y aportaciones metodológicas, vol. 4, pp. 1003-1018.

PARELLA, Sònia (2003). La internacionalización de la reproducción. La inserción laboral de la mujer inmigrante en los servicios de proximidad, Tesis doctoral, Universitat Autònoma de Barcelona, Departamento de Sociología. [http://ldei.ugr.es/cddi/uploads/tesis/ParellaRubio2002.pdf] (última consulta: 30 de abril de 2013).

PATTON, Michael Quinn (1980). Qualitative Research and Evaluation Methods, 3a edición, Thousand Oaks (California): SAGE Publications, 2002.

PENN, Nolan E., Snehendu KAR, Joyce KRAMER, John SKINNER y Ruth E. ZAMBRANA (1995). "Ethnic Minorities, Health Care Systems, and Behavior" en Health Psychology, vol. 14, no 7, pp. 641-646.

PÉREZ, María Dolores (2008). “Mujeres inmigrantes: realidades, estereotipos y perspectivas educativas" en Revista Española de Educación Comparada, 14, pp. 137-175.

PHELAN, Mary (2001). The Interpreter's Resource, Clevedon: Multilingual Matters Ltd.

PHELAN, Mary y Mayte C. MARTíN (2010). "Interpreters and cultural mediators - different but complementary roles" en Translocations, 6 (1), pp. 4-20.

PHELAN, Mary y PARKMAN, Sue (1995). "How To Do It. Work with an interpreter" en BMJ, vol. 311, pp.555-557.

PLAZA DEL PINO, Fernando Jesús y Encarnación SORIANO (2009) “Formación de los profesionales de enfermería: Cuidar en la sociedad multicultural del siglo XXI" en Index de Enfermería (versión impresa), vol. 18, no 3, pp. 190-194.

PÖCHHACKER, Franz (1999). "The evolution of community interpreting" en Interpreting, 4(1), pp. $125-140$.

PÖCHHACKER, Franz (2004). Introducing Interpreting Studies, Londres: Routledge. 
PÖCHHACKER, Franz (2008). "Interpreting as mediation" en VALERO, Carmen y Anne MARTIN (eds.) Crossing Borders in Community Interpreting. Definitions and Dilemmas, Amsterdam/Filadelfia: John Benjamins Publishing, pp. 9-26.

PÖCHHACKER, Franz y SHLESINGER, Miriam (2007). Healthcare Interpreting. Amsterdam: John Benjamins Publishing.

POYATOS, Fernando (1994). La comunicación no verbal. Paralenguaje, kinésica e interacción, Madrid: Istmo.

QSR International (2012). "NVivo 10. Getting started guide" [http://download.qsrinternational.com/Document/NVivo10/NVivo10-Getting-StartedGuide.pdf] (última consulta: 16 de febrero de 2013).

QUINN PATON, Michael (2002). Qualitative Research \& Evaluation Methods, Londres: SAGE Publications.

RAGA, Francisco (2003). "Para un análisis empírico de las interacciones comunicativas interculturales" en Grupo CRIT. Claves para la comunicación intercultural, Castellón de la Plana: Publicacions de la Universitat Jaume I, pp. 37-81.

RAGA, Francisco (2006a). "Conversaciones interculturales: algo más que palabras" en Grupo CRIT. Culturas cara a cara. Relatos y actividades para la comunicación intercultural, Madrid: Edinumen, pp. 25-42.

RAGA, Francisco (2006b). “Grupo CRIT. Comunicación intercultural y mediación en ámbito sanitario" en VALERO, Carmen y Francisco RAGA (eds.) Nuevo Mapa Lingüístico y Cultural de España: Retos del Siglo XXI en Comunicación Intercultural. RESLA, Volumen Monográfico, Logroño: Resla, pp. 217-230.

RAGA, Francisco (2008). Mediaciones interculturales. Valencia: Universitat de València, Centro de Estudios sobre Comunicación Interlingüística e Intercultural. Lynx.

RAGA, Francisco (2009). "Atención sanitaria a la población de origen chino" en Grupo CRIT Culturas y atención sanitaria. Guía para la comunicación y la mediación intercultural, Barcelona: Octaedro, pp. 53-85.

RAGA, Francisco (2009). "Atención sanitaria a la población de origen subsahariano occidental" en Grupo CRIT Culturas y atención sanitaria. Guía para la comunicación y la mediación intercultural, Barcelona: Octaedro, pp.122-142. 
RAGA, Francisco. "Metodología de la investigación en interpretación/mediación en el ámbito sanitario" (inédito).

RAGIN, Charles C. y Howards S. BECKER (2000). What is a Case? Exploring the Foundations of Social Inquiry, Cambridge: Cambridge University Press.

RAPLEY, Tim (2007). Doing Conversation, Discourse and Document Analysis, Londres: SAGE Publications.

Real Decreto-ley 16/2012, de 20 de abril, de medidas urgentes para garantizar la sostenibilidad del Sistema Nacional de Salud y mejorar la calidad y seguridad de sus prestaciones. [http://www.boe.es/boe/dias/2012/04/24/pdfs/BOE-A-2012-5403.pdf] (última consulta: 8 de agosto de 2013).

Red Comunica (2011). “Panorámica de la formación universitaria en traducción e interpretación en España" en Gobierno de España, Ministerio de Asuntos Sociales y de Cooperación Libro Blanco de la Traducción Institucional, pp. 123-127. [http://www.ritap.es/wpcontent/uploads/2012/11/libro_blanco_traduccion_vfinal_es.pdf] (última consulta: 10 de septiembre de 2013).

RICHARDS, Lyn. (1999). Using NVivo in Qualitative Rsearch, London: SAGE Publications.

RICHARTE, Inés (coord.) (2008). Una aproximación transnacional a la Mediación Intercultural: Realidades en Francia, Italia y España, Valencia: Fundación CeiMigra.

RICHARTE, Inés y Luis DÍE (2008). “La mediación intercultural y la puerta hacia otro mundo posible" en Documentación Social. Revista de estudios sociales y sociología aplicada, 148, Monográfico La mediación: caja de herramientas ante el conflicto social, pp. 133155.

ROBERTS, Roda (1994). "Community Interpreting Today and Tomorrow" en KRAWUTSCHKE, P. (ed.) Proceedings of the 35th Annual Conference of the American Translators Association, Medford: NJ Learned Information, pp. 127-138.

RODRIGO ALSINA, Miquel (1999). Comunicación intercultural, Barcelona: Anthropos Editorial.

RODRIGO ALSINA, Miquel (2000). "La comunicación intercultural” en Portal de la Comunicación InCom-UAB, Lecciones del Portal. [http://portalcomunicacion.com/uploads/pdf/1_esp.pdf] (última consulta: 3 de septiembre agosto de 2013). 
RODRIGO ALSINA, Miquel (2009). “(In)comunicación intercultural” en GARCÍA, Alonso (dir.) EI diálogo intercultural, Murcia: Servicio de Publicaciones de la Universidad de Murcia, pp. 83-116.

RODRÍGUEZ, Almudena y Ester SOUTO (coords.) (2009). Inmigración y resolución de conflictos: La mediación intercultural, Madrid: Editorial DYKINSON.

ROS, Marisa y Carmen OLLÉ (2006). “Acceso y utilización de los servicios de salud: atención al paciente inmigrante, dificultades y posibles soluciones" en Ministerio de Sanidad y Consumo La prevención de la infección del VIH/SIDA en la población inmigrante, Madrid: Centro de Publicaciones del Ministerio de Sanidad y Consumo, pp.85-96.

ROSENBERG, Brett Allen (2005). “Un análisis de la interpretación telefónica” en VALERO, Carmen (ed.) Traducción como mediación entre lenguas y culturas, Alcalá de Henares: Servicio de Publicaciones Universidad de Alcalá, pp. 243-249.

ROSENBERG, Brett Allen (2007). "A data driven analysis of telephone interpreting" en WADENSJÖ, Cecilia, Birgitta ENGLUND DIMITROVA and Anna-Lena NILSSON (eds.) The Critical Link 4: Professionalisation of Interpreting in the Community, Amsterdam/Filadelfia: John Benjamins Publishing, pp. 65-76.

RUDVIN, Mette y Elena TOMASSINI (2011). Interpreting in the Community and Workplace. A Practical Teaching Guide, Basingstoke: Palgrave Macmillan.

SALAMANCA, Ana Belén y Cristina MARTíN-CRESPO (2007). "El muestreo en la investigación cualitativa" en Nure Investigación. Revista científica de enfermería, 27, marzo-abril 07. [http://www.nureinvestigacion.es/FICHEROS_ADMINISTRADOR/F_METODOLOGICA/F Metodologica_27.pdf] (última consulta: 20 de febrero de 2013).

SALES, Dora (2005a). "Creación de una base de datos bibliográfica sobre mediación intercultural y traducción e interpretación en los servicios públicos" en Revista Española de Documentación Científica, vol. 28, № 4, pp.519-528. [http://redc.revistas.csic.es/index.php/redc/article/view/234/290] (última consulta: 18 de noviembre de 2012).

SALES, Dora (2005b). "Panorama de la mediación intercultural" en Translation Journal, vol. 9(1). [http://translationjournal.net/journal/31mediacion.htm] (última consulta: 12 de julio de 2013). 
SALES, Dora (2009). "Atención sanitaria a la población de origen indio y paquistaní" en Grupo CRIT Culturas y atención sanitaria. Guía para la comunicación y la mediación intercultural, Barcelona: Octaedro, pp. 86-121.

SAMOVAR, Larry A., et al. (2001). Communication between cultures, 7ạ edición, Boston: Wadsworth CENGAGE Learning, 2010.

SAMOVAR, Larry A., Richard E. PORTER y Edwin R. MCDANIEL (1972). Intercultural Communication: A Reader, 12ª edición, Boston: Wadsworth CENGAGE Learning, 2009.

SÁNCHEZ, Enric (2009). "Atención sanitaria a la población de Europa del Este" en Grupo CRIT Culturas y atención sanitaria. Guía para la comunicación y la mediación intercultural, Barcelona: Octaedro, pp. 143-170.

SÁNCHEZ-REYES Mạ Sonsoles y Manuel MARTÍN (2005). "Intérpretes profesionales e intérpretes ad hoc en un entorno sanitario" en VALERO, Carmen (ed.) Traducción como mediación entre lenguas y culturas, Alcalá de Henares: Servicio de Publicaciones Universidad de Alcalá, pp. 139-146.

SANDÍN, María, Isabel Río y Rosana LARRAZ (2012). “Diseño de un catálogo de recursos online para la mejora de la comunicación sanitario-paciente inmigrante" en Revista Española de Comunicación en Salud, 3(1), pp. 38-48.

SANTOS GUERRA, Miguel Ángel (1999). “La observación en la investigación cualitativa. Una experiencia en el área de salud" en Aten Primaria, vol. 24, no 7, pp. 425-30.

SAUVÊTRE, (2000). "De l'interprétariat au dialogue à trois. Pratiques européennes de I'interprétariat au milieu social", en The Critical Link 2: Interpreters in the Community, Amsterdam/Filadelfia: John Benjamins Publishing, pp. 35-45.

SCHULER, Margaret (1997). "Los derechos de las mujeres son derechos humanos: la agenda internacional del empoderamiento" en LEÓN, Magdalena (comp.) Poder y empoderamiento de las mujeres, Bogotá: Tercer Mundo Editores/Fondo de Documentación Mujer y Género de la Universidad Nacional de Colombia, pp. 34-37.

SCRIBANO, Adrián Oscar (2007). El proceso de investigación social cualitativo, Buenos Aires: Prometeo Libros.

SEMFYC (Sociedad Española de Medicina de Familia y Comunitaria), Grupo de trabajo Inmigración y Salud (2007) "Inmigración y Salud en Aragón". [http://www.semfyc.es/es/grupos_trabajo/inmigraci\%F3n+y+salud/documentos_grup 
o/detalle/Inmigraci\%F3n+y+Salud+en+Arag\%F3n/] (última consulta: 10 de agosto de 2013).

SEMFYC (Sociedad Española de Medicina de Familia y Comunitaria), Grupo de trabajo Inmigración y Salud (2012). "Por la equidad en el acceso de todas las personas al sistema sanitario". [https://www.semfyc.es/grupos_trabajo/inmigraci\%F3n+y+salud/noticias_grupo/detal le/GdT_Inmigracion_TarjetaSanitaria/] (última consulta: 10 de agosto de 2013).

SETIÉN, María Luisa y Arantxa LÓPEZ (2002). "Mujeres inmigrantes en Bilbao" en SETIÉN, María Luisa y Arantxa LÓPEZ (eds.) Mujeres inmigrantes y formación. Perspectivas europeas, Bilbao: Universidad de Deusto, pp. 43-70.

SIX, Jean-François (1990). Le temps des médiateurs, París: Seuil.

Sociedad Española de Contracepción (2012). Libro blanco sobre la percepción de los anticonceptivos las mujeres españolas. [http://www.sec.es/area_cientifica/estudiosyencuestas/LIBROBLANCO.pdf] (última consulta: 27 de septiembre de 2013).

Sociedad Española de Ginecología y Obstetricia (2007). "Utilización de métodos anticonceptivos en España por grupos de edad: resultados de 4 encuestas nacionales" en Progresos de Ginecología y Obstetricia, vol. 50, no 6, pp. 335-339. [http://zl.elsevier.es/es/revista/progresos-obstetricia-ginecologia-151/utilizacionmetodos-anticonceptivos-espa\%C3\%B1a-grupos-edad-resultados-13106408-articulosoriginales-2007] (última consulta: 6 de agosto de 2013).

SOLÉ, Carlota (1994). La mujer inmigrante, Madrid: Ministerio de Asuntos Sociales/Instituto de la Mujer.

SPECTOR, Rachel E. (1999). "Cultura, cuidados de salud y enfermería" en Cultura de los cuidados, Año III, 6, pp. 66-73.

SPECTOR, Rachel E. (2001). "Valoración de la herencia cultural" en Cultura de los Cuidados, Año V, 9, pp. 71-81. [http://culturacuidados.ua.es/enfermeria/article/view/106] (última consulta: 23 de agosto de 2013).

SPECTOR, Rachel E. (2003). Las culturas de la SALUD, Madrid: Pearson Educación. Traducción de María José Muñoz.

SPINDLER, George Dearborn y Louise Schaubel SPINDLER (1987). Interpretive Ethnography of Education: At Home and Abroad, Hillsdale, NJ: Lawrence Erlbaum. 
STAKE, Robert E. (1995). The Art of Case Study Research, Thousand Oaks (California): SAGE Publications.

TAFT, Ronald (1981). "The role and personality of the Mediator", en BOCHNER, S. (eds.) The Mediating Person: Bridges between Cultures, Cambridge: Schenkman, pp. 53-58.

TAYLOR, Samuel James y Robert BOGDAN (1987). Introducción a los métodos cualitativos de investigación: la búsqueda de significados, 13a edición, Barcelona: Ed. Paidós, 2010. Traducción de Jorge Piatigorsky.

TERRAZA, Rebeca et al. (2010). "Políticas sanitarias de ámbito estatal y autonómico para la población inmigrante en España" en Gaceta Sanitaria, vol. 24, no 2, pp. 115.e1-115.e7. [http://scielo.isciii.es/scielo.php?pid=S0213-91112010000200004\&script=sci_arttext] (última consulta: 6 de agosto de 2013).

TORRES DÍAZ, María Gracia (2003). "Interpretación comunitaria médica e investigación" en ORTEGA, Emilio (dir.) Panorama actual de la investigación en Traducción e Interpretación, vol. I, Granada: Atrio, pp. 447-453.

VALDEMOROS, Ma Ángeles et al. (2011). "Fundamentos en el manejo del NVivo9 como herramienta al servicio de estudios cualitativos" en Contextos educativos, 14, pp.11-29.

VALERO, Carmen (2003a). Traducción e Interpretación en los Servicios Públicos. Contextualización, actualidad y futuro, Granada: Editorial Comares.

VALERO, Carmen (2003b). "Responding to communication needs. Current issues and challenges in community interpreting and translation in Spain" en BRUNETTE, Louise et al. The Critical Link 3: Interpreters in the Community, Amsterdam: John Benjamins Publishing, pp. 175-192.

VALERO, Carmen (2005). "El papel del intérprete desde una perspectiva multidisciplinar" en ROMANA, María Luisa (ed.) II AIETI. Actas del II Congreso Internacional de la Asociación Ibérica de Estudios de Traducción e Interpretación, Madrid: AIETI, pp. 450-463.

VALERO, Carmen (2008). Formas de mediación intercultural. Traducción e interpretación en los servicios públicos. Conceptos, datos, situaciones y práctica, Granada: Editorial Comares.

VALERO, Carmen (ed.) (2005). Traducción como mediación entre lenguas y culturas, Alcalá de Henares: Servicio de Publicaciones Universidad de Alcalá. 
VALERO, Carmen y Anne MARTIN (eds.) (2008). Crossing Borders in Community Interpreting. Definitions and Dilemmas, Amsterdam/Filadelfia: John Benjamins Publishing.

VALERO, Carmen y Francisco RAGA (eds.) (2006) Nuevo Mapa Lingüístico y Cultural de España: Retos del Siglo XXI en Comunicación Intercultural. RESLA Volumen Monográfico, Logroño: Resla.

VALERO, Carmen y TAIBI, Mustapha (2004). "Professionalizing Public Service Translation and Interpreting in Spain", Conference papers presented in the Critical Link 4: Professionalisation of Interpreting in the community, Estocolmo, 2004. [http://criticallink.org/wp-content/uploads/2011/09/CL4_ValeroGarces_Taibi.pdf] (última consulta: 23 de julio de 2012)

VALLES, Miguel S. (2001). “Ventajas y desafíos del uso de programas informáticos (e.g. ATLAS.ti y MAXqda) en el análisis cualitativo. Una reflexión metodológica desde la grounded theory y el contexto de la investigación social española", Seminario sobre Investigación Avanzada, noviembre de 2001, Granada. [http://public.centrodeestudiosandaluces.es/pdfs/S200105.pdf] (última consulta: 16 de octubre de 2012).

VALLES, Miguel S. (2007). Técnicas cualitativas de investigación social. Reflexión metodológica y práctica profesional, Madrid: Síntesis.

VARGAS, Mireia (2012). La interpretació als serveis públics i la mediació intercultural amb el collectiu xinès a Catalunya, Tesis doctoral, Universitat Autònoma de Barcelona, Departament de Traducció i Interpretació. [http://pagines.uab.cat/mireia_vu/sites/pagines.uab.cat.mireia_vu/files/tesi_completa .pdf] (última consulta: 23 de septiembre de 2013).

VASILEVA, Katya (2012). "Nearly two-thirds of the foreigners living in EU Member States are citizens of countries outside the EU-27" en Eurostat Statistics in Focus [http://epp.eurostat.ec.europa.eu/cache/ITY_OFFPUB/KS-SF-12-031/EN/KS-SF-12-031EN.PDF] (última consulta: 10 de junio de 2013).

VÁZQUEZ, Ma Luisa et al. (2007). "Politiques sanitaries per a la població immigrant en el context nacional i internacional", Barcelona: Consorci Hospitalari de Catalunya. [http://www.consorci.org/publicacions/cataleg-de-publicacions/informestecnics/politiques-sanitaries-per-a-la-poblacion-immigrant-en-el-context-nacional-iinternacional] (última consulta: 12 de marzo de 2013). 
VERREPT, Hans (2008). "Intercultural mediation. An answer of health care disparities?" en VALERO, Carmen y Anne MARTIN (eds.) Crossing Borders in Community Interpreting. Definitions and Dilemmas, Amsterdam/Filadelfia: John Benjamins Publishing, pp. 187202.

VICENTE, Trinidad L. (2002). "Presencias y ausencias de las mujeres en los movimientos migratorios" en SETIÉN, María Luisa y Arantxa LÓPEZ (eds.) Mujeres inmigrantes y formación. Perspectivas europeas, Bilbao: Universidad de Deusto, pp.29-42.

VINYAMATA, Eduard (2003). Aprender mediación, Barcelona: Paidós.

WADENSJÖ, Cecilia (1998). Interpreting as Interaction. New York: Addison Wesley Longman Inc.

WADENSJÖ, Cecilia (1999). "Telephone Interpreting and the Synchronization of Talk in Social Interaction" en The Translator, 5(2), pp. 247-264.

WOLCOTT, Harry F. (1994). Transforming Qualitative Data. Description, Analysis, and Interpretation, Londres: SAGE Publications.

WRIGHT MILLS, Charles (1959). The Sociological Imagination, Oxford: Oxford University Press.

YIN, Robert K. (1984). Case Study Research. Design and Methods, 4a edición, Londres: SAGE Publications, 2009.

ZEIGLER, J. W. (1998). The Mediation Kit, Nueva York: John Wiley and Sons Inc. 